\title{
Escherich
}

Forstinsekten Mitteleuropas

Erster Band

(3) 


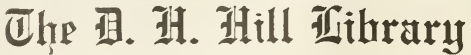

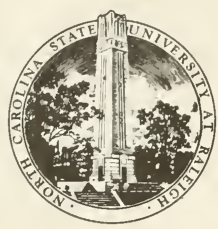

Ainrth Caraling State Aniuersity SB761

48

$\mathrm{v} \cdot 1$

Oberförster RLAMM 
THIS BOOK IS DUE ON THE DATE INDICATED BELOW AND IS SUBJECT TO AN OVERDUE FINE AS POSTED AT THE CIRCULATION DESK.

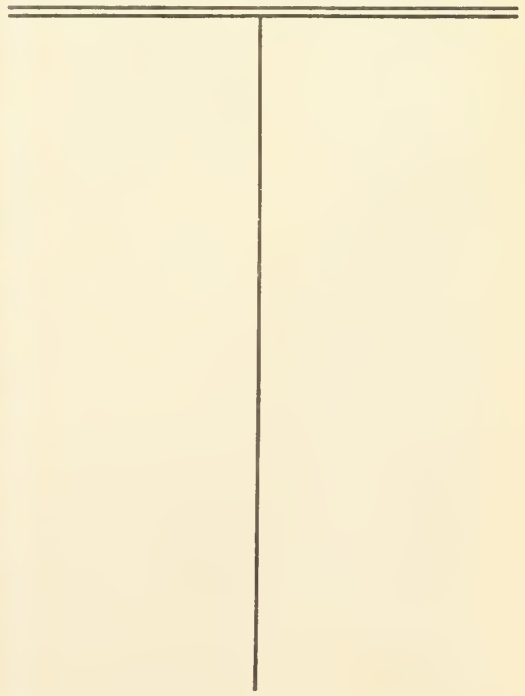






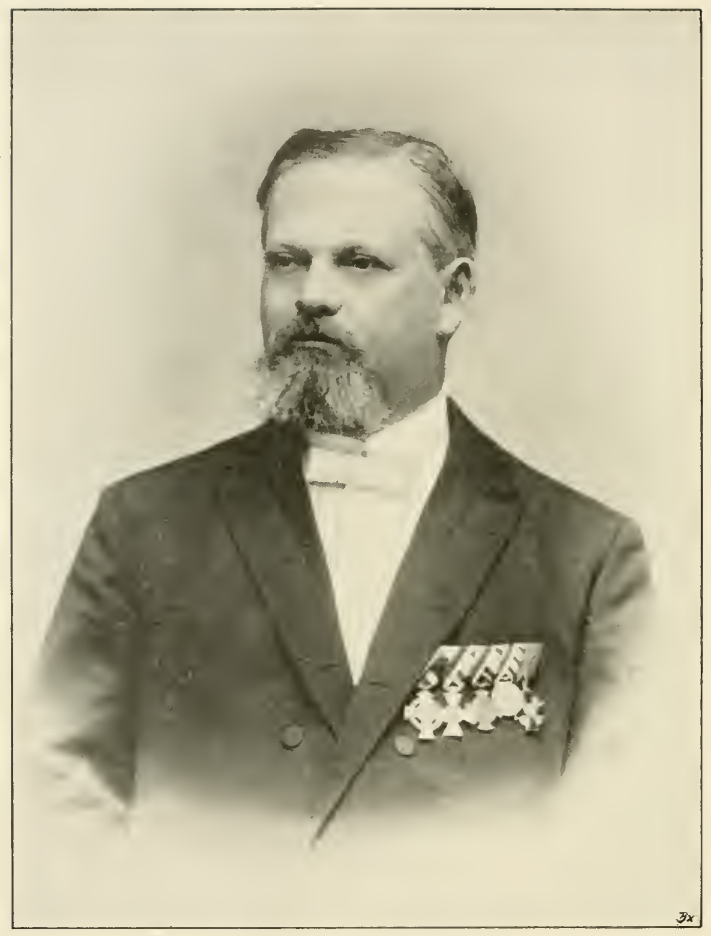

\section{HINRICH NITSCHE}

geboren 14. Februar 1845, gestorben 8 . November 1902

1876-1902 Professor der Zoologie an der Kgt. Forstakademie in Tharandt 


\title{
Die
}

\section{Forstinsekten Mitteleuropas.}

\author{
Ein Lehr- und Handbuch \\ ron
}

\section{K. Escherich,}

Dr. med. et phil., o. Professor der Zoologie an der Forstakademie Tharandt.

Als Neuauflage von

Judeich-Nitsche, Lehrbuch der mitteleuropäischen Forstinsektenkunde

bearbeitet.

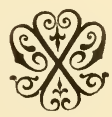

\section{Erster Band.}

\begin{abstract}
Allgemeiner Teil.
Einführung in den Bau und die Lebensweise der Insekten, sowie in die allgemeinen Grundsätze der praktischen Forstentomologie.
\end{abstract}

Mit 248 Textabbildungen.

BERLIN

VerlagsbuchHandlung PaUl Parey

Verlag fur Landwirtschaft, Gartenbau und Foratwenen

SW. 11, Hedemannstraße 10 u. 11 
Alle Rechte, auch das der Übersetzung, vorbehalten.

Copyright by Paul Parey, Berlin 1914. 
Dem Andenken

\section{Hinrich Nitsches.}





\section{Vorwort.}

Als vor einigen Jahren die Verlagsbuchhandlung Paul Parey auf Anraten von Prof. Pauly (München) sich an mich wandte mit dem Antrage, die Neuauflage von Judeich-Nitsches Lehrbuch der mitteleuropäischen Forstinsektenkunden zu besorgen, fühlte ich mich natürlich einerseits sehr erfreut über das Vertrauen, das man mir mit diesem Antrag entgegenbrachte, andererseits aber war es mir vollkommen klar, daß ich eine sehr schwierige und verantwortungsvolle Arbeit zu übernehmen hatte. Stellte doch JudeichNitsches Lehrbuch das Standard-Werk der forstentomologischen Wissenschaft dar und war es gewissermaßen tonangebend in allen forstentomologischen Fragen. Aber noch weit über die forstentomologischen Kreise hinaus erstreckte sich der Ruf des Nitscheschen Insektenwerkes; ja man darf getrost sagen, daß es sich bei allen wissenschaftlichen Entomologen der Welt des höchsten Ansehens erfreute.

Beinahe drei Jahrzehnte sind nun verflossen, seitdem die erste Abteilung von "Judeich-Nitsche" erschienen — drei Jahrzehnte voll des Schaffens und Ringens in unserer Wissenschaft. Überall, vor allem in Nord-Amerika, hat man - in der Erkenntnis von der tief in unser Kulturleben einschneidenden Bedeutung der Insekten - der angewandten Entomologie mit einem vordem noch nicht gekannten Eifer und wissenschaftlichem Ernste sich hingegeben. Eine Unmenge neuer Tatsachen von allgemeiner Bedeutung sind dadurch zutage gefördert worden, und andererseits mußte manche der früheren Anschauungen mehr oder weniger modifiziert oder auch gänzlich über Bord geworfen werden, so daf3 unsere Wissenschaft heute ein wesentlich anderes Bild darbietet und auch wesentlich höhere Anforderungen an das Wissen und Können ihrer Vertreter stellt als vor 30 Jahren: Weit mehr als damals trachtet man heute danach, den Ursachen der Schädlingsvermehrung nachzuforschen und die bestehenden Kausalzusammenhänge aufzudecken. Denn nur dann, wenn wir die Ursache eines Übels erkennen, sind wir imstande, es an der Wurzel zu fassen und auszurotten. Die Zusammenhänge aber, welche das organische Gleichgewicht erhalten, sind gewöhnlich von ungemein komplizierter Struktur, deren Aufdeckung ein tiefes Eindringen in das Problem erfordert: Es genügt nicht mehr, daß wir über die Entwicklungsgeschichte eines Schädlings Bescheid wissen, sondern wir müssen auch alle seine Abhängigkeiten von der Umwelt, der organischen wie der anorganischen, genau kennen. Wir müssen wisssen, wie der Schädling, resp. jedes einzelne Stadium desselben, sich gegen die verschiedenen klimatischen Einflüsse wie Hitze, Kälte, Feuchtigkeit, Trockenheit, ferner gegen 
die verschiedenen Kulturformen, Pflanzenrassen usw. verhält, welche Feinde er hat und in welchem Verhältnis die verschiedenen Feinde auf ihn einwirken; ferner muß wieder jeder der Feinde ebenso genau wie der Schädling selbst studiert werden, d. h. wir müssen von jedem Feind die Entwicklungsgeschichte sowie seine Abhängigkeiten von der gesamten Umwelt zu eruieren suchen. Die Feinde haben wieder ihre Feinde, und so müssen auch diese nach ihren Entwicklungsbedingungen eingehend erforscht werden usw. Dazu kommen die verschiedenen Infektionskrankheiten der Schädlinge, die ebenfalls als gleichgewichtserhaltende Faktoren in Betracht zu ziehen sind und deren Studium zu den schwierigsten Aufgaben der organischen Naturwissenschaft überhaupt gehört.

Diese vielseitigen Aufgaben fordern gebieterisch, da $B$ der moderne Forstentomologe über sein eigenstes Spezialgebiet hinausblickt und auch die Arbeiten der anderen $Z$ weige der angewandten Entomologie, vor allem der landwirtschaftlichen Entomologie, aufmerksam verfolgt, um überall das für ihn Brauchbare aufnehmen zu können. WVenn z. B. irgendwo in der Welt Studien über Tachinen oder über eine Krankheit irgend eines Schädlings (sei es Obst- oder Wein- oder Getreideschädlings) gemacht werden, so können die Ergebnisse dieser Forschungen auch für den Forstentomologen von größtem Werte sein, und wenn es auch nur die Methodik der Forschung ist, die er sich auf diese Weise aneignen kann. Eine Fülle von Anregung wird dadurch dem Forstentomologen zuteil, während andererseits die ängstliche Beschränkung auf das Spezialgebiet zu Arbeitsvergeudung, Stagnation und Selbsterschöpfung führen muß.

Allen diesen aus den Forschungen der letzten Dezennien sich ergebenden Forderungen mußte in der neuen Auflage vollauf Rechnung getragen werden, wenn der Ruf der alten Auflage gewahrt werden sollte. Dies konnte aber nur dadurch erreicht werden, daß wenigstens der allgemeine Teil, der das Fundament und die Richtlinien der forstentomologischen Wissenschaft enthält, einer nahezu völligen Neubearbeitung unterzogen wurde. Eine solche stellt denn auch der vorliegende erste Band, der dem allge meinen Teil der alten Auflage entspricht, dar. Ich habe mich bemüht, die Fortschritte der angewandten Entomologie aller Länder, soweit sie für die Ausgestaltung der Forstentomologie in Betracht kommen können, darin zu verwerten und im Geiste Nitsches zu verarbeiten, und hoffe damit zu einem einigermaßen zutreffenden Bild des heutigen Standes unserer Wissenschaft gelangt zu sein.

Es mag wohl sein, daß manchem die Bearbeitung des allgemeinen 'Teiles in einigen Kapiteln zu ausführlich und eingehend erscheint. Ich mache mich von vornherein auf derartige Einwände gefaßt. Denn solange man noch die Ansicht vertreten findet, daß ein einzelner Forscher imstande wäre, ein so ungemein kompliziertes, aus zahlreichen schwierigen Einzelfragen zusammengesetztes Problem wie z. B. die Nonnenbekämpfung in wenigen Jahren zu lösen, solange ist die Erkenntnis von dem eigentlichen Wesen der Forstentomologie noch keineswegs Allgemeingut der forstlichen Kreise geworden. Es dürfte aber - so wage ich zu hoffen - die Zeit nicht mehr allzuferne sein, in der jene Erkenntnis sich durchgerungen, in der man die Schwierig- 
keit der forstentomologischen Probleme allgemein einzusehen gelernt haben wird (wie dies ja bei den anderen Heilwissenschaften, z. B. der Medizin, längst der Fall ist), in der man versteheu wird, daß nur eine von der breitesten Basis ausgehende Forschung erfolgreich sein kann, und in der endlich auch der forstliche Praktiker zusammen mit dem Forscher gerne und verständnisvoll die schwierigen und gewundenen Wege wandeln wird, die in die Tiefe der Probleme führen.

Dann werden auch die Fortschritte nicht ausbleiben und viele der verheerenden Insekteninvasionen, die heute eine stete schwere Sorge des Forstmannes bilden, allmählich ihre Schrecken verlieren, gleichwie manche der ehedem so fürchterlich wütenden menschlichen Seuchen dank der fortgesetzten intensiven Arbeit zahlreicher medizinischer und hygienischer Forscher auf ein erträgliches Maß herabgedrückt wurde. Möge der vorliegende Band dazu beitragen, den Weg zum Fortschritt zu zeigen und dem uns vorschwebenden Ziele näher zu kommen.

Was die Anlage des ganzen Werkes betrifft, so sind vier Bände vorgesehen, von denen der vorliegende erste der Einführung in den Bau und die Funktion des Insektenkörpers sowie in die allgemeinen Grundsätze der praktischen Forstentomologie gewidmet ist, während die drei übrigen Bände der speziellen Forstentomologie (Behandlung der einzelnen Forstschädlinge) dienen sollen, und zwar soll der zweite Band die Käfer (mit den Orthopteren s. 1., mit den Amphibiotica und den Neuropteren), der dritte in der Hauptsache die Schmetterlinge und der vierte die Hymenopteren, Dipteren und Hemipteren enthalten.

Der erste Band ist in seinem Umfange wesentlich (mehr als um das Doppelte) stärker geworden als der entsprechende Teil der alten Auflage, was einmal in der notwendigen ausführlicheren Behandlung der Anatomie, Physiologie und Entwicklungsgeschichte der Insekten, und sodann besonders in der eingehenden Darlegung der vermehrungsbeschränkenden Faktoren (Kap. VI) und der für eine rationelle Bekämpfung geltenden Grundsätze (Kap. VII) begründet ist. Gerade die letzteren beiden Gebiete konnten meiner Ansicht nach nicht eingehend genug bearbeitet werden, da sie die Grundlage der forstentomologischen Praxis darstellen. Wer in diesen Punkten richtig denken gelernt hat, wird in der Praxis vor groben Fehlern bewahrt bleiben.

Um auch auf den mir ferner liegenden Gebieten zu einer möglichst zuverlässigen Darstellung zu gelangen, habe ich für die Bearbeitung der betreffenden Abschnitte bewährte Spezialforscher herangezogen. So wurden die insektentötenden Pilze (S. 258-291) von Dr. Georg Lakon, früher Assistent am hiesigen botanischen Institut, jetzt Abteilungsvorstand an der landwirtschaftlichen Hochschule in Hohenheim bearbeitet, während die Behandlung der „kulturellen Vorbeugungsmaßregeln“ (S. 315-326) aus der Feder des Herrn Prof. Dr. W. Borgmann Tharandt stammt. Den beiden Herren Mitarbeitern sei für diese so überaus wertvolle Unterstützung auch hier herzlichst gedankt. 
Bezüglich der Literatur habe ich es so gehalten, daß am Ende jeden Kapitels ein Verzeichnis der wichtigsten einschlägigen Schriften gegeben wird: es sind da einmal die Titel aller jener Schriften angeführt, auf die im vorhergehenden Text Bezug genommen ist, und außerdem auch noch solche im Text nicht zitierte Arbeiten, in denen ausführliche Literaturnachweise zu finden sind, so daß der wissenschaftlich arbeitende Forstentomologe sich unschwer über die gesamte Literatur der ihn gerade interessierenden Fragen orientieren kann.

Besonderer Wert wird auf die Illustrierung des Werkes gelegt werden, und es ist beabsichtigt, die Gesamtzahl der Abbildungen gegenüber der alten Auflage um ein Mehrfaches zu erhöhen. Schon in dem vorliegenden ersten Band ist die Zahl der Figuren um weit mehr als das Doppelte gestiegen gegenüber dem entsprechenden Teil der alten Auflage. Nur relativ wenige Abbildungen (durch den Buchstaben „N.“ am Schluß der Figurenerklärung kenntlich gemacht) konnten von der alten Auflage übernommen werden, da heute die Ansprüche an die Ausführungen der Zeichnungen und Reproduktionen wesentlich gesteigert sind. Die neuen Abbildungen sind teils anderen Werken entnommen, teils nach neuen Vorlagen angefertigt. Die letzteren wurden, soweit Zeichnungen in Betracht kommen, von Herrn Dr. O. Römer-Dresden, ferner von Fräulein Margarete Hummel-Dresden und Fräulein Gertrud Kunze-Tharandt ausgeführt. Die photographischen Vorlagen verdanke ich zum großen Teil Herrn Forstassessor Fr. Scheidter, Assistent am forstzoologischen Institut in München, z. T. wurden sie im hiesigen Institut von Präparator Herpig hergestellt. Ihnen allen sei herzlichst gedankt.

Vielen Dank schulde ich ferner noch Herrn Prof. Dr. SchwangartNeustadt a. Haardt, Herrn Dr. H. Prell-Tübingen und Herrn Assistenten W. Baer-Tharandt, welche mich beim Lesen der Korrekturen in der hingebendsten Weise unterstützt haben und mir dabei manche wertvolle Hinweise zuteil werden ließen. Letzterer hat sich außerdem noch der mühevollen Arbeit der Herstellung der beiden Register unterworfen.

Endlich sei des Verlegers in dankbarer Gesinnung gedacht, der keine Mittel scheute, dem Werke eine würdige Ausstattung zu geben, der allen meinen oft recht weitgehenden Wünschen in der bereitwilligsten Weise entgegengekommen ist, und der oft eine Geduld bewies, die ich aufrichtig bewundere.

Tharandt, Ende November 1913.

\section{K. Escherich.}




\title{
Inhalt des ersten Bandes.
}

\author{
Kapitel I.
}

Stellung der Insekten im System.

Die Stämme des Tierreichs . . . . . . . . . . . . . . . . . . . 1

Definition und allgemeine Charakteristik der Arthropoden . . . . . . . . . 1

Die Klassen der Arthropoden . . . . . . . . . . . . . . . . . . . . . . 8

Literatur . . . . . . . . . . . . . . . . . . 11

Kapitel II.

Die äußere Erscheinung der Insekten (Morphologie).

1. Der Kopf . . . . . . . . . . . . . . . . . . . . . . . . . . . 13

A. Die Kopfkapsel . . . . . . . . . . . . . . . . . . . . . . . . . 13

B. Die Anhänge (Extremitäten) des Kopfes: Fühler, Mundgliedmaßen . . . 17

2. Die Brust . . . . . . . . . . . . . . . . . . . . 25

A. Die Segmente . . . . . . . . . . . . . . 25

B. Die thorakalen Anhänge: Beine, Flügel . . . . . . . . . . . . 29

3. Der Hinterleib (Abdomen) . . . . . . . . . . . . . . . . . 36

A. Zusammensetzung und Form des Hinterleibes . . . . . . . . . . . . 36

B. Die Anhänge des Hinterleibes . . . . . . . . . . . . . . . . . . . . 38

4. Skulptur und Färbung der Haut. . . . . . . . . . . . . . . . . . . 40

5. Polymorphismus bezw. Dimorphismus . . . . . . . . . . . . . . . . . . 44

Literatur . . . . . . . . . . . . . . . . . . . . 48

Kapitel III.

Der innere Bau der Insekten (Anatomie und Physiologie).

Allgemeines (Lagerung der Organe) . . . . . . . . . . . . . . . 50

1. Die Haut . . . . . . . . . . . . . . . . . . . . . . . . . . . . . . . . 51

2. Das Muskelsystem und seine Tätigkeit. . . . . . . . . . . . 54

Allgemeines (Bau der Muskulatur) . . . . . . . . . . . . . . 54

Ortsbewegungen .................. . . . . . . 55

Lautäußerungen . . . . . . . . . . . . . . . . 59

3. Der Darmkanal und seine Anhänge (Verdauungs- und Excretionsorgane) • 62

4. Die Atmungsorgane (Tracheensystem) . . . . . . . . . . . . . . . 71

Stigmenatmung . . . . . . . . . . . . . . . . 71

Hautatmung (Tracheen- und Blutkiemen) . . . . . . . . . . . 76

5. Die Kreislauforgane . . . . . . . . . . . . . . . . . . . . . . . . . . 77

6. Temperatur der Insekten . . . . . . . . . . . . . . . . 81

7. Fettkörper einschl. Oenocyten, Pericardialzellen und Leuchtorgane . . . . 85 
8. Nervensystem und Sinnesorgane

Nervensystem . . . . . . . . . . . . . . . . . 88

Sinnesorgane (Tast-, Geruch-, Geschmacks-, Gehör- und Sehorgane) . . 92

9. Fortpflanzungsorgane . . . . . . . . . . . . . . . . . . . . . . . . . . . 104

Allgemeines . . . . . . . . . . . . . . . . . . . . . . . . . 104

Die weiblichen Fortpflanzungsorgane . . . . . . . . . . . 105

Die männlichen Fortpflanzungsorgane . . . . . . . . . . . . . . . 111

Literatur . . . . . . . . . . . . . . . . . . . . . . . . . . 114

Kapitel IV.

\section{Fortpflanzung.}

Allgemeines . . . . . . . . . . . . . . . . . . . . . . 116

Die Keimzellen (Ei und Samen) . . . . . . . . . . . . . . . . . . 117

Das Ei . . . . . . . . . . . . . . . . . . . . . . . . 117

Der Samen . . . . . . . . . . . . . . . . . . . 119

Die Begattung . . . . . . . . . . . . . . . . . . . . . 120

Parthenogenese und verwandte Erscheinungen . . . . . . . . . . . . 124

Parthenogenese und Heterogonie . . . . . . . . . . . . . . . . 124

Paedogenesis . . . . . . . . . . . . . . . . . . . 127

Polyembryonie oder Germinogonie . . . . . . . . . . . . . . . 128

Eiablage . . . . . . . . . . . . . . . . . . . . . . . . . . . 129

Die Embryonalentwicklung . . . . . . . . . . . . . . . 138

Die nachembryonale Entwicklung . . . . . . . . . . . . . . . 142

Allgemeines üter die Larven . . . . . . . . . . . . . . . . . 142

Die Häutung . . . . . . . . . . . . . . . . . . . . . . . . . . . . . 144

Entwicklungsstadien . . . . . . . . . . . . . . . . . . 145

Provisorische (larvale) Organisation . . . . . . . . . . . . . . 146

Die Imaginalanlagen der Larven . . . . . . . . . . . . . . . . 150

Die Puppe . . . . . . . . . . . . . . . . . . . . . . 151

Die verschiedenen Formen der Entwicklung. . . . . . . . . . . 153

Epimorphose . . . . . . . . . . . . . . . . . . . 153

Metamorphose . . . . . . . . . . . . . . 155

Hemimetabolie . . . . . . . . . . . . . . . 155

Prometabolie . . . . . . . . . . . . . . . 156

Holometabolie . . . . . . . . . . . . . . . 156

Hypermetabolie (Polymetabolie) . . . . . . . . . . . . . . . 158

Die verschiedenen Larvenformen . . . . . . . . . . . . . . . . . . . . 161

Primäre Larven . . . . . . . . . . . . . . . . . . . . . . . . . . . . 161

Sekundäre Larven . . . . . . . . . . . . . . . . . . . . . . 161

Tertiäre Larven . . . . . . . . . . . . . . . . . . . . . . . 162

Die verschiedenen Formen der Puppe . . . . . . . . . . . . 165

Der Vorgang des Ausschlüpfens . . . . . . . . . . . . . . . . . . 168

Das Ausreifen . . . . . . . . . . . . . . . . . . . . . 170

Zeitlicher Ablauf der Entwicklung (Dauer der Gesamtentwicklung) . . . 170

Generation . . . . . . . . . . . . . . . . . . . . 176

Überwinterungsstadium . . . . . . . . . . . . . . . . . . . . . . . . . 179

Flugzeit . . . . . . . . . . . . . . . . . . . . . . . . . . . . . . . 181

Lebensdauer der Insekten . . . . . . . . . . . . . . . 183

Literatur . . . . . . . . . . . . . . . . . . 184 
Die Insekten als natürliche und wirtschaftliche Macht im allgemeinen und besonders in forstlicher Beziehung.

Die Bedeutung der Insekten im allgemeinen Naturhaushalt . . . . . . . . 186

Nutzen und Schaden der Insekten im allgemeinen . . . . . . . . . . . . 192

Nutzen und Schaden der Insekten für die Forstwirtschaft (Die Forstinsekten) 194

Die nützlichen Forstinsekten . . . . . . . . . . . . . . . . . . . . 194

Die schädlichen Forstinsekten . . . . . . . . . . . . . . . . . . . . 196

1. Physiologisch und technisch schädliche Insekten . . . . . . . . . 196

2. Primär und sekundär schädliche Insekten . . . . . . . . . . . 197

3. Kultur- und Bestandsverderber . . . . . . . . . . . . . . . 198

Die verschiedenen Arten der Pflanzenbeschädigungen durch Forstinsekten 199

1. Verletzungen durch Zerstörung fester Pflanzensubstanz . . . . . . . 199

Fraß an Blattorganen . . . . . . . . . . . . . . . . . . 199

Fraß an Stamm und Zweigen . . . . . . . . . . . . . . 201

Fraß an Wurzeln. . . . . . . . . . . . . . . 203

2. Verletzungen, die nur Saftverlust zur Folge haben . . . . . . . . 204

3. Verletzungen, welche Gallbildungen zur Folge haben . . . . . . 205

Folgen der Angriffe auf die Pflanzen . . . . . . . . . . . . 209

Grad der Schädlichkeit der Forstinsekten . . . . . . . . . . . 213

Wirkung der Insektenschäden auf den forstlichen Wirtschaftsbetrieb . . . 219

Literatur . . . . . . . . . . . . . . . 220

Kapitel VI.

\section{Natürliche Beschränkung der Insektenvermehrung.}

Allgemeines . . . . . . . . . . . . . . . . . . . . . . 222

1. Insektenvertilgung durch Witterungseinflüsse . . . . . . . . . . 223

2. Insektenvertilgende Tiere . . . . . . . . . . . . . . . . . . . 224

a) Säugetiere . . . . . . . . . . . . . . . . . 225

b) Vögel . . . . . . . . . . . . . . . . . . . . . . . 227

c) Schmarotzer und Raubinsekten, und andere insektentötende Arthropoden 237

Allgemeines . . . . . . . . . . . . . . . 237

Parasiten . . . . . . . . . . . . . . . . . 244

Raubinsekten . . . . . . . . . . . . . . . . 253

Andere räuberische Arthropoden . . . . . . . . . . . . . 257

3. Die insektentötenden Pilze (Mykosen). Bearbeitet ron Dr. Georg Lakon 258

A. Systematik und Biologie . . . . . . . . . . . . . . . 258

Algenpilze . . . . . . . . . . . . . . . . . . . 260

Fadenpilze . . . . . . . . . . . . . . . . . . . . . 268

Fungi imperfecti. . . . . . . . . . . . . . . . . . . 276

B. Wirtschaftliche Bedeutung der insektentötenden Pilze. . . . . . . . . 284

Literatur über die Pilzkrankheiten der Insekten . . . . . . . . . . . . . 289

4. Pathogene Mikroorganismen (Spaltpilze und Protozoen) . . . . . . . . . 291

a) Bakterienkrankheiten . . . . . . . . . . . . . . . . . . . . . 292

b) Nosema-Krankheiten (Pébrine) . . . . . . . . . . . . . . . . 29 . . . . . . . . . . .

c) Polyederkrankheiten . . . . . . . . . . . . . . . . . . . 299

Literatur . . . . . . . . . . . . . . . . . 304

Kapitel I'II.

Entstehung und Bekämpfung von Insektenkalamitäten.

A. Die Entstehung von Kalamitäten . . . . . . . . . . . . . . . . . . 307

B. Vorbeugung und Bekämpfung von Insektenkalamitäten . . . . . . . . . 312 
Seite

Allgemeines . . . . . . . . . . . . . . . . . . . . . . . 312

1. Die kulturellen Vorbeugungsmaßregeln. Bearbeitet von Prof. Dr. W. Borgmann . . . . . . . . . . . . . . . . . 315

a) Allgemeine Grundsätze . . . . . . . . . . . . . . . . . . . . 315

b) Die besonderen Maßnahmen . . . . . . . . . . . . . . . . 320

2. Die biologische Bekämpfung . . . . . . . . . . . . . . . . . . . . 327

a) Schutz und Verwendung von insektenvertilgenden Säugern . . . . . . 327

b) Schutz und Verwendung insektenvertilgender Vögel . . . . . . . . . 328

c) Schutz und Verwendung von Parasiten, Raubinsekten und anderen räuberischen Arthropoden . . . . . . . . . . . . . . . . . . 332

d) Verbreitung von Mykosen und anderen Infektionskrankheiten . . . . 344

3. Die technische Bekämpfung . . . . . . . . . . . . . . . . . . . . 350

a) Allgemeine Gesichtspunkte . . . . . . . . . . . . . . . . . . . . . . 350

b) Die chemischen Methoden . . . . . . . . . . . . . . . . . 351

c) Die mechanischen Methoden . . . . . . . . . . . . . . . . . . 362

Direktes Entfernen und Vernichten . . . . . . . . . . . . . 362

Anlockung der Schädlinge durch Darbietung von Brut- und Nahrungsgelegenheiten . . . . . . . . . . . . . . . . . . . 364

Fanggräben, Fanglöcher usw. . . . . . . . . . . . . . . 366

Leimring . . . . . . . . . . . . . . . . . . . . . . . 368

4. Beurteilung der Notwendigkeit und Möglichkeit der Bekämpfung . . . . . 379

Untersuchung über den Vermehrungsgrad der Schädlinge . . . . . . . 380

Untersuchung des Gesundheitszustandes der Schädlinge . . . . . . . . 383

Untersuchung des befallenen Bestandes . . . . . . . . . . . . . . . . 387

Durchführung der Bekämpfung . . . . . . . . . . . . . . . . . . 389

Literatur . . . . . . . . . . . . . . . . . . . . 390

Kapitel VIII.

Allgemeine Übersicht über das System der Insekten.

Mit einem Anhang:

Anleitung zur Anlegung einer forstentomologischen Sammlung.

Das System der Insekten . . . . . . . . . . . . . . . . . . . . . 393

Die Nomenklatur . . . . . . . . . . . . . . . . . . . . . . . . . 397

Anhang: Anleitung zur Anlegung einer forstentomologischen Sammlung . . 401

Das Sammeln der Forstinsekten . . . . . . . . . . . . . . . . . 401

Die Zucht der Insekten . . . . . . . . . . . . . . . . . . . . . . 405

Das Präparieren der Insekten und Fraßstücke . . . . . . . . . . . 410

Die Bestimmung der Forstinsekten . . . . . . . . . . . . . . . . . . 416

Aufbewahrung und Einordnung der präparierten Insekten . . . . . . 419

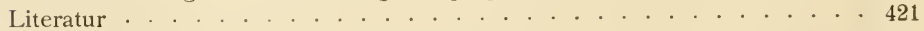

Namenregister . . . . . . . . . . . . . . . . . . . . . . . . . 423

Sachregister . . . . . . . . . . . . . . . . . . . . . . . 426 


\section{Allgemeiner Teil.}

\section{Kapitel 1. \\ Stellung der Insekten im System.}

\section{Die Stämme des Tierreichs.}

Das Tierreich wird gewöhnlich in sieben Stämme oder Phyla eingeteilt:

1. Die Protozoa (Urtiere),

2. Die Coelenterata (Hohldarm- oder Pflanzentiere),

3. Die Vermes (Würmer),

4. Die Arthropoda (Gliederfüßler),

5. Die Mollusca (Weichtiere),

6. Die Echinodermata (Stachelhäuter),

7. Die Chordata (Chordatiere), die Tunicata (Manteltiere) und die Vertebrata (Wirbeltiere) umfassend.

Die Insekten gehören dem vierten Stamm der Arthropoden (abgeleitet

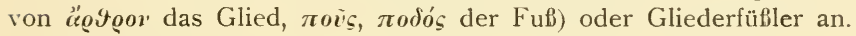

\section{Definition und allgemeine Charakteristik der Arthropoden.}

Die Arthropoden sind bilateral symmetrische ${ }^{1}$ ) Tiere mit meist kräftigem, chitinisiertem Aufenskelett (Cuticula), mit heteronom segmentiertem Körper und paarig angeordneten, gegliederten Segmentanhängen oder Extremitäten.

Durch die Zerlegung des Körpers in eine Anzahl hintereinander gelegener Ringel, Metameren oder Segmente erinnern die Arthropoden deutlich an die Ringelwürmer oder Anneliden, mit denen sie auch bezüglich der inneren Organisation vielfach übereinstimmen und von denen sie phylogenetisch wahrscheinlich abzuleiten sind. Wurden doch früher die beiden sogar zu einem gemeinsamen Stamm (Articulata oder Annulata) vereinigt.

Den übereinstimmenden Zügen stehen jedoch so wesentliche und charakteristische Unterschiede gegenüber, daß die Trennung der beiden und die Berechtigung zur Aufstellung des Stammes der Arthropoden ohne weiteres

$\left.{ }^{1}\right)$ D. h. die rechte Hälfte des Körpers ist spiegelbildlich gleich der linken Hälfte, während die gliedmaßentragende Bauchseite von der gliedmaßenlosen Rückenseite verschieden ist. 
einleuchtet. - Die Unterschiede sind hauptsächlich bedingt durch zwei Momente: durch die Ausbildung eines Außenskeletts und durch das Auftreten gegliederter Extremitäten.

Das Aubenskelett besteht zum größten Teil aus Chitin, einer organischen Substanz (von der Formel $\mathrm{C}_{15} \mathrm{H}_{26} \mathrm{~N}_{2} \mathrm{O}_{10}$ ), die ungemein hart und widerstandsfähig ist, und nur durch Kochen in konzentrierten Mineralsäuren oder Kalilauge angegriffen resp. gelöst werden kann Sie wird ron den Epidermiszellen nach aufen abgeschieden, wo sie die ganze Oberfläche des Körpers überzieht und an der Luft allmählich zu einer festen Schicht erhärtet. Wir haben es also nicht mit einem aus Zellen bestehenden Gewebe zu tun wie etwa bei der Hornschicht der menschlichen Haut -, sondern mit einem erhärteten Sekret, einer Cuticula. Da die Epidermis durch die Überlagerung der Cuticula von der Oberfläche abgerückt wird, so bezeichnet man sie als Hypodermis. Sie wird übrigens, nachdem sie ihre Hauptfunktion (Chitinabscheidung) erfüllt hat, mehr oder weniger rückgebildet.

Das Chitinskelett dient sowohl der Bewegung (indem es Anheftungsstellen für die von der Haut losgelöste und in einzelne Muskeln zerlegte Be-
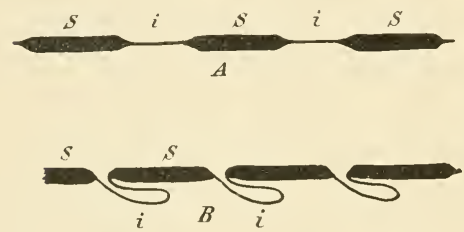

Fig. 1. Segmentplatten $(S)$ und Intersegmentalhäute (i). In $A$ die letzteren freiliegend, in $B$ eingefaltet, so daß Platte an Platte zu liegen kommt, wodurch der Schutz erhöht wird. wegungsmuskulatur darbietet) als auch dem Schutz. Um bei der Starrheit des Panzers eine ausgiebige Bewegungsmöglichkeit $\mathrm{zu}$ erlangen, ist es notwendig, dal jener in kleinere Stücke zerlegt wird, die beweglich miteinander verbunden sind - ähnlich wie die Ritterrüstungen des Mittelalters. Es ist dies bei den Arthropoden in der Weise durchgeführt, daß dicke starre Hautabschnitte mit dünnen beweglichen abwechseln (Fig. 1) (mit und ohne Ausbildung eigentlicher Gelenke). Erstere werden (soweit der Körperstamm in Betracht kommt) als Segmentplatten bezeichnet, letztere als Intersegmentalhäute. Von dem gegenseitigen Größenverhältnis der beiden hängt der Grad der Beweglichkeit $\mathrm{ab}$, $\mathrm{d}$. h. je mehr die Intersegmentalhäute den Segmentplatten gegenüber an Ausdehnung gewinnen, desto größer ist die Beweglichkeit und umgekehrt. Da die Intersegmentalhäute bei ihrer Feinheit wenig Schutz gewähren, so liegen diese für gewöhnlich nicht frei an der Oberfläche, sondern sind so weit unter die Segmentplatten eingefaltet, dab die Ränder der letzteren direkt aneinanderstoßen resp. über- oder untereinander zu liegen kommen (Fig. $1 B$ ).

Die Abschnitte (Segmente), in welche der Körper in dieser Weise zerlegt ist, sind keineswegs alle einander gleichwertig, sondern oft recht ungleichwertig oder mit anderen Worten: die Segmentierung ist eine heteronome. Die Heteronomie ist aber nicht als ursprünglicher Zustand zu betrachten, sondern ist in der Hauptsache durch Verschmelzungen (sodann auch durch Reduktion) einer größeren oder geringeren Anzahl von im Embryo homonomen Segmentanlagen hervorgegangen. So entspricht also der Grad der Heteronomie der 
Ausdehnung der stattgehabten Verschmelzungen (resp. Reduktionen). Am geringsten ist die Heteronomie ausgebildet bei den Tausendfüßen oder Chilopoden (Fig. 2), bei denen der einzige ungleichwertige Abschnitt der Kopf (Cephalon) ist, der aus nicht weniger als sechs Segmenten verschmolzen ist, also morphologisch auch sechs der folgenden Rumpfsegmente gleichzusetzen ist. Weitere Verschmelzungen finden wir bei den Insekten (Fig. 3), bei denen außer dem aus 5 Segmenten gebildeten Kopf einmal auch die folgenden

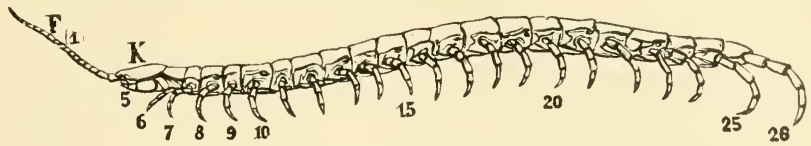

Fig. 2. Ein Tausendfuß, Scolopendra morsitans $L$.

$K$ Kopf; $\left.F_{(1}^{\prime}\right)$ Fühler; 5-26 Extremitäten des Rumpfes. - (N.)

3 Segmente zur Brust (Thorax) verwachsen, und sodann auch mehr oder weniger ausgedehnte Verschmelzungen (und auch Reduktionen) an dem auf die Brust folgenden Stammabschnitt, dem Hinterleib (Abdomen) stattfinden können. Ausgedehnte Verwachsungen finden wir auch bei den Spinnentieren, deren Cephalon aus 7 Segmenten zusammengesetzt ist, und deren

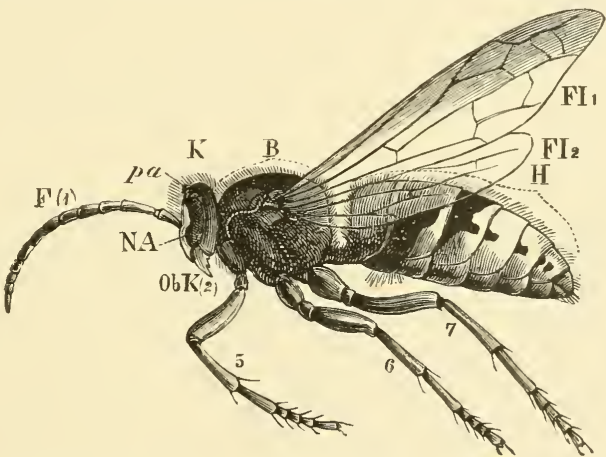

Fig. 3. Männliche Hornisse, Vespa Crabro L. $K$ Kopf; $B$ Brust; $H$ Hinterleib mit sieben Segmenten; $F$ Fühler (erstes Gliedmaßenpaar); $N A$ Seitenauge; $p a$ Punktauge; $O b K$ Vorderkiefer (zweites Gliedmaßenpaar); die 2 folgenden Kieferpaare sind in dieser Ansicht nicht wahrzunehmen; 5, 6, 7 Beine (fünftes bis siebentes Gliedmaßenpaar); $F l_{1}$ Vorderflügel; $F l_{2}$ Hinterflügel. - (N.)

Hinterleib ebenfalls starke Verschmelzungen aufweisen kann; stellt doch bei vielen Spinnen der Hinterleib einen völlig einheitlichen Abschnitt dar (Fig. 4). Ja, es kann sogar das Abdomen auch noch mit dem Vorderleibe (Cephalon) verschmelzen, so daß die Segmentierung vollkommen verschwindet (Fig. 5) und der Körper gänzlich ungegliedert erscheint (Milben). -.- In wieder anderer Weise vollziehen sich die Segmentverschmelzungen bei den höheren Krebsen, indem hier der Kopf mit der Brust verwachsen ist (13 Segmente) und als sog. Kopfbruststück oder Cephalothorax dem größtenteils homonom gegliederten Hinterleib gegenübersteht usw. (Fig. 6). So finden wir also bez. 
der Heteronomie der Segmentierung eine ungeheure Mannigfaltigkeit, die, wie wir gleich sehen werden, für die systematische Einteilung von Wichtigkeit ist.

Die Heteronomie hängt innig zusammen mit der verschiedenartigen Ausbildung der gegliederten Extremitäten. Wir müssen davon ausgehen, daf ursprünglich jedem Segment ein Extremitätenpaar angehörte, welches lediglich der Fortbewegung diente (wie wir es z. B. noch am

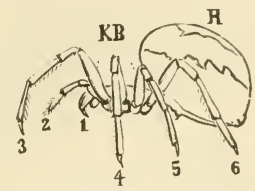

Fig. 4. Kreuzspinne, Epeira diadema $L$. $K B$ Kopfbrust (richtiger Kopf); $H$ Hinterleib. $1 / 1$ n. Gr. - (N.)

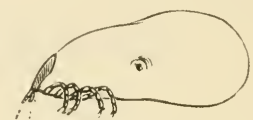

123456

Fig. 5. Holzbock, Ixodes ricinus $L$. $2 / 1$ n. (ir. $-(\mathrm{N}$.)

Rumpf der Tausendfüfie [Scolopender] beobachten können). Mit der besseren Ausgestaltung der einzelnen Extremität und der Bewegungsmuskulatur wurde eine Reduktion der Zahl der lokomotorischen Extremitäten ermöglicht, resp. konnte die Fortbewegung des Körpers von einigen wenigen Paaren allein besorgt werden. Die dadurch frei werdenden Extremitätenpaare konnten nun entweder für andere Dienste herangezogen oder, wo solche nicht nötig, gänzlich entfernt werden. So sehen wir denn auch in der Tat die ver-

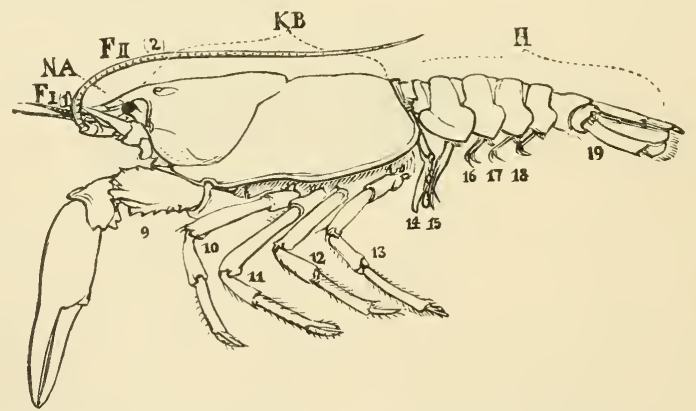

Fig. 6. Der Flußkrebs, Astacus fluviatilis Fabr. KB Kopfbruststïck; H Hinterleib; NA gestieltes Netz auge; FI vorderer Fühler; FII hinterer Fühler; 9-13 die Extremitäten der Brnst; 14-19 Extremitäten des Hinterleibes. - (N.)

schiedensten Funktionen der für die Fortbewegung entbehrlich gewordenen Extremitäten übertragen, indem die einen zu Sinnesorganen (Fühler), die anderen zu Greif- und Kauorganen, wieder andere zu Atmungsorganen geworden sind, und sich endlich in den Dienst der Fortpflanzung (Begattungshülfsapparate) gestellt haben. Die Umgestaltungen, die mit einem solchen Funktionswechsel notwendig verbunden sind, konnten nicht ohne Einflub auf die Form der zu den betreffenden Extremitäten gehörenden Segmente bleiben. Besonders 
stark mußte der Einfluß da sein, wo eine größere Anzahl Extremitätenpaare zu einer gemeinsamen Funktion zusammentreten (wie z. B. die Mundgliedmafien); das dadurch bedingte Zusammenrücken der betr. Extremitätenpaare führte natürlich auch zu einem engeren Anschluß der Segmente und schlieflich zur völligen Verschmelzung dieser.

Wenn, wie wir oben ausführten, zu jedem Segment ursprünglich ein Extremitätenpaar gehört, so müssen wir auch bei stattgehabten Verschmelzungen die Zahl der verwachsenen Segmente an der Zahl der an dem betr. Abschnitt vorhandenen Extremitäten ohne weiteres ermitteln können; d. h. wo z. B. 3 Extremitätenpaare vorhanden sind, muf der Abschnitt aus 3 Segmenten zusammengesetzt sein, auch wenn keine sonstigen äuferen Anzeichen (Nähte) auf eine Zusammensetzung schliefien lassen. Dies trifft auch im allgemeinen zu, so sagen uns z. B. die 3 Beinpaare der Insekten, daß der Brustabschnitt aus 3 Segmenten besteht; so läft uns ferner der Umstand, daß bei den Diplopoden (Tausendfüfe) an jedem Segment 2 Beinpaare vorkommen, erkennen, daß hier jedes Segment morphologisch 2 Segmenten der übrigen Tausendfüfe entspricht resp. daf es sich um "Doppelsegmente“ handelt usw. Doch müssen wir dabei uns stets vergegenwärtigen, daf auch Rückbildungen von Extremitäten stattgefunden haben können, so daf also die Zahl der in einem Abschnitt vereinigten Segmente recht wohl auch gröber sein kann als die Zahl der sichtbaren Extremitäten. Solche Fälle sind gar nicht selten; so weist der Kopf der Insekten 4 Paare Extremitäten (1 Paar Fühler, 3 Paare Mundgliedmafen) auf, enthält aber trotzdem die Elemente von 5 Segmenten, von denen 1 (Intercalarsegment) stark rückgebildet resp. nur noch in der Embryonalanlage deutlich nachweisbar ist.

Vielfach kommen aber auch wohlausgebildete Segmente ohne Extremitäten vor, wie z. B. die meisten Hinterleibssegmente der Insekten; doch lassen sich in allen diesen Fällen wenigstens embryonal noch mehr oder weniger deutlich Extremitätenanlagen nachweisen, so daf jene Extremitätenlosigkeit demnach ebenfalls einen abgeleiteten (sekundären) Zustand darstellt - und also unser oben ausgesprochener Satz, daf zu jedem Segment ein Extremitätenpaar gehört, dadurch keine Einbufe erleidet.

Der Chitinpanzer, der den Arthropodenkörper umgibt, ist durch seine Starrheit dem Wachstum natürlich sehr hinderlich. Es ist daher notwendig, daß derselbe von Zeit zu Zeit gesprengt und abgeworfen und durch einen neuen geräumigeren Panzer (der unter dem alten vorgebildet wird) ersetzt wird - ein Vorgang, den man als Häutung bezeichnet. Das Wachstum eines jeden Arthropoden ist also mit Häutungen verbunden, deren Zahl recht verschieden sein und selbst bei ein und derselben Art schwanken kann (z. B. bei der Nonne, deren Raupe 4 oder 5 Häutungen durchmachen kann). Daraus folgt, dab da, wo die Zahl der Häutungen begrenzt ist, auch das Wachstum beschränkt ist, d. h. mit der letzten Häutung die definitive Größe des Tieres bestimmt ist; ein ausgeschlüpfter Käfer z. B. oder Schmetterling kann daher nicht mehr wachsen. 
Infolge der Zerlegung des Hautskelettes in Segmente ist auch die an der Innenseite dieses Skelettes angeordnete Körpermuskulatur — die bei den Ringelwürmern einen kontinuierlichen Hautmuskelschlauch bildet - in einzelne segmentale Muskelgruppen gesondert. Die Muskeln, gleichgültig ob willkürliche oder unwillkürliche, sind (mit seltenen Ausnahmen) quergestreift (rasche Reaktionsfähigkeit!).

Was die innere Organisation betrifft, so stimmen die Arthropoden bez. der Lağerung der Hauptorgane mit den Ringelwürmern überein, indem die Leibeshöhle (die allerdings nur teilweise der Annelliden-Leibeshöhle entspricht) dorsal von dem Zentralorgan des Kreislaufes (Herz), in der Mitte vom Darm und ventral vom Zentralnervensystem durchzogen wird (Fig. 7) - also gerade umgekehrt wie bei den Wirbeltieren, bei denen das Herz auf der Bauchseite und das Nervensystem (Rückenmark) auf der Rückenseite verläuft.

Die Leibeshöhle ist mit der entweder farblosen oder verschieden gefärbten und stets Zellen enthaltenden Blutflüssigkeit, welche alle Organe bespült, angefüllt. Das Blut der Arthropoden ist demnach identisch mit der Leibesflüssigkeit oder dem „Körpersaft“. Die Zirkulation des Blutes wird im einfachsten Fall durch Bewegungen des ganzen Tieres, meist aber durch ein

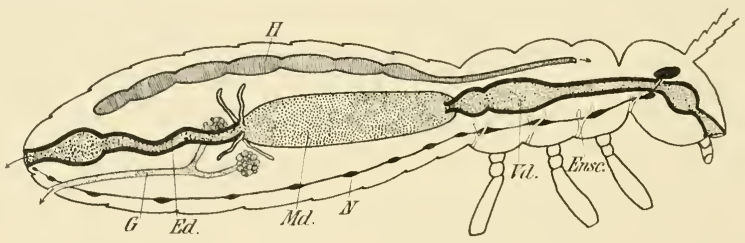

Fig. 7. Lagerung der Organe im Insektenkörper. $H$ Herz; $\boldsymbol{V} d, \boldsymbol{M} d, \boldsymbol{E} d$ Vorder-, Mittel- und Enddarm: $N$ Nervensystem (Bauchmark); $G$ Geschlechtsorgane; Ensc Endoskelett.

bei den verschiedenen Gruppen sebr verschieden gebautes Herz bewirkt. An dieses schlieft sich bei vielen Formen ein mehr oder weniger kompliziertes, aber niemals vollkommen gegen die Leibeshöhle abgeschlossenes Gefäß system an. - Die Ausbildung des Herzens- und Gefäfsystems hängt innig zusammen mit der Ausbildung der Atmungsorgane: wo einerseits solche ganz fehlen (Hautatmung) oder aber wo der ganze Körper von Atemröhren (Tracheen) durchzogen wird, da treten die Gefäßje zurück; wo andererseits die Atmung auf bestimmte Körperstellen lokalisiert ist (Kiemen der Krebse, Lungen der Spinnen), finden wir auch ein gut ausgebildetes Gefälisystem. Im letzteren Fall hat ja auch das Blut den Transport des Sauerstoffs von den Kiemen oder Lungen nach allen Körperregionen hin zu besorgen, während diese Funktion bei den Tracheen-Atmern wegfällt, indem hier die im ganzen Körper verzweigten Tracheen selbst die Zuleitung des Sauerstoffs zu allen Zellen übernehmen.

Der verschieden gegliederte und mit verschiedenen Anhangsdrüsen versehene Darmkanal, der nur in sehr seltenen Fällen verkümmert, ist zwischen dem vorn (auf der Bauchseite) gelegenen Mund und der Afteröfnung ausgespannt. Er besteht aus 3 Abschnitten, dem Vorder-, Mittel- und Hinter- 
darm, von denen der erste und letzte durch Hauteinstülpungen entstehen und daher mit einer Chitinkutikula, die stellenweise zu Zähnen, Leisten usw. verdickt sein kann, ausgekleidet sind (Fig. $7 V d, M d$ und $E d$ ).

Das Zentralnervensystem, welches dem "gangliösen Typus" angehört, besteht aus dem über dem Darm gelegenen Gehirn (aus 3 Ganglienpaaren verschmolzen), dem unter dem Darm von vorn nach hinten ziehenden Bauchmark (Fig. $7 N$ ) und endlich der diese beiden verbindenden Schlundkommissur. Das Bauchmark besteht der Anlage nach in jedem Segment aus je zwei rechts und links von der Medianlinie gelegenen Ganglien (Nervenknoten), welche sowohl unter sich durch eine Querkommissur, als auch mit den jeweils vorhergehenden und folgenden Ganglienpaaren durch je ein paar Längskommissuren verbunden sind. Dadurch erinnert das Bauchmark ein wenig an eine Strickleiter, weshalb man auch von einem "StrickleiterNervensystem" spricht. Gewöhnlich aber tritt diese Form bei der Entwicklung mehr oder weniger wieder zurück, indem ausgedehnte Verschmelzungen, sowohl der Länge als der Quere nach stattfinden. Die Konzentration kann so weit gehen, dab das ganze Bauchmark aufer dem vordersten, sog. Unterschlundganglien, nur noch aus einem einzigen Nervenknoten besteht, der dann natürlich auch entsprechend grob ist.

Als Exkretionsorgane finden sich entweder den Nephriden der Ringelwürmer homologe Organe (wie die Schalen- und Antennendrüsen der Krebse, die Coxaldrüsen der Spinnen) oder aber völlig neu auftretende Organe, die sog. Malpighischen Gefäße, die als Ausstülpungen des Mitteldarms (Spinnen) oder des Hinterdarms (Insekten) entstehen.

Auch bezügl. der Geschlechtsorgane weichen die verschiedenen Klassen der Arthropoden mehr oder weniger voneinander ab. Den meisten kommt blof ein Paar Keimdrüsen zu, die durch (auf Nephridien rückführbare) Ausführgänge entweder mit paarigen oder unpaaren Mündungen nach aufen führen. -- Nur ganz wenige Arthropoden (wie z. B. die Cirripedien oder Entenmuscheln, oder die bei Termiten parasitierende Fliegengattung Termi-

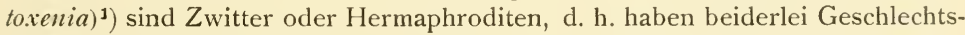
organe in einem Individuum vereinigt. Alle übrigen sind getrennten Geschlechts; allerdings scheinen in einigen Fällen die Männchen ganz in Wegfall gekommen zu sein, so daf alle die betr. Arten nur noch im weiblichen Geschlecht existieren.

Die Fortpflanzung der Arthropoden ist ausnahmslos eine geschlechtliche, geschieht also ausschlieflich durch Keimzellen. Nicht selten kommt jedoch Parthenogenese, d. h. Entwicklung unbefruchteter Eier, vor, und zwar entweder rein oder in regelmäfiger Abwechselung mit Gamogonie (Entwicklung nach vorhergegangener Befruchtung). Die Eier sind meist dotterreich und haben in der Regel die Fähigkeit zur totalen Furchung verloren. Es wird nur die oberflächliche Schicht des Eies in Zellen zerlegt, während der im Innern befindliche Dotter lange Zeit oder auch dauernd ungefurcht bleibt. Wir bezeichnen diese Art der Furchung, die sonst nirgends mehr im bestritten.

1) Der Hermaphroditismus von Termitoxenia wird neuerdings (von Bugnion) 
'Tierreich vorkommt, als superficielle. - Aus dem ursprünglich gleichartigen Blastoderm - wie jene oberflächlich gelegene Zellschicht benannt wird - sondert sich als erste Anlage des Embryos der deutlich segmentierte „Keimstreif" ab, welcher der Bauchseite des jungen Tieres mit dem Nervensystem und den Extremitätenpaaren entspricht. Die Ausbildung des Rückens vollzieht sich erst viel später, und zwar ineist erst ganz am Ende der Embryonalentwicklung. ${ }^{1}$ )

Nur wenige Arthropoden verlassen das Ei in der dem erwachsenen Tiere eigentümlichen Form; die meisten durchlaufen vielmehr im Anschluß an die Embryonalentwicklung noch eine Reihe unter mehr oder weniger zahlreichen Häutungen (siehe oben) sich vollziehender Umgestaltungen, die je nach Art und Kompliziertheit als Ana-, Epi- oder Metamorphose bezeichnet werden. Das bekannteste Beispiel ist die Entwicklung des Schmetterlings, welcher vor seiner definitiven Ausbildung ein Raupen- und Puppenstadium durchzumachen hat (Metamorphose).

\section{Die Klassen der Arthropoden.}

Der Stamm der Arthropoden enthält vier natürliche Gruppen, Klassen, die unter dem Namen Krebstiere (oder Crustacea), Spinnentiere (oder Arachnoidea oder Chelicerata), Tausendfüle (oder Myriapoda) und Insekten (oder Hexapoda) bekannt sind. Als Unterscheidungsmerkmale verwendet man die Verschiedenheit der Segmentierung, die Zahl und Ausbildung der Extremitäten, die Beschaffenheit der Atmungsorgane, die Art der Exkretionsorgane (Nieren), das Vorhandensein oder Fehlen gewisser Darmdrüsen (Leber) usw. - Ziehen wir unter Berücksichtigung aller dieser Merkmale Vergleiche zwischen jenen 4 Klassen, so ergibt sich, dass zwischen den Myriapoden und Insekten eine weit größere Übereinstimmung besteht, als zwischen diesen und den Spinnen oder Krebsen. Die Übereinstimmungen bezieht sich auf den wohlausgebildeten Kopf (Cephalon) mit nur einem Paar Fühler (Antennen), auf die Tracheenatmung, auf das Fehlen von Leberdrüsen und auf das Vorkommen von Malpighischen Gefäßen Man hat daher die Insekten und Tausendfüße unter dem Namen Atelocerata (auch Antennata, Eucephalica) zu einer höheren systematischen Kategorie, einem Unterstamm oder Subphylum, zusammengefabt.

Auch die beiden anderen Klassen, die Krebse und Spinnen, zeigen ihrerseits nähere Beziehungen untereinander, wie in dem Vorkommen von Leberdrüsen am Mitteldarm oder in der Ausbildung des vordersten Körperabschnittes, der aufer den eigentlichen Mundgliedmafen (und event. Fühlern meist auch noch andere Extremitäten trägt (und deshalb auch als Cephalothorax bezeichnet wird). Doch stehen hier den Übereinstimmungen so viele wesentliche Unterschiede gegenüber, daß eine Vereinigung der beiden besser unterbleibt.

1) Im Gegensatz zu den Wirbeltieren, bei denen zuerst die Rückenfläche mit dem dort befindlichen Rückenmarke angelegt wird, während der Bauch zuletzt ausgebildet wird und sich auch zuletzt schließt, wie die Stellung des Nabels zeigt. Man kann sich diesen Unterschied am besten an gekochten Krebseiem einerseit. und an jungen, eben ausgeschlüpften Forellen andererseits veranschaulichen. 
Der Zusammenfassung der Spinnen und Krebse al- "Cephalothoracica", wie sie von Goette vorgeschlagen wird, steht der Lmstand entgegen, daß die Spinnen nach den vergleichend embryologischen Untersuchungen von Heymons gar keinen eigentlichen Cephalothorax, der aus einer Verschmelzung des Kopfemit Teilen des Brustabschnittes hervorgegangen ist, besitzt. Der vordere Körperabschnitt der Spinnen enthält vielmehr, trotzdem er neben den Mundgliedmaßen noch die 4 Beinpaare trägt, keine Elemente des Brustabschnitts, sondern ist ein reines Cephalon. Die Laufbeine sind also auch keine Brust-, sondern Kopfextremitäten und die Spinnen demnach richtige "Kopffüßler “. Der Körper der Spinnen zerfällt also nicht in Cephalothorax und Hinterleib (Abdomen), sondern in Kopf (Cephalon) und Rumpf. Nur bei wenigen Formen läßt sich noch eine Teilung des Rumpfes in Brust und Hinterleib erkennen, wie z. B. beim Skorpion, desien breiter auf den Kopf folgender Rumpfabschnitt (früher als Praeabdomen bezeichnet) dem Thorax, und dessen schmaler hinterer Teil (der sog. Schwanz) mit dem Giftstachel (früher Postabdomen) dem Abdomen der übrigen Arthropoden ent-pricht. - Auch bei primitiven (ausgestorbenen) Formen und bei den Embryonen jetzt lebender Spinnen ist jene Teilung des Rumpfes meist noch deutlich erhalten, und besitzt der Thorax auch noch mehr oder weniger vollkommene

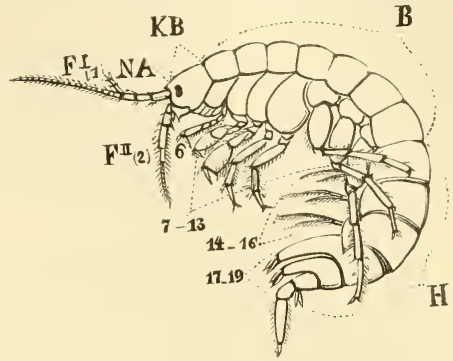

Fig. 8. Flohkrebs. Gammans $K B$ Kopfbruststiick; $B$ die 7 freien Brustringe; $H$ Hinterleib; $N A$ sitzendes Netzange; $F I$ vorderer Fübler (er'stes Gliedmaßenpaar); FII hinterer Fühler (zweites Gliedmaßenpaar). Die 3 folgenden Gliedmaßenpaare, die Kiefer, sind nur angedeutet; 6 Kieferfuß (6. Gliedmaßenpaar, das letzte des Kopfbruststückes : 7-13 die 7 Fußpaare der freien Brustringe; 14-16 Schwimmfüße des Hinterleibes (14.-16. Gliedmaßenpaar); 17-19 Springfüße des Hinterleibes (17,-19, Gliedmaßenpaar). $5 / 2$ n. Gr. - (N.) Extremitäten.

Vielfach findet sich in den zoologischen Lehrbüchern eine andere Gruppierung der obigen Arthropodenklassen, welche in erster Linie die Beschaffenheit der Atmungsorgane berücksichtigt und dabei zu zwei Hauptgruppen gelangt: die Kiemenatmer (oder Branchiaten) und die Tracheenatmer (oder Tracheaten). Die ersteren entsprechen in der Hauptsache den Krebsen, die letzteren den Spinnen + Tausendfüßen + Insekten. Nachdem aber nachgewiesen ist, daß die Tracheen der Spinnen keineswegs den Insektentracheen homolog sind, sondern vielmehr-von den Kiemen der Krebse abzuleiten sind, hat diese Gruppierung die Berechtigung verloren.

Wir teilen also den Stamm der Arthropoden am besten in drei Unterstämme oder Subphyla ein, nämlich: 1. die Teleiocerata (oder Crustacea, Branchiata, Krebstiere); 2. die Chelicerata (Arachnoidea, Spinnentiere); 3. die Atelocerata (Eucephalica, Eutracheata). Sehen wir von ein-

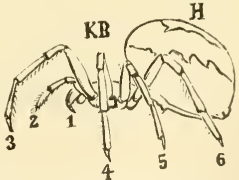

Fig. 9. Kreuzspinne, Epeira diademal $L_{.}-(\mathrm{N}$. zelnen ganz aborranten Formen ab, so können wir diese drei Gruppen folgendermaben charakterisieren:

Teleiocerata (Krebstiere). Kopf mit 2 Fühlerparen und 3 Paaren Mundwerkzeugen (Mandibeln und zwei Maxillenparen), meist mit der Brust (Fig. 6) oder wenigstens Teilen der Brust (Fig. 8) verwachsen (Cephalothorax). Atmung durch die Haut oder 
durch Kiemen. Mitteldarm mit „Leber“. Exkretionsorgane (Niere) kopfständig, nephridienartig (Antennen- und Maxillendrüse).

Chelicerata (Spinnentiere). Kopf ohne eigentliche rückenständige Fühler, mit 6 Extremitätenpaaren, von denen die ersten beiden (Cheliceren und Pedipalpen) als Mundgliedmafien und die folgenden 4 als lokomotorische Extremitäten (Laufbeine) dienen. Rumpf gewöhlich einheitlich, nur selten in Thorax und Abdomen geschieden. Atmung durch Tracheenlungen oder Tracheen. Mitteldarm meist mit leberartigen Drüsen. Exkretionsorgane meist in den Mitteldarm, zuweilen auch an den Coxen direkt nach aufen mündend („Coxaldrüsen“).

$\mathrm{Zu}$ den Spinnentieren werden vielfach auch die sog. Bärtierchen oder Tardigraden gestellt. Es sind dies mikroskopisch kleine, im Wasser oder feuchten Moos lebende Tiere, welche an einem unsegmentierten Körper 4 Paar mit "Krallen" bewaffnete Extremitätenstummel besitzen. Nachdem aber die "Krallen", die so

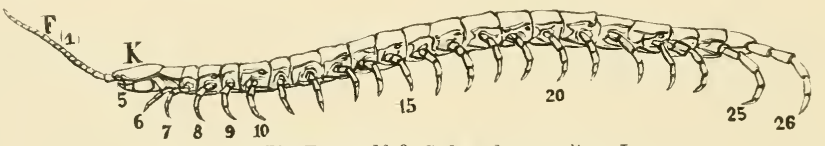

Fig. 10. Ein Tausendfuß, Scolopendra morsitans $L$.

$K$ Kopf; $F\left({ }_{1}\right)$ Fühler; 5-26 Extremitäten des Rumpfes. - (N.)

ziemlich das einzige Arthropodenmerkmal darstellen, als eine Gruppe von Borsten sich erwiesen haben, die viel Ähnlichkeit mit den Borsten der Annelliden-Parapodien haben, sind die Tardigraden aus dem Stamm der Arthropoden zu entfernen und den Annelliden anzugliedern.

Atelocerata (Insekten- und Tausendfüfse). Kopf mit einem Paar Fühler (nur ganz selten fehlend: Protura und verschiedene Larven) und 3 Paaren Mundgliedmaßen (Mandibeln und zwei Maxillenpaaren). Körper in 2 (Kopf und Rumpf) oder 3 deutliche Abschnitte (Kopf, Brust und Hinterleib) zerlegt. Atmung durch Tracheen. Mitteldarm ohne Leber. Als Exkretionsorgane dienen Ausstülpungen des Hinterdarms (Malpighische Gefäle).

$\mathrm{Zu}$ den Atelocerata werden neben den Tausendfüßen und Insekten gewöhnlich auch noch die Protracheaten oder Onychophoren angeführt, die mit wenigen (5) Gattungen, von denen Peripatus am bekanntesten ist, und ca. 50 Arten in weit entfernten Gegenden (Süd-Afrika, Westindien, Neuseeland) vorkommt. Diese Angliederung an die Antennaten beruht lediglich auf dem Vorkommen ron Tracheen. Da aber gerade die Tracheen, wie wir oben schon sahen, ganz unabhängig voneinander auf verschiedenem Wege sich bilden können, so i.st dieses Merkmal allein jedenfalls nicht genügend, eine so abweichende Tiergruppe, die in ihrer inneren wie äußeren Organisation (ohne Hautskelett und ohne deutliche äußere Gliederung, mit Hautmuskelschlauch, mit undeutlich gegliederten Stummelfüfen, mit Segmentalorganen und mit größtenteils glatter Muskulatur) noch weit mehr Annellidenals Arthropodencharaktere zeigt, in eine so scharf umschriebene und speziali-ierte Gruppe, wie die Ateloceraten, einzureihen. Wenn wir die Onychophoren überhaupt bei den Arthropoden belassen wollen, so müssen wir sie jedenfalls als einen besonderen Unterstamm auffassen. 
Die beiden Klassen der Ateloceraten lassen sich, wie folgt, leicht voneinander trennen: ${ }^{1}$ )

Myriapoden: Körper nur in zwei deutlich gesonderte Regionen (Kopf und Rumpf) geteilt; letzterer meist mit zahlreichen Segmenten, die fast sämtlich mit gut gegliederten Extremitäten versehen sind (Fig. 10).

Insekten: Körper stets in drei Regionen gesondert, Kopf, Brust (Thorax) und Hinterleib (Abdomen). Thorax mit drei Paaren ansehnlicher Bewegungsextremitäten (Beine) und häufig auch am 2. und 3. Segment mit zwei dorsalen Flügelpaaren. Abdomen meist ohne ausgebildete Extremitäten (Fig. 11).

Von den Krebsen, Spinnen und Tausendfüfen wird, soweit sie Interesse für den Forstmann haben, am Schlusse des Werkes in einem besonderen Anhang noch die Rede sein. Wir wenden uns im folgenden gleich zu den Insekten.

\section{Literatur.}

Berlese, A., Monographia dei Mrrientomata. Redia. Bd. 6. 1910.

Bütschli, O., Vorlesungen über die vergleichende Anatomie. Bd. I und II. Leipzig 1910 und 1912.

Claus-Grobben, Lehrbuch der Zoologie. 8. Aufl. Narburg 1910.

Götte, Alexander, Lehrbuch der Zoologie. Leipzig 1902.

Handlirsch, A., Die fossilen Insekten und die Phylogenie der recenten Formen. Leipzig $1906-1908$.

Hertwig, Richard, Lehrbuch der Zoologie. 10. Aufl. Jena 1912.

Heymons, R., Die Entwicklungsgeschichte der Scolopender. (Zoologica Heft 33.) Stuttgart 1901.

Pocock, R. J., On the classification of the Tracheate Arthropoda. Zool. Anzeiger, XVI. Jahrg. 1893, p. $271-275$.

Prell, H., Das Chitinskelett von Eosentomen. Stuttgart 1913 (Zoologica).

$\left.{ }^{1}\right)$ Der wahren Stammverwandtschaft näher kommt wohl die Einteilung Pococks nach der Lage der Geschlechtsöffnungen.

Unter Berücksichtigung späterer Modifikationen zerfallen darnach die Ateloceraten in zwei Reihen:

1. Die Progoneaten: Die Geschlechtsöffnung befindet sich im vorderen Teil des Rumpfes. Hierher die Diplopoden, Pauropoden, Symphylen.

2. Die Opisthogoneaten: Die Geschlechtsöffnung befindet sich am Hinterende des Rumpfes. Hierher die Chilopoden und Insekten. 
Kapitel 11

\section{Die äußere Erscheinung der Insekten (Morphologie).}

Der Körper der Insekten zerfällt in drei mehr oder weniger deutlich voneinander gesonderte Abschnitte, die als Kopf (Cephalon), Brust (Thorax) und Hinterleib (Abdomen) bezeichnet werden (Fig. 11). Der Kopf trägt ein Paar rückenständiger Fühler (Ausnahme Protura) und 3 Paar bauchständiger Kiefer, die Brust 3 Paar Beine und meist 2 Paar Flügel. während der Hinterleib im allgemeinen gliedmaßenlos ist.

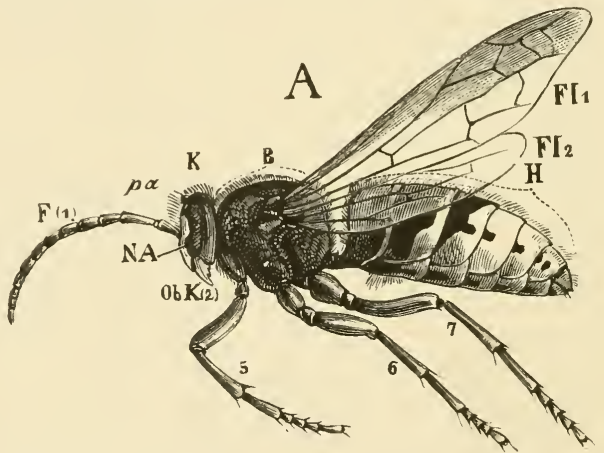

Fig. 11. Männliche Hornisse, Vespa Crabro $L . \quad K$ Kopf; $B$ Brust; $H$ Hinterleib mit sieben Segmenten; $F$ Fühler (erstes Gliedmaßenpaar); NA Seitenauge; $p a$ Punktauge; $O b K$ Vorderkiefer (zweites Gliedmaßenpaar); die 2 folgenden Kieferpare sind in dieser Ansicht nicht wahrzunehmen; 5, 6, 7 Beine (fünftes bis siebentes Gliedmaßenpaar); Fl1 Vorderflügel; Fl2 Hinterflügel. - (N.)

Um die Zusammensetzung des Insektenkörpers richtig zu beurteilen, müssen wir auf die embryonalen Anlagen zurückgreifen; denn selbst bei den primitivsten Insekten haben so viele Umbildungen und Reduktionen usw. stattgefunden, daß die ursprüngliche Zusammensetzung teilweise stark verdeckt wird. - Nach Heymons, dem wir die umfassendsten und bezüglich der Klarheit geradezu klassischen Untersuchungen verdanken, besteht der Insektenkörper aus folgenden Teilstücken: einem vor der Mundöffnung gelegenen extremitätenlosen Oralstück oder Acron, einem hinter. der Afteröffnung gelegenen, ebenfalls extremitätenlosen Analstück oder Telson und 19 zwischen diesen beiden gelegenen homonomen, mit je einem Paar Extremitäten versehenen Segmenten (Fig. $12 \mathrm{~A}$ ). Wir haben also zwei morphologisch verschiedenwertige Elemente in der Anlage zu unterscheiden, nämlich einerseits die extremitätenlosen Kopf- und Schwanzstücke, Acron und Telson, und andererseits 
die dazwischenliegenden echten Segmente. Von diesen 19 Segmenten gehen nun nicht weniger als 5 in die Bildung des Kopfes ein, 3 in die Bildung der Brust, während die restlichen 11 auf das Abdomen entfallen. - Die weitgehendsten Umbildungen erleiden die Kopfsegmente, indem sie teilweise ihre ursprüngliche Lage und Formen verändern und auch ihre Extremitäten teils gänzlich verlieren (2. Segment), teils stark umbilden (1. und 3.-5. Segment). Die ersten zwei Segmente, das Antennal- und Intercalarsegment (und damit auch die Extremitäten des 1. Segments, die Fühler oder Antennen) rücken über die Mundöffnung, so daß also nur noch drei Segmente, das Mandibelsegment und die beiden Maxillensegmente, hinter der Mundöffnung verbleiben (Fig. $12 \mathrm{~B}$ ). - Die Brust läßt ihre Zusammensetzung aus $3 \mathrm{Seg}$ -

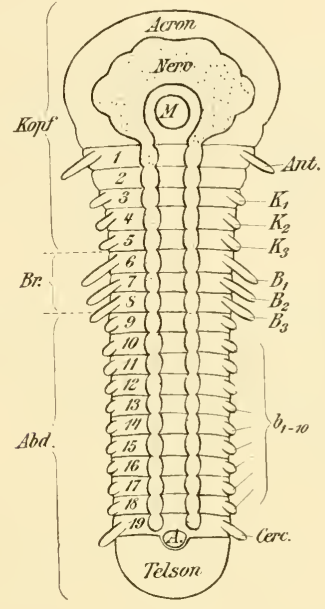

$A$

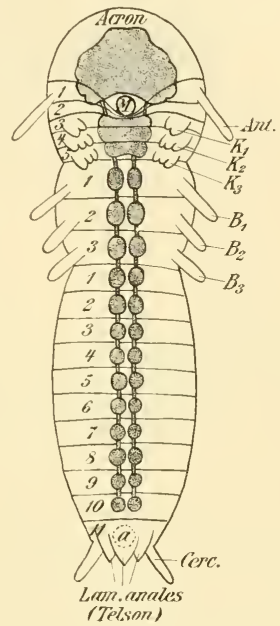

$B$

Fig. 12. Schematische Darstellung der embryonalen Segmentierung. $A$ junges, $B$ älteres Stadium. Zwischen Acron und Telson liegen 19 Segmente, von denen die ersten 5 in die Bildung des Kopfes, die folgenden 3 die Bildung der Brust und die letzten 11 in die Bildung des Abdomens eingehen. Beim jüngeren Stadium zeigen die Abdominalsegmente noch die rndimentären Beinanlagen. M Mund; $A$ und $a$ After (ist in Fig. $B$ unter der mittleren Lam. anal. liegend, also endständig zu denken); Nerv Anlage des Nerveusystems; Ant. Fühler; $K_{1-3}$ Kiefer $1-3 ; B_{1-3}$ Beine $1-3 ; b_{1-10}$ rudimentäre Beinanlagen der Abdominalsegmente; Cerc. Cerci.

menten bei allen Insekten, auch beim erwachsenen Tiere, der sog. Imago, noch deutlich erkennen, sowohl an dem Vorhandensein der 3 Beinpaare, als auch an den Segmentgrenzen. - Die Abdominalsegmente bleiben meist deutlich gegeneinander abgegrenzt, verlieren aber größtenteils ihre Extremitäten, nur das 11. Segment behält bei einer Anzahl Insekten seine Extremitäten in Form von langen fühlerähnlichen Anhängen (Cerci) bei. Bei den meisten Insekten sind jedoch auch diese verloren, wie überhaupt die Zahl der Segmente mehr oder weniger reduziert wird.

\section{Der Kopf.}

\section{A. Die Kopfkapsel.}

Der vorderste Abschnitt der Insekten, der Kopf, stellt eine starre, meist sehr kräftig chitinisierte Kapsel dar, welche gewöhnlich zwei Öffnungen be- 
sitzt: die ventral gelegene Mundöffnung und das auf der Hinterseite befindliche Hinterhauptsloch, durch welches die Speiseröhre, das Nervensystem usw. in den folgenden Brustabschnitt übertritt.

Die Trennung des Hinterhauptsloches von der Mundöffnung wird durch eine Kehlplatte (Gula) und Teile der Unterlippe bewirkt. Bei niederen Insekten bleibt die Gula frei oder verschmilzt mit der Unterlippe, bei höheren bildet sie durch Vereinigung mit den Seitenteilen des Kopfes eine Brücke zwischen denselben. (Prell.)
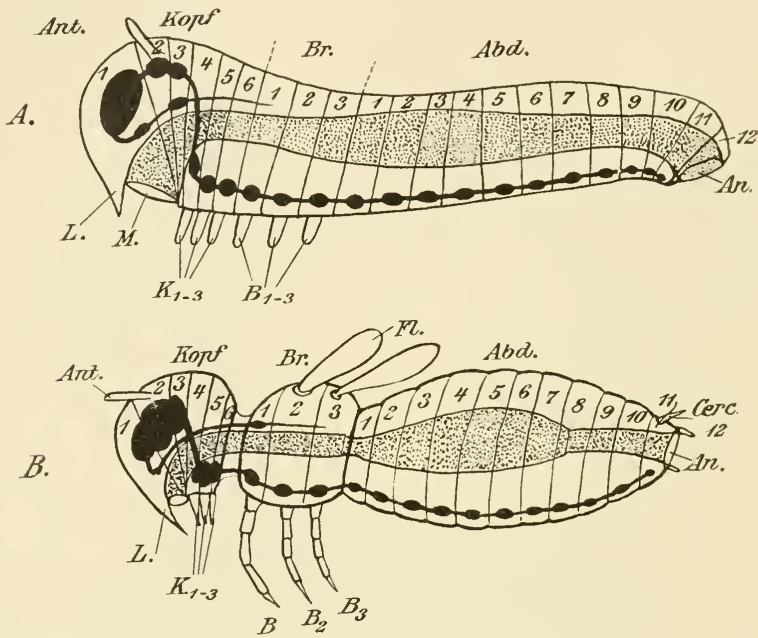

Fig. 13. Schematische Darstellung der Segmentierung und Regionenbildung. A die drei Regionen noch nicht voneiuander gesondert; $B$ Kopf, Brust und Abdomen deutlich geschieden. Kopf aus Acron und 5 Segmenten sich zusammensetzend. 1 Acron-, 2 Antennal-, 3 Intercalar-, 4-6 Kiefersegmente; Ant. Fühler; $B r$ Brust; $A b d$. Abdomen; $L$ Oberlippe; $M$ Mund; $K_{1-3}$ Kiefer $1-3 ; B_{1}{ }_{3}$ Brustbeine $1-3$. Nach Berlese, etwas verändert.

Der Kopf ist der Träger der wichtigsten Sinnesorgane (Geruch, Gesicht, Tast und Geschmack) und der der Nahrungsaufnahme dienenden M undwerkzeuge. Letztere sind es vor allem, welche die Konfiguration des Kopfes bestimmen. Das notwendige enge Zusammenrücken der drei Kieferpaare bedingt natürlich auch einen ebenso engen Anschlnß der betr. Segmente (Fig. 13), und die Muskulatur für die Kiefer verlangt kräftige Ansatzpunkte, was zu einer Verschmelzung der Segmente und kräftigen Chitinisierung führt. So können wir überall deutliche Beziehungen zwischen der Ausbildung der Mundgliedmaßen und der Größe und Festigkeit der Kopfkapsel feststellen: Je stärker die Mundgliedmaßen ausgebildet und je höhere Anforderungen an ihre Kraft gestellt werden, desto größer und härter ist auch die Kopfkapsel.

Es wäre also gänzlich verfehlt, aus der Größe des Kopfes etwra auf die Höhe der geistigen Fähigkeiten schließen zu wollen. Ein sehr schönes Beispiel dafür 
bieten die sog. Soldaten der Ameisen und Termiten dar, deren Köpfe mitunter enorme Dimensionen erreichen und um ein Vielfaches größer sein können als die Köpfe der Arbeiter, obwohl die Soldaten den Arbeitern geistig unterlegen sind. Die riesigen Köpfe sind lediglich bedingt durch die überaus kräftige Muskulatur, welche für die der Verteidigung dienenden starken Vorderkiefer notwendig ist.

Obwohl der Kopf, wie gesagt, eine einheitliche starre Kapsel darstellt, lassen sich doch einige durch Nähte oder Furchen usw. mehr oder weniger deutlich begrenzte Abschnitte oder Regionen unterscheiden. Betrachten wir z. B. die Vorderseite des Kopfes einer Küchenschabe (Fig. 14), so sehen wir zu oberst eine mediane Längsnaht, die sich nach kurzem Verlaufe gabelt. Dazu kommen weiter unten (ventralwärts) noch 2 weitere, kürzere Quernähte. Den dorsal gelegenen, durch die Längsnaht in உ Hälften geteilten Abschnitt

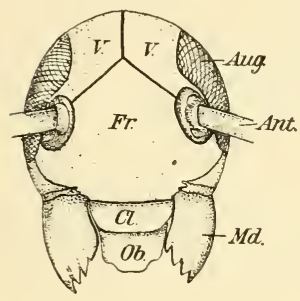

$A$

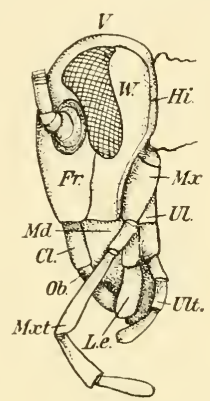

$B$

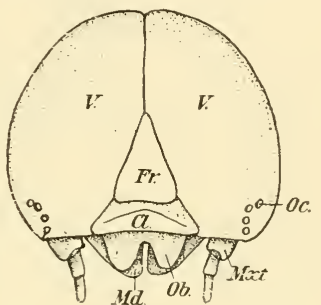

$C$

Fig. 14. Regionen der Kopfkapsel. A Kopf von Periplaneta (Kiichenschabe) von vorn gesehen; $B$ derselbe von der Seite gesehen; $C$ Kopf einer Schmetterlingsranpe. $V$ Vertex (Scheitel); $F r$ Frons (Stirne); $C l$ Clypeus; $W$ Wange; $H i$ Hinterhaupt; Ob Oberlippe; $\boldsymbol{M} d$ Mandibel; $\boldsymbol{M} x$ Maxille; $M x t$ Maxillartaster; L.e Lobus exterior; UI Unterlippe; Ut Unterlippentaster; Oc Ocellen; Ant Fühler. Nach B erles e.

bezeichnen wir als Scheitel (Vertex); die darauf folgende Region, die einerseits durch die Gabelnaht, andererseits durch die vor den Fühlern gelegene Quernaht begrenzt ist, stellt die Stirne (Frons) dar. Der durch die letztere Naht von der Stirne abgegrenzte Teil wird als Kopfschild (Clypeus) bezeichnet, auf welchen endlich die durch eine weitere Quernaht abgetrennte und meist mit dem Clypeus gelenkig verbundene Oberlippe (Labrum) folgt, die dicht über der Mundöffnung gelegen ist, und deren Unterseite gelegentlich besonders ausgebildet ist und dann als Epipharynx bezeichnet wird. - An der Hinterseite des Kopfes unterscheiden wir eine über (dorsal) dem Hinterhauptsloch gelegene Region, das Hinterhaupt (Occiput), und eine ventral davon gelegene, die Kehle (Gula), welche das Hinterhauptsloch von der Mundöffnung trennt (häufig stark reduziert). - Die seitlichen Partien des Kopfes endlich, welche von der Stirne, den Augen, dem Scheitel, Hinterhaupt, der Kehlplatte und der Basis der Vorderkiefer begrenzt werden, benennt man als Wangen (Genae und Postgenae).

Manche Autoren gehen in der Regioneneinteilung noch weiter und unterscheiden eine Vorder- und Hinterstirn (Prae- und Postfrons), ferner einen Ante- und Postclypeus und ein Ante- und Postlabrum. - Ubrigens ist die Begrenzung der 
Regionen keineswegs überall so klar wie im obigen Beispiel, sondern im Gegenteil meist undeutlicher, so daß es oft schwer fällt, die Regionen richtig zu deuten. Es liegt dies gewöhnlich daran, daß die Nähte mehr oder weniger verschwinden, oder daß einzelne Regionen besonders ansehnlich ausgebildet und dadurch andere stark reduziert sind, oder aber daf. besondere Bildungen (Hörner, Zacken usw.) auftreten, welche die Grenzen verdecken oder verschieben.

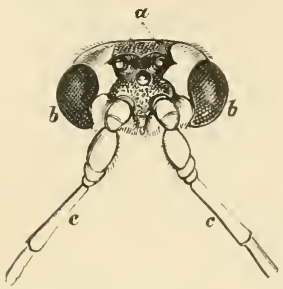

Fig. 15. Kopf einer schlupfwespe. $\%$ n. Gr. a die 3 Punktaugen; $b b$ die paarigen seitenangen; $c c$ die Fühler. - (N.)

Was die Beteiligung der verschiedenen Segmente an der Bildung der Kopfregionen betrifft, so lehrt die Embryologie, daß das Acron und die ersten 3 Segmente an dem Aufbau der Stirne nebst Clypeus und Labrum beteiligt sind, während der Scheitel, das Occiput und die Wangen von den Seiten- und Rückenteilen der Segmente $4-6$ gebildet werden. ${ }^{1}$ ) In welcher 1 'eise dies geschieht, dürfte am besten aus den schematischen Figuren $13 A$ u. $B$ hervorgehen.

An der Bildung der Kopfkapsel nehmen auch die Augen teil, und zwar mitunter in hervorragendem Małe. Wir unterscheiden Seitenaugen, die zu beiden Seiten der Stirne (zwischen Stirne, Scheitel und Wange [siehe Fig. 15]), und Stirna ugen, die in verschiedener Zahl (1-3) zwischen den

Seitenaugen auf der Stirne gelegen sind. Die letzteren sind meist klein und erlangen nur ganz selten eine nennenswerte Größe; die ersteren dagegen können eine solche Ausdehnung erreichen, daß der größte Teil der Kopfkapsel von ihnen eingenommen wird (einige Dipteren, Libellen usw.), während die übrigen Regionen (Stirne, Scheitel usw.) stark reduziert sind. - Näheres über
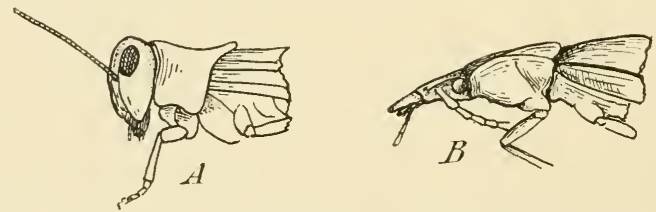

Fig. 16. Beispiele für die verschiedene Kopfstellung. A hypognather Typus (Feldheuschrecke $B$ prognather Typus (Laufkäfer, Cychrus spec.).

die Formenmannigfaltigkeit der Augen wird unten bei Besprechung der Sinnesorgane noch vorgebracht werden.

Was die Stellung des Kopfes gegen den folgenden Körperabschnitt, den Thorax, betrifft, so kommen zwei verschiedene Typen vor: entweder steht der Kopf so, daf die Mundteile nach unten, d. h. ventralwärts (und also die Stirne nach vorne), oder aber so, daf die Mundteile nach vorne (und die Stirne nach oben) gerichtet sind. Ersterer Typus, der als hypognath (Fig. $16 \mathrm{~A}$ ) bezeichnet wird, stellt, wie aus obigen embryologischen Andeutungen hervorgeht, den ursprünglichen Zustand vor, letzterer, der sog. prognathe,

$\left.{ }^{1}\right)$ Nach Riley, dem sich neuerdings auch Prell anschließt, werden von den Kiefersegmenten $(4-6)$ nur das Occiput und die Postgenae gebildet, während der Scheitel und die Wangen (Vertex und Genae) dem Acron ihre Entstehung verdanken. 
den abgeleiteten. - Auch die Verbindung des Kopfes mit dem Brustabschnitt kann eine verschiedene sein, indem der Kopf entweder mit seiner ganzen hinteren Breite dem Thorax aufsitzt oder nur durch einen dünnen Hals mit ihm zusammenhängt. Im ersten Fall ist der Kopf oft mehr oder weniger tief in den ersten Brustring eingesenkt, mitunter so weit, da $\beta$ er bei der Ansicht von oben völlig von diesem verdeckt wird (Borkenkäfer, Fig. 17).
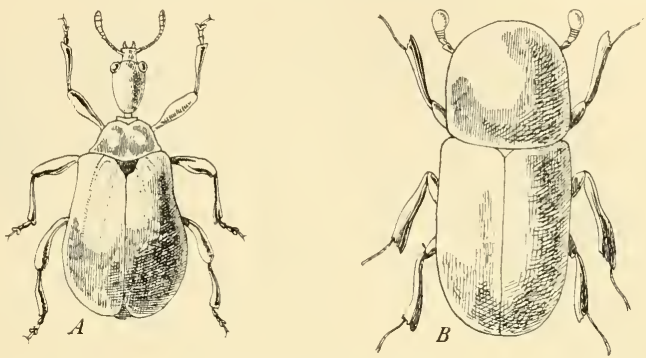

Fig. 17. Zwei extreme Formen der Verbindung des Kopfes mit der Brust. Bei A (Blattwickler, Apoderus coryli) ist der Kopf vollkommen frei, hängt nur mit einem dünuen Hals mit der Vorderbrust zusammen; bei $B$ (Borkenkäfer) ist der Kopf in den ersten Brustring (Halsschild) eingesenkt, so daß er von oben überhaupt nicht zu sehen ist. Aus $\mathrm{Oudemans.}$

Im Innern der Kopfkapsel ist bei den meisten Insekten ein gut ausgebildetes Entoskelett, das sog. Tentorium, vorhanden. Dasselbe stellt ein Stützgerüst dar, von dessen mittlerer Platte je ein Paar Arme nach vorn, hinten und oben sich erstrecken. Die Platte liegt zwischen dem Ober- und Unterschlundganglion, unter dem Oesophagus, welch letzterer zwischen den Armen hindurchzieht.

\section{B. Die Anhänge (Extremitäten) des Kopfes.}

Trotz seiner Zusammensetzung aus Acron und 5 Segmenten besitzt der Kopf nur 4 Gliedmaßenpaare, von denen das vorderste, die Fühler oder Antennen, als Sinnesorgan dient, während die 3 folgenden zur Ergreifung und Aneignung der Nahrung eingerichtet sind und daher als Mundgliedmaßen bezeichnet werden.

Die Fühler.

Die Fühler oder Antennen sind stets nur in einem Paar vorhanden und stellen die vordersten, vor der Mundöffnung gelegenen Gliedmaßen dar; sie sind stets gegliedert und mit der Kopfkapsel gelenkig verbunden. Die Stelle der Insertion kann sehr verschieden gelegen sein: entweder vor den Augen (zwischen diesen und der Basis der Vorderkiefer), oder an der Innenseite der Augen (mehr oder weniger der Stirnmitte genähert), oder aber an der Außenseite, oder endlich auch (allerdings selten, z. B. Flöhe) an der Hinterseite der Augen.

Bezüglich der Gliederung herrscht eine schier unermeßliche Mannigfaltigkeit, sowohl was die Zahl der Glieder als die Form derselben betrifft. Wir kennen einerseits Fühler mit nur 2 oder 3 Gliedern, andererseits solche 
mit 40 und mehr. ${ }^{1}$ ) - Die Glieder können entweder alle annähernd einander gleich gebaut sein, oder aber es können einzelne Glieder oder ganze Gliedergruppen bedeutende Formabweichungen von den übrigen zeigen; im ersteren Fall spricht man von „gleichartigen" (antemnae aequales), im zweiten von "ungleichartigen Fühlern" (antennae inaequales).
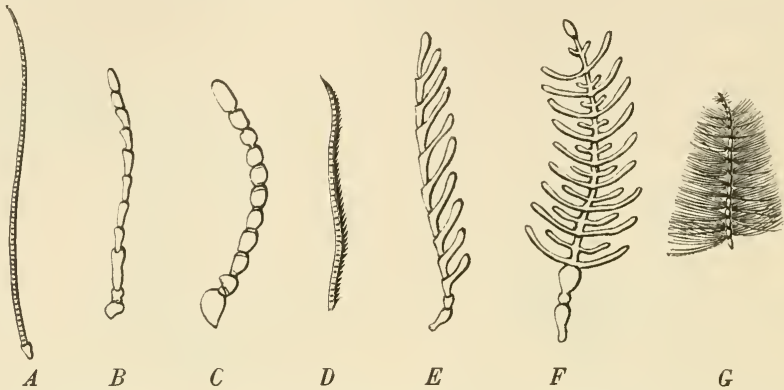

C

$D$

E

G

Fig. 18. Gleichartige Fühler. $A$ borstenförmig (Laubheuscbrecke); $B$ fadenförmig (Laufkäfer); $C$ perl schnurförmig; $D$ gesägt (Schwärmer); $E$ gekämmt (Schnellkäfer); $F$ doppelt gekämmt (Kammmücke); $G$ wirtelförmig behaart (Stechmückenmännchen), - (N.)

Unter den gleichartigen Fühlern kann man wieder, je nach der Gestaltung der einzelnen Glieder, verschiedene Formen unterscheiden, wie: borstenförmige, fadenförmige, perlschnurförmige, gesägte, einfach und doppelt gekämmte und gefiederte (Fig. 18).
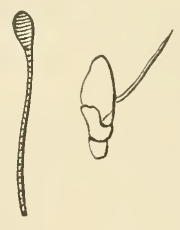

$$
\text { A } \quad B
$$

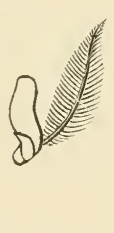

$C$

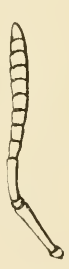

D

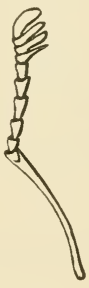

E

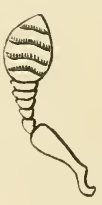

F

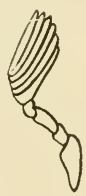

G

Fig. 19. Ungleichartige Fühler. $A$ gekeult (Kohlweißling); $B$ mit nackter Fühlerborste; $C$ mit behaarter Fühlerborste (Fliegen); $D$ gebrochener Fühler mit Schaft und einfacher Geißel (Hornisse; $E$ gebrochener Fühler, Geißel mit viergliedriger, gekämmter Keule (Hirschkäfer); $F$ gebrochener Fühler, Geißel mit einfacher Keule (Borkenkäfer); $G$ gebrochener Fühler mit geblätterter Keule (Maikäfermännchen). - (N.)

Bei den „ungleichartigen Fühlern" handelt es sich meistens um eine Veränderung der Endglieder, die gewöhnlich in größerer oder geringerer Ausdehnung verdickt sind, einen Knopf oder eine Keule bildend (Fig. 19). Wir sprechen dann von geknöpften oder gekeulten Fühlern (und zwar einfacher, gekämmter oder geblätterter Keule). Andererseits können

1) Bei manchen Insekten (den Proturen und den $q$ der Stylopiden) und zahlreichen Larven sind die Fühler vollkommen rückgebildet. 
die Endglieder aber auch stark reduziert und verdünnt sein, wie z. B. bei vielen Fliegen, bei denen die letzten Glieder verschmolzen und zu einer Borste ("Endborste“) rückgebildet sind, die höchstens noch an der Ringelung die Zusammensetzung aus Gliedern erkennen läßt. - Außerdem kann die Ungleichartigkeit auch auf der starken Verlängerung (und erent. Verdickung) des 1. Gliedes beruhen, wodurch der Fühler gewissermaßen in zwei Teile zerlegt wird: den durch das lange erste Glied gebildeten "Schaft" (scapus) und die aus den übrigen Gliedern bestehende "Geißel" (flagellum). Ist die Geißel winkelig gegen den Schaft eingelenkt, so bezeichnet man den Fühler als "gebrochen" oder „gekniet", eine Eigenschaft, die häufig (z. B. Borkenkäfer) mit einer Keulenbildung kombiniert ist (Fig. 19, $E$ u. $F$ ). Endlich kommen auch noch gänzlich "unregelmäßige“ Fühler vor, die auf Verwachsungen, Fortsatzbildungen, Knickungen usw. beruhen und auf spezielle, oft mit Funktionswechsel verbundenen Anpassungen an eine ganz besondere Lebensweise zurückzuführen sind.

Zwischen den gleichartigen und ungleichartigen Fühlern kommen auch Übergänge vor, so daß es schwierig ist, sie einem der beiden Typen zuzuteilen. Streng genommen existieren "gleichartige" Fühler überhaupt nicht, da das 1. Glied bei allen Fühlern in einem gewissen Gegensatz zu den übrigen Gliedern steht, sowohl funktionell als morphologisch (durch seine Größe, Struktur usw.), und man daher bei allen Fühlern gewissermaßen von einer Zweiteilung in Schaft und Geißel reden könnte. Vom praktischen Standpunkte aus ist jedoch die oben vorgeschlagene Einteilung trotzdem wohl gerechtfertigt und in den weitaus meisten Fällen auch gut durchzuführen.

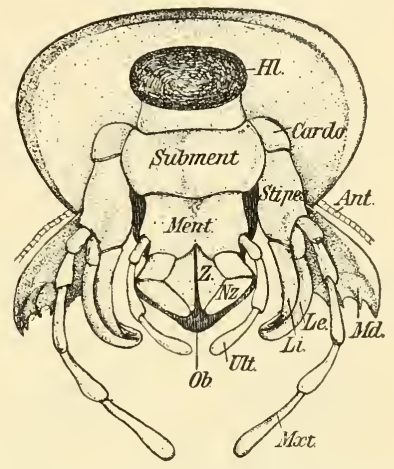

Fig. 20 A. Kauende Mundgliedmaßen einer Feldgrille (Gryllus campestris) in situ, von hinten gesehen. Hl Hinterhauptsloch; Ant Fühler; Md Mandibel; Mxt Maxillartaster; Le Lobus externus (äußere Lade); $L i$ L. internus (innere Lade); $O b$ Oberlippe; $U t$ Unterlippen- (=Labial) taster; $Z$ Zunge (Glossa); $N z$ Nebenzunge (Paraglossa).

\section{Die Mundgliedmaßen.}

Die Mundgliedmaßen dienen in der Hauptsache zur Ergreifung und Aneignung der Nahrung und sind deshalb um die Mundöffnung herum gruppiert. Entsprechend der ungeheuren Mannigfaltigkeit der Nahrung der Insekten und der Art des Nahrungserwerbes treten uns auch die Mundgliedmaßen in großer Verschiedengestaltigkeit entgegen. Je nachdem die Nahrung fest oder flüssig ist, sind die Mundwerkzeuge zum Kauen oder zum Lecken oder Saugen eingerichtet. So sehr nun auch dadurch der Bau jener Organe beeinflußt wird und so grundverschieden auch die kauenden und saugenden Mundwerkzeuge erscheinen (man denke an die Kiefer eines Käfers oder den Rüssel eines Schmetterlings!), so lassen sich doch, wie die vergleichende Morphologie und Embryologie lehrte, die einzelnen Formen voneinander ableiten; d. h. alle entstehen aus den drei am 3., 4. und 5. embryonalen Kopf- 
segment auftretenden Extremitätenpaaren (oder wenigstens aus Teilen derselben).

Dem ursprünglichen Zustand am nächsten stehen die kauenden oder beißenden Mundwerkzeuge. Bei ihnen lassen sich die drei Extremitätenpaare unschwer erkennen (Fig. $20 \mathrm{~A} \mathrm{u.} \mathrm{20} \mathrm{B):} \mathrm{das} \mathrm{vorderste} \mathrm{stellt} \mathrm{die} \mathrm{Vorderkiefer}$ (auch Oberkiefer oder Mandibeln) dar, das darauffolgende die Mittelkiefer (auch Unterkiefer oder Maxillen) und das dritte Paar die Hinterkiefer (auch Unterlippe oder Labium).

Die Vorderkiefer oder Mandibeln stellen einfache, ungegliederte, meist äußerst stark chitinisierte Gebilde dar, die, direkt hinter der Oberlippe
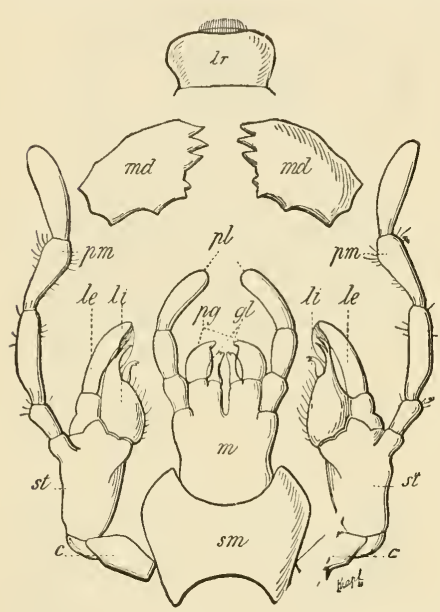

Fig. 20 B. Kauende Mundgliedmaßen der Küchenschabe (Periplaneta orientalis), zerlegt. lr Labrum (Oberlippe); ma Mandibeln; $c$ Cardo; st Stipes; le und $l i$ Lobus externus und internus; $p m$ Maxillarpalpus; $s m$ Submentum; $m$ Mentum; $g l$ Glossen (Zunge); $p g$ Paraglossen (Nebenzungen); $p l$ Labialpalpus (Unterlippentaster). Aus Hertwig.

sogar durch dicke Bleiplatten fressen können. gelegen, mit der Kopfkapsel gelenkig (Scharniergelenk) verbunden sind und mit Hilfe einer kräftigen Muskulatur gegeneinander bewegt werden können. Am Innenrand befinden sich meist mehrere Zähne, von denen häufig der basal gelegene eine besondere Größe und Bedeutung als "Mahlzahn " erreicht.

Die Form der Mandibeln ist sehr wechselnd, je nach der Verwendung. Bei Raubinsekten (z. B. Laufkäfer) sind sie meist lang, spitz und mit ebensolchen Zähnen besetzt und greifen mit ihren Enden übereinander (siehe Fig. 28), bei Pflanzenfressern (z. B. Maikäfer) dagegen breit und kurz usw. Bei manchen Larven (Dytiscus, Lampyris usw.) sind die Mandibeln zum Saugen eingerichtet, indem sie mit einem feinen Kanal versehen sind. - Die Mandibeln dienen aber auch noch anderen Zwecken als dem Nahrungserwerb, wie dem Wohnungsbau (Bienen, Wespen, Ameisen und Termiten), der Verteidigung (Ameisen und Termitensoldaten) usw., was natürlich auch wieder zu besonderen Formbildungen führte. Welch enorme Kraft die Oberkiefer besitzen können, zeigen die Borkenkäfer, die das härteste Holz durchnagen, oder gewisse Laufkäfer, die starke Schneckenschalen zerbrechen, oder die Holzwespen, die sich

Die Mittelkiefer (auch Unterkiefer oder Maxillen), zu beiden Seiten der Mundöffnung gelegen, sind weit weniger kräftig als die Mandibeln ausgebildet, andererseits aber viel komplizierter gebaut, indem sie aus einer Anzahl mehr oder weniger gegeneinander beweglichen Glieder zusammengesetzt sind. Wir unterscheiden zunächst Stammglieder und Endglieder; die ersteren zerfallen wieder in die Angel (oder Cardo) und den Stamm (oder Stipes), die letzteren in die Taster (Palpus) und die beiden Laden (Lobus internus und externus). Am Stamm kann sich noch ein weiteres 
Stück abgliedern, welches den Palpus trägt und daher als Tasterträger oder Palpiger bezeichnet wird.

Bei den Mittelkiefern ist die Extremitätennatur noch deutlich erhalten, und wir finden auch an ihnen sämtliche Teile eines Laufbeines wieder. Die Stammglieder entsprechen der Coxa und die Laden Coxalanhängen, während der Palpus allen auf die Coxa folgenden Beingliedern (wie Trochanter, Schenkel, Schiene, Tarsus) gleichzusetzen ist. - Die Funktion der Mittelkiefer besteht teils im Zerkleinern der Nahrung, teils in der Formung des Bissens und teils in der Aufsuchung und Prüfung der Nahrung (Taster). Natürlich kommen auch hier - entsprechend der mannigfaltigen Nahrung große Formverschiedenheiten vor, die sich hauptsächlich auf die Ausgestaltung der beiden Laden

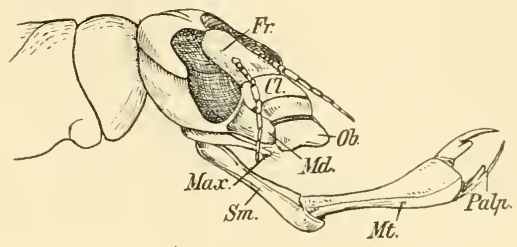

Fig. 21. Kopf einer Libellenlarve mit vorgestreckter Unterlippe ("Maske ${ }^{\star}$ ), die zum Fang eingerichtet ist. Fr Stirne; $C l$ Clypeus; $O b$ Oberlippe; $M d$ Mandibel; Max Maxille; Sin Submentum; Hit Mentum; Palp Unterlippentaster. beziehen.

Die Hinterkiefer (oder Unterlippe, Labium) endlich, die hinter der Mundöffnung gelegen sind, stehen bezüglich ihrer Gliederung den Mittelkiefern nahe, unterscheiden sich jedoch dadurch wesentlich von diesen, daß sie in der Regel zu einem unpaaren Stück verwachsen sind. Die Verwachsung bezieht sich in erster Linie auf die Stammstücke (d. h. die beiderseitigen Cardines und Stipites), die zu 2 hintereinander gelegenen unpaaren Platten, dem Submentum und Mentum (Kinn), verschmolzen sind. Sodann verschmelzen auch die inneren Laden gewöhnlich miteinander zur sog. Zunge oder Glossa, während die äußeren (wenn überhaupt vorhanden) paarig bleiben (Nebenzungen, Para-

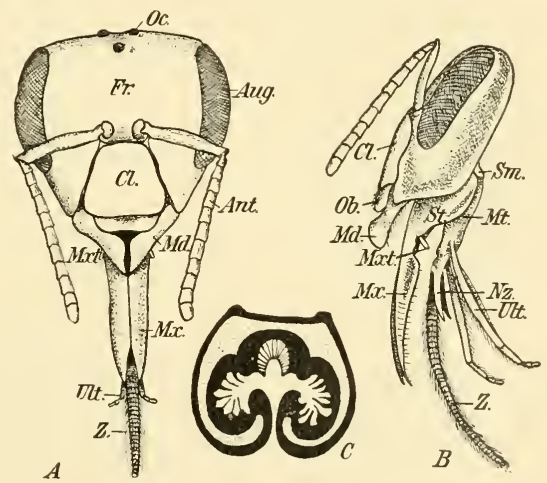

Fig. 22. Kopf und leckende Mundteile einer Bienenarbeiterin. $A$ von vorn, $B$ von der Seite gesehen. $C$ Querschnitt durch die Zunge. - Ant Fühler; Aug Seitenaugen; $O c$ Stirnaugen; Fr Stirn; $C l$ Clypeus; Ob Oberlippe; Md Mandibel ; Mrt Maxillartaster; $M I x$ Maxille; Ut Labial-(Unterlippen-) taster; $Z$ Zunge; Nz Nebenzungen; Mt Mentum; Sm Submentum. (Nach Z and er.) glossen), ebenso die mehrgliedrigen Taster (Lippentaster, Palpi labiales).

Häufig treten noch weitgehendere Verschmelzungen und Reduktionen ein, so $\mathrm{dab}$ die Unterlippe aus einer einzigen ungegliederten unpaaren Platte besteht, an denen als einzige Anhänge nur noch die Taster sitzen. - Die Unterlippe hat im allgemeinen die $\mathrm{B}$ edeutung eines $\mathrm{Hilfs}$ organes, welches dazu dient, ,ein Ausgleiten der Nahrungsbrocken, die von den beiden Kieferpaaren ver- 
arbeitet werden, zu verhindern" (H esse). In manchen Fällen ist die Unterlippe besonderen Funktionen angepaßt und dementsprechend umgebildet. So ist bei den Libellenlarven Mentum und Submentum stark verlängert und gelenkig miteinander verbunden, so daß die Unterlippe wie ein Arm weit ausgestreckt werden kann, um Beute zu ergreifen (Fig. 21).

Bei den Raupen (und wohl noch bei vielen anderen kauenden Insekten, welche Stücke aus Blättern usw. herausreißen) dient die Unterlippe (im Verein mit der Oberlippe) zum Halten und Führen des Blattes während des Reißaktes. Hierüber gibt Jordan gelegentlich der Beschreibung des Freßaktes von Bombyx mori folgende treffende Schilderung: „Unsere Raupen fressen stets am Rande des Blattes, das sie mit den vorderen Beinen festzuhalten pflegen. Der Kopf mit einem Teil des Vorderkörpers beschreibt halbkreisförmige Bewegungen, je einen regelmäßigen Halbkreis in den Blattrand fressend. Schicht um Schicht konzentrisch abweidend, dringt der Kopf — von oben nach unten fressend, von unten nach oben

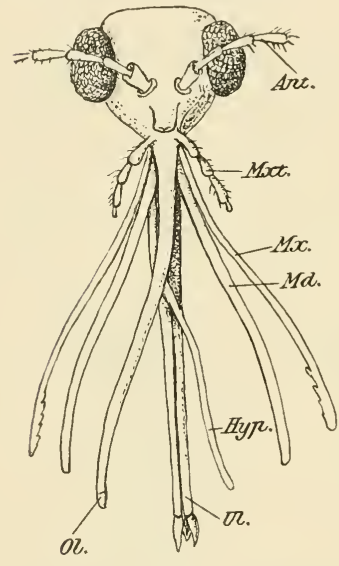

$A$

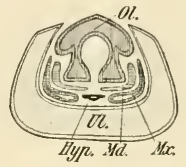

$B$

Fig. 23. A Kopf einer weiblichen Stechmücke mit auseinander gelegten Mundteilen. $B$ vergrößerter Querschnitt durch die Mundteile. - Ant Fühler; Mx Maxille; Mxt Maxillartaster; Md Mandibel; Hyp Hypopharynx; Ol Oberlippe; $U l$ Unterlippe. - (N.) „leerlaufend" und den Ausgangspunkt wieder gewinnend - weiter und weiter in das Blatt vor. Die Mandibeln schneiden auch bei diesen Raupen nicht eigentlich; sie packen ein Stück Blattrand, dann wird der ganze Kopf ein Stückchen zurückgezogen und dadurch das zwischen den Kiefern eingeklemmte Stück abgerissen, wie von einer weidenden Kuh das Gras abgerissen wird. Das Zurückziehen des Kopfes führte an sich nicht zum Ziele, der Blattrand würde jeweils mitgezogen werden und das geklemmte Stück sich nicht ablösen. Hier treten nun Oberlippe und Unterlippe in Tätigkeit. Ihre Bewegungsrichtung ist etwa senkrecht zur Längsachse der Raupe, d. h. vom Munde aus senkrecht nach unten (ventral, wie wenn wir die Zunge gerade herausstrecken). Dabei erfolgt jeweilig solch ein Vorstoß genau dann, wenn der Kopf nach Mandibelschluß sich zurückzieht. Da nun beide Lippen auf den Blattrand sich aufstützen, so drücken sie ihn von dem zwischen den Mandibeln eingeklemmten Stücke ab, es muß losgerissen werden. Es ist schön zu sehen, mit welcher Präzision dieser Apparat arbeitet, gleich der Kolbenstange einer Dampfmaschine zwischen zwei Steuerungsstangen. Und obwohl der Kopf mit den Mandibeln Stück für Stück in Windeseile aus dem Blattrand zupft, so rührt sich das z. B. lose auf dem Tisch liegende Blatt nicht vom Flecke Die Oberlippe ist mit einem Einschnitt in der Mitte versehen; in diesen Einschnitt paßt der Blattrand. Ähnliches finden wir bei der Unterlippe. Der Blattrand stützt sich auf die Zunge, während die beiden Maxillen ein Abrutschen verhindern. So wird einmal vermieden, daß das Blatt bei der geschilderten Funktion der beiden Lippen von diesen abrutscht, zugleich aber leisten die beiden Organe hierdurch der Nahrungsaufnahme einen neuen Dienst. In den beiden Einschnitten läuft das Blatt - bei 
den schnellen Halbkreisen, die der Raupenkopf beim Fressen ausführt - in sicherer Führung, wie in einer Nute. Trotz aller Eile treffen daher die Mandibeln stets den erwünschten Rand. So wird es auch verständlich, daß die Raupen so große Schwierigkeiten haben, ein Blatt in der Mitte anzufressen. Ist dies aber einmal gelungen, haben sie in die Mitte der Blattspreite ein Loch gefressen, so wird von da an der Rand des Loches gleich dem Blattrande behandelt."

Im Anschluß an die Unterlippe ist noch ein Organ zu erwähnen, welches der Innenseite der Unterlippe anliegt und häufig auch mit dieser verwachsen ist und welches als "Innenlippe“ oder Hypopharynx bezeichnet wird. Dieses Organ stellt gewissermaßen das Gegenstück zur Oberlippe resp. dem Epipharynx dar, insofern, als es die Unter- oder Hinterseite des Schlundeinganges einnimmt, wie die Oberlippe (resp. der Epipharynx) den Schlundeingang oben resp. vorne begrenzt.

Die Ausbildung des Hypopharynx der kauenden Insekten ist eine sehr verschiedene: bei manchen (besonders niederen) Formen ist er groß und in mehrere Teile (Mittelstïck und 2 seitliche Stücke) gegliedert, bei anderen relativ klein, einfach, zapfenförmig; bei wieder anderen mehr oder weniger vollkommen rückgebildet. Früher erblickte man in dem Hypopharynx ein weiteres Paar echter Mundgliedmaßen (Extremitäten); neuere embryologische Studien (Heymons) haben jedoch dargetan, daß der Hypopharynx mit Extremitäten nichts zu tun hat, sondern vielmehr als Reste der Bauchplatten (Sternite) der 3 (oder wenigstens 2) letzten Kopfsegmente (Mandibel- und Maxillensegment) aufzufassen ist.

Die Mundöffnung der kauenden Insekten wird also von folgenden Skelettstücken umgeben: zu oberst (resp. vorn) von der Oberlippe und dem Epipharynx, zu beiden Seiten

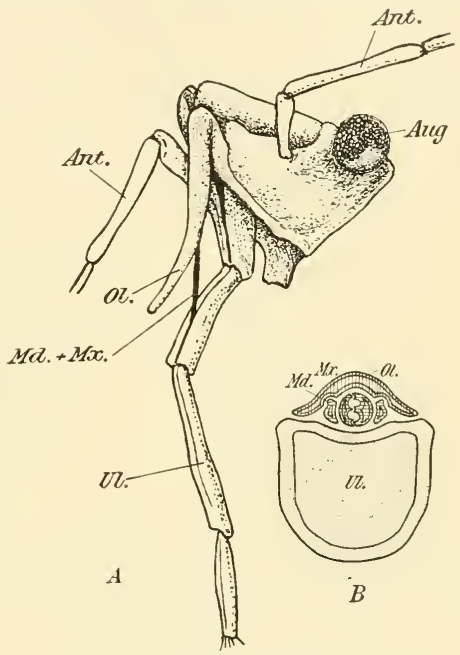

Fig. 24. A Kopf einer Feldwanze (Pentatoma). $B$ Vergrößerter Durchschnitt in der Höhe der Oberlippe. Bezeichnungen wie auf den vorigen Figuren. - (N.) von den Mandibeln und Maxillen, zu unterst (resp. hinten) ron dem Hypopharynx und der Unterlippe.

Alle diese Teile liegen (in der Anlage) auch den leckenden, stechenden und saugenden Mundgliedmaßen zugrunde; nur haben hier teilweise derartige Umbildungen, Reduktionen, Verwachsungen usw. stattgefunden, daß es mitunter schwierig ist, die einzelnen Stücke wiederzuerkennen, und daß oft nur die Embryologie die richtige Deutung zu geben vermochte.

Den kauenden Mundwerkzeugen am nächsten stehen die leckenden der Hymenopteren (Bienen, Hummeln usw.). Hier gelingt die morphologische Analyse ohne Schwierigkeit (Fig. 22). Das Labrum und die Mandibeln sind überhaupt nicht verändert; dagegen haben Maxillen und 
Unterlippe wesentliche Umbildungen erfahren, besonders die Unterlippe, die hier (im Gegensatz zu den kauenden Mundwerkzeugen) die Hauptrolle bei der Nahrungsaufnahme spielt. Das hervorstechendste Merkmal ist die mächtig verlängerte $Z$ unge (hervorgegangen aus den beiden inneren Laden), die durch Einrollung der Ränder eine Rinne oder ein Rohr bildet (Fig. 22, C). Die Nebenzungen sind wesentlich kürzer geblieben, dennoch deutlich ausgebildet; sehr lang dagegen sind die Labialtaster, deren ersten beiden Glieder beinahe die Länge der Zunge erreichen. Bei den Maxillen fällt vor allem die ansehnliche Ausbildung der beiden Laden auf, die zu einem lanzettförmigen Gebilde verwachsen, während die Taster stark rückgebildet sind. Von den Stammstücken sind die Stipites und das Mentum verlängert, während die Cardines und das Submentum nur ganz kleine Skelettstücke darstellen.

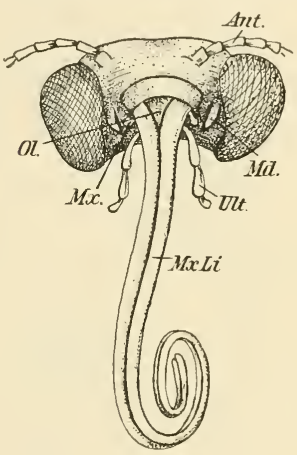

$A$

Weit mehr weichen die stechenden und saugenden Mundwerkzeuge der Dipteren (wie z. B. der Stechmücken) von dem ursprünglichen Typus ab. Sie setzen sich in der Hauptsache aus vier Bestandteilen zusammen (Fig. 23):

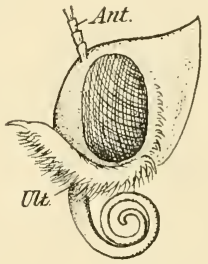

$B$

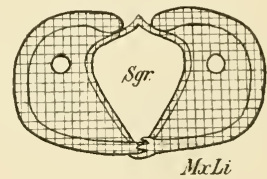

$C$

Fig. 25. A Kopf eines Schmetterlings von vorn gesehen; $B$ derselbe von der Seite gesehen mit eingerolltem Rüssel; $C$ vergrößerter Querschnitt durch den Rüssel. Mx Li Innere Lade der Maxille; Sgr Saugrohr. Die übrigen Bezeichnungen wie auf den vorigen Figuren. - (N.)

1. den Stechborsten zum Verwunden, 2. dem Gleitrohr zur Führung der dünnen Stechborsten, 3. dem Saugrohr zur Hebung der aus der Wunde fließenden Flüssigkeit, und 4. dem Speichelrohr zur Zuführung entzündungserregender Speichelsekrete zur Wunde. - Die Stechborsten, 5 an der Zahl, entsprechen den Mandibeln, Maxillen und dem Hypopharynx, welch letzterer zugleich das Speichelrohr enthält; das Gleitrohr wird gebildet von der Unterlippe und Oberlippe, und das Saugrohr größtenteils von der Oberlippe (in Verbindung mit dem Hypopharynx). Von den Tastern sind nur die der Maxillen gut ausgebildet.

Einigermaßen ähnlich liegen die Verhältnisse bei den Schnabelkerfen (Wanzen usw.), indem auch hier der (meist gegliederte) Rüssel (das Gleitrohr) von der Ober- und Unterlippe gebildet wird (Fig. 24). Dagegen sind nur 4 Stechborsten vorhanden, zwei mittlere und zwei äußere, von denen die letzteren den Mandibeln entsprechen, und die ersteren den Maxillen, resp. nur den 
inneren Laden derselben (der Stamm wird zur Bildung der Kopfkapsel mit verwandt). Die beiden mittleren Borsten besitzen an ihrer Innenseite 2 Rinnen und legen sich damit so aneinander, daß 2 getrennte Röhren entstehen (Fig. 24, B), von denen die eine als Saugrohr, die andere als Speichelrohr dient. Maxillartaster sind höchstens noch rudimentär vorhanden.

Gänzlich verschieden von diesen beiden Typen saugender Mundgliedmaßen ist der Saugrüssel der Schmetterlinge aufgebaut. Da die Schmetterlinge nur freiliegende Säfte (Nektar) aufsaugen, sind bei ihnen Stechorgane unnötig und stellt der Rüssel nur ein einfaches Rohr dar (Fig. 25). Dasselbe wird gebildet von den beiderseitigen, mächtig in die Länge gezogenen Innenladen der Maxillen, die, auf der Innenseite rinnenförmig ausgehöhlt, sich der ganzen Länge nach aneinanderlegen und miteinander verbinden (Fig. 25, C). Alle übrigen obengenannten Komponenten der ursprünglichen kauenden Mundwerkzeuge treten dagegen mehr oder weniger zurück. Die Mandibeln sind zu unscheinbaren Höckern reduziert;

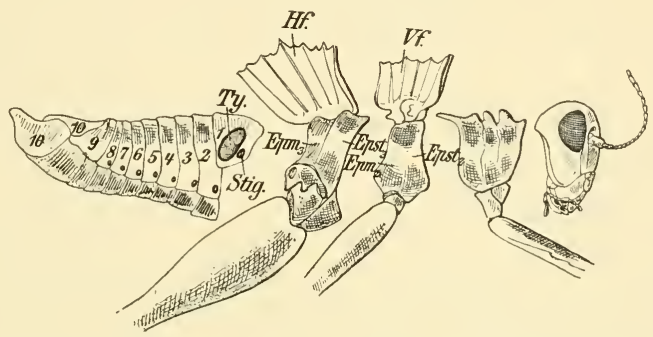

Fig. 26. Eine Feldheuschrecke, in die verschiedenen Körperregionen zerlegt: Kopf, Brust (VorderMittel-, Hinterbrust) und Abdomen. Epm Epimernm; Epst Episternum; Ty Tympanalorgan; Stig Stigma; $H f$ Hinterflïgel; Vf Vorderflügel. Nach Packard.

die Oberlippe und Unterlippe stellen nur noch kleine, dreieckige Stücke dar, welche kleine Lücken an der Rüsselbasis ausfüllen, und von den Tastern ist meist nur ein Paar gut entwickelt, und zwar entweder die Maxillar- oder aber die Labialtaster, während das entsprechende andere Paar stark rückgebildet oder auch gänzlich geschwunden ist.

Die Mundgliedmaßen der saugenden Insekten sind also auf recht verschiedene Weise zustande gekommen; so wird das Saugrohr bei den Fliegen zum größten Teil von der Oberlippe, bei den Bienen von der Unterlippe und bei den Wanzen und Schmetterlingen von den inneren Laden der Maxillen gebildet. Das deutet darauf hin, daß die verschiedenen Saugapparate nicht direkt voneinander abzuleiten sind, sondern unabhängig, nebeneinander aus der Urform der kauenden Mundgliedmaßen hervorgegangen sind.

\section{Die Brust (Thorax).}

\section{A. Die Segmente.}

Wie wir den Kopf als den Träger der Mundwerkzeuge und hauptsächlichen Sinnesorgane gekennzeichnet haben, so können wir den Thorax als 
den Träger der hauptsächlichsten lokomotorischen (zur Fortbewegung dienenden) Organe (Beine und Flügel) auffassen. Im Gegensatz zum Kopf sind hier die Segmente mehr oder weniger deutlich (wenigstens teilweise) in ihrem ursprünglichen Aufbau erhalten, wenn auch durch mannigfaltige Verwachsungen usw. (infolge der verschiedenen Ausbildung und Gruppierung der Bewegungsmuskeln) manchmal die richtige Deutung der Segmentgrenzen mit Schwierigkeiten verbunden ist.

Bei den meisten Insekten setzt sich die Brust aus 3 Segmenten zusammen, die wir als Vorderbrust (Prothorax), Mittelbrust (Mesothorax) und Hinterbrust (Metathorax) bezeichnen. Jedes der 3 Segmente trägt ventral ein Paar gegliederte Extremitäten, außerdem kann der Mesound Metathorax auch noch dorsal je ein Paar beweglicher Anhänge zum Fliegen (Flügel) besitzen (Fig. 26). - Jedes Segment stellt einen geschlossenen Ring dar, der aus einer dorsalen und ventralen Platte (Tergum und Sternum) und den diese verbindenden beiderseitigen Weichen (Pleuren)

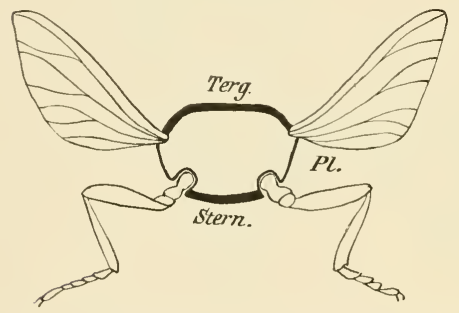

Fig. 27. Schematischer Durchschnitt durch den mittleren Brustring eines Insekts. Terg Tergum (Notum); Stem Sternum; $\mathrm{Pl}$ Pleura. Nach Kolbe. gebildet wird. Zwischen den letzteren und dem Sternum befindet sich die Einlenkungsstelle für die Beine, wie zwischen den Pleuren und dem Tergum die Einlenkungsstelle für die Flügel gelegen ist (Fig. 27).

Meist bleibt es nicht bei diesen einfachen Gliederungen, sondern kommt es durch sekundäre Teilungen resp. Neubildungen zu weiterer Regionenbildung. Vor allen stellen sich solche an den Terga des Meso- und Metathorax ein in Verbindung mit dem Auftreten von Flügeln resp. der kräftigen Flügelmuskulatur, welche natürlich (durch ihre Anheftung) nicht ohne Einfluß auf die Gestaltung des Chitinskelettes bleiben konnte. Wir können an jedem der genannten Terga nicht selten 4 durch Nähte getrennte Regionen unterscheiden, die (in der Reihenfolge von vorne nach hinten) als Praescutum, Scutum, Scutellum und Postscutellum bezeichnet werden. Der größte Anteil fällt dem Scutum und Scutellum zu, während die beiden anderen meist nur unansehnliche Stücke am Vorder- und Hinterrand des Tergums darstellen (Fig. 28 B). Besondere Beachtung verdient das Scutellum des Mesothorax (auch Schildchen genannt), weil es bei den Flügeldecken tragenden Insekten (bei geschlossenen Flügeldecken) der einzige von oben sichtbare Teil der beiden letzten Brustabschnitte ist und weil es mitunter durch seine enorme Ausdehnung auch einen wesentlichen Einfluß auf den Habitus erlangen kann (siehe Fig. 35, S. 33). - Weit weniger wird das Tergum des Prothorax von sekundären Teilungen betroffen (Mangel der Flügelmuskulatur!); dasselbe stellt meist eine einheitliche Platte dar, welche bei den mit Flügeldecken versehenen Insekten als Halsschild bezeichnet wird (Fig. 28 B). 
Auch die Pleuren zerfallen gewöhnlich in 2 durch eine deutliche Naht getrennte, hintereinander gelegene Stücke, deren vorderes das Episternum und deren hinteres das Epimerum darstellt (Fig. 26, 28 u. 30). Die Bauchplatten (Sterna) dagegen bleiben meist einheitlich, wiewohl sie embryonal aus je drei Stücken (einem mittleren und 2 lateralen) sich zusammensetzen.

Die sekundäre Teilung der Segmentelemente geht vielfach Hand in Hand mit der Ausbildung eines Entoskelettes, d. s. Fortsätze und Leisten, die an der Innenseite des Skelettes entstehen und als Ansatzpunkt für die Muskulatur dienen. Gewöhnlich lassen sich 3 Gruppen von Entoskeletteilen unterscheiden: dorsale von den Terga entspringende plattenförmige Fortsätze (Entoterga oder Phragmen), seitliche, von den Pleuren entspringende zapfenförmige Fortsätze (Entopleura oder Apodemen) und ventrale von der Sterna entspringende Fortsätze (Entosterna oder Apophysen); die letzteren sind gewöhnlich gabelförmig und dienen außer als Ansatzstellen für die Muskulatur, vor allem auch dem Schutze der Ganglien, die zwischen den Zinken gelegen sind (vgl. S. 6, Fig. 7, Ensc).

Bei manchen Insekten (Hymenopteren) tritt

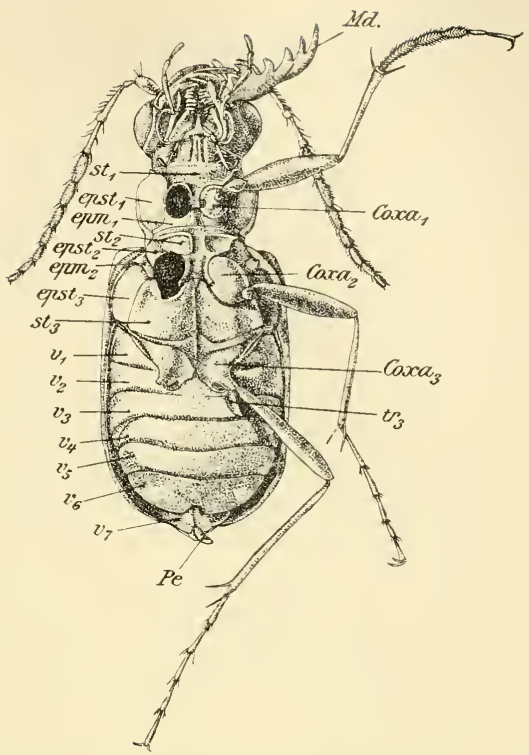

Fig, $28 \mathrm{~A}$. Unterseite eines Sandläufers (Cicindela), $s t_{1}, s t_{2}$ und $s t_{8}$ Sternum des 1., 2. und 3. Brustringes; epst Episternum; epm Epimerum; $v_{1 \rightarrow}$ Ventralplatten des 1.-7. Ábdominalsegmentes; Pe Penis; $t r_{3}$ Trochanter des 3. Beinpaares; Md Mandibeln.

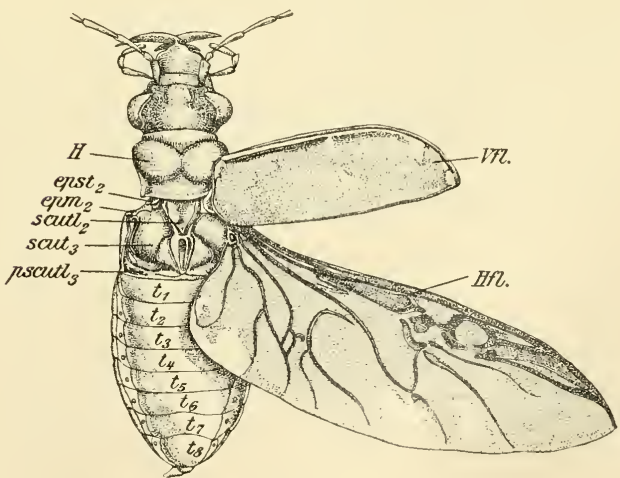

Fig. 28 B. Oberseite eines Saudläufers (Cicindela). epst Episternum epm Epimerum; $H$ Halsschild; scutl $_{2}$ Scutellum (Schildchen); scut ${ }_{3}$ Scutum des Metathorax; pscut? Pontscutellum des Metathorax; Vfl Vorderflügel (Flügeldecke); $H f$ Hinterflügel; $t_{1}-t_{8}$ Tergum des 1.-8. Abdominalsegmentes. Nach Ganglbauer. 
zu den drei typischen Thoraxsegmenten noch ein viertes, das sog. Mediansegment („segment médiaire"), welches dem 1. Abdominalsegment der anderen Insekten entspricht. Dasselbe tritt während der postembryonalen Entwicklung (Metamorphose) in innige Verbindung mit dem Metathorax und bildet so den hinteren Abschluß des Brustabschnittes (Fig. $30 \mathrm{epn}$ ).

Die Form und Größe der einzelnen Segmente ist ungeheueren Schwankungen unterworfen, und zwar in unverkennbarer Abhängigkeit von der Ausbildung der lokomotorischen Anhänge resp. der diese bedienenden Muskulatur. Wo an die Extremitäten der drei Segmente annähernd gleiche Anforderungen gestellt werden (wie z. B. bei den Larven oder den flügellosen „Silberfischchen“), da sind auch die Segmente von annähernd gleicher Gestaltung. Wo jedoch einzelnen Paaren besondere Leistungen zufallen, da finden wir die dazu gehörigen Segmente auch besonders umfangreich ausgebildet. So ist z. B. bei der Maulwurfsgrille, die die Vorderbeine zum Graben gebraucht, die Vorderbrust am größten, während sie bei Fliegen oder Bienen sehr klein ist; so übertrifft ferner bei den Fliegen, Schmetterlingen, Bienen, Wespen usw., wo die Fortbewegung hauptsächlich durch die Vorderflügel bewirkt wird, der Mesothorax (der diese Flügel trägt) den Metathorax

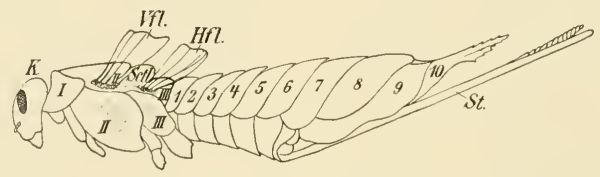

Fig. 29. Seitenansicht einer Holzwespe (Sirex). I, II, III erster, zweiter, dritter Brustring; 1-10 erstes bis zehntes Abdominalsegment; St Legestachel; $V f$, Hfl Vorder- und Hinterflügel; Sctl Scutellum; $K$ Kopf. Mit Benutzung einer Figur von $Z$ ander.

sehr beträchtlich an Ausdehnung, während bei den Käfern, bei denen die Hinterflügel allein dem Flug dienen, der Metathorax die größere Ausdehnung besitzt.

Wie sehr die Konfiguration des Thorax von den Flügeln abhängig ist, läßt sich am auffallendsten bei solchen dimorphen oder polymorphen Insekten erkennen, die in einer ungeflügelten und geflügelten Form auftreten. Man vergleiche nur den mächtigen gewölbten Thorax des geflügelten Ameisenweibchens mit der flachen Brustform der ungeflügelten Arbeiter; oder den großen Unterschied, der zwischen dem Thorax einer geflügelten und ungeflügelten Form einer Blattlausart besteht.

Aber nicht nur auf die Größe, sondern auch auf die Art der Verbindung der 3 Segmente hat die Bewegungsmuskulatur den größten Einfluß. Im allgemeinen gilt der Satz, daß die ursprüngliche Selbständigkeit (gelenkige Verbindung) der Segmente um so mehr verschwindet, je mehr die Insekten von der Laufbewegung zur Flugbewegung übergehen. Sind doch bei ausgesprochenen Fluginsekten, wie den Fliegen oder Schmetterlingen, alle drei Segmente fest miteinander verbunden, so daß die ganze Brust eine einheitliche Chitinkapsel bildet, die nur an den Nähten ihre Zusammensetzung erkennen läßt. Bei anderen, mehr auf Gehbewegungen und den selbständigen Gebrauch der Vorderbeine angewiesenen Insekten (Käfer, Wanzen, Heuschrecken) bleibt dagegen die Vorderbrust völlig selbständig und gegen den 
aus Meso- und Metathorax bestehenden hinteren Brustabschnitt beweglich verbunden.

\section{B. Die thorakalen Anhänge.}

An der Brust können wir ventrale und dorsale Anhänge unterscheiden. Erstere, die Beine, sind in ihrem Vorkommen überaus konstant, indem (wenigstens bei den Imagines) fast stets 3 Paare vorhanden sind; letztere dagegen, die Flügel, sind in recht verschiedener Weise ausgebildet, entweder in 2 Paaren oder nur in einem Paare oder können aber auch ganz fehlen.

\section{Die Beine.}

Die drei Beinpaare stellen die Extremitäten der drei Brustsegmente dar. Sie sind auf der ventralen Seite eingelenkt, und zwar zwischen den Pleuren und den betreffenden Sterna. Jedes Bein besteht aus folgenden Abschnitten: 1. der Hüfte (Coxa), 2. dem Schenkelring (Trochanter), 3. dem Schenkel (Femur), 4. der Schiene (Tibia), 5. dem Fuß (Tarsus) und 6. dem Klauenapparat (Prätarsus) (Fig. 31).

Die Hüfte, das Grundglied des Beines, stellt die gelenkige Verbindung mit dem Brustskelett her. In Größe und Form sehr verschieden, ist sie oft nur ein kleines, größtenteils in der Gelenkpfanne verborgenes Stück, kann jedoch auch einen ansehnlichen Um-

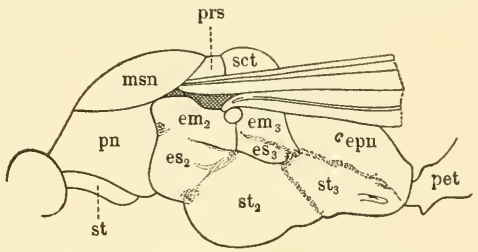

Fig. 30. Brust einer Ameise. $p n$ Pronotum (Tergum des Prothorax); msn Mesonotum; prs Proscutellum; sct Scutellum; epn Epinotum (M ediansegment); pet Stiel; st, $s t_{2}$ u. $s t_{3}$ Sternum von Pro-, Meso- und Metathorax; em Epimerum; es Episternum. (Aus Escherich, Die Ameise.) fang annehmen und entweder plattenförmig zwischen die ventralen Skelettelemente sich einfügen oder stielartig vom Sternum abstehen.

Bei manchen Insekten läßt sich noch ein besonderes Verbindungsstück zwischen Sternit und Coxa (sog. Subcoxa oder Trochantinus) feststellen. Bei primitiven Insekten (Machilis) iragen die Mittel- und Hinterhüften ziemlich große, griffelförmige Anhänge, die als $\mathrm{H}$ ü f $\mathrm{tg}$ r iff el oder Styli bezeichnet werden.

Das auf die Hüfte folgende Glied, der Schenkelring, ist meist relativ klein und gewöhnlich einfach. Nur bei einigen Gruppen der Hymenopteren ist er in zwei aufeinanderfolgende Teile gegliedert, so daß man hier von einem „doppelten Schenkelring“ spricht.

Die Doppelnatur ist nicht auf eine Zweiteilung des eigentlichen Trochanter zurückzuführen, sondern auf Abgliederung des obersten Schenkelstückes.

Der Schenkel ist fast stets das größte und dickste Glied des Beines; enthält er doch auch die hauptsächlichste Beinmuskulatur. - Die Schiene, deren Gelenkverbindung mit dem Schenkel als „Knie“ bezeichnet wird, ist meist weit dünner, nimmt allerdings gegen das periphere Ende am Umfange gewöhnlich wieder mehr oder weniger beträchtlich zu. Hier finden sich häufig auch 1 oder 2 (oder mehrere) „Sporen“ (Calcaria); ferner mitunter auch ein tiefer Einschnitt, der in Verbindung mit den Sporen als Putzapparat dient. 
Während Schenkel und Schiene aus einem Stück bestehen, ist der FuB in den meisten Fällen mehrfach gegliedert; nur selten begegnen wir eingliedrigen Füßen (Pediculiden, Cocciden $\sigma^{\top}$, Collembolen). Am häufigsten finden wir den 5 gliedrigen Tarsus, weniger häufig den 4- und 3 gliedrigen.

Auf den Tarsus folgt als letztes Beinglied der Prätarsus oder Klauenapparat, der 1 oder 2 (einfache oder gespaltene, gezähnte oder gekämmte)

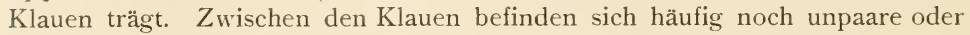
paarige oder dreiteilige lappenförmige Anhänge von der verschiedensten Form und Ausbildung, die als Haftorgane (beim Laufen auf glatten Flächen usw.) dienen und mit den verschiedensten Bezeichnungen, wie Afterklaue, Empodium, Pulvillus, Onychium usw. belegt werden (Fig. 31).

Bei manchen Insekten (Ateuchus, Onitis usw.) sind die beiden letzten Beinabschnitte, Tarsus und Prätarsus, an den Vorderbeinen gänzlich rückgebildet, bei anderen fehlt nur der Prätarsus, während der Tarsus mehr oder weniger erhalten

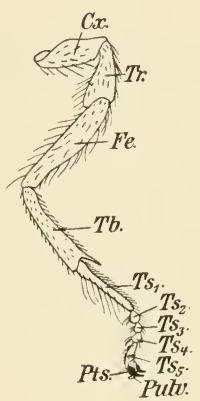

Fig. 31. Mittleres Bein einer Biene. $C x$ Coxa (Hüfte); $T r$ Trochanter (Schenkelring); $\mathrm{Fe}$ Femur (Schenkel); Tb Tibia (Schiene); $T s_{1}-T s_{5}$ Tarsenglied $1-5 ; P t s$ Prätarsus; Pulv Pulvillus. Nach $\mathrm{Z}$ ander. durch Bewaffnung mit Dornen, Haken, Zähnen, durch dichten Haarbesatz usw. werden die verschiedensten Formen erzielt und die verschiedensten Funktionen ermöglicht. Die Umgestaltungen betreffen nicht immer alle 3 Beinpaare in gleicher Weise, sondern sehr oft nur ein Paar. So sind in vielen Fällen nur die Vorderbeine verändert, die ja überhaupt (auch in bezug auf die Stellung) in einem gewissen Gegensatz zu den beiden übrigen Paaren stehen und auch weit mehr wie diese zu anderen (als lokomotorischen) Leistungen herangezogen werden (zum Graben, Ergreifen von Beute usw.).

Die meisten Insekten haben gewöhnliche Laufbeine, z. B. die Laufkäfer. Tritt eine Sohlenbildung an dem Fuße auf, so spricht man von Gangbeinen, z. B. bei den Bockkäfern. Werden die Beine lang und schlank, so nennt man sie Schreitbeine, z. B. bei den Gespenstheuschrecken. Beine, welche infolge starker Muskelausstattung des Schenkels das Insekt zum Springen befähigen, heißen Springbeine, so bei Heuschrecken und Erdflöhen. Kann die Schiene wie die Klinge 
eines Taschenmessers gegen das Heft, so gegen den Schenkel eingeschlagen werden, daß hierdurch ein Ergreifen der Beute möglich wird, so heißen die Beine Raubbeine, z. B. bei dem Wasserskorpion. Eine Verbreiterung der Schiene macht das Bein zum Graben geschickt: Grabbeine, welche z. B. bei der Werre und den Mistkäfern vorkommen. Bei manchen der letzteren, z. B. bei Ateuchus, kann, wie schon gesagt, außerdem auch der Tarsus und Prätarsus verkümmern. Eine starke Verkleinerung der Fußglieder kommt auch bei den zu Putzbeinen verkümmerten Vorderbeinen der Schmetterlinge vor. Stärkere Ausstattung der Hinterbeine mit Haaren, in welchen sich der abgestreifte Blütenstaub festsetzen kann, oder das Auftreten eines von Haaren umgebenen "Körbchens" an der Schiene der Hinterbeine zum Transporte des Pollens, wie sie sich bei vielen Blumenbienen finden, lassen diese als Sammelbeine erscheinen. Die im Wasser lebenden Insekten haben vielfach breite, zusammengedrückte, an der Schneide mit Schwimmhaaren versehene Hinterbeine, Schwimmbeine, z. B. die Schwimmkäfer und viele Wasserwanzen.

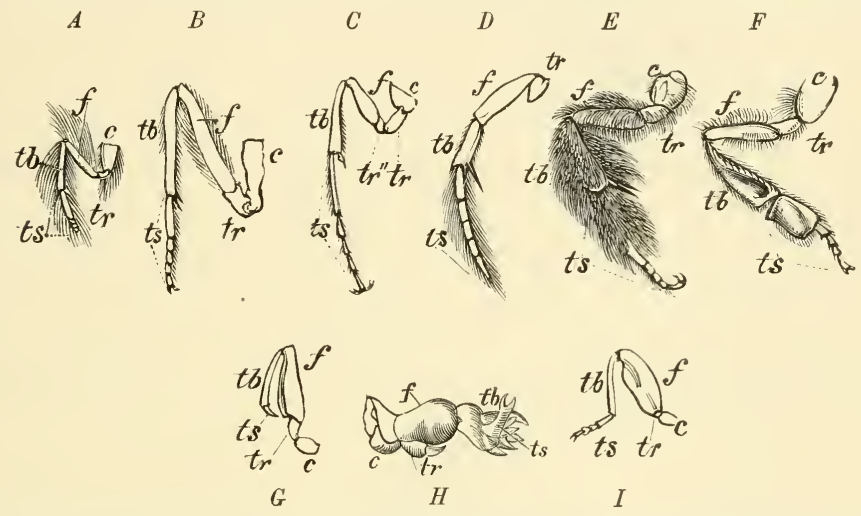

Fig. 32. Verschiedene Beinformen. A verkümmertes Putzbein und $B$ gut entwickeltes Schreitbein eines Talgschmetterlings, Vanessa polychloros; $C$ !Bein mit doppeltem Schenkelring und langer Ferse von einer Holzwespe, Sirex gigas; $D$ Schwimmbein eines Wasserkäfers, Dytiscus; $E$ behaartes Sammelbein der Bürstenbiene, Dasypoda; $F$ Sammelbein mit „Körbchen“ an der Schiene und stark entwickelter Ferse einer Arbeitsbiene von Apis mellifica; $G$ Raubbein des Wasserskorpions, Nepa cinerea; $H$ Grabbein der Werre, Gryllotalpa, I Springbein eines Erdflohkäfers, Haltica. $-c$ Hüfte; $t r$ Srhenkelring; $f$ Schenkel; tb Schiene; ts Fuß. - (N.

\section{Die Flügel.}

Die Flügel stellen häutige, flächenhaft ausgebreitete Anhänge der Mittel- und Hinterbrust dar, welche rückenständig, zwischen Pleura und Tergum, beweglich eingelenkt sind. Meistens werden sie durch ein mehr oder weniger kompliziertes System von stärker chitinisierten Adern und Rippen gesteift. Ursprünglich sind $2 \mathrm{Paar} F \mathrm{Flügel}$ vorhanden, welche als Vorder- und Hinterflügel unterschieden werden. Mehr als 2 Paar kommen niemals vor, dagegen tritt nicht selten eine Rückbildung des einen Paares (meist der Hinterflügel) ein, so daß nur noch ein Paar funktionierender Flügel übrig bleibt.

Die Flügel sind keine Extremitäten in morphologischem Sinne, sondern stellen vielmehr einfache Hautausstülpungen dar, die sich sekundär abgegliedert haben unter gleichzeitiger Ausbildung von Gelenken (d. s. eine Reihe dorsaler und 
ventraler Gelenkstücke, von denen die dorsalen jedenfalls nur Abgliederungen der Hauptflügeladern darstellen). Dieser Entstehung nach setzen sie sich aus einer oberen und unteren Chitinlamelle zusammen, die an den Flügelrändern ineinander übergehen und zwischen denen während der Bildung der Flügel die zellige Matrix liegt. Letztere schwindet bei den fertigen Flügeln wieder und die beiden Chitin-

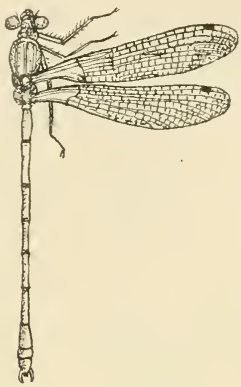

Fig. 33. Eine Libelle, deren Vorder- und Hinterflïgel annähernd gleich sind. lamellen legen sich enge aneinander, so daß der sie trennende, anfänglich auch von der Blutflüssigkeit des Körpers durchströmte Hohlraum stark reduziert wird bis auf die in den "Adern" zurückbleibenden Kanäle, die als Bahnen für Tracheen und Nerven dienen. - Wie man sich die erste Entstehung der Flügel vorzustellen hat, ist ein schwer $\mathrm{zu}$ beantwortendes Problem, welches schon eine vielseitige Erörterung von Seiten der vergleichenden Anatomen erfahren hat. Die bekannteste Hypothese ist die von Gegenbaur aufgestellte, wonach die Ausstülpungen ursprünglich zur Atmung dienten und demnach also die Flügel aus Tracheenkiemen hervorgegangen wären; während Börner die Tracheenkiemen auf echte ventrale Extremitäten zurückführen möchte. Eine weitere viel behandelte Frage ist die, ob bei den Urinsekten auch der Prothorax Flügel getragen hat. Nach den paläontologischen (Palaeodictyopteren) und entwicklungsgeschichtlichen (manche Termitenlarven tragen flügelähnliche Prothoracalanhänge) Befunden ist die Möglichkeit, daß3 3 Paar Flügel vorhanden waren, nicht ausgeschlossen.

Die Form der Flügel ist eine überaus mannigfaltige; es kann dieselbe rechteckig, dreieckig, oval, gestreckt oder gedrungen usw. sein, ferner ausgeschnitten, geschwänzt oder am Rande mit Fransen besetzt (gefranst), oder gefiedert usw. - Auch bezüglich der Struktur und des Größenverhältnisses zueinander herrschen beträchtliche Verschiedenheiten, die wir etwa folgender-

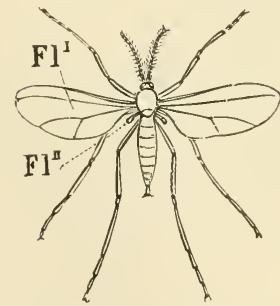

Fig. 34. Weibliche Gallmücke (Cecidomyia), stark vergrößert. $F \eta^{I}$ Vorderflügel gut ausgebildet; $F \eta \mathbf{I}$ Hinterflügel zu Schwingkölbchen umgebildet. - (N.) maßen gruppieren können:

I. Vorder- und Hinterflügel von gleicher häutiger Struktur; Hinterflügel können auch fehlen.

a) Hinter- und Vorderflügel von annähernd gleicher Größe und Form (Beispiele: Libellen), Fig. 33;

b) Hinterflügel kleiner als die Vorderflügel (Beispiele: Schmetterlinge, Bienen, Wespen);

c) Hinterflügel zu einem winzigen Rudiment reduziert oder ganz fehlend (Beispiele: manche Eintagsfliegen [Baëtis], Männchen der Schildläuse usw.);

d) Hinterflügel $\mathrm{zu}$ mehr oder weniger langgestielten Schwingkölbchen (Halteren) umgewandelt (Beispiele: Dipteren), Fig. 34.

II. Vorderflügel in ihrer ganzen Ausdehnung oder wenigstens in ihrer vorderen Hälfte stärker chitinisiert und als Flügeldecken (Elytra) oder Halbdecken (Hemielytra) ausgebildet, die entweder (meistens) den Hinterleib mehr oder weniger vollkommen bedecken (Fig. 35, $36^{1}$ ) u. 38), oder aber auch stark verkürzt sein können, nur über die ersten Hinterleibssegmente reichend (Fig. 37); Hinterflügel häutig, meist wesentlich größer als die Flügeldecken, seltener reduziert oder fehlend.

1) Fig. 36 (untere Figur auf S. 33) ist fälschlich dort als Fig. 34 bezeichnet. 
e) Hinterflügel in der Ruhelage weit über die Elytren hinausragend (Beispiel: Grillen), Fig. 37.

f) Hinterflügel in der Ruhelage vollkommen unter den Elytren verborgen (Fig. 38).

g) Hinterflügel reduziert oder ganz fehlend, dabei die beiderseitigen Elytren oft miteinander zu einer einheitlichen Decke verwachsen (Beispiele: manche Rüsselkäfer).

III. Vorderflügel stark reduziert, Hinterflügel gut ausgebildet. Kommt selten vor (Stylopiden).

IV. Vorder- und Hinterflügel stark reduziert oder gänzlich rückgebildet.

Die Reduktion kann beide Geschlechter betreffen (Bettwanze, Kleiderlaus), oder aber nur auf ein Geschlecht beschränkt sein, und zwar dann meistens auf das weibliche (Leuchtkäfer, Frostspanner). Nur in einem Fall ist das Weibchen geflügelt und das Männchen

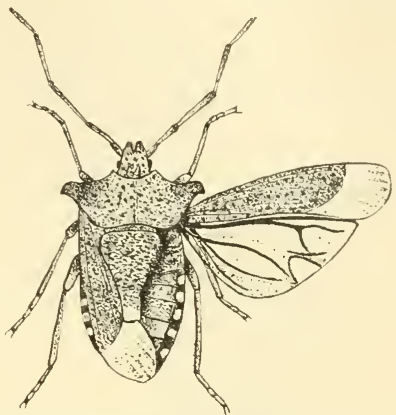

Fig. 35. Eine Schildwanze, deren Vorderflügel zu Semielytren umgebildet sind. flügellos, bei der parasitischen Ameisengattung Anergates. - Es können auch ein und dieselben Individuen zuerst geflügelt sein und dann durch Abwerfen der Flügel flügellos werden, wie die Weibchen der Ameisen und die beiden Geschlechter der Termiten, die nach dem Hochzeitsflug sich selbst ihrer Flügel berauben, indem sie sie an der Wurzel abbrechen.

Endlich ist auch noch darauf hinzuweisen, daf es auch eine primäreFlügellosigkeit gibt (z. B. Lepisma, Machilis usw.), die sich von sekundären dadurch unterscheidet, dafi in keinem Entwicklungs-

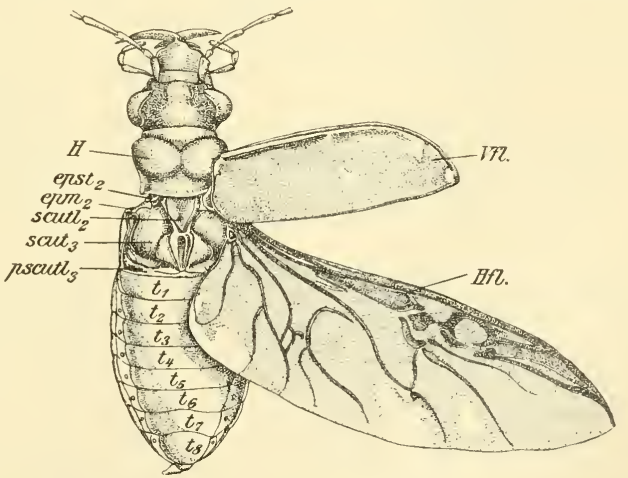
stadium irgendwelche, wenn auch noch so rudimentäre, Flügelanlagen sich nachweisen lassen.

Wir sehen aus dieser Übersicht, daf schier alle Möglichkeiten bezüglich des morphologischen Verhaltens der 2 Flügelpaare verwirklicht sind. Diesem entspricht auch das funktionelle Verhalten insofern, als in der ersten Gruppe 
die Flugbewegung entweder von beiden Flügeln in gleicher Weise (I. a.), oder aber hauptsächlich (I. b.), oder auch ausschlieflich (I. c. und d.) von den Vorderflügeln besorgt wird, während in der zweiten und dritten Gruppe ausschlieflich die Hinterflügel am Flug beteiligt sind. Die Flügeldecken machen keine Flugbewegungen mit, sondern werden beim Flug meistens ruhig seitlich gespreizt gehalten und dienen als Balancierorgan. (Nur relativ selten [z. B. bei den Rosenkäfern] bleiben die Flügeldecken nach Entfaltung der Flügel in der normalen geschlossenen Stellung über dem Abdomen, wobei die Bewegung der Hinterflügel durch einen besonderen Ausschnitt an den Seitenrändern der Elytren ermöglicht wird.) - Wo die beiden Flügelpaare (1. Gruppe)

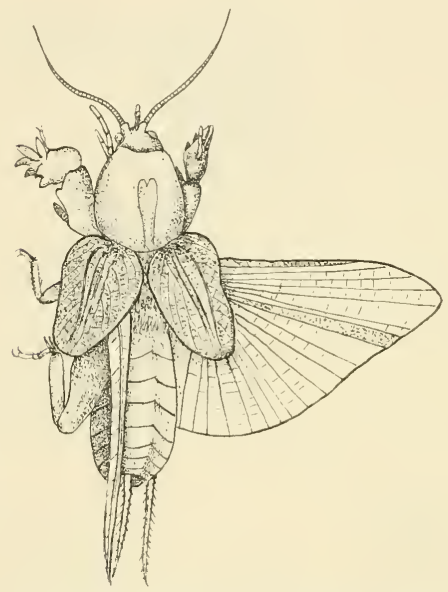

Fig. 37. Maulwurfsgrille. Vorderfligel kurze Elytren, unter denen die gefalteten Hinterflügel weit hervorragen (siehe linker Flügel).

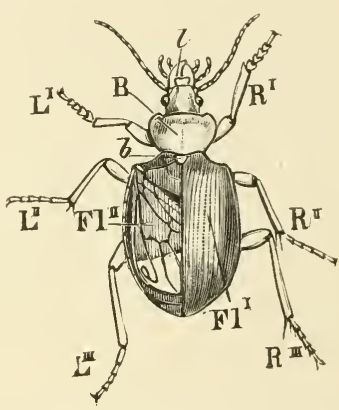

Fig. 38. Kletterlaufkäfer, Calosoma sycophanta $L$. $l$ Oberlippe; $B$ Vorderbrust, Halsschild; $b$ Schildchen; Fl 1 zu einer Flügeldecke umgewandelter Vorderflügel der rechten Seite; FlII der zusammengefaltete Hinterflügel der linken Seite. - (N.)

den Flug ausführen, sind Vorder- und Hinterflügel vielfach durch feine Häkchen (Hymenopteren) oder durch eine kräftige Borste, die vom Vorderrand der Hinterflügel ausgeht und in einen Haken des Vorderflügels eingreift (Schmetterlinge), derartig miteinander verbunden, dab sie wie eine einheitliche Fläche wirken.

Bei den mit Flügeldecken versehenen Formen sind die Hinterflügel in der Ruhelage meistens gefaltet, um unter den kleineren Elytren Platz zu finden. Die Faltung findet der Länge und Quere nach statt, und zwar in umso ausgedehnterem Maße, je größer das Mißverhältnis zwischen Flügeldecken und Hinterflügel ist. Am meisten also in den Fällen, in denen die Flügeldecken stark verkürzt sind, wie bei den kurzflügligen Käfern (Staphylinen) oder den Ohrwürmern (Forficula). Das Einfalten und Entfalten geschieht nicht etwa durch einen besonderen Muskelapparat (Muskeln sind niemals innerhalb 
der Flügelfläche), sondern automatisch, zugleich mit dem Zurücklegen und Ausspannen der Flügel, wovon man sich bei jedem frisch getöteten Käfer überzeugen kann.

„Beim Zurücklegen wird die Vorderrandader der ihr folgenden parallel laufenden genähert; der zwischen ihnen gelegene Teil der Flügelmembran faltet sich nach unten und zugleich klappt die Flügelspitze nach unten um. Umgekehrt wird beim Ausspannen die Flügelmembran zwischen den beiden Adern gespannt und damit zugleich das Aufklappen der Flügelspitze bewirkt" (nach Hesse).

Das Flügelgeäder, das zur Festigung der häutigen Flügel dient, kann je nach den Ordnungen, Familien, Gattungen und Arten recht verschieden sein und findet deshalb auch in der Systematik reichliche Verwendung. Es besteht in der Hauptsache aus einer Anzahl von der Flügelwurzel ausgehenden Längsadern, die sich mehrfach verzweigen können, und mehr oder weniger zahlreichen Queradern, welche die Längsadern und ihre Abkömmlinge miteinander in Verbindung bringen. Dadurch wird der Flügel in verschiedene grölere und kleinere häutige Felder zerlegt, die als „Zellen" bezeichnet werden.

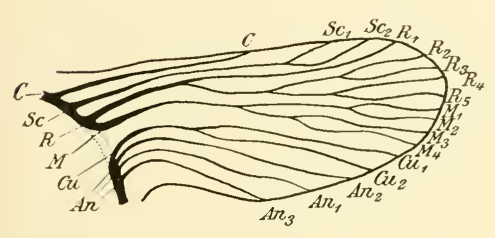

A

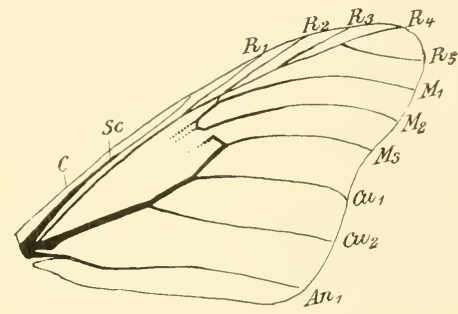

$B$

Fig. 39. Flügelgeäder (nach Comstok und Needham). A Hypothetische Grundform der Aderbildung. $B$ Flügelgeäder eines Schmetterlings. $C$ Costa; $S c$ Subcosta; $R$ Radius; $M$ Mediana; $C u$ Cubitus; An Analader.

Die einzelnen Adern werden mit verschiedenen Namen bezeichnet (wie Costal-, Subcostal-, Radial-, Median-, Cubital-, Analader usw.), ebenso die „Zellen“, die als Costal-, Cubital-, Analzellen usw. unterschieden werden. Jedoch werden diese Bezeichnungen keineswegs von allen Autoren in gleichem Sinne gebraucht, so daß man in den verschiedenen Ordnungen von Fall zu Fall sich erst in die gebräuchliche Nomenklatur einarbeiten muß. Wir werden im speziellen Teil uns noch öfter damit $\mathrm{zu}$ beschäftigen haben. - Es hat nicht an Versuchen gefehlt, die mannigfaltigen Bilder, die das Flügelgeäder in den verschiedenen Gruppen zeigt, in genetische Verbindung miteinander $z u$ bringen, d. h. die eine Form aus der anderen abzuleiten (Adolph, Redtenbacher, Comstók und Needham); doch keiner dieser Versuche führte $\mathrm{zu}$ einem befriedigenden Resultat. Es ist dies auch nicht zu verwundern, wenn man bedenkt, daß doch die meisten der heutigen Insektenordnungen sich unabhängig voneinander aus der Insektenurform entwickelt haben. Der neueste Bearbeiter des Flügelgeäders, Woodworth, hat denn auch jene Idee aufgegeben und sucht die verschiedene Ausbildung des Geäders in der Hauptsache auf mechanische Prinzipien zurückzuführen. - Aus praktischen Gründen dürfte es 
sich empfehlen, überall, wo irgend angängig, die Nomenklatur von Comstok und Needham anzuwenden (Fig. 39).

Was nun endlich die Ruhestellung der Flügel betrifft, so ist aúch diese eine recht wechselnde, je nach den verschiedenen Ordnungen oder Familien. So werden z. B. bei den Libellen die 4 Flügel horizontal und quer abstehend getragen, oder es werden die Vorderflügel bei noch wesentlich horizontaler Stellung etwas über die Hinterflügel nach hinten und innen übergeschoben (bei vielen Schmetterlingen), oder es werden die Vorderflügel so vollständig über die Hinterflügel hinübergeschoben, daß sie die letzteren gänzlich verbergen, und dabei entweder dachförmig den Hinterleib decken, indem sich eine mehr weniger steile Firste über dessen Medianebene bilden (viele Nachtfalter und Zikaden), oder aber dem Hinterleibe horizontal aufliegen, z. B. bei den Blattwespen. Die Mehrzahl der Tagfalter und einige Spanner tragen die Flügel vertikal in der Medianebene aufgerichtet, so daf die oberen Flächen beider Flügelpaare sich berühren.

Außer den Flügeln kommen bei einigen Insektenordnungen noch ein oder zwei Paar kleiner dorsaler Anhänge vor, die als Patagia und Tegulae (Schulterdecken, Squamuli usw.) bezeichnet werden. Die Patagia, die hauptsächlich bei Schmetterlingen vorkommen, sind am Prothorax zwischen Rückenschild und Seitenteil beweglich eingelenkt und stellen ein Paar kleiner flügelähnlicher Anhänge dar, die kräftig chitinisiert und meist dicht mit Haaren und Schuppen bekleidet sind. Die Tegulae sind kleine, muschelförmig gewölbte, häutige Anhänge, welche am Mesothorax vor den Vorderflügeln eingelenkt sind, deren Wurzel bedeckend. Sie finden sich ebenfalls bei Schmetterlingen, dann aber auch noch bei vielen anderen Insekten, wie Trichopteren, Hymenopteren, Fulgoriden usw. - Manche Autoren haben die Patagia als Flügel des Prothorax aufgefaßt, doch zeigten vergleichend anatomische Studien, daß sie morphologisch eher mit den Tegulae zu vergleichen sind.

\section{Der Hinterleib (Abdomen).}

\section{A. Zusammensetzung und Form des Hinterleibes.}

Der Hinterleib oder das Abdomen beherbergt den größten Teil der Verdauungsorgane und die Geschlechtsorgane. Da diese, speziell die letzteren, von wechselnder Ausdehnung sind, so müssen auch die Wände des Abdomens entsprechend ausdehnungsfähig sein. So finden wir denn auch - im Gegensatz zu Kopf und Brust - nur relativ wenig ausgedehnte Verwachsungen zwischen den das Abdomen zusammensetzenden Segmenten. Diese sind vielmehr meist durch mehr oder weniger umfangreiche Intersegmentalhäute voneinander getrennt, von deren Länge natürlich der Grad der Ausdehnungsfähigkeit abhängt. Wie weit letztere gehen kann, zeigen am drastischsten die Termitenweibchen, deren Abdomen durch völlige Entfaltung der Intersegmentalhäute das Zehnfache der ursprünglichen Länge erreichen kann, wobei dann die eigentlichen Segmentplatten nur noch als schmale Striche auf dem mächtigen weißen Hinterleib erscheinen.

Wie der Kopf und Thorax, setzt sich auch das Abdomen aus einer konstanten Zahl von Segmenten zusammen, die, in der Embryonalanlage stets nachweisbar, sekundär durch Verwachsungen, Reduktionen usw. während 
der postembryonalen Entwicklung eine wesentliche Verringerung erfahren kann. Es steht heute fest, dab das Abdomen der Anlage nach aus $12 \mathrm{R}$ ingen besteht (11 echten Segmenten und einem Schwanzstück oder Telson), deren Bestandteile bei manchen niederen Insekten (z. B. Libellen) dauernd erkennbar sind.

Die einzelnen Segmente stimmen in ihrem Aufbau mehr oder weniger miteinander überein und bestehen typischerweise aus folgenden Teilen: 1. einer Rückenplatte (Tergum), 2. einer Bauchplatte (Sternum) und 3. den sie verbindenden Pleuralhäuten, in denen sich meist das Stigmenpaar vorfindet. Nicht selten gelangen in der Umgebung der Stigmen noch selbständige Chitinplättchen zur Ausbildung, die dann als „Pleurite“ zu betrachten sind. - Die Segmentplatten können sehr stark chitinisiert und infolgedessen hart und

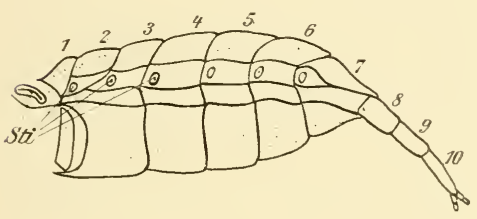

$A$

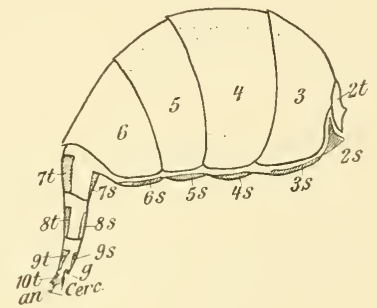

$B$

Fig. 40. Verschiedene Abdomina. A von einem weiblichen Bockkäfer (Cerambyx), $B$ von einer weiblichen Fliege (Calliphora). Die letzten 3 oder 4 Segmente sind fernrohrartig ausgestülpt; und dienen als Legeröhren; in der Rnhelage sind dieselben in den Hinterleib eingezogen. Sti Stigmen; $t$ Tergum; $s$ Sternum. A nach Kolbe, $B$ nach Berlese.

starr sein, andererseits aber auch weich, biegsam und faltbar. Bei den Flügeldecken tragenden Insekten sind die von den Flügeldecken bedeckten Terga meist weichhäutig oder jedenfalls stets viel dünner als die unbedeckten Terga und die Sterna. Sehr schön kann man dies z. B. beim Maikäfer sehen, dessen von den Flügeldecken freigelassenes letztes Tergum (sog. Pygidium) stark chitinisiert ist - im Gegensatz zu den vorhergehenden, im Bereich der Flügeldecken liegenden Rückenplatten.

Embryonal entstehen die Rückenplatten aus zwei lateralen Hälften, die sich in der dorsalen Medianlinie aneinanderfügen und dort miteinander verschmelzen. Die Sterna dagegen sind ursprünglich dreiteilig, indem mit einem medianen Abschnitt sich zwei laterale verbunden haben, welch letztere zum Teil auf die abgeplatteten Extremitätenanlagen zu beziehen sind (vgl. Fig. 41).

Das Schwanzstück oder Telson, das in morphologischem Sinne kein eigentliches Segment darstellt, tritt gewöhnlich in Form von drei Platten auf, die als Afterklappen oder Lamina anales bezeichnet werden und von denen die eine unpaare (Laminae supraanalis) dorsal, und die beiden paarigen (Laminae subanales) lateroventral der Afteröffnung angelagert sind. 
Nur bei relativ wenigen Insekten ist die ursprüngliche Zusammensetzung des Abdomens (11 Terga, 11 Sterna und 3 Laminae anales) im Imagozustand noch zu erkennen. Gewöhnlich finden wir eine geringere Zahl, ja bei manchen Insekten sind äuferlich nur 3-4 Abdominalsegmente sichtbar. Dies beruht entweder darauf, daf die hinteren Segmente von den vorderen überwachsen resp. in die vorderen fernrohrartig eingezogen sind, oder aber auf wirklichen Rückbildungen. - Im ersten Fall können die eingezogenen Segmente meist auch wieder ausgestülpt werden und dienen so als "Legeröhre" zum Unterbringen der Eier in schmale Spalten, unter Rindenschuppen usw. (z. B. bei vielen Fliegen, Schmetterlingen, Käfern usw.). - Was die Reduktion anbetrifft, so spielen sie sich zunächst ebenfalls am Hinterende ab, indem zuerst das 11. Segment, dann die 3 Analplatten, dann das Sternum des 10., dann event. auch das Tergum desselben rudimentär wird. Auch das 9. Segment kann noch starke Veränderungen zeigen, und zwar ebenfalls (wie beim 10.) zuerst an der Ventralplatte, was durch das Auftreten von Genitalanhängen bedingt wird. Als eine Verkümmerungserscheinung muß ferner das ständige Fehlen der Stigmen in den letzten 3 Segmenten gelten (das hinterste Stigmenpaar pflegt schon am 8. Segment [Ausnahme: Lepisma am 9.] sich zu befinden). - Aber auch am Vorderrande des Abdomens können Reduktionen erfolgen, die sich ebenfalls meist zuerst auf die Sterna beziehen, während die zugehörigen Terga noch länger sich erhalten können; so fehlen z. B. bei den meisten Käfern die beiden ersten Sterna. - Um die Verhältnisse der Glieder des Abdomens kurz und übersichtlich auszudrücken, bedient man sich besonderer Formeln, z. B.: $\frac{\mathrm{D} 1,2,3,4,5,6,7,8,9,(10)}{\mathrm{V}}$, d. h., dorsal sind die Segmentplatten 1-9 gut ausgebildet, 10 dagegen mehr oder weniger reduziert; ventral fehlen die Platten 1, 2 und 10 ganz, 9 ist rudimentär, nur $3-8$ sind vollkommen vorhanden.

Die Form des Abdomens kann recht verschieden sein: parallelseitig, stabförmig, oval, rund, nach hinten verbreitert usw. Ferner kann der Hinterleib von rechts nach links zusammengedrückt sein (komprimiert), oder aber von oben nach unten (deprimiert). Endlich kommt es noch auf die Art der Verbindung des Hinterleibes mit der Brust an: Ist das 1. Hinterleibssegment so breit wie der Metathorax und sitzt es diesem auch mit seiner ganzen Breite an, so spricht man von einem festsitzenden Hinterleib (Käfer, Blattwespen, Fliegen); sitzt es nur mit einem kleinen Teil seiner Vorderfläche an, so spricht man von einem anhängenden Hinterleib (Wespen); sind dagegen die ganzen ersten Segmente stielartig verdünnt, so haben wir einen sog. gestielten Hinterleib vor uns (Ameisen, Scblupfwespen usw.).

\section{B. Die Anhänge des Hinterleibes.}

Wenn auch das Abdomen der erwachsenen Insekten im allgemeinen (im Gegensatz zu Kopf und Brust) als der gliedmafenlose Abschnitt bezeichnet wird, so kommen doch bei manchen niederen Insekten noch echte abdominale Extremităten als sog. Cerci (Raife) und Styli (Griffel) vor; auferdem finden sich bei den meisten Insekten noch verschiedene andere 
(allerdings wohl nur zum Teil auf Extremitäten zurückführbare) Anhänge, die um die Geschlechtsöffnung gelegen sind, und daher als Genitalanhänge bezeichnet werden. -

Die Cerci (Raife) die bei Thysanuren, Orthopteren, Ephemeriden, Perliden usw. vorkommen, sind der Anlage nach dem 11. Segment zuzusprechen (können aber nach Rückbildung des 11. Segmentes an das 10. sich anfügen) und stellen entweder lange, gegliederte, fühlerartige Anhänge ( Afterfühler") dar, (wie z. B. die Schwanzfäden der Eintagsfliegen und Silberfische), oder kräftige ungegliederte, gegeneinander bewegliche Zangen (wie z. B. bei den Ohrwürmern).

Bei manchen Insekten kommt neben den paarigen Schwanzfäden (Cerci) noch ein dritter, unpaar er, über der Afteröffnung gelegener Schwanzfaden vor. Auch dieser gehört dem 11. Segment an und stellt das langausgezogene Tergum desselben dar.

Während es sich also bei den Cerci um relativ gut ausgebildete Extremitäten handelt, haben wir in den Styli nur noch kleine Extremitätenreste vor uns, die noch mehr auf die primitiven Insektenformen beschränkt sind als die Cerci. Sie stellen kurze eingliedrige Zapfen dar, die, am Hinterrand der Sterna jederseits gelenkig eingefügt, bei einigen Formen noch in 8 Paaren (Fig. 41) am 2. bis 9. Segment auftreten können, gewöhnlich aber nur noch an den hinteren Segment zur Ausbildung gelangen.

Die abdominalen Styli sind den Hüftgriffeln, die wir oben an den Mittel- und Hinterbeinen von Machilis kennen gelernt haben, morphologisch gleichwertig. Das Vorkommen von Styli an 8 Abdominalsegmenten zeigt uns wieder, daß die Vorfahren der Insekten an allen Segmenten Beine besaßen (was ja, wie schon gesagt, auch durch die embryologischen Befunde bewiesen ist).

Die Genitalanhänge sind je nach dem Geschlecht verschieden. Beim Männchen handelt es sich um 2 oder 4 klappenartige, kräftig chitinierte

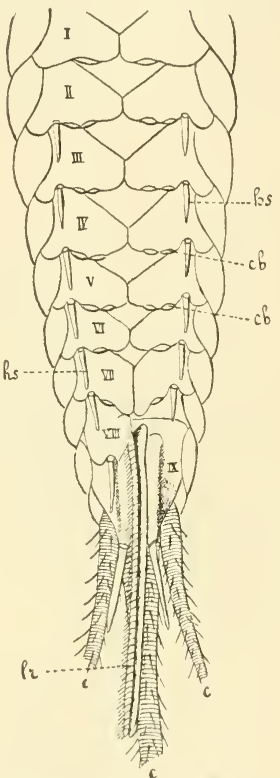

Fig. 11. Hinterleib von Machilis (nach Lang). c Cerci; hs Styli; Ir Ovipositor. Gebilde, die neben einem unpaaren medianen Anhang, dem Penis, sich erheben, und als Parameren bezeichnet werden. Sie dienen wohl meistens als Haltzangen zur Befestigung der beiden Geschlechter während der Copula. - Im weiblichen Geschlecht sind es gewöhnlich 6 (bei Thysanuren nur 4) längere stabförmige Gebilde, welche sich zu einem gemeinsamen Legeapparat (auch Legescheide oder Ovipositor genannt) zusammenfügen (Fig. 42). Letzterer hat vor der oben erwähnten "Legeröhre" den Vorzug, daß er infolge seiner Härte auch in festere Körper einzudringen vermag, wobei vielfach auch sägeoder bohrerartige Vorrichtungen mitwirken können. Wir finden daher Legescheiden hauptsächlich bei solchen Insekten ausgebildet, welche ihre Eier in den Boden (z. B. Heuschrecken), oder parasitisch in andere Tiere (Schlupf- 
wespen), oder in Holz (z. B. Holzwespen) usw. legen. Die Länge des Legeapparates kann mitunter sehr beträchtlich werden, wie manche Schlupfwespen zeigen, bei denen der Legebohrer länger ist als das ganze Tier. - Bei manchen Hymenopteren (Bienen, Wespen, Ameisen usw.) bekommt der Legeapparat entweder neben der ursprünglichen Funktion (Weibchen) oder auch ausschließlich (Arbeiter) die Bedeutung eines Giftstachels, indem der Ausfuhrgang einer Giftdrüse mit ihm in Verbindung tritt (Funktionswechsel).

Der Legebohrer besteht meist aus 2 Bohrern oder Sägen, aus einer Rinne, welche zur „Führung“ dieser Bohrer dient (Stachelrinne, Gleitrinne), und zwei den Bohrapparat beiderseits bedeckenden Scheidenklappen (Fig. 43). - Wahrscheinlich sind die Genitalanhänge auf Extremitäten zurückzuführen, wenn "sie auch embryoonal an einer anderen Stelle, nämlich unmittelbar an der Medianlinie entstehen. Möglicherweise verhalten sich aber die verschiedenen Insekten in dieser Beziehung

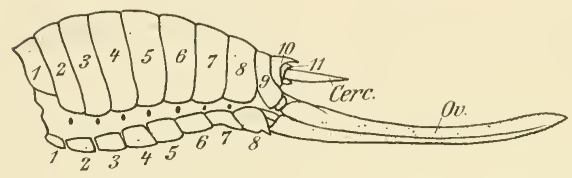

Fig. 42. Hinterleib einer weiblichen Laubheuschrecke mit langem, kräftigem' Legesäbel $O v$, der aus Anhängen des 8 . und 9. Segmentes gebildet wird. Nach Berlese.

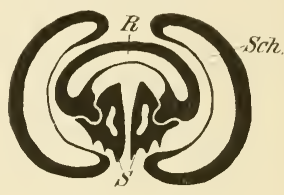

Fig. 43. Querschnitt durch den Legestachel einer Holzwespe. S die beiden Sägen; $R$ Gleitrinue; Sch Scheidenklappe. Nach Taschenberg.

verschieden. - Die männlichen Genitalanhänge finden in der Systematik reichliche Verwertung; sind sie doch auch einerseits fast bei jeder Art verschieden geformt, während sie andererseits innerhalb der Art eine relativ hohe Konstanz besitzen.

\section{Skulptur und Färbung der Haut.}

Skulptur.

Die Chitincuticula, die den Abschluß des Insektenkörpers nach außen bewirkt, ist, wie aus dem Vorhergehenden ersichtlich, sehr verschieden stark ausgebildet, und kann von dem zartesten Häutchen bis zum mehrfach geschichteten dicken starren Panzer variieren. Auch die Oberflächenskulptur zeigt große Mannigfaltigkeiten, indem sie glatt, fein oder grob gerunzelt, genetzt, höckerig, genarbt, bedornt, mit Poren besetzt usw. sein kann. - Dazu kommt, daß die Cuticula meistens auch mit Anhängen, Chitinhaaren oder Schuppen bedeckt ist.

Die ersteren sind allgemein verbreitet und es gibt kein Insekt, welches der Haare vollkommen entbehrt. Allerdings ist die Behaarung oft nur sehr spärlich und nur auf einzelne Stellen beschränkt (Extremitäten, Flügeldeckenränder usw.); andererseits kann sie aber so dicht werden, daß sie wie ein Pelz das ganze Tier umhüllt. Die Behaarung kann ferner anliegend oder abstehend, lang oder kurz, seidenartig weich oder borstig sein. Auch die Form der einzelnen Haare kann recht verschieden sein, wie: ge- 
dreht, gespalten, gekämmt, gefiedert, geknöpft oder am Ende glockenförmig erweitert usw. (Fig. 44).

Wie die Form, so ist auch die Funktion der Hare eine recht vielseitige. Die wichtigste Aufgabe besteht in der Übermittlung äußerer Reize (Sinneshaare); andere Haare dienen zum Schutz, wieder andere zum Sammeln von Blütenstaub (Sammelhare), oder zum Putzen (Putzhare), oder zum Anheften an andere Gegenstände (Hafthaare). Oft stehen sie auch im I)ienst der Sekretion, wobei sie sogar kleine ballonartige Auftreibungen zeigen können (siehe Fig. 52, S. 53), die als Sammelreservoir für die abgeschiedenen Sekrete dienen (Drüsen-oder Gifthaare, Toxophore, Trichome). Bei manchen Wasserinsekten dient das Haarkleid dazu, Atemluft festzuhalten; bei Holzinsekten können die Haare zur Reinigung der Gänge von Bohrmehl mitbenutzt werden.

Nicht so allgemein verbreitet wie die Haare sind die Schuppen; immerhin kommen auch sie bei einer grossen Anzahl von Insekten vor: wie bei den Apterygoten, Psociden, Trichopteren, Lepidopteren, einigen Coleopteren und Dipteren. Bei den flügellosen Apterygoten (Silberfischchen, Felsenspringer usw.), bei den meisten Schmetterlingen und vielen Käfern (ror

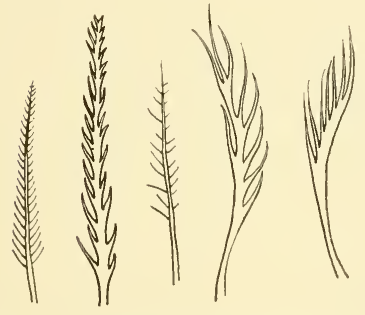

Fig. 44. Verschiedene Haarformen. Nach Berlese.
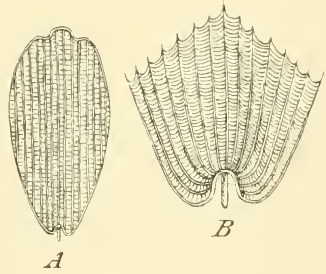

$B$

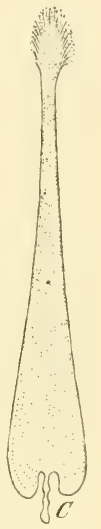

Fig. 45. Verschiedene Schuppenformen. A von einem Schmetterling: $B$ von Lepisma; $C$ Duftschuppe eines Schmetterlings.

allem aus der Familie der Rüsselkäfer, Hirschkäfer, Maikäfer, Borkenkäfer usw.) ist häufig der ganze Körper mit einem mehr oder weniger lückenlosen Schuppenkleid überzogen, bei anderen dagegen (Trichopteren, einige Dipteren) sind die Schuppen hauptsächlich auf die Flügel beschränkt oder vielmehr sogar nur auf einzelne Regionen derselben (z. B. die Adern). - Wo es sich um eine geschlossene Schuppendecke handelt (wie z. B. auf den Schmetterlingsflügeln), sind die Schuppen gewöhnlich in regelmäßigen Reihen angeordnet, dachziegelförmig übereinandergreifend.

Von den Haaren unterscheiden sich die Schuppen einmal gewöhnlich durch ihre Kleinheit (mit bloßem Auge erscheinen sie als Staub), sodann durch ihre Form (meistens flache, breite Blättchen mit dünnem Stiel) und endlich durch ihren losen Zusammenhang mit der Cuticula; genügt doch meistens schon eine leise Berührung, die Schuppen abzustreifen, während die Haare gewöhnlich 
so fest sitzen, dass sie nur durch gewaltsames Ziehen entfernt werden können.

Die Formenmannigfaltigkeit der Schuppen ist mindestens ebenso groß wie die der Haare; wir kennen rechteckige, breite, schmale, dreieckige, ovale, runde Schuppen, mit gerade abgestutzter, ausgerandeter, gerundeter, mehrzackiger Spitze usw. (Fig. 45). Manche Schuppen sind so schmal, dass sie der Haarform nahekommen (haarförmige Schuppen), andere (ebenfalls lange, schmale) sind an der Spitze gefranzt (Federbusch- oder Duftschuppen) oder fächerartig verbreitert (Fächerschuppen). Oft finden sich verschiedene Formen auf ein und demselben Tier. Im allgemeinen aber kommen doch den Schuppen der einzelnen Insektenordnungen ganz charakteristische Merkmale zu, so daß man z. B. ohne Schwierigkeit eine Käferschuppe von einer Schmetterlingsschuppe zu unterscheiden vermag.

Wie die Haare, besitzen auch die Schuppen verschiedene (wenn auch nicht so vielseitige) Funktionen; in erster Linie geben sie den betreffenden Insekten Färbung und Zeichnung; sodann können sie zur Verdunstung aromatischer Sekrete (zwecks Anziehung der Geschlechter) dienen (Duftschuppen), oder sie können dazu verwandt werden, die abgelegten Eier zu bedecken und schützen iEideckschuppen der Prozessionsspinner) usw.

Im Anschluß an die Haare und Schuppen sei noch auf die sog. W achsbildungen hingewiesen, die aus besonderen Hautdrüsen (Wachsdrüsen) abgeschieden werden, und in Form von weißen Haaren, Fäden, oder eines flaumartigen Überzuges oder einer festen Schicht die Oberfläche des Körpers (von Blattläusen, Zikaden, Schildläusen usw.) bedecken. Diese Bildungen, die wohl als Schutzeinrichtungen aufzufassen sind, können mitunter eine sehr ansehnliche Größe erreichen und um ein mehrfaches länger als der ganze Körper werden.

Färbung.

Die Farbenpracht der Insekten ist allbekannt; sie ist es ja in erster Linie, welche die Insekten zu den populärsten Tieren gemacht hat. Die Färbung ist entweder bedingt durch Farbstoffe oder durch Struktureigentümlichkeiten der Cuticula (verschiedene Lichtbrechung). Wir unterscheiden demnach Pigmentfarben oder Strukturfarben (auch optische Farben genannt); zu den ersteren gehören die roten, schwarzen, braunen und gelben Töne, zu den letzteren hauptsächlich die blauen und grünen (vor allem die Schillerfarben). Die schönsten Farbeneffekte werden durch Kombination der Pigment- und Strukturfarben bewirkt; dadurch entsteht der wunderbare Glanz, der über den satten Farben mancher Schmetterlinge liegt, und den nachzuahmen keinem Künstler gelingt.

Die Ursache der Färbung (Pigment oder Struktur) kann entweder in der Haut selbst, oder in den Anhängen (Schuppen oder Haaren) gelegen sein; bei den Schmetterlingen z. B. sind es größtenteils die Schuppen, welche die Färbung bedingen, bei den Käfern liegt der Farbstoff gewöhnlich in der Cuticula oder der Hypodermis oder in beiden (bei einigen allerdings auch in Schuppen) usw. 
Bei manchen Rüsselkäfern (z. B. Lixus, Larinus) beruht die Färbung auf farbigen (gelben, gelbgrünen usw.) Exkreten, die als puderartiger Belag die Haut bedecken. Derselbe läßt sich leicht abstreifen, erneuert sich aber beim lebenden Tier in kurzer Zeit wieder.

Die Färbung und Zeichnung spielt in der Systenatik eine große Rolle; jedoch kann ihr nicht überall der gleiche Wert beigelegt werden, da sie nicht überall konstant, sondern bei vielen Arten sogar recht inkonstant und variabel ist; so gibt es Arten, bei denen man kaum 2 völlig gleich gefärbte Individuen trifft (z. B. Tetropium luridum, Callidium variabile).

Die Skulptur und Färbung dienen in vielen Fällen dem Schutze des Tieres. - Es ist sicherlich kein Zufall, daß viele Insekten bezüglich ihrer Färbung oder Skulptur so sehr mit ihrem gewöhnlichen Aufenthaltsort übereinstimmen, daß man das ruhig sitzende Insekt von seiner Umgebung kaum zu unterscheiden vermag. Diese Übereinstimmung bedeutet für die betreffenden Insekten zweifellos einen großen Schutz gegen die sie verfolgenden Vögel usw., die an solchen Insekten natürlich eher vorbeifliegen, als an abstechend gefärbten, auffallenden Tieren. Man bezeichnet daher eine derartige Anpassung an die Umgebung als "schützende Ähnlichkeit.“

Einheimische Beispiele dafür sind die grüne Färbung vieler Gras- und Baumtiere, z. B. die Laubheuschrecken; die bräunliche Färbung des Kiefernspinners, welcher sich in der Ruhe nur schwer von der Kiefernborke unterscheiden läßt; die rötliche (gescheckte) Färbung des Kieferntriebwicklers (Tortrix buoliana), die den auf dem ebenso gefärbten Maitrieb sitzenden Schmetterling kaum entdecken läßt; oder die plattgedrückten Baumwanzen (z. B. Aradus), welche einem abgelösten Rindenschüppchen täuschend ähneln usw. Noch auffallender sind die „schützenden Ähnlichkeiten" in den Tropen; wir erinnern nur an das allbekannte wandelnde Blatt, das genau wie ein grünes Blatt aussieht, oder an die Stabheuschrecken, die kleine Äste copieren, oder an die sog. Blattschmetterlinge, die in der Ruhestellung ganz und gar einem verdorrten Blatt gleichen.

Bei allen diesen schützenden Ähnlichkeiten sind meist nur diejenigen Körperteile übereinstimmend (mit der Umgebung) gefärbt, welche in der Ruhestellung nach aufen gekehrt, d. h. sichtbar sind. So ist bei den letztgenannten Blattschmetterlingen nur die Unterseite der Flügel blattähnlich, weil in der Ruhestellung nur diese zu sehen sind; bei Tortrix buoliana hat nur die Oberseite der Vorderflügel die triebähnliche Färbung, da beim Sitzen nur diese offen daliegen; und noch bei vielen anderen Schmetterlingen (z. B. Ordensbänder) läßt sich die differente Färbung zwischen Hinter- und Vorderflügel in der gleichen Weise erklären.

Eine andere Form der schützenden Ähnlichkeit besteht darin, daß eine Insektenart einer anderen systematisch gänzlich verschiedenen Art in Habitus und Farbe täuschend ähnelt, so daß die beiden bei oberflächlicher Betrachtung leicht miteinander verwechselt werden können. Man bezeichnet diese Erscheinung als Nachahmung oder Mimikry. Biologisch ist dieselbe dadurch verständlich, daß die nachgeahmte Art meistens wehrhaft ist (mit Giftstachel ausgerüstet usw.), oder einen ekelerregenden Geruch oder Geschmack besitzt, und deshalb von den Insektenfressern verschmảht wird, während die nachahmende Art gewöhnlich weder die eine noch die andere Eigenschaft besitzt. Die letztere profitiert also durch ihre Nachahmung (die gewissermaßen eine Verkleidung darstellt) von dem Respekt, den die nachgeahmten Vorbilder infolge ihrer Waffen usw. genießen. 
Eines der bekanntesten Beispiele von Mimikry aus unserer Fauna ist der Hornissenschwärmer, ein harmloser Schmetterling, der in Zeichnung und Form der gefürchteten Hornisse sehr ähnlich ist (Fig. 46). Ferner gibt es unter den Schwebefliegen mehrere Arten, welche Hummeln oder Bienen zum Verwechseln ähneln; auch einige Käfer (Necydalis) ahmen Wespen nach. - Häufiger noch kommt die Mimikry in der tropischen Insektenwelt vor, wobei es sich hauptsächlich um Schmetterlinge aus verschiedenen Gattungen oder Familien handelt, die sich nachahmen. Manchmal ahmt nur das weibliche Geschlecht ein geschütztes Vorbild nach, während das Männchen sein Familienkleid unverändert bewahrt; bedarf doch auch das weibliche Geschlecht im Interesse der Erhaltung der Art weit mehr des Schutzes als das Männchen.

\section{Dimorphismus (bezw. Polymorphismus).}

Unter Polymorphismus verstehen wir die Eigenschaft einer Art, sich in mehrere verschiedene Formen zu differenzieren, die alle mehr oder weniger regelmäßig bei jeder Generation oder bei gewissen Generationen als Kinder gleicher Eltern wieder erzeugt werden. Polymorphe Arten sind also solche, welche in verschiedenen Formen auftreten, sei es gleichzeitig, oder zu verschiedenen Zeiten oder in einem mehr oder weniger regelmäßigen Zyklus.
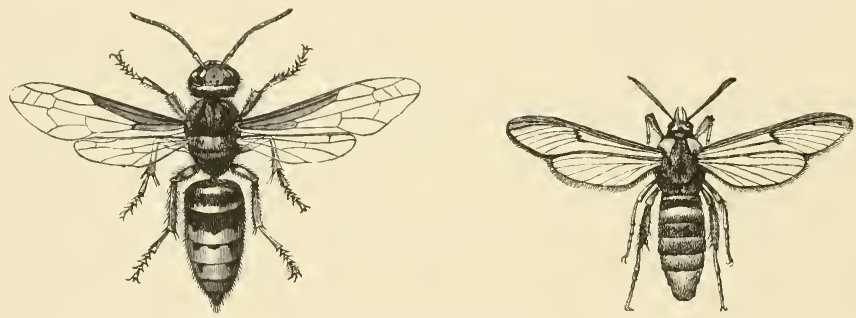

Fig. 46. Mimikry: Wespe und Hornissenschwärmer. (Aus Claus-Grobben.)

Es lassen sich (nach Döderlein) mehrere Kategorien ron Polymorphismus resp. Dimorphismus unterscheiden, von denen wir folgende hier erwähnen wollen:

1. Sexueller Dimorphismus. Ein solcher liegt da vor, wo die beiden Geschlechter sich nicht nur durch die eigentlichen Geschlechtsorgane (primäre Geschlechtscharaktere) unterscheiden, sondern außerdem auch noch durch die Gestalt, Färbung, Struktur usw. (sekundäre Geschlechtscharaktere) wesentlich voneinander abweichen. Dadurch ist in vielen Fällen die Möglichkeit gegeben, auf den ersten Blick Männchen und Weibchen einer Art zu erkennen. Die Unterschiede können einerseits nur geringe sein, so daß man danach suchen muß, andererseits aber auch so groß, daß Zuchtversuche und die Beobachtung der regelmäßigen Begattung notwendig waren, um die Zusammengehörigkeit der betr. Formen zu einer Art festzustellen.

Es seien im folgenden einige der auffallenderen und häufigeren Beispiele aus unserer einheimischen Fauna genannt. Bei vielen Insektenarten, besonders lebhaft gefärbten Formen, unterscheiden sich die beiden Geschlechter durch eine verschiedene Färbung oder Zeichnung, so z. B. der Aurorafalter (Pieris Cardamines L.): beim ơ Spitzenhäfte der Vorderflügel mit oranger, beim $q$ mit 
weißer Grundfarbe; der Kohlweißling (Pieris Brassicae): \& mit zwei schwarzen Flecken auf dem Vorderflügel, die dem $\sigma^{\tau}$ fehlen; viele Bläulinge (z. B. Lycaena Bellargus Rott.): Flügel des $\sigma^{\prime}$ schön himmelblau, des $q$ dunkelbraun mit rotgelben Randflecken; der Schwammspinner Liparis dispar L.): Grundfarbe der Flügel beim $\sigma^{\pi}$ graubraun, beim o gelblich weiß; zwei Bockkäfer, Leptura testacea L.: $\sigma^{\pi}$ Halsschild schwarz, Flügeldecken lehmgelb, ㅇ Halsschild und Flügeldecken rotbraun

und den verwandten Toxotus cursor $L$.: $\sigma^{\top}$ schwarz, \& rötlich gelbbraun mit einem roten Längsstreif auf jeder Flügeldecke; von Orthopteren die Wasserjungfer, Calopteryx virgo L.: $0^{\top}$ Körper und Flügel tiefblau, $q$ Körper grün, Flügel braun.

Die als Größendifferenzen sich ausprägenden sekundären Geschlechtsunterschiede können in zwei Richtungen ausgebildet sein; bei vielen Insekten ist das Weibchen, bei anderen das Männchen der stärkere Teil. Der erstere und bei weitem häufigere Fall hängt zusammen mit dem Umstande, daß die von dem Weibchen produzierten Eier den von dem Männchen produzierten Samen an Volumen bedeutend übertreffen. Kleiner sind die Männchen bei vielen Feldheuschrecken, bei vielen Bockkäfern, z. B. bei Pachyta cerambyciformis Schrank, bei den Ölkäfern, Meloë, und der spanischen Fliege, Lytta vesicatoria L., bei den Blatt- und Holzwespen, z. B. bei Lophyrus pini L. und Sirex juvencus L., sowie bei den Ameisen; bei vielen Spinnern, z. B. dem Kiefernspinner, den Flöhen und der Hirschlausfliege, Lipoptena cervi L. Der extremste Fall in unserer Fauna ist wohl bei Tomicus dispar Fabr., einem Laubholzborkenkäfer, vorhanden. Der andere Fall, daß die Männchen größer sind, tritt besonders bei den Formen ein, bei welchen die Männchen um den Besitz der Weibchen kämpfen. Stärkerer Statur sind 2. B. die Männchen vieler Schaben, ferner der Lucanidae, z. B. bei Dorcus parallelopipedus $L$. und bei unserer Honigbiene.

Die eben erwähnten geschlechtlichen Färbungs- und Größenunterschiede sind häufig verbunden mit der dritten Kategorie der sekundären Geschlechtscharaktere, mit den Strukturverschiedenheiten gewisser Körperteile. Die solche Auszeichnung zeigenden Körperteile können einmal stärker ausgebildet, andererseits reduziert sein. Ersteres ist meist das Teil der Männchen. Diese haben häufig stärker ausgebildete Sinnesorgane als das Weibchen, eine Ausstattung, welche ihnen das Auffinden der Weibchen erleichtert. Die als Tast- und Geruchsorgane dienenden Fühler sind stärker gebaut bei den Männchen vieler Käfer, z. B. des Maikäfers und des Walkers, vieler Bockkäfer, z. B. Prionus corıarius L. und Astynomus aedilis L. mancher Hymenopteren, z. B. Lophyrus pini, vieler Schmetterlinge aus den Giuppen der Schwärmer, Spinner und Spanner, z. B. Kiefernspinner und Kiefernspanner, der Stechmücken, Culex pipiens L. u. s. f. Die Augen sind größer, ja sogar gedoppelt, bei den Männchen mancher Eintagsfliegen, z. B. der Ephemera vulgata L. und Cloëon dipterum L. und vieler bienenartigen Insekten, z. B. bei den Drohnen der Honigbiene, bei welchen sie auf dem Scheitel zusammenstoßen, während sie bei Arbeiterinnen und Königin getrennt bleiben; bei den Männchen mancher Zweiflügler, z. B. Bibio marci L., nehmen die Augen den ganzen Kopf ein, während sie bei den Weibchen klein und getrennt bleiben. Die Männchen verschiedener Geradflügler besitzen ferner Tonorgane, welche den Weibchen abgehen, während allerdings in anderen Gruppen beide Geschlechter mit solchen Lockmitteln versehen sind. (Vgl. den Abschnitt über die Lautäußerungen der Insekten in Kap. III.)

Der bedeutenderen Größe mancher Männchen gesellen sich noch ausgeprägte Kampforgane bei, wie wir sie z. B. in den geweihartig verlängerten Vorderkiefern des Hirschkäfer k kennen, sowie Apparate zum Festhalten des sich sträubenden Weibchens, wie z. B. die Haftscheiben an den Vordertarsen vieler Schwimmkäfer, z. B. des Dytiscus marginalis, und die Sohlenbildungen an den Vordertarsen vieler Laufkäfermännchen, z. B. bei Calosoma sycophanta L. Hierzu kommen noch eine Reihe von Auszeichnungen der Männchen, welche, da ihr Zusammenhang mit dem Geschlechtsleben nicht ohne weiteres verständlich, uns als bloße Zierraten erscheinen, so die Hörner auf Kopf- und Halsschild, welche bei vielen exotischen Lamellicorniern ihre höchste Ausbildung erreichen, aber auch in unserer Fauna 
vorkommen, z. B. bei dem Nashornkäfer, Oryctes nasicornis L. und dem Sinodendron cylindricum $L$.

Andererseits sehen wir bei vielen Weibchen, welche infolge des eierbeschwerten Hinterleibes schon ohnehin häufig weniger beweglich sind als die Männchen, die Bewegungsorgane und besonders die Flügel verkümmert. Die schönsten Beispiele hierfür geben uns viele Schmetterlinge. So sind $z$. B. bei einer häufigen einheimischen Motte, Chimabacche fagella, die Flügel des Weibchens noch annähernd halb so lang als beim Männchen, bei dem Frostspannerweibchen, Cheimatobia brumata $L$., sind sie bereits auf Rudimente reduziert, bei Orgyia antiqua L. im Verhältnis zu dem Körper des Weibchens schon verschwindend, und die Weibchen der Gattung Psyche, welche madenförmig bleiben, ermangeln der Flügel und ausgebildeter Beine völlig. Auch einige Käfer, z. B. unser gewöhnlicher Leuchtkäfer Lampyris splendidula, haben larvenähnliche, ungeflügelte, sowie auch der Flügeldecken entbehrende Weibchen.

Es kommen aber auch Fälle vor, in welchen den Weibchen besondere, den Männchen fehlende Ausstattungen zukommen; dieselben beziehen sich immer auf die Brutpflege. Hierher können wir den verlängerten Rüssel der Weibchen der Rüsselkäfergattung, Balaninus, rechnen, welche zur Unterbringung der Eier in der Tiefe der Fruchtknoten dienen, sowie die zum Sammeln des als Larvennahrung dienenden Blumenstaubes eingerichteten Hinterbeine der Weibchen vieler Blumenbienen.

Wenn auch die Insekten normalerweise getrennten Geschlechts sind, so kommen doch hier und da als Monstrositäten $Z_{w}$ itter vor. Bezieht sich der Hermaphroditismus auf sexuell dimorphe Arten, so prägt sich derselbe meist schon äußerlich aus; so existieren z. B. Zwitter vom Frostspanner, die auf der einen Seite die wohlausgebildeten Flügel der Männchen tragen, auf der anderen Seite dagegen nur mit den stark verkümmerten Flügelresten der Weibchen ausgestattet sind. Auch beim Schwammspinner und Kiefernspinner sind solche regelmäßig seitliche Zwitter bekannt, bei denen die eine Seite die männliche, die andere die weibliche Zeichnung trägt (siehe unten).

2. Der alternierende Polymorphismus. Die verschiedenen Formen treten in regelmäßigem Wechsel in aufeinanderfolgenden Generationen auf. Wir finden diesen Polymorphismus da, wo parthenogenetische und gamogenetische (doppelgeschlechtliche) Generationen miteinander abwechseln, wie bei den Gallwespen, wo die Unterschiede zwischen den Tieren der beiden Generationen so bedeutend sind, daß man sie früher vielfach als verschiedene Arten aufgefaßt, ja sogar in verschiedene Genera gestellt hat (z. B. Tereas terminalis Hrtg. und Biorhiza aptera F.). Oder bei den Afterblattläusen (Chermesiden), wo nicht nur zwei, sondern mehrere in einem regelmäßigen Zyklus aufeinanderfolgende verschiedene Formen vorkommen.

3. Der Saisondimorphismus. Dieser kamn als eine besondere Form des alternierenden Polymorphismus aufgefaßt werden, wobei die Formverschiedenheiten direkt durch den Klimawechsel während der verschiedenen Jahreszeiten veranlaßt werden. Hierher gehören die sog. Winter- und Sommerformen (resp. in den Tropen die Regen- und Trockenformen) bei den Schmetterlingen, deren bekanntestes Beispiel l'anessa levana (braune Winterform) und $V$. prorsa (dunkle Sommerform) ist (Fig. 47).

4. Der fakultative Polymorphismus. Die Kinder der gleichen Mutter treten ohne ersichtlichen äußeren Anlaß mehr oder weniger regelmäßig in verschiedener Gestalt auf, und zwar gleichzeitig nebeneinander. 
Der fakultative Polymorphismus kann sich nur auf das eine Geschlecht beschränken, wie z. B. bei dem Gelbrandkäfer (Dytiscus), bei dem die Weibchen mit gerippten oder glatten Flügeldecken vorkommen; oder aber auf die beiden Geschlechter in gleicher Weise sich beziehen, wie bei der Nonne, wo oft dunkle und helle Formen ( $q$ und $\sigma^{\pi}$ ) nebeneinander vorkommen, und bei vielen anderen stark variablen Schmetterlingen und Käfern.

5. Der soziale

Polymorphismus. Bei den sozialen Insek-
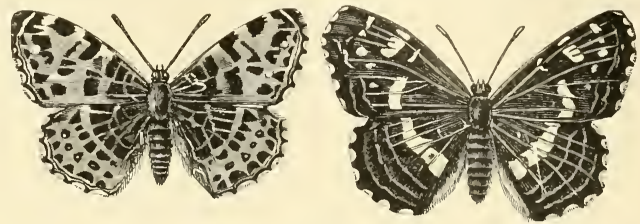

Fig. 47. Saisondimorphismus. Vanessa levana, Sommmerform (rechts) und Winterform (links).

ten treten neben den Geschlechtsindividuen (Männchen und Weibchen), die für die Fortpflanzung zu sorgen haben, noch die sog. Arbeitstiere oder Arbeiter auf, welchen der Nestbau, die Herbeischaffung der Nahrung, die Pflege der Larren usw. obliegt. Die Arbeiter unterscheiden sich von den Geschlechtstieren durch eine ganze Reihe auffallender Merkmale; im einfachsten Fall (Wespen) nur durch kleinere Statur, bei den Bienen durch die längere Zunge, das Vorhandensein eines Sammelapparates usw., bei den Ameisen und Termiten durch Flügellosigkeit und (damit zusammenhängend andere Thoraxbildung) ferner kräftigere Mandibeln und meist auch noch durch ihre kleinere Statur. Die Unterschiede zwischen Arbeitern und

Geschlechtstieren können bei den Ameisen und Termiten so groß werden, daß es eingehender Untersuchung und direkter Beobachtung bedarf, um sie

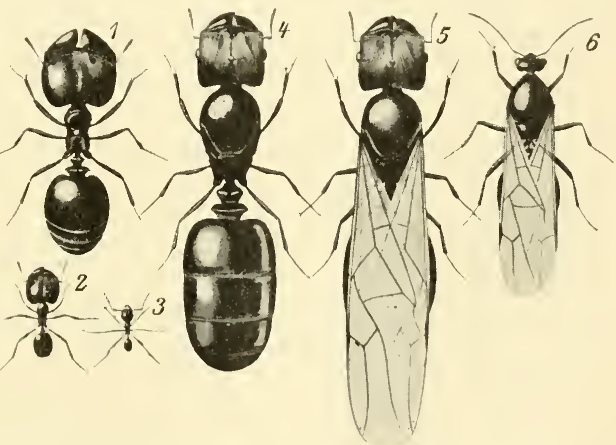

Fig. 48. Sozialer Polymorphismus bei Ameisen (Aphaenogaster). 1-3 großer, mittlerer und kleiner Arbeiter; $\neq$ Königin (älteres, entflügeltes Weibchen); 5 junges, geflügeltes Weibchen vor dem Hochzeitsflug; 6 Männchen. Nach Emery (Wandtafelu zur allgemeinen Biologie, Verlag von Erwin Nägele, Leipzig). als zusammengehörig zu erkennen; gibt es doch Ameisenweibchen, die 10 mal so lang sind als die dazu gehörigen Arbeiter (Fig. 48).

Die Formspaltung geht bei den Ameisen und Termiten aber vielfach noch weiter, indem sich die Arbeiter wieder in 2 verschiedene Kasten teilen: die Arbeiter s. str. und die „Soldaten“, die speziell der Verteidigung angepaßt sind, und die mitunter (vor allem durch Vergrößerung und Umgestaltung des Kopfes nebst den Kiefern) mindestens ebenso sehr von den Arbeitern ab- 
weichen, wie diese von den Geschlechtstieren. Endlich können auch inneıhalb der Soldaten und der Arbeiterkaste nochmals Differenzierungen Platz greifen: in große, mittlere und kleine Soldaten resp. Arbeiter.

Die morphologische Differenzierung geht Hand in Hand mit einer immer weiter greifenden Arbeitsteilung, indem die verschiedenen Funktionen mehr und mehr auch von verschiedenen, besonders angepaßten Individuen ausgeführt werden. Die Arbeiter stellen in den meisten Fällen rückgebildete Weibchen dar mit verkümmerten Geschlechtsorganen (die aber nötigenfalls event. wieder in Funktion treten können); nur bei den Termiten besteht das Arbeiterheer sowohl aus männlichen als auch aus weiblichen (natürlich rückgebildeten resp. nicht gänzlich ausgereiften) Individuen.

\section{Literatur.}

Lehr- und Handbücher.

Berlese, Antonio, Gli Insetti. Bd. I. (1004 S. und 1292 Fig. im Text und 10 Taf.) Mailand 1909.

Es ist dies weitaus das beste der heute existierenden Handbücher der

Entomologie, das jedem wissenschaftlich arbeitenden Entomologen unentbehrlich ist.

Escherich, K., Die Ameise, Schilderung ihrer Lebensweise. Braunschweig 1906. - _ Die Termiten oder weißen Ameisen. Leipzig 1911.

Folsom, I. IV Entomologv. Philadelphia 1909.

Graber, V., Die Insekten. 2 Bände. München 1877-1879.

Groß, J., Die Insekten (Sammlung Göschen). Berlin 1911.

Henneguy, L. F., Les Insektes. 804 S., 622 Fig. und 4 Taf. Paris 1904.

Hesse-Doflein, Tierbau und Tierleben. Bd I. Der Tierkörper als selbständiger Organismus von R. Hesse. 799 S., 480 Fig. und 15 Taf. Leipzig 1910.

Ein vorzügliches Werk, indem die Form des Tierkörpers und seiner Teile aus der Lebensweise resp. aus seiner Funktion zu erklären versucht wird.

Houlbert C, Les Insektes. Paris 1901. 370 S., 202 Fig.

Kolbe, H. J., Einführung in die Kenntnis der Insekten. 709 S., 324 Fig. Berlin 1893. Miall, L. C., The natural history of aquatic Insects. London 1895.

Packard, A. S., A. Text-Book of Entomology. 729 S., 654 Fig. Newyork 1898.

Schröder, Chr. Handbuch der Entomologie. Im Erscheinen begriffen.

Sharp, David, Insects. The Cambridge Natural history Bd. V und VI. London 1895 und 1899.

Wheeler. W. M., Ants. 63 S., 284 Fig. Newyork 1910.

Zander, Enoch, Handbuch der Bienenkunde. III. Der Bau der Biene. Stuttgart.

Eine klare Darstellung des Baues der Biene, welche auch zur ersten Einführung in die Insektenkunde geeignet ist.

\section{Spezialarbeiten, auf die im vorstehenden Kapitel Bezug genommen ist.}

Börner, C., Die Tracheenkiemen der Ephemeriden. Zoologischer Anzeiger, 33. Bd., 1908 , S. $806-823$.

- - Die Gliederung der Laufbeine der Ateloceraten. Sitzungsbericht der Gesellschaft naturforschender Freunde zu Berlin 1902, Heft 9.

_ - Zur Klärung der Beingliederung der Ateloceraten. Zoologischer Anzeiger, 27. Bd., 1904, S. $227-243$.

Comstok u. Kochi C., The sceleton of the head of Insects. Amer. Nat. Vol. 36, 1902.

Comstok u. Needham, The wings of Insects. Amer. Nat. Vol. 32 und 33, 1898 bis 1899 .

Döderlein, Über die Beziehungen nahverwandter Tierformen zueinander. Zeitschr. f. Morphol. und Anthropol., Bd. 4, 1902, S. 394-442.

Heymons, R., Die Segmentierung des Insektenkörpers. Abhandl. der Kgl. Preuß. Akademie der Wissenschaften, 1895.

- - Zur Morphologie der Abdominalanhänge bei den Insekten. Morphol. Jahrbuch, 24. Bd., 1896, S. 178-204. 
Heymons, R., Der morphologische Bau des Insektenabdomens. Zoologisches Zentralblatt, 4. Jahrgang 1899, S. 537-556.

- - Uber die Zusammensetzung des Insektenkopfes. Sitzungsbericht der Gesellschaft naturforschender Freunde zu Berlin 1897.

- Die Hinterleibsanhänge der Libellen und ihrer Larven. Annalen des K. K. Naturhist. Hofmuseums. Wien 1904, S. 21-58.

Jordan, H., Die Wirkungsweise der Mundwerkzeuge bei Seidenraupen. Biologisches Zentralblatt, 31. Bd., 1911, S. 111-114.

Prell, H., Das Chitinskelett von Eosentomon. Stuttgart 1913.

Verhoeff, K. W., Zur Kenntnis der vergleichenden Morphologie der weiblichen Coleopteren. Deutsche Entom. Zeitschr. 1894, S. 177-188.

- - Zur Morphologie der Segmentanhänge der Insekten und Myriopoden. Zoologischer Anzeiger, 19. Bd.

- Über vergleichende Morphologie des Kopfes der niederen Insekten. Abhandl. Kais. Leop.-Carol. Akademie der Naturforscher, Bd. LXXXIV, Nr. 1, 1904.

Voß, Friedrich, Über den Thorax von Gryllus domesticus, Zeitschr. f. wissensch. Zoologie, Bd. LXXVIII, 1904.

Woodworth, C. W., The Wing veins of Insects. University of California Publications. Entomology. Vol. Nr. 1, 1906. 
Kapitel III.

\section{Der innere Bau der Insekten (Anatomie und Physiologie).}

Zur übersichtlichen Orientierung über die Anordnung der Organe resp. Urgansysteme und deren Lagebeziehungen zueinander betrachten wir am besten einen Längsschnitt durch den Insektenkörper (Fig. 49). Da sehen wir zu äußerst die Leibeswand, bestehend aus Cuticula, Hypodermis und Muskulatur; die von ihr umschlossene Körperhöhle wird in der Mitte durch-

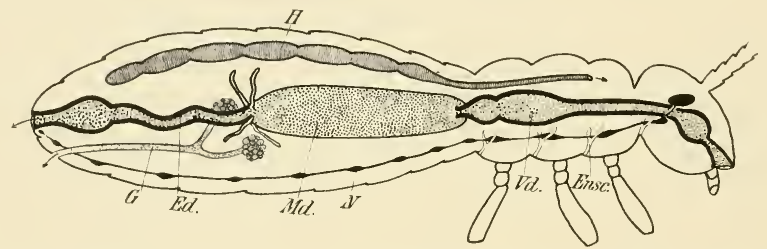

Fig. 49. Schematische Darstellung der Lage der Organe im Insektenkörper. $H$ Herz (Rückengefäß); Vd Vorder-, Md Mittel-, Ed Enddarm; N Nervensystem; $G$ Geschlechtsorgan; Ensc Endoskelett.

zogen von dem Darmkanal, der am Vorder- und Hinterende durch Mund und After mit der Außenwelt in Verbindung steht, und der meist mehrere Anhangsdrüsen besitzt, von denen vor allem die Speicheldrüsen und die Malpighischen Gefäße (Harngefäße) größeren Umfang annehmen können. Dorsal vom Darmrohr liegt das zarte, mit segmentalen Einschnürungen versehene „Rückengefäß“ oder Herz, während ventral davon der größte Teil des Zentralnervensystems, das Bauchmark, sich hinzieht. Nur im vordersten Körperabschnitt, im Kopf, ist das Nervensystem dorsalwärts gerückt und liegt als sog. Gehirn über dem Darmrohr resp. Schlund; eine jederseits des Darmes herabziehende Kommissur (Schlundkommissur) verbindet den dorsalen Teil des Zentralnervensystems mit dem ventralen. Im hinteren Körperabschnitt, der Bauchhöhle, sehen wir neben dem Darm die mehr oder weniger umfangreichen Geschlechtsorgane (Ovarien oder Hoden und deren, meist mit Anhangsdrüsen versehenen Ausfuhrgänge), die stets auf der Bauchseite, unterhalb des Darmes (resp. vor demselben) nach aufen münden. Endlich ist noch das Respirationsorgan, das sog. Tracheensystem, zu erwähnen, welches von den segmental angeordneten Luftlöchern 
oder Stigmen entspringt und ein oder mehrere Paare Längsstämme bildet, von denen zahlreiche, sich immer feiner verzweigende Äste abgehen.

Diese einfache Anordnung der Hauptorgane wird teilweise verschoben, indem der Darmkanal länger wird, als der gerade Abstand von Mund zu After, und auch die Ausführungsgänge der Fortpflanzungsorgane sich strecken. Alsdann liegen Darm und Fortpflanzungsorgane, die seitliche Symmetrie störend, aufgeknäuelt im Hinterleibe. - Der Raum zwischen den einzelnen Eingeweiden wird zum Teil ausgefüllt von den regellosen Zellballen des Fettkörpers. Festgehalten in ihrer Lage werden die sämtlichen Organe durch die feinen und feinsten Verzweigungen der Tracheen, welche alle Organe dicht umspinnen. Um- und durchspült wird das Ganze von der Blutflüssigkeit, die (da ja kein geschlossenes Blutgefäbsystem vorhanden ist) frei in der Leibeshöhle zirkuliert.

\section{Die Haut.}

Die Haut der Insekten setzt sich von außen nach innen aus folgenden Schichten zusammen: 1. der Cuticula, 2. der Hypodermis und 3. der Grundmembran oder Membrana basilaris.

Die Cuticula ist ein Abkömmling der Hypodermis und besteht in der Hauptsache aus Chitin, über dessen chemische Beschaffenheit oben bereits einiges erwähnt ist (S. 2). Man kann an ihr deutlich zwei Lagen unterscheiden, nämlich eine dünnere äußere, oder dickere innere (Fig. 50), die auch als „primäre“ und „sekundäre" Cuticula bezeichnet werden. Erstere ist vollkommen homogen, letztere dagegen meist deutlich geschichtet und gewöhnlich von feinen Kanälen durchsetzt. Wo Farbstoffe in der Cuticula vorhanden sind, haben sie ihren Sitz stets in der äußeren, primären Lage.

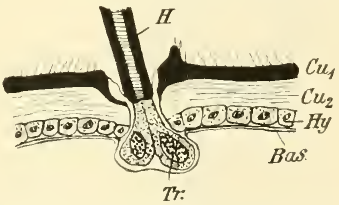

Fig. 50. Durchschnitt durch die Haut einer frisch geschlüpften Fliege mit noch gut ansgebildeter Hypodermis $(\boldsymbol{H y})$. C $u_{1}$ primäre, $C u_{2}$ sekundäre Cuticula; Bas Basalmembran; H Haar; $\mathrm{Tr}$ trichogene Zelle. Nach Berlese.

Von der Skulptur und den Anhängen

der Cuticula (Haare, Schuppen) war oben (S. 40) schon die Rede. Es sei hier nur noch hervorgehoben, daß wir unter den letzteren zu unterscheiden haben zwischen rein cuticularen und solchen, welche in direkter Beziehung zu Hypodermiszellen stehen. Häufig sind beide gleichzeitig vorhanden: ein dichtes, feines, rein cuticulares Börstchen- oder Haarkleid, und daneben größere hypodermoidale Borsten oder Haare (Fig. 50).

Die unter der Cuticula liegende Hypodermis besteht aus einer Schicht mehr oder weniger deutlich voneinander abgegrenzter, polygonaler Epithelzellen, welche nach außen, wie schon erwähnt, die Chitinsubstanz als ein anfangs zähflüssiges, erst später erhärtendes Sekret absondern. In Hinblick auf diese Funktion bezeichnet man die Hypodermis auch als chitinogene Schicht oder Matrix. Die Gleichmäßigkeit der Hypodermis ist häufig unterbrochen durch auffallend große Zellen, welche nach innen weit hervorragen und auch nach außen durch die Cuticula hindurch einen 
Fortsatz entsenden, der mit einem Haar in Verbindung steht, resp. in dasselbe eindringt. Es sind dies die sog. trichogenen oder Haarbildungszellen, denen die meisten Haare ihre Entstehung verdanken, indem auf der Oberfläche jener Zellfortsätze sich Chitin abscheidet (Fig. 50, Tr). Die so entstandenen (hypodermoidalen) Haare bilden an ihrer Ansatzstelle meist eine Art Gelenk aus. - Auch die Schuppen entstehen auf ähnliche Weise, indem auch sie von Zellfortsätzen abgeschieden werden, welche ebenfalls ron besonders großen Zellen, den Schuppenbildungszellen ausgehen.

Beim ausgebildeten Insekt hat die Hypodermis keine Aufgabe mehr zu erfüllen, da ja keine neue Cuticula mehr gebildet zu werden braucht (ausgewachsene Insekten häuten sich nicht mehr). Sie bildet sich daher, wie alle außer Funktion gesetzten Organe zurück und ist meist nur als ganz dünne, aus platten Zellen bestehende Haut unter der Cuticula aufzufinden.

Die Grundmembran (Membrana basilaris) ist äußerst fein und besteht aus sternförmigen Zellen, welche eine die $Z$ wischenräume zwischen ihnen ausfüllende Intercellularsubstanz ausscheidet. - Sie liegt der Innenseite der
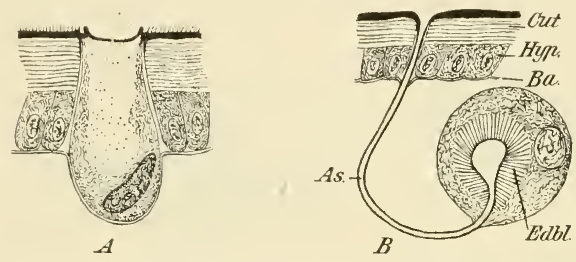

Fig. 51. Zwei verschiedene Typen einzelliger Hautdrüsen. Cut Cuticula; Hyp Hypodermis: Ba Basalmembran; As Ausfuhröhrchen; Edbl Endblase. Nach Berlese.
Hypodermis an und überzieht auch die großen Haarbildungszellen usw., soweit sie aus der Нypodermis nach innen zu vorragen (Fig. 50, Bas).

Bei den meisten Insekten ist die Haut mehr oder weniger reichlich mit Drüsen hypodermalen Ursprungs ausgestattet, deren Form, Aufbau und Funktion ungemein wechselnd ist. Da haben wir auf der einen Seite einzellige Drüsen, die sich nur wenig von den Hypodermiszellen unterscheiden, andererseits höchst komplizierte vielzellige Drüsenorgane mit besonderen Ausführgängen, Sammelreservoir usw., -- und zwischen diesen Extremen alle möglichen $Z$ wischenformen.

Schon die einzelligen Drüsen weisen eine große Mannigfaltigkeit der Form auf; neben solchen, die den gewöhnlichen Hypodermiszellen noch recht ähnlich sehen, finden sich andere, die mehr und mehr von diesen abweichen, in erster Linie durch ihre bedeutendere Größe und sodann auch durch die Struktur, die sehr charakteristisch ist. Es senkt sich nämlich von der Ausfuhröffnung in der Cuticula ein feines cuticulares Röhrchen bis tief in das Zellplasma hinein, wo es in einem eigentümlichen radiär gestreiften Körper (Endblase) endet. Durch Verlängerung des freien Teiles dieses Röhrchens (Fig. 51) rückt die sezernierende Zelle mehr oder weniger von der Haut ab ins Innere des Körpers. - Einzellige Drüsen finden sich allenthalben: auf den Flügeldecken, an den Abdomensegmenten, an den Beinen, an den Fühlern usw., sowohl einzeln zerstreut, als auch zu größeren oder kleineren Gruppen vereinigt, und so 
Übergangszustände zu den vielzelligen Drüsen bildend. Die von ihnen ausgeschiedenen Sekrete sind sehr vielseitiger Natur, den verschiedensten Zwecken entsprechend; vielfach handelt es sich um wachsartige Körper,

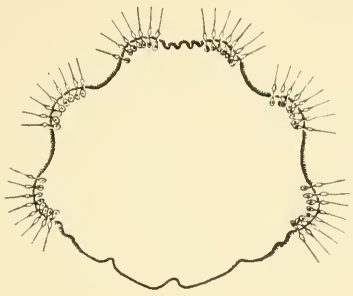

$A$

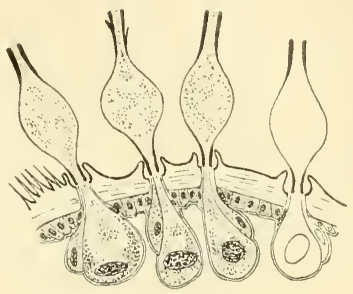

$B$

Fig. 52. Drüsenhaare mit blasenförmigen Erweiterungen (Toxophore), in denen das Sekret sich ansammelt. Kommen bei verschiedenen Schmetterlingsraupen (Spinnern) vor. A Durchschnitt durch eine Raupe; $B$ Drüsenhaare, vergrößert. Nach Berlese.

die zum Schutz gegen Nässe oder tierische Feinde dienen (Blattläuse usw.) oder als Baumaterial für die Brutstätte verwandt werden (Bienen); andere Sekrete (aus Gelenkdrüsen) dienen als Schmiermittel für die Gelenke; wieder andere enthalten angenehme oder widrige Geruchsstoffe zum Anlocken oder zur Abwehr, in welchem Fall die Drüsenzellen häufig mit Haaren oder Schuppen (Duftschuppen) in Verbindung stehen (siehe oben).

Bei den Wachsdrüsen der Honigbiene handelt es sich streng genommen nicht um einzellige Drüsen, sondern es beteiligen sich an der Wachsabsonderung ganze Strecken der Hypodermis der abdominalen Ventralplatten, deren Zellen von den gewöhnlichen chitinogenen Zellen nur wenig sich unterscheiden.

Noch mannigfaltiger fast als die einzelligen sind die vielzelligen Drüsen. Meist sind dieselben mit einer mehr oder weniger ausgedehnten Einstülpung der Haut verbunden, entweder in der Weise, daß die ganze eingestülpte Partie von Drüsenzellen besetzt ist, oder aber so, daß die letzteren nur um den geschlossenen Endteil herum sitzen, während der übrige Teil als Ausfuhrgang resp. Sammelreservoir dient (Fig. 53). Oft ist der Ausfuhrweg mit einer komplizierten Muskulatur, und anderen Vorrichtungen (Gasrezipienten usw.) ausgerüstet, wodurch ein rasches explosionsartiges Ausstoßen der Sekrete ermöglicht wird (z. B. die neben dem After ausmündenden Explosionsdrüsen der Bombardierkäfer). Bei manchen

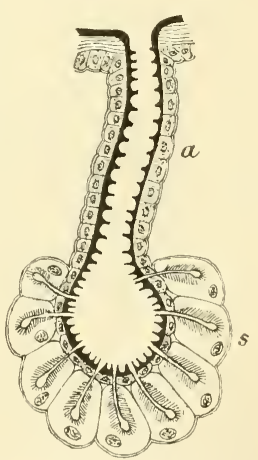

Fig. 53. Beispiel einer vielzelligen Drüse mit deutlicher Scheidung eines sezernierenden $(s)$ und aus. fuihrenden Abschnittes $(a)$. Nach Berlese. Insekten können die Hauteinstülpungen handschuhfingerähnlich nach außen vorgestülpt werden, so daß deren mit Sekret bedeckte Innenfläche direkt nach außen zu liegen kommt (z. B. die roten Drüsensäcke am Thorax von Malachius, oder die Pygidialdrüsen mancher 
Staphylinen). Bei den Giftdrüsen der Bienen, Wespen usw. steht der Ausfuhrgang mit einem kräftigen Stachel in Verbindung, mit dessen Hilfe das Gift in den Körper des Feindes injiziert werden kann. - Wie diese drei hier genannten Beispiele, so stehen die meisten übrigen der vielzelligen Hautdrüsen im Dienste der Verteidigung und Abwehr.

\section{Das Muskelsystem und seine Tätigkeit.}

An die Hypodermis schließt sich nach innen $\mathrm{zu}$ eine mehr oder weniger geschlossene Muskelschichte an. Dieselbe setzt sich aus einer großen Anzahl von Einzelmuskeln zusammen, deren Anordnung deutlich segmental ist, d. h. in jedem Segment sich in gleicher Weise wiederholt. Nur in stark abgeänderten Segmenten oder Segmentkomplexen, wie im Kopf und in der Brust, ist davon wenig zu merken, und scheint die Muskulatur gänzlich abweichend von der des Hinterleibes. Immerhin dürfte es sich auch hier nur um Modifikationen der ursprünglichen segmentalen Muskeln handeln und wird es auch wohl einem eingehenden vergleichenden Studium noch gelingen, die verschiedenen Brustund Kopfmuskeln auf die letzteren zurückzuführen. Die Zahl der Einzelmuskeln ist eine ungeheuer große; hat doch Lyonet für eine Schmetterlingsraupe nicht weniger als 2000 Muskeln berechnet.

Wir können die Muskulatur einteilen in Stam m - und Extremitätenmuskeln. Erstere besorgen die Bewegungen des Kopfes und Hinterleibes gegen dieBrust, die Krünmungen des Hinterleibes und seine Ausdehnung resp. Zusammenziehung (Atembewegung), ferner die Bewegungen der

Fig. 54. Muskulatur eines Insektenbeines (Lepisma). $C x$ Coxa; Fe Femur; $T r$ Trochanter; $T b$ Tibia; Ts Tarsenglied; Pts Praetarsus; Ks Krallensehne.

Mundwerkzeuge, Beine, Flügel, Genitalanhänge usw. gegen den Stamm; letztere dagegen führen die Bewegungen der einzelnen Glieder der Extremitäten gegeneinander aus (Fig. 54). Je nachdem ferner die Bewegung in einer Beugung, Streckung, Ausdehnung, Zusammenziehung, Drehung usw. besteht, teilt man die Muskeln in Flexoren, Extensoren, Elevatoren, Depressoren, Rotatoren usw. ein.

Näher auf die einzelnen Muskeln einzugehen, ist hier nicht der Platz. Eine sehr ausführliche Darstellung der teilweise überaus komplizierten Verhältnisse findet sich in Berleses großem Handbuch (und außerdem bei Voß und A. Bauer [siehe Literatur]).

Die Muskeln der Insekten bestehen aus farblosen oder weißlichen Fasern, die eine deutliche Querstreifung erkennen lassen. Ihre Inser- 
tion findet meist mittels einer aus chitinösen Fasern (aus Hypodermiszellen hervorgegangen) zusammengesetzten Sehne direkt an der Cuticula statt.

Die Kraftleistung der Muskeln ist (relativ genommen) eine sehr bedeutende; können doch die meisten Insekten ein Vielfaches ihres eigenen Körpergewichts tragen. So kann z. B. der große Nashornkäfer (Oryctes nasicornis) das $4^{3} / 4$ fache, der etwas kleinere Mistkäfer (Geotrupes stercorarius) das ca. 10 fache und der viel kleinere Onthophagus das $14^{1} /_{2}$ fache seines Körpergewichts heben. Bei manchen Käfern steigert sich die Leistung sogar bis zum 40 fachen des Körpergewichts (z. B. Trichius fasciatus, Donacia, Crioceris usw.). - Auch die gewaltigen Sprünge, die ein Floh macht (etwa das 200 fache seiner Körperhöhe) oder die langen anhaltenden Flüge der Wanderheuschrecken oder Libellen, oder das oft stundenlange Musizieren der Grillen geben uns einen Begriff von der gewaltigen Kraftleistung der Insektenmuskeln.

Die Tätigkeit des Muskelsystems ist eine ungemein vielseitige; wir wollen hier jedoch nur auf einige der auffallendsten Muskelwirkungen näher eingehen: nämlich die Ortsbewegungen und die Lautäußerungen.

\section{Ortsbewegungen.}

Unter diesen Begriff fallen in der Hauptsache die Schreit-, Schwimm-, Sprung- und Flugbewegungen.

Die Schreitbewegungen werden von den Beinen der Brust ausgeführt, und zwar in folgender Weise: Es werden zuerst das rechte Vorder- und Hinterbein zugleich mit dem linken Mittelbein vorgesetzt (vgl. Fig. 38, S. 34, $R_{I}, R_{I I I}$ und $\left.L_{I I}\right)$ und sodann, während der Körper vorwärts gezogen resp. geschoben wird, das linke Vorder- und Hinterbein zugleich mit dem rechten Mittelbein. Das Insekt ruht also beim Gehen stets auf einem für das Körpergleichgewicht durchaus nötigen Dreieck, welches gebildet wird von dem Vorder- und Hinterbein der einen und Mittelbein der anderen Seite, während es die drei übrigen Beine hebt und nach vorn setzt (Packard). Entsprechend der Beinstellung (die Vorderbeine sind nach vorn, die Hinter- und Mittelbeine nach hinten gerichtet) ist beim Vorsetzen der drei Beine das Vorderbein gestreckt, das Mittel- und Hinterbein dagegen gebeugt. Der Körper wird nun durch das vorgesetzte Vorderbein gezogen und durch das aufgesetzte Mittelbein der einen und Hinterbein der anderen Seite vorwärts geschoben. Unmittelbar darauf treten die drei entsprechenden anderen Beine in dieselbe Tätigkeit. Dabei leisten die Hinterbeine (wie bei den Säugern) die Hauptarbeit, was meist auch in dem kräftigeren Bau derselben zum Ausdruck kommt.

Viele Insekten haben bekanntlich die Fähigkeit, an glatten senkrechten Wänden in die Höhe zu klettern oder an der Unterseite einer horizontalen Fläche zu laufen (wie z. B. die Stubenfliegen, Bienen, Heuschrecken usw.). Dieses Vermögen beruht auf besonderen an der Sohle oder zwischen den Klauen angebrachten Heftvorrichtungen, wie Saugnäpfen, Hafthaare oder Haftlappen, deren Oberfläche auch noch häufig durch Drüsensekrete feucht gehalten wird - zwecks Verstärkung der Adhäsionswirkung. Umgekehrt ist 
bei den auf der Wasseroberfläche laufenden sog. Wasserläufern (W'anzen) die Unterseite und das Ende der Füße so ausgestattet, daß keine Wasserteilchen an ihnen adhärieren. Denn würden die Füße einmal benetzt, so würden die Tiere (infolge Störung der Oberflächenspannung des W'assers) einsinken, ähnlich wie eine sorgfältig gereinigte Nähnadel untersinkt, während eine schwach eingefettete und so vor dem Benetzen geschützte auf der Wasseroberfläche schwimmt (Hesse.)

Die Schwimmbewegungen werden durch die stark abgeplatteten Mittel- und Hinterbeine oder durch die Hinterbeine allein ausgeführt, welche hierbei weniger eine Beugung und Streckung als eine mit einer Drehung um ihre Achse verbundene Vor- und Rückwärtsbewegung ausführen.

Dies geschieht stets nach der Art der Bewegung eines Bootsruders, indem die mehr weniger abgeplatteten Extremitäten bei ihrer Bewegung nach hinten ihre breite Fläche dem Wasser zukehren, während sie bei der Zurückbewegung nach vorn ihre schneidende Kante verwenden, so daf sie also bei letzterer Bewegung einen geringeren Widerstand tinden als bei ersterer. Schöne Beispiele hierfür sind die Schwimnkäfer (Dytiscus) und Wasserwanzen (Notonecta).

Die Springbewegungen werden in den meisten Fällen von den Hinterbeinen bewirkt, die durch ihre verdickten Schenkel auch morphologisch sich als Sprungbeine dokumentieren. Diese Verdickung ist bedingt durch die überaus starke Ausbildung der Streckmuskeln, durch deren plötzliche Kontraktion die in der Ruhelage dem Schenkel dicht anliegenden Schienen so kräftig gestreckt resp. gegen die Unterlage gestemmt werden, daß der Körper mit großer Wucht nach vorn und oben geschleudert wird. In dieser Weise springen z. B. die Heuschrecken, Flöhe, Springrüßler, Erdflöhe usw. Doch kennen wir auch andere Vorrichtungen zum Springen; so besitzen die sog. Springschwänze (zu denen der "Gletscherfloh" gehört) an der Bauchseite des Abdomens eine Sprunggabel, die mit großer Kraft nach hinten und unten geschlagen werden kann, wodurch das Tier natürlich in entgegengesetzter Richtung in die Luft geworfen wird. Bei den Felsenspringern oder Steinhüpfern (Machilis) sind es die jedem Abdominalsegment in je 1 Paar zukommenden sog. Abdominalgriffel (Styli), welche in ähnlicher Weise wirken wie die Sprunggabel der Springschwänze (siehe Fig. 41). Wieder anders springen ferner manche Ameisen (exotische), indem sie durch rasches $\mathrm{Zu}$ sammenschlagen ihrer langen Kiefer auf weite Strecken sich fortschnellen. Eine ganz besondere Art des Springens kommt endlich den Schnellkäfern (Elateriden) zu, worüber im speziellen Teil (bei der Besprechung dieser Käfer) noch näheres berichtet wird.

Die Flugbewegung. - Der Flug der Insekten, diese sie vor allen anderen Arthropoden charakterisierende Bewegungsart, wird vermittelt durch die gleichzeitig ausgeführten, schlagenden Bewegungen der Flügel beider Seiten. Eine Erhebung in die Luft, d. h. eine Überwindung der Schwerkraft, wird dadurch möglich, daß bei dieser Bewegung die Flügel beim Niederschlag einem größeren Widerstande begegnen als beim Aufschlage. Hierdurch 
gewinnt der beim Niederschlage entstehende, nach oben wirkende Rückstoß, der Luft die Oberhand und das Insekt wird gehoben.

Die Verschiedenheit des Luftwiderstandes wird bewirkt durch die ver. schiedene Einstellung der Flügelebenen beim Auf- und Niederschlag. Da nämlich die Vorderzone der Flügel durch eine stärkere Aderung viel mehr gesteift wird als die Hinterzone, so wird beim Niederschlag der Hinterrand gegenüber dem Vorderrand gehoben, beim Aufschlag dagegen ungekehrt, was, bei der gewöhnlich schiefen Einstellung des fliegenden Insektes gegen die Ebene des Horizontes, eine Änderung des Luftwiderstandes in obigem Sinne bedeutet. Eine Verkleinerung der Flugfläche zur Verminderung des Luftwiderstandes bei der Hebung der Flügel, wie sie durch Zusammenfalten bei den Vögeln und Fledermäusen erfolgt, kommt bei den Insekten nicht vor. „Hält man ein Insekt, etwa eine Fliege oder Wespe fest, so daß es seine Flügel schwirrend bewegt, so beschreiben die Flügelspitzen eine Figur von der Form einer 8 ; d. h. beim Senken schiebt sich die Flügelspitze nach vorn, unten wird sie nach hinten gezogen, um sich beim Hub wieder nach vorn $\mathrm{zu}$ bewegen, worauf oben wieder eine Verschiebung nach hinten erfolgt. Bei der Vorwärtsbewegung des Insektes muß sich die Achterfigur in eine Zickzacklinie mit kleinen Schleifen an den Wendepunkten auflösen“ (Hesse). (Fig. 55.)

Die Zahl der Flügelschläge ist bei den verschiedenen Insekten recht wechselnd, entsprechend der Größe der Flugflächen und der Schnelligkeit des Fluges. So machen die langsam fliegenden Tagschmetterlinge mit ihren großen breiten Flügeln nur relativ wenig Schläge (ein Weißling ca. 9 pro Sekunde), dagegen die schnellfliegenden

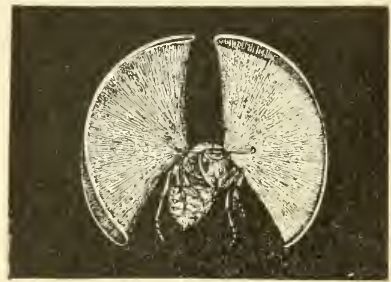

Fig. 55. Schema der Flügel bewegung einer Wespe. (Nach Marey, aus Z ander.) Nachtschwärmer mit ihren viel kleineren schmalen Flügeln 70-80. Noch größer ist die Zahl der Schläge bei der Biene (ca. 190), oder gar bei der Stubenfliege, bei der sie 330 pro Sekunde beträgt. Ist doch auch bei der letzteren die wirkende Flugfläche durch Reduktion der Hinterflügel besonders klein. Wo die 4 Flügel am Fluge sich beteiligen, sind, wie wir oben bereits erwähnt (S. 34), die Vorder- und Hinterflügel jeder Seite häufig derartig zusammengekoppelt, daß sie der Wirkung nach nur eine Flugfläche bilden; und auch da, wo eine solche mechanische Verkoppelung fehlt, geschieht die Bewegung der Vorder- und Hinterflügel meist so gleichzeitig, daß sie ebenfalls wie eine Fläche wirken. Nur gewisse Libellen machen davon eine Ausnahme, indem sie ihre Vorder- und Hinterflügel unabhängig voneinander bewegen.

Die Bewegung der Flügel wird durch die im Meso- und Metathorax befindliche Flugmuskulatur hervorgebracht, die, besonders bei den guten Fliegern, eine gewaltige Ausbildung erreichen kann. Bei weitaus den meisten Insekten wirken die Muskeln jedoch nicht direkt auf die Flügel, sondern indirekt durch Veränderung der Thoraxform; längsverlaufende Muskeln 
steigern bei der Kontraktion die Wölbung der Brust (resp. der beiden Brustsegmente), während dorsoventral (von der Rücken- zur Bauchseite) verlaufende Muskeln die Rückenfläche herabziehen; dadurch werden auch die Flügel, die ja mit dem Brustskelett verbunden sind, bewregt, und zwar bei der Wölbung gesenkt und bei der Abflachung gehoben. Es greifen zwar, wie die Fig. 56 zeigt, einige kleinere Muskeln auch direkt an der Flügelbasis an, doch dienen diese nicht der eigentlichen Flugbewregung, sondern nur dazu, den Flügeln eine bestimmte Richtung zu geben, sie bei ihrer höchsten und tiefsten Stellung von vorne nach hinten zu ziehen usw. (Hesse). - Nur bei den oben schon genannten Libellen kommen direkte Flugmuskeln vor, die an der Flügelbasis selbst angreifen; diese Tiere sind daher auch in der Lage, die beiden Flügelpaare unabhängig voneinander zu bewegen, so daß z. B. in demselben Moment die Hinterflügel gesenkt und die Vorderflügel gehoben sein können.

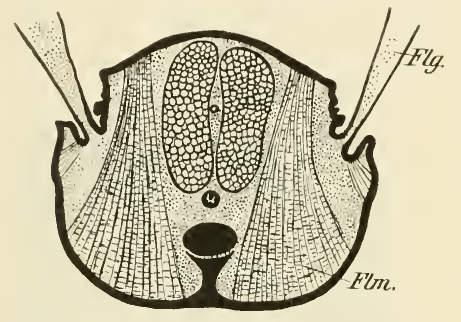

Fig. 56. Querschnitt durch den mittleren Brustring einer Biene. Flm vertikale (indirekte) Hebemuskeln der Vorderfligel; Flg Flügel. Nach $\mathrm{Z}$ ander.

Bei den Ameisenweibchen, die nach dem Hochzeitsflug die Flügel abwerfen, wird die überflüssig gewordene Muskulatur wieder rückgebildet resp. aufgelöst und zur inneren Ernährung benützt.

Die Bestimmung resp. Änderung der Flugrichtung wird auf verschiedene Weise bewerkstelligt. Viele Insekten (Schmetterlinge, Hymenopteren usw.) benutzen als Steuer ihren Hinterleib; bei den meisten Käfern werden die Flügeldecken, die ja im Flug seitlich gespreizt gehalten werden, dazu verwandt, und bei den Fliegen spielen die kleinen, die Stelle der Hinterflügel einnehmenden Schwingkölbchen eine wichtige (allerdings noch nicht völlig aufgeklärte) Rolle bei der Steuerung.

Was endlich die Flugleistungen der Insekten betrifft, so finden wir auch hierin die größten Unterschiede. Auf einer Seite haben wir schlechte Flieger, die nur eine kurze Strecke unsicher dahinflattern können, nachdem sie vorher in die Luft gesprungen (Schnarrheuschrecken); auf der anderen Seite dagegen brillante Flieger, die viele hundert Kilometer in kurzer Zeit zurückzulegen vermögen. Man denke nur an die Wanderheuschrecken, die in oft riesigen Schwärmen von Land zu Land nach Nahrung ziehen oder an die weiten Wanderungen der Libellen. Der Oleanderschwärmer, der südlich der Alpen beheimatet ist, ist schon in Finnland gefangen worden, muf also eine Strecke von ca. $1200 \mathrm{~km}$ durchflogen haben. Bei vielen Schmetterlingen (z. B. Spinnern) fliegen die Männchen leichter als die Weibchen, da die letzteren durch die Eier beträchtlich beschwert sind. Wie groß die Schnelligkeit des Insektenfluges ist, darüber wissen wir wenig; immerhin deuten die wenigen Beobachtungen darauf hin, daß manche Insekten hohe Schnelligkeitsziffern erreichen. Die schnellsten Flieger sind wohl die großen Libellen, die selbst der flüchtigen Schwalbe zu entkommen vermögen 
und danach mindestens $15 \mathrm{~m}$ pro Sekunde zurücklegen. Auch die Schwärmer bringen es zu hohen Leistungen, und es ist z. B. für das Abendpfauenauge ca. $6 \mathrm{~m}$ pro Sekunde festgestellt worden, während die Geschwindigkeit anderer Insekten wieder viel geringer sein kann (so z. B. von der Stubenfliege ca. $1^{1} / 2 \mathrm{~m}$ pro Sekunde). Manche der guten Flieger (z. B. die Libellen, Schwärmer, Schwebefliegen) haben die Fähigkeit, unter beschleunigtem Flügelschlag, gleichwie die rüttelnden Raubrögel, längere Zeit in der Luft an ein und derselben Stelle „stehen" zu bleiben. Viele Tagfalter (z. B. Segelfalter) mit breiten Flügeln vermögen andererseits bei eingestelltem Flügelschlag, lediglich getragen von den ausgebreiteten Flügeln, einige Zeit dahinzuschweben, wobei die letzteren wie Papierdrachen wirken (Hesse).

\section{Lautäußerungen.}

Viele Insekten sind imstande, dem menschlichen Ohr wahrnehmbare Töne hervorzubringen, deren Erzeugung in letzter Instanz stets auf Muskelwirkung beruht. Die biologische Bedeutung dieser Laute ist verschieden: da, wo die Lauterzeugung ausschließlich (oder wenigstens in höherem Maße) dem männlichen Geschlecht zukommt, dienen die Töne wohl sicher zur Anlockung der Weibchen, wo jedoch die beiden Geschlechter in gleichem Maße Töne hervorbringen, dürfte der Zweck wohl vielfach in einer Abschreckung der Feinde gelegen sein.

Nach der Art der Erzeugung können wir verschiedene Kategorien von Insektenlauten unterscheiden, nämlich:

1. Klopflaute,

2. Reibungs- oder Stridulationslaute,

3. Fluglaute und

4. Trommellaute.

Die Klopflaute werden erzeugt durch Aufschlagen eines festen Körperteiles, meistens des Kopfes, auf eine tönende Unterlage.

Hierher gehört z. B. das Klopfen der verschiedenen Anobium-Arten, welche im alten Holz leben und durch Aufschlagen der Vorderkiefer auf die Wandungen der Gänge ein tickendes Geräusch hervorbringen, welches diesen Käfern den populären Namen "Totenuhr" eingebracht hat. Auch die weithin hörbaren raschelnden Geräusche, welche gewisse Termiten und Ameisen bei Beunruhigung ihrer Nester ertönen lassen, werden dadurch erzeugt, daß die Soldaten mit ihren großen Köpfen schnell aufeinanderfolgende Zitterschläge auf die aus Holz oder Blättern bestehende Unterlage geben.

Die Reibungs- oder Stridulationslaute werden dadurch hervorgebracht, daß zwei harte Teile des Chitinpanzers gegeneinander gerieben werden, von denen der eine gewöhnlich aus einer fein gerillten oder bezahnten Reibleiste besteht, während der andere eine scharfe Kante darstellt. Indem nun die letztere über die Reibleiste (oder auch umgekehrt) hin und her gestrichen wird, entstehen jene charakteristischen Geräusche, die wir von den Grillen, Heuschrecken usw. kennen, und die je nach der Zahl und Feinheit der Rillen usw. starke Verschiedenheiten aufweisen können. Bei manchen Insekten sind auch noch besondere Resonanzapparate vorhanden, wodurch die Töne eine wesentliche Verstärkung erfahren. Der Sitz der Stridulationsapparate ist sehr wechselnd, je nach der Insektenart; bei den 
einen finden wir die Reibleisten an den Vorderflügeln, bei den anderen an den Beinen, und wieder bei anderen an der Brust oder am Abdomen angebracht usw:

Um einige Beispiele zu erwähnen, beginnen wir mit den bekanntesten Musikanten, den Heuschrecken und Grillen. Bei den Laubheuschrecken und den Grillen sitzen die Schrillleisten an der Basis der Flügeldecken, und wir sehen daher diese Tiere beim Musizieren ihre Vorderflügel gegeneinander reiben (Fig. 5̌ 8 ). „Die Oberflügel der zirpenden Feldgrille bewegen sich in einer Sekunde 6-8mal hin und her, da sich aber beide Oberflügel gleichzeitig bewegen, ist die Geschwindigkeit doppelt so grob. Es liegen also die Verhältnisse so, als ob die Schrillkante 32 mal in der Sekunde über die 131-138 Zähnchen der ruhenden Schrillader vorbeigeführt würde; das gäbe einen Ton von $131 \times 32=4192$ Schwingungen, was mit der beobachteten Tonhöhe ( $\left.c^{\prime}\right)$ gut stimmt" (Hesse). Zur Schallverstärkung dienen bestimmte "Schrillfelder" der Flügel, die durch das Reiben der Schrillleisten in Schwingung versetzt werden. - Bei den Gras- oder Feldheuschrecken befindet sich die Schrillleiste an der Innenseite der hinteren Oberschenkel (Fig. 57), mit denen sie über die starke Randader der Vorderflügel schnell hin und her fahren und dadurch dieselbe in Schwingung versetzen. Die landläufige Meinung, daß nur den männ-

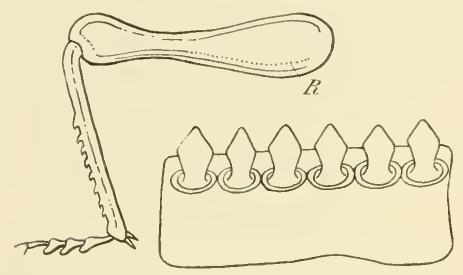

$A$

$B$

Fig. 57. Stimmorgan einer Feldheuschrecke, $A$ Hinterbein (von der Innenseite) mit der Reibleiste $(R)$; $B$ Reibleiste, vergrößert. Nach Petrunkewitsch u. v. Gaita. lichen Heuschrecken ein Tonapparat zu kommt und daß auch nur die Männchen Laute hervorzubringen vermögen, ist übrigens in dieser Allgemeinheit nicht zutreffend; denn Petrunkewitsch und Guaita haben gezeigt, daß eine ganze Anzahl von Heuschreckenarten auch im weiblichen Geschlecht einen Tonapparat besitzen, und außerdem wurde auch von Graber direkt beobachtet, daß gewisse weibliche Ileuschrecken, „wenn auch nur schwache Laute" hervorbringen können.

Auch unter den Käfern gibt es viele, welche Reibegeräusche erzeugen können; allerdings sind dieselben meist viel schwächer als bei den eben genannten Orthopteren und of nur in der

nächsten Nähe hörbar. So können die Totengräberkäfer (Necrophorus) ein Geräusch hervorbringen, indem sie zwei geriefte Längsleisten auf dem Rücken des fünften Hinterleibsringes gegen eine am Hinterende der Flügeldecken angebrachte Querleiste reiben. Die Bockkäfer erzeugen Töne durch Reibung des Hinterrandes des Vorderrückens auf einem unter ihm vorragenden, fein quergerieften Fortsatz des Mittelrückens. Bei den Dungkäfern sind sogar, wie Verhoeff zeigte, zwei verschiedene Stridulationsorgane vorhanden, von denen eines an der Hinterhüfte und das andere auf den Rückenplatten des vierten bis siebenten Hinterleibsegmentes gelegen ist. Das letztere besteht aus zahlreichen steifen Börstchen, die an die rauhe Unterseite der Flügeldecken reiben, während das erstere mit einer richtigen Reibleiste ausgestattet ist. Übrigens vermögen auch die Larven der Dungkäfer und deren Verwandten deutliche Geräusche zu erzeugen, und zwar durch Reibapparate, welche am zweiten oder dritten Beinpaar oder auch an den Mundteilen ihren Sitz haben.

Gewisse Wanzen (Reduviiden) streichen mit der besonders bewaffneten Spitze ihres Rüssels über eine an der Vorderbrust gelegene Reibplatte, und erzeugen so ein Geräusch; andere Wanzen benützen als Fiedelbogen ihre Beine, und zwar in verschiedener Weise, z. B. so, daß sie mit dem Vorderfuß der einen Seite über die auf der Innenseite des Vorderschenkels der anderen Seite gelegene 
Reibleiste dahinstreichen, oder daß sie mit den Hinterfüßen auf Reibplatten spielen, welche hinter ihnen gelegen sind (Pachycoris) usw.

Unter den Hymenopteren sind vor allem die Ameisen mit Stridulationsorganen ausgestattet; meist handelt es sich dabei um eine geriefte Platte, die am ersten Tergum des Hinterleibes gelegen ist und über die ein Fortsatz vom zweiten Stielgliedchen durch Auf- und Abbewegen des Abdomens hin und her gerieben wird.

Auch Schmetterlinge können Reibgeräusche hervorbringen, die am auffallendsten und bekanntesten beim Totenkopf sind. Eine Menge verschiedener Ansichten wurden über die Lauterzeugung des Totenkopfs aufgestellt, und man ist auch heute noch nicht ganz klar darüber, wie die Geräusche entstehen. Immerhin steht so viel fest, daß es sich um Reibgeräusche handelt, die in der Kopfregion hervorgebracht werden. Cobelli vertritt neuerdings die Anschauung, daß die beiden Rüsselhälften gegeneinander gerieben werden, während früher Landois angenommen hatte, daß das Geräusch durch Reibung einer fein gerieften Stelle der Lippentaster gegen die Basis des Saugrüssels entsteht.

Die Fluglaute entstehen dadurch, daß durch die Flügelschläge der fliegenden Insekten die Luft in so zahlreiche Schwingungen versetzt wird, daf sie für uns als Ton wahrnehmbar sind. Sie sind demnach nur bei schnellfliegenden Insekten (mindestens 20 Flügelschläge pro Sekunde) zu beobachten, während der Flug der langsamen Flieger wie z. B. der Tagfalter völlig geräuschlos ist. Die Tonhöhe hängt ganz und gar von der Zahl der Flügelschläge $a b$, d. h. der Ton ist um so höher, je

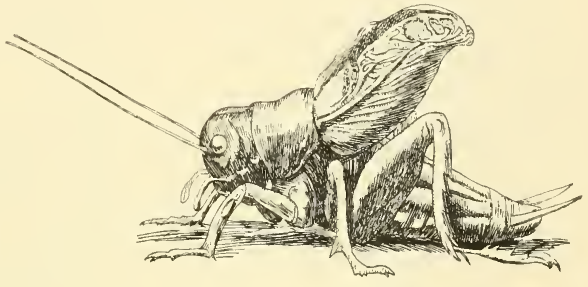

Fig. 58. Musizierende Grille. Nach Regen. zahlreicher die Flügel-

schläge sind. Darum finden wir auch die höchsten Töne bei den Fliegen und Mücken, die ja, wie oben schon erwähnt, auch die höchste Zahl der Flügelschläge erreichen; dann kommen die Bienen und Hummeln, deren Flugton schon weniger hoch ist, dann die Schwärmer, die mit mehr oder minder tiefem Brummen fliegen und endlich die größeren Noctuiden (z. B. Catocalen), deren Flugton sehr tief ist und beinahe an das Unhörbare grenzt (Prochnow).

Die Höhe des Flugtones gestattet auf die Zahl der Flügelschläge zu schliefen, indem die letztere der bekannten Schwingungszahl des Tones gleich sein muß. So bestimmte Landois z. B. den Flugton der Stubenfliege auf e', was 330 Flügelschlägen pro Sekunde entspricht. Daß die Fliege auch tatsächlich so viel Schläge macht, wurde später durch andere Methoden bestätigt.

Neben dem eigentlichen Flugton ist häufig noch ein zweiter Ton hörbar, der auch als "zweiter" oder "sekundärer Flugton" bezeichnet wird, und der stets höher als der erste ist. Landois nahm an, daß dieser Ton durch Membranen erzeugt wird, welche in den Tracheen in der Nähe der Stigmen eingefügt sind, und wie die Stimmbänder des menschlichen Kehlkopfes wirken, indem sie durch die austretende Atmungsluft in Schwingung versetzt werden; man sprach daher auch von „Respirationstönen“. Nach neueren Untersuchungen scheint aber diese Theorie nicht haltbar zu sein, sondern entsteht der zweite Ton durch Schwingungen 
der Thoraxwandung, die wegen der Elastizität des Chitins schneller erfolgen als die normalen Muskelkontraktionen resp. die Flügelschläge. Um zu einer klaren Entscheidung zu kommen, sind allerdings noch eingehende Studien notwendig.

Die Trommellaute sind nur einer kleinen Gruppe von Insekten eigen, nämlich den Singcicaden. Der Trommelapparat besteht aus zwei paarig angeordneten, ziemlich großen Hohlräumen, welche an der Basis des Abdomens gelegen und von breiten plattenförmigen Fortsätzen des Metasternums bedeckt sind. In den Hohlräumen befindet sich eine trommelfellartige, elastische Membran, an welcher sich ein an der gegenüberliegenden festen Wand entspringender Muskel anheftet. Durch rasch hintereinander erfolgende Kontraktionen des letzteren wird die Membran in Schwingungen versetzt, wodurch der charakteristische Cicadenton entsteht. Verstärkt wird der Ton durch den großen, zum größten Teil mit Luft gefüllten Hinterleib, der gewissermaßen als Resonanzapparat dient.

\section{Der Darmkanal und seine Anhänge.}

\section{Verdauungs- und Exkretionsorgane.}

Der Darm beginnt an der von den Mundwerkzeugen umgebenen Mundöffnung und geht zu der am Ende des Abdomens gelegenen Afteröffnung, je nach seiner Länge in geradem oder mehr oder weniger gewundenem Verlauf. Er gliedert sich stets in drei ihrer Funktion und Entstehung nach verschiedene Abschnitte, den Vorder-, Mittel- und Enddarm. Vorder- und Enddarm entstehen durch Einstülpung des äußeren Keimblattes (Ektoderms), während der Mitteldarm aus dem inneren Keimblatt, dem Entoderm, hervorgeht. Dementsprechend zeigen auch die beiden ersteren Abschnitte einen anderen geweblichen Aufbau als der letztere, was sich vor allem darin dokumentiert, daß Vorder- und Enddarm mit einer chitinigen Cuticula (Intima) austapeziert sind, die dem Mitteldarm fehlt.

Im Einklang mit der großen Verschiedenheit der Nahrungsaufnahme, die bei den Insekten herrscht, zeigt auch der Darm eine schier unerschöpfliche Mannigfaltigkeit und zwar nicht nur bei den verschiedenen Arten, sondern auch bei den verschiedenen Stadien ein und derselben Art.

Vorderdarm. - Naturgemäß macht sich diese Mannigfaltigkeit am meisten am Vorderdarm geltend, da ja dieser Abschnitt von der Verschiedenartigkeit der Nahrungsaufnahme am direktesten und unmittelbarsten betroffen wird. - Im allgemeinen können wir an ihm folgende Teile unterscheiden: die Mundhöhle, den Schlund oder Pharynx, die Speiseröhre (Oesophagus), den Kropf und endlich den Vor- oder Kaumagen.

Die Mundhöhle stellt den vordersten Abschnitt dar, welcher von den oben beschriebenen Mundgliedmaßen und dem Epi- und Hypopharynx begrenzt wird.

Der auf die Mundhöhle folgende Schlund oder Pharynx zeichnet sich meist durch eine stark verdickte Cuticula und eine kräftige Muskulatur aus. Letztere besteht sowohl aus Ringmuskeln, durch deren Kontraktion das Lumen verengert wird, als auch aus solchen Muskeln, welche die Darmwand 
mit der Kopfwand verbinden und durch deren Kontraktion die Schlundwände auseinandergezogen (dilatiert) werden. Besonders stark ist diese Muskulatur bei den saugenden Insekten ausgebildet, wo durch die abwechselnde Kontraktion der Ringmuskeln und der Dilatatoren eine Pump- und Saugwirkung erzielt wird.

Die Speiseröhre (Oesophagus) stellt gewöhnlich ein einfaches dünnwandiges Rohr dar, dessen Muskulatur nur schwach ausgebildet und dessen Intima mehr oder weniger gefaltet ist.

Der $\mathrm{Krop} f$ ist eine Erweiterung der Speiseröhre, die sich aber von dieser meist auch strukturell etwas unterscheidet durch stärkere Faltelung der Intima

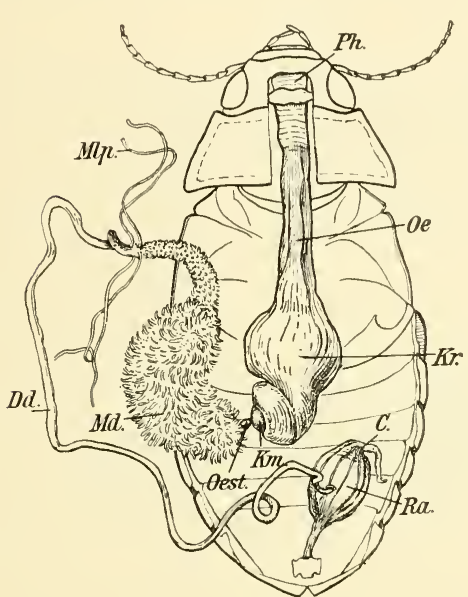

$A$

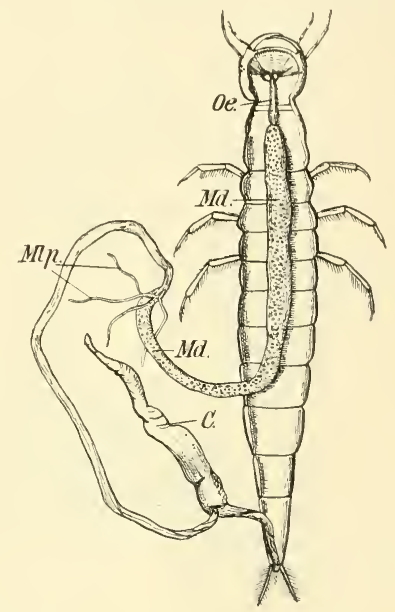

$B$

Fig. 59. Darmkanal des Gelbrandkäfers (Dytiscus marginalis $L_{*}$ ). A Imago, $B$ Larve. Ph Pharynx; Oe Oesophagus; Oest Oesophagusstiel ; $K r$ Kropf; $K m$ Kaumagen; Md Mitteldarm; Dd Diinndarm; Ra Rectalampulle; $C$ Coecum (Blinddarm); $\Lambda_{L} p$ Malpighische Gefäße. Nach Rungius.

und bisweilen auch durch kräftigere Muskulatur. Der Übergang von der Speiseröhre zum Kropf ist entweder ein allmählicher, so daß die beiden Abschnitte gar nicht scharf voneinander abzugrenzen sind oder aber der Kropf erscheint als eine (manchmal auch paarige) Ausstülpung der Speiseröhre, wobei er oft weit von dieser abgerückt und nur durch einen dünnen Stiel mit ihr verbunden ist (Fig. 61, Sm).

Letzteres trifft vor allem für solche Insekten $z u$, welche flüssige Nahrung zu sich nehmen, weshalb man den gestielten Kropf mit der Saugtätigkeit in Zusammenhang brachte und ihn fälschlicherweise auch als "Saugmagen" bezeichnete (Honigblase). Bei manchen Insekten ist der Kropf ungemein ausdehnungsfähig und kann durch Anhäufung von Nahrung (oder auch Anfüllung mit Luft) so groß werden, daß er nicht nur den größten Teil des Hinterleibes ausfüllt, sondern den letzteren auch noch mächtig kugelförmig auftreiben kann, wie z. B. bei den Honigameisen, bei 
denen die Kröpfe einzelner Individuen als Sammeltöpfe zum Aufspeichern von Honig für die ganze Gesellschaft benützt werden.

Der Vormagen (auch Kau-, Pumpmagen, Ventiltrichter, Gésier genannt) ist durch die Stärke der Intima, die gewöhnlich mit zahlreichen Zähnen, Borsten usw. besetzte Falten bildet, und durch eine sehr kräftige Muskulatur ausgezeichnet. Die Anordnung der chitinösen Falten, Zähne, Borsten usw. ist meist sehr regelmäßig (Fig. 60), so daß auf Querschnitten überaus zierliche Bilder entstehen, zeigt aber je nach den Familien, Gattungen und Arten große Verschiedenheiten, so daß man sie vielfach auch in der Systematik verwertet hat (z. B. bei den Borkenkäfern). Bei den Käfern herrscht die Vierzahl in der Faltenbildung vor, bei den Orthopteren die Sechszahl, wobei gewöhnlich gleiche Falten alternieren.

Über die Funktion des Vormagens gehen die Anschauungen der Autoren vielfach auseinander: während die einen in ihm einen Kauapparat sehen, in dem die Nahrung zerkleinert und zerrieben wird, erblicken die

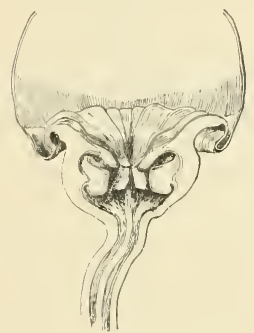

Fig. 60. Längsschnitt durch den Kaumagen von Dytiscus. Nach Rungius. anderen in ihm einen Schling-, oder Pump-, oder Reußenapparat, dem die Funktion zufällt, die Nahrungszufuhr zum Mitteldarm zu regeln, Nahrung vom Kropf in den Magen zu pumpen (Ameisen, Bienen), oder ungeeignete Nahrung vom Eintritt in den Magen abzuhalten usw. Wahrscheinlich bestehen alle diese Anschauungen mehr oder weniger $z u$ Recht, indem die Funktion des Vormagens bei den verschiedenen Insekten zweifellos verschieden ist. Jedenfalls ist es nicht gerechtfertigt, wie es einige neuere Autoren getan haben, dem Vormagen eine Kaufunktion durchweg absprechen zu wollen; denn bei manchen Insekten, wie z. B. bei den Borkenkäfern, Schwimmkäfern usw., fällt ihm zweifellos eine solche Funktion zu.

Auf den Vormagen folgt gewöhnlich noch ein dünnerer Vorderdarmabschnitt, welcher die Verbindung zwischen jenem 'und dem Mitteldarm herstellt, und entweder frei vor dem letzteren gelegen ist ("Oesophagusstiel“, Fig. 59, Ocst), oder mehr oder weniger tief in den Mitteldarm hineinragt (Rüssel, Ventilschlauch, Appendix vermiformis usw. Fig. 62, $V_{t r}$ ). Das hintere Ende dieses dünnen Abschnittes oder aber auch der ganze Abschnitt bildet zugleich einen Verschlußapparat zwischen Mittel- und Vorderdarm (Valvula cardiaca), der verhindert, daf Nahrungsteile aus dem ersteren in den letzteren zurücktreten können. Meist handelt es sich um eine Ringfalte mit Ringmuskulatur; bei manchen Insekten jedoch (Bienen) geschieht der Verschluss dadurch, daß der rüsselartig in den Mitteldarm hineinragende, zartwandige „Ventilschlauch“ beim leisesten Druck von hinten her zusammengequetscht wird.

Im AnschluB an den Vorderdarm sind auch noch die Speicheldrüsen zu erwähnen, die zwar, zum Teil wenigstens, morphologisch nicht eigentlich diesem Darmabschnitt angehören, aber doch physiologisch ihm zu- 
zurechnen sind. Speicheldrüsen kommen bei den meisten Insekten vor, und zwar in sehr verschiedener Zahl und Ausbildung: manchmal nur in einem, manchmal in zwei oder auch in drei Paaren. Oft sind es einfache oder verzweigte Schläuche, die länger als der ganze Körper und daher mehrfach gewunden sind (z. B. die Speicheldrüsen der Fliegen), oft handelt es sich auch um kleinere oder größere Drüsenpackete, und bisweilen finden sich auch neben den eigentlichen Drüsen noch größere Reservoire, in welchen das Sekret angesammelt wird. Die Ausmündung erfolgt gewöhnlich an der Basis der Mundgliedmaßen, weshalb die betreffenden Drüsen auch als Mandibular-, Maxillar- und Labialdrüsen unterschieden werden. Die letzteren besitzen gewöhnlich einen unpaaren Ausführungsgang (Speiche].

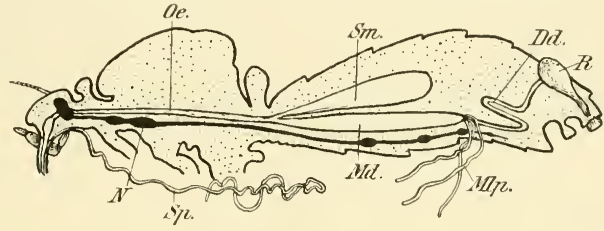

$A$

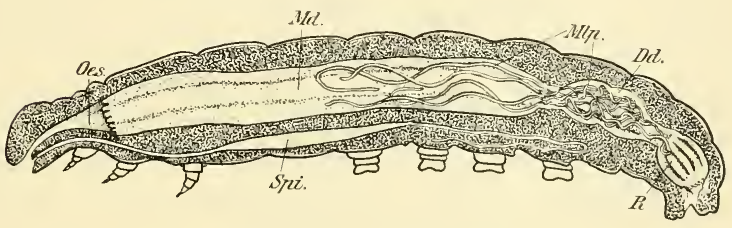

$B$

Fig. 61. Darmkanal eines Schmetterlings. A Imago; B Larve; Oe Ösophagus; Sm „Saugmagen “ (Kropf); $M d$ Mitteldarm; $M p$ Malpighische Gefäße; $D d$ Dünndarm; $R$ Rektum; $S p$ Speicheldrüse; Spi Spinndrüse.

gang), und sind nur in ihrem drüsigen Teil paarig (Fig. 62 B). Nicht selten münden auch noch in den Schlund ein paar Drüsen, welche als Pharyngeal- oder Schlunddrüsen (Fig. 62 A, $D r_{1}$ ) bezeichnet werden und die bei den Bienen eine Länge von zusammen $2 \mathrm{~cm}$ (doppelt so lang als der ganze Bienenkörper) erreichen können.

Die Funktion der genannten Drüsen ist eine verschiedene. Meistens stehen sie im Dienst der Verdauung; die Labialdrüsen sind bei vielen Larven zu Spinndrüsen umgebildet, der Schlunddrüse der Bienen kommit die Funktion der Futtersaftabscheidung zu usw.

Mitteldarm. - Entsprechend der einheitlichen Funktion des Mitteldarmes (Verdauung der zugeführten Nahrung) zeigt auch der Bau dieses Darmabschnittes bei weitem nicht so mannigfaltige Differenzierungen als der Vorderdarm. Er stellt ein mehr oder weniger weites Rohr von verschiedener Länge dar, dessen Außenseite entweder glatt oder mit dicht 
stehenden Zotten oder mit einzelnen fingerförmigen Anhängen besetzt ist. Nicht selten lassen sich verschiedene Abschnitte an ihm unterscheiden, je nach seinem dickeren oder dünneren Umfang, oder je nachdem der eine Teil mit längeren, der andere mit kürzeren Zotten besetzt oder ganz glatt ist usw.; so spricht Sedlaczek bei den Borkenkäfern von 4 Mitteldarmregionen: der erweiterten, der engeren, der Blindschlauch- und der Divertikelregion.

Die Hauptarbeit im Mitteldarm fällt den Epithelzellen zu, welche die verdauenden Sekrete zu liefern und auch die Resorption zu besorgen haben; daher sind dieselben hier auch besonders gut ausgebildet, meist als hohe Zylinderzellen. Eine chitinöse Intima fehlt, wie oben schon gesagt, dagegen sind die freien Zellenden gewöhnlich von einem feinen "Stäbchensaum“ eingefaßt, über dessen Entstehung und Bedeutung noch keine volle Klarheit herrscht. Auf die Zellschicht folgt nach außen eine feine Membran, die als Basal- oder Stützmembran oder als Grenzlamelle bezeichnet wird, und welche die Zellen zusammenhält; und endlich kommt zu äußerst eine dünne Muskelschicht, die aus Rings- und Längsmuskeln besteht.

Die meisten Verschiedenheiten finden wir an der Zellschicht, die nicht nur bei den verschiedenen Arten, sondern auch bei Larve und Imago deutliche Abweichungen zeigen kann. Ja sogar bei der Imago selbst kann das Epithel recht verschieden erscheinen, je nach dem jeweilisen Stand der Verdauung, denn meistens hat die Sekretion der Verdauungssäfte eine relativ rasche Zerstörung der Zellen zur Folge. Bei munchen Insekten wird dabei die ganze Zellschicht von Zeit zu Zeit (alle paar Tage) im Zusammenhang abgeworfen (Hydrophilus), bei anderen dagegen erfolgt die Zellabstoßung partiell und allmählich, geht dafür aber ununterbrochen vor sich.

Der Ersatz für die abgestoßenen Zellen erfolgt von Gruppen junger Zellen aus, die als Regenerations-, oder Epithelmutter- oder Cryptenzellen, oder auch kurzweg als Crypten bezeichnet werden. Sie liegen entweder als kleine Nester zerstreut unter dem Epithel, oder aber am Grunde jener ausgestülpten Zellschläuche, die außen als Zotten hervortreten.

Hinterdarm. - Der Hinterdarm, der wie der Vorderdarm eine Hauteinstülpung darstellt und daher mit einer chitinigen Intima austapeziert ist, läßt bei den meisten Insekten nach seiner äußeren Konfiguration zwei differente Abschnitte unterscheiden: den Dünndarm und den Mast-oder Enddarm, auch Rektum oder Kotblase genannt. Der Anfang des Hinterdarms ist durch die hier entspringenden Malpighischen Gefäße (siehe unten) äußerlich stets gut gekennzeichnet.

Der Dünndarm ist der längere der beiden Abschnitte und zeigt meist einen mehr oder weniger gewundenen Verlauf. Er beginnt mit dem sog. Pylorus (Valvula pylorica), welcher aus hohen in das Lumen vorspringenden Falten und einer kräftigen Ringmuskulatur besteht, und welcher die Beförderung des Darminhaltes vom Mittel- zum Enddarm regelt.

Die Pylorusregion geht allmählich in das eigentliche Dünndarmrohr über, indem die Muskulatur dünner und die Epithelzellen merklich größer und vielfach anders strukturiert (streifig) erscheinen. Die Intima des Dünndarms (wie auch des Rektums) ist oftmals mit verschieden geformten Zähnen und Borsten, die meist nach hinten gerichtet sind, besetzt. 
Das Rektum (Fig. 61 u. 62, R) ist durch die starke (oft blasenförmige) Erweiterung deutlich rom Dünndarm abgesetzt; auch im geweblichen Aufbau unterscheidet es sich wesentlich von dem rorhergehenden Abschnitt, und zwar vor allem durch die Reduktion der Zellschicht, die gegenüber der starken Intima gänzlich in den Hintergrund tritt. Nur an einigen Stellen bleiben Streifen von hohen Epithelzellen erhalten, die als Längswülste in das Lumen vorragen und
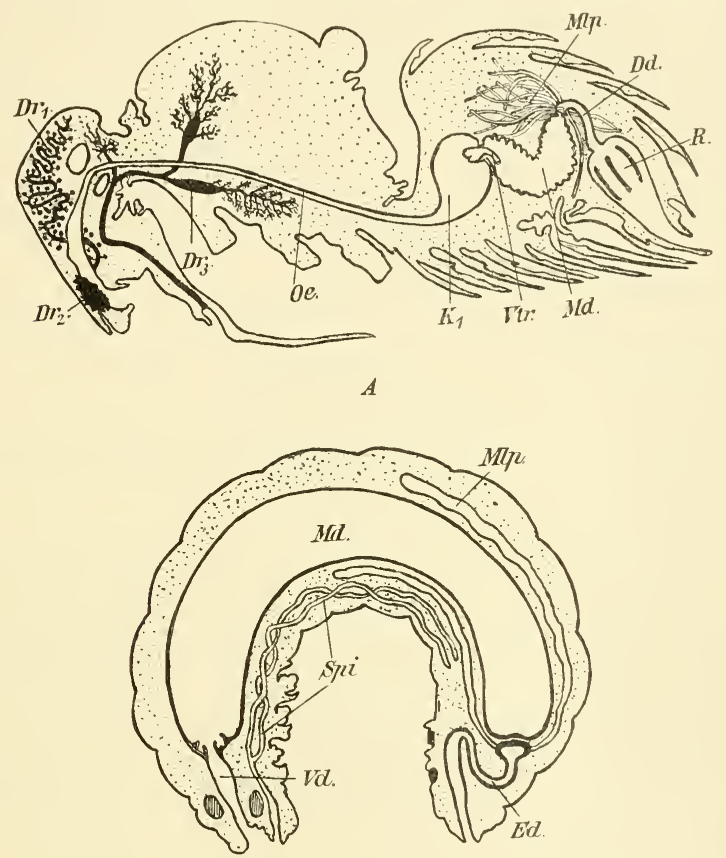

$B \quad$.

Fig. 62. Darmkanal einer Biene. $A$ Imago; $B$ Larve; $D r_{1}$ Schlunddrüse; $D r_{2}$ Mandibulardrüse; $\mathrm{Ir}_{3}$ Labialdrïse; Vtr Ventiltrichter; Vd Vorderdarm; Ed Enddarm. Die ubrigen Bezeichnungen wie auf den Fig. 60 u. 61. Nach $\mathrm{Z}$ ander.

die als Rektaldrüsen bezeichnet werden. Ihre Funktion ist noch nicht mit Sicherheit festgestellt, vielleicht spielen sie bei der Bildung der Kotballen eine Rolle. - Auch die Muskulatur des Rektums ist von der des Dünndarms verschieden durch ihre wesentlich stärkere Ausbildung; sie besteht aus einer Anzahl Längsmuskelbündeln und einer Ringsmuskulatur, die in der Afterregion als Sphinkter wirkt. Der After ist im letzten Segment gelegen und stellt einen schmalen Spalt dar, dessen Wände durch den Besitz zahlreicher Falten stark erweiterungsfähig ist. 
Bei manchen Insekten besitzt das Rektum eine blindsackartige Ausstülpung, die mitunter von der halben Länge des ganzen Tieres sein kann (z. B. Dytiscuslarve).

Der Bau des Darmkanals (Länge und Differenzierung der einzelnen Abschnitte) ist, wie oben schon betont, ungemein verschieden, je nach der Ernährungsart und dem Bau des betr. Insekts. Im allgemeinen kann man wohl sagen, daß der Darm bei Pflanzenfressern länger ist als bei Fleischfressern; doch trifft dies nicht ausnahmslos $z u$, so ist $z$. B. der Darm des pflanzenfressenden Kolbenwasserkäfers (Hydrophilus) nicht nur nicht länger, sondern sogar (relativ) kürzer als der Darm des fleischfressenden Gelbrandkäfers (Dytiscus). Dies kann damit erklärt werden, daß bei diesen Fleischfressern durch die große Energie ihrer Lebenstätigkeit ein rascherer Verbrauch der Körpersubstanzen und damit zugleich ein beträchtlicherer Ersatz bedingt ist (Leuckart), oder daß die Art der Lebensweise es nötig macht, daß das betr. Tier auf einmal größere Mengen verschlingt, um für längere Zeit versorgt zu sein (Rungius).

Um einen Begriff zu geben von dem Verhältnis $\mathrm{zw}$ is chen $\mathrm{Darm}$ länge und Nahrung, seien hier einige Beispiele von verschiedenen Käfern (nach Gorka) angeführt:

bei coprophagen (kotfressenden) Käfern (Geotrupes usw.) beträgt die Länge des

Darms das 5-8 fache der Körperlänge;

bei phytophagen (z. B. Melolontha) das $3-7$ fache;

bei succiphagen (saftleckenden) Käfern (Cerambyciden) das 2-3 fache;

bei saprophagen (von modernden Substanzen lebenden) Käfern das $21 / 2-4$ fache;

bei sarcophagen (Fleischfressern) das 1,7-3,2 fache und

bei necrophagen (Aasfressern) das $4-7$ fache.

Auch das Längenverhältnis der einzelnen Darmabschnitte zueinander ist recht verschieden. Bei manchen Insekten ist der Mitteldarm der längste Abschnitt (z. B. bei den coprophagen Käfern, bei denen er $80-90 \%$ der gesamten Darmlänge ausmacht, dann auch bci den phytophagen Käfern usw.); in anderen Fällen ist der Vorderdarm der längste Abschnitt (z. B. bei den Ameisen und Verwandten) und in, wieder anderen Fällen überragt der Hinterdarm die anderen Abschnitte wesentlich an Länge, so z. B. bei den Totengräbern (Necrophorus), bei denen er ca. ${ }^{3 / 4}$ des gesamten Darmkanals beträgt, oder bei Dytiscus, bei dem er beinahe doppelt so lang als Vorder- und Mitteldarm zusammen ist.

Was die Differenzierung der einzelnen Darmabschnitte betriff, so steht diese in bezug auf ihre Mannigfaltigkeit den eben besprochenen Verhältnissen kaum nach, was sich in dem Fehlen oder Vorhandensein von einem Kropf, Vormagen, Rektum, Rectaldrüsen usw. kund tut.

Natürlich weichen auch Larve und Imago der gleichen Art im Bau des Darmkanals wesentlich voneinander ab, wenn die beiden eine verschiedene Ernährungsweise besitzen; so kann man sich kaum größere Gegensätze vorstellen als den Darm der von Blattsubstanz sich nährenden Raupe und dem von Nektar lebenden Schmetterling (Fig. $61 \mathrm{~A} \mathrm{u.} \mathrm{B).}$

Bei manchen Insekten treten starke R e duktion e $\mathrm{n}$ a $\mathrm{m} \mathrm{Dar} \mathrm{m} \mathrm{roh} \mathrm{r} \mathrm{ein;}$ so ist bei den Eintagsfliegen, die während ihres kurzen Imagolebens überhaupt keine Nahrung zu sich nehmen, der Vorderdarm verkümmert, resp. völlig zusammengepreßt, so daß er unpassierbar ist. In anderen Fällen ist der $\mathrm{H}$ in te r d a $\mathrm{rm}$ funktionslos geworden, indem die Verbindung zwischen ihn und dem 
Mitteldarm fehlt, resp. die Valvula pylorica geschlossen bleibt (Fig. 62 B). Solche Zustände finden wir bei den Bienen und Wespenlarven, die ja eine sehr konzentrierte Nahrung dargereicht erhalten, welche fast restlos verdaut wird. Erst während der Umwandlung zur Imago wird die Verbindung zwischen den beiden Darmabschnitten hergestellt, worauf die wenigen unverdauten Reste nach außen entleert werden.

Über die Verdauungsvorgänge sind wir noch recht schlecht unterrichtet. Nach dem wenigen, was wir bis jetzt darüber wissen, können wir uns ungefähr folgendes Bild machen: Die Verdauung beginnt schon in der Mundhöhle, wo durch die Sekrete der Speicheldrüsen (wie bei den Wirbeltieren) Stärke in Zucker verwandelt wird. Im Kropf und Vormagen setzt sich dieser Vorgang weiter fort, und daneben beginnt bereits (bei den Fleisch. fressern) die Verdauung des Eiweißes, d. h. die Überführung der unlöslichen Eiweißstoffe in lösliche (Peptonisierung); die nötigen Fermente hierzu stammen zweifellos aus dem Mitteldarm.

Die Untersuchung des Kropfinhaltes bei Dytiscus durch De e g e ne r ergab, daß die Erweichung der Nahrung mehrere Stunden in Anspruch nimmt. Die ersten verflüssigten Bestandteile traten hier nach $3 / 4-1$ Stunde in den Mitteldarm ein. Noch 17 Sturden nach der Nahrungsaufnahme waren im Kropf einige gequollene Fleischreste zu finden, erst nach 20 Stunden waren größere ungelöste Bestandteile im Kropfinhalt nicht mehr wahrnehmbar.

Wo ein Kaumagen vorhanden ist, wird die Nahrung weiter zerkleinert und zerrieben und mit dem Magensaft durchgeknetet, um dann, soweit sie richtig vorverdaut ist, in den Mitteldarm abgepreßt zu werden.

Der Mitteldarmsaft (Chylus), der von den Mitteldarmzellen ausgeschieden wird, ist nach Biedermann stark eiweißverdauend und enthält außerdem stärkelösende und fettzersetzende Fermente. Merkwürdigerweise findet sich in ihm kein zelluloselösendes Mittel, so daß also nur der Inhalt derjenigen Blattzellen verdaut werden kann, die beim Kauen angeschnitten und eröffnet sind, während der Verdauungssaft zu den übrigen noch von der Zellulosemembran umschlossenen Zellen keinen Zutritt hat (Hesse). Daher besteht demn auch der Kot der Raupen aus vielen kleinen Blattstückchen, die, mit Ausnahme der Randzellen, meist noch gut erhalten sind. Die aufgenommene Nahrung kann also hier nur sehr unvollkommen ausgenutzt werden, womit sich auch der außerordentliche Futterverbrauch der Raupen erklären läßt: frißt doch die Raupe des Kiefernspinners rom Ei bis zur Verpuppung ca. 1000 Kiefernnadeln und die Nonnenraupe bis zu 1300 Fichtennadeln.

In Mitteldarm findet nicht nur die Verdauung, sondern auch die Resorption statt, so daß also die gleichen Zellen zwei recht rerschiedene Funktionen zu erfüllen haben (vielleicht hängt damit auch ihr stetiger Zerfall zusammen).

Übrigens scheint sich der Resorptionsrorgang auch auf den Dünndarm, wenigstens auf seinen Anfangsteil fortzusetzen, wofür jedenfalls die oft sehr respektable Länge dieses Darmabschnittes und seine relativ großen und oft auch besonders strukturierten Epithelzellen sprechen. Der hintere Abschnitt des Dünndarms, wie auch das Rektum, dienen wohl lediglich zur Aufsammlung und Ausfuhr der unverdauten Nahrungsreste. 
Bei einigen Insekten findet die $V$ e rda u u $\mathrm{g} \mathrm{resp}$. Vorverda u u $\mathrm{ug}$ a u B erhalb des Körpers statt (extraintestinale Verdau ung), wie z. B. bei der Dytiscus-Larve, deren Mandibeln, wie bereits erwähnt, mit einem feinen Kanal versehen und zum Saugen eingerichtet sind. Diese Zangen bohrt sie ihrem Opfer in den Leib, dann läßt sie aus der Kanalmündung einen Saftropfen austreten, der vorab durch Giftwirkung das Opfer tötet und sodann das Fleisch auflöst. Den Speibewegungen (durch welche Gift und Fermentsaft in die Beute gespritzt wird) folgen regelmäßig Saugbewegungen, und nach einer Viertelstunde ist das Opfer (etwa eine Schmeißfliege) völlig ausgesogen (N a g el). Ganz ähnliche Vorgänge spielen sich auch bei der Larve der Leuchtkäfer (nach R. Vog e 1), des Ameisenlöwen (Myrmeleo) und der Florfliege ab. Neuerdings stellte J o r d a n auch bei einem ausgesprochen kauendem Insekt. bei unserem Goldlaufkäfer (Carabus auratus) eine extraintestinale Verdauung fest. Wenn dieser Käfer ein Stück Fleisch fressen will, so versenkt er den Kopf in das Fleisch, sich mit den Mandibeln den Weg bahnend, und läßt einen braunen Saft aus dem Munde austreten, der fermenthaltig ist und das Fleisch auflöst. So verschwindet denn letzteres zusehends, ohne daß der Käfer ein Stück davon verschluckte, während gleichzeitig sein Hinterleib immer mehr anschwillt. Nach Jor dan dauerte die Auflösung eines Stückchen Fleisches von $1 \mathrm{~cm}$ Länge und $1 / 2 \mathrm{~cm}$ Dicke 3 Stunden und 15 Minuten.

Die Malpighischen Gefäße (Harngefäße). — Die Malpighischen Gefäße sind längere oder kürzere, meist blind endigende, dünne Schläuche, welche an der Grenze von Mittel- und Hinterdarm entspringen. Sie entstehen als Ausstülpungen des Hinterdarmes, sind also diesem Darmabschnitt zuzuzählen. Ihr geweblicher Aufbau ist ein sehr einfacher: die Wand besteht aus großen Zellen, deren Grenzen oft undeutlich und deren Kerne meist recht unregelmäßig geformt (mitunter verzweigt) sind. Eine chitinöse Intima fehlt oder sie ist äußerst fein und nur teilweise erhalten. Außen ist die Zellschicht von einer feinen Grundmembran umgeben, die von einem dichten Netz feinster Tracheenäste umsponnen wird.

Bezüglich der Zahl, Form und Farbe der Malpighischen Gefäße herrschen die größten Verschiedenheiten: Die Farbe kann weißlich, gelblich, grünlich oder bräunlich oder sogar dunkelrot sein. Die Form ist meist einfach zylindrisch, doch kommen auch keulenförmige (Phora), oder mehrfach ausgebuchtete oder geweihartig verzweigte Gefäße (Wachsmotte) vor. Auch bezüglich der Länge und Dicke sind große Schwankungen vorhanden. Im allgemeinen gilt der Satz, daß die Länge umgekehrt proportional ist der Zahl der Gefäße; d. h. wo nur wenige $(4-6)$ vorhanden sind, wie z. B. bei den Käfern und Schmetterlingen, da sind sie sehr lang; je zahlreicher aber die Gefäße werden, desto kürzer und zugleich auch dünner werden sie, wie das z. B. bei den Geradeflüglern oder den Bienen und Wespen, bei denen die Zahl 100 und mehr betragen kann, deutlich zu sehen ist. Im letzteren Fall vereinigen sich die Gefäße zuweilen büschelförmig, um mit einem gemeinsamen Gang in den Enddarm zu münden (Grillen). Übrigens auch da, wo nur wenige Gefäße vorhanden sind, können sich zwei oder mehrere Gefäße zu einem gemeinsamen Mündungskanal vereinigen. Bei gewissen Insekten zeigen die Malpighischen Gefäße untereinander deutliche Verschiedenheiten; so haben die Borkenkäfer zwei dünnere und vieı dickere Gefäße oder es tritt ein Teil der Gefäße mit ihren Enden in eine feste Verbindung mit dem Darm, während die anderen frei endigen usw. 
Was die Funktion der Malpighischen Gefäße betrifft, so stellen sie zweifellos in der Hauptsache Exkretionsorgane (Harnorgane) dar. Denn in ihren Ausscheidungen läßt sich stets reichlich Harnsäure nachweisen; außerdem sind in ihnen auch noch Kristalle von oxalsaurem Kalk und Taurin, ferner Kugeln von Leucin und harnsaurem Natron gefunden worden.

Daneben können allerdings noch andere Funktionen ausgeübt werden; so werden bei einigen Insekten (Neuropteren) Spinnsekrete von den Malpighischen Gefäße ausgeschieden, und einige Autoren schreiben ihnen auch eine resorbierende Funktion zu. An solche Doppelfunktionen könnte man am ersten da denken, wo die Gefäße untereinander verschieden sind (siehe oben).

\section{Die Atmungsorgane (Tracheensystem).}

Stigmenatmung.

Die Insekten atmen durch Tracheen, das sind Luftröhren oder Kanäle, welche einerseits meist durch paarige, segmental angeordnete Öffnungen oder Stigmen mit der Außenwelt in Verbindung stehen, andererseits durch reich verzweigte feinste Äste überall im Körper sich verbreiten, um alle Organe zu umspinnen und zu allen Zellen zu gelangen. So wird der Sauerstoff, der durch die Stigmen eindringt, direkt und unmittelbar den Geweben zugeführt und ebenso die ausgeschiedene Kohlensäure direkt auf demselben Wege ausgeführt. Die Insekten bedürfen also keines besonderen Transportorganes zum Hin- und Hertransport von Sauerstoff und Kohlensäure, wie dieses z. B. bei den Wirbeltieren der Fall ist (Blutgefäßsystem).

Der gewebliche Aufbau der Tracheen ist fast überall der gleiche. Da die Tracheen als eine Einstülpung der Körperwand entstehen, so ist ihre Innenwand ron einer Cuticula ausgekleidet, welche die Fortsetzung der äußeren Chitinhaut des Körpers darstellt. Sie zeigt eine sehr charakteristische Struktur, an der die Tracheen stets leicht zu er-

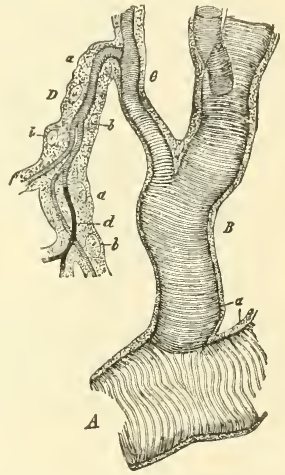

Fig. 63. Bau einer Trachee nach Hertwig). A Hauptstamm; $B, C, D$ Verästelungen; $a$ Epithel mit Kernen (b). kennen sind: nämlich eine fadenförmig, spiralig fortlaufende Verdickung, den sog. Spiralfaden, welcher durch seine Elastizität dafür sorgt, daß die Röhre offen gehalten wird (Fig. 63). Nur in den dünnsten Endteilen der Tracheen und in den Luftsäcken fehlt der Spiralfaden, sonst ist er stets vorhanden. Die Zellschicht, welche die Intima ausgeschieden hat, und welche als die Fortsetzung des Epithels der Körperwand zu betrachten ist, besteht gewöhnlich aus sehr niedrigen, platten Zellen.

Die Stigmen zeigen große Verschiedenheiten bezügl. ihres Baues; schon ihre Form ist recht verschieden und kann sowohl rund, als auch breit- oder schmaloval sein. Noch weit mehr aber variiert ihre Struktur; so finden wir innerhalb des stark chitinisierten Stigmenringes, welcher zur Offenhaltung der Stigmen dient, die mannigfaltigsten aus Falten, Borsten und Haaren bestehenden Bildungen, die den Zweck haben, das Eindringen von Staub 
und anderen Fremdkörpern in das Tracheensystem zu verhindern und also gewissermaßen als Filter oder Reusenapparat anzusehen sind.

Innerhalb der Filterapparate liegen an den von den Stigmen ausgehenden Tracheenstämmen gewöhnlich mehr oder weniger komplizierte VerschluBapparate, welche dazu dienen, die eingetretene Luft festzuhalten, so daß dieselbe durch die Atembewegungen bis in die feinsten Verzweigungen vorgedrückt werden kann. Sie bestehen aus Klappen oder Zangen oder einer mit einem Hebel versehenen, mehrteiligen Chitinspange, welche um die Trachee gelegt ist und durch Muskelwirkung dieselbe zusammenquetscht (Fig. 64).

Was die Anordnung des Tracheensystems betrifft, so sind ursprünglich 10 Paar Stigmen vorhanden, die bei den Imagines folgendermaßen verteilt sind: Je ein Paar am Meso- und Metathorax und den ersten acht Hinterleibsringen. Kopf und Prothorax sind bei den Imagines, mit wenigen Ausnahmen (z. B. Floh), ohne Stigmen. Bei den Larven dagegen besitzt meist der Prothorax ein Stigma, während Meso- und Metathorax frei sind.

Die Stigmen liegen
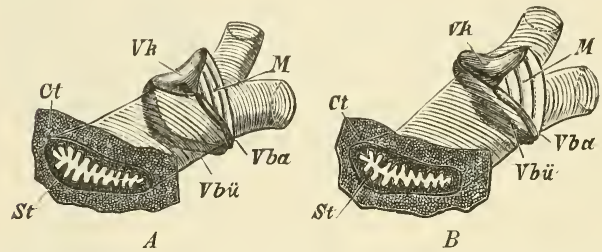

Fig. 64. Schematische Darstellung des Tracheenverschlusses bei einem Hirschkäfer. $A$ der geöffnete, $B$ der geschlossene Apparat; St Stigma mit vorspringendem Gitterverschlub; $C t$ Cuticula der Leibeswaud; $\nabla k$ Verschlußkegel; Vbü Verschlußbügel; Vba Versehluß. band; $M$ Muskel. - (N.) im allgemeinen in den Intersegmentalhäuten; doch rücken sie häufig des besseren Schutzes halber dorsal- oder ventralwärts in die eigentlichen Segmentplatten; so liegen die Abdominalstigmen bei den Käfern meistens derart, daß sie von den Flügeldecken vollkommen bedeckt werden; bei vielen Bienen liegen sie am Vorderrand der Segmentplatten, so daß sie durch die übergreifenden vorhergehenden Platten geschützt sind usw.

Von den Stigmen tritt gewöhnlich je ein stärkerer Tracheenstamm nach innen, der sich nach kurzem Verlauf gabelt, um mit den vom vorhergehenden und nachfolgenden Stigma entspringenden Gabelästen in Verbindung zu treten. So entsteht jederseits ein geschlossener Längsstamm, der den ganzen Körper von hinten nach vorn durchzieht. $\mathrm{Zu}$ diesen seitlichen Hauptiängsstämmen können dadurch, daß die von diesen abgehenden Äste nochmals Längsverbindungen eingehen, noch ein oder ¿ weitere l’aare solcher Stämme (1 Paar ventraler und 1 Paar dorsaler) hinzutreten, so daß der Körper also von 3 Paar Längsstänmen durchzogen wird, die alle durch Querkommissuren miteinander verbunden sind (Fig. 65). Von diesen Stämmen und Kommissuren gehen wieder zahlreiche Äste ab, die sich immer mehr verzweigen und immer feiner werden, um alle Organe mit einem dichten Netz zu umspinnen und schließlich als Capillaren in die Gewebe einzudringen.

Nur bei den niedersten Insekten finden wir bisweilen eine andere Anordnung des Tracheensystems, indem hier die von den Stigmen abgehenden Tracheen- 
stämme mit den benachbarten nicht in Verbindung treten, sondern völlig unabhängig voneinander sich verästeln, um die nächstliegenden Organe zu versorgen ein Zustand, der zweifellos als der primitivere anzusehen ist.

Bei vielen fliegenden Insekten sind die Tracheen stellenweise zu Luftsäcken erweitert, deren Wände, wie schon erwähnt, des versteifenden Spiralfadens entbehren (Fig. 66). Bei manchen Insekten (Bienen, Fliegen, Schmetterlingen, Maikäfer usw.) können sie so groß und zahlreich werden, daß, wenn sie mit Luft gefüllt, den größten Teil der Leibeshöhle einnehmen. Da die Luftsäcke nur den fliegenden Arten zukommen (den Larven fehlen sie ganz und ebenso gehen sie auch da, wo nur ein Geschlecht flugfähig, dem flugunfähigen Geschlecht $a b)$, so dürfen wir sie wohl mit dem Flugvermögen in $\mathrm{Zu}$ sammenhang bringen, und zwar wahrscheinlich in dem Sinne, daß sie als Sauerstoffreservoir während des Fluges, während dem die Atembewegung stark gehindert ist, dienen.

Die lange geltende Anschauung, daß durch die Füllung der Säcke mit Luft das spezifische Gewicht des Körpers gegenüber der Luft verringert werde, ist heute gänzlich aufgegeben.

Die 10 stigmige Anordnung erleidet mancherlei Modifikationen, was hauptsächlich in einer Reduktion der Stigmenzahl sich

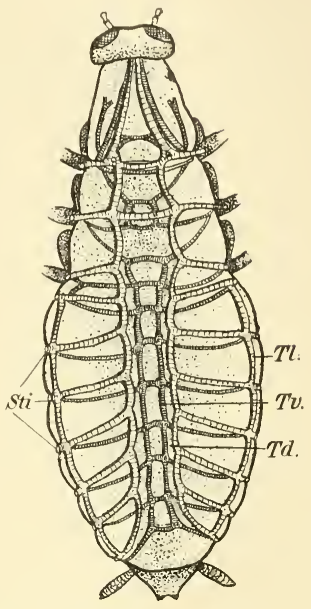

Fig. 65 Schematische Darstellung des Tracheensystems der Küchenschabe (Periplaneta). Sti Stigmen; $T l$ seitlicher, $T v$ ventraler, $T d$ dorsaler Längsstamm. Nach Hatsehek.

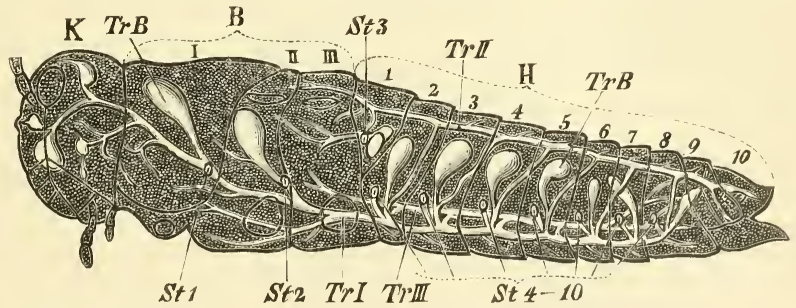

Fig. 66. Schematische Darstellung des Tracheensystems einer weiblichen Feldheuschrecke nach Emerton und Packard. $K$ Kopf; $B$ Brust mit ihren 3 Segmenten $I-I I I ; H$ Hinterleib mit seinen 10 Segmenten $1-10$; St die Stigmen; $\operatorname{Tr} B$ die Tracheenblasen; $\operatorname{Tr} I$ der äußere linke bauchständige Tracheenhauptstamm; TrII der linke rü̊kenständige Tracheenhauptstamm; TrIII der linke innere bauchstandige Tracheenhauptstamm. Die entsprechenden rechten Stämme fehleu in dieser einseitigen Darstellung. - (N.)

kund tut. Dieselbe kann so weit gehen, daß nur noch 22 Paare Stigmen (1 am Thorax und 1 am Ende des Hinterleibes) bestehen bleiben (amphipneustischer Typus) (Fig. 67), oder gar nur noch ein Paar, das entweder am Vorderende (propneustisch) oder am Hinterende des Körpers (metapneustisch) gelegen sein 
kann. Derartig weitgehende Reduktionen finden sich hauptsächlich bei Larren, welche im Wasser oder einem anderen für die Stigmenatmung un-

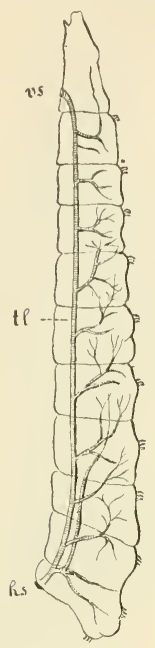

Fig. 67. Amphipneustische Fliegenlarve nach Lang). vs vorderes, hs hinteres Stigmenpaar. geeigneten Medium leben, wie z. B. die Larven von Wasserkäfern, die Larve der Schlammfliege, die Culex- oder Tipula-Larven, die Larven der parasitisch lebenden Raupenfliegen (Tachiniden) usw. Bei manchen Larven und Puppen sitzen die Stigmen auf langen Röhren, mit deren Hilfe sie Luft von der Oberfläche des Wassers her beziehen können, ohne sich selbst an die Oberfläche begeben zu müssen, wie z. B. bei gewissen Tipuliden (Fig. 68) oder die als "Rattenschwanzlarve" bekannte Larve der Schlammfliege, oder bei den freibeweglichen Puppen der Stechmücken, bei denen die Atemröhıen am Vorderende des Thorax sitzen („Hörnchen“). Uin das Hängen an der Oberfläche zu ermöglichen, sind die

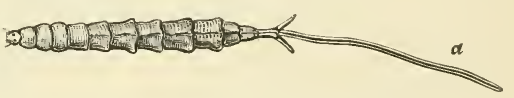

Fig. 68. Larve von Ptychoptera contaminata $L$. inach Brauer). a Atemröhre. - (N.)

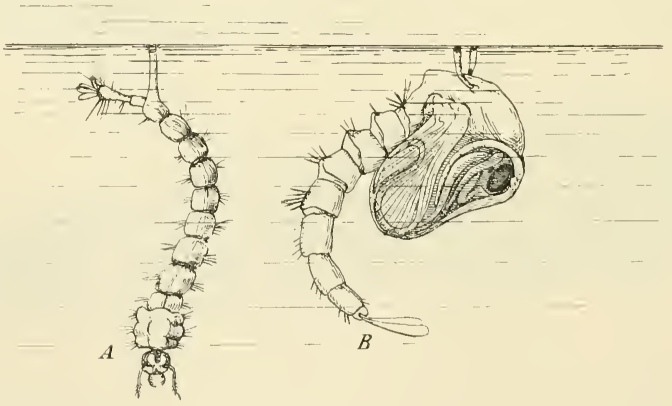

Fig. 69. Larve und Puppe einer Stechmücke. Beide atmen durch Atemröhren, die bei der Larve vom Hinterende, bei der Puppe vom Thorax abgehen.

Stigmen oft mit Borstenkränzen usw. umgeben, die als Schwebeapparate dienen (Fig. 69).

Die rückgebildeten Stigmen lassen sich meist noch deutlich erkennen, besonders an dem soliden Zellstrang, der von der Stelle, an der später (in der Imago) das Stigma zum Durchbruch kommt, zu dem Tracheenlängsstrang zieht, und der dem vom Stigma ausgehenden Tracheenstamm entspricht. 
Die Stigmenredultion betrifft übrigens durchaus nicht alle im Wasser lebende Insektenformen; so haben die Imagines der Wasserinsekten meist die volle Stigmenzahl. Natürlich müssen diese zum Luft holen stets an die Oberfläche heraufkommen; doch haben sich vielfach Vorrichtungen herausgebildct, die ein längeres Verbleiben im Wasser ermöglichen; der Kolbenwasserkäfer nimmt einen größeren Luftvorrat in seinem die Bauchseite bedeckenden Haarkleid mit; der Gelbrandkäfer (Dytiscus) saugt so reichliche Luft in den unter den gewölbten Flügeldecken gelegenen Hohlraum ein, daß er ca. 8 Minuten unter Wasser bleiben kann, usw.

Die Bewegung der Luft in den Tracheen wird durch abwechselnde Zusammenziehung und Erweiterung des Körpers, vor allem des Hinterleibes bewirkt (Atembewegung). Das Zusammenziehen geschieht durch Muskeltätigkeit, während die Ausdehnung größtenteils auf der Elastizität des Chitinskeletts beruht. Die Erweiterung des Körpers hat natürlich auch eine Erweiterung der Tracheen zur Folge und diese bewirkt ein Einströmen von Luft (Einatmung). Die Verengerung kann eine zweifache Wirkung haben: bei geschlossenem Verschlußapparat wird die Luft aus den Hauptstämmen weiter in den Körper hineingepreßt bis in die feinsten Gefäße; bei offenem Verschlußapparat dagegen wird die Luft nach außen geschafft (A usatmung). Die Zahl der Atembewegungen wechselt je nach der Art des Insekts und den jeweiligen Lebensbetätigungen. Der Hirschkäfer und Wolfmilchschwärmer z. B. machen ca. 20-25, eine Libelle 30-35, das große grüne Heupferd (Locusta) 50-55 Ein- und Ausatmungen in der Minute. Bei den fliegenden Insekten kann man oft eine Vermehrung der Atembewegungen vor dem Abfliegen bemerken (die z. B. beim Maikäfer als "Zählen“ bekannt ist), was zweifellos mit der Füllung der oben erwähnten Luftsäcke (Einnahme von Sauerstoffvorrat für die Luftreise) zusammenhängt.

Das Sauerstoffbedürfnis der Insekten ist vielfach ein sehr großes, was in Anbetracht der regen Lebenstätigkeit nicht zu verwundern ist. Es übertrifft zweifellos das aller anderen Wirbellosen und auch der Fische und kommt wohl dem der Amphibien mindestens gleich. Ja, es soll sogar der Sauerstoffverbrauch des Maikäfers etwa dem des Hundes gleich sein (natürlich relativ!) und der des fleischfressenden Schwimmkäfers oder gar der Bienen noch weit größer.

Das Atembedürfnis der Bienen scheint besonders groß zu sein, worüber $\mathrm{Z}$ ander (nach $\mathrm{P}$ arhon) folgende Zahlen angibt: Bei $20^{\circ}$ C. verbraucht pro $1 \mathrm{~kg}$ Körpergewicht in jeder Stunde:

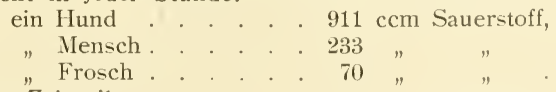

In derselben Zeit gibt ein Hund . . . $674 \mathrm{ccm}$ Kohlensäure,

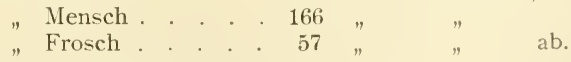

Dagegen bedarf $1 \mathrm{~kg}$ Bienen bei $20^{\circ} \mathrm{C}$.

im Frühling . . . . $29774 \mathrm{ccm}$ Sauerstoff,

"Sommer . . . . . 17336

"Herbst. . . . . 24795" "

"Winter. . . . $22549 ", "$

und gibt auch annähernd die gleichen Mengen Kohlensäure ab. 
Die Bienen veratmen also (je nach der Jahreszeit) $20-250$ mal mehr Sauerstoff und Kohlensäure als die genannten Tiere.

Solche Vergleiche sind allerdings, worauf $\mathrm{H}$ esse hinweist, nicht allzu wörtlich zu nehmen; im allgemeinen haben bei gleicher Lebhaftigkeit kleinere Tiere einen regeren Stoffwechsel als größere und es sollten daher nur Tiere von gleicher Größe verglichen werden. „Immerhin läßt sich aus jenen Angaben entnehmen, daß die Atmung der Insekten eine relativ sehr intensive ist."

Hautatmung (Tracheen- und Blutkiemen).

Die oben beschriebenen Anpassungen der Stigmenatmung an das Wasserleben sind alle mehr oder weniger unvollkommen, indem die betreffenden Tiere zum Luftholen stets an die Oberfläche sich begeben und wenigstens in der Nähe der Oberfläche sich aufhalten müssen. Von einer vollkommenen Anpassung können wir erst da reden, wo die Tiere in den Stand gesetzt sind, den Sauerstoff dem Wasser selbst zu entnehmen, wie es

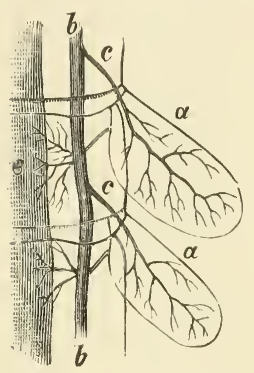

Fig. 70. Tracheenkiemen der Larve von Baetis binoculatus $L$. nach Palmén. a Kiemenblätter; $b$ Tracheenlängsstamm; $c$ Stämme, welche die Kiemenblätter versorgen; $e$ Darm (N.) die Krebse, Fische und Amphibienlarven usw. mit ihren Blutkiemen zu tun vermögen.

Bei zahlreichen wasserlebenden Insektenlarven sind derartige Einrichtungen vorhanden, und zwar in den sog. "Tracheenkiemen" (auch Pseudobranchien genannt). Dieselben stimmen mit den echten Kiemen darin überein, daß es sich um sehr zartwandige Hautausstülpungen handelt, unterscheiden sich aber von jenen dadurch wesentlich, daß sie an Stelle des Blutkapillarnetzes (welches die echten Kiemen auszeichnet) ein Tracheenkapillarnetz in sich bergen (Fig. 70). Der Sauerstoff, der auf osmotischem Wege die Haut der Kiemen passiert, gelangt also direkt in die Luftgefäße und von da zu den Geweben; ebenso tritt die Kohlensäure direkt aus den Tracheenkapillaren durch die Kiemenhaut nach außen. Die Stigmen fehlen in allen diesen Fällen, so daß das Tracheensystem also vollkommen geschlossen ist.

Die Tracheenkiemen sind sehr verbreitet und kommen den Larven der Ephemeriden (Eintagsfliegen), Libellen, Perliden, Trichopteren (Köcherfliegen) zu; ferner auch einigen Schmetterlingsraupen (Paraponix), Käferlarven (Gyrinus, Hydrochares, Pelobius, Hydrobius usw.), Fliegenlarven usw.

Auch bei den Imagines finden sich zuweilen Tracheenkiemen (z. B. bei Perla); doch gehören diese Fälle zu den Ausnahmen.

Die Form und Lage der Tracheenkiemen ist ungemein wechselnd (Fig. 71): bald treten sie uns in Form von runden und lanzettförmigen Blättchen mit einfachen oder gefiederten Rändern, und bald in Form von schlauchförmigen Anhängen, einfachen und verästelten und gegliederten, einzelnstehend oder zu Büscheln vereinigt, entgegen. Bald sitzen sie paarweise an den ersten 6- 7 Hinterleibssegmenten, an der Seite oder am Rücken und am Bauch, bald an der Brust, an der Basis der Extremitäten usw. Bei manchen Libellenlarven (Agrion) erscheinen sie als drei lange Anhänge am letzten Hinterleibsring; bei anderen (Libellula, Aeschma) sind die Tracheenkiemen in den End- 
darm verlagert, wo sie in dessen Lumen als Hautfalten (4-12) hineinragen (wahrscheinlich aus den „Rektaldrüsen" hervorgegangen).

Wie bei den Blutkiemen, so ist auch bei den Tracheenkiemen eine ständige Erneuerung des Atemwassers notwendig. Diese geschieht entweder durch die Fortbewegung des betr. Tieres, oder dadurch, daß sie durch Teilbewegungen des Körpers, die vielfach in Bewegungen der Tracheenkiemen selbst bestehen, einen Wasserstrom erzeugen. Die Libellenlarven mit rektalen Tracheenkiemen versorgen die letzteren in der Weise mit neuem WVasser, daß sie von Zeit zu Zeit Wasser in den Enddarm einsaugen und es wieder ausstoßen, was so heftig geschehen kann, daß sie durch den Rückstoß nach vorne getrieben werden.

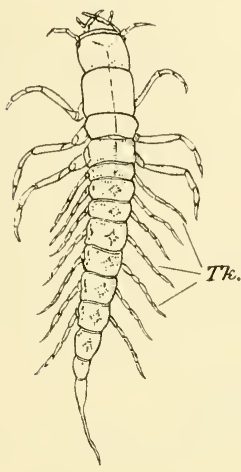

A

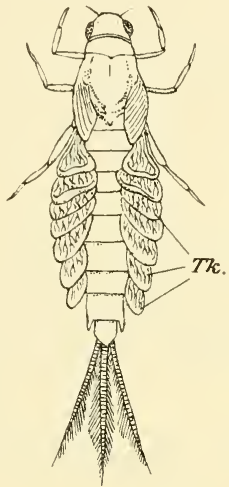

$B$

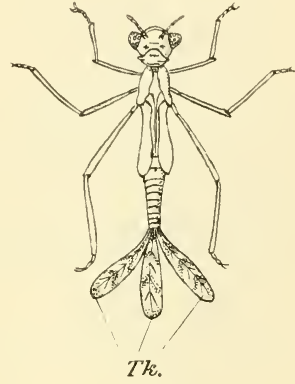

$C$

Fig. 71. Verschiedene Formen von Tracheenkiemen. A Sialiden-Larve; $B$ Ephemeriden-Larve; $C$ Libellenlarve. $T k$ Tracheenkiemen. (Nach Berlese).

Außer der Atmung durch Stigmen und Tracheenkiemen kommen auch noch andere Atmungsarten bei Insekten vor. So besitzen einige Mückenlarven (Chironomus) richtige $\mathrm{Blutk}$ i e me $\mathrm{n}$, d. h. Hautausstülpungen, die mit Blut gefüllt sind. Über die Atmung der parasitisch lebenden Larven sind wir noch nicht überall genügend unterrichtet; R a t z e bu r g hält die Endblase, die man bei vielen parasitischen Hymenopteren findet, für ein Atmungsorgan. Eingehendere Untersuchungen in dieser Richtung wären sehr wünschenswert.

\section{Die Kreislauforgane.}

Die Kreislauforgane der Insekten bestehen in der Hauptsache aus einem propulsatorischen Apparat (Herz), welcher für die Bewegung der Blutflüssigkeit sorgt. Derselbe stellt einen Schlauch dar, welcher den Körper von hinten nach vorne dicht unter der Rückendecke durchzieht und deshalb auch als Rückengefäß bezeichnet wird. Sein hinteres Ende, das meist im vorletzten Segment liegt, ist stets geschlossen, sein vorderes, in die Brust- oder Kopfregion reichendes Ende dagegen mündet offen in die Leibeshöhle (Fig. 72). 
Meist lassen sich zwei Abschnitte an dem Rückengefäß unterscheiden, von denen der hintere breitere und deutlich segmentierte das eigentliche Herz darstellt, während der vordere schmälere und unsegmentierte als aus-

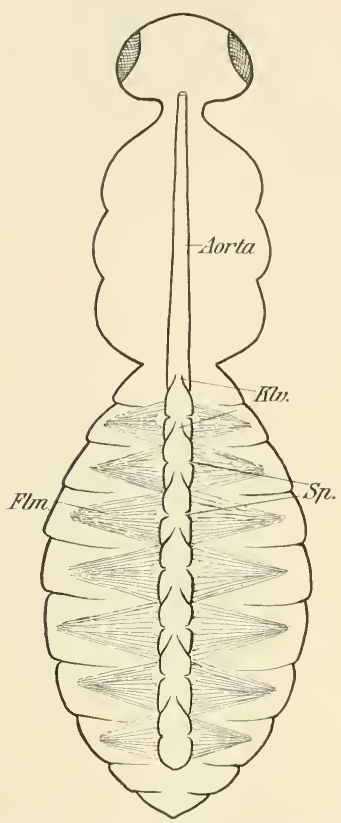

Fig. 72. Schematische Darstellung des Rückengefäßes. Hintere Hälfte das eigentliche Herz (propulsatorischer Apparat), vordere Hälfte die Aorta. Das Herz ist in eine Anzahl Kammern eingeteilt, die durch Klappenventile $(K l v)$ miteinander in Verbindung stehen. Jede Kammer ist mit einer Spaltöffnung (Sp) versehen, durch die das Blut in das Herz zurückfließt. Unter dem Herzschlauch das ans den Flïgelmuskeln $(\mathrm{Flm})$ bestehende Septum.

Unter Anlehnung an eine Figur $\mathrm{Z}$ anders. leitendes Gefäß funktioniert und daher auch als Aorta bezeichnet wird. Letztere ist verschieden lang, manchmal viel länger als das Herz, mehrere Windungen und Schlingen bildend (z. B. bei der Biene), manchmal aber auch kürzer und dann gerade verlaufend.

Der hintere Abschnitt (das eigentliche Herz) ist in eine Anzahl (bis 9) Kammern eingeteilt, die durch Klappenventile miteinander in Verbindung stehen. Außerdem ist jede Kammer mit einem Paar Spaltöffnungen versehen, die seitlich gelegen und ebenfalls mit nach innen vorspringenden Klappen versehen sind. Die zarten Wandungen des Herzschlauches enthalten eine aus glatten Muskeln bestehende Ringsmuskulatur, durch deren Kontraktion der Schlauch zusammengedrückt wird. Außerdem gehen vom Herzschlauch zu den benachbarten Geweben, vor allem zu

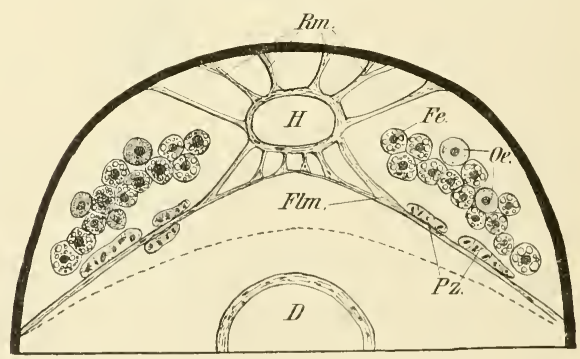

Fig. 73. Querschnitt durch das Rückengefäß einer Ameise. $H$ Herz; $R m$ radiäre Muskeln (Dilatatoren); $F e$ Fettzellen; Oe Oenocyten; $P z$ Pericardialzellen; Flm Flügelmuskel; $D$ Darm. Die punktierte Linie unter den Flügelmuskeln zeigt die Lage des Septums bei kontrahierten Muskeln an. Nach J anet aus Wheeler.

dem darunter liegenden Zwerchfell und zu der Rückendecke noch einzelne radiäre Muskelfasern, welche den Herzschlauch in seiner Lage erhalten und außerdem als Dilatatoren wirken (Fig. $73, R m$ ).

Der so gestaltete Herzschlauch allein genügt aber nicht, das Blut durch die ganze Leibeshöhle zu drücken und dann von da auch wieder anzusaugen. Dazu sind noch Hilfsapparate notwendig, von denen das dorsale $Z$ werch- 
fell die Hauptrolle spielt. Es ist dies ein Septum, welches, von den Seiten der Rückenplatten ausgehend, dicht unter dem Herzschlauch ausgespannt ist, und so einen schmalen Rückenraum, in welchem das Herz liegt, von der übrigen Leibeshöhle abtrennt. Mit dem Herzschlauch selbst ist es, wie eben erwähnt, nur lose durch feine Radiärfasern verbunden. Das Septum besteht in der Hauptsache aus fächerförmig von außen nach innen sich verbreiternden Muskeln, welche „Flügeln gleichen, die am Herzschlauch hängen“ und deshalb auch als „Flügelmuskel" bezeichnet werden. In ihnen befinden sich eine Anzahl Spalten, die mit den Spaltöffnungen des Herzschlauches ungefähr korrespondieren. Im Ruhezustand der Flügelmuskeln ist das Zwerchfell stark dorsalwärts gekrümmit und infolgedessen der Rückenraum beträchtlich eingeengt. Bei der Kontraktion der Muskeln dagegen wird es herab (ventralwärts) gezogen, wodurch der Rückenraum und zugleich auch der Herzschlauch erweitert und der darunter gelegene Teil der Leibeshöhle verengert wird (Fig. 73); was zur Folge hat, dass die hier befindliche Flüssigkeit nach dem Rücken gepreßt wird. Außer dem dorsalen Zwerchfell existiert noch ein ventrales $Z$ werchfell, welches, von den Seiten der Bauchplatten aus-

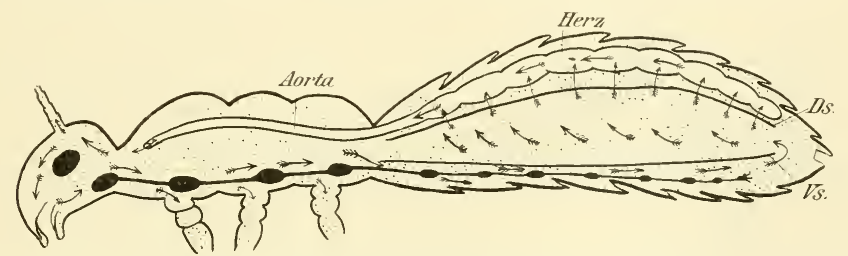

Fig. 74. Schematische Darstellung des Blutkreislaufes eines Jnsekts. Vs ventrales, Ds dorsales Septum. (Unter Anlehuung an $\mathrm{Z}$ ander.)

gehend, über das Bauchmark hinweg durch die Leibeshöhle zieht, und einen ventralen Raum, in dem das Bauchmark liegt (Ventralsinus), von dem darüber gelegenen Teil der Leibeshöhle abtrennt.

Wenn wir nun den aus dem Zusammenwirken dieser Organe resultierenden Blutkreislauf verfolgen wollen, so beginnen wir am besten mit der Systole (Kontraktion) des Herzens (Fig. 74). Diese betrifft nicht gleichzeitig den ganzen Herzschlauch, sondern beginnt an der letzten Kammer und schreitet von da von einer Kammer zur anderen nach vorne zu fort, und preßt so das im Herzschlauch befindliche Blut nach vorne, zunächst in die Aorta und von da in die Leibeshöhle. Ein Rückfließen des Blutes von einer vorderen Kammer in eine hintere wird durch die Kammerventile verhindert, ebenso wie die Klappen der seitlichen Spaltöffnungen, die sich durch den Flüssigkeitsdruck schließen, ein Entweichen der Flüssigkeit nach der Seite unmöglich machen. Das aus der Aorta herausgedrückte Blut gelangt zunächst in den Kopf und seine Extremitäten, dann in die Brust, um von da aber nicht gleich in den Hauptraum der Hinterleibshöhle zu strömen, sondern zuerst unter dem ventralen $Z$ werchfell, das Bauchmark umspülend, nach hinten zu fliessen und erst dann in die Bauchhöhle zu treten. Nachdem es hier den Darm, die 
Malpighischen Gefäße, die Geschlechtsorgane umspült, wird es durch den Druck des dorsalen Zwerchfelles nach dem Rücken gepreßt, gelangt durch die Spalten jenes in den Rückenraum, und wird von da in den gleichzeitig erweiterten Herzschlauch (durch die seitlichen Spaltöffnungen) eingesaugt. So wechseln also Kontraktion des Herzens (Systole) einerseits, Kontraktion der Flügelmuskeln und Erweiterung des Herzens (Diastole) andererseits in rhytmischer Weise miteinander ab.

Die Zahl der Herzschläge ist sehr verschieden, je nach der Lebhaftigkeit der Art und nach der jeweiligen Tätigkeit. Ein ruhender Schwärmer z. B. hat 40-50 Schläge in der Minute, unmittelbar nach dem Fluge dagegen bis 140. Nach $\mathrm{N}$ ew port zeigen auch die verschiedenen Entwicklungsstadien große Unterschiede, so zählte er im ersten Raupenstadium von Sphınx ligustri 82 Schläge pro Minute, im zweiten 89 , im dritten 63 , im vierten 45 , im letzten nur 39 , und bei der Puppe gar nur 29. Im Winterschlaf ist natürlich die Herztätigkeit noch weit mehr herabgesetzt.

Das Blut der Insekten ist meist eine farblose oder schwach gelbliche, grünliche oder bräunliche Flüssigkeit, in der mehr oder weniger zahlreiche Zellen (Blutkörperchen) schwimmen. Letztere treten im Gegensatz zu den Blut-

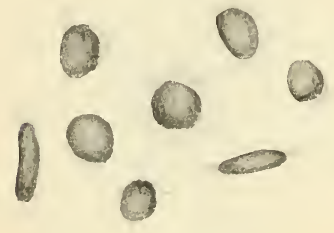

Fig. 75. Blutkörperchen aus dem Blut der Nonnenraupe. körperchen der höheren Tiere nur in einer Form auf, welche mit einem großen Kern ausgestattet und amoeboid beweglich sind und somit etwa den weißen Blutkörperchen der höheren Tiere entsprechen (Fig. 75).

Ste che stellte neuerdings fest, daß die F a r be des Blutes in den beiden Geschlechtern gelegentlich verschieden ist, was vor allem bei den Raupen der Schmetterlinge in Erscheinung tritt. Bei den meisten der untersuchten Raupen erschien die Blutflüssigkeit im männlichen Geschlecht wasserklar und farblos, im weiblichen dagegen von leuchtend grüner Farbe. Letztere rührt, wie die chemische Untersuchung lehrte, von Chlorophyllderivaten her; es liegt deshalb der Schluß nahe, daß im weiblichen Organismus das Chlorophyll in wenig modifizierter Form in die Blutbahnen gelangt, während es beim Männchen abgebaut wird. Und das deutet darauf hin, daß die Darmzellen im weiblichen Geschlecht anders organisiert sind als im männlichen, indem jene das Chlorophyll in ziemlich unveränderter Form durchgehen lassen, diese aber nicht. Das heißt aber nichts geringeres, als daB bei den Insekten nichtnurdie Sexualorgane, sondern alle Körperzellen von vornherein sexuell differenziert sind.

Die abweichende Beschaffenheit des Insektenblutes von dem der höheren Tiere erklärt sich ohne weiteres daraus, daß beim Insektenblut die respiratorische Funktion (Transport von Sauerstoff und Kohlensäure) in Wegfall kommt, da ja, wie wir oben gehört haben, bei den Insekten der Sauerstoff durch die Luftröhren direkt zu den Geweben hingebracht wird. Und so bleiben also für das Insektenblut nur die zwei anderen Aufgaben des Wirbeltierblutes übrig, nämlich:

1. die verdauten Nahrungsstoffe vom Darm aufzunehmen und sie den Geweben zuzuführen, und 
2. die unbrauchbaren Stoffwechselprodukte nach außen zu schaffen, resp. den Exkretionsorganen (Malpighischen Gefäßen) zuzubringen und so den Körper von diesen Schlacken zu reinigen.

\section{Temperatur der Insekten.}

Über die Eigenwärme der Insekten hatten die früheren Untersuchungen vielfach widersprechende Resultate ergeben, welche wohl zumeist auf die Mangelhaftigkeit der Untersuchungsmethoden zurückgeführt werden müssen. Erst durch Bachmetjews im letzten Jahrzehnt angestellte Untersuchungen sind uns einwandfreie Daten geliefert worden.

B a chmetjew wandte, um möglichst genaue Werte zu erhalten, die in der Physiologie schon länger gebräuchlichen thermoelektrischen Temperaturmessungen an. Es wurde eine thermoelektrische Nadel aus Stahl und Manganin in den Thorax des zu untersuchenden Insektes unter Beobachtung gewisser Vorsichtsmaßregeln eingestochen. Die zweite Lötstelle befindet sich in einem Paraffinbad, dessen Temperatur gemessen wird. Die Ableitung erfolgt zu einem $1 \mathrm{~V}$ i e dem a n n schen Galvanometer, dessen Empfindlichkeit noch $0,001^{\circ} \mathrm{zu}$ messen gestattet.

Nach Bachmetjews Untersuchungen variiert die Temperatur der Insekten innerhalb sehr weiter Grenzen, ohne scheinbar schädliche Folgen für das Leben nach sich zu ziehen. Die Eigentemperatur der in Ruhe befindlichen Insekten ist gleich der Temperatur der umgebenden Luft oder nur ganz unbedeutend höher. Es sind demnach die Insekten den „wechselwarmen“ oder "poikilothermen" Organismen zuzuzählen.

Die Anpassung der Eigentemperatur an die der umgebenden Luft erfolgt aber nur innerhalb gewisser Grenzen und wird sehr wesentlich von äußeren Faktoren, vor allem Feuchtigkeit, beeinfluBt. Versuche an Deilephila euphorbiae bei gewöhnlicher Luftfeuchtigkeit ergaben, daß die Temperatur des Schmetterlings mit der Zunahme der Luftemperatur zuerst immer mehr und mehr hinter der letzteren zurückbleibt und kurz vor der partiellen Lähmung der Flügelmuskel (siehe unten) der Lufttemperatur sich wieder zu nähern beginnt. Beim Tode sind die Temperaturen der Luft und des Schmetterlings einander gleich.

Ist die umgebende Luft sehr feucht, dann besitzt der Schmetterling immer eine höhere Temperatur als die umgebende Luft, wobei mit der Steigerung der Lufttemperatur die Differenz zunimmt. Daraus geht hervor, daß die Eigentemperatur des Schmetterlings von der Luftfeuchtigkeit genau so beeinflußt wird wie die der Warmblüter. Andererseits zeigte sich bei niedriger Luftfeuchtigkeit die Temperatur der Insekten geringer als die der umgebenden Luft, was zweifellos mit der raschen Verdunstung der Körpersäfte zusammenhängt, wobei die durch die Tracheen zirkulierende Luft sich rasch mit dem Wasserdampf beladet und schnell entführt wird, während minder gesättigte immer wieder an ihre Stelle tritt.

Nicht minder wichtig für die Höhe der Eigentemperatur der Insekten ist die Körperbewegung, indem die Temperatur bei intensiver Muskeltätigkeit steigt und mit dem Aufhören der Muskelarbeit sofort wieder fällt. Genauere Untersuchungen über den Einfluß der Körperbewegung stellte Bachmetjew 
an Sphinx pinastri an mit dem Ergebnis, daß der Schmetterling durch Summen (sehr schnelle Flügelschläge) seine Eigentemperatur wesentlich erhöht (um $10^{\circ}$ und mehr), wogegen durch bloßes Flattern keine Temperaturerhöhung eintrat. Wenn eine gewisse Erhöhung der Eigentemperatur eingetreten war $\left(36^{\circ}\right)$, hörte der Schmetterling sofort mit dem Summen auf und vertauschte es mit Flattern, oder verfiel auch gar in Ruhe, was nach Bachmetjews auf eine plötzliche Verminderung der Muskelkraft unter dem Einfluß der Temperatursteigerung („partielle Muskelparalysation“) hinweist. Bemerkenswert ist auch die Beobachtung, daß der Schmetterling bei einer desto höheren Temperatur zu summen aufhört, je höher die Temperatur der umgebenden Luft ist; so brachte z. B. Deilephila elpenor seine Eigentemperatur durch Summen bei einer Luftemperatur von $19,2^{\circ}$ auf $34,8^{\circ}$, bei einer Lufttemperatur von $28,5^{\circ}$ auf $37,0^{\circ}$ und bei einer Lufttemperatur von $29-34^{\circ}$ gar bis auf $42,1^{\circ}$. Es finden also zweifellos Anpassungen an die höheren Temperaturen statt.

Von großem Einfluß auf den Eintritt der Muskelparalysation (Wärmestarre) ist auch der Feuchtigkeitsgehalt der Luft, und zwar in der Weise, daß die Lähmung um so eher eintritt, je trockener die Luft ist. Dies erklärt sich ohne weiteres daraus, daß trockene Luft eine starke Verdunstung bewirkt, wodurch wiederum der Wasserreichtum der Gewebe abnimmt.

Über die optimale Temperatur sind noch wenig genaue Angaben vorhanden, doch scheint daraus hervorzugehen, daß das Optimum sowohl für die Bewegung des Protoplasmas in den Zellen als auch für die vitalen Funktionen der Insekten bei ca. $26^{0}$ liegt.

Wenn wir uns vom Temperaturoptimum entfernen, sowohl nach oben als nach unten (oder auf der nebenstehenden Kurve nach rechts oder links), so tritt nach gewissen Temperaturen (über- resp. unteroptimale Zone) zunächst eine vorübergehende Wärme-resp. Kältestarre ein, die bei noch höheren resp. tieferen Temperaturen in die permanente Wärme-oder Kältestarre übergeht, wobei der Tod der Insekten stattfindet.

Wärmestarre, Wärmetod. - Die vorübergehende Wärmestarre tritt je nach den äußeren Umständen bei recht verschiedenen Temperaturen ein; schwankte sie doch in dem oben mitgeteilten Beispiel von Deilephila elpenor zwischen $28,8^{\circ}$ und $42,1^{\circ}$, je nachdem die Lufttemperatur $19^{\circ}$ oder $30^{\circ}$ betrug. Die permanente Wärmestarre scheint im allgemeinen bei $46^{\circ} \mathrm{zu}$ liegen. Doch wurden bei manchen Insekten weit niedrigere Temperaturen beobachtet, so bei Phyllopertha horticola ca. $43^{\circ}$, bei Dytiscus marginalis ca. $40^{\circ}$, bei Blatta orientalis gar nur $33^{\circ}$. Andererseits gibt es auch Insekten, welche wesentlich höhere Temperaturen ertragen können; so wurde für Ameisen $49^{n}$ und für Schildläuse nicht weniger als $54^{0}-55^{0}$ als oberste Temperaturgrenze festgestellt. Übrigens hängt das vitale Temperaturmaximum sehr viel von der Zeit ab, während welcher das betreffende Insekt die hohen Temperaturen auszuhalten hat. So blieben bei den Versuchen von Reh die Schildläuse bei einer Temperatur von $54^{0}$ noch 40 Minuten am Leben, während sie bei $55^{0}$ schon nach 22 Minuten abstarben. 
Außerdem spielen bei der Einwirkung erhöhter Temperaturen noch folgende Faktoren eine nicht zu unterschätzende Rolle:

a) Der Stoffwechsel: Ist die Temperatur der Luft erhöht, so steigt die Pulsation und die Atmung des Insektes, folglich verbraucht es von seinem Körper mehr Material, welches in Form von Kohlensäure und Wasser entweicht, als bei gewöhnlicher Temperatur. Das Insekt stirbt in diesem Falle nicht infolge der erhöhten Temperatur, sondern an Erschöpfung, besonders wenn es keine Nahrung einnimmt.

b) Die Feuchtigkeit: Ist die Luftfeuchtigkeit gering, oder die Luft gar trocken, so verdampft das Wasser der Insektensäfte viel stärker als sonst, und das Insekt stirbt wiederum nicht direkt wegen der erhöhten Temperatur, sondern infolge der Austrocknung.

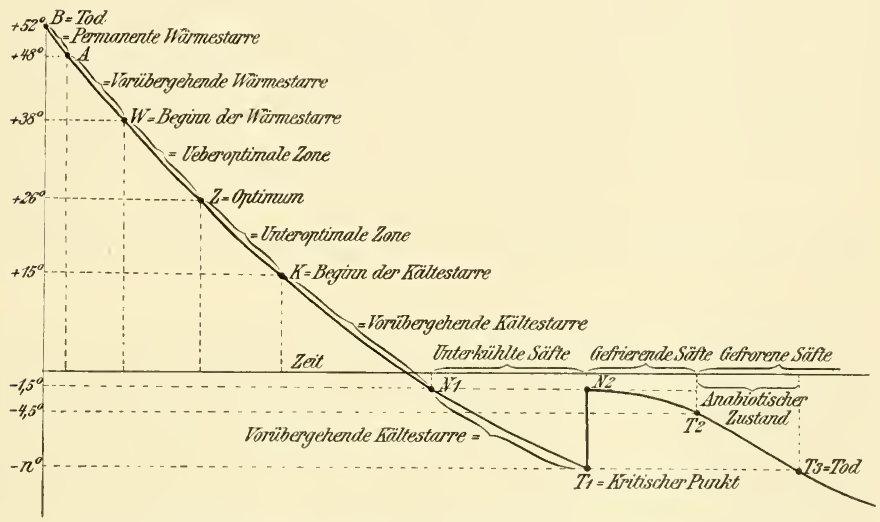

Verhalten der Insekten gegen hohe und niedere Temperaturen (nach Bachmetjew).

c) Die Wärmeleitungsfähigkeit des Insektenkörpers: Kleine Differenzen an der Behaarung, an der Beschaffenheit der Oberfläche usw. des Insektes einer und derselben Spezies können offenbar auf die Größe des vitalen Temperaturmaximums einen gewissen Einfluß haben. Die Folge davon wird sein, daß unter sonst gleichen Umständen ein Exemplar derselben Spezies stirbt und ein anderes noch am Leben bleibt.

d) Die Größe: Dieselbe Rolle wie unter c.

e) Der Säftekoeffizient: Unter sonst gleichen Umständen wird dasjenige Exemplar einer Spezies früher sterben, welches mehr Wasser in seinen Säften enthält, d. h. bei welchem die Säfte wässeriger sind. Denn das Eiweiß gerinnt bei um so höheren Temperaturgraden, je wasserärmer es ist; somit ist die Gerinnungsfähigkeit der Insektensäfte, welche ja Eiweiß enthalten, von ihrem Wassergehalte abhängig.

Zieht man alle diese Umstände in Betracht, so stellt sich heraus, daf, wenn bei erhöhten Temperaturen das Insekt 1. nicht erschöpft wäre, d. h. 
künstlich gefüttert wäre, 2. nicht austrocknete, d. h. in entsprechender feuchter Luft sich befinden würde, 3. gleiche Wärmeleitungsfähigkeit und gleiche Größe seines Körpers für eine gegebene Spezies hätte, sein Leben nur davon abhängen würde, ob seine Säfte resp. das Eiweiß des Körpers bei der gegebenen Temperatur gerinnen würden oder nicht. Dann würde das vitale Temperaturmaximum nichts anderes ausdrücken, als daß bei dieser Temperatur seine Säfte gerinnen.

Kältestarre, Kältetod. - Während der Weg zum Wärmetod, wie wir eben gesehen, in einfacher Linie vom Optimum aus verläuft, zeigt der Weg zum Kältetod einige sehr interessante Komplikationen, die wir am besten an der Hand der beigegebenen Kurve verfolgen wollen: Bei einer Abkühlung gelangen wir von der optimalen Temperatur aus zunächst durch die unteroptimale Zone zu Punkt K, bei dem die vorübergehende Kältestarre beginnt. Die Lage dieses Punktes ist ungemein verschieden: bei gewissen Arten (z. B. Tagfaltern) setzt die vorübergehende Kältestarre schon bei $+15^{0}$ ein, während sie bei anderen erst bei viel tieferen Temperaturen, sogar weit unter $0^{0}$ beginnt. So beobachtete Reh die reifen Fonscolombia fraxini Kalt. bei $-2,5^{0}$ bis $-3,7^{0}$ auf der Suche nach Weibchen; und nach GrumGrschimajlo führen die Mücken in der Mongolei noch bei $-8^{0}$ ein aktives Leben. Lichtenstein beobachtete bei $-7^{0}$ das Kopulieren der Aphis brassicae und Mordwilko fand die erwachten Wurzelläuse Pemphigus coerulescens bei $-3^{\circ}$.

Die letzteren Angaben deuten bereits darauf hin, daß die Insektensäfte unterkühlt werden können, ohne zu frieren, was durch Bachmetjews eingehende thermoelektrische Messungen zur Gewißheit erhoben wurde, und was zweifellos zu den interessantesten Erscheinungen der Biologie gehört. Der Grad der möglichen Unterkühlung hängt wesentlich von der Abkühlungs geschwindigkeit ab; außerdem weichen auch die verschiedenen Arten in dieser Beziehung noch mehr oder weniger stark roneinander ab.

Ist nun der tiefste Punkt der Unterkühlung, der „kritische Punkt“, erreicht, so macht die Temperatur plötzlich einen gewaltigen Sprung bis zum Punkt $N_{2}\left(-1,5^{0}\right)$, wobei nun die Säfte zu erstarren (gefrieren) beginnen. Unter weiterer Abkühlung schreitet das Gefrieren der Säfte fort, bis zu dem Punkt $T_{2}$ (normaler Erstarrungspunkt), bei dem alle Säfte gefroren sind, und bei dem der sog. "anabiotische Zustand" beginnt. Wird ein in diesem Zustand befindliches, also völlig erstarrtes, hart gefrorenes Insekt erwärmt, so lebt es von neuem wieder auf. Somit bedeutet also das Gefrieren der Säfte eines Insektes an und für sich noch lange nicht dessen Tod. Dieser tritt vielmehr erst dann ein, wenn das gefrorene Insekt bis ungefähr auf seinen kritischen Punkt $T_{3}$ abgekühlt wird. Dann tritt die permanente Kältestarre ein, die zum Tode führt.

Die Temperatur der permanenten Kältestarre ist sehr verschieden und liegt nach Bachmetjew bei Larven zwischen $-4^{0}$ und $-42^{\circ}$, bei Puppen zwischen $-4^{0}$ und $-25^{\circ}$, und bei Imagines zwischen $-1,5^{\circ}$ und $-35^{\circ}$. Wir können also sagen, daß, je höher das Entwicklungsstadium des Insekts 
ist, um so weniger tief die Temperatur der permanenten Kältestarre für dasselbe liegt.

„Die Anabiose, die vor dem Eintritt der permanenten Kältestarre gelegen ist, stellt einen Zustand des Insektes dar, in welchem es keinen Stoffwechsel haben kann, denn seine Säfte sind erstarrt, wodurch die Blutzirkulation unmöglich wird. Ein Insekt ohne Stoffwechsel kann nicht als lebend betrachtet werden; es ist aber auch nicht gestorben, da es den Punkt $T_{3}$ noch nicht erreichte. Es befindet sich folglich zwischen $T_{2}$ und $T_{3}$ in leblosem (anabiotischem) Zustande.“

„Dieser Zustand ist nicht ein lethargischer; denn bei der Lethargie geht der Stoffwechsel, wenn auch sehr langsam, dennoch vor sich, bis das Insekt schließlich an Erschöpfung stirbt. Dieser Zustand kann vielmehr mit einer Pendeluhr verglichen werden, bei welcher das Pendel absichtlich zum Stillstehen gebracht wurde. Die Uhr ist dabei nicht verdorben, geht aber nicht. Ein Stoß auf das Pendel und die Uhr ist wieder intakt. Wie die Uhr mit stillstehendem Pendel unbegrenzt lange Zeit unverdorben bleiben kann, so kann vermutlich auch das Insekt im anabiotischen Zustande beliebig lange Zeit verbleiben, ohne dabei zu sterben" (Bachmetjew), vorausgesetzt natürlich, daß keine Verdunstung stattfindet.

\section{Fettkörper einschl. Oenocyten, Pericardialzellen und Leuchtorgane.}

\section{Fettkörper usw.}

Wenn wir eine Larve (z. B. eine Fliegenmade) öffnen, so tritt uns zuerst eine weißliche Masse entgegen, die den größten Teil der Leibeshöhle ausfüllt und alle Organe umgibt. Es ist dies der sog. Fettkörper, der aus zahlreichen Fettzellen zusammengesetzt ist, und der in den verschiedensten Formen, als Schollen, Lappen, dünne Platten oder lange Bänder auftreten kann. Am reichlichsten ist er bei den Larven ausgebildet, bei denen er gewöhnlich den größten Teil der Leibeshöhle einnimmt. Während der Puppenzeit dagegen erfährt er eine starke Reduktion, so daß nur ein kleiner Teil der enormen larvalen Fettmassen in das Imagostadium übergeht.

Die Fettzellen sind meist ziemlich große, mit einem ansehnlichen runden Kern ausgestattete Zellen, die vor allem daran kenntlich sind, daß ihr Plasma mehr oder weniger dicht mit Fettkügelchen von verschiedenem Durchmesser angefüllt ist. Je zahlreicher die Fettkugeln werden, desto mehr wird das Plasma verdrängt und desto größer wird der Umfang der Zelle.

Was die Funktion des Fettkörpers betrift,. so stellt er zweifellos in erster Linie Reservematerial für die Ernährung dar. Alle jene Nährstoffe, die bei der Versorgung der Organe übergeblieben sind, werden im Fettkörper abgelagert, um später, wenn die Nahrungszufuhr von außen geringer wird oder ganz unterbleibt, zur Ernährung herangezogen zu werden. (Daraus erklärt sich auch die starke Abnahme des Fettkörpers während der Puppenruhe.)

Damit scheint aber die Aufgabe des Fettkörpers nicht erschöpft zu sein. $\mathrm{Da}$ in ihm bisweilen harnsaure Salze gefunden werden, so hat man ihm auch eine exkretorische Funktion zugeschrieben. Und manche Autoren wollen in der reich- 
lichen Durchsetzung des Fettkörpers mit feinsten Tracheenästen auch Anzeichen für eine respiratorische Funktion erblicken.

In dem Fettkörper liegen vereinzelte differente Zellen zerstreut, die durch ihr gleichmäßiges Plasma (Fig. 73, Oe) und vor allem durch ihre weingelbe Färbung auffallen, und daran ohne weiteres von den Fettzellen zu unterscheiden sind. Man bezeichnet dieselben ihrer Färbung halber als Oenocyten. Die weingelbe Färbung rührt von gelben Körnchen her, die mit der Zeit im Plasma sich ansammeln, und wahrscheinlich Abscheidungsprodukte aus dem Blut darstellen. Daher findet man diese Körnchen bei alten Tieren meist viel zahlreicher als bei jungen. So fehlen sie z. B. bei jungen Bienen, nach Zander, noch vollständig; bei alten Königinnen dagegen sollen sie massenhaft vorhanden sein.

Über die Funktion der Oenocyten ist man noch nicht ganz klar. Während die einen Autoren sie für ausfuhılose Drüsen halten mit einer physiologisch vielleicht wichtigen inneren Sekretion, sehen die anderen in ihnen „Harnorgane ohne Ausführgang, deren Inhalt erst nach dem Tode des betr. Insektes frei wird" (Zander).

Eine ähnliche Unklarheit bezügl. der Funktion herrscht über die zweite der oben genannten Zellkategorien, die Perikardialzellen, das sind Zellen mit feinkörnigem Plasma, die wesentlich kleiner sind als die Oenocyten und die meist in größeren oder kleineren Reihen den Flügelmuskeln anliegen (Fig. 73, $P z$ ). Nach $\mathrm{Cu}$ en ot besitzen auch diese Zellen eine (wenigstens indirekte) exkretorische Funktion, insofern als sie gewisse Stoffe aus dem Blute nehmen und dieselben so verarbeiten sollen, daß sie, wieder in das Blut zurückgebracht, nunmehr durch die Malpighischen Gefäße ausgeschieden werden können. Andere Autoren jedoch sind der Meinung, daß von den Perikardialzellen eine Neubildung der Blutkörperchen ausginge.

\section{Leuchtorgane.}

Die Leuchtorgane sind am besten im Anschluß an den Fettkörper zu besprechen, da die jene Organe aufbauenden Zellen, die Leuchtzellen, wohl zweifellos Derivate von Fettzellen sind. Wenn auch der Bau der Leuchtorgane bei den verschiedenen Insekten im einzelnen mehrfache Abweichungen zeigt, so stimmen sie doch wenigstens in den Grundzügen mehr oder weniger überein. Wir haben es in den meisten Fällen mit zwei Zellschichten oder Platten zu tun, die durch ihr Lichtbrechungsvermögen deutlich voneinander verschieden sind, indem die innere Platte undurchsichtig, die äußere dagegen durchsichtig erscheint. Die Undurchsichtigkeit der inneren Zellplatte beruht auf der Anhäufung zahlreicher Kristalle im Zellplasma, die in der Hauptsache aus harnsaurem Ammoniak bestehen. Mit den Zellplatten tritt ein dichtes Tracheennetz in Verbindung, deren feinsten in verschiedener Weise verzweigten Enden (die nach manchen Autoren mit Flüssigkeit gefüllt sein sollen) die Zellen (besonders der äußeren Leuchtplatte) umspinnen und teilweise wohl auch in dieselben eintreten. Endlich zeigen auch die über den Leuchtorganen gelegenen Hautstellen eine Veränderung, indem dieselben unpigmentiert und durchsichtig sind, so daß das Licht durchtreten kann. Durch diese Hautfenster sind natürlich 
auch die hellen Zellschichten sichtbar, so daß die Leuchtorgane auch äußerlich als weißliche oder gelbliche Flecke hervortreten.

Über die Physiologie des Leuchtens ist heute, trotzdem viele Forscher sich mit dieser Frage beschäftigt haben, noch keine Klarheit erzielt. Die reichliche Versorgung mit Tracheen deutet darauf hin, daß es sich um einen Oxydationsproze $B$ handelt. Welche Stoffe es aber sind, die diesem Prozeß unterliegen, darüber sind die Meinungen noch sehr geteilt.

$\mathrm{Nach}$ den einen ist der eigentliche Leuchtstoff in den harnsauren Kristallen zu erblicken, nach den anderen dagegen in feinen Körnchen, die in der äußeren Schichte sich finden (photogenic granules) usw. Daß es sich um einen sehr beständigen Stoff handeln muß, geht daraus hervor, daß Leuchtorgane, die völlig ausgetrocknet 10 Monate lang in einem Vakuum aufbewahrt wurden, durch einfaches Anfeuchten wieder zum Leuchten gebracht werden konnten (B o n g a r d t). Diese Tatsache lehrt zugleich, daß „das Leuchten als eine sekundäre Erscheinung scharf von den Lebensvorgängen zu trennen ist", etwa wie die eiweißlösende Eigenschaft des Pepsins unabhängig vom Leben des Organismus fortdauert.

Zweifellos ist das Leuchten vom Willen des Tieres abhängig, indem es das Insekt gewissermaßen in der Hand hat, das Licht abzustellen, schwächer oder stärker leuchten zu lassen. Man braucht, um sich davon zu überzeugen, nur einmal einen Leuchtkäfer zu beunruhigen, so wird man sofort eine Abnahme der Lichtintensität wahrnehmen können. Wahrscheinlich geschieht diese Regulierung durch eine Veränderung der Luftzufuhr, die wiederum durch Verengerung oder Erweiterung der Tracheen bewirkt werden kann. Für eine Beeinflußbarkeit des Leuchtens spricht auch die reichliche Versorgung des Leuchtorganes mit Nerven, deren feinsten Endäste mit den Tracheenkapillaren und mit den Leuchtzellen in Zusammenhang stehen.

Das von den Leuchtkäfern ausgehende Licht ist dadurch besonders bemerkenswert, daß es $\mathrm{k}$ e in e warmen $\mathrm{Str}$ a h 1 en besitzt und also vollkommen kalt ist; $d$. h. a 11 e von den betreffenden Organen ausgehenden Strahlen werden als Licht empfunden. Was das heißt, wird uns sofort klar, wenn wir bedenken, daß eine Gasflamme nur 3\%, eine elektrische Bogenlampe nur $10 \%$ und selbst das Sonnenlicht nicht mehr als $35 \%$ Lichtstrahlen aussendet, während alle übrigen (Wärmestrahlen und chemisch wirksamen Strahlen) nicht als Licht empfunden werden. Danach kann also das Licht der Leuchtkäfer geradezu als "Ideallicht" bezeichnet werden.

Leuchtorgane kommen fast nur bei Käfern vor, und unter diesen in erster Linie in der Gruppe der Weichkäfer oder Malacodermata (unter denen es ca. 1000 leuchtende Arten geben dürfte) und sodann auch bei einer Anzahl (nur tropischer) Schnellkäfer oder Elateriden und noch einigen anderen tropischen Käfern. Bei den Weichkäfern sitzen die Organe meistens am Abdomen in einer je nach der Spezies und dem Entwicklungsstadium verschiedenen Anordnung; bei den Elateriden dagegen auf dem Halsschild.

Auf unsere Fauna entfallen nur wenige Arten von Leuchtkäfern, unter denen die im Volksmund als "Glühwürmchen" bezeichneten Lampyris splendidula und noctiluca die bekanntesten sind. Bei beiden Arten liegen die Leuchtorgane auf der Bauchseite, und zwar an den hinteren Segmenten, wenn auch in einer nach der Spezies und dem Geschlecht etwas verschiedenen Anordnung.

Das $\sigma^{r}$ von L. splendidula trägt sie am vor- und drittletzten Abdominalsegment. Das ơ von noctiluca dagegen nur am letzten Segment (da bei dieser Art 
auch das „Hautfenster" nicht so durchsichtig ist, so ist das Organ weit weniger deutlich als bei splendidula). Das (flügellose, larvenähnliche) $\Varangle$ von splendidula hat ein großes Leuchtorgan am 6. Segment und einige kleinere am 5. und 3. Segment, und außerdem noch an jedem Abdominalsegment an den beiden Seiten je ein kleineres (,knollenförmiges"). Das (ebenfalls flügellose) o von L. noctiluca besitzt am 5 . und 6 . Segment je ein großes Leuchtorgan, das fast die ganze Ventralplatte einnimmt, und ferner noch einige kleinere Organe im 7. und 4. Segment. Auch die Larven haben Leuchtorgane, die an den Seiten der Abdominalsegmente gelegen sind (bei splendidula zahlreicher als bei noctiluca).

Wenn wir endlich nach der biologischen Bedeutung des Leuchtens fragen, so dürfte diese wohl in erster Linie in der Anlockung der Ge-

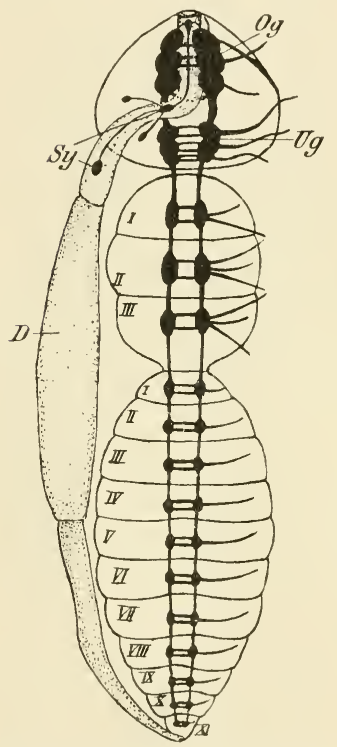

Fig. 76. Schematische Darstellung des Zentralnervensystems (Strickleiterform) eines Insekts. Og Oberschlund-, Ug Unterschlundganglien; $D$ Darm; Sy sympathisches Nervensystem. Nach Berlese. schlechter (Liebessignal) zu sehen sein. Dafür spricht $u$. a. die Beobachtung Bongardts, daß die Weibchen von noctiluca während der Flugzeit ausschließlich auf dem Rücken liegen, so daß die Leuchtorgane sichtbar sind, während sie nach der Flugzeit stets in natürlicher Lage, den Rücken nach oben, angetroffen werden. - Daneben kann das Leuchten vielleicht auch als Schreckmittel dienen zur Abhaltung von Feinden. Allerdings scheint das Leuchten keinesfalls auf alle nachstellenden Tiere abschreckend zu wirken, da verschiedentlich Frösche, Kröten und Fledermäuse beim Wegschnappen und Verzehren der leuchtenden Tiere beobachtet werden (Riedel).

\section{Nervensystem und Sinnesorgane.}

Nervensystem.

Das Nervensystem der Insekten ist nach dem gangliösen Typus gebaut, d. h. es besteht aus einer Anzahl Anschwellungen, Nervenknoten oder Ganglien genannt, die durch Nervenstränge oder Kommissuren untereinander verbunden sind. Ursprünglich kommt jedem Segment ein Paar Ganglien zu, die unter sich durch Querkommissuren und mit den vorhergehenden und nachfolgenden durch Längskommissuren in Verbindung stehen (Fig. 76). Dieses ursprüngliche Verhalten ist jedoch nur noch bei Embryonen, Larven und einigen tiefstehenden Insekten zu beobachten, wogegen bei allen höheren Insekten mehr oder weniger umfangreiche Verwachsungen stattgefunden haben, die sich sowohl auf die paarigen Ganglien der gleichen Segmente beziehen, - die zu einem unpaaren Knoten verwachsen (wobei gelegentlich auch die paarigen Längskommissuren zu einem unpaaren Strang zusammentreten) - als auch auf die Ganglien der verschiedenen Segmente, von denen eine ganze Anzahl zu einem größeren oder kleineren Ganglienkomplex verschmelzen kann. 
Der Grad der Verschmelzung (oder Konzentration) kann sehr mannigfaltig sein, nicht nur bei den verschiedenen Arten, sondern auch bei den verschiedenen Entwicklungsstadien; so nähern sich die Larven im allgemeinen weit mehr dem ursprünglichen Typus, d. h. haben ein viel weniger konzentriertes Nervensystem als die Imagines, doch kommt auch das umgekehrte Verhalten vor. Es ist keineswegs die systematische Stellung der betreffenden Insekten, welche den Konzentrationsgrad bestimmt, sondern es können in ein und derselben Ordnung einerseits recht ursprüngliche und andererseits extrem konzentrierte Folmen vorkommen (z. B. bei den Dipteren (Fig. 77).

$\mathrm{Da}$ die Anordnung des Zentralnervensystems an eine Strickleiter oder auch an eine Kette erinnert, so spricht man von einem "Strickleiter-
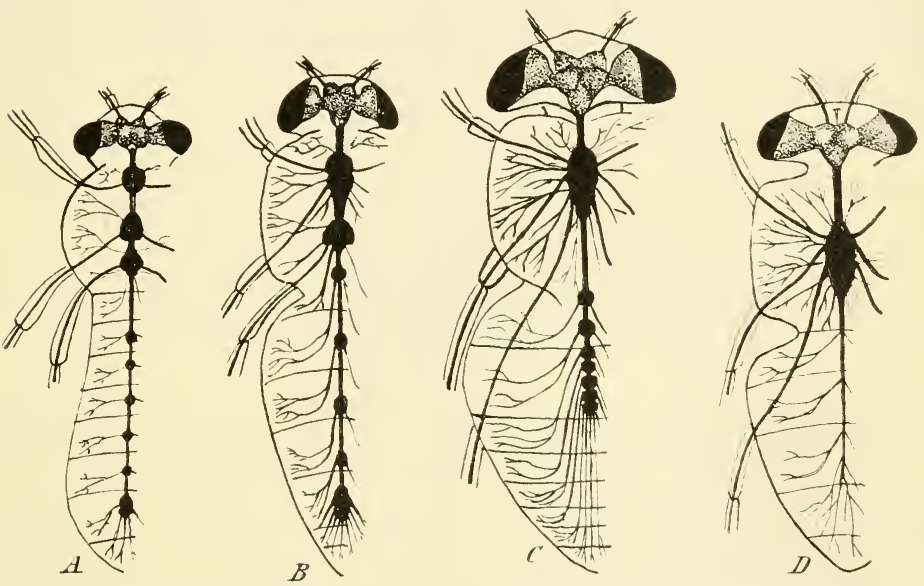

Fig. 77. Das Nervensystem von 4 Dipterenarten zur Demonstration des verschiedenen Grades der Konzentration. A von Chironomus; $B$ von Empis; $C$ von Tabanus und $D$ von Sarcophaga. Nach Lang.

nervensystem" oder einer "Ganglienkette." Da ferner diese Kette zum weitaus größten Teil an der Bauchseite, unter dem Darmrohr gelegen ist, so bezeichnet man diesen Teil des Nervensystems auch als Bauchmark, wodurch zugleich der Unterschied gegenüber den Wirbeltieren, bei denen das Zentralnervensystem am Rücken liegt (Rückenmark), betont wird.

Die Variabilität der Form des Bauchmarkes bezieht sich in der Hauptsache auf den Rumpfteil (Brust und Hinterleib), während die Anordnung der Ganglien des Kopfteiles eine relatir große Konstanz aufweist. Der Kopfteil enthält sechs Ganglien, von denen die ersten drei über dem Darm und die folgenden unter dem Darm gelegen sind. Sowohl die oberen als auch die unteren sind stets zu einer einheitlichen Masse verschmolzen, an denen die Zusammensetzung aus drei Ganglien meist noch deutlich erkennbar ist. Die beiden Ganglienmassen sind durch Kommissuren, die 
jederseits des Darmes herabziehen, miteinander verbunden, so daß also der Darm (resp. der Schlund) von einem förmlichen Nervenring umfaßt wird, der auch als "Schlundring" bezeichnet wird.

Der oberhalb des Darms gelegene Ganglienkomplex stellt in seiner Gesamtheit das Oberschlundganglien oder Gehirn dar, während die dasselbe zusammensetzenden Ganglienpaare als erster, zweiter, dritter Gehirnabschnitt oder Proto-, Deuto- und Tritocerebrum unterschieden werden. Das Gehirn nimmt eine gewisse Sonderstellung unter den Ganglien, resp. Ganglienkomplexen, ein und zwar nicht nur durch seine bedeutende Größe, sondern auch durch seinen komplizierten Bau (Fig. 78).

Dies bezieht sich vor allem auf das Protoc er ebrum, welches den größten Teil des Gehirnes bildet und durch den Besitz der sog. „pilzförmigen Körper“ ausgezeichnet ist. Letztere bestehen aus einer Anhäufung von Ganglienzellen und Fasermassen, die so angeordnet sind, daß sich auf Schnitten ungefähr

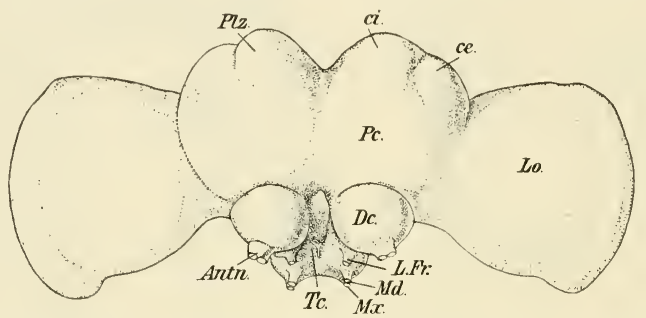

Fig. 78. Gehirn der Arbeitsbiene. $P_{c}$ Proto-, $D c$ Deutero-, $T c$ Tritocerebrum; Plz pilzhutförmige Körper; Lo Lobus opticus (Augenlappen); $c i$ innerer Becher; $c e$ äußerer Becher; Antn Antennennerven; M Nerven zu den Maxillen; Ma Nerven zu den Mandibeln; LFr Nerven zur Oberlippe und Stirn. Nach Jonescu.

die Form eines Pilzes ergibt (Fig. 79); äußerlich treten dieselben als geringere oder stärkere Anschwellung oder Verdickung der Protocerebrum-Hälften hervor.

Man unterscheidet an ihnen die Stiele und die Becher, die aus Fasermasse bestehen, ferner die in nere Zellmasse, welche in der Höhlung der Becher liegt, und die äußere Zellmasse, welche die Becher außen umgibt. Die pilzförmigen Körper sind besonders $\mathrm{stark}$ bei den sozialen Insekten (Ameisen, Bienen, Wespen) ausgebildet, und da diese Insekten in psychischer Beziehung zweifellos am höchsten stehen, so hat man in jenen Körpern die $\mathrm{O}$ r g a n e der Intellige nz erblickt (F o r e 1). Neuerdings hat man jedoch diesen Standpunkt etwas modifiziert, und es scheint wenigstens nach den Forschungen von Jonescu (Biene), P i etschker (Ameise) die Größe der pilzförmigen Körper a 11 e i n nicht maßgebend für die Höhe der geistigen Fähigkeiten zu sein (Fig. 79).

Vom Protocerebrum gehen auch die Sehnerven ab, von denen die zu den seitlichen Augen gehenden als breite Lappen (Ganglia optica) erscheinen, während die zu den Stirnaugen ziehenden, entsprechend der Kleinheit der Ocellen, nur dünne Stränge darstellen.

Der zweite Hirnabschnitt, das D eutocerebrum, ist wesentlich kleiner und besteht in der Hauptsache aus den Riechlappen, von denen die Antennennerven entspringen. Außer dem Geruchszentrum enthält das Deutocerebrum wahrscheinlich auch noch das Zentrum für die Tast-, Geschmacks-und 
vielleicht auch Gehörsempfindungen. Der dritte Abschnitt, das Tritocerebrum, auch Oesophagusganglion genannt, liegt unter, resp. hinter dem Deutocerebrum und geht nach hinten in die Schlundkommissuren über. Es entsendet Nerven zu der Oberlippe und der Schlundwand.

Das Tritocerebrum entspricht dem Schlundganglion der Krebse, die deren zweites Antennenpaar mit Nerven versorgen. Bei gewissen apterygoten Insekten kommen auch noch kleine Anhänge am Tritocerebrum vor, die als rudimentäre Antennennerven (für ein zweites Antennenpaar) zu betrachten sind (Folsom).

Der unter dem Darm gelegene Ganglienkomplex der Kopfregion wird als Unterschlundganglion bezeichnet. Es ist viel einfacher gebaut als das Gehirn und gleicht seiner Struktur nach mehr den übrigen Bauchganglien. Entsprechend seiner Zusammensetzung aus drei Ganglien gehen auch drei Nervenpaare von ihm ab, von denen das erste zu den Mandibeln, das zweite zu den Maxillen und das dritte zu der Unterlippe zieht.

Die Rumpfganglien versorgen im allgemeinen die den zugehörigen Segmenten eigene Muskulatur mit Nerven; so gehen von den Brustganglien

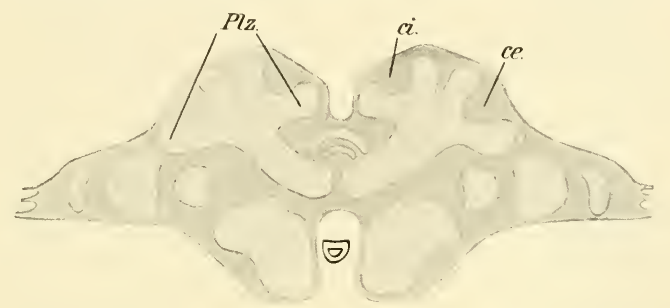

Fig. 79. Schematisierter Frontalschnitt durch das Gehirn einer Ameisenarbeiterin, zur Demonstration der pilzhutförmigen Körper $(\boldsymbol{P l z})$; $c i$ innerer, ce äußerer Becher. Nach Pi etschker.

eine Anzahl Nervenpaare zu den Bein- und Flügelmuskeln, während von den Abdominalganglien die Muskulatur des Hinterleibes und außerdem auch die Geschlechtsorgane innerviert werden.

Neben dem hier besprochenen Zentralnervensystem mit den peripheren Nerven kommt den Insekten (wie den Wirbeltieren) auch ein sympathisches oder Eingeweidenervensystem zu, von denen wir einen dorsalen, vom Gehirn entspringenden und einen ventralen, vom Bauchmark entspringenden Teil unterscheiden können. Ersterer verläuft auf der Dorsalwand des Vorderdarmes, teils als unpaarer Strang in der Medianlinie, teils als paarige Stränge zu beiden Seiten, und ist mit verschiedenen Ganglien ausgestattet, von denen das hinterste an der Grenze zwischen Vorderdarm und Mitteldarm liegt (siehe Fig. 76, Sy). Von diesem dorsalen Teile aus wird der Vorderdarm und wohl zum Teil auch der Mitteldarm, ferner die Speicheldrüsen, die Tracheen des Kopfes und das Rückengefäß versorgt. Der ventrale Sympathicus, der, von den Ganglien des Bauchmarkes entspringend, feine paarige Äste aussendet (Fig. 80), versorgt in der Hauptsache die dem Willen nicht unterworfene Muskulatur des Hinterleibes (Darm, Tracheen usw.) mit sympathischen Nerven. 
Die Zentralisation des Nervensystems geht bei den Insekten lange nicht so weit als bei den höheren Tieren. So kann man einem Insekt ruhig den Kopf abschneiden, ohne damit das Nervensystem zugleich völlig außer Funktion zu setzen. Die einzelnen Ganglien sind auch getrennt voneinander noch längere Zeit (mitunter wochenlang) für sich allein selbständiger Tätigkeit fähig. Jedoch reagieren sie dann nur auf direkte Reize; hören diese auf, so hören auch die Bewegungen der von ihnen innervierten Organe (Beine, Flügel usw.) auf. Entfernt man einem Insekt, z. B. einer Ameise, das Gehirn resp. die pilzförmigen Körper, so sucht sie nicht mehr nach Nahrung, obwohl sie die Nahrung, die man ihr zwischen die Mundteile schiebt, frißt; sie sucht ferner nicht mehr zu fliehen, nicht mehr anzugreifen, nicht mehr in ihr Nest zurückzukehren, auch nicht mehr vor Wasser oder Kälte usw. sich zurückzuziehen, obwohl sie ihre Beine auf direkte Reize hin bewegt; sie hat die elementarsten Instinkte der Furcht und Selbsterhaltung vollkommen verloren. Es geht daraus hervor, daß im Gehirn das eigentliche Asso-

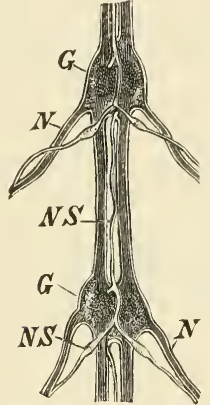

Fig. 80, Zwei Ganglienpaare des Bauchmarkes der Laubheuschrecke (Locusta viridissima L.) (nach Leydig). G Ganglien; $N$ peripherische Nerven: NS Atmungsnerv (Nervus sympathicus). - (N.)

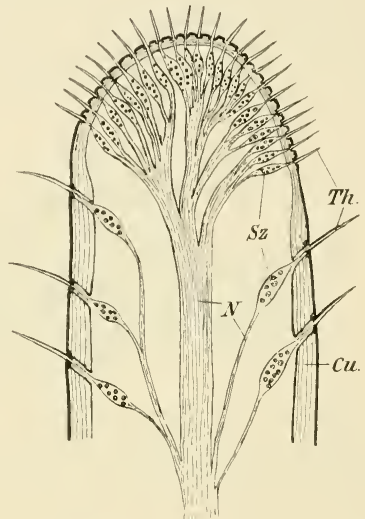

Fig. 81. Tasthaare $(T h)$ an der Spitze des Unterlippentasters von Decticus (Laubheuschrecke). $S z$ Sinneszellen; $N$ Nerven; $C u$ Cuticula.

ziationszentrum gelegen ist, in dem die Sinneseindrücke aufgespeichert, fixiert und in verschiedener Weise assoziiert werden, und von dem aus auch die Koordination (zweckmäßige Zusammenarbeit) geleitet wird.

Sinnesorgane.

Die biologische Beobachtung lehrt, daß die Insekten im allgemeinen derselben Sinneswahrnehmungen fähig sind wie der Mensch, d. h. daß sie einen Tast-, Geruchs-, Geschmacks-, Gesichts- und Gehörsinn besitzen. Allerdings ist der Umfang der verschiedenen Sinneseindrücke nicht immer der gleiche wie bei uns; so können z. B. die Ameisen die unserem Auge unsichtbaren ultravioletten Strahlen wahrnehmen, während sie dagegen unempfindlich gegen die von unserem Ohr als Töne empfundenen Schallschwingungen $\mathrm{zu}$ sein scheinen.

Tast, Geruch und Geschmack. - Wir können diese drei Arten von Sinnesempfindungen gemeinsam behandeln, da die rezipierenden Endorgane der gleichen Kategorie angehören. Gleichgültig ob es sich um eine Tast-, Geruchs- oder Geschmacksempfindung handelt, stets sind es sog. Haut- 
sinnesorgane, welche den adaequaten Reiz aufnehmen und nach innen weitergeben. Dieselben stellen Cuticularbildungen dar, welche durch Vermittlung von Sinneszellen (umgewandelte Hypodermiszellen) mit Nervenfasern in Verbindung stehen. Sie können überall auf der Körperoberfläche vorkommen, wenn sie auch am zahlreichsten an den Extremitäten zu finden sind, vor allem auf den Fühlern und Tastern, dann auch an den Beinen (besonders den Trochanteren und Tarsen) und den verschiedenen Abdominalanhängen (Schwanzfäden usw.).

Bezüglich der Form der Hautsinnesorgane herrscht die größte Mannigfaltigkeit, und man kann fast bei jeder Insektenart, die man genauer untersucht, größere oder geringere Abweichungen finden. Trotzdem aber lassen sich dieselben in einige gut umschriebene Kategorien einordnen, und können wir etwa folgende Formengruppen unterscheiden:

1. Die Sinnesha are (oder - borsten oder - schuppen), auch Tast$\mathrm{h}$ a a r e oder T a st borst e n oder S e n silla t richod e a genannt (Fig. 81). Sie ähneln ganz den gewöhnlichen Haaren oder Borsten oder Schuppen, unterscheiden sich aber hauptsächlich dadurch von diesen, daß sie mit Sinneszellen und Nervenfasern in Verbindung stehen; auch sind sie meist gelenkig mit der Cuticula verbunden. Sie sind weitaus die verbreitetsten und häufigsten Hautsinnesorgane, die außer auf

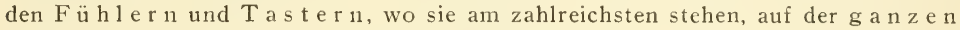
$\mathrm{K}$ örperoberfläche vorkommen. Zweifellos haben wir in ihnen die eigentlichen Organe des Tast sinnes zu erblicken.

2. Die Sinneskegel.

a) Die Leydigschen Kege 1, auch kurzweg „Sinneskegel“ oder Sensilla b a siconic a genannt (Fig. $82 \mathrm{~A}$ ). Diese stellen kürzere oder längere Chitinzapfen dar, deren Wände äußerst zart sind und an der Spitze of eine feine Öffnung besitzen, und die entweder der Cuticula direkt aufsitzt oder auf besonderen Stielen gelegen sind (Sensilla styloconica). Die Leydigschen Kegel finden sich vor allem auf den $F$ ühlern und $T$ as te $\mathrm{r} n$ und dann auch in der Mundhöhle, und stellen zweifellos sowohl Geruchs - als auch Gesch mack sor g a 11 e dar.

b) Grubenkegel, auch Sensilla coeloconic a genannt. Sie unterscheiden sich von den vorigen dadurch, daß sie nicht frei auf der Oberfläche hervorragen, sondern in Gruben liegen, wodurch sie mehr geschützt sind (Fig. 82 B). Die Gruben können die verschiedensten Formen aufweisen; sie können seicht oder tief, offen oder mit einer feinen Membran bedeckt sein, und häufig sind ihre Ränder auch noch mit Borstenkränzen umstellt, die zweifellos eine Vermehrung des Schutzes bedeuten. - Bei manchen Insekten, z. B. bei den Ameisen, kommen neben den rormalen Grubenkegeln auch noch ganz eigenartig gestaltete Gruben vor, die in ihren Umrissen an Champagnerpfropfen erinnern, und daher von $F$ orel auch als ,Champagnerpfropfenorgan e" bezeichnet wurden. Sie sind meist tief in die Haut eingesenkt und stehen nur noch durch eine kleine Offnung mit der Oberfläche in Verbindung (Fig. 82 C). Eine Abart dieser "Champagnerpfropfen" stellen die ,flaschenförmigen Sinnesorgane" (Sensilla ampullacea, Forelsche Flaschenorgane) dar, bei denen die Grube zu einem außerordentlich langen, halsförmig verengten Kanal ausgezogen ist. - Die Grubenkegel kommen speziell auf den Fühlern vor und sind wohl ebenfalls als Geruchsorgane anzusehen.

d) Porenplatten (Sensilla placodea). Sie stellen dünne Chitinplättchen dar, die über einer Spalte gelegen und mit der benachbarten Cuticula durch eine feine elastische Haut verbunden sind. An die Platte tritt von innen her ein Nerv heran. Erfährt die Platte von außen einen Druck, so rückt sie infolge ihrer elastischen Verbindung nach innen und übt einen Reiz auf den darunter liegenden Nerv aus. Nach Schenk stellen die Porenplatten Organe $\mathrm{zur}$ Em p findung des Luftdruckes dar. Nähert sich z. B. eine fliegende Biene einer 
Wand, so soll die zusammengepreßte Luft die Plättchen eindrücken und so die Biene vor dem Anprallen bewahren. Die Porenplatten wurden bis jetzt hauptsächlich an den Fühlern gefunden.

Als eine Abart der Porenplatten können vielleicht die "S in n esk u p p e 1 n“" betrachtet werden. Hier wird der Hauptteil des Organes nicht durch eine ebene Platte, sondern durch eine gleichmäßig gewölbte Kuppel dargestellt. An die Innenwand dieser nach außen völlig geschlossenen Chitinkuppel tritt die Sinneszelle mit einem sehr charakteristischen Endapparat heran; derselbe besteht aus dem "Achsenfaden" (Fig. 82 E $A x$ ), welcher zunächst die „V a c u o $1 \mathrm{e}^{\prime \prime}$

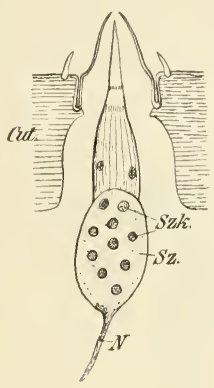

$A$
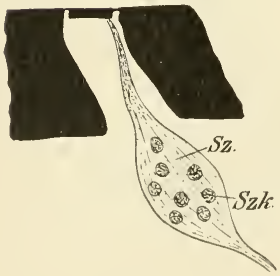

$D$

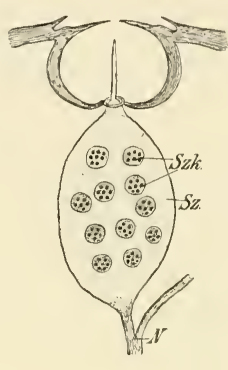

$B$

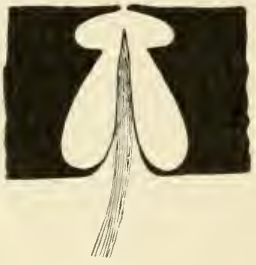

$C$

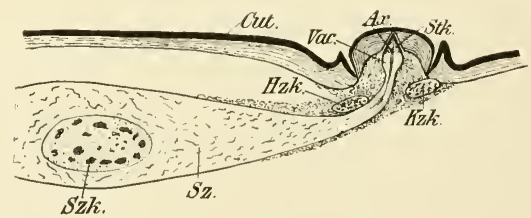

E

Fig. 82. Verschiedene Hautsinnesorgane. A Leydigscher Kegel; $B$ Grubenkegel; $C$ Champagnerpfropforgan; $D$ Porenplatte; $E$ Sinneskuppel. $N$ Nerv; Sz Sinneszelle; Szk Sinneszellenkern; Hzk Hüllzellenkeru; Kzk Kappenzellenkern; Tac Vacoule; Ax Axenfaden; Stk Stiftkörperchen; Cut Cuticula. Nach Hauser, Schenk, Vogel.

(eine Erweiterung des Endschlauchs der Sinneszelle) und dann das sog. „S t if t körperchen" durchzieht, um endlich an die Kuppelmembran zu stoßen. Zu der eigentlichen Sinneszelle treten stets noch zwei andere Zellen, die Hü11- und die Kappenzelle, welche den Endapparat umgeben. - Die Sinneskuppeln, deren nervöser Endapparat große Ähnlichkeit mit dem der Hörzellen besitzt, kommen auf den Flügeln der Schmetterlinge (in Gruppen und einzeln, längs der Adern) vor und dienen nach R. Vog e 1 als Flughilfsorgane, die es dem Schmetterling ermöglichen, „seinen Flug auf Reize hin zu regulieren, kurz gesagt, zu steuern".

Die hier besprochenen Hautsinnesorgane stehen oft auf engem Raum durcheinander gemengt beisammen, ein Umstand, der die richtige Erkennung 
der Funktion der einzelnen Formen sehr erschwert. Es ist auch recht gut möglich, ja sogar wahrscheinlich, daß verschiedene Formen ein und derselben Kategorie von Sinnesempfindungen (z. B. dem Geruch) dienen. Wir können allerdings aus der Lage der Hautsinnesorgane, in Verbindung mit der Häufigkeit ihres Vorkommens, einen gewissen Schluß auf ihre Funktion ziehen, wie es z. B. nahe liegt, den in der Gegend der Mundöffnung gelegenen und am zahlreichsten vertretenen Hautsinnesorganen Geschmacksfunktion zuzuschreiben.

Am besten unterrichtet sind wir über die Geruchsorgane. Spielt doch auch der Geruch eine überaus wichtige Rolle im Leben der Insekten, und werden doch die wichtigsten Lebensbetätigungen, wie die Nahrungssuche, Aufsuchung der Geschlechter und geeigneter Brutplätze, bei den sozialen Insekten die Erkennung von Freund und Feind, Heimfinden zum Nest usw. durch den Geruch geleitet. Die Insekten sind ausgesprochene Geruchstiere; beraubt man sie des Geruchsvermögens, so sind sie verloren. Es steht heute zweifelhaft fest, daß die Geruchsorgane (wenigstens in der Hauptsache) in den Fühlern ihren Sitz haben. Man hat dies mehrfach experimentell nachgewiesen. Schneidet man einem Aaskäfer die Fühler ab, so findet er selbst naheliegendes Aas nicht mehr, oder nimmt man einer Ameise die Fühler, so kennt sie nicht mehr Freund und Feind auseinander und ist infolgedessen unbrauchbar für das Gesellschaftsleben, oder schneidet man dem Männchen eines Spinners die Fühler weg, so findet es das Weibchen nicht mehr, usw.

Diese experimentellen Beweise werden auch noch durch andere Befunde gestützt: bekanntlich bedürfen nicht alle Insekten in gleichem Maße des Geruchssinnes, und dem entspricht auch in jeder Weise die Ausbildung der Fühler, indem solche Insekten, die ein besonders hohes Geruchsvermögen nötig haben, auch eine besonders große Fühleroberfläche besitzen. Am deutlichsten kann man dieses bei den Männchen jener Insekten sehen, die ihre Weibchen auf weite Entfernung aufsuchen müssen; so haben z. B. die Männchen der Spinner langgefiederte Fühler, die Weibchen dagegen nur ganz schwach gefiederte; oder man denke an das Männchen unseres Maikäfers mit seiner mächtigen Blätterkeule im Gegensatz zu der viel kleineren Keule des Weibchens. Der Vergrößerung der Fühleroberfläche entspricht auch die Vermehrung der Einzelsinnesorgane, resp. der Grubenkegel, so sind deren (nach Hesse) auf den weiblichen Maikäferfühlern ca. 8000 , auf den männlichen dagegen nicht weniger als ca. 50000 .

Die Geruchsschärfe der Insekten ist vielfach eine ganz erstaunliche, und für uns beinahe an das Wunderbare grenzend. Daß Aas- und Mistkäfer den vom Aas und Mist ausgehenden Geruch auf weithin riechen, können wir noch verstehen, daß aber eine Schlupfwespe (Rhyssa) eine tief im Holz sitzende Holzwespenlarve durch das dicke Holz hindurch zu riechen vermag, und daß die Spinnermännchen ein Weibchen mitunter kilometerweit wittern können, das geht über unsere Begriffe, da wir ja selbst in unmittelbarer Nähe und bei der Anwesenheit zahlreicher Weibchen geruchlich 
nicht das Geringste wahrnehmen. Eine solche Geruchsschärfe können wir mit Hesse nur darauf zurückführen, daß „die Zahl der verschiedenen Gerüche, für die das Riechorgan dieser Insekten zugänglich ist, sehr gering ist. Wir dürfen annehmen, daß sie Geruchsspezialisten sind; der Duft, durch den sie vorwiegend erregt werden, ist aufs engste mit ihrer Lebensweise verknüpft: ein Männchen wird durch den Duft seines Weibchens gereizt, und nur durch diesen; eine Pflanze, die das eine Insekt von weitem anlockt, läßt eines von einer anderen Art unberührt."

Weit weniger als über die Geruchsorgane wissen wir über die Geschmacksorgane. Daß die Insekten Geschmacksempfindungen besitzen, ist nicht zu bezweifeln. Wissen wir doch, daß viele Insekten sehr wählerisch bezüglich ihrer Nahrung sind und nur ganz bestimmte Pflanzen annehmen, auch sind verschiedentlich Experimentc in dieser Richtung gemacht, die alle zu dem gleichen Resultat geführt haben, daß die Insekten recht wohl schmecken kömnen. Wo aber diese Geschmacksorgane lokalisiert sind, darüber wissen wir noch nicht allzuviel, wahrscheinlich liegen sie an verschiedenen Stellen verteilt; so dürften die zahlreichen Grubenkegel, die man vielfach in der Mundhöhle am Hypo- und Epipharynx findet, wohl sicher der Geschmacksempfindung dienen; daneben mögen auch die Kegel an den Maxillarloben und den Tastern als Geschmacksorgane funktionieren, desgleichen die Hautsinnesorgane, die an der Spitze des Schmetterlings-, Wanzen- und Fliegenrüssel und an der Zunge der Bienen, Wespen usw. gelegen sind.

Gehör. - Daß den Insekten ein Gehörvermögen zukommt, läßt sich schon daraus schließen, daß viele Insekten Töne hervorbringen, welche zweifellos dem $Z$ wecke dienen, das andere Geschlecht anzulocken oder zu erregen. Zudem ist auch durch Versuche nachgewiesen, daß manche Insekten prompt auf Гöne reagieren: „Küchenschaben halten beim Anstreichen einer Violinsaite im Laufen inne, die Wasserwanzen Corixa und Notonecta fahren wie wild durcheinander, wenn man das d' einer Violine anstreicht" usw. (Hesse).

Früher glaubte man den Sitz des Gehörorgans in die Fühler legen zu müssen (nach Analogie mit den Ohren des Menschen); doch heute weiß man, daß die Ohren der Insekten an den verschiedensten Stellen des Körpers gelegen sein können: in den Fühlern, Beinen, Flügeln, im Abdomen usw.

Wie die Lage, so zeigt auch der Bau der Gehörorgane eine große Mannigfaltigkeit. Wenn wir in dieser Beziehung auch noch nicht überall ganz klar sehen, so können wir nach den bis jetzt vorliegenden Untersuchungen doch wenigstens zwei Haupttypen aufstellen: nämlich die Saiten-oder Chordotonalorgane und die Trommelfell- oder Tympanalorgane.

Die Chordotonalorgane bestehen aus einer oder mehreren sehr charakteristischen Sinneszellen, welche einerseits mit einer Nervenfaser, andererseits mit der Haut verbunden sind. Die Verbindung mit der Haut geschicht mittels eines aus mehreren Zellen bestehenden Schlauches, der als Stiftchenträger oder Scolopophor bezeichnet wird. In ihn tritt nämlich 
von der Sinneszelle her ein Fortsatz der Nervenfaser ein, der nach längerem Verlauf in einem hohlen Stifte mit kegelförmiger Spitze (Hörstift) endigt. Der gesamte Apparat (Sinneszelle nebst Stiftchenträger) wird als Ėndschlauch bezeichnet (Fig. 83, Edsch).

Selten kommt nur ein Endschlauch allein vor, gewöhnlich ist eine größere oder geringere Zahl von solchen zu einem Bündel vereinigt. Die Endschläuche verlaufen entweder in der Richtung des Nerven, so daß sie zwischen dem Nerven und Haut ausgespannt sind, oder aber sie sind rechtwinklig gegen den Nerven abgeknickt. In diesem Falle tritt an die Knickungsstelle von der anderen Seite her ein Band (Fig. 83, $B d$ ), welches die Endschläuche mit der Haut verbindet, so daß sie also hier zwischen zwei Hautstellen ausgespannt sind.

Gerät nun die Haut in Schwingung, so überträgt sich diese auch auf die ausgespannte Saite und damit auch auf die Hörstifte, wodurch eine Schallempfindung zustande kommen kann. - Chordotonalorgane sind an den verschiedensten Körperteilen, doch meist in den Anhängen (Fühlern, Beinen, Tastern, Flügeln) gefunden worden.

Die tympanalen Organe schließen sich bezüglich der nervösen Endapparate den Chordotonalorganen an, insofern als auch hier jenc Endschläuche vorkommen. Während jedoch hier die darüberliegende Haut keine Änderung erfahren hat, ist bei den Tympanalorganen die betr. Hautstelle stark verdünnt, so daß sie an ein Trommelfell erinnert, zumal die verdünnte Stelle zwischen einem verdickten Rahmen ausgespannt sein kann. Dieses Trommelfell liegt entweder frei, oder ist durch eine Hautfalte, die nur einen schmalen Schlitz

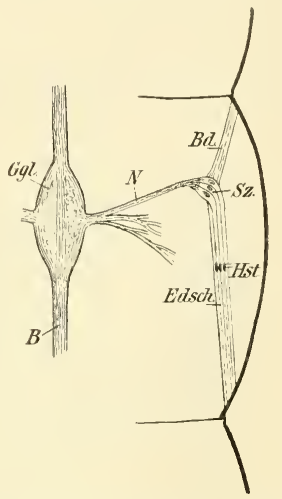

Fig. 83. Chordotonalorgan. $B$ Bauchstrang; Ggl Ganglion; $N$ Nerv vom Ganglion abgehend und zu den Sinneszellen $(S z)$ ziehend; Hst Hörstifte; Edsch Endschlauch; $B d$ Band, welches den Endschlanch in Spannung hält. Nach Graber. als Zugang offen läßt, geschützt. Unter dem Trommelfell befindet sich eine Trachee, welche blasenförmig erweitert, oder in zwei dicht aneinander gelegene Äste gespalten ist. Auf dieser Trachee oder zwischen derselben und dem Trommelfell liegen die Endschläuche mit ihren Hörstiften, in einer Reihe nach ihrer Größe angeordnet. Infolge der Verdünnung der Haut und der darunter liegenden Tracheenblasen kommen die Schwingungen, die die Haut treffen, weit mehr zur Geltung, resp. besitzen eine weit größere Wirkung als bei den Chordotonalorganen, bei denen ja die darüberliegende Haut ihre gewöhnliche Stärke besitzt, und so stellen also die Tympanalorgane viel höher entwickelte und feiner empfindende Gehörorgane dar.

Am bekanntesten und auffälligsten sind die Tympanalorgane der Heuschrecken und Grillen, und da gerade diese Insekten durch ihre laute Tonerzeugung sich auszeichnen, so hat man schon seit langem in jenen Organen Gehörorgane vermutet. Sie liegen bei den Feldheuschrecken (Acridiern) frei 
an den Seiten des ersten Abdominalsegments (siehe S. 25, Fig. 26, Ty), bei den Grillen und Laubheuschrecken (Locustiden) dagegen an den Schienen der Vorderbeine, und zwar bei den ersteren ebenfalls frei, bei den letzteren ron Hautfalten bedeckt (Fig. $84 \mathrm{~A}$ ). Neuerdings hat man auch bei Schmetterlingen tympanale Organe entdeckt, die an den Seiten des Thorax, resp. an der Grenze zwischen Abdomen und Thorax, oder abes in der Wurzel der Vorder- und Hinterflügel gelegen sind (nach Deegener, Eggers, Vogel).

Sehorgane. ${ }^{1}$ - Die Sehorgane der Insekten liegen stets am Kopfe und empfangen ihre Nerven vom Gehirn, resp. dem Protocerebrum. Man unterscheidet zwei Arten: die einfachen Augen, auch Punktaugen oder Ocellen genannt, und die zusammengesetzten Augen, auch als Netz-oder Facettenaugen bezeichnet (Fig. 85).

Die einfachen Augen (Ocellen), die sich als glänzende, durchsichtige Vorwölbungen der Cuticula präsentieren, liegen bei den Imagines meistens

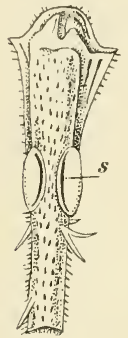

$A$

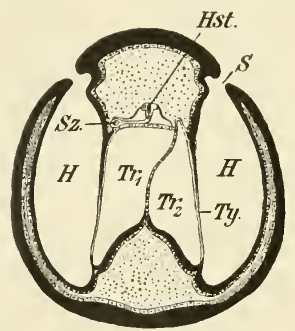

$B$

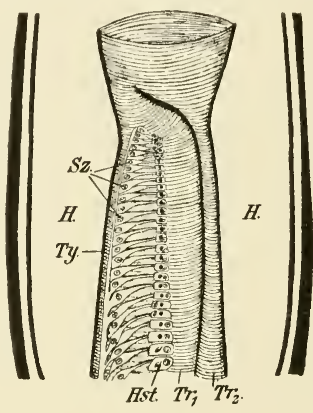

$C$

Fig. 84. Tympanalorgan einer Laubheuschrecke. A Vorderschiene mit dem Tympanalorgan ( $s$ schlitz förmiger Eingang); $B$ Querschnitt, $C$ Längsschnitt durch die Vorderschiene. $H$ Trommelfellhöhle: Tr Trachee; Sz Sinneszelle; Ty Trommelfell; Hst Hörstifte. Nach J. Schwabe.

zwischen den seitlichen, zusammengesetzten Augen auf der Mitte der Stirne oder des Scheitels (in der Zahl von 1-3), und werden deshalb auch Stirnoder Scheitelaugen genannt. Nur bei den niederen Insekten (Springschwänze, Silberfischchen) und einigen parasitisch lebenden oder bezügl. des Sehvermögens in Rückbildung begriffenen höheren Insekten (Flöhe, Läuse, Federlinge, einige Ameisen usw.) liegen sie an den Seiten des Kopfes, wo sie die Stelle der zusammengesetzten Augen einnehmen. Was bei den Imagines Ausnahme ist, ist bei den (echten) Larven Regel, d. h. bei ihnen liegen die Ocellen stets an den Seiten und stellen überhaupt die einzigen Sehorgane dar. Während die Zahl der scheitelständigen Ocellen auf $1-3$ fixiert ist, ist dieselbe bei den seitlichen Ocellen großen Schwankungen unterworfen; so sind es deren bei den Springschwänzen bis 8, bei den Silberfischchen 12, bei den Flöhen und Läusen nur je 1 , bei den Käferlarven $1-6$, bei den

1) In der Darstellung der Sehorgane folge ich in erster Linie $\mathrm{H}$ es se, dem wir die umfassendsten Untersuchungen in dieser Beziehung verdanken. 
Afterraupen der Blattwespen 1, bei den echten Raupen der Schmetterlinge $6-7$ usw.

Der feinere Bau der Ocellen ist recht verschieden, doch lassen sich stets folgende Teile daran unterscheiden: zu äußerst die biconvexe, durchsichtige L in se, hinter dicser liegt eine gleichfalls durchsichtige, aus der Hypodermis entstandene Zellenlage, der G lask ö r p e r, und auf sie folgt nach innen die Sin ne szellen schichte, die Netzhaut oder Retina. Die Netzhautzellen bestehen an ihrem der Linse zugewandtcn Ende aus $\mathrm{Stäbchen} \mathrm{(Rhabdomen),} \mathrm{welche}$ die eigentliche Lichtwahrnehmung vermitteln, und gehen an dem anderen in die Fasern des Sehnervs über (Fig. 86). Die Verschiedenheiten im Bau, auf die hier nicht näher eingegangen werden kann, beziehen sich auf die Dicke der Linse, auf die Form und Zusammensetzung der unter der Linse liegenden Zellenschichte und auf die Zahl und Form der Netzhautzellen usw.

Die zusammengesetzten Augen, die stets an den Seiten des Kopfes liegen (und daher im Gegensatz zu den Stirnaugen auch als Seitenaugen bezeichnet werden), kann man sich durch den Zusammenschluß einer größeren

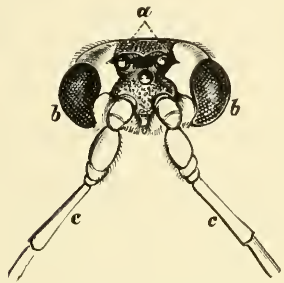

Fig. 85. Kopf einer Schlupfwespe. $\% / \mathrm{n}$. Gr. $a$ die 3 Punktaugen; $b b$ die paarigen Seitenaugen; $c c$ die Fühler. - (N.)

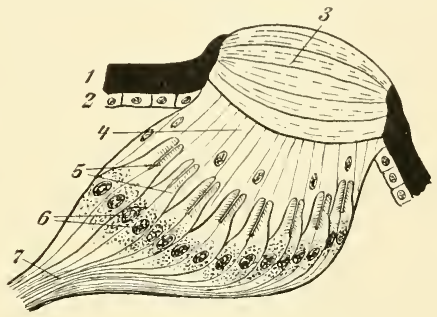

Fig. 86. Stirnocelle einer Blattlaus (Medianschnitt), $1 \mathrm{n}$. 2 Cuticula; 3 Linse; 4 Corneabildungszellen; 5 Sehzellen mit ihren Rhabdomen (6). Nach Hesse.

Zahl von Ocellen entstanden denken. Äußerlich läßt sich die Zusammensetzung daran erkennen, daß die Oberfläche in eine größere oder kleinere Anzahl von meist sechseckigen Feldern oder Facetten zerfällt, von denen jede der Linse eines Ocellus entspricht.

Die Größse der Netzaugen ist sehr verschieden; während sie bei den meisten Insekten nur einen Teil der Seitenflächen des Kopfes einnehmen und daher durch die Stim getrennt werden, stoßen sie bei anderen, z. B. bei den Drohnen der Honigbiene, in der Mitte zusammen, und bei den Männchen einer Mückengattung, Bibio, nehmen sie die gesamte freie Kopffläche ein (Fig. 88).

Die Anzahl der sie zusammensetzenden Facetten kann von einigen 20 bis zu vielen Tausenden wechseln. So hat z. B. Pselaphus, ein kleiner Käfer, 20 , die Stubenfliege 4000 , der Weidenbohrer 11000 , eine Wasserjungfer 12000 , der Schwalbenschwanz 17000 und ein anderer kleiner Käfer Mordella, 25000 Facetten in jedem Auge.

Die Form der Netzaugen ist meist rund, wird aber häufig länglich, und bei vielen Käfern vorn nierenförmig eingebuchtet. In dieser nier enförmigen Einbuchtung der Augen lenken sich häufig die Fühler ein, und es kann 
der Einschnitt so tief werden, daß die obere und untere Augenhälfte sich nur in einem Punkte berühren, z. B. bei gewissen Borkenkäfern, Polygraphus,

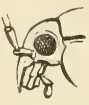

A

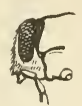

$B$

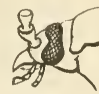

C

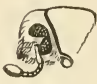

$D$

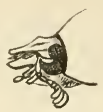

E

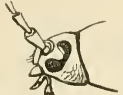

F

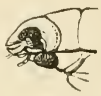

G

Fig. 87. Augenformen von Käfern. A Calosoma: rundes Auge; B Chrysobothrys: ovales Auge; $C$ Prionus: nierenförmiges Auge; $D$ Polygraphus: von der Fühlergrube eingeschnittenes Auge: $E$ Geotrupes: von einer Leiste des Kopfschildes eingeschnittenes Auge; $F$ Tetropium: Augen zweigeteilt, aber durch eine kleine Facetten tragende Leiste verbunden; $G$ Gyrinus: Augen zweigeteilt, jederseits ein oberes und ein unteres Auge bildend. Die Größenverhältnisse der Köpfe untereinander blieben unbeachtet. - (N.)

oder bei Bockkäfern, Tetropium; andererseits werden die Augen auch mitunter durch den Rand des Kopfes in eine obere und untere Hälfte geteilt,
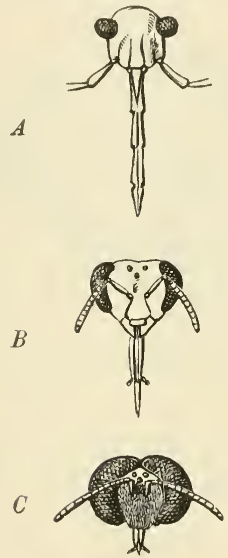

D

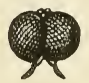

Fig. 88. Köpfe verschiedener Insekten, um die verschiedene Ausdehnung und Vorragung der Augen. A von der Feuerwanze (Pyrrhocoris); $\boldsymbol{B}$ von der Arbeitsbiene; $C$ von der Drohne; $D$ von einer männlichen Mücke (Bibio). - (N.) z. B. bei den gewöhnlichen Grabkäfern Geotrupes, und den Taumelkäfern, Gyrinus, unserer stehenden Gewässer. Hier erscheint die Sonderung der Augen in ein oberes und unteres Paar vollendet (Fig. 87).

Der feinere Aufbau der zusammengesetzten Augen ist sehr einförmig, indem jedes Einzelauge (Augenkeil, Ommatidium) durch annähernd die gleiche Zahl von Zellen gebildet wird. Zu äußerst liegt die Li nse (Cornea), die meist einen sechseckigen Umriß besitzt, darauf folgen nach innen vier Zellen, welche den lichtbrechenden Kegel bilden und als Kegelzellen bezeichnet werden, und auf diese folgen endlich
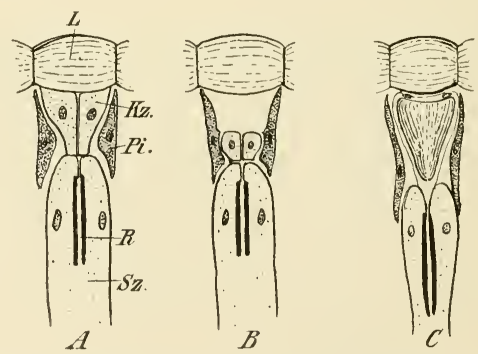

Fig. 89. Augenkeil $A$ eines aconen, $B$ eines pseudoconen, $C$ eines euconen Auges. $L$ Linse; $K z$ Kegelzelle; Pi Pigmentzelle; $S z$ Sehzelle mit dem Rhabdom $(R)$.

sieben bis zehn langgezogene Sehzellen. Letztere treten zu einem keilförmigen Bündel zusammen, und besitzen auf ihren inneren Längsseiten (d. h. der Achse des Augenkeiles zugekehrt) die lichtrezipierenden Teile, d. s. feine Stäbchensäume, die zu einem einheitlichen Stab oder $\mathrm{R} h \mathrm{hbdom}$ verschmelzen können. Am zentralwärts gelegenen schmalen Ende treten die Sehzellen mit den Fasern des 
Sehnervs in Verbindung. Um jeden Augenkeil ist ein mehr oder weniger ausgedehnter Pigmentmantel gelegt, welcher als optischer Isolator dient. Je nach der Beschaffenheit der Kegelzellen unterscheidet man drei verschiedene Typen von Augen: a c on e, p s e u d o c o n e und e u c on e. Bei den aconen Augen haben die Kegelzellen ihre Zellennatur unverändert beibehalten ( $\mathrm{Z}$ e $11 \mathrm{k}$ e ge 1 ); bei den pseudoconen haben die Kegelzellen nach außen gegen die Linse zu eine durchsichtige Sekretmasse abgeschieden (Sekretkegel), und bei den euconen ist der gesamte Zellinhalt in eine Masse von kutikularer Konsistenz und hoher Lichtbrechung umgewandelt, der die Kerne distal aufliegen ( $\mathrm{Kr}$ istall kege 1 ) (Fig. 89). Zell- und Sekretkegel verhalten sich bez. der Lichtbrechung anders als die Kristallkegel, wovon unten noch die Rede sein wird.

Nach dem hier geschilderten Bau leuchtet es ein, daß jeder einzelne A ugenkeil für sich a rbeitet, d. h. nur einen einheitlichen Reiz in sich aufnehmen kann; - wenigstens wenn die Pigmentscheide so angeordnet ist, daß lediglich die in die Längsachse des Keiles fallenden Strahlen bis zu den lichtempfindlichen Elementen durchdringen können. So gelangt z. B. auf dem beigegebenen Schema (Fig. 90) von allen von der Spitze A des Pfeiles A F auf das Netzauge fallenden Strahlen, also von allen zwischen $\mathrm{a}^{\mathrm{I}}$ und $\mathrm{a}^{\mathrm{V}}$ vorhandenen, nur der durch die Linie a dargestellte Strahl bis zum Punkte AI, während alle anderen Strahlen, z. B. aII bis aIV von Pigmentscheiden aufgefangen werden. Dasselbe gilt von den von den Punkten $\mathrm{B}-\mathrm{F}$ des Pfeiles ausgehenden Strahlen, so daß also lediglich die Strahlen a, b, c, d, e und $f$ bis zu den lichtempfindlichen Nervenendigungen der Einzelaugen 6-11 gelangen und hier ein aus sechs Einzeleindrücken zus a m m engesetztes, verkleinert es, gekrümmtes, aber a uf recht stehendes Bild (AI FI) des Pfeiles erzeugen. Da das Bild wie Mosaik aus lauter Teilstückchen zusammengesetzt ist, so hat man das Sehen mittels Facettenaugen als $\mathrm{mus}$ ivis che s $\mathrm{S}$ e he $\mathrm{n}$ bezeichnet ( $\mathrm{J}$ o h. $\mathrm{M}$ ülle r). Und wie ein Mosaik um so genauer ist, je feiner die Stückchen sind, aus denen es zusammengesetzt ist, so wird auch das Bild i m F a c e t e na uge um so detaillierter und schärfer sein, je zahlreicher die Augenkeile sind, die in einem gegebenen Winkel Platz haben. So fassen z. B. die Schenkel eines Winkels von $40 \mathrm{Grad}$ im Auge des Windigschwärmer (sp, Sphinx convulvuli) 50-60 Augenkeile zwischen sich, beim Gelbrandkäfer nur 30 und beim Ohrwurm nur 5-6. Danach sieht also der Windigschwärmer 10 mal schärfer als der Ohrwurm.

Die so erzielte Erhöhung der Sehschärfe bringt aber einen Nachteil mit sich, daß nämlich das $\mathrm{S}$ e h f eld verk le i n e r t wird. Denn, damit möglichst viele Augenkeile in einen gegebenen Winkel fallen, dürfen diese möglichst wenig divergieren, wodurch aber natürlich das Sehfeld kleiner wird. Um diesen Nachteil auszugleichen, ist bei vielen Insekten eine Arbeitsteilung durchgeführt, in der Weise, daß, in einem Teil des Auges die Augenkeile stark divergieren, also ein großes Sehfeld bei geringer Bildschärfe beherrschen, während in einem anderen Teil die Divergenz gering und daher die Bildschärfe groß, das Sehfeld aber klein ist“. Die Vergrößerung des Sehfeldes kann aber auch durch die Bewegung der Augen erzielt werden. Da jedoch die Augen der Insekten unbeweglich mit der Kopfkapsel $\mathrm{K}$ verbunden sind, so bleibt nichts anderes übrig, als den ganzen Kopf zu bewegen. Und so können wir bei solchen Insekten, deren Lebensweise ein möglichst großes Sehfeld erheischt, wie bei den Libellen, Raubfliegen usw., eine auffallend große Beweglichkeit des Kopfes konstatieren.

Der Kleinheit der Linsenoberfläche entspricht die geringe Lichtstärke des Facettenauges. Dieser Nachteil kann dadurch gemindert werden, daß die A ugenkeile möglichst lang werden, wodurch die Facetten natürlich größer werden. Außerlich macht sich diese Verlängerung durch eine mächtige Auftreibung der Augen bemerkbar, wie wir dies z. B. bei den Männchen vieler Eintagsfliegen, die infolge ihres Dämmerungslebens einer besonders hohen Lichtstärke bedürfen, sehen können (sog. „Turbanaugen"). Oder aber die Vermehrung der Lichtmenge geschieht durch eine Úberein- 
anderlagerung von Strahlenbündeln aus verschiedenen benachbarten Kegeln in einem Rhabdom. Ein solcher Fall tritt nur bei den euconen Augen ein, indem die Kristallkegel das Licht so brechen, daß die Strahlen zu dem zugeordneten Rhabdom nicht nur durch den zugeordneten Kegel, sondern auch durch dessen Nachbarkegel gelangen, wie aus Fig. 91 deutlich zu ersehen ist. „Anstatt des nur auf eine Oberfläche fallenden Lichtes kommt daher die 6 fache oder 18 fache Lichtmenge mehr zu dem Rhabdom, je nachdem nur die zunächst oder auch die in zweiter Linie benachbarten Kristallkegel für diese Strahlenbrechung in Betracht kommen." Man nennt solche aus übereinandergelagerten Strahlenbündeln entstandenen Bilder Superpositionsbilder im Gegensatz zu den oben geschilderten und in Fig. 90 dargestellten A p o s it ions bildern.

Natürlich muß bei den Superpositionsaugen die zwischen dem Kristallkegel und dem Rhabdom gelegene Zone pig m e n t f r e i sein, so daß die von den Nachbarkeilen herkommenden Strahlen eintreten können. Und so finden wir auch bei

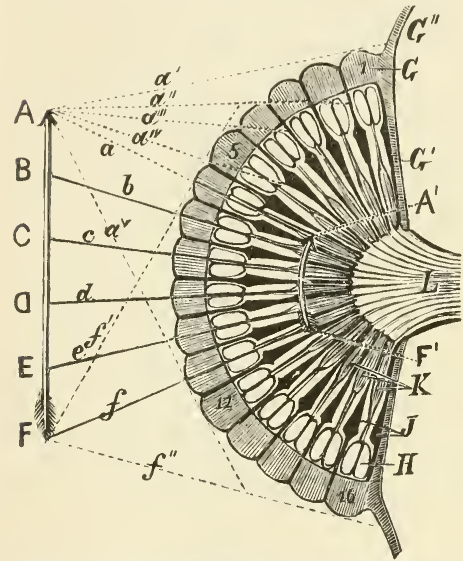

Fig. 90. S'chematische Darstellung der Wirkungsweise eines Netzauges. - (N.)

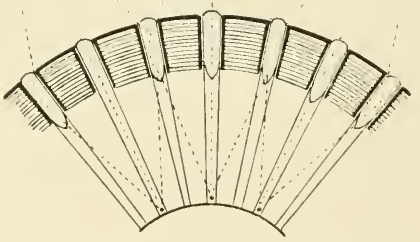

Fig. 91. Schematische Darstellung des Strahlengangs im Superpositionsauge. Nach Hesse.

solchen Augen die Erscheinung der Pigmentwanderung: bei hellem Sonnenlicht sind die Augenkeile durch eine ausgedehnte Pigmentscheide voneinander isoliert, so daß keine Strahlen von den Nachbarkegeln eintreten können und ein einfaches Appositionssehen stattfindet. „Im Dämmerlicht dagegen wandert das Pigment gegen die Augenoberfläche, häuft sich zwischen den Kristallkegeln an und gibt die mittlere Zone für die durchgehenden konvergenten Strahlen frei. Su per positionsaugen treffen wir hauptsächlich bei Dämmerungstieren, wie vor allem bei Nachtschmetterlingen und sodann auch bei vielen Käfern, wie z. B. bei den Glühwürmchen usw.

Während über die Funktion und die Bedeutung der zusammengesetzten Augen schon seit langem eine ziemliche Übereinstimmung herrscht, ist man über die B edeutung der Stirnocellen bis vor kurzem im Dunkeln getappt. An Meinungen hat es allerdings nicht gefehlt, doch keine konnte recht befriedigen. Nach den einen sollten die Stirnaugen zur Regulation der Körperhaltung beim Fluge dienen, nach den anderen zum Fernsehen, und wieder nach anderen zum Nachtsehen oder zum Dämmerungssehen, oder zur Orientierung nach dem Licht, oder man brachte sie in Beziehung zur schnellen Fortbewegung usw. Endlich wollten eine Anzahl Forscher den Stirnaugen eine besondere Funktion überhaupt ab- 
sprechen. - Nun ist in neuester Zeit Demoll mit einer Anschauung hervorgetreten, die einer Lösung des Problems nahe zu kommen scheint. Nach D e m oll wirken die Ocellen nicht für sich allein, sondern $\mathrm{nur}$ in Verbindung mit den Seitena ugen, und zwar in dem Sinne, daß sie das Insekt in den Stand setzen, die Entfernung der gesehenen Gegenstände zu empfinden (Entfernungslokalisation). Auf welche Weise durch die Verkettung der Impulse der beiden Augenarten eine Entfernungslokalisation zustande kommen kann, läßt sich am besten aus der beistehenden Fig. 92 ersehen, dieselbe stellt einen Frontalschnitt durch den Kopf der Skorpionfliege (Panorpa communis) dar, auf dem sowohl der laterale Ocellus sowie das Facettenauge getroffen sind. Nehmen wir nun einen beliebigen Objektpunkt (J) - die Entfernungen der Objekte sind hier aus praktischen Gründen sehr kurz gewählt - so ist leicht zu verstehen, daß dieser Punkt in einer bestimmten Entfernung jeweils auf dieselbe Sehzelle im Facettenauge (P) und auf dieselben im Ocellus (A) einen Reiz ausüben muß. Verschiebt sich das Objekt $J$ in der Richtung gegen $\mathrm{K} z u$, so wird zwar im Facettenauge stets das gleiche Rhabdom affiziert werden. Im Ocellus dagegen wandert der Ort des Bildpunktes von A nach B, und zwar so, daß jedem Punkt auf der Geraden $\mathrm{K}-\mathrm{J}$ ein besonderer Bildpunkt entspricht.

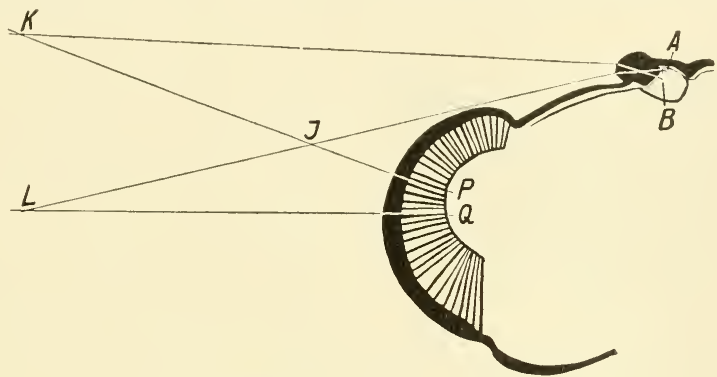

Fig. 92. Funktion der Ocellen. Nach Demoll.

Verschiebt sich andererseits der Punkt $J$ gegen $L$ zu, so bleibt die Affektionsstelle im Ocellus dieselbe, während die des Facettenauges von $\mathrm{P}$ nach $\mathrm{Q}$ wandert. Hieraus ersieht man, daß bei einer bestimmten Lage des Objekts jeweils in den beiden Augen zwei ganz bestimmte Sehzellen gereizt werden oder umgekehrt; werden in den beiden Augen zwei Partien von demselben Objekt aus affiziert, so muß sich auch das Objekt in einer ganz bestimmten Entfernung befinden. Diese Tatsache gibt die Möglichkeit an die Hand, durch Verkettung der Erregungen beider Augen eine Entfernungsempfindung entstehen zu lassen (Demoll und S c heuring).

Eine ganze Anzahl von Insekten sind vollkommen augenlos. Es handelt sich dabei stets um eine Verkümmerung der Augen, infolge Dunkellebens. Daher finden wir blinde Formen hauptsächlich unter solchen Insekten, welche in Höhlen leben oder unter Steinen oder im Holz usw. Die bekanntesten Beispiele sind die Höhlenlaufkäfer (Anophthalmus), dann verschiedene bei Ameisen lebende Käfer (Ameisengäste), ferner die Arbeiter der meistenteils unterirdisch lebenden Termiten usw. Noch mehr augenlose Formen als unter den Imagines gibt es unter den Larven, von denen nur an die Fliegenmaden, an die Larven der Bienen, Ameisen und Wespen, der Schlupfwespen, der Borken- und Bockkäfer erinnert sei. 
Übrigens sind diese augenlosen Insekten keineswegs jeder Lichtempfindung bar, sondern viele von ihnen reagieren ganz deutlich auf hell und dunkel. Besonders auffallend ist dies bei den Fliegenmaden, die sogar die Richtung der Strahlen unterscheiden können. Man nimmt an, daß solche Empfindungen durch die Haut (resp. Hautsinnesorgane) übermittelt werden, weshalb man auch von einem photodermatischen Sinn der Insekten spricht (Graber). Damit soll aber nicht gesagt sein, daß diese Insekten vermittelst der Haut "sehen“ können; sondern die photodermatischen Eindrücke dürfen viel eher unseren Empfindungen von Wärme und Kälte, oder Schmerz oder Berührung usw. als unseren optischen Empfindungen rerwandt sein, so daß also das Licht, resp. seine Intensitätsabstufungen und die Länge der Wellen, wohl nur "gefühlt" wird.

\section{Fortpflanzungsorgane.}

Die Insekten sind normalerweise fast ausschließlich getrennten Geschlechtes. Nur in ganz seltenen Fällen kommt Hermaphroditismus als

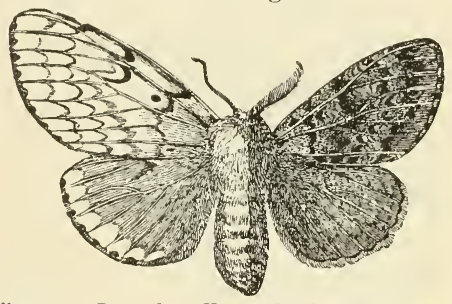

Fig. 93. Lateraler Hermaphroditismus eines Schmetterlings (Ocneria dispar). Links weiblich, rechts männlich (aus Hertwig). normale Erscheinung vor, nämlich bei einigen in Termitenbauten Ostindiens lebenden winzigen Fliegen (Termitoxenien), die auch sonst - in Anpassung an die parasitische Lebensweise - die sonderbarsten Um- und Rückbildungen zeigen. ${ }^{1}$ ) - Pathologische Zwitter, auf anormalen Entwicklungsvorgängen beruhend, kommen dagegen durchaus nicht so selten vor, und zwar in den verschiedenen Insektenordnungen. Am eingehendsten hat man dieselben bei den Schmetterlingen und Ameisen studiert. Bezüglich der Verteilung der männlichen und weiblichen Charaktere herrscht (wenigstens bei den Ameisen) die größte Mannigfaltigkeit, so daß man kaum zwei Formen findet, die nach genau dem gleichen Schema gebaut sind.

Im allgemeinen unterscheidet man folgende Kategorien von Zwittern:

Laterale $\mathrm{Hermaphroditen:} \mathrm{rechts} \mathrm{weiblich,} \mathrm{links} \mathrm{männlich} \mathrm{oder}$ umgekehrt (Fig. 93).

Transversale Hermaphroditen: dorsal weiblich, ventral männlich oder umgekehrt.

Frontale Hermaphroditen: vorn weiblich, hinten männlich oder umgekehrt.

Ge $\mathrm{mischte} H$ e r m a phoditen: unregelmäBige Verteilung der zwei Geschlechter.

Die Zwitter sind natürlich um so auffallender, je größer der sexuelle Dimorphismus ist, d. h. je verschiedener gestaltet Männchen und Weibchen sind. Die auffälligste Form entsteht da, wo das eine Geschlecht geflügelt, das andere ungeflügelt ist (z. B. Frostspanner), indem hier beim lateralen Hermaphroditismus ein Tier entsteht, welches auf der einen Seite ausgebildete Flügel besitzt, auf der anderen Seite dagegen vollkommen flügellos ist.

1) Der Hermaphroditismus von Termitoxnia wird neuerdings, wie oben schon erwähnt, bestritten. 
Im Bau der Fortpflanzungsorgane läßt sich in den beiden Geschlechtern der gleiche Grundplan erkennen, und können wir überall folgende Hauptteile unterscheiden: (siehe Fig. 94 u. 99) ein Paar Geschlechts oder Keimdrüsen (Hoden, Eierstock), in denen die Geschlechtsprodukte (Samen, Eier) gebildet werden; ferner parige Ausfuhrkanäle (Samenleiter oder Vasa deferentia, Eileiter oder Ovidukte), welche die Geschlechtsprodukte von den Keimdrüsen aufnehmen; und endlich ein unpaarer Endkanal (Samengang oder Ductus ejaculatorius, Scheide oder Vagina), in welche jene paarigen Kanäle münden, und welche die Geschlechtsprodukte nach außen leiten. $\mathrm{Zu}$ diesen Hauptteilen kommen noch folgende Nebenresp. Anhangsteile: Schleim- oder Kittdrüsen, welche Sekrete für verschiedene $Z$ wecke liefern, und welche in verschiedener Zahl und an verschiedenen Stellen (entweder an den paarigen Kanälen und dem unpaaren Kanal) auftreten können; ferner Erweiterungen oder Ausstülpungen der ausführenden Kanäle, welche zur Aufbewahrung der Geschlechtsprodukte oder Aufnahme der Begattungsorgane dienen.

Ihrer Entstehung nach setzen sich die Geschlechtsorgane aus zwei differenten Teilen zusammen: der $\mathrm{unp}$ a a re Endkanal entsteht nämlich als $\mathrm{H}$ a u te instülpung, ist also ektodermal und daher meist mit einer Chitincuticula ausgekleidet, während die paarigen A bschnit te (Keimdrüsen nebst Ausführgängen) aus dem Mesoderm hervorgehen und daher stets ohne Cuticula sind. Die beiden so (unabhängig voneinander) entstandenen Abschnitte wachsen einander entgegen, um sich schließlich miteinander zu verbinden.

Nur bei wenigen Insekten (Eintagsfliegen, Termitenweibchen, manchen Ohrwürmern, Proturenmännchen usw.) fehlt der unpaare Endkanal, so daß die paarigen Ausfuhrgänge direkt nach außen münden, und demnach auch paarige Geschlechtsöffnungen vorhanden sind.

Die gesamten Fortpflanzungsorgane liegen stets im Hinterleib, dessen Lumen sie, wenigstens im weiblichen Geschlechte, im reifen Zustand, oft zum größten Teil einnehmen. Die Geschlechtsöffnung liegt beim Männchen zwischen dem 9. und 10., beim Weibchen zwischen dem 8. und 9. Hinterleibssegment.

\section{Die weiblichen Fortpflanzungsorgane.}

Die weiblichen Keimdrüsen, die Eierstöcke oder Ovarien, bestehen aus einer größeren oder geringeren Anzahl von Eiröhren. Diese sind kurz vor der Stelle, wo sie dem Eileiter, resp. dem erweiterten Endteil desselben, dem sog. Eikelch, aufsitzen, am breitesten, um sich nach vorne, nach der Spitze zu, allmählich zu verjüngen. Hier gehen sie in einen feinen Faden, den sog. Endfaden, über, durch den sie an der Rückenwand in der Nähe des Herzens befestigt werden. In diesen Eiröhren entstehen die Eier in linearer Aneinanderreihung, so daß das dem Eikelch zunächst gelegene das reifste und größte, das am weitesten nach der Spitze zu gelegene das jüngste und kleinste ist. Da die Wandungen der Eiröhren sich (teils durch Muskeln) dicht den Eiern anschmiegen, so nehmen die Röhren perlschnurartige Gestalt an (Fig. 96).

Jede Eiröhre besteht aus einer bindegewebigen, häufig mit Muskelfäden bekleideten Membran, welche einen aus Zellen bestehenden Inhalt umschließt. Dieselben sind zweierlei Natur, indem die einen einfache Epithelzellen darstellen, welche zur Auskleidung der Eiröhren, resp. zur Umhüllung der 
Eier dienen (Hüll-oder Follikelzellen), während in den anderen die eigentlichen Keimzellen zu erblicken sind. Von den letzteren wird aber gewöhnlich nur ein Teil zu wirklichen Eiern, während die übrigen zur Ernährung der Eier als sog. Nährzellen verwendet werden. Nur bei niederen Insekten (ganz ausnahmsweise auch bei höheren [Floh]) kommt es vor, daß sämtliche in den Eiröhren vorhandenen Keimzellen zu Eiern heranwachsen. In diesem Falle spricht man von panoistischen, in jenem von meroistischen Eiröhren. Letztere lassen wiederum zwei verschiedene Typen unterscheiden, je nachdem alle Nährzellen im vorderen Ende der Eiröhren, in einer besonderen, oft kolbig angeschwollenen Nährkammer liegen (Eiröhren mit endständiger Nährkammer oder telo1rophe Eiröhren), oder aber die Nährzellen über die ganze Eiröhre verteilt und zwischen den
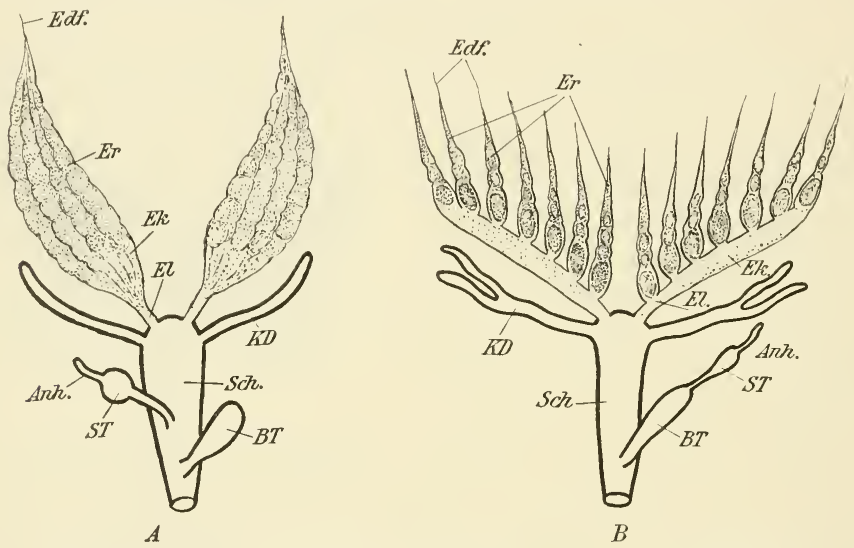

Fig. 94. Schematische Darstellung der weiblichen Geschlechtsorgane. $A$ mit büschelförmigen, $B$ mit kammförmigen Ovarien. Elf Endfaden; Er Eiröhren; Ek Eikelch; El Eileiter; Sch Scheide (Vagina); $B T$ Begattungstasche (Bursa copulatrix); ST Samentasche (Recept. seminis); Anh Anhangsdrïse derselben; $K D$ Kittdrüse.

Eizellen gelagert sind, so daß also Ei- und Nährkammern miteinander abwechseln (Eiröhren mit wechselständigen Nährkammern, oder polytrophe Eiröhren). Die Ernährung der Eier in den telotrophen Eiröhren geschieht in der Weise, daß von der endständigen Nährkammer Nähr- oder Dotterstränge zu den einzelnen Eiern ziehen, durch welche den letzteren die Nährsubstanzen zugeführt werden (Fig. $95 \mathrm{C}, d s$ ).

Ursprünglich, d. h. im unreifen Ovarium erscheinen die Zellen der Eiröhren noch annähernd gleichartig; erst allmählich tritt eine deutliche Sonderung ein, die sich in der Größe und dem Aussehen kund tut. Dadurch entstehen drei Arten von Zellen: 1. die kleinen Epithel-oder Follikelzellen; 2. die größeren, rundlichen Nährzellen und 3. die ganz großen vereinzelten Eizellen. Sie gruppieren sich in bestimmten Abständen hintereinander und zwar in der Weise, daß eine Eizelle und eine bestimmte Anzahl 
von Nährzellen (z. B. bei den Bienen 48, bei den Schmettertlingen meist 5, bei Chironomus nur eine) durch einen Mantel von Hüllzellen zu einem Eiherd oder Eifach vereinigt werden. Die Eizelle schiebt einen Fortsatz zwischen die ihr zunächst liegenden Nährzellen, um die ihr bereiteten Dotterstoffe aufzunehmen und wächst dabei rasch heran, ohne daß die Nährzellen merklich kleiner werden. Sobald die Eizelle ihre volle Größe erlangt hat, resorbieıt sie die Nährzellen. Die Hüllzellen ziehen sich um das Ei zu einer einheitlichen Schicht zusammen und sondern eine Cuticula ab, welche die Eischale bildet, während unter dieser, von der Eizelle aus, noch eine zweite, sehr feine Haut, die sog. Dotterhaut, entsteht ( $Z$ ander).

Die reifen Eier werden durch Platzen des Hüllmantels (Follikels) aus der Eiröhre ausgestoßen und gelangen in den Eikelch, Eileiter usw. Die zurückgebliebenen Follikelzellen sammeln sich an der Basis des Eifaches an, degenerieren fettig und erzeugen gelbliche Anhäufungen, die sog. „gelben Körper“ oder "Corpora lutea“ (Fig. 98 III, L). Diese stellen demnach ein Kriterium des vollzogenen Eidurchganges, resp. der geschehenen Eiablage dar (NüBlin).

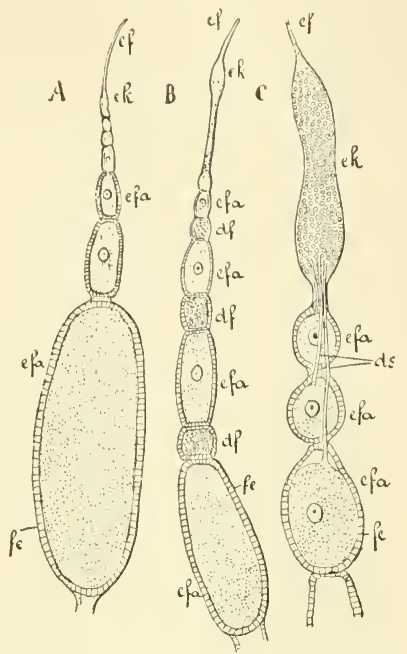

Fig. 95. Verschiedene Typen von Eiröhren. $A$ panoistisch, $B$ meroistisch (polytroph), $C$ meroistisch (telotroph). ef Endfaden; ek Endkammer; efa Eifächer; $f e$ Follikelepithel; $d f$ Nährkammer; $d s$ Verbindungsstränge zwischen End- und Eikammer (aus Lang).

Die Gestalt des Eierstockes hängt ab einmal von der Zahl und Länge der Eiröhren und sodann von der Art und Weise, wie die Eiröhren dem Eikelch sich anfügen. Man hat nach diesen Merkmalen eine ganze Anzahl von Typen aufgestellt, die sich aber alle mehr oder weniger leicht auf zwei

Grundformen zurückführen lassen, deren Bau aus der beigegebenen

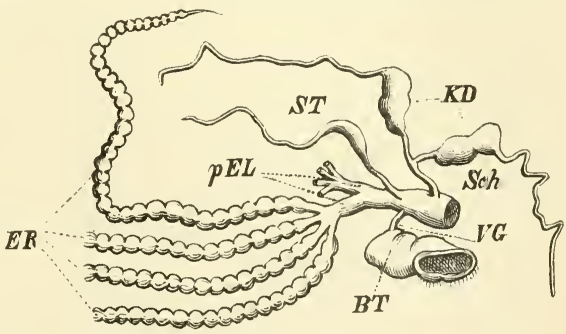

Fig. 96. Weibliche Fortpflanzungsorgane des grofen Kiefernspinners (Bombyx pini L.) (nach Suckow). ER die vier Eiröhren des einen Eierstockes, der andere Eierstock ist abgeschnitten; $p E L$ paarige Eileiter; $S T$ Samentasche mit Anhangsdrüse; $K D$ Kittdrüsen; Sch Scheide; $B T$ Begattungstasche; IG Verbindungsgang zwischen Begattungstasche und Scheide. - (N.) schematischen Figur 96 ohne weiteres hervorgeht: nämlich 1. die büschelförmigen mit kurzem, trichterförmigem Eikelch, der alle Eiröhren zu einem Büschel vereinigt 
trägt; 2. die kammförmigen mit langgestrecktem, schlauchförmigem Eikelch, der in seiner ganzen Länge mit Eiröhren besetzt ist.

$\mathrm{B} \ddot{\mathrm{s}} \mathrm{ch}$ elförmige Ovarien finden sich bei den Orthopteren (zahlreiche panoistische Eiröhren), dem größten Teil der Coleopteren, den Lepidopteren (meist 4 lange polytrophe Eiröhren), den Hymenopteren [2 (Andrena) bis 180 (Honigbiene) polytrophe Eiröhren], den brachyceren und pupiparen Dipteren (2-100 polytrophe Eiröhren), den Siphonapteren (5 panoistische Eiröhren) u. a. $\mathrm{K}$ a m m förmige Ovarien kommen vor bei den Libellen, den Panorpaten, einem Teil der Coleopteren (Lampyriden, Canthariden usw.), den nematoceren Dipteren u. a.

Die Formen der Eierstöcke resp. die Zahl der Eiröhren steht in innigem Zusammenhang mit der Eiproduktion der betreffenden Art. Je zahlreicher und je länger die Eiröhren sind, desto mehr Eier können produziert werden; und andererseits in je geringerer Zahl und zugleich je kürzer die Eiröhren sind, desto geringer ist auch die Produktivität. Ferner können wir aus der

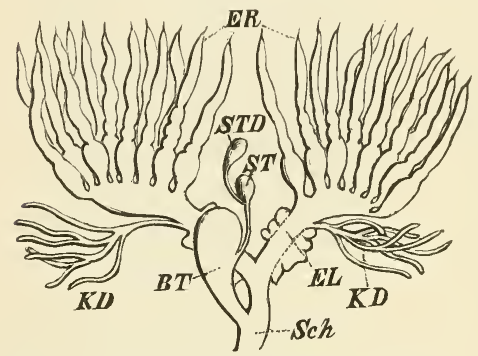

Fig.97. Weibliche Geschlechtsorgane eines Schwimmkäfers (Dytiscus) (nach Stein). ER Eiröhren; $S T$ Samentasche ; STD Samentaschendrüse ; $B T$ Begattungstasche ; $E L$ Eileiter mit drüigen Wandungen; $K D$ Kittdrüsen; Sch Scheide. - (N.)

Zahl der Eiröhren auch annähernd schließen, wieviel Eier gleichzeitig abgelegt werden können, insofern als nur soviel Eier gleichzeitig reifen können, als Eiröhren vorhanden sind.

Bei langlebigen Insekten, welche ihre Eier in größeren Zwischenräumen ablegen, werden wir demnach in den meisten Fällen nuı wenige, aber entsprechend lange Eiröhren mit vielen Eianlagen finden (Borkenkäfer, Rüsselkäfer usw.); kurzlebige Insekten dagegen, welche ihre gesamte Eiproduktion in kurzer Zeit erledigen müssen, werden zahlreiche, dafür aber kurze Eiröhren besitzen. Die Schmetterlinge machen darin allerdings eine Ausnahme; sie haben im allgemeinen nur ein kurzes Imagoleben, und trotzdem nur wenig Eiröhren (in der Regel nur 4, selten mehr). Dieser scheinbare Widerspruch erklärt sich aber daraus, daß die Eiröhren der Schmetterlinge sehr lang sind, und daß die Eier schon während der Puppenruhe völlig ausgebildet werden, so daß bereits bei den frischgeschlüpften Schmetterlingen eine große Zahl fertiger Eier in den Eiröhren enthalten sind.

Die Gestalt der Ovarien kann aber auch noch durch andere Faktoren als die obengenannten beeinflußt werden, so vor allem durch den Grad der Reife. Keineswegs alle Insekten treten nämlich mit völlig reifen Geschlechtsorganen in das Imagostadium ein, sondern bei einer ganzen Anzahl findet die Reifung vielmehr erst während des Imagolebens statt, wie z. B. bei den Rüssel- und Borkenkäfern. Untersuchen wir nun ein junges Weibchen eines solchen Käfers, so treffen wir die Ovarien noch ganz klein und die einzelnen Eiröhren noch kaum angedeutet (Fig. 98 I). Anders bei einem 
älteren, ausgereiften Weibchen (Fig. 98 II): Hier sind die Eiröhren mächtig entwickelt und durch Einschnürungen in Eifächer getrennt, welche von der Nährkammer bis zum Eikelch allmählich an Größe zunehmen (Nüßlin).
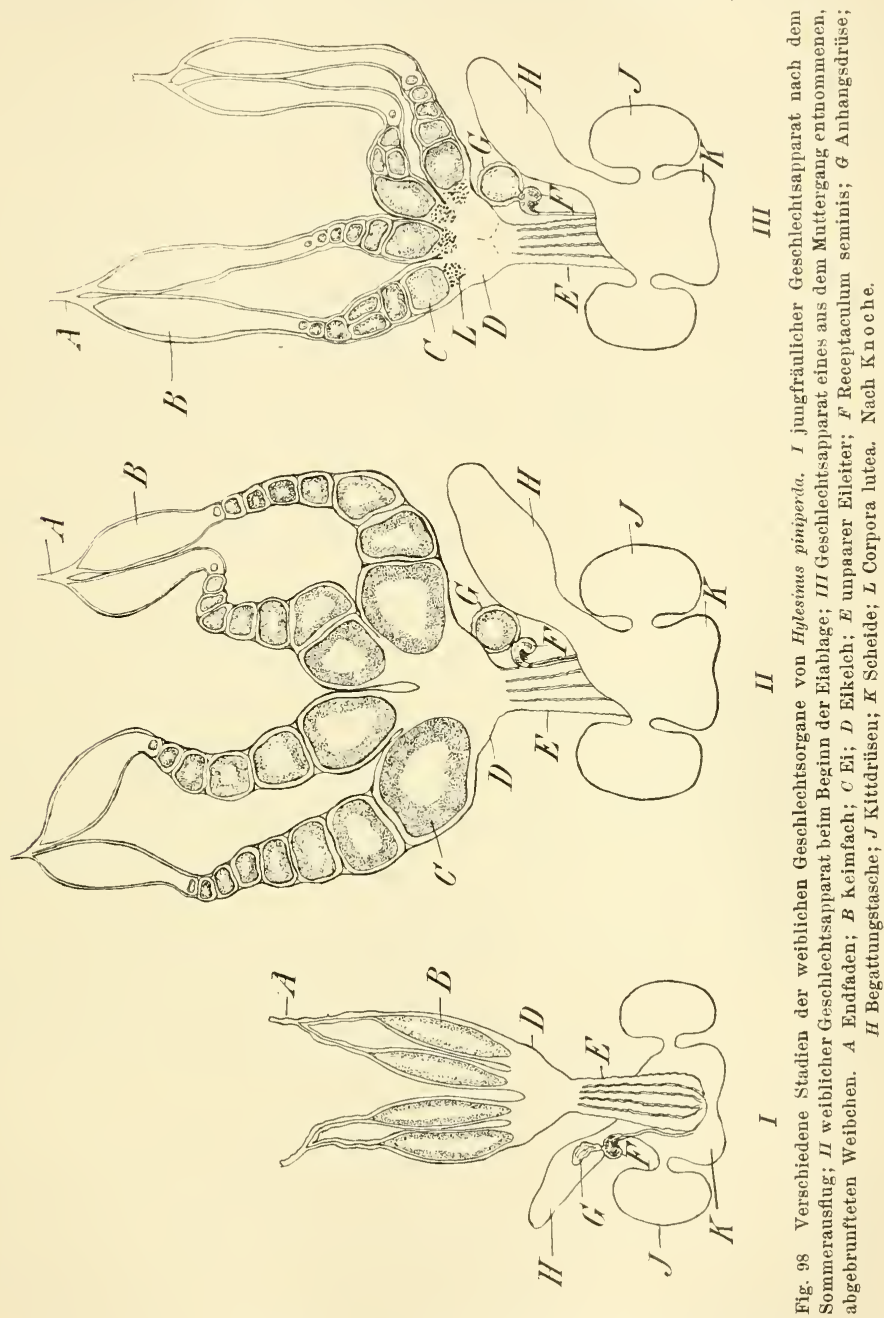

Die Eiröhren münden in die Eikelche, die sich nach hinten in die Eileiter oder Ovidukte fortsetzen. Diese stellen einfache dünne Schläuche dar und münden in den unpaaren Endkanal, die Scheide (Vagina), die 
wie oben bereits bemerkt, als eine Hauteinstülpung entstanden ist und infolgedessen mit einer Chitincuticula ausgekleidet ist.

Bei einigen Insekten machen die Eier, bei anderen (Pupiparen) sogar die Larven ihre ganze Entwicklung in der Scheide durch, so daß sie als Puppen geboren werden. In allen diesen Fällen bezeichnet man die Scheide, die auch deutlich erweitert ist, als Fruchthälter oder Uterus.

An der Scheide sitzen gewöhnlich eine Anzahl Anhangsgebilde, welche sämtlich durch Ausstülpung der Scheidenwand entstanden sind und daher ebenfalls eine Chitinauskleidung besitzen.

Am regelmäßigsten kommt die Samentasche (Receptaculum seminis) vor, welche die Funktion hat, den Samen aufzunehmen und aufzubewahren. Da viele, ja die meisten Insekten nur einmal begattet werden, so muß der Samen oft lange Zeit, bis zu mehreren Jahren (Bienen und Ameisen) bewahrt werden. In die Samentasche münden häufig noch Drüsen, deren Sekret wohl mit der Lebendigerhaltung der Samenfäden in Zusammenhang steht. Die innere Wand der Samentasche, resp. die Chitinauskleidung, zeigt oft sehr charakteristische Bildungen, wie Wülste, Borsten, Haare usw. Die Samentasche hängt meist durch einen kürzeren oder längeren Gang mit der Scheide direkt zusammen; oder aber sie kann auch in die ron der Scheide ausgestülpte Begattungstasche münden. Bei manchen Insekten kommen auch mehrere Samentaschen vor, wie z. B. bei den Tachinen, wo sie mitunter in der Dreizahl auftreten.

Von der Samentasche aus geschieht die eigentliche Befruchtung, indem das Weibchen während des Durchgleitens der reifen Eier durch die Scheide Samenfädchen aus jener austreten läßt, die auf die Eier resp. in die Micropylen gelangen. Manchmal ist der Samentaschengang mit kompliziertem Pump- und Verschlußapparaten versehen, durch welche der Samen gewissermaßen aus der Tasche herausgepumpt, und der Durchtritt des Samens reguliert wird. Dies ist der Fall bei der Bienenkönigin, die es ja bekanntlich „in der Hand“ hat, die Eier zu befruchten oder unbefruchtet $\mathrm{zu}$ lassen, und so das Geschlecht zu bestimmen (unbefruchtete Eier ergeben die Männchen).

Neben der Samentasche kommt gelegentlich an der Scheide noch ein zweiter größerer taschenförmiger Anhang vor, die sog. Begattungstasche (Bursa copulatrix) die dazu dient, das männliche Glied bei der Begattung aufzunehmen. Bei den Schmetterlingen münden Begattungstasche und Scheide völlig getrennt voneinander nach außen, während sie innen durch einen engen Kanal miteinander verbunden sind (Fig. 96).

Außerdem besitzt die Scheide auch noch Anhangsdrüsen (Kittoder Schmierdrüsen), die in verschiedener Zahl auftreten und verschiedene Formen aufweisen können (einfach schlauchförmig oder mehrfach verzweigt oder sackförmig usw.). Ihre Sekrete dienen dazu, die Eier an der Unterlage festzukleben, oder aber sie mit besonderen Kokons zu umgeben, oder die in Wasser abzulegenden Eier in Gallerte (Laich) einzubetten, und noch zu vielen anderen $Z_{\text {wecken. }}$

Wie aus der oben gegebenen Darstellung hervorgeht, kann die Untersuchung der weiblichen Geschlechtsorgane wertvolle biologische 
Aufschlüsse liefern; und es wurden auch in der Tat manche interessante und für die Praxis wichtige Entdeckungen (Generationsverhältnisse der Rüsselund Borkenkäfer) nur durch eingehende Berücksichtigung der weiblichen Geschlechtsorgane ermöglicht. Nach Nüßlin sind es hauptsächlich folgende Punkte, die dabei zu beachten sind:

1. Winzige, nicht in Eifächer gesonderte Eiröhren sind ein sicheres Kriterium für geschlechtlich Unreife;

2. Perlschnuraıtig gegliederte lange Eiröhren zeigen die mehr oder weniger entwickelte Reife an;

3. Corpora lutea sind ein Kriterium des vollzogenen Eidurchganges;

4. Gefüllte Begattungs- oder Samentaschen beweisen die vollzogene Begattung;

5. Leere Begattungs - oder Samentaschen beweisen (wenigstens in den meisten Fällen) jungfräulichen Zustand.

Auch in systematischer Beziehung liefern die weiblichen Geschlechtsorgane mitunter recht brauchbare Merkmale, wovon im speziellen Teil noch mehrfach die Rede sein wird.

Die männlichen Fortpflanzungsorgane.

Die männlichen Keimdrüsen, die Hoden, setzen sich meistens aus einer größeren Anzahl von Blindschläuchen zusammen, welche in der Anlage den Eiröhren entsprechen, aber gemäß dem

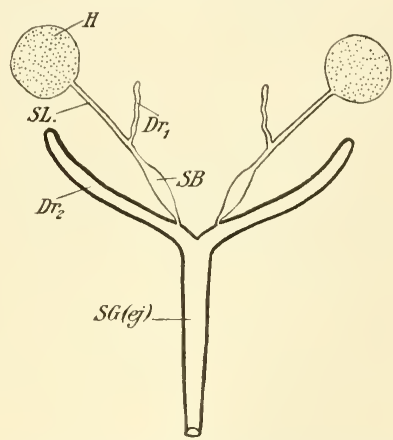

Fig. 99. Schematische Darstellung der mänılichen Geschlechtsorgane. Die dicken Liuieu stellen die ektodermalen, die dünnen die mesodermalen Abschniite dar. $H$ Hoden; $S L$ Samenleiter (Vas deferens); $S B$ Samenblase; $S G(e j)$ Samengang (Ductus ejaculatorius); $D r_{1}$ u. $D r_{2}$ Kittdrüsen (Mesadenien und Ektadenien). geringeren Volumen der produzierten Samenmasse wesentlich kleiner bleiben als jene. In einigen Fällen (Laufkäfer u. a.) besteht jeder Hoden nur aus einem einzigen Blindschlauch, der dafür aber sehr lang und zu einem dichten Knäuel aufgewunden sein kann (Fig. 100).

Jeder Hodenschlauch besteht aus einer äußeren Hülle und einem zelligen Inhalt. Letzterer enthält - wie die Eiröhren - zweierlei Zellen: die Epithel- oder Hüllzellen, und die Keimzellen, die als Ursamenzellen oder Spermatogonien bezeichnet werden. Sie sind ähnlich angeordnet wie in den Eiröhren, indem eine Anzahl Ursamenzellen durch einige Hüllzellen zu einem Samenherd (Spermatocyste) zusammengefaßt werden. Aus jeder Ursamenzelle entstehen durch Teilung sog. Samenmutterzellen, und aus diesen die Samenfäden. Es wird also im männlichen Geschlecht jede Keimzelle zur Bildung von Geschlechtsprodukten verwendet, während im weiblichen Geschlecht, wie wir gehört haben, nur ein Teil derselben zu wirklichen Eiern werden und die anderen zu deren Ernährung dienen. Ein weiterer Unterschied zwischen Ei- und Samen. 
bildung besteht darin, daß dort aus einer Keimzelle stets nur ein Ei, hier aber aus einer Keimzelle mehrere (vier) Samenfäden hervorgehen.

Bezüglich der Gestalt der Hoden herrscht

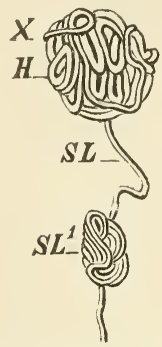

Fig. 100. Der eine Hoden eines Schwimmkäfers (Dytiscus) (nach Burmeister). $X$ blindes Ende des einfachen Hodenschlauches $H$; $S L$ samenleiter; $S L^{1}$ aufgeknäulter Teil desselben, der sog. Nebenhoden. - (N.) eine schier unerschöpfliche Mannigfaltigkeit. Wo die Schläuche durch eine Hülle zusammengefaßt und bedeckt sind, stellen die Hoden meist runde oder ovale oder nierenförmige Körper mit glatter Oberfläche dar (Fig. 103). Wo aber die Schläuche

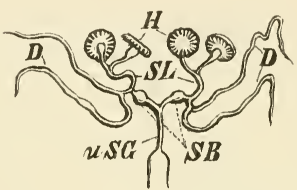

Fig. 101. Männliche Geschlechtsorgane vom großen braunen Rüsselkäfer (Hylobius abietis $L$.). H Hoden; $S L$ parrige Samenleiter ; $D$ Schleimdrüsen; $S B$ Samenblase und $S G$ unpaarer Samengang. - (N.) frei liegen, da nehmen die Hoden büschel-, trauben- oder beerenförmige Gestalt an. Oft ist auch jeder Hoden in mehrere kleine $(2$ bis 12) sekundäre Hoden (Testiculi) zerlegt, von denen ebenso viele feine Ausfuhrkanäle abgehen, die sich nach kurzem Verlauf zu dem gemeinsamen Samenleiter vereinigen (Fig. 102). Meistens sind die beiderseitigen Hoden mehr oder weniger weit voneinander getrennt, doch sind auch solche

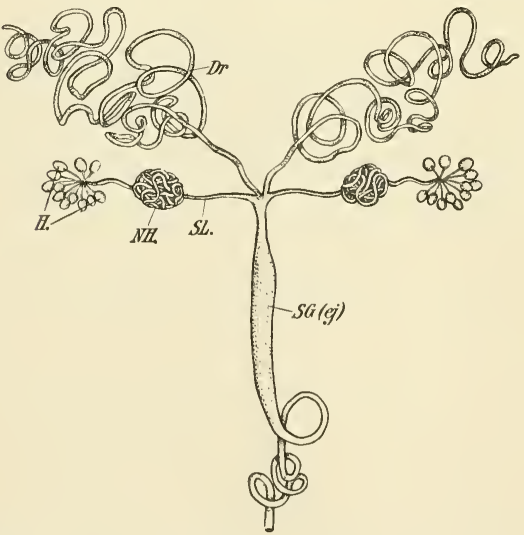

Fig. 102. Männliche Geschlechtsorgane von Lucanus cervus. NH Nebenhoden; $H$ Hoden in eine größere Anzah! Testiculi zerlegt. Die übrigen Bezeichnungen wie in den vorhergehenden Figuren. Nach Escheric'h.

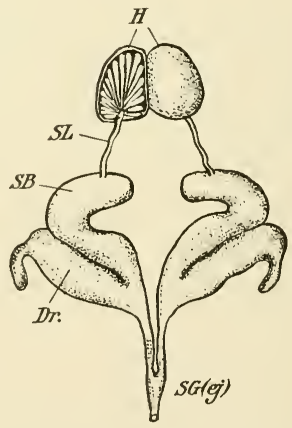

Fig. 103. Männliche Geschlechtsorgane einer Wespe. Die beiden Hoden verwachsen; beim linken Hoden ist die Hülle entfernt. Nach Bordas aus Berlese.

Fälle nicht selten, in denen die Hoden dicht beisammen liegen, und sogar durch eine gemeinsame Hülle vereinigt sind, so daf sie den Eindruck eines einzigen unpaaren Hodens machen (Schmetterlinge, Wespen, gewisse Käfer usw.) (Fig. 103). 
Die von den Hoden ausgehenden Samenleiter (Vasa deferentia) stellen längere oder kürzere einfache Schläuche dar, deren Wände nur eine schwache Muskulatur besitzen. Sie sind stets paarig, auch da, wo die Hoden zu einem scheinbar unpaaren Organ verschmolzen sind. Fast stets stehen mit ihnen Drüsen in Verbindung, deren Sekret dem Samen beigemischt wird. Außerdem finden sich an ihrem hinteren Ende oft blasenförmige Erweiterungen (Samentaschen oder Vesiculae seminales), die zur Aufsammlung des Samens dienen. Wo die Samenleiter sehr lang sind, können sie in ihrem Verlaufe an einer Stelle knäuelförmig zu einer Art Nebenhoden (Fig. 102) aufgewunden sein (Laufkäfer, Schwimmkäfer, Hirschkäfer usw.).

Die paarigen Samenleiter münden in den als Hauteinstülpung entstandenen unpaaren Endkanal oder Ductus ejaculatorius. Nur in seltenen Fällen fehlt dieser und dann münden die Samenleiter paarig nach außen

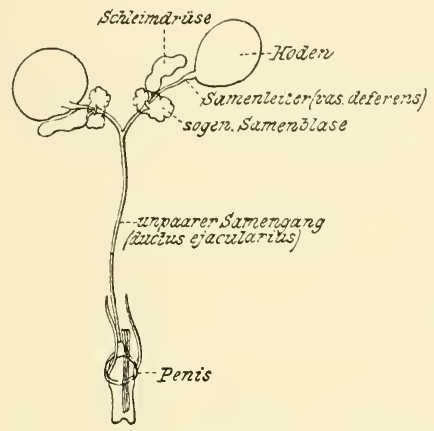
(Eintagsfliegen, Protura). Der Ductus ejaculatorius unterscheidet sich in seinem feineren Aufbau wesentlich von den paarigen Samenleitern, indem er einmal eine sehr starke Muskulatur besitzt (durch deren Kontraktion der Samen ausgespritzt wird), und sodann

Fig. 104. Reife und unreife männliche Geschlechtsorgane vom Buchdrucker (Ips typographus). Aus $N$ üBlin.

seine Innenseite mit einer Chitincuticula, die eine verschiedene Struktur aufweisen kann, ausgekleidet ist. Auch ihm kommen Anhangsdrüsen zu, die an Zahl und Form sehr verschieden sein können, und deren Sekret mehrfachen Zwecken dient (z. B. die Samenfäden zu Paketen oder Patronen zu vereinigen oder bei der Copula die Überführung des Samens in den weiblichen Körper zu erleichtern und zu sichern, usw.).

Da die Drüsen der paarigen Samenleiter dem Mesoderm entstammen, und die des ektodermalen Endkanals natürlich dem Ektoderm, so hat man die beiden Kategorien von Drüsen auch namentlich als Mesadenien und Ektadenien unterschieden.

Wie bei den weiblichen Geschlechtsorganen vollzieht sich auch bei den männlichen die Reifung nicht überall in der gleichen Lebensperiode und in dem gleichen Tempo, sondern bei den einen Insekten früher, bei den anderen später. Bei den kurzlebigen Arten gewöhnlich schon während der Puppenzeit, bei den langlebigen vielfach erst während des Imagolebens. Im letzteren Fall (wie z. B. bei den Borkenkäfern) kann uns also auch die Untersuchung der männlichen Geschlechtsorgane Aufschluß geben, ob ein Escherich, Forstinsekten. 
Jungkäfer oder Altkäfer vorliegt. Im unreifen Zustand sind die Spermatozoen noch nicht in die Samenleiter oder Samenblasen eingetreten, und die verschiedenen Anhangsdrüsen noch wenig entwickelt; im reifen Zustand dagegen finden sich zahlreiche Samenfäden in den Ausfuhrwegen, die Drüsen sind bedeutend verlängert und dicker und prall mit Sekreten gefüllt, und auch die Samenblasen erscheinen stark erweitert (NüBlin). (Fig. 104.)

Auch in systematischer Beziehung lassen sich die (inneren) männlichen Geschlechtsorgane teilweise recht gut verwenden, wenn auch nicht in dem weitgehenden Maße wie äußere Genitalanhänge oder Kopulationsorgane.

\section{Literatur.}

Die Lehr- und Handbücher wie oben S. 48. In erster Linie ist wieder auf $\mathrm{B}$ erlese hinzuweisen und sodann auf $\mathrm{Hesse}$, welch beide Autoren bei der Bearbeitung am meisten benutzt wurden.

Außerdem ist auf folgende Einzelarbeiten namentlich Bezug genommen:

Muskulatur.

$\mathrm{B}$ a u e r, A 1 b e r t, Die Muskulatur von Dytiscus marginalis. Zeitschr. f. wissensch. Zoologie, XCV. Bd., 1910.

$\mathrm{VoB}, \mathrm{Friedrich}$, Über den Thorax ron Gryllus domesticus. Die Muskulatur. Zeitschr. f. wissensch. Zoologie, LXXVIII. Bd., 1905.

L a u t ä $\mathrm{B}$ e r ung e n.

L a n d o is, H., Tierstimmen. Freiburg 1874.

Prochnow, Oskar, Die Lautapparate der Insekten. Berlin 1908.

Verhoeff, K. W., Die zusammengesetzten Zirpvorrichtungen von Geotrupes. Sitzber. Ges. Naturf. Freunde (Berlin 1902), Nr. 7/8.

Petrunkewitsch und Guaita, Utber den geschlechtlichen Dimorphismus bei den Tonapparaten der Orthopteren. Zool. Jahrb., Abt. f. Syst., Bd. 14, Heft 4.

\section{$\mathrm{D}$ a r m k a n 1 .}

Biedermann, W., Beiträge zur vergleichenden Physiologie der Verdauung. Die Verdauung der Larve von Tenebrio molitor. Archiv f. d. gesamte Physiologie, Bd. 72, 1898.

Deegener, Beiträge zur Kenntnis der Darmsekretion. I und II. Archiv f. Naturgeschichte, 76. Jahrgang, 1909 und 10.

Gorka Sandor, Beiträge zur Morphologie und Physiologie des Verdauungsapparates der Coleopteren. Allg. Zeitschr. f. Entomologie 1901.

Jordan, Herm a n n, Utber extraintestinale Verdauung im allgemeinen und bei Carabus auratus im besonderen. Biolog. Zentr.-Bl. 1910 (XXX), S. 85-96.

$\mathrm{N}$ üBlin, Otto, Phylogenie und Systematik der Borkenkäfer. Zeitschr. f. wissensch. Insektenbiologie, VII. und VIII. Bd.

Rungius, Hein rich, Der Darmkanal von Dytiscus marginalis. Zeitschr. f. wissensch. Zoologie, Bd. 98, 1911.

S e d l a c z e k, W., Uber den Darmkanal der Scolytiden. Zentralblatt f. d. gesamte Forstwesen 1902.

\section{$\mathrm{Kr}$ e is 1 a uforgane.}

J a net, Charles, Anatomie du Gaster de la Myrmica rubra. Paris 1902.

$\mathrm{S}$ te ch e, O., Beobachtungen über Geschlechtsunterschiede der Haemolymphe von Insektenlarven. Verh. Deutsch. Zool. Ges. 1912.

$$
\text { Temperatur der Insekten. }
$$

$\mathrm{B}$ a chmet jew, P., Experimentell-entomologische Studien. I. Temperaturverhältnisse bei Insekten. II. Einfluß der äußeren Faktoren auf Insekten. Leipzig 1901 und Sophia 1907.

Dieses grundlegende Werk, in dem neben den eigenen Untersuchungen die gesamte Literatur verarbeitet ist, ist bis jetzt von seiten der Entomologen viel $\mathrm{zu}$ wenig berücksichtigt worden. 
Leuch torgan e.

B o n g a rdt, Beiträge zur Kenntnis der Leuchtorgane einheimischer Lampyriden. Zeitschr. f. wissensch. Zoologie, LXXV. Bd.

R i ed el, M ax, Aus der Welt der Kleintiere. Serie I Nr.2 Leuchtkäfer. Dresden 1911.

G e hirn.

For e 1, A., Das Sinnesleben der Insekten. München 1910.

$\mathrm{H}$ e y m o n s, R., Die Entwicklungsgeschichte der Scolopender. Zoologica, Heft 33. Stuttgart 1901.

Jonescu, C. N., Vergleichende Untersuchungen über das Gehirn der Honigbiene. Jenaische Zeitschr., 45. Bd., 1909.

Piet s chker, Hein rich, Das Gehirn der Ameise. Ebenda 1910.

Tastorgane usw.

Hochreuter, Rudolf, Die Hautsinnesorgane von Dytiscus marginalis $L$. Zeitschr. f. wissensch. Zoologie Bd. C III, 1912.

V o g e 1, R., Über die Innervierung der Schmetterlingsflügel und über den Bau und die Verbreitung der Sinnesorgane auf denselben. Zeitschr. f. wissensch. Zoologie, Bd. XCVIII, 1911.

\section{S e horgan e.}

Demo11, R., Die Physiologie des Facettenauges. Ergebnisse und Fortschritte der Zoologie, 2. Bd., 1910.

Demoll und Scheuring, Die Bedeutung der Ocellen der Insekten. Zoolog. Jahrb., Abt. f. Allgemeine Zoologie und Physiologie, 31. Bd., 1912.

$\mathrm{H}$ es se, R i ch a rd, Untersuchungen über die Organe der Lichtempfindung bei niederen Tieren. VII. Von den Arthropodenaugen. Zeitschr. f. wissensch. Zoologie, LXX. Bd., 1901.

J o h n a s, W., Das Facettenauge der Lepidopteren. Zeitschr. f. wissensch. Zoologie, XCVII. Bd., 1911.

$$
\text { Gehörorgane. }
$$

Eg gers, Fritz, Uber das thorakale Tympanalorgan der Noctuiden. Sitzungsbericht Nat. Ges. Dorpat, XX., 1911.

$\mathrm{Schwabe}$, J., Beiträge zur Morphologie und Histologie der tympanalen Sinnesorgane der Orthopteren. Zoologica. Stuttgart 1906.

V o g e 1, R., Uber die Chordotonalorgane in der Wurzel der Schmetterlingsflügel. Zeitschr. f. wissensch. Zoologie, C. Bd., 1912.

Fortpflanzungsorgane.

D e m a ndt, Carl, Der Geschlechtsapparat von Dytiscus marginalis. Zeitschr. f. wissensch. Zoologie, CIII. Bd., 1912.

Escherich, K., Anatomische Studien über das männliche Genitalsystem der Coleopteren. Zeitschr. f. wissensch. Zoologie, Bd. LVII, 1899.

$\mathrm{K}$ noch e, E., Beiträge zur Generationsfrage der Borkenkäfer. Forstw. Zentralbl. 1909.

$\mathrm{N}$ ü $B 1$ i n, O t t o, Leitfaden der Forstinsektenkunde, 2. Aufl., 1912. 
Kapitel IV.

\section{Fortpflanzung.}

Das Fortpflanzungsgeschäft ist es, welches den Hauptinhalt der Lebenstätigkeit des erwachsenen Insektes ausmacht. Ist die Fortpflanzungsfähigkeit zu Ende, so sterben Weibchen wie Männchen ab. Bei den meisten Weibchen ist das ganze Fortpflanzungsgeschäft mit einer einmaligen Eiablage erledigt, so daß ihre Lebensdauer nur von sehr kurzer Dauer ist (wenige Tage oder gar nur Stunden); andererseits sind doch auch viele Fälle von langlebigen Insekten bekannt, bei denen sich die Fortpflanzung über mehrere Jahre hinzieht, indem die Weibchen nach kürzeren oder längeren Pausen immer wieder zu erneuten Eiablagen schreiten (z. B. Laufkäfer, Rüssel- und Borkenkäfer, die 2-3 Jahre, Ameisen- und Termitenweibchen, die bis zu 15 Jahre alt werden können).

Alle Fortpflanzungsvorgänge bezwecken die Erhaltung der Art. Man kann im Tierreich eine geschlechtliche und ungeschlechtliche Fortpflanzung unterscheiden. Bei der ungeschlechtlichen wachsen beliebige Zellen des Körpers zu einem neuen Individuum aus, das sich dann später vom Muttertier trennt (Knospung usw.); bei der geschlechtlichen sind es schon frühzeitig gesonderte ganz bestimmte Zellen, die sog. Keimzellen (Eier und Samenfäden), denen die Vermehrung obliegt. Bei den Insekten kommt nur der letztere Fortpflanzungsmodus vor; alle Insekten entwickeln sich aus Eiern. Jedes Insekt hat also einmal den Eizustand durchlaufen, und dies gilt auch für diejenigen, welche bereits als Larve geboren werden. Diese durchlaufen den Eizustand eben im Leibe des Muttertieres.

Der alte Aberglaube, daß Insekten direkt aus anderen organischen Substanzen sich bilden können, die Fliegenmade aus faulendem Fleische, der Floh aus mit Harn befeuchteten Sägespänen, ist längst widerlegt. Nicht aus diesen Substanzen, sondern aus Eiern, welche die Fliegenmutter auf das faulende Fleisch, oder der weibliche Floh in die Sägespäne legte, sind diese Geschöpfe entstanden.

In den meisten Fällen hat das $\mathrm{Ei}$ aber nicht ohne weiteres die Fähigkeit, ein neues Tier aus sich hervorgehen zu lassen. Die Eizelle bedarf, um sich zu einem Embryo zu entwickeln, vielmehr meistens der Befruchtung durch den männlichen Samen. Die Fortpflanzung durch befruchtete Eier, bei welcher also beide Geschlechter mitwirken, wird eine gamogenetische

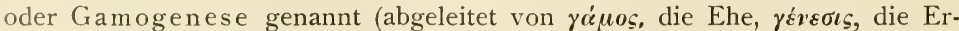
zeugung), im Gegensatz zu den selteneren Fällen, in welchen eine Fortpflanzung durch unbefruchtete Eier stattfindet und welche man als parthenogenetische 
Fortpflanzung oder Parthenogenese bezeichnet (abgeleitet von $\pi \alpha \varrho \vartheta \dot{s} \mathbf{r} \boldsymbol{s}$, die Jungfrau).

\section{Die Keimzellen (Ei und Samen).}

Das Ei.

Das Insektenei besteht aus Eizelle und Eischale oder Chorion. Die Eizelle ist eine stark gewachsene und gereifte Keimzelle und besteht, wie jede Zelle, aus Protoplasma und Kern, welch letzterer auch Keimbläschen genannt wird. Dem Protoplasma ist eine größere oder kleinere Menge von Reservestoffen (Deutoplasma oder Dotter) beigemischt, welche zur Ernährung des im Ei sich entwickelnden Embryos dient, und deren Bildung unter Mitwirkung der Nährzellen (siehe oben) vor sich geht. Die äußerste Schichte des Protoplasmas, resp. Dotters, ist zu einer äußerst feinen Haut, der Dotterhaut, erhärtet (Fig. 105).

Die so gestaltete Eizelle wird umgeben von einer mehr oder weniger starken Schale, die als Schalenhaut oder Eischale oder Chorion bezeichnet wird. Sie wird nicht von der Eizelle aus gebildet, sondern stellt vielmehr ein Abscheidungsprodukt der Follikelzellen (siehe oben) dar und besteht „aus einer Substanz, welche eine oberflächliche Ähnlichkeit mit Chitin hat, sich aber von ihm durch Gehalt an Schwefel und einige andere chemische Eigenschaften unterscheidet" (Groß). Sie ist außer von mehr oder weniger zahlreichen feinsten Poren, die vielleicht der Atmung des Eies dienen, stets noch von einem oder mehreren dicht beisammenstehenden größeren Kanälen durchsetzt, die Mikropylen genannt werden, und welche den $Z$ weck haben, den Samenfäden den Durchtritt zu gestatten (Fig. 106). Sie setzen sich nach innen zu durch die Dotterhaut fort, so daß der Samen ohne Hindernis zum Protoplasma der Eizelle gelangen kann. Meist ist die Umgebung der Mikropyle durch eine besondere Struktur der Schale ausgezeichnet, ja oft kommen

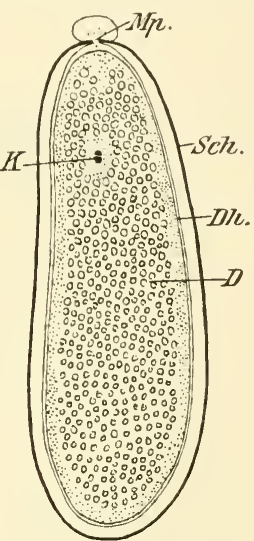

Fig. 105. Längsschnitt durch ein Fliegenei. $K$ Kern; $D$ Dotter; $D h$ Dotterhaut; Sch Schalenhaut (Chorion), Mp Mikropyle.

Nach Henking und Blochmann.

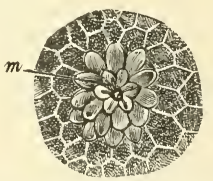

Fig. 106. Oberer Teil eines Eies des Hornissenschwärmers (Trochilium apiforme $C$.) (nach Lenckart) mit dem Mikropylapparat. $m$ einer der 5 Mikropylkanäle, welche von den äußeren Mikropylgrübchen divergierend nach innen laufen. - (N.) sehr komplizierte und höchst auffallende Mikropylenapparate vor, die aus Anhängen aller Art, schlotförmigen Aufsätzen usw. bestehen.

Die Gestalt der Eier ist ungeheuer mannigfaltig; wir können von den langgestreckten, schlauchartigen Eiern der Gallwespen bis zu den flachen, scheiben- oder deckelförmigen Eiern mancher Kleinschmetterlinge alle möglichen 
Übergänge beobachten, wie aus Fig. $107 \mathrm{zu}$ ersehen ist. Dazu kommen die verschiedensten Fortsätze, Anhänge, Rippen, Warzen usw., welche den Eiern mitunter die zierlichsten an Seesterne, Seeigel, Pflanzensamen, Blüten usw. erinnernde Formen verleihen können; manche Eier gleichen Krügen mit Deckeln, andere sitzen auf langen, dünnen Stielen usw. Und auch da, wo die Struktur der Schale bei oberflächlicher Betrachtung glatt erscheint, läßt

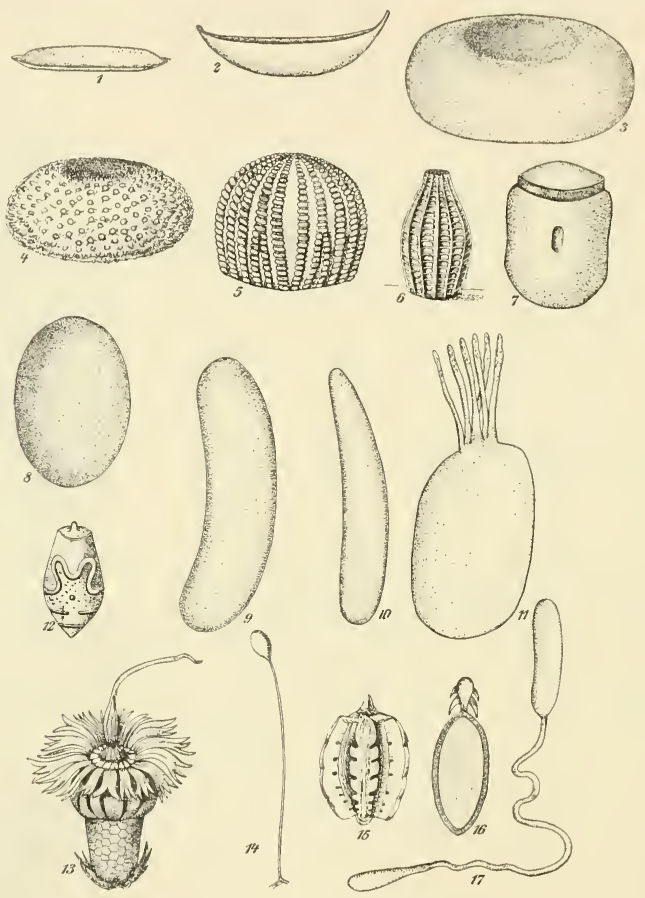

Fig. 107. Verschiedene Eiformen. 1 Tortrix sp; 2 Lyda stellata; 3 Nonne; 4 Thecla (Tagfalter); 5 Oeneis aélto (Tagfalter); 6 Pieride (Weißling); 7 Pentatoma (Schildwanze); 8f Melolontha (Maikäfer); 9 Honigbiene; 10 Laubheuschrecke; 11 Nepa (Wasserskorpion); 12 Phasmide (Stabheuschrecke); 13 Menopon biseriatum (Federling vom Pfau); 14 Chrysopa (Florfliege); 15 Phyllium (Wandelndes Blatt); 16 Oestromyia Satyrus (Hantbremse); 17 Cynipide (Gallwespe). Teils Originale, teils aus S harp, Packard, Spuler, Brauer.

die mikroskopische Untersuchung meist noch sehr feine, charakteristische Strukturen (netzförmige Felderung usw.) erkennen. Auch bezüglich der Härte, Dicke und Zähigkeit usw. der Eischale gibt es große Unterschiede: wir haben auf der einen Seite so dünn beschalte Eier, daß sie ihre Form verändern können, andererseits aber Schalen, die an Härte und Sprödigkeit dem Glas nicht viel nachstehen. Den erstgenannten Zustand treffen wir hauptsächlich bei solchen Eiern, welche in pflanzliche und tierische Gewebe abgelegt werden, 
den letzteren dagegen bei solchen, welche völlig frei abgelegt sind und des Schutzes bedürfen.

Die Funktionen der verschiedenartigen Bildungen an den Eiern ist noch keineswegs überall klar; doch dürften die meisten Anhänge usw. als Haftapparate (zum Haften an der Unterlage oder zur gegenseitigen Verbindung mehrerer Eier) dienen; oft stehen sie auch, wie schon erwähnt, mit der Mikropyle in Verbindung; bei gewissen Wanzen werden die am Deckelrand stehenden Fortsätze als Einrichtungen zum Gasaustausch (Atmung) angesehen (Heymons, Groß) usw.

\section{Der Samen.}

Der Samen besteht aus Samenfäden, welche in einer Flüssigkeit schwimmen. Die Flüssigkeit stammt aus den Anhangsdrüsen der Samenleiter, die Samenfäden aus den Hoden (siehe oben). Im Gegensatz zu den Eiern sind die Samenfäden mikroskopisch klein; sie bestehen aus zwei deut-
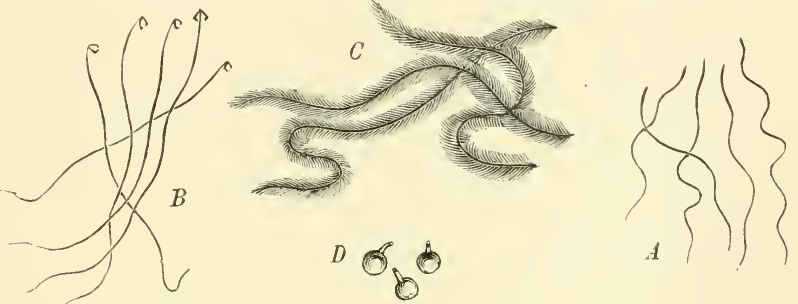

Fig. 108. A Einfache Samenfäden von Blaps mortisaga $L_{\text {; }}$ B Bamenfäden mit ankerförmigen Köpfchen von einer Heuschrecke (Decticus vermecivorus L.); $C$ Vereinigung von Samenfäden einer anderen Heuschrecke (Locusta viridissima L.) zu federförmigen Gebilden; $D$ Spermatophoren von Decticus. $B-D$ nach v. Siebold. - (N.)

lich voneinander unterscheidbaren Abschnitten, dem starren unbeweglichen Kopf, und dem beweglichen, sich lebhaft hin und her schlängelnden Schwanz (Fig. 108). Trotz der Kleinheit und der ungewöhnlichen Form entspricht jeder Samenfaden morphologisch einer Zelle, deren Kern im Kopf gelegen ist, während der Schwanz das Protoplasma enthält

Wenn die Samenfäden auch in ihrer Grundform bei den meisten Insekten übereinstimmen, so weisen sie doch in den Einzelheiten große Verschiedenheiten auf. So ist der Kopf in Form, Zusammensetzung und Größe sehr variabel: bei den einen Insekten endet er in einer feinen Spitze, bei den anderen in einem feinen Knöpfchen, bei wieder anderen liegen mehrere Knöpfchen übereinander oder es ist der Kopf ankerförmig gebaut usw. Auch der Schwanz ist, wie Ballowitz gezeigt hat, in seinem feineren Aufbau recht mannigfaltig, und besteht bei den einen aus mehr, bei den anderen aus weniger nebeneinander liegenden und verschieden strukturierten Fasern. Häufig sind mehrere Samenfäden (zwei bis zahlreiche) mit ihren Köpfen entweder dirckt miteinander verbunden oder um einen axialen Körper befestigt, während die Schwänze frei bleiben (Spermatozeugma); bei manchen 
Heuschrecken reihen sich die Köpfe in linearer Anordnung derart aneinander, daß die frei abstehenden Schwänze seitlich ansitzen wie die Federfahnen dem Schaft.

Der Samen, möge er isoliert oder zu Gruppen vereinigte Samenfäden enthalten, ist in den meisten Fällen eingehüllt in eine feste, von den Anhangsdrüsen abgesonderte Hülle, welche als Samenpatrone oder Spermatophor bezeichnet wird, so daß also der Samen bei der Begattung nicht lose, sondern in fester Verpackung in den weiblichen Körper übertragen wird.

\section{Die Begattung.}

Die Übertragung des Samens in den Geschlechtsapparat des Weibchens geschieht durch den Vorgang der Begattung oder Kopulation. Die Haupt-

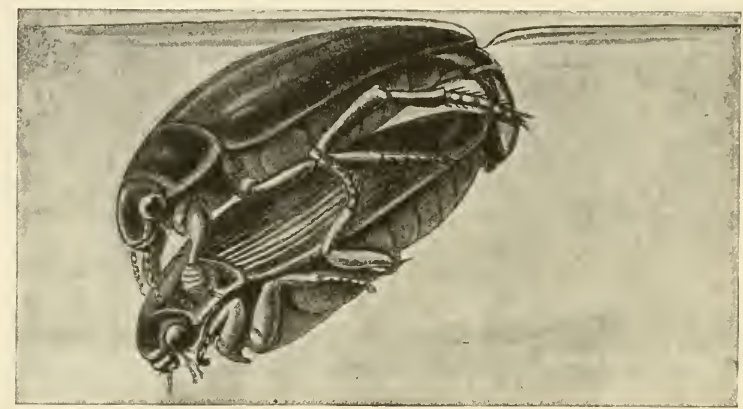

Fig. 109. Kopulationsstellung des Gelbrandkäfers (Dytiscus marginalis). Das Männchen sitzt auf dem Weibchen, wobei es sich mit den Haftscheiben der Vorderbeine auf dem Halsschild des Weibchens festsaugt. Nach Blunk.

rolle dabei spielt der Penis, der in die weibliche Begattungstasche eingeführt wird, und durch den die Samenmasse, resp. die Samenpatrone, in den weiblichen Körper übergeleitet wird. Damit nun dieser Vorgang, der doch stets einige Zeit beansprucht, sich richtig abspielen kann, ist es notwendig, daß die beiden Tiere fest miteinander verankert werden. Dies geschieht vielfach durch besondere Zangen (Parameren), die $z u$ beiden Seiten des Penis liegen und mit den verschiedenartigsten Zähnen, Haken usw. besetzt sind. Außerdem finden sich bei vielen Insekten auch noch an anderen Organen Vorrichtungen, die dem Zwecke des Festhaltens während der Kopula dienen. So haben z. B. die Männchen vieler Laufkäfer stark erweiterte Vordertarsen, mit denen sie sich auf dem Rücken des Weibchens anklammern, oder die Männchen der Schwimmkäfer (Dytiscus) besitzen richtige Haftscheiben an den Vorderbeinen, um sich auf dem Halsschild der Weibchen festzusaugen, usw. 
Die Art und Weise, wie die Kopula ausgeführt wird, ist ungemein verschieden; manche Insekten begatten sich im Fluge (z. B. Fliegen, Bienen, Ameisen, Eintagsfliegen usw.), manche im Laufen oder Schwimmen, manche im Sitzen (Schmetterlinge), manche im Sonnenschein, manche im Schatten oder in der Nacht, oder in unterirdischen oder in Holz gegrabenen Gängen usw. Auch die Stellung, die sie einnehmen, ist verschieden: Entweder sitzen die beiden Geschlechter aufeinander (meist das Männchen auf dem Weibchen, selten [z. B. beim Floh] umgekehrt), so daß sie also in die gleiche Richtung sehen (Fig. 109); oder sie sitzen hintereinander, Hinterende gegen Hinterende gekehrt, wobei sie meistens in die direkt entgegengesetzte

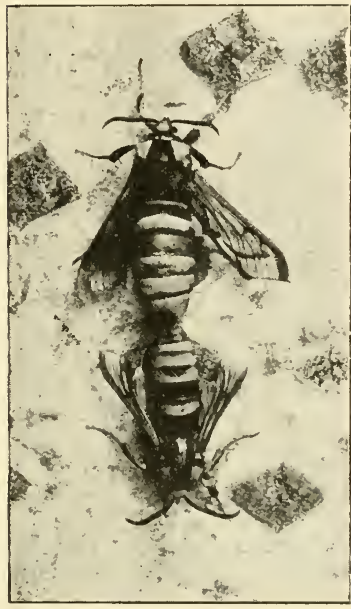

$A$

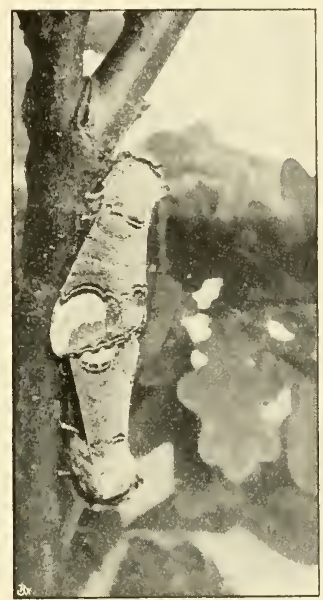

$B$

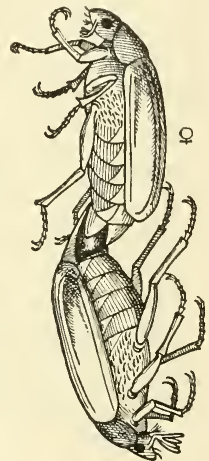

$C$

Fig. 110. A u. B Schmetterlinge in Kopula. A Hornissenschwärmer (Trochitium apiforme); $B$ Mondvogel (Phalera bucephala). Oben das Weibchen. Phot. Fr.Scheidter. - C Maikäfer in Kopula, das Weibchen hält sich an einem Zweig fest, während das Männcheu frei herabhängt. Nach Götte.

Richtung sehen (Fig. 110). Doch kommt es auch vor, daß diese verbundenen Tiere sich gegeneinander abbiegen, so daß die Längsachse ihrer Körper nicht mehr in einer Linie liegen, sondern einen Winkel bilden. Dieses Abbiegen kann entweder nach der Seite hin geschehen (Fig. 111), so daß die linke und rechte Seite der beiden Tiere sich einander nähern und die Tiere gewissermaßen nebeneinander sitzen; oder ventralwärts, so daß die Bauchseiten einander näher kommen. Bei Chlö̈on sind die beiden Geschlechter (nach C. Bernhard) während der im Fluge stattfindenden Kopula Bauch gegen Bauch gewandt, wobei das Männchen den Thorax des über ihm befindlichen Weibchens mit den langen Vorderbeinen umklammert. 
Eine ganz abweichende Kopulationsstellung nehmen die Libellen ein. Bei den Männchen dieser Tiere liegt das Kopulationsorgan weit getrennt von der am Hinterende befindlichen Geschlechtsöffnung, nämlich an der Bauchseite an dem zweiten Hinterleibsring. Wenn nun das Männchen zur Begattung schreiten will, so biegt es seinen Hinterleib ventralwärts und nach vorne, um das Kopulationsorgan mit Samen zu füllen; dann ergreift es mit den am Ende seines Hinterleibes befindlichen Zangen das Weibchen am Nacken, und zieht es so mit sich auf den Hochzeitsflug. Während desselben biegt das Weibchen seinen Hinterleib so um, daß ${ }^{\circ}$ es mit seinem Ende dem Kopulationsorgan des Männchens

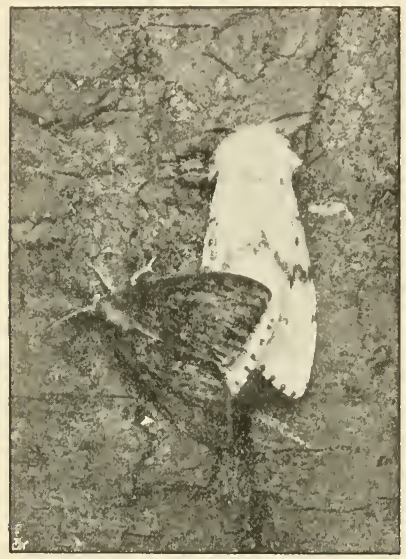

Fig. 111. Schwammspinner in Kopula. Oben das Weibchen. Das kleinere dunkelgefärbte Männchen befindet sich in seitlich abgebogener Stellung. Phot. Fr. Scheidter. sich nähert, und nun die Begattung vollzogen werden kann (Fig. 112).

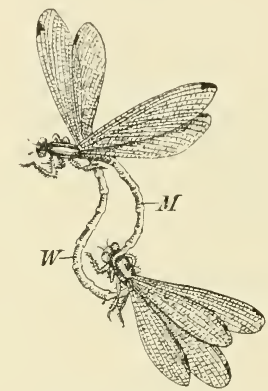

Fig. 112. Libellen in Kopula. Das Männchen (M) ergreift mit seinen Hinterleibszangen das Weibchen am Nacken, während dieses seinen Hinterleib nach vorn biegt, um zu dem am 2. Hinterleibssegment des Männchens befindlichen Kopulationsorgan zu gelangen. Aus Henzeguey.

Die Dauer der Kopula kann sehr verschieden lang sein: bei manchen Insekten nur wenige Minuten, bei anderen mehrere Stunden, ja sogar Tage. Bei den meisten Insekten ist es mit einer einmaligen Begattung getan; ja in einigen Fällen (bei der die Bienenkönigin befruchtenden Drohne) hat die Begattung den sofortigen Tod des Männchens zur Folge. Andererseits gibt es auch gar nicht so selten Fälle, in denen die Mänuchen eine öftere Begattung mit demselben Weibchen ausführen oder auch von einem Weibchen zum anderen gehen. So sind z. B. bei Spinnern und auch bei anderen Schmetterlingen (Saturniden, Psychiden usw.) Männchen bei wiederholter Begattung mit verschiedenen Weibchen beobachtet worden; ferner ist die Polygamie bei den Borkenkäfern eine ganz verbreitete Erscheinung; auch bei den Schwimmkäfern und Blattkäfern ist sie festgestellt worden usw. Öftere Begattung eines Weibchens durch rerschiedene Männchen (Polyandrie) 
ist bis jetzt nur selten beobachtet und dürfte wohl als abnormer Zustand zu betrachten sein. Dagegen kommt wiederholte Begattung durch ein und dasselbe Männchen gar nicht so selten vor; so wurden z. B. 2 DytiscusWeibchen von 1 Männchen innerhalb $5^{1 / 2}$ Monaten $14 \mathrm{mal}$, und 2 Lucanus cervus-Weibchen von 1 vilännchen in 12 Tagen õmal begattet. Bei manchen Insekten bildet die öftere Begattung des Weibchens geradezu die Regel, so bei gewissen Borkenkäfern, die, nachdem sie einige Eier abgelegt, immer wieder von neuem befruchtet werden, und sodann vor allem bei den Termiten, bei denen das Männchen viele (bis zu 15) Jahre mit einem Weibchen in der Königskammer zusammengesperrt ist, um das letztere von Zeit zu Zeit (alle 4-6 Wochen) zu begatten und mit neuem Samenvorrat $\mathrm{zu}$ versorgen.

Nicht immer, wenn zwei Insekten in Kopulationsstellung sich befinden, wird auch eine wirkliche erfolgreiche Begattung ausgeführt; kann man doch oft zwei Tiere, die noch gar nicht reif sind, aufeinander sitzen sehen. Um also ganz sicher zu gehen, ob eine erfolgreiche Begattung stattgefunden hat, muß man die Samentasche des Weibchens auf die Anwesenheit von Samenfäden untersuchen. Nur bei einigen wenigen Insekten gibt es auch äußere Kennzeichen (sog. „Begattungszeichen“), an denen man die erfolgte Begattung untrüglich erkennen kann. So weiß der Imker ganz genau, daß eine Königin befruchtet ist, wenn er in dessen Scheide abgerissene Teile des Penis findet; ferner kann man beim Weibchen des Schwimmkäfers die erfolgte Begattung an einer weißen Platte erkennen, welche die letzten Abdominalsegmente bedeckt, und welche von einem die Überführung des Samens sichernden Drüsensekret herstammt, usw.

Die Regel ist, daß nur die zu einer Art gehörigen Individuen miteinander kopulieren. Doch kommen auch Ausnahmen vor, und man kann garnicht so selten verschiedene Insektenarten (besonders Käfer) miteinander kopulieren sehen. Ob freilich solche Paarungen von Erfolg begleitet sind, darüber ist wenig bekannt. Bei Schmetterlingen (vor allem bei Schwärmern und Spinnern) kennen wir allerdings eine ganze Reihe von Bastarden, doch sind die meisten davon künstlich gezüchtet. - Wenn wir die große Zahl der existierenden Insekten berücksichtigen, und ferner die geringen Unterschiede, durch welche die Arten vielfach voneinander getrennt sind, so muß die kleine Zahl von Bastarden auffallen. Worauf die geringe Neigung zur Bastardierung beruht, darüber sind wir noch wenig genau orientiert. In manchen Fällen scheint eine Kreuzung aus mechanischen Gründen, durch den oft gerade bei nahe verwandten Arten sehr verschiedenen Bau der Kopulationsorgane unmöglich gemacht zu sein. Sicherlich dürften aber auch psychische Momente (Erregung durch ganz bestimmte Gerüche oder Geräusche) für das seltene Vorkommen von Kreuzungen verantwortlich zu machen sein. 


\section{Parthenogenese und verwandte Erscheinungen.}

Parthenogenesis und Heterogonie.

Wenn es auch, wie schon gesagt, die Regel ist, daß die Eier der Insekten wie die der anderen Tiere zur Entwicklung der Befruchtung bedürfen, so gibt es doch gerade unter den Insekten eine verhältnismäßig große Zahl von Ausnahmen, in denen sich die Eier auch ohne vorhergegangene Befruchtung zu normalen Imagines entwickeln. Diese eingeschlechtliche Art der Fortpflanzung bezeichnet man als "Jungfernzeugung“ oder Parthenogenese.

Das Vorkommen von Parthenogenese wurde zwar schon seit langem (18. Jahrhundert) behauptet, doch man war im allgemeinen so sehr von der Notwendigkeit der Befruchtung überzeugt, daß man den von einigen wenigen Forschern aufgestellten Angaben keinen Glauben schenkte. Erst um die Mitte des 19. Jahrhunderts gelang es dem schlesischen Imker Drierzon (bei der Biene) und dem Zoologen Siebold (bei einem Schmetterling, Psyche) die Jungfernzeugung einwandfrei nachzuweisen, so daß der Widerspruch aufgegeben wurde.

Die Parthenogenese tritt entweder als anormale Erscheinung auf, oder aber stellt den normalen Fortpflanzungsmodus dar.

Eine anormale oder exzeptionelle Parthenogenese liegt da vor, wo für gewöhnlich die zweigeschlechtliche (amphigone) Fortpflanzung stattfindet und wo nur ausnahmsweise auch unbefruchtete Eier zur Entwicklung gelangen. Solche Fälle sind bis jetzt hauptsächlich bei Schmetterlingen beobachtet worden (Liparis dispar, similis, Lasiocampa pini), seltener bei anderen Insekten, wie Hemipteren, Blattwespen, Stabheuschrecken usw. Die aus den unbefruchteten Eiern hervorgehenden Tiere sind in diesen Fällen meist weiblichen Geschlechtes (Thelytokie).

Die normale Parthenogenese tritt sowohl gemischt mit Amphigonie auf, als auch, wenn auch viel seltener, rein, d. h. als einziger Fortpflanzungsmodus. Im ersteren Fall kommt die Jungfernzeugung entweder direkt neben der zweigeschlechtlichen Fortpflanzung vor, so daß die Kinder einer Mutter, also die Geschwister, teils aus befruchteten, teils aus unbefruchteten Eiern entstanden sein können; oder aber die zweigeschlechtliche und die eingeschlechtliche Fortpflanzung wechseln in den verschiedenen Generationen miteinander ab, so daß also sämtliche Kinder einer Mutter entweder nur aus befruchteten oder aber nur aus unbefruchteten Eiern hervorgehen (alternierende Parthenogenese).

Für das erste Vorkommnis liefert uns die Biene das bekannteste Beispiel. Hat es doch, wie oben schon gesagt, die Bienenkönigin gewissermaßen „in der Hand“, die Eier zu befruchten oder nicht, je nachdem sie auf die in der Scheide herabgleitenden Eier Samenfäden aus der Samentasche austreten läßt oder nicht. Auch hier hat die Befruchtung oder Nichtbefruchtung einen Einfluß auf die Bestimmung des Geschlechtes; doch ergeben hier die unbefruchteten Eier, im Gegensatz zu den obigen Fällen, nur Männchen (Drohnen), während aus den befruchteten die Weibchen und die 
Arbeiter (die ja nichts anderes als rückgebildete Weibchen sind) helvorgehen (Arrhenotokie). Ist nun der Samenvorrat der Bienenkönigin ausgegangen, so kann letztere natürlich nur noch unbefruchtete Eier ablegen und also nur noch Männchen erzeugen. So erklärt sich, warum alte Königinnen häufig „drohnenbrütig“ werden. Diese von Dzierzon aufgestellte und inzwischen noch vielfach (auch durch mikroskopische Untersuchungen) bestätigte Lehre gilt auch für die anderen sozialen Hautflügler, die Wespen, Hummeln, Ameisen und ferner auch für einige solitär lebende Bienenarten.

Die alternierende Parthenogenese kann unregelmäBig oder regelmäßig sein. Bei der unregelmäßigen Form folgt eine unbestimmte (mitunter sehr große) Zahl parthenogenetischer Generationen eine ganz unbestimmte Zeit lang aufeinander, ehe wieder Männchen auftreten und Gamogenie stattfindet. Hierher möchte ich jene Arten rechnen, bei denen die Männchen sehr selten sind oder oft viel Jahre ganz verschwunden $\mathrm{zu}$ sein scheinen (manche Aphiden u. a.).

Bei der regelmäßigen alternierenden Parthenogenese wechseln einund zweigeschlechtliche Fortpflanzung in einem einigermaßen be-

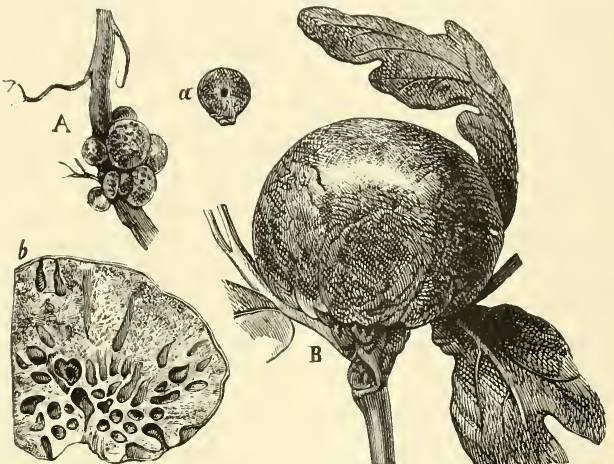

Fig. 113. Die Gallenformen der beiden Generationen von Biorhiza terminalis Htg. A die Wurzelgalle, aus der die Biorhiza aptera Fabr. schlüpft, $a$ Galle mit dem Loche, durch welches die Wespe auskam. $B$ Terminalgalle mit schwammigem Gefüge, aus der die Tereas terminalis genannte, aus Männchen und Weibchen bestehende Generation schlüpft. $-(\mathrm{N}$.) stimmten, regelmäBigen Zyklus miteinander ab. Man bezeichnet einen solchen in dieser Weise zusammengesetzten Fortpflanzungsmodus als Heterogonie.

Die einfachste Form der Heterogonie ist die, bei welcher je eine gamogenetische und eine parthenogenetische Generation miteinander abwechseln. Eine solche Heterogonie finden wir nach der schönen Entdeckung von Adler bei vielen Gallwespen, die hier noch dadurch besonders auffällig ist, da $B$ nicht nur die Tiere selbst, sondern auch die von ihnen erzeugten Gallen der beiden Generationen wesentlich voneinander sich unterscheiden. Als bekanntestes Beispiel hierfür sei Biorhiza terminalis genannt: Aus den großen, fleischig schwammigen, an den Triebenden unserer Eichen so häufig vorkommenden sog. Kartoffelgallen schlüpfen ungeflügelte weibliche und geflügelte männliche Gallwespen aus, welche früher mit dem Namen Tereas terminalis belegt wurden (Fig. 113). Nachdem sich diese begattet, steigt das Weibchen an die Wurzeln der Eiche hinab, um an dieselben mit Hilfe seines Legestachels seine Eier abzusetzen. Als Folge davon entwickelt sich während 
des Hochsommers und Herbstes an den Wurzeln eine kleine rötliche Galle, welche im Winter reift, und aus ihr schlüpfen nun ausschließlich ungeflügelte Weibchen heraus, die unter dem Namen Biorhiza aptera bekannt sind. Diese pflanzen sich alsbald parthenogenetisch fort, indem sie sofort nach ihrem Ausschlüpfen den Baum erklettern und die Terminalknospen der Zweige anstechen und mit Eiern belegen. Darauf kommt hier wieder die erstgenannte Kartoffelgalle zur Entwicklung, aus der im Sommer Männchen und Weibchen auskriechen. Es entstehen also hier aus den befruchteten Eiern ausschließlich Weibchen, während aus den von diesen abgelegten unbefruchteten Eiern die beiden Geschlechter hervorgehen.

Wesentlich komplizierter wird die Heterogonie, wenn zwischen je zwei gamogenetischen Generationen eine größere Anzahl von parthenogenetischen Generationen, die auch wieder in verschiedener Gestalt auftreten, eingeschoben werden. Dies ist bei den meisten Pflanzenläusen der Fall; so wird z. B. bei den Chermiden der Entwicklungszyklus aus einer ganzen Reihe verschiedener Generationen zusammengesetzt (Fig. 114). Da haben wir 1. die zweigeschlechtliche Generation, die aus zwerghaft kleinen flügellosen Männchen und Weibchen (Sexuales) besteht; dieselbe tritt nur einmal im Jahre (Herbst) auf der Fichte auf, um ein sog. Winterei zu erzeugen. 2. Aus diesem kommt im folgenden Jahr ein Weibchen hervor, das ebenfalls flügellos ist und auf der Fichte eine Galle erzeugt; sie wird Stammutter oder Fundatrix genannt. 3. Die Fundatrix bringt (parthenogenetisch natürlich) eine Anzahl Kinder hervor, und zwar nur Weibchen, die geflügelt sind und von der Gallenpflanze auf eine Nichtgallenpflanze (Lärche, Kiefer, Weißtanne) überwandern; sie werden Fundatrigeniae oder Migrantes alatae oder Cellares genannt. 4. Diese erzeugen (wiederum parthenogenetisch) die sog. Virginogeniae oder Emigranten, das sind ebenfalls (wenigstens meistens) flügellose Weibchen, die auf der Nichtgallenpflanze verbleiben. 5. Diese können nun im Sommer und Winter in mehreren gleichartigen Generationen auftreten, bis aus der Frühjahrsgeneration andere Formen (die sog. Sexuparae) sich entfalten, die Flügel besitzen und die von der Nichtgallenpflanze zu der Gallenpflanze zurückwandert, um dort Eier zweierlei Geschlechts zu legen, aus denen die kleinen, flügellosen Männchen und Weibchen hervorgehen, von denen wir ausgegangen sind.

Dieser fünfteilige Entwicklungszyklus kann sogar noch komplizierter werden, indem die Emigranten sich in mehrere Formen gliedern können, die als Hiemales und Aestivales unterschieden werden. Die Hiemalis erzeugen meist wieder ihresgleichen und auch Aestivales; und ebenso erzeugen die Aestivales sowohl ihresgleichen, als auch Hiemalis. Nur aus den Aestivales gehen aber Sexuparae hervor, während die Hiemalis die Sexuparapotenz verloren haben. So kann also neben dem fünfteiligen Hauptkreis noch ein besonderer parthenogenetischer, nur aus Hiemalis bestehender Kreis nebenherlaufen, wie aus dem beigegebenen Schema (Fig. 114) zu ersehen ist.

Reine Parthenogenese. Nehmen wir nun an, daß in jenem Entwicklungszyklus die Sexuales, Sexuparae usw. in Wegfall kommen, so bleibt nur der auf der Nichtgallenpflanze sich abspielende parthenogenetische Kreis 
über und wir haben nunmehr eine reine Parthenogenese, bei der die Fortpflanzung der betreffenden Art ausschließlich auf parthenogenetischem Wege stattfindet. Dies ist bei einigen Chermes-Arten auch wirklich der Fall, wie z. B. bei Chermes piceae, strobi und nüßlini. Man hat früher angenommen, daß rein parthenogenetische Fortpflanzung nicht gut möglich sei, da sie allmählich eine Schwäche oder Degeneration zur Folge haben inüsse. Dies trifft aber nach den neueren Forschungen Börners, NüBlins usw. durchaus nicht zu; danach steht es vielmehr fest, daß die parthenogenetische Fortpflanzung sich unbegrenzte Zeit zu erhalten imstande ist, ohne daß wir auch nur irgend ein Zeichen pathologischer Veränderung daran wahrnehmen können.

Bei manchen Insekten scheint die Parthenogenese geographisch begrenzt zu sein, so pflanzt sich ein Sackträgerschmetterling (Psyche helix), in manchen Gegenden nur parthenogenetisch fort, während an anderen Orten auch Männchen, wenngleich nur selten, vorkommen. Man muß übrigens in dieser Beziehung sehr vorsichtig sein, und es ist jedenfalls nicht gerechtfertigt, allein aus dem Umstand, daß von einer Art bis jetzt noch kein Männchen gefunden ist, ohne weiteres auf das Vorhandensein einer reinen Parthenogenese zu schließen, denn das Nichtauffinden der Männchen kann ja auch auf deren großen Seltenheit oder auf ihrer versteckten Lebensweise, oder noch auf verschiedenen anderen Momenten be-

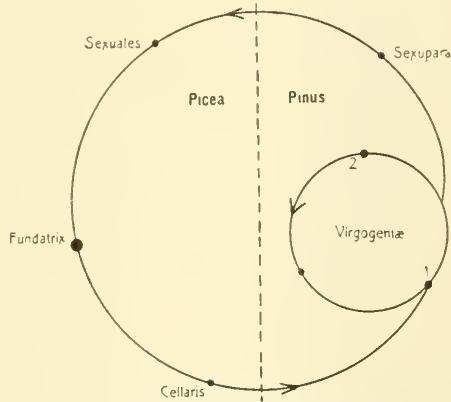

Fig. 114. Entwicklungszyklus von Chermes. Nach Börner. ruhen.

\section{Paedogenesis.}

Die Paedogenesis - abgeleitet von $\pi \alpha \tilde{\iota}$ Genitiv, $\pi \alpha \iota \delta \varsigma_{\varsigma}$ das Kind, und

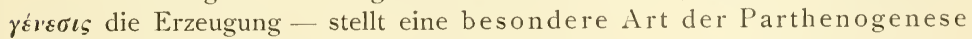
dar, bei welcher das betr. Weibchen sich bereits im Larvenstadium fortpflanzt. Dieser auffallende Fortpflanzungsmodus wurde 1861 von dem russischen Zoologen N. Wagner bei den unter alter Baumrinde allenthalben nicht selten vorkommenden Larven einer Gallmückenart (Miastor metroloas Meinert) entdeckt.

Hier entwickeln sich die Anlagen der Eiröhren, ohne daß es zu der Bildung von Ausführungsgängen kommt; sie zerfallen vielmehr in einzelne Abschnitte, die aus je einem Eifach mit Eizelle und Epithel und einem Dotterfache bestehen. Diese Abschnitte liegen frei in der Leibeshöhle der Mutterlarve; jede Eizelle entwickelt sich nun auf Kosten der anliegenden Zellen zu einem Embryo, der bald die Eihülle durchbricht, sich von dem Fettkörper und den übrigen, zerfallenden Organen des Muttertieres ernährt und so heranwächst, so daß schließlich nur die Chitinhülle des letzteren übrig bleibt 
(Fig. 115), die endlich von den Tochterlarven gesprengt wird. Letztere können nun entweder selbst wieder paedogenetisch Junge erzeugen, oder nach vorhergehender Verpuppung sich in die Imagines verwandeln, die sowohl männlichen wie weiblichen Geschlechts sind. Es findet eine Befruchtung statt, das Weibchen legt die befruchteten Eier unter die Borke $\mathrm{ab}$ und es entwickelt sich daraus wieder eine Larvengeneration, die den Anfang einer Reihe paedogenetischer Generationen bildet. Nach Kahle, dem wir die neuesten eingehenden Untersuchungen darüber verdanken, können mehrere Jahre hintereinander nur Larvengenerationen existieren, ehe die Metamorphose eintritt und die Imagines erscheinen. - Es wechseln

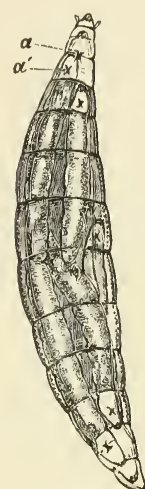

Fig. 115. Paedogenetisch sich fortpflanzende Fliegenlarve aus verdorbenen Zuckerrübenrückständen nach Pagenstecher. a Augenfleck der mütterlichen Larve. Sie enthält fünf junge Larven, deren Kopfenden aurch den gleichen Augenfleck $a^{\prime}$ angezeichnet sind. $-\left(N_{\text {. }}\right)$

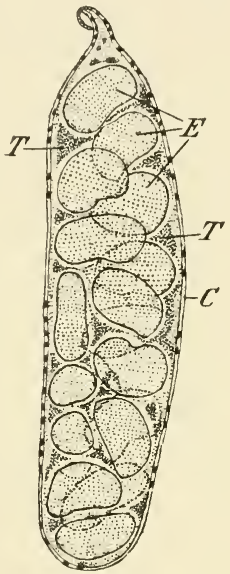

Fig. 116. Polyembryonie von Encyrtus fuscicollis. Ei mit 17 Morulae (Embryonen), $E$ Em. bryonen; $T$ Trophamnion (Nähr. gewebe): $C$ Cystenhülle. Nach Silvestri. also eine Anzahl paedogenetischer resp. parthenogenetischer Generationen mit je einer gamogenetischen $a b$, so daß wir also auch hier von einer Heterogonie zu sprechen berechtigt sind.

\section{Polyembryonie oder Germinogonie.}

Im Jahre 1904 hat der französische Entomologe $\mathrm{Paul}$ Marchal an einigen parasitisch lebenden $\mathrm{Hy}$ menopteren, nämlich bei dem in Hyponomeuta schmarotzenden Encyrtus fuscicollis und dem in der Hessenfliege schmarotzenden Polygnotus minutus, die überraschende Entdeckung gemacht, daß aus einem einzigen Ei eine ganze Anzahl Embryonen hervorgehen, die sich alle zu richtigen Imagines entwickeln. Er nannte diesen Vorgang Polyembryonie oder Germinogonie.

Bei Encyrtus spielt sich derselbe ungefähr folgendermaßen ab: Das befruchtete Weibchen legt in die Larve von Hyponomeuta ein Ei. Dieses teilt sich zunächst in 5 Furchungskerne, einen sehr großen exzentrisch gelegenen und 4 kleine. Ersterer, der sog. Paranucleus, wächst zu einer Art Nährgewebe (Trophamnion) heran, welches die Übertragung der vomi Wirt stammenden Nährstoffe zu den heranwachsenden Embryonen vermittelt. Die anderen 4 Kerne dagegen stellen den Ausgangspunkt für die Vermehrung der Embryonen dar. Wenn die Kerne sich auf 8-10 vermehrt haben, bildet sich aus dem Gewebe des Wirtes um das Ei eine Cyste, welche später 
mit dem riesigen Wachstum des letzteren stets Schritt hält (Fig. 116). Während des Winters, wo die gegen Ende September ausgeschlüpften Raupen der Hyponomeuta nicht wachsen, gelangt auch das Ei des Parasiten nur bis zu 20 Furchungskernen; aber im nächsten Frühjahr wächst es rasch auf über $1 \mathrm{~mm}$ heran und wird bereits im Mai zu einem 3-4 mm langen Schlauche, der oft Seitensprossen treibt, und dann etwa 100 Morulae enthält. Aus jeder Morula entsteht eine Larve resp. Imago, so daß also aus einem Ei ca. 100 Imagines hervorgehen. Manchmal findet man auch mehr, ca. 180 Larven in einer Hyponomeuta-Raupe, was aber darauf beruhen dürfte, daß zwei Eier in eine Raupe gelegt wurden. Alle aus einem Ei hervorgehenden Imagines besitzen das gleiche Geschlecht, und wenn daher aus einer Raupe männliche und weibliche Encyrtus auskommen, so ist dies ein Zeichen, daß mehrere, mindestens zwei Eier in die betr. Raupe abgelegt worden waren.

Die Polyembryonie wurde einige Jahre nach Marchals Entdeckung von Silvestri auch noch bei einem anderen Encyrtiden, nämlich dem in verschiedenen Schmetterlingen (Plusia gamma und anderen Eulen) schmarotzenden Encyrtus (Litomastix) truncatellus festgestellt, wobei sich aber aus einem Ei nicht weniger als 1000 Larven entwickeln. Wahrscheinlich werden bei eingehenden Nachforschungen noch weit mehr derartige Fälle bekannt werden, - im Hinblick darauf, da 6 die polyembryonal sich fortpflanzenden Parasiten gegenüber den anderen monoembryonal sich fortpflanzenden Arten einen großen Vorsprung bezügl. der Vermehrung und Sicherung der Arterhaltung haben.

\section{Eiablage.}

Die Zahl der Eier, die ein Weibchen ablegen kann, ist sehr verschieden, und kann von einigen wenigen bis zu vielen Millionen betragen; so legt z. B. das Weibchen vom Floh ca. ein Dutzend Eier, vom Totengräber (Necrophorus) ca. 30, von der Seidenraupe (Bombyx mosi) ca. 500, vom großen Bären (Arctia caja) ca. 1600 usw. Dann kommen die ganz starken Eierleger: die Kolumbatschermücke, die ca. 5-10000 Eier legt, die sozialen Wespen, die während ihres Lebens ca. 20-30000, die Honigbiene, die bis 60000 Eier legt, und endlich die Termiten, die mit mehreren Millionen Eiern (deren Ablage sich allerdings über viele Jahre erstreckt) den Rekord halten.

Was speziell die Forstinsekten betrifft, so ist bei ihnen die Eizahl gewöhnlich nicht allzu hoch; so legen z. B. die Borkenkäfer nicht mehr als 30-100 Eier, Lyda hypotrophica nur 25, Lyda stellata ca. 80, die Nematiden $60-150$, die Kieferneule $200-300$, die Nonne bis 350 (ausnahmsweise auch bis 400). Bei einigen kommen allerdings auch noch höhere Zahlen vor, so zählte Scheidter beim Schwammspinner 600-800 Eier, bei Agelastica alni 800, und bei Melasoma populi sogar 1000 Eier; auch die Cossiden und Sesiiden sind sehr produktiv, und dürfte ihre Eizahl wohl ebenfalls an 1000 heranreichen.

Über die Dauer der Eiablage ist oben schon einiges gesagt. Bei vielen Insekten werden die Eier alle auf einmal resp. in kürzester Zeit ab- 
gelegt (wie z. B. bei vielen Spinnern); bei anderen dagegen zieht sich die Eiproduktion und Ablage über Wochen, Monate und Jahre hin, indem jedesmal entweder nur ein kleineres, aus einem Bruchteil der Gesamtzahl bestehendes Häufchen oder gar nur ein Ei abgelegt wird (z. B. Borkenkäfer, Bockkäfer, Pissodes usw.).

Bezüglich des Ortes der Eiablage läßt sich als allgemeine Regel aufstellen, daß die Eier gewöhnlich da abgelegt werden, wo die auskommenden Larven die ihnen zusagenden Lebensbedingungen, vor allem die nötige Nahrung finden. Der Instinkt, der die Weibchen dabei leitet, arbeitet ungemein sicher, so daß Irrungen nur relativ selten vorkommen. ${ }^{1}$ ) Wenn natürlich die Weibchen abgehalten werden, die normalen Ablagestellen aufzusuchen, so läßt sie ihr starker Legedrang die Eier auch an anderen Orten ablegen; so weiß jeder Schmetterlingszüchter, daß die Schmetterlingsweibchen in Gefangenschaft überall, selbst in den kleinsten Zündholzschachteln, ihre Eier absetzen.

Um für die oben ausgesprochene Regel einige Beispiele anzuführen, so sehen wir, daß die Schmetterlinge in der Freiheit ihre Eier gewöhnlich an der Pflanze ablegen, welche der Raupe als Nahrung zusagt; dabei wird oft auch auf die verschiedenen Teile der Pflanze Rücksicht genommen, so legt z. B. die Kieferneule ihre Eier an die Nadeln, der Kieferntriebwickler dagegen an die Spitze der Triebe, da eben die Raupen der ersteren sich von den Nadeln nähren, während die Raupen der letzteren sich in die Triebe einbohren. Diejenigen Insekten, deren Larven von Wurzeln leben, versenken ihre Eier mehr oder weniger tief in die Erde. Mist- und Aaskäfer legen ihre Eier an tierische Exkremente oder Tierleichen. Insekten, deren Larven sich von Blattläusen nähren, z. B. die Florfliege (Chrysopa), legen ihre gestielten Eier auf mit Blattläusen besetzte Blätter. Wo die Larven an das Wasser gebunden sind, wie die der Eintagsfliegen, Libellen usw., da sorgen die Weibchen dafür, daß die Eier in das Wasser abgelegt werden. Die Borken-, Bock-, Prachtkäfer und verschiedene Rüsselkäfer, deren Larven unter Rinde oder in Holz leben, legen auch ihre Eier in oder unter die Rinde (teils in besondere dafür ausgenagte Gänge), und zwar geht dabei jede Spezies nur an eine ganz bestimmte Baumart, und nicht nur das, sondern die Weibchen wissen auch jeweils den für die Larve zusagenden Gesundheitszustand der betreffenden Bäume auszuwählen, indem die einen völlig gesunde Bäume aufsuchen, andere dagegen nur kränkelndes, wieder andere nur abgestorbenes Material belegen. Der Aspenbock (Saperda populnea) nagt sogar um die Stelle, wo das Ei abgelegt ist, die Rinde in Form eines Hufeisens durch, um den Saftstrom hier zu unterbrechen (Fig. 117). Die Blattwickler (Rhynchites) versetzen die Gewebe der Blätter, in welche die Eier eingewickelt werden, durch Anstechen der Blattstiele oder Mittelrippen, in den der Larve zusagenden Zustand (Fig. 118). Die

$\left.{ }^{1}\right)$ Als eine Instinktsirrung darf es wohl betrachtet werden, wenn Weibchen der Nonnentachine, trotz der Anwesenheit zahlreicher untachinierter Raupen an ein und dieselbe Raupe ein halbes Dutzend Eier ablegt, da doch nur eine oder höchstens 2 Larven in einer Raupe sich entwickeln können. 
parasitischen Insekten legen ihre Eier in oder außen auf den Körper ganz bestimmter Raupen usw., von deren Geweben und Säften die Larven sich nähren. Mit welch fabelhaftem Spürsinn dabei manche Insekten begabt sind, zeigt das Beispiel der großen Ichneumonen (Rhyssa, Thalessa usw.), welche mit Hilfe ihres langen Legebohrers die Eier den tief im $\mathrm{Holz}$ sitzenden Holzwespenlarven zuführen (Fig. 119).

Es gibt auch eine ganze Reihe von Insekten, welche zu den Eiern die für die auskommenden Larven nötige Nahrung besonders zufügen, wie z. B. die Grabwespen und viele andere solitäre Wespen und

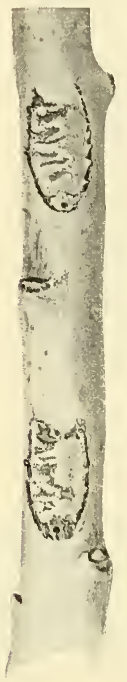

Fig. 117. Aspenzweig mit zwei von Saperda populnea-Weibchen genagten "Hufeisen" (Brutpflege). Nach Boas.

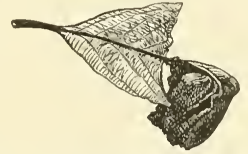

Fig. 118. Blattrolle von dem Blatte einer echten Kastanie, gefertigt von Attelabus curculionoides $L$.

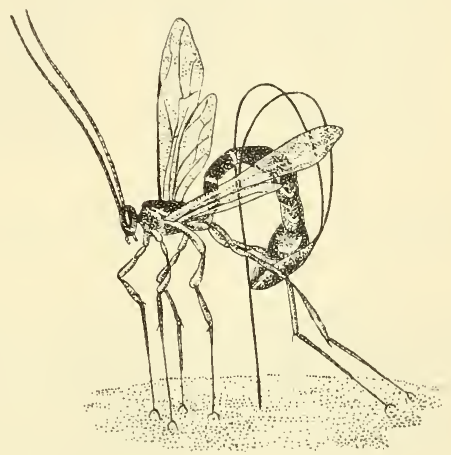

Fig. 119. Ein Ichneamonide (Thalessa lunator) bei der Ablage der Eier in einen von Holzwespen bewohnten Stamm. Die nach hinten und oben umgebogenen beiden Spangen sind die Scheidenklappen; der eigentliche Legebohrer geht von der Hinterleibsspitze direckt in das Holz. Nach Riley.

Bienen. Die Grabwespen tragen die verschiedensten Insekten und Spinnen (jede Grabwespenart hat ihre bestimmten Beutetiere), nachdem sie sie mit einem Stich in einen Nervenknoten gelähmt, in das Nest, so daß die aus den Eiern auskommenden Wespenlarven genügend frische Nahrung vorfinden. Bei den sozialen Insekten wird die auskommende Brut in täglicher Brutpflege gefüttert, was natürlich den sichersten Modus für die Larvenernährung darstellt.

Auch die Form der Eigelege ist ungemein rerschieden, und oft sehr charakteristisch für die einzelnen Arten; die einen legen ihre Eier in unregelmäßiger Anordnung ab, wie z. B. der Kiefernspinner (Fig. 120), die Schmeißfliege usw.; auf der anderen Seite aber finden wir Eigelege von 
großer Regelmäßigkeit, wie z. B. die Eiringel des Ringelspinners (Fig. 122), oder die Eizeilen des Kiefernspanners (Fig. 126) oder der Kiefern-

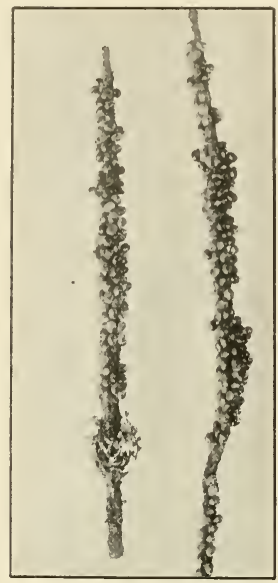

$A$

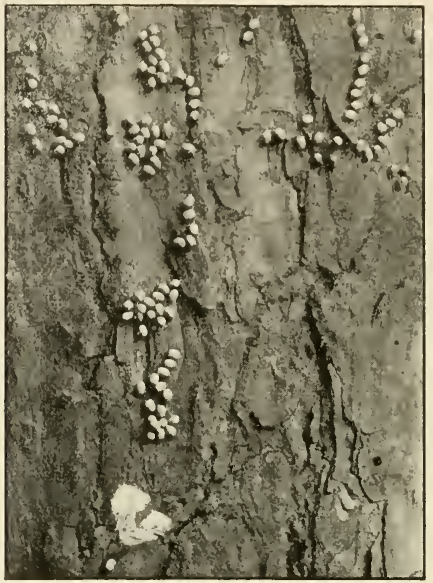

$B$

Fig. 120. Eiablage des Kiefernspinners (Bombyx pini). Beispiel für unregelmäßige Eiablage. $A$ an Zweigen; $B$ am Stamm (der weiße Fleck am unteren Ende rührt von der Harnausscheidung des frischgeschlïpften Weibchens her). Phot. Fr. Scheidter.

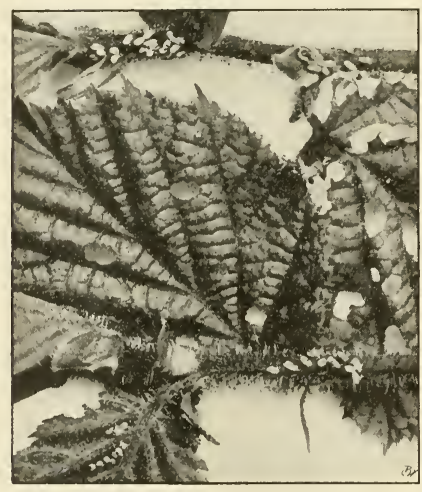

Fig. 121. Unregelmäßige Eiablage von Haltica zwischen den klebrigen Haaren eines Haselstrauches. Phot. Fr. Scheid ter.

Kapsel so regelmäßig nebeneinander, (Fig. 127). eule, oder die Eip latt en des Eichenprozessionsspinners und anderer Schmetterlinge (Fig. 123). Auch viele Blattkäfer und Wanzen legen ihre Eier in Form einer einschichtigen Platte ab (Fig. 124 u. 125), wenn auch nicht immer so regelmäfig wie beim Eichenprozessionsspinner usw. Bei den Stechmücken sind die aus dünnen zylindrischen Eiern zusammengesetzten Eiplatten muldenförmig vertieft, so daß sie wie ein Kahn auf dem Wasser schwimmen. Die Eier von Chironomus sind in Gallertschnüren in mehr oder weniger regelmäßiger zeilen- oder hufeisenförmiger Anordnung eingebettet. Die langen Eier der Küchenschaben liegen in ihrer wie Zigaretten in einem Etui 
Wo die Eier, wie im letztgenannten Fall, in besonderen Kapseln oder in Rinde oder Holz abgelegt sind, bedürfen sie keiner besonderen Anheftung. Wo sie aber äußerlich an den Pflanzen abgesetzt werden, sind sie mit einem aus den Anhangsdrüsen stammenden, klebenden Sekret an der Unterlage befestigt; desgleichen sind mit demselben Sekret oft auch die nebeneinanderliegenden Eier zusammengeklebt. Manchmal sitzen die Eier so fest auf der Unterlage, daß sie nur schwer daron $\mathrm{zu}$ entfernen sind, wie z. B. beim Ringelspinner. Oft besitzen, wie oben

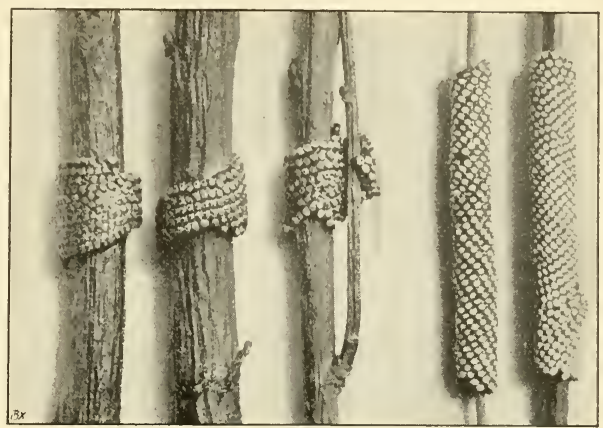

A B

Fig. 122. "Eiringel". A vom Ringelspinner (Bombyx neustria L.) $B$ vom Bombyx castrensis L.. Phot. Fr. Scheidter. bereits erwähnt, die Eier selbst besondere Haftapparate, mit denen sie sich mit der Umgebung verankern. Manchmal werden die Eier zwischen die klebrigen Haare der Futterpflanze abgelegt, wo sie ohne weiteres haften bleiben (Fig. 121).

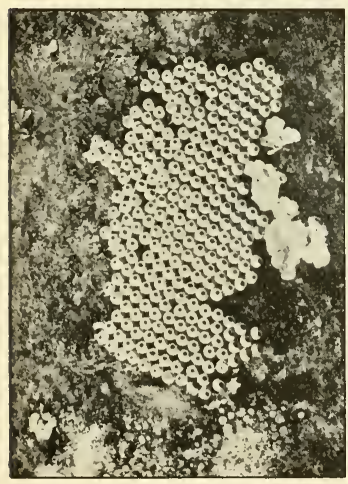

$A$

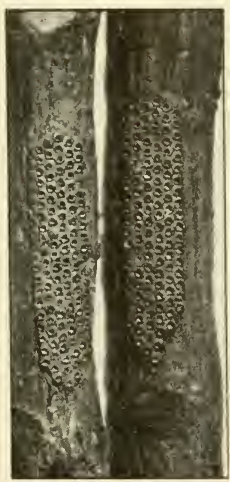

$B$

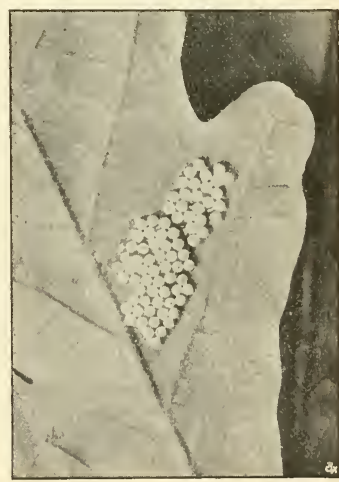

$C$

Fig. 123. „Eiplatten". A vom Buchenspinner (Das. pudibunda); B vom Eichenprozessionsspinner (Cneth. processionea); $c$ vom Mondvogel (Phalera bucephala). Phot. Fr. Scheidter.

Es liegt im Interesse der Erhaltung der Art, daß die Eier vor schädlichen äußeren Einflüssen, vor allem vor Feinden, möglichst ge- 
schützt sind; und so sehen wir auch den Instinkt des Weibchens vielfach in dieser Richtung tätig, indem er das Weibchen leitet, seine Eier entweder versteckt (in Ritzen, unter Rindenschuppen, auf die Unterseite der Blätter

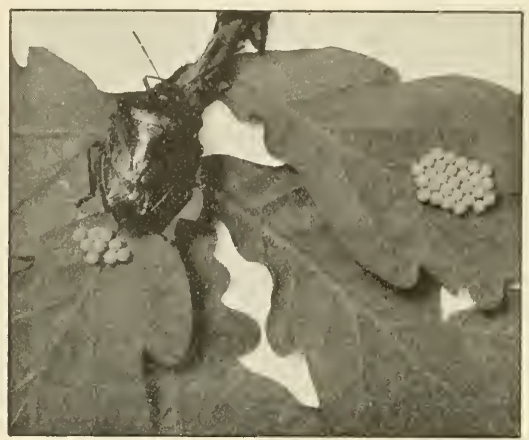

Fig. 124. „Eiplatten" einer Schildwanze (Pentatoma). Phot. Fr. Scheidter. usw.) abzulegen, oder aber besondere Schutzvorrichtungen zu treffen. Wir haben oben schon von den Laichschnüren von Chironomus und den Eikapseln der Küchenschaben gesprochen. Ähnliche Bildungen kommen noch bei vielen anderen Insekten vor, z. B. bei Hydrophilus, Mantis usw. (Fig. 127). Die Feldheuschrecken verfertigen mit Hilfe von Hinterleibssekreten Schutzgehäuse aus Sand um die Eier (Fig.128). Des weiteren führe ich als hierher gehörige Beispiele an: die Blattwespen, welche in das Pflanzengewebe Taschen (Fig. 129) zur Unterbringung der Eier sägen, oder den Gelbrandkäfer oder gewisse Wasserwanzen oder Zikaden, die es ganz ähnlich machen. Vielfach bestehı

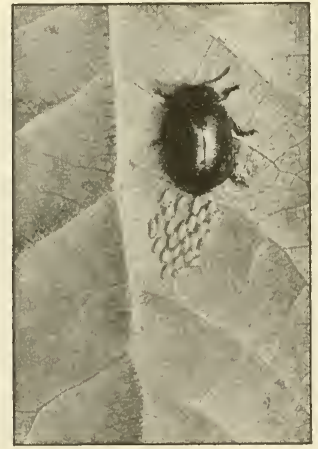

$A$

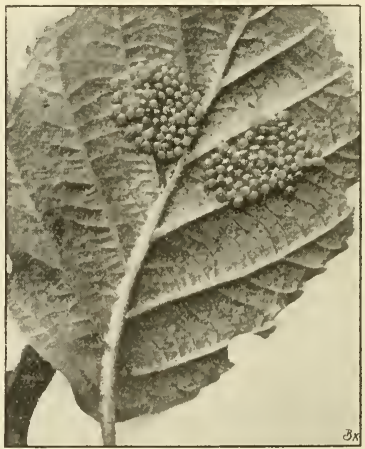

$B$

Fig. 125. ${ }_{n}$ Eiplatten ${ }^{\prime}$ von Blattkäfern. A Melasoma tremulae; B Agelastica alni. Phot. Fr. Scheidter.

auch die Gewohnheit, die Eier mit Haaren, Schuppen oder erstarrten Sekreten zu bedecken. Hierher gehören die "Eischwämme" des Schwammspinners und Goldafters (Fig. 131), ferner die „Schuppenkolben“ des Kiefernprozessionsspinners (Fig. 133), die „Wollringel“ des Birkenspinners 


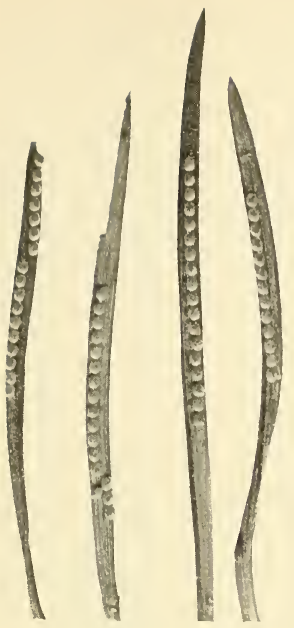

Fig. 126. „Eizeilen" des Kiefernspanners (Bupalus piniarius). Phot. Fr. Scheidter.
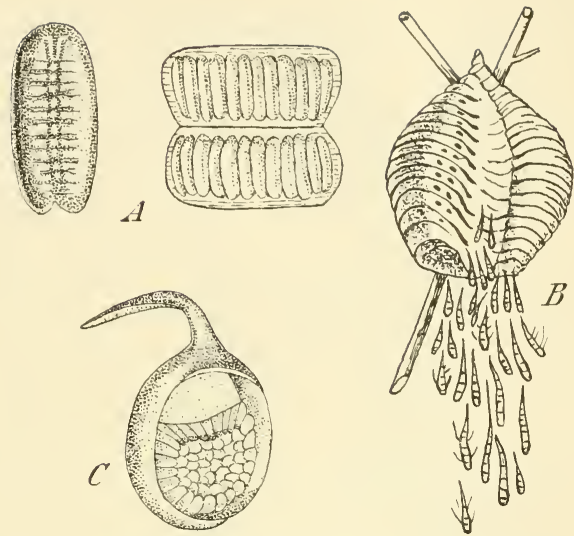

Fig. 127. "Eikapseln". $A$ von der Küchenschabe (Blatta); $B$ von Mantis (mit ausschlüpfenden Juugen); $C$ von Hydrophilus. Nach Henneguey und Brongniart.

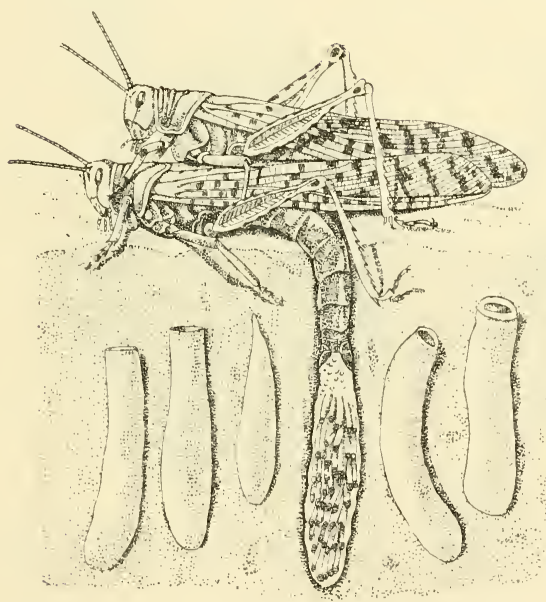

Fig. 128. Eiablage eines Acridiers (Wanderheuschrecke). Das Männchen sitzt noch von der Kopula her auf dem Weibchen. Letzteres legt die Eier in die Frde, in besondere, mit Hilfe von Sekreten aus Sand hergestellte Eikapseln. Nach Kunckel d'Herculais.

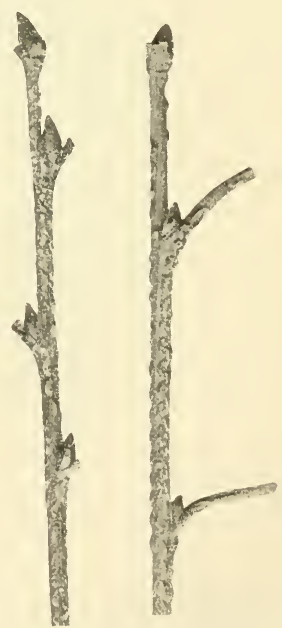

Fig. 129. „Eitaschen ${ }^{4}$ einer Weidenblattwespe (Nematus miliaris). 
(Fig. 132) und der "Schaumfleck“ des Weidenspinners (Fig. 134), die Wachswolle der Pflanzenläuse usw. Bei den Schildläusen deckt sich der Körper der Mutter als schützendes Schild über die Eier.
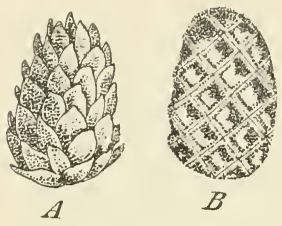

Fig. 130. Ei (stark vergrößert) von Clytra laeviuscula (Blattkäfer). A bedeckt mit einer größtenteils aus dem eigenen Kot gefertigten Schutzhülle; $B$ Schuppen der Schutzhülle entfernt. Nach Lécaillon.

Manche Weibchen schleppen ihre Eier längere Zeit mit sich herum, wie z. B. die Küchenschaben, bei denen die mit Eiern gefüllte Eikapsel in die Geschlechtsöffnung eingezwängt wird, oder die Ephemeriden und Perliden, bei denen die Eierklumpen an der Bauchseite hängen. $Z$ weifellos dürfen wir auch darin eine Schutzhandlung erblicken.

Manche Insekten bauen auch besondere Wohnungen für die Eier resp. Brut, und manche üben endlich auch einen direkten Schutz aus. Unter den einzellebenden Insekten gibt es allerdings nur wenige, welche die abgelegten Eier direkt beschützen, wie die Ohrwürmer, deren Weibchen neben den abgelegten Eiern (unter Steinen usw.) verbleiben, um sie gegen Angriffe zu verteidigen, ferner Gryllotalpa und gewisse Wanzen (Elasmostethus). Sodann hat Mc. Attee neuerdings eine nordamerikanische Tabanide (Goniops
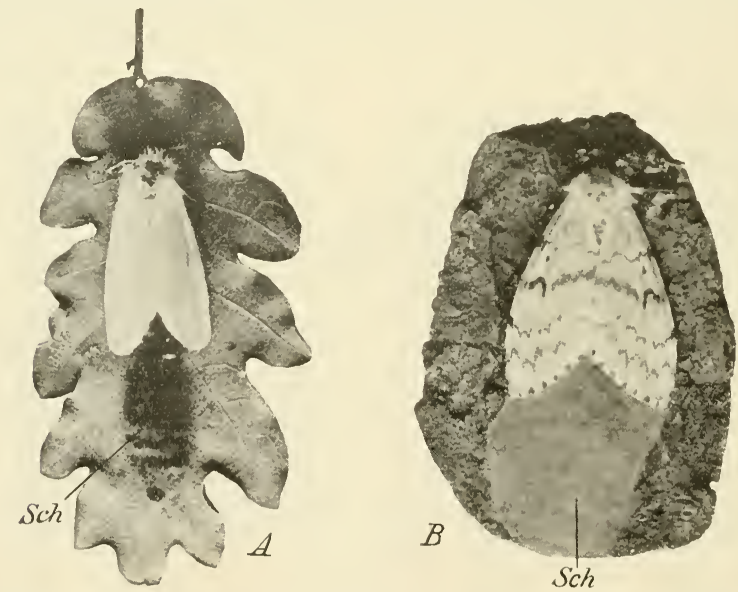

Fig. 131. „Eischwämme ${ }^{4}$ A vom Goldafter (Liparis chrysorrhoea); B vom Schwammspinner (Liparis dispar).

chrysocoma) beobachtet, wie sie, mitunter mehr als eine W'oche lang, die auf einem Blatt abgelegten Eier bewacht und die nahenden Feinde durch ein lautes summendes Geräusch abzuschrecken sucht. - Bei den sozialen Insekten dagegen (Ameisen, Wespen, Termiten usw.) finden wir den direkten Schutz 
ganz allgemein, indem hier die Eier ron Tausenden von mutigen und wehrhaften Arbeitern und Soldaten bewacht und beschützt und außerdem auch noch gepflegt (beleckt, in die jeweils zusagend temperierten Räume geschleppt usw.) werden. Die hohe Ausbildung der Brutpflege wird auch von manchen nicht sozialen Insekten ausgenützt, indem diese ihre Eier z. B. in Ameisennestern ablegen, wo sie dann ron den Ameisen gleich der eignen Brut gepflegt werden (Brutparasitismus).

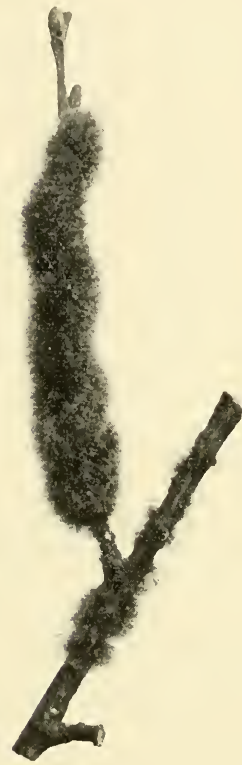

Fig. 132. "Wollringel" vom Birkenspinner (Bombyx lanestris).
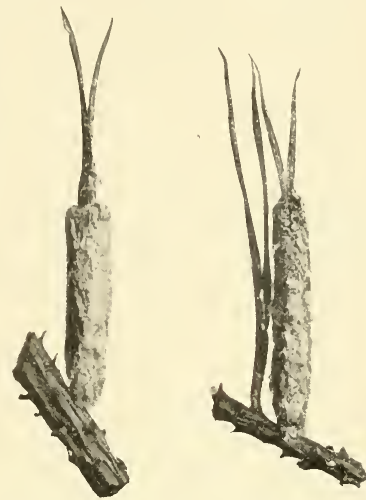

Fig. 133. „Schuppenkolben“ rom Pinienprozessionsspinne (Cneth, pithyocampa).

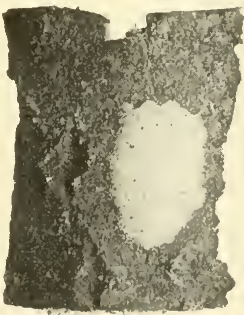

Fig. 134. "Schaumfleck" vom Weidenspinner (Liparis salicis).

Als Beispiele für direkten Eischutz (allerdings im weiteren Sinne) können auch noch diejenigen Fälle angesehen werden, wo die Eier sich im Mutterleibe entwickeln, wobei entweder noch die Eier eben ror dem Abschluß der Embryonalentwicklung abgelegt, oder sogar schon weiter entwickelte Stadien (Larven und Puppen) geboren werden, was vor allem bei den Zweiflüglern (Tachinen, Schmeißfliege, Rachendasselfliege, Lausfliege usw.) vorkommt, sodann aber auch bei einigen Käfern (Staphylinen) und anderen Insekten. 


\section{Embryonalentwicklung.}

Die Entwicklung im Ei umfaßt eine Reihe von Formbildungsvorgängen, die darauf hinauslaufen, die gesamte Masse der Eizelle innerhalb der Eischale in ein vielzelliges Tier, den Embryo, überzuführen. Eingeleitet wird die Entwicklung durch die Teilung des Eikernes in eine Anzahl Tochterkerne, die sich mit Bildungsplasma umgeben und unter fortwährender Vermehrung durch den Dotter hindurch nach der Oberfläche zu wandern, bis sie unter die Dotterhaut zu liegen kommen. Hier geht die Vermehrung weiter, bis die Kerne - die mit ihrem kleinen Plasmahof als „Furchungszellen“ bezeichnet werden - so zahlreich geworden sind, daß sie einander berühren und eine zusammenhängende Schicht um das ganze Ei, resp. den Dotter bilden. Diese Hüllschicht nennt man das Blastoderm. Zunächst ist dasselbe vollkommen gleichmäßig ausgebildet, d. h. allenthalben aus gleich hohen Zellen zusammengesetzt. Bald jedoch differenzieren sich die Zellen,
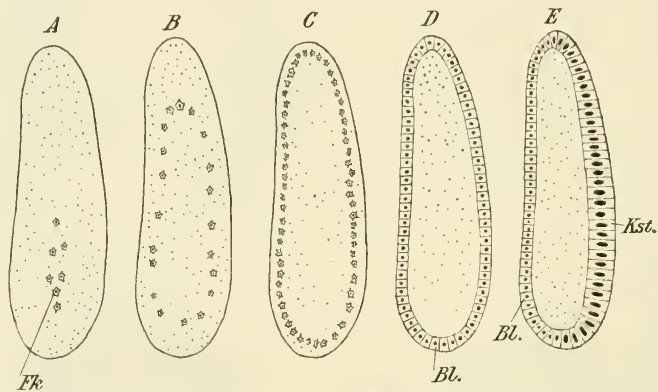

Fig. 135. Furchung und Keimstreifenbildung. $A$ Teile des Eikerns; $B$ u, $C$ die Furchungskerne rücken unter fortwährender Vermehrung nach der Oberfläche, bis sie in $D$ eine zusammenhängende Schichte, das Blastoderm $(B l)$, bilden; $E$ auf der Ventralseite werden die Zellen höher und bilden den Keimstreifen (Kst).

indem sie in einem gewissen Umkreis höher werden. Diese so entstandene verdickte Region des Blastoderms, die meist von länglich-ovaler Form ist, stellt den sog. Keimstreif dar, der das Fundament des künftigen Insektenkörpers bildet (Fig. 135).

Der nächste Vorgang ist der, daß der Keimstreif, der der Bauchseite des Embryos entspricht, in der Mitte sich einsenkt und so eine Längsrinne bildet, welche als "Primitivrinne“ den Keimstreif von vorne nach hinten durchzieht. Indem diese Furche sich dann abschnürt, entstehen im Keimstreifenbezirk zwei Zellschichten, von denen die äußere das äußere Keimblatt oder das Ektoderm, und die innere zum größten Teil das mittlere Keimblatt oder das Mesoderm repräsentiert. Gleichzeitig mit der Primitivrinnenbildung, oder auch etwas früher, treten am Vorder- und Hinterende des Keimstreifes je eine Gruppe differenzierter Zellen auf, welche das dritte Keimblatt des Entoderm darstellen (Fig. 136). Dasselbe ist also bei den Insekten keine zusammenhängende Schicht (wie bei den übrigen Tieren), sondern wird vielmehr durch zwei isolierte, weit voneinander getrennte Zell- 
haufen, den sog. Entodermkeimen, gebildet. Aus diesen Keimen, die mit der ektodermalen Vorder- und Hinterdarmeinstülpung eng verbunden sind, sprossen Zellstränge hervor, die sich allmählich verbreitern und gleichzeitig einander entgegenwachsen (Fig. 140), um schließlich ein jene beiden Einstülpungen verbindendes Rohr (den Mitteldarm) zu bilden.

Nach Heymons und vielen anderen soll bei den meisten Insekten ein eigentlicher Entoderm an dem Aufbau des Insektenkörpers nicht beteiligt sein, sondern der Mitteldarm sich direkt aus dem Ektoderm der Vorder- und Hinterdarmeinstülpung entwickeln, so daß also die Insekten (im Gegensatz $z u$ allen anderen höher organisierten Tieren) nur aus 2 Keim-

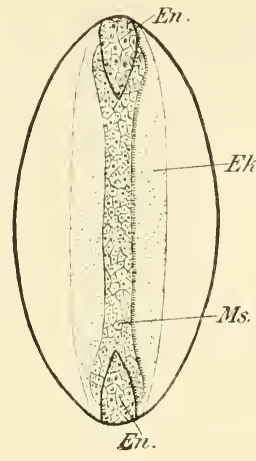

A

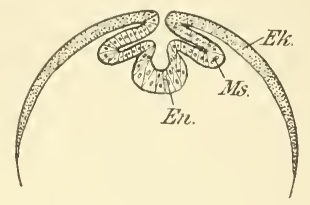

B

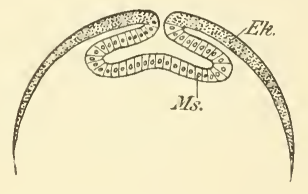

C

Fig. 136. Schematische Darstellung der Keimblätterbildung. A Totalansicht des Keimstreifs. Die Entodermkeime treten nur an den beiden Enden auf. $B$ u. $C$ zwei Querschnitte durch das Vorderende des Keimstreifs mit Entodermkeim $(B)$ und durch die Mitte ohne Entoderm $(C)$. En Entodermkeim; Ek Ektoderm; $\boldsymbol{M} s$ Mesoderm. Nach Escherich aus Berlese.

blättern bestünden. Dem wird aber neuerdings allgemein widersprochen (siehe Korschelt und Heider).

Während der Keimblätterbildung hat der Keimstreif auch an Ausdehnung ganz beträchtlich zugenommen, ror allem in die Breite, indem seine Seitenränder, unter den dünn gebliebenen Partien des Blastoderms sich hinschiebend, den Dotter allmählich umwachsen, bis sie am Rücken zusammenstoßen.

Dadurch, daß der Keimstreif sich unter die dünngebliebene Hüllschicht schiebt, bilden sich Falten, welche sich immer mehr über den Keimstreifen ausbreiten und, miteinander verwachsend, ihn schließlich vollkommen bedecken, so daß jetzt über dem Embryo zwei Hüllen liegen, die als äußere und innere Eihaut oder als Serosa und Amnion bezeichnet werden (Fig. 137). Bei manchen Insekten (z. B. Libellen) wandert der Keimstreif tiefer in den Dotter ein, so daß er schließ-
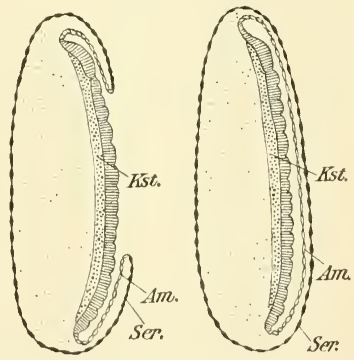

Fig. 137. Bildung der Embryonalhüllen (Amnion und Serosa) durch Überwachsnng der Blastodermränder. Am Amnion; Ser Serosa; Kst Keimstreif. Nach K ors chelt und Heider.

lich allseits von der Oberfläche abgerückt ist und zwischen Serosa und Amnion noch eine Schichte Dotter gelegen ist (Fig. 138).

Als weiterer Vorgang folgt die Segmentierung des Keimstreifs, d. h. letzterer wird durch Querfurchen in eine Anzahl hintereinandergelegene 
Abschnitte (Segmente) zerlegt, von denen die vorderen (die sog. Kopflappen) durch ihre starke Verbreiterung besonders auffallen. Zugleich treten an jedem Segment paarige, sackförmige Ausstülpungen auf, welche die Anlagen für die Gliedmaßen darstellen, von denen allerdings nur die dem Kopf- und Brustabschnitt angehörigen zur vollen Ausbildung yelangen, während die übrigen (an den Hinterleibssegmenten) wieder rückgebildet werden. Zwischen den Gliedmaßenanlagen bilden sich in jedem Segment Verdickungen, aus denen das Nervensystem hervorgeht (Fig. 139). Weiter entsteht an dem Vorder- und Hinterende des Keimstreifes je eine Einstülpung, die zur Bildung des Vorder- und Hinterdaı mes führt (Fig. 140).

Auf weitere Einzelheiten der Organbildung kann hier nicht eingegangen werden; es sei nur erwähnt, wie die Keimblätter zu den einzelnen Organen sich verhalten. Aus dem äußeren Keimblatt geht hervor:

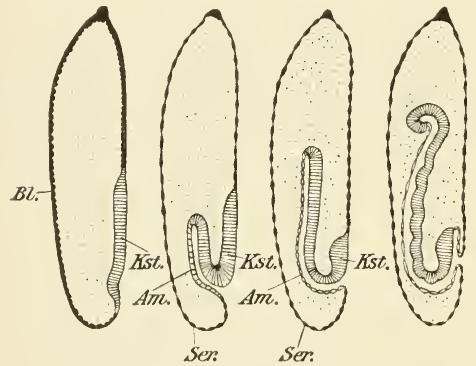

Fig. 138. Bildung der Embryonalhüllen durch Einstülpung des Keimstreifs (Libellen-Ei). Bezeichnungen wie in Fig. 137. Nach Brandt aus $\mathrm{K}$ orschelt und Heider.

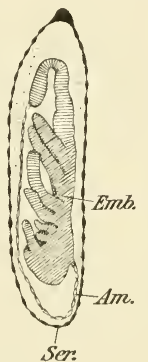

Fig. 139. Totalansicht eines Käferembryos auf dem Dotter des Eies.

Nach Korschelt.

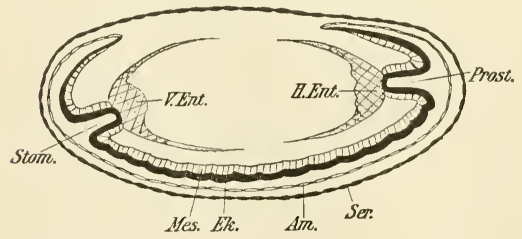

Fig. 140. Einstülpung des Vorder-(Stom) und Hinterdarms (Prost); Am Amnion; Ser Serosa; Mes Mesoderm; Ek Ektoderm; $H E n t$ hinterer Entodermkeim; VEnt vorderer Entodermkeim. die Haut mit ihren Anhängen und Drüsen, Vorder- und Enddarm, die Tracheen, das Nervensystem und die Sinnesorgane und endlich ein Teil der Geschlechtsorgane (der unpaare Ausführgang mit seinen Drüsen und sonstigen Ausstülpungen); aus dem mittleren Keimblatt: das Muskelsystem, der Herzschlauch, die Blut- und die Fettzellen

und ebenfalls ein Teil der Geschlechtsorgane (Keimdrüsen und paarige Ausführgänge); und aus dem inneren Keimblatt (Entoderm): der Mitteldarm. 
Hat der Embryo die ihm zukommende höchste Entwicklungsstufe erreicht, so öfnet er die Eierschale und schlüpft aus, entweder indem er durch seine Bewegungen die allmählich morsch gewordene Hülle sprengt, oder, wenn er mit beißenden Mundwerkzeugen versehen ist, die Schale durchnagt. Bei solchen Insekten, bei welchen die Eischale gegen das Ende der Entwicklung nicht spröde und brüchig wird, sondern ihre Zähigkeit bis zuletzt behält, kommen nicht selten besondere Apparate zur Sprengung der Eischale vor, und zwar gewöhnlich in Form eines unpaaren medianen Stachels oder einer Leiste oder eines Kammes, der im Stirnteil des Kopfes sitzt. Wir kennen solche „Eisprenger" bei einer ganzen Reihe von Insekten aus den verschiedenen Ordnungen, wie z. B. beim Floh, bei verschiedenen Libellen, Phryganiden, Grillen ( $V o B)$, Ohrwürmern, bei Lepisma saccharina, ferner bei verschiedenen Blattläusen und Schildwanzen. Bei den letzteren ist der Eisprenger besonders auffallend und daher schon mehrfach beschrieben, am ausführlichsten von Heymons, der auch eine allgemeine Übersicht über die Eisprenger gibt. „Diese Öffnungsapparate haben bei den Insekten immer nur eine provisorische Bedeutung, sie sind lediglich beim Embryo oder bei der ganz jungen Larve vorhanden, werden aber nach Erfüllung ihres Zweckes meist schon sehr bald, und zwar in der Regel sogar unmittelbar beim Verlassen des Eies, jedenfalls aber bei der ersten Häutung wieder beseitigt und sind demnach im späteren Leben des Insekts nicht mehr vorhanden" (Heymons).

Was die Dauer des Eistadiums betrifft, so ist dieselbe je nach den Insektenarten sehr verschieden, und kann zwischen wenigen Stunden und vielen Wochen und Monaten schwanken. So währt sie z. B. bei der Schmeißfliege kaum 24 Stunden, bei Calosoma sycophanta 3-10 Tage, bei den Blattwespen 10-12 Tage, bei den Leuchtkäfern $5-6$ Wochen und bei der Nonne ca. 9 Monate. Doch ist im letzteren Fall die Dauer des Eistadiums nicht gleichbedeutend mit der Dauer der Embryonalentwicklung. Diese ist bei der Nonne vielmehr in wenigen Wochen schon ziemlich abgeschlossen, so daß bereits im September - das Ei wird Ende Juli oder Anfangs August abgelegt - das fertige Räupchen in der Eischale liegt. Wenn es nach der Entwicklung nicht gleich auskriecht, sondern den ganzen Winter in der Schale verbleibt, so ist hierin zweifellos eine Schutzanpassung zu erblicken, da das kleine Räupchen in der Eischale vortrefflich gegen die Unbilden des Winters geschützt ist.

Die Dauer des Eistadiums hängt übrigens deutlich von der Temperatur ab; so braucht z. B. das Ei von Calosoma sycophanta (nach Burge B) in den kälteren Frühjahrsmonaten 7-10 Tage und in den heißen Sommermonaten nur 3-5 Tage. So kann man ferner das im Nonnenei liegende Räupchen schon im November oder Dezember (anstatt April) zum Auskriechen bringen, wenn man das Ei in den Wärmschrank stellt; oder andererseits auch das Auskriechen auf Wochen und Monate hinausschieben, wenn man die Eier auf Eis oder in Kühlräume stellt.

Man hat auch die Ansicht ausgesprochen, daß solche Eier, die normalerweise überwintern, nicht ohne weiteres durch Wärmeeinwirkung zur beschleunigten Entwicklung gebracht werden können, sondern daß sie zuerst eine gewisse Kälte genossen haben müssen, bevor die Wärme ihre entwicklungsfördernde Wirkung aus- 
zuüben vermag (Escherich). Und so senden auch in dieser Annahme verschiedene italienische Seidenzüchtereien die Eier des Seidenspinners in die Berge, damit ihnen eine andauernde Kälteperiode zuteil werde. Doch scheint es nach den neueren Untersuchungen Knoches an Nonneneiern, daß der Kälte eine solche Rolle nicht in dem Maße zukommt, indem zwischen kältebehandelten und nicht behandelten Eiern kein Unterschied bezügl. ihres Auskommen zu beobachten war.

\section{Nachembryonale Entwicklung.}

Die aus dem Ei schlüpfenden jungen Insekten stimmen darin alle überein, daß sie kleiner als die Imago, flügellos und nicht geschlechtsreif sind. Im übrigen aber verhalten sie sich je nach den Ordnungen, denen sie angehören, recht verschieden: die einen gleichen in ihrer Form vollkommen den Eltern, die anderen dagegen zeigen einen mehr oder weniger davon verschiedenen Bau, so daß man oft gar keinen Anhaltspunkt dafür hat, was für eine Imago daraus entstehen wird.

Die ersteren brauchen nur auszuwachsen und event. Flügel hervorsprossen zu lassen, um zur fertigen Imago zu werden; die letzteren dagegen bedürfen dazu außer des Wachstums noch einer mehr oder weniger starken Verwandlung. Erstere gleichen, wenn wir an höhere Tiere denken wollen, in ihrer nachembryonalen Entwicklung dem Menschen oder den übrigen Säugetieren oder den Vögeln, letztere etwa den Fröschen, die ja bekanntlich das $\mathrm{Ei}$ als sog. Kaulquappe verlassen.

Wie wir nun die jungen Vögel oder Menschen nicht als Larven bezeichnen, so sollten wir diesen Namen eigentlich auch nicht für die imagoähnlichen jungen Insekten anwenden. Jedenfalls machen wir uns damit einer nomenklatorischen Inkonsequenz schuldig; und es würde logischerweise viel richtiger sein, derartig gebildete junge Insekten als Jugen'd- oder Juvenalformen zu bezeichnen. Doch hat sich der Name "Larve“ für die Jugendstadien aller Insekten bereits so allgemein und in allen Sprachen eingebürgert, daß kaum noch etwas dagegen auszurichten sein dürfte (Heymons), und daß auch wir ihn hier in dieser weiten Fassung beibehalten wollen. Immerhin ist es zweckmäßig, die verschiedenen Kategorien von Larven auch namentlich $\mathrm{zu}$ unterscheiden, und so wollen wir mit Deegener diejenigen Jugendformen, welche keinerlei provisorischen Organe (die der Imago nicht zukommen) besitzen, sondern sich lediglich durch eine unvollkommenere Organisation (geringere Größe, Fehlen oder unvollständige Ausbildung bestimmter Körperanhänge, wie Genitalanhänge, Flügel, Fühler) von dem ausgewachsenen Tier unterscheiden, als „primäre Larven“ bezeichnen. Diejenigen Jugendformen dagegen, welche durch den Besitz von provisorischen Organen, die der Imago fehlen, ausgezeichnet sind, als "sekundäre" und „tertiäre Larven“. Die provisorischen Organe stelien Anpassungen an speziell der Larve zukommende Funktionen dar, und so werden wir eine um so reichere provisorische Organisation finden, je verschiedener die Lebensweise von Larven und Imago ist.

Dieser letzte Moment, d. h. die Abänderung der Lebensweise von seiten des jungen Insektes, ist als der erste Anstob für die Entstehung der sekundären und tertiären Larven zu betrachten. Wenn die Jugendform eines 
frei auf der Pflanze lebenden Insektes zur unterirdischen Lebensweise übergeht, so bedarf sie besonderer grabender Organe (z. B. die Grabbeine der Zikadenlarven); oder wenn die Larven luftlebender Insekten ins Wasser gehen, so bedürfen sie besonderer für die Wasseratmung geeigneter Vorrichtungen; oder wenn die Larven ron saugenden Insekten dazu übergehen, von fester Blattsubstanz sich zu nähren, so bedürfen sie kauender Mundwerkzeuge usw. Da nun die Imagines phylogenetisch älter sind als die Larven, so sind die larvalen Organe als sekundär erworbene, auf die Veränderung der Lebensweise zurückzuführende Eigenschaften aufzufassen. Je mehr provisorische Organe also vorhanden sind, desto weiter hat sich die Larve von der Imago entfernt, desto imagounähnlicher wird sie.

Danach lassen sich die sekundären und tertiären Larven folgendermaßen voneinander unterscheiden: Bei den einen besitzen die Larven neben den provisorischen Organen noch zahlreiche imaginale Charaktere, so daß der Habitus der Imago mehr oder weniger gewahrt bleibt: „sekundäre Larven"; bei den anderen sind die imaginale Charaktere so zurückgedrängt gegenüber den larvalen, daß ein völlig fremder, imagounähnlicher Habitus entsteht: "tertiäre Larven.“

Wir können also in ganzen folgende drei Gruppen von nachembryonalen Jugendformen aufstellen:

1. imagoähnliche ohne provisorische Organe: primäre Larven;

2. imagoähnliche mit provisorischen Organen: sekundäre Larven;

3. imagounähnliche mit vorwiegend provisorischer Organisation: tertiäre Larven.

Es versteht sich von selbst, daß der Weg, den die zur Imago führende nachembryonale Entwicklung zurückzulegen hat, um so länger und komplizierter ist, je imagounähnlicher das junge Insekt dem Ei entschlüpft, und umgekehrt, um so kürzer, je imagoähnlicher das junge Insekt ist. Wir werden also die einfachste Form der nachembryonalen Entwicklung bei den Insekten mit primären Larven, die komplizierteste dagegen bei den Insekten mit tertiären Larven finden.

Wo primäre Larven vorhanden sind, da besteht die ganze nachembryonale Entwicklung in einem einfachen Auswachsen und einer event. Umformung einiger Teile; die Entwicklung geht geradewegs von dem $\mathrm{Ei}$ auf das Endstadium, die Imago, los. Wir bezeichnen diesen Vorgang als Epimorphose.

Wo es sich aber um sekundäre und tertiäre Larven handelt, da kann die Entwicklung nur auf Umwegen, unter Rückbildung der provisorischen und Ausbildung der imaginalen Organe zur Imago führen, ein Vorgang, den man als Metamorphose bezeichnet.

Der Umweg ist, wie schon gesagt, um so größer, je zahlreicher die provisorischen Organe sind und umgekehrt. So schlägt die Entwicklung bei den Insekten und mit sekundären Larven (z. B. Libellen) schon bald den Weg zur Imago ein, während die tertiären Larven (z. B. die Schmetterlingsraupen) bis zu ihrer Vollwüchsigkeit in ihrer weit von der Imago abweichenden Richtung verharren, um dann plötzlich, gewissermaßen mit einem Sprung zur Imago, sich zu rerwandeln. 
Diese plötzliche Verwandlung bedingt eine mächtige Revolution im Innern, welche ihrerseits natürlich möglichst viel Ruhe nach außen verlangt. Und so sehen wir bei allen Insekten mit tertiären Larven auf das letzte Larvenstadium wenigstens ein Ruhestadium folgen, welches wir als "Puppe“ bezeichnen.

Die Metamorphose verläuft also verschieden, je nachdem sie Insekten mit sekundären oder tertiären Larven betrifft. Im ersten Fall haben wir meist nur: Ei - Larve - Imago, im zweiten Fall dagegen stets wenigstzns: Ei Larve - Puppe - Imago. Wir bezeichnen die erste Form der Metamorphose als „Hemimetabolie“, die letzte als "Holometabolie“.

Während alle diese Verwandlungsformen: Epimorphose, Hemi- und Holometabolie das eine gemeinsam haben, daß die Segmentzahl konstant bleibt, resp. nicht vermehrt wird (Holomerie), gibt es noch eine zweite Entwicklungsform, bei der eine Vermehrung der Segmente stattindet (Anamerie). Die letztere ist bei den niederen Arthropodengruppen weit verbreitet, während sie unter den Insekten nur auf die Proturen beschränkt ist.

Wir werden unten noch einige weitere Formen von Metamorphose kennen lernen; bevor wir aber auf diese Einzelheiten näher eingehen, seien einige Punkte, die zum Verständnis der nachembryonalen Entwicklung notwendig sind, erörtert.

\section{Die Häutung.}

Das Larvenstadium ist das Stadium der Ernährung. In ihm sammelt das aus dem Ei entstandene Tier durch eigene Nahrungsaufnahme diejenige Körpermasse, aus welcher der verhältnismäßig große Leib des erwachsenen Insektes aufgebaut wird. Nach Lyonet ist die reife Weidenbohrerraupe ungefähr 72000 mal schwerer, als das neu ausgeschlüpfte Räupchen, und die Schmeißfliegenlarve kann in 24 Stunden um das 200 fache ihres Anfangsgewichtes zunehmen.

Es fällt daher auch das gesamte Körperwachstum des Einzelinsektes in diese Zeit hinein. Da aber die fertige Chitincuticula nur wenig oder gar nicht ausdehnungsfähig ist, so tritt jedesmal, wenn die Körpermasse der Larve so weit zugenommen hat, daß die ursprüngliche Cuticula dieselbe nicht mehr zu fassen vermag, eine Häutung ein. Die alte Chitincuticula hebt sich zunächst von ihrer Matrix, der Hypodermis, ab, und die Hypodermiszellen bilden neue Cuticularsubstanz auf ihrer Oberfläche. Zu gleicher Zeit scheiden besondere Drüsen, sog. Häutungsdrüsen, die bei verschiedenen Insekten in verschiedener Zahl und Anordnung vorhanden sind, reichliche Mengen eines flüssigen Sekretes ab (Exuvialflüssigkeit), die zwischen die alte losgelöste und die neu sich bildende Haut tritt, und so der letzteren die Möglichkeit einer freieren Entfaltung ihrer Anhänge usw. verschafft. Nachdem die neue Haut fertig gebildet ist, zerreißt die alte Cuticula (meist in der Kopfregion) und die Larve tritt aus ihrer alten Haut heraus (Fig. 141).

Die Häutung erstreckt sich nicht nur auf die Haut der Körperoberfläche, sondern auch auf die chitinöse Auskleidung der Tracheen, des Vorderund Enddarms, verschiedener Drüsen usw. Daneben spielen sich auch sonst noch gewisse Degenerations- und Erneuerungsprozesse an verschiedenen 
Organen, z. B. Darm und Fettkörper ab, so daß die Häutung also einen in das Leben der Insekten tief einschneidenden Vorgang darstellt. Daher kommt es, daß die Insekten während der Häutungsperiode in ihrer Lebensenergie stark herabgedrückt sind, und träge und freßunlustig werden. Oft suchen die Larven in dieser Zeit besondere geschützte Plätze auf, um dort so lange zu bleiben, bis die Häutung überstanden ist. In extremen Fällen sinken die Larven sogar bei jeder Häutung in einen völlig apathischen, an die Puppenruhe erinnernden Zustand; dies kommt z. B. bei den Termiten vor, bei denen die Larven schon einige Tage vor der Häutung in einen starren und völlig unbeweglichen Zustand verfallen, und in denselben bis mehrere Tage nach dem Abwerfen der alten Haut verbleiben.

\section{Entwicklungsstadien.}

Als „Entwicklungsstadium" bezeichnen wir den Zustand der Larve, der zwischen zwei Häutungen gelegen ist. Mit dem Abwerfen oder der völligen Ablösung der alten Chitinhaut beginnt also jedesmal ein neues

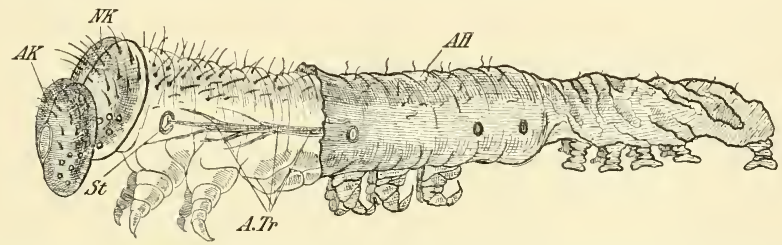

Fig. 141. Häutung einer Schmetterlingsraupe. Die Raupe ist zur Hälfte aus der alten Haut $(A H)$ herausgekrochen. Die alte Kopf kapsel $(A K)$, die von der Rumpfhaut abgerissen ist, hängt noch an der neuen Kopfkapsel $(N K)$. Ferner sieht man die alte Tracheenintima $(A T r)$, die bei der Häutung aus dem nenen Stigma (St) heransgezogen wird. Nach der Wandtafel von Pfurtscheller, etwas verändert.

Stadium, das dann wieder mit der nächsten Häutung sein Ende findet. Durch die Häutung werden somit die Stadien begrenzt, während das erste Larvenstadium mit der Entfernung der embryonalen Cuticula seinen Anfang nimmt. Die Zahl der Häutungen ist bei den verschiedenen Insekten sehr ungleich; sie beträgt z. B. bei der Stubenfliege 3, bei den Schmetterlingen durchschnittlich 5, bei den Wespen und Bienen wenigstens 8 , bei den Küchenschaben 7 , bei den Feldheuschrecken im allgemeinen 5, bei der Eintagsfliege 22 und bei der 17 jährigen Zikade gar bis 30 ; bei den niederen Insekten ist vielfach die $Z$ ahl der Häutungen überhaupt nicht streng fixiert.

Die einzelnen Stadien unterscheiden sich nicht immer nur durch die Größe, sondern sehr häufig auch noch durch eine verschiedene Färbung, verschiedene Struktur, Auftreten neuer Organe, andere Form usw., und zwar nicht nur bei den primären und sekundären, sondern auch bei den tertiären Larven. So z. B. besitzt das erste Raupenstadium bei der Nonne das sog. Spiegelräupchen, eigentümliche, mit blasenförmigen Erweiterungen versehene Haare (Toxophore), die dem zweiten Stadium fehlen. Ja, es gibt sogar Fälle (gewisse Ichneumoniden usw.), in denen zwei aufeinanderfolgende Stadien habituell so verschieden sind, daß der Un- 
eingeweihte ihre Zusammengehörigkeit nicht erkennen kann (interlarvaler Dimorphismus).

\section{Provisorische (larvale) Organisation.}

Als provisorische Organe werden solche Organe bezeichnet, welche nur der Larve zukommen, und der Imago fehlen. Es würde hier zu weit führen, sämtliche vorkommenden larvalen Organe zu besprechen, und so sollen nur einige besonders augenfällige Unterschiede zwischen larvaler und imaginaler Organisation genannt werden.

Im allgemeinen ist die Haut der Larve (speziell der ertiären) dünner und weicher als bei der Imago. Dabei besteht eine sehr deutliche Abhängigkeit von der Lebensweise, insofern, als die Larven, die ein verborgenes Leben führen (wie die unter Rinde oder im $\mathrm{Holz}$ lebenden Larven der Borken-, Rüssel- oder Bockkäfer, oder die in Bauten geschützten Larven der Ameisen, Wespen und Bienen, oder die im Körper anderer Insekten parasitierenden Larven der Schlupfwespen usw.),

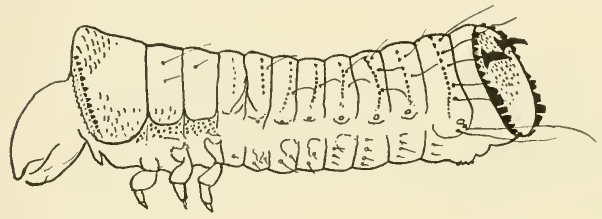

Fig. 142. Haut einer frischgeschlüpften Larve von Hylecoetus dermestoides $L_{\text {., }}$ mit zahlreichen zur Fortbewegung dienenden Dornen. Nach Leisewitz. viel weichhäutiger sind, als die ein freies Leben führenden Larven, wie die vom offenen Raub lebenden Larven der Laufkäfer oder die von Blättern lebenden Raupen der Schmetterlinge oder Afterraupen der Blattwespen. Bei Larven, welche in Gehäusen leben, wie z. B. die Köcherfliegen (Fig. 147), sind die stets im Gehäuse verbleibenden Teile viel weichhäutiger als die daraus hervorragenden vordersten und hintersten Abschnitte.

Ungefähr das gleiche gilt von der Färbung, indem dieselbe ebenfalls von dem Aufenthalt der Larve wesentlich beeinflußt wird; bei den verborgen lebenden Larven ist die Haut meist pigmentlos, so daß sie infolge des durchschimmernden Fettkörpers weiß erscheinen, bei den frei lebenden Larven dagegen finden wir die verschiedensten Färbungen und Zeichnungen, die oft mit der Umgebung mehr oder weniger übereinstimmen und dadurch den betreffenden Tieren einigen Schutz verleihen.

So können wir also aus der Beschaffenheit der Haut und der Färbung schon einen einigermaßen sicheren Schluß auf die Lebensweise der Larve ziehen, insofern als wir weichen und ungefärbten Formen eine verborgene, und härter chitinisierten oder lebhaft gefärbten Formen eine offene freie Lebensweise zuschreiben können.

Die Larvenhaut ist gewöhnlich auch mit Anhängen der verschiedensten Art besetzt, die der Imago fehlen (Fig. 142). So hat Leisewitz eine Menge larvaler Haare, Borsten und Dornen beschrieben, welche den Larven zur Fort- 
bewegung dienen. Man denke ferner an das dichte Haarkleid der Bärenraupen, von dem bei der Imago nichts mehr vorhanden ist usw.

Groß ist auch die Zahl der provisorischen Drüsen. Es sei nur an die langen, hornartig ausstülpbaren Drüsen in der Nackengegend der Papilioraupen, die sog. Nackengabeln erinnert, oder an die am Rücken des 9. und 10. Segmentes gelegenen Trichterwarzen der Nonnenraupen, oder an die Drüsen gewisser Chrysomelidenlarven (Lina populi), deren Sekret den charakteristischen, „schützenden“ Geruch verbreitet.

Wie verschieden von der Imago ist ferner meist die ganze Körperform und die Segmentierung der tertiären Larven. In allgemeinen sind die Larven länger und schmäler als die Imagines, und auch ursprünglicher segmentiert, sowohl bezügl. der Zahl der Segmente als auch der Gleichartigkeit ihres Baues. Vor allem sind die Brustsegmente, mangels funktions.

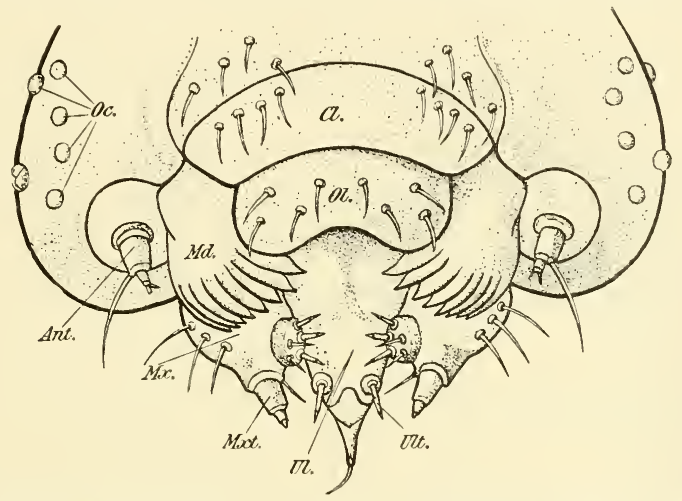

Fig. 143. Mundgliedmaßen einer Raupe. Cl Clypeus; Ol Oberlippe; $M d$ Mandibeln; Mx Maxille; Mxt Maxillartaster; Ul Unterlippe; Ult Unterlippentaster; Ant Fühler. Nach der zoolog. Wandtafel Nr. 23 von Pfurtscheller.

fähiger Flügel, in ihrem Umfang und ihrer Konfiguration oft nur wenig oder gar nicht von den Hinterleibssegmenten verschieden, so daß die Trennung des Rumpfes in Brust und Abdomen mitunter undeutlich wird oder auch ganz verschwindet.

Nicht weniger unterschiedlich resp. provisorisch verhalten sich die Extremitäten. So sind die Fühler der Larven im allgemeinen viel kürzer und auch ganz anders gebaut als die Fühler der dazu gehörigen Imagines. Ja, nicht selten sind sie auch ganz rückgebildet, wie bei den Rüsselkäferlarven, Fliegenmaden usw. Beim großen Eichenbock besitzt die Larve nur winzige, kaum bemerkbare Fühler, während sie bei der Imago bekanntlich mächtig entwickelt sind. Auch die Mundgliedmaßen der Larven weichen vielfach stark von den imaginalen ab. Die Raupen der Schmetterlinge haben kauende Mundwerkzeuge (Fig. 143), die Imagines dagegen einen Saugrüssel; bei der Larve vom Gelbrandkäfer sind die Mandibeln zum Saugen 
eingerichtet, während sie bei den erwachsenen Tieren als einfache Greifzangen dienen. Oder man denke an die aus wenigen Stücken bestehenden Schlundhaken der Fliegenmaden und dem komplizierten Rüssel der ausgewachsenen Fliegen. Aber selbst da, wo Larve und Imago kauende Mundwerkzeuge besitzen, sind dieselben bei der Larve meist ganz anders gebaut, als bei der Imago.

Die lokomotorischen Extremitäten (Beine) sind bei den Larven gewöhnlich viel schwächer entwickelt und in ihrer Gliederung viel einfacher als bei der Imago. Wir brauchen nur die Beine einer Raupe mit den Beinen eines Schmetterlinges zu vergleichen, um uns davon zu überzeugen. Bei vielen Larven sind die Brustbeine rudimentär und nur noch als kleine Stummel vorhanden (z. B. Bockkäfer), oder sie fehlen auch ganz (Borkenkäfer, Fliegenmaden usw.). Bei einer Anzahl von Larven (Raupen und Afterraupen) treten auch am Hinterleib noch mehrere Beinpaare auf, die sich in ihrem Bau wesentlich von den Brustbeinen unterscheiden und die als Pedes spurii oder Bauch-oder Afterfüße bezeichnet werden. Sie stellen

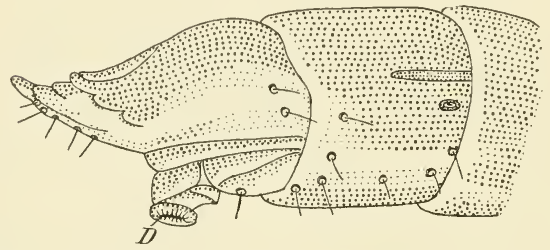

Fig. 144. Ausgestiulptes Ende des Enddarmes $(D)$ als Fortbewegungsorgan bei einer Elateridenlarve. Nach G. W. Müller. eigentlich nur ausgestülpte Hautzapfen dar, die auf der Endfläche mit einem Kranz kurzer Dörnchen ausgerüstet sind. Ihre Zahl ist verschieden; bei den Schmetterlingsraupen treten sie gewöhnlich in 5 Paaren (bei den Spannern nur 2) auf, bei den Larven der Blattwespen, den sog. Afterraupen, in 6-8 Paaren.

Bei manchen Larven kommen noch andere Fortbewegungsorgane vor: wir haben oben schon von den Dornen und Borsten gehört, die der Fortbewegung dienen; oft finden sich außerdem auch noch Warzen und Wülste (und zwar sowohl am Bauch, als auch am Rücken), die beim Vorwärtsbewegen in engen Gängen, Röhren usw. in Funktion treten. Auch das ausstülpbare Ende des Enddarmes, welches mitunter noch mit bewaffneten Schläuchen versehen ist, dient bei gewissen Larven (Elateriden, Staphyliniden, Carabiciden, Lampyriden und vielen anderen), wie G. W. Müller neuerdings beschrieben hat, als Fortbewegungsorgan (Fig. 144).

Gehen wir nun zur inneren Organisation über, so treten uns auch da eine Menge echt larvaler Bildungen entgegen. So ist der Darmkanal der Larven meist sehr verschieden vom imaginalen Darm, namentlich dann, wenn die Nahrung der Larve von der der Imago wesentlich abweicht. Am deutlichsten prägt sich dieses bei den Schmetterlingen aus. Während nämlich die auf flüssige Nahrung (auf Blumensäfte) angewiesenen Imagines einen verhältnismäßig wenig umfangreichen, dünnen, nur mit einem seitlich angesetzten großen Kropf, dem „Saugmagen“, versehenen Darm haben, ist der Darm der Raupe ein in gerader Linie von Mund zu After verlaufender, 
dicker Schlauch, bei welchem besonders der Mitteldarm zu einem weiten massigen Behälter für die reichliche Pflanzennahrung ausgebildet ist (Fig. 145).

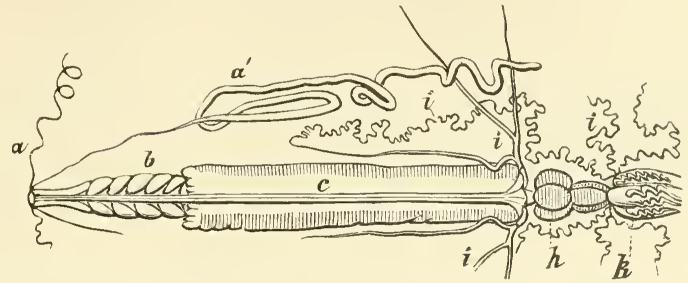

Fig. 145. Darmkanal nebst Anhängen der Raupe von Bombyx pini L. (nach Suckow), a Speicheldrüse; $a^{\prime}$ Spinndrüse; $b$ Schlund; $c$ Mitteldarm; $h$ Dünndarm; $k$ Mastdarm; $i$ Harngefäße, von denen 2 Paar der rechten Seite und alle linksseitigen abgeschnitten erscheinen. - (N.)

Im übrigen sei auf das oben (S. 65) über den Darmkanal gesagte verwiesen, und besonders auf die dort gegebenen Abbildungen, welche die
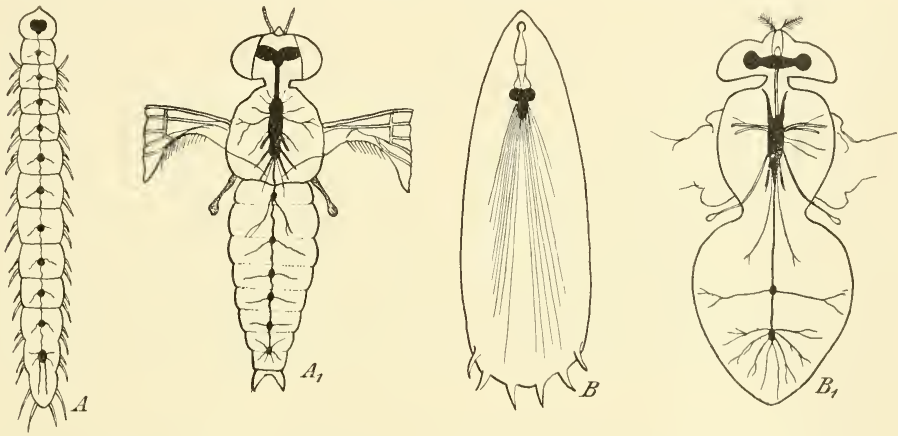

Fig. 146. Unterschiede des Nervensystems vou Larve und Imago. In A (Bibio hortulanus, Diptere) ist die Ganglienkette bei der Larve weniger konzentriert als bei der Imago; in $B$ (Volucella, Diptere) ist das Umgekehrte der Fall. Nach Künckel d'Herculais aus Henueguey.

großen Unterschiede zwischen larvalem und imaginalem Darm ohne weiteres erkennen lassen. Viele Larven besitzen ferner mächtig entwickelte Spinndrüsen, welche den Imagines fehlen.

Große Unterschiede zwischen Larve und Imago bestehen ferner im Bau des Tracheensystems. Ist doch bei manchen Larven die Zahl der Stigmen auf 2 oder gar nur 1 Paar reduziert (Dipteren),

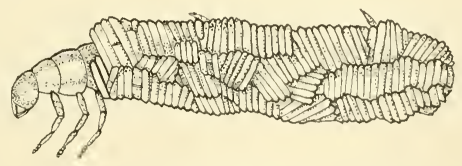

Fig. 147. Phryganidenlarve im Gehäuse. während die Imagines die volle Zahl besitzen. Besonders auffallend werden die Differenzen da, wo die Larven dem Wasserleben angepaßt sind, während 
die Imagines ein Luftleben führen, indem hier die Stigmen geschlossen sind und funktionell an ihre Stelle verschieden geformte, dünne Anhänge (sog. Tracheenkiemen) treten, die einen Gasaustausch unter Wasser ermöglichen (siehe S. 76).

Endlich sei noch auf die Verschiedenheiten des Nervensystems bei Larve und Imago hingewiesen (Fig. 146), die meist darin bestehen, daß die Ganglienkette bei der Larve meist weniger konzentriert ist, als bei der Imago (selten umgekehrt), was ebenfalls oben schon des Näheren erörtert ist.

\section{Die Imaginalanlagen der Larven.}

Die tertiäre Larve (siehe S. 143) hat in ihrer Organisation kaum noch irgend welche imaginalen Züge, alles an ihr ist spezifisch larval, sie ist zu einem ganz anderen Tier geworden als die Imago, weil sie eine andere Lebensweise angenommen und sich an diese in sehr vollkommener Weise angepaßt hat. Die Anpassung an die veränderte Lebensweise konnte nur dann eine vollkommene werden, wenn die Larve nicht durch den Ballast imaginaler Organisation beschwert war. „Denn über eine gewisse Grenze des Zugleichexistierens larvaler und imaginaler Organe hinaus konnte das Tier nicht zur selben Zeit provisorisch und imaginal organisiert sein, ohne daß ein Monstrum zustande kam, eine Mischform zwischen Larve und Imago, welche an keine mögliche Lebensweise mehr erhaltungsfähig angepaßt sein könnte. Wie weit die Vereinigung einer larvalen und unvollkommenen imaginalen Organisation höchstens gehen kann, lehren uns die sekundären Larven. Darüber hinaus ist eine Steigerung der provisorischen Organisation nur noch möglich unter gleichzeitiger Unterdrückung der imaginalen Organisation, das heißt: je mehr die fortschreitende Entwicklung zur Imago zurückgehalten wurde, und je länger dies geschah, um so längere Zeit konnte die Larve in unveränderter, also in für sie zweckmäßigster Gestalt leben und ihre Aufgabe erfüllen." (D eegener.)

Wie ist es nun möglich, daß die tertiäre Larve nach der letzten Häutung auf einmal ein ganz anderes Wesen wird? Dieser überraschende Vorgang, der ehedem als das größte Wunder angestaunt wurde, wird uns verständlicher, wenn wir die Gewebe der Larven genauer untersuchen. Wir werden dann überall im Larvenkörper Keime finden, welche die Anlagen der verschiedenen imaginalen Organe darstellen, und deshalb auch als Imaginalanlagen bezeichnet werden.

Sehen wir uns z. B. die Flügelbildung an. Während bei der primären und sekundären Larve die Flügel allmählich hervorsprossen, und in jedem Stadium länger werden, findet sich selbst an der vollwüchsigen tertiären Larve keine Spur von Flügelanlagen, äußerlich wenigstens. Untersuchen wir aber die Segmente, an denen später die Flügel sitzen, etwas näher, so werden wir innerlich sehr wohl Flügelanlagen entdecken, und zwar in Form von Hauteinstülpungen. Bei der letzten Larvenhäutung stülpen sich dieselben nach außen vor, so daß sie also bei der Puppe äußerlich als Flügel in Erscheinung treten. 
Was hier für die Flügel gesagt ist, trifft für alle imaginalen Organe zu, d. h. dieselben sind in der tertiären Larve meistens bereits vorhanden als sog. Keime oder Anlagen, die aber während der Larvenperiode mehr oder weniger latent bleiben, um sich erst nach Auflösung der larvalen Organe in die imaginalen zu entfalten. So finden wir in den bein- und kopflosen Fliegenmaden bereits ganz deutlich die Bein- und Kopfanlagen in Form von Einstülpungen (Fig. 148); so finden wir als Ausgangspunkt für den imaginalen Hautpanzer allenthalben in der larvalen Hypodermis größere oder kleinere Zellgruppen eingelagert, die sog. Imaginalscheiben; so finden wir ferner im larvalen Darm bereits die Anlagen für den imaginalen Darm ebenfalls in Form einzelner Zellgruppen usw.

\section{Die Puppe.}

Wenn wir die Larve und die Puppe eines Schmetterlings miteinander vergleichen, so fällt ohne weiteres ein großer Unterschied zwischen beiden

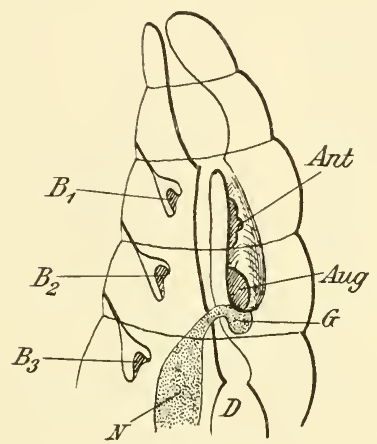

$A$

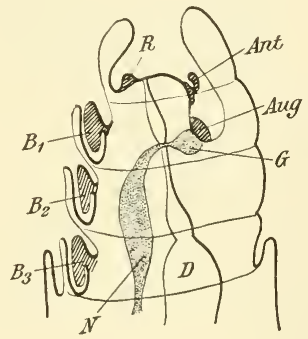

$B$

Fig. 148. Imaginalscheiben: $A$ in der Larve (eingestülpt), $B$ in der Puppe (ausgestülpt) der Stubenfliege (Musca). $B_{1}-3$ Beinanlagen; Ant Fühleranlagen; Aug Augenanlagen; $R$ Rüsselanlage; $D$ Darm; $G$ Gehirn; $N$ Bauchmark. Nach van Rees aus Korschelt und Heider.

auf: die Larve ist völlig imagounähnlich, die Puppe dagegen erscheint der Imago sehr ähnlich, indem sie mit allen imaginalen Organen ausgestattet ist, während ihr die larvalen Organe samt und sonders fehlen. Wir rechnen daher die Puppe auch dem Imagostadium zu, d. h. fassen sie als eine unvollkommene oder noch unfertige Vorstufe der Imago auf. Und so haben wir also gewissermaßen nicht nur ein, sondern mehrere Imagostadien zu unterscheiden.

Diese Auffassung, die hauptsächlich von Heymons, Deegener und Boas vertreten wird, erhält dadurch eine kräftige Stütze, daß bei niederen Insekten die Zahl der Häutungen (und Stadien) oft gar nicht fest fixiert ist, und bei einigen Urinsekten (Machilis, Collembolen) selbst im ausgewachsenen Zustand und nach erlangter Geschlechtsreife nochmals Häutungen statt- 
finden können. Es scheint, daß erst die Entstehung der Flugwerkzeuge eine Änderung hierin herbeigeführt hat und bewirkt hat, daß die Häutungen bei den Insekten fortan im Imagozustand unterblieben. Denn durch den Häutungsprozeß wird die Brauchbarkeit der Flügel zweifellos stark herabgedrückt.

Es gibt allerdings noch einige wenige Insekten, die im geflügelten $\mathrm{Zu}$ stande, d. h. mit funktionsfähigen Flügeln, sich nochmals häuten; es sind dies die Eintagsfliegen oder Ephemeriden. Das letzte, vor der Imago gelegene Stadium dieser Insekten, die sog. Subimago, gleicht vollkommen der Imago, und unterscheidet sich von ihr hauptsächlich durch mangelnde Geschlechtsreife. Es stellt also eine unfertige Imago dar, und ist in dieser Beziehung der Puppe der höheren Insekten gleichzustellen.

Die Fähigkeit der Ortsbewegung, die der Subimago der Ephemeriden zukommt, spricht keineswegs gegen diese Auffassung, da es ja auch be-
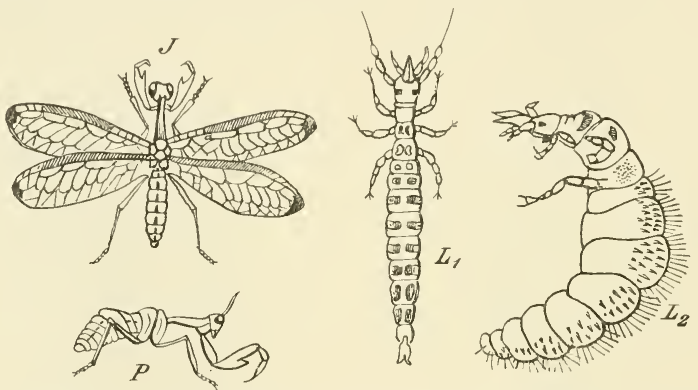

Fig. 149. Entwicklung von Mantispa (Neuroptere) mit larvalem Dimorphismus und frei beweglicher, herumwandelnder Puppe. $L_{1} L_{2}$ Larve; $P$ Puppe; $J$ Imago. Nach Bra uer und Packard aus Hey mons.

wegungsfähige Puppen gibt. Abgesehen von den allgemein bekannten beweglichen Puppen gewisser Dipteren oder Lepidopteren, bei denen die Beweglichkeit eine sekundär erworbene Eigenschaft darstellt, kommen bei gewissen Neuropteren und Trichopteren noch Puppen vor, die mit Hilfe ihrer Extremitäten munter einherwandern oder sich schwimmend vorwärts bewegen können.

Als Beispiel sei hier die Entwicklungsgeschichte von Mantispa styriaca angeführt (Fig. 149). Aus dem Ei dieser Neuroptere schlüpft eine 1. freibewegliche mit kräftigen Beinen versehene Larve $\left(L_{1}\right)$, die sich in einem Spinnenkokon einbohrt, um sich von den in diesen enthaltenen Eiern zu ernähren. Sie wandelt sich dort in eine 2. abweichend gestaltete kurzbeinige Larve $\left(L_{2}\right)$ um, die im Innern des Kokons eingeschlossen liegt und dann 3. in das Puppenstadium übergeht. Beim Puppenstadium von Mantispa sind aber zwei verschiedene Phasen zu unterscheiden, nämlich eine Phase, in der die Puppe unbeweglich in einem Gespinst im Innern des Spinnenkokons ruht, und eine weitere Phase, in der die Puppe Beweglichkeit erhält. In diesem letzteren Zustande verläßt sie den Spinnenkokon und lebt frei als 
subimagoartige Form $(P)$, bis 4. die Umwandlung zur geflügelten geschlechtsreifen Imago sich rollzieht.

Auch bei anderen Neuropteren kommen nach anfänglicher Ruheperiode beweglich werdende Puppen vor. Ja, nach den Untersuchungen von Thienemann kann bei Trichopteren von einer eigentlichen Puppenruhe überhaupt keine Rede sein, denn die Trichopterenpuppe führt im Innern des Köchers mit dem Hinterleib fortwährende Bewegungen aus, um das Atemwasser zu erneuern, sie bedient sich besonderer Putzapparate zur Entfernung von Fremdkörpern, und wenn sie schließlich ihr Gehäuse verläßt, so schwimmt sie frei im Wasser, bis sie das Land erreicht hat, um sich dort zur Imago umzuwandeln.

\section{Die verschiedenen Formen der Entwicklung.}

Nachdem nun die Begriffe Larve, Puppe usw. erläutert sind, können wir dazu übergehen, die verschiedenen Formen der nachembryonalen Entwicklung, die der beigegebenen Tabelle (im Anschluß an Heymons) übersichtlich dargestellt sind, zu besprechen. ${ }^{1}$ )

Anamera.

Anamorpha.

Insekten mit

Segment-

vermehrung

(vgl. S 144).

\section{Epimorpha.}

(s. lat.)

Insekten

mit UT -

wandlung.

Protura.

Thysanura,
Orthoptera,
Isoptera,
Rhynchota
(part.) usw.

\section{Holomera.}

Zikaden,

Libellen,

Perliden.

\section{Metamorpha.}

Insekten mit V'erwandlung.

\begin{tabular}{cccc} 
Hemi- & Prome- & \multicolumn{2}{c}{ Holometabola. } \\
metabola. & tabola. & Holome- & Hyper- resp. \\
(Ei, sekun- & (Ei, sekun- & tabola typica. & Polyme- \\
däre Larve, däre Larve, & (Ei, tertiäre & tabola.
\end{tabular}
Imago.
Subimago, Imago.)

Larve,
Puppe,
Imago.)

(Ei,dimorphe tertiäre Larve, Scheinpuppe [oder 2 Puppen], Imago.)

$\begin{array}{cc}\begin{array}{c}\text { Epheme- } \\ \text { riden. }\end{array} & \text { Neuropteren } \\ \text { (part.), } \\ \text { Coleopteren } \\ \text { (part.), } \\ \text { Dipteren, } \\ \text { Lepido- } \\ \text { pteren. }\end{array}$

Meloiden, Lebia u. a.

\section{Epimorphose.}

Bei allen denjenigen Insekten, die beim Ausschlüpfen aus dem Ei schon mit der Imago in den Grundzügen übereinstimmen, und sich nur durch eine unvollkommene Organisation von ihr unterscheiden, stellt die nach-

1) Die hier aufgestellten Kategorien stehen sich keineswegs völlig unvermittelt gegenüber, sondern es kommen auch mancherlei Übergangsformen vor, deren Einreihung in diese oder jene Kategorie dem Empfinden des einzelnen überlassen bleibt. 
embryonale Entwicklung eine Epimorphose dar, d. h. ein einfaches Auswachsen, unter gleichzeitigen verschiedentlichen Umformungen, aber ohne Verwandlung. Der Grad der Unvollkommenheit, durch den sich die junge Larve von der geschlechtsreifen Imago unterscheidet, unterliegt allerdings sehr weiten Schwankungen. Die Unterschiede können einerseits sehr bedeutend sein, sie können aber auch andererseits so geringfügig werden, daß sie sich kaum nachweisen lassen. Hier zwischen gibt es alle Übergänge (Heymons).

$\mathrm{Zu}$ den Epimorpha gehören die sog. niederen Insekten, die Apterygoten, die Orthopteren, Dermapteren, Corrodentia, Isoptera, dann auch die Rhynchoten, die Pediculiden usw.

Als einfaches Beispiel einer solchen Verwandlung wählen wir die einer Feldheuschrecke (Fig. 150). Die dem Ei $A$ entschlüpfende Larve $B$ ist dem Muttertiere bereits in seinen wesentlichen Zügen ähnlich, hat aber einen

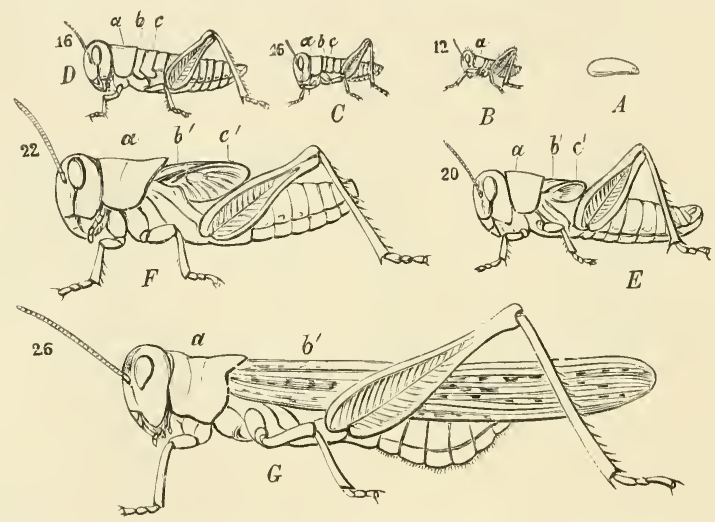

Fig. 150. Epimorphose einer Feldheuschrecke nach Emerton. $A$ Ei; $B-F$ fünf Larvenstadien; $G$ das erwachsene Tier; $a, b, c$ die 3 Ringe der Brust; $b^{\prime}$ Vorderflügel; $c^{\prime}$ Hinterflügel. Die den Fühlern beigedruckten Zahlen bezeichnen die Anzahl der Fühlerglieder. - (N.)

sehr großen Kopf, und nur 12 Fühlerglieder. Meso- und Metathorax tragen keine Spur von Flügeln und sind zusammen ungefähr so lang, als der Prothorax. Mit der ersten Häutung tritt die Larve in das zweite Stadium $C$; es dehnt sich nun das Abdomen etwas aus, so daß der Kopf im Verhältnis kleiner erscheint. Der Hinterrand des Prothorax schiebt sich faltenartig über den vorderen Teil des Mesothorax, und die Antennen haben 16 Glieder. Bei der nun eintretenden zweiten Häutung tritt die Larve in das dritte Stadium $D$. Die Antennen bleiben in demselben 16 gliedrig, dagegen ziehen sich die hinteren und unteren Ecken des Meso- und Metanotum in kleine lappenartige Vorsprünge aus, die ersten Anlagen der Flügel. Die dritte Häutung läßt die Larve in das vierte Stadium $E$ übertreten. In diesem hat die Larve $20 \mathrm{Fühlerglieder,} \mathrm{und} \mathrm{die} \mathrm{nun} \mathrm{bereits} \mathrm{stärker} \mathrm{gewachsenen} \mathrm{Flügel-}$ stummel sind nach oben ungeschlagen, so daß die Anlage der Hinterflügel einen Teil der Vorderflügelanlage deckt. In dem mit der vierten Häutung 
beginnenden fünften und letzten Stadium $F$ erhält die Larve ein weit nach hinten vorspringendes Halsschild, die Flügelstummel sind gewachsen, aber noch in ihrer alten Lage, die Fühler haben 22 Glieder. Bei der letzten oder fünften Häutung erscheint nun die vollkommene Imago $G$ anfänglich weich, mit noch dicht zusammengefalteten Flügeln, welche sich aber bald ausdehnen und nach geschehener Erhäıtung zurecht legen, so daß die Vorderflügel als pergamentartige Flügeldecken nun die Hinterflügel vollkommen decken. Die Imago hat 26 Fühlerglieder.

\section{Metamorphose.}

Eine Metamorphose findet überall da statt, wo die Larven provisorische Organe besitzen, die der Imago fehlen. Wir haben aber oben gesehen, $\mathrm{da}$ h hierin große Verschiedenheiten existieren; bei den einen sind neben den provisorischen Organen die imaginalen noch in der Überzahl vorhanden, bei den anderen dagegen sind die imaginalen Charaktere gänzlich zurückgedrängt, so daß die Larven einen völlig fremden Habitus besitzen.

Bei den ersteren strebt die Entwicklung allmählich der Imago zu; die Larven werden mit jeder Häutung imagoähnlicher, um dann mit der letzten Häutung, bei der die provisorischen Organe mit einem Male abgeworfen werden, in die Imago überzugehen: Hemimetabolie. Bei den letzteren dagegen behält die Larve während ihres ganzen Lebens bis zur Vollwüchsigkeit ihre abweichende provisorische Organisation bei, um dann plötzlich mit Hilfe eines Puppenstadiums in die Imago sich zu verwandeln: Holometabolie. Zwischen diesen beiden liegt der Entwicklungsmodus der Ephemeriden, bei denen die Larvenentwicklung im allgemeinen nach dem hemimetabolen Typus verläuft, aber zwischen die letzte Larve und die Imago noch ein

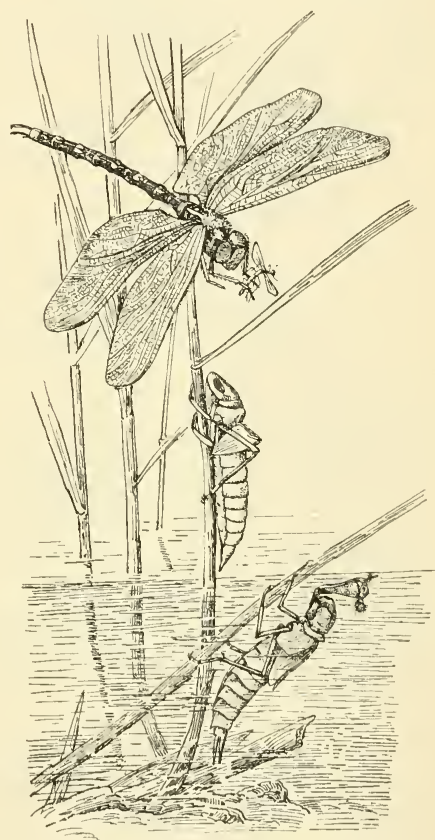

Fig. 151. Beispiel einer Hemimetabolie. Ent. wicklung einer Libelle. Unten Larve mit ausgestreckter, in der Mitte Larve mit eingezogener „Maske“, oben die Imago. Nach Schmeil. besonderes Stadium, die Subimago, eingeschoben ist: Prometabolie.

\section{Hemimetabolie.}

Die Hemimetabolie kommt in der typischen Form bei den Odonaten (Libellen) und den Plecopteren (Perliden) vor, deren Larven durch Ausbildung 
von Tracheenkiemen an das Wasserleben angepaßt sind; ferner bei gewissen Zikaden, deren Larven zu unterirdischer Lebensweise übergegangen sind und in Anpassung daran ihre Vorderbeine zu Graborganen umgebildet haben.

Als Beispiel einer Hemimetabolie sei die Entwicklung einer Libelle angeführt: Die dem Ei entschlüpfte Larve unterscheidet sich durch mehrere Merkmale von der Imago: ihr Auge ist wesentlich kleiner, die Fühler sind kürzer, die Flügel fehlen noch. Dazu kommen als provisorische Organe (die die Libellenlarve erst zur sekundären Larve stempeln) die Tracheenkiemen am Hintertnde des Abdomens.

Die Entwicklung schreitet allmählich der Imago zu; es sprossen Flügel-

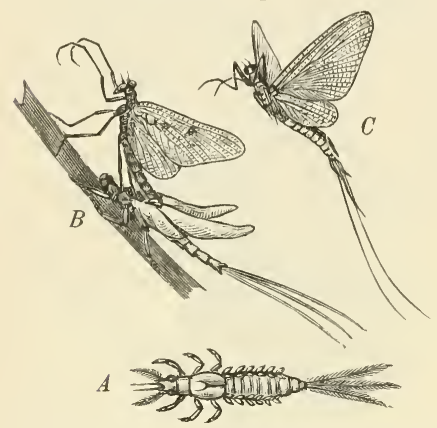

Fig. 152. Beispiel von Prometabolie. A Larve der gemeinen Eintagsfliege (Ephemera vulgata $L$.) mit Tracheenkiemen nach West w oo d; $B$ deren männliche Imago aus der Subimago schlüpfend; $C$ Imago von Palingenia virgo Oliv., dem gemeinen Uferaas. (N.) stummel hervor, die immer länger werden, der Thorax wird immer kräftiger, die Zahl der Fühlerglieder vermehrt sich usw., so daß die ausgewachsene Larve der Imago schon ganz nahe steht. Nur die Tracheenkiemen stellen noch ein fremdes Element dar. Mit der letzten Häutung werden auch diese abgeworfen und nun ist die Imago fertig.

Nicht immer nähert sich die Larve so schrittweise, wie in diesen Beispielen der Imago. Bei den Zikaden ist die Flügelentwicklung auf die letzten Stadien verschoben, während die zahlreichen früheren Stadien keine Spur von Flügelanlagen zeigen. Dies erklärt sich ohne weiteres daraus, daß bei der unterirdischen Lebensweise den Larven die Flügelanlage nur hinderlich sein würde.

Als besondere Form der Hemimetabolie wird von Börner die Entwicklung der männlichen Cocciden aufgefaßt, während andere Autoren sie bald als epimorph (Heymons), bald holometabol (Reh) betrachten. Im speziellen Teil wird genauer darauf zurückzukommen sein.

\section{Prometabolie.}

Bei dieser nur den Ephemeriden zukommenden Entwicklungsform können wir uns kurz fassen (Fig. 152). Die Entwicklung verläuft (unter zahlreichen, bis 22 Häutungen) zunächst nach dem eben beschriebenen, hemimetabolen Typus. Erst nach der letzten Häutung tritt ein Unterschied gegenüber diesem auf, indem hier nicht gleich die fertige Imago, sondern erst die „Subimago“ folgt, ein mit der Imago fast völlig übereinstimmender und auch flugfähiger Zustand, aus dem aber erst durch eine nochmalige Häutung die fertige geschlechtsreife Imago hervorgeht.

Holometabolie.

Wesentlich verschieden von den bisherigen Entwicklungsformen ist die Holometabolie, indem die gänzlich imagofremden, tertiären Larven sich der 
Imago nicht nähern, sondern in ihrer abweichenden Richtung bis zum Schluß verbleiben, um dann sich plötzlich in die Imago zu verwandeln. Diese plötzliche Verwandlung erheischt ein Ruhestadium, die Puppe, deren Vorhandensein (neben der vollkommen provisorischen Organisation der Larve) als Hauptcharakteristikum für die Holometabolie zu gelten hat.

Wir wählen als Beispiel einer solchen die Entwicklung des männlichen Kiefernspinners (Fig. 153). Das aus dem im Hochsommer gelegten Ei $A$ geschlüpfte 16 füßige Räupchen $B$ macht nacheinander vier Häutungen durch, von denen zwei noch in den Herbst des Geburtsjahres fallen, die beiden anderen dagegen in den folgenden Frühling. Hierbei wächst die Larve von ca. $6 \mathrm{~mm}$ bis auf $80 \mathrm{~mm}$ Länge heran. Bei seiner Geburt durch die

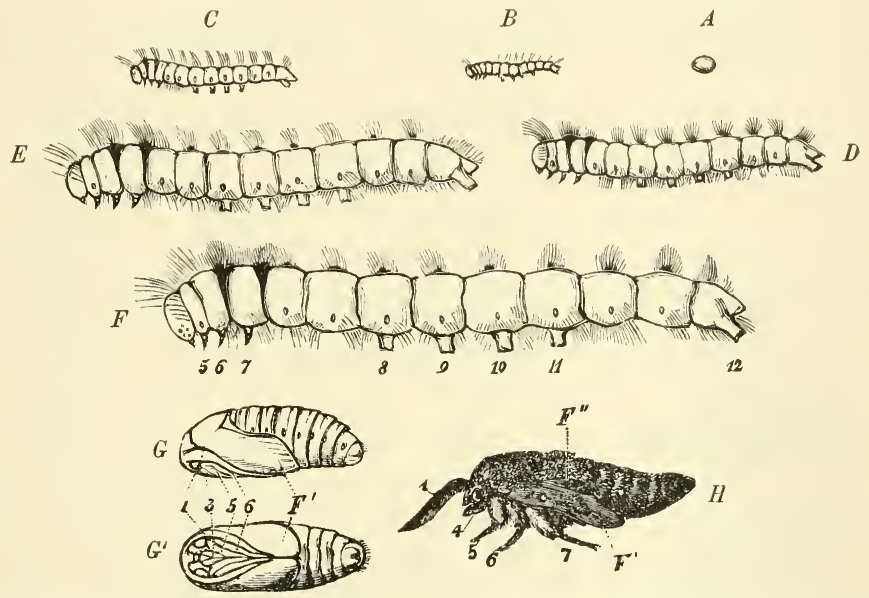

Fig. 153. Beispiel einer Holometabolie. Die Metamorphose eines Kiefernspinners. $A$ Ei; $B-F$ die fünf Raupenstadien; $G$ die Puppe von der Seite, $G^{\prime}$ dieselbe von unten geseheu; $H$ der eben ausgeschlüpfte Falter, vor Entfaltung der Flügel. Die Zahlen bezeichnen die Gliedmaßenpaare. $F^{*}$ Vorderflïgel; $F^{u t}$ Hinterflügel. - (N.)

Zeichnung von der erwachsenen Raupe noch deutlich unterschieden, nimmt sie bereits bei der ersten Häutung alle Auszeichnungen der letzteren an, so daß sich die vier Stadien $C$ bis $F$ in Fig. 153 lediglich durch die Größe unterscheiden und einander viel ähnlicher sind, als die entsprechenden Jungstadien $C$ bis $F$ bei der Feldheuschrecke (Fig. 150). Die fünfte Häutung ist es, welche den definitiven Wendepunkt der Entwicklung bringt. Nach Abstreifung der alten Haut erscheint nun die bekannte Puppe $G$, aus welcher nach einer dreiwöchentlichen Ruhe der Schmetterling $H$ ausschlüpft, anfänglich noch mit zusammengeschrumpften, kleinen, weichen Flügeln, welche aber bald, durch Eintreibung von Luft in die innerhalb ihres Geäders verlaufenden Tracheen ausgebreitet, erhärten und nun dem Schmetterling das bekannte Aussehen verleihen. 
Ganz ähnlich verläuft die Entwicklung des Maikäfers: der aus dem Ei geschlüpfte junge Engerling verwandelt sich, allmählich wachsend, durch eine Reihe von Häutungen zu dem im wesentlichen der neugebornen Larve bis auf die bedeutendere Gr̈öße völlig gleichen erwachsenen Engerling, der durch die nun folgende Häutung plötzlich in die Puppe übergeht. Die Puppe verwandelt sich durch eine weitere Häutung in die bekannte Imago des Maikäfers.

Hypermetabolie (Polymetabolie).

Mit der typischen Holometabolie ist der Gipfelpunkt der Insektenmetamorphose noch nicht erreicht. Denn es gibt noch eine kompliziertere

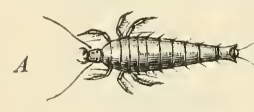

B

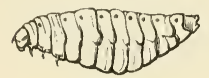

C

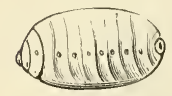

D

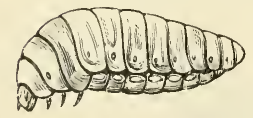

E

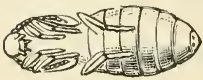

Fig. 154. Hypermetabolie von Sitaris nach Fabre. A erstes sechsbeiniges, aktives Larvenstadium (Triungulinus); $B$ die zweite mit Stummelbeinen versehene, madenartige Larve; $C$ die folgende Scheinpuppe (Pseudochrysalis); $D$ letztes madenartiges Larvenstadium; $E$ die eigentliche freie Puppe. - (N.) Puppe oder Chrysalis verwandelt, das bald darauf 6. die Imago liefert (Heymons) (Fig. 154).

Die biologische Bedeutung dieser verschiedenen Entwicklungsstadien ist, wie Heymons ausführt, leicht verständlich: Die Differenz zwischen der ersten und zweiten Larvenform erklärt sich durch den verschiedenartigen Zweck der letzteren. Der Triungulinus hat die Aufgabe, die Futterquelle aufzusuchen, die zweite Larve soll dieselbe möglichst intensiv ausnützen. Ist dies geschehen, so ist die Ernährung überhaupt beendet, es sind genug 
Reservestoffe aufgespeichert; aber da inzwischen die ungünstige Jahreszeit hereinbricht, so kann die Entwicklung nicht mehr ohne Unterbrechung weitergeführt werden und die Larve geht bei der nächsten Häutung in ein Ruhestadium (Pseudochrysalis) über, welches dadurch besonders geschützt ist, daß es in der tonnenförmig erstarrten abgehobenen Chitinhaut des zweiten Larvenstadiums regungslos verbleibt. Es finden während des Pseudochrysalisstadiums keinerlei innere Umwandlungen statt, so daß es sich also lediglich um eine schlafähnliche Periode handelt (weshalb Künckel d'Herculais vorgeschlagen hat, den Namen Hypermetamorphose durch Hypnodie und den Ausdruck Pseudochrysalis durch Hypnotheke zu ersetzen, was jedoch keinen Anklang fand).

Es sind zwei Momente, welche die Meloiden-Entwicklung von der typischen Holometabolie unterscheiden: 1. der Dimorphismus zwischen
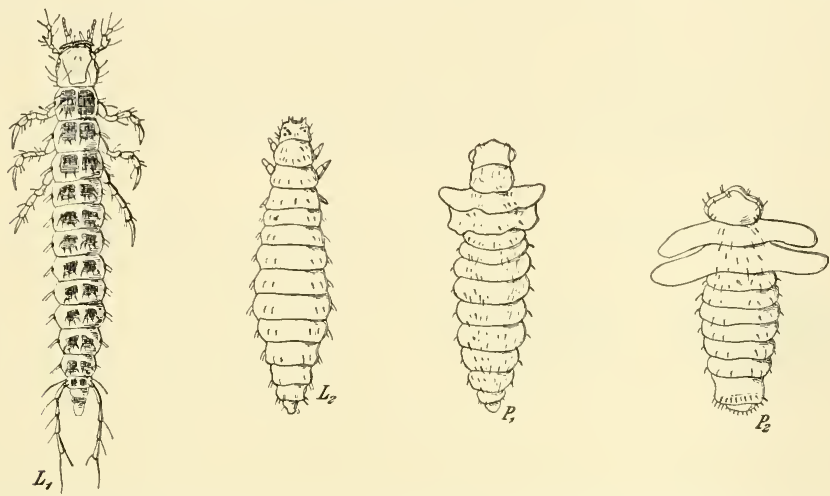

Fig. 155. Entwicklung von Lebia scapularis (Carabicide) mit larvalem Dimorphismus $\left(L_{1}\right.$ u. $\left.I_{2}\right)$ und zwei Puppenstadien: $P_{1}$ Präpupa, $P_{2}$ Pupa. Nach Silvestri aus Heymons.

dem ersten und zweiten Larvenstadium, und 2. das Auftreten der Scheinpuppe. Diese beiden Eigentümlichkeiten kommen aber keineswegs nur den Meloiden zu, sondern finden sich mehr oder weniger ähnlich auch noch bei einer ganzen Reihe anderer Insekten.

So ist der larvale Dimorphismus eine ziemlich häufige Erscheinung: Am bekanntesten sind die dimorphen Larven der Ichneumoniden, Bruchiden, Lymexyloniden, Stylopiden usw. Neuerdings hat Silvestri auch eine Laufkäferlarve mit starkem Dimorphismus beschrieben, nämlich die Larve von Lebia scapularis (Fig. 155). Da der ziemlich komplizierte Entwicklungsgang dieses Käfers auch noch in anderer Beziehung unser Interesse beansprucht, so sei dieselbe hier kurz mitgeteilt: Die aus dem Ei ausschlüpfende erste Larve ist langgestreckt und mit gut entwickelten Extremitäten versehen $\left(L_{1}\right)$; sie lebt in diesem Zustand räuberisch von den Larven und Puppen eines Chrysomeliden (Galeruca luteola). 
Da es an Futter nicht mangelt, so bekommt sie bald eine unförmige Gestalt, wird schwerfällig und umgibt sich mit einem Kokon. Darauf verwandelt sie sich in ein zweites, gänzlich verschiedenes Stadium, das durch seine spindelförmige Gestalt, durch kurze Fühler und Mundteile, sowie durch die sehr kurzen Beine ausgezeichnet ist $\left(L_{2}\right)$. Danach folgt eine Präpupa, bei der der Thorax schon deutliche Flügelansätze zeigt und auch die Facettenaugen schon erkennbar werden. Erst hierauf kommt es zur Puppe, die sich durch eine etwas andere Gliederung des Abdomens und längere Flügelansätze von der Präpupa unterscheidet. Die genannte Lebia hat also nicht nur zwei verschiedene Larvenformen, sondern auch zwei Puppenstadien.

Der larvale Dimorphismus wird sich wahrscheinlich als weit allgemeiner herausstellen, als man heute annimmt, wenn man erst spezielle Untersuchungen daraufhin anstellt. Denn geringfügige Unterschiede in Färbung, Struktur, Behaarung usw. werden sich wohl in den meisten Fällen bei den verschiedenen Stadien nachweisen lassen. Es ist daher jedenfalls schwierig, eine Grenze zu ziehen, wo der larvale Dimorphismus anfängt, weshalb auch eine lediglich auf diesem begründete Einteilung (resp. weitere Zerlegung der Holometabolie) stets mehr oder weniger willkürlich sein wird.

Auch die Scheinpuppe der Meloiden hat ihre Analoga bei anderen Insekten. So ist ihr z. B. das letzte Larvenstadium gewisser Blattwespen

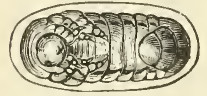

A

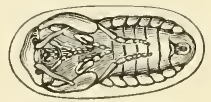

B
Fig. 156. Kokon eiuer Blattwespe, $A$ mit der noch nicht verpuppten Larve; $B$ mit der Puppe. ${ }^{2 / 1}$. (z. B. Lophyrus) ohne Zweifel an die Seite zu stellen; denn hier wie dort handelt es sich um ein durch zwei Häutungen begrenztes Larvenstadium, das sich in einem schlafähnlichen Zustand befindet(Fig. 156). Würde man also die Scheinpuppe als das Hauptkriterium der Hypermetabolie nehmen, wie Heymons will, so müßte man auch die LophyrusEntwicklung als solche auffassen.

Aus dem Gesagten geht hervor, daß der Begriff Hypermetabolie heute lange nicht mehr so präzise zu definieren ist als zur Zeit seiner Begründung; und es frägt sich, ob es nicht besser wäre, den Begriff zu erweitern und ihn auf alle jene Entwicklungsformen auszudehnen, die überhaupt eine Komplikation der Holometabolie darstellen. Stößt man sich aber daran, daß der Name Hypermetabolie speziell für die den Meloiden eigentümliche Entwicklungsform aufgestellt ist, so möge man zu der von Börner vorgeschlagenen Bezeichnung "Polymetabolie“ greifen.

Unter diesen Begriff würde dann auch die Entwicklung der bienenund wespenartigen Insekten fallen, bei denen zwischen die Puppe und das

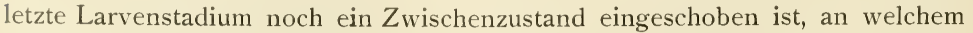
zwar bereits die Leibesanhänge der Imago angelegt sind, aber in viel rudimentärerer Form als bei der eigentlichen Puppe, ein Zustand, der als Semipupa (oder Pseudonymphe) bezeichnet wird (Fig. 157). 


\section{Die verschiedenen Larvenformen.}

Die Mannigfaltigkeit der Larvenformen ist schier unerschöpflich, so daß eine einigermaßen umfassende Darstellung derselben einen dicken Band füllen würde. Wir müssen es uns daher hier mit einer kurzen Übersicht über die Haupttypen genügen lassen, was wir um so eher tun können, als im speziellen Teil bei den einzelnen Insektenordnungen die verschiedenen Larven noch eingehender besprochen werden.

Wir können die Larven der Insekten nach ihrer Form, Gliederung usw. in eine Anzahl Kategorien einteilen; doch sei gleich ausdrücklich betont, daß diese Einteilung lediglich praktischen Rücksichten entspringt, und daß ihr keineswegs etwa eine phylogenetische Bedeutung beizumessen ist. Denn da die Larven Anpassungsformen par excellence darstellen, so haben wir natürlich mit zahlreichen Konvergenzerscheinungen zu rechnen. Des weiteren ist auch darauf aufmerksam zu machen, daß die einzelnen Kategorien

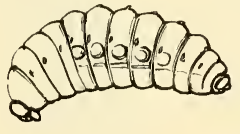

$A$

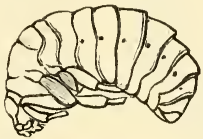

$B$

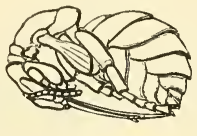

C

Fig. 157. Die Verwandlung der Hummel nach Packard. $2 /$. . $A$ ausgewachsene, fußlose Larve; $B$ die Halbpuppe (Semipupa) mit stummelförmigen Leibesanhängen; $C$ die eigentliche, freie Puppe mit den deutlich ausgebildeten Gliedmaßen der Imago. - (N.)

nicht immer scharf abgegrenzt sind, sondern daß vielfache Übergänge zwischen ihnen vorkommen.

Es lassen sich etwa folgende Gruppen von Larvenformen unterscheiden:

Primäre Larven.

1. Die Larve ist in allen wesentlichen Zügen der Imago ähnlich und unterscheidet sich von ihr nur durch geringere Größe und mangelnde Geschlechtsreife. Beispiele hierfür bieten die sog. "Silberfischchen“ (Lepisma) oder die ungeflügelten Tierläuse (Pediculiden) oder die Haarlinge oder Federlinge (Mallophagen) usw.

2. Die Larve ähnelt der geflügelten Imago ebenfalls noch so sehr, daß auch der unbefangene Beobachter sie ohne weiteres als deren Jugendform erkennt, unterscheidet sich aber von ihr durch Flügellosigkeit, durch kleine Details in der Ausbildung der Gliedmaßen und mitunter auch durch ein verschiedenes Verhältnis in der Größe der einzelnen Leibesabschnitte. Dies ist z. B. bei den typischen Geradflüglern der Fall. So ist die auf Fig. 150B (S. 154) abgebildete erste Larve einer Feldheuschrecke nicht nur kleiner als die Imago und flügellos, sondern es ist auch der Hinterleib im Verhältnis zu Kopf und Brust weniger entwickelt als bei der Imago, und die Fühler, welche bei jener 26 Glieder zeigen, haben deren vorläufig nur 12.

\section{Sekundäre Larven.}

3. Die Larve zeigt ebenfalls noch eine unverkennbare Ähnlichkeit mit der geflügelten Imago, unterscheidet sich aber von ihr, aufer durch die 
Flügellosigkeit und die verschiedenen kleineren Details, noch durch den Besitz besonderer larvaler oder provisorischer Organe (Tracheenkiemen, Grabbeine). Hierher gehören die Larven der Libellen, Plecopteren (Perliden), gewisser Cicaden usw.

\section{Tertiäre Larven.}

4. Die Larve weicht in ihrem gesamten Habitus rollkommen von der Imago ab.

A. Larven ohne Bauchfüße.

a) Larven mit gut ausgebildeten Brustbeinen.

a) Larven mehr oder weniger kräftig chitinisiert; Brustabschnitt oder wenigstens das erste Brustsegment von den übrigen Rumpfsegmenten meistens deutlich verschieden (größer oder stärker
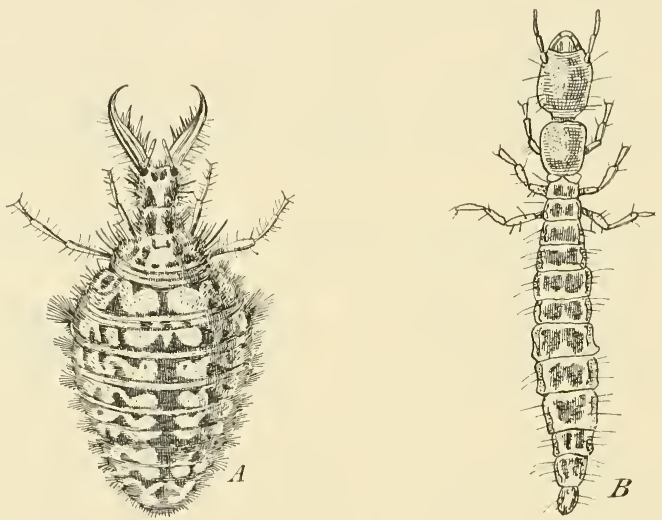

Fig. 158. Larven von Neuropteren. A Ameisenlöwe (Myrmeleo formicarius). Nach Rösel von Rosenhof. $B$ Kamelhalsfliege (Rhaphidia). Nach Sharp.

chitinisiert oder anders skulpturiert usw.); Kopf gewöhnlich mit seitenständigen Punktaugen ausgerüstet.

Die hierher gehörigen Larven zeigen bezügl. der Form des Körpers und seiner einzelnen Abschnitte, der Ausbildung der Extremitäten usw. die allergrößte Mannigfaltigkeit. Als Beispiele seien erwähnt: die Larven der Kamelhalsfliege und des Ameisenlöwens (Fig. 158), ferner die Larven zahlreicher Käfer, wie der Carabiciden, Dytisciden, Silphiden, Coccinelliden, Elateriden usw. (Fig. 159).

$\beta)$ Larven schwach chitinisiert, weichhäutig und meist weißlich, mit Ausnahme des kräftig chitinisierten und daher auch dunkler gefärbten Kopfes; Brustsegmente nur wenig von den übrigen Segmenten verschieden; Punktaugen in der Regel fehlend. Hierher die Engerlinge (Larven der Maikäfer, Hirschkäfer, Dungkäfer usw.) (Fig. 160), die Larven der Anobien usw. 
b) Larven mit nur schwach ausgebildeten, resp. rudimentären Brustfüßen, die kaum mehr als alleinige Fortbewegungsorgane geeignet sind. Hierher die Larven mancher Bockkäfer und der Holzwespen (Fig. 161).
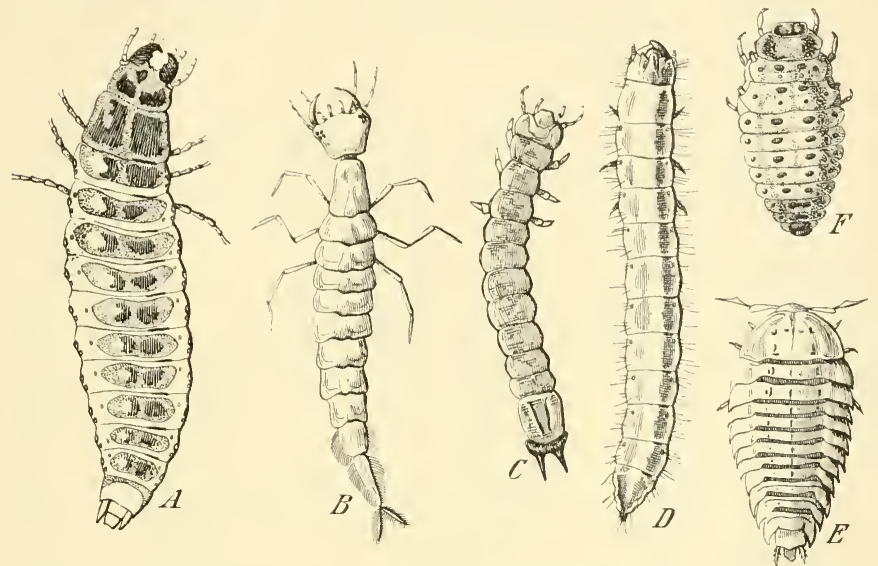

Fig. 159. Verschiedene Käferlarven mit gut ausgebildeten Brustfüßen. A Calosoma; B Dytiscus; C Pyro. chroa: $D$ Elateride; $E$ Silpha; $F$ Chrysomelide. Nach Ratzeburg, Boas, Miall und Schrödter.

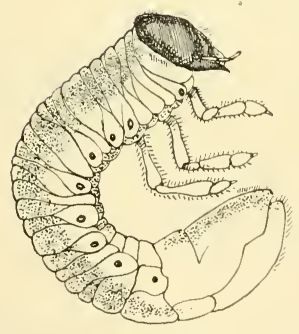

Fig. 160. Engerling des Maikäfers.
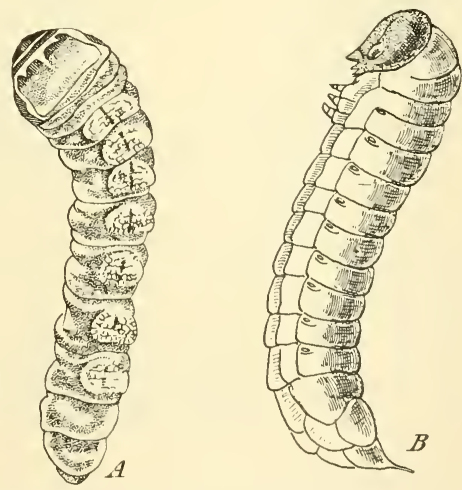

Fig. 161. A Larve des großen Eichenbockes (Cerambyx cerdo) nach Ratzeburg; $B$ Larve einer Holzwespe (Sirex).

c) Brustbeine gänzlich rückgebildet.

c) Larven mit Kopfkapsel und typisch ausgebildeten (kauenden) Mundgliedmaßen (Fig. 162). Ein großer Teil der hierher 
gehörenden Larven sind weichhäutig und weißlich und führen ein verborgenes Leben: wie die Larven der Borken- und Rüsselkäfer, der Bienen, Wespen, Ameisen und der Schlupfwespen. Andere Larven jedoch, wie die eucephalen Dipterenlarven, die ebenfalls, wenn auch etwas gezwungen, in diese Gruppe einzureihen sind, führen vielfach ein freies Leben und sind deshalb meist auch stärker chitinisiert.

$\beta$ ) Larven ohne Kopfkapsel und stark rückgebildeten, resp. umgebildeten Mundgliedmaßen; im übrigen meistens weichhäutig und weißlich. Hierher die Larven der Fliegen (Stubenfliege, Tachinen usw.) (Fig. 163), die auch als „Maden“ bezeichnet werden.
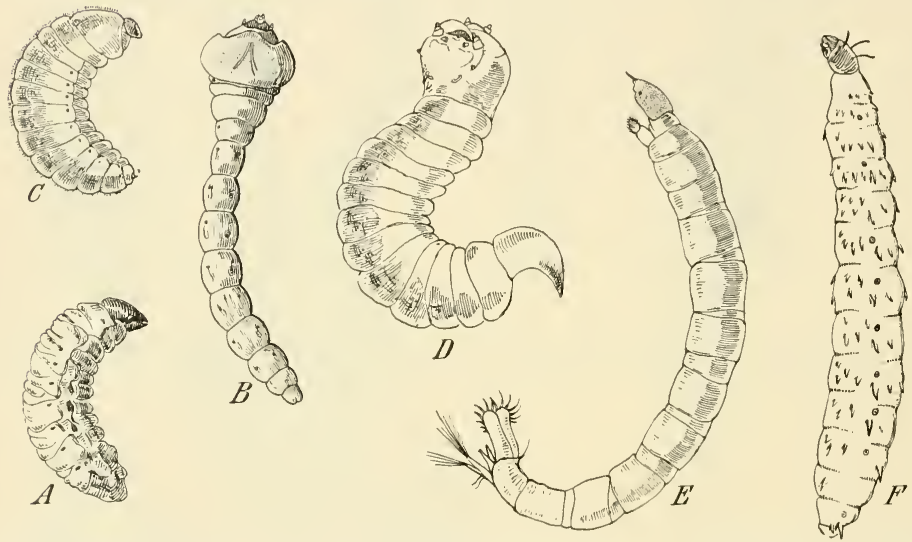

Fig. 162. Beispiele für Larven mit völlig rückgebildeten Brustfüßen. A Rüsselkäfer; $B$ Buprestidel; $C$ Ameise; $D$ Ichneumonide (Anomalon); $E$ Tanypus (Chironomide); F Bibio (Haarmücke). Nach Boas, Meinert, Ratzeburg und Sharp.

B. Larven mit BauchfüBen (Raupen und Afterraupen). Die hierher gehörigen Larven sind langgestreckt, mehr oder weniger gleichmäßig segmentiert, mit ausgeprägtem Kopf und gut ausgebildeten kauenden Mundgliedmaßen, ferner 3 Paar Brustfüßen und außerdem noch mit einer Reihe von Afterfüßen an den Hinterleibssegmenten. Dieser Kategorie gehören in der Hauptsache die Larven der Schmetterlinge an, die als Raupen, und die Larven der Blattwespen, die als Afterraupen bezeichnet werden (Fig. 164).

Der Unterschied der beiden besteht einmal in der Zahl und der Stellung resp. dem Sitz der Afterfüße: Die Zahl derselben beträgt bei den echten Raupen 5 oder 2 Paare, bei den Afterıaupen dagegen meist mehr (seltener weniger). Ferner ist darauf $\mathrm{zu}$ achten, ob nurdas erste oder die beiden ersten Hinterleibssegmente ohne Afterbeine sind; ist nur das erste Segment frei, so handelt es sich meist um eine Afterraupe 
(Ausnahme: Lyda, deren Larve überhaupt nur 1 Paar Afterbeine am letzten Hinterleibssegment besitzt). Sind dagegen die ersten zwei (oder auch mehr: bei Spannern) Segmente frei, so haben wir es in den allermeisten Fällen mit einer Schmetterlingsraupe zu tun. Auch bezüglich der Augen unterscheiden sich die beiden deutlich voneinander: Die Afterraupen haben nur ein Punktauge jederseits, die echten Raupen dagegen 5-6.

\section{Die verschiedenen Formen der Puppe.}

Als Puppe bezeichnen wir das dem Imago vorhergehende, keine Nahrung aufnehmende Stadium der holometabolen Insekten. Die Puppe ist, wie wir oben sahen, der Imago viel ähnlicher als dem letzten Larvenstadium und zeigt bereits dieselbe Körpereinteilung und dieselbe Anzahl von Gliedmaßen und Flügeln wie die Imago.

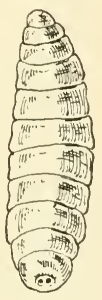

Fig. 163. Made einer Tachine.

Man unterscheidet zwei Hauptformen von Puppen:

1. Die freie oder gemeißelte Puppe (pupa libera), bei der die Gliedmaßen frei dem Körper anliegen (Fig. 165).

2. Die bedeckte Puppe oder Mumienpuppe (pupa obtecta), bei der die Gliedmaßen durch eine zähe erhärtende Ausscheidung fest an den Körper angebacken werden und infolgedessen auch in ihren Konturen meist nicht so deutlich hervortreten wie bei der freien Puppe (Fig. 166).
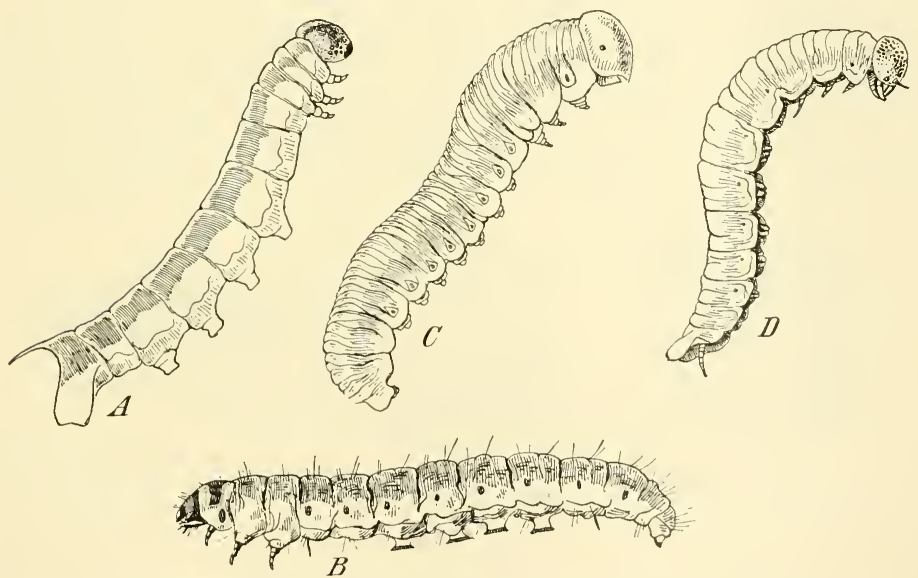

Fig. 164. Raupen $(A$ u. $B$ ) und Afterraupen $(C$ u. $D) . A$ Sphingide; $B$ Cossus; $C$ Cimbex; $D$ Lyda.

Daß die bedeckte Puppe wirklich bereits dieselben Anhänge usw. wie die Imago besitzt, kann man deutlich sehen, wenn es glückt, die Schmetterlingspuppe in dem Moment zu überraschen, in dem sie die Larvenhaut ab- 
streift; sie ist dann gewissermaßen noch eine pupa libera und zeigt auch in diesem Zustand eine viel größere Übereinstimmung mit dem Schmetterling als in dem fertigen Puppenzustand. Auf Fig. 167 A ist eine solche, eben der Raupenhaut entschlüpfte Puppe des Kiefernspinners abgebildet, bei welcher Fühler, Mundwerkzeuge, Beine und Flügel noch deutlich vom

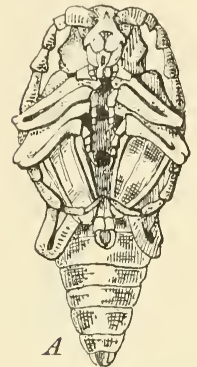

Fig. 165. Beispiele von "freien Puppen" (Pupae liberae). $A$ Bockkäfer (Cerambyx); $B$ Hornisse. Nach Ratzeburg.
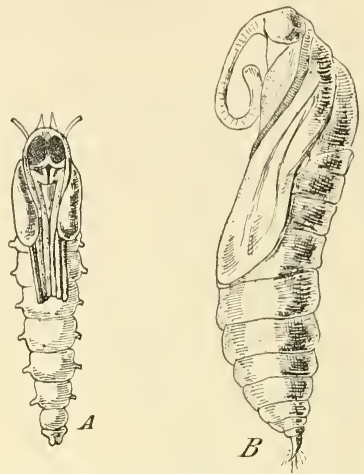

Fig. 166. Beispiele von bedeckten Puppen. A Gallmïcke (n. Ki effer); $\boldsymbol{B}$ Schmetterling (Sphingide).

Leibe abstehen und die Hinterleibsringe noch nicht so weit in der Längsrichtung zusammengezogen sind, wie dies bei der fertigen Puppe der Fall ist, bei welcher auch z. B. das dritte Beinpaar und das zweite Flügelpaar fast völlig von dem ersten Flügelpaar verdeckt wird (Fig. 167 B).

Aus dieser Tatsache, daß die Teile der Puppe sich bereits unter der Haut des letzten Larvenstadium anlegen und die Puppe eben alle Teile des Schmetterlings bereits besitzt, erklärt sich auch die hübsche, früher als höchstes Wunder an-
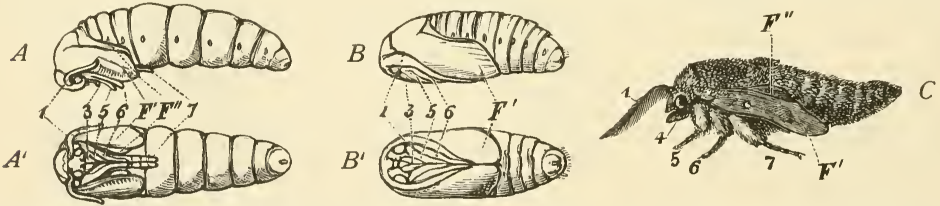

Fig. 167. Entstehung der bedeckten Puppe des Kiefernspinners. A eben der Raupenhaut entschlïpfte Puppe, von der Seite, $A^{\prime}$ dieselbe von unten; $B$ fertige Puppe, von der Seite, $B^{\prime}$ dieselbe von unten; $C$ eben ausgeschlüpfter Schmetterling; 1 Fühler, 3 Mittelkiefer (Saugrüssel), $5-7$ die Brustfüße, $F^{v}$ Vorderflügel, $F^{\prime \prime}$ Hinterflügel. - (N.)

gestaunte Geschichte, wie es dem berühmten Johann Swammerdamm zu Amsterdam gelang, im Jahre 1668 dem Großherzog von Toskana zu zeigen, wie „ein Zwiefalter mit seinen zusammengerollten und verwickelten Teilen in einer Raupe steckt".

Die Pupa libera kommt allen Coleopteren, Hymenopteren, Neuropteren und einem Teil der Dipteren zu, während der andere Teil der Dipteren (die Brachyceren) und die meisten Schmetterlinge eine Pupa obtecta besitzen. 
Da die Puppe einer aktiven Abwehr oder Flucht nicht fähig ist, so sorgt meistens schon die Larve für einen möglichst ausgiebigen Schutz der Puppe, und zwar in verschiedener Weise: Viele Larven verpuppen sich an verborgenen Orten in der Erde, unter Rinde, im Holz oder unter Steinen usw., wobei oft noch besondere mit Speichel geglättete Höhlungen oder mit Nagespänen gepolsterte „Puppenwiegen“ gefertigt werden (z. B. Pissodes). Andere verpuppen sich in den ausgebauten Larvengehäusen, wodurch diese ihren Schutz auch auf die Puppe übertragen. Wir führen als hierhergehörige Beispiele an: die wasserbewohnenden Larven der Köcherfliegen (Phryganiden), die Larven mancher Blattkäfer, z. B. die in Ameisenhaufen lebenden Clytra quadripunctata, welche das aus ihren Exkrementen verfertigte Gehäuse alsdann mit einem Deckel verschließt, ferner viele sacktragende Raupen, wie die Gattung Psyche und Verwandte, und endlich unter den forstschädlichen Kleinschmetterlingen die Lärchenminiermotte (Coleophora laricella). Wieder andere Insekten endlich verfertigen besondere Schutzhüllen, sog. Kokons, um die Puppe (Fig. 168).

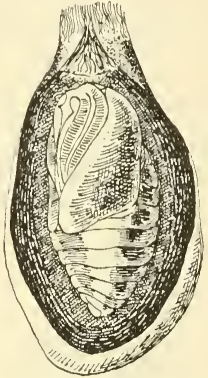

Fig. 168. Kokon von Saturnia pyri geöffnet, mit der darinliegenden Puppe. Am oberen Ende des Kokons ist der Reusenapparat $z u$ erkennen.

Diese Kokons zeigen bezüglich der Art der Verfertigung und des Materials eine große Mannigfaltigkeit; entweder werden sie lediglich aus Seidenfäden hergestellt, oder es sind auch noch Holz- oder Sandteilchen mit eingesponnen, oder der Kokon besteht hauptsächlich aus fremdem Material (Holz, Erde), welches durch Speichelsekrete zusammengekittet wird, oder endlich der Kokon wird gar nicht erst gefertigt, sondern wird einfach durch die letzte Larvenhaut gebildet.
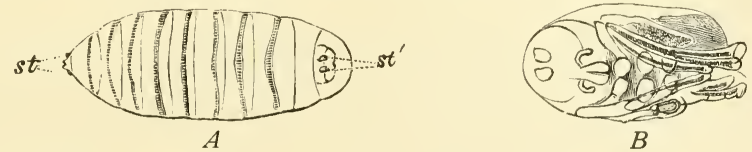

Fig. 169. A Tönnchen der gemeinen Stubenfliege, an dem man deutlich die Segmente der Larvenhaut, sowie die vorderen und hinteren Stigmen (st u. st') erkennt; $B$ die in diesem Tönnchen eingeschlossene freie Puppe. Nach Packard.

Bezüglich der rein gesponnenen Seidenkokons kann man bei den Schmetterlingen alle möglichen Übergänge von einem einfachen die Puppe an der Unterlage befestigenden Gürtelfaden an (wie beim Kohlweißling) zu lockeren aus wenig Fäden bestehenden (Schwammspinner) und zu völlig dichten Gespinsten (Seidenspinner) finden. Außer Schmetterlingen verpuppen sich auch sehr viele Hymenopteren in seidenen Gespinsten: Am bekanntesten sind die seidenen Kokons der Ameisen, vom Volksmund fälschlich Ameiseneier genannt; forstlich am häufigsten genannt werden die 
Kokons der parasitisch in der Kiefernspinnerraupe und anderen Forstschädlingen lebenden Schlupfwespen.

Für die größtenteils aus fremdem Material bestehenden Kokons seien als bekannte Beispiele die aus kleinen Holzstückchen und Erde hergestellten Kokons der Rosenkäfer (Cetonia) erwähnt.

Was endlich die Verpuppung in der letzten Larvenhaut betrifft, so ist diese den Fliegen eigen, von denen in forstlicher Beziehung die Tachinen am meisten interessieren. - Man hat die in der letzten Larvenhaut eingeschlossene Puppe als eine besondere Art von Puppe aufgefaßt und als "Tönnchenpuppe“ oder pupa coarctata der pupa libera und obtecta gegenübergestellt. Hierin liegt aber eine gewisse Inkonsequenz, insofern als
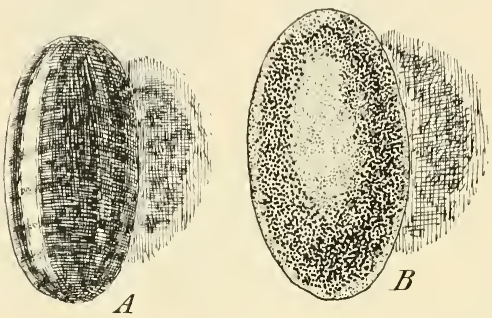

Fig. 170. A Tönnchen einer Tachine; $B$ Kokon eines Ichneumoniden (Banchus). Ersteres unterscheidet sich durch die Segmentierung und den stärkeren Glanz deutlich vou dem letzteren. die eigentliche Dipterenpuppe eine freie Puppe ist, genau wie z. B. die Puppe der Käfer (Fig. 169), und das Tönnchen also nichts anderes darstellt als eine Schutzhülle, entsprechend den aus Seide usw. gefertigten Kokons.

Als charakteristisches Merkmal des Dipterentönnchens ist die Segmentierung zu beachten, die bei genauerem Zusehen stets zu erkennen ist. Daran sind z. B. die Tachinentönnchen ohne weiteres von den ihnen in Größe, Form und Farbe nahestehenden Kokons gewisser Ichneumoniden (kleiner Banchus-Arten usw.) zu unterscheiden (Fig. 170).

\section{Der Vorgang des Ausschlüpfens.}

Nachdem die Puppe eine Zeitlang geruht - die Dauer der Puppenruhe ist sehr verschieden, je nach der Spezies und den äußeren Einflüssen springt die Puppenhülle an einer für jede Art fest bestimmten Stelle auf (Fig. 171), und das fertige Insekt arbeitet sich durch eigene Tätigkeit heraus. Anfänglich weich und mit noch zusammengefalteten Flügeln, erhärtet es bald, nachdem es die Flügel durch Einpumpen von Luft in die sie durchziehenden Tracheen ausgedehnt hat. Insekten, deren Färbung nicht, wie das bei den Schmetterlingen der Fall ist, durch Schuppen und Haare bedingt wird, sind im Anfang matter und heller gefärbt als die bereits völlig ausgebildeten; so sind z. B. die frisch geschlüpften Borkenkäfer anfänglich noch gelblich, während die Altkäfer dunkelbraun oder schwarz gefärbt sind. Kurz nach dem Ausschlüpfen erfolgt eine Ausleerung der während der Puppenzeit erzeugten Harnsubstanzen, wie man am besten an den Schmetterlingen sehen kann, die bald, nachdem sie die Puppenhülle verlassen, einen großen Tropfen gelben oder rötlichen Harnes fallen lassen. 
Bei den offen liegenden Puppen gelangt die Imago unmittelbar nach dem Ausschlüpfen aus der Puppenhaut in die Freiheit. Nicht so einfach ist "der Sprung in die Welt" bei solchen Insekten, deren Puppen verborgen in der Erde, unter Rinde, im Holz usw. liegen, oder von einem Kokon umschlossen sind. Alles, was durch diese verborgene Lage bisher der Puppe zum Schutz gereichte, stellt sich nunmehr dem neugeborenen Insekt als ein Hindernis dar, das erst noch überwunden werden muß, wenn das junge Tier die volle Freiheit erlangen will.

Wo es sich um Insekten mit kauenden Mundwerkzeugen handelt, da bedient sich das betreffende Tier einfach seiner Kiefer, um sich den Weg ins Freie zu bahnen: es gräbt sich damit aus der Erde heraus, es nagt sich damit einen Gang durch das Holz oder die Rinde, es beißt damit den Kokon durch usw.

Wo die Imagines jedoch dieser ausgezeichneten Werkzeuge entbehren, sind verschiedene andere Einrichtungen getroffen, durch welche die Befreiung bewerkstelligt werden kann. Vielfach treffen noch die Raupen Vorkehrungen, das Herauskommen der Imagines zu ermöglichen; so nagen die im Pflanzengewebe lebenden Raupen meist einen Gang von der Verpuppungsstelle bis zur Oberfläche der Pflanze, resp. lassen da nur noch eine ganz dünne Haut (das sog. Fenster) stehen, so daß die Imago ohne Schwierigkeit ins Freie gelangen kann.
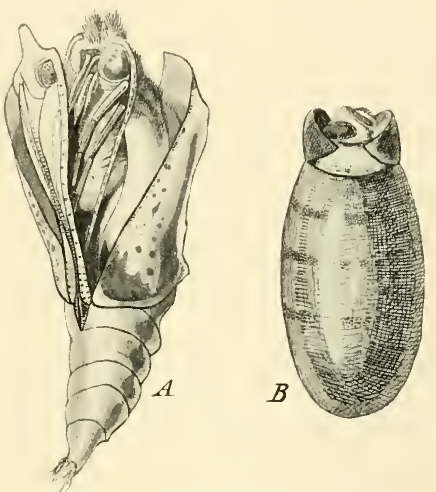

Fig. 171. Vorgang des Ausschlüpfens (A) eines Schmetterlings unter Sprengung der Flügelnähte. nach Pfurtschellers Wandtafel Nr. 23; $B$ bei der Tachine unter Sprengung des Vorderteiles des Tönnchens längs einer kreisförmigen Naht.

Bei den Cossiden, Sesien usw. schiebt sich die Puppe, die mit besonderen zur Fortbewegung dienenden Dornkränzen versehen ist, so weit nach außen hervor, daß der Schmetterling beim Ausschlüpfen gleich ins Freie kommt. Auch beim Verfertigen des Kokons sorgen manche Raupen schon dafür, daß sie später als Imagines leicht herauskommen, entweder dadurch, daß sie am Kopfende eine Öffnung frei lassen, welche durch Borsten derartig verschlossen ist, daß der ausschlüpfende Schmetterling ohne weiteres hinaus-, aber kein Fremdling durch sie hereindringen kann (Fig. 168); oder aber dadurch, daß ein besonderer nur durch wenige Spinnfäden angefügter Deckel vorgebildet wird.

Wo keine besondere Vorsorge von Seiten der Raupen getroffen ist, geschieht die Befreiung aus dem Kokon bei Schmetterlingen meist dadurch, daß eine Flüssigkeit abgesondert wird, welche das Kokongewebe so weit aufweicht oder auflöst, daß der Schmetterling sich durch dasselbe leicht hin- 
durchschieben kann. Bei anderen Schmetterlingen finden sich in der Stirnregion besondere „Kokonbrecher“, das sind spitze Dornen oder Zähne, mit denen die Wand des Kokons so lange bearbeitet wird, bis eine Öffnung entsteht. Auch manche parasitischen Dipteren befreien sich auf ähnliche Weise aus den Kokons ihrer Wirtstiere. So perforiert die in Tachinen oder Schlupfwespen schmarotzende Fliege Anthrax morio ("Trauerschweber"), durch fortwährende kräftige Stöße mit den auf der Stirne befindlichen Dornen den Kokon und schneidet so einen kreisförmigen Deckel heraus. - Bei den Dipteren mit Tönnchenpuppen geschieht die Sprengung des Tönnchens mit Hilfe der sog. Kopfblase, das ist eine starke Auftreibung oder Vorwölbung des Kopfes, die durch Pressen der Blutflüssigkeit in die Kopfregion hervorgerufen wird.

\section{Das Ausreifen.}

Wenn die Imago äußerlich fertig erscheint, so ist damit noch nicht gesagt, daß sie auch innerlich fertig ist. Bei vielen Insekten ist letzteres wohl der Fall, so sind z. B. die Schmetterlinge nach Verlassen der Puppe und Erhärtung der Haut auch innerlich völlig ausgereift, so daß sie unverzüglich zur Fortpflanzung schreiten können. Doch gibt es auch eine ganze Anzahl von Insekten, die beim Antritt des Imagostadiums geschlechtlich noch gänzlich unreif sind, und noch längerer Zeit (mitunter $1 / 2 \mathrm{Jahr}$ und mehr) bedürfen, bis sie ihre geschlechtliche Reife erlangen und fortpflanzungsfähig werden. Hierher gehören z. B. die Pissodes-Arten, viele Borkenkäfer, die Tachinen und viele andere. Es ist dies ein sehr wichtiges Moment, durch deren Entdeckung (Nüßlin, Knoche und andere) unsere früheren Anschauungen über die Zahl der Generationen usw. verschiedentlich umgestaltet wurden (siehe unten). Wir dürfen danach nicht mehr ohne weiteres den Abschluß der Entwicklung mit der Erhäıtung und event. Ausfärbung der Imago zusammenfallen lassen; die Entwicklung ist vielmehr erst dann als beendet anzusehen, wenn die Imago ihre völlige Geschlechtsreife erlangt hat (was meist nur durch Untersuchung der Geschlechtsorgane festzustellen ist).

Die Zeitdauer der Ausreifung ist sehr verschieden, je nach der Spezies und auch den verschiedenen äußeren Einflüssen. Wie wesentlich die letzteren sich geltend machen können, geht aus den Versuchen von Hennings hervor, wonach das "Jungkäferstadium" (d. i. die Zeit des Ausreifens) von Ips typographus bei $24^{\circ} \mathrm{C}$. und $55^{\%}$ Luftfeuchtigkeit $9^{1 / 2}$ Tage währte, während es bei $14^{\circ} \mathrm{C}$. und $95 \%$ Lufteuchtigkeit nicht weniger als 28 Tage in Anspruch nahm. Fällt die Jungkäferzeit in den Winter, so bleiben die Geschlechtsorgane bis nach der Überwinterung auf nahezu der gleichen (unreifen) Stufe beharren, eine Erscheinung, die Nüßlin als "Latenz" bezeichnet hat.

\section{Zeitlicher Ablauf der Entwicklung.}

Dauer der Gesamtentwicklung.

Wir haben oben mehrfach betont, wie ungemein verschieden die Dauer der einzelnen Hauptentwicklungsstadien (Ei, Larve, Puppe, Reifungszeit) bei den verschiedenen Arten ist. Betrachten wir aber die Dauer der Gesamtentwicklung vom Ei bis zur geschlechtsreifen Imago, so stellt sich 
heraus, daß hierin die Abweichungen weit geringer sind. Dieses rührt daher, daß eine etwaige besonders lange Dauer des einen Entwicklungsstadiums (z. B. des Eies) meist durch eine um so kürzere Dauer der anderen Stadien wieder ausgeglichen wird, so daß trotz der größeren Differenzen, die bezüglich der einzelnen Stadien bei den verschiedenen Arten herrschen, bei dem größten Teil der Insekten als Gesamtentwicklungsdauer 12 Monate resultieren. Einige konkrete Beispiele werden dies am besten klar machen:

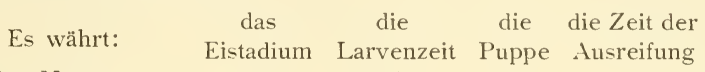

\begin{tabular}{|c|c|c|c|c|c|}
\hline bei der Nonne & . & $21 / 2$ & $1 / 2$ & - & $=12$ Monate, \\
\hline beim Kiefernspinner & 1 & 10 & 1 & - & $=12$ \\
\hline Kieferneule. & . 1 & $21 / 2$ & 84 & & $=12$ \\
\hline i Pissodes & . $1 / 2$ & 3 & $1 / 2$ & 8 & $=12$ \\
\hline
\end{tabular}

Doch gibt es auch eine Anzahl Insekten, die wesentlich länger zu ihrer Entwicklung brauchen, was in den meisten Fällen auf das langsame Wachstum der Larven zurückzuführen ist. So bedürfen viele Insekten, deren Larven im nährstoffarmen Holz leben, 2 Jahre zu ihrer Entwicklung; der Maikäfer braucht 3-4 Jahre und eine nordamerikanische Zikade gar 17 Jahre.

Andererseits gibt es aber auch eine Reihe ron Insekten, die weit weniger als 12 Monate bedürfen, so daß in einem Jahre mehrere Generationen aufeinander folgen können.

Die Entwicklungsdauer wird aber nicht von inneren Faktoren allein bestimmt, sondern hängt auch wesentlich von äußeren Einflüssen ab, so daß3 durch Änderung der letzteren bei den meisten Insekten die Entwicklungsdauer verlängert oder verkürzt werden kann.

Es hängt dies damit zusammen, daß die Insekten kaltblütige resp. wechselwarme (poikylotherme) Tiere sind, deren Eigenwärme sich nach der Temperatur des umgebenden Mediums richtet. Da nun für die Entwicklung im allgemeinen eine gewisse Wärmesumme notwendig ist, so erklärt sich ohne weiteres, daß bei wechselwarmen Tieren die Entwicklung bei niederen 'Temperaturen längere Zeit beansprucht als bei höheren (im Gegensatz zu den warmblütigen Tieren, bei denen die Entwicklungsdauer vollkommen unabhängig von diesen äußeren Faktoren ist). Die bekanntesten Beispiele hierfür liefern die Fische, deren Entwicklungsdauer sich genau nach der Wasserwärme richtet; so beträgt die "Inkubationsdauer" beim Lachs bei $4^{0} \mathrm{R}$. 106 Tage und bei $8^{0}$ R. 53 Tage, beim Bachsaibling bei $5,5^{0} 73$ und bei $8^{0}$ 50 Tage. Dies hat dazu geführt, daß man direkt mit einem konstanten Faktor der Wärmemenge rechnet, die im ersten Falle $424^{\circ}(4 \times 106$ oder $8 \times 53)$, im zweiten Fall $400^{\circ}(5,5 \times 73$ oder $8 \times 50)$ beträgt. Umgekehrt kann man - wie dies praktisch bei der künstlichen Fischzucht durchgeführt wird die Inkubationsdauer beliebig regulieren, indem man dem Wasser eine entsprechende Temperatur gibt.

Man hat nun versucht, die Verhältnisse, wie sie bei den Fischen herrschen, ohne weiteres auch auf die Insekten zu übertragen, d. h. auch für sie eine 
ganz bestimmte konstante Wärmesumme, die die verschiedenen Arten zu ihrer Entwicklung notwendig haben, anzunehmen. Man glaubte dazu um so mehr berechtigt zu sein, als man von vielen Insekten schon seit langem wußte, daß sie in wärmeren Gegenden sich rascher entwickeln als in kälteren, so z. B. vom Maikäfer, der in Norddeutschland 4 Jahre zu seiner Entwicklung braucht, in Südwestdeutschland und in der Schweiz dagegen nur 3 Jahre. Daher meinte auch Ratzeburg, im Hinblick auf diesen Käfer: „Schließlich kommt hier alles, wie bei den Pflanzen, auf die "Wärmesumme“ in Boden und Luft an, welche eine Gattung oder Art zu ihrer Entwicklung braucht."

Auch viele Borkenkäferarten verhalten sich je nach dem Ort ihres Vorkommens verschieden, indem sie in wärmeren Gegenden eine doppelte, ja event. 3 fache Generation haben können, während sie es in kälteren Gegenden nur auf eine bringen. Ja, selbst an ein und demselben Ort können sich die Generationsverhältnisse wesentlich ändern, wenn die Temperaturen der verschiedenen Jahre stark abweichen. Interessant sind in dieser Beziehung die Angaben, die Hennings über das verschiedene Verhalten vom Ips typographus in den Jahren 1903, 1905 und 1907 (in Herrenwies, bad. Schwarzwald) macht:

„1903: Der Anflug war Ende Mai erfolgt, am 5. August zeigte sich der Beginn des Jungkäferstadiums, welches durch die ungünstige Witterung derartig in die Länge gezogen wurde, daß am 30. September die Mehrzahl der Jungkäfer noch unausgefärbt unter der Rinde in der Nähe der Puppenwiegen zu finden war; eine zweite Generation war demnach nicht mehr zu erwarten und die einzige Generation 1903 dauerte also ca. 12 Monate.

1905: Nachdem der Anflug am 12. Mai erfolgt war, gelangte die junge Brut in ungefähr einem Monat bis zur Verpuppung; nach weiteren 11 Tagen war das Puppenstadium beendet und der Ausflug der Jungkäfer geschah im Juli; diese Jungkäfer gingen sofort an die Begründung der zweiten Generation. 1905 hatten wir also zwei Generationen, von denen die erste nur 2 Monate 9 Tage, bezw. sogar nur 1 Monat 25 Tage brauchte.

1907: Der Anflug war am 12. bezw. 21. Mai erfolgt; am 14. Juli waren Puppen noch nicht zu finden; die am weitesten vorgeschrittenen Larven waren voll erwachsen, zu einer Zeit also, zu welcher 1905 bereits der Ausflug der Jungkäfer erfolgte. Es ist nicht anzunehmen, daß die diesjährige Brut noch im Laufe des so ungünstigen Sommers zum Ausflug kommen konnte, so daß wir also 1907 wieder eine Beschränkung auf eine Generation hatten."

Allbekannt war ferner schon längst, daß bei Insekten mit doppelter Generation die Sommergeneration wesentlich kürzer ist als die Wintergeneration. Endlich weiß jeder Schmetterlingszüchter, daß man die Entwicklung vieler Schmetterlinge durch „Treiben“ wesentlich verkürzen kann, d. h. dadurch, daß man sie erhöhten Temperaturen aussetzt, - eine Methode, die vor allem bei überwinternden Raupen und Puppen angewandt wird. 
Es wurden auch vereinzelte Versuche angestellt, die für die Entwicklung notwendige Wärmesumme ${ }^{1}$ ) zu berechnen. So fand Förster Uhlig in Tharandt bei täglich 3 maliger Temperaturbeobachtung während einer Generation des Fichtenborkenkäfers vom 30. Mai bis 21. Juli eine Wärmesumme von $1145^{\circ} \mathrm{C}$.

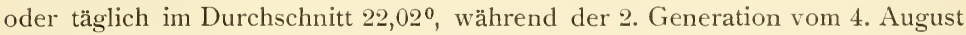
bis 3. Oktober eine Summe von $1228,5^{\circ}$ oder täglich im Durchschnitt $20,48^{\circ}$. Nach Knoche hat derselbe Käfer im Botanischen Garten zu Halle die Wärmesumme von $1371,70^{\circ}$ (Tagesdurchschnitt $15^{\circ}$ ) aufgebraucht, wobei auf das Eistadium $424,4^{\circ}$ (Tagesdurchschnitt $12,5^{\circ}$ ), auf die Larvenzeit $445,30^{\circ}$ (Tagesdurchschnitt $15,5^{\circ}$ ) und endlich auf die Puppen- und die Reifungszeit $502,0^{\circ}$ (Tagesdurchschnitt $18,6^{\circ}$ ) entfallen.

Doch hat dieser Autor bereits darauf hingewiesen, daß außer der Temperatur auch noch andere Momente, wie z. B. die Feuchtigkeit, mit zu berücksichtigen sind. Auch Versuche mit Nonneneiern, die darauf hinzielten, ein früheres Aufkommen zu bewirken, lehrten, daß neben der Temperatur dem Feuchtigkeitsgehalt der Luft ein großer Einfluß zukommt, indem bei trocken gehaltenen Eiern, selbst stark erhöhten Temperaturen das Auskriechen der jungen Räupchen nur unwesentlich beschleunigt werden konnte, während bei feucht gehaltenen die Differenz viele Monate betrug (Knoche, Escherich).

Wie verfehlt es in der Tat war, zur Erklärung der Verschiebungen in den Entwicklungsvorgängen der Insekten lediglich die einfachen (auf der Lufttemperatur basierten) Wärmesummen heranziehen zu wollen, zeigen am deutlichsten die Versuche, die von Hennings an Ips typographus vorgenommen wurden. Es wurde der genannte Käfer unter 8 verschiedenen Bedingungen gezogen, nämlich bei $24^{\circ}, 20^{\circ}, 17^{\circ}$ und $14^{\circ}$, und für jede dieser Temperaturen wieder sowohl bei ca. $55 \%$ (im folgenden als "trocken" bezeichnet) wie bei ca. $96 \%$ Luftfeuchtigkeit („feucht"), wobei sich folgendes ergab:

Die Entwicklung beanspruchte (an Tagen) für das

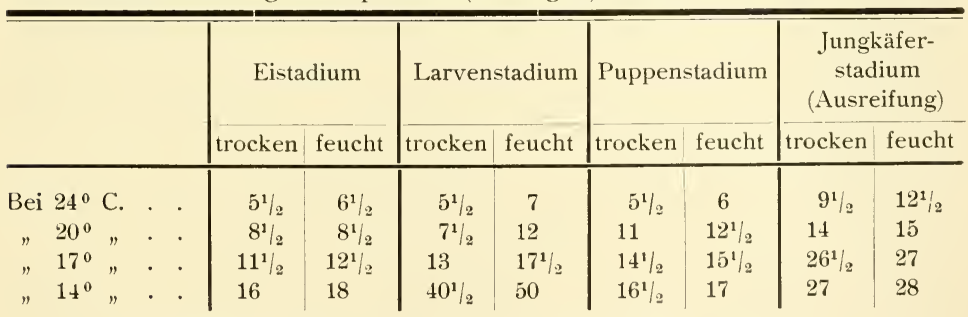

Die Gesamtentwicklung vom Ei bis zum Freikäfer währte: bei $24^{\circ}$ trocken . . . 26 Tage,

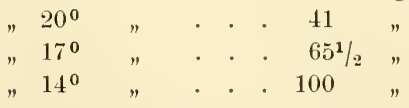
bei $24^{\circ}$ feucht . . 32 Tage,

1) Dem allgemeinen praktischen Gebrauch entsprechend ist hier die Wärmesumme in Graden angegeben, wiewohl sie natürlich richtiger in Kalorien umgerechnet werden sollte. 
Daraus geht einmal hervor, wie stark durch äußere Faktoren die Entwicklung beeinflußt werden kann (konnte doch die Entwicklungsdauer um mehr als das Vierfache, von 26 bis auf 113 Tage, verlängert werden!) und sodann auch, daß nicht die Temperatur allein für die Differenzen verantwortlich zu machen ist. Wenn auch, wie $\mathrm{K}$ noche dargetan hat, Hennings vielleicht den direkten EinfluB der Feuchtigkeit in seinen Experimenten etwas überschätzt hat, und es vielleicht mehr die durch die Feuchtigkeit hervorgerufene Veränderung der Nahrung war, welche die großen Unterschiede in der Entwicklungsdauer der trocken und feucht gehaltenen Tiere bewirkt hat, so zeigen die Henningsschen Versuche doch drastisch, wie sehr neben der Temperatur noch andere äußere Faktoren (Bachmetjew nennt außer der Temperatur noch die Feuchtigkeit, die Nahrung, Licht und Elektrizität) die Entwicklung beeinflussen können.

Wir erfahren aus den Henningsschen Versuchen ferner, daß die einzelnen Stadien in ungleichem Maße beeinflußbar sind; betrug doch die Differenz bei der Eizeit ca. 13 Tage, bei der Larvenzeit ca. 45 Tage und bei der Puppenzeit ca. 12 Tage; also weitaus am meisten wurde die Larvenzeit von der Veränderung der äußeren Faktoren getroffen.

Aber nicht nur die verschiedenen Stadien, sondern auch die einzelnen Arten zeigen große Verschiedenheiten bezügl. der BeeinfluBbarkeit, wie den Schmetterlingszüchtern wohl bekannt ist (siehe darüber Stand$\mathrm{fu} B$ und Bachmetjew) und wie auch in der letzten Zeit durch zahlreiche Versuche wiederum an Borkenkäfern (von Fuchs, Hennings, Knoche u. a.) gezeigt wurde. Unterscheidet doch Hennings bei den Borkenkäfern geradezu zwei biologische Gruppen, die er als die „BeeinfluBbaren“ und die „Nichtbeeinflu Bbaren " bezeichnet. Zu den letzteren gehört z. B. Eccoptogaster (Scolytus) Ratzeburgi, der bei einer konstanten Temperatur von $22^{\circ} \mathrm{C}$. und $60 \% \mathrm{Luft}$ feuchtigkeit keine Beschleunigung gegenüber der zur Vollendung einer Generation im Freien nötigen Zeit aufwies, während die übrigen EccoptogasterArten, ferner Ips, Polygraphus und viele andere zu den „Beeinflußbaren“ gehören. Allerdings kommen auch unter diesen große Schwankungen vor, indem die einen mehr und die anderen weniger zu beeinflussen sind, so daß eine scharfe Grenze zwischen den obigen Gruppen überhaupt wohl kaum gezogen werden kann.

Bei manchen Insekten kommt die merkwürdige Erscheinung vor, daß ohne jeden erkennbaren Grund die Entwicklung bei einer Anzahl von Individuen sich weit über die Normaldauer hinaus erstreckt und das Doppelte, ja 3-, 4bis 8 fache der letzteren beträgt. Man bezeichnet diese Erscheinung, die sich meist auf das Puppenstadium bezieht, als „Überliegen“, „Überjährigkeit“ oder "Latenz" (NüBlin). Lyda stellata z. B. hat gewöhnlich eine einjährige Generation; dagegen findet man häufig, daß aus der im Anfang Mai entstandenen Puppe nicht Ende Mai oder im Juni die Wespe ausfliegt, wie eigentlich die Regel wäre, sondern daß der Puppenzustand bis zum nächsten Mai dauert und dann erst das vollendete Insekt fliegt. Relativ häufig ist die Erscheinung des Überliegens bei den Schmetterlingen, was den meisten Züchtern bekannt ist. So erscheint nach Standfuß der Falter von Saturnia 
spini nur zum Teil nach dem ersten Winter, zum größten Prozentsatz (70 bis $75 \%$ ) erst nach mehrmaliger Überwinterung, und Bombyx var. arbusculae am häufigsten erst nach 4 nnaliger Überwinterung der Puppe, doch auch nach 5 oder 6 maliger, in dem äußersten bis jetzt bekannten Falle sogar erst nach 8 maliger Überwinterung. Siebenmal überwintert auch Biston alpinus; es können daher diese schmucken Tiere Geduld und Sorgfalt des Züchters auf eine genügende Probe stellen. ${ }^{1}$ ) „Zweimalige Überwinterung (einmaliges Überliegen) der Puppen ist ganz und gar keine Seltenheit und man werfe daher die Puppen nach einmaliger Überwinterung ja nicht ohne weiteres weg." Standfuß führt eine große Reihe ron Schmetterlingen an, bei denen er ein Überliegen der Puppen beobachtet hat.

Welche Faktoren die Erscheinung des Überliegens hervorrufen, ob wirklich, wie es den Anschein hat, lediglich innere Ursachen dabei wirksam sind, darüber wissen wir heute noch gar nichts zu sagen. Die biologische Bedeutung des Überliegens ist nach Standfuß vielleicht darin zu suchen, daß die Inzucht verhindert wird, indem durch das Überliegen die Nachkommenschaft desselben Elternpaares auseinandergezogen und so die beiden Geschlechter der gleichen Brut um Jahre voneinander getrennt werden.

Eine gewisse Parallele zu dem Überliegen der Puppe bildet die verschieden lange und mit einer Vermehrung der Häutungen verbundene Entwicklungsdauer der aus ein und demselben Eigelege stammenden und unter den gleichen Bedingungen aufwachsenden Raupen gewisser Schmetterlinge, insofern als auch hier (ebenso wie bei den überliegenden Puppen) äußere Gründe für die Verlängerung der Entwicklung eines Teiles der Nachkommenschaft nichit erkennbar sind. Ein solcher Fall liegt z. B. bei der Nonne vor, bei der nach Metzgers Versuchen ein Teil der Raupen unter 4 maliger Häutung 46 Tage zur Beendigung braucht („Vierhäuter“), während die anderen unter 5̃maliger Häutung 56 Tage brauchen („Fünfhäuter"). Hier kommt nun außerdem noch dazu, daß, was bei vielen Insekten der Fall ist, die männliche Puppe etwas länger liegt (ca. 19 Tage) als die weibliche (ca. 161/2 Tage), so daß also die Falter aus ein und demselben Gelege zu vier verschiedenen Terminen herauskommen: Die ersten (Weibchen) nach $62^{1 / 2}=46+16^{1} / 2$ Tagen, die zweiten (Männchen) nach $65=46+19$ Tagen, die dritten (Weibchen) nach

1) Daß dies physiologisch möglich ist, beruht nach Gräfin von Linden darauf, daß Schmetterlingspuppe imstande ist, wie die Pflanze zu assimilieren, d. h. Kohlensäure aus der Luft zu absorbieren, sie zu spalten und den Kohlenstoff als organische Substanz sich einzuverleiben; daß sie ferner aus der Luft den Stickstoff „sich nutzbar machen, und zwar in einem Grade, wie es bis jetzt nur für die Pflanze unter Beihilfe von Bakterien erwiesen ist" (wie von den Pflanzen, so wird auch von den Puppen vorwiegend bei Tage assimiliert und bei Nacht geatmet). Sie vermögen dadurch bei langer Puppenruhe wenigstens einen Teil der zerfallenden Körpersubstanz wieder zu ersetzen. „Nur bei einer derartigen Ökonomie des Stoffes und der Kraft ist es auch zu begreifen, daß Puppen in einem, un ein Mehrfaches verlängerten Winterschlaf nicht ihren ganzen Vorrat an Brenmmaterial, der auf eine viel kürzere Zeit berechnet war, verbrauchen und auch dem Schmetterling noch Stoff und Energie zur Entwicklung einer reichen Nachkommenschaft mitgeben können." - Die hier wiedergegebenen Anschauungen der Gräfin von Linden haben übrigens mehrfachen Widerspruch erfahren. 
$72^{1} / 2=56+16^{1} / 2$ Tagen und die vierten (Männchen) nach $75=56+19$ Tagen. Auch hier dürfte die biologische Bedeutung die gleiche sein, wie wir sie für das Überliegen angenommen haben, nämlich die Inzucht möglichst zu verhindern.

Aus dem Wenigen, was wir hier über die Entwicklungsdauer, deren große Verschiedenheit bei den einzelnen Stadien, deren große Abhängigkeit von äußeren Faktoren usw., sagen konnten, geht schon zur Genüge hervor, welch weites und interessantes Gebiet hier vorliegt. Es würde jedenfalls eine überaus dankbare Aufgabe für physiologisch geschulte Entomologen sein, diesem Probleme sich mehr zu widmen; die Ergebnisse werden nicht nur vom allgemeinsten biologischen Interesse, sondern auch zweifellos von großem Wert für die Praxis sein.

\section{Generation.}

Die Zeit, welche eine Insektenart braucht, um einen einfachen Entwicklungszyklus zu vollenden, nennt man (mit cinem Anklange an den Gebrauch, z. B. Großvater, Vater und Sohn als drei "Generationen“ ein und derselben Familie zu bezeichnen) die "Generation“ des betreffenden Insektes. Diese Zeit reicht also von dem Augenblicke der Ablage eines Eies bis zum Eintritt der Geschlechtsreife und zum Beginn der Fortpflanzungstätigkeit bei dem aus diesem Ei entstandenen Tiere: kurz gesagt, von Ei zu Ei.

Bedarf ein Insekt, was am häufigsten der Fall ist, zu seiner Entwicklung 12 Monate, so sprechen wir von einer einjährigen Generation. Die Raupe, welche aus dem vom Kiefernspannerweibchen im Mai abgelegten Ei schlüpft, verwandelt sich im nächsten Mai wieder in den fortpflanzungsfähigen Falter.

Ein Insekt, welches zu seinem Entwicklungszyklus dagegen 24, 36, 48 Monate u.s.f. braucht, hat eine zwei-, drei- oder vierjährige Generation. Ein Beispiel der letzteren ist im nördlichen Deutschland der Maikäfer, dessen „Flugjahre“ an einem bestimmten Orte stets nur jedes vierte Jahr, z. B. alle Schaltjahre wiederkehren. Die längste bekannte Generation hat eine nordamerikanische Zirpe, welche 17 Jahre zu ihrer Entwicklung braucht und eben nach dieser Eigentümlichkeit von Linné Cicada septemdecim getauft wurde.

Es fällt aber auch jede einjährige Generation stets in zwei verschiedene Kalenderjahre und jede xjährige Generation verteilt sich also, wenn $\mathrm{x}$ eine ganze Zahl darstellt, auf $x+1$ Kalenderjahre. Vergleiche hierzu die unten folgenden Tabellen.

Andererseits gibt es, wie eben bereits erwähnt, Insekten, welche ihren Entwicklungszyklus zwei- oder mehreremale innerhalb von 12 Monaten vollenden, und man sagt alsdann, daß das betreffende Insekt eine doppelte, dreifache bezw. mehrfache Generation hat. Ein Beispiel für doppelte Generation bietet die kleine Kiefernblattwespe (Lophyrus pini L.), während einige Blattläuse unter normalen Verhältnissen sogar eine 9-14fache Generation haben können.

Bei der Beurteilung der doppelten usw. Generation ist darauf zu achten, daß die Generation wirklich in dem genetischen Verhältnis der direkten Nach- 
folge (wie Mutter-Tochter-Enkelgeneration) zueinander stehen; sonst kann man zu einer ganz irrtümlichen Auffassung gelangen. Denn doppelte und mehrfache Generationen können leicht vorgetäuscht werden, entweder dadurch, daß die Legezeit sich sehr lang hinzieht, oder dadurch, daß das Weibchen nach längeren oder kürzeren Pausen (Regeneration der abgebrunfteten Geschlechtsorgane!) wiederholt zur Eiablage schreitet. In beiden Fällen kann es, zumal bei einem raschen Verlauf der Ei-, Larven- und Puppenentwicklung, vorkommen, daß man frisch geschlüpfte Imagines und Eier zur gleichen Zeit findet. Früher nahm man dann gewöhnlich ohne weiteres an, daß die Eier von den jungen Imagines stammten und daß demnach eine doppelte Generation vorliege. Heute dagegen ist man, auf Grund der Entdeckungen Nüßlins und Knoches, von der Langlebigkeit der Mutterkäfer einerseits und der mitunter sich über Monate hinziehenden langsamen Ausreifung der Imagines andererseits, weit vorsichtiger und kritischer geworden, und hat auch in vielen Fällen, da man bisher an einer doppelten Generation festhielt, nur eine einjährige Generation feststellen können. So haben z. B. die PissodesArten, wie Nüßlin gezeigt hat, in der Regel nur eine einjährige Generation, obgleich die zuerst abgelegten Eier schon im Juli, und die im Juli abgelegten Eier schon wieder im November Jungkäfer liefeın, und zwar aus dem Grunde, weil alle Eier nur ron überwinterten Weibchen stammen, die Jungkäfer dagegen im Jahre der Geburt überhaupt nicht mehr zur Geschlechtsreife kommen (siehe auch oben S. 170).

Wir werden unten bei den wichtigeren Forstschädlingen die Verhältnisse ihrer Generation graphisch darstellen.

Die hierbei von uns für die einzelnen Entwicklungsstadien der Insekten gewählten Zeichen sind derartig beschaffen, daß sie einigermaßen an das durchschnittliche Aussehen der entsprechenden wirklichen Stadien erinnern und daher verhältnismäßig leichter im Gedächtnis behalten werden können, als die sonst zu diesem Zwecke beliebten Buchstaben oder Farben.

Es wird also das Ei durch einen Punkt (.), die Larve durch einen Strich (-), die unverpuppt in Kokon liegende Larve durch einen von einer liegenden Null umschlossenen Strich $(\odot)$, die Puppe durch eine liegende ausgefültte Null (•) und die Imago, also das fliegende Tier, durch ein Kreuz (+), die Zeit, in welcher das betreffende Insekt frißt, durch einen starken dicken Strich $(-)$ bezeichnet. Letzterer wird bei Larvenfraß unter, bei Imagofraß über den Zeichen tür das betreffende Stadium angebracht sein. In den Fällen, wo die Imago noch einige Zeit zur Ausreifung der Geschlechtsorgane bedarf, ist die Zeit der Unreife daran kenntlich, daß unter dem Kreuz das Eizeichen fehlt.

Es sind die Tabellen ferner so eingerichtet, daß sie auf zirka zehn Tage, d. h. ein Drittel Monat, genau die Lebensgeschichte eines Insektes darzustellen gestatten.

Folgende Beispiele mögen dieses erläutern: 
Liparis monacha L., mit einjähriger Generation.

\begin{tabular}{|c|c|c|c|c|c|c|c|c|c|c|c|c|}
\hline Jahr & Jan. & Febr. & März & April & Mai & Juni & Juli & Aug. & Sept. & Okt. & Nov. & Dez. \\
\hline 1880 & & & & & & & + & + \pm & . . & $\cdot \cdot \cdot$ & . . & . . \\
\hline 1881 & . . & . . & $\cdots$ & $\cdot \cdot-$ & --- & --- & $\bullet \bullet+$ & ++ & & & & \\
\hline
\end{tabular}

Nonnentachine (Parasetigena segregata) mit einjähriger Generation.

\begin{tabular}{|c|c|c|c|c|c|c|c|c|c|c|c|c|}
\hline Jahr & Jan. & Febr. & März & April & Mai & Juni & Juli & Aug. & Sept. & Okt. & Nov. & Dez. \\
\hline 1910 & & & & + & ++ & + & -0 & & - & -0 & $-c$ & $\bullet-\circ$ \\
\hline 1911 & -0 & -0 & - & $\bullet \bullet+$ & +++ & + & & & & & & \\
\hline
\end{tabular}

Cnethocampa pinivora, mit zweijähriger Generation.

\begin{tabular}{|c|c|c|c|c|c|c|c|c|c|c|c|c|}
\hline Jahr & Jan. & Febr. & März & April & Mai & Juni & Juli & Aug. & Sept. & Okt. & Nov. & Dez. \\
\hline 1910 & & & & & & & + & $+t$ & . & $\cdot$ & $\cdots$ & $\cdots$ \\
\hline 1911 & $\cdot \cdots$ & $\cdots$ & $\cdot \cdot$ & $\cdot \cdot-$ & --- & --- & --- & -- & 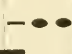 & - & - & - \\
\hline 1912 & $\circ 0$ & $\circ-0$ & $\bullet \bullet$ & $\bullet \bullet$ & - & - & -. & $+t$ & & & & \\
\hline
\end{tabular}

Melolontha vulgaris $L$., mit vierjähriger Generation.

\begin{tabular}{|c|c|c|c|c|c|c|c|c|c|c|c|c|}
\hline Jahr & Jan. & Febr. & März & April & Mai & Juni & Juli & Aug. & Sept. & Okt. & Nov. & Dez. \\
\hline 1880 & & & & & ++ & \pm+ & $\cdot--$ & --- & & -- & & --- \\
\hline 1881 & --- & & --- & -- & - & - & --- & - & & 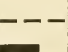 & --- & --- \\
\hline 1882 & --- & - & - & & & & --- & & & --- & - & -- \\
\hline 1883 & --- & --- & --- & --- & --- & --- & --- & - & - & - & +++ & +++ \\
\hline 1884 & +++ & +++ & +++ & +++ & +++ & + & & & & & & \\
\hline
\end{tabular}


Lophyrus Pini L., mit doppelter Generation.

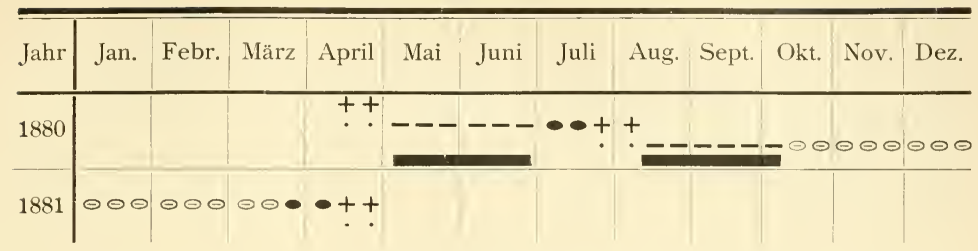

Wenn man mit dieser graphischen Darstellung einigermaßen vertraut geworden ist, kann man sich mit einem Blick über die Generationsverhältnisse orientieren. Allerdings lassen sich diese Schemata nicht überall anwenden. „Im Falle langer Lebensdauer der Imagines, langhingezogener Eiablage, Ineinandergreifen der geschwisterlichen Generationen (wie bei den Borkenkäfern, Pissodes usw.) sind solche graphische Darstellungen unmöglich; ihre Anwendung würde höchstens die Wahrheit entstellen und verwirrend wirken" (Nüßlin). Die Entwicklung des einzelnen Individuums läßt sich natürlich auch in solchen Fällen ohne weiteres in das Schema bringen, nicht aber lassen sich die Entwicklungsverhältnisse der Art in dieser Weise darstellen.

\section{Überwinterungsstadium.}

Bei den meisten forstschädlichen Insekten ist der Winter die beste Zeit, in der man die Prognose für die kommende Saison stellt; so kann man sich durch Untersuchung der Zahl und des Gesundheitszustandes der Nonneneier ein ungefähres Bild davon machen, welcher Grad von Fraß im nächsten Sommer zu erwarten ist, ebenso kann man sich durch Feststellung der Zahl der in der Bodendecke überwinternden Kiefernspinnerraupen oder Spanner- oder Eulenpuppen darüber orientieren, was uns die kommende Saison bescheren wird usw., wodurch man in den Stand versetzt wird, in Ruhe Vorbereitungen für die eventuelle Bekämpfung zu treffen.

Es ist daher von großer Wichtigkeit, zu wissen, in welchem Stadium die einzelnen Insekten überwintern. Allgemeine Regeln lassen sich darüber nicht aufstellen, da in dieser Beziehung die größte Mannigfaltigkeit herrscht, so daß nichts anderes übrig bleibt, als für jeden Schädling das Überwinterungsstadium sich besonders zu merken. Wie regellos die Insekten sich darin verhalten, zeigt eine Zusammenstellung Werneburgs, wonach von unseren einheimischen Großschmetterlingen, im ganzen betrachtet, $3,4 \%$ als Ei, $66,9 \%$ als Raupe, $28,2{ }^{\circ}$ als Puppe und $1,5 \%$ als Falter überwintern, während bei Betrachtung einzelner Familien die Resultate sich ganz anders stellen. So überwintern alle Zygaeniden als Raupen, die meisten Sphingiden als Puppe und von den Tagfaltern $9 \%$ als Ei, $54 \%$ als Raupe, $28 \%$ als Puppe und $9 \%$ als Falter. Ja es kommt sogar ror, daß Insekten, welche man bei nicht allzu enger Begrenzung der Genera zu einem und demselben Genus rechnen kann, in ganz verschiedenen Stadien überwintern. Dies geht deutlich aus der folgenden Darstellung der Generation dreier unserer gemeinsten Spinner hervor. 
Generation von Bombyx neustria $L$.

\begin{tabular}{|c|c|c|c|c|c|c|c|c|c|c|c|c|}
\hline Jahr & Jan. & Febr. & März & April & Mai & Juni & Juli & Aug. & Sept. & Okt. & Nov. & Dez. \\
\hline 1880 & & & & & & & $+t+$ & . & $\cdot \cdot$ & . & $\cdot \cdot$ & $\cdot \cdot$ \\
\hline 1881 & . & . . & . . & $\cdot \cdots-$ & --- & -0 & $++t$ & & & & & \\
\hline
\end{tabular}

Generation von Bombyx Pini L.

\begin{tabular}{l|l|l|l|l|l|l|l|l|l|}
\hline Jahr & Jan. & Febr. & März & April & Mai & Juni & Juli & Aug. Sept. Okt. Nov. Dez. \\
\hline 1880 & & & & & & & & & \\
1881 & & & & & &
\end{tabular}

Generation von Bombyx lanestris $L$.

\begin{tabular}{|c|c|c|c|c|c|c|c|c|c|c|c|c|}
\hline Jahr & Jan. & Febr. & März & April & Mai & Juni & Juli & Aug. & Sept. & Okt. & Nov. & Dez. \\
\hline 1880 & & & & $t+t$ & --- & -- & --0 & 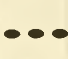 & $0^{\circ}$ & $\bullet$ & 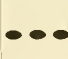 & - \\
\hline 1881 & -0 & 00 & $\bullet-0$ & $+t+$ & & & & & & & & \\
\hline
\end{tabular}

Bei manchen Insektenarten überwintern ferner nur die Weibchen nach vorhergehender Begattung im Herbste, z. B. bei manchen Mückenarten und unseren gewöhnlichen Faltenwespen (Vespa); und die Tatsache, daß die Honigbienen über Winter in ihren Stöcken keine Drohnen dulden, dieselben vielmehr vorher in der "Drohnenschlacht“ töten, so daß nur die Königin nebst den Arbeitern den Winter überdauert, ist jedem Bienenfreunde bekannt.

Abnorme Witterungsverhältnisse können es aber auch veranlassen, daß eine Insektenart ausnahmsweise einmal in einem anderen Lebensstadium als gewöhnlich überwintert. Allerdings sind Fälle, daß ein Tier in einem anderen der vier Hauptentwicklungszustände als gewöhnlich den Winter verbringt, doch selten. Dagegen ist es häufig, daß z. B. Raupen, welche gewöhnlich halbwüchsig das Winterquartier beziehen, dies als ganz junge Tiere zu tun gezwungen werden, so die Kiefernspinnerraupe nach der ersten Häutung, statt wie gewöhnlich nach der zweiten.

Insekten, welche eine mehrjährige Generation haben, müssen natürlich auch mehrere Male überwintern. Es kann dies in den gleichen oder in verschiedenen Hauptlebensstadien geschehen; so überwintern z. B. die eine zwei- 
bis dreijährige Generation aufweisenden Eintagsfliegen stets als Larven im Wasser, während der Maikäfer drei Winter als Larve, den vierten dagegen meist als Imago überdauert.

Vielfach suchen die Insekten zur Überwinterung besondere Winterquartiere auf, so bohren sich manche Borkenkäfer speziell zum Zweck des Überwinterns oft massenhaft an der Basis von Stämmen ein, manchmal sogar in anderen Hölzern als den normalen; so suchen die Laufkäfer alte morsche Baumstümpfe auf, in denen man sie im Winter mitunter in großer Zahl finden kann, so geht der Engerling den Winter über tiefer in die Erde, um aus der Frostregion zu kommen, und so wandert die Kiefernspinnerraupe vor Eintritt des Winters herab, um die kalte Zeit in der Bodendecke zu verbringen, usw.

Für die Vermehrung resp. für die Schädlichkeit eines Insektes kommt es wesentlich darauf an, in welchem Stadium die Überwinterung stattfindet, da die einzelnen Stadien sich sehr verschieden gegen die Unbilden des Winters verhalten. So ist das Ei meist überaus widerstandsfähig gegen Kälte und Nässe, während die Raupe diesen Einflüssen eher unterliegt. Die Kiefernspinnerraupe z. B. geht während der Winterruhe im Boden oft massenhaft an Pilzinfektionen (Cordiceps militaris) zugrunde. Abgesehen davon ist der Fall, daß die Raupe zur Überwinterung in den Boden geht, noch insofern besonders günstig für uns, als sie dadurch vollkommen in unsere Hände gegeben sind, indem wir sie ja durch Leimringe vom Aufsteigen in die Krone verhindern können.

\section{Flugzeit.}

Unter Flugzeit versteht man im entomologischen, besonders im forstentomologischen Sinne die Zeit, in welcher die Imago zur Fortpflanzung schreitet. Der Ausdruck findet seine Rechtfertigung darin, daß die Zeit der Fortpflanzung gewöhnlich die gesamte Lebenszeit der Imago, des einzigen geflügelten Zustandes umfaßt, oder daß, wo dies nicht stimmt, die Imago doch meist nur während der Fortpflanzungszeit von ihrem Flugvermögen ausgiebigeren Gebrauch macht.

Neuere Untersuchungen haben uns allerdings eine ganze Reihe von Insekten kennen gelehrt, bei denen die Dauer des Imagolebens durchaus nicht mit der Zeit der Fortpflanzung zusammenfällt, sondern sich wesentlich länger ausdehnt. Außerdem gibt es doch auch Insekten, welche in ihrer Fortpflanzungszeit nicht oder nur wenig fliegen (Hylobius), sowie endlich auch zahlreiche ungeflügelte Insekten. Nüßlin hat daher an und für sich gewiß recht, wenn er an Stelle des Ausdruckes Flugzeit den Ausdruck Fortpflanzungsbereitschaft gesetzt wissen will; doch hat sich der Ausdruck Flugzeit bereits so sehr in der Praxis eingebürgert, daß es uns am zweckmäßigsten-erscheint, denselben beizubehalten, wenn er auch dem eigentlichen Sinne des Wortes nach nicht überall völlig zutreffend ist.

Die Flugzeit der einzelnen Insektenarten ist eine sehr verschiedene: Während sie z. B. bei der Kieferneule bereits in das zeitige Frühjahr, Ende Mäız oder Anfang April, fällt, tritt sie beim Kiefernspinner erst im Hoch- 
sommer ein, und der Frostspanner fliegt gar erst im Spätherbst, von Mitte Oktober bis in den Dezember hinein. Die Kiefernblattwespe (Lophyrus pini) fliegt sowohl im April als auch im Juli und August.

Im allgemeinen ist die Flugzeit der einzelnen Insekten, speziell der praktisch beachtenswerten, genau bekannt. Doch ist nicht zu übersehen, daß der Beginn der Flugzeit durch klimatische Verhältnisse wesentlich verschoben werden kann, insofern als er durch ungünstige Witterung rerzögert, durch günstige beschleunigt wird. Besonders macht sich dies bei solchen Insekten bemerkbar, deren Flugzeit in das erste Frühjahr fällt. Dabei lassen sich oft unverkennbare Beziehungen zur Pflanzenwelt feststellen, indem die Beschleunigung oder die Verzögerung des Eintrittes der Flugzeit gleichen Schritt hält mit dem vorzeitigen oder verspäteten Erwachen der Pflanzenwelt. Die phänologischen Aufzeichnungen, die wir in den meisten modernen Jahresberichten der landwirtschaftlichen Versuchsstationen resp. Sammelstellen finden, bringen hierfür zahlreiche Beispiele.

Auch die Dauer der Flugzeit ist ungemein verschieden je nach der Insektenart: Bei den Eintagsfliegen währt sie nur wenige Stunden, bei den meisten Schmetterlingen, Käfern, Fliegen usw. mehrere Tage bis ca. zwei Wochen, während sie bei anderen über die ganze Saison sich hinziehen kann. Letzteres trifft hauptsächlich für Insekten mit langsamer Geschlechtsreife und langer Lebensdauer zu, wie für Pissodes, gewisse Borkenkäfer usw.

Wie auf den Beginn, so üben klimatische Einflüsse auch auf die Dauer der Flugzeit eine deutliche Wirkung aus, und zwar sowohl auf die Flugzeit des Individuums als die der Art. Schöne warme Februar- oder Märztage bewirken bei vielen Insekten einen frühzeitigen Beginn der Flugzeit; folgt nun darauf ein Temperatur-Rückschlag, so wird das Fortpflanzungsgeschäft, das soeben eingesetzt hatte, sogleich wieder unterbrochen und zwar so lange, bis wieder wärmere Tage (mit einer für die Fortpflanzung nötigen Temperatur) eintreten. Diese Unterbrechung kann Wochen dauern, und so kann die Fortpflanzungszeit weit über das normale Maß hinaus verlängert werden. Als Beispiel hierfür sei eine Beobachtung Knoches an Hylesinus piniperda angeführt: Am 26. Februar 1900, der eine abnorm hohe Temperatur hatte, und dem eine Reihe ebenfalls sehr warmer Tage vorausgegangen waren, wurden die ersten piniperda beim Einbohren und der Herstellung der Muttergänge beobachtet; es trat darauf ein Temperatur-Rückschlag ein, der beinahe den ganzen März und auch noch die ersten Tage des April anhielt. Als am 20. März einige der am 26. Februar in Angriff genommenen und damals sofort markierten Muttergänge geöffnet wurden, befanden sich im fortgeschrittensten nicht mehr als 7 Eier, eine Zahl, die unter Umständen in einem Tage abgelegt wird. Die Eiablage war also durch die kalte Temperatur unterbrochen. Diese Unterbrechung hielt bis in den April hinein an, und so kam es, daß bei einer Untersuchung vom 16. April ein erheblicher Unterschied in der Förderung zwischen den Muttergängen vom 26. Februar und denen, die erst am 11. und 12. April in Angriff genommen worden waren, nicht zu finden war. 
Es ist daher also nicht angängig, vom Eintritt der Flugzeit ohne weiteres auf das Erscheinen der nächsten Imagines (durch einfaches Hinzurechnen der normalen Entwicklungsdauer) zu schließen, da wir stets mit Unterbrechungen und Verzögerungen durch klimatische Einflüsse rechnen müssen.

In dem eben erwähnten Beispiel betraf die Flugzeitverlängerung in gleicher Weise das Individuum wie die Art. Es können aber auch Fälle eintreten, in denen die Flugzeit des Individuums die normale bleibt, wogegen die Gesamtflugzeit der Art wesentlich verlängert wird. Nehmen wir als Beispiel hierfür die Nonne: ihre Flugzeit zieht sich gewöhnlich über 4 Wochen, von Mitte Juli bis Mitte August, hin; hatten wir nun einen Sommer mit stark wechselnden klimatischen Verhältnissen (abwechselnd Hitze und Kälte, Nässe und Trockenheit usw.), so ergibt sich daraus oft eine Ungleichheit in der Entwicklung der Raupen, so daß wir neben ganz kleinen mittelgroße und beinahe vollentwickelte Raupen finden können; und daraus resultiert natürlich eine weitere Ausdehnung der Flugzeit, die sich bis Mitte, ja bis Ende September hinziehen kann. Was hier für die Nonne gesagt ist, gilt in gleicher Weise auch noch für viele andere Insekten.

Alle hier angeführten Punkte über die Flugzeit können für die Praxis die größte Bedeutung erlangen, es muß daher der Praktiker völlig vertraut damit sein. Er muß nicht nur die normalen Flugzeiten der wichtigeren Schädlinge kennen, sondern auch wissen und berücksichtigen, wie sehr und in welcher WVeise dieselben durch Witteıungseinflüsse verschoben und verändert werden können.

\section{Lebensdauer.}

Wenn ein Insekt den Imagozustand einmal erreicht hat, so wächst dasselbe, wie wir oben kennen gelernt haben, nicht mehr. Die Funktionen der Imago beschränken sich denn auch im wesentlichen auf die Ernährung und Fortpflanzung, und in sehr vielen Fällen tritt erstere derartig zurück, daß die ganze Lebenstätigkeit lediglich mit dem Fortpflanzungsgeschäft erfüllt ist. Das klarste Beispiel hierfür ist die Eintagsfliege, welche nach Erreichung des Imagozustandes nur wenige Stunden lebt, um Begattung und Eiablage ausführen zu können. Ähnlich verhalten sich die Psychiden, deren Männchen, kaum entwickelt, in rasendem oder tanzendem Flug das Weibchen aufsuchen und sogleich nach der Kopulation absterben (nach StandfuB betrug das gesamte Imagoleben zweier Psyche apiformis-Männchen vom Moment des Ausschlüpfens bis zum Tode nur 32 bezw. 58 Minuten!). In den meisten anderen Fällen beträgt das Imagoleben mehrere Tage bis mehrere (2-3) Wochen; so lebt z. B. der Kiefernspinner ca. 16 Tage als Imago, die Nonne wohl noch etwas weniger, Lyda stellata ca. 4 Wochen usw. Bei denjenigen Arten, die als Imago überwintern, wie z. B. die Tagfalter und viele Eulen, zieht sich das Imagoleben über viele Monate hin, am längsten wohl bei den Caplocampa-Arten (Eulen), die Ende August, Anfang September schlüpfen und bis zum Mai, Juni des nächsten Jahres am Leben bleiben, um dann erst die Eier abzulegen.

In allen diesen Fällen und sogar auch dann, wenn zwar das Imagostadium überwintert, aber im Frühjahr bald nach ausgeübter Fortpflanzungs- 
tätigkeit eingeht, deckt sich die Dauer der einzelnen Generation ungefähr mit der Lebensdauer des Insektenindividuums ( $\mathrm{Ei}$ - Imago).

Es kommen allerdings in dieser Beziehung auch Ausnahmen vor; so gibt es unter den Käfern eine Anzahl von Arten, welche mehrere Jahre als Imago leben und in dieser Zeit mehrmals zur Fortpflanzung schreiten, wie z. B. die Pissodes-Arten, Hylobius, einzelne Borkenkäfer, ferner Calosoma und andere Laufkäfer. Das längste Imagoleben führen zweifellos die Weibchen der sozialen Insekten; so kann eine Bienenkönigin bis 5 Jahre alt werden, eine Ameisenkönigin bis 12 und eine Termitenkönigin wohl gar bis 15 Jahre, wobei sie fast ununterbrochen dem Fortpflanzungsgeschäft obliegt.

Auch auf die Dauer des Imagolebens können äußere Einflüsse wirksam sein, indem das Fortpflanzungsgeschäft bei niederer Temperatur sich wesentlich langsamer vollzieht als bei hoher, was wenigstens bei solchen Arten, die nach Erledigung der Fortpflanzung absterben, gleichbedeutend mit einer Verlängerung des Imagolebens ist.

\section{Literatur.}

(Lehr- und Handbücher siehe oben S. 48.)

Keimzellen - Eiablage.

Ballowitz, E., Untersuchungen über die Struktur der Spermatozoen. Die Spermatozoen der Insekten. Zeitschr. f. wissensch. Zoologie, 50. Bd., 1890.

Bernhard, C., Über die vivipare Ephemeride Chloeon dipterum. Biolog. Centr.-BI. 1907 , S. $468 \mathrm{ff}$.

Blunck, Hans, Das Geschlechtsleben von Dytiscus marginalis L., I. Teil: Die Begattung. Zeitschr. f. wissensch. Zoologie, CII. Bd., 1912.

Börner, C., Untersuchungen über die Chermiden. Mitteil. Kais. Biol. Anstalt f. Land- und Forstwirtschaft, Heft 8, Februar 1909, S. 50-60.

Groß, J., Untersuchungen über die Histologie des Insektenovariums. Zoolog. Jahrb., Abt. Anat., Bd. 18, 1903, S. 71-186.

Kahle, W., Die Paedogenesis der Cecidomyiden. Zoologica, Heft 5̌5, Stuttgart 1908.

Korschelt und Heider, Lehrbuch der Entwicklungsgeschichte der wirbellosen Tiere. I. und II. Auflage.

Mc. Attee, Facts in the Life History of Goniops chrysocoma, Proc. Ent. Soc., Washington, Vol. XIII, 1911, S 21-30, 3 Taf.

Marchal, Paul, Recherches sur la biologie et le développement des Hyménoptères parasites. 1. La polyembryonie spécifique ou germinogonie. Arch. de. Zoolog. Experim. (4), Tome 2, 1904, S. 257-335.

Scheidter, Fr., Über Begattung und Eiablage von Lymantria dispar. L. Nat. Zeitschr. f. Land- und Forstwirtschaft, 1909.

Silvestri, Fil., Contribuzioni alla conoscenza biologica degli Imenotteri parassiti. 1. Biologia del Listomastix truncatellus (Dalm). Ann. Scuol. Agric. Portici, Vol. VI, 1906, 51 Seit., 13 Fig., 5 Taf.

\section{Embryonalentwicklung.}

Escherich, K., Über die Bildung der Keimblätter bei den Musciden. Nova acta Leopold. Bd. LXXVII, 1900.

Heymons, R., Die Embryonalentwicklung von Dermapteren und Orthopteren unter besonderer Berücksichtigung der Keimblätterbildung, Jena 1895.

- Über einen Apparat zum Öffnen der Eischale bei den Pentatomiden. Zeitschr. f. wissensch. Ins. Biol., 1906.

Korschelt und Heider, Lehrbuch der vergleichenden Entwicklungsgeschichte der wirbellosen Tiere. Allgemeiner Teil (2. Aufl.), 4. Lief., Jena 1910 (Keimblätterbildung).

Hierin findet sich die gesamte Literatur über die Keimblätterfrage verarbeitet.

Knoche, E., Nonnenstudien. Naturwissensch. Zeitschr. für Forst- und Landwirtsch., 1912. 
Nachembryonale Entwicklung.

Börner, C., Die Verwandlungen der Insekten. Sitzbericht, Ges. f. Nat. Freunde, Nr. 5, 1909, S. 290-311.

Deegener, P., Die Metamorphose der Insekten. Leipzig 1909.

- Wesen und Bedeutung der Metamorphose bei den Insekten (Populäre Darstellung). Leipzig 1910.

Fabre, J., Memoire sur Hypermetamorphose et les moeurs des Meloides. Annal. Sc. nat. (4) Zoolog., Vol. VII, 1857.

Heymons, R., Die verschiedenen Formen der Insektenmetamorphose. Ergebn. und Fortschr. der Zoologie, I. Bd., 1909, S. 137-188.

Knoche, E., Beiträge zur Generationsfrage der Borkenkäfer. Forstwissenschaftl. Zentr.-Bl. 1904

Leisewitz, W. Über chitinöse Fortbewegungsapparate einiger Insektenlarven. München 1906.

Müller, G. W., Der Enddarm einiger Insektenlarven als Bewegungsorgane. Zoolog. Jahrb., Supplement, XV, 3. Bd., 1912, S. 219-240, Taf. 7.

NüBlin, Otto, Über Generation und Fortpflanzung der Pissodes-Arten. Forst.-nat. Zeitschr. VI, 1897.

Silvestri, Fil., Contribuzione alla conoscenza della metamorfosi e dei costumi della Lebia scapularis Foucr con descrizione dell' apparato sericiparo della larva. Redia, Bd. II, 1905.

\section{Zeitlicher Ablauf der Entwicklung.}

Bachmetjew, P., Experimentell-entomologische Studien vom physik. - chem. Standpunkt aus. II Bd., Einfluf der äußeren Faktoren auf Insekten. Sophia 1907.

Escherich, K., Tote Nonneneier. Nat. Zeitschr. f. Forst- und Landwirtsch., 1911.

Fuchs, Gilbert, Uber die Fortpflanzungsverhältnisse der rindenbrütenden Borkenkäfer, München 1907.

Hennings, Curt, Experimentell-biologische Studien an Borkenkäfern. I-IV. Nat. Zeitschr. f. Land- und Forstwirtsch, 1907-1908.

- Beiträge zur Kenntnis der die Insektenentwicklung beeinflussenden Faktoren. Biol. Zentr.-Bl., XXVII. Bd., 1907.

Linden, M. von, Die Assimilationstätigkeit bei Schmetterlingspuppen. Leipzig 1912.

Knoche, E., Beiträge zur Generationsfrage der Borkenkäfer. Forstwissensch. Zentr.-Bl. 1904.

- Fortpflanzungsverhältnisse bei Borkenkäfern. Ebenda 1907.

- Über Borkenkäferbiologie und Borkenkäfervertilgung. Ebenda 1908.

- Über Methodik der Borkenkäferforschung. Nat. Zeitschr. f. Forst- und Landwirtsch. 1907.

NüBlin, Otto, Leitfaden der Forstinsektenkunde. II. Aufl., 1913.

Ratzeburg, J. T. C., Die Waldverderber und ihre Feinde. 7. Aufl., Berlin 1876.

Standfu B, M., Handbuch der paläarktischen Groß-Schmetterlinge. Jena 1896.

Uhlig, Zur Borkenkäferfrage. Tharandter Jahrb., 25. Bd., 1875. 
Kapitel V.

\section{Die Insekten als natürliche und wirtschaftliche Macht im allgemeinen und besonders in forstlicher Beziehung.}

\section{Die Bedeutung der Insekten im allgemeinen Naturhaushalt.}

Trotz der durchschnittlich geringen Größe der Einzeltiere spielen die Insekten im allgemeinen Haushalt der Natur doch eine ganz hervorragende Rolle, was hauptsächlich durch die ungeheuere Anzahl der Arten und Individuen bedingt ist.

Utber die geringe $\mathrm{D}$ u r chs chn it $\mathrm{sg}$ r ö Be der heimischen Insekten belehrt uns am besten ein Blick in eine Sammlung. Ein Käfer oder eine Heuschrecke, welche an Körpergröße dem kleinsten Säugetiere unserer Fauna, der Zwergspitzmaus, oder dem kleinsten einheimischen Vogel, dem Goldhähnchen, Regulus cristatus Koch, gleichkommen, gehören schon zu den größten Erscheinungen, und die scheinbar ziemlich bedeutenden Dimensionen der Großschmetterlinge kommen fast ausschließlich auf Rechnung der nur sehr wenig feste Körpermasse enthaltenden Flügel. Hirschkäfer, Lucanus cervus L., Wanderheuschrecke, Pachytylus migratorius L., einige Wasserjungfern aus den Gattungen Anax und Aeschna, das große Nachtpfauenauge, Saturnia Pyri Schiff., sowie die Hornisse, Vespa Crabro L., dürften die größten Insektenformen unserer Fauna darstellen. Dagegen sind ganze Gruppen sehr verbreiteter und wichtiger Insekten von durchschnittlich zwerghafter Gestalt. Wir erwähnen hier beispielsweise nur die Borkenkäfer, die Gallwespen und unter den Schlupfwespen im weiteren Sinne die Chalcididae und Proctotrypidae.

Um so bedeutender ist die Anzah 1 der Gat $\mathrm{tung}$ en und Arten. Wir brauchen ja nur die dickleibigen und vielbändigen Kataloge, die von den verschiedenen Insektenordnungen erschienen sind und die nur die Namen der beschriebenen Formen enthalten, anzusehen, um einen Begriff von der ungeheuren Zahl der Insekten zu bekommen. P a ck a r d schätzt die Zahl der bis jetzt beschriebenen Arten auf 250000 , wovon der größte Teil auf die Käfer und Hymenopteren entfällt. Die Zahl der tatsächlich existierenden Insektenarten beträgt aber sicherlich ein mehrfaches davon. Wenn wir bedenken, wie wenig die Tropen noch durchforscht sind, speziell auf die kleineren Formen - gelang es mir doch z. B. in Ceylon innerhalb des soviel durchsuchten botanischen Gartens von Peradenia und seiner unmittelbaren Umgebung in der kurzen Zeit von 8 Wochen annähernd 40 für die Wissenschaft neuen Formen zu entdecken - so dürfen wir ruhig behaupten, daß heute erst ein kleiner Bruchteil der dort lebenden Kerfe bekannt ist.

$\mathrm{Da} B$ auch die $\mathrm{M}$ enge der Individue n häufig eine sehr bedeutende ist, lehrt schon der Umstand, daß die Insekten trotz ihrer geringen Durchschnittsgröße einen sehr wesentlichen Zug des sommerlichen Naturbildes auch in unseren Gegenden abgeben. In einzelnen Fällen steigert sich bei der Einzelart die Individuenzahl aber in das Unglaubliche. Wir erinnern an die schon bei uns mitunter so lästig 
werdenden Mückenschwärme, die in tropischen Ländern und auf nordischen Hochmooren sich zu sonnenverfinsternden Wolken vermehren können. Die riesigen Wanderheuschreckenzüge und die von ihnen verursachten Verheerungen sind bekannt; die Züge der Libellula quadrimaculata $L$. können bei uns mitunter ununterbrochen 1-2 Tage dauern, und wandernde Raupenmassen haben schon ganze Eisenbahnzüge zum Stehen gebracht. $\mathrm{Zu}$ welch ungeheuren Mengen verschiedene forstliche Schmetterlinge sich vermehren können, hat der Forstmann leider nur zu oft zu erfahren. Wenn der Kot ununterbrochen von den Bäumen herabrieselt, den Boden zentimeterhoch bedeckend, oder wenn der ganze Wald so dicht mit Raupenschleiern durchwebt ist, daß man kaum durchdringen kann oder wen11, wie das im Jahre 1856 der Fall war, die kurländische Küste von Libau bis Windau auf eine Strecke von $70 \mathrm{~km} 15 \mathrm{~cm}$ dick und $2 \mathrm{~m}$ breit von angespülten Leichen der durch einen Sturm ins Meer hinausgetriebenen Nonnenfaltern bedeckt war, so ist die Zahl der Individuen sicherlich nach vielen Milliarden zu berechnen.

Die $\mathrm{räumliche} \mathrm{Verbreitung} \mathrm{dieses} \mathrm{unzählbaren} \mathrm{Insektenheeres} \mathrm{ist}$ fast ausschließlich auf das feste Land und die Binnengewässer beschränkt. Im Meere wird es durch das dort nicht minder zahlreiche Heer der krebsartigen Tiere ersetzt. Allerdings gibt es auch einige im Salzwasser lebende Insekten - besonders ist Halobates, eine nach Art unserer einheimischen Hydrometra auf der Meeresoberfläche herumlaufende Wasserwanze, zu erwähnen - indessen sind sie höchstens nach Dutzenden zu zählen und verschwinden gegen die Hauptmenge der übrigen Insekten völlig.

Ja sogar so weit scheint sich der Antagonismus zwischen Meer und Insektenorganismus zu erstrecken, daß die Insekten im allgemeinen die Kontinente den Inseln vorziehen, und daß bei den auf kleineren, heftigen Winden ausgesetzten Iuseln lebenden Insektenformen häufig die Flugfähigkeit, also eines der typischsten Merkmale der Insektenorganisation, verloren geht, wie die Käferfauna von Madeira und die gesamte Insektenfauna der Kerguelen beweist.

Auch die Süßwasserinsekten können nur als ein zwar großer, aber doch immerhin nicht völlig ty pischer Zweig der Kerfwelt angesehen werden, da viele von ihnen nur die Entwicklungszeit im Wasser zubringen, und diejenigen, welche das Süßwasser als dauerndes Lebenselement wählen, dasselbe doch auch stets wenigstens zeitweilig verlassen können und ihre Atmungsorgane immer zur direkten Atmung atmosphärischer Luft eingerichtet sind.

Dagegen hat sich, soweit der Mensch auch auf der festen Erdoberfläche vorgedrungen ist, überall Insektenleben vorgefunden, wenngleich nicht zu verkennen ist, daß vom Aquator nach den Polen und von dem Meeresspiegel nach den Berggipfeln zu eine Abnahme der Arten- und in vielen Fällen auch der Individuenzahl, welche mit dem sich vermindernden Pflanzenwuchs Hand in Hand geht, zu verzeichnen ist.

Es sind verschiedene Richtungen, in denen die Tätigkeit der Insekten besonders wichtig ist:

1. Sie beschleunigen den Zerfall abgestorbener Organismen;

2. sie vernichten zahlreiche lebende Organismen und tragen so zur Erhaltung des organischen Gleichgewichts bei;

3. sie bilden die notwendige Nahrungsquelle für viele andere Tiere;

4. „ vermitteln die Kreuzbefruchtung vieler Pflanzen;

5. " tragen zur Verbreitung der Pflanzenwelt bei, und

6. „ nehmen an der Bodenbearbeitung teil.

Die Insekten als Zerstörer abgestorbener Organismen. - Eine große Anzahl von Insekten leben von toten Tieren und Pflanzen und bewirken dadurch, daß deren Substanzen eher wieder in den Kreislauf des organischen Lebens zurückgeführt werden, als es durch den einfachen Verwesungsprozeß ge- 
schehen würde. Es ist ein häufig wiederholter Ausspruch L in né s, daß Fliegen einen Pferdekadaver ebenso schnell aufzufressen vermögen, als ein Löwe, ein Paradoxon, welches allerdings durch die Schnelligkeit, mit der die Schmeißfliegen sich vermehren und mit der ihre Larven wachsen, eine gewisse Berechtigung erhält. Besonders aber die gegen Witterungseinflüsse widerstandsfähigeren abgestorbenen Pflanzenteile, Stengel, Stämme, Wurzeln usw. werden durch die Tätigkeit der Insekten rascher in Humus verwandelt, als es sonst der Fall wäre. Ein Baumstumpf, in den eine Ameisenkolonie sich einnistet, zerfällt z. B. viel schneller als ein anderer, insektenfreier. Am auffallendsten tritt einem diese Tätigkeit der Insekten in den Tropen entgegen, wo die gestürzten Baumriesen in kurzer Zeit von den Termiten aufgearbeitet werden.

Die Insekten als Erhalter des organischen Gleichgewichts. - Nicht minder groß ist die Anzahl solcher Insekten, die sich von lebenden Organismen nähren, teils, indem sie dieselben nach Art der Raubtiere einfach verzehren, teils, indem sie parasitisch auf oder in ihnen leben. Dadurch wird die übermäßige Vermehrung der als Nahrung oder als Wirte dienenden Organismen wesentlich beschränkt. Wie wichtig dieser Faktor für die Erhaltung des organischen Gleichgewichtes sein kann, zeigen uns solche Fälle, in denen an und für sich wenig schädliche Insekten, in ein fremdes Land verschleppt, dort zu einer furchtbaren Plage wurden, indem sie sich eben in der neuen Heimat, in der die Parasiten und Raubinsekten fehlten, uneingeschränkt vermehren konnten. Amerika liefert uns eine ganze Reihe drastischer Beispiele hierfür, worüber unten noch näheres berichtet wird.

Die Insekten als $\mathrm{N}$ ahrungsquelle für andere Tiere. - DaB viele Tiere ausschließlich von Insekten leben, und andere, z. B. viele körnerfressende Vögel, wenigstens zu Zeiten einen großen Teil ihres Lebensunterhaltes dem Insektenreiche entnehmen, ist allgemein bekannt. Namentlich liefern die Gliederfüßler und Wirbeltiere ein großes Kontingent an Insektenfressern. Die hauptsächlichsten Formen der einheimischen Insektenfresser sind im nächsten Kapitel übersichtlich zusammengestellt, ebenso wie die parasitisch von Insekten lebenden Formen.

Die Insekten als Befruchter. - Die Anschauungen über die Art der Bestäubung der Pflanzen hat im Laufe der Zeit mehrfache Wandlungen durchgemacht, wie $\mathrm{Kirchner}$ in seinem schönen Werke „Blumen und Insekten“ so übersichtlich ausführt. Ursprünglich war man der Meinung, daß in Zwitterblüten regelmäßig die Narbe durch solchen Pollen bestäubt werde, der aus Staubblättern derselben Blüte herstammte, eine Bestäubungsform, die später als Selbstbest ä u bung oder A u tog a mi e bezeichnet worden ist. Als nun im Jahre 1793 Christian Conrad Sprengel mit seinem berühmten Buche: „D as entdeckte Geheimnis der Naturim Bau und in der Befruchtung der Blumen" hervortrat, verfiel man bald in das gegenteilige Extrem. Sprengel selbst sprach den Satz aus "die Natur scheine es nicht haben zu wollen, daß irgendeine Blume durch ihren eigenen Staub befruchtet werden solle." Je eingehender man aber die Verhältnisse studierte, und je mehr Beobachtungen und Erfahrungen man sammelte, desto mehr kam man zu der Einsicht, daß die Wahrheit in der Mitte liegt, d. h. daß die verschiedenen Arten der Blütenpflanzen in der Ausbildung und Verwendung jener beiden Bestäubungsformen, der Autogamie und der Allogamie (Fremdbestäubung), höchst mannigfaltig sich verhalten. Sie stellen eine fortlaufende Reihe dar, an deren Anfang die eine und an deren Ende die andere Bestäubungsform herrscht, während beide im mittleren Teil der Reihe einander mehr oder weniger das Gleichgewicht halten. Allerdings stellt die a u s $\mathrm{sch} 1 \mathrm{i}$ e $\mathrm{B} 1 \mathrm{i}$ ch e und a $\mathrm{d}$ a u e r nde Autogamie einen seltenen Weg zur Hervorbringung von Samen dar, der von den Blütenpflanzen nur in äußerster Notwehr gegen ungünstige Lebensbedingungen betreten wird.

Die $\mathrm{Kreuzbefruchtung}$ bedeutet einen großen Vorteil fü r die $\mathrm{N}$ a chkommenschaft, insofern, als die aus gekreuzten Blüten entstandenen Nachkommen den aus nichtgekreuzten hervorgegangenen in verschiedenem Grade 
und in mannigfaltigen Beziehungen überlegen sind, nämlich an Größe und an Gewicht, an Fruchtbarkeit und an vermehrter Widerstandsfähigkeit gegen ungünstige Witterung usw. So ist es wohl verständlich, daß die Natur Einrichtungen getroffen hat, die Kreuzbefruchtung in möglichst ausgedehntem Maße zu gewährleisten. Die Mittel, die dazu angewandt werden, sind der mannigfaltigsten und oft ,raffiniertesten" Art. Naturgemäß setzt die Kreuzbefruchtung eine außerhalb der Blüte liegende Instanz voraus, welche den Transport des Blütenstaubes aus den geöffneten Staubbeuteln auf die zu seiner Aufnahme bereite Narbe übernimmt. Bleibt eine solche Hilfe aus, so kann die Blüte vergeblich blühen und der Unfruchtbarkeit anheimfallen. - Als Vermittler der Bestäubung kommen drei Faktoren in Betracht, nämlich der $\mathrm{W}$ ind, das $\mathrm{W}$ as ser und die $\mathrm{T}$ i e $\mathrm{r}$ e.

Bei der Bestäubung durch den W in d (Anemogamie) wird der Blütenstaub den Luftströmungen anvertraut, die ihn zufällig an den Ort seiner Bestimmung übertragen. Solcher Windblütler gibt es eine beträchtliche Anzahl, indem sie in Mitteleuropa etwa $19 \%$ aller Blütenpflanzen ausmachen. Es gehören hierher die Nadelhölzer und diejenigen Mono- und Dikotyledonen, welche wenig auffallende Blüten haben, also beiläufig gesagt, die meisten unserer forstlich wichtigen Holzarten.

Die Bestäubung durch Wasser (Hydrogamie) gehört zu den selteneren Fällen; es gelangt hier der Pollen in das Wasser, welches die Blüten umspült, und wird von dessen Strömung zu den Narben gefördert.

Die häufigste Form der Kreuzbefruchtung ist die Zoogamie, d. h. die Übertragung des Pollens durch Tiere. Und zwar spielen hierbei - wenigstens im Bereich unserer einheimischen Pflanzenwelt - die hauptsächlichste, ja nahezu die ausschließliche Rolle die Insekten. Sind doch annähernd $80 \%$ der europäischen Blütenpflanzen Insektenblütler.

Es ist im allgemeinen nicht schwer, vom Bau der Blüten auf die Art der Bestäubung zu schließen, insofern, als die Windblütler unscheinbare und duftlose Blüten besitzen, während die Insektenblütler durch Augenfälligkeit der Blüten und mehr oder weniger stark ausgeprägte Düfte sich auszeichnen. All die Eigenschaften, die die Blumen den Menschen so lieb machen, stellen nichts anderes dar als Anlockungsmittel für die Insekten, welche den Pollen von einer Blüte zur anderen tragen sollen. „Augenfälligkeit und Duft sind es, welche die Reklame für die Blumen besorgen, welche die vorüberfliegenden Insekten auf das Vorhandensein der Blumen aufmerksam machen, ähnlich wie ein den Gästen winkendes Wirtshausschild." Doch genügen diese beiden Eigenschaften noch nicht, die Insekten zu regelmäßigem und stetem Blumenbesuch, wie er für die Sicherheit der Kreuzbefruchtung notwendig ist, zu veranlassen und zu gewöhnen. Dazu gehört noch, daß die Insekten auch zusagende Nahrung im „Wirtshaus“ finden; erst wenn das der Fall ist, werden sie immer wieder einkehren. Daher finden wir denn auch als weiteres, $\mathrm{ja}$ als das wesentlichste Merkmal der typischen Insektenblütler A bsonderung und Darbietung von Honigoder Nektar. „Der Nektar ist sozusagen der Angelpunkt, um den sich die ganze Blüteneinrichtung dreht, er ist, wie S p r e ng el sich ausdrückte, in den Blumen das, was in der Uhr die Feder ist." Meist findet seine Ausscheidung am Grunde der Blüte statt; jedenfalls stets an solchen Stellen, daß das Insekt, das zu ihm gelangen will, die Staubbeutel berühren muß und sich so mit Pollenkörnern belädt.

Es sind vornehmlich Insekten mit leckenden und saugenden Mundgliedmaßen, welche die Kreuzbefruchtung besorgen. Obenan stehen die Hymenopteren, die etwa die Hälfte aller als Blumenbesucher beobachteten Insekten liefern; und unter ihnen spielen die $\mathrm{B}$ i en en und $\mathrm{Hummeln}$ weit a us die größte Rolle, einmal wegen ihrer großen Individuenzahl und sodann auch deshalb, weil sie für ihre Brut den ganzen Sommer über Pollen und Nektar bedürfen und daher immer wieder die Blumen besuchen müssen. Kein anderes Insekt übertrifft bezügl. Häufigkeit und Eifer des Blumenbesuches unsere Honigbiene. - Eine besondere Berühmtheit unter den Hymenopteren hat auch die Feigengallwespe (Blastophaga grossorum), die in 
inniger Symbiose mit dem Feigenbaum lebt, und von deren Anwesenheit die Bildung fruchtbarer Feigen abhängig ist. - Auf die Hymenopteren folgen an Wichtigkeit für die Befruchtung der Blumen die Schmetterlinge. Bezügl. des Grades der Anpassung an die Blumen nehmen dieselben aber unter allen Insekten die höchste Stufe ein, denn sowohl nach ihrem Körperbau als ganz besonders nach der Ausbildung ihrer Mundteile sind sie durchaus auf die Gewinnung von Blumennektar eingerichtet. Auch die $\mathrm{Z}$ we if 1 ü gler. Dipteren, enthalten eine ganze Anzahl von Blumenbesuchern, von denen hier vor allem die Syrphiden, Empiden, Bombiliiden und Conopiden genannt seien. Die Käf e r treten gegenüber den bisher genannten Ordnungen ganz in den Hintergrund, wenn auch einige Gattungen sich an ausschließliche Blumenernährung gewöhnt haben und gelegentlich auch Bestäubungen vollziehen, wie Clytus, Leptura und andere Bockkäfer, ferner manche Canthariden, Oedemeriden, Mordelliden, Cisteliden usw

Die Insekten a ls Verbreiterder Pflan zen. - Die Rolle, welche die Insekten für die Verbreitung der Pflanzen spielen, ist erst in der letzten Zeit richtig erkannt und gewürdigt worden, und zwar vor allem durch die eingehenden Studien des schwedischen Botanikers Sernander.

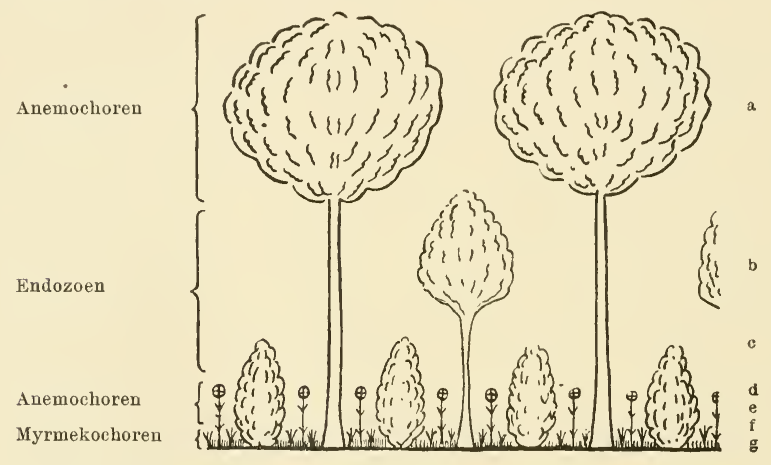

Fig. 172. Schnitt durch einen Wald zur Veranschaulichung der häufigsten Typen der Pflanzenverbreitung. Nach $R$. Sernander.

In erster Linie sind es die Ame is en, welche an der Verbreitung der Pflanzen beteiligt sind. - Daß gewisse Ameisen Samen sammeln und eintragen, ist schon seit alters her bekannt; doch über den Umfang und die große Bedeutung, welche diese Gewohnheit für die Verbreitung der Pflanzen besitzt, sind wir erst von S e rn a nder aufgeklärt worden. Dieser Forscher hat durch zahlreiche Versuche dargetan, daß eine Menge Phanerogamen a us chlie Blich auf die Verbreitung durch Ameisen angewiesen sind. $\mathrm{Zu}$ diesen gehören vor allem die Schattenformen, also die der untersten Vegetationsschichte unserer Wälder angehörigen Pflanzen. Es ist unschwer einzusehen, warum gerade diese einer solchen Verbreitungsart am meisten bedürfen. Kommen doch für sie die anderen Verbreitungsgelegenheiten, die den oberen Vegetationsschichten so ausgiebig zur Verfügung stehen, gar nicht oder nur in ungleich geringerem Maße in Betracht. (Fig. 172.)

Die oberste Schicht, die sog. "Hochwaldschicht" (a), ist in hohem Maße windexponiert; außerdem erreicht der Wind zwischen den Baumstämmen und Strauchgruppen eines fertig gebildeten Waldvereins auch noch in der ,höchsten und mittleren Feldschicht" (d und e) eine größere Kraft. Daher finden sich in diesen Schichten hauptsächlich Anemochoren, d. h. Pflanzen, deren Samen durch den Wind verbreitet werden. In der zwischen diesen beiden 
gelegenen Schichte, der untersten „W a ld- und Gebüs ch schicht“ (b und c) kann der Wind weniger ausrichten, wofür hier eine andere Verbreitungsart in den Vordergrund tritt, nämlich die endozoische. Denn im Buschwerk verleben eine Menge kleiner beerenfressender Vögel einen guten Teil ihres Daseins. - In den beiden untersten Schichten endlich tritt nun einerseits sowohl die Kraft des Windes stark zurück und kommt andererseits auch die endozoische Verbreitung durch Vögel kaum in Betracht, so daß also die hierher gehörigen Pflanzen anderer Verfahren sich bedienen müssen, unter denen die Myrmekochorie, d. h. die Verbreitung durch Ameisen, einen hervorragenden Platz einnimmt.

In Anbetracht der auf dem Boden überall zahlreich herumwimmelnden Ameisen, und in Anbetracht ferner der diesen eigenen Gewohnheit, Nahrungs- und Nestobjekte in ihren Kiefern of weite Strecken nach Hause zu tragen, war es naheliegend genug, daß die Bodenpflanzen, die ja die Hauptverbreitungsfaktoren kaum ausnützen können, sich dieser beweglichen und flüchtigen Transporteure zu bedienen versuchten. Dem stand jedoch im Wege, daß die Verbreitungseinheiten (Samen usw.) der Pflanzen im allgemeinen von Haus aus wenig Anziehungskraft auf die Ameisen ausüben. Es mußten daher die Samen, wenn wirklich deren ausgiebige Verbreitung durch Ameisen bewirkt werden sollte, erst noch mit besonderen Anlockungsmitteln versehen werden. Und solche finden sich denn auch bei einer ganzen Anzahl von Phanerogamen: sie bestehen in Anhängseln, W Wülsten usw. der Samen, welche stark ölhaltig und gewöhnlich noch mit einem feinen Haarfilz besetzt sind. S e r n a n d e r bezeichnet sie als „E1 a i os o me“ und die damit begabten Samen als „m y r me k oc hor".

Genaue und oft wiederholte Beobachtungen führten Sernander zu dem Schluß, daß die Menge der Samen, die in der Natur von den Ameisen transportiert werden, ganz enorm sein muß. Ergab doch die Berechnung als Minimumzahl für die durch eine einzige Formica rufa-Kolonie verbreiteten Samen während einer Vegetationsperiode nicht weniger als 36480 !

Was die Verbreitung der Myrmekochoren in unseren Wäldern betrifft, so sei kurz erwähnt, daß die Eichenmischwälder mit 80 Arten und die Buchenwälder mit etwa 45 Arten die reichste Myrmekochorenflora aufweisen. Besonders die an und für sich nicht gerade zahlreiche Kräuter- und Gräservegetation des reinen Buchenhochwaldes besteht zu einem erstaunlich hohen Prozentsatz aus Myrmekochoren. Viel ärmer ist dagegen die Myrmekochorenflora der Birkenwälder (mit 16 Arten) und ebenso der Fichten- und Kiefernwälder, in denen gar nur 9 bezw. 4 Arten nachgewiesen sind.

Um noch ein weiteres Beispiel für die pflanzenverbreitende Tätigkeit der Insekten zu nennen, sei nur noch auf die Verschleppung der Pilze durch die verschiedenen pilzzüchtenden Arten der Ameisen, Termiten, Borkenkäfer, Gallmücken usw. hingewiesen, über die uns in neuerer Zeit die Arbeiten von $\mathrm{H} \mathrm{ub} \mathrm{e} \mathrm{r,} \mathrm{N} \mathrm{e} \mathrm{ger,}$ Schneider-Orelli u. a. Aufklärung brachten.

Di e Insekten a ls Bodenbe a r be it e r. - Wenn auch die. Bedeutung der Insekten für die Bodenbearbeitung bei weitem nicht an die der Regenwürmer heranreicht, so darf doch die bodenbearbeitende Tätigkeit der Insekten auch nicht unterschätzt werden. Gibt es doch eine große Anzahl von Insekten, welche zeitweise oder dauernd im Boden leben, entweder um da ihre Nahrung zu holen, oder aber um ihre Wohnung dort einzurichten. Ich erinnere nur an die Drahtwürmer, Engerlinge, Cicindelenlarven, ferner die Grillen, Mistkäfer, Sandwespen usw. und vor allem an die Ameisen und Termiten. In welch hervorragender Weise die Termiten den Boden durchøühlen, zeigen die mächtigen bis haushohen Bauten, die zum größten Teil aus Erde, die aus der Tiefe geholt, errichtet werden. Es kann daher recht wohl zutreffend sein, daß, wie ein Naturforscher behauptete, $3 / 4$ der ganzen Insel Ceylon von den Termiten unterminiert ist. Doch auch unsere Ameisen leisten großes bezügl. der Bodenbearbeitung; kann man doch in geeigneten Gegenden auf manchen Wiesen einen Erdhaufen neben dem andern finden, herrührend von Lasius flavus oder anderen Lasius-Arten. 


\section{Nutzen und Schaden der Insekten im allgemeinen.}

Für die allgemeine Würdigung der Beziehungen zwischen Insekten und Gesamtheit der organischen Natur gibt es die Begriffe „nützlich“ und "schädlich" nicht. Ihr erscheint jedes Insekt als ein jedem anderen Geschöpfe gleichberechtigtes, notwendiges Glied der organischen Welt. Erst in dem Augenblicke, in welchem der Mensch den Anspruch erhebt, „Herr der Natur" zu sein und als wirtschaftliche Macht in die Natur eintritt, $\mathrm{sch}$ afft er diese Begriffe.

Als nützlich bezeichnet er nun alles, was seine Existenz zu sichern und seine wirtschaftlichen Maßregeln zu fördern geeignet scheint, als schädlich alles, was seine Existens oder den Erfolg seiner wirtschaftlichen Maßregeln bedroht.

Es darf aber hierbei nicht übersehen werden, daß eine absolute Entscheidung der Frage, ob ein Tier nützlich oder schädlich ist, in vielen Fällen gar nicht beigebracht werden kann. Diese Entscheidung wird verschieden ausfallen je nach den speziellen Interessen des jeweiligen Beurteilers, und sogar ein und dieselbe Person wird von verschiedenen Gesichtspunkten aus ein und dasselbe Tier bald als nützlich, bald als schädlich zu bezeichnen haben. Hase und Fuchs sind deutliche Beispiele hierfür. Dem die Jagdfreuden schätzenden und das Wildpret verwertenden Jäger erscheint derselbe Hase als nützlich, welchen der Gärtner, dem er die Baumschule ruiniert und den Kohl abgefressen hat, als sehr schädlich bezeichnet, und derselbe Forstmann, der als Waidmann und Pfleger der Niederjagd den Fuchs als überaus schädlich verfolgt, beginnt an Schonung Reinekes jedesmal dann zu denken, wenn ein Mäusefraß seine Kulturen bedroht und er seinen früheren Feind nun als nützlichen Bundesgenossen im Kampfe gegen die verderblichen Nager begrüßt. Auf diese Weise erklärt sich auch die Schwierigkeit der Aufstellung eines Verzeichnisses der nützlichen Vögel.

Wenden wir nun die obigen Begriffe auf die Insekten an, so können wir im allgemeinen als nützliche Insekten solche bezeichnen, welche entweder für den Menschen selbst unmittelbar verwertbar sind, bezw. verwertbare Produkte liefern, oder aber durch ihre Tätigkeit die Erträge der Kulturpflanzen fördern, sei es dadurch, daß sie die Bestäubung besorgen, oder dadurch, daß sie der Vermehrung von Schädlingen entgegenarbeiten. In den ersten Fällen sprechen wir von „direkt nützlichen“, in den letzteren von „indirekt nützlichen Insekten“.

Als Beispiele für direkt nützliche Insekten seien erwähnt: die verschiedenen Seidenspinnerarten, die dem Menschen die Seide liefern, die Cochenilllaus, aus welcher der Karminfarbstoff gewonnen wird, gewisse Gallwespen, in deren Gallen große Mengen von Gerbstoff enthalten sind, und vor allem die Honigbiene, der wir Honig und Wachs verdanken. Welche großen Erträge der Mensch aus dem Fleiß dieser Tiere zieht, zeigt die Statistik, die den jährlichen Erlös aus Honig und Wachs für Deutschland auf 20-30 Millionen Mark, für die Vereinigten Staaten von Nord-Amerika auf 80-90 Millionen Mark berechnet. - Die Honigbiene erweist sich aber zugleich auch als indirekt $\mathrm{nützlich}$, indem sie durch Bestäubung der Obstblüten wesentlichen Einfluß auf den Ausfall der Obsternte ausübt. Ja, dieser indirekte Nutzen wird von einsichtigen Forschern weit höher veranschlagt als der direkte aus der Honig- und Wachserzeugung resultierende Nutzen. Schätzt doch C. F. Phillips den Wert, den die Biene durch ihre Bestäubungstätigkeit schafft, 5 mal so groß als den jährlichen Honig- und Wachsertrag, was für die Vereinigten Staaten einer Summe von über 400 Millionen Mark pro Jahr entsprechen würde. Auch die meisten der übrigen Blumenbesucher sind, sofern sie sich an der Bestäubung von Nutzgewächsen beteiligen, zu den indirekt nützlichen Insekten zu 
stellen. Weitaus das größte Kontingent der indirekt nützlichen Insekten lieferı aber die $\mathrm{R}$ a ubinsekten und $\mathrm{P}$ arasite $\mathrm{n}$, welche durch ihre fortwährende Vertilgung der zahlreichen, unsere Nutzgewächse bedrohenden Schädlinge dem Menschen unschätzbare Dienste erweisen. Welche enormen Werte durch sie dem Menschen erhalten werden können, lehrt das Beispiel des Coccinelliden Novius cardinalis, der es in kurzer Zeit fertig brachte, die Wollschildlaus Icerya Purchasi, welche die ganzen Orangen- und Zitronen-Kulturen Kaliforniens zu vernichten drohte, unschädlich zu machen, und so ungezählte Millionen Dollar rettete.

Als schädliche Insekten haben solche zu gelten, welche entweder das Leben und die Existenz des Menschen selbst bedrohen, oder die Objekte, lebende (Haustiere, Nutzpflanzen) wie tote, welche der Mensch wirtschaftlich nützt, gefährden oder beschädigen. Dabei können wir wiederum wie oben direkt und indirekt schädliche Insekten unterscheiden.

In früher ungeahnter Weise haben sich im letzten Dezennium die Insekten als direkte Schädiger des Menschen erwiesen, indem eine ganze Reihe von Arten (meist blutsaugende Dipteren) als Überträger von Krankheits k e imen erkannt wurden. So wird die Malaria von verschiedenen AnophelesArten, das gelbe Fieber von einer anderen Stechmücke, Stegomyia fasciata auf den Menschen übertragen. Auch die Schlafkrankheit, die große Strecken Landes in Afrika der Kultur unzugänglich macht, wird von einem Insekt, der Tsetsefliege Glossina palpalis, dem Menschen eingeimpft. Selbst unsere gemeine Stubenfliege ist durchaus nicht so harmlos, als gewöhnlich angenommen wird, nachdem durch die neueren Forschungen festgestellt ist, daß verschiedene bazilläre Krankheiten, wie Typhus, Tuberkulose usw., durch sie verschleppt werden können. In einem ror kurzem erschienenen Buch von A. Göldi findet sich eine übersichtliche Zusammenstellung aller hierhergehörigen, bis jetzt bekannten Fälle. Durch die Erkenntnis des Zusammenhanges zwischen gewissen Krankheiten und Insekten ist ein ganz neuer $Z$ weig der praktischen Entomologie entstanden, der heute bereits zahlreiche Forscher beschäftigt und der noch viel interessante Entdeckungen und Uberraschungen verspricht. - Neben diesen krankheitsübertragenden Insekten gibt es viele andere, welche den $M$ enschen als $P$ arasiten heimsuchen und ihm vielerlei Beschwerden verursachen, wie die Flöhe, Wanzen, Läuse usw. Wenn diese auch im allgemeinen weit harmloser sind, als die eben besprochenen, so gibt es unter ihnen doch auch einige recht bösartige Formen, wie z. B. die im tropischen Amerika und Afrika heimischen Sandflöhe, die schwere, mit Substanzverlusten verbundene Entzündungen verursachen können.

Weit zahlreicher und mannigfaltiger sind die indirekt schädlichen Insekten. Da haben wir zunächst jene Insekten, welche die $\mathrm{H}$ a u $\mathrm{s}-\mathrm{u}$ n d J a g d tiere belästigen und ihre Gesundheit mitunter schwer ge$\mathrm{f} a ̈ \mathrm{hrden}$. Wir nennen hier nur die Dasselfliegen oder Oestriden, die unter der Haut oder in der Nasenhöhle oder im Magen von verschiedenen Wiederkäuern (Rind, Hirsch, Reh usw.) und Pferden leben und schwere Störungen, oft mit tödlichem Ausgang, verursachen; ferner die Bremsen, die eine arge Plage für die Pferde, Rinder usw. darstellen und in manchen Ländern wahrscheinlich auch Krankheitskeime übertragen (die ",Surra“ der Pferde in Asien); weiter die in Ungarn vorkommende Kolumbatscher Mücke, Simulia columbatschensis, die ganze Viehherden zu Schaden bringen kann, und endlich verschiedene Tsetsefliegen, welche die ,Tsetseseuche“ oder „Nagana" übertragen, eine Krankheit, welche der Viehzucht in Afrika große Verluste bringt. - Sodann sei an die Haus - und M a ga zin insek te n erinnert, welche die Küchenvorräte, Kleider, Möbel in unseren Wohnungen, die Getreide- und Mehlvorräte in den Magazinen, die Bücher der Bibliotheken, die Insektensammlungen und Herbarien in den Museen usw. usw. beschädigen oder auch völlig vernichten und wertlos machen können, wobei nur an die Anobien, die Kleidermotten, die Ameisen und Termiten zu erinnern ist. - Und endlich gehört den indirekt 
schädlichen Insekten das $R$ i e senheer der Pflanzenschädlinge an, die an Zahl alle übrigen Schädlinge überragen. Wir brauchen nur den von $\mathrm{R}$ e h bearbeiteten Insektenband des S or a u e r schen Handbuches für Pflanzenkrankheiten einzusehen, um einen Begriff von dem Umfang dieses Zweiges der angewandten Entomologie zu erhalten. Es gibt kaum eine Kultur oder Nutzpflanze, die nicht von einer oder mehreren Insektenarten heimgesucht wäre; ja den meisten steht ein ganzes Heer von feindlichen Insekten gegenüber und oft genug muß lediglich wegen Úberhandnahme der Schadinsekten von der Kultivierung dieser oder jener Pflanzenart Abstand genommen werden. Im allgemeinen macht man sich keinen richtigen Begriff von der Höhe des Schadens, der der Landwirtschaft durch die Insekten zugefügt wird, es seien deshalb einige Zahlen angeführt. Den jährlichen Schaden des Maikäfers schätzt man in Frankreich auf 250 Millionen Francs, in Hauptflugjahren sogar auf eine Milliarde! Der Heu- und Sauerwurm soll 1897 an der Mosel und Saar für 40-50 Millionen Verlust gebracht haben; im Jahre 1910 in der Pfalz allein 20 Millionen. Der Baumwollkapselkäfer (ein Rüsselkäfer, Anthonomus grandis) verursacht in Texas jährlich ca, 100 Millionen Mark Ausfall; der Schaden, der die unter dem Namen Hessenfliege bekannte Gallmücke dem Getreidebau der Vereinigten Staaten zufügt, wird auf ca. 80 Millionen Mark pro Jahr geschätzt; die Tschintschwanze soll den Erlös des Weizen- und Maisbaues der Vereinigten Staaten um 140 Millionen Mark jährlich schmälern; der auch bei uns schädliche Apfelwickler verursacht in Amerika jährlich 40-50 Millionen Mark Schaden usw. usw. Der Gesamtverlust, den die Land- und Forstwirtschaft in den Vereinigten Staaten durch die schädlichen Insekten erleidet, wird auf nicht weniger a $1 \mathrm{~s} 3 \mathrm{Mi} 11 \mathrm{i}$ a rde n M a rk jährlich veranschlagt! Diese enormen Zahlen reden eine deutliche Sprache und zeigen uns aufs drastischste, wie tief die Insekten ins menschliche Kulturleben eingreifen; sie lehren uns zugleich, welche wichtige Rolle der angewandten Entomologie zufällt und welche großen Aufgaben diese Wissenschaft noch zu erfüllen hat.

\section{Nutzen und Schaden der Insekten für die Forstwirtschaft. Die Forstinsekten.}

Als Forstinsekten werden alle diejenigen Insekten bezeichnet, welchefür den Forstmann eine praktischeBedeutung haben, sei es, daB sie ihm in seiner Wirtschaft nützen oder aber schaden.

\section{Die nützlichen Forstinsekten.}

Direkt nützliche Forstinsekten kommen in unserem rationell bewirtschafteten Walde nur in äußerst spärlichem Maße vor, und wir können für Mitteleuropa nur zwei Arten nennen, die in diese Kategorie zu stellen sind: nämlich die spanische Fliege (Lytta vesicatoria), die ihres Kantaridingehaltes wegen in der Medizin Verwendung findet und daher (in getrocknetem Zustand) einen Handelsartikel bildet, und sodann die Knopperngallwespe (Cynips calycis), deren gerbstoffhaltige Gallen eine nicht unbedeutende Nebennutzung der Eichenwälder in Ungarn bilden.

Früher konnte man auch noch die wilden Bienen dazuzählen, deren Zucht noch Ende des 18. Jahrhunderts eine sehr bedeutende Einnahmequelle in Staatsund Privatforsten, speziell in Westpreußen, bildete. Es wurden Beuten, d. h. Bienenstöcke, dadurch hergestellt, daß in die stärksten Kiefernstämme Löcher von 4 bis 5 Fuß Länge, $1-1 \frac{1}{2}$ Fuß Tiefe und nur 8 Zoll breiter Öffnung, oft mehrere übereinander, eingehauen und bis auf ein Flugloch durch eine breite, platte, mit Weidenruten vorgebundene Holzklobe wieder verschlossen wurden. Diese, von einer besonderen Innung der Waldbewohner, den „Beutnern“, hergestellten Stöcke wurden ihnen gegen Zins oder Naturalhoniglieferung überlassen, und es brachte noch in 
Jahre 1773 im Schlochauer Beritt die Beutenpacht fast ebensoviel ein, nämliclı 507 Taler, wie die Holznutzung mit 523 Taler 25 Sgr. Im Jahre 1785 waren in eben diesem Beritt noch 821 beflogene und 3060 unbeflogene Beutenstämme vorhanden, und es dürften bei der preußischen Besitznahme im Jahre 1772 leicht 20000 Beuten i1 den westpreußischen königlichen Forsten vorhanden gewesen sein ( $v$ o n P a n n ew it z, Das Forstwesen Westpreußens 1829).

Eine um so größere Bedeutung besitzen die indirekt nützlichen Forstinsekten, die einer ungezügelten Vermehrung der Schädlinge entgegenarbeiten und dadurch als die treuesten Bundesgenossen des Forstmanns sich erweisen. Zweifellos sind sie es in erster Linie, welche dafür sorgen, daß die schädlichen Insekten in erträglichen Grenzen gehalten werden. Wenn man diesen nützlichen Tieren auch schon seit langem aufmerksame Beachtung schenkt, so beginnt man doch erst in der neuesten Zeit ihre hohe Bedeutung und Wichtigkeit voll zu würdigen.

Die Zahl der indirekt nützlichen Insekten ist eine sehr große und dürfte der Zahl der Schädlinge kaum nachstehen, ja wahrscheinlich noch übertreffen. Sie lassen sich in zwei Kategorien zusammenfassen: die Raubinsekten und die Parasiten. Die ersteren töten ihr Opfer sofort beim Angriff, indem sie es entweder stückweise verzehren oder aussaugen; die letzteren machen ihre ganze Entwicklung auf Kosten ihres Opfers durch, d. h. sie nähren sich als Larven von den Säften des lebenden Tieres, welches erst allmählich zugrunde geht, gewöhnlich dann, wenn der Parasit zur Verpuppung reif ist und keiner Nahrung mehr bedarf. In beiden Fällen bedeutet das Endresultat dasselbe, nämlich den Tod des angegriffenen Insektes. In welchem Grade die Tätigkeit der Raubinsekten und Parasiten für die Erhaltung des organischen Gleichgewichtes in Betracht kommt, wird im nächsten Kapitel noch im einzelnen besprochen werden. Hier sollen nur einige allgemein orientierende Angaben gemacht werden.

Die Raubinsekten befinden sich gegenüber den Parasiten weit in der Minderheit; sie rekrutieren sich größtenteils aus der Ordnung der Käfer, von denen die Laufkäfer (Calosoma, Carabus), die Aaskäfer (Silphiden), ferner Clerus formicarius, und die Coccinelliden die wichtigsten und bekanntesten sind, wenngleich auch die zahlreichen anderen Raubkäfer aus den Familien der Staphyliniden, Nitiduliden, Cucujiden, Colydiden usw. ebenfalls recht beachtenswerte Dienste leisten. Aus den übrigen Insektenordnungen seien als die wichtigsten Räuber genannt die A meisen, die enorme Mengen Insekten aller Art in ihre Bauten einschleppen, ferner die verschiedenen Wespen, die Raubfliegen, die Libellen, die nach Falkenart die Insekten im Fluge fangen, verschiedene Wanzen, welche ihre Opfer (meist Raupen) anstechen und aussaugen, ferner die Larve des Ameisenlöwen, die alles verzehrt, was in ihre Mördergrube fällt, sodann die überaus bewegliche Larve der Kamelhalsfliege, welche in den feinsten Rindenritzen nach den Eiern der Nonne und kleinen Insekten sucht, die Larven der Florfliegen, welche es speziell auf die Blattläuse abgesehen haben, und endlich die Ohrwürmer, Maulwurfsgrillen u. a. m.

Unter den Parasiten spielen die Hauptrolle die Raupenfliegen und die Schlupfwespen im weitesten Sinne. Die Zahl der letzteren ist Legion, 
und wir sind heute noch unendlich weit von einer einigermaßen befriedigenden Kenntnis dieser so überaus wichtigen Insektengruppe entfernt. Wenn Sharp die Zahl der tatsächlich existierenden Hymenopteren auf 250000 Arten veranschlagt, trotzdem bis heute erst ca. 30000 beschrieben sind, so basiert er diese Schätzung in erster Linie auf die zahlreichen noch unbeschriebenen kleinen und kleinsten Schlupfwespen. Gegenüber den Raupenfliegen und den Schlupfwespen spielen die wenigen Parasiten aus anderen Insektenordnungen nur eine sehr untergeordnete Rolle. Wir werden, wie gesagt, unten noch ausführlich auf dieses Thema zu sprechen kommen.

\section{Die schädlichen Forstinsektcn.}

Wie bei den nützlichen, so treten auch bei den schädlichen Forstinsekten die direkt den Menschen angehenden Arten gänzlich in den Hintergrund, und können wir als hierher gehörig nur gewisse Raupen (Prozessionsspinner, Goldafter und Verwandte) nennen, deren Haare, auf weiche Hautstellen, vor allem Schleimhäute des Menschen gebracht, unangenehme und nicht selten gefährliche Entzündungen hervorrufen. Welch empfindliche Störungen auch des Allgemeinbefindens daraus entstehen können, darüber haben manche amerikanische Entomologen, die sich mit dem dort als schwerer Schädling auftretenden Goldafter eingehend beschäftigen mußten, recht traurige Erfahrungen gemacht.

Die Hauptrolle unter den schädlichen Forstinsekten spielen die indirekt schädlichen Arten, welche durch Zerstörung der Forstprodukte schaden. Sie sind es, die dem Forstmann auf Schritt und Tritt begegnen und die fortwährend seinen Bestrebungen entgegenarbeiten und seine Pläne durchkreuzen, und sie sind es auch, welche im Mittelpunkt der Forstinsektenkunde stehen. Ist es doch die Hauptaufgabe der forstentomologischen Wissenschaft, die indirekt schädlichen Forstinsekten zu erforschen, und Mittel und Wege ausfindig zu machen, wie ihrem schädlichen Treiben am besten entgegengetreten werden kann.

Das große Heer der hierher gehörigen Insekten setzt sich aus Vertretern aller Insektenordnungen zusammen; dementsprechend läßt sich schon von vornherein mit einer großen Mannigfaltigkeit bezüglich ihrer Angriffe und der Art und der Höhe ihres Schadens usw. für die Forstwirtschaft erwarten.

Wir gruppieren je nach dem Gesichtspunkt, von dem aus wir die Schädlichkeit betrachten, die indirekt schädlichen Insekten in verschiedene Kategorien, auf die wir gleich jetzt mit einigen Worten eingehen wollen, um wenigstens eine gewisse Ordnung in die bunte Gesellschaft zu bringen.

\section{Physiologisch und technisch schädliche Insekten.}

Wir bezeichnen Insekten als physiologisch schädlich, wenn sıe durch ihre Angriffe die Gesundheit der Pflanzen gefährden oder wenigstens die Lebenskraft der Pflanzen herabsetzen, und als technisch schädlich, wenn durch ihre Zerstörungen die technische 
Verwertbarkeit der Forstprodukte und damit auch ihr Marktwert vermindert wird.

Als typische Beispiele von physiologischen Schädlingen erwähnen wir den Engerling, welcher die Wurzeln der Pflanzen vernichtet, ferner den großen braunen Rüsselkäfer, die verschiedenen Pissodesarten und Borkenkäfer, welche die saftleitenden Rindenschichten mehr oder weniger beschädigen, und dadurch den Saftstrom unterbrechen, ferner die Raupen der meisten Schmetterlinge und Afterraupen der Blattwespen, welche die Pflanze ihrer Assimilationsorgane berauben und dadurch die Bäume in ihrer Lebenskraft schwächen und bei stärkerer Ausdehnung des Fraßes auch zum Absterben bringen können.

Als Beispiele für rein technische Schädlinge sind vor allem solche Insekten anzuführen, welche bereits totes, gefälltes Holz angehen, wie z. B. der Werftkäfer Lymexylon navale L., welcher die für Schiffsbau bestimmten Eichenhölzer noch auf der Werft zu schädigen imstande ist, viele der in abgestorbenen Hölzern lebenden Bockkäfer, Hylotrupes bajulus L., Callidium violaceum L. und variabile L., welche Balken in den Häusern, Hausgeräte und Holzsammlungen oder Vorräte beschädigen, ebenso viele Arten der Anobiiden aus den Gattungen Anobium, Ptilinus, Lyctus. Auch die Holzwespen, Sirex, und die Nutzholzborkenkäfer können rein technisch schädlich sein; sie können aber auch physiologisch schädlich werden, wenn sie lebende, kränkelnde Bäume angehen und deren Tod beschleunigen.

Gleichzeitig technisch und physiologisch schaden alle jene Insekten, welche in den Holzkörper lebender Pflanzen eindringen, wie z. B. Cerambyx cerdo $L$, dessen Larve ganz gesunde Eichen mit daumenstarken Fraßgängen durchsetzt, Tetropium luridum L., dessen Gänge in Fichten- und Lärchenholz gefunden werden, Saperda carcharias L. in Pappeln und Aspen; ferner die Cossus-Arten, namentlich Cossus ligniperda Fabr., dessen Raupe in verschiedenen Laubhölzern starke Gänge frißt, einige Sesien, namentlich Sesia apiformis Cl. in Aspen und Pappeln und viele andere. Sodann auch solche insekten, welche neben der von ihnen verursachten Beeinträchtigung des Baumlebens zugleich Verkrüppelungen der nutzbaren Teile hervorrufen. Beispiele hierzu sind die Kieferntriebwickler, welche junge Kiefern nicht bloß physiologisch schädigen, sondern auch durch die bekannten posthornartigen Verkrüppelungen entwerten. Die Weidenrutengallmücke, Cecidomyia salicis Schrk., stört nicht bloß das Wachstum der einjährigen Ruten von Salix purpurea, sondern vernichtet durch die von ihr verursachte Gallbildung auch die Verwendbarkeit der Ruten zu Korbarbeiten vollständig.

\section{Primär und sekundär schädliche Insekten.}

Wenn wir von primären und sekundären Schädigungen reden, so legen wir dieser Einteilung den jeweiligen Gesundheitszustand der Pflanzen zugrunde, indem wir als primär solche schädlichen Insekten bezeichnen, welche völlig gesunde Pflanzen angehen, und als sekundär solche, welche für gewöhnlich nur kränkelndes Pflanzenmaterial mit schwachem oder stockendem Saftstrom befallen. Eine scharfe Grenze lässt sich aber auch hier nicht ziehen, indem zwischen den ausgesprochen primären und den ausgesprochen sekundären Insekten eine ganze Reihe von $Z$ wischenstufen liegen, von denen man mitunter im $Z_{\text {weifel sein }}$ kann, ob sie in die erste oder zweite Kategorie zu stellen sind. Ferner kann es auch vorkommen, dass ausgesprochen sekundäre Schädlinge primär werden, wenn nämlich nach eingetretener Übervermehrung ein Mangel an geeignetem kränklichen Material eintritt. Dann treibt der übermächtige Fortpflanzungstrieb die Tiere dazu, auch völlig gesunde Pflanzen anzugehen, was allerdings oft vielen der betr. Insekten das Leben kostet. 
Ausgesprochen primäre Schädlinge haben wir z. B. in den Raupen der meisten Großschmetterlinge, wie der Nonne, des Kiefernspinners und Spanners, der Kieferneule, des Schwammspinners, Goldafters usw., ferner in dem großen braunen Rüsselkäfer, dem Maikäfer (Larve und Imago), den Elateridenlarven (Drahtwürmern), den Imagines der beiden Waldgärtner usw.

$\mathrm{Zu}$ den sekundären Forstinsekten gehören z. B. die Larven der meisten Borkenkäfer (übrigens in sehr verschiedenem Grade), ferner Pissodes harzyniae, der ein charakteristischer Begleiter rauchbeschädigter Fichtenbestände ist, und wohl auch die meisten der übrigen Pissodes-Arten, sodann der Fichtenbock (Tetropium luridum) und viele andere Bockkäfer, der Erlenrüsselkäfer (Cryptorhynchus lapathi), der sich besonders an solchen Erlen einfindet, die an zu trockenem Stand stehen und andere.

Die primären Insekten stellen im allgemeinen die größere Gefahr für den Forstmann dar, indem sie seine völlig gesunden Bestände gefährden und binnen kurzer Zeit vernichten können, während die sekundären oft nur eine Beschleunigung des Absterbens ohnehin kranker und dem Tode geweihter Bäume bewirken. Doch können auch die sekundären Insekten eine schwere Gefahr bedeuten, wenn sie z. B. im Gefolge einer primären Kalamität auftreten und dadurch die Rekonvaleszens der durch dieselbe geschwächten Bäume verhindern. So fallen manche Bestände, die aus einer schweren Nonnenkalamität in noch einigermaßen hoffnungsvollem Zustand hervorgegangen sind, oft noch den darnach folgenden sekundären Schädlingen (Borkenkäfern, Rüsselkäfern usw.) zum Opfer.

\section{Kultur- und Bestandsverderber.}

Vom forstwirtschaftlichen Standpunkt aus teilt man die schädlichen Insekten auch in Kultur- und Bestandsverderber ein. Unter den ersteren versteht man im allgemeinen jene Insekten, welche die Gründung eines Bestandes erschweren oder verhindern, unter den letzteren dagegen jene, welche das Absterben oder Kränkeln älterer Bäume oder ganzer Bestände verursachen. Wie jedoch der Unterschied zwischen technischen und physiologischen, primären und sekundären Insekten durch zahlreiche Übergänge verwischt wird, so ist dies auch hier der Fall, und zwar um so mehr, als nicht einmal forstlich eine scharfe Grenze zwischen Kultur und Bestand gezogen werden kann.

$\mathrm{Zu}$ den Kulturverderbern gehören einmal alle den ausgesäeten Samen zerstörenden Insekten, z. B. die Larven einiger Elateriden, und sodann alle jene, welche vorzugsweise die jungen Pflanzen an ihren oberirdischen oder unterirdischen Teilen beschädigen. Unter den Wurzelbeschädigern (am Laub- und Nadelholz) ist in erster Linie der Engerling zu nennen; speziell für Nadelhölzer die Kiefernsaateule, Agrotis vestigialis Hfn. und die Larven verschiedener Otiorhynchus-Arten. Noch weit zahlreicher sind die Beschädiger der oberirdischen Teile der Pflanzen. Einer der schädlichsten oberirdischen Kulturverderber ist der große braune Rüsselkäfer, Hylobius abietis L., in etwas älteren Kiefernkulturen oft auch Pissodes notatus Fabr. Eine große Anzahl anderer Rüsselkäfer, die sog. grünen und grauen Laub- und Nadelholzrüsselkäfer, sowie einige Borkenkäfer (vor allem die wurzelbrütenden Hylesinen), zahlreiche Mikrolepidopteren, einige Blattwespen, Schild- und Rindenläuse usw. können als Beispiele gleichfalls hier genannt werden.

Als Beispiele von Bestandsverderbern sind $\mathrm{zu}$ nennen in erster Linie die Raupen vieler Großschmetterlinge (Nonne, Kiefernspinner, -spanner, -eule, Schwammspinner, Prozessionsspinner, Rotschwanz usw.), sodann die Afterraupen 
mancher Blattwespen (Nematus, Lyda, Lophyrus usw.), ferner viele Borkenkäfer (vor allem Ips typographus), Rüsselkäfer (Pissodes harzyniae) usw.

Sehr viele Insekten sind gleichzeitig Kultur- und Bestandsverderber; sei es, daß sie dies in demselben Stadium der Entwicklung sind, sei es, daß sie in dem einen Stadium nur Kulturen, in dem anderen nur Bestände beschädigen. So schädigt z. B. Tortrix buoliana $S$. $V$. als Larve sowohl Kulturen als Bestände, der Maikäfer dagegen als Engerling durch Wurzelfraß hauptsächlich die jungen Pflanzen, als Imago durch Entblätterung auch ältere Bäume. Hylesinus piniperda L. tötet als Larve durch seine Fraßgänge alte Bäume, schädigt hingegen als Imago durch das Aushöhlen der Triebe nicht bloß diese, sondern auch junge Kiefern.

\section{Die verschiedenen Arten der Pflanzenbeschädigungen durch Forstinsekten.}

Die Angriffe der Forstinsekten auf Holzpflanzen bestehen:

1. in Verletzungen, die mit Zerstörungen fester Pflanzensubstanz verbunden sind;

2. in Verletzungen, die nur Saftverlust zur Folge haben, und

3. in dauernden Reizwirkungen, welche die Pflanze zur Erzeugung krankhafter Neubildungen, sog. Gallen, veranlassen.

\section{Verletzungen durch Zerstörung fester Pflanzensubstanz.}

Diese sind bei weitem die häufigsten und wichtigsten; sie können natürlich nur durch solche Insekten (Imagines oder Larren) erzeugt werden, die kauende Mundwerkzeuge besitzen. Je nach der Insektenart, nach dem Entwicklungsstadium (Larve oder Imago) und je nach dem Pflanzenteil, der befallen wird, sind die Verletzungen ungemein verschieden.

\section{Fraß an Blattorganen.}

Handelt es sich um einen Blatt- oder Nadelfraß, so können die Blätter oder Nadeln entweder mit Stumpf und Stiel abgefressen werden (Beispiel: Kiefernspinnerraupe) oder aber es bleiben Teile davon verschont. Manche Insekten (wie z. B. die jungen Nonnenraupen oder die Raupen der Frostspanner) begnügen sich meistens damit, Löcher aus den Blättern herauszufressen ("Löcherfraß") (Fig. 173); andere fressen von den Seitenrändern her Scharten in die Blätter oder Nadeln ("Schartenfrab"), was besonders deutlich bei verschiedenen Nadelinsekten in Erscheinung tritt (z. B. beim Kiefernspanner oder bei verschiedenen Rüßelkäfern) (Fig. 174). Der Fraß von den Seitenrändern kann so weit gehen, daß nur die Mittelrippe der Blätter oder Nadeln stehen bleibt, was z. B. sehr charakteristisch für gewisse Blattwespen (Lophyrus) ist. Manche Raupen, wie die älteren Raupen der Nonne, des Schwammspinners, Goldafters usw., lassen außer der Mittelrippe auch noch die Spitzenteile der Blätter stehen, so daß die Form eines Ankers entsteht, weshalb man in solchen Fällen auch von "Ankerfraß" spricht (Fig. 173B). Da die betreffenden Raupen nach vollendetem Fraß gewöhnlich die Mittelrippen an der Basis abbeißen, so fallen die „Blattanker“ zu Boden, wodurch der Kundige auf die Anwesenheit jener Schädlinge aufmerksam gemacht wird. - Wieder andere Insekten skelettieren die Blätter, indem sie entweder das Blattgewebe bis auf die Rippen herausfressen, oder aber indem sie außer den letzteren auch 
noch die Epidermis der einen Seite verschonen, so daß die Rippen durch eine feine durchsichtige Haut miteinander verbunden sind (in dieser Weise fressen z. B. viele Blatt- und Rüsselkäfer) (Fig. 175). - Und ferner gibt es eine ganze Reihe von Insekten, welche in die Blätter eindringen und das Blattparenchym herausfressen, dabei die Epidermis der beiden Seiten

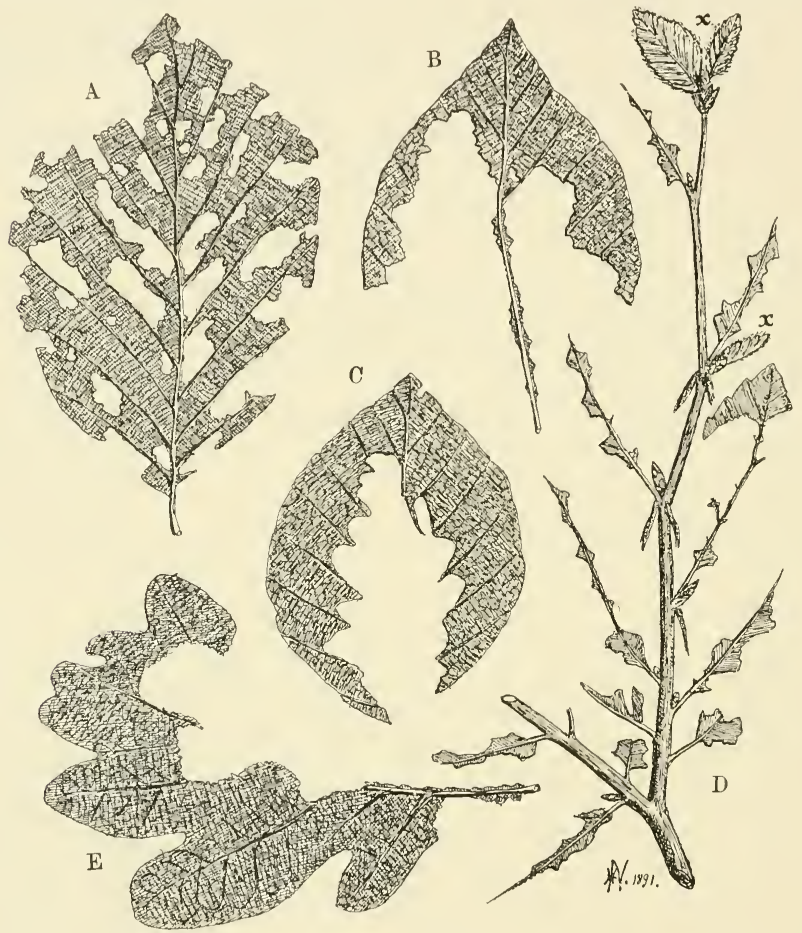

Fig. 173. Beispiele für Löcher- und Ankerfraß. $A$ Löcherfraß der jungen Nonnenraupe an Buche $B$ typischer Ankerfraß der älteren Raupe an Buche; $C$ zu Boden gefallenes Buchenblatt mit Ankerfra $B$ und oben durchgebissener Mittelrippe; $D$ Buchenzweig mit stehengebliebenen Rippen und Blattresten, die Ergänzungsstücke zu $C$ darstellen; $E$ Ankerfraß an Eiche. - (N.)

verschonend; dadurch entstehen Hohlräume in den Blättern, die als Blattminen bezeichnet werden, und welche die verschiedensten und für manche Spezies ganz charakteristischen Formen aufweisen. Ich erwähne hier nur die an der Mittelrippe schmal beginnende und sich nach außen zu immer mehr verbreiternde Blattmine der Larve von Orchestes fagi (Springrüßler) (Fig. 176), an die mehr rundlichen und blasenförmig aufgetriebenen Minen der Eichenminiermotte (Gracilaria complanella) oder an die mehrfach geschlängelten, schmalen und gewundenen Miniergänge verschiedener anderer Motten usw. 
Endlich können wir noch an die eigenartigen Beschädigungen der Blätter durch die sog. Blattwickler (Rhynchites usw.) erinnern, bei denen aber die direkten Verletzungen, die nur in einigen kurzen Schnitten bestehen, geringfügig sind gegenüber den Veränderungen, die das Blatt durch das Aufrollen erleidet (manche Arten wickeln die Blätter auch ohne vorher Einschnitte gemacht zu haben).

\section{FraB an Stamm und Zweigen.}

Wir beginnen mit den Bes chädigungen der Rinde, die besonders nach zwei Richtungen in Erscheinung treten: entweder machen die Insekten ihre Angriffe nur von außen her, indem sie die Rinde entfermen und so den Holzkörper völlig frei legen, oder aber sie dringen in die Rinde ein, um in derselben oder in dem darunter befindlichen Weichbast Gänge zu fressen.

Die Verletzungen der ersteren Art, die wir unter dem Namen „Rindenplatzfraß" zusammenfassen, können von sehr verschiedener Form und Ausdehnung sein: so frißt der große braune Rüsselkäfer meist runde pockennarbenähnliche Löcher in die Rinde, während die wurzelbrütenden Hylesinen gewöhnlich längere Gänge oder Furchen eingraben; die Hornissen schälen die Rinde in unregelmäßiger Weise und oft in sehr ausgedehntem Maße, während gewisse Blattwespen (Cimbex) sich mit schmalen Ringelungen begnügen usw. (Fig. 177). - Weit mannigfaltiger und zahlreicher als die Verletzungen durch die plätzenden Insekten sind die Beschädigungen durch die Rindenminierer. Nur wenige von ihnen (z. B. Anobium emarginatum oder die Blattwespe Strongylogaster) bleiben in der

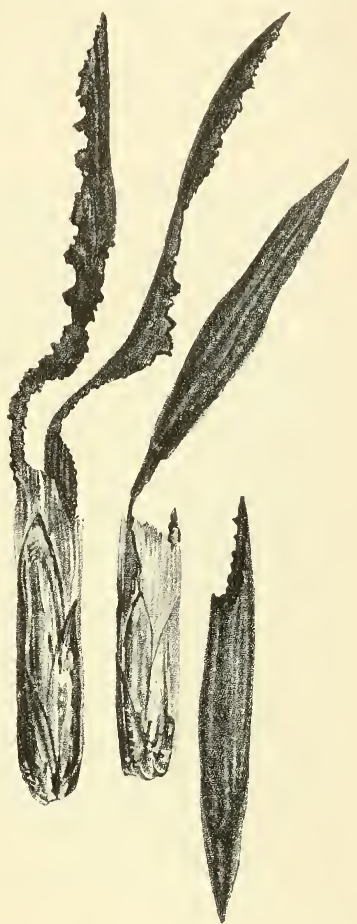

Fig. 174. Schartenfraß an Kiefernnadeln, ausgefuhrt von Cneorhinus geminatus (Rüsselkäfer). (Stark vergrößert.) Aus Eckstein. toten Borke, wo der Fraß natürlich ohne jede

Folgen ist. Die meisten dringen tiefer ein in die saftleitenden Schichten, in den Bast oder auch in den Splint. Die Gänge werden entweder nur von den Larven genagt (Bockkäfer, Buprestiden, Pissodes, verschiedene Kleinschmetterlinge usw.), in welchen Fällen die Fraßbilder mehr oder weniger unregelmäßig sind; oder aber es beteiligt sich auch die Imago daran, indem die Mutter selbst einen Gang gräbt, um darin die Eier, meist einzeln und in regelmäßiger Anordnung, unterzubringen (Borkenkäfer). Dann haben wir es gewöhnlich mit mehr oder weniger regelmäßigen und für jede Spezies sehr charakteristischen Fraßbildern (aus Mutter- und Larvengängen zusammen- 
gesetzt) zu tun, so daß meist schon allein nach ihnen die sichere Bestimmung der Spezies möglich ist (Fig. 178). Wir werden unten im zweiten Teil des Werkes, bei Besprechung der Borkenkäfer, noch näher auf diese Fraßbilder einzugehen haben.

Schon unter den Rindenminieren gibt es viele, welche sich nicht auf den Bast und die oberflächlichen Splintschichten beschränken, sondern, wenigstens zur Verpuppung, tiefer in den Holzkörper eindringen; so verpuppen sich die meisten Bock- und Prachtkäferlarven in einem mehr oder weniger tief in den Holzkörper greifenden sog. „Hackengang“. Diese führen zu

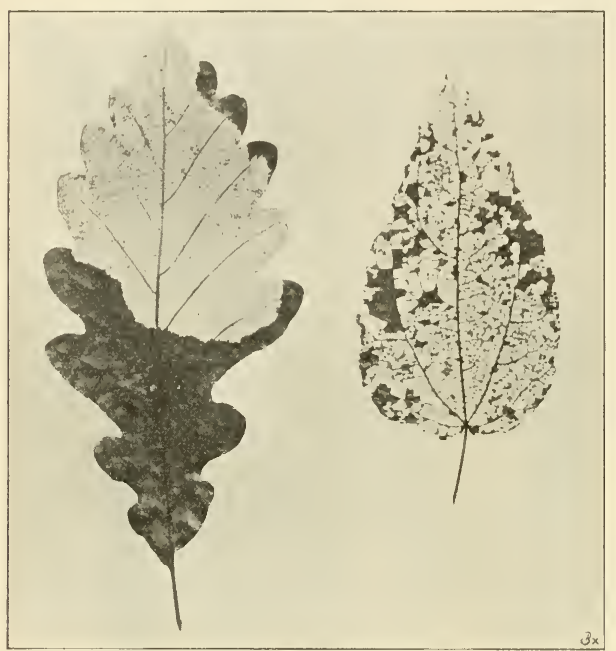

$a$

b

Fig. 175. Beispiele von Blattskelettierungen. a durch eine Blattwespe; $b$ durch einen Blattkäfer. Bei $b$ ist die gesamte Blattsubstanz bis auf die Adern herausgefressen; bei $a$ ist die Oberhaut stehen geblieben. jenen Insekten über, welche ihre Entwicklung ganz oder wenigstens zum größten Teil im Holzkörper durchmachen, oder welche sogar ihren ständigen Wohnsitz da aufschlagen. Wir brauchen

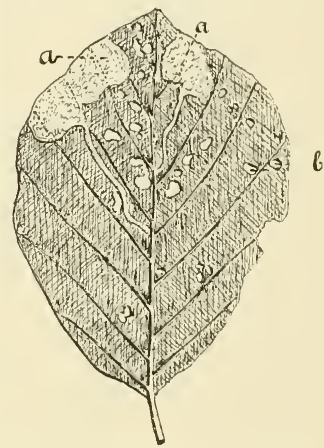

Fig. 176. Blattminen (a) gefressen von der Larve des Buchenspring. rüßlers (Orchestes fagi); $b$ Löcherfraß durch die Imago des genannten Rüßlers. - (N.)

in dieser Hinsicht nur an die Larven gewisser Bockkäfer (Cerambyx, Lamia, Saperda usw.) oder an die Raupen des Weidenbohrers, des Blausiebs, der Sesien usw. zu erinnern, welche nur in ihrer ersten Lebenszeit unter der Rinde fressen, um dann die ganze übrige Entwicklung im Holze durchzumachen, wo sie unregelmäßig gewundene oder auch einfache längsverlaufende Gänge nagen; - oder an die holzbrütenden Borkenkäfer, deren von Mutter und Larven oder auch nur von der ersteren genagten mehr oder weniger regelmäßigen Frafgänge tief in den Holzkörper eindringen; - oder an die Holzwespen, deren Eier vermittelst langer Legebohrer in das Holz eingeführt werden, so daß bereits der Beginn der Fraßgänge in den Holzkörper verlegt ist; - oder endlich an die Holzameisen, die gleich ganze 
Jahresringe so ausfressen, daß nur dünne aus hartem Herbstholz bestehende Ringwände erhalten bleiben und der Stamm in seinem Innern mehr oder weniger vollständig in konzentrisch ineinandersteckende Hohlzylinder zerlegt wird, die der Ameisenkolonie als Nest dienen. - Auch der „Markröhrenfraß", wie er in den Kieferntrieben von den Imagines der Waldgärtner und den Larven von Anobium nigrinum, in Weidenruten von Oberea oculata und Nematus angustus, in Fichtentrieben von Phycis abietella geübt wird, und welcher gewöhnlich mit dem Absterben der befallenen Teile begleitet ist, muß hier erwähnt werden; ebenso wie der Fraß der Kieferntriebwickler und anderer Kleinschmetterlinge, welche die ganz jungen, noch weichen Triebe oder auch die Knospen befressen resp. aushöhlen. Und endlich haben wir noch einige Forstinsekten zu nennen, welche wenigstens bei jungen Pflanzen - die Stämmchen völlig durchbeißen (Beispiel: die Kiefernsaateulen).

Fraß an den Wurzeln.

Der Wurzelfraß besteht entweder in einem Benagen der Rinde oder in einem Abbeißen und Abfressen ganzer Wurzelpartien. Welche der beiden Arten vorkommt, hängt sowohl ron der Insektenart ab als auch ganz besonders von

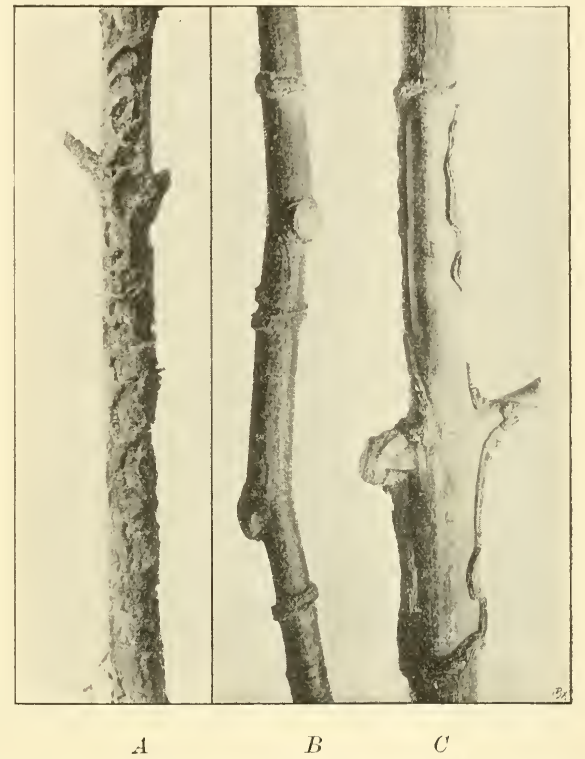

Fig. 177. Verschiedene Rindenverletzungen. A PockennarbenPlätzfraß durch Hylobius; $B$ Ringelungen durch Cimbex; $C$ Schälung durch eine Hornisse.

der Stärke der Wurzeln. Der schlimmste Wurzelschädling ist zweifellos der Engerling, der alle Wurzeln, die seine Mundwerkzeuge bewältigen können, radikal abfrißt, so daß bei jüngeren Pflanzen nur noch die einzige Pfahlwurzel übrig ist; auch von dieser wird überdies meist auch noch die Rinde abgenagt, so daß sie "nackt und kahl wie eine Rübe“ ist, und man in solchen Fällen auch von einem „Rübenfraß“ spricht. Wo es sich um stärkere Wurzeln handelt, da beschränkt sich der Engerlingfraß auf platzweises Benagen der Rinde. Die anderen Wurzelfresser verfahren meist nicht so radikal wie der Engerling, wenn auch manche von ihnen demselben nicht viel nachstehen: ich erinnere nur an die Raupen der Kiefernsaateulen, welche 
ebcnfalls arge Beschädigungen durch Abbeißen ganzer Wurzelteile verursachen können; ferner an die Drahtwürmer, die Larven gewisser Rüsselkäfer (Otiorhynchus, Brachyderes usw.), die Tipulidenlarven und andere mehı, deren Beschädigungen gewöhnlich im Benagen der Wurzelrinde bestehen; und endlich an die Maulwurfsgrille, die alle Wurzeln, die ihr bei ihren unterirdischen Jagdausflügen in den Weg kommen, kurzweg abbeißt (oder auch mit ihren scharfen Grabklauen abreißt). - Nur in sehr seltenen Fällen kommt ein dem obigen Markröhrenfraß entsprechender Fraß an den Wurzeln vor; uns ist bisher nur ein einziger derartiger Fall an Forstgewächsen bekannt geworden, der den Hopfenspinner betraf, welcher

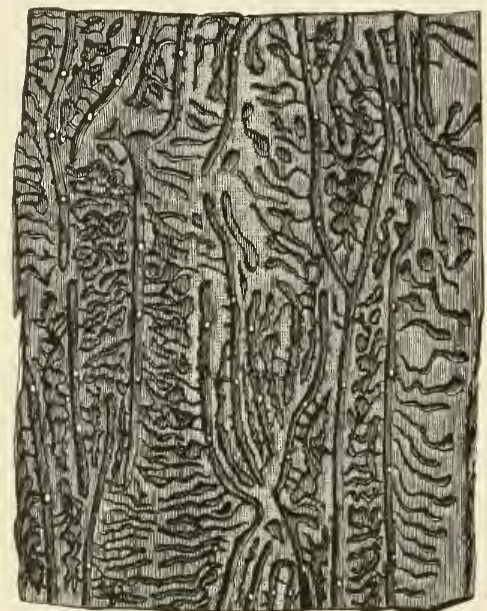

Eig. 178. Rindenstück mit den Fraßgängen von Ips amitinus. $-(\mathrm{N}$. das schwammige Mark von Hickorywurzeln aushöhlte.

Fraß an Samen.

Es gibt eine ganze Reihe von Insekten, deren Larven im Samen von Forstgewächsen ihre Entwicklung durchmachen und dabei denselben

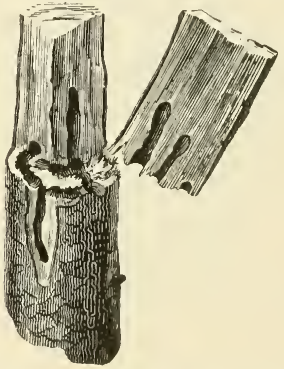

Fig. 179. Fraßgänge im Holz, verursacht durch Xyleborus dispar. - (N.)

vernichten. So leben z. B. in den Fichtenzapfen die Larven von Anobium abietis, die Raupen von Grapholita (Tortrix) strobilella und Diorictria abietella; in Kiefernzapfen ebenfalls die letztere und außerdem Pissodes validirostris, in Bucheln Grapholita grossana, in Eicheln Grapholita splendana, Balaninus turbatus, glandium und elephas usw.

\section{Verletzungen, die nur Saftverlust zur Folge habcn.}

Solche werden nur von Insekten mit saugenden Mundwerkzeugen bewirkt. Die durch die feinen Saugrüssel angerichteten direkten Verletzungen sind meist sehr unbedeutend gegenüber den Nachteilen, die der Pflanze durch den Saftverlust treffen. Die Zahl der auf diese Weise wirkenden Forstschädlinge ist weit geringer als die Zahl der in die vorige Kategorie gehörenden; auch tritt ihre forstliche Bedeutung gegenüber den letzteren sehr zurück. Alle 
Stellen der Pflanze können den kleinen Saugern zum Angriff dienen, sowohl die Blattorgane als der Stamm als auch die Wurzeln. In der Hauptsache sind es Blatt- und Schildläuse, welche in dieser Weise den Pflanzen Schaden zufügen.

\section{Verletzungen, welche Gallbildungen zur Folge haben.}

Bei dieser Art von Schädigung liegt das wesentliche weder in dem Verlust an Pflanzensubstanz, noch im Verlust an Saft, sondern in der Entstehung krankhafter Neubildungen, der sog. "Gallen" oder "Cecidien".

Eine präzise, allgemeingültige Definition des Begriffes "Galle“ oder "Cecidium" (ron cecis, das Herrorquellende) wird durch die außerordentliche Mannigfaltigkeit dieser Bildungen sehr schwer, ja beinahe unmöglich gemacht. Nach Thomas, dem wir die erste wissenschaftliche Begriffserklärung verdanken, hat man unter Galle jede durch einen Parasiten veranlaßte aktive Bildungsabweichung zu verstehen, welche Definition Küster noch dahin ergänzt wissen will, daß die Bildungs abweichung der Entwicklung des Parasiten Vorschub leistet und insofern für diese „zweckmäßig“, für die Entwicklu»g der gallentragenden Pflanze jedoch schädlich ist. - Die Bildungsabweichungen beruhen entweder auf einem außergewöhnlichen Wachstum einzelner Zellen, größerer Gewebepaıtien, ganzer Organe oder Organkomplexe, oder aber auf Neubildungen von oft komplizierter Beschaffenheit. Vielfach tritt gleichzeitig vermindertes Wachstum bestimmter Organe, Gewebe oder Zellen ein, so daß Verkürzungen der verschiedensten Art (Hemmungsbildungen) mit der Neubildung Hand in Hand gehen (RoB).

Als gallenerzeugende Organismen kommen sowohl Pflanzen als auch Tiere in Betracht, unter welch letzteren die Milben und Insekten weitaus die größte Rolle spielen. Das Hauptkontingent der Insekten stellen die Dipteren, von welchen nach Houard für Europa und das außereuropäische Mittelmeergebiet 420 Cecidomyiden und 66 Musciden als gallenbildend bekannt sind. Ihnen folgen die Hymenopteren mit 290 Gallenbildnern (26 Tenthrediniden, 244 Cynipiden, 20 Chalcididen), die Hemipteren oder Rhynchoten mit 243 Arten (darunter 169 Aphididen, 45 Psylliden, 16 Cocciden), die Coleopteren mit 113 Arten (darunter 104 Curculioniden) und die Lepidopten mit 61 Arten (darunter 24 Tortriciden). Von Orthopteren kommt nur eine Locustide (Meconema varium auf Quercus) und von den Neuropteren nur eine Agrionide (Lestes viridis auf Pinus strobus) in Betracht ( $\mathrm{K}$ üster).

Über die Ätiologie (Entstehungsursache) der Gallen sind wir noch recht schlecht unterrichtet; es sind zwar schon eine Reihe Untersuchungen in dieser Richtung unternommen worden, doch sind die erzielten Resultate bis jetzt noch in mancher Beziehung lückenhaft geblieben. Grundbedingung für die Entstehung einer Galle ist, daß der Parasit auf möglichst junge, in der Entwicklung begriffene, bezw. noch im Wachstum befindliche Pflanzenteile, oder auf Gewebe einwirkt, welche sich im teilungsfähigen Zustand befinden oder doch in diesen Zustand zurückkehren kömnen. Die Galle wächst in der Regel mit dem sich entwickelnden Organe der Pflanze. Völlig 
ausgebildete oder nur aus Dauergewebe bestehende Pflanzenteile vermögen daher keine Cecidien hervorzubringen. Ferner scheint so viel festzustehen, daß eigenartige, nicht näher bekannte Stoffe, die von dem Parasiten abgeschieden werden und einen chemischen Reiz auf das umgebende Gewebe ausüben, eine große Rolle bei der Erzeugung der Gallen spielen. Bei gewissen Arten (Potonia proxima $=$ Nematus Vallisneri) genügt nach Beijerinck das gleichzeitig mit dem $\mathrm{Ei}$ in das Pflanzengewebe beförderte cecidogene Gift allein, die Galle hervorzurufen, ohne daß ein weiterer von dem Ei oder der Larve ausgehender Reiz notwendig wäre. Beijerinck konnte in diesem Falle zeigen, daß die Bildung der Galle auch dann ihren Fortgang nimmt, wenn man das $\mathrm{Ei}$ bald nach der Ablage tötet. Daß allerdings ein gewisser Einfluß durch die Gegenwart des Eies resp. der Larve auf die Regelmäßigkeit der Entwicklung des Cecidiums, z. B. auf die Entstehung des Innenraumes ausgeübt wird, kann uns nicht Wunder nehmen, wenn wir überlegen, wie außerordentlich verschieden die Ernährungsbedingungen in dem Gallengewebe sein müssen, wenn sich das an sich gewiß einer spezifischen Eiweißnahrung bedürftige $\mathrm{Ei}$ darin fortentwickelt oder nicht (Küster). - In anderen Fällen scheint aber auch dem Ei und der Larve ein wesentlicher Anteil bei der Gallbildung zuzukommen, so daß letztere unterbleibt, sowie das $\mathrm{Ei}$ abstirbt oder künstlich vernichtet wird. Erst mit der fortschreitenden Ausbildung des Embryos im Ei oder mit dem Ausschlüpfen der Larve beginnen die Veränderungen in den umgebenden Geweben. Geht die Larve zugrunde oder wird sie entfernt oder getötet, so hört die Weiterentwicklung der Galle ebenfalls auf. Es genügt hier also nicht ein einmaliger Reiz für diesen Entwicklungsvorgang, sondern die Larve scheint die betreffenden Stoffe, welche wahrscheinlich den Speicheldrüsen entstammen, fortgesetzt auszuscheiden. Bezüglich der Herkunft des Sekretes ist auch die Ansicht ausgesprochen worden, daß bei den Gallwespen die gallenerzeugenden Stoffe zum Teil den Malpighischen Gefäßen entstammen (Rössig nach Roß).

Das den Reiz ausübende Tier kann seinen Sitz entweder an der Außenseite oder im Innern des betreffenden Pflanzenteiles haben. Als Beispiel eines durch äußerliche Angriffe Gallen erzeugenden Tieres führen wir die eine Art des Buchenkrebses hervorbringende Blattlaus Lachnus exsiccator Alt. auf. Alle Blattlausgallen entstehen überhaupt ursprünglich durch äußere Angriffe; die dieselben erzeugenden Tiere werden aber mitunter allmählich von der wuchernden Galle umschlossen, so z. B. die die taschenartigen Beutelgallen an den Ulmenblättern verursachenden Formen. In diesen Fällen ist der Gallerzeuger meist eine Imago, indessen können, wenngleich seltener, auch gleichzeitig Larven durch äußere Angriffe gallbildend wirken, z. B. die Larven von Chermes. Gallerzeuger, die im Innern des Pflanzenteiles ihren Sitz haben, sind stets Larven, bezw. noch in der Eischale eingeschlossene Embryonen, die in der Galle ihre Veıwandlung durchmachen. Solche Larven können entweder durch eigene Tätigkeit in die Pflanzensubstanz eindringen, wie z. B. die aus einem äußerlich an die Rinde abgelegten Ei schlüpfende Larve von Saperda populnea L., welche an Aspen 
knotige Anschwellungen der Äste hervorruft; - oder aber bereits innerhalb derselben aus einem von dem Muttertiere mit Hilfe des Legbohrers in den Pflanzenteil versenkten Ei ausschlüpfen, was z. B. bei den eigentlichen Gallwespen (Cynipidae) der Fall ist.

Der Ort der Gallbildung ist sehr wechselnd, und man kann wohl sagen, daß kein zur Erzeugung von Neubildung fähiger Pflanzenteil von den Angriffen der Gallentiere verschont bleibt. Wurzeln und Stamm, Blätter und Knospen, Blüten und Früchte können Gallen tragen, bezw. sich in solche verwandeln.

Auch die Form und der Aufbau der Gallen ist ungemein mannigfaltig, und es ist durchaus nicht leicht, eine einigermaßen befriedigende Einteilung der Gallen zu geben. Es sind schon mehrere Versuche in dieser Richtung unternommen worden, wobei die verschiedensten Gesichtspunkte zugrunde gelegt wurden. So teilt Thomas die Gallen ein in "Akro-undPleurocecidien", je nachdem die Gallenbildung am Vegetationskegel eines Sprosses oder aber an den übrigen Teilen der Pflanze stattfindet. Beijerinck unterscheidet "Gallen mit unbegrenztem und begrenztem WVachstum“ (unbegrenzt: „mehrere Generationen der Bewohner bilden während einiger Zeit die Form der Galle um; der Galle erste Anlage geht jedoch von einem erwachsenen Individuum aus. Fortpflanzung und Ernährung findet im Innern der Galle statt“, - begrenzt: „der einzige oder mehrere Bewohner verbleiben nur während der Nährzeit ihres Larvenstadiums in den Gallen. Diese reifen schnell und sind sehr viel eher als die Larven erwachsen"). Kerner teilt die Zoocecidien ein in „einfache und zusammengesetzte Gallen“, je nachdem die Galle auf ein einzelnes Pflanzenglied beschränkt bleibt, oder aber mehrere Pflanzenglieder in Anspruch nimmt. Und Küster endlich spricht von „organoiden und histioiden Gallen", je nachdem es sich um abnormale Umgestaltungen von Organen, bezw. um Neubildung von solchen handelt, oder um Bildung von abnormalen Geweben. Organoide Gallen liegen vor, wemn z. B. Laubblätter statt Nebenblätter gebildet werden, oder Niederblätter anstatt der Laubblätter entstehen, oder wenn Adventivwurzeln oder Adventivsprossen an dem infizierten Organ sich bilden. Histioide Gallen repräsentieren sich als Schwellungen von Blättern, Achsen und anderen Organen, als lokale Wucherungen von irgend welchen Formen, als Haarbildungen usw.“

Die Küstersche Einteilung verdient in wissenschaftlicher Beziehung zweifellos den Vorzug vor den übrigen; trotzdem wollen wir hier, wo wir zu den Praktikern reden, uns mehr an die Kernersche Einteilung halten, da diese auf für den Nichtbotaniker leichter erkennbare Merkmale gegründet ist.

Wir unterscheiden:

1. Einfache Gallen: die Galle ist auf ein einziges Pflanzenglied beschränkt.

a) Filzgallen: scharf umschriebene, mit dichtem Haarfilz bedeckte Stellen an Blättern (Erzeuger: Gallmilben); 
b) Mantelgallen: bei ihnen leben die Gallenerzeuger oberflächlich und regen das Pflanzengewebe zu Wachstumsvorgängen an, deren Produkte die Parasiten wie mit einem Mantel einhüllen. Hierher gehören die mannigfaltigsten Bildungen, wie Krümmungen, Rollungen, Faltungen und Umrißveränderungen an Blättern, Blattstielen und Stengeln, ferner die sog. Beuteltaschen und Nagelgallen usw. an Blättern (Fig. 180);

c) Markgallen (die „eigentlichen Gallen“ Nitsches): Gewebswucherungen, welche sich um einen im Gewebe befindlichen Parasiten (Larve) bilden. Hierher gehören die Gallen der Gallwespen (Cynipiden), sodann auch von Blattwespen (z. B. Nematus Vallisneri), Gallmücken (z. B. Cecidomyia saliciperda), Kleinschmetterlingen (z. B. Graph. zebeana) und Käfern (z. B. Saperda populnea).

2. Zusammengesetzte Gallen: Es handelt sich dabei um Gallen, zu deren Aufbau mehrere unmittelbar aneinandergrenzende Glieder einer
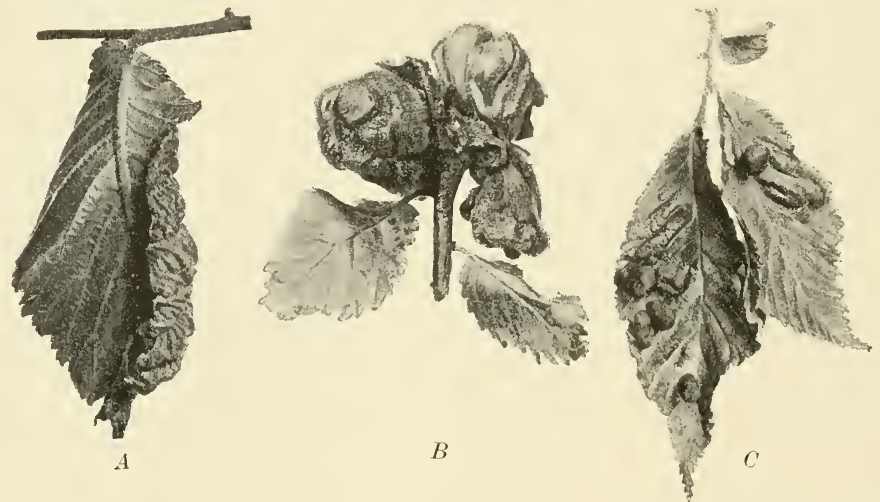

Fig. 180. Verschiedene Blattgallen an Ulme. A Blattrandgalle von Schizoneura ulmi; $B$ drei Beutelgallen von Schiz. lanuginosa; $C$ Taschengallen von Pemphigus ulmi. - (N.)

Pflanze einbezogen wurden. Es sind dies meist Knospenanschwellungen und Triebspitzendeformationen, oft verbunden mit kurzbleibender Achse und überhäufter Blätterbildung. Sie werden teils als Knopperngallen, teils als Kuckucks- oder Ananasgallen, teils als Klunkern, Wirrzöpfe, Weidenrosen usw. bezeichnet. Als Erzeuger kommen meist Hemipteren (z. B. Chermes als Erzeuger der Ananasgallen) (Fig. 181) oder Gallmücken (z. B. Cecidomyia rosaria als Erzeuger der Weidenrosen) in Betracht.

3. Krebsbildungen: d. s. bösartige, zu Gewebszerstörungen führende äußere Anschwellungen an Zweigen und Wurzeln. Hierher sind z. B. die von der Blutlaus (Schizoneura lanigera) an Apfelbäumen oder die von Lachuus exsiccator an der Buche erzeugten Wucherungen und Zerstörungen zu stellen. 


\section{Folgen der Angriffe auf die Pflanzen.}

Es sind hauptsächlich zwei Richtungen, in denen sich die Wirkung der Insektenangriffe bemerkbar machen: einmal in Deformationen, d. h. Veränderungen der normalen Form der Pflanze und sodann in einer allgemeinen Schwächung der Lebenskraft.

Was die Formveränderungen betrifft, so können diese auf Wachstumsbeeinflussungen beruhen, oder aber darauf, daßs bereits ausgebildete Teile der Pflanze abgetötet werden und abfallen. Als bekanntestes Beispiel für den ersten Modus seien die Kieferntriebwickler erwähnt, auf deren Triebfraß die als "Posthorn" bezeichneten Verkrümmungen an der Kiefer zurückzuführen sind, oder die Fichtenblattwespe (Nematus abietum), deren wiederholtes

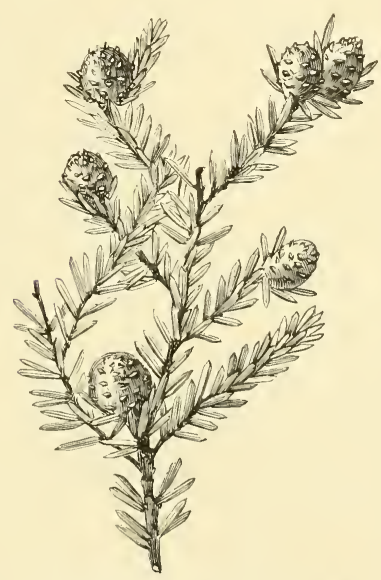

Fig. 181. Ananasgallen von Chermes strobilobius. an Fichte. - (N.)

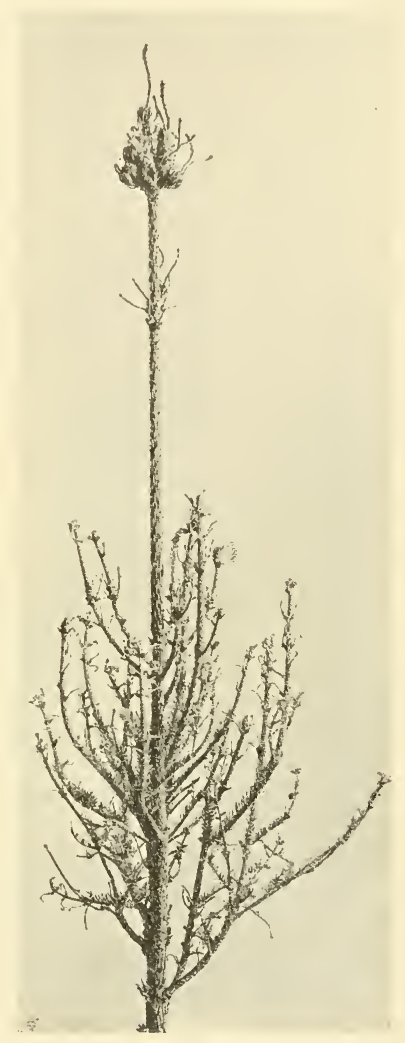

Fig. 182. Schopfbildung an einer Fichte infolge wiederholten Nematus-Fraßes. Nach W. Baer.

Befressen der Maitriebe ausgedehnte Schopfbildungen am Wipfel verursachen können (Fig. 182). Bezüglich der zweiten Art von Formveränderung sei in erster Linie auf den Markröhrenfraß der Waldgärtner hingewiesen, der das Abfallen der Triebenden veranlafit. Wo der Waldgärtner sich stärker vermehren kann, da verlieren ältere Kiefern so viele Triebe an dem Mantel der Krone, daß diese wie zerzaußt aussieht und ihre gewölbte Form gänzlich Escherich, Forstinsekten. 
einbüßt, um dafür die Gestalt einer Fichte oder Cypresse zu erhalten. Andere Insekten bringen ganze Äste zum Absterben, was ebenfalls zu einer Lichtung der Krone führt, wie z. B. der Prachtkäfer Agrilus bifasciatus, der die Gewohnheit hat, Äste älterer Eichen tief zu ringeln und so von der Saftzufuhr abzuschneiden, was natürlich das Absterben zur Folge hat. Auch der Lindenprachtkäfer, Buprestis rutilans, ferner das Kiefernböckchen, Pogonochaerus bifasciatus, kann in ähnlicher Weise zur Lichtung der Krone beitragen.

Die häufigste Folge von Insektenangriffen ist eine allgemeine Schwächung der Gesundheit der Pflanze, die je nach der Dauer und Ausdehnung des Angriffes von verschiedenem Grad sein und bis zum Absterben führen kann. Mag es sich um einen Blattfraß handeln, der die Pflanzen der assimilatorischen Organe beraubt, oder um einen Rindenfraß, der die Saftleitung unterbricht, oder um einen Wurzelfraß, durch den die Wasser- und Nährstoffaufnahme gehindert wird, oder um ein bloßes Abzapfen der Säfte durch saugende Insekten, stets tritt eine Schwächung der Gesundheit, resp. ein Kränkeln ein. Nehmen die Angriffe keinen allzu großen Umfang an, und dauern sie nicht allzu lange, so kann die Pflanze in kürzerer oder längerer Zeiı die Folgen dieser Angriffe überwinden und die erlittenen Beschädigungen wieder ausgleichen; so tritt nach Beschädigung der Wurzeln oder Triebe eine neue Bildung von solchen ein, so wird der Verlust der Laubblätter durch Neubildung blättertragender $Z$ weige, durch das sog. Wiedergrünen, ausgeglichen und so werden die Rinden- und Holzbeschädigungen durch allmähliche Überwallung der Wunden wieder verheilt usw.

Erreichen jedoch die Zerstörungen eine größere Ausdehnung, werden z. B. die meisten Nadeln vernichtet oder kommt es gar zu einem völligen Kahlfraß, oder werden die saftleitenden Schichten von massenhaften Borkenkäfern oder anderen Minierinsekten so zerstört, daß überhaupt kein Saft mehr aufsteigen kann, oder werden die Wurzeln derart zerfressen, daß die Wasseraufnahme kaum mehr stattfinden kann, so tritt meist der Tod der betreffenden Pflanze ein.

Ubrigens spielt beim Absterben nach Kahlfraß noch ein anderes Moment als die Vernichtung der Assimilationsorgane mit herein, nämlich die Ưberhitzung des Kambiums, worauf $\mathrm{R}$. H a r tig hingewiesen hat. Wenn die Nadeln entfernt sind, hört natürlich die Verdunstung, die ja wesentlich durch die Nadeloberfläche geschieht, auf, und damit hat natürlich auch das Aufsteigen des Wasserstroms ein Ende. Dieser aber, der aus dem kühleren Boden kommt, ist es, der normalerweise die Temperatur der vegetierenden Kambium- und äußeren Splindschichten soweit herabsetzt, daß eine zu hohe Erwärmung derselben infolge der Besonnung während der heißen Tagesstunden vermieden wird. Die Kambialtemperatur einer entnadelten Fichte ist nach $\mathrm{R}$. H a r tig im Sommer durchschnittlich um $8{ }^{\circ} \mathrm{C}$. höher, als die einer benadelten unter gleichen Verhältnissen. In kahlgefressenen, schattenlosen Fichtenbeständen steigerte sich nach $\mathrm{H}$ a $\mathrm{r}$ tig bei direkter Besonnung die Temperatur des Kambiums bei $26^{\circ} \mathrm{C}$. Luftemperatur bis auf $44^{\circ}$. So wird auf der Sonnenseite der Bäume das Kambium bis über die Grenze der Lebensfähigkeit der Zellen erwärmt oder doch wenigstens seine Temperatur soweit erhöht, daß im Folgejahr das nahrungslose Kambium abstirbt.

In denjenigen Fällen, in denen die Pflanze die Krankheit übersteht, machen sich häufig verschiedene Folgeerscheinungen bemerkbar, teils 
vorübergehender, teils dauernder Natur, die mehr oder weniger deutlich erkennen lassen, daß die betreffende Pflanze einen Angriff durchzumachen hatte. Sie bestehen entweder in Kümmerungserscheinungen oder aber in Bildung von Ersatzteilen.

$\mathrm{Zu}$ den Kümmerungserscheinungen gehört z. B. das Kleinbleiben der Blätter und Nadeln im Jahre nach der Beschädigung. Bei den Nadelhölzern entstehen dann jene kurznadeligen Triebe, die als „Bürstentriebe“ bezeichnet werden (Fig. 183). Als Kümmerung ist ferner die Verminderung des Blühens und Samentragens aufzufassen, die so häufig nach stärkerem Raupenfraß, wie z. B. nach dem der Nonne, des Goldafters, Rotschwanzes usw. zu beobachten ist, und die in forstlicher Beziehung (durch Verminderung oder gänzlichen Ausfall der Mast) weit wichtiger ist als die oben erwähnte direkte Zerstörung der Samen durch die verschiedenen Sameninsekten. Und endlich ist als die wichtigste Kümmerungserscheinung der Zuwachsverlust zu nennen, der sich sowohl auf das Längenals auf das Dickenwachstum beziehen kann.

Die Verminderung des Längenzuwachses zeigt sich darin, daß in den auf die Beschädigung folgenden Jahren die Endtriebe der Zweige und besonders die Gipfeltriebe der Nadelhölzer kürzer bleiben. Erst später erhalten sie wieder ihre normale Länge, wie aus dem in Fig. 184 abgebildeten Wipfel einer Fichte $\mathrm{zu}$ ersehen ist, die nach einer im Jahre 1857 erlittenen Schädigung zunächst bis 1855 nur ganz kurze

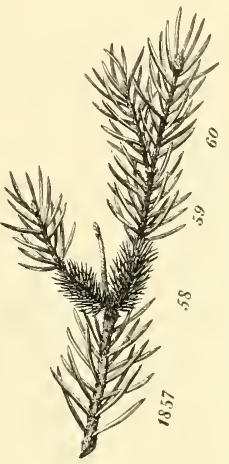

Fig. 183. Seitenzweig einer im Jahre1856 durch Nonnenfraß geschädigten Fichte, welche im Jahre 1858 nur Bürstennadeln produzierte. - (N.)

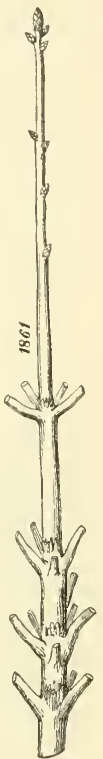

Fig. 184. Entasteter Wipfel einer im Jahre 1857 von der Nonne kahlgefressenen Fichte, die verschiedene Länge der Jahrestriebe zeigend. - (N.) Gipfeltriebe gebildet und erst im Jahı 1861 wieder einen kräftigen Trieb erzeugte. Solche Verkürzungen finden wir sehr häufig als Folge des Fraßes von Raupen, Blattwespen usw.

Die Minderung des Stärkenzuwachses tritt mitunter schon im Fraßjahr, häufiger aber erst im Nachjahr ein. Er prägt sich am deutlichsten an den Jahresringen aus, die nach einem größeren Fraß stets schmäler und schwächer werden, und zwar mitunter auf viele Jahre hinaus (Fig. 185). Bei alleı größeren Raupenkalamitäten, sofern sie nicht zum Absterben der Bestände führen, stellt der Zuwachsverlust das wichtigste Moment bei der Beurteilung des Schadens dar. 
Was die Bildung ron Ersatzteilen betriff, so kann diese recht rerschiedener Art sein; wir erimmern z. B. an die "Rosettentriebe" (Fig. 186), die bei der Kiefer nach Kahlfraf proleptisch aus Seitenknospen entstehen, und die ganz kurz bleibende Triebe darstellen, die dichtstehende, verkürzte, breite und gesägte einfache Nadeln tragen; ferner an die sog. "Scheidentriebe“, die aus den am Vegetationspunkt der Kurztriebe zwischen je zwei Kiefernnadeln befindlichen, gewöhnlich ruhenden Scheidenknospen sich entwickeln, und welche zwar in der Regel kein hohes Alter erreichen, jedoch provisorisch für das Leben des Baumes von hoher Bedeutung sein können; ferner an die Knospenwucherungen, die nach völliger Entnadelung und Zerstörung der Maitriebe der Fichte am Grund der rorjäbrigen oder älteren Triebe oft in überreicher Fülle auftreten (Fig. 18i); - ferner an den Ersatz des Wipfeltriebes durch einen Seitentrieb des obersten Quirls, wie er nach Zerstörung des ersteren durch Retinia buoliana usw. oft eintritt. Endlich sind hier auch

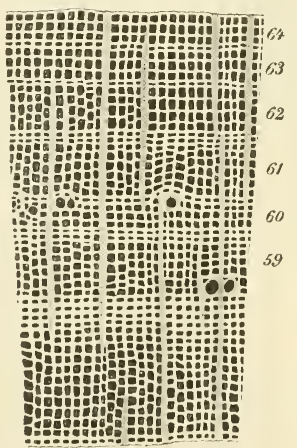

Fig. 185. Die letzten $7 \mathrm{Hol}^{2}$. ringe einer im Jahre 1958 fast ganz kahl gefressenen Kiefern. stange. Nach Ratzeburg. $-(\mathrm{N}$.

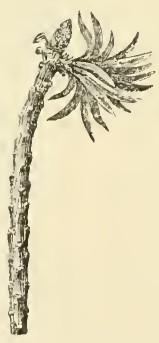

Fig. 186. Rossettentriebe an Kiefer. Nach Ratzeburg. - (N.)

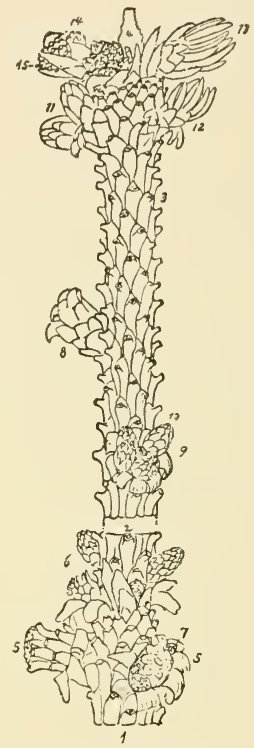

Fig. 187. Ersatztriebbil. dung der Fichte nach völliger Entnadelung und Zer. störung der neuen Maitriebe (4). Die an deren Grunde stehenden Knospenanlagen haben sich zu kräftigen Knospen $(9,10,11)$ oder zu kurzen Ersatztrieben $(12,13,14,15)$ entwickelt. Aus Hartig.

noch die Fälle zu erwähnen, in denen nach ausgedehnten Knospenzerstörungen die aus dem übrig bleibenden Rest sich bildenden Organe, z. B. Nadeln oder Blätter ungewöhnlich groß werden, indem ihnen eben nunmehr der gesamte Saftzufluß zugute kommt.

Solche Verhältnisse wurden von $\mathrm{Kr}$ as an (Englers Botanische Jahrbücher Bd. V, S. 350) nach Blattverletzungen durch Orchestes quercus an Stieleichen beobachtet. Während nämlich häufig der erste Trieb durch die direkten, vom Weibchen dieses Springrüßlers beim Unterbringen seiner Eier verübten An- 
griffe geradezu sistiert erscheint und die verletzten Blätter verkrümmt sind, werden die am Johannistrieb direkt über den verletzten stehenden Blätter ungewöhnlich groß und abnorm geformt, während die am Gipfel stehenden wieder ihre normale Form annehmen.

\section{Grad der Schädlichkeit der Forstinsekten.}

Vom rein theoretischen Standpunkte aus betrachtet, ist jedes Insekt forstschädlich, welches auf einem verwertbaren Forstgewächs Wohnung und Nahrung findet, ebenso wie in der Theorie schon das Abbrechen eines Blattes den Baum schädigt, indem dadurch die respiratorische Oberfläche desselben verringert wird. Aber der hierdurch angerichtete Schaden ist in der Praxis nicht nachweisbar, und auch die durch manche auf Forstgewächsen lebende Insekten bewirkte Schädigung derselben ist so gering, daß wir sie in praktischer Hinsicht durchaus vernachlässigen können. So rerzeichnet z. B. Kaltenbach nicht weniger als $\check{5} 3$ auf und von der Eiche lebende Insekten, von denen wir aber noch nicht einmal dem zehnten Teil eine wirtschaftliche Bedeutung beimessen können.

Doch auch unter den wirtschaftlich in Betracht kommenden Insekten herrschen große Unterschiede bezügl. des Grades ihrer Schädlichkeit; wir teilen daher nach altem Brauche die Forstinsekten ein in "unmerklich schädliche“, "merklich schädliche“ und "sehr schädliche“.

Als „unmerklich schädlich“ bezeichnen wir solche Insekten, welche infolge ihres selteneren Vorkommens oder der Art ihrer Angriffe nur ganz unbedeutende Zerstörungen anrichten, so daß der Wuchs und die Brauchbarkeit des Holzes kaum darunter zu leiden haben. Hierher gehört eine große Anzahl von Insekten, deren Vorkommen und Tätigkeit zwar die Aufmerksamkeit des Forstmannes erregen, die ihm jedoch niemals ernste Sorge bereiten, und ihn auch nur ganz selten zur Ergreifung von Gegenmaßregeln veranlassen werden. Als Beispiele erwähnen wir die Blattwickler (Rhynchites usw.), die meisten der gallbildenden Insekten, ferner viele Blattminierer usw.

„Merklich schädlich“ nennt man solche Insekten, die durch zahlreicheres Auftreten oder durch die Zerstörung wichtiger Pflanzenteile das Wachstum merklich beeinflussen und einzelne Bäume auch zum Absterben bringen können. Ihr Vorkommen kann wohl auch über größere Bestände sich erstrecken, ohne jedoch in diesen Fällen ein größeres oder allgemeines Sterben zu verursachen. In diese Kategorie gehört die Mehrzahl der Forstinsekten; immer und überall treten sie dem Forstmann entgegen, ihm stets kleinere oder größere Unannehmlichkeiten, Arbeit, Ausgaben (für die Bekämpfung) und Verluste bereitend. Als Beispiele seien genannt die Bockkäfer, die meisten Borkenkäfer, Pracht- und Blattkäfer, die meisten Kleinschmetterlinge, viele Schild- und Blattläuse usw.

Unter den „sehr schädlichen“ sind je nach ihrem biologischen Verhalten und der Art ihrer Wirkung zweierlei Kategorien von Insekten zu unterscheiden: Die einen wirken, kurz gesagt, chronisch, die anderen akut. Die ersteren schließen sich biologisch den "merklich schädlichen" 
Insekten an, insofern, als sie sich durch eine gewisse Ständigkeit ihres Vorkommens auszeichnen, unterscheiden sich aber von ihnen durch die größere Ausdehnung des Schadens, indem ihnen zahlreiche Pflanzen, ja ganze Kulturen oder auch Bestände zum Opfer fallen können. Als die wichtigsten Vertreter dieser Gruppe seien genannt Hylobius und der Engerling. - Die akut wirkenden Insekten treten dagegen für gewöhnlich nur sehr selten auf, viel seltener als die „merklich schädlichen“, so daß sie dem Forstmann mitunter jahrzehntelang nicht begegnen. Dann auf einmal aber setzt explosionsartig eine enorme Massenvermehrung ein, wodurch jene gefürchteten Kalamitäten oder Katastrophen verursacht werden, durch welche in kurzer Zeit die schönsten Wälder vernichtet werden können. Die Zahl dieser „katastrophalen Insekten“ ist verhältnismäßig gering; es genügen aber die wenigen vollkommen, die forstliche Welt fortwährend in Atem zu halten und aufs schwerste zu beunruhigen. Die wichtigsten Forstschädlinge dieser Art sind die Nonne, die neuerdings geradezu in erschreckendem Maße überhand nimmt, ferner der Kiefernspinner, die Kieferneule, der Kiefernspanner, der Fichtenborkenkäfer, verschiedene Blattwespen usw.

Natürlich sind die hier aufgestellten Begriffe keine absolut feststehenden und die Gruppen keine scharf abgrenzbaren, da es einmal manche Insekten gibt, deren Beschädigung es zweifelhaft erscheinen läßt, ob man sie zu der einen oder der anderen Gruppe stellen soll, und andererseits es auch vorkommen kann, daß für gewöhnlich „unmerklich schädliche“ Insekten „merklich schädlich" oder „merklich schädliche" „sehı schädlich" werden. In den meisten Fällen jedoch bietet die Einordnung der Schädlinge in jene drei Gruppen keine Schwierigkeit, so daß es sich im Interesse der einfachen Verständigung wohl empfiehlt, die angegebenen Bezeichnungen im obigen Sinne beizubehalten.

Die Forstinsektenkunde beschäftigt sich in erster Linie und am eingehendsten mit den sehr schädlichen und den merklich schädlichen Insekten, während die unmerklich schädlichen dagegen wesentlich zurücktreten. Völlig gleichgültige oder indifferente Insekten haben überhaupt nur dann Interesse für sie, wenn deren Aussehen oder Tätigkeit eine Verwechslung mit Schädlingen als möglich erscheinen lassen und den Forstmann dazu verleiten können, Maßregeln gänzlich ohne Not zu ergıeifen; also wenn es sich, wie Ratzeburg sagt, um „täuschende Forstinsekten“ handelt.

Der Grad der Schädlichkeit ist nicht etwa für jedes Forstinsekt cin für allemal feststehend, sondern hängt von einer ganzen Reihe verschiedener Faktoren ab.

In erster Linie kommt natürlich die Biologie des betreffenden Insekts in Betracht, d. h. die Art und Weise seines Angriffes, ob kauend, ob saugend, ob an Wurzeln, Blättern, Knospen, Zweigen, alten oder jungen Trieben, Haupt- oder Nebentrieben, oder am Stamm fressend, ob es verschwenderisch, ob sein Nahrungsbedürfnis ein großes ist; sodann seine Ver- 
mehrungsfähigkeit, die wiederum einerseits von der Zahl der Eier, andererseits von der Zahl der Parasiten und anderer Feinde, sowie von der Widerstandsfähigkeit der veı schiedenen Entwicklungsstufen gegen Witterungsunbilden usw. abhängig ist; des weiteren seine Beweglichkeit resp. sein Wandervermögen usw.

Doch ist es nicht allein der angreifende Teil, der die Größe des Schadens bestimmt, sondern eine sehr wesentliche Rolle spielt dabei auch die Empfindlichkeit der Pflanze selbst, und zwar insofern, als nicht nur jede einzelne Pflanzenart auf die gleichen Angriffe verschieden reagiert, sondern auch ein und dieselbe Pflanzenart je nach ihrem Alter, Gesundheitszustand und je nach der Jahreszeit, in welcher der Angriff erfolgt, sich sehr ungleich verhalten kann. Außerdem kommen auch noch andere Momente, wie Witterung, die waldbaulichen Verhältnisse, die Höhenlage des Forstortes in Betracht, so daß man also viele Punkte berücksichtigen muß, wenn man sich ein richtiges Bild von der Schädlichkeit eines Insektes in einem bestimmten Fall machen will.

Was das verschiedene Verhalten der einzelnen Holzarten gegenüber Insektenangriffen betrifft, so lehrt die Erfahrung, daß das weit weniger reproduktionsfähige Nadelholz viel mehr Schaden leidet als das Laubholz. Die für Mitteleuropa forstlich wichtigen Laubhölzer treiben alljährlich vollständig neue Blattorgane, die meisten Nadelhölzer erzeugen solche nur in den neuen Trieben; kein Wunder, daß eine ausgedehnte Entnadelung die Kiefer, Fichte oder Tanne viel mehr benachteiligen muß, als die Entlaubung eine Buche oder Eiche schädigt. Eine vollständige Entnadelung bringt unseren Nadelhölzern (mit Ausnahme der Lärche) gewöhnlich den Tod, während die meisten Laubhölzer selbst einen wiederholten Kahlfraß relativ gut ertragen; die sommergrüne Lärche verhält sich in dieser Beziehung ähnlich wie die Laubhölzer; so wird sie z. B. durch den Jahr für Jahr wiederkehrenden Fraß der Miniermotte nur selten völlig getötet. Dieser Unterschied zwischen Laub- und Nadelholz wird physiologisch dadurch bedingt, daß die Laubhölzer in Holz, Rinde und Markgewebe durchschnittlich weit mehr Reservestoffe und auch einen weit größeren Vorrat an schlafenden Knospen besitzen als die Nadelhölzer. Ferner ist zu bedenken, daß die Nadeln eines Nadelbaumes in einer längeren Reihe von Jahren erworben sind, so daß ein kahlgefressener Nadelbaum, um wieder zu seiner vollen Belaubung zu kommen, in kurzer Zeit das neubilden müßte, zu dessen Erzeugung er mehrere Jahre gebraucht hat, während die Blätter des Laubbaumes stets einjährig sind.

Auch gegen andere Schädigungen, z. B. Borkenkäferfraß, verhalten sich die Laubhölzer im allgemeinen widerstandsfähiger als die Nadelhölzer, so können z. B. Birken jahrelang von Eccoptogaster Ratzeburgi, oder alte Ulmen jahrelang von E. scolytus, oder Eschen jahrelang von Hylesinus fraxini bewohnt werden, ehe sie völlig absterben, während den Nadelhölzern ein stärkerer oder länger dauernder Borkenkäferfraß gewöhnlich schon bald den Tod bringt. Die verschiedensten Arten Bockkäfer, die Larven der Gattungen Sesia und Cossus hausen in alten Laubbäumen jahrelang, während Fichten oder Lärchen, 
dic ron Tetropium luridum befallen sind, in kurzer Zeit absterben. Hierhergehöriger Beispiele ließen sich noch viele bringen. Jedenfalls ist Tatsache, daß ein so ausgedehnter Schaden, wie ihn der Borkenkäfer oder die Nonne in Fichtenwaldungen, oder der Kiefernspinner oder -spanner in Kiefernwaldungen hervorrufen, dem Laubwald vollständig fremd ist. - Am empfindlichsten unter unseren Nadelhölzern ist im allgemeinen die Fichte, dann folgt die Kiefer und die Tanne, und endlich die Lärche, welch letztere ja, wie schon erwähnt, in dieser Beziehung dem Laubholz nahe kommt. Natürlich unterliegen auch die widerstandsfähigeren Hölzer den Insektenangriffen, wenn diese intensiv genug sind; so wird z. B. die W eißtanne, die erfahrungsgemäß viele Mißhandlungen verträgt, garnicht selten durch Borken- und Rüsselkäferfraß (Ips curvidens und P'issodes piceae) getötet, und die Lärche wird in ihrer Heimat leider nur zu häufig ein Opfer des grauen Lärchenwicklers, so daß sie aus manchen Gegenden sogar bereits gänzlich verdrängt wurde.

Nicht weniger als die Holzart ist das Alter der befallenen Pflanzen bei der Abschätzung der Schädlichleit eines Forstinsektes zu berücksichtigen. Im allgemeinen erweisen sich gegen die meisten Insektenangriffe - mögen diese in Blatt- oder Knospen-, Rinden- oder Wurzelfraß bestehen - die jungen Pflanzen empfindlicher als die alten. Eine ein- oder zweijährige Kiefer oder Fichte wird viel leichter von dem großen braunen Rüsselkäfer getötet als eine schon etwas kräftigere, fünf- bis sechsjährige Pflanze; die einjährigen Kiefernpflänzchen werden durch die Saateule sicher getötet, zweijährige und ältere dagegen meist nur mehr oder weniger beschädigt. Es gibt jedoch auch Fälle, in denen umgekehrt die jüngeren Pflanzen einen Fraß besser überstehen als die älteren. So berichtet Hartig, daß kleine Fichtenpflanzen von einigen Dezimeter Höhe nach Nonnenkahlfraß3 sich sofort wieder begrünen und so sich völlig gesund erhalten können, während ältere Pflanzen von $1 \mathrm{~m}$ an aufwärts, selbst wenn sie sich wieder begrünt haben, meist schon im Herbst des Fraßjahres zum Absterben kommen.

Von nicht zu unterschätzender Bedeutung für die Höhe des Schadens ist ferner der Gesundheitszustand der Pflanzen. Eine geschwächte Konstitution der Pflanze - mag sie eine Folge von ungünstigen Standortsverhältnissen sein oder von Rauchschäden oder von vorhergegangener großer Trockenheit usw. - bedeutet stets eine Erhöhung des Insektenschadens. So kann man z. B. bei einem gewissen Grad von Lichtfraß einem Kiefern- oder Fichtenbestand auf besseren Standortsklassen eine weit günstigere Prognose stellen als einem Bestand auf schlechteren Standortsklassen. Ferner ist es eine bekannte Erscheinung, daß Laub- und Nadelhölzer, welche bald nach der Verpflanzung, also ehe sie sich vollständig erholt haben, von Insekten angegangen werden, viel leichter ein Opfer dieser Angriffe werden als ein oder zwei Jahre später. Außerdem ist für viele Insekten eine geschwächte Konstitution der Pflanze geradezu Bedingung für eine stärkere Vermehrung, so daß das gelegentliche Vorkommen solcher (sekundärer) Insekten in völlig gesunden Wäldern uns weit weniger zu beunruhigen braucht als in schlecht wüchsigen und kümmernden Beständen. 
So werden z. B. Erlen, deren Standort zeitweiser Trockenheit ausgesetzt ist, gewöhnlich so stark von Cryptorhynchus lapathi und anderen Erleninsekten befallen, daß sie verkrüppeln und mit der Zeit auch eingehen, während in gut stehenden Erlen der Rüsselkäfer und die anderen stammbewohnenden Schädlinge nur selten in größerer Zahl angetroffen werden.

Auch die Bodenheschaffenheit an und für sich kann einen wesentlichen Einfluss auf die Schädlichkeit eines Insektes haben, insofern, als trockene, durchlässige Böden für solche Forstinsekten, die im Boden überwintern (wie z. B. Kiefernspinner und -spanner, Kieferneule usw.) weit günstiger sind als feuchte Böden, die vor allem der Vermehrung der verschiedenen insektentötenden Pilze Vorschub leisten.

Des weiteren kommen in Betracht die Witterungsverhältnisse, die in zweierlei Richtungen wirken können: einmal dadurch, daß sie die Entwicklung und Vermehrung der Insekten begünstigen oder benachteiligen, und sodann dadurch, daß sie auch die Widerstandskraft der beschädigten Pflanzen erhöhen oder vermindern können. Es ist bereits oben erwähnt, welch bedeutenden Einfluß die Temperatur auf die Dauer der Entwicklung haben kann, so daß in sehr warmen Jahren sogar die Zahl der Generationen vermehrt werden kann, wie das auf S. 172 erwähnte Beispiel von Ips typographus deutlich lehrte. Daß dadurch natürlich die Schädlichkeit eines Insektes wesentlich gesteigert wird, ist ohne weiteres klar. Andererseits kann durch Witterungseinflüsse die Vermehrungsenergie der Insekten auch herabgesetzt werden. Man hat in dieser Beziehung früher allerdings etwas zu optimistisch gedacht, indem man z. B. dem Frost eine weit schädlichere Wirkung auf das Insektenleben zuschrieb, als ihm nach den neueren Untersuchungen, nach denen manche Insekten erstaunliche Kältegrade ohne Schaden ertragen können, zukommt. Immerhin kann plötzlich eintretende starke Kälte, und vor allem öfterer jäher Wechsel von hohen und niederen Temperaturen sehr ungünstig auf die Vermehrung der Insekten einwirken, und dadurch also die Gefahren für den Forstmann herabmindern. -- Der Einfluß der Witterung auf die Pflanzen ist nicht minder groß: so gehen manche durch Insekten beschädigte Pflanzen, die bei normaler Witterung sich leicht wieder erholt haben würden, in sehr kalten Wintern (durch Erfrieren der mangelhaften verholzten Triebe) oder auch in sehr heißen Sommern (durch Vertrocknen oder Überhitzung) zugrunde. Sehr heiße trockene Sommer sind oft auch die erste Veranlassung für eine starke Vermehrung der Schädlinge; so hat das außergewöhnlich trockene Jahr 1911 vielerorts zu einer beängstigenden Vermehrung der Borkenkäfer geführt, indem eben durch die anhaltende Trockenheit der Saftzustand der Bäume auf ein den Borkenkäfern zusagendes Maß gebracht wurde.

Ferner ist auch die Jahreszeit, in welcher die Schädigung erfolgt, in Rechnung zu ziehen. Denn die Wirkung eines Insektenangriffes kann sehr rerschieden sein, je nachdem derselbe schon zeitig im Frühjahr oder Vorsommer, oder aber erst im Herbst einsetzt, wobei außerdem auch die einzelnen Holzarten sich ungleich rerhalten. Bezüglich des Nadel- oder Blattfraßes kann man im allgemeinen sagen, daß für Nadel- 
hölzer ein im Frühjahr oder im ersten Sommer erfolgender Fraß schädlicher ist als ein später Herbstfraß. Dies hängt wohl damit zusammen, daß die Nadelhölzer nur relativ wenig Reservestoffe besitzen, so wenig, daß sie allein nicht einmal zur vollständigen Ausbildung der neuen Jahrestriebe und Nadeln ausreichen, sondern daß auch die assimilatorische Tätigkeit der alten Nadeln dazu notwendig ist, um die noch erforderlichen Bildungsstoffe zu produzieren. Ein Frühjahrs- oder früher Sommerfraß trifft demnach den Nadelbaum meist zu einer Zeit, in der die Reservevorräte in den $Z$ weigen durch die Ausbildung der Maitriebe größtenteils erschöpft sind. Aus diesem Grunde ist z. B. der Nonnenfraß, der ja in die Monate Mai und Juni fällt, so sehr verderblich; und daher entscheidet auch beim Kiefernspinner nicht der Herbst-, sondern der Frühjahrsfraß, zumal bei dem letzteren häufig auch die Knospen und jungen Triebe mit zerstört werden. Bein Kiefernspannerfraß werden solche Kiefern, die noch bis Ende September gut benadelt waren, und erst im Oktober kahl gefressen werden, im nächsten Jahr wieder ergrünen und sich erholen, da die Triebe und Knospen nicht nur völlig ausgebildet waren, sondern auch schon einen größeren Vorrat an Reservestoffen abgelagert enthielten, vermöge dessen im nächsten Frühjahr neue, wenn auch nur relativ kurze Triebe entstehen (Hartig). - Den Laubhölzern schadet ein Frühjahrsfraß weit weniger, da sie infolge der reichlich vorhandenen Reservestoffe auch nach völligem Kahlfraß sich im gleichen Jahre wieder begrünen können. So sehen wir die Wiederbegrünung der vom Eichenwickler kahl gefressenen Eichen sehr rasch, sogar unter Verfrühung der Johannistriebe, erfolgen. ${ }^{1}$ ) Darin kann allerdings auch eine gewisse Gefahr liegen, insofern als die neugebildeten Blätter oft viel später abfallen, und dann zeitig kommender Schnee großen Schaden anrichten kann. - Auch die Angriffe der Borkenkäfer und anderer rindenminierenden Insekten ergeben ein verschiedenes Bild, je nach der Jahreszeit, in der sie erfolgen. „Wenn die erste Generation der Borkenkäfer im Frühjahr den Baum zur Zeit des aufsteigenden Saftes befällt und dadurch Saftausfluß und Hemmung des Saftstroms zur Krone verursacht, so ist die Wirkung des Fraßes, insbesondere bei warmem Wetter, rasch an der jungen Krone zu bemerken, welche vergilbt und den Tod des Baumes beim Nadelholz ankündigt, während die Rinde fest bleibt. Ganz anders ist die Wirkung der späteren Generationen im Nachsommer: ihr Angriff trifft den Baum in der Periode des absteigenden Saftes, weshalb zunächst keine Reaktion von Seiten der Krone erfolgt, die grün und unversehrt bleibt. Dagegen strömt der nahrungsreiche Saft aus den Bohrlöchern der Rinde, und es wird nun die kambiale Schichte, welche jetzt im Zuwachs und der Neubildung steht, notleiden, was den Abfall der Rinde zur Folge haben kann. Der Tod erfolgt in diesem Fall natürlich viel langsamer." (NüBlin.)

Von großer Bedeutung für die Schädlichkeit eines Insekts sind ferner auch die waldbaulichen Verhältnisse, insofern, als reine, gleichalterige

1) Prof. Borgman $\mathrm{n}$ beobachtete (nach persönlicher Mitteilung) in Eberswalde, daß ein von der Nonne völlig kahlgefressener Buchenunterstand (unter Kiefern) im September wieder völlig grün war, gleich als ob nichts passiert wäre. 
Bestände im allgemeinen einer Massenvermehrung von Schädlingen weit günstiger sind und demgemä $B$ eine höhere Gefahr bedeuten als die gemischten Bestände. „Solche Bestände stellen gleichsam künstliche Brutstätten für dic Schädlinge dar". Mit vollem Recht betont daher Nüßlin, daß „in der Waldwirtschaft die Einführung der künstlichen Verjüngung und die Erziehung reiner Bestände von gleichem Alter im Sinne der praktischen Forstinsektenkunde überall da ein Mißgriff ist, wo die Natur eine andere gleichrentable waldbauliche Behandlung gestattet“.

Auch andere wirtschaftliche Maßregeln können von wesentlichem Einfluß auf die Größe des Schadens sein. In welchem Maße dies der Fall sein kann, können wir z. B. daraus ersehen, daß die Borkenkäfer in unseren sauber gehaltenen Wäldern unter normalen Witterungsverhältnissen usw. kaum eine nennenswerte Gefahr bedeuten, während sie in Nordamerika, wo man noch kaum eine Forstwirtschaft in unserem Sinne, geschweige denn eine saubere Forstwirtschaft kennt, die größten Verwüstungen in den Wäldern anrichten und in manchen Gegenden sogar die Fortexistenz der Wälder überhaupt in Frage stellen.

Endlich sei noch auf die geographische Lage als wichtigen Faktor bei der Bestimmung des Schädlichkeitsgrades hingewiesen. Viele Insekten, die in gewissen Lagen zu Besorgnissen Anlaß geben, sind in anderen Gegenden völlig harmlos. So sind z. B. in Norwegen ein großer Teil der Schädlinge, die bei uns sehr beachtenswert sind, ohne jede praktische Bedeutung, weil eben ihre Vermehrung (wohl infolge der klimatischen Verhältnisse) in engeren Grenzen bleibt. Auch in der vertikalen Verbreitung machen sich solche Unterschiede deutlich bemerkbar; so braucht man z. B. in 6-700 m Meereshöhe die Nonne wenig zu fürchten, während sie vielleicht nicht weit davon entfernt, in tieferen Lagen, arge Verwüstungen anrichtet.

\section{Wirkung der Insektenschäden auf den forstlichen Wirtschaftsbetrieb.}

Jedes schädliche Auftreten von Forstinsekten ist mit einer Störung oder Beeinträchtigung des forstlichen Wirtschaftsbetriebes verbunden, einmal weil die Vorbeugungs - und Vertilgungsmaßregeln Zeitverlust und Kosten verursachen, und sodann, weil unter (Jmständen das ganze Einrichtungswerk (der Betriebsplan) umgestoßen werden kann. Beides bedeutet natürlich eine Verminderung des Waldertrages, und zwar das letztere Moment noch in weit höherem Maße wie das erstere, besonders wenn die Notwendigkeit entsteht, noch hiebsunreife Bestände einzuschlagen. Dagegen kommt das, was man in früheren Zeiten als unangenehme Folge von ausgedehnten Insektenkatastrophen fürchtete, nämlich das Sinken der Holzpreise durch Überfüllung des Marktes, heute kaum mehr in Betracht, da einmal die Verkehrsverhältnisse viel besser gestaltet sind, und da sodann auch der Holzbedarf Deutschlands so enorm ist, daß er nicht annähernd aus unseren Wäldern gedeckt werden kann. Hat man doch für die vielen Spanner-, Nonnen- und Windbruchhölzer, die in den letzten Jahren auf den 
Markt gekommen sind, überraschend gute Preise erzielt. Immerhin können ausgedehnte Insektenschäden auch bezügl. der Holzverwertung erhebliche Schwierigkeiten zur Folge haben, die hauptsächlich darin begründet sind, daß das Holz rechtzeitig und rasch eingeschlagen werden muß und die hierzu nötigen Arbeitskräfte nicht immer so schnell zu beschaffen sind. In solchen Fällen kann dann allerdings eine Entwertung des Holzes eintreten, abgesehen davon, daß dadurch der Vermehrung sekundärer Insekten Vorschub geleistet wird.

Wo die Bestände nicht getötet, sondern nur licht gefressen werden, besteht der Schaden hauptsächlich darin, daß der Zuwachs einzelner Bäunie oder ganzer Bestände herabgedrückt wird. Die Verminderung des Bestandzuwachses kann durch Beschädigung sämtlicher oder wenigstens der meisten der den Bestand bildenden Bäume erfolgen, wie z. B. durch Nonnenfraß in Kiefernwäldern. In solchen Fällen ist der Schaden nicht so groß, weil nach wenigen Jahren der volle Zuwachs wieder eintritt. Die Bestandszuwachsverminderung kann aber auch dadurch erfolgen, daß eine größere oder kleinere Anzahl von Einzelbäumen getötet wird (z. B. durch den Harzrüsselkäfer), während die anderen unversehrt bleiben. Dann ist der Schaden weit beträchtlicher, weil die Verminderung der den Bestand bildenden Bäume eine starke Verlichtung zur Folge haben kann, die ihrerseits mit einer schädlichen Rückwirkung auf den Bodenzustand verbunden ist (Verangerung, Graswuchs usw.); und dies bedeutet wiederum eine Verringerung des Gesamtzuwachses und meist auch ein Hindernis für die spätere Kultur.

Sehr störend im Wirtschaftsbetrieb machen sich auch die Kulturverderber, vor allem der Rüsselkäfer und Engerling bemerkbar. Denn die durch deren Zerstörungen fortwährend notwendig werdenden Ausbesserungen zum Ersatz der getöteten Pflanzen beanspruchen einen großen Aufwand an Zeit, Arbeitskräften und Kosten.

Endlich ist noch die Entwertung des Holzes durch die technischen Schädlinge in Betracht zu ziehen, die natürlich ebenfalls an der Verminderung des Waldertrages einen größeren oder geringeren Anteil haben können. Doch tıitt dieses Moment insofern sehr zurück gegenüber den vorhergenannten Störungen des Wirtschaftsbetriebes, als Gegenmaßnahmen, wie z. B. rechtzeitiges Schälen der Hölzer (bei $X$. lineatus), vielfach unschwer durchführbar sind.

\section{Literatur.}

Insekten im allgemeinen Naturhaushalt usw. (S. 187-194).

Escherich, K., Ameisen und Pflanzen, eine kritische Skizze mit besonderer

Berücksichtigung der forstlichen Seite. Thar. forstl. Jahrb., Bd. 60, 1909,

S. $66-96$.

-- Die angewandte Entomologie in den Vereinigten Staaten. Berlin 1913.

G öl d i, E. A., Die sanitarisch-patholog. Bedeutung der Insekten usw. Berlin 1913. K i r c h ne r, O. v o n, Blumen und Insekten. Leipzig 1911.

Pillips, C. F., The status of apiculture in the United Staates. Bur. of Entom., Bull. Nr. 75, Pat. VI. 1909.

$\mathrm{R}$ a $\mathrm{m}$ a $\mathrm{r} \mathrm{n}$, Bodenkunde. III. Aufl., Berlin 1912.

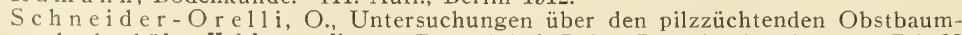
borkenkäfer Xyleborus dispar. Zentralbl. f. Bakt., Parasitenkunde usw., Bd. 38 
(1913). Hierin findet sich die übrige Literatur über pilzzüchtende resp. pilzverbreitende Insekten.

Sernander, Rutger, Entwurf einer Monographie der europäischen Myrmecochoren. Upsala 1906 (Kungl. Svenska Vetenskapsakademiens Handlingar, Bd. 41, Nr. 7).

Nützliche und schädliche Forstinsekten usw. (S. 194-220).

A $1 \mathrm{tu}$ m, B., Forstzoologie, III. Bd. Berlin 1875.

Eckste in, K., Forstliche Zoologie. Berlin 1897.

H a r tig, R., Lehrbuch der Pflanzenkrankheiten, 3. Aufl., 1900.

H e s s, Der Forstschutz, 3. Aufl. 1898.

$\mathrm{K}$ a $1 \mathrm{t}$ en bach, J. H., Die Pflanzenfeinde aus der Klasse der Insekten. Stuttgart 1874 .

Kernervon Marila un, Pflanzenleben, 2. Aufl. Leipzig und Vien 1896.

$\mathrm{K}$ üster, Ernst, Die Gallen der Pflanzen. Ein Lehrbuch für Botaniker und Entomologen. Leipzig 1911.

$\mathrm{N}$ ü B 1 i n, O., Leitfaden der Forstinsektenkunde, 2. Aufl. Berlin 1912.

$\mathrm{R}$ a tz e burg, J. T. H., Die Forstinsekten. Berlin 1839-44.

- Die Waldverderbnis usw. Berlin 1866-68.

R os s, H., Die Pflanzengallen Mittel- und Nordeuropas, ihre Erreger und Biologie. Jena 1911.

R übs a a men, Ew. H., Die Zoocecidien. I. Liefer., Stuttgart 1911. 
Kapitel VI.

\section{Natürliche Beschränkung der Insektenvermehrung.}

Der Wald stellt eine Lebensgemeinschaft dar, welche außer den ihn bildenden Bäumen auch noch zahlreiche andere pflanzliche und tierische Organismen umfaßt, deren Artenzahl je nach der Art des Waldes (Laub-, Nadelwald, rein oder gemischt) und je nach seinem Zustand und seiner geographischen Lage usw. recht verschieden ist. So kommen z. B. in einem gemischten Wald weit mehr Insektenarten vor, als in einem reinen Fichtenwald. Doch können wir für jeden Wald mit bestimmten Eigenschaften und in einer bestimmten geographischen Lage eine annähernd bestimmte Fauna oder Flora voraussetzen, und zwar nicht nur bezügl. der artlichen Zusammensetzung, sondern auch der Individuenzahl; d. h. unter normalen Verhältnissen wird in einem gegebenen Wald auf die Flächeneinheit eine annähernd bestimmte Zahl von Individuen der verschiedenen Tier- und Pflanzenarten entfallen („Normalzahl“ oder „eiserner Bestand“). Diese Zahl ist je nach den Lebensbedürfnissen und der Vermehrung der einzelnen Arten, sowie nach der Zahl ihrer Feinde usw. sehr verschieden, so daß die einen Arten häufiger, die anderen seltener vertreten sind. So herrscht also zwischen den Mitgliedern der Lebensgemeinschaft ein gewisses Zahlenverhältnis, welches unter normalen Umständen annähernd konstant bleibt.

Diese Beständigkeit der Fauna und Flora ist uns eine so alltägliche und gewohnte Erscheinung, daß sie uns ganz selbstverständlich dünkt. Sie ist aber in Wirklichkeit keineswegs so einfach zu erklären. Wenn wir die vielen Faktoren (die zum Teil reine Zufälligkeiten darzustellen scheinen) berücksichtigen, durch deren Zusammenwirken die Beständigkeit gewährleistet wird, so müssen wir uns vielmehr darüber wundern, daß das Floren- und Faunenbild eine verhältnismäßig so große Konstanz aufweist.

Schon die Art der Vermehrung der Organismen scheint in einem direkten Gegensatz zu jener Beständigkeit zu stehen; denn sämtliche Organismen vermehren sich in geometrischer Progression, d. h. die Individuenzahl jeder folgenden Generation stellt ein mehrlaches der Individuenzahl der vorhergegangenen Generation dar. Demnach müßte die Zahl der Nachkommen von Generation zu Generation eine Steigerung erfahren. Nehmen wir z. B. einen Schmetterling, der 150 Eier legt, so kann unter günstigen Umständen wohl ein Drittel dieser Eier im nächsten Jahr Weibchen liefern, die begattet werden und selbst wieder je 150 Eier, also im ganzen 7500 Eier legen. Nehmen wir nun wieder an, daß nur ein Drittel dieser Eier (also 
2500 Stück) im darauffolgenden Jahr sich zu fortpflanzungsfähigen Weibchen entwickeln, so beträgt die Zahl der von den Nachkommen eines einzigen Weibchens produzierten Eier schon im zweiten Jahre 375000 Stück. Aber auch bei einer weit geringeren Fortpflanzungsziffer erreicht die Zahl der Nachkommen bereits in relativ kurzer Zeit eine schwindelnde Höhe. „Eine Vogelart, die 5 Jahre lebt und die in diesem Leben 4 mal je 4 Junge erbrütet, würde sich in bereits 15 Jahren auf $=2$ Milliarden vermehren" (Weismann).

Da nun aber, wie oben betont, unter normalen Bedingungen keine merkliche Steigerung der Individuenzahl eintritt, so muß also stets ein großer Teil der Nachkommen zugrunde gehen, resp. vernichtet werden, und zwar, bevor sie zur Fortpflanzung gelangen. Es sind eine ganze Reihe von Faktoren, welche sich in dieses Vernichtungswerk teilen, und so bewirken, daß die den Organismen innewohnende gewaltige Vermehrungsenergie eingedämmt und das „organische Gleichgewicht" erhalten bleibt.

Es kommen dabei hauptsächlich folgende Momente in Betracht:

1. Vernichtung durch Witterungseinflüsse,

2. Vernichtung durch die organische Umwelt,
a) durch Tiere,
b) durch Pilze,
c) durch Mikroorganismen.

\section{Insektenvertilgung durch Witterungseinflüsse.}

Bezüglich der Temperatur lehren uns die oben mitgeteilten Versuche Bachmetjews, daß die Insekten sehr große Schwankungen ertragen und selbst hohe Kältegrade überstehen können, wenn der Übergang langsam vor sich geht. Wenn dagegen der Temperaturfall plötzlich eintritt, dann können allerdings schon weniger tiefe Temperaturen tödlich wirken, vor allem dann, wenn die Insekten noch nicht ihre Winterquartiere aufgesucht haben. Von solchen Frostkatastrophen werden hauptsächlich diejenigen Insekten betroffen, welche bis spät in den Herbst hinein ihren Fraß auf den Bäumen ausüben, wie die Raupen des Kiefernspinners und -spanners, bei welchen denn auch schon mehrmals ein massenhaftes Erfrieren nach früh eintretenden Frösten beobachtet wurde. (Ratzeburg, Waldverderber I, S. 64.)

Befinden sich die Insekten bereits in ihren Winterquartieren oder in ihren normalen Überwinterungsstadien, so sind sie der Gefahr des Erfrierens weit weniger ausgesetzt; ich erinnere an das Nonnenei, welches selbst bei Temperaturen von $-30^{\circ} \mathrm{C}$. nicht zugrunde geht oder an die im Boden überwinternden Tachinentönnchen, welche bei $-20^{\circ}$ noch lebensfähig bleiben usw.

Eine sehr schädliche Wirkung können Temperatureinflüsse aber wieder erlangen, wenn die überwinternden Insekten durch einige abnorm warme Tage vorzeitig aus ihrer Winterruhe geweckt oder zu früh zum Auskriechen veranlaßt werden, indem dann bei Temperaturrückschlägen viele derselben durch Erfrieren zugrunde gehen.

Auch große Hitze und Trockenheit können zur Beschränkung der Insektenvermehrung beitragen, worauf Knoche hingewiesen hat. Nach 
diesem Autor vermögen Temperaturen ron $30-40^{\circ} \mathrm{C}$., wie sie in kahl oder stark lichtgefressenen Beständen in heißen Sommertagen vorkommen können, das frisch gelegte Nonnenei dermaßen zu schädigen, daß der sich entwickeinde Embryo abstirbt, oder wenigstens so geschwächt wird, daß das auskommende Räupchen den geringsten Unbilden zum Opfer fällt.

Die Feuchtigkeit (Regen) kann ebenfalls als insektenvernichtender Faktor wirken. So können starke Platzregen zur Flugzeit der Schmetterlinge eine große Menge derselben vertilgen oder wenigstens das Fortpflanzungsgeschäft empfindlich stören; auch Raupen und Larven können dadurch massenweise zugrunde gehen, entweder direkt (durch Ertrinken), oder auch indirekt (durch Veränderung des Futters und darnach folgende Krankheiten). Auch starke Durchfeuchtung des Bodens im Winter kann den überwinternden Larven und Puppen recht gefährlich werden, und zwar ebenfalls sowohl direkt als auch indirekt, durch Begünstigung der Pilzvegetation.

Endlich können auch noch starke Winde dem Insektenleben Verluste beibringen, besonders, wemn es sich um Gegenden handelt, die nicht weit von der Küste entfernt liegen. Daß große Schwärme von Insekten weit im Meer angetroffen werden, ist garnicht so selten; auch findet man häufig die Küste bedeckt mit angeschwemmten Insekten, welche durch den Sturm aufs Meer verschlagen wurden und dort den Tod fanden. So sind schon mehrfach große Flüge der Nonne durch heftige Stürme auf die Ostsee getrieben worden und daselbst umgekommen.

Wir haben ja oben schon der im Jahre 1856 von den Mellen angespülten enormen Mengen von Nonnenfaltern Erwähnung getan, die die Kurländische Küste auf eine Strecke, von $70 \mathrm{~km}$ bedeckten. Auch an den preußischen Küsten sind 1854, 55 und 56 Nonnenfalter in unzählbaren Mengen vom Wasser, mitunter noch lebend, angetrieben, bis fast nach Danzig hinauf, bei Labiau am kurischen Haff, beim Seebad Kranz, bei Pillau und längs der Nehrung. Ebenso bcrichteten zu jener Zeit Seefischer, daß sie größere Schwärme dieser Falter 3-5 Meilen vom Strande auf der Ostsee angetroffen haben, wobei Boot und Segelzeug mit Faltern stark beflogen waren.

Als indirekten Beweis dafür, wie verderblich der Wind für fliegende Insekten werden kann, können wir auch die oben schon berühıte Erscheinung auffassen, daß3 auf Inseln die Mehrzahl der Insekten die Flügel rückgebildet haben, was zweifellos eine Anpassungserscheinung bedeutet, dusch welche die Gefahr, ins Meer verweht zu werden, wesentlich reduziert wird.

\section{Insektenvertilgende Tiere.}

Diese spielen eine weit größere Rolle für die Niederhaltung der Forstinsekten als die Witterungseinflüsse; ja, auf ihre Tätigkeit ist in erster Linie dic Erhaltung des organischen Gleichgewichtes zurückzuführen. Es kommen dafür hauptsächlich in Betracht die Säugetiere, Vögel, Insekten und andere Arthropoden. Der Anteil, welcher den einzelnen Tieren bei der Eindämmung der Schädlingsvermehrung zukommt, ist sehr verschieden je nach der Art des Schädlings; so spielen bei dem einen die Säugetiere oder Vögel, bei dem anderen die Raubinsekten oder Parasiten die Hauptrolle. Es muß dies jedenfalls ron Art zu Art besonders 
festgestellt werden, und es ist durchaus unstatthaft, in diesem Punkte verallgemeinern zu wollen, und z. B. etwa anzunehmen, daß, wenn wir nur eine genügende Anzahl Vögel in unseren Wäldern hätten, sämtliche Forstinsekten aus den letzteren verschwinden würden.

Leider sind wir heute noch recht ungenügend über die Rolle der verschiedenen insektenvertilgenden Tiere (vor allem der Insekten) im einzelnen unterrichtet, und es wird eine der dringendsten Aufgaben der zukünftigen Forschung sein, darüber möglichste Klarheit zu schaffen. Denn damit wird sicherlich in vielen Fällen auch das Dunkel, das über die Entstehung der Insektenkalamitäten meistenteils noch herrscht, erhellt werden.

Im folgenden sei nur eine allgemeine Übersicht über die insektentötenden Tiere gegeben, während im speziellen Teil bei der Besprechung der verschiedenen Forstschädlinge noch näher im einzelnen darauf eingegangen wird, indem bei allen wichtigeren Schädlingen die hauptsächlichsten Feinde genannt werden.

\section{a) Säugetiere.}

Wenn auch die Säugetiere infolge ihrer relativ geringen Arten- und Individuenzahl den anderen insektentötenden Tieren wesenılich nachstehen, so bedeuten sie doch im Kampfe gegen gewisse Schädlinge eine nicht zu unterschätzende Hilfe für den Forstmann.

Beginnen wir mit den Fledermäusen (Chiroptera), so stellen diese ein stattliches insektenvertilgendes Heer dar. Leben doch die meisten der deutschen Arten ausschließlich von Insekten, und ist auch ihr Nahrungsbedürfnis ein sehr großes, so daß z. B. durch ein Dutzend Maikäfer oder hundert Fliegen, während einer Mahlzeit genossen, der Hunger einer größeren Art bei weitem nicht gestillt wird. Sie liegen denn auch während der ganzen Nacht mit nur wenigen, kurzen Ruhepausen der Jagd auf fliegende Insekten ob, die sie in großer Zahl erbeuten. Diese Art der Jagdausübung schließst auch fast vollkommen aus, daß etwa nützliche Tiere, wie Parasitenlarven oder auch die Imagines von Parasiten und Raubinsekten vernichtet werden, da ja fast keine der letzteren eine nächtliche fliegende Lebensweise besitzen. So ist also die Insektenvertilgung der Fledermäuse ziemlich einwandfrei, indem neben den völlig gleichgültigen fast nur schädliche Insekten ihr zum Opfer fallen, und wir können daher mit Recht „die Waldfledermäuse im engeren wie im weiteren Sinne als des Forstmanns beste Freunde und Gehilfen" (Altum) bezeichnen. Wie sehr die Fledermäuse auch zur Erhaltung des organischen Gleichgewichtes beitragen können, zeigt ein von Altum berichteter Fall, in dem nach Vertreibung der Fledermäuse durch Fällen alter, zahlreiche Verstecke bietender Eichen die Prozessionsspinnergefahr wesentlich erhöht wurde. Die forstlich wichtigste Fledermaus ist zweifellos unsere größte Art, die sog. frühfliegende Fledermaus (Vesperugo noctula), indem diese einmal typische Waldbewohnerin ist und sodann auch sehr häufig vorkommt. Sie ist unersättlich bei der Vertilgung der Maikäfer und größerer und kleinerer Nachtschmetterlinge, z. B. der Prozessionsspinner, Eichenwickler usw. Ihr gegenüber treten die anderen 
den Wald bewohnenden oder wenigstens besuchenden Arten, wie $V$. discolor, pipistrellus, serotinus, Leisleri, murinus usw. an Bedeutung für den Forstmann mehr oder weniger zurück, wenn natürlich auch durch sie fortwährend eine Anzahl Forstinsekten vernichtet wird.

Aus der Ordnung der Insektenfresser (Insectivora) seien zunächst die Spitzmäuse genannt, welche ebenfalls einen nicht geringen Anteil an der Vernichtung der Insekten haben. Forstlich am wichtigsten ist die Waldspitzmaus (Sorex vulgaris), welche als Waldbewohnerin zahlreiche Larven und Puppen von Forstinsekten verzehrt. Tauber fand im Magen einer Waldspitzmaus 17 Tipulalarven, in anderen verschiedene Eulenraupen, Bibiolarven, Rüsselkäfer usw., und Borries berichtet, daß er eine Menge Lophyrus-Kokons gefunden habe, welche in ganz charakteristischer Weise von Spitzmäusen geöffnet und ausgefressen waren. Überaus wertvoll als Insektenvertilger ist ferner der Maulwurf (Talpa europaea). Weın auch für gewöhnlich seine Hauptnahrung in Regenwürmern besteht, ${ }^{1}$ ) so stiftet er doch in engerlingreichen Gegenden großen Nutzen durch massenhaftes Vernichten dieser so überaus schädlichen Larven. Wie sehr der Maulwurf durch Engerlinge angezogen wird, konnte ich deutlich im Kammerforst bei Bruchsal in Baden sehen, wo in solchen Gebieten, die vom Engerling besetzt waren, eine Unmenge Maulwurfshaufen, einer dicht neben dem anderen, vorhanden waren, während in benachbarten engerlingfreien Gebieten die Haufen fast völlig fehlten. Daß auch der Igel (Erinaceus europaeus) sich an der Insektenvertilgung beteiligt, ist ja allbekannt. Magenuntersuchungen ergaben die Reste von großen und kleinen Laufkäfern, Rüsselkäfern, Blattflöhen, Ameisen, Ohrwürmern usw.

Auch Mitglieder der Ordnung der Raubtiere (Carnivora) nehmen gelegentlich oder auch als Hauptnahrung Insekten zu sich. Dem Waidmann am bekanntesten ist dieses vom Fuchs, in dessen Losung sich sehr häufig die unverdauten Reste aller möglichen Insekten finden. Forstlich bemerkenswert in dieser Beziehung ist eine Notiz aus Lieberose in der Lausitz, nach welcher in den dortigen Kiefernwäldern gelegentlich eines Spinnerfraßes die Losung des Fuchses voll von Eiern der Schmetteılinge gefunden wurde, welche er verzehrt hatte (Wagner, Tharandter Jahrb., 23. Band); dasselbe berichtet Altum aus Eberswalde, und die Tharandter Sammlung besitzt eine Fuchslosung aus einem bayerischen Nonnenrevier, die mit Resten von Nonnenfaltern und -eiern durchsetzt ist. Ähnliches gilt vom Dachs, dessen Exkremente nach Altum stets eine Menge Käferfragmente, besonders der großen Geotrupes-Arten enthalten; nach Boas wird der Dachsmagen häufig auch mit Engerlingen angefüllt gefunden.

Von den Nageru (Rodentia) kommen als Insektenfresser das Eichhorn, der Gartenschläfer und verschiedene Mäuse in Betracht. Nach Altum

1) $\mathrm{Cr}$ is p fand (nach $\mathrm{T}$ a u b e r) in mehr als 1000 Mägen des Maulwurfs fast ausschließlich Regenwürmer und $\mathrm{B}$ o a s berichtet von einem Wintervorrat in einer Maulwurfswohnung, der neben 1280 Regenwürmern (4 $1 / 4$ Pfund!) nur 18 Engerlinge enthielt. T a u b $\mathrm{r}$ untersuchte 50 Mägen und fand in allen Regenwürmer, nur 11 enthielten außerdem noch Schmetterlingspuppen, Käferlarven (Elateriden, Phyllopertha, Carabiden, Staphyliniden), Ohrwürmer, Eulenraupen, Tipula- und Bibio-Larven. 
findet man bisweilen im Frühjahr den Magen des Eichhörnchens mit den Resten des Maikäfers angefüllt, und E. Jordan fand bei mehreren im Erzgebirge zur Fraßzeit von Lyda hypotrophica erlegten Exemplaren den Magen bis zum Bersten mit den Larven dieser Blattwespe vollgestopft (Deutsche Jäger-Zeitung, 44. Bd., 1904, S. 26); derselbe beobachtete ferner, wie die Eichhörnchen bei Eichenwicklerkalamitäten die Raupen des Eichenwicklers systematisch aus ihren Gespinsten herausholten und verzehrten. Von den Mäusen werden vor allem Mus silvaticus und Arvicola arvalis als Vertilger von Forstinsekten, spez. von Lophyrus-Kokons genannt.

Als ein wichtiges Gegengewicht gegen die in der Erde lebenden oder überwinternden Insekten ist schließlich noch ein Tier aus der Ordnung der Paarzeher (Artiodactyla) zu nennen, nämlich das sonst so schädliche IVildschwein. Drei der wichtigsten Forstinsekten, Engerling, Kiefermspanner und -Eule werden vom Schwarzwild wesentlich in ihrer Vermehrung beschränkt. Auch die halbwüchsig überwinternden Raupen des Kiefernspinners werden von ihm verzehrt, oder jedenfalls durch das Brechen der Sauen empfindlich gestört, herausgewühlt, verschüttet und zertreten. Wagner berichtet aus Lieberose, daß die Wildschweine auch die Schmetterlinge des Spinners verzehrten; es wurden Sauen beobachtet, die sogar mit den Vorderläufen sich an den Bäumen aufrichteten, um der Schmetterlinge habhaft zu werden.

\section{b) Vögel.}

Viel allgemeiner bekannt als die insektenvertilgende Rolle der Säugetiere ist der Nutzen, welche die Vögel der Garten-, Land- und Forstwirtschaft durch Vernichtung schädlicher Insekten bringen. Bei der großen Arten- und Individuenzahl der Vögel und bei ihrer offenen Lebensweise, die dem Gärtner, Land- und Forstwirt die Insektenvertilgung täglich gewissermaßen ad oculos demonstriert, ist dies ohne weiteres verständlich. Dazu kommt, daß die Vögel infolge ihres Gesanges, ihrer Brutpflege usw. dem Empfinden des Menschen besonders nahestehen und daher von jeher auch seine besondere Aufmerksamkeit erregt haben.

Daß die Vögel einen gewaltigen Faktor in der Dezimierung der überschüssigen Nachkommen der Insekten spielen müssen, läßt sich einmal schon aus der großen Zahl der insektenfressenden Vögel ableiten und sodann auch aus ihrem starken Nahrungsbedürfnis. Wie groß letzteres ist, darüber geben uns die Versuche, die Rörig in den Flugkäfigen der Biologischen Reichsanstalt in Dahlem vorgenommen hat, einigen Aufschluß: 2 Kohlmeisen verzehrten zusammen von 6 Uhr morgens bis 7 Uhr abends 187 Puppen des Weiden- und Ringelspinners; 3 Blau- und 3 Tannenmeisen zusammen täglich eine zeitlang 9500-10000 Eier des Kiefern- und Prozessionsspinners; 3 Sumpfmeisen, 1 Tannenmeise, 1 Schwanzmeise und 3 Goldhähnchen brauchten zur Verzehrung von 600 Kiefernspannerraupen etwas mehr als $1 \frac{1}{2}$ Stunde; dieselben Vögel verzehrten von vormittags $1 / 211 \mathrm{Uhr}$ bis zum Abend 1096 und an einem ganzen Tag 1876 Raupen. Außer diesen Ergebnissen liefern auch die oft überraschend großen Zahlen, die bei den 
Magenuntersuchungen zutage gefördert werden, deutliche Beweise dafür, wie groß das Nahrungsbedürfnis der Vögel im allgemeinen ist.

Es steht also fest, daß enorme Mengen von Insekten durch die Vögel vernichtet werden. Doch diese Erkenntnis allein kann dem Forstentomologen nicht genügen; er muß vielmehr auch wissen, welcher Art die Insekten, die den Vögeln zum Opfer fallen, sind: handelt es sich in der Hauptsache um forstlich völlig gleichgültige Insekten, so hat die Tätigkeit der Vögel für den Forstentomologen nur wenig Wert; oder werden gar nüıliche Insekten von den Vögeln getötet, so muß ihre Tätigkeit geradezu als schädlich bezeichnet werden. Nur wenn wirklich forstlich schädliche Insekten in merklicher Anzahl von den Vögeln verzehrt werden, bedeuten letztere eine Hilfe für den Forstmann. Diese Frage stellt geradezu die Grundlage des ganzen Vogelproblems dar, und es ist daher notwendig, daß die wissenschaftliche Erforschung hier einsetzt.

Es ist in dieser Beziehung auch schon viel geschehen, wie vor allem aus der großen Menge der vorgenommenen Magenuntersuchungen, die uns ja am besten Auskunft über die verzehrten Insekten geben, hervorgeht. Da diese Untersuchungen außerdem vielfach auch noch Ergänzungen durch direkte Beobachtungen erfahren haben, so sind wir heute über die Ernährungsart, resp. den Speisezettel der wichtigsten der unsere Wälder bevölkernden Vögel recht gut unterrichtet. ${ }^{1}$ )

Wir wollen mit dem Kuckuck beginnen, der in bezug auf die forstliche Bedeutung ohne $Z_{\text {weifel }}$ in die erste Reihe zu stellen ist. Es sind hauptsächlich zwei Eigenschaften, welche dem Kuckuck diesen Ehrenplatz sichern: einmal die aus dem Brutparasitismus sich ergebende örtliche Ungebundenheit, die es ihm ermöglicht, stets dahin zu ziehen, wo große Raupenansammlungen usw. vorhanden sind, und sodann seine eigenartige Geschmacksrichtung, die ihn neben anderen vor allem solche Insekten fressen läßt, welche von den meisten anderen Vögeln nur ungern genommen oder gänzlich gemieden werden, nämlich besonders die haarigen Raupen (wie die Prozessionsspinner-, Nonnen-, Kiefernspinner-, Goldafter-, Schwammspinnerraupen usw.), ferner die Blattwespenlarven (Cimbex, Lophyrus, Lyda) und die Larven gewisser Blattkäfer usw., - Insekten, die teilweise zu den schlimmsten Forstschädlingen gehören.

Um über die Qualität und die Quantität der Kuckucksnahrung einen Begriff zu geben, seien hier einige Magenbefunde mitgeteilt. In je 1 Kuckucksmagen befanden sich:

88 halbwüchsige Raupen des Eichenprozessionsspinners,

97 zweidrittelwüchsige Raupen des Eichenprozessionsspinners,

43 erwachsene Raupen des Eichenprozessionsspinners,

98 Raupen des Eichengoldafters (Euproctis chrysorrhoea),

60 Raupen des Eichengoldafters, zusammen mit Maikäfern,

50 Raupen des hellen Goldafters (Porthesia similis),

49 Raupen des Schwammspinners,

17 Raupen und 1 Puppe der Nonne,

1) Vergl. hierzư Baer, W., Die Bedeutung der insektenfressenden Vögel für die Forstwirtschaft („Aus der Natur“ 1913), worauf in den folgenden Ausführungen mehrfach Bezug genommen ist. 
9 Raupen und 10 Puppen der Nonne,

173 junge Raupen des Ringelspinners,

63 flügellose Weibchen des Schlehenspinners (Orgyia antiqua), darunter 5 mit den noch anhängenden begattenden Männchen,

110 Raupen des Eichenwicklers, zusammen mit 10 Maikäfern,

5.2 erwachsene Larven von Lyda hypotrophica,

18 fast erwachsene Raupen des Kiefernspinners,

20-30 erwachsene Raupen des Wollafters (Bomb. lanestris).

Außerdem wurden durch die Magenuntersuchungen zutage gefördert: Raupen des Kiefernschwärmers in allen Größen, des Trauermantels, Eichenspinners (L. quercus), von Agrotis Arten (bis 16 Stück in einem Magen), ferner von Cossus, Hybernia defoliaria, des weiteren Larven von Hemichroa alni, Junikäfer (Rhizotrogus solstitialis), Walker (Polyphylla fullo), Saperda carcharias, Drahtwürmer, und sehr häufig endlich die Maulwurfsgrille.

Geht schon aus diesen Magenuntersuchungen hervor, daß der Kuckuck in der Hauptsache schädliche Forstinsekten, und zwar in großer Menge, frißt, und sich daher forstlich sehr nützlich macht, so zeigen uns auch noch eine Anzahl direkter B e ob a chtungen, wie sehr der Kuckuck zur Verminderung der Raupenplagen usw. beitragen kann. Ein drastisches Beispiel hierfür berichtet A $1 \mathrm{tu} \mathrm{m}$ : In einem isolierten Kiefernstangenholz in Pommern hatte sich die Nonne mehrere Jahre hindurch immer bedrohlicher vermehrt, so daß hier ein schlimmer Ansteckungsherd für die Umgebung zu entstehen drohte. Als die Raupen ziemlich erwachsen waren, sammelten sich in kurzer Zeit etwa 100 Kuckucke an, deren Zahl trotz Abschuß von 57 Stück (zum $Z$ weck von Magenuntersuchungen) infolge neuen Zuzuges nicht abnahm. Nach ca. zwei Wochen verschwanden sie wiederum, und - der Nonnenherd war, wie die Folge lehrte, vollständig gesäubert. - Eine ähnliche Erfahrung machte A $1 \mathrm{tu}$ mit dem Schwammspin $\mathrm{mer}$ : Einst wandte sich ein Weidenzüchter an A $1 \mathrm{tu}$ m mit der Bitte um Abhilfe gegen den genannten Schädling, der seine Heger bereits teilweise kahlgefressen hatte. Noch bevor der Notschrei beantwortet war, hatte sich eine Menge Kuckucke eingefunden, die in kurzer Zeit der Plage ein Ende machten. Auch den Schwammspinnerkalamitäten in Ungarn erwies sich der Kuckuck meist als der weitaus wichtigste Gegner. Ebenso wurde manche beginnende Massenvermehrung des Eichenprozessions spinners und des Kiefernspinners nach Altum durch die zahlreich zuwandernden Kuckucke im Keime erstickt. Ähnliche Berichte liegen über die eindämmende Wirkung des Kuckucks bei Massenvermehrungen der verschiedenen B 1 a t t w e s p e n, vor allem Lyda und Lophyrus vor, - so daß wir also dem Kuckuck jedenfalls eine sehr bedeutende Rolle bei der Niederhaltung der Vermehrung unserer wichtigsten Forstschädlinge zuschreiben müssen. -

Dem Kuckuck am nächsten bezügl. der Nahrung kommt der Pirol (Oriolus galbula), indem derselbe ebenfalls ein ausgesprochener Liebhaber von behaarten Raupen ist; vor allem scheint er Ringel- und Kiefernspinnerraupen zu lieben, doch auch in Nonnenrevieren hat man schon größere Ansammlungen des schönen Vogels gesehen. Er macht sich außerdem auch als ständiger Bekämpfer des Maikäfers und des Eichenwicklers dem Forstmanne nützlich.

Eine hervorragende Stellung unter den insektenfressenden Vögeln nimmt der Star (Sturmus vulgaris) ein; denn einmal hat er einen sehr großen reichhaltigen Speisezettel, der auch behaarte Raupen und übel schmeckende Blattwespenlarven mit einschlieft, und sodann ist er sehr häufig und tritt meist in großen Schwärmen auf. Dazu kommt, daß ihn der Wirtschafter sozusagen in der Hand hat, indem er ihn durch Anbringen einer entsprechenden Zahl von Nistkästen beinahe überallhin ziehen kann, wo er 
ihn braucht. Mit wenigen Ausnahmen, die reine Spezialitäten des Kuckucks sind (wie z. B. Goldafterraupen), nimmt der Star so ziemlich alle Forstschädlinge, die ihm vor den Schnabel kommen, zu sich, seien es im Boden lebende Engerlinge, Drahtwürmer, Schnakenlarven oder Eıdraupen, oder seien es Maikäfer, Rüsselkäfer, Nonnenraupen, oder andere Spinner, oder Eichenwickler usw. Bei großen Nonnenkalamitäten sammelt er sich oft in ungeheuren Schwärmen in den befallenen Revieren an, und räumt dann gehörig unter den Raupen, Puppen oder Faltern auf.

Unter den rabenartigen Vögeln (Corvidae) besitzen die Krähen (Nebel-, Saat- und Rabenkrähen) bezügl. der Insektenvertilgung eine gewisse Ähnlichkeit mit dem Star. Gleich diesem sind sie wenig wählerisch in der Nahrung und gleich ihm treten sie auch in größeren Gesellschaften oder Scharen auf. Wie der Star bilden die Krähen ein ständiges Gegengewicht gegen die Engerlinge, Drahtwürmer und die anderen in der Erde lebenden Larven, und ebeuso erscheinen sie auch bei Nonnen-, Kiefernspinner-, Eichenwickler- und Maikäferkalamitäten usw. auf dem Schauplatz, um tatkräftig an der Vertilgung dieser Schädlinge teilzunehmen.

Nach Altum haben Saatkrähen durch Vertilgung großer Mengen Kiefernspinnerkokons in zwei Fällen dem preußischen Staat namhafte Summen erspart, in dem einen mindestens 5000 M. - Magenuntersuchungen, die hauptsächlich an Raben und Nebelkrähen durch Rörig und andere vorgenommen wurden, förderten den verschiedensten Inhalt zutage; so fand sich z. B. in je einem Magen 294 Zangen des Ohrwurms, 50 Nonnenraupen, 30 Nonnenpuppen, 19 Maikäfer, ferner wurde häufig in den Mägen angetroffen Rhizotrogus, Phyllopertha, Schnell- und Rüsselkäfer (Hylobius, Otiorhynchus), ferner Puppen des Kiefernspinners und eierstrotzende Nonnen- und Schwammspinnerweibchen.

Der ebenfalls zu den Corviden gehörende Eichelhäher steht in einem gewissen Gegensatz zu den Krähen, insofern, als er den Sommer über ein stilles und einsames Leben führt und durch sein ständiges Vertilgen der einzelnen auf den Bäumen lebenden Insekten mehr vorbeugend als kalamitätenlindernd wirkt. Wie mannigfaltig seine Nahrung ist, lehren wiederum die Magenuntersuchungen, welche die bunteste Insektensammlung lieferten.

„Da stöBt man auf die beerenartigen Weibchen der Fichtenschildlaus (Lec. hemicryphum), Buchen- und Eichenblattgallen (Hornomyia fagi und Neuroterus numismalis), ausgehöhlte Fichtennadeln mit den darin befindlichen Räupchen von Graph. tedelln, Raupen, Puppen und eierstrotzende Weibchen des Kiefernschwärmers, die Raupen des Mondvogels, von Agrotis und anderen Eulen, Ameisen, Lophyrus-Kokons, Schnell- und Rüsselkäfer, besonders Hylobius. Ein Magen fand sich bis zum Bersten gefüllt mit den geflügelten Weibchen der Holzameise (Camponotus), ein anderer enthielt 40 Stück der Eichenblätter abfressenden Raupen von Brachionycha sphinx, weitere Puppen von Tortrix murinana und besonders Raupen des Kiefernspanners, von letzterem bis zu 47 Stück. Eine besondere Eigenheit des Eichelhähers ist, im Winter die Eierringel des Ringelspinners samt dem Zweigstück, an dem sie sitzen, auszubrechen und im ganzen zu verschlingen. Nicht nur aus wiederholten Funden ist dies zu schließen, sondern es ist auch direkt beobachtet worden. $\mathrm{DaB}$ es sich dabei um ein wirkliches planmäßiges Absammeln handelt, geht daraus hervor, daß ein Kropf bis zum Bersten mit solchen Bruchstücken angefüllt war." (W. Baer.)

Unter den Kleinvögeln nehmen die Meisen (Paridae) im weiteren Sinne (also inklusive Goldhähnchen, Spechtmeise und Baumläufer) die erste Stelle 
ein, ja sie gehören neben dem Kuckuck und Star entschieden zu den forstlich nützlichsten Vögeln überhaupt. Verschiedene Momente begründen diese hervorragende Nützlichkeit: Die Meisen sind immer in großer Anzahl im Wald vorhanden, indem ihre bedeutende Fruchtbarkeit stets reichlich die Lücken ergänzt, die ein ungünstiger Winter in ihre Reihen gebracht hat. Besonders wichtig ist ferner, daß sie nicht fortziehen, sondern im Sommer und Winter ununterbrochen ihre nützliche Arbeit verrichten. Ihre geringe Größe, dabei ihre außerordentliche Geschicklichkeit im Klettern gestatten ihnen, auch die kleinsten Ästchen nach Eiern, Puppen und Larven abzusuchen; was sie an dem einen Tage nicht finden, das verzehren sie an dem anderen, denn in größeren und kleineren Gesellschaften bejagen sie regelmäßig wiederkehrend ihre Reviere. Dabei verteilen sie sich auf die verschiedensten Insekten, indem die einzelnen Arten auf rerschiedene Holzgruppen und Höhen besonders angewiesen sind. Sie stellen also gewissermaßen eine über den ganzen Wald ausgebreitete Polizei dar, welche mit großer Beständigkeit an der Entfernung überschüssigen Insektenlebens arbeitet und so in eminentem Maße als vermehrungsbeschränkender und kalamitätenvorbeugender Faktor wirkt. In deutlicher Weise können wir dies in den Eichenwaldungen der Umgebung der berühmten Vogelschutzstation des Freiherrn von Berlepsch ersehen, die infolge der zahlreichen dort angesiedelten Meisen unter dem Eichenwickler garnicht zu leiden haben, während die unweit davon gelegenen Wälder, in denen nichts für die Vermehrung der Meisen geschehen ist, von dem genannten Schmetterling bereits wiederholt kahl gefressen wurden. Auch da, wo eine Massenvermehrung stattgefunden hat, helfen sie an deren Bekämpfung mit; so berichtet Rörig, daß in einem Nonnenrevier große Meisenschwärme erschienen sind, welche die Stämme nach den unter den Rindenschuppen abgelegten Nonneneiern absuchten, wobei es so lebhaft zuging, daß ein eigenartiges Geräusch den Wald erfüllte. Und bei einer vor kurzem in Oberbayern eingetretenen Kiefernblattwespenkalamität scheinen die Meisen im Verein mit Spechten und Staren das Ende des Fraßes herbeigeführt zu haben. Man sah die Meisen in auffallender Zahl den ganzen Winter über den in den Rindenritzen befindlichen Kokons der genannten Wespe nachstellen, so daß die Stämme infolge der Säuberung bald „wie gerötet" erschienen, und es fand dann auch im folgenden Sommer kein weiterer Fraß statt (Deutsche Forstzeitung 1906, S. 422). Die Nahrung der Meisen ist eine sehr vielseitige: außer den genannten Insekten werden von ihnen gefressen die Eier des Schwamm- und Ringelspinners, die Puppen der Nonne, des Kiefernspinners, Prozessionsspinners und vieler anderer Spinner, ferner die ungeflügelten Weibchen des Frostspanners, die Räupchen der verschiedenen Kleinschmetterlinge, wie der Lärchenminiermotte, des Kieferntriebwicklers, der Fichtennadelminierer, der Tannenwickler (es wurden einmal 122 Räupchen von Tortrix rufimitrana im Magen einer Tannenmeise gefunden), des Eichenwicklers usw., ferner Blattläuse, Schildläuse, Erdflöhe, Rüsselkäfer, Borkenkäfer usw.

Auch die Wiirger (Laniidae), die in Deutschland durch 4 Arten vertreten sind, gehören zu den Vertilgern schädlicher Insekten. Sie durchsuchen 
nicht das Gezweige wie die eben besprochenen Vögel, sondern machen, gleich Raubvögeln von Spähsitzen aus, ihre Jagd auf Insekten. Es sind daher auch meist andere Tiere, als die eben genannten, die ihnen zur Beute fallen, wie Laufkäfer, Mai- und Junikäfer, Schnell- und Rüsselkäfer, Laubund Feldheuschrecken, und mitunter auch Hummeln und Wespen. Bei Lanius collurio fanden sich im Magen auch Saperda populnea, ausnahmsweise auch Engerlinge und Cossus-Raupen.

Die Drosseln (Turdidae) und ihre Verwandten (Nachtigall, Rotkehlchen, Rotschwänzchen) machen sich hauptsächlich durch das Verzehren der unter der Laub- und Moosdecke des Waldes lebenden Insekten wie der Spannerund Eulenpuppen, Weichkäfer- und Schneckenlarven, Drahtwürmer usw. forstlich nützlich.

Die Grasmiicken (Syliidae) und ihre Verwandten (Laubvögel), sind ebenfalls eifrige Insektenvertilger, halten sich aber im Gegensatz zu den vorigen mehr an die im Dickicht oder auf Bäumen lebenden Insekten, wie vor allem Spanner und Kleinschmetterlingsraupen. Ein besonderes Lob unter ihnen verdient nach Altum der Weidenlaubsänger (Phylloscopus rufus), der allen Wicklern und Spannerraupen bis in die Gipfel der Eichen und Kiefern so emsig nachstellt, wie wohl keiner seiner Verwandten.

Auch die Bachstelzen (Motacillidae) beteiligen sich, wenn sie auch keine eigentlichen Waldbewohner sind, an der Vernichtung von Forstschädlingen. So vertilgen sie auf den Schlägen und an den Waldrändern eine Menge Insekten, sie suchen ferner emsig die Meterstöße ab, namentlich im warmen Sonnenschein, wenn Borkenkäfer usw. gern fliegen.

Unter den Piepern (Anthus) und den Lerchen (Alauda) erlangen nur der Baumpieper und die Heidelerche einige forstliche Bedeutung; sie vertilgen alle möglichen Insekten, wie Grashüpfer, kleine Rüssel- und Schnellkäfer, Eulenraupen usw.

Die Finkenvïgel (Fringillidae) machen sich, wenngleich sie in erster Linie Körnerfresser sind, ebenfalls forstlich nützlich. Einmal nehmen sie ja in ihrer Jugend fast ausschließlich Insektennahrung $\mathrm{zu}$ sich, und sodann lassen sich auch die alten Vögel durch überreich sich darbietende Insektennahrung dazu veranlassen, zeitweilig wieder ganz den Insekten sich zuzuwenden. Ihre Bedeutung besteht daher weniger darin, daß sie, wie das von den Meisen in so hervorragendem Maße gilt, ein beständiges Gegengewicht gegen die Übervermehrung der Insekten bilden, als vielmehr darin, daß sie bei ausgebrochenen Kalamitäten an deren Bekämpfung sich beteiligen. Es ist vor allem der Buchfink, der infolge seiner Häufigkeit und seiner Eigenschaft als Waldvogel forstlich in Betracht kommt, worüber eine Reihe von Berichten vorliegen: So sah Rörig große Finkenschwärme in Nonnenrevieren einfallen, wo sie, wie die Magenuntersuchungen zeigten, große Mengen von Puppen und auch Raupen der Nonne verzehrten; IV achtl beobachtete sie bei Kalamitäten des Tannenwicklers; v. Chernel stellte ihr kräftiges Eingreifen bei Schwammspinnerfraß fest, und Prof. Vater berichtete mir von einem Masseneinfall von Finken in einigen von Brachyderes stark bedrohten Kiefernkulturen. Auch bei starkem Auftreten der Lärchen- 
miniermotte nimmt der Buchfink eifrig an der Vertilgung teil. Letztere Motte zieht übrigens auch noch andere Finkenvögel an, wie den Erlenzeisig und Goldammer und sogar „die zuweilen aus dem hohen Norden kommenden Schaaren des Birkenzeisigs (Acanthis linaria) suchen den Winter hindurch die erst halbwüchsigen Säckchen ab." Auch die so einseitig angepaßten Körnerfresser, wie Kreuzschnabel und Kernbeißer wurden gelegentlich bei der Vertilgung von Insekten (Eichenwickler, Nonne) bemerkt.

Die Schwalben (Hirundo) und Manersegler (Apus) kommen forstlich kaum in Betracht, da sie ja für gewöhnlich den Wald meiden. Natürlich fallen auch ihnen bei ihren unermüdlichen Jagden mitunter forstliche Insekten, die weiter ausschwärmen, zur Beute, doch treten diese gegenüber den forstlich indifferenten Insekten, die die Hauptnahrung bilden, sehr zurück.

Die Fliegenschnäpper (Muscicapa) sind zwar vorzugsweisc Waldbewohner, doch die Art ihrer Insektenjagd - sie fangen meist von Spähsitzen aus vorbeifliegende Insekten - bringt es mit sich, daß sie mehr indifferente Insekten oder gar nützliche, wie Tachinen, vertilgen. Doch wurde Muscicapa atricapilla auch schon bei der Bekämpfung von Kalamitäten beobachtet, wie z. B. von der Lärchenminiermotte und Muscicapa grisola verschlingt, wenigstens in der Gefangenschaft, Nonnenraupen jeder Größe.

Eine größere forstliche Bedeutung als den eben genannten Vögeln kommt der Nachtschwalbe (Caprimulgus) zu, die auf ihren nächtlichen Jagdflügen mit ihrem weiten Rachen alle, selbst die größten Insckten, die ihr in den WVeg kommen, wegfängt; in ihren Mägen findet man denn auch häufig große Schwärmer und Spinner (Kiefernschwärmer, Nonne, Prozessionsspinner usw.) neben Maikäfern, Eulen, Tipuliden usw.

Der Wiedehopf (Upupa) ist forstlich dadurch beachtenswert, daß er die im Boden lebenden schädlichen Insekten rertilgt; es fallen ihm regelmäßig zur Beute Schnackenlarven, Drahtwürmer, Raupen und Puppen ron Eulen und Spannern, ferner Feldheuschrecken, und vor allem Engerlinge und Maulwurfsgrillen.

Die Blaurake (Coracias) teilt sich mit dem vorigen hauptsächlich in die Vertilgung der Maulwurfsgrille und des Maikäfers; sonst wurden in ihrem Magen vielerlei Käfer (Schnellkäfer, Prachtkäfer, Bockkäfer, Laufkäfer, Walker, Junikäfer) gefunden, und ferner verschiedene Raupen ron Eulen, Cossus usw. Auch bei Nonnenfraß findet sie sich zuweilen in großen Flügen ein, wobei sie allerdings neben Nonnen auch den nützlichen Puppenräuber frißt.

Eine ganz besondere Stellung unter den insektenfressenden Vögeln nehmen die Spechte (Picus) ein; ihr Körperbau ist darauf eingerichtet, daß sie sich von den unter der Rinde oder im Holz usw. lebenden Insekten ernähren. Dadurch bilden sie ein Gegengewicht gegen die zahlreichen, teils sehr schädlichen rinden- und holzbrütenden Insekten. Es ist dies um so höher anzuschlagen, als gerade diese Insekten sonst relativ wenig unter den Nachstellungen ron Feinden - seien es Vögel oder Raubinsekten oder 
Parasiten - zu leiden haben. Die Spechte stellen gewissermaßen einen Ausgleich für dieses Manko an Parasiten usw. dar, und es würde zweifellos die Vermehrung der Borken-, Bock- und Rüsselkäfer einen weit größeren und für den Forstmann recht unangenehmen Umfang erreichen, wenn die Tätigkeit der Spechte in Wegfall käme. Es ist zwar des öfteren der Einwand erhoben worden, daß durch die Spechte doch meist nur ein kleinerer oder größerer Prozentsatz der betreffenden Schädlinge vertilgt wird. Jedoch abgesehen davon, daß mehrfache Beobachtungen vorliegen, wonach die Spechte die Stämme vollständig säuberten, bedeutet jener Einwand nicht mehr, als wenn man den Parasiten zum Vorwurf machen wollte, daß sie nur einen Teil der ihnen zukommenden Insekten töten. Die Spechte stellen ja nicht - ebensowenig wie eine bestimmte Parasitenart - das alleinige Gegengewicht dar, sondern bilden nur ein Glied in der Kette der vernichtenden Faktoren, allerdings ein sehr wesentliches. Immerhin darf bei der Beurteilung der forstlichen Bedeutung der Spechte auch nicht außer acht gelassen werden, daß die meisten der von den Spechten kontrollierten Insekten durch die moderne Forstwirtschaft, die auf möglichste Sauberkeit im Walde dringt, an und für sich ihre Schrecken verloren haben, indem ihre Vermehrung schon durch den Entzug geeigneten Brutmaterials gewöhnlich hinreichend eingedämmt wird. Es ist jedoch selbst bei der saubersten Wirtschaft nicht zu vermeiden, daß stets da und dort sich kleinere Vermehrungsherde von Borkenkäfer und Pissodes usw. bilden; - und hier greift nun der Specht ein, indem er einmal der Übervermehrung direkt steuert, und sodann indem er, was beinahe noch höher zu schätzen ist, den Forstmann auf die entstehenden Herde, die äußerlich anfangs kaum zu erkennen sind, aufmerksam macht. So möchten wir also auch in unseren modernen Wäldern den Specht auf keinen Fall missen.

Weitaus der vielseitigste und dadurch der nützlichste von unseren Spechten ist der große Buntspecht: „Er bildet das Hauptgegengewicht gegen Pissodes, Saperda populnea und carcharias, den Fichtenbock, und teilweise auch gegen die Borkenkäfer, vor allem den großen Dendroctonus micans. Im einzelnen sind Einschläge von ihm bereits auf fast allen Borkenkäferarten nachgewiesen, in besonders großem Umfang auf Ips sexdendatus, typographus, amitinus und curvidens, $P$. polygraphus, Hylesinus fraxini, Eccoptogaster Ratzeburgi, scolytus und multistriatus. Ferner finden sich an den Fraßstellen der Holzwespen, Sesien, Cossus, des Moschusbockes, Erlenrüßlers (Chryptorhynchus lapathi), des Agrilus biguttatus (26 Larven in einem Magen!) und namentlich in den angeschwollenen Weidenästen mit der Brut von Cecidomyia salicis meistens die Spuren seiner Tätigkeit. Auch dem Hylobius kommt er am Stockholz bei. Als eine besondere Wohltat erweist er sich in Gegenden, in denen, z. B. wie im südlichen Rußland, das Blausieb, Zeuzera, eine Plage ist, da schon eine einzelne Raupe ein gesundes Laubholzstämmchen zu töten vermag. Auch freilebende Schädlinge, zumal solche, die sich an Stämmen und in Rindenritzen befinden, fallen ihm zahlreicher, als man im allgemeinen annimmt, zur Beute; so beobachtete man ihn bei der Vertilgung von Lophyrus-Kokons, Puppen der Nonne, des Kiefern- und Weidenspinners, der Maikäfer, der Raupen der Kieferneule und des Kiefernspanners, die massenhaft in den Mägen vorkamen, und endlich des Eichenwicklers, von denen in einem Magen über 30 Raupen und 17 Puppen gefunden wurden" (B a e r). Der mittlere und kleine Buntspecht schließen sich in ihrer Ernährung dem vorigen an, bleiben aber infolge ihres beschränkteren Vorkommens an 
forstlicher Bedeutung wesentlich hinter diesem zurück. Der Sch w a r z s p e cht liat es in erster Linie auf die großen Holzameisen (Camponotus) abgesehen, gegen die er wohl das Hauptgegengewicht bildet; doch stellt er auch anderen Holz- und Rindenbrütern nach, wie Holzwespen, Pissodes, Bockkäfer und Borkenkäfer, von ¿cnen einmal 650 Eccopt. Ratzeburgi in einem Magen gefunden wurden (S o b o l e w, Z. f. F. u. Jagdw. 1899 Seite 444). Bisweilen, wenn auch seltener, sah man ihn in die Bodendecke einschlagen, wo sich zahlreiche Puppen vom Kiefernschwärmer, von der Kieferneule und dem Kiefernspanner befanden.

Der Gr ünspecht wie der Gra us p e h t sucht seine Nahrung vornehmlich im Boden, weshalb die beiden auch als Erdspechte bezeichnet werden. In erster Linie plündern sie die Haufen der roten Waldameisen, in die sie tiefe Löcher einschlagen, dann auch die Nester der übrigen im Boden wohnenden Ameisen. Ferner verzehren sie natürlich auch sonstige im Boden lebende Insekten, wie Engerlinge, Maulwurfsgrillen, Lophyrus-Kokons, die Puppen der verschiedenen Kiefernschmetterlinge usw. Endlich beteiligen sie sich auch, wenn auch nur in sehr geringem Maße, an der Vertilgung von Rindeninsekten. Der We nde $\mathrm{nh}$ a $1 \mathrm{~s}$ schließt sich in großen und ganzen dem Grünspecht und Grauspecht an.

Weit mehr, als man bis vor kurzem annahm, haben die Raubvögel (Raptatores) an der Vertilgung forstschädlicher Insekten teil, wie durch die zahlreichen Magenuntersuchungen, die gerade von diesen Vögeln mit besonderem Eifer vorgenommen wurden, nachgewiesen wurde. Als die fleißigsten Insektenvertilger sind der Turmfalk, Mäusebussard, Wespenbussard und Baumfalk zu nennen, dann auch die verschiedenen Eulen und einige Adler. Letztere kommen allerdings wegen ihrer Seltenheit praktisch kaum in Betracht, dagegen sind die anderen, vor allem die beiden erstgenannten in forstlicher Beziehung durchaus nicht zu unterschätzen. Einige Magenbefunde mögen dieses erhärten:

Beim Turmfalk wurden häufig Maulwurfsgrillen (bis zu 8 Stück in einem Kropf), Maikäfer und Eulenraupen zutage gefördert. In je einem Magen des Mäusebussards fanden sich: bis zu 28 Stück Kiefernschwärmerraupen, bis zu 80 Stück Eulenraupen, bis zu 200 Stück Spannerraupen und bis zu 39 erwachsene Engerlinge. In einem Magen des Wespenbussards wurden nicht weniger als 1400 Spannerraupen gezählt (Leisewitz); und ein Magen des Waldkauzes enthielt nicht weniger als 675 Raupen des Kiefernspanners.

Bei den Hiihnervögelı (Rasores) spielt die Insektennahrung nur eine untergeordnete Rolle; immerhin verdienen einige von ihnen die Beachtung des Forstentomologen, vor allem der Fasan, der schon mehrmals beim Vertilgen von Kieferspinnerraupen beobachtet wurde, und in dessen Magen verschiedentlich Erdraupen- und Blattwespenkokons in großen Mengen gefunden wurden.

Auch die Tauben (Gyrantes) müssen hier erwähnt werden; diese,galten zwar bisher als ausgesprochene Vegetarianer, doch lehrten die Magenuntersuchungen, daß wenigstens die Ringeltaube $(C$. palumbus) zuweilen auch zur Insektennahrung übergeht, wenn diese in besonders reichlichem Maße sich darbietet. So fand man in ihren Kröpfen wiederholt zahlreiche Eichenwicklerraupen und -puppen, Spannerraupen, Puppen und Raupen der Tannenwickler (nach Wachtl in einem Kropf gegen 1000 Puppen von Tortrix murinana) und Blattwespenlarven (über 500 Larven von Nematus abietum in einem Kropf, vergl. Sinz, Tharandter Jahrb. 1909, S. 318).

Die Wasser- und Sumpfvögel (Grallatores und Natatores) vertilgen zwar viele Insekten, doch halten sie sich im allgemeinen vom Walde fern, 
so daß sie forstlich kaum in Betracht kommen. Wir können höchstens die Lachmöve (Larus ridibundus) hier anführen, die als eifrige Vertilgerin des Engerlings bekannt ist.

Wir haben hier eine stattliche Reihe von Vögeln kennen gelernt, welche die Vertilgung forstschädlicher Insekten betreiben, und andererseits haben wir erfahren, daß es wohl kaum ein wichtigeres Forstinsekt gibt, welches nicht ron einem oder mehreren Vögeln verfolgt und deren Vermehrung nicht durch ihre Tätigkeit eingeschränkt würde, so daß wir also in den insektenfressenden Vögeln einen ständig wirkenden vermehrungseindämmenden Faktor zu erblicken haben. Derselbe ist allerdings je nach der Insektenart verschieden groß (im allgemeinen wohl für die im Boden, unter der Rinde oder im Holz lebenden Insekten relativ, d. h. im Verhältnis zu den anderen Faktoren, besonders Parasiten, größer als bei den freilebenden), dürfte jedoch für jede Insektenart unter normalen äußeren Bedingungen annähernd konstant bleiben. Jedenfalls stellen die Vögel ein durchaus notwendiges Glied in der Kette der die Erhaltung des organischen Gleichgewichtes gewährleistenden Organismen dar.

Diese hier geschilderte, dem Forstmann so nützliche Tätigkeit der Vögel erfährt aber eine gewisse Einschränkung durch den Umstand, daß die Vögel in ihrem Vertilgungswerk sich nicht nur auf die schädlichen Insekten beschränken, sondern auch nützliche Insekten, d. h. Parasiten und Raubinsekten verzehren. Wenn ein Kuckuck 100 Nonnenraupen frißt, wovon 50 oder 75 mit erwachsenen Tachinenlarven besetzt sind, so wird dadurch das Ende der Nonnenkalamität nur hinausgeschoben; denn jedes Tachinenweibchen kann den Tod von 2-300 Nonnen-

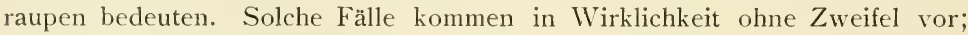
denn einmal ist eine Tachinose von $75 \%$ bei der Nonne gar keine Seltenheit, und sodann machen die Vögel nachgewiesenermaßen keinen Unterschied, ob die Raupen mit Parasiten besetzt oder parasitenfrei sind. Es geht dies vor allem aus Magenuntersuchungen hervor, bei denen nicht selten Tachinen und andere Parasiten gefunden wurden. - Außerdem hat man verschiedentlich Vögel auch direkt bei der Jagd auf Parasiten und Raubinsekten beobachtet. So konnte ich selbst mehrfach den Trauerfliegenfänger in Nonnenrevieren von seinem Spähsitz Tachinen wegfangen sehen; ferner wurde mir berichtet, daß eines Tages große Schwärme von Schwalben im Glastener Revier, wo eine starke Nonnenkalamität herrschte, einfielen, um die dort massenweise fliegenden Tachinen wegzuschnappen; auch Amseln wurden beim Suchen von Tachinentönnchen beobachtet (Oberförster Weiske im Leipziger Universitätswald). Oben wurde schon darauf hingewiesen, daß die Blaurake neben den Nonnenraupen auch deren Feinde, vor allem den Puppenräuber vertilgt; die Spechte fressen neben den Borkenkäferlarven auch die Larven des hauptsächlichsten Borkenkäferfeindes, des Clerus formicarius; der Grünspecht dezimiert die forstlich so nützliche rote Waldameise usw.

Nach diesen Beispielen kann also nicht geleugnet werden, daß die Vögel unter Umständen dem Forstmann einen gewissen Schaden bringen können. Dies darf uns aber nicht etwa dazu bestimmen, die Nützlichkeit der 
Vögel überhaupt in Abrede zu stellen, wie es z. B. von Seiten einiger amerikanischer Entomologen geschieht. Wir tun vielmehr wohl am richtigsten, uns auf folgenden Standpunkt zu stellen: Die nützliche Tätigkeit der Vögel (durch Vertilgen forstschädlicher Insekten) überwiegt wesentlich die schädliche Tätigkeit der Vögel (durch Vertilgen forstnützlicher Insekten). Der Wert der Vögel besteht aber weniger darin, einmal ausgebrochene Kalamitäten zu bekämpfen und zum Stillstand zu bringen (dazu besitzen die Vögel eine viel zu geringe Vermehrungsziffer im Verhältnis zu den Insekten), als vielmehr darin, einer Übervermehrung der Insekten überhaupt vorzubeugen. In normalen Zeiten sind ja auch die Parasiten in weit geringerer Anzahl (auch relativ!) vorhanden als in Zeiten der Massenvermehrung, so daß das Verhältnis der von den Vögeln vertilgten Parasiten zu den vertilgten Schädlingen ein weit günstigeres sein wird als in den oben gewählten Beispielen. Ferner ist zu bedenken, daß es doch auch eine ganze Anzahl schlimmer Forstschädlinge gibt, welche überhaupt nur sehr wenig Parasiten haben, wie z. B. der Engerling, die Maulwurfsgrille und viele andere im Boden lebende Insekten, ebenso die rinden- und holzbrütenden Insekten; und bei anderen Schädlingen sind wenigstens gewisse Stadien parasitenfrei, wie z. B. bei der Nonne das Ei- und Imagostadium. In allen diesen Fällen können die Vögel doch nur Nutzen stiften. Dasselbe gilt auch für diejenigen Vögel, die nur des Nachts auf fliegende Insekten jagen, da sie hierbei weder freiliegende Parasiten, noch auch parasitenhaltige Stadien von Schädlingen vor ihren Schnabel bekommen. Endlich ist auch noch darauf hinzuweisen, daß auch Hyperparasiten, die durch starke Überhandnahme mitunter sehr schädlich werden können, durch die Vögel vernichtet werden. Ein drastisches Beispiel von Hyperparasitismus erlebte ich im Glastener Revier, wo der in den Tachinen parasitierende Trauerschweber (Anthrax) so sehr überhand nahm, daß die Tachinose der Nonnenraupen von Jahr zu Jahr zurückging und dadurch das Ende der Kalamität wesentlich verzögert wurde. Wenn in diesem Falle durch Vögel Tachinentönnchen, die mit Hyperparasiten besetzt sind, oder schwärmende Anthrax vertilgt werden, so kann dadurch ein großer Nutzen gestiftet werden, indem der Hyperparasitismus eingeschränkt und infolge davon die Tachinose gefördert werden kann.

Die hier angeschnittene Parasitenfrage bringt in das Vogelproblem zweifellos eine ziemliche Komplikation, deren endgültige Lösung mit großen Schwierigkeiten verbunden sein wird. Immerhin aber dürfen wir wohl heute schon als sicher annehmen, daß durch sie unsere oben vertretene Ansicht von der Bedeutung der insektenfressenden Vögel für die Erhaltung des organischen Gleichgewichtes resp. für die Niederhaltung der verschiedenen Schädlinge kaum wesentllich verändert werden wird.

\section{c) Schmarotzer und Raubinsekten, und andere insektentötende Arthropoden.}

Die wichtigste Rolle bei der Beschränkung der Schädlingsvermehrung spielen in den meisten Fällen die parasitischen und räuberischen 
Insekten, und es ist zweifellos, daß ein großer Teil der Vermehrungskatastrophen durch ein Mißverhältnis zwischen der Zahl dieser stets der Übervermehrung entgegenwirkenden Tiere und den Schädlingen herbeigeführt wird. Wir kennen eine Reihe von Beispielen, die das eklatant beweisen. Ich brauche nur an die Geschichte der Einführung des Schwammspinners in Amerika zu erinnern. Im Jahre 1868 gelangten durch Unvorsichtigkeit eines im Staate Massachusets wohnenden Züchters einige aus Europa bezogene Schwammspinnerraupen ins Freie. Diese gaben den Anlaß zu einer der größten Insektenkalamitäten, die wir überhaupt kennen und zu deren Bekämpfung jährlich Unsummen (4 Millionen Mark) aufgewandt werden, ohne indes bis jetzt der Plage Einhalt bieten zu können. Der Grund für diese schwere Kalamität ist darin zu erblicken, daß der Schädling ohne seine Parasiten und Räuber eingeführt wurde und daß auch von den amerikanischen Parasiten nur ganz wenige an dem Fremdling Gefallen fanden, so daß der Schmetterling seine ganze Vermehrungsenergie beinahe ungezügelt betätigen konnte, — während in seinem Heimatland ihm so viele Parasiten und Raubinsekten gegenüberstehen, daß er nur selten zu einer und dann meist nur kurz währenden Übervermehrung gelangt. Ähnlich ist es mit dem Ulmenblattkäfer (Galeruca xanthomelaena), der bei uns wohl manchmal explosionsartig in großen Mengen auftritt, und auch mitunter die Ulmen einer Allee kahlfressen kann, aber meist im folgenden Jahr wieder verschwindet, während er in Amerika zu einer dauernden schlimmen Plage wurde, da ihm eben drüben keine Parasiten gegenüber stehen, die ihn in seiner Übervermehrung einholen und wieder hinunterdrücken. Und noch viele andere derartige Beispiele ließen sich aus Amerika berichten; sind doch mehr als $50 \%$ der schlimmsten amerikanischen Schädlinge dorthin eingeschleppt (vergl. K. Escherich, Die angewandte Entomologie in den Vereinigten Staaten).

Das Mißrerhältnis zwischen Parasiten und Schädling kann aber auch noch auf eine andere Weise als durch Verschleppung herbeigeführt werden, wie durch plötzlich eintretende ungewöhnlich günstige Bedingungen (klimatische, trophische usw.) für die Vermehrung des Schädlings, wodurch letzterem ein Vorsprung den Parasiten gegenüber gegeben wird, oder durch ungünstige Bedingungen für die Parasiten, oder durch beide Momente zugleich. Nehmen wir z. B. an, daß mehrere Jahre hindurch während der Schwärmzeit der Nonnentachine (Mai bis Juni) stürmisches und regnerisches Wetter ist, so daß die Tachinen an der Eiablage gehindert werden, so kann dadurch sehr wohl ein Mißverhältnis zwischen der Zahl der Nonnen und Tachinen entstehen, welches event. auch zu einer Kalamität Anlaß geben kann, zumal wenn vielleicht gleichzeitig die Entwicklungsbedingungen für die Nonne besonders günstige sind.

In solchen Fällen wird aber der Parasit den Vorsprung in einiger Zeit wieder einholen, und die Vermehrung bald wieder in normale Grenzen bringen, vorausgesetzt, daß die ungünstigen Bedingungen für die Parasiten nur vorübergehender Natur waren. Ist letzteres nicht der Fall, und wird die Parasitenvermehrung dauernd zurückgehalten (etwa infolge gewisser Kultur- 
methoden oder dergl.), so wird auch die Kalamität einen dauernden Charakter ammehmen, gleichwie bei den obengenannten verschleppten Schädlingen.

Es ist nicht notwendig, daß der Parasit eine besonders hohe Vermehrungsziffer besitzt, um den Vorsprung des Schädlings einholen zu können; er wird es vielmehr auch dam tun können, wenn er die gleiche (oder selbst eine geringere) Vermehrungsziffer aufweist wie der Schädling.

Nehmen wir z. B. einen Schmetterling und eine Tachine, welche beide die gleiche Vermehrungsziffer 100 haben und beginnen wir damit, daß von 300 Raupen 100 tachiniert sind, das gibt 200 Schmetterlinge (100 우) und 100 Parasiten (50 q \&). Im nächsten Jahr haben wir $100 \times 100=10000$ Raupen, ron denen $50 \times 100=5000$ tachiniert sind, das macht 5000 Schmetterlinge und 5000 Parasiten (mit je 2500 우). So müßten also (theoretisch) bereits im dritten Jahr sämtliche Raupen mit Parasiten besetzt sein. Daß ähnliche Vorgänge in der Natur sich tatsächlich abspielen, daron kennt jeder praktisch tätige Entomologe genügend Beispiele. So haben wir selbst bei der großen Nonnenkalamität in Sachsen des öfteren Gelegenheit gehabt, das rasche sprungweise Fortschreiten der Tachinose zu beobachten, wobei die Zunahme ca. $20-25^{\circ}$ pro Jahr betrug, so daß bereits im 4 . oder 5 . Jahr $90-100 \%$ der Raupen tachinös waren (besonders deutlich war dies in Okrilla, Bezirk Dresden, zu sehen. Auch bei Anomalon circumflexum, einem der bekanntesten Parasiten des Kiefernspinners, läßt sich das stetige Anwachsen von Jahr zu Jahr deutlich beobachten.

Es wird übrigens meistens jeder Schädling nicht nur von einer, sondern von einer ganzen Anzahl von Parasitenarten und Raubinsekten heimgesucht, und zwar vielfach in der Weise, daß jedes Entwicklungsstadium ihre besonderen Arten (je eine oder mehrere) besitzt. So wird z. B. der Kiefernspinner im Eistadium, ferner in den jüngeren und dann wieder in den älteren Raupenstadien von anderen Arten befallen, und erst durch das Zusammenwirken der ganzen „Parasitenfolge“ („sequence of parasites“, wie die Amerikaner sagen) wird die normale Vermehrungsbeschränkung des Schädlings gewährleistet. Fehlt nur ein Glied in der Kette, so kann dies unter Umständen schon zu einem Anwachsen des Schädlings führen.

Es ist das Verdienst der amerikanischen Entomologen, vor allem von L. O. Howard und Fiske, diese wichtige Erscheinung eingehend studiert zu haben. Sie haben dafür auch eine sehr übersichtliche graphische Darstellung eingeführt, aus der, wie die beistehenden beiden Tabellen über die Parasitenfolge des Schwammspinners in Japan und in Europa lehren, mit einem Blick zu ersehen ist, in welcher Weise die Parasiten und Raubinsekten auf den Schädling einwirken.

(Siehe Tabelle S. 240.)

Eine nähere Erklärung dieser Tabellen ist kaum nötig; nur bezügl. der feinen punktierten Linien sei bemerkt, daß diese die Zeitdauer anzeigen, während welcher die einzelnen Stadien dem Angriff des betreffenden 
Parasiten ausgesetzt sind, während die dicken Linien die Stadien angeben, in welchen der Parasit überhaupt im Körper des Wirtes anzutreffen ist. So erstreckt sich z. B. in den beiden obigen Beispielen die Angriffszeit von

Tabelle 1. Parasitenfolge des Schwammspinners in Japan.

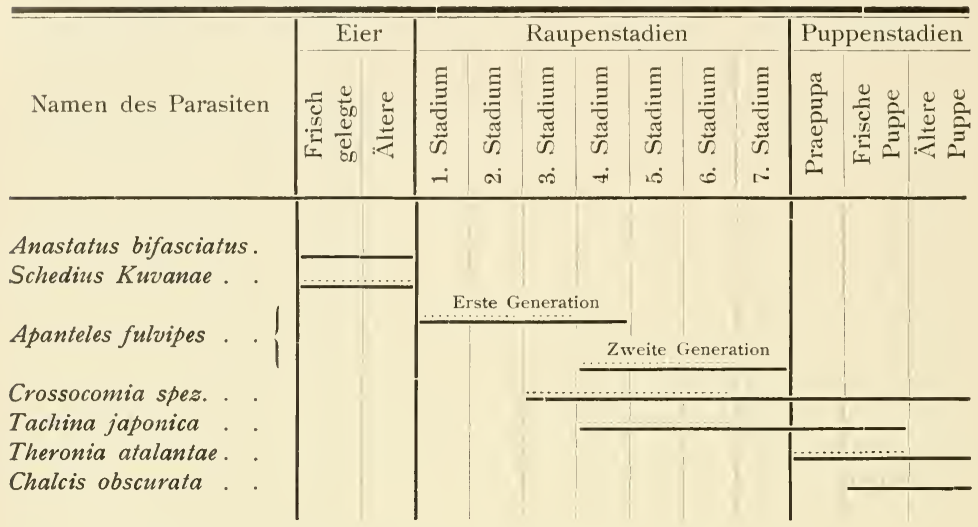

Tabelle 2. Parasitenfolge des Schwammspinners in Europa.

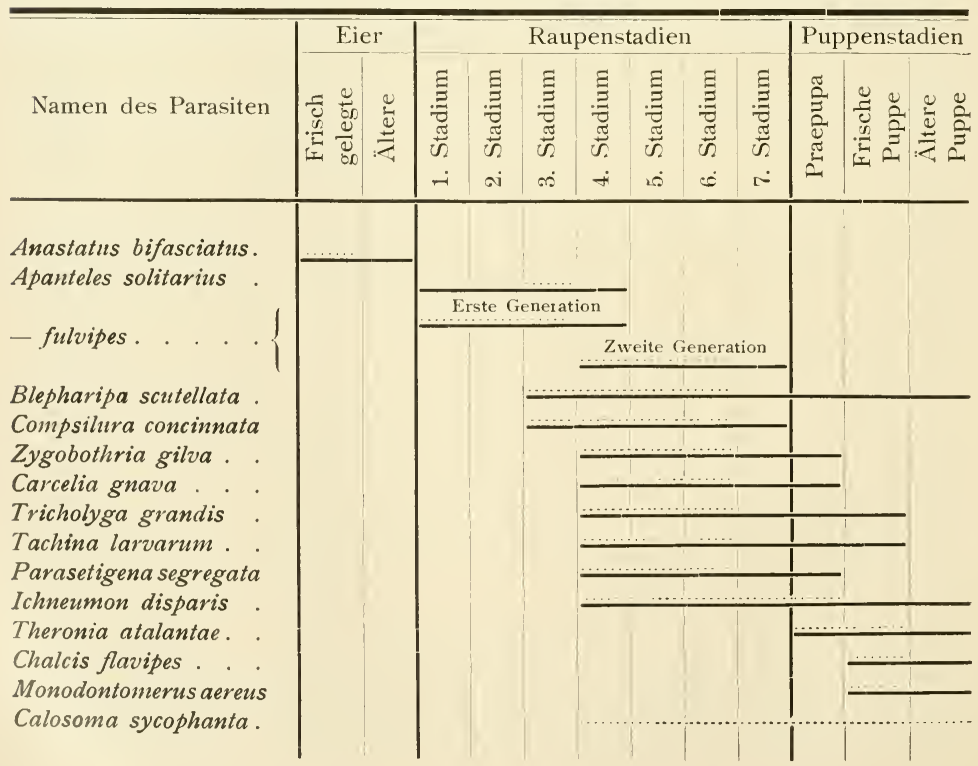


Anastatus bifasciatus nur auf die ersten 10 Tage des Eistadiums, die von Schedius Kuvanae dagegen auf die ganze Eizeit, die nicht weniger als ca. 280 Tage währt; oder, so zeigt uns die Tabelle 2 , daß die beiden Tachinen Blepharipa und Compsilura zwar in ihrer Angriffszeit völlig übereinstimmen, daß aber die erstere noch während des ganzen Puppenstadiums im Wirte bleibt, während die letztere bereits vor der Verpuppung den Wirt verläßt.

Ein Moment ist in den Fiskeschen Tabellen noch zu wenig berücksichtigt, nämlich der Grad der Wichtigkeit der einzelnen Parasiten für die Beschränkung des Schädlings. Es sind nämlich keineswegs alle Arten einer Parasitenfolge von der gleichen Bedeutung für den betr. Schädling, sondern manche davon können vielmehr ganz unwichtig sein, während anderen eine hohe, ja ausschlaggebende Bedeutung zukommt. So ist z. B. bei der Nonne der Hauptwert der Tachine zuzuschreiben, während die verschiedenen Ichneumonen eine mehr untergeordnete Rolle spielen; beim Kiefernspinner dagegen kommt es weit mehr auf die Ichneumonen an, während die Tachinen zurücktreten usw. Diese Verschiedenwertigkeit der einzelnen Parasitenarten eines Schädlings ist eine hundertfach beobachtete Tatsache; worin sie begründet ist, muß im einzelnen crst noch erforscht werden. In der graphischen Darstellung ließe sich die Verschiedenwertigkeit leicht dadurch kennzeichnen, daß man für die Hauptparasiten dickere Linien oder vielleicht noch besser fetten Druck der Namen anwendet.

Ein Vergleich der beiden Tabellen lehrt uns, daß die Parasitenfolge für einen und denselben Schädling in den verschiedenen Gegenden seines Verbreitungsgebietes sehr verschieden sein kann; besonders dann, wenn das letztere genügend groß ist, wie dies ja für den Schwammspinner in hohem Maße zutrifft, der über ganz Europa bis nach Japan hin verbreitet ist. Wir würden noch eine größere Reihe voneinander abweichender Parasitenfolgen des Schwammspinners erhalten, wenn wir die verschiedenen Teile Europas, wie Süd-, Nord-, West- und Osteuropa besonders behandeln würden. Ja selbst in ganz nahe beieinanderliegenden, direkt benachbarten Gebieten kann die Parasitenfolge ein anderes Bild zeigen, indem hier eine Parasitenart fehlt, die dort sehr häufıg ist usw. So enthielten z. B. von 5 Paketen von Eischwämmen des Schwammspinners, die aus verschiedenen Gegenden Ungarns stammten und zum Zwecke der Parasitenzüchtung nach Amerika versandt wurden, das eine Paket Nr. 1 keinen einzigen der gesuchten Eiparasiten (Anastatus bifasciatus), die Pakete Nr. 2 und 3 ergaben nur ganz wenige daron, während aus den restlichen Paketen Nr. 4 und 5 nicht weniger als 80000 Individuen auskamen. Ähnliches hat auch schon Ratzeburg für die Parasiten des Kiefernspinners beschrieben: er hatte die Beobachtung gemacht, daß die Schmarotzer häufig in kleinen Horsten zusammen auftreten, während sie anderwärts fehlen.

Außerdem verhalten sich auch die verschiedenen Arten der Schädlinge recht ungleich bezüglich der Vollkommenheit der Parasiten- 
folge, indem manche Arten überhaupt nur eine mehr oder weniger lückenhafte Parasitenfolge aufzuweisen haben; so fehlt z. B. der Nonne ein Eiparasit.

Es ist klar, daß alle diese Verhältnisse für die Praxis von der größten Bedeutung sind; können wir doch in solchen Gegenden oder bei solchen Arten, bei denen eine wirksamere und lückenlosere Parasitenfolge vorhanden ist, event. eine günstigere Prognose für den Verlauf der Kalamität stellen als in solchen Gegenden, wo die Parasitenfolge unvollkommen ist und größere und kleinere Lücken aufweist. Daher ist es unbedingt notwendig, daß das Parasitenvorkommen eingehend beachtet und studiert wird, und es dürfte eine der nächstliegenden und vornehmsten Aufgaben der

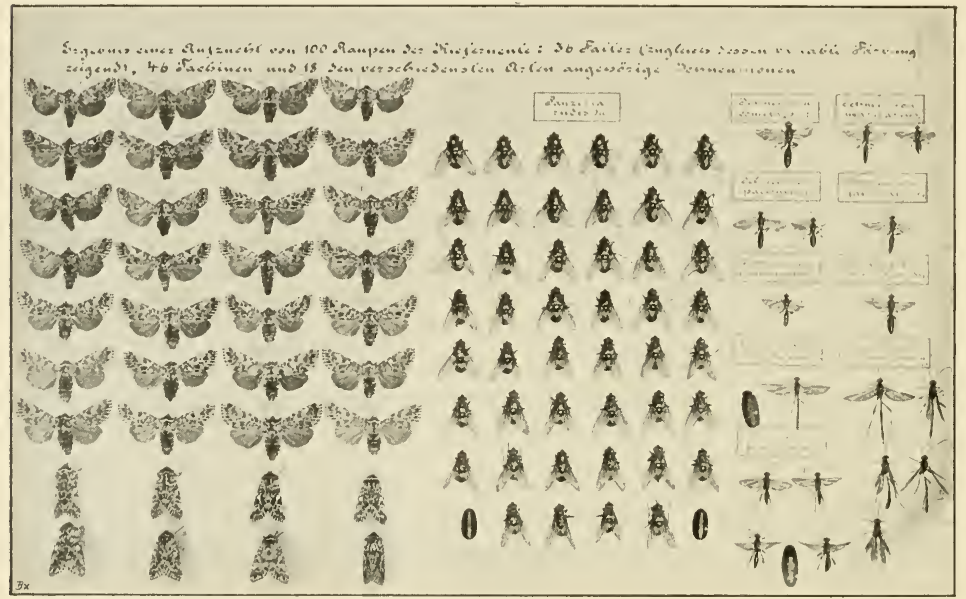

Fig. 188. Parasitenwirkung: Durchschnittliches Ergebnis einer Aufzucht von 100 Kiefereulenraupen (36 Falter, 46 Tachinen and 18 Ichneumonen).

forstentomologischen Wissenschaft sein, für unsere wichtigsten Schädlinge die Parasitenfolge festzustellen, in ebenso gründlicher Weise, wie es die Amerikaner für Schwammspinner und Goldafter getan haben. Und es wird hoffentlich die Zeit nicht mehr fern sein, wo bei jedem wichtigeren Schädling eine Tabelle der Parasitenfolge beigefügt ist. Dann werden wir vielleicht auch verstehen lernen, warum die Kalamitätsintensität und -dauer bei den einzelnen Schädlingen so verschieden sein kann.

Für einige unserer Schädlinge können wir heute schon, wenn auch vorläufig nur umrißweise, den Zusammenhang zwischen $Z$ ahl und Vermehrungsziffer der Parasitenarten einerseits und Dauer der Kala mität andererseits erkennen, wie z. B. aus einem Vergleich des Kalamitätenverlaufes der Kieferneule, des Kiefernspinners und der Nonne hervorgeht. 
Alle dıei stimmen darin überein, daß die Übervermehrung gewöhnlich explosionsartig auftritt, d. h. daß auf ein plötzliches Aufsteigen der Vermehrungskurve nach einiger Zeit gleichsam automatisch ein Zurückgehen auf die normale Höhe folgt. In einem Punkte jedoch verhalten sie sich wesentlich verschieden, nämlich bezüglich des zeitlichen Ablaufes jenes Vorganges: Am kürzesten währt die Kieferneulenplage (2-3 Jahre), etwas länger die Kiefernspinnerplage ( $3-5$ Jahre) und am längsten die Nonnenkalamität ( 5 bis 7 Jahre und auch noch mehr). Dieser Unterschied entspricht ungefähr der Zahl resp. der Vermehrungsziffer der Parasiten usw., welche dem betr. Schädling gegenüberstehen. So tritt gegen die Kieferneule gleich von Anfang an ein ganzes Heer von Feinden auf; wir haben vor einiger Zeit, als in der Nähe von Dresden (in Okrilla) eine Eulenvermehrung stattfand, im ersten Jahre der Kalamität (d. h. in dem Jahre, in welchem sie zum erstenmal die Aufmerksamkeit der Forstbeamten erregte) das Parasitenverhältnis festgestellt, und sind dabei zu dem überraschenden Ergebnis gelangt, daß aus 100 Raupen sich nur 36 Schmetterlinge entwickelten, während die übrigen 64 Parasiten ergaben (Fig. 188). Diese hohe Parasitenzahl im Anfangsstadium einer Über. vermehrung ist in erster Linie in der hohen Vermehrungsziffer der Eulentachine begründet, und sodann darin, daß an die Eule viele auch an anderen Schmetterlingen usw. schmarotzende Parasiten gehen. - Anders beim Kiefernspinner; dieser besitzt zwar ebenfalls eine ganz ansehnliche Parasitenreihe, doch dauert es gewöhnlich mehrere Jahre, bis die Parasiten zu einer stärkeren Vermehrung gelangen. So konnten wir z. B. beim Beginn einer Spinnerkalamität in den schlesischen Heiden in den ersten zwei Jahren nur einen sehr geringen Parasitenbefall nachweisen, indem die Raupen aus dem Winterlager nur zu je $1 \%$ mit Apanteles fulvipes und Anomalon circumflexum, und mit etwa je $5 \%$ mit dem Braconiden Meteorus versicolor und der Tachine Argyrophylax bimaculata besetzt waren. Erst nach weiteren zwei Jahren konnte man von einem wirksamen Parasitenbefall reden, indem 50\% der Raupen (und teilweise auch mehr) angegangen waren. - Noch ungünstiger liegen die Verhältnisse bei der Nonne; denn bei ihr ist die Parasitenreihe weit geringer und unvollkommener als bei den vorgenannten Schädlingen, und außerdem erreichen auch nur wenige von den Parasiten eine größere Bedeutung. Es ist wohl in der Hauptsache die Tachine (hier in Sachsen war es Parasetigena segregata), welche der Nonnenvermehrung in wirksamer Weise entgegentritt; die genannte Art ist aber für gewöhnlich so selten, daß die Fliegensammler Mühe haben, sie für ihre Sammlung zu erlangen. Wenn also die Nonnenvermehrung plötzlich durch irgendwelche besonders günstige Bedingungen größere Dimensionen annimmt, so wird es immer einer längeren Zeit bedürfen, bis die Tachine den Vorsprung eingeholt haben wird, zumal sie (nach unseren neuesten Versuchen) eine weit geringere Fortpflanzungsziffer als die Eulentachine besitzt und außerdem auch noch ziemlich stark unter Hyperparasiten und Raubinsekten zu leiden hat. So findet also der oben erwähnte Unterschied in der Zeitdauer der verschiedenen Kalamitäten eine ganz ungezwungene Erklärung in dem Verhältnis der Parasiten zu den betr. Schädlingen. 
Den explosionsartigen Vermehrungskatastrophen stehen die chronischen hartnäckigen Kalamitäten gegenüber, die stets wiederkehren und meist in annähernd der gleichen Höhe verharren; ich erinnere nur an den Maikäfer, den Eichenwickler, die Fichtenblattwespe, die Lärchenminiermotte u. a. In allen diesen Fällen finden wir gewöhnlich, daß den betr. Schädlingen nur wenige oder nur wenig wirksame Parasiten und Räuber gegenüberstehen, und daß der Parasitenbefall, wenn überhaupt von einem solchen die Rede sein kann, stets auf einer sehr geringen Höhe stehen bleibt (aus uns bis jetzt noch unbekannten Ursachen).

In diesen hier mitgeteilten Tatsachen, die unschwer noch vermehrt werden könnten, dürfte wohl die eingangs aufgestellte Behauptung, daß für die Niederhaltung der Schädlinge zumeist in erster Linie die Parasiten und Raubinsekten in Betracht kommen, eine kräftige Stütze erhalten.

Ein Moment darf dabei allerdings nicht außer acht gelassen werden, nämlich, daß die Parasiten und Raubinsekten selbst wieder ihre Feinde haben, durch welche event. ihre Vermehrung stark beschränkt werden kann, so stark sogar, daß sie den Vorsprung, den der Schädling genommen hat, nur sehr langsam oder überhaupt garnicht mehr einzuholen vermögen. Eine sehr drastische Erfahrung dieser Art habe ich, wie oben schon bemerkt, in dem von der Nonne so schwer heimgesuchten Staatsforstrevier Glasten gemacht: Dort konnte im Jahre 1910 eine Tachinose von ca. 50\% festgestellt werden, die eine gute Prognose zu rechtfertigen schien; doch im folgenden Jahre machte der Tachinenbefall nicht nur keine Fortschritte, sondern ging vielmehr wesentlich zurück, und zwar auf $25 \%$, um im Jahre 1912 noch weiter auf $10 \%$ herabzusinken. Der Grund für diese überraschende Erscheinung ließ sich unschwer ermitteln: die verschiedenen Feinde der Tachine, vor allem die Hyperparasiten, wie der Trauerschweber (Anthrax) und kleine Schlupfwespen (Chalcidier), dann auch eine räuberische Elateridenlarve, zu denen sich auch noch Pilze hinzugesellten, hatten inzwischen so in ihrer Zahl zugenommen, daß ein hoher Prozentsatz der Tachinennachkommen ihnen zum Opfer fielen. Solche Fälle gehören glücklicherweise zu den Ausnahmen; immerhin ergibt sich daraus für die Praxis, daß es, um zu einer richtigen Kalkulation zu gelangen, nicht genügt, einfach das Vorhandensein von Parasiten festzustellen, sondern da $\beta$ auch auf das Vorkommen der Hyperparasiten und anderer Feinde der Parasiten $\mathrm{zu}$ achten und deren Zahl in die Rechnung mit einzustellen ist.

Auf die einzelnen Parasiten und Raubinsekten soll hier nicht näher eingegangen werden, da dieselben im speziellen Teil noch eine ausführliche Besprechung finden; dagegen halten wir es für zweckmäßig, den obigen Ausführungen wenigstens eine kurze allgemeine Übersicht über Lebensweise jener nützlichen Tiere anzufügen.

Parasiten.

Unter den Parasiten spielen weitaus die wichtigste Rolle die Schlupfwespen und die Raupenfliegen. Ihnen gegenüber kommen die wenigen 
Schmarotzer aus anderen Familien und Ordnungen, wie z. B. der Käfer Anthribus varius, der in der Fichtenquirlschildlaus parasitiert, oder die zoologisch so merkwürdigen Stylopiden, die in Wespen schmarotzen, in forstlicher Beziehung nur wenig oder gar nicht in Betracht. ${ }^{1}$ )

Die Schlupfwespen gehören den Hymenopteren (Hautflüglern) an und stellen ein ungemein zahlreiches Heer dar, welches sich auf 5 Familien verteilt: die Ichneumoniden (im engeren Sinne), die Braconiden, die Evaniiden, die Chalcididen und Proctotrupiden.

Die Ichneumoniden (im engeren Sinne) bilden infolge der Menge der Arten und ihrer Größe (es sind meist große oder mittelgroße Arten) die auffallendste Familie der Schlupfwespen. Sie schmarotzen :hauptsächlich in Raupen und Puppen von Schmetterlingen, in Larven von Blatt- und Holzwespen, in holzbewohnenden Käterlarven usw. (Fig. 189).

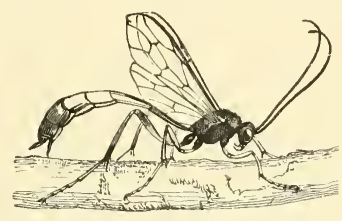

a

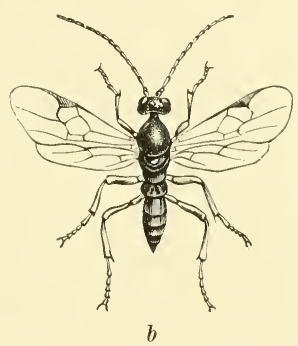

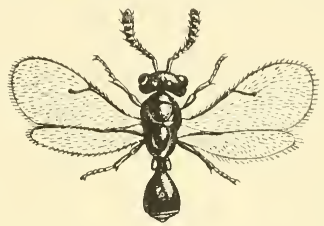

c

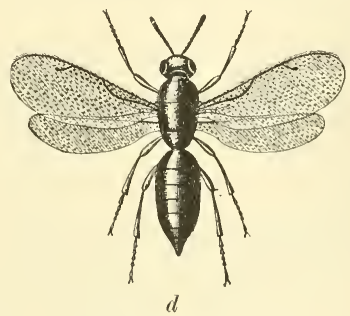

Fig. 189. Verschiedene Typen von Schlnpfwespen. a Ichneumonide (Anomalon) $1 /{ }_{1} ; b$ Braconide (Microgaster $=$ Apanteles) ${ }^{8} / 1 ; c$ Proctotrupide (Teleas) ${ }^{18} / 1 ; d$ Chalcidide (Pteromalus) $8 / 1$. Aus Eckstein.

Einige artenreiche Gattungen (Mezochorus, Hemiteles und Pezomachus) sind durchweg Schmarotzer 2. Grades oder Hyperparasiten, die bei anderen Ichneumoniden oder bei Braconiden schmarotzen und dadurch deren wohltätige Wirkung event. stark beeinträchtigen können (siehe oben).

Die Braconiden sind eine viel kleinere Familie als die Ichneumoniden, die meist kleine und nur relativ wenige mittelgroße Arten enthält. Sie sind als Schmarotzer bei fast allen Insektenordnungen (mit Ausnahme der Orthopteren und Neuropteren) gefunden worden. Hyperparasitismus scheint bei ihnen nicht vorzukommen.

1) Dasselbe gilt, soviel bis jetzt bekannt ist, auch für die verschiedenen Parasiten aus anderen Tierklassen, wie die Würmer (Mermis, Gordius, Nematoden), die gelegentlich in Forstschädlingen gefunden werden. 
Die Evaniiden stellen eine noch kleinere Familie dar, enthalten aber größere Formen, die bei Blattiden, Bienen und Grabwespen, sowie holzbewohnenden Käfern und Holzwespen usw. schmarotzen.

Die ungeheuer artenreichen Familien der Chalcididen (in Mitteleuropa ca. 350 Gattungen, von denen die Gattung Pteromalus allein über 300 Arten umfaßt) und Proctotrupiden enthalten meist nur sehr kleine Formen. Ihr Parasitismus bezieht sich dementsprechend großenteils auf kleine Insekten, wie Blattläuse, Gallwespen, Gallmücken, Rüssel-, Borkenkäfer usw. oder aber auf die Eier von größeren Insekten. Allerdings kommen sie nicht selten auch in den Larven und Puppen der letzteren vor, dann aber gewöhnlich in großer Menge in einem Individuum (Pteromalus in vielen Tagfalterpuppen, Eulophus in der Puppe des Kiefernspinners usw.) Ihre wirtschaftliche Bedeutung wird dadurch etwas herabgedrückt, daß unter ihnen zahlreiche Parasiten 2. Grades sich befinden, was aber vielleicht durch das Vorkommen von Parasiten 3. Grades, welche in den Hyperparasiten schmarotzen und dadurch deren schädliche Wirkung abschwächen, wieder etwas ausgeglichen wird.

Fast alle Schlupfwespen leben als Larven parasitisch in oder an anderen Insekten, nur einige wenige Chalcidier machen davon eine Ausnahme, wie die Isosoma-Arten, welche in Getreidestengeln leben, ferner die Megastigmus-Arten, die größtenteils zur Samennahrung übergegangen sind, dann Blastophaga, die durch Gallbildung die Befruchtung der Feige besorgt, u. a. m.

Bezüglich der Art des Parasitismus der Schlupfwespen herrschen die größten Unterschiede, und zwar nicht nur je nach den verschiedenen Familien, sondern auch in ein und derselben Familie und sogar bei nahverwandten Arten.

Schon bei der Eiablage tritt dies in Erscheinung, indem die Eier entweder in den Wirt hinein, oder aber außen auf dem Wirt abgelegt werden. Im letzteren Falle bohrt sich dann das ausschlüpfende Lärvchen durch die Haut des Wirtes in die Leibeshöhle ein, oder sie kann auch außen bleiben, um nach Art der Ektoparasiten von außen her dem Wirte die Säfte zu entziehen. Bei den tiefer im Holze lebenden Wirten (Bockkäfer-, Holzwespenlarven usw.) begnügen sich die Ichneumonen damit, das $\mathrm{Ei}$ in die Nähe des Wirtes in den Fraßkanal zu bringen, so daß die ausschlüpfende Larve selbständig den Wirt aufsuchen muß. Die langgestielten oder langgezogenen Eier, die vielen Schlupfwespen eigen sind (siehe oben S. 118, Fig. 107, 17), werden in der Weise auf dem Wirt angebracht, daß das dicke Ende außen bleibt, während der dünne Stiel durch die Haut hindurch nach innen ragt, so daß der Eiinhalt von dem äußeren Teil nach innen fließen kann.

Die Ablage der Eier geschieht mit Hilfe des Legebohrers, der übrigens auch als Waffe zur Abwehr dienen kann, wie die empfindlichen Stiche, die die größeren Arten den Menschen beibringen können, beweisen. Die Länge des Bohrers ist sehr verschieden, je nach der Lage und dem Sitz des Wirtes: „er muß lang sein, wenn er die Brut an sehr versteckte Stellen, wie in die Tiefe des Holzes, an Bockkäfer oder Holzwespenlarven hinbringen 
soll, er kann dagegen kürzer sein, wenn freilebende Larven oder Puppen, wie z. B. die des Spinners, der Eule, oder Blattläuse usw. mit Eiern belegt werden sollen" (Ratzeburg).

Beim Angriff wird der Bohrer senkrecht gegen den Hinterleib abgebogen oder aber der Hinterleib selbst stark nach unten oder sogar nach vorn gekrümmt, daß dann der Stachel in derselben Richtung wie der Hinterleib geführt wird (Fig. 190 u. 191). Die angegriffenen Opfer suchen sich meist nach Kräften zu wehren, was aber den Parasiten nicht abhält, seine Anstrengungen so lange fortzusetzen, bis er seinen Zweck erreicht hat, allerdings sind auch Fälle beobachtet, daß die Raupen sich gänzlich ruhig verhielten, ja nicht einmal zuckten, wenn der Parasit seinen todbringenden Stich ausführte.

Der Vorgang der Eiablage voll-

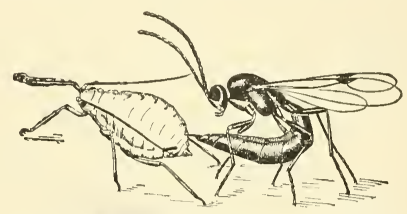

Fig. 190. Blattlaus (Lysiphlebus), eine Blattlaus anstechend. Nach Webster aus Escherich. zieht sich meistens sehr rasch, blitzschnell, wie z. B. bei den bekannten Kiefernspinnerparasiten Anomalon circumflexum; andere dagegen brauchen längere Zeit, besonders wenn der Bohrer, um zum IVirt zu gelangen, hartes Material durchdringen muß. Dieses trifft vor allem für die bei holzbewohnenden Larven parasitierenden Arten zu, wie z. B. für Rhyssa und Ephialtes. Letzterer bohrt die Stöcke von oben her an, wobei der drehrunde Bohrer erstaunlich schnell in die Tiefe rückt, während Rhyssa ihren flachen bandartigen Bohrer von der Seite her radial in den stehenden Stamm hineinzwängt.

Ein Teil der Schlupfwespen ist monophag, d. h. ist ganz speziell auf einen bestimmten Wirt angewiesen, während andere dagegen polyphag sind und also an verschiedene Wirte gehen. Früher hielt man den größeren Teil der Schlupfwespen

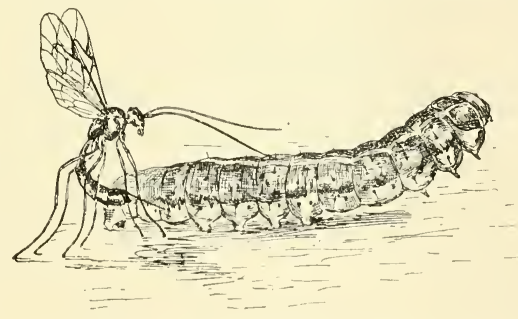

Fig. 191. Eine Schlupfwespe (Paniscus ocellaris), eine Raupe anstechend. Nach Chewyreux. für streng monophag, während sich bei Häufung der Zuchten immer mehr herausstellt, daß viele der früher als monophag gehaltenen Tiere bei mehreren Wirten vorkommen. Die Polyphagie kann verschiedene Grade aufweisen, je nachdem sie sich nur auf nahverwandte Wirte erstreckt oder aber ganz verschiedene Insekten betrifft. So gehen manche Arten, z. B. Ichneumon disparis nur an einige nahestehende Spinnerarten, während dagegen andere, wie z. B. gewisse Pimpla-Arten gleichzeitig bei Schmetterlingen, Käfern, Blattwespen und Fliegen parasitieren.

Besonders bemerkenswert sind jene Fälle von Polyphagie, in denen ein und dieselbe Art sowohl als Parasit als auch als Hyperparasit auftritt; bis jetzt sind 
zwei derartige Fälle bekannt, die durch $\mathrm{H}$ ow a $\mathrm{r}$ d und $\mathrm{Fisk}$ e beschrieben sind: der erste Fall betrifft den Chalcididen Pteromalus egregius, der die ruhenden kleinen Raupen des Goldafters belegt; wenn er dann im Frühjahr ausschlüpft, greift er sofort die um dieselbe Zeit aus den Goldafterräupchen sich ausbohrenden Larven einer anderen Schlupfwespenart an, und belegt sie mit seinen Eiern. Der zweite Fall handelt von Monodontomerus aereus, der in den Puppen vom Schwammspinner und Goldafter lebt, zugleich aber auch in anderen Schlupfwespen und in Tachinentönnchen schmarotzt.

Bei den polyphagen Arten kommen mitunter auffallende Größenunterschiede vor, die mit den Größenunterschieden der Wirte ungefähr Hand in Hand gehen. So schwankt z. B. die ungemein polyphage Pimpla instigator in ihrer Größe zwischen 7 und $30 \mathrm{~mm}$; so ergeben ferner, wie wir selbst beobachten konnten, die Raupen der Kieferneule weit kleinere Exemplare von Anomalon circumflexum, als die Raupen des weit größeren Kiefernspinners.

Wie wir oben bei der Besprechung der Parasitenfolge bereits angedeutet haben, verhalten sich die Parasiten auch bezügl. des Entwicklungsstadiums des Wirtes recht verschieden, indem die einen das Ei, die andern die jungen, wieder andere die älteren Raupen, noch andere die Puppen und die Imagines befallen. Am meisten haben die Larven und Puppen unter Schlupfwespenangriffen zu leiden, dann die Eier und am wenigsten die Imagines. Auch bezügl. des Alters der einzelnen Stadien werden vielfach Unterschiede gemacht; so belegt z. B. Anastatus bifasciatus das Ei des Schwammspinners nur in den ersten 10 Tagen des Eistadiums, während Schedius Kuwanae das Ei erst von da ab, dann aber die ganze übrige Zeit des Eistadiums (das ca. 280 Tage dauert) befällt.

Sehr verschieden ist auch die Zeit, die der Parasit in dem Wirt verbleibt und demnach auch das Stadium des Wirtes, in welchem derselbe von seinem Parasiten verlassen wird. Die Eiparasiten sind meist auf das Eistadium beschränkt, während die Larvenparasiten oft noch in die Puppe, ja mitunter sogar in die Imago übergehen.

Viele Schlupfwespen machen die ganze Entwicklung im Wirtstier durch und verpuppen sich dann meist ohne Kokons in der Puppe des Wirtes; andere verlassen ihren Wirt bereits als ausgewachsene Larve, in welchem Falle sie sich also außerhalb des Wirtes, entweder direkt auf seiner äußeren Oberfläche oder in dessen unmittelbarer Nähe oder aber ganz unabhängig von ihm im Boden oder sonstwo verpuppen (meist in Kokons).

Die Ausbohr- oder Schlupföffnungen, die von den Parasiten in den Eiern oder Puppen der Wirte gemacht werden, unterscheiden sich vielfach deutlich von den Schlupföffnungen der rechtmäßigen Eigentümer, so daß man daran gut erkennen kann, ob eine Raupe oder Schmetterling ausgekrochen ist oder ein Parasit, was natürlich für die Praxis (Feststellung der Höhe des Parasitenbefalls) von großer Bedeutung ist. Es wird z. B. bei den Kiefernspinnereiern niemand im Zweifel sein, ob das Räupchen herausgekommen ist oder aber Schlupfwespen, da im letzteren Fall nur eine kleine runde Öffnung vorhanden ist, während im ersteren der größte Teil der Eischale abgenagt ist (Fig. 192).

Über die Generationsverhältnisse der Schlupfwespen sind wir noch sehr schlecht unterrichtet; das meiste, was wir darüber wissen, ver- 
danken wir den Arbeiten der Amerikaner. Ein großer Teil der Schlupfwespen hat zweifellos eine einfache Generation. Bei Arten, die im Spätsommer auskommen, findet meist eine Überwinterung der befruchteten Weibchen statt (während die Männchen gleich nach der Befruchtung absterben). Der Eiparasit Anastatus bifasciatus belegt das frisch gelegte Ei des Schwammspinners, seine Larve ist bereits nach drei Wochen erwachsen, sie ruht aber dann zehn Monate innerhalb des abgestorbenen Wirtseies, so daß seine Imagoflugzeit erst dann eintritt, wenn wieder neue Schwammspinnereier vorhanden sind.

Andererseits ist auch eine doppelte Generation nicht selten. So hat Apanteles glomeratus zwei Generationen, entsprechend der doppelteu

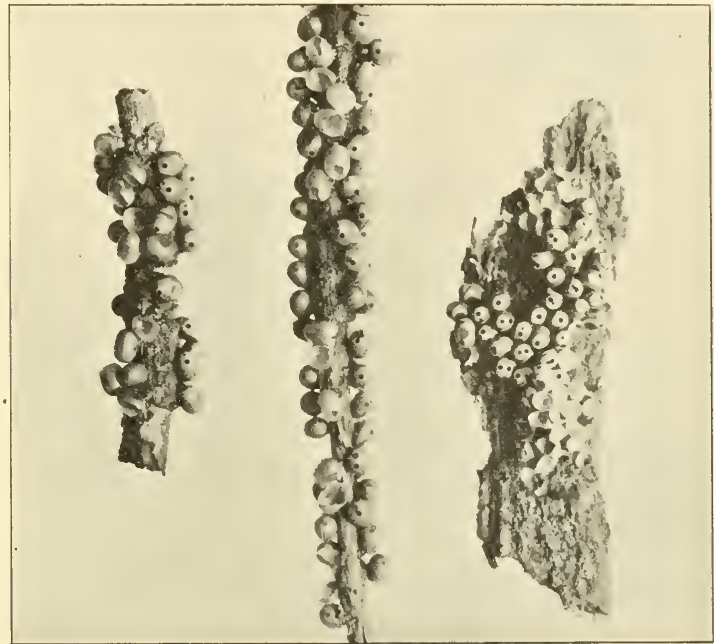

$a$

b

$c$

Fig. 192. Schmetterlingseier, von kleinen Schlupfwespen verlassen (mit kleinen Löchern versehen), daneben Schalenreste ausgeschlïpfter Eier. $a$ und $b$ Kiefernspinner; $c$ Brombeerspinner.

Generation seines Wirtes, des Kohlweißlings. So hat ferner nach Fiske Apanteles fulvipes wenigstens zwei Generationen, von denen die erste in den kleinen, die zweite in den erwachsenen Raupen des Schwammspinners lebt, - also zwei Generationen während einer Raupensaison; wahrscheinlich sind derartige Fälle ziemlich häufig. Bei den letztgenannten Apanteles, dessen Entwicklungsdauer nur wenige Wochen beansprucht, ist es recht wohl möglich, daß er im Herbst noch auf einen anderen Wirt übergeht, um eine dritte Generation zu machen.

IVirtswechsel spielt zweifellos eine große Rolle bei den Schlupfwespen: Teleas ovulorum hat eine ganze Reihe ron Wirten, darunter auch 
die Eier des Ringel- und des Kiefernspinners; er kann also, wenn er im August aus den Eiern des letzteren herauskommt, immer noch mehrmals einen Zwischenwirt benutzen. Ebenso hat der in jungen Nonnenräupchen schmarotzende Apanteles solitarius mehrere als Zwischenwirte benutzbare Wirte, wie z. B. die zweite Generation von Orgyia antiqua, so daß er, wenn er die jungen Nonnenräupchen verlassen hat, sofort neues passendes Brutmaterial zu einer zweiten Generation vorfindet. - Die Frage des Wirtswechsels kann für die Praxis von der größten Wichtigkeit sein, besonders, wenn man die Parasiten zur Bekämpfung künstlich heranziehen will, da es bei Parasiten mit regelmäßigem Wirtswechsel notwendig ist, daß auch der Zwischenwirt vorhanden ist. Manche Fälle von gänzlichem Versagen der Parasiteneinfuhr, z. B. Apanteles fulvipes in Amerika, ist vielleicht auf den Mangel geeigneter Zwischenwirte zurückzuführen.

Die Anzahl der in einem Wirte lebenden Schlupfwespenlarven wechselt sehr, von einer einzigen bis zu mehreren Hundert, ja Tausend; selbst in den Eiern können bis zu zwanzig Larven und mehr vorkommen, dagegen bewohnt Anastatus bifasciatus das Schwammspinnerei immer nur in 1 Stück. Die größte Zahl ist wohl von Howard beobachtet worden, der in einer Schmetterlingsraupe 2-3000 Stück eines winzigen Chalciders feststellte. Von Apanteles fulvipes sind in kleineren Schwammspinnerraupen oft nur 2 bis 3 Larven, in großen 100 und mehr. Und von Pteromalus puparum werden mitunter 6-700 Stück in einer Puppe gefunden. Im allgemeinen hängt die Zahl der Larven ron der Größe der Schlupfwespen ab, indem um so weniger vorhanden sind, je größer die betr. Schlupfwespe ist und umgekehrt. Doch ist dies keine feststehende Regel, indem z. B. der kleine Chalcis flavipes stets nur in 1 Stück in der großen Puppe des Schwammspinners vorkommt. Selten gehen an eine Raupe zwei verschiedene Schlupfwespenarten; doch sind auch schon solche Fälle beobachtet worden, z. B. Anomalon und Apanteles in einer Spinnerraupe.

Die Zahl der Larven entspricht nicht immer der Zahl der abgelegten Eier, da, wie wir oben gehört haben, durch Polyembryonie aus 1 Ei eine ganze Menge Larven sich bilden können.

Die alte Ratzeburgsche Hypothese, daß die Schlupfwespen nur kranke Wirte befallen, ist heute völlig aufgegeben. Hundertfältige Erfahrungen haben das Gegenteil gezeigt. Liegt es doch auch im Interesse des Parasiten, möglichst gesundes Material zu belegen, da in solchem seine Entwicklung viel sicherer sich vollziehen kann, als in kränklichen, absterbenden Wirten.

Die zweite wichtige Gruppe von Schmarotzerinsekten, die Raupenfliegen oder die „Tachinen“ (sens. lat.) gehören der Dipterenfamilie der Tachiniden an, wo sie sich auf 3 Unterfamilien die Tachininae, Dexiinae und Sarcophaginae verteilen. ${ }^{1}$ )

1) Die Tachininae enthalten 98 (mitteleuropäische) Gattungen mit zusammen ca. 375 Arten, die Dexiinae 60 Gattungen mit 120 Arten, die Sarcophaginae ca. 20 parasitische Gattungen mit über 50 Arten (exk1. der Gattung Sarcophaga). 
Sie bilden im Gegensatz zu den Schlupfwespen eine ziemlich einförmige Gruppe, und die Arten stehen sich vielfach so nahe, daß die Bestimmung meist mit großen Schwierigkeiten verbunden ist. Trotzdem zeigen sie in biologischer Hinsicht eine erstaunliche Vielseitigkeit, und stehen darin den Schlupfwespen kaum nach. Bis vor kurzem waren unsere biologischen Kenntnisse dieser wirtschaftlich so bedeutsamen und wissenschaftlich so interessanten Tiere beinahe gleich Null; erst im letzten
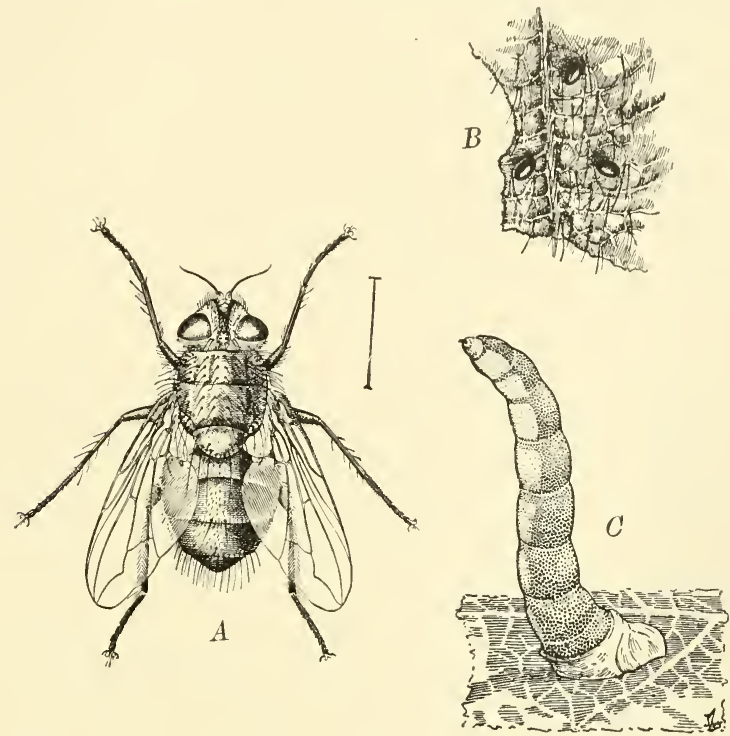

Fig. 193. Tachinen. A Blepharipa scutellata; $B$ deren kleine schwarze Eier auf einem Blatt befestigt, wo sie von den Raupen zugleich mit dem Blatt gefressen werden; $C$ Larve von Eupeleteria magnicomis, die mit ihrem Hinterende an einem Blatt befestigt ist, um mit ihrem freien Vorderende sich an eine vorüberkilechende Larve festzuheften. Nach Howard und Fiske aus Escherich.

Jahrzehnt ist darin etwas Wandel geschaffen worden, vor allem durch die Arbeiten von Townsend, Fiske, Pantel, Nielsen und Prell, so daß wir heute wenigstens von einigen wenigen Arten die Lebensgeschichte einigermaßen kennen.

Die Verschiedenartigkeit in der Biologie dokumentiert sich wie bei den Schlupfwespen auch bei den Tachinen schon bei der Eiablage: die einen Arten (wohl die Mehrzahl) legen ihre Eier außen auf die Haut des Wirtes ab, so daß also die auskommenden Larven sich durch die Haut durchbohren müssen (z. B. Tachina larvarum, Parasetigena segregata); die anderen legen gleich die Larven auf den Wirt ab (z. B. Exorista); wieder 
andere bringen die Larven gleich in den Körper des Wirtes, indem sie mit Hilfe eines besonderen Legeapparates die dünne Haut zwischen den Segmentplatten durchbohren (Compsilura concinnata); wieder andere setzen ihre Larven auf Blättern ab, von wo aus sie auf vorüberlaufende Raupen zu gelangen suchen (Eupeleteria, Panzeria), und noch andere endlich legen ihre Eier (die in diesem Falle winzig klein und hartschalig sind) auf Blätter ab, wo sie von den Raupen gefressen und so in den Körper des Wirtstieres gelangen (Blepharipa [Sturmia] scutellata).

Auch die Zahl der Eier, die ein Tachinenweibchen produzieren kann, ist sehr unterschiedlich und schwankt zwischen wenigen Hundert und mehreren Tausend, je nach der Größe der Eier. Da meist nur je 1 Ei an einem Wirtsindividuum gefunden wird, so kann die Zahl der produzierten Eier event. die Zahl der einem Tachinen- $q$ zum Opfer fallenden Raupen usw. bedeuten. In Wirklichkeit dürfte dieser Fall jedoch nur selten eintreten; denn einmal finden wir auch Ausnahmen von obiger Regel, indem mitunter eine ganze Anzahl Eier an 1 Wirtsindividuum gelegt werden, und sodann werden viele Eier bei der Häutung des Wirtes wieder abgestreift, so daß sie also nicht alle zur Entwicklung gelangen können. Im Hinblick auf letzteren Punkt unterscheiden wir zwischen Tachinierung und Tachinose, indem wir als "tachiniert" überhaupt alle mit Eiern besetzten Raupen bezeichnen, als "tachinös" jedoch nur solche, die wirklich infiziert, d. h. bei denen die Larven bereits in den Körper eingedrungen sind. Die Zahl der tachinierten Raupen allein kann also nicht ohne weiteres als genauer Maßstab für die Höhe der Tachinose verwandt werden, wenn sie auch in den meisten Fällen ein annähernd richtiges Bild davon geben dürfte.

Gewöhnlich kann sich in einem Wirtsindividuum nur eine oder höchstens zw.ei Tachinenlarven gut entwickeln. Wo mehr eindringen, sterben die überzähligen meistens, wohl aus Raum- oder Nahrungsmangel, ab. Es sind jedoch bei kleinen Tachinenarten auch Fälle beobachtet worden, in denen 5 oder 7 oder sogar noch mehr Tachinenlarven sich in einer Schmetterlingsraupe voll entwickelt haben; ja Präparator Herpig hat aus einer Puppe von Sphinx pinastri nicht weniger als 18 entwickelte Tachinenlarven auskommen sehen. Immerhin ist der erstere Vorgang (Absterben der überzähligen Larven) wohl als die Regel anzusehen; es ist daher keineswegs immer, wie vielfach in der Praxis angenommen wird, ein besonders crfreuliches Zeichen, wenn auf einer einzigen Raupe eine große Anzahl Tachineneier gefunden werden, sondern es bedeutet dies meistens eine (wohl auf Instinktsirrtum resp. -mangel beruhende) Vergeudung der Vernichtungskraft der Tachine.

Wie bei den Schlupfwespen gibt es auch bei den Tachinen sowohl monophage als auch polyphage Arten, doch überwiegen hier zweifellos die letzteren.

Meistens bohrt sich die Tachinenlarve, wenn sie ausgewachsen ist, aus dem Wirte aus, um sich entweder in der Nähe des Wirtes oder aber im Boden in den charakteristischen Tönnchen (siehe S. 168, Fig. 170, A) zu 
verpuppen. Nur ganz wenige Formen verpuppen sich in dem Wirtstier, wie z. B. die Viviana cinerea im Abdomen von Carabus, oder Carcelia comata in der Puppe von Malacosoma castrensis.

Die Tachinen haben sowohl einfache als doppelte Generation. Als Beispiel für die erstere nenne ich die Nonnentachine Parasetigena segregata, die im Juli sich verpuppt und als Puppe überwintert, um erst im nächsten Mai, wenn wieder Nonnenraupen vorhanden sind, auszuschlüpfen. Eine doppelte Generation hat z. B. Tachina larvarum, Actia pilipennis oder Phryxe vulgaris; meist ist dieselbe mit einem Wirtswechsel, wie wir ihn bereits oben bei den Schlupfwespen kennen gelernt haben, verbunden. So wurde z. B. von der sehr polyphagen Tachina larvarum eine Sommer- und eine Winter-Herbstgeneration beobachtet, die erstere in Malacosoma castrensis, die letztere in Spilosoma lubricipeda. Ebenso hat Actia pilipennis wenigstens zwei Generationen: die erste schmarotzt in der Larve des Harzgallenwicklers (Evetria resinella), aus der im Mai die Imagines auskommen. Diese belegen alsdann die um diese Zeit bereits ziemlich erwachsenen Raupen des Kieferntriebwicklers (Ev. buoliana), woraus im Juli bis August die Fliege zum zweitenmal im Jahre erscheint.

Über die Wirksamkeit (Vernichtungsgröße) der Tachinen haben wir oben schon einiges gesagt. Bei manchen Schädlingen spielen die Tachinen die Hauptrolle, wie z. B. bei der Kieferneule (siehe oben Fig. 188, S. 242) und der Nonne. Hängt doch bei der letzteren das Ende der Kalamität vielfach $(\mathrm{d}$. h. neben der Wipfelkrankheit, deren Rolle noch nicht genügend aufgeklärt ist) von der Zahl, resp. von den Entwicklungsbedingungen der Tachine ab, wie wir bei der gegenwärtigen Nonnenkalamität in Sachsen mehrfach beobachten konnten. Auch Nielsen teilt einen Fall mit, der die Beendigung einer Kalamität durch die Tätigkeit der Tachinen zeigt: 1905 wurde eine Weidenhecke vom Weiden- und Ringelspinner belegt, 1906 und 1907 vermehrten sich die Raupen so sehr, daß die Hecke röllig kahl gefressen wurde, 1907 ward zum erstenmal die Tachinose festgestellt (Carcelia gnava), 1908 zeigte sich bereits ein Rückgang der Raupen bei gleichzeitiger Zunahme der Tachinose, 1909 waren schon 50\% der Raupen tachinös und 1910 waren nur noch wenig Raupen vorhanden, die fast alle von Tachinen befallen waren.

\section{Raubinsekten.}

Wirtschaftlich stehen die Raubinsekten den Parasiten im allgemeinen zweifellos nach. Schon die Zahl der Arten ist eine ungleich geringere, und auch die Vermehrungsgröße reicht gewöhnlich nicht an die der Parasiten heran. Dennoch gibt es auch Fälle, in denen die Wirkung der Raubinsekten derjenigen der Parasiten gleichkommt und sie sogar noch übertrifft. So können wir z. B. der raschen und radikalen Vernichtung der nach Amerika verschleppten Wollschildlaus Icerya Purchasi durch den Coccinelliden Novius cardinalis kaum ein ebenbürtiges Beispiel aus der Reihe der Parasiten an die Seiten stellen. Auch viele andere Coccinelliden (aller Weltteile) sind als überaus wirksame Bekämpfer von Schädlingen, vor allem 
der Blatt- und Schildläuse, beobachtet worden. Vor kurzem hatten wir Gelegenheit, uns von der Wirksamkeit der Coccinelliden im Walde zu überzeugen. Vor einigen Jahren trat im Reudnitzer Revier (Sachsen) eine Schildlaus, Palaeococcus fuscipennis, in ungeheueren Mengen an Kiefern auf, so daß an einzelnen Stämmen faustgroße Ballen der weißen Wolle zu finden waren. Die Vermehrung machte jedoch bald Halt, und zwar gleichzeitig mit dem häufigeren Auftreten von Novius cruentatus, dessen Larve und Imago von der Schildlaus sich nährt. Der Coccinellide wurde in der Folgezeit immer häufiger, während damit Hand in Hand die Schildlaus immer mehr zurückging und schließlich nach wenigen Jahren vollständig verschwand. - Nach allem, was wir bis jetzt über die Coccinelliden wissen, dürfen wir diese Käferfamilie bezügl. ihrer wirtschaftlichen Bedeutung (Vernichtungskraft) in die erste Reihe unter den Raubinsekten stellen.

Eine bedeutende Rolle im Kampfe gegen die Schädlinge spielen auch die Ameisen, von denen ja viele Arten großenteils oder sogar ausschließlich von Insekten sich nähren, und deren Nahrungsbedürfnis infolge der großen Individuenzahl ein ungemein hohes ist. Das höchste Lob unter

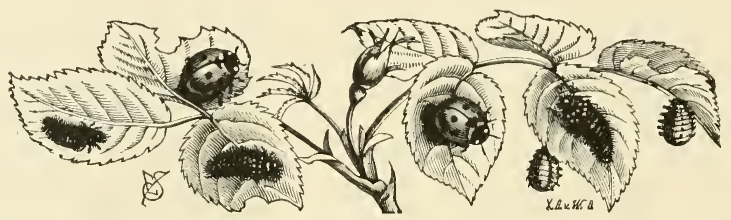

Fig. 194. Verschiedene Coccinellen mit ihren Larven und Puppen. Aus Ritzema Bos.

ihnen verdient - wenigstens in unseren Landen - unstreitig die rote Waldameise (Formica rufa), die infolge ihrer großen Haufen zu den bekanntesten Ameisenarten unserer Fauna gehört. Von früh bis nachts sehen wir von ihren Bauten aus ununterbrochene Reihen von Arbeitern ausziehen, um die ganze Umgebung sowohl auf dem Boden als auch auf den Bäumen nach Insekten zu durchstreifen. Versuchen wir, Zählungen anzustellen, so gelangen wir zu höchst überraschenden Zahlen. Forel berechnete, daß von den Bewohnern eines einzigen großen Nestes an einem Tage mindestens 100000 Insekten vertilgt werden; das macht in einem Sommer mindestens 10 Millionen.

Gegenüber den Ameisen spielen die übrigen Hymenopteren eine geringere Rolle. Immerhin machen sich die Grabwespen (Fig. 195), welche die Gewohnheit haben, Insekten für ihre Nachkommenschaft in die Nester einzutragen, durch Vertilgung zahlreicher Forstschädlinge recht nützlich; vor allem scheinen sie an der Bekämpfung der verschiedenen Kurzrüßler, wie Brachyderes, Phyllobius, Polydrusus usw. einen nicht zu unterschätzenden Anteil zu nehmen. Auch die Faltenwespen (die einsamen sowohl, wie die geselligen) beteiligen sich an der Vernichtung von Schädlingen, indem sie zahlreiche Larven aller Art usw. in ihre Nester eintragen. 
Übrigens ist die Tätigkeit der Raubwespen keineswegs eine uneingeschränkt nützliche, denn es fallen ihr nicht nur schädliche, sondern auch nützliche Tiere zum Opfer, und einige Arten haben sogar eine spezielle Vorliebe für nützliche Tiere; so tragen z. B. verschiedene Arten der Gattung Crabro vorzugsweise Fliegen, darunter viele Syrphiden und Tachinen ein.

Nach den Ameisen dürften - hinsichtlich der wirtschaftlichen Bedeutung - die Laufkäfer (Fig. 196) zu nennen sein, vor allem die beiden Puppenräuber, Calosoma sycophanta und inquisitor, deren nützliche Tätigkeit (Vertilgen der Raupen und Puppen der verschiedensten Arten, wie Nonne, Kiefernspinner, Schwammspinner usw.) jedem Praktiker geläufig ist. Trotz dieser allgemein bekannten Eigenschaft und der doch ziemlich auffallenden Erscheinung der beiden Käfer waren unsere Kenntnisse darüber bis vor kurzem nur sehr mangelhafte; erst in der allerjüngsten Zeit sind wir besser

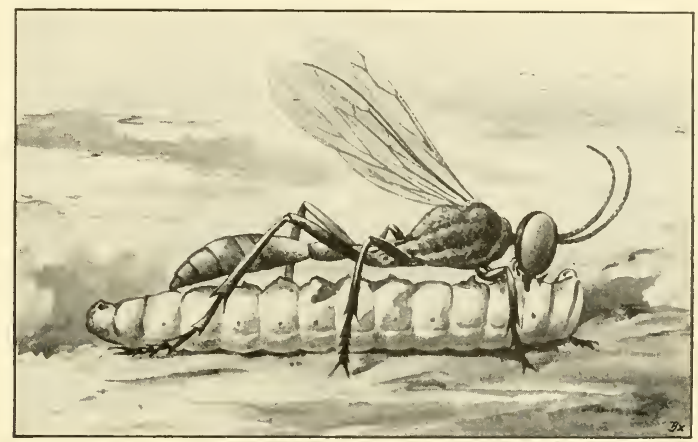

Fig. 195. Eine Grabwespe, eine Raupe eintragend. Nach Peckham.

unterrichtet worden, und zwar durch die Amerikaner, welche den Sycophanten seiner ausgezeichneten Kletterfähigkeit wegen bei sich eingeführt haben (mit bestem Erfolg!) zur Unterstützung des Kampfes gegen den Schwaumspinner und zu diesem Zwecke vorher eingehende Studien über seine Lebensweise angestellt haben. Darnach hat der Käfer eine Lebensdauer von 3 Jahren und vertilgt in dieser Zeit pro Jahr 2-400 erwachsene Schwammspinnerraupen, während die Larve zu ihrer vollen Entwicklung nur ca. 40 ausgewachsene Raupen oder gar nur ein Dutzend Puppen bedarf. Die Vermehrungsziffer ist eine relativ hohe, indem ein Weibchen während seiner dreijährigen Lebensdauer durchschnittlich gegen 300 Eier legt. Diese Zahlen machen den wirtschaftlichen Wert der Puppenräuber ohne weiteres klar. Auch die verschiedenen anderen großen Carabiden beteiligen sich an der Insektenvertilgung, doch bei weitem nicht in dem Maße wie die ebengenannten.

Von den übrigen als Insektenräuber bekannten Käfern, wie den verschiedenen Kurzflüglern (Staphyliniden), von denen die kleineren Arten 
vielfach in den Gängen von Borkenkäfern gefunden werden, oder den Aaskäfern (Silpha), deren Larven den Raupen der Nonne und anderer Schmetterlinge nachstellen, oder dem Clerus formicarius, dem allgemein bekannten Borkenkäferfeind, oder den vielen kleinen Nitiduliden, Cucujiden usw. besitzen wir leider noch sehr wenig positive Angaben, betr. des Umfanges ihrer vertilgenden Tätigkeit, so daß sich der Grad ihrer wirtschaftlichen Bedeutung schwer einschätzen läßt; sehr hoch scheint derselbe nach den gelegentlich gemachten Erfahrungen allerdings nicht zu sein.

Neuerdings wurden auch Elateridenlarven mehrfach als Räuber festgestellt. So konnte Forstmeister Grohmann (Königstein) solche beim Vertilgen von Hylobius-Larven beobachten, und zwar in ziemlich ausgedehntem Maße, so daß er in ihnen einen nicht zu unterschätzenden Faktor in der Be-

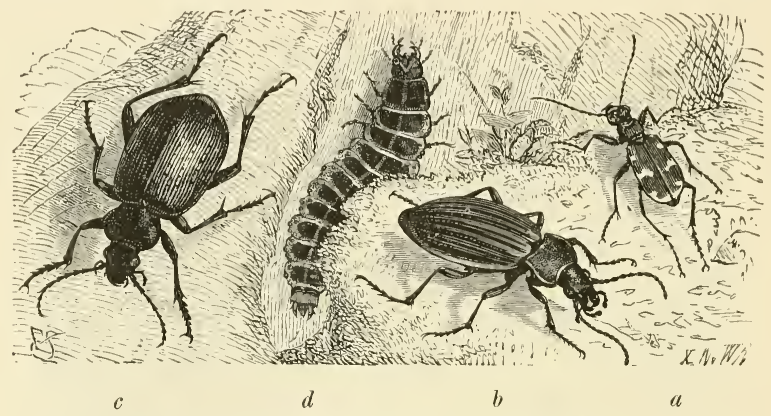

Fig. 196. Verschiedene nützliche (räuberische) Laufkäfer. a Cüıindela hybrida; b Carabus auratus; $c$ Calosoma sycophanta; $d$ dessen Larve. Aus Taschenberg.

schränkung der Rüsselkäfervermehrung erblickt (Thar. forstl. Jahrb. 1913). Leider beschränkt sich aber die räuberische Tätigkeit der Drahtwürmer nicht bloß auf schädliche Tiere, sondern es fallen ihnen auch, wie ich im vergangenen Jahre feststellen konnte, zahlreiche Tachinentönnchen zum Opfer.

Eine nicht unbeträchtliche Rolle als Insektenvertilger spielen die Schwebefliegen (Syrphiden), deren Larren fast ausschließlich von Blattläusen sich nähren. Ähnliches gilt für die Larven der zu den Netztlüglern gehörigen Florfliegen oder Chrysopiden, welche wegen ihrer Blattlausvernichtung auch als „Blattlauslöwen“ bezeichnet werden. Forstlich bedeutsamer als die Florfliegen ist ein anderer Netzflügler, nämlich die sog. Kamelhalsfliege (Raphidie), deren Larve als fleißige Vertilgerin von Nonneneiern, von Lyda hypotrophica und auch von Borkenkäfern (nach C. Keller) beobachtet ist.

Weiter sind als Insektenvertilger zu nennen die verschiedenen Orthopteren oder Geradeflügler, vor allem die sog. Ohrwürmer (Forficula), welche sich durch Verzehren von Raupen und Puppen, und besonders auch von Blattläusen (nach C. Verhoeff) sehr nützlich machen. 
Endlich sei noch der räuberischen Schildwanzen Erwähnung getan, die bei Nonnenkalamitäten usw. oft in großer Anzahl beim Anstechen und Aussaugen von Nonnenraupen beobachtet werden; es handelt sich dabei meist um die zu den Asopiden gehörigen Gattungen Troilus und Picromerus.

\section{Andere räubeı ische Arthropodeı.}

Im Anschluf an die Raubinsekten sei noch auf einige andere räuberische, ron Insektenraub lebende Arthropoden hingewiesen: die Tausendfüße (resp. Hundertfüße) und die Spinnen.

Von den Tausendfüßen (Myriapoden) kommen als räuberisch nur die Chilopoden („Hundertfüße“) in Betracht, die durch Vermittlung der in den Kieferfüßen enthaltenen Giftdrüsen ihre Opfer bewältigen. Der verschiedenen Körpergestalt entsprechend ist auch der Hauptschauplatz der Tätigkeit bei den verschiedenen Gruppen recht verschieden. So jagen die Spinnenasseln mit reißender Geschwindigkeit an Wänden, Steinen und Bäumen nach Fliegen und anderen Insekten; die Steinläufer dagegen kriechen im Laubwerk des Waldbodens, oder unter der Rinde alter Bäume umher, um dort Jagd auf Schnecken, Insekten und anderes Getier zu machen. Da die Chilopoden alles fressen, was ihnen in den Weg kommt, so werden sie ebensoviel nützliche wie schädliche wie indifferente Insekten vertilgen, so daß ihnen im allgemeinen keine größere Bedeutung weder nach der einen noch nach der anderen Seite hin zukommen resp. ihre Wirkung sich aufheben dürfte. Doch kann natürlich da, wo weit mehr schädliche als nützliche Insekten vorhanden sind, die räuberische Tätigkeit einen ausgesprochenen

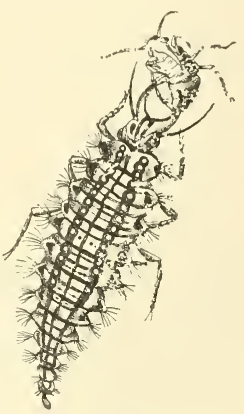

Fig. 197. Hemerobius Larve, eine Blattlaus aussaugend. Nach Buckton aus Eckstein. Nutzen bedeuten. So beobachtete z. B. Keller des öfteren, daß der braune Steinkriecher, Lithobius forficatus unter die sich ablösende Rinde der von Borkenkäfern besetzten Bäume kriecht, um die dort befindlichen Käfer zu verzehren.

Einigermaßen ähnlich wie die Tausendfüße verhalten sich die Spinnen, insofern als auch sie meistens ohne Unterschied sowohl nützliche als auch schädliche Insekten vertilgen. Immerhin scheinen doch wenigstens manche Arten eine Vorliebe für gewisse Schädlinge zu haben, und so ein wirkliches Gegengewicht gegen die Vermehrung der letzteren darzustellen, wie besonders aus den Untersuchungen von Keller hervorgeht. So werden z. B. die ChermesArten stark von den Spinnen verfolgt und in großen Mlengen vernichtet. Keller fand, daß den Läusen, wenn sie den Gallen entfliegen, von verschiedenen Jagd- und Radspinnen eifrig nachgestellt wird. Ja, diese Räuber zogen sich förmlich nach den befallenen Fichtenbeständen zusammen, wo nun zahlreiche vorher fehlende Spinnennetze zu sehen waren. Außer den echten Spinnen (von denen Epcira diadema, Theridium nerwosum, redimitum und irroratum, Tetragnatha extensa usw. genannt werden), beteiligen sich 
auch die Afterspinnen an der Chermes-Vernichtung. So beobachtete Keller, wie eine Phalangium-Art (Weberknecht) mit besonderer Gier die Weibchen von Chermes strobilobius vor der Eiablage ergriff, ihnen die Eimassen aus dem Hinterleib quetschte und auffraß, während er die anderen härteren Teile liegen ließ. Versuche ergaben, daß ein Phalangium-o eine große Anzahl von Chermes-Weibchen vernichten kann. - Auch die Verbreitung der Fichtenquirlschildlaus, Lecanium hemicryphum, wird nach Keller wesentlich durch Spinnen, und zwar vor allem durch Micryphantes rubripes C. L. Koch und Thomisus calycinus C. L. Koch beschränkt.

Ferner betont Keller den Nutzen, den die Spinnen durch Abfangen der Kleinschmetterlinge (namentlich von Tortrix tedella, resinella und buoliana) und der blatt- und nadelfressenden Rüsselkäfer bringen. Letzteres konnte ich anläßlich eines größeren Brachyderes-Fraßes in Schlesien bestätigen, wo in den stark befressenen Kulturen auffallend viele Spinnen aller Art herumwimmelten.

Eckstein berichtet, daß sich 1886 eine Webspinne, Steatodia sisyphia, in dem Schutzbezirk Brahlitz (Fieienwalde) durch den Fang der Imagines ron Lophyrus pini nützlich gemacht habe; und Wagener meldet, daß 1888 in der fürstlich Lippeschen Oberförsterei Varenholz gleichfalls eine Webspinne, Epeira scalaris, die Raupen des Rotschwanzes (Orgyia pudibunda) in ihren auf dem Unterwuchse angelegten Gespinsten gefangen und ausgesaugt habe. Während der jetzigen Nonnenkalamität in Sachsen konnte man zahlreiche Spinnen aller Art unter den Leimringen auf die dort angesammelten Raupen Jagd machen sehen.

Schwangart schreibt besonders den Springspinnen (Salticoidae) und den Mord- oder Krabbenspinnen (Laterigradae) eine größere wirtschaftliche Bedeutung zu; letztere wurden von ihm als eifrige Schmetterlingsjäger auf Wiesen beobachtet, auBerdem nehmen sie nach seinen Versuchen auch behaarte Raupen, selbst solche mit Brennhaaren (Goldafter usw.) an, was andere Spinnen nicht tun.

Zweifellos kommt also den Spinnen eine gewisse wirtschaftliche Bedeutung bei der Bekämpfung der schädlichen Insekten zu. Doch wissen wir leider noch sehr wenig positives darüber und es würde sicherlich eine dankbare Aufgabe sein, die Spinnenfrage zum Gegenstand eingehender Untersuchungen zu machen.

\section{Die insektentötenden Pilze ${ }^{1}$ ) (Mykosen).}

(Bearbeitet von Dr. Georg Lakon)

\section{A. Systematik und Biologie.}

Unter der Bezeichnung Pilze (Fungi) versteht man im allgemeinen alle diejenigen niederen, sporenbildenden Organismen (Kryptogamen, Thallo-

$\left.{ }^{1}\right)$ In der vorigen Auflage war dieser Abschnitt unter Mitwirkung von de Bary bearbeitet. Für die vorliegende Auflage hat Herr Dr. Georg Lakon, Assistent am hiesigen Botan. Institut, die völlige Neubearbeitung, die infolge der vielen neuen Forschungsergebnisse notwendig geworden war, übernommen, wofür ich ihm auch an dieser Stelle meinen herzlichsten Dank aussprechen möchte. 
phyten), welche jeglicher assimilierender, farbstofführender Körper (Chromatophoren) entbehren und somit auf saprophytische oder parasitische Lebensweise angewiesen sind.

Derartige Organismen werden jedoch heute, nach genauer Kenntnis ihrer Entwicklungsgeschichte, unter Zugrundelegung ihrer natürlichen verwandtschaftlichen Beziehungen in mehrere selbständige Abteilungen geteilt, welche verwandtschaftlich zueinander $z$. T. weniger nahe stehen als zu anderen, assimilierende Chromatophoren führenden, also nicht pilzlichen Thallophyten.

Man unterscheidet drei Hauptabteilungen, nämlich die Bakterien oder Spaltpilze (Bakteria, Schizomycetes), die Schleimpilze (Myxomycetes) und die echten Pilze (Eumycetes).

Pilze im engeren Sinne sind nur die Vertreter der letzten Kategorie, welche auch allein hier unser Interesse beanspruchen. Die Bakterien werden im nächsten Abschnitt besprochen werden, während die Myxomyceten, also die in ihrem vegetativen Stadium nur aus nackten Protoplasten bestehenden Organismen unberücksichtigt bleiben, da unter ihnen keine Art zu finden ist, welche auf Insekten parasitisch lebt. ${ }^{1}$ )

Unter den echten Pilzen gibt es eine große Anzahl von Arten, welche auf Insekten parasitisch leben, d. h. auf Kosten und zur Beeinträchtigung lebender Insekten. Letztere werden infolge des Befalles krank, und diese Erkrankung führt in den meisten Fällen nach kürzerer oder längerer Zeit schließlich den Tod des befallenen Tieres herbei. Solche Erkrankungen, die man im allgemeinen als „Mykosen“ bezeichnet, sind unter den Insekten sehr verbreitet und treten bisweilen epidemisch auf, große Verheerungen unter den betr. Insekten verursachend. Es sind auch vielfach Fälle bekannt, bei welchen große, durch Insekten verursachte Forstverheerungen durch den epidemischen Ausbruch von Mykosen beendet und völlig unterdrückt wurden. Solche Krankheiten von Forstschädlingen können also von großem wirtschaftlichem Nutzen sein und beanspruchen daher das Interesse des Forstmanns.

Der einfach gebaute Körper (Thallus) der echten Pilze besteht aus feinen farblosen, meist verzweigten fadenförmigen Zellen oder Zellenreihen, den Hyphen; die Gesamtheit dieser vegetativen Hyphen, welche das Substrat durchziehen, oder auch zu größeren Knäueln lose miteinander verwebt sein können, heißt Mycelium. Einige Pilzarten bilden durch festes Zusammenweben von kurzgliedrigen Hyphen größere, harte, pseudoparenchymatische Körper, die sog. Sklerotien, welche, ähnlich den Knollen der

$\left.{ }^{1}\right)$ In der neueren Zeit sind allerdings einige wenige Fälle bekannt geworden, bei welchen in den Malpighischen Gefäßen von Insekten zu den Nyxomyceten gehörige Organismen nachgewiesen wurden, so z. B. bei Olocrates abbreviatus (nach Lèger, in Compt. rend. Ac. sc. CXLIX, 1909, S. 239-241) und Dorcus parallelepipedus (nach Lèger und Hesse ebenda, S. 303-304). Die Art der Beeinflussung des Wirtes durch diesen Parasitismus ist jedoch keinesfalls klar gelegt. 
höheren Pflanzen, nach Verlauf einer längeren Zeit der Ruhe unter bestimmten Bedingungen wieder auszukeimen vermögen.

Die Vermehrung der Pilze findet durch Sporen statt; die Entstehung derselben geschieht entweder auf geschlechtlichem oder ungeschlechtlichem Wege, doch ist letzterer Vermehrungsmodus nur bei verhältnismäßig wenigen Pilzen vertreten. Die Form der Sporen und ihre Bildungsart ist bei den verschiedenen Gruppen verschieden und für letztere charakteristisch (siehe unten).

Die echten Pilze werden in zwei große Gruppen geteilt, nämlich in Algenpilze (Phycomycetes) und Fadenpilze (Hyphomycetes). Das Mycelium ersterer besteht, selbst wenn es vielfach verzweigt ist, aus einer einzigen ungegliederten Hyphe, während die Fadenpilze ein septiertes, d. h. durch Querwände in mehrere Zellen gegliedertes Mycelium besitzen. In folgendem werden nur diejenigen Familien dieser beiden Hauptgruppen besprochen, welche auf Insekten schmarotzende Vertreter aufweisen.

\section{Algenpilze.}

Entomophthoraceen.

Von den Algenpilzen interessiert uns in erster Linie die Familie der Entomophthoraceen und von dieser wiederum vornehmlich die Gattungen Entomophthora Fres. und Empusa Cohn, welche ausschlieBlich epizoische Arten enthalten. ${ }^{1}$ ) Diese Pilze dringen in die Leibeshöhle lebender Insekten ein und entwickeln sich hier auf Kosten des Wirtes; nach dem Tode des erschöpften Tieres bildet der Pilz seine Fruchtträger, d. h. besondere, abgegliederte sporentragende Hyphen, welche die Körperdecke des Insektes durchbrechen, um hier durch Abschnürung Sporen von bald erlöschender Keimkraft, die sog. Konidien zu bilden. Die konidientragenden Hyphenäste nehmen begierig Wasser auf, so daß durch den entstehenden inneren Druck die Spitze der Konidienträger aufplatzt und der plasmatische Inhalt samt der aufsitzenden Konidie einige Zentimeter weit fortgeschleudert wird (Fig. 198, F). Diejenigen Konidien, welche dadurch auf andere in der Nähe stehende Insekten gelangen, sind imstande, durch sofortiges Auskeimen und Bildung eines die Chitinhaut durchbohrenden Keimschlauches die betr. Insekten zu infizieren. Auf totem Substrat bei genügender Feuchtigkeit keimt dagegen die Konidie zu einer Sekundärkonidie aus, welche wiederum abgeschleudert wird; dies kann mehrmals wiederholt werden, wobei jede neue Konidie an Größe abnimmt. Durch diese Einrichtung wird die Möglichkeit gegeben, daß jede Konidie doch schließlich auf ein Insekt abgeschleudert wird.

1) Eine Zwischenform bildet die Gattung Lamia (auf Mücken). Zu den insektentötenden Entomophthoraceen gehören höchstwahrscheinlich ferner die ungenügend bekannten, zweifelhaften Gatıungen Massosporı Pcck., Epichloea Giard., Chromostylium Giard, Polyrrhizium Giard, Metarrhizium Giard, Halisaria Giard und Sorosporella Sorok, auf verschiedenen Insekten. 
Sind dagegen die Konidien auf ungeeignetes Substrat gefallen und haben keine Gelegenheit zu keimen, so verlieren sie nach kurzer Zeit ihre Keimfähigkeit; sie sind also nicht imstande, die Überwinterung des Pilzes zu vermitteln. $\mathrm{Zu}$ diesem $Z_{\text {weck }}$ bilden die Entomophthoraceen eine besondere Sporenform, die sog. Dauersporen, d. h. Sporen, welche mit einer dicken Membran versehen und imstande sind, nach einer längeren Ruheperiode zu

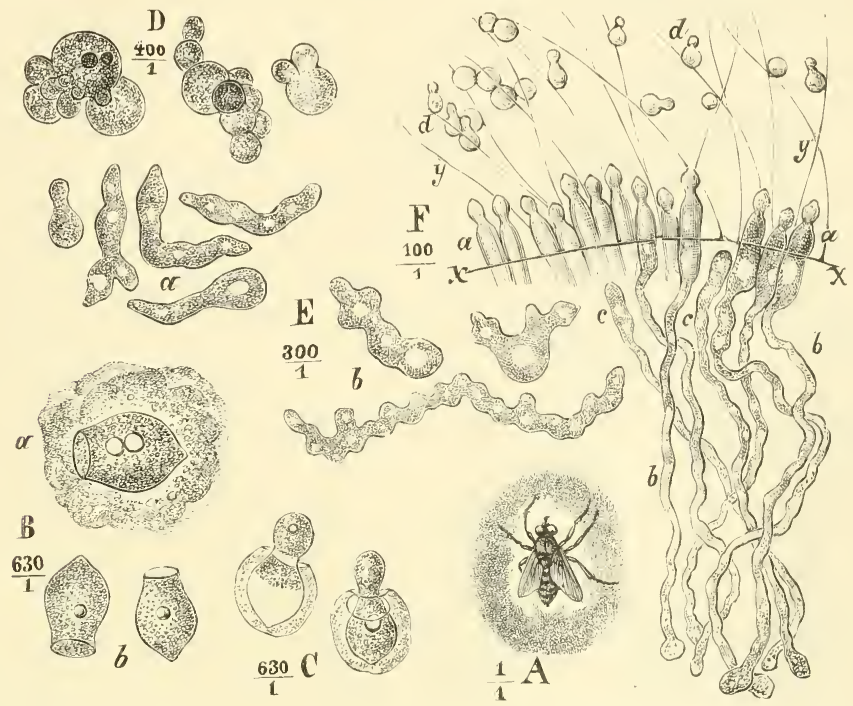

Fig. 198. Empusa muscae Cohn. A Eine vom Pilz getötete Stubenfliege mit dem sie umgebenden Hofe weggeschleuderter Sporen; $B$ Sporen bei $a$ mit umgebendem Protoplasmahof, bei $b$ obne denselben; $C$ Sporen, keimend und sekundäre Sporen bildend; $D$ hefeartig sprossende Empusazellen aus dem Fettkörper einer Fliege: $E a$ Empusazellen aus dem Fettkörper im Auswachsen zu Schlänchen begriffen, $b$ solche weiter fortgeschrittene Schläuche; $F$ balbschematische Darstellung der Fruktifikation; $x$ Andeutung der Leibeswand, $y$ Chitinhaare des Fliegenleibes, $a$ die durch die Leibeswand durchgebrochenen, sporentragenden Hyphenenden, $b$ die im Körper bleibenden Hyphenschläuche, $c$ noch nicht durchgebrochene Schläuche, $d$ weggeschleuderte, aber an den Haaren der Fliege hängengebliebene Sporen, zum Teil bereits sekundäre Sporen erzeugend. (Nach Brefeld [9].)

keimen. Diese Dauersporen entstehen im Innern des Tieres, und zwar entweder als Azygosporen durch einfache Anschwellung von seitlichen oder terminalen Auswüchsen der Hyphen, oder auf geschlechtlichem W'ege als

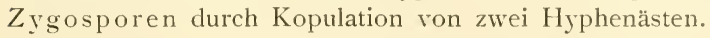

\section{Die Gattung Empusa.}

Bei der Gattung Empusa ist das Mycelium anfangs schlauchförmig, später zerfällt es in rundliche oder verzweigte kurze Glieder (Fig. 198, D u. 199, b-g), welche oft hefeartige Sprossung zeigen. Die Konidienträger sind einfach un- 
verzweigt (Fig. 198, $F, a b$ ), und die Dauersporen entstehen als Azygosporen (Fig. 199, $q-u$ ).

Von großer forstlicher Bedeutung ist Empusa aulicae Reich., eine auf dem Forstschädling Panolis piniperda (Kieferneule) parasitisch lebende Art.

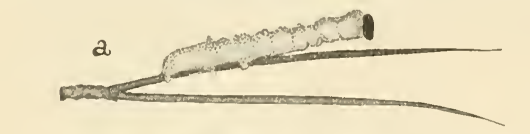

Ihre Entwicklung ist etwa folgende (v. Tubeuf [41]):

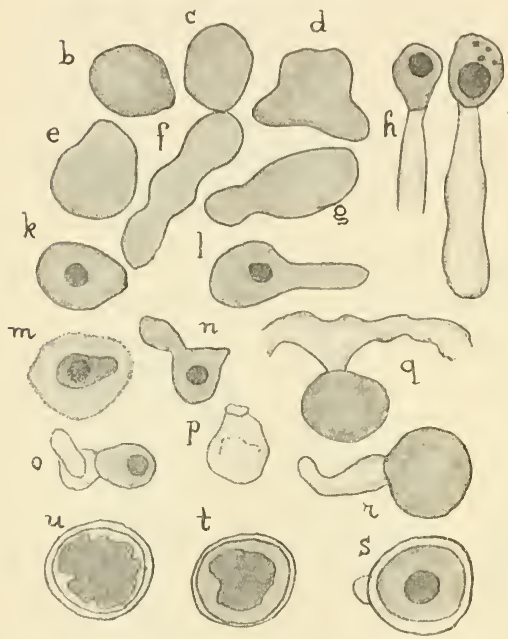

Fig. 199. Empusa auticae Reich, a eine auf einer Kieferunadel sitzende, vom Pilz gatötete und mit Konidien bedeckte Kieferneule; $b \rightarrow g$ Pilzzelleu im Raupeninnern, aus dem zerfallenen Mycelium stammend; $h-i$ einzelne Konidienträger mit Konidien; $k$ eine Konidie; $l$ eine keimende Konidie; $m$ eine Tertiärkonidie mit dem aus der sekundären Mutterkonidie stammenden Plasmahof; $n$ eine zu einer Tochterkonidie wachsende Mutterkonidie; o die ausgebildete Tochterkonidie in Zusammenhang mit der schou entleerten Mutterkonidie; $p$ eine entleerte Mutterkonidie; $q-u$ Bildung von Dauersporen. a natürl. Größe, $b-u$ stark vergrößert. (Nach v. Tubeuf [41].)

Die keimende Spore sendet durch die Haut des Tieres einen Schlauch in das Tierinnere hinein; hier wuchert der Pilz durch das Tier hindurch, alle Weichteile desselben aufzehrend. Die erkrankten Raupen klammern sich mit den hinteren Beinpaaren an die Kiefernnadeln, auf denen sie sitzen, fest, den vorderen Körperteil und den Kopf rom Substrat abhebend; in dieser Stellung werden sie später tot vorgefunden (Fig. 199, a). Aus der ganzen Körperfläche erheben sich in dichtem Rasen die Konidienträger, so daß die Raupe wie von einem gelbgrünen Mehl eingestäubt erscheint; das Substrat zeigt ebenfalls in der Nähe des verendeten Tieres eine feine Mehlbestäubung. Letztere rührt von den in der schon geschilderten Weise abgeschleuderten Konidien her. Dieselben sind eiförmig, 27 bis 38 " lang, 20-27 $\mu$ breit (Fig. $199, k)$.

Für die Überwinterung des Pilzes werden Dauersporen, und zwar Azygosporen gebildet; sie entstehen im Innern der in das feuchte Winterlager gekrochenen Raupe, end- oder seitenständig an den Hyphen (Fig. 199, $q-r$ ), sind kugelförmig und von einer dicken, glatten Membran umgeben $(s-u)$.

Diese Art befällt außer der Kieferneule auch die Raupen verschiedener Schädlinge der Laubbäume, wie Porthesia chrysorrhoea (Goldafter) und Orgyia pudipunda (Rotschwanz) und ferner Euprepia aulica und E. villosa, Gastropacha neustria, Ocneria dispar u. a. 
Auf pflanzenschädlichen Insekten kommen ferner folgende EmpusaArten ror: E. grylli (Fres.) Nowak. auf Heuschrecken, mit ei- bis birnförmigen, bräunlichen, 33-34 $\mu$ langen und 25-37 " breiten Konidien und kugeligen Dauersporen von $34-40 \mu$ Durchmesser.

E. Fresenii Nowak. auf Aphis-Arten, mit eiförmigen, $18-20 \mu$ langen und $15-18 \mu$ breiten Konidien. Thaxter konnte die Bildung von elliptischen Zygosporen beobachten, weshalb er diese Art von der Gattung Empusa trennte.

E. planchoniana (Comm) Thaxt. ebenfalls auf Aphis-Arten, mit 33 bis $40 \mu$ langen und $28-30 \mu$ breiten Konidien und Dauersporen von $35-50 \mu$ Durchmesser.

Schließlich sei auch auf die in der gemeinen Stubenfliege schmarotzende E. muscae Cohn aufmerksam gemacht (Fig. 198). Die Krankheit ist überall verbreitet und tritt jeden Herbst regelmäßig auf; wir finden die Fliegen auf den Wänden, Fensterscheiben u. a. sitzend tot vor, von einem aus den abgeschleuderten Konidien bestehenden Hof umgeben (Fig. 198, $A$ ). Die Konidien sind 20-30 $\mu$ lang und 18-25 $\mu$ breit, die Dauersporen von 30 bis 50 $\mu$ Durchmesser.

Zahlreiche andere Empusa-Arten kommen auf anderen europäischen sowie außereuropäischen Insekten vor, die aber unser Interesse nicht beanspruchen.

\section{Die Gattung Entomophthora.}

Bei der Gattung Entomophthora ist das Mycelium stark entwickelt und reich verzweigt; ebenso verzweigt sind die Konidienträger, ein für die Gattung charakteristisches Merkmal (Fig. 200, D). Das Mycelium tritt stellenweise aus der Raupe heraus in Form eines aus starken Strängen bestehenden Luftmyceliums, wodurch das tote Insekt auf dem Substrat befestigt wird (Haftfäden, Fig. 200, $A a$ ). Dauersporen als Zygo- sowie Azygosporen, kugelig mit einer dicken, gelben oder braunen Membran versehen.

Am vollständigsten ist die Entwicklung von Entomophthora sphaerosperma Fres. (Syn. E. radicans Bref.) bekannt (Fig. 200). Im Herbst zeigt sich häufig eine Pilzseuche unter den Raupen des Kohlweißlings, Pieris brassicae L. Man erkennt den Eintritt derselben an der Trägheit, welche sich der vorher lebhaften Raupen bemächtigt. Plötzlich sterben die Tiere und noch an Todestage hüllen sie sich in einen grünlich-weißen Schimmel (Fig. 200, B), der schon nach wenigen Stunden verblüht und die Raupe völlig unkenntlich, in Form einer braunen verschrumpften Haut zurückläßt, in unmittelbarer Nähe umgeben von ganzen Haufen weißer Sporen, den abgeworfenen Konidien des verblühten und wieder verschwundenen Pilzes.

Diese Konidien sind kleine, $15-26 \mu$ lange und $5-8 \mu$ dicke, farblose Spindeln (Fig. 200, E). Gelangt eine solche wiederum auf die Haut einer Raupe, so beginnt sie einen Keimschlauch zu treiben, der sich schon in kurzer Entfernung ron der Spore in die Haut einbohrt, dieselbe in der Umgebung der Einbohrungsstelle bräunend (Fig. 200, G). Der Keimschlauch 
durchsetzt nun fortwachsend und sich in mehrere Zellen gliedernd, von denen nur die vorderste Protoplasma enthält, die Leibeswand der Raupe, bis er allmählich gewöhnlich am dritten Tage - in dem Fettkörper anlangt. Hier wächst nun die Endzelle auf Kosten des Fettkörpers, den sie mit unglaublicher Schnelligkeit durchwuchert, zu einem verästelten und verfilzten Mycel aus (Fig. 200, J). Jetzt beginnt die schon erwähnte Trägheit der bis dahin anscheinend völlig gesunden Raupe; aber erst wenn der Pilz den

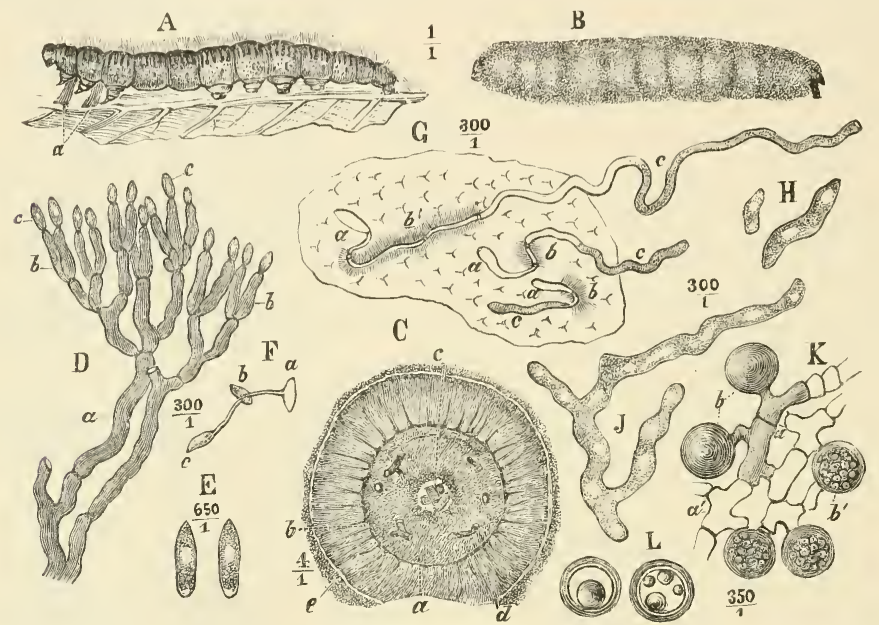

Fig. 200. Entomophthora sphaerosperma Fres. (=Eadicans Bref.) A Raupe von Pieris brassicae durch den Pilz getötet, $a$ die sie an die Unterlage befestigenden Hyphenbischel; $B$ dieselbe Raupe in einem späteren Stadium, eingehüllt in dem Schimmelflaum; $C$ Querschnitt durch eine solche Raupe, $a$ Cuticula der Raupe, $b$ Tracheen, $c$ im Darmkanal vorhandene Speisereste. Alle Weichteile der Raupe sind auf. gezehrt und durch ein dichtes Mycelgeflecht ersetzt, das bei $d$ einen dichten Hyphenrasen durch die Haut getrieben hat. Dieser hat wieder die Sporen $e$ abgeschnïrt: $D$ die Fruchthyphen $a$, mit dem Endgliede $b$ und Sporen $c$; $E$ Einzelsporen stärker vergrößert; $F$ Spore $a$, welche einen Mycelfaden erzeugt hat, an dem wieder sekundäre Sporen $b$ und $c$ entstanden sind; $G$ ein Stück Haut der Raupe, auf dem Sporen a gekeimt haben, deren Keimschläuche die Haut bei $b$, sie bräunend, durchsetzt und an der Spitze $c$ fortwachsend, weitergewuchert haben; $H$ abgetrennte Myceläste im Ranpenblute frei schwimmend; $J$ verästelter Mycelfaden; $K$ Dauersporen tragende Mycelfäden, $a$ mit Protoplasma gefüllt, $a^{\prime}$ leer; $b$ in der Entwicklung begriffene, $b^{\prime}$ reife Dauersporen; $L$ reife Dauersporen mit dicker Hülle und Fettropfen im Innern. (Nach Brefeld [9 u. 10].)

gesamten Fettkörper aufgezehrt hat und sich bereits isolierte, abgeschnürte, längliche Hyphen (Fig. 200, $H$ ) im Blute zeigen, tritt die dem Tode vorausgehende Unbeweglichkeit ein. Die in das Blut gelangenden, abgeschnürten Hyphenäste verbreiten den Pilz bis in die letzten Schlupfwinkel des Körpers, und die nun straff rom Pilzmycelium ausgefüllten Raupen sterben, nachdem der Pilz alle inneren Organe, mit alleiniger Ausnahme der Cuticula und der Chitinhäute von Darm und Tracheen, aufgezehrt hat (Fig. 200, C), gewöhnlich im Laufe des fünften Tages nach der Infektion. Zwölf Stunden nach dem Tode brechen dicke Büschel paralleler, in Zellen gegliederter Pilzfäden oder 
Hyphen zwischen den Beinen der Raupe auf der Bauchseite hervor (Fig. 200, $A a$ ), dieselbe wie mit Wurzeln auf der Unterlage befestigend, und bald darauf beginnen auch die fruchttragenden Hyphen die Haut der Raupe zu durchbrechen, die sie bald als ein dichter Schimmelüberzug umgeben (Fig. 200, B). Die beim Durchtritt durch die Haut einfachen Hyphen verästeln sich bald (Fig. 200, D) und diese Zweige gliedern sich an ihrer Spitze durch Scheidewände zu kurzen Gliedern ab (Fig. 200, D, b), an deren Ende nun die kurzspindelförmigen Konidien entstehen (Fig. 200, D, $c$ und $E$ ). Letztere werden in der schon geschilderten Art und Weise abgeschleudert. Jedoch nicht alle infizierten Raupen bedecken sich mit dem schimmelartigen Überzug der Konidienträger. Manche schrumpfen vielmehr, nachdem sie infolge einer völligen Durchwucherung ihres Inneren durch das Pilzmycelium abgestorben und durch die oben erwähnten sterilen Hyphenbündel auf der Unterlage fixiert worden sind, nach vorhergehender Erweichung zu zerbrechlichen Mumien ein. Diese bestehen aus der wenig veränderten Raupenhaut, welche eine dichte Masse großer, dickwandiger (Membran glatt, gelb) Dauersporen von kugliger Form und 20-35 " Durchmesser (Fig. 200, L) als einen weißlichen Inhalt umschließt. Diese Dauersporen entstehen als Azygosporen an dem Mycelium, sobald dasselbe den ganzen Raupenleib ausgefüllt hat, als seitliche Auswüchse der Fäden, denen sie fast unmittelbar aufsitzen (Fig. 200, $K$ ).

Außer des Kohlweißlings befällt die eben beschriebene Art auch andere Raupen, so z. B. den Forstschädling Grapholitha tedella Cl., in Nordamerika die Puppe des auch in ganz Europa verbreiteten Kleeblattrüsselkäfers Phytonomus nigrirostris Fab. u. a. Im Jäschkental wurde von Bail eine ausgedehnte Epizootie des kleinen Laufkäfers Nebria brevicollis beobachtet, welche ebenfalls durch $E$. sphaerosperma verursacht war.

Andere bemerkenswerte Entomophthora-Arten sind folgende: E. aphidis Hoffm. auf zahlreichen Aphis-Arten in Europa und Nordamerika, mit elliptischen, farblosen, 25-40 $\mu$ langen und 12-16 " breiten Konidien und kugligen Dauersporen (Azygosporen) von 33-43 $\mu$ Durchmesser.

E. tenthredinis Fres, auf den Larven von Tenthredo auf Ahorn, mit rundlichen Konidien von 47-62 $\mu$ Durchmesser.

E. muscivora Schroet, auf SchmeiBfliegen (Calliphora vomitoria) mit eiförmigen, 20-24 $\mu$ langen, $11-13 \mu$ breiten Konidien und braunen kugligen Dauersporen (Azygosporen) von 24-30 $\mu$ Durchmesser.

E. plusiae Giard auf den Larven der Gammaeule (Plusia gamma) in Frankreich, mit eiförmigen, $15 \mu$ breiten, $30 \mu$ langen Konidien; Dauersporen unbekannt.

E. forficulae Giard auf dem Ohrwurm (Forficula auricularia) in Frankreich, mit länglich-elliptischen, 6-8 " breiten, 20-25 "/ langen Konidien; Dauersporen unbekannt.

E. colorata Sorok. auf Grillen in Rußland, ähnelt der Empusa grylli, hat aber runde, farbige Konidien.

E. aphrophorae Rostr. auf Aphrophora spumaria in Dänemark; Konidien 16-18 $\mu$ lang, $7-8 \mu$ breit; Dauersporen unbekannt. 
E. Richteri Bubik (Syn. E. lanxaniae Bubrik) auf Lauxania aenea (auf den Blättern von Crepis paludosa und Spiraca ulmaria) in Böhmen; Konidien unbekannt, Dauersporen (Azygosporen) kuglig, 25-50 $\mu$ Durchmesser.

E. cimbicis Bubik auf Cimbex-Larven.

E. dissoliens I'oss. auf einer Eulenraupe, wahrscheinlich Cerastis ratellitia L. (auf Eichenblatt, bei Stuttgart); Konidien unbekannt, Dauersporen (Azygosporen) 35-40 $\mu$ Durchmesser.

Wie aus den angeführten Beispielen ersichtlich, sind vielfach Entomophthoraceen bekannt, bei welchen die eine von beiden Sporenformen fehlt. Wenn die Konidienform unbekannt ist, so ist es in den meisten Fällen unmöglich, zu entscheiden, ob es sich um eine Empusa- oder EntomophthoraArt handelt, da ja das wesentlichste Merkmal auf der Verschiedenheit der Konidienträger beruht. Solche zweifelhafte Arten werden unter eine besondere Gattung Tarichimm Cohn gestellt. Eine interessante Art dieser Gattung ist T. megaspermum Colm, welche auf den Raupen des gefürchteten Saatschädlings Agrotis segetum Hübn. vorkommt (die sog. „schwarze Muscardine" verursachend). Die Lebensgeschichte dieses Pilzes ist folgende: Die erkrankten grau- oder grünlich-braunen Raupen beginnen, vom Kopf anfangend, sich dunkel zu färben, bis sie ganz schwarz geworden sind. Nun schwellen sie zunächst an, trocknen, während sie eine ölige Flüssigkeit durchschwitzen lassen, allmählich zu verschrumpften Mumien ein und füllen sich im Innern mit einer kohlschwarzen, zunderartigen Masse, welche aus undurchsichtigen, kugelrunden, 36-55 $\mu$ Durchmesser haltenden Dauersporen besteht. Die äußere Membran dieser Sporen ist dick, braun, häufig von unregelmäBigen Furchen durchzogen.

Das erste Anzeichen der Krankheit ist, daß in dem bei gesunden Tieren gelblichen Blute zahllose schwarze Pünktchen auftreten, die ihm unter dem Mikroskop das Aussehen von eingeriebener Tusche geben. Auch sind zahlreiche Kristalle in ihm vorhanden. Dann beginnen sich die Anfänge des Pilzes als freie kuglige Zellen von $7-15 \mu$ Durchmesser zu zeigen, die durch den Zerfall länglicher, gleichfalls im Blute vorkommender Schläuche entstehen. Aus diesen kugligen Keimen entwickeln sich 5-10 $\mu$ dicke, nur wenige Querscheidewände zeigende Hyphen, die sich verästeln und ein den Körper völlig durchsetzendes Mycelium bilden. Dieses zehrt die Eingeweide der Raupe auf, seine Spitzen schwellen kuglig an und bilden sich schließlich zu den oben beschriebenen Dauersporen aus.

Eine zweite Art ist Tarichium uvella Krass. mit rundlichen Dauersporen von 8-10 " Durchmesser; sie kommt in RuBland auf den Larven von Coleopteren vor, oft auf Cleonus punctiventris Germ., einem gefürchteten Feinde der Zuckerrüben.

\section{Mucoraceen.}

Eine Schwesterfamilie der Entomophthoraceen ist die der Mucoraceen; sie unterscheidet sich ron jener in der Hauptsache dadurch, daß sie Pilze umfaßt, welche die ungeschlechtlichen Sporen in besonderen Behältern, den sog. Sporangien bilden. Hier gehört eine große Anzahl gewöhnlicher 
Schimmelpilze, welche auf faulenden tierischen und pflanzlichen Stoffen saprophytisch leben. Die Familie verdient hier einer besonderen Besprechung, da sie, unter der Gattung Mucor, auch einige für Insekten pathogene Vertreter aufweist.

Als typisches Beispiel eines Mucors sei hier der auf faulendem Brot, Früchten, Samen, Mist u. dgl. überall sehr verbreitete Kopfschimmel Mucor mucedo L. erwähnt; er ist von Interesse, da er auch lebende Honigbienen angreifen soll.

Das reichverzweigte aber unseptierte Mycelium durchwächst das Substrat nach allen Richtungen. Die Fruchtträger wachsen auf der Oberfläche des Substrates als lange feine, zunächst weiße, später bräunliche Fäden, mit einem schwärzlichen Kopf an der Spitze, so daß die Substratoberfläche wie mit einem feinen, lockeren, baumwollartigen Filz mit eingewebten Kügelchen bedeckt erscheint. Diese kleinen kugligen Köpfe sind die mit zahlreichen Sporen erfüllten Sporangien des Pilzes (Fig. 201, $A$ ); die Membran des reifen Sporangiums platzt auf, wodurch die Sporen frei werden. Die Sporangien haben einen Durchmesser von $100-200 \mu$; die Sporen sind schwach gelblich, ellipsoidisch, $7-12 \mu$ lang, 4-6 $\mu$ breit.

Die Dauersporen entstehen auf geschlechtlichem Wege als Zygosporen folgendermaßen: einige Myceläste schwellen keulenförmig auf und stoßen paarweise aufeinander (Fig. 201, $C$ ); durch Bildung ron Querwänden werden

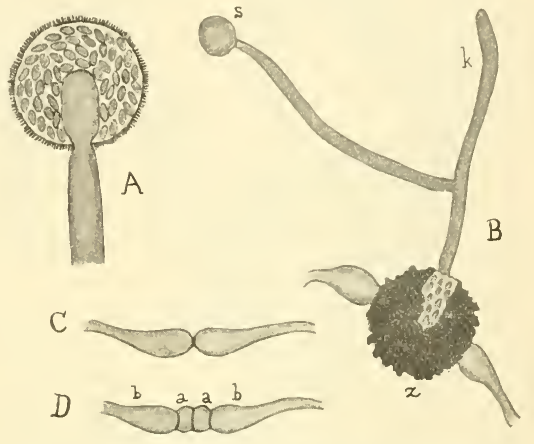

Fig. 201. Hucor mucedo L. A sporangium im optisehen Längsschnitt; $B$ Keimung einer Zygospore $z$; am Keimschlauch $k$ ist ein Sporangium $s$ entstanden; $C$ zwei Hyphenäste im ersten Kopulationsstadium; $D$ Abgrenzung der die Zygospore liefernden Zellen a a von den Suspensoren $b b$ alles stark vergrößert). (Nach $\mathrm{Sachs,} \mathrm{aus}$ Engler-Prantl, Die natürlichen Pflanzenfamilien.) zwei Zellen $(B, a a)$ abgegliedert, nach deren Verschmelzung die mit einer schwarzen, dicken, warzigen Membran versehene Zygospore entsteht (Fig. 201, $B, z)$. Dieselbe ist imstande, nach Verlauf einer längeren Ruheperiode auszukeimen $(B)$.

Mucor mucedo ist diözisch, d. h. die Zygosporen können nur durch Kopulation von Hyphenästen zweier Mycelindividuen von verschiedenem Geschlecht entstehen; daher kann hier die Zygosporenbildung leicht unterbleiben, wenn innerhalb der Kultur keine Mycelindividuen beiderlei Geschlechts vorhanden sind. Andere Mucoraceen sind dagegen monözisch, d. h. die Zygosporen entstehen durch Kopúlation von zwei Hyphenästen eines und desselben Myceliums, so daß hier die Möglichkeit zur Zygosporenbildung stets vorhanden ist.

Als insektenschädlich sind folgende Mucor-Arten bekannt: 
M. melitophthorus Hoffm. ist ein Feind der Honigbiene und wurde im Chylusmagen des Tieres nachgewiesen. Er stellt eine ungenügend bekannte, zweifelhafte Art dar.

M. exitiosus Massee auf Heuschrecken in Südafrika; Sporangien von 60-100 $\mu$ Durchmesser, Sporen farblos, ellipsoidisch, $5-6 \mu$ lang, 3,5 bis $4 \mu$ breit; Zygosporen unbekannt.

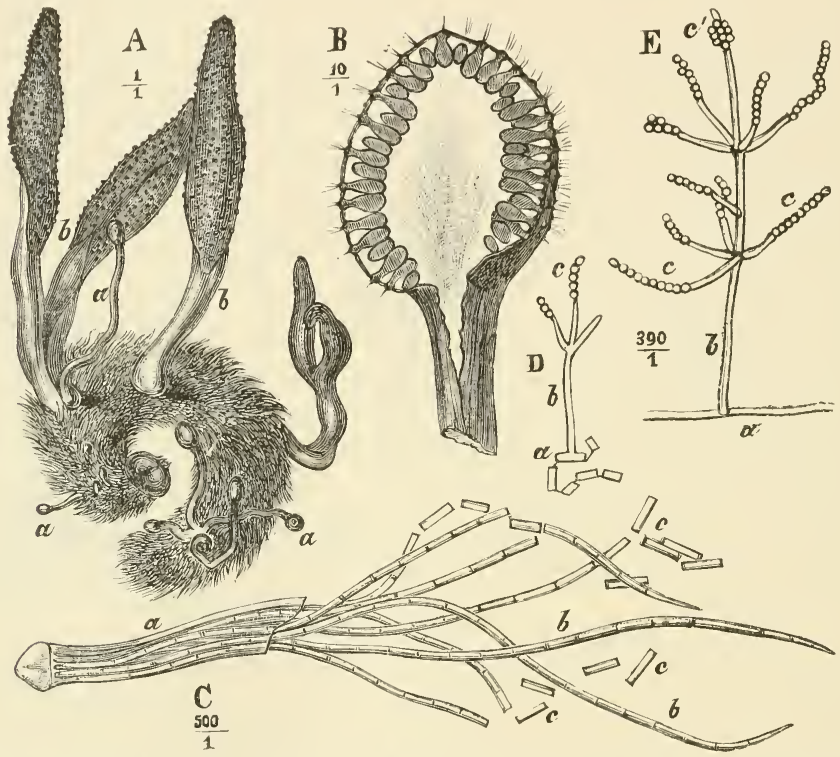

Fig. 202. Cordyceps Fries. A. C. militaris (L, Link, auf eiuer Raupe von Bombyx nubi, a unentwickelte, $b$ entwickelte Fruchtträger mit den vorspringenden pupillenartigen Mündungen der Perithecien; $B$, C. entomorrhiza, Längsschnitt durch die Keule eines Fruchtträgers, die Anordnung der flaschenförmigen Perithecien zeigend; $C$ geplatzter Ascus desselben Pilzes mit den acht langen, in Teilsporen zerfallenden Ascosporen; $D$ Konidienträger $b$, aus Teilsporen $a$ von $C$, militaris gezüchtet und kuglige Konidien $c$ abschnürend; $E$ älterer Konidienträger $b$ desselben Pilzes, von einem Mycelfaden $a$ entspringend, $c$ kuglige Konidien, $c^{\prime}$ ovales Spitzenkonidium. ( $A-C$ nach Tulasue [45], $D-E$ nach de Bary [5a].)

M. locusticola Lindau befällt ebenfalls die Heuschrecken in Südafrika; Sporangien von $15-23 \mu$ Durchmesser, Sporen fast farblos, ellipsoidisch, 4-6 $\mu$ lang und 2,5 $\mu$ breit; Zygosporen unbekannt.

Es ist nicht sicher entschieden, ob beide letztgenannte Pilze zwei voneinander verschiedene Arten darstellen.

\section{Fadenpilze.}

Die zweite große Gruppe der echten Pilze, die Fadenpilze (Hyphomycetes) werden auf Grund ihrer Vermehrungsorgane in zwei große Klassen 
geteilt: in Ascomyceten (Schlauchpilze) und Basidiomyceten. Uns interessieren nur die ersteren.

\section{Ascomyceten.}

Für die Ascomyceten ist die Hauptform der Sporenbildung charakteristisch; bei dieser entstehen nämlich die Sporen in besonderen schlauchförmigen Sporangien durch freie Zellbildung. Diese schlauchförmigen Behälter, in welchen die Sporen liegen, nennt man Asci (Schläuche), die Sporen selbst Ascosporen (Fig. 202, C).

Die Ascomyceten bilden außer den Ascosporen in der erwähnten Hauptfruchtform auch zahlreiche andere Nebenfruktifikationen, besonders Konidien (Fig. 202, $E, c$ ), und zwar in den mannigfaltigsten Formen. In der einfachsten Form werden die Konidien am Ende von einfachen oder verzweigten Fruchthyphen (Fruchtträgeın) abgeschnürt, welche sich von dem Mycelium senkrecht abheben. Das Substrat erscheint in diesen Fällen als mit einem schimmelartigen Flaum bedeckt. In anderen Fällen treten eine größere Anzahl von dem Mycelium entspringenden Hyphen zu einem soliden, sehr verschiedenartig geformten Körper, dem sog. Coremium zusammen und erst von diesem erheben sich nun die konidienbildenden Hyphen.

Für die Erkennung eines Pilzes als Ascomyceten ist das Vorhandensein der Hauptfruchtform unerläßlich. Gewöhnlich treten beide Fruktifikationen nicht gleichzeitig auf, so daß ihr Zusammenhang nur nach einer längeren Kultur des Pilzes sicher zu eruieren ist. In vielen Fällen pflanzt sich der Pilz längere Zeit hindurch ausschließlich durch Konidien fort, so daß seine systematische Stellung schwer zu erkennen ist. In früheren Zeiten, wo die Zugehörigkeit der Nebenfruchtformen mehrerer Pilzarten zu einer Hauptfruchtform nicht erkannt war, hielt man viele konidienbildende Pilzformen für besondere Arten; ihre systematische Einteilung wurde auf Grund der Form der Konidienträger vorgenommen. Auch heute noch ist die Hauptfruchtform von zahlreichen konidienbildenden Pilzformen unbekannt; es ist sogar wahrscheinlich, daß sie bei einigen Arten vollständig fehlt. Man ist daher genötigt, diese Arten zweifelhafter Zugehörigkeit auf Grund der Form ihrer Konidienträger mit besonderen Gattungsnamen zu belegen. Die Gattungen sind keine natürlichen, sie enthalten vielfach heterogene Arten, welche bloß die Form der Konidienträger gemeinsam haben; der Gattungsname bezeichnet demnach hier eben diese Form. Diese Gattungen werden unter eine besondere Pilzgruppe gestellt, die der "Fungi imperfecti“.

\section{Pyrenomyceten.}

Die Ascomyceten werden in verschiedene Unterabteilungen geteilt; von diesen interessiert uns vornehmlich die der Pyrenomycetes oder Kernpilze. Dieselben sind dadurch ausgezeichnet, daß sie ihre Asci innerhalb besonderer, kugliger oder flaschenförmiger Behälter ausbilden, die am Scheitel eine natürliche enge Mündung haben; diese Behälter heißen Perithecien. 
Eine sehr wichtige Gattung insektentötender Pyrenomyceten ist diejenige von Cordyceps Fries. Am vollständigsten bekannt ist von dieser Gattung C. militaris (L.) Link. Dieser Pilz befällt einheimische Raupen und Puppen und tötet sie; wir finden leicht in den Wäldern im Herbst die toten, mit dem Pilz behafteten Tiere. Er ist besonders durch die orangebis purpurnfarbenen, keulenförmigen, bis $6 \mathrm{~cm}$ langen, gestielten Fruchtkörper (Fig. 202, $A$ und 203) ausgezeichnet, die aus dem Leibe der Insektenleiche hervorbrechen. Das keulenförmige Köpfchen dieser Fruchtkörper trägt die oberflächlich hervorragenden, $0,2 \quad 0,3 \mathrm{~mm}$ langen und $0,13-0,2 \mathrm{~mm}$ dicken Perithecien (Fig. 202, B), welche die Asci enthalten. Die schlauchförmigen Asci erzeugen je 8 lange, fadenförmige, ca. 1,3 $\mu$ breite primäre Sporen, welche sich bei ihrer Rejfe noch innerhalb des Ascus in eine Reihe von $3 \mu$ langen, hyalinen Teilsporen gliedern (Fig. 202, C). Die Sporen

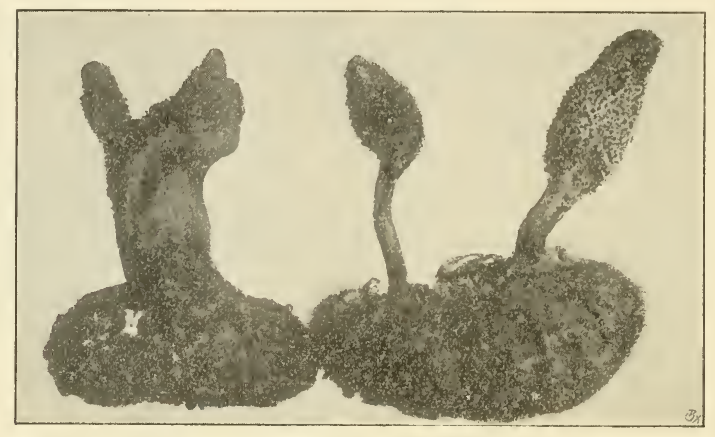

Fig. 203. Cordyceps militaris $(L$. Link. Kiefernspinnerraupen aus der Bodenstreu mit den Fruchtträgern des Pilzes. $2 / 1$ natïrl. Größe. (Nach Escherich und Baer [16].

werden später aus den Perithecien ejaculiert und zerfallen schließlich in die abgegliederten Teilsporen. Gelangen letztere auf feuchtes Substrat, z. B. auf die Haut einer lebenden Raupe, so beginnen sie, unter Anschwellung auf das Doppelte ihres ursprünglichen Volumens, Keimschläuche zu treiben (Fig. 202, D), welche, die Chitinhaut des Tieres durchbrechend, ohne auf der Oberfläche der Haut dunkle mißfarbene Flecken zu erzeugen, in die Leibeshöhle gelangen; hier verzweigen sich die Keimschläuche und beginnen kleine, blasse, zylindrische Konidien (Fig. 206, $B$ und $C$ ) zu bilden. Dieselben gelangen ins Blut und vermehren sich hier durch wiederholte Aussprossung auf Kosten der Blutmasse. Hiermit hält eine Erkrankung der Raupe gleichen Schritt, welche nach 14 Tagen bis 3 Wochen mit dem Tode derselben endigt. Die Raupe ist kurz nach dem Tode durchaus weich und schlaff; liegt sie aber in feuchter Umgebung, so beginnen die zahllosen zylindrischen Konidien zu Mycelfäden auszuwachsen, alle Organe, insbesondere den Fettkörper durchwuchernd und auf ihre Kosten sich nährend. So wird der Raupenleib von dem Mycelium prall ausgestopft (mumifiziert), er schwillt und 
erhärtet, d. h. er wird zu einem Sklerotium umgewandelt. ${ }^{1}$ ) Dieser aus einem dichten Mycelgeflecht bestehende Körper, welcher jetzt den Raupenleib repräsentiert, ist imstande, bei genügender Feuchtigkeit die erwähnten keulenförmigen Fruchtkörper zu bilden; beim Vertrocknen verfällt er in einen Ruhezustand, um bei späterer passender Gelegenheit zur Fruchtkörperbildung überzugehen.

Nicht selten, kurz nach der Mumifizierung der Leiche und vor der Perithecienbildung, treten Äste der Mycelfäden durch die Haut an die Oberfläche des Körpers und dieser bedeckt sich allmählich völlig mit einem kurzen Flaum weißer, kaum 0, ̄ mm hoher Fruchthyphen. Diese treiben zahlreiche Äste, welche auf abstehenden, selten vereinzelten, meist in zwei- bis fünfgliedrige Viertel geordneten, pfriemenförmigen Seitenzweigen runde Sporen ron 2,̌̃ $\mu$ Durchmesser, kuglige Konidien, in perlschnurförmiger Verbindung, also reihenweise, succedan erzeugen (Fig. 202, $E, c$ ). Die erstgebildete, also oberste Konidie jeder Reihe ist meist ellipsoidisch und öfters fallen die succedan entwickelten Ketten zu einem unregelmäßigen, die

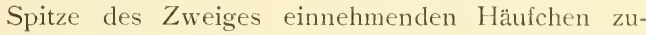
sammen (Fig. 202, $E, c^{\prime}$ ). Später erscheinen in dem weißen Flaum orangefarbene Hervorragungen, welche nun allmählich zu perithecientragenden Fruchtkörpern heranwachsen.

Bei künstlicher Kultur in Nährlösung wachsen die aus den Perithecien ejaculierten Glieder der Ascosporen zu Keimschläuchen aus, welche unmittelbar die kuglige Konidien tragenden Fruchthyphen bilden.

$\mathrm{Zu}$ dem typischen Entwicklungskreis von Cordyceps militaris yehört also eine regelmäßige, notwendige Abwechslung zwischen dem Auftreten der in den Ascis der Perithecien gebildeten Sporen und deren Teilungsprodukten einerseits, und den im Blute des Insektes von den Keimschläuchen abgegliederten zylindrischen Konidien anderer-

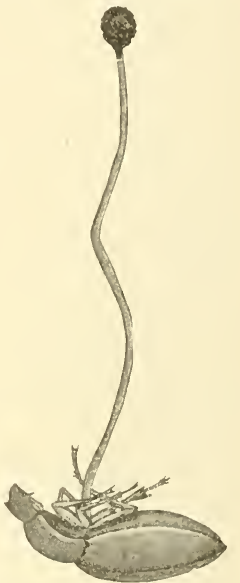

Fig. 204. Cordyceps cinerea (Tul.) Sacc. Ein Laufkäfer mit dem Fruchtträger des Pilzes. Nat. Größe. Nach Lindau in Engler-Prantl, Die naturlichen Pflanzeufamilien.)

seits. Dagegen sind die einfachen Fruchthyphen eine sekundäre, morphologisch nebensächliche Form von Fruchtträgern und die auf ihnen succedan abgeschnürten kugligen Konidien bei ihrer schnellen Entwicklung Einrichtungen zur raschen Verbreitung des Pilzes, denn wir haben allen Grund,

1) In diesem Zustande sind die getöteten von den gesunden im Winterlager befindlichen Raupen äußerlich schwer zu unterscheiden. Escherich und B a e r [16] geben folgende Kennzeichen: ,Schon beim Öffnen einer derartigen Raupe, die sich an den Segmenträndern leicht auseinander brechen läßt, entströmt derselben ein kaum zu verkennender aromatischer Pilzgeruch; ferner findet sich kein Raupenblut, sondern das ganze Innere des Balges scheint von einer zwar feuchten, sonst aber ka utschukartigen Masse erfüllt, die von der gleichmäßigen Myceldurchwucherung desselben herrührt." 
zu glauben, daß die Kugelkonidien in derselben Weise auf der Haut einer Raupe keimen, in diese eindringen, und Zylinderkonidien erzeugen können wie die Segmente der Ascosporen (De Bary [ö]).

$\mathrm{Zu}$ Cordyceps militaris gehört höchstwahrscheinlich ferner eine besondere Konidienform, welche morphologisch zu den noch zu besprechenden „Fungi imperfecti“ gestellt wird, nämlich Isaria farinosa Fries. Die Beschreibung derselben mußte schon der Einheitlichkeit wegen mit anderen Isaria-Arten zweifelhafter Zugehörigkeit unter den „Fungi imperfecti“ behandelt werden; sie ist also dort nachzusehen.

Außer C. militaris ist eine sehr große Anzahl von weiteren insektentötenden Cordyceps-Arten bekannt; sie sind größtenteils in den Tropen und nur wenige in Europa heimisch. Von den letzteren seien hier die wichtigsten wiedergegeben:

C. cinerea (Tul.) Sacc. (Fig. 204) kommt auf Käfern (besonders Carabusund Calosoma-Arten), vornehmlich ihren Larven vor. Der Fruchtkörperstiel ist zylindrisch, glatt, schwärzlich-braun, meist $4-6 \mathrm{~cm}$ (seltener bis $19 \mathrm{~cm}$ ) lang, 1-2 mm dick; das Köpfchen verkehrt-eiförmig bis kuglig, erbsengroß, anfangs grau. Sporen fadenförmig, hyalin, in 7-10 " lange Glieder zerfallend. - Als Konidienform gehört vermutlich dazu Isaria eleutheratorum Nees. (siehe dies unter den „Fungi imperfecti“).

C. entomorrhiza (Dicks.) Fr. auf verschiedenen Insektenlarven, mit gelbem, $2-8 \mathrm{~cm}$ langem Fruchtkörperstiel und rundlich-eiförmigem, lebhaft goldgelbem und braun punktiertem, ca. 5-8 mm langem, $4 \mathrm{~mm}$ dickem Köpfchen. Sporen fadenförmig, hyalin, in $6-8 \mu$ lange, $4 \mu$ breite Glieder zerfallend.

C. Ditmari Quél. auf V'espa crabro L. in Frankreich, mit fadenförmigem, blass-zitronengelbem Stiel und eiförmigem, gelbem, purpurpunktiertem, $3-4 \mathrm{~mm}$ dickem Köpfchen. Sporen fadenförmig, $45-50 \mu$ lang, in $12 \mu$ lange Glieder zerfallend. - Hierher gehört vermutlich als Konidienform Isaria sphecophila Ditm. (siehe unten!)

C. helopis Quil. auf Helops caraboides in Frankreich, mit langem, gekrümmtem, weißglänzendem und rosagestreiftem Stiel, länglich-ellipsoidem, 5-6 mm langem, gelbbraunem, schwärzlich-purpurn punktiertem Köpfchen und fadenförmigen, in 2,5-3 $\mu$ dicke Glieder zerfallenden Sporen.

C. callidii Quél. in den Larven von Callidium in Frankreich, mit glattem, violett-rosafarbigem, $3-7 \mathrm{~cm}$ langem Stiel und länglich-spindelförmigem, 5-8 $\mathrm{mm}$ langem Köpfchen; Sporen haarartig, rosenkranzförmig, 50 -60 $\mu$ lang, in Glieder von $2 \mu$ Durchmesser zerfallend.

C. formicivora Schr. auf Formica ligniperda, mit schwärzlichem, kugligem Köpfchen auf sehr kurzem Stiel (bis $2 \mathrm{~mm}$ ); Sporen 100-110 $\mu$ lang, 2,5--3 " breit, gelblich-hyalin, gegliedert.

C. sphingum (Tul.) Sacc, auf verschiedenen Schmetterlingen, besonders Sphinx- (z. B. Sph. pinastri) und Phalaena-Arten, mit steifem, 5-40 mm langem Stiel und dünnen, fadenförmigen Sporen. - Vermutlich gehört hierzu als Konidienform Isaria sphingum Schwein., ein auf Sphin.x-Arten (Carolina) und Dipterenpuppen (Schottland) aufgefundener Pilz. 
C. odyneri Quél. auf Odynerus-Larven in Frankreich, mit schlankem, $10-20 \mathrm{~cm}$ langem, bereiftem, blaßgrauem Stiel und eiförmigem, olivengrauem Köpfchen; Sporen haarförmig, $80 \mu$ lang, $5 \mu$ breit, hyalin.

C. carabi Quel. auf Carabus (auronitens?) -Larven in den Tridentinischen Alpen, mit $5-6 \mathrm{~cm}$ langem, glattem, violettem Stiel, kugligem, $3-4 \mathrm{~mm}$ durchmessendem Kopf und haarförmigen, hyalinen, in $4 \mu$ lange Glieder zerfallenden Sporen.

Ferner ist eine Varietät von C. militaris (var. sphaerocephala Kunze et Schw.) mit sehr langem (bis ¿ Zoll), dünnem Stiel und kugligem Kopf auf Chrysaliden beobochtet worden.

In der neueren Zeit hat Olsen-Sopp eine neue Riesenart beschrieben, nämlich $C$. norvegica Sopp (in Norwegen); sie ähnelt dem $C$. militaris, hat aber $15-20 \mathrm{~cm}$ langen und $15 \mathrm{~mm}$ dicken Stiel, mehr orangegelbe Farbe und soll von außerordentlicher Pathogenität sein. Sie befällt die Kiefernspinnerlarven und allerhand andere Insekten.

Eine weitere erwähnenswerte Gattung der Pyrenomyceten ist Sphacrostilbe Tul.; sie ist mit der bekannten Gattung Nectria sehr verwandt und hat kuglige, meist rote, weichfleischige Fruchtkörper und längliche zweizellige Sporen. Auf Insekten parasitiert eine einzige Art, S. coccophila Tul., und zwar auf verschiedenen Schildläusen (Coccus- und Aspidiotus-Arten); sie ist über die ganze Erde verbreitet. Die Asci sind länglich, 60-80 $\mu$ lang, 6,5 $\mu$ breit; die Ascosporen zweizellig, $10 \mu$ lang, $5 \mu$ breit, eiförmig, fast hyalin. Die zugehörige Konidienform (sonst als Microcera coccophila Desm. unter die Fungi imperfecti gestellt) hat kleine, etwas rasige, kegelförmig-stiftartige, unverzweigte, rosafarbige Fruchtlager, welche an ihrer Basis mit einer feinen, weißen, aus Konidienträgern gebildeten Membran umgeben sind. Die Konidienträger sind fädig, lang, 2,5 " dick; die Konidien verlängert, beidendig spitz, gebogen, mit 3-5 Scheidewänden, hyalin, 70-100 "lang, 4-5 $\mu$ breit.

Der Vollständigkeit halber seien schließlich noch folgende Ascomycetengattungen kurz erwähnt:

Die Pyrenomycetengattung Torubiella Boud. umfaßt auf Tieren (meist Schildläusen und Spinneu) parasitierende, größtenteils außereuropäische Arten.

Die Pyrenomycetengattung Ophionectria Sacc. ist nur insofern bemerkenswert, als sie eine auf Schildläusen (in West-Indien und Florida) parasitierende Art (O. coccicola Ell. et Ev.) aufweist.

Von der Pyrenomycetengattung Melanospora Cord. wurde früher die Art $M$. parasitica $7 u l$. als insektentötend angegeben, und zwar (von Tulasne) als die Schlauchfruchtform der noch zu besprechenden Botrytis Bassiana Bals. angesehen. Nach den neueren Untersuchungen von Kihlmann soll jedoch der Pilz kein Tierparasit sein, sondern auf anderen insektentötenden Pilzen (Botrytis Bassiana, Isaria farinosa, Cordyceps militaris usw.) parasitisch leben (Überparasit).

Als letzte Pyrenomycetengattung sei noch die Gattung Ceratostomella erwähnt, welche holzbewohnende Pilze umfaßt. Neger ${ }^{1}$ ) beobachtete in

1) Nach gütiger Mitteilung.

Escherich, Forstinsekten. 
Dalmatien zahlreiche Leichen des Holzbohrkäfers Xyleborus dispar, welche Ceratostomella-Fruchtkörper trugen. Hier handelt es sich wahrscheinlich um bloßen Saprophytismus.

$$
\text { Perisporiaceen. }
$$

Die Perisporiaceengattungen ${ }^{1}$ ) Aspergillus, Myriangium und Apiosporium enthalten ebenfalls einige wenige für Insekten pathogene Vertreter. A. flavus parasitiert auf Bienen und ihrer Brut (in Deutschland, nach Maaßen) und ruft eine als Stein- oder Kalkbrut bekannte Mykose hervor. Die Krankheit soll eine größere Verbreitung haben (Europa, Amerika). A. flavus und A. glaucus befallen ferner die Seidenıaupenkokons in Japan, die sehr gefürchtete Raupenkrankheit „Uchikabi“ verursachend. Myriangium Duriaei Mont. befällt Schildläuse (die Mottenschildlaus Aleurodes citri) in Westindien und Florida. Apiosporium oleae, welches auf dem Ölbaum parasitiert, befällt und tötet (nach Ruby und Raybaud [36]) die ebenfalls auf dem Ölbaum parasitierende Schildlaus Lecanium oleae; der Tierkörper enthält im Innern Hefezellen des Pilzes.

\section{Saccharomyceten.}

$\mathrm{Zu}$ den Ascomyceten gehören auch die Hefe- oder Sproßpilze (Saccharomycetes), die bekannten Gärungserreger, einzellige, konidienförmige Organismen, welche unmittelbar zu neuen Individuen aussprossen und unter gewissen Bedingungen kleine kuglige Asci, mit wenigen Sporen, bilden. Bei den tierbewohnenden Saccharomyceten handelt es sich wohl meistens um eine Symbiose. Dies ist bekanntlich bei zuckersaugenden Insekten (Cocciden) der Fall, in welchen vielfach Hefepilze intrazellular leben, olne einen nachteiligen Einfluß auf den Wirt auszuüben. Die Infektion geht vom Muttertier aus, bei der Eiablage, so daß die Symbiose von Generation zu Generation vererbt wird (vgl. Buchner). Auch bei anderen Insekten sind solche Fälle bekannt; so fand z. B. Escherich [15 a] in dem Darmepithel des Käfers Anobium paniceum eine Saccharomyces-Art, welche das Tier keinesfalls beeinträchtigt, sondern vermutlich im Gegenteil dadurch nützt, daß sie verdauungsfördernd wirkt. Das Vorhandensein solcher Sproßpilze ist allerdings auch mit Erkrankungen von Insekten in ursächlichen Zusammenhang gebracht worden. So fand Hartig im Blute der Nonnenraupen einen Hefepilz, den er für sehr pathogen hält. Lindner [29] fand einen hefeartigen Pilz (Saccharomyces apiculatus parasiticus) in der Schildlaus Aspidiotus nerii (auf Oleander, Lorbeer, Myrte und Efeu), den er mit dem von Hartig in der Nonne aufgefundenen für identisch hält; er schlägt sogar vor, durch Kultur dieser Schildlaus auf Efeu im großen eine Ansteckung der Nonne zu versuchen. Es ist jedoch wahrscheinlich, daß es sich auch hier um eine harmlose Symbiose handelt.

\section{Laboulbeniaceen.}

Eine weitere Unterabteilung der Ascomyceten bilden die wegen ihrer eigenartigen Organisation und Lebensweise sehr interessanten Laboulbeniaceen. Dieselben beanspruchen hier ebenfalls unser Interesse, da sie ausschließlich auf Insekten, meist hydrophilen Coleopteren (Lauf- und Wasserkäfern) parasitisch

1) Die Perisporiaceen bilden eine weitere Unterabteilung der Ascomyceten mit völlig geschlossenen kugligen Perithecien. 
leben; dieser Parasitismus ist jedoch ungefährlicher Natur, wenigstens tötet er die Insekten nicht. Dank der Arbeiten von Thaxter sind uns heute die Laboulbeniaceen genau bekannt. Die Vertreter dieser Gruppe sind winzig kleine unscheinbare Pilze, welche ein sehr kurzes, zwei- bis vielzelliges vegetatives Mycel bilden und in der Hauptsache nur aus dem Fruchtkörper bestehen. Sie setzen sich durch einen schnabelförmigen Fortsatz der untersten Zelle an den Chitinpanzer des Insektes fest; nur bei wenigen Arten findet Bildung von Rhizoiden statt, welche in die Weichteile des Tieres eindringen. Die meisten bisher bekannten Laboulbeniaceen sind in Nordamerika aufgefunden worden, während aus Europa nur wenige Arten bekannt sind; es ist jedoch sehr wahrscheinlich, daß auch hier diese Pilzgruppe eine größere Verbreitung hat.

Sehr verbreitet auf Stubenfliegen in Europa ist Stigmatomyces Baeri Peyr.; die Entwicklungsgeschichte dieses Pilzes sei hier als typisches Beispiel der Laboulbeniaceenorganisation kurz geschildert: Die Infektion geschieht durch Übertragung der zweizelligen, mit einer Schleimhülle umgebenen Sporen (Fig. $205, A)$ von den infizierten auf die gesunden Tiere. Hier vergrößern sich die beiden Zellen der Spore und die unterste bildet zunächst den erwähnten schnabelförmigen Fortsatz $(B)$, wodurch erst der Pilz festen Fuß faßt. Nun beginnt eine wiederholte Teilung der beiden Sporenzellen $(C, D)$; die obere Zelle liefert ein Anhängsel mit mehreren flaschenförmigen Gebilden, den Antheridien (an). Aus den durch die Teilung der untersten Sporenzelle gebildeten Zellen $a, b, c$ und $d(D)$, entwickelt sich die eine $(D a)$ durch weitere wiederholte Teilungen zu einem weiblichen Apparat. Die wichtigsten Teile desselben ist die zentral liegende Eizelle,
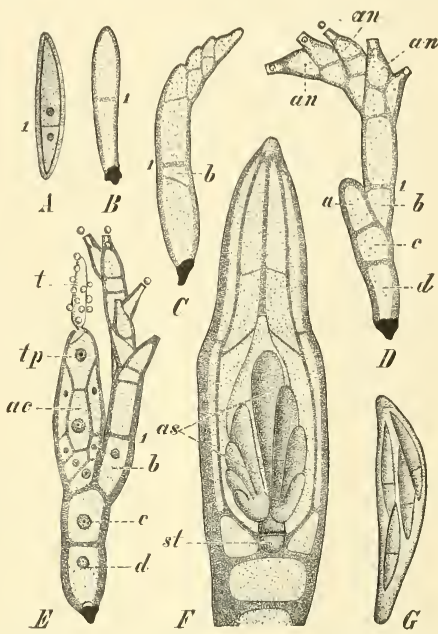

F'ig. 205. Stigmatomyces Baeri Peyr. A Spore; $B-F$ Aufeinanderfolgende Entwicklungsstadien nach der Sporenkeimung; $D$ Bildung von Antheridien an, aus denen Spermatien austreten; $E$ das geschlechtsreife Individuum mit den vollständig ausgebildeten Antheridien (rechts) und weiblicuem Apparat (links); bei $t$ das Trichogyu desselben; $F$ der zu einem Perithecium umgewandelte weibliche Apparat mit den sich entwickelnden Asci (Sporenschläuchen); $G$ ein reifer Ascus, vier Spore» enthaltend. Alles stark vergrößert. Nach Thaxter, aus dem Bonner Lehrbuch, 9. Aufl. 1908.) Carpogon $(E, a c)$ und das schmale Trichogyn $(E, t)$. Die erwähnten männlichen Organe, die Antheridien bringen kuglige Spermatien hervor, welche sich an das Trichogyn setzen. Das weitere Schicksal der Kerne des Spermatiums und des Carpogons konnte nicht festgestellt werden. Wahrscheinlich findet hier, ähnlich wie bei den analoge Verhältnisse zeigenden Rotalgen (Florideen), eine Befruchtung statt. Die Eizelle teilt sich auf jeden Fall in drei Zellen, von denen die mittlere zur Bildung der Ascis $(F, a s)$ fortschreitet, während die die Eizelle um- 
gebenden Zellen durch wiederholte Teilung eine Wandung bilden; der ganze weibliche Apparat hat sich somit zu einem Perithecium ausgebildet $(F)$. Jeder darin eingeschlossene Ascus enthält vier zweizellige Sporen $(G)$. Einige Laboulbeniaceen sind diözisch, d. h. sie bilden die männlichen und weiblichen Organe nicht an einem, sondern verschiedenen Individuen.

Eine größere praktische Bedeutung kommt den Laboulbeniaceen kaum zu, da, wie schon erwähnt, die befallenen Insekten nicht zugrunde gehen; jedoch scheint eine Beschränkung der Vermehrung der Käfer durch den Befall wahrscheinlich.

\section{Fungi imperfecti.}

Hierher gehören, wie schon erwähnt, Pilze mit gegliedertem Mycelium und von unbekannter Hauptfruchtform, welche jedoch größtenteils als die Konidienformen von Ascomyceten zu betrachten sind. Die Gruppe und ihre Einteilung ist keine natürliche. Man unterscheidet drei Hauptabteilungen: I. Sphaeropsidales, mit Konidien in kammerartigen Höhlungen (Pykniden). II. Melancoliales, mit Konidien auf Konidienlagern, die zuletzt ganz frei stehen. III. Hyphomyceten, mit Konidien in Konidienträgern, die einzeln oder höchstens in Coremien (d. h. aus parallelen Hyphen bestehenden Stromata, welche sich über das Substrat erheben) zusammenstehen. Von diesen drei Unterabteilungen weisen nur die erste und die letzte insektentötende Vertreter auf.

$$
\text { Sphaeropsidales. }
$$

Von den Sphaeropsidales kommt nur die Gattung Aschersonia Mont. für uns in Betracht. Die Pilze dieser Gattung bilden fleischige, halbkuglige, polsterförmige Stromata, welche die Pyknidenkammer in sich bergen. Sporen spindelförmig, hyalin, mehrzellig, auf fadenförmigen Trägern.

Als insektenbewohnend werden folgende Arten angegeben: A. tahitensis Mont., A. turbinata Beck., A. parasitica P. Henn., A. flavocitrina P. Henn. und $A$. aleurodis $W e b b$, welche sämtlich auf außereuropäischen Cocciden, insbesondere Aleurodes citri (auf Citrus-Bäumen in Florida) parasitieren und sie zum Absterben bringen. Die größte Häufigkeit zeigt vor allem die letztgenannte Art.

$$
\text { Hyphomyceten. }
$$

Von den imperfekten Hyphomyceten gibt es eine größere Anzahl von Gattungen, welche auf Insekten parasitierende Vertreter aufweisen. Diese sind, der systematischen Reihenfolge nach, folgende:

\section{Oospora Wallr.}

Diese Pilze leben parasitisch oder saprophytisch auf Pflanzen und Tieren $^{1}$ ) und bilden ausgebreitete oder polsterförmige, schimmelartige Rasen. Die Fruchthyphen sind kurz, zart, einfach oder sparsam verzweigt; die Konidien sind kuglig oder eiförmig und werden in regelmäßigen Ketten gebildet.

$\left.{ }^{1}\right)$ Hierher gehören, oder sind mindestens nahe verwandt, diejenigen Pilze, welche die unter den Namen "Herpes" und „Favus" bekannten Hautkrankheiten bei Menschen und Tieren verursachen. 
Die wichtigste aller insektenbewohnenden Arten ist Oospora destructor Delacr. $;^{1}$ ) sie bildet rundliche, zusammenfließende, staubige, zuerst weiße, später grüne Rasen. Die regetativen Hyphen kriechend, die Fruchthyphen einfach oder wenig verzweigt, mit sehr undeutlichen Scheidewänden, fast hyalin, 3-3,5 " dick. Konidien in Ketten zu 3-5, zylindrisch, beidendig abgerundet, blaugrün, $7-15 \mu$ lang, 2,5-3,3 $\mu$ dick. Der Pilz kommt auf verschiedenen Insekten, vornehmlich den Pflanzenschädlingen Cleonus punctiventris und Anisoplia austriaca in Frankreich und Rußland vor, die sog. "grüne Muscardine“ verursachend. Der Pilz wurde in Frankreich auch auf Seidenraupen beobachtet.

Weitere Arten sind O. Guerciana Cav. auf Larven von Agrotis aquilina in Italien, O. Saccardiana Berl. auf Ceroplastes rusci in Italien und O. ovorum Trab. auf Eiern von Haltica ampelophaga in Algerien. Letztere Art wurde von Petri in Italien in den von Phylloxera bewohnten Gallen aufgefunden; es gelang ihm in einigen Fällen, mit dem Pilz gesunde Phylloxera-Eier zu infizieren.

\section{Cephalosporium Corda.}

Hyphen weithin kriechend; Konidienträger kurz, aufrecht, an der Spitze nicht aufgeblasen. Konidien kuglig oder eiförmig, hyalin oder blaß gefärbt, sitzend, zu einem Köpfchen angehäuft.

Als insektentötend ist nur eine Art aus Westindien bekannt, nämlich C. lecanii Zimm. auf Schildläusen.

\section{Sporotrichum Link.}

Hyphen reich verzweigt, weit verbreitet, alle niederliegend. Konidien endständig, an der Spitze von Ästen oder von kurzen Trägern, meist einzeln, eiförmig oder kuglig.

Von den insektentötenden Arten kommt hauptsächlich S. globuliferum Speg. in Betracht; dieser Pilz befällt Heuschrecken (in.Argentinien) und soll auch die Getreidewanze (Blissus leucopterus) und andere Insekten (z. B. Cocciden) angreifen können.

\section{Botrytis Mich.}

Hyphen kriechend, verzweigt, septiert; Konidienträger unregelmäßig, baumartig verzweigt, selten einfach, aufrecht. Äste entweder dünn, an der Spitze zugespitzt, oder dicker, stumpf, oder aufgeblasen warzig oder kammförmig zähnig. Konidien an der Spitze der Äste gehäuft, aber nicht eigentlich kopfig, kuglig, ellipsoidisch oder länglich, hyalin oder lebhaft gefärbt, einzellig. Einige Arten bilden Sclerotien.

Diese Gattung ist von großer Bedeutung, da sie mehrere in Europa auf Insekten parasitierende Arten umfaßt. Die wichtigste dieser Arten ist Botrytis Bassiana Bals., welche zuerst (1763) an der Seidenraupe beobachtet wurde; sie ist die Ursache der unter dem Namen "Muscardine", "Calcino" oder „Kalksucht“2) bekannten Krankheit."3)

1) Die Art wird von einigen Forschern zu Isaria gestellt (als I. anisopliae Pettit, neuerdings von Vuillemin zu Penicillinm als Penicillium anisopliae Vuill.).

2) Wegen des kalkartigen Aussehens der erkrankten Raupen.

$\left.{ }^{3}\right)$ Vuillemin hat neuerdings diese Art von der Gattung Botrytis getrennt und unter eine neue Gattung Benuveria Vuill. (als B. Bassiana Vuill.) gestellt. 
Der Pilz tritt meistens nur in der Form einfacher, einen schimmelartigen Flaum bildender Fruchthyphen auf, ${ }^{1}$ ) kann aber zuweilen isariaähnliche Stromata bilden. Die aus dem Innern von infolge des Befalls verendeten Raupen hervorbrechenden Fruchthyphen sind aufrecht, unverzweigt oder seltener gabelig mit kurzen Ästen, farblos und durch Scheidewände in lange Zellen geteilt (Fig. 206, A). Sie treiben einzelne oder gegenständige,

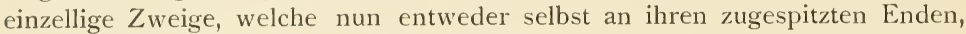
oder an denen der von ihnen entspringenden Zellen zweiter Ordnung, köpfchenweise (bis 16 Stück an einem Hyphenästchen) kuglige Konidien von 2-3 - Durchmesser abschnüren (Fig. 206, $A$ ). Gelangt eine dieser, monatelang ihre Keimfähigkeit bewahrenden Konidien auf die Haut einer Raupe, so keimt sie; der Keimschlauch dringt durch die Haut und während der außenbleibende Teil derselben abstirbt, wächst das eingedrungene Stück, zahlreiche, verzweigte, von dem Punkte des Eindringens aus strahlig diver-

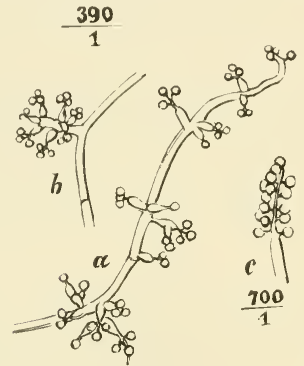

A

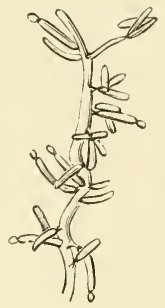

B

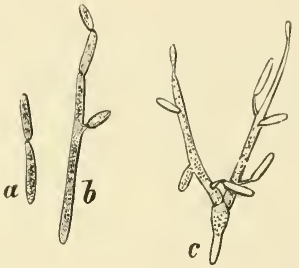

C

Fig. 206. Botrytis Bassiana Bals. A Konidientragende Fruchtbyphen, $a$ mit schwächerer, $b$ und $c$ mit reichlicher Sporenproduktion; $B$ konidienabschnürende Keimschläuche aus der Raupenhaut; $C$ zylindrische Konidien und Hyphenansätze, sekundäre Konidien abschnürend, aus dem Raupenblute. (Nach de Bary [5].)

gierende Äste treibend, weiter. Die Umgebung dieser Stelle wird zu einem mißfarbigen Flecke. Die Fäden durchwachsen nun die Leibeswand, die Muskeln und den Fettkörper, indem sie diese Teile zerstören und es bilden sich teils an ihren freien Enden, teils seitlich, auf kurzen, dünnen Stielen sitzende, $7-15 \mu$ lange und $2 \mu$ breite, zylindrische Konidien, die gleichfalls köpfchenweise abgeschnürt werden (Fig. 206, B). Nach vollendeter Reife lösen sich diese zylindrischen Konidien von ihren Trägern und gelangen in die Blutmasse des Tieres, wo sie entweder unmittelbar oder nachdem sie sich auf das zwei- bis dreifache ihrer Länge gestreckt haben, neue, sekundäre zylindrische Konidien abschnüren (Fig. 206, C). Wenn diese Konidienbildung ihren Höhepunkt erreicht hat, ist das Blut des Tieres mit den Konidien reichlich versehen und erscheint weißlich getrübt.

4) Diese einfache Form dieses Pilzes erinnert an die schon erwähnte kuglige, konidienbildende Nebenfruktifikation von Cordyceps militaris (Fig. 202, E, D), so daß die Vermutung naheliegt, daß sie eine Nebenfruktifikation einer Cordyceps-Art darstellt. 
Nach Einstellung der weiteren Konidienbildung beginnen die zahlreich vorhandenen Konidien zu verästelten Hyphen auszuwachsen. Die Ausbildung der braunen Hautflecken, welche die Infektion der Raupen anzeigen, beginnt erst am 8. oder 9. Tage nach der Infektion. Sobald diese sich vergrößern, werden die Tiere träge und hören auf zu fressen, werden allmählich regungslos und sterben meist am 12.-14. Tage nach der Infektion, nachdem sie zuvor eine schlaffe, weiche Beschaffenheit angenommen. Bald beginnt aber unter dem Drucke der nun eintretenden Mycelbildung die Leiche wieder zu schwellen und das Mycelium durchwuchert den Körper vollständig, die inneren Organe auflösend und sie, mit Ausnahme der Höhlung des Darmes, völlig durchdringend. Es folgt nun in feuchter Umgebung der Durchbruch der Fruchthyphen, während die trocken liegende Leiche zur Mumie zusammenschrumpft, aus welcher noch nach Monaten bei Wiederbefeuchtung Konidienträger hervorbrechen.

Außer der Seidenraupe befällt der Pilz auch zahlreiche andere Insekten, wie die Kiefernspinnerraupe, den Traubenwickler (Conchylis), die Larven des Rebenschädlings Haltica ampelophaga usw., und soll auch die Nonnenraupen anzustecken imstande sein.

Eine weitere insektentötende Art ist Botrytis tenella Sacc., welche auf verschiedenen Insekten, insbesondere Maikäfern und ihren Larven (Engerlinge)

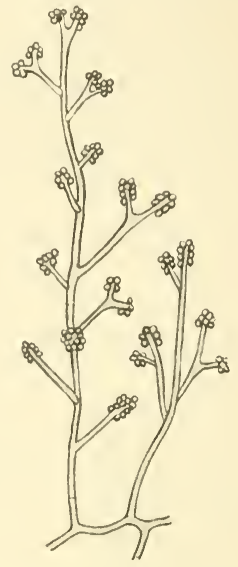

Fig. 207. Botrytis tenella Sacc. Fruchttragende Hyphen nach S a c cardo, stark vergrößert (aus Lindau, in Rabenhorst, Kryptogamenflora). vorkommt und sie tötet (Fig. 207 u. 208). Der Pilz soll in Schweden auch auf den Nonnenpuppen spontan vorkommen. Der Pilz bildet ausgebreitete, weiße, ziemlich feste, aus septierten, verzweigten, 1,5- 2 " dicken Hyphen bestehende Rasen. Konidienträger (Fig.207)aufsteigend, mannigfach verzweigt, wenig septiert, hyalin. Konidien eiförmig, zu 2-3 köpfig gehäuft, $2,5-3 \mu \times 1,5-2 \mu$, hyalin, bisweilen mit Öltropfen.

Die besprochenen Botrytis-Arten sind schwer voneinander zu unterscheiden; auch ihre Zugehörigkeit zu dieser Gattung wird angezweifelt. Da die Fruchthyphen ron Botrytis, wie schon hervorgehoben, unter Umständen zu isariaförmigen Bündeln sich vereinigen, so werden sie bisweilen mit
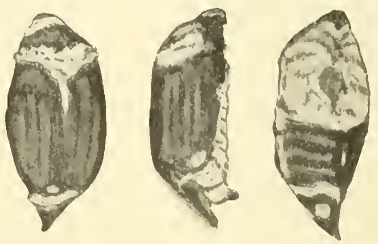

Fig 208. Botrytis tenella Sacc. Vom Pilz befallene Maikäfer. Die weißen Polster der konidientragenden Hyphen brechen an den chitinfreien Teilen der toten Maikäfer hervor. (Nach Tubeuf [44].)

Isaria verwechselt; in der Tat wird Botrytis tenella vielfach als zu Isaria gehörig angesehen und Isaria densa (Link.) Fr. benannt. Zur sicheren Unterscheidung beider genannter Arten gibt Delacroix auf Grund von Kulturen folgende Unterscheidungsmerkmale an: 
B. tenella: Konidien oval, Kartoffelscheiben und Gelatineplatten werden intensiv rot gefärbt.

B. Bassiana: Konidien rund, Kartoffelscheiben werden nicht, Gelatinekulturen hellbraun gefärbt.

In Frankreich soll ferner auf den Seidenraupen neuerdings eine neue, von B. Bassiana abweichende Form auftreten, die als B. effusa Beauv. bezeichnet wird. Sie unterscheidet sich im wesentlichen von jener Art dadurch, daß sie das Substrat (sowohl die Seidenraupen wie Kartoffelscheiben) rot färbt ( "rote Muscardine“). ${ }^{1}$ )

\section{T'erticillium Nees.}

Hyphen kriechend, rasenbildend, verzweigt, septiert. Konidienträger aufrecht, verzweigt, septiert. Zweige quirlständig. Konidien einzeln oder zu mehreren stehend, bald abfallend, kuglig bis eiförmig, hyalin oder lebhaft gefärbt.

Die Gattung enthält zahlreiche Arten, welche auf toten Insekten aufgefunden werden; ihre Pathogenität (Parasitismus) ist jedoch in vielen Fällen zweifelhaft.

I. capitatum Ehrenb., bildet sehr zarte, weiße, kaum sichtbare, lockere, ausgedehnte Überzüge. Hyphen $4-5$ " dick, und Konidienträger zerstreut stehend, 0,15-0,2 mm hoch, weiß, $3 \mu$ dick, mit 2-3 zwei- bis vierwirteligen Verzweigungen. Zweige $2 \mu$ dick und bisweilen noch einmal dreiwirtelig verzweigt. Konidien endständig, einzeln, kuglig, $1-1,5$ „ Durchmesser. Auf kleinen Insekten und Larven beobachtet, wahrscheinlich nur ein Saprophyt; es wächst auch auf Zweigen von Pflanzen und Ilolz.

$V$. heterocladum Penz., überzieht den Körper des Insektes wie mit einem weißen Filz und bildet kriechende, verlängerte, wenig verzweigte Hyphen und aufsteigende Konidienträger mit abstehenden, geraden, zugespitzten Ästen (zu drei- bis vieıgliedrigen Wirteln). Konidien an den Astspitzen einzeln, zu zwei oder drei, öfter sehr kurz gestielt, länglich, 5,5 bis $6 \mu$ lang, 2-3 $\mu$ breit, hyalin. Auf Lecanium hesperidum (auf den Blättern des Zitronenbaumes in Oberitalien) und Aleurodes-Arten (auf Citrus-Arten in Florida).

$I$. corymbosum Lebert, bildet weiße schimmelartige Rasen und aufrechte, $2 \mu$ dicke, coremienartig zusammentretende Konidienträger mit opponierten

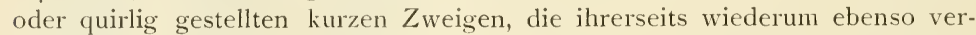
zweigt sein können. Endzweig fast ellipsoidisch, ca. 4 " breit. Konidien kuglig oder leicht eiförmig, etwa $3 \mu$ lang und 2,5 $\mu$ breit. Auf Puppen des Kiefernspanners Fidonia piniaria (in Schlesien). ${ }^{2}$ )

Ferner ist vielfach eine I'erticillium-Art ( $V$. aphidis) auf Aphiden (in Ungarn und Dänemark) und weitere ( $I$. oxana Dan. et Hize) auf Cleonus punctiventris (in Rußland) beobachtet worden.

1) $\mathrm{Zu}$ Botrytis wird ferner ein Pilz gestellt, der bei einer Invasion von Wanderheuschrecken in Algerien vernichtend aufgetreten ist. Giard [24] stellt ihn zu einer neuen Gattung Lachnidium; dieselbe ist jedoch nach Saccardo nichts anderes als ein Fusarium.

a) Der Pilz wird vielfach mit Botrytis Bassiana verwechselt. Er wird auch als die Konidienform eines Cordyceps angesehen. 


\section{Cladosporium Link.}

Hyphen im Substrat oder auf dessen Oberfläche kriechend, verzweigt, septiert, dunkelfarbig. Konidienträger aufrecht oder niederliegend, büschelig hervorbrechend oder dichte Rasen bildend, meist septiert, einfach oder verzweigt, dunkelfarbig. Konidien fast kuglig bis zylindrisch, leicht dunkelfarbig bis schwarz, meist zweizellig (selten ein- oder mehrzellig), oft eingeschnürt.

Cladosporium-Arten werden vielfach auf toten Insekten angetroffen $(C$. aphidis v. Thüm. auf Aphis-Arten, C. penicillioides Preuss, auf Chrysaliden usw.), sie sind jedoch meistens nur Saprophyten (oder in einigen Fällen Epiphyten). Sie sollen bisweilen den Insekten dadurch schädlich werden, daß sie die Tracheen verstopfen und in dieser Weise Asphyxie und den Tod der Tiere herbeiführen können.

\section{Isaria Pers.}

Mycel häufig weit ausgebreitete feste Lager bildend, meist weiß (seltener hellfarbig). Fıuchthyphen septiert, hellfarbig zu massigen Bündeln, Coremien,

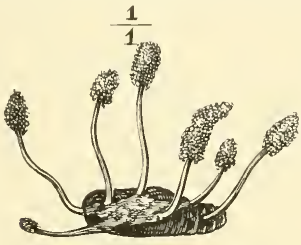

$A$

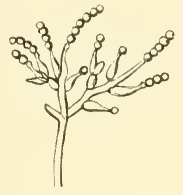

$B$

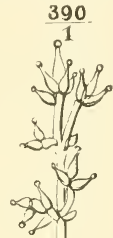

$C^{\prime}$

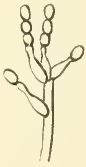

D

Fig. 209. Isaria Pers, A Puppe mit den Coremien von I. farinosa (Dicks.) Fries. (nach Nees von Esenbeck); $B$ Fruchthyphtnende von demselben Pilz mit kugligen Konidien; $C$ desgleichen mit schwachen sporenprodukten; $D$ desgleichen mit ovalen Konidien von $I$. strigosa Fries. ( $B-D$ nach de $\operatorname{Bary}[5]$.

parallel vereinigt; dieselben erheben sich meist aufrecht auf dem Substrat (Fig. 209, $A$ ) und sind stiftförmig oder keulig, einfach oder verzweigt. Die Konidien entstehen als letzte Verzweigungen der das Coremium bildenden Hyphen, das keulenförmige Köpfchen desselben dicht überziehend; der Stiel des Coremiums ist dagegen als der sterile Teil zu bezeichnen, auf ihm befinden sich also keine Konidienträger. Die Konidien entstehen akrogen und sind sehr klein, kuglig oder ellipsoidisch, einzellig, hyalin.

Wie schon an anderer Stelle hervorgehoben wurde, werden einige IsariaArten als die Konidienform von Cordyceps-Arten angesehen und bei $C$. militaris ist es de Bary anscheinend auch gelungen, durch Aussaat der CordycepsAscosporen die Isaria-Form zu erhalten ${ }^{\mathbf{1}}$; der umgekehrte Versuch ist aber bisher ohne Erfolg geblieben. Bei der großen Anzahl der insektenbewohnenden Isariapilze ist es übrigens keine leichte Aufgabe, die Zugehörigkeit zu eruieren. Es ist auch nicht ausgeschlossen, daß bei vielen Arten das Vermögen der Bildung der Ascusfruchtform verlustig gegangen ist.

Die systematische Stellung der "Isaria“-Pilze ist auch unter den Imperfecti eine sehr zweifelhafte. Der Hauptcharakter, die Bildung der

1) Da es sich in diesem Falle nicht um eine Reinkultur handelt, so ist der Versuch für die Zugehörigkeit dieser Pilzformen nicht unbedingt beweisend. 
eigentümlichen Coremien, ist kein sicheres Gattungsmerkmal, da sie in hohem Maße von der physikalischen und chemischen Beschaffenheit des Substrates abhängt, während sie andererseits auch bei Pilzen anderer Gattungen anzutreffen ist. Vom Standpunkt der Form der Konidienträger aus betrachtet, sind die verschiedenen Isariapilze wohl unter verschiedene Gattungen zu stellen. Dies ist auch zweifellos unbewußt öfter geschehen, in den Fällen, wo die typische Coremienbildung unter dem $Z$ wang der herrschenden Bedingungen ausblieb. Der Gattungsbegriff "Isaria" steht also auf ungemein schwachen Füßen; es ist daher begreiflich, wenn die Isariapilze eine Unmenge von Synonymen aufweisen. Dadurch aber, daß man, der sonst richtigen Bestrebung der Benennung von Imperfekten nach der etwaig entdeckten Hauptfruchtform folgend, die Isarien kurzweg unter Cordyceps stellte, erreichte die Konfusion den Gipfel. Dieser kurze Prozeß ist bei den Isarien tatsächlich untunlich, da nur bei Isaria farinosa der Zusammenhang mit Cordyceps militaris, wenn auch nicht absolut sicher, doch höchstwahrscheinlich ist, während viele der übrigen schlechtweg als "Isaria" bezeichneten Pilze höchstwahrscheinlich mit Isaria farinosa keinerlei verwandtschaftliche Beziehungen haben und demnach auch nicht zu Cordyceps zu gehören brauchen. Eine gründliche Neubearbeitung der Isarien auf Grund von Versuchen mit Reinkulturen tut dringend not. Den Anfang hat schon Vuillemin [47, 48] gemacht. Nach diesem Autor ist z. B. I. farinosa unter die Gattung Spicaria Harz ${ }^{1}$ ) zu stellen. Es ist in der Tat unzweifelhaft, daß viele Isarien zu Spicaria oder zu der nahverwandten Gattung I'erticillium gehören. Fron [20, 21] fand einen parasitischen Pilz auf den Puppen der Traubenwickler (Conchylis und Polychrosis) in Frankreich, den er als eine Varietät von Isaria farinosa erkannte und als Spicaria farinosa var. verticilloides bezeichnete. Nach der Beschreibung und den beigegebenen Abbildungen handelt es sich in der Tat um eine Spicaria. Der Pilz ist, wie Fron mit Recht hervorhebt, mit dem von Schwangart [38] ebenfalls an den Traubenwicklern in Deutschland aufgefundenen identisch. Der Pilz scheint eine größere Verbreitung zu haben; ich habe ihn an einem "Isaria"-Belag an den Puppen von Panolis piniperda, die ich rom Zoologischen Institut der Forstakademie zu Tharandt erhielt, erkannt. Diesen erst in der allerletzten Zeit in Angriff genommenen Untersuchungen will ich jedoch durch weitere Mitteilungen hier nicht vorgreifen.

Gegenwärtig, solange es an einer gründlichen Bearbeitung der Isarien fehlt, ist es aber jedenfalls vorteilhafter, an der alten Gattung Isaria festzuhalten; man muß sie nur als eine biologische Sammelgattung von insektentötenden, zu Coremienbildung neigenden Imperfekten auffassen.

Die wichtigste und am besten bekannte Art ist Isaria farinosa (Dicks.) Fries (vgl. Cordyceps militaris, S. 272), welche über ganz Europa, auf verschiedenen Raupen und Puppen, besonders von Bombyx rubi und B. pini, sowie Conchylis ambiguella u. a. verbreitet ist. Sie bildet auf den Insektenleichen weiße, 2-4 cm hohe, keulenförmige Coremien mit deutlich abgesetztem, unverzweigtem, glattem Stiel und verdicktem, einfachem, seltener

1) Dieselbe ähnelt der Gattung Verticillium, unterscheidet sich aber von dieser dadurch, daß die Konidien nicht einzeln, sondern in langen perlschnurartigen Ketten entstehen. 
verzweigtem Köpfchen, dessen Oberfläche durch Bildung zahlreicher, dichtstehender Konidienträger sehr deutlich mehlig bestäubt erscheint (Fig. 209, $A$ ). Die einzelnen Fruchthypen, welche sich stets nur gabelig verästeln, tragen meist nur paarweise opponierte $Z$ weige (Fig. 209, $B$ u. C), zeigen also nicht die wirtelförmige Anordnung der weit abstehenden Äste, wie sie bei der einfachen Konidienform von Cordyceps militaris beschrieben wurde (v̀gl. S. 271, sowie Fig. 202, E). Die Zweige und Äste bestehen aus je einer kurzen, zylindrischen Zelle, welche sich von zylindrischem oder flaschenförmigem Grunde aus in ein pfriemenartiges Ende zuspitzt, auf dem kuglige, hyaline, $2 \mu \mathrm{im}$ Durchmesser messende Konidien abgeschnürt werden (Fig. 209, $B$ u. $C$ ).

Die Art bildet auch mehrere vom Typus abweichende Formen, und zwar variiert bei diesen die Farbe der Coremien, ihre mehr oder minder rasige Anhäufung, die Art ihrer Verzweigung, die Beschaffenheit des Stiels (ob glatt oder behaart, ob konidientragend oder steril, ob an der Basis weiß oder gelblich) u. dgl. ${ }^{1}$ )

Die aus den Sporen entstehenden Keimschläuche dringen nicht durch die Haut in das Innere der Raupe ein, sondern durch die Stigmata in die Tracheenhauptstämme und erst nachdem sie die Substanz dieser durchwuchert und sie ebenso wie das anliegende Gewebe dunkelbraun gefärbt haben, gelangen sie in die Leibeshöhle.

Von anderen insektentötenden europäischen 1saria-Arten seien noch folgende erwähnt:

I. strigosa Fries, mit rasig gehäuften, pfriemlichen, einfachen oder verzweigten, 4-10 $\mathrm{mm}$ hohen Coremien. Der Stiel derselben ist ziemlich glatt, das Köpfchen von den Konidien bestäubt, fast strohgelb. Konidien (Fig 209, D) an einfachen Trägern von ca. $4 \mu$ Dicke entstehend, eiförmig, an der Basis spitz, farblos, in Masse strohgelb, $4 \mu$ lang, $2 \mu$ dick. Sie ist auf Puppen von Agrotis ypsilon und anderen Schmetterlingen aufgefunden worden.

I. corallina Fries, mit reich verzweigten, büscheligen, langen, zarten, korallenroten, an der Spitze mehrere, oft hängende Keulen tragenden Coremien. Konidien ellipsoidisch bis kuglig, rötlich. Auf der Puppe von Taeniocampa incerta Hufu. in Deutschland und auf Lepidopterenlarven in Oberitalien.

I. exoleta Fries, mit geselligen, verlängerten, zerbrechlichen, fädig zusammengedrückten Coremien. Dieselben sind kaum in Stiel und Köpfchen geschieden, staubig, hellbraun. Auf den Raupen von Calocampa exoleta.

1. floccosa Fries, mit rasig gehäuften, pfriemlichen, unverzweigten, weißen, hydnumartigen, 2-4 mm hohen, auf der ganzen Fläche flockig-zottigen Coremien. Auf Raupen und Puppen ron Bombyx jacobeac.

I. cinnabarina Preuss., mit geselligen, 6-8 $\mathrm{mm}$ hohen, fleischroten Coremien. Dieselben sind mehrfach verzweigt, dick, flockig-staubig, nicht in Stiel und Köpfchen geschieden. Konidien eiförmig, rot. Auf Sphinx ligustri.

1) Diese Abweichungen werden von einigen Autoren als Artenmerkmale drei weiterer Arten (I. truncatu Pers., I. crassa Pers. und I. velutipes Link.) aufgefaßt. 
I. leprosa Fries, mit rasigen, roten Coremien. Stiel und Köpfchen verdickt, allseitig flockig-staubig. Köpfchen verschieden gestaltet. Konidien zahlreich, locker anliegend, kuglig. Auf den Puppen von Orthosia incerta.

1. sphecophila Dittn., mit geselligen, fädigen, starren, hellbraunen, unverzweigten, 10-11 cm langen Coremien. Dieselben sind an der Basis glatt, an der Spitze behaart. Auf l'espa crabro (vgl. Cordyceps Ditmari, S. 272).

I. cleutheratorum Nees., mit fädigen, kurz verzweigten, weißlichen, überall behaarten Coremien. Konidien endständig, länglich-eiförmig, hyalin, 6 bis $7 \mu$ lang, 3,5 $\mu$ dick. Auf verschiedenen Käferarten (vgl. Cordyceps cinerea, ง. 272$)$.

I. lecaniicola Jaap, mit geselligen, zylindrischen oder keuligen, unverzweigten, zuweilen oben breitgedrückten und zweiteiligen, weißen, später ockergelben bis bräunlichen, 2,5-4 mm hohen und $0,2-0,4 \mathrm{~mm}$ dicken Coremien. Konidienträger unverzweigt. Konidien eiförmig, ellipsoidisch oder länglich-eiförmig, stumpf zugespitzt oder an einem Ende abgerundet, hyalin, oft mit 2 kleinen, undeutlichen Öltropfen, $5-8 \mu$ lang und $2-3,5 \mu$ breit. Auf Lecanium persicae (an Zweigen von Corylus avellana in Kärnten).

\section{Aegerita Pers. und Fusarium Link.}

Schließlich sei noch auf die Gattungen Aegerita Pers. und Fusarium Link. kurz hingewiesen. Erstere umfaßt vornehmlich Pilze, welche auf Holz und Baumrinden leben. Eine Art, A. Webberi Faur. parasitiert auf Mottenschildläusen (Aleurodes-Arten) in Florida. Zu der durch die charakteristischen, sichelförmigen, septierten Sporen gekennzeichneten Gattung Fusarium gehört ein auf Heuschrecken (in Algerien) parasitierender Pilz, F. acridiorum (von Giard zu einer besonderen Gattung Lachnidium gestellt; siehe S. 280, Anmerkung).

Im vorstehenden haben wir besonders diejenigen Pilzkrankheiten kennen gelernt, welche in Mitteleuropa vorkommen. Auch von den außereuropäischen insektentötenden Pilzen sind einige praktisch wichtige Arten besprochen worden, und zwar diejenigen, welche Gattungen angehören, die in Europa keine Vertreter aufweisen. Die Kenntnis dieser letzteren Gattungen ist nicht nur deshalb von Bedeutung, als es nicht unmöglich ist, daß sie auch in unserem Gebiet noch aufgefunden werden, sondern auch deshalb, weil mit diesen Pilzen praktische Bekämpfungsversuche in diesen Ländern ausgeführt wurden, dessen Kenntnisnahme unser Interesse in hohem Maße beansprucht.

Auf Grund dieser Übersicht wird jeder mit Hilfe eines Mikroskopes in der Lage sein, beim Ausbruch einer Pilzkrankheit an Insekten den Urheber derselben zu bestimuen.

\section{B. Wirtschaftliche Bedeutung der insektentötenden Pilze.}

Von den behandelten Krankheiten sind nur relativ wenige von praktischer Bedeutung, d. h. solche, welche epidemisch auftreten und ein massenhaftes Absterben von Insekten herbeiführen können. Im folgenden sei ein kurzer Hinweis auf diese praktisch wichtigen Arten gegeben, und zwar besonders auf diejenigen, welche Forstschädlinge befallen. 
Große Epizootien ron Insekten sind vielfach durch Pilze aus der Gruppe der Entomophthoraceen verursacht worden. Es ist höchstwahrscheinlich, daß sie schon in älteren Zeiten die Ursache des plötzlichen gänzlichen Verschwindens von massenhaft aufgetretenen forstschädlichen Insekten gewesen sind, wie aus einigen älteren Berichten zu schließen ist. Bestimmte Angaben sind erst in Berichten der zweiten Hälfte des vorigen Jahrhunderts enthalten. Bail [3, S. 244] berichtet über eine in der Tuchler Heide im Jahre 1867 unter den Kiefernspinnerraupen ausgebrochene Epizootie. Hier wurden die Raupen, welche bereits ca. 5000 ha kahl gefressen oder doch stark geschädigt hatten, fast vollständig durch eine Empusa-Art vernichtet. Ferner teilt Oberförster Schultz mit, daß bei einem im Sommer 1868 im Forstrevier Biezdrowo der Königl. Oberförsterei Zirke bei Posen ausgebrochenen Kieferneulenfraße Ende Juni binnen 8 Tagen ca. $70 \%$ der Raupen an einer Empusa-Krankheit starben, $20 \%$ noch erkrankt und nur $10 \%$ gesund erschienen [4, S. 138]. Um welche Empusa-Art es sich in diesen Fällen handelt, ist aus diesen Berichten nicht ohne weiteres ersichtlich, wahrscheinlich aber um Empusa aulicae. Hartig [26, S. 478] bezeichnet als Ursache der von ihm beobachteten EmpusaErkrankungen des Kiefernspinners, der Kieferneule und des Rotschwanzes ohne weiteres Empusa muscae. Diese Annahme muß jedoch bezweifelt werden, da nach den Erfahrungen Brefelds [9, S. 39] diese Art nicht imstande ist, Raupen anzustecken. Die Darstellungen Hartigs sind andererseits nicht genau genug, um eine sichere Identifizierung der fraglichen Art zu gestatten.

Bei den späteren Berichten über Entomophthoraceeninvasionen finden wir die genaue Bestimmung der Art, und zwar wird in erster Linie Empusa aulicae erwähnt. Bei dem großen Eulenfraß in Schlesien in Jahre 1884 sollen im Ganzen in den Saganer, Sprottauer, Mallmitzer, Bunzlauer, Primkenauer, Modlauer Kiefernforsten ca. 5000 Morgen fast kahl gefressen worden sein; die Invasion fand durch den Ausbruch einer durch Emp. aulicae verursachten Erkrankung ein plötzliches Ende (vgl. v. Tubeuf $[41$, S. $38-39]) .^{1}$ ) Im Jahre 1888 wurden die im Hauptmoor massenhaft rorhandenen Eulenraupen durch ungünstige Witterungsverhältnisse stark dezimiert; durch das Auftreten von Emp. aulicae wurden alle übrigen, den schädlichen Einflüssen entgangenen Raupen nahezu vollständig vernichtet (v. Tubeuf 1. c.). In demselben Jahre wurde durch denselben Pilz eine Eulenraupenepidemie in Miltenberg plötzlich beendet. Im Sommer 1892 zeigte sich die Krankheit bei Grafenwöhr [41, 42], im Jahre 1895 bei Landstuhl in der Pfalz [43].

Empusa aulicae hat sich als ein sehr wirksamer natürlicher Feind auch anderer massenhaft auftretender forstschädlicher Insekten erwiesen. So konnte der Pilz einer Invasion des Rotschwanzes (Dasychira pudipunda) im Jahre 1894 in den oldenburgischen Waldungen bei Fischbach an der Rhein-Nahe-Bahn sehr wirksam entgegentreten (r. Tubeuf [43, S. 474]).

1) Eine aus der Primkenauer Heide stammende kranke Eulenraupe war auch nach einer Bestimmung von de Bary ebenfalls von Emp. aulicae befallen. 
Nach Lindau [28] traten im Jahre 1897 die Raupen des Goldafters (Porthesia chrysorrhoea) massenhaft auf den Eichen des Berliner botanischen Gartens auf und fraßen sie kahl; plötzlich brach unter den Raupen eine durch Emp. aulicae verursachte Mykose aus, und vernichtete sie im Zeitraum von ungefähr einer Woche fast vollständig.

Eine weitere nennenswerte Mykose trat im Jahre 1898 an den Raupen des Wicklers Grapholitha tedella auf; das Insekt hatte seit einem Jahre die Fichtenwaldungen der meisten sächsischen Staatsforstreviere heimgesucht. Die Erkrankung war durch Entomophthora sphaerosperma verursacht, und ihr war wahrscheinlich, wenigstens teilweise, das Erlöschen des Fraßes zu verdanken (Baer [1]).

Von epidemisch aufgetretenen Entomophthoraceen seien ferner Emp. grylli auf Heuschrecken (in Bernau im Jahre 1896 [nach v. Tubeuf, 43], im Görzer Karst im Jahre 1910 [nach Gvozdenovič, 25] u. a.), Entom. aphidis auf Blattläusen (auf Zuckerrüben und Rübensamenfeldern im Jahre 1911 [nach Störmer und Kleine, 39]) als nützlich hervorgehoben.

Tarichium megashermum dürfte unter Umständen ein mächtiger Bundesgenosse im Kampfe gegen die den Nadelholzkulturen so schädlichen Ackereulenraupen werden (Cohn [11]).

Von den Mucoraceen ist nur die auf den Heuschrecken in Südafrika auftretende Mucor-Art („Locust fungus“), welche das praktische Interesse beansprucht. Der Pilz soll das öfter beobachtete Massensterben von Heuschrecken in Südafrika verursacht haben. Inwieweit er als ein echter Parasit die primäre Ursache des Absterbens ist, kann nicht als festgestellt gelten; seine praktische Bedeutung ist jedenfalls nach den neuen Versuchen mehrerer Autoren fraglich.

Von den Ascomyceten kommt für die Praxis in erster Linie Cordyceps militaris in Betracht. Abgesehen von einer brieflichen Mitteilung Tulasnes an Oberförster Middeldorpf über das epidemische Auftreten des Pilzes an den Raupen des Pinienprozessionsspinners in den südfranzösischen „Landes“, haben wir genaue Mitteilungen über epidemische Eskrankungen durch C. militaris nur beim Kiefernspinner. Beim oder unmittelbar nach dem Ausbruch einer Cordyceps-Mykose wird der Pilz selten in seiner charakteristischen Perithecienform angetroffen; meist haben wir es hier mit den mumifizierten, durch das Ausgestopftsein mit Mycelium steifen Raupen zu tun, oder höchstens mit der Konidienform (Isaria) des Pilıes. Die Perithecienform tritt dagegen später auf. Bail [2, S. 16] macht ausführliche Mitteilungen über einen an Oberförster v. Chamisso, Oberförsterei Balster bei Callies im Reg.-Bez. Köslin, in Jahre 1869 beobachteten Fall. $68^{\circ}{ }_{0}$ der eingesandten Raupen waren an Cordyceps bezw. Isaria verendet.

In der neueren Zeit finden wir vielfach in der Literatur Angaben über ein mehr oder weniger massenhaftes Absterben des Kiefernspinners (im Winterlager) infolge des Befalles mit $C$. militaris. Eckstein macht in den Jahren 1907 und 1908 [15] auf das Auftreten toter Raupen aufmerksam und nennt zahlreiche Forstreviere, in welchen die Epizootie beobachtet wurde. 
Ausführliche Mitteilungen machen Escherich und Baer [16]; aus diesen ist besonders eine von Oberförster Blüthgen in der Muskauer Heide beobachtete Epizootie hervorzuheben. Nach diesen Beobachtungen ist in den Jahren 1898-1899 ein zunächst lokal beschränkter Kiefernspinnerfraß durch Cordyceps militaris auf seinen Herd beschränkt und schließlich völlig unterdrückt worden.

Sehr bemerkenswert sind die Mitteilungen ron Olsen-Sopp [32] über die völlige Unterdrückung einer in den Jahren 1906-1907 in Mykland (Norwegen) ausgebrochenen großen Kiefernspinnerepidemie durch Cord. norvegica. Die im Winterlager befindlichen Raupen waren bis zu $80 \%$ vom Pilz befallen und mumifiziert. Olsen-Sopp hält dort, wo der Pilz in der Natur vorhanden ist, ein Überhandnehmen des Kiefernspinnerfraßes - zu mindesten, wenn keine für den Pilz besonders ungünstige Bedingungen herrschen - für unmöglich.

Von praktischer Bedeutung scheint ferner Sphaerostilbe coccophila zu sein. Mit dem Pilz sind mehrfach Versuche zur Unterdrückung von Schildlausepidemien gemacht worden. Rolfs [35] hat z. B. den Pilz zur Bekämpfung der San-Jose-Schildlaus (Aspidiotus perniciosus) in Florida herangezogen; der Pilz wurde auf Brot künstlich gezogen, mit Wasser gemengt und auf die Bäume gespritzt, oder Zweige, welche mit durch den Pilz getöteten Läusen dicht besetzt waren, an Bäume mit gesunden Läusen gehängt. Die Versuche sollen vom Erfolg begleitet worden sein. Dem Pilze hat man in Florida große Aufmerksamkeit auch für die Bekämpfung der lästigen Mottenschildlaus, Aleurodes citri, zugewendet, doch haben die Versuche der künstlichen Verbreitung des Pilzes keine durchschlagenden Erfolge zu verzeichnen. Die Versuche sind auch mit anderen pilzlichen Parasiten dieser Schildlaus gemacht worden, nämlich mit Ophionectria coccicola und einigen, im theoretischen Teil schon erwähnten imperfekten Pilzen. Berger [7] hält die Bekämpfung der Mottenschildlaus durch diese pflanzlichen Parasiten als das wirksamste und am wenigsten kostspielige Mittel; die Anwendung von Insektiziden soll ungefähr um das 7 fache teurer sein.

Zur Bekämpfung des Zuckerrübenschädlings Cleonus punctiventris hat man in Rußland vielfach versucht, den auf den Larven dieses Insektes parasitierenden und für dieselben sehr schädlichen Pilz Oospora destructor heranzuziehen. Die Versuche im freien Felde haben jedoch den gehegten Hoffnungen nicht entsprochen.

Dasselbe gilt für Sporotrichum globuliferum, welcher vornehmlich Heuschrecken, Cocciden und Haltica ampelophaga befällt.

Von den Imperfekten beanspruchen unser Interesse am meisten Botrytis und Isaria, wegen ihrer großen Verbreitung und Häufigkeit, sowie wegen ihres epidemischen Auftretens. Bei Besprechung des Cordyceps militaris ist auch Isaria farinosa mit behandelt worden. Den lsariapilzen ist in Hinsicht der praktischen Bekämpfung von Insekten vielfach besondere Aufmerksamkeit geschenkt worden, doch haben die künstlichen Infektionsversuche im großen meistens versagt. Nur bei der Traubenwicklerbekämpfung scheinen damit befriedigende Resultate erzielt worden zu sein. (Schwangart.) 
Von der Gattung Botrytis beanspruchen, wie schon an anderer Stelle hervorgehoben wurde, zwei Arten größeres Interesse für die forstliche Praxis, nämlich B. Bassiana und B. tenella.

B. Bassiana als Kampfmittel gegen schädliche Insekten zu verwenden, ist schon vielfach angestrebt worden. In erster Linie sind diejenigen Versuche von Interesse, welche zur Bekämpfung der Nonne gemacht worden sind. Nachdem Harz bereits 1891 den Vorschlag gemacht hat, die Nonnenraupen durch künstliche Infektion mit diescm Pilz zu vertilgen, führte Tangl [40] die Versuche aus, indem er von Reinkulturen Emulsionen in sterilisiertem Wasser herstellte und diese in verschiedener Weise auf Versuchsraupen brachte. Im Laboratorium gelangen die Versuche vollkommen, alle infizierten Raupen gingen an „Muscardine“ ein. Infektionsversuche im Freien, im Königl. Württembergischen Forstrevier Weingarten, bei welchen stark mit Nonnenraupen besetzte junge Fichten reichlich mit Botrytis-Enulsion begossen wurden, fielen dagegen ergebnislos aus; die Raupen blieben gesund. Über ähnliche Versuche berichtet in neuer Zeit Bolle [8] aus der k. k. landw. Versuchsstation in Görz; die Versuche in kleinen gelangen, während die Infektionen im Freien zu keinem positiven Resultat führten. Bemerkenswert ist eine Mitteilung von Bengtsson [6], daß im südlichen Norwegen im Sommer 1900 die Nomnenpuppen zu 0,78\% an Botrytis tenella starben; diese Pilzkrankheit griff spontan sowohl die Raupen wie die Puppen an. Vaney und Conte [46] empfehlen - für die Gegenden, wo keine Seidenraupen gezüchtet werden - die Anwendung von B. Bassiana zur Bekämpfung der Larven des Rebenschädlings Haltica ampelophaga. Die Larven werden durch das Fressen von mit Sporen des Pilzes behafteten Weinblättern angesteckt und gehen an Muscardine zugrunde. Ob die Anwendung dieser Bekämpfungsart im Freien von gutem Erfolg begleitet sein würde, muß dahingestellt bleiben.

Große Hoffnungen hat man seinerzeit auf die Bekämpfung der Maikäfer durch Botrytis tenella gesetzt. Die ersten Mitteilungen stammen von Le Moult [30], Prillieux et Delacroix [33, 34] und Giard [22, 23] und berichten über das epidemische Auftreten der Krankheit und die Infektionsversuche, welche im Laboratorium von Erfolg begleitet worden waren. In Frankreich sind sogar, zum Zweck einer Bekämpfung der Engerlinge im großen durch den Pilz, Reinkulturen in den Handel gebracht worden („Tubes Le Moult“). Die Nachprüfungen, welche von verschiedenen Seiten angestellt wurden, haben jedoch gezeigt, daß der Methode eine praktische Verwendbarkeit in großen nicht zukommt. Von diesen Versuchen sind in erster Linie diejenigen von Frank [19] und Dufour [13] zu nemnen. Beide fanden übereinstimmend, daß die künstliche Infektion im Laboratorium wohl leicht gelingt, während die Hervorrufung von Epidenien im Freien unmöglich ist. Ein spontanes Auftreten der Krankheit ist in Deutschland wiederholt beobachtet worden, so z. B. in der Königl. preuß. Oberförsterei Cladow in der Neumark, sowie von v. Tubeuf in Füßen in Oberbayern [44].

Die angeführten Erfahrungen aus der Praxis zeigen, daß trotz der großen Verbreitung mannigfacher Pilzkrankheiten die künstliche Verwendung 
derselben im großen auf Schwierigkeiten stößt. Es ist unzweifelhaft, daß manche dieser Krankheiten, vornehmlich Empusa, durch spontanes epidemisches Auftreten große Insektenkalamitäten schließlich fast vollständig unterdrücken können und somit bei der Wiederherstellung des Gleichgewichtes im Haushalt der Natur wesentlichen Anteil haben, jedoch ihre Wirksamkeit erst nach rollendetem Kahlfraß einsetzt, wo also durch die ungeheure Vermehrung der Insekten einerseits, und die erfolgte Erschöpfung der Nahrungsquellen andererseits, die Existenzbedingungen des einzelnen Individuums sich immer mehr ungünstig gestalten. Eine ausgedehnte Ansteckung und Erkrankung scheint also meistens erst nach eingetretener Schwächung der Insekten möglich. Diese Tatsachen sind auch vielfach benutzt worden, um der Möglichkeit der Verwendung von Pilzkrankheiten im Kampfe gegen schädliche Insekten jede Zukunft abzusprechen. Damit ist jedoch die Sache keinesfalls abgetan, denn einerseits ist es in manchen Fällen vielleicht doch möglich, die nötige Prädisposition künstlich zu fördern. ${ }^{1}$ ) und andererseits darf die Prädisposition auch nicht überschätzt werden. Es ist im Gegenteil angezeigt, die Versuche weiter zu verfolgen, um zu sehen, ob nicht durch geeignete Anstellung auch ohne ausgesprochene Prädisposition die Ansteckung möglich ist. - Außerdem können wir sehr wohl auf die Erhaltung wirksamer Infektionsherde Rücksicht nehmen. So ist z. B. von verschiedenen Seiten hervorgehoben worden, daß die Bodenstreu im Walde die mit Pilzkrankheiten behafteten Insekten beherbergt und somit den besten Infektionsherd darstellt; sie sollte also nicht vernichtet werden. Ferner wird sich vielleicht das Bereithalten von künstlichen Pilzkulturen als empfehlenswert erweisen; bei vorübergehender, selbst schwacher Prädisposition infolge ungünstiger Witterung wird dann durch künstliche Infektion die Seuche in der Weise an Ausdehnung gewinnen, daß ein Wiedererholen der Tiere nicht mehr möglich ist. Die Möglichkeit des Gelingens hängt natürlich auch von der Ausdehnung des Krankheitsgebietes ab; insofern sind die Verhältnisse im forstlichen Betriebe am ungünstigsten gestaltet.

\section{Literatur über Pilzkrankheiten der Insekten.}

Für die systematische Stellung und Abgrenzung der Familien und Gattungen: Engler-Prantl, Die natürlichen Pflanzenfamilien, 1. Teil, Abt. 1 u. 1 \%, 1897, 1900. - Für die Diagnosen ${ }^{2}$ ) und Fundorte der einzelnen Arten: Rabenhorst, Kryptogamenflora, 2. Aufl., I. Bd.: Die Pilze, 1884-1910, und Saccardo, Syllogae Fungorum. -- Eine Zusammenstellung von Pilzkrankheiten von Tieren nach den Wirten geordnet bei: Zopf, W., Die Pilze, im Handbuch der Botanik von A. Schenk, Bd. IV, 1890, S. 497-534.

Von den zahlreichen Arbeiten, welche einzelne Fragen behandeln, seien hier nur folgende genannt, auf welche im Text Bezug genommen wurde: 1. Baer, W.,

1) Eine künstliche Schaffung der Prädisposition liegt vielleicht bei der "Anhäufelungsmethode" Schwangarts bei den Puppen der Traubenwickler (Conchylis) vor.

2) Die Diagnosen von vielen Arten sind aus den hier angeführten Werken z. T. wörtlich entnommen.

Escherich, Forstinsekten. 
Beobachtungen über Lyda hypotrophica Htg., Nematus abietinus Chr. und Grapholitha tedella Cl., Thar. forstl. Jahrb. LIII, 1903, S. 171-208, Taf. I-IV. - 2. Bail, Über Pilzepizootien der forstverheerenden Raupen. Danzig 1869, 26 S., 1 Taf. 3. Derselbe, Pilzepidemie an der Forleule, Noctua piniperda L. Danckelm. Ztschr. f. Forst- u. Jagdw., Bd. I, 1869, S. 243-247. - 4. Derselbe, Weitere Mitteilungen über den Fraf und das Absterben der Forleule, Noctua piniperda. Ebenda, Bd. II, 1870 , S. 135-144. - 5. de Bary, A., Zur Kenntnis insektentötender Pilze. Botan. Ztg. a) Bd. 25,1867 , S. $1-7,9-13,17-21$, Taf. I, und b) Bd. 27, 1869, S. 585-593, 602-606. -- 6. Bengtsson, S., Biologiska undersökninger öfver nunnan (Lymantria monacha L.) dess parasitiser och sjudomar. Upps. i. prakt. Entomol. 12, Stockholm 1902, p. 65-136, 2 Taf. - 7. Berger, E. W., Whitefly control. Florida Exp. Stat. Bull. 103, 1910, 28 S., 2 Fig. - 8. Bolle, J., Tätigkeitsbericht der k. k. landw. Versuchsstation in Görz usw. Ztschr. f. d. land. Versuchsw. in Österr. XI, 1908, p. 279. - 9. Brefeld, O., Untersuchungen über die Entwicklung der Empusa muscae und Empusa radicans usw. Abhdlg. d. Naturf. Gesell. zu Halle, Bd. II, 1871, S. 1-50, Taf. I-IV. - 10. Derselbe, Botanische Untersuchungen über Schimmelpilze. IV. Heft, Leipzig 1881, S. 97-111, Taf. VII. - 10 a. Buchner, P., Neue Erfahrungen über intrazellulare Symbionten bei Insekten. Nat. Wochenschr. N. F., Bd. XII, 1903, p. $401 \mathrm{ff}$. - 11. Cohn, F., Über eine neue Pilzkrankheit der Erdraupen. Beitr. z. Biol. d. Pfl. 1870, S. ว8-86, Taf. IV, V. - 12. Danysz, J., et Wize, K., Les Entomophytes chr. Charançon des betteraves à sucre (Cleonus punctiventris). Ann. Inst. Pasteur. XVII, 1903, p. 421-446. - 13. Dufour, J., Einige Versuche mit Botrytis tenella zur Bekämpfung der Maikäferlarven. Ztschr. f. Pflanzenkr. II, 1892, S. 2-9. - 14. Derselbe, Über die mit Botrytis tenella zur Bekämpfung der Maikäferlarven erzielten Resultate. Forstl.-Naturw. Ztschr. 1894, S. 249-255. 15. Eckstein, Deutsche Forstztg. XXII, 1907, S. 1063 und XXIII, 1908, S. 80. 15 a. Escherich, K., Über das regelmäßige Vorkommen von Sproßpilzen in dem Darmepithel eines Käfers. Biol. Zentr.-Bl. Bd. XX, S. 350-358. - 16. Escherich u. Baer, Tharandter zoolog. Miscellen, 3. Reihe. Naturw. Ztschr. f. Forst- u. Landw. 1910, VIII, S. 159. - 17. F awcett, H. S., Fungi parasitic upon Aleurodes citri Bull. Univ. St. Augustine. Florida 1908, 41 p., 8 Taf. - 18. Derselbe, An important entomogenous fungus. Mycologia II, 1910, S. 164-168, Taf. 28-29. - 19. Frank, A., Über das neuerdings vorgeschlagene Mittel, die Maikäferlarven mit Botrytis tenella zu vertilgen. Ztschr. f. Forst- u. Jagdw. XXV, 1893, S. 223-226. - 20. Fron, G., Note sur quelques Mucédinées observées sur Conchylis ambiguella. Bull. Soc. Mycol. France, T. 27, 1911, p. 482-487, pl. XIX. - 21. Derselbe, Sur une Mucédinée de la Conchylis. Ebenda, T. 28, 1912, p. 151-154. - 22. Giard, A., L'Isaria parasite de la larve du hanneton. Compt. Rend. Ac. Sc. CXII, 1891, p. 1270-1273. - 23. Derselbe, Sur l'Isaria densa, parasite du Ver blanc. Ebenda, CXIII, 1891, p. 269-271. - 24. Derselbe, Sur le champignon parasite des criquets pélerins (Lachnidium acridiorum Gd.). Ebenda, CXIII, 1891, p. 813-816. - 25. Gvozdenoviě, Fr., Beobachtungen über den Stand der Heuschreckeninvasion am Görzer Karst im Jahre 1910. Ztschr. f. d. Landw. Versuchsw. in Österr. XIII, 1910, S. 957. - 26. Hartig, R., Mitteilungen über Pilzkrankheiten der Insekten im Jahre 1868 . Ztschr. f. Forst- u. Jagdw., Bd. I, 1869, S. 476-500, 1 Taf. - 27. K rassilistschik, J. M., Insektenkrankheiten durch Pilze verursacht. Mem. neuruss. Naturf. Ges. XI, Odessa 1886, S. 74-171 (russisch), Ref. in Justs Bot. Jahresbericht, XVI, 1888, 1. Teil, S. 309 bis 310. - 28. Lindau, G., Über eine im Berliner botanischen Garten beobachtete Raupenkrankheit. Verhandg. Brand., Bd. 39, 1897, S. XLVIl. - 29. Lindner, P., Das Vorkommen der parasitischen Apiculatus-Hefe in auf Efeu schmarotzenden Schildläusen und dessen mutmaßliche Bedeutung für die Vertilgung der Nonnenraupe. Wochenschr. f. Brauerei XXIV, Nr. 3. - 30. le Moult, Le parasite du hanneton. Compt. Rend. Ac. Sc. CXI, 1890, p. 653-655, CXII, 1891, p. 272 ff. und 1081-1083. - 31. Derselbe, Sur la destruction de certains Hemiptéres par les parasites végétaux. Ebenda, CLV, 1912, p. 656-657. - 32. Olsen-Sopp, Untersuchungen über insektenvertilgende Pilze bei den letzten Kiefernspinnerepidemien in Norwegen. 
Videnskap. Skrifter., I. Mat.-naturw. Kl., 1911, Nr. 2, Kristiania 1911, p. 1-56, Taf. I bis V. - 33. Prillieux et Delacroix, Le champignon parasite de la larve du hanneton. Compt. Rend. Ac. Sc., CXII, 1891, p. 1079-1081. - 34. Dieselben, Sur la muscardine du ver blanc. Ebenda, CXIII, 1891, S. 158-160. - 35. Rolfs, P. H., A fungous disease of the San Jose Scale. Florida. Agric. Exp. Stat., Bull. 41, p. 515-543, 2 Taf. - 36. Ruby et Raybaud, L'Apiosporium olex, parasite de la Cochenille de l'Olivier. Compt. Rend., Soc. Biol., Bd. 71, 1911, p. 214-216. 37. Sauvageau, C., et Perrand, J., Sur une Champignon parasite de la Conchylis. Compt. Rend, Ac. Sc, CXVII, p. 189-191. - 38. Schwangart, Über die Traubenwickler (Conchylis ambiguella Hübn. und Polychrosis botrana Schiff.) und ihre Bekämpfung, mit Berücksichtigung natürlicher Bekämpfungsfaktoren. Hertwigs Festschrift, Bd. II, Jena 1910 - 39. Störmer u. Kleine, in 1ll. landw. Ztg., XXXI, 1911, S. 558. - 40. Tangl, Fr., Bakteriologischer Beitrag zur Nonnenraupenfrage. Forstw. Zentrlbl. 1892, S. 209-230. - 41. v. Tubeuf, Empusa aulicae Reich. und die durch diesen Pilz verursachte Krankheit der Kieferneulenraupe. Forstl.-naturw. Ztschr. II, 1893, S. 31. - 42. Derselbe, Die Eulenraupe in den Staatswaldungen bei Grafenwöhr in Bayern. Ebenda, S. 126-127. - 43. Derselbe, Beendigung von Raupenepidemien durch Empusa. Ebenda 1897, S. 474. - 44. Derselbe, Bekämpfungsversuche der Maikäfer. Naturw. Ztschr. f. Forst- u. Landw., 1908, S. 73 bis 75. - 45. Tulasne, L. R. et C., Selecta fungorum carpologia. Paris 1861-1865, 3 Bde., mit Taf. - 46. Vaney, C. et Conte, A., Utilisation des champignons entomophages pour la destruction des larves d'Altises. Compt. Rend., Ac. Sc. CXXXVIII, 1904 , p. 159-161. - 47. Vuillemin, P., Les Conidiosporès. Bull. Soc. Sc. Nancy 1910, Sec. 3. t., XI, p. 129-172. - 48. Derselbe, Les Isaria de la Famille des Verticilliacées (Spicaria et Gibellulla). Bull. Soc., Myc., France XXVII, 1911, p. 75-82.

\section{Pathogene Mikroorganismen.}

(Spaltpilze und Protozoen.)

Es gibt eine ganze Reihe von epidemisch auftretenden Krankheiten unter den Insekten, die durch Mikroorganismen verüsacht werden, und durch welche oft große Mengen von Insekten dahingerafft werden. Leider sind heute unsere Kenntnisse darüber noch sehr lückenhaft und beschränken sich in der Hauptsache auf die auffallenderen Krankheiten einiger ökonomisch besonders wichtiger Insekten. Am eingehendsten sind bis jetzt die Krankheiten der Seidenraupe und der Biene studiert, durch die ein sehr empfindlicher Schaden verursacht wird. Hat doch die französische Seidenkultur lediglich durch die Pebrinekrankheit vom Jahre 1845 (in dem sie zum erstenmal aufgetreten) bis zum Jahre 1867 einen Verlust von mehr als 1 Milliarde Francs erlitten. Nebst den Seuchen der beiden Hausinsekten haben auch die Krankheiten einiger unserer Waldschädlinge (vor allem der Nonne) die Aufmerksamkeit der Praxis wie der Wissenschaft erregt und mehrfache Bearbeitung gefunden. Der Endzweck der Studien ist natürlich im letzteren Fall ein anderer als in den beiden ersteren, indem man dort nach Mitteln sucht, die Krankheit zu bekämpfen, hier dagegen, sie möglichst zu verbreiten.

Im folgenden sollen die wichtigsten epidemischen Insektenkrankheiten kurz geschildert werden. Wenn ich dabei nach der Art der Erreger resp. nach besonders hervorstechenden Symptomen einige Kategorien aufstelle, so 
können diese vorläufig nur provisorischen Charakter haben, da die Ätiologie von manchen Krankheiten noch nicht völlig klargestellt ist. Wir wollen hier sprechen a) von den Bakterienkrankheiten, b) von den Nosema-Seuchen und c) von den Polyederkrankheiten.

\section{a) Bakterienkrankheiten.}

Hierher gehören die Faulbrut der Bienenlarven, ferner die Schlaffsucht (oder Flacherie) und vielleicht auch die Schwindsucht der Seidenraupe und endlich die Heuschreckenpest.

Die „Faulbrut" ist die gefürchtetste Brutseuche, welche der Imkerei enorme Verluste zufügt (in Amerika wird der Schaden auf 8 Millionen Mark jährlich geschätzt), und welche in der letzten Zeit eine von Jahr zu Jahr steigende Verbreitung erfahren hat. Die Faulbrut tritt in zwei verschiedenen Formen auf, die als "amerikanische Faulbrut" oder „Brutpest" und als „europäische Faulbrut“ oder kurzweg „Faulbrut" unterschieden werdeı. Die beiden Formen zeigen in ihren Symptomen viel Ähnlichkeit, insofern als die davon befallenen Larven nach kürzerer oder längerer Zeit ihre äußere Form verlieren und sich zu unförmigen gelblichen bis bräunlichen Massen auflösen. Andererseits fehlt es auch nicht an guten differentialdiagnostischen Merkmalen, die eine einigermaßen sichere mikroskopische Unterscheidung ermöglichen: so sind die zerflossenen Larvenmassen bei der Bıutpest breiartig bis schleimig und verbreiten einen ekelhaften, an alten Käse oder Fußschweiß erinnernden Geruch, während sie bei der Faulbrut mehr gummiartig sind und einen wenig auffallenden Geruch besitzen. Als Erreger der Brutpest ist der von dem amerikanischen Bakteriologen White entdeckte Bacillus larvae anzusehen. Bezüglich der europäischen Faulbrut sind die Meinungen noch nicht völlig einig; während man auf der einen Seite den von Chesire und Cheyne entdeckten Bacillus alvei (allerdings im Verein mit Streptococcus apis) für die Ursache dieser Seuche hält, wird dies von White stark bezweifelt. Es ist ihm jedenfalls niemals gelungen mit Reinkulturen dieses Bazillus die Krankheit zu erzeugen, außerdem konnte er denselben in einer Anzahl typisch faulbrutkranken Larven überhaupt nicht feststellen. Dagegen fand White einen anderen Bazillus, Bacillus pluton, der in faulbrutkranken Larven niemals fehlte und mit dessen Reinkulturen auch positive Infektionsversuche ausgeführt werden konnten, so daß aller Wahrscheinlichkeit nach in ihm der eigentliche Erreger der europäischen Faulbrut zu erblicken ist. -- Die beiden Formen der Faulbrut sind sehr ansteckend und können sowohl durch alte Gerätschaften, als auch durch Futterhonig, als sogar auch durch nackte Völker und Königinnen (die mitunter in ihrem Darmkanal zahlreiche Krankheitskeime beherbergen) verbreitet werden. Es ist daher größte Vorsicht mit tremden Imkern und peinlichste Reinlichkeit im eigenen Betriebe dringend geboten, wenn dem weiteren Fortschreiten der verheerenden Krankheit Einhalt geboten werden soll ( $Z$ ander).

Die „Schlaffsucht" (Flacherie, italienisch: Flaccidezza) gilt heute, nachdem die Pebrine (siehe unten) ihre Schrecken verloren, als die verderb- 
lichste Krankheit der Seidenraupe, welche dem Seidenzüchter den meisten Schaden anrichtet. Sie tritt in der Regel unmittelbar vor der Spinnreife plötzlich und verheerend auf. Die Symptome der Schlaffsucht schildert Bolle folgendermaßen: Wenn sich die Häutungen zu sehr in die Länge ziehen, wenn unter den frisch gehäuteten und umgebetteten Raupen kleinere angetroffen werden, welche ungern fressen und die Häutung noch nicht begonnen haben, und wenn schließlich besonders nach der vollzogenen dritten oder vierten Häutung auf dem alten Bette schlaffe oder bereits tote Raupen gefunden werden, da kann der Seidenzüchter von seiner Aufzucht nur das schlimmste erwarten. Es geschieht dann, und zwar vor der Einspinnung, daß die scheinbar noch gesunden Raupen, deren After allerdings von einer braunen Materie beschmutzt ist, vorerst das Futter verschmähen, über die Betten umherirren, um sich zu den Hürdenrändern zu begeben, wo sie mit dem Kopf nach außen gerichtet, unbeweglich bleiben. Dabei wird der Körper immer länger und schmäler und derart weich und schlaff, daß, wenn man eine kranke Raupe mit den Fingern ergreift, dieselbe wie ein leerer Sack herabhängt. Wenige Stunden darauf ist die Raupe schon tot, der mittlere Teil des Körpers bräunt sich allmählich und binnen 12 Stunden wird der ganze Körper schwarz, die inneren Organe verwandeln sich in eine schwarzbraune stinkende Jauche, die bei der geringsten Verletzuug der Haut ausrinnt. Beim Betreten des Zuchtlokales, in welchem die Schlaffsucht ausgebrochen ist, spürt man sofort einen eigentümlichen ungemein widerlichen Geruch. - Als Erreger der Schlaffsucht wird von Bocchia ein Bazillus angesprochen, der in gewissen Charakteren dem oben (bei der Faulbrut) genanten Bac. alvei, ferner auch dem Bac. mesentericus, subtilis usw. ähnelt, ohne aber mit einem derselben identifiziert werden zu können. Es ist Bocchia gelungen, mit Reinkulturen dieses Bazillus die Schlaffsucht experimentell zu erzeugen.

Die Schlaffsucht ist auferordentlich ansteckend, so daß gewöhnlich die ganze Aufzucht dahingerafft wird und der unglückliche Seidenzüchter gezwungen ist, seine Raupen gerade in dem Augenblick, in dem sich dieselben hätten einspinnen sollen, wegzuwerfen. - Es wird angenommen, daß diese Krankheit vorzugsweise in Jahrgängen mit ungünstigen Witterungsverhältnissen auftritt. Doch ist zweifellos die Schlaffsucht unter solchen Aufzuchten besonders häufig, denen man nicht die nötige Sorgfalt angedeihen läßt. $\mathrm{Ob}$ die Schlaffsucht erblich ist, ist bis jetzt wissenschaftlich noch nicht festgestellt.

Der Name Schlaffsucht oder Flacherie wurde bisher kritiklos auf ziemlich alle seuchenartig auftretenden Raupenkrankheiten angewandt; so wird $z$. $B$. die Wipfelkrankheit der Nonne oder die "Wilt" des Schwammspinners häufig noch als Flacherie bezeichnet. Nachdem uns aber durch die neueren Forschungen einige sichere differentialdiagnostische Merkmale an die Hand gegeben sind $(z$. B. Auftreten von „Polyedern" bei der Wipfelkrankheit, Fehlen von solchen bei der Flacherie), so ist der Name Schlaffsucht oder Flacherie nur auf solche Krankheiten zu beschränken, die ätiologisch und symptomatisch mit der Seidenraupenflacherie übereinstimmen. ${ }^{1}$ ) Da bis jetzt nur in den

1) Vgl. darüber auch Wahl, Bruno, Über die Polyederkrankheit der Nonne I. Zentralbl. f. d. ges. Forstwesen 1910. 
wenigsten Fällen darauf geachtet ist, so können wir den Angaben über das Vorkommen der Flacherie bei den verschiedenen Raupenarten nur bedingten Wert beilegen. Immerhin erscheint es nach den vorliegenden Angaben doch recht wahrscheinlich, daß die echte Schlaffsucht eine weitere Verbreitung unter den Insekten hat.

Die „Schwindsucht“ stelle ich nur mit einem gewissen Vorbehalt zu den Bakterienkrankheiten, da der Nachweis, daß Spaltpilze die Ursache der Krankheit sind, noch nicht sicher erbracht ist. Wenn ich sie trotzdem hier im Anschluß an die Schlaffsucht bespreche, so geschieht dies deshalb, weil von manchen Seiten die Schwindsucht mit der Schlaffsucht in gewisse Beziehungen gebracht wird. Die Symptome der Schwindsucht sind allerdings gänzlich verschieden von denen der Schlaffsucht, wie aus der folgenden Beschreibung Bolles hervorgeht: „Schwindsüchtige Raupen“ sind nur während der Häutungen und nach denselben, nicht aber zur Zeit der Spinnreife zu beobachten. In einer von der Schwindsucht befallenen Aufzucht bemerkt man, daß die Raupen nach der dritten oder vierten Häutung nur unregelmäßjg und langsam erwachen, während sie sonst normal aussehen. Allmählich verlieren sie die Freßlust und irren unruhig in den Käfigen umher; dabei wird ihre Haut durchsichtig, ohne jedoch weiß oder blässer zu werden. Bald darauf fließt aus dem Mund und After der Raupen eine klare Flüssigkeit heraus, welche sich an der Luft schwärzt. In diesem Zustande verbleiben die Raupen mehrere Tage, ohne dabei an Körpergröße zuzunehmen; ja sie werden immer kleiner und sterben endlich ab. Der Tod tritt also nicht so plötzlich, wie bei der Schlaffsucht ein; auch zersetzt sich die Raupe nach dem Tode nicht, sondern trocknet vollständig aus und erhält eine erdbraune Farbe. Die Schwindsucht ist keine so gefährliche Krankheit wie die Schlaffsucht, wenn sie auch gelegentlich ganze Aufzuchten zugrunde richten kann.

Die Ursache der Krankheit ist noch nicht sicher festgestellt; es scheint indeß, daß ein Micrococcus dabei im Spiele ist. Der Schwindsucht folgt in den Züchtereien sehr häufig die Schlaffsucht, so daß manche Autoren, wie schon gesagt, der Ansicht zuneigen, daß unter diesen beiden Krankheiten eine gewisse Beziehung besteht. Ja einige behaupten sogar, daß die erstere nur eine besondere mildere Form der zweiten sei. -

Die „Heuschreckenpest“ wurde erst vor wenigen Jahren entdeckt, und zwar unter den Wanderheuschrecken Mexikos. Sie äußert sich in einem rapiden Massensterben der Heuschrecken. Als Ursache dieser Krankheit wurde von F. d'Herelle ein kurzer Bazillus, Coccobacillus acridiormm, festgestellt, der sich stets im Darmkanal der erkrankten Tiere, beinahe in Reinkultur sich vorfand. D'Herelle züchtete den Bazillus in Bouillion, in der er sehr gut gedieh, und machte damit Infektionen, die stets von Erfolg begleitet waren; d. h. alle infizierten Heuschrecken starben innerhalb 1-23 Stunden an den typischen Erscheinungen der Heuschreckenpest. - Der Bazillus verliert allerdings rasch seine Virulenz: die erste Kultur tötet per os in 8 bis 24 Stunden, die 2. in $12-36$, die 3 . in $36-39$, die 4 . Kultur läßt bereits die Mehrzahl der infizierten Tiere überlebend, und die 10. hat überhaupt gar 
keine Wirkung mehr. Wenn die leichter befallenen Tiere die Krankheit überstanden haben, so eriangen sie eine Immunität gegen den Coccobazillus. In welcher Weise die Heuschreckenpest event. zur Bekämpfung rerwendet werden kann, darüber wird im nächsten Kapitel noch einiges erwähnt werden.

Ein ganz ähnlicher Coccobazillus wurde neuerdings von F. Picard und G. R. Blanc als der Erreger einer schweren Seuche unter den Bärenraupen (Arctia caja) festgestellt. Die befallenen Raupen werden vor ihrem Tode schlaff und erregen einen ekelhaften Geruch; ihr Darm ist von einer klaren Flüssigkeit, die oft vollständig frei von Bakterien ist, erfüllt. Dagegen enthält das Blut beinahe Reinkulturen des betr. Coccobazillus. Es gelang, mit Bouillionkulturen des letzteren durch Infektion gesunder Raupen die geschilderten Symptome hervorzurufen. Die infizierten Raupen starben regelmäßig in 3 Tagen bei $15^{\circ} \mathrm{C}$., bei höheren Temperaturen erfolgte der Tod schon nach 12 bis 25 Stunden. Infektionsversuche mit anderen Insekten ergaben teils positive Resultate (z. B. bei Liparis chysorrhoea), teils negative (bei verschiedenen Käfern und Wanzen usw.).

\section{b) Nosema-Krankheiten (Pébrine).}

Die Nosema-Seuchen werden durch Nosema-Arten verursacht, d. s. Protozoen, die zu den Mikrosporiden, einer Unterordnung der Sporozoen, gehören. Die Nosema sind sämtlich Zellschmarotzer, die ihre Entwicklung in den Zellen des Wirtes und auf Kosten derselben durchmachen.

Charakteristisch für Nosema (wie für alle Microsporidien) sind (nach Doflein) die Sporen (die Cornaliaschen Körperchen der Seidenzüchter) die von klappenförmigen Schalen umhüllt sind und im Innern außer dem

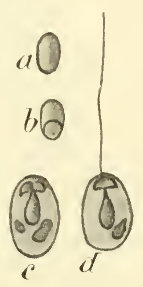
Keimling eine oder mehrere „Polkapseln“ beherbergen

(Fig. 210). Die Polkapseln erinnern in ihrem Bau sehr an die Nesselkapseln der Coelenteraten. Sie bestehen aus einem etwa birnförmigen Körperchen, welches am verschmälerten Ende in einem langen Faden verlängert ist. Dieser Faden ist in das Innere der Kapse]n handschuhfingerartig eingestülpt und an der Wand derselben spiralförmig aufgewickelt. Bei der Einwirkung gewisser Reagentien, besonders im Darmsaft des infizierten Wirtes, werden die Fäden der Polkapseln ausgeschnellt, und auf diese Weise wird die Spore an der Darmwand fixiert, worauf sie in zwei Schalenhälften auseinanderklafft und den "Amoeboidkeim“ entläßt. Letzterer durchbohrt die Darmcuticula, und bleibt entweder in den Darmepithelzellen oder gerät in irgend welche andere Organe. In den Zellen wachsen sie auf Kosten des Zelleibes rasch heran und vermehren sich, indem sie in zahlreiche Teilstïcke zerfallen. Da sich aber die Teilstücke meistens zunächst nicht roneinander lösen, so entstehen lange ketten- oder pilzartige Gebilde, die zahlreiche hintereinander gereihte Kernstücke bergen. Indem dieser Prozeß ununterbrochen fortschreitet, so bilden sich ganze Haufen, förmliche Nester von solchen Ketten, die von der zerstörten oder verflüssigten Zellsubstanz umschlossen werden 
(Fig. 211). Die Vermehrungsvorgänge spielen sich sehr rasch ab, so daß bereits in wenigen Tagen ein großer Teil der Zellen des Körpers von den Parasiten befallen sein können. Sobald nun die Ernährungsverhältnisse ungünstiger werden, zerfallen die Ketten in zahlreiche einzelne Stücke, aus denen nach mannigfaltigen Unwandlungen und Abscheidung einer derben Schale die Sporen sich entwickeln, von denen wir ausgegangen sind (Zander).

Von den vielen beschriebenen Nosema-Arten interessiert uns hier vor allem Nosema bombycis Naegeli, der Erreger der Pébrine (Gattina, Fleckenkrankheit) der Seidenraupe. Die Pébrine war früher eine der

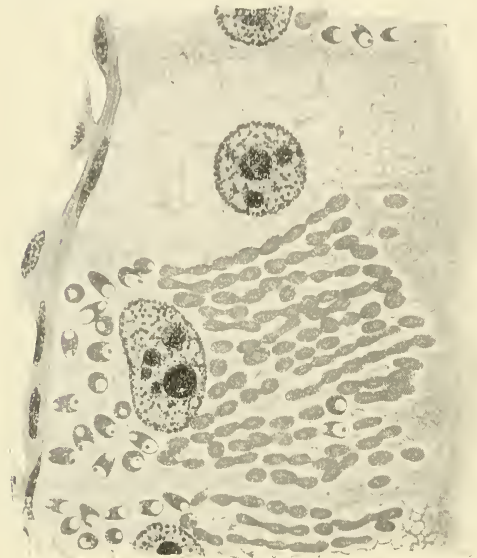

Fig. 211. Nosema bombycis Naeg. Darmepithel einer Seideuraupe mit Sporen und den eigenartigen, pilz. ähnlichen, agamen Fortpflanzungsketten. Vergr. 1100. (Nach Stempell aus Doflein.) verlustbringendsten Seidenraupenkrankheiten, sie hat aber heute infolge der Pasteurschen Separationsmethode (siehe unten) ihre Schrecken verloren.

Die äußerlich erkennbaren Symptome der Pébrine sind nach Bolle folgende: $\mathrm{Zu}$ nächst fällt die große Ungleichheit der aus einer Zucht stammenden Raupen auf, ferner die Unregelmäßigkeit in den Häutungen, die soweit gehen kann, daß, während ein Teil der Raupen die alte Haut bereits verlassen hat, der übrige Teil entweder noch schläft oder gar die Häutung noch nicht begonnen lat. Die letztere, die sog. "Spätlinge" sind es, welche zuerst der Krankheit zum Opfer fallen. Nach der dritten oder vierten Häutung bedeckt sich die Haut mit sehr kleinen nahezu punktförmigen, mitunter aber auch größeren verschieden geformten Flecken, mit verschwommenen Rändern, welche über den Körper der Raupen unregelmäßig verteilt sind (daher der Name „Fleckenkrankheit"). Hat die Krankheit ihr letztes Stadium erreicht, so verschmäht die Raupe das Futter völlig, der Körper schrumpft zusammen und wird immer kleiner, und schließlich stirbt sie ab. Nicht immer führt die Krankheit zum Tode, sondern schwächer infizierte Raupen können sich verpuppen und sogar noch den Falter ergeben; diese sind aber dann ebenfalls mit Parasiten besetzt, und zwar sind meistens alle Organe, einschließlich der Geschlechtsorgane befallen. Von letzteren auswerden auch die Eier infiziert und so die Krankheit auf die Nachkommen übertragen. Aus den sporenhaltigen Eiern entwickeln sich schwächliche kleine Raupen, welche gewöhnlich früh sterben; aber mitlerweile können sie Hunderttausende von anderen Raupen infiziert haben, denn die Haupt- 
infektionsquelle bildet der auf den Maulbeerblättern liegende Kot. — So kann die Epidemie mit großer Schnelligkeit über die seidenzüchtenden Bezirke eines Landes sich verbreiten (Doflein).

In Frankreich brach die Epidemie zuerst im Jahre 1845 im Departement Vaucluse aus, im nächsten Jahre hatte sie schon drei weitere Departements ergriffen. Schon im Jahre 1851 war in den wichtigsten Distrikten der Seidenbau fast vernichtet; im Jahre 1856 war die Produktion auf $1 / 4$ der üblichen Ziffer gefallen. Im Jahre 1854 wurde Italien von der Seuche ergriffen, die bald von einem Ende bis zum anderen sich ausbreitete. Die französische Seidenkultur hatte bis zum Jahre 1867 einen Verlust von mehr als einer Milliarde erlitten, gewiss ein Beweis von der wirtschaftlichen Bedeutung dieser Sporozoeninfektion (Doflein).

Um die Erforschung der Krankheit haben sich besonders Pasteur und Balbiani verdient gemacht. Vor allem hat sich ersterer unsterbliche Verdienste um die Seidenzucht erworben, indem er die speziellen Bedingungen der Krankheit studierte und den Züchtern einen Weg zeigte, wie sie dem Ausbruch der Krankheit vorbeugen können, nämlich das Samenbereitungsverfahren nach dem "Zellensystem", welches heute in allen im Seidenbau vorgeschrittenen Ländern eingeführt ist.

Es ist ein überraschend einfacher Gedanke, der diesem „Zellensystem“ zugrunde liegt: Es werden die einzelnen Schmetterlingspaare in kleinen Säckchen aus Tüll oder aus pergamentartigem, durchlöchertem Papier isoliert und nach erfolgter Eiablage dahin untersucht, ob sie gesund sind oder nicht. Nur die von gesunden Eltern herstammenden Nosema-freien Eier werden behalten und zur Nachzucht benutzt, während die übrigen weggeworfen, resp. verbrannt werden. Wenn diese Separationsmethode mit der nötigen Sorgfalt durchgeführt wird, so kann man sich mit ziemlicher Sicherheit vor der Krankheit schützen.

Übrigens verursacht das Vorkommen von Nosema in der Raupe nicht imner das oben geschilderte Krankheitsbild; es können vielmehr die davon befallenen Raupen auch recht gesund bleiben. „So sollen nach Bolle in Japan die dortigen Aufzuchten durch Nosema nicht fühlbar zu leiden haben, obschon die Verseuchung so allgemein ist, daf nosemafreie Raupen nur schwer aufzutreiben sind. Stempell hält es daher für wahrscheinlich, daß die japanischen Seidenraupenrassen eine größere Immunität gegen den Schmarotzer bewahrt haben, als die europäischen. Demgegenüber ist indessen zu bemerken, daß - wie auch Bolle hervorhebt - die Pébrine in Japan zuweilen dasselbe Unheil unter den Raupen anrichtet wie in Europa" (Maßßen). Es scheint demnach, daß auch die Pébrine ebenso wie die Polyederkrankheiten zu ihrer Entwicklung eine besondere Disposition der Raupen fordert.

Nosema bombycis ist nicht nur auf die Seidenraupe beschränkt, sondern ist auch noch bei einer ganzen Anzahl anderer Raupen beobachtet worden (Arctia caja, Gastropacha neustria, Saturnia pernyi usw.).

Nach StandfuB (Handbuch der palaearkt. Großschmetterlinge) kommt die Pébrine sowohl bei Rhopaloceren (IVanessa polychloros, io, antiopa) als bei Sphingiden (Deilephila euphorbiae) und bei Spinnern vor; von letzteren nennt er popupli, neustria, lanestris, quercus, pini u. a. Bezüglich der äuBeren Symptome gibt Standfuß folgende Anhaltspunkte: Größere Haarraupen tragen in ihrer Färbung in der Regel keine deutlichen Anzeichen der Krankheit, nur der After ist feucht und die Haare in dessen Nähe sind zusammengeklebt. Raupen ohne Haarkleid dagegen verändern ihre Farbe meist sehr deutlich, indem grüne Raupen gelblich werden und häufig dunkle 
Flecken erhalten, und bunte Raupen die Lebhaftigkeit ihrer Färbung verlieren; außerdem zeigt sich am After stets eine gelbliche schmutzige Materie in Tropfen oder angetrocknet. Für diejenigen Individuen, welche zur Verpuppung kommen, ist besonders charakteristisch, daß an der Puppenspitze das Afterende der Raupen festhaften bleibt und der ausschlüpfende Falter am Afterende meist verklebt und unsauber, auch sehr oft in den Flügeln und in den Füßen nicht vollkommen ausgebildet ist; ferner im weiblichen Geschlecht trotz vielleicht großen Leibesumfanges gewöhnlich nur einen sehr spärlichen Eivorrat enthält.

Außer dem Nosema bombycis sei hier noch eine zweite Art genannt, welche ebenfalls in wirtschaftlicher Hinsicht eine bedeutungsvolle Rolle zu spielen scheint: nämlich Nosema apis, welches von seinem Entdecker Zander als der Erreger der sog. „ansteckenden Ruhr“ der Bienen gehalten wird.

Das wesentlichste Kennzeichen dieser Krankheit ist das massenhafte plötzliche Absterben der Bienen innerhalb und außerhalb der Beute. Die Bienen werden unruhig, lösen sich vom Winterknäuel, fallen von den Waben auf das Bodenbrett, und kriechen aufgeregt und ängstlich mit mehr oder weniger aufgetriebenem Hinterleib zum Flugloch heraus. Flugunfähig fallen sie zu Boden, sammeln sich an Grashalmen und Erdklumpen, um nach längerer oder kürzerer Zeit zu verenden. Manchmal ist die Krankheit von starker Kotentleerung und Schmutzerei begleitet, doch ist dies durchaus kein notwendiges Symptom.

Nosema apis kommt in allen ruhrkranken Bienen vor; befällt jedoch - im Unterschied zu dem Pébrine-Nosema - nicht alle Organe, sondern ist auf den Mitteldarm beschränkt, dessen Zellen dicht mit den Sporen angefüllt sind. Die Anhäufung von Milliarden dieser hellglänzenden Sporen verleiht dem Darm ein vollkommen milchigweißes Aussehen, welches im deutlichen Kontrast zu dem rötlich oder bräunlich gefärbten gesunden Bienendarm steht und ein untrügliches Kennzeichen der Krankheit abgibt. - Die Ruhr ist sehr ansteckend, wird jedoch, wie es scheint, im Gegensatz zur Pébrine, nicht durch die Eier auf die Nachkommen übertragen.

Nachdem Zander das Nosema apis entdeckt und in allen untersuchten ruhrkranken Bienen festgestellt hatte, war es - besonders im Hinblick auf die Bedeutung des verwandten Nosema bombycis für die Pébrine - naheliegend genug, in demselben den Erreger der ansteckenden Ruhr zu erblicken. Wenn nun neuerdings $Z$ weifel in dem von $Z$ ander angenommenen Zusammenhang laut werden, so gehen diese dahin, ob das Nosema apis allein genügt, die typische Ruhr hervorzurufen. Und das scheint in der Tat nicht der Fall zu sein; denn es steht heute fest, daß das Nosema auch bei anscheinend ganz gesunden Völkern vorkommt, ja daß es in den meisten Bienenvölkern zu finden und daß es „in Deutschland wohl nur wenige Bienenstände gibt, in den die Völker völlig frei davon sind". „Fast immer ließen sich in den Völkern, selbst in schwach befallenen, Bienen auffinden, die die Sporen der Parasiten in solch ungeheueren Mengen enthielten, wie bei der akuten Form der Krankheit" (MaAen). - Wir haben hier eine Analogie mit dem Vorkommen von Nosema bombycis in ganz gesunden japanischen Raupen, von dem oben berichtet wurde; es scheint also, daß auch hier der Parasit nur dann eine stärker schädigende Wirkung auf den Wirt hervorzurufen vermag, wenn eine gewisse Disposition vorhanden ist. Es ist auch möglich, daß noch andere Mikroorganismen dazukommen müssen, wenn die typische Ruhr entstehen soll; doch auch in diesem Fall wird dem Nosema eine gewisse Anteilnahme an der Erzeugung der Kıankheit nicht abzusprechen sein.

Außer den Nosema-Arten finden wir noch ein großes Heer anderer Protozoen als Schmarotzer bei Insekten; es sei nuı an jene Formen 
erinnert, welche durch Insekten auf Menschen oder Säugetiere übertragen werden, wie z. B. die Malariaparasiten (Haemosporidien), welche in der Stechmücke einen Teil ihrer Entwicklung durchmachen, oder an den Erreger der Schlafkrankheit (Trypanosoma), der in der Tse-Tse-Fliege schmarotzt, ferner an die zahlreichen Gregarinen, Cocciden und Amoeben, die bei Insekten vorkommen usw.; jedoch in den meisten dieser Fälle haben die Wirtsinsekten nur wenig unter den Parasiten zu leiden, oder wenn sie auch schließlich erkranken und event. auch daran zugrunde gehen, so kommt es doch selten zu größeren Epidemien, die ein Massensterben zur Folge haben und infolgedessen von einem wesentlichen Einfluß auf die Vermehrungsgröße der Insekten sein könnten. Es ist daher hier nicht der Platz, näher auf diese Schmarotzer einzugehen.

\section{c) Polyederkrankheiten. ${ }^{1}$ )}

Während von den bisher besprochenen Krankheiten die Erreger mehr oder weniger sicher festgestellt sind, tappen wir bezügl. des Erregers der Polyederkrankheit noch ziemlich im dunkeln.

Die Polyederkrankheiten sind scharf charakterisiert durch das Auftreten von sog. "Polyedern" in den Geweben und dem Blut der Insekten (Fig. 212). Unter Polyedern verstehen wir mikroskopisch kleine (1-12 u), stark lichtbrechende, kristallähnliche Körperchen, die teilweise je nach der befallenen Insektenart verschiedene Formen (Tetraeder, Rhombendodekaeder, Oktaeder) aufweisen, und zuerst als vereinzelte winzige Individuen in den Kernen der Blut- und Gewebezellen (vor allem den Zellen der Tracheenmatrix und des Fettgewebes) in Erscheinung treten, dann immer zahlreicher und zugleich größer werden, bis die mächtig aufgetriebenen Kerne prall von ihnen erfüllt sind, und schließlich platzen, so daß die Polyeder frei in der Blutflüssigkeit schwimmen. Beim Fortschreiten der Krankheit werden sämtliche Gewebe auf diese Weise zerstört, so daß das befallene Insekt schließlich zu einem jauchigen Brei zerfließt, in welchem dichte Mengen von Polyedern in allen Größen schwimmen.

Die Dauer der Krankheit ist sehr verschieden lang und hängt wesentlich von der Widerstandsfähigkeit der befallenen Raupen resp. von äußeren Einflüssen ab. Sie kann sich einerseits mehrere Wochen hinziehen, so daß die befallenen Raupen sich noch verpuppen und sogar Falter geben können, sie kann aber andererseits auch schon in 8-10 Tagen zum Tode führen. Escherich und Miyajima beobachteten bei künstlich infizierten Nonnenraupen die ersten Polyeder am 3.-5. Tage nach der Infektion. Die Polyeder sind in diesem Stadium sehr spärlich, sehr klein und ausschließlich in den Kernen der Blutzellen anzutreffen. Nach weiteren $3-4$ Tagen sind diese intranucleären Polyeder größer und auch zahlreicher, indem etwa $5-10 \%$ der Blutzellen davon befallen sind, und zwar die meisten mit mehreren Polyedern (Fig. 213). Wieder nach einigen Tagen findet man $10-20 \%$ der Blutzellen mit mehr oder weniger zahlreichen Polyedern besetzt, und neben diesen intracellulären die ersten freien in der Blutflüssigkeit. Auf diesem „mittleren“ Befall kann die Krankheit längere Zeit ziemlich un-

$\left.{ }^{1}\right)$ Der Name „Polyederkrankheit“ wurde von Br. Wahl eingeführt. 
verändert stehen bleiben, ja die Polyeder können sogar wieder weniger werden. In den meisten Fällen aber schreitet die Kranheit weiter: die intracellularen und die freien Polyeder werden immer zahlreicher und größer, so daß bald die Hälfte der Blutzellen und mehr dicht mit ihnen erfüllt sind und außerdem auch in der Blutflüssigkeit massenweise freie Polyeder herumschwimmen. Ist die Krankheit einmal soweit fortgeschritten, so geht es rapid zu Ende, in wenigen Tagen oder Stunden tritt die allgemeine Verjauchung ein.

Wir können also eine leichte, resp. chronische und schwere oder akute Form der Polyederkrankheit unterscheiden. Für die Art des Verlaufes scheinen äußere Einflüsse von großer Bedeutung zu sein, so be-
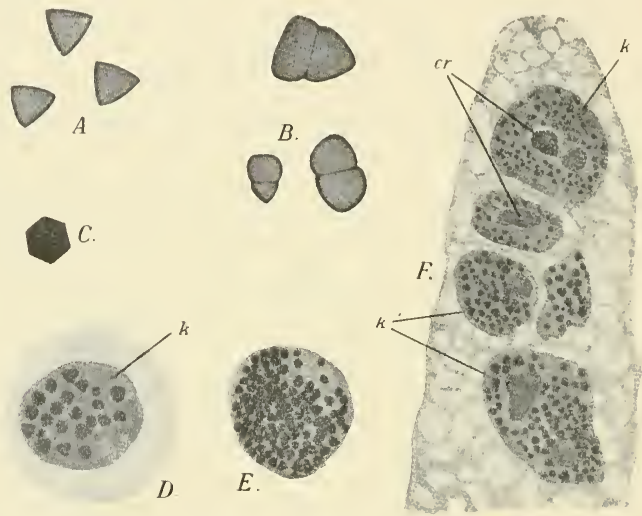

Fig. 212. A Umriß der Polyeder wipfelkranker Nonnenraupen $(\times 2000) ; B$ Doppelpolyeder aus Nonnenpuppen; $C$ Umriß von Polyedern gelbsüchtiger Seidenraupen $(\times 1300) ; D$ Blutzelle, deren Kern mit Polyedern erfüllt ist; $E$ Ausgestoßener Zellkern mit Polyedern; $F$ Schnitt durch einige Fettzellen, deren Kerne $(k)$ mit Polyedern erfüllt sind; or Chromatinreste. Nach W a hl.

obachteten Escherich und Miyajima, daß bei Raupen mit mäßigem Befall sofort eine rapide Vermehrung der Polyeder eintrat, wenn die Raupen kurze Zeit (es genügten mitunter zwei Stunden) der prallen Sonne ausgesetzt wurden. Ähnliches ließ sich durch Behandlung mit Kälte erzielen, und nach den Angaben Sasakis scheinen auch noch andere Einflüsse, wie die Einwirkung von Formalin und Kampferdämpfen, die Krankheit zu beschleunigen. Wenn in dieser Beziehung auch noch manches aufzuklären sein wird, so scheint doch so viel festzustehen, daß äußere Einflüsse eine hervorragende, ja entscheidende Bedeutung für den Verlauf der Polyederkrankheit besitzen können, indem es von ihnen zum großen Teil abhängt, ob die Krankheit latent bleibt oder in das akute Stadium übergeht Es dürfte sich hierbei wohl hauptsächlich um solche Einwirkungen handeln, welche die Lebensenergie resp. die Widerstandsfähigkeit der Raupen gegen das Virus herabzusetzen imstande sind.

Was die äußerlich sichtbaren, makroskopischen Symptome betrifft, so sind solche im Anfangsstadium der Krankheit, so lange der Polyeder- 
befall die mittlere Höhe nicht überschritten hat, überhaupt nicht festzustellen; die betreffenden Raupen machen vielmehr einen völlig gesunden Eindruck, zeigen eine ungeschwächte Freßlust, häuten sich in normaler Weise usw. Erst im vorgeschrittenen Stadium treten äußere Anzeichen auf, die zunächst in einer Veränderung der Haut (Verfärbung, Änderung des Glanzes, Schadhaftwerden der Beborstung usw.) und in einer immer mehr zu Tage tretenden Freßunlust sich kund tun. Des weiteren werden die Tiere vollkommen schlaff, wobei sie meist eine ganz charakteristische Stellung einnehmen; sie haften nur noch mit einem Paar Bauchfüße an der Unterlage fest, so daß die beiden Hälften der Raupe schlaff herabhängen. - Außerdem kommen bei verschiedenen Raupenarten noch besondere Eigentümlichkeiten dazu, die die Diagnose der Krankheit wesentlich erleichtern; so haben z. B. die polyederkranken Nonnenraupen (wenigstens wenn sie auf Fichte leben) die Gewohnheit, vor dem Verenden die Wipfel der Bäume zu erklettern, so daß
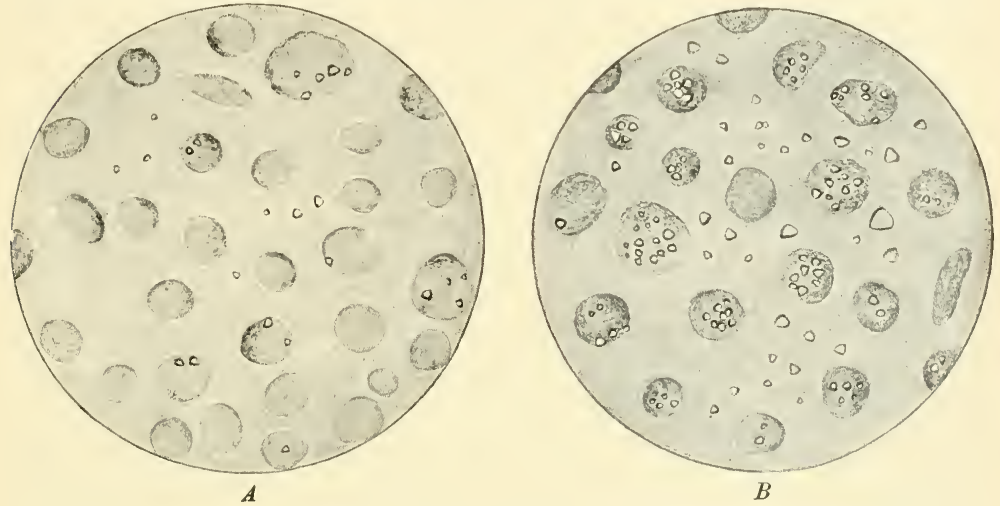

Fig. 213. Nonnenblut mit mittlerem $(A)$ und starkem $(B)$ Polyederbefall. Nach Escherich und Miyajima.

sich hier oft große weithin sichtbare Klumpen von Raupen bilden, was ja auch dazu geführt hat, die Polyederkrankheit der Nonne als „Wipfelkrankheit“ zu bezeichnen.

Wenn nun auch der Kundige nach den äußeren Symptomen in den meisten Fällen, wenigstens bei vorgeschrittener Krankheit, die richtige Diagnose zu stellen vermag, so ist trotzdem zu empfehlen, stets, wenn der Verdacht auf die Krankheit vorliegt, die mikroskopische Untersuchung auf Polyeder vorzunehmen, die einerseits durchaus nicht schwierig ist und andererseits der Diagnose eine absolute Sicherheit verleiht - abgesehen davon, daß die mikroskopische Untersuchung das Vorhandensein der Krankheit schon in einem weit früheren Stadium ermöglicht als die bloße makroskopische Beobachtung.

Die Polyederkrankheit ist, wie durch die verschiedentlich angestellten einwandfreien Infektionsversuche der letzten Zeit bewiesen ist, eine an steckende Krankheit, und zwar kann das Virus sowohl durch Injektion, 
als auch das Futter übertragen werden; ob durch die Luft, ist noch nicht erwiesen. Es scheint indes die Ansteckungsenergie keine allzu große zu sein, und vor allem auch stark von der Disposition der Raupen abzuhängen.

Über die Natur des Virus herrscht heute noch keine volle Klarheit und es stehen sich in dieser Beziehung zwei grundsätzlich verschiedene Meinungen gegenüber: die eine nimmt an, daß die Polyeder selbst die Erreger, also echte Parasiten seien, während nach der anderen Meinung die Polyeder lediglich Reaktionsprodukte, also eine Begleiterscheinung der Krankheit darstellen, und die eigentlichen Erreger in anderen Organismen zu suchen wären.

Die erste Meinung wird in der bestimmtesten Form von Bolle vertreten, welcher die Polyeder als Mikrosporidien auffaßt und ihnen auch den Namen Microsporidium polyedricum beilegt. Zur Bolleschen Anschauung neigen ferner hin Marzocchi, der nach seinen mikroskopischen Befunden die Parasitennatur der Polyeder nicht ohne weiteres von der Hand weisen möchte, dann Escherich und Miyajima, welche annehmen, da $\beta$ das Virus wenigstens in inniger Verbindung mit den Polyedern steht, und endlich E. Knoche, welcher in den Polyedern die Dauerform eines Mikrosporidiums erblicken möchte (von welcher Anschauung er aber in der neuesten Zeit wieder etwas abgekommen zu sein scheint).

Der zweiten Auffassung (Polyeder als Reaktionsprodukte) huldigen v. Tubeuf, Krassilschtschik, Glaser und Chapman, Prowazek, Wolff u. a. Welcher Organismus aber in diesem Falle als der Erreger in Betracht kommen würde, darüber sind die Meinungen unter den eben genannten Autoren noch recht geteilt: v. Tubeuf, Krassilschtschik, Glaser und Chapman nennen Bakterien als Erreger (Bacterium monachae, Micrococcus lardarius, Gyrococcus); Prowazek dagegen hält Chlamydozoen für die Ursache der Krankheit, und Wolff glaubt, daß Chlamydozoen und Bakterien in gemeinsamen Zusammenwirken die Krankheit hervorrufen.

Chlamydozoen stellen winzige, von einer gallertigen Hülle umgebene Körperchen dar, welche sich durch Querteilung vermehren. Über ihre systematische Stellung und ihr biologisches Verhalten läßt sich bis jetzt noch gar nichts näheres aussagen. Sie sind noch viel kleiner als Bakterien und gehen daher auch durch die gebräuchlichen Bakterienfilter (Berkefeld) hindurch. Doch scheint bezüglich der letzteren Eigenschaft nach den neuesten Erfahrungen Prowazeks eine gewisse Einschränkung geboten, insofern als die Bakterienfilter sich durchaus nicht alle völlig gleich verhalten, sondern „jedes einzelne Filter im Hinblick auf das Filtrationsresultat ein Individuum, behaftet mit dem Stigma des Zufälligen“ darstellt, so daß also ein negatives Resultat mit Berkfeldfiltraten nicht ohne weiteres als Beweis gegen das Vorhandensein von Chlamydozoen gelten darf.

Aus dieser kurzen Übersicht lässt sich ersehen, wie unsicher unsere Kenntnisse über die Ätiologie der Polyederkrankheiten heute noch sind Es wird noch ein grosser Aufwand von Arbeit und Scharfsinn notwendig sein, um volle Klarheit darüber zu schaffen.

Die Polyederkrankheit scheint eine sehr weite Verbreitung unter den Insekten zu haben und wir kennen sie schon bei einer ganzen Anzahl von Arten, so bei der Nonne, wo sie als „Wipfelkrankheit" bezeichnet wird (näheres darüber im III. Bd. bei der Nonne), bei der Seidenraupe (unter den Namen "Gelb- oder Fettsucht" oder "Grasserie“), beim Schwammspinner und Goldafter (unter der englischen Bezeichnung „Wilt"), ferner beim Kiefernspanner, bei Deilephila, bei Saturnia, Harpyia und verschiedenen amerikanischen Spinnern, und fortwährend kommen neue Fälle hinzu. So fand sie neuerdings E. Fischer bei Smerinthus atlantica, Schwangart bei Conchylis ambiguella, Gough in Ägypten bei der dort so 
schädlichen Prodenia litosia (nach Bolle) und Escherich bei den Larven von Lophyrus rufus. Es scheint fast, als ob es sich um eine allgemeine Insektenkrankheit handelte, die bei einer gewissen Disposition der Raupen resp. Larven in Erscheinung tritt.

Wirtschaftlich kommt der Polyederkrankheit zweifellos eine nicht zu unterschätzende Bedeutung zu, weniger dadurch, daß sie den Seidenzüchtern Schaden zufügt (denn dieser ist im Verhältnis zu dem aus anderen Krankheiten entstehende Schaden selten ein erheblicher), als vielmehr dadurch, daß sie der Übervermehrung der Schädlinge entgegenarbeitet. Es liegen in dieser Beziehung eine ganze Reihe von Beobachtungen vor, nach denen Kalamitäten durch den Ausbruch der schweren Form der Polyederkrankheit ihr plötzliches Ende gefunden haben. Vor allem gilt dies von der Wipfelkrankheit der Nonne, die sowohl beim grossen bayerischen (1890 bis 1892) als auch bei dem jetzigen sächsischen und böhmischen Nonnenfraß die Kalamität in einigen Fällen tatsächlich beendet hat.

Andererseits muß davor gewarnt werden, die Wirkung der Polyederkrankheit zu überschätzen. Denn die Erfahrungen, die beim sächsischen und böhmischen Nonnenfraß gemacht wurden, lehrten, daß trotz eines wiederholten Ausbruches der Wipfelkrankheit die Kalamität fortdauern kann, indem eben die Seuche oft nur auf kleine Bezirke beschränkt bleibt und sodann auch durchaus nicht alle in diesen Bezirken befindlichen Raupen von der Krankheit dahingerafft werden. Jedenfalls ist die frühere Anschauung, die nach dem bayerischen Nonnenfraß sich herausgebildet hatte, daß nämlich die Krankheit, wenn sie einmal in einem Walde ausgebrochen ist, sich pestartig mit IVindeseile über den ganzen Wald verbreitet, durchaus ırrig. Zur Erzeugung der Krankheit gehört, wie auch die oben genannten Versuche gezeigt haben, nicht nur das Vorhandensein des Erregers, sondern vor allem auch eine geeignete Disposition der Raupen, die durch Hunger, schlechtes Futter, ungünstige klimatische Einflüsse und andere Faktoren hervorgerufen sein kann. Es ist doch auch eine oft beobachtete Erscheinung, daß die Wipfelkrankheit erst dann als schwere allgemeine Epidemie auftrat, wenn die Übervermehrung bereits einen sehr hohen Grad erreicht hatte, so daß es zu Kahlfraß gekommen war; dann waren eben sämtliche Raupen infolge Nahrungsmangels in ihrer Konstitution geschwächt und gaben nun einen geeigneten Boden für die Verbreitung der Krankheit ab. Man hat deshalb die Polyederkrankheiten, speziell die Wipfelkrankheit der Nonne und die "Wilt" des Schwammspinners auch als „Übervölkerungskrankheiten" bezeichnet.

Unsere Erfahrungen sind heute noch zu gering, um ein definitives Urteil über die wirtschaftliche Bedeutung der Polyederkrankheiten sich bilden zu können. Es wird die Aufgabe der zukünftigen Beobachtung, vor allem auch von Seiten der Praktiker, sein, über das Vorkommen der Krankheit bei den verschiedenen Schädlingen, über die Art ihres Auftretens und ihrer Verbreitung, über die Wirkung auf den Verlauf der Kalamitäten usw. möglichst reiches neues Tatsachenmaterial herbeizuschaffen. Dabei sei aber nochmals daran erinnert, daß Mitteilungen darüber nur dann wissenschaftlich verwertbar sind, wenn die Natur der Krankheit durch mikroskopische Untersuchung sicher festgestellt ist. 


\section{Literatur.}

1. A $11 \mathrm{gem}$ eines.

B a chmetjew, P., Experimentelle Entomolog. Studien. Sophia 1907.

Escherich, K., Die elementare Macht der Fortpflanzung. Beil. z. Allgem. Zeitung (München) 1907.

N ü Bl i n, O., Leitfaden der Forstinsektenkunde. 2. Aufl. 1912.

We is ma n n, A., Vorträge über Deszendenztheorie. Jena 1902.

\section{Wit t e r u ng se in $\mathrm{f} l$ üs s e.}

K n o c he, E., Nonnenstudien. Nat. Zeitschr. f. Forst- und Landw. 1912. S t a nd f u B, M., Handbuch der paläarkt. Großschmetterlinge. Jena 1896.

\section{Insektenvertilgende Tiere.}

\section{Säugetiere und Vögel.}

A $1 \mathrm{tu} \mathrm{m}$, B., Forstzoologie (2. Auf1.), I. und II.

- Parasitische Fortpflanzung und wirtschaftlicher Wert des Kuckucks. Ornith. Monatschr. 23. (1898).

Ba e r, W., Verschiedene Aufsätze in der Ornith. Monatschr. 1903, 1908, 1909 und 1910.

- Die Bedeutung der insektenfressenden Vögel für die Forstwirtschaft. „Aus der Natur" 1913.

B o a s, J. C. v., Dansk Forstzoologie. Kopenhagen 1898.

Borries, Herm., Verschiedene Aufsätze über schädliche Insekten in „Tidsr. f. Skovvaesen 1895 u. Entomol. Meddel 1896.

Cris p, siehe $\mathrm{T}$ a u ber.

H e in z e, K., Meisen- und Nonneneier. Nat. Zeitschr. f. Forst- u. Landw. 8. 1910.

$\mathrm{H}$ e n n i cke- $\mathrm{N}$ a u m a n n, Naturgeschichte der Vögel Mitteleuropas. Gera.

Le is ewitz, W., Verschiedene Aufsätze über die Nahrung der Vögel in: Verhandl. der Ornit. Gesellschaft Bayerns. 1904, 1905 u. 1906.

L i n k, J. A., Beobachtungen am Kuckuck. Ornith. Monatschr. 14. 1889.

Parrot, C., und Leise witz, W., Untersuchungen zur Nahrungsmittellehre der Vögel. Verhandl. der Ornit. Gesellschaft Bayerns. 5. 1904.

Rey und Reichert, Mageninhalt einiger Vögel. Ornith. Monatschr. 1908 u. 1910.

Rörig, G., Ansammlungen von Vögeln in Nonnenrevieren. Ornith. Monatschr. 24. (1899.)

- Magenuntersuchungen land- und forstwirtschaftl. wichtiger Vögel (mit einem Literaturverzeichnis als Anhang). Arb. der Biol. Abt. f. Forst- und Landwirtsch. 1. (1900.)

- Studien über die wirtschaftliche Bedeutung der insektenfressenden Vögel. Ebenda. 4. (1905.)

S chleh, Nutzen und Schaden der Krähen. Berlin 1904.

T a uber, P., Om Tandsact og Levemaade hos de Flagermuus og Insektädere. Kopenhagen 1872 (Naturh. Tidsskr.).

W a cht1, Fr., Der Weißtannentriebwickler. Wien 1892.

\section{Schmarotzer und Raubinsekten.}

Bu r g e s s, A. F., Calosoma sycophanta: As life history, behavior etc. Bur. of Ent. Bull. 101. (1911.)

D a 11 a Torre, Catalogus Hymenopterorum, Vol. III. Leipzig 1901.

Escherich, K., Die angewandte Entomologie in den Vereinigten Staaten. Berlin (Parey) 1913.

Heidrich, Beobachtungen und Bemerkungen über Nematus-Fraß. Allg. Forstu. Jagdzeit. 1909, S. 281 (Vertilgung durch Spinnen).

How a rd, L. O., und Fiske, W. F., The importations into the United States of the Parasites of the Gipsy moth. Bureau of Ent. Bull. 91. 1911.

Kel1er, C., Untersuchungen über die forstl. Bedeutung der Spinnen. Schweiz. Zeitschr. f. d. Forstwesen. 1883 u. 1884. (Ferner auch in Recueil zoolog. Luisso 1885.)

Loos, Kurt, Beobachtungen an einem bedeutungsvollen Fliegenschmarotzer an dem Nonneninsekt. Zentralbl. f. d. ges. Forstwesen. 1908. 
Niels e n, J. C., Jagtagelser over entoparasit. Muscidelarver hos Arthropoder. Entom. Meddel. (2. R.). 4. Bd. (1909) u. Vidensk. Meddel. f. d. naturh. Foren. 1911 u. 1912.

- Gravenvespe og Gedehamse. (1. Band aus Danmarks Fauna. Kopenhagen 1907.)

O u d e m a n s, J. Th., De Mederlandsche Insecten. s'Gravenhage 1900.

$\mathrm{P}$ a n t e 1, J., Recherches sur les Diptères à larves entomobies. La Cellule XXVI. 1910.

$\mathrm{P}$ e ckh a m, G. und E., Instinkt und Gewohnheit der solitären Wespen. (Übersetzt von Dr. Walther Schoen ichen). Berlin (Parey) 1904.

Pre11, H., Die Lebensweise der Raupenfliegen. Verhandlungen der Deutschen Gesellschaft f. angewandte Entomologie 1913.

- Die Biologie der Tachinen Parasetigena segregata Rdi. und Panseria rudis Fall. Zeit. f. angew. Entom. Bd. I. 1914.

R a t z e burg, J. Th., Die Ichneumonen der Forstinsekten. Berlin 1844-1852.

Sh a r p, D a vid, Insekts. In: Cambridge Natural History. London 1899.

S c hew y r e uv, Les Parasites. Petersburg 1913.

$\mathrm{S} c \mathrm{~h}$ w a $\mathrm{g}$ a rt, Fr., Über die Traubenwickler und ihre Bekämpfung. I u. II. Jena 1910 u. 1913.

Tima e us, Fr., Beobachtungen über die Nonnentachine. Nat. Zeit. f. Forstund Landw. Bd. IX. 1911.

Townsend, Charles H. T., A. record of results form rearings and dissections of Tachinidae. Bur. of Ent. Technical Series Nr. 12. Part. VI. 1908.

Verho eff, C. W., Über Dermapteren. VII. Zeit. f. wiss. Insekt. Biologie. 1913.

4. In sekt e n töt e n de Pilze.

Die Literatur hierüber befindet sich auf S. 289-291 im direkten Anschluß an die Behandlung dieses Themas.

5. Pathogene Mikroorganismen.

A u e r b a ch, M., Die Cnidosporidien. Eine monographische Studie. Leipzig 1910.

B o c chia, I c ili o, Osservazioni sulla flaccidezza del baco da seta. Boll. della Soc. Medica Parma. 1908.

Bolle, Joh a n n, Der Seidenbau in Japan. Wien und Leipzig 1898.

- Anleitung zur Kultur des Maulbeerbaumes und zur rationellen Aufzucht der Seidenraupe. Görz 1908.

- L'Allevamento ragionale del Baco da seta. 286 Seiten. Görz 1913.

- Außerdem zahlreiche Mitteilungen über die Gelbsucht usw. in den Berichten über die Tätigkeit der K. K. landw.-chem. Versuchsstation in Görz 1905 bis 1912 .

D'Herelle, F., Sur une epizootie de nature bactérienne sévissant sur les sauterelles au Mexique. Compt. Rend. Ac. Paris. 22. Mai 1912.

D of 1 e in, Fr., Lehrbuch der Protozoenkunde. 3. Aufl. 1911.

Escherich, K., und M i y a j ma, M., Studien über die Wipfelkrankheit der Nonne. Nat. Zeitschr. f. Forst- und Landw. 1911.

Escherich, K., Neues über Polyederkrankheiten. Ebenda 1913. (2. Heft.)

Fischer, E., Uber die Ursachen der Disposition und über die Frühsymptome der Raupenkrankheiten. Biol. Zentr.-Bl. 26. Bd. 1906.

G 1 a ser, R. W., und $C$ hapma n n, W., Studies on the „Wilt" disease or „Flacherie" of the Gipy moth. Science XXXVI. 1912.

Knoche, E., Uber den Erreger der Wipfelkrankheit der Nonne und seine Entwicklung. Jahreshefte des Vereins für Vaterl. Naturfreunde in Württemberg. 68. Jahrgang. 1912.

M a a $B$ e n, Zur Aetiologie und Epidemiologie der Ruhr bei den Bienenvölkern. Mitteil. d. Kais. Biol. Anst. f. Land- und Forstwirt. Heft 11. (März 1911.) S. $50 \mathrm{ff}$.

Marzocchi, V., Sul parassita del giallume del Bombyx mori. Arch. de Parasitol. Bd. 12.1909.

Metzger, A., und Müller, N. J. C., Die Nonnenraupe und ihre Bakterien. Berlin 1895.

P ic a rd, F., et Blanc, G. R., Sur une septicaemie bacillaire des chenilles d'Arctia caja. Compt. Rend. Acad. Paris. 28. Avril 1913.

Escherich. Forstinsekten. 
Prowazek, S. v., Chlamydozoa. II. Gelbsucht der Seidenraupe. Arch. f. Protistenkunde Bd. 10.1907.

- S. v., Untersuchungen über die Gelbsucht der Seidenraupen. Zentralbl. f. Bakt. usw. V. Abt., Bd. 67, Heft 4. 1912.

- Handbuch der pathogenen Protozoen. Leipzig 1912.

St a nd f u B, M., Handbuch der pal. Groß-Schmetterlinge. (2. Auf1.) Jena 1896. S. $153 \mathrm{ff}$.

St empe11, W., Uber Nosema bombycis Nag. usw. Arch. f. Protistenkunde. Bd. 16. 1909 .

T u beuf, C. v., Zur Geschichte der Nonnenkrankheit. Nat. Zeit. f. Forst- und Landw. 1911.

Wahl, Bruno, Uber die Polyederkrankheit der Nonne. I-IV. Zentr. gesamte Forstw. 1910-1913.

Wh it e, G. F., The bacteria of the apiary, with special reference to bee diseases. Bur. of Ent., Techn. Lerres. No. 14. 1906.

- The cause of european Foul brood. Bur. of Ent. Circular No. 157. 1910.

Wolff, Max, Über eine neue Krankheit der Raupen von Bupalus piniarius. L.-Mitt. Kaiser Wilh.-Institut Bromberg. III. 1910.

$\mathrm{Z}$ ander, Enoch, Handbuch der Bienenkunde. I. Die Faulbrut. II. Krankheiten und Schädlinge der erwachsenen Bienen. Stuttgart 1910 und 1911. 
Kapitel VII.

\section{Entstehung und Bekämpfung von Insektenkalamitäten.}

\section{A. Die Entstehung von Kalamitäten.}

Wir haben im vorigen Kapitel gehört, daß die Beständigkeit des Faunenbildes unserer Wälder (das organische Gleichgewicht) auf dem Zusammenwirken einer ganzen Reihe von regulatorischen Faktoren beruht. Fallen nun einige von diesen Faktoren (oder auch nur einer) weg, oder werden sie an ihrer vollen Wirkung gehemmt, so wird eine Störung des Gleichgewichtes die Folge sein, indem die durch jene niedergehaltenen Organismen ihre Vermehrungsenergie nunmehr stärker entfalten, und eine größere Zahl von Nachkommen zu fortpflanzungsfähigen Imagines sich entwickeln können. Welchen Umfang die Gleichgewichtsstörung annimmt, hängt einmal von der Art und Dauer der in Wegfall gekommenen regulatorischen Faktoren und sodann von der Vermehrungsgröße und der Ausdehnungsmöglichkeit (vorhandene Nahrungsmengen, Brutgelegenheit) der von ihnen in Schach gehaltenen Schädlinge $a b$.

Die Ausschaltung der regulatorischen Faktoren kann auf die verschiedenste Weise geschehen. Es können z. B. Witterungseinflüsse daran beteiligt sein, in dem abnorme Temperaturverhältnisse die Vermehrung eines Schädlings direkt begünstigen oder aber die Vermehrung seiner Feinde zurückhalten können. Oder es kann der durch plötzliche Naturereignisse erfolgte Eintritt abnorm reichlicher Ernährungs-und Brutgelegenheiten dem Schädling die Möglichkeit geben, über das gewöhnliche Maß hinaus sich zu vermehren, was vor allem für sekundäre Schädlinge (Borkenkäfer, Bockkäfer usw.) zutrifft, die nach Wind oder -Schneebruch, oder nach vorangegangenen anderen Waldkrankheiten (Pilze, Raupenfraße usw.) häufig zu Kalamitäten anwachsen.

In sehr vielen Fällen ist es der Mensch selbst, der durch sein gewaltsames Eingreifen in die Natur das Gleichgewicht der Organismenwelt stört, und dadurch die Veranlassung zu verheerenden Kalamitäten gibt. Zweifellos sind ein großer Teil der Insektenkalamitäten Kulturkrankheiten (gleichwie ja auch zahlreiche Leiden der Menschheit in der Kultur ihre Wurzel haben). Sind doch in unseren modernen Forsten alle Bedingungen gegeben, eine Massenvermehrung von Insekten, die sich von bestandsbildenden Holzarten nähren, zu begünstigen. 
Besonders sind in dieser Beziehung die großen, gleichalterigen reinen Bestände zu nennen, welche die Forstwirtschaft aus wirtschaftlichen Rücksichten seit Anfang des vorigen Jahrhunderts geschaffen hat. Solche Bestände stellen die reinen Brutstätten für gewisse Insekten dar, indem die letzteren, sobald sie einen Baum kahl gefressen, ringsum in unmittelbarer Nähe, die gleichen zusagenden Bedingungen für sich und die Nachkommen in Hülle und Fülle vorfinden. Es ist auch eine alte Erfahrung, daß gemischte Bestände weit weniger unter Insektenverheerungen (z. B. Nonne) zu leiden haben als reine. Verschiedentlich mag dies auch daran liegen, daß in reinen Beständen die Entwicklungsbedingungen für manche Parasiten recht ungünstige sind, wenn nämlich die Parasiten auf $Z$ wischenwirte angewiesen sind, die auf anderen Pflanzen leben.

Wirtschaftliche Rücksichten haben ferner dazu geführt, daß weniger insektengefährdete Holzarten, wie vor allem Laubhölzer und speziell die Buche, auf weite Strecken hin durch stark gefährdete Holzarten, nämlich Nadelhölzer, ersetzt wurden.

In Norddeutschland ist dieser Vorgang ein sehr häufiger. Am westlichen Harze, in vielen Waldrevieren des Erzgebirges hat z. B. die Fichte ziemlich allgemein die Buche verdräıgt; im Grimmaer Bezirk in Sachsen sind seit Anfang des vorigen Jahrhunderts große Flächen Laubwaldes durch künstliche Verjüngung in Nadelwald übergeführt worden. Folgen einer solchen Umwandlung nun zwar durchaus nicht immer Insektenverheerungen auf dem FuB, so ist die Gefahr doch jedenfalls eine viel größere geworden. Im Grimmaer Bezirk sind denn auch bereits schwere Insektenschäden eingetreten (Nematus), die derartig hartnäckig sind, daß die Weiterexistenz mancher Bestände in Frage gestellt ist und man mit dem Plane umgeht, die Fichte wieder durch Laubholz zu ersetzen.

Auch die saubere Wirtschaft im Walde, die alle anbrüchigen Stämme so schnell wie möglich entfernt, kann störend in das feste Gefüge der Lebensgemeinschaft eingreifen, indem dadurch den nützlichen Höhlenbrütern (Meisen und anderen insektenfressenden Vögeln) die Brutgelegenheit genommen wird.

Ebenso kann die Entfernung der Streudecke von förderndem Einfluß auf die Schädlingsvermehrung sein, indem dadurch den mitunter sehr wirksamen insektentötenden Pilzen die geeigneten Bedingungen entzogen und außerdem mit der Streu eine Menge Parasitenpuppen entfernt werden können.

Des weiteren ist auch die Kahlschlagwirtschaft und die durch sie bedingte Bestandsgründung durch Nachverjüngung nicht ohne Einfluß auf die Insektenvermehrung geblieben. Ist doch z. B. erst durch diese Maßnahmen der große braune Rüsselkäfer zu dem schlimmen Schädling herangezüchtet worden, wie er uns heute entgegentritt, da ihm dadurch Nahrungs- und Brutgelegenheit in der denkbar günstigsten Vereinigung geschaffen werden.

Was den ersten Beginn einer Massenvermehrung betriff, so tritt dieselbe sehr häufig zuerst in eng begrenzten Lokalitäten, sog. „Herden“, auf, von denen sich die Kalamität mehr oder weniger rasch konzentrisch über weitere Strecken ausdehnt. Dabei ist des öfteren beobachtet worden, daß manchen Lokalitäten eine gewisse Prädisposition als Entstehungsherde für Massenvermehrungen zukommt (z. B. Nonne). Worauf die Prädisposition beruht, muß von Fall zu Fall erst eingehend untersucht werden. Heute bewegen wir uns in dieser Beziehung fast nur in Vermutungen. 
Als besonders bemerkenswerte Erscheinung bei der Entstehung von Kalamitäten ist das häufig beobachtete gleichzeitige Auftreten eines Schädlings in den verschiedensten Gebieten eines Landes zu nennen. Kommt es doch garnicht selten vor, daß ein Schädling, der lange Zeit nichts hat von sich hören lassen, plötzlich von allen Seiten her als im Anzug befindich gemeldet wird. So z. B. hat die Nonne sich zu Anfang dieses Jahrhunderts gleichzeitig in Sachsen, Ostpreußen, Bayern, Böhmen usw. bemerkbar gemacht oder so trat die Kieferneule in diesem Jahr (1913) in den verschiedensten weit voneinander gelegenen Gegenden ziemlich unvermutet in verderbenbringender Weise auf usw., so daß man also gewissermaßen von Schädlingsperioden (Nonnenperioden, Eulenperioden usw.) reden kann. Interessant ist dabei, daß in diesen Perioden der betreffende Schädling auch an solchen Orten, wo er infolge der ihm wenig zusagenden Lebensbedingungen nur selten vorkommt, merklich häufiger wird; so ist z. B. in der gegenwärtigen Eulenperiode die Eule auch hier in Tharandt, wo sie sonst ein seltenes Vorkommnis ist, uns auffallend häufig begegnet. Über die Ursachen dieser Erscheinung sind wir ebensowenig unterrichtet wie über die Ursachen der örtlichen Prädisposition, und es ist dringend geboten, auch diesem Problem mit wissenschaftlichen Methoden nachzugehen.

Gewöhnlich begnügt man sich damit, kurzweg „W itterungsein flüsse" (z. B. große Hitze und Trockenheit) als Ursachen solcher Schädlingsperioden anzuführen. Das mag auch in vielen Fällen stimmen; solange wir jedoch die Zusammenhänge zwischenWitterung und Schädlingsvermehrung nicht genauer präzisieren können, ist mit diesen „Witterungseinflüssen" wenig anzufangen. Bis jetzt ist nur bei gewissen sekundären Schädlingen der Zusammenhang einigermaßen klar, so z. B. bei Borkenkäfern, die nach sehr trockenen heißen Sommern, in denen die Bäume unter der Trockenheit mehr oder weniger zu leiden hatten, sich stärker zu vermehren pflegen, da sie eben dann reichlichere Brutgelegenheit vorfinden. Bei den meisten übrigen Schädlingen jedoch sind uns die näheren $\mathrm{Zu}$ sammenhänge noch unbekannt; sie dürften mitunter wohl auch recht komplizierter Natur sein, indem die Witterungseinflüsse sich nicht nur direkt auf den Schädling, sondern auch auf die Parasiten und Hyperparasiten, die Raubinsekten, Pilze und anderen Nützlinge sich geltend machen.

Um zu zeigen, in welcher Weise Witterung, Schädling, Parasit aufeinander einwirken können, führe ich ein sehr lehrreiches Beispiel eines nordamerikanischen (d. h. eines von Europa dorthin eingeschleppten) Schädlings, Toxoptera graminum Rond., an, einer Blattlaus, die von Zeit zu Zeit (die letzten Perioden waren 1890, 1901 und 1907) in Unmassen auftritt und dann enorme Verluste am Getreide verursacht, in der Zwischenzeit jedoch ziemlich harmlos ist. Daß eine starke Massenvermehrung dieses Schädlings nur relativ selten stattfindet, ist darin begründet, daß eine solche von ganz bestimmten Witterungsverhältnissen abhängig ist: Die genannte Blattlaus überwintert nämlich in normalen Wintern als $\mathrm{Ei}$, welches von cinem befruchteten Weibchen stammt. Bleibt aber der Winter und Spätherbst warm, so unterbleibt die Entstehung von Sexualen, und es setzt sich die während des Sommers herrschende parthenogenetische Fortpflanzung auch durch die warmen Wintermonate hindurch fort, so daß also bereits im ersten Frühjahr ein großes Heer von Blattläusen vorhanden ist. Nun kann aber immer noch die Gefahr durch die Natur abgewendet werden, wenn nämlich der Frühling warm ist. Dann entsteht den Blattläusen ein noch größeres Heer von Feinden, das bald mit ihnen aufräumt. Der Hauptfeind ist eine kleine Schlupfwespe (Lysiphlebus tritici), welche immer und überall da vorhanden ist, wo die Blattlaus vorkommt, und welche die Vermehrung der Blattlaus für gewöhnlich in engen Grenzen hält (s. Fig. 190, S. 247). Die Schlupfwespe bedarf aber einer wesentlich höheren Temperatur 
zu ihrer Vermehrung als die Blattlaus, daher muß der Frühling warm sein, wenn der Feind die zur wirksamen Bekämpfung nötige Zahl erlangen soll. Bleibt dagegen das Frühjahr kalt (nach einem milden Winter), so können sich wohl die Blattläuse weiter vermehren und ins Unermeßliche anwachsen, nicht aber die Schlupfwespen. Und wenn dann die Temperatur auch später für die letzteren hoch genug ist, dann haben die Blattläuse bereits einen solchen Vorsprung erlangt, daß die Schlupfwespen längere Zeit brauchen, bis sie denselben wieder eingeholt haben - und die Folge davon ist dann eine Blattlauskalamität. - Wir haben wenige Beispiele in der gesamten Schädlingskunde, die die Ursachen der Entstehung einer Kalamität so klar und deutlich erkennen lassen, wie dieser Fall von der Getreideblattlaus. Deshalb glaube ich, denselben hier nicht vorenthalten zu dürfen.

Eine besondere und recht eigentümliche Anschauung über die Ursachen der periodenweisen Massenvermehrungen hat Sim rot h geäußert: er sucht dieselben auf kosmische Vorgänge zurückzuführen und mit den 11 jährigen Sonnenfleckenperioden in Zusammenhang zu bringen. Zur Stütze dieser Anschauung bringt er eine Reihe von Beispielen, in denen Massenvermehrungen gewisser Insekten (Eccoptogaster scolytus, Wespen usw.) mit diesen Perioden annähernd zusammenfielen. Es wäre aber ein leichtes, ebenso viele Beispiele anzuführen, in denen Massenvermehrungen sich nicht im geringsten um die Sonnenflecken kümmerten.

In weitaus den meisten Fällen sind die Kalamitäten „autochthonen" Ursprungs, d. h. entstehen an Ort und Stelle infolge irgend einer hier eingetretenen Gleichgewichtsstörung. Es kommen aber auch Ausnahmen vor, in denen eine Kalamität von auswärts, durch einen plötzlichen Einfall oder Einwanderung großer Schädlingsmengen in ein bisher gänzlich gesundes Revier hineingetragen werden; wir sprechen in solchen Fällen von „Überflug“. Es gab eine Zeit, in der man Überflüge als etwas selbstverständliches auffaßte, und überall da, wo man plötzlich vor einer Massenvermehrung stand, dieselbe ohne weiteres auf einen Überflug zurückführte. Wie konnte es auch anders sein, da nach Ansicht des betroffenen Forstmannes sein Revier bis dahin nichts von einer abnormen Insektenvermehrung habe erkennen lassen. Es war eine schöne Zeit für die Forstbeamten, da sie die Schuld für eine ausgebrochene Kalamität ohne Schwierigkeit auf den Nachbarn abwälzen konnten.

Heute ist man aber in dieser Beziehung wesentlich skeptischer resp. kritischer geworden, und die Ausrede mit „Überflug“ stößt von vornherein auf starkes Mißtrauen. Man hat eben bei sorgfältiger Prüfung in vielen Fällen, in denen Überflug als Entstehungsursache einer Kalamität angegeben worden war, sichere Anzeichen (z. B. Puppenhüllen, Raupenkot, hoher Parasitenprozentsatz usw.) dafür gefunden, daß der betr. Schädling schon längere Zeit hindurch in stärkerer Vermehrung begriffen, aber bisher übersehen worden war. Wenn dann die Zahl des Schädlings groß genug war, daß er nicht mehr übersehen werden konnte, dann kam die „Überraschung“, auf welche prompt die Annahme des Überfluges folgte. Die ersten Anzeichen einer beginnenden Massenvermehrung sind mitunter sehr geringfügig, und das Anwachsen der Individuenzahl erfolgt nach Entfernung der vermehrungsbeschränkenden Faktoren meist so rasch (infolge der Propagation in geometrischer Progression, siehe S. 223), daß oft gar nicht allzuviel Sorglosigkeit dazu gehört, den Anfang einer Massenvermehrung zu übersehen, zumal wenn die Entstehungsherde engbegrenzt und an wenig zugänglichen Orten gelegen sind. Jedenfalls beweist die in solchen Fällen oft zu hörende Behauptung: 
„Die Vermehrung hätte uns unmöglich entgehen können“, gar nichts gegen eine autochthone Entstehung einer Kalamität. Daß derartige Überraschungen noch so oft vorkommen können, beweist höchstens, daß die forstentomologische Schulung des Forstwirtes noch zu wünschen übrig läßt.

Andererseits haben wir doch auch gut beglaubigte Beispiele von Masseneinwanderungen. Daß gewisse Insekten weite Wanderungen in großen Gesellschaften unternehmen, ist ja allgemein bekannt; wie z. B. die Heuschreckenschwärme, die in ungeheuren Massen WVolken gleich dahinziehen, überall, wo sie einfallen, Vernichtung bringend; oder die langen Züge der Libellen, oder des Baumweißlings, oder die schlangenartig dahinkriechenden Verbände der Trauermückenlarven (Heerwurm) usw. Worauf dieses gesellschaftliche Wandern beruht, ist uns in den meisten Fällen noch unbekannt; die Ursachen mögen von Fall zu Fall verschieden sein, jedenfalls dürfte es nicht angängig sein, kurzweg Nahrungsmangel für alle diese Wanderungen rerantwortlich zu machen; in manchen Fällen trifft dies sogar sicher nicht zu. Wir müssen uns daher rorläufig mit der Konstatierung der Tatsache begnügen, daß gewissen Insekten der Trieb, in größeren Gesellschaften zu wandern, innewohnt.

Es frägt sich nun, ob auch unter den Forstinsekten solch wanderlustige Tiere sich befinden. Einigermaßen sicher wissen wir es nur von wenigen, wie z. B. von den Borkenkäfern, dem grauen Lärchenwickler, der Nonne usw.

So wurde bezüglich der Borkenkäfer des öfteren beobachtet, daf von Holzvorratsplätzen und Brettsägen aus, welche borkenkäferhaltiges $\mathrm{Holz}$ aus anderen Gegenden erhielten, bis dahin völlig borkenkäferfreie Waldungen plötzlich stark infiziert wurden. Fraglich und schwer $\mathrm{zu}$ bestimmen ist dagegen, bis zu welchen Entfernungen ein Überschwärmen möglich ist.

Ein Beispiel für weites Überfliegen von typographus erblickt $\mathrm{Nits}$ h $\mathrm{e}$ in einer Mitteilung von Oberforstmeister $\mathrm{T}$ iedemann aus dem Gouverment Nishny-Nowgorod. „Mitten in einem im Kreise Arsamaß liegenden Kronforst von 2500 ha, der fast ausschließlich aus Laubholz besteht, befinden sich zwei 50 bezw. 60 ha große Fichtenbestände. In beiden war kein Windbruch, keine Lichtung, vielmehr guter voller Schluß, und es waren nie Borkenkäfer in ihnen aufgetreten. Da zeigt sich plötzlich im Jahre 1883 der Borkenkäfer so stark, daß sofort 1000 Fichtenstämme gefällt und geschält werden mußten. Das Auftreten der Borkenkäfer ist hier nur (? ? der Verf.) durch Uberfliegen zu erklären. Die nächsten Fichtenbestände sind aber 15-20 km entfernt, und solche, in denen ein starker Borkenkäferfraß zur Zeit der Infektion herrschte, gar ca. 50 km.“

Daß der graue Lärchenwickler durch Úberflug über Pässe usw. benachbarte Täler infizieren kann, hatte der Verfasser selbst zu konstatieren Gelegenheit, und zwar auf der Iffigenalp im Berner Oberland. Dort war plötzlich der genannte Schädling in solchen Mengen aufgetreten, daß sämtliche Lärchen völlig kahl gefressen wurden. Vorher war nicht die geringste Spur von $\mathrm{Be}-$ schädigungen dort zu bemerken, wie der Besitzer, ein gewissenhafter Naturbeobachter, versicherte. Wohl aber war der Schädling im benachbarten Wallis seit Jahren in der bedenklichsten Weise aufgetreten. Es lag daher nahe, anzunehmen, daß die Infektion von dort her stattgefunden habe, und wir konnten auch eine gewisse Bestätigung dafür erbringen, indem wir auf dem Wildstrubelgletscher, der die Iffigenalp vom Wallis trennt, eine Unmasse der fraglichen Falter im Schnee erstarrt oder noch zappelnd antrafen, - möglicherweise die Reste eines die Höhen überflogenen Heeres. $\mathrm{Ob}$ es sich hierbei um eine Überwehung oder um ein aktives Utberfliegen gehandelt hat, ließ sich natürlich nicht entscheiden. 
Am geläufigsten ist dem Praktiker das Uberfliegen der Nonne. Werden doch auch bei jeder Nonnenkalamität von zahlreichen Seiten Uberflüge als sichere Entstehungsursache ins Feld geführt. Und doch wurde nach den kritischen Untersuchungen Sedlaczeks auch hier weit über das Ziel hinausgeschossen. Zahlreiche der scheinbar sicher begründeten Annahmen von Überflügen erwiesen sich nach diesem Autor bei der genaueren Analyse als nicht stichhaltig, und nur in ganz wenig Fällen sind wir tatsächlich berechtigt, von einer Nonneninfektion durch Masseneinwanderung zu reden. Auch über die Entfernungen scheint man sich unrichtige Vorstellungen gemacht zu haben; denn nach Sedla c z ek dürften $20 \mathrm{~km}$ schon ein Maximum für die Flugfähigkeit der Nonne darstellen. Durch Wind kann die Entfernung allerdings noch mehr oder weniger vergrößert werden (siehe auch S. 224). Die Überwanderung findet ferner selten in kompakten Schwärmen statt, sondern meist durch sukzessiven Überflug zahlreicher Individuen. Näher soll hier darauf nicht eingegangen werden, da unten bei Besprechung der Nonne (Bd. III) diese wichtige Frage noch ausführlich behandelt werden wird.

Fassen wir das Gesagte zusammen, so kommen wir zu dem Ergebnis, daß die Überflüge bei Forstinsektenals Ausnahmeerscheinungen anzusehen sind. Wir haben demnach bei allen Kalamitäten zunächst an einen autochthonen Ursprung zu denken; nur dann, wenn der strikte Nachweis erbracht werden kann, daß der betr. Schädling in den vorhergehenden Jahren nicht in einer den Normalstand überschreitenden Zahl vorhanden war, und außerdem irgend welche positiven Angaben über die Herkunft des Überfluges usw. gemacht werden können, nur dann dürfen wir die Annahme einer Masseninfektion von außen als berechtigt anerkennen.

Eine Infektion kann natürlich auch durch Einwanderung oder Verschleppung einzelner Individuen geschehen, ist doch eine der größten aller Insektenkalamitäten, die des Schwammspinners in Amerika, durch die Verschleppung ganz weniger Exemplare verursacht worden (siehe S. 238); es verläuft aber dann die Vermehrung nach dem Typus der autochthonen Kalamitäten.

\section{B. Vorbeugung und Bekämpfung von Insektenkalamitäten.}

Die beste Begegnung eines jeden Übels ist die Vorbeugung. Wie das Ziel des Hygienikers der menschlichen Gesellschaft darin besteht, die Lebensformen derselben so zu gestalten, daß den Krankheitskeimen ein möglichst ungünstiger Boden geschaffen wird, so daß die Krankheiten überhaupt nicht mehr aufkommen können, so muß der Waldhygieniker darnach streben, die Waldkultur so einzurichten, daß den Schädlingen möglichst geringe Angriffsflächen dargeboten werden. Das Vorhandensein von Kulturkrankheiten soll uns nicht etwa (wie manche Reformatoren der menschlichen Gesellschaft meinen) dazu führen, die Kultur völlig aufzugeben, sondern vielmehr dazu, eine höhere Stufe der Kultur zu erstreben, welche die Entwicklungsmöglichkeit jener Krankheiten mehr und mehr einengt oder ganz ausschaltet. Es wird ja gewiß Fälle genug geben, in denen tie Kultur stets mit Gefahren verbunden sein wird, d. h. in denen eine Abänderung der Kulturart im Sinne einer Prophylaxe nicht ausführbar ist (so kann man z. B. auf gewissen Böden nur ganz bestimmte Baumarten pflanzen, trotzdem man vielleicht weiß, wie stark dieselbe an den betreffenden Orten Insekten- 
verheerungen ausgesetzt ist); andererseits können wir aber bei einer großen Zahl von Schädlingen durch besondere kulturelle Maßnahmen die Vermehrungsbedingen zweifellos wesentlich einschränken.

Wo es durch kulturelle Methoden durchaus nicht gelingt, dem Aufkommen einer Kalamität vorzubeugen, da muß der Forstwirt versuchen, mit anderen Mitteln der Vermehrung entgegenzutreten und das Übel direkt bekämpfen. Dabei ist als oberster Grundsatz festzuhalten, daß die Bekämpfung um so mehr Aussicht auf Erfolg hat, je früher dieselbe einsetzt. Hat die Vermehrung einmal ein gewisses Maß überschritten, so ist in vielen Fällen wenig mehr mit den menschlichen Kräften auszurichten, und bleibt uns dann nichts anderes übrig, als das Übel sich selbst zu überlassen, bis es sein natürliches Ende findet, oder böchstens zu versuchen, es auf seinen Herd zu beschränken.

Viele der Mißerfolge in der forstlichen Schädlingsbekämpfung sind darauf zurückzuführen, daß der richtige Zeitpunkt beim Eingreifen versäumt worden ist. Und dies hängt wieder mit der oben bereits erwähnten Tatsache zusammen, daß die für eine erfolgreiche Bekämpfung so überaus wichtigen Anfangsstadien einer Kalamität meistens übersehen werden. In dieser Beziehung ist ja auch der Forstwirt weit schlechter daran als der Landwirt oder der IVeinbauer, welchen bei der übersichtlichen Art ihrer Kulturen das Auftreten eines Schädlings kaum entgehen kann, auch wenn dieser erst in geringer Zahl vorhanden ist. Bei den Forstschädlingen dagegen spielen sich oft die ersten Stadien einer Übervermehıng so verborgen $\mathrm{ab}$, daß es einer großen Aufmerksamkeit, eines gut geschulten Blickes und einer genauen Kenntnis der Lebensgeschichte der betr. Schädlinge bedarf, um ihr Vorhandensein zu bemerken. Es ist daher auch bei der Schulung des zukünftigen Forstwirtes vor allem darauf zu achten, daß er mit den ersten Kennzeichen einer beginnenden Kalamität gut vertraut wird; denn rechtzeitiges Erkennen ist schon die halbe Bekämpfung. Stets hat der Forstmann bei seinen Gängen durch das Revier das Insektenleben scharf im Auge zu behalten, und doppelte Aufmerksamkeit ist dann geboten, wenn eine stärkere Vermehrung eines für ihn in Betracht kommenden Schädlings aus anderen Gegenden gemeldet wird (vgl. das oben über die Schädlingsperioden gesagte) oder Umstände eingetreten sind, welche die Insektenvermehrung überhaupt begünstigen, wie z. B. abnorm heiße und trockene Sommer, Wind- und Schneebrüche, Raupenfraß, Rauchschäden usw. Um ganz sicher zu gehen, wird er in solchen Fällen event. Probefänge (mit Fackeln oder Leimringen, oder Prellen mit unterhaltenen Tüchern usw.) vornehmen.

„So schwierig und zeitraubend diese Orientierung auf den ersten Blick erscheinen mag, so gestalten sich die Verhältnisse in der Praxis doch viel einfacher. Der einzelne Wirtschafter hat meist relativ einförmige Verhältnisse, vor allem nur wenig Hauptholzarten. In ihnen aber ist für eine bestimmte Gegend die Zahl der wirklich gefährlichen Insektenarten keine allzu große, so $\mathrm{daB}$ es sich meist nur um die kontrollierende Beobachtung eines oder anderthalb Dutzend von Arten handeln wird“" (N ̈̈ B $1 \mathrm{i}$ n). 
Ein klassisches Beispiel dafür, was durch rechtzeitige Erkenuung und rechtzeitiges Ergreifen von Gegenmaßregeln erreicht werden kann, liefert die Bekämpfung der letzten Nonnenkalamität in Sachsen. Dadurch, daß man schon bei einem ganz geringen Befall (teilweise schon bei 150 Eier pro Stamm!) mit Vollleimung vorging, gelang es, die Nonne so in Schach zu halten, daß nur auf ganz minimalen Flächen Kahlfraß eingetreten ist, während in anderen Gegenden, wo man zu einem weit späteren Zeitpunkt zur Leimung griff, große Zerstörungen erfolgten ( $\mathrm{P}$ u t s c h e r).

Auf die Merkmale der beginnenden Insektenvermehrungen im einzelnen hier einzugehen, würde zu weit führen, zumal im speziellen Teil bei Besprechung der verschicdenen Forstschädlinge dieser Punkt besondere Berücksichtigung finden wird. Es sei hier nur kurz erwähnt, daß neben den direkten Kennzeichen, wie z. B. Bohrmehl und Harzerguß an den Stämmen, Raupenkot, abgebissene Nadeln, befressene Blätter, Lichterwerden der Krone, Verfärbung der Nadeln usw., auch noch indirekte Kennzeichen uns mitunter zur Verfügung stehen, die uns auf das Vorhandensein von Schädlingen aufmerksam machen können. Dazu gehört z. B. die auffallende Vermehrung leicht sichtbarer Parasiten oder Raubinsekten (wie Tachinen oder Kletterlaufkäfer usw.), oder insektenfressender Vögel oder Säugetiere. So hat Altum auf die zunehmende Häufigkeit des Kuckucks im Falle einer ausbrechenden Raupenkalamität hingewiesen, auch die Tätigkeit des Spechtes kann zur Entdeckung von verborgenlebenden Schädlingen führen, und das Erscheinen zahlreicher Maulwurfshaufen kann uns die Zunahme von Engerlingen oder anderen Erdinsekten verraten.

Die Bekämpfung kann auf verschiedenen Wegen versucht werden, entweder auf biologischem Wege, indem man sich der natürlichen Feinde des Schädlings bedient, dieselben nach Kräften schont und womöglich künstlich zu vermehren und zu verbreiten sucht, oder auf technischem Wege, indem man dem Schädling direkt zu Leibe geht und ihm mit allen möglichen mechanischen und chemischen Mitteln (Spritzgiften, Fangapparaten, Leimgürteln usw.) zu vernichten sucht.

Die biologische und technische Bekämpfung schließen einander keineswegs etwa aus, sondern können recht wohl auch kombiniert angewandt werden, ebenso wie die beiden mit den eingangs crwähnten kulturellen Begegnungsmethoden verbunden werden können.

Die „biologische Methode“ steht der kulturellen sowohl bezügl. der Wirkung als der Grundlagen ziemlich nahe. Denn wie diese, so läuft auch jene auf eine Unterstützung der natürlichen Faktoren hinaus, und auch die Wirkung der biologischen Bekämpfung ist, wenn auch nicht so radikal wie die der kulturellen (deren höchstes Ziel der Entzug der nötigen Lebensbedingungen des Schällings ist), so doch langatmiger und tiefgehender als bei der technischen. Wir können daher die beiden Methoden als die „natürlichen Bekämpfungsmethoden" bezeichnen, zumal ja beide vielfach auch ineinander greifen (wenn z. B. im Interesse von insektenfressenden Vögeln oder Parasiten gewisse kulturelle Maßnahmen notwendig werden). Die biologische Methode erfordert das eingehendste Studium der Biologie und Physiologie nicht nur des Schädlings, sondern auch aller seiner natürlichen Feinde, 
ein Studium, welches ungemein zeitraubend ist und eines großen wissenschaftlichen Apparates bedarf.

Die „technische Bekämpfung" ist zweifellos kurzatmiger, insofern als sie gewöhnlich nicht der Grundursache des Übels, sondern lediglich dem Übel selbst zu Leibe geht. Die Erfolge sind Augenblickserfolge. Handelt es sich daher um von Natur relativ kurze Kalamitäten, so kann die technische Bekämpfung zweifellos Ausgezeichnetes leisten; je schwerer aber die Gleichgewichtsstörung ist und je länger die Kalamität währt, desto problematischer wird jene Bekämpfung werden. Jedenfalls muß sie dann immer wieder von Jahr zu Jahr (oder wenigstens von Zeit zu Zeit) wiederholt werden. Dabei dürfen wir nicht übersehen, daß dadurch event. auch die natürlichen Heilfaktoren ungünstig beeinflußt werden können, wenn nämlich mit der Vernichtungsaktion auch die natürlichen Feinde des Schädlings entfernt werden, was auf die Wiederherstellung des Gleichgewichtes verzögernd wirken kann.

Trotzdem werden wir die technische Bekämpfung niemals ganz entbehren können, sie wird vielmehr stets eine hervorragende Rolle in der Schädlingsbekämpfung spielen. Es wird aber sicherlich eine Zeit kommen, in der die biologische Methode ihr wenigstens ebenbürtig zur Seite stehen und sie vielleicht auch aus manchen Plätzen verdrängen wird. Vor allem wird zu versuchen sein, in solchen Fällen die biologische Methode heranzuziehen, in denen die technische Bekämpfung bei hohen Kosten nur zweifelhafte Erfolge zeitigt.

Wir werden im folgenden eine kurze allgemeine Übersicht über die hauptsächlichsten Grundsätze der genannten Vorbeugungs- und Bekämpfungsmethoden geben, und zwar: 1. der kulturellen Vorbeugung, 2. der biologischen und 3. der technischen Bekämpfung.

\section{Die kulturellen Vorbeugungsmaßregeln.}

(Von Prof. Dr. W. Borgmann-Tharandt.)

\section{a) Allgemeine Grundsätze.}

Dem modernen Wirtschaftswald sind die verschiedenartigsten, im Wechsel der Zeiten und ihrer Anschauungen entstandenen Betriebssysteme, die nur zu oft extremen Richtungen ihre Entstehung verdankten, wie ein unauslöschlicher Stempel aufgedrückt. Nicht jedes System wird der Forderung von Vorbeugungsmaßnahmen gegen Insektenschäden gerecht. Berücksichtigt man die Entwicklungsgeschichte unserer noch jungen Forstwirtschaft, die auf kaum mehr als ein Jahrhundert geordneter Pflege zurückblicken kann, so ist es zumal bei den langen Produktionszeiträumen der Waldwirtschaft, die meist erst kommenden Geschlechtern die Entscheidung über den Erfolg von Maßnahmen, die wir heute treffen, vorbehalten, verständlich, wenn bald die natürlichen Produktionsfaktoren unter Betonung der Aufgaben der Standortspflege und des Waldbaues, bald die ökonomischen Erwägungen vom Standpunkt der Forsteinrichtung und forstlichen Statik zur Vorherrschaft gelangten, nicht immer zum Nutzen des W/aldes, nur zu häufig unter Verkennung der wichtigsten Vorbeugungsmaßnahmen im Kampf gegen die Schäden aus der Insektenwelt. 
Geschichtlich ist eine der älteren Auffassungen aus W. G. M o s e r s „Grundsätzen der Forstökonomie“ 1757, II. Bd. 2. Kap. $§ 31$, S. 569 interessant, woselbst zu lesen ist:

„R a u pen und $\mathrm{K}$ ä f e r thun auch öfters großen Schaden, und zwar eigentlich denen Laubhölzerı, besonders den Eichen. Sie gehören zu denen allgemeinen Land-Strafen, und ist noch zur Zeit kein Mittel dagegen bekannt; dann das Ablesen, so leicht solches an sich wäre, würde Kosten und Umstände erfordern, welche den verhoffenden Nutzen weit übersteigen."

Aber bereits zu Ende des 18. Jahrhunderts, nachdem im Jahre 1783 im Harz ein bedeutender Borkenkäferfraß, in den Jahren 1791-94 in der Mark Brandenburg ein großer Kiefernspinnerfraß gewütet hatte, war diese uns heute unverständliche Auffassung verlassen, und schon lange hat sich die Utberzeugung Bahn gebrochen, daß der Forstmann den Insektenschäden zunächst durch $V$ or b e u g u n g s m a $\beta$ r c g e $1 \mathrm{n}$ entgegenwirken muß.

Mag es vielfach die mangelnde Kenntnis über die Entstehungsursachen und den Verlauf größerer Insektenkalamitäten gewesen sein, die eine Inangriffnahme grundlegender Maßnahmen häufig wieder vereitelte, so ließ vor allem die einseitige Betonung einer bestimmten ökonomischen oder waldbaulichen Richtung die Bedeutung des Forstschutzes nicht in dem Maße zur Geltung kommen, wie er es tatsächlich verdient.

Denn wo bleibt das bestdurchdachte, in Zeiten ungestörter Entwicklung zu den erfreulichsten Hoffnungen berechtigende waldbauliche Verfahren, wo das kunstvollste Gebäude der Forsteinrichtung, wo die feinste Berechnung einer höchsten Rentabilität, wenn Kalamitäten über den Wald hereinbrechen und ihm ein völlig verändertes Gepräge geben, das auf lange Zeit hinaus alle Pläne wieder über den Haufen wirft?

Gegen Sturm und Feuer hat man die Wälder, wo diese Gefahren, wie namentlich im reinen Fichten- und Kiefernhochwald eine erheblichere Rolle spielen, durch entsprechende Maßnahmen, wie z. B. der Sturmrichtung Rechnung tragende Hiebszüge und Loshiebe, oder eine der Verbreitung von Waldbränden entgegenwirkende Trennung der Altersklassen und durch Feuerschutzstreifen gesichert. In Schneebruchlagen wählt man weitere Pflanzverbände und bevorzugt frühzeitig einsetzende, stärkere Durchforstungen zur Erziehung gleichmäßig bekronter, widerstandsfähiger Stämme, man zieht dort die Provenienz der Gebirgskiefer mit fichtenartiger Kronenausbildung der breitästigen Flachlandskiefer vor, ebenso wie man bestrebt ist, für die Fichte in Hochlagen auch nur wiederum Samen aus Hochlagen zu verwenden. Handelt es sich um Frostlagen, so baut man frostharte Holzarten an oder mischt sie als Schutzholz der im übrigen standortsgemäßen Holzart bei, endlich wählt man die Schirmschlagverjüngung, sei es auf natürlichem oder künstlichem Wege. Kurzum man ist bestrebt, ebensowohl durch gegenwärtig nützliche Hilfen wie weitvorausschauende Maßnahmen den Gefahren der genannten Art vorzubeugen.

Wie sehr treten hiergegen die Maßnahmen, welche als Gegengewicht gegen Insektenschäden dienen sollten, zurück.

An Ansätzen mannigfaltiger Art, aber meist nur bescheideneren Umfanges und rein örtlicher Natur, hat es gewiß nicht gefehlt. Oft lassen auch die besonderen standörtlichen Verhältnisse Vorbeugungsmittel 
größeren Umfanges schwer durchführbar erscheinen. Man braucht hierbei nur an die ausgedehnten reinen Kiefernbestände in vielen Teilen des norddeutschen Diluvialgebietes zu denken, wo auf weite Strecken die Kiefer als die allein anbaufähige Holzart in Frage kommt, wo zudem bei mangelnder Naturverjüngung noch auf lange Zeit hinaus der Kahlschlag und die künstliche Kultur die herrschende Verjüngungsmethode bleiben wird. Mit dem oft gehörten Mittel gemischter Bestände, der Naturverjüngung oder gar des Plenterwaldes ist hier nicht viel anzufangen.

Die klimatischen und standörtlichen Verhältnisse des deutschen Waldes sind zu verschieden, als daß mit Mitteln, die überall gleich durchführbar und erfolgreich wären, etwas erreicht werden könnte.

Was in klimatisch bevorzugten Teilen des süddeutschen Mittelgebirges möglich ist, wo die Natur in unerschöpflicher Fülle die natürliche Verjüngung wie ein freies Geschenk bietet, wo mehrere Holzarten auf dem gleichen Standort gutes Gedeihen finden und zwanglos zum gemischten Walde führen, das kann nicht auch in den Kienheiden Posens oder Westpreußens zum Wirtschaftsziel werden. Und doch lassen auch im norddeutschen Flachland so manche Mischbestandsbilder von Kiefer, Buche und Eiche auf besseren Böden die Sicherung des Waldes gegen die ihm drohenden Gefahren aus der Insektenwelt aussichtsvoller erscheinen.

Andererseits treten bei bestimmten Insekten, wie z. B. beim Kiefernspinner und großen braunen Rüsselkäfer, deren unmittelbare technische Bekämpfung in der Regel von durchschlagendem Erfolg begleitet ist Leimring bezw. Käfergraben und eine vom Frühjahr bis zum Herbst systematisch durchgeführte Bekämpfung mit Fangknüppeln —, die Vorbeugungsmaßnahmen rein kultureller Natur mehr in den Hintergrund.

Alle diese Erwägungen können aber nicht dazu führen, die Forderung der Verhütung von Insektenkalamitäten durch entsprechende Maßnahmen der Wirtschaftsführung als minder bedeutungsvoll aufzufassen, weil die Durchführung teils schwierig erscheint, teils weil förmliche Katastrophen anscheinend doch nicht abgewendet werden können.

Ebensogut könnte man auch in der Frage der Sturmgefahr sagen, daß bei meist von Westen oder Südwesten her zu erwartenden Stürmen die von Ost gegen West oder von Nordost gegen Südwest geführten Hiebszüge zwar in der Regel einen ausreichenden Schutz böten, daß aber trotzdem einmal ein Sturn aus Nord, Nordost oder Ost das ganze Gebäude wieder über den Haufen werfen könnte, und daher jegliche Vorbeugung doch wieder nutzlos wäre.

Es wäre unrichtig, aus solchen Gründen die Hände in den Schoß legen zu wollen und jene großen Kalamitäten, wie sie der deutsche Wald schon genügsam hat erleben müssen, über sich ergehen zu lassen, wie man dies heute leider des öfteren hören kann.

Erst in jüngster Zeit ist anläßlich der großen Nonnenkalamität in Ostpreußen, der Millionen von Festmetern meist noch in gutem $\mathrm{Zu}$ wachs stehender Hölzer zum Opfer fielen, das Wort gefallen, daß so ein 
„kräftiger Aderlaß“ dem großen Staatsforstbesitz Preußens nicht sonderlich geschadet habe!

Auch von der Bekämpfung des Kiefernspinners kann man hören, man solle erst dann leimen, wenn es sich um die Existenzfrage der befallenen Bestände handele. Würden diese nur stark befressen, so möge man den Zuwachsverlust und den Abgang eines Teils der Bestockung lieber in Kauf nehmen, als die in der Regel höheren Kosten des Leimens aufwenden.

Wird dann aber nicht der Massenvermehrung in solchem Maße Vorschub geleistet, daß schließlich doch, nach bereits mehrjährigen Zuwachsverlusten, geleimt werden muß, um die Bestände vor dem sicheren Untergang $\mathrm{zu}$ retten? Und kann dann die Kalamität nicht zu einem solchen Umfang angewachsen sein, daß zuletzt die menschlichen Kräfte nicht mehr ausreichen, sie überhaupt noch wirksam zu bekämpfen? Rechtzeitig den Kampf aufnehmen, heißt in weitestem Sinne vorbeugen.

Die Erhaltung der Bestände durch Mittel der technischen Bekämpfung des Schädlings im ersten Stadium seiner Vermehrung ist eins der wichtigsten kulturellen Vorbeugungsmittel. Namentlich bei Nonnenkalamitäten sollte man nicht resigniert zusehen, weil die Leimung bei schon ausgedehntem Fraß keinen Erfolg mehr bringt, sondern rechtzeitig mit Aufbietung aller Kräfte den Kampf beginnen, dadurch einer Katastrophe vorbeugend, wie dies bei der jüngsten Nonnenkalamität in Sachsen durchgeführt wurde. Mögen auch die Ansichten über die in Sachsen hervorgetretenen Erfolge des Leimens gegen die Nonne geteilt sein, mögen günstige Umstände mitgewirkt haben, ein gewisser Erfolg wird der rechtzeitig in Sachsen eingeleiteten Bekämpfung nicht streitig gemacht werden können.

Wir sehen in einem rechtzeitig aufgenommenen Kampf ein wesentliches Vorbeugungsmittel: Es ist nicht ein Teilstück, nicht nur der Anfang einer technischen Bekämpfung, sondern, wie schon gesagt wurde, bereits eine Verhütungsmaßnahme kultureller Natur.

Durch rechtzeitig eingeleitete, oft auch, wie z. B. beim großen braunen Rüsselkäfer, ständig fortgesetzte Bekämpfung verringert man die Stärke des Fraßes, man zieht die Kalamität hin, gewinnt damit an Zeit und gibt den Beständen die Möglichkeit, sich immer wieder neu zu kräftigen, wenn ihnen wenigstens ein größerer Teil ihrer wichtigsten Lebensorgane von einem Jahr zum anderen erhalten bleibt.

Die Erhaltung der Bestände, zumal der mittleren und jüngeren Altersstufen, die noch im besten $Z$ uwachs stehen, ist ein dringendes Gebot, das durch eine Rechnung, daß die Kosten der Gegenmaßnahmen etwa größer seien, als der dadurch verhinderte Zuwachsverlust, nicht erschüttert werden kann.

Solche Bestände, wie wir sie hier im Auge haben, sind uncntbehrlich für den Aufbau unseres heutigen Wirtschaftswaldes, sie sind ein werbendes Betriebskapital, das wir ohne ernstliche Gefährdung der Stetigkeit und Nachhaltigkeit der Wirtschaft nicht missen können. 
Mit der Vernichtung ausgedehnter Bestände ist aber der Verlust noch nicht erschöpft. Auf den großen Kahlflächen folgt in jahrelangem Mühen die Neuaufforstung mit dem nur allzuhäufigen Kulturelend, das Dürre, Bodenverangerung, Graswuchs und ein ganzes Heer von kulturverderbenden Insekten heraufbeschwört.

Wir stehen auf dem Standpunkt, daß in der ersten Entwicklung begriffene Massenvermehrungen aus den angegebenen Gründen vorbeugend bekämpft werden müssen.

$\mathrm{Ob}$ die Kosten in einem richtigen Verhältnis zu dem verhinderten mutmaßlichen Zuwachsverlust stehen, kommt so lange nicht in Frage, als es noch gilt, eine förmliche Katastrophe zu verhindern. Ist diese erst hereingebrochen, dann sollte die Anwendung untauglicher Mittel - wie z. B. die Leimung bei einer schon ausgedehnten Nonnenkalamität - besser unterbleiben. Aber auch erst dann ist man berechtigt, die Ergreifung von Gegenmaßnahmen zu unterlassen und, wie zuletzt in Preußen, den Kampf gegen die Nonne gänzlich aufzugeben.

Es ist zwar ein gewisser Trost, daß bei der heutigen günstigen Holzkonjunktur solche Kalamitätshölzer - das hat der Spannerfraß in der Letzlinger Heide 1899-1903, der Schneebruch rom Jahre 1903 in Schlesien, Brandenburg usw., der letzte Nonnenfraß in Ostpreußen 1907-1910 bewiesen - noch leidlich gut, z. T. sogar recht günstig verwertet werden können. Denn Deutschland ist zur Deckung seines Bedarfs auf den Bezug von jährlich nicht weniger als 14 Millionen Festmeter für Nutzholz vom Auslande angewiesen. Die gute Verwertung der eingeschlagenen Hölzer mildert einigermaßen das trübe Bild der Katastrophe. Man soll sich aber darum nicht der angenehmen Selbsttäuschung hingeben, daß eine große Kalamität im Hinblick auf die reichlich fließenden Summen aus der Holzverwertung garnicht so schlimm sei, wie sie aussähe. Der „Aderlaf" bringt freilich steigende Reinerträge. Der Forstetat sieht fast glänzend aus. Dem Finanzminister sind die größeren Überschüsse, die ihm die Nonne ablieferte, nicht unerwünscht.

Aber der Wald hat es geben müssen. Es waren nicht bloße Renten, es steckten große, für den Wald unentbehrliche Kapitalwerte darin. Werden sie ihm gutgeschrieben? Oder verschwinden sie in den jährlichen Etats?

Im Bestand der Altersklassen ist eine klaffende Lücke, die sich später, wenn nicht sogar bald schon heute empfindlich fühlbar machen muß. Zum mindesten gehören solche dem Wald unfreiwillig entzogene Kapitalwerte in einen Forstreservefonds.

Wertvoller ist die Verhütung großer Verluste im Vorratskapital der Bestände durch gute Vorbeugung. Eine wohlgeordnete Forstwirtschaft, die scharf zwischen Kapital und Rente unterscheidet, die auf die Stetigkeit und Nachhaltigkeit der Wirtschaft Wert legt, kann njcht achtlos an der Forderung energischer Vorbeugungsmaßnahmen gegen Insektenverheerungen vorübergehen.. Der Wille zur Tat und die Mittel zur Ausführung müssen vorhanden sein. Wäre am Ende nicht ein Forstreservefonds, dem auch die Summen, die eine Kalamität einbrachte, zugeführt werden, neben seinen zahlreichen sonstigen Aufgaben dazu berufen, jederzeit die 
Mittel zu gewähren, die in das Kapitel „Vorbeugung und Bekämpfung von Insektenkalamitäten" gehören?

Wenn erst die angewandte Entomologie, wie dies Escherich ${ }^{\mathbf{1}}$ ) mit Recht fordert, auch in Deutschland auf eine breitere Grundlage gestellt wird, wenn durch umfassende und wohlorganisierte, unablässige Arbeit unser Wissen von der Entstehung und dem Verlauf von Massenvermehrungen vervollkommnet wird, dann wird auch im Walde mehr als seither das Interesse den auf kulturellem Gebiet liegenden VorbeugungsmaBnahmen gegen Insektengefahren sich zuwenden.

Die seitherigen Erörterungen haben die Bedeutung und Tragweite der Entschließungen auf dem Gebiet der vorbeugenden Maßnahmen dargetan.

Wie wenig oft nach dieser Richtung der Blick im Walde geschärft war und noch heute ist, das beweist die Geschichte des Waldes im letzten Jahrhundert, das beweisen noch manche Anzeichen unserer heutigen Wirtschaftsführung, auf die im folgenden näher eingegangen werden soll.

\section{b) Die besonderen Maßnahmen.}

Wenn die nachhaltige Erzeugung wertvollsten Holzzuwachses an einem nach Bestandesdichte und Produktionszeitraum auf sein günstigstes Maß zurückgeführten Holzvorratskapital das Ziel jeder wohlgeordneten Forstwirtschaft bildet, so müssen zunächst alle Maßnahmen des Betriebes auf eine so vollkommen und zugleich naturgemäß als möglich gestaltete Ausnutzung der natürlichen Produktionsfaktoren gerichtet sein.

Die Pflege des Standorts und die Erhaltung der standortsgemäßen Holzart bezw. Holzartenmischung steht in erster Linie. Demnächst bildet eine frühzeitig begonnene, intensive Bestandspflege, welche auf die Förderung der nach Schaft- und Kronenbildung bestveranlagten Stammindividuen gerichtet ist, die sicherste Gewähr für die Erziehung nicht nur zuwachsfreudiger, sondern auch gesunder und widerstandsfähiger Bestände. Eine möglichst naturgemäß gestaltete, durch die Bestandeserziehung von langer Hand her verbreitete Verjüngung, die auf eine möglichst vollkommene Ausnutzung der natürlichen Ansamung abzielt, bildet den Schlußstein im Aufbau der wirtschaftlichen Maßnahmen, denen ein Bestand in der Zeit von der Saat bis zur Ernte unterworfen wird. Im geordneten Betriebsganzen des Waldes vollziehen sich gleichzeitig nebeneinander die Maßnahmen, die im Einzelbestand in zeitlichen Abständen sich folgen.

Die rein finanziellen Erwägungen über das günstigste Maß der Bestandsdichte und des Produktionszeitraumes decken sich mit den Forderungen des natürlichen Prinzips hinsichtlich der Maßnahmen der Bodenpflege, der Methode der Bestandserziehung und des günstigsten Zeitpunktes der Bestandsverjüngung. ${ }^{2}$ )

1) Die angewandte Entomologie in den Vereinigten Staaten. Berlin 1913, Paul Parey. Als erster Erfolg der Anregungen ist die Gründung einer „Deutschen Gesellschaft für angewandte Entomologie" hervorzuheben, die ihre 1. Jahresversammlung in Würzburg vom 21.-25. Oktober 1913 unter dem Vorsitz des Prof. Dr. Es c h e rich-Tharandt abhielt.

2) Vgl. Borgma n n, Uber die Beziehungen zwischen dem natürlichen und ökonomischen Prinzip in der Forstwirtschaft (Antrittsrede, gehalten den 24. Mai 1911, am 100 jährigen Gedenktage an Heinrich Cottas Einzug in Tharandt). Tharandter Forstliches Jahrbuch, Jahrg. 1911, 62. Bd., Heft 1, S. 101. 
Wird das natürliche und ökonomische Prinzip im Hinblick auf die Ziele und Aufgaben des heutigen Wirtschaftswaldes in allen Konsequenzen korrekt erfaßt, so besteht zwischen beiden Richtungen, von denen die eine auf naturwissenschaftlicher, die andere auf mathematischer Grundlage ruht, kein Zwiespalt, vielmehr vereinigen sich beide zu einer Resultante, die nach Richtung und Stärke dem erstrebten wirtschaftlichen Erfolg am vollkommensten entspricht.

Auch die Fragen des Forstschutzes, namentlich was die hier zu erörternden Vorbeugungsmaßnahmen im Kampfe gegen Insekten kalamitäten betrifft, werden alsdamn in grundlegender Beziehung am besten gelöst.

Jede einseitige Betonung bald des einen, bald des anderen Prinzips, besonders aber eine irrige Auffassung über das Wesen und die Bedeutung der natürlichen Produktionsfaktoren einerseits, der ökonomischen Ziele andererseits, hat noch stets zu extremen Maßnahmen, bald auf dem Gebiet des Waldbaues, bald der Forsteinrichtung und damit zu einer Kluft zwischen diesen beiden wichtigsten Gebieten des forstlichen Betriebs geführt. Gleichzeitig hiermit wurden auch die Aufgaben des Forstschutzes, nicht zuletzt auf dem Gebiet der Verhütung von Insektenschäden, am unrollkommensten erfüllt, ja sogar viele Kalamitäten damit förmlich heraufbeschworen.

Nicht der moderne Wirtschaftswald an sich leistet der Insektenvermehrung Vorschub, sondern die in ihm vertretenen extremen Richtungen solcher Wirtschaftssysteme, die von dem natürlichen Prinzip sich am weitesten entfernen und damit zugleich auch dem vollen ökonomischen Erfolg auf die Dauer nicht gerecht zu werden vermögen.

Die Geschichte des deutschen Waldes und noch viele seiner heutigen Wirtschaftsbilder liefern dafür Belege.

Zunächst wird eine nicht standortsgemäße Holzart mehr oder minder hinter der kraftvollen Entwicklung zurückbleiben, die sie in ihrer eigentlichen Heimat oder auf solchen Standorten zeigt, die den heimatlichen Bedingungen gleich oder nahe stehen. Dadurch wird aber ihre Widerstandskraft beeinträchtigt, sie wird empfänglich für eine ganze Reihe von Krankheiten und Schäden, bietet dadurch der Massenvermehrung schädlicher Insekten günstige Vorbedingungen und erliegt oft schon dem ersten stärkeren Ansturm ihrer Feinde.

So hat man sich durch die hohen Ertragsziffern der Fichte, die aber lediglich ihren Leistungen auf frischen Gebirgsböden und in Klimaten mit höherer Luftfeuchtigkeit und reichen Niederschlagsmengen entsprechen, verleiten lassen, diese Holzart in reinen Beständen auch auf manche Böden des Flachlandes, namentlich die diluvialen Sand- und Lehmböden zu bringen, auf denen die Kiefer neben der Eiche und Buche standortsgemäß ist. Nimmt schließlich die Fichte in solchen Gebieten größere Flächen in reinen Beständen ein, dann sind bei dem außerdem wärmeren und trockeneren Klima die günstigsten Vorbedingungen für eine Massenvermehrung der Nonne ge- 
schaffen, andere Kalamitäten kommen hinzu, wie die Folgen von Dürrejahren, ferner auf Standorten mit flachem Grundwasserstand, wie z. B. vielerorts in Oberschlesien auch die Wind- und Schneebruchgefahr, und im Gefolge die Borkenkäfer.

In noch viel höherem Maße ist die Weißtanne auf Standorten, die jenen ihres Heimatsgebietes im Schwarzwald und in den Vogesen nicht mehr entsprechen, gefährdet.

Ein klassisches Beispiel bietet die Lärche, wo und so oft sie nur auf Standorte verpflanzt wurde, die nach Klima, Lage und Boden ihren Ansprüchen nicht genügen: Krebs und Motte bilden hier ihre ständigen Begleiter, die ihre Nachzucht unmöglich machen.

Selbst bei der Kiefer, die vom ärmsten Sand bis zum nassen Moor vorkommt, kann man zumal auf ausgesprochenen Laubholzböden beobachten, daß hier die Wickler in weit stärkerem Maße und Umfang die Deformation des an sich schon geil gewachsenen, ästigen Schaftes hervorrufen, als auf den ihr am besten zusagenden reinen, aber frischen Sandböden.

Auch die Eiche ist auf ihr nicht mehr zusagenden Böden weit empfindlicher gegen Insektenbeschädigungen als auf gutem Standort.

Weit mehr als der Anbau der einen oder anderen Holzart auf ihr nicht zusagendem Standort leistet der generelle, auf Kosten der weit weniger von Insekten gefährdeten Laubhölzer erfolgende reine Nadelholzanbau einer Massenvermehrung zahlreicher Insekten Vorschub: Nonne, Kiefernspinner, Kiefernspanner, Forleule, Triebwickler, Rüsselkäfer, Borken- und Bastkäfer u. a. finden dort ihre stärkste Verbreitung.

Die Erhaltung des Laubholzes auf laubholzfähigen Böden, zum mindesten als Mischholz im Nadelholz, ist nicht nur ein Gebot der Bodenpflege, sondern auch des Bestandesschutzes zur Abschwächung von Insektenschäden.

Die schon im Interesse der Nachzucht einer Mehrheit von Holzarten liegende Erhaltung und Ausdehnung des gemischten Waldes, der je nach dem Standort in stetem Wechsel aus reinen wie gemischten Beständen sich zusammensetzt, bietet zugleich auch die sicherste Gewähr für erfolgreiche Vorbeugungsmaßnahmen im Kampfe gegen die Massenvermehrung der gefährlichsten Insekten. Der stete Wechsel in der Zusammensetzung der Bestände, die getrennte Lagerung der Altersklassen, Schirmschlag-, Blenderschlag- und Saumschlagverjüngungen führen zu einer räumlichen Trennung der Fraßherde, erleichtern deren rechtzeitige Entdeckung und Bekämpfung, verhindern die Ausdehnung einer Kalamität auf große zusammenhängende Flächen, und selbst bei förmlichen Katastrophen bleiben im gemischten Wald viele Bestände verschont, andere werden nur beschädigt und können erhalten bleiben, die Niederlegung großer Flächen im Zusammenhang fällt fort, das Waldbild mag sogar stark verändert sein, doch ist es nicht völlig zerstört.

Ferner bietet die Naturverjüngung eine weitaus größere Sicherheit allen sogen. „Kulturverderbern“ gegenüber, als die Saat oder Pflanzung nach vorausgegangenen Kahlschlägen. 
Der Rüsselkäfer ist in den meisten reinen Nadelholzgebieten mit Kahlschlag und künstlicher Kultur eine ständige Gefahr. Wird ihm nicht dauernd durch Stockrodung, Käfergräben, Fangknüppel, Fangrinden usw. Abbruch getan, so folgt oft in kürzester Zeit eine solche Ausbreitung des Insekts, daß man dann nur schwer seiner noch Herr werden kann.

Es wäre nicht richtig, der mehrjährigen Schlagruhe das Wort zu reden. Zwar werden die Schäden am Jungwuchs, wenn erst die im Boden verbliebenen Stöcke als Brutmaterial nicht mehr tauglich sind, erträglichere sein, auch erspart man nicht unwesentliche Kosten der Bekämpfung, doch stehen als negative Faktoren die Bodenverangerung, eine erschwerte und teuerere Kultur und ein mehrjähriger Zuwachsverlust gegenüber, die an sich schon die erstgenannten Vorteile mehr als aufwiegen. Vor allem aber kann der Rüsselkäfer von Jahr zu Jahr sich ungehindert vermehren, sodaß man schließlich doch vor der Notwèndigkeit steht, Vertilgungsmaßnahmen in größerem Umfang anzuwenden. Darum verzichte man auf die Schlagruhe mit ihren Nachteilen in bodenpfleglicher, kultureller und finanzieller Beziehung. Denn für die hierin sich häufenden Summen, deren man verlustig geht, kann man schon viele Rüsselkäfer Jahr für Jahr in systematischer Arbeit vernichten und damit einer förmlichen Kalamität dauernd vorbeugen. Dann sind auch die Schäden der Kahlschlagwirtschaft, die in der großen Mehrzahl der reinen Kiefern- und Fichtengebiete noch auf lange Zeit hinaus die herrschende Verjüngungsmethode wird bleiben müssen, wesentlich gemildert, die Abtriebsflächen sind alsbald wieder in Bestand gebracht, der Boden ist gedeckt, neuer Holzzuwachs erwächst auf dem Boden in unmittelbarem Anschluß an die Nutzung des seitherigen Altbestandes.

Weit größere Gefahren als der Kahlschlag an sich, wenn er in mäßigen Grenzen gehalten wird, ist der Kahlschlag auf großer Fläche: der ausgesprochene Großkahlschlag. Hier pflegen die Kulturverderber: Maikäfer, Hylobius, Pissodes u. a. in Verbindung mit Graswuchs, Schütte, Hallimasch und Wurzelpilz am verheerendsten aufzutreten.

Man mag dem Großkahlschlag in bestimmten Wirtschaftsgebieten ${ }^{\mathbf{1}}$ ) heute wieder das Wort reden - ein anderes Extrem will heute den reinen Plenterwald, und zwischen beiden Extremen werden auch heute wieder mehr denn je alle denkbaren Zwischenstufen von Verjüngungsformen und Betriebssystemen eifrig erfochten -, ein Ideal stellt der Großkahlschlag in bodenpfleglicher und waldbaulicher Beziehung, namentlich aber vom Standpunkt der Verhütung von Insektenschäden ebensowenig dar, wie die Wirtschaft in zusammenhängenden, gleichalterigen und reinen Beständen auf großer Fläche.

Solche Waldbilder verdankten seither vielfach der alten Fachwerksmethode extremster Richtung mit Zusammenlegung der Altersklassen, Großkahlschlägen und dem vermeintlichen waldbaulichen Ideal kunstvoller

1) Vgl. die Verhandlungen des Schlesischen Forstvereins vom 4.-6. Juli 1912 in Beuthen (Oberschlesien): Uber Groß- und Kleinkahlschläge bei Kiefern (Berichterstatter Forstm. J u n a ck in Neudeck O.-S.). 
Saat- und Pflanzmethoden zur Nachzucht reiner Nadelholzbestände ihre Entstehung.

Die auf mathematischer Grundlage sich entwickelnde, noch junge Forsteinrichtung führte zum Schematismus, sie wurde in Norddeutschland zur Schablone der Großflächenwirtschaft und zwang dem IValde ein System räumlicher Ordnung auf, das seinem natürlichen Aufbau nicht entsprach, das namentlich in Verbindung mit der irrigen Lehre vom höchsten Waldreinertrag in hohen Umtrieben, bei unzureichender Bestandspflege und dem Ideal reiner Nadelholzbestände die Kunst des Waldbaus verkümmern ließ und einen Mischbestand nach dem andern einem verfehlten System opferte.

Die Kunst der Naturverjüngung, die noch bis Anfang des 19. Jahrhunderts gelang, schwand mit den hohen Waldreinertragsumtrieben und ihren verangerten, längst nicht mehr empfänglichen Böden dahin. Auf den ausgedehnten Kahlschlagkulturen richteten Maikäfer und Rüsselkäfer große Verheerungen an. In den ausgedehnten reinen und gleichalterigen Stangenhölzern hielten Spinner, Spanner und Eule ihren Einzug.

Eine einseitige Auffassung der Aufgaben der Forsteinrichtung und des ökonomischen Wirtschaftszieles schuf Waldbilder, die ebensowenig der Bodenpflege, der Erhaltung einer Mehı heit standortsgemäßer Holzarten im gemischten Wald und einer naturgemäßen Erziehung und Verjüngung der Bestände entsprach, als den Grundsätzen der vorbeugenden Maßnahmen gegen eine Massenvermehrung zahlreicher Insekten.

Die romehmste Aufgabe der Forsteinrichtung ist die Sicherung eines möglichst naturgemäßen und frei gestalteten Waldbaues im Hinblick auf das ökonomische Ziel der nachhaltigen Erzeugung wertrollsten Holzzuwachses im Rahmen eines zeitlich und räumlich wohlgeordneten Betriebes. Damit erfüllt sie zugleich auch am besten die Aufgaben des Forstschutzes, die auf eine Verhütung größerer Insektenschäden hinauslaufen.

Dann werden die Extreme eines übertriebenen Nadelholzanbaues, der Zusammenlegung ausgedehnter reiner Bestände gleichen Alters, der Großkahlschlagwirtschaft und forcierten künstlichen Kultur vermieden, die sämtlich der Entstehung großer Insektenschäden Vorschub leisten.

Die Erhaltung einer Mehrheit von Holzarten im gemischten Wald und ihre möglichst naturgemäße Verjüngung genügt aber allein noch nicht zur Schaffung einer sicheren Grundlage für die Verhütung von größeren Insektenkalamitäten, vielmehr muß eine sorgsame und planmäßig gehandhabte Bestandserziehung jene wichtigste Grundlage weiter festigen und erhalten.

Rationelle Durchforstungen, die schon frühzeitig allen gutveranlagten Stämmen eine kraftrolle Entwicklung sichern, alles kränkelnde, beschädigte oder sonst anfällige Material beseitigen und damit den Angriffen bestimmter Insekten, namentlich der Borken- und Bastkäfer schon erheblich vorbeugen, lassen Bestände erwachsen, die im übrigen durch ihre kräftigen Kronen weitaus widerstandsfähiger gegen Nonne, Spinner, Spanner, Eule, Blattwespen usw. sind, als in drangvoller Enge stammzahlreich erwachsene Stangenhölzer mit hoch hinaufgeschobenen kleinen Kronen, die an sich schon kümmerlich entwickelt und der Ernährung des 
Baumes in gesunden Tagen kaum das Notwendigste vermittelnd, bei dem ersten stärkeren Insektenfraße völlig aufgezehrt und mit einem Schlage vernichtet werden, so daß die Bestände auf großen Flächen absterben. Wie viel günstiger stehen kräftig erzogene, zwar weniger stammzahlreiche, aber mit einer wesentlich größeren Kronenmasse ausgerüsteten Bestände da. Sie werden nicht in dem Maße kahlgefressen, daß schon im ersten Jahr ihre Erhaltung zweifelhaft erscheint.

Die Nonne bevorzugt zur Eiablage zuden dicht geschlossene Bestände, zumal undurchforstete Stangenhölzer, zu denen WVind und Sonne wenig Zutritt haben. Dort sind auch häufig die ersten Fraßherde zu beobachten.

Noch weit freiere Hand hat der Wirtschafter in der Bestandspflege gemischter Bestände. Die führende Holzart, z. B. Kiefer mit Buche, Kiefer mit Fichte, kann in lockerer Kronenstellung gehalten werden, das Mischholz bietet neben dem Boden- und Bestandsschutz reichlichen Ersatz, die Buchen, die Fichten schieben sich in das gelockerte Kronendach herauf, die Hauptholzart — in dem gedachten Beispiel die Kiefer — ist nicht nur an sich kräftiger entwickelt und widerstandsfähiger, sondern es wird auch bei einem Nonnenfraß ein erheblicherer Teil der zu Boden kommenden Raupen auf die Mischhölzer abgelenkt. Bei reichlicherem Buchenunter- und zwischenstand ist dessen Stammzahl um ein Vielfaches größer als die Stanmzahl des herrschenden Kiefernbestandes. Die Mehrzahl aller wiederaufbaumenden Raupen gelangt auf die Buchen oder Fichten. Der Kiefernbestand wird entlastet. Die Buchen ertragen den Kahlfraß. Mag auch der Fichtenunterstand vernichtet werden, der Hauptbestand der Kiefer ist gerettet.

Ähnlich verhalten sich Mischbestände von Fichte mit Buche. Und wenn dort selbst ein Teil der Fichten einem Nonnenfraße zum Opfer fällt, dann bleiben die Buchen erhalten, und wenn sie nur noch einen Schirmbestand abgeben, in dessen Schutz ein neuer Jungbestand erzogen werden kann.

Auch bei der Holzernte lassen sich manche Vorbeugungsmaßnahmen unschwer durchführen. Hierher gehört namentlich die rechtzeitige Entrindung der Nadelhölzer, tunlichst schon in Verbindung mit dem Hiebe, um den Borken- und Bastkäfern das Brutmaterial zu entziehen. Ferner ist es eins der wirksamsten Vorbeugungsmittel gegen den großen braunen Rüsselkäfer, wenn, wie dies im norddeutschen Kieferngebiet üblich ist, die Stämme stehend gerodet und mit dem "Waldteufel“ so gefällt werden, daß der ganze Wurzelstock herausgezogen wird. Endlich gehört die saubere Aufarbeitung aller Hölzer und ihre tunlichst rasche Abfuhr hierher.

Überblickt man die vielfachen Maßnahmen, die in erster Linie auf dem Gebiete der Standortspflege und des Waldbaues, in zweiter Linie auf jenem der Forsteinrichtung und Forstbenutzung liegen, so ist es nicht schwer, in dem Gesamtbild als Kernpunkt aller Vorbeugungsmaßnahmen das Ergebnis zu erkennen, daß in einer wohlgeordneten, den Grundsätzen eines natürlichen Waldbaues wie den öknomischen Forderungen gleichermaßen gerecht werdende, von schablonenhafter Einseitigkeit sich freihaltenden Wirtschaft zugleich auch die besten Grundlagenzur Verhütung größerer Insektenkalamitäten geschaffen sind. 
Nicht überall werden sich in idealer Weise diese Grundlagen vereinigen lassen. Wo wirtschaftliche Fehler in der Zusammensetzung und der Lagerung der Bestände vorliegen, läßt sich nicht von heute auf morgen WVandel schaffen.

Das Streben muß aber immer wieder in erster Linie auf die Nachzucht der standortsgemäßen Holzarten, wo irgend angängig in gemischten Beständen, in Verbindung mit guter Bodenpflege, auf eine rationelle Bestandserziehung und tunlichst naturgemäße Verjüngung gerichtet sein. Wo der Standort nur eine Holzart zuläßt, wie namentlich im reinen Kiefern- und Fichtengebiet, vermeide man die großen Kahlschläge, trenne die Altersklassen, schaffe eine genügende $Z$ ahl von Anhieben und bekämpfe dauernd die kulturverderbenden Insekten, namentlich den Rüsselkäfer durch Stockrodung, Fanggräben und Fangknüppel bezw. -rinden.

Wo die künstliche Kultur, wie wiederum in den meisten reinen Kiefern- und Fichtengebieten, die Regel bildet und meist wohl noch lange Zeit bilden wird, sorge man für die Verwendung besterzogener, kräftiger Pflanzen aus eigenen Kämpen, für sorgsame Kulturausführung, und meide zu weite Verbände, da bei größerer Pflanzenzahl die Insektenschäden sich verteilen. Bei der Kiefer besitzen die Streifenkulturen, die bodengleich oder etwas erhöht gegraben werden, große Vorzüge, da sie in den ersten Jahren leicht von einwachsendem Gras, Heide usw. durch Behacken freigehalten, auch sehr viel erfolgreicher mit Bordelaiser Brühe gegen die Schütte bespritzt werden können. Dadurch werden von vornherein kräftige Pflanzen erzogen. Zugleich aber wirkt der den nackten Boden in den Streifen treffende Regenschlag, daß der aufspritzende lockere Boden an den kleinen Stämmchen der Pflanzen haften bleibt und diese mit „Erdhöschen" umgibt, die gegen Rüsselkäferfraß erfolgreich schützen. Das Freihalten der Pflanzen vom Graswuchs in solchen Streifen wirkt auch vorbeugend gegen die wurzelbrütenden Hylesinen, deren Imagines besonders in Lochpflanzungen mit eingelagertem Grasfilz schädlich werden. Auch für dic Fichte wird vielfach, insoweit es sich um Verhältnisse ähnlicher Art handelt, die Streifenpflanzung neuerdings empfohlen.

In Maikäferfraßgebieten empfiehlt sich die Kultur in durchlaufenden Streifen weniger, da der Engerling gern den Reihen nachgeht und so leichter Pflanze für Pflanze auffindet. Hier empfiehlt sich eine häufige Unterbrechung der Streifen in der Form von hochgegrabenen Stückriefen.

Die größere Pflanzenzahl liegt gleichermaßen im Interesse der kräftigen Bestandserziehung, da man bei frühzeitigem Eingriff unter einer größeren Zahl von Stämmen Auslese halten und somit nur wirklich gut veranlagte Bestandsglieder in Pflege zu nehmen in der Lage ist.

Die Erziehung zuwachsfreudiger, widerstandsfähiger Bestände mit kräftiger Kronenbildung, die schon von Jugend an etwa ein Drittel der Schaftlänge umfaßt, in guter räumlicher Verteilung der Altersklassen bildet eine der wichtigsten Grundlagen der Waldwirtschaft.

Sie ist zugleich auch das wertvollste Vorbeugungsmittel kultureller Art im Kampfe gegen die Insektenschäden. 


\section{Die biologische Bekämpfung.}

Die biologische Bekämpfung (im weiteren Sinn) schließt alle jene Maßnahmen in sich, die auf eine Unterstützung der natürlichen Feinde der Schädlinge hinauslaufen, also:

a) Schutz und Verwendung der insektenvertilgenden Säugetiere,

b) Schutz und Verwendung von insektenvertilgenden Vögeln,

c) Schutz, Vermehrung und Verbreitung von Parasiten und räuberischen Arthropoden, und

d) Begünstigung und Verbreitung von Mykosen und anderen Infektionskrankheiten.

\section{a) Schutz und Verwendung von insektenvertilgenden Säugern.}

Eine direkte Schonung nützlicher Säuger kommt nur in seltenen Fällen in Anwendung. Wenn der Forstmann darauf sieht, daß Fledermäuse, die in gefällten, hohlen Bäumen gefunden werden, nicht mutwillig von den Waldarbeitern getötet und die betreffenden Bäume im Winter bis zum Frühjahr unzerstückt liegen gelassen werden, daß ferner der Maulwurf nicht unnötig weggefangen und der Fuchs nicht übermäßig dezimiert werde, so hat er seine Pflicht völlig erfüllt. Wie wichtig speziell die Schonung der Fledermäuse ist, geht aus den oberen (S. 225) mitgeteilten Tatsachen über die her vorragende Rolle dieser Tiere im Kampfe gegen gewisse Schädlinge ohne weiteres hervor.

Wir dürfen aber nicht vergessen, daß viele als Insektenvertilger nützliche Säuger oft aus anderen Gründen verfolgt werden müssen. So wird man den Maulwurf trotz seiner Feindschaft gegen den Engerling z. B. in Saatkämpen nicht dulden, ebenso wird das Schwarzwild, das so wesentlich bei der Vertilgung von der in der Bodendecke überwinternden Schädlinge mitwirkt, in einem fein bewirtschafteten Forste seiner übrigen forstschädlichen Eigenschaften halber, dennoch nicht geschont werden können, ganz abgesehen davon, daß schon die Rücksicht auf die angrenzenden Felder dies häufig verbietet (N.).

Dieser letzte Punkt stellt ein sehr lehrreiches Beispiel dar, wie durch die Kultur notwendigerweise ein für die Erhaltung des Gleichgewichtes sehr wesentlicher Faktor ausgeschaltet werden mußte. Es ist zweifellos, daß der Rückgang oder die gänzliche Entfernung des Schwarzwildes ein gut Teil Schuld an der Vermehrung so mancher schlimmer Schädlinge (wie der Kieferneule, des Kiefernspanners, der verschiedenen Blattwespen usw.) tragen. Man sucht denn auch den Ausfall vielerorts dadurch wieder auszugleichen, daß man die Wildschweine durch Kulturschweine ersetzt, indem man letztere in die befallenen Bestände eintreibt. Die Erfolge, die damit erzielt wurden, sind zum Teil recht befriedigende; sie hängen natürlich von verschiedenen Umständen ab, wie von der Zahl und der Rasse der zur Verfügung stehenden Schweine (am besten eignen sich die gewöhnlichen noch wenig veredelten Landrassen, die noch täglich zur Weide getrieben werden und infolgedessen die Fähigkeit, in der freien Natur Nahrung zu finden, noch nicht in dem hohen Maße verlernt haben wie die hochgezüchteten Rassen), - sodann von 
der Bodenbeschaffenheit (im lockeren Boden werden die Schweine leichtere Arbeit haben als im Lehm- oder Tonboden), - ferner von der Zeit, die für den Eintrieb zur Verfügung steht (Blattwespenkokons, die mehrere Jahre überliegen, stellen natürlich ein günstigeres Obiekt dar als die Eulenpuppen, die nur während des Winterhalbjahres im Boden sich befinden), ferner von der Dichtigkeit der Besetzung und der Ausdehnung des befallenen Gebietes usw. (Ausführlichere Angaben über die Haltung der Schweine und alle beim Schweineeintrieb zu beachtenden Maßregeln gibt Eckstein in seiner Technik des Forstschutzes).

\section{b) Schutz und Verwendung insektenvertilgender Vögel.}

Weit wichtiger als der Schutz der Säugetiere ist der Vogelschutz, wie sich ja schon aus einer einfachen Vergleichung der oben mitgeteilten Tatsachen über die Bedeutung der Säugetiere und Vögel im Kampf gegen die Forstschädlinge ohne weiteres ergibt. Auf dem Gebiet des Vogelschutzes sind in den letzten Jahren große Fortschritte gemacht worden, speziell in Deutschland, welches in dieser Beziehung gegenwärtig an der Spitze der Nationen steht. Ist doch Deutschland auch die Heimat des wissenschaftlichen Vogelschutzes. Denn erst durch die Versuche des Freiherrn v. Berlepsch auf Seebach ist der Vogelschutz auf eine sichere Grundlage gestellt worden, die eine Anwendung im großen ermöglichte. In erstaunlich kurzer Zeit haben sich die v. Berlepschen Grundsätze die Welt erobert, so daß heute bereits in den meisten Kulturländern Vogelschutz in der von v. Berlepsch ausgearbeiteten Methode getrieben wird. In Deutschland vor allem hat die Vogelschutzbewegung mächtig an Boden gewonnen und alle Kreise der Bevölkerung ergriffen. Zahlreiche Vereine sind allenthalben entstanden, die lediglich der Förderung des Vogelschutzes dienen, in den meisten Bundesstaaten sind Vogelschutzkommissionen gebildet worden, welche die Aufgabe haben, den Vogelschutzgedanken möglichst allgemein zu verbreiten und die nötige Organisation in die Wege zu leiten. Kurz es geschieht von staatlicher wie von privater Seite alles, was geschehen kann, um den Rückgang der Vogelwelt, den die Kultur mit sich gebracht hat, möglichst wieder auszugleichen. So erfreulich dieser hohe Enthusiamus ist, so birgt er - wenigstens in praktischer Hinsicht — doch auch eine Gefahr in sich: Er kann nämlich allmählich die Meinung erzeugen, daß der Vogelschutz das Allheilmittel gegen alle landwirtschaftlichen und forstlichen Schädlinge darstellt, und daß man mit Ausübung des Vogelschutzes genug gegen diese Ver derber getan habe. Man kann auch in der Tat gar nicht so selten Äußerungen hören, die sich in dieser Richtung bewegen. Es kann demgegenüber nicht oft genug daran erinnert werden, daß dem Vogelschutz in seiner Wirkung deutliche Grenzen, und zwar mitunter recht enge, gezogen sind. Die Regulierung der Vermehrungszahl wird eben bei vielen Schädlingen weit mehr durch andere Faktoren (wie vor allem Parasiten und Raubinsekten) bewirkt als durch die vertilgende Tätigkeit der Vögel, und in solchen Fällen kann man die Gleichgewichtserhaltung natürlich auch nicht von den Vögeln erwarten. Daß von dem Rückgang der Vögel allein (oder in der Hauptsache) die Zunahme der Schädlinge nicht ohne weiteres ab- 
geleitet werden darf, geht aus der Tatsache hervor, daß doch viele Schädlinge (wie z. B. die Nonne) oft jahrzehntelang sich nicht bemerkbar gemacht haben (und zwar in einer Zeit, wo man noch keinen Vogelschutz trieb), um dann plötzlich zu einer Massenvermehrung zu gelangen, ohne daß aber in diesen Zeiten ein auffallender Unterschied in der Zahl der Vögel bemerkt worden wäre. Die Tätigkeit der Vögel kommt gewiß bei allen Schädlingen als einer unter den vielen vermehrungsbeschränkenden Faktoren in Betracht; doch ist seine Bedeutung bei den verschiedenen Schädlingen sehr ungleich, wie ja oben des näheren ausgeführt wurde; und dementsprechend werden wir auch unsere Erwartungen bezügl. der Wirkung des Vogelschutzes je nach der Art des Schädlings verschieden hoch einzustellen haben.

Der Vogelschutz ist ein eigenes Gebiet für sich geworden (gibt es• doch auch besondere Beamte für Vogelschutz), und verfügt bereits über eine überaus umfangreiche eigene Literatur. Es kann daher davon Abstand genommen werden, hier* ausführlich darauf einzugehen, zumal es eine Anzahl ausgezeichneter, billiger Schriften gibt, die jedermann zugänglich sind, und die die ganze Vogelschutzfrage in kurzer bündiger Weise behandeln (wie vor allem: Hiesemann, lösung der Vogelschutzfrage nach Freiherrn v. Berlepsch; Hennicke, Vogelschutzbuch und das ausführlichere Handbuch des Vogelschutzes; Ha enel, Unsere heimischen Vögel und ihr Schutz). Nur die Hauptgrundsätze des Vogelschutzes seien hier mit wenigen Worten angeführt.

Der erste und wichtigste Punkt
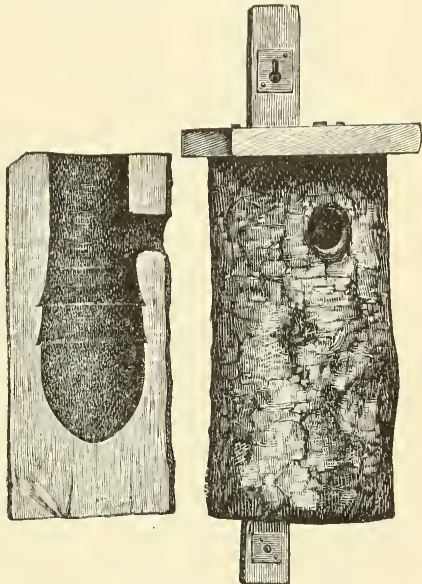

Fig. 214. Berlepsche Nisthöhle. Aus Hiesemann.

bei der Ausübung des Vogelschutzes

ist die Schaffung von Nistgelegenheiten; denn ohne geeignete Nistplätze ist trotz Vogelschutzgesetze und sonstiger Bemühungen eine gedeihliche Entwicklung des Vogellebens von vornherein ausgeschlossen. Für den Forstmann kommt es dabei vor allem auf die Höhlenbrüter an, denn diese sind es ja in erster Linie, die unter der modernen Forstkultur am meisten Not leiden, und außerdem befinden sich gerade unter diesen auch die wichtigsten Vertilger der Forstschädlinge. Und so hat sich die vogelschützlerische Tätigkeit des Forstmannes vor allem auf das Aushängen von Nisthöhlen zu beziehen. Über die Art der zu wählenden Nistkästen dürften heute wenig Zweifel bestehen, da ja die v. Berlepschen Nisthöhlen (Fig. 214) allgemein als die besten und wirksamsten anerkannt sind. Da es sich im Walde in der Hauptsache um die Heranziehung der Meisen und Stare handelt, so kommen vor allem die Größen $A$ und $B$ (A- und B-Höhle) in Betracht, während die übrigen Größen und die sog. Halbhöhlen im forstlichen Vogelschutz in weit geringerem Maße zur Verwendung gelangen. Auch die 
Erhaltung und Vermehrung der Freibrüter wird sich der Forstmann angelegen sein lassen, wenn diese für den Wald auch bei weitem nicht die Rolle spielen wie die Höhlenbrüter. Er kann in dieser Beziehung schon manches erreichen, wenn er die dichten Junghölzer während der Monate April bis Juni sperrt, und wenn er außerdem strenge darauf sieht, daß

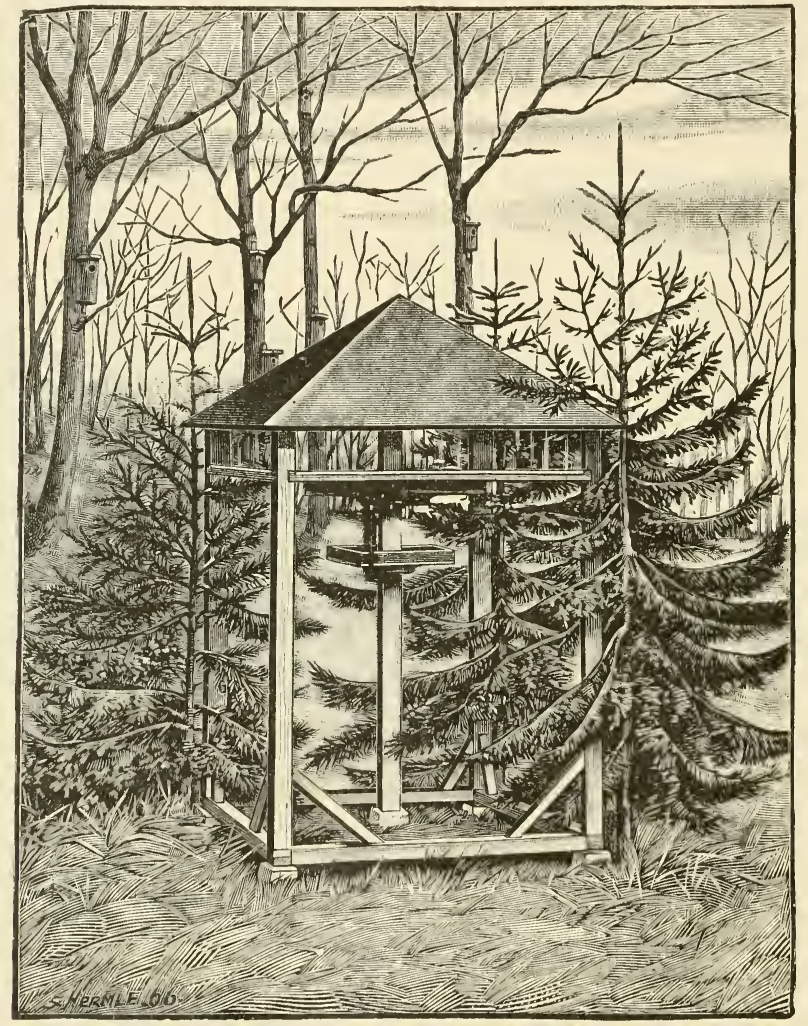

Fig. 215. Hessisches Futterhaus. Auf dem unteren Futtertisch wird nur so lange gefuttert, bis die Vögel den oberen, eigentlichen Futterplatz gefunden haben. Aus Hi es emann.

während der Brutzeit die Holz- und Reisigabfuhr unbedingt ruht (Haenel). Ferner hat er sein Augenmerk auf die Erhaltung und Anpflanzung von geeigneten Sträuchern aller Art, Hecken, Unterholz usw. zu richten, wobei ev. durch eine besondere Schnittbehandlung die Nistgelegenheit noch wesentlich erhöht werden kann. Wo sich die Gelegenheit bietet, eigene Vogelschutzgehölze, die durch geschickte Auswahl, Anordnung und Behandlung der Pflanzen (nach den v. Berlepschen Vorschriften) zur höchst erreichbaren 
Konzentration von Brutstätten führen, anzulegen, mag diese Gelegenheit ergriffen und ausgenützt werden.

Der zweite Punkt bei der Ausübung des Vogelschutzes betrifft die Winterfütterung, deren Hauptzweck darin besteht, die im Winter bei uns verbleibenden Vögel über die schlimmste Zeit hinwegzubringen. Es steht fest, daß in strengen Wintern eine große Anzahl von Vögeln an Nahrungsmangel zugrunde gehen; dieser Ausfall, der natürlich auch nicht ohne Wirkung auf das Insektenleben bleibt, kann durch eine rationelle Winterfütterung wesentlich herabgedrückt werden. Die Fütterung muß, wenn sie ihren Zweck erreichen soll, so eingerichtet werden, daß das Futter den Vögeln stets unter allen Witterungsverhältnissen selbst beim schroffesten Witterungswechsel, wie Wirbelschnee, Wind, Regen, Glatteis, unbedingt, und zwar in bester Beschaffenheit zugänglich bleibt, und daß außerdem nichts davon verloren geht, sondern das gesamte Futter bis zum letzten Rest ausschließlich den Vögehn zugute kommt. Diesen Bedingungen entspricht am besten das sog. „hessische Futterhaus", das man sich event. selbst herstellen kann (Fig. 215). Empfehlenswert ist außerdem noch die automatische Futterglocke (Fig. 216), die völlig mäusesicher ist, und die Bruhn sche Meisendose mit dem Futtertrog Antispatz.

Mls dritter Punkt kann die Schaffung von Tränken und Badegelegenheiten genannt werden. „Einige Vogelarten sind zwar in ihren Ansprüchen an das flüssige Element

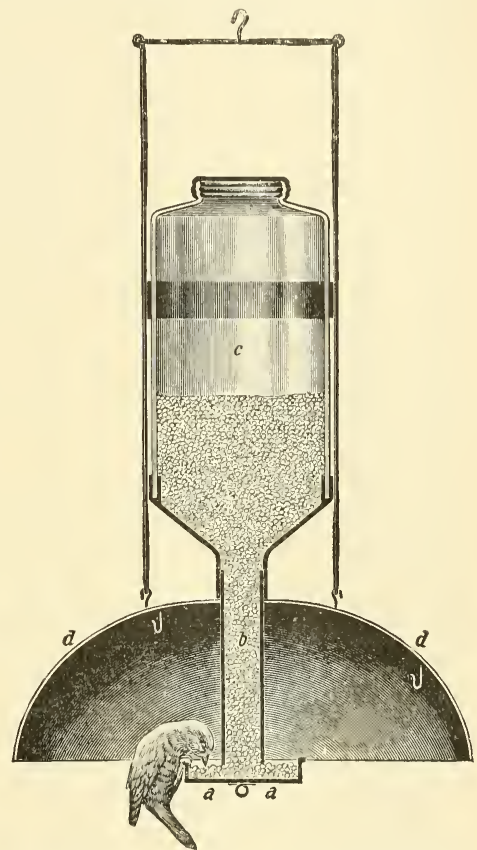

Fig. 216. Futterglocke (Längsschnitt). a a Futterschale; $b$ Zufuhrrohr; $c$ Futterbehälter; $d d$ Metallglocke. Aus Hiesemann. so bescheiden, daß sie selbst in den trockensten Gebieten sich wohl und munter fühlen, wie z. B. die Hauben meise, die in den dürrsten Föhrenkrüppelbeständen, stundenweit vom offenen Wasser entfernt, angetroffen wurde. Doch kann nicht bestritten werden, daß die Anwesenheit von Wasser die Ansiedelung der meisten Vögel wesentlich erleichtert“. „Die Arbeit des praktischen Vogelschützers in dieser Beziehung wird sich unter normalen Verhältnissen darauf beschränken können, das von Natur aus schon vorhandene IVasser zu erhalten, d. h. übermäßige Entwässerung zu verhïten und weiter dafür zu sorgen, daß die vorhandenen Wasserstellen den kleinen Vögeln auch zugänglich gemacht werden“ (Haenel). In ganz trockenen Gegenden wird man allerdings dazu greifen 
müssen, künstliche Wasserstellen (kleine Becken aus Zement u. dgl.) zu schaffen, die regelmäßig mit frischem Wasser beschickt werden (vgl. Schwangart, Vogeltränken).

Die letzte aber durchaus nicht unwichtigste Aufgabe des praktischen Vogelschutzes ist die Niederhaltung der ausgesprochenen Vogelfeinde. Als solche sind vor allem Hühnerhabicht, Sperber und die verschiedenen Würger zu nennen, sodann Elster und Eichelhäher, ferner Eichhörnchen, Iltis, Marder, Wiesel und die wildernde Katze. Im allgemeinen wird der Forstmann schon aus jagdlichen Gründen dafür sorgen, diese Tiere nicht allzusehr aufkommen zu lassen und sie nach Kräften abzuschießen. Mit besonderem Nachdruck sollte die Vertilgung der wildernden Katzen betrieben werden, wozu man sich am besten der sog. Kasten- oder Prügelfallen bedient. Nicht zu vergessen ist auch der Sperling, der durch sein wüstes Gebahren und fortgesetztes Lärmen andere Vögel von den Futter- und Nistplätzen vertreiben und den Erfolg der Vogelschutzmaßnahmen wesentlich beeinträchtigen kann: „Je nach der Abnahme der Sperlinge steigt die Zunahme der anderen Vögel“, sagt mit Recht v. Berlepsch. Daher ist gegen dieses überall gegenwärtige Gesindel der Kampf mit allen Mitteln aufzunehmen, am besten im Winter, da sie auf einem mit Futter bestreuten, schneefreien Platz oft massenweise mit einem Schuß erlegt oder mit einem großen Zugnetz gefangen werden können.

Endlich erfährt die Ausübung des Vogelschutzes durch gesetzliche Vorschriften eine kräftige Unterstützung. So wurde am 30. Mai 1908 für das Deutsche Reich ein Vogelschutzgesetz erlassen, das „bis auf wenige Kleinigkeiten als ganz vorzüglich bezeichnet werden müßte, wenn es überall mit dem nötigen Nachdruck durchgeführt würde" (Haenel). Außerdem haben verschiedene Bundesstaaten durch besondere landesgesetzliche Regelung noch ergänzende Bestimmungen erlassen, von denen wohl die Bayerische Verordnung rom 5. Mai 1913 am weitesten geht, indem dadurch sämtliche insektenfressenden Singvögel während des ganzen Jahres vollkommen geschützt sind.

Außer dem Schutz der Vogelwelt kommt auch noch die direkte Verwendung von zahmem Geflügel zur Vertilgung von Schädlingen in Betracht, und zwar in Form von „Hühnereintrieb“. Haushühner und Puten sind imstande, große Mengen von Puppen, die in der Bodendecke sich befinden, zu vertilgen. Man kann sie daher dazu benützen, bei Spannerkalamitäten usw. die befallenen Abteilungen von den Puppen zu reinigen, indem man mit ihnen in großer Zahl in den verschiedenen Orten herumzieht, sie überall so lange haltend, his sie die Reinigungsarbeit gründlich vollendet haben. Natürlich müssen ihnen Ställe zur Verfügung gestellt werden, die des ständigen Ortswechsels halber entweder als Ganzes transportabel sind, oder so konstruiert sind, daß sie leicht abgerissen und wieder aufgeschlagen werden können. (Näheres darüber siehe bei Eckstein, Technik des Forstschutzes S. $147 \mathrm{ff}$.)

\section{c) Schutz und Verwendung von Parasiten, Raubinsekten und anderen räuberischen Arthropoden.}

Während in bezug auf Vogelschutz Deutschland in der ersten Reihe steht, so befindet es sich in bezug auf die Bekämpfung mittels Parasiten und 
Raubinsekten in arger Rückständigkeit. Es mag sein, daß die zu starke Betonung des Vogelschutzes die anderen Bekämpfungsrichtungen etwas in den Hintergrund drängte; zum größten Teil jedoch dürfte die Ursache der Rückständigkeit darin gelegen sein, daß es bisher an der nötigen Organisation gefehlt hat. Denn die parasitäre Bekämpfung setzt ein ungemein eingehendes Studium der Parasiten usw. voraus, welches sehr viel Zeit kostet, ${ }^{1}$ ) und ein größeres Personal von Hilfskräften, die Errichtung von temporären Waldlaboratorien usw. erfordert. Alles Dinge, die uns gegenwärtig noch fehlen. Da es aber zweifellos schon in der nächsten Zukunft in dieser Beziehung besser werden und die parasitäre Bekämpfung auch bei uns eine größere Rolle spielen wird, so dürfte es angezeigt sein, einen kurzen historischen Überblick über die bisherigen Meinungen und Erfolge auf diesem Gebiet zu geben; um so mehr, als es für die zukünftige Forschung von Interesse sein muß, die bisher vorgeschlagenen und beschrittenen Wege kennen zu lernen.

Die Idee, Parasiten und Raubinsekten im Kampfe gegen Schädlinge zu verwenden, ist schon sehr alt. Sogar schon aus dem 12. Jahrhundert haben wir Nachrichten darüber. So haben die Chinesen bereits $\mathrm{zu}$ jener Zeit Ame is en gesammelt, um sie in ihre Gärten zu verpflanzen und gegen die Schädlinge ihrer Orangen- und Mandarinenbäume loszulassen. Es ist sogar eine besondere Arbeiterklasse, die ,Ameisensammler“, entstanden. Und auch die Javaner benutzen seit uralter Zeit Ameisen, um die Früchte der Mangrovebäume gegen die Angriffe eines Rüsselkäfers zu schützen; sie verbinden dabei die einzelnen Bäume durch Taue u. dgl., um den Ameisen direkte Wege von einem Baum zum anderen darzubieten und ihnen so einen größeren Wirkungskreis zu verschaffen.

$\mathrm{Zu}$ Beginn des vorigen Jahrhunderts machten $\mathrm{K}$ i r by und $\mathrm{Spence}$ (Einleitung in die Entomologie. Bd. I. S. 292) auf die nützliche Rolle der Coccinelliden aufmerksam und sprachen zugleich auch den Gedanken aus, dieselben künstlich zu vermehren. Ich führe die Stelle wörtlich an, da hier wohl die erste Außerung nach dieser Richtung hin von wissenschaftlicher Seite vorliegt: „Im Jahre 1807 waren die Küste von Brighton und alle Wasserplätze auf der südlichen Küste ganz bedeckt mit Marienkäfern, zum großen Erstaunen der Einwohner, welche nicht wußten, daß diese kleinen Gäste von den benachbarten Hopfengärten hergewandert waren, wo sie in ihrem Larvenzustand jeder seine Tausend oder zehnmal Tausend Blattläuse erlegt hatten, welche die Hoffnung des Hopfenbauers so oft vernichten. Es ist ein Glück, daß in vielen Ländern die Kinder diese freundlichen Coccinellen in Schutz genommen haben. In Frankreich betrachten sie dieselben als der heiligen Jungfrau geweiht und nennen sie Vaches de Dieu, bête de la Vierge usw., und bei uns sichert ihnen das Mitleid für das harte Schicksal einer Mutter, deren, Haus in Flammen steht und deren Kinder verbrennen wollen', eine milde Behandlung und Freiheit zu. Selbst die Hopfenbauern erkennen ihre Nützlichkeit, und wie ich erfahre, dingen sie Buben, um Vögel abzuhalten, daß sie sie nicht zerstören. Wenn wir uns eine $M$ ethode erfänden, um diese Kerfe zu vermehren, so würden wir nicht nur, was Dr. Darwin vorgeschlagen, unsere Gewächshä user von Blat tläusen säubern, auch unsere Hopfenernte viel sicherer

1) So werden z. B. seit 2 Jahren im hiesigen Institut Studien über die Lebensweise der Tachinen gemacht. Diese Zeit reicht aber noch lange nicht hin, die Lebensweise nur einer einzigen Tachinenart so $\mathrm{zu}$ erhellen, daß man zu eine11 abgeschlossenen Urteil über ihre eventuelle Verwendbarkeit zur Bekämpfung gelangt. Dazu dürften noch weitere 2 Jahre notwendig sein. Schon allein geeignete Methoden für die Untersuchung ausfindig $\mathrm{zu}$ machen, ist ein Studium für sich (vgl. P r e l1). 
machen a $1 \mathrm{~s}$ jetzt. Selbst ohne diese Kenntnis ist nichts so leicht, wie ich erfahren habe, eine Pflanze oder einen Baum zu reinigen, als wenn man mehrere Larven von Coccinellen oder von blattlausfressenden Fliegen, von weniger geschätzten Pflanzen gesammelt, auf dieselben setzt."

In Frankreich versuchte um das Jahr 1840 Prof. Boisgiraud in Poitiers verschiedene Schädlinge mit Hilfe von Raubinsekten zu bekämpfen, wie den Schwammspinner mit Calosoma sycophanta, ferner Forficula mit Hilfe von Staphylinus olens und Carabus auratus usw., worüber von N. Joly in der "Revue zoologique" 1842 berichtet wurde. Diese Arbeit scheint Aufsehen erregt zu haben; denn im Jahre 1843 schrieb die „Commissione tecnica della Sociétà d'incoraggiamento d'arti e mestieri di Milano" einen Preis (Goldene Medaille) aus für denjenigen, der eine gute Methode fände zur künstlichen Vermehrung der räuberischen Insekten, die zur Vernichtung der Schädlinge verwendet werden können. Daraufhin wurde von Villa eine Arbeit eingereicht (,Degli insetti carnivori adoperati a distruggere le specie dannose all'agricoltura“), die in der Hauptsache den Vorschlag enthielt, für Schädlinge, die auf Bäumen leben, kletternde Carabiden, für Blumenschädlinge $\mathrm{Staphy}$ lin iden, und für solche Schädlinge, die am Boden leben, die nicht kletternden Laufkäfer zu verwenden.

Später machte der Franzose D e c a $\mathrm{x}$ den Vorschlag, bei der Bekämpfung des A p f elblü tenstechers (Anthonomus pomorum) dessen Parasiten mit $\mathrm{zu}$ verwenden. Und zwar in der Weise, daß man die abgeschnittenen Knospen nicht gleich verbrennen, wie das bisher Gebrauch war, sondern sie in Gazekäfigen aufbewahren solle, die von Zeit zu Zeit geöffnet werden müssen, um die entschlüpften Parasiten (Ichneumoniden und Braconiden) herauszulassen. Im Jahre 1880 führte er diese Idee in der Praxis aus: er sammelte in der Picardie von 800 Bäumen etwa 1 Million befallene Knospen und behandelte sie in obiger Weise, wobei er ca. 250000 Parasiten erhielt, welche im folgenden Jahr das Zerstörungswerk kräftig unterstützten. Die gleiche Prozedur wurde noch einmal ausgeführt, und es gelang dadurch, den Blütenstecher in dem betreffenden Obstgarten völlig zu unterdrücken.

Ein ähnlicher Gedanke kommt in dem Vorschlag Marchals zum Ausdruck, die Stoppeln der von der Hessenfliege befallenen Felder nicht zu verbrennen, da man das Risiko läuft, daß der Schädling bereits ausgeflogen ist und nur die in den Stoppeln verbleibenden Parasiten vernichtet werden.

Auch in Deutschland hat man sich mehrfach mit der Frage der Parasitenverwendung beschäftigt, und zwar vor allem von seiten der Forste 11 tomologie. - Der erste Vorschlag nach dieser Richtung ging wohl von Hartig (1827) aus, indem er die Anlage von sog. „R a u penzwingern“ empfahl. „Das Wesentliche dieser Maßregel besteht darin, daß man auf durch Gräben isolierten Garten- oder Waldorten eine möglichst große Menge von Raupen vereinigt, in der Hoffnung, daß an solchen künstlich gebotenen Brutstätten sich die Schlupfwespen alsbald in Menge zusammenfinden, und so stark vermehren würden, daß diese, wenn sie ausflögen, den benachbarten Wald oder Garten von Raupen säuberten" ( $\mathrm{Nitsche).} \mathrm{-} \mathrm{Dann} \mathrm{hat} \mathrm{der} \mathrm{Oberforstmeister}$ v. B ü low-Ri eth, ein ganz vorzüglicher Beobachter, dessen Schriften zul lesen auch heute noch ein Genuß ist, mehrfach auf die praktische Bedeutung der Parasiten mit Nachdruck hingewiesen. „Die Fliegen und Schlupfwespen sind die Schutzengel unserer Kienwaldungen!" ruft er in seiner Schrift über die Nonne aus; und er wirft die Frage auf, ,o b es nicht e rfolgreichersein möchte, die menschlichen Bemühungen nicht sowohl auf die unmittelbare Vernichtung des schadenbringenden Insekts zu richten als auf die Erhaltung der Gegenkraft" (d. h. der Parasiten) - ebenso wie der Mensch ja auch zur Verminderung der Kaninchen Frettchen, und zur Ausrottung der Ratten und Mäuse Katzen benutzt. „Die Raupenausbreitung ist unbedenklich eine Folge der örtlich verschwundenen Raupenfeinde; das Verschwinden der letzteren kann nur 
aus eingetretenen Mangel an Entwicklungswerkzeugen erfolgt sein; und hieraus ergibt sich, daß man ihre Erhaltung bewirkt, wenn man Raupen aussetzt, die aber, um sie gegen ihre zahllosen Feinde zu schützen, in $\mathrm{H}$ ä s ern erzogen werden $\mathrm{m}$ üssen; erste Bedingung ist jedoch, daß dieses in einer ununterbrochenen Reihenfolge geschieht; denn unterbleibt die Aussetzung ein Jahr, so sind keine Raupenfeinde dieser Gattung mehr vorhanden, und die Verhältnisse sind wieder eingetreten, die eine Raupenausbreitung begünstigen." - Es ist erstaunlich, mit welch klarem Blick dieser praktische Forstmann die verwickelten Beziehungen zwischen Schädling und Parasit bereits erkannt hat - zu einer Zeit, da unser Wissen von den Parasiten noch sehr gering war.

Sehr eingehend hat sich ferner unser Altmeister $\mathrm{R}$ atzeburg mit der Frage der biologischen Bekämpfung beschäftigt. Hat er sich doch mit Vorliebe dem Studium der Parasiten gewidmet, wovon sein klassisches Werk „Die Ichneumonen der Forstinsekten" beredtes Zeugnis ablegt. Bezüglich der Bedeutung der Parasiten für die Bekämpfung äußert sich R a tzeburg folgendermaßen: „Wir lassen die liebe Natur ruhig walten und beschränken uns auf das Erhalten der nützlichen Insekten. Hin und wieder können wir zu dieser Erhaltung wirklich etwas beitragen. Denn, wenn wir z. B. die jungen, eben ausgekommenen Räupchen der Nonne zerstören, so sind wir sicher, daß keine Schmarotzer mit ihnen zerstört werden, sondern daß diese die der Vertilgung entgehenden aufsuchen und mit ihnen viel eher fertig werden, als wenn sie es mit dem ganzen Heer zu tun gehabt hätten. Man hat sich aber nicht mit dem bloßen Schutz der Schmarotzer begnügen, sondern diese Tiere auch $\mathrm{k}$ ü $\mathrm{s} \mathrm{t} l \mathrm{ich}$ vermehren wollen. Von den sinnlosen früheren Vorschlägen, durch ausgelegte Kadaver die Ichneumonen und Fliegen anzulocken, kann jetzt nicht mehr die Rede sein. Wohl aber muß ich die jetzt fast allgemein verbreitete Lehre von der künstlichen Erziehung der Schmarotzer mittels auf Zwingern ausgesetzten Raupen ausführlich durchnehmen, so wenig ich ihr auch beistimme." Er führt dann eine ganze Reihe von Gründen an, die gegen die $Z$ winger-Methode sprechen; vor allem seien die Schwierigkeiten, die Raupen in dem Zwinger festzuhalten und $\mathrm{zu}$ ernähren, sehr große usw.

$\mathrm{R}$ a tzeburg war übrigens nicht ganz konsequent in seinen Anschauungen über die Parasiten. So spricht er einerseits die Überzeugung aus, daß die Schmarotzer nur kranke Insekten befallen, also zur Beendigung einer Kalamität wenig beitragen können, ${ }^{1}$ ) andererseits empfiehlt er Übertragung von Parasiten aus parasitenreichen in parasitenarme Abteilungen. Er hat die Beobachtung gemacht, daß die Schmarotzer häufig in kleinen Horsten auftreten, während sie anderwärts fehlen. Man sollte in solchen Fällen, schlägt R a tzeburg vor, zahlreiche Raupen oder Eier oder Puppen in jenen Horsten sammeln und in die parasitenfreien Abteilungen überführen. „Im Jahre 1838 übertraf der Erfolg dieser Operation alle Erwartungen. Die übertragenen Raupen suchten die in der Nähe stehenden Kiefern auf, blieben in den Schäften und Ästen sitzen und ergossen bis zur Mitte des August die kleinen

1) So sagt er an einer Stelle (Forst-Ins. III, S. 24): „Es wird immer mehr klar, daß man Ursache und Wirkung verwechselt hat. Nicht weil die Ichneumonen sich vermehren, hört der Insektenfraß auf, sondern weil der Insektenfraß sich seinem Ende naht, vermehren sich die Ichneumonen so ungewöhnlich. Bei einem zu Ende gehenden Fraße werden die Fresser so allgemein von Krankheiten befallen, daß eben die Ichneumonen dadurch herbeigezogen werden, gleich wie die Schmarotzer bei Menschen und Tieren durch Krankheit begünstigt werden, woran jetzt kein Mensch mehr zweifelt." „Der wahre Nutzen der Ichneumonen liegt meiner Ansicht nach in folgenden: Sie versetzen manchem Insekt, welches noch in geringem Maße kränkelt und vielleicht noch kümmerliche, jedoch immer noch fressende Nachkommen gebracht hätte, den Todesstoß; sie räumen zahllose kranke und sterbende Insekten schnell auf und verhindern, daß deren sich entmischenden Säfte nicht die Luft mit verpestendem Gestank erfüllen." 
Ichneumonen in solchen Massen, daß die Kiefern von den Gespinsten derselben in der Ferne wie weiße Federbüsche aussahen. Diese Gegenden wurden durch die Nachkommenschaft der übertragenen Schlupfwespen vollkommen von Raupen gesäubert." Wenn man Eier zur Übertragung von $T$ ele as überführen will, so empfiehlt er, die Eimassen mit geteerten Brettern zu umgeben, um das Entkommen der aus den gesunden Eiern ausschlüpfenden Raupen zu verhindern. Auch kann man, „sobald die Ichneumonen ausgeflogen sind, den Ort mit trockenem Reisig überdecken und anzünden, um alle etwa noch lebenden Räupchen zu verbrennen“. Hiervertrit also Ratzeburg ganz deutlich die Anschaung, daß der Mensch durch sein Eingreifen die Ausbreitung der Parasiten und damit a u ch die Beendigung einer Kalamität recht woh 1 beschleunigen könne. Auch bezüglich gewisser R a u binsekt en nimmt er diesen Standpunkt ein, indem er den Vorschlag macht, die so überaus nützliche rote Waldameise (Formica rufa) durch künstliche Ableger von alten Haufen zu vermehren.

So kann also $\mathrm{R}$ atze burg durchaus nicht kurzweg als Gegner der „biologischen Bekämpfung " bezeichnet werden, wie es hin und wieder geschehen ist, sondern er hat sich, wie die letztgenannten Beispiele zeigen, mehrfach unzweideutig für die Möglichkeit einer solchen ausgesprochen.

Weit skeptischer äußert sich $\mathrm{Nitsche} \mathrm{zur} \mathrm{Parasiten-Frage.} \mathrm{Er} \mathrm{hält} \mathrm{eine}$ künstliche Vermehrung oder Verbreitung der Parasiten praktisch für „kaum durchführbar“. Dagegen erscheint es ihm ,,gewiß richtig, etwa angezeigte Vertilgungsmaßregeln gegen forstschädliche Insekten möglichst derartig einzurichten, daß die in ihnen enthaltenen Schmarotzer möglichst verschont bleiben“. Nur bezüglich der Vermehrung der Ameisen urteilt er etwas optimistischer und stützt sich dabei auf eine Angabe von Oberförster $\mathrm{Middeldorpf,} \mathrm{wonach} \mathrm{es} \mathrm{diesem} \mathrm{gelang} \mathrm{(im}$ pommerschen Revier Pütt) die Ameisenhaufen durch künstliche Ableger, welche ohne jede Vorbereitung auf dem bloßen Boden ausgeschüttet wurden, zu vermehre1. Allerdings siedelten sich die Ameisen nie genau an der Stelle, wo sie hingeschüttet worden waren, an, legten aber doch in der Nähe einen neuen Haufen an ( $\mathrm{M}$ i d d e 1dorpf, Die Vertilgung der Kienraupe durch Teerringe. Berlin 1872, S. 33 u. 34).

Während man in allen diesen Fällen nicht viel über die Anregungen oder über das erste Versuchstadium hinausgekommen ist, blieb es erst den amerika$n$ ischen Entomologen vorbehalten, die biologische Methodezu cinem brauchbaren System auszuarbeiten und deren Anwe ndbarkeit in dergroßen Praxis darzutun. Es ist kein Zufall, daß gerade Amerika sich dieser Methode mit besonderem Eifer zuwandte, da doch der größte Teil der schlimmsten Schädlinge von anderen Ländern dorthin importiert sind und die zügellose Vermehrung derselben auf dem Fehlen der ihnen zugehörigen Parasiten, die nicht mit importiert wurden, zurückzuführen ist. Hier lag der Gedanke der parasitären Bekämpfung natürlich besonders nahe, und so richteten sich die Bestrebungen schon seit mehreren Dezennien darauf, im Heimatland der Schädlinge die Parasiten aufzusuchen und sie dem Schädling nachzusenden, um die natürlichen Bedingungen, unter denen der letztere in seiner Heimat lebt, auch in dem neuen Lande einigermaßen wieder herzustellen.

Die Bestrebungen setzten mit einem großen Erfolg ein: Es handelte sich darum, die Wolls childla us, Icerya Purchasi die um das Jahr 1886 aus Australien in Californien eingefüht worden war und dort ungeheueren Schaden in den Orangen- und Zitronen-Pflanzungen anrichtete, zu bekämpfen. Nachdem man mit technischen Bekämpfungsmitteln längere Zeit ohne durchschlagenden Erfolg gegen den Fremdling angekämpft, entsandte man den Entomologen $\mathrm{K}$ o e b e le (einen Deutschen) nach Australien, um dort nach den natürlichen Feinden der Schildlaus zu suchen. Dieser erkannte bald als den Hauptfeind, der die Vermehrung der Icerya in Australien in sehr engen Grenzen hält, den Coccinelliden Novius cardinalis. Er sandte eine Anzahl davon nach Californien, von denen aber 
nur wenige lebend ankamen, und brachte dann selbst bei seiner Rückkehr noch ca. 100 Stück lebend mit. Diese wurden an einen mit einem Gasezelt bedeckten Orangenbaum gesetzt, wo sie sofort über die darauf befindlichen Schildläuse herfielen. Sie gediehen bei der reichen Kost ausgezeichnet und vermehrten sich so schnell, daß ihre Zahl im folgenden Jahr schon über 10000 Stück betrug und man daran gehen konnte, dieselben an die Farmer zur Aussetzung zu verteilen. Die Wirkung dieser Maßregel übertraf alle Erwartungen, denn schon $11 / 2$ Jahr nach der Einführung hatte die Icerya ihre Schrecken verloren, d. h. sie war auf eine ganz ungefährliche Zahl herabgedrückt. Die Farmer glaubten vor einem Wunder zu stehen. Die ausgedehnten Orangenpflanzungen, deren Ertrag gleich Null war, und deren Bäume mit weißen Krusten bedeckt und bereits als unheilbar aufgegeben waren, fingen plötzlich an, neues Leben zu zeigen und wieder reiche Früchte zu tragen. Die Icerya erlangte auch in der Zukunft keine größere Bedeutung mehr (wenigstens in Kalifornien); denn wenn sie irgendwo wieder in größerer Zahl auftauchte, so wurde sie durch Aussetzen von Novius, der im Staatsinsektarium von Kalifornien fortwährend in großen Mengen gezüchtet und bereit gehalten und jedem Farmer bei Bedarf unentgeltlich zur Verfügung gestellt wird, in kurzer Zeit wieder hinuntergedrückt.

Dieser unzweideutige große Erfolg, der um die neunziger Jahre des vorigen Jahrhunderts sich abspielte, machte natürlich einen tiefen Eindruck und löste bei den Farmern Amerikas, die ja alle stark unter Insekten zu leiden haben, einen beispiellosen Enthusiasmus aus. Man glaubte nun, auf die gleiche einfache und billige Weise sich aller lästigen Insekten entledigen zu können, was als unausbleibliche Folge eine bittere Enttäuschung nach sich ziehen mußte. In der ersten freudigen Aufregung ging man wenig kritisch vor; man glaubte, es genüge die bloße Einführung eines Feindes, um jeden Schädling damit bekämpfen zu können. Gab man sich doch sogar der Hoffnung hin, mit Einführung unseres Clerus formicarius die in den amerikanischen Wäldern so schrecklich wütenden Borkenkäfer bekämpfen zu können und entsandte zu diesem Zwecke einen Entomologen (Hopkins) nach Deutschland, um den Clerus in größeren Mengen zu sammeln und nach Amerika zu bringen!

Eine Reihe von Mißerfolgen, die nach der Lage der Dinge nicht ausbleiben konnten und unbedingt vorauszusehen waren, brachte die Begeisterung bald auf das richtige Maß zurück. Man ging nun in der Folgezeit etwas kritischer und mit wissenschaftlichem Ernste vor, und hat dann auch wieder eine Reihe schöner Erfolge erzielt. So ist es $\mathrm{K}$ oebele gelungen, verschiedene schlimme Zuckerrohrschädlinge auf Hawai (vor allem eine Zikade (Perkinsiella) durch Parasiteneinfuhr wesentlich zurückzudrängen; des weiteren hat man die Ölbaumschildlaus (Lecanium oleae) durch Einfuhr einer kleinen Schlupfwespe (Scutellista cyanea) erfolgreich bekämpft. Man hat auch sogar bereits begonnen, durch Ausführung amerikanischer Parasiten anderen Ländern zu Hilfe zu kommen. Der neueste Erfolg in dieser Beziehung ist die wirksame Bekämpfung der in Italien und Südtirol so schädlich auftretenden Maulbeerschildlaus, die mit der aus Amerika stammenden kleinen Schlupfwespe Prospaltella Berlesei How. in ihrer Vermehrung wesentlich reduziert werden konnte.

Eine besondere Art der parasitären Bekämpfung hat man gegen den Baumwollkapselkäfer, einen Rüßler aus der Gattung Anthonomus, versucht, indem man sich nicht auf die dem genannten Käfer eigentümlichen Parasiten beschränkte, sondern a ch die bei verwandten Rüsselkäfern vorkommenden Parasiten heranzuziehen suchte. Eine ganze Reihe verwandter Rüßler lebt auf verschiedenen Unkräutern, und so ließ man diese Kräuter stehen (oder pflanzte sie sogar eigens an), aber nur so lange, bis die Parasiten der darauf lebenden Käfer ausgeflogen waren. Dann entfernte man die betreffenden Pflanzen, so daß die meist streng monophagen Käfer zugrunde gingen, während ein Teil der Parasiten, durch die Not gezwungen, auf den überall in Massen vorhandenen verwandten Baumwollkäfer über flogen. Und so konnte durch die 
künstliche Herbeiführung von sog. „biologischen Krisen“ die Zahl der auf dem Baumwollschädling schmarotzenden Nützlinge wesentlich vermehrt werden.

Alle bisher geschilderten Versuche von parasitärer Bekämpfung werden - wenigstens was Größe und Kühnheit des Feldzuges betrifft - weit übertroffen von dem gegenwärtig unter der Leitung L. O. H ow a r d s, des genialen Organisators der amerikanischen angewandten Entomologie, geführten $\mathrm{K}$ a m p f es gegenden Schwammspinner, auf den heute die Blicke aller angewandten Entomologen der Welt gerichtet sind. - Wie schon erwähnt, ist der Schwammspinner durch Unvorsichtigkeit im Jahre 1868 in wenigen Exemplaren im Staate Massachusetts eingeführt worden und hat sich, da seine natürlichen Feinde fehlten, derart vermehren können, daß er heute über die ganzen Neuenglandstaaten verbreitet ist und zu den schlimmsten Insektenkalanitäten, die die Geschichte kennt, herangewachsen ist. Nachdem die Vermehrung einmal eine gewisse Ausdehnung erlangt hatte, war es jedermann klar, daß mit techuischen Bekämpfungsmethoden allein nichts mehr auszurichten war, und daß der einzige noch gangbare Weg darin bestehen konnte, durch $\mathrm{Zufuhr}$ der nat ü $\mathrm{lichen} \mathrm{Feinde} \mathrm{ähnliche}$ Verhältnisse zuschaffen wie in der Heimat des Schwammspinners, wo dieser ja durchaus nicht zu den schlimmsten Schädlingen gehört. Bei der Ausführung des Unternehmens ließ man sich von folgenden Grundsätzen leiten:

1. Da die Niederhaltung eines Schädlings nicht durch ei ne $n$, sondern durch eine ganze Reihe von Parasiten und Räubern bewirkt wird, so sollte danach gestrebt werden, möglichst alle Parasiten, a $1 \mathrm{so}$ die ganze "Parasitenreihe" des betreffenden Schädlings, einzuf ühren.

2. Da der Schwammspinner ein sehr großes Verbreitungsgebiet hat und in den verschiedenen Gegenden voll verschiedenen Arten von Parasiten heimgesucht wird, so sollte man sich womöglich die Parasiten aus den versehiedensten Gegenden einführen, um dadureh noch mehr als eine normale "Parasitenreihe" zu erreichen und damit die Parasitenwirkung noch über das europäische Durchschnittsmaß zu erheben.

3. Da die Parasitenwirkung im Heimatlande dureh Hyperparasiten wesentlich beeinträchtigt wird, so sollte man darauf achten, daß bei dem Import der Parasiten die Hyperparasiten möglichst ausgeschaltet we r d e $n$.

So gedachte man zu einer energischen Parasitenwirkung zu gelangen, die diejenige in Europa zum mindesten erreichen, wenn nicht sogar übertreffen konnte. Die Grundsätze zeugen jedenfalls von einem weiten biologischen Blick H o w a r d s; ihrer Verwirklichung stellten sich aber sehr große Hindernisse entgegen, so daß es amerikanischer Zähigkeit bedurfte, um sich nicht vom Ziele abdrängen zu lassen. Vor allem stellte sich bald heraus, daß die Kenntnisse über die Biologie der Parasiten des Schwammspinners ganz unzureichend und unzuverlässig waren; daher mußte zunächst das Studium der Parasiten ganz von vorne angefangen werden, um eine wissenschaftliche Basis zu erhalten. Das bedeutete aber eine enorme Arbeit, und wenn dieselbe in einer verhältnismäßig kurzen Zeit (begonnen wurden diese Studien 1905), zum Teil wenigstens, erledigt worden ist, so konnte dies nur dadurch geschehen, daß man durch $\mathrm{Her}$ a $n \mathrm{z}$ e h ung eine r g roßen Anzahl wissensehaftlicher A r beiter-zeitweise waren nicht weniger als 40 Entomologen in der eigens dafür errichteten Parasitenstation in Melrose Highlands Mass, beschäftigt! - die weitgehendste Arbeitsteilung durchführen konnte, so daß für $\mathrm{jede}$ einzelne $\mathrm{P}$ arasitenart mindestens $\mathrm{je} 1$, meistens aber mehrere Bearbeiter vorhanden waren. Durch diese gründliche Forscherarbeit wurden der europäischen und speziell d e r de u t schen Forstentomologie unschätzbare Dienstegeleistet, indem dadurch die Lebensweise vieler wichtigen, unserem Faunengebiet angehörigen Parasiten und Raubinsekten (wie Tachinen, Calosoma, Ichneumoniden) wesentlich erhellt wurde. 
Außerdem wurden bei diesen Untersuchungen Methoden ausgearbeitet, die für die weiteren Parasitenstudien von größtem Wert sind.

Von prinzipieller Wichtigkeit für die Zukunft der biologischen Bekämpfung ist vor allem die Art, wie die Ansiedelung der importierten Nützl i 11 g e betrieben wurde. Nachdem man erkannt hatte, daß es in den meisten Fällen nicht (wie bei dem obengenannten Novius) genügte, einfach einige Exemplare auszusetzen, sondern eine große Zahl von Individuen (wenigstens 1000) zu einer erfolgreichen Ansiedelung notwendig ist, ging man daran, die betreffenden $\mathrm{N}$ ü t z 1 ing e i m groben-gewissermaBen fabrikmäßig-zu züchten, um ein hinreichendes Material in die Hand zu bekommen. Diese Zuchten sind zum Teil recht gut geglückt und haben das Ansiedelungswerk wesentlich erleichtert. Ist es doch z. B. gelungen von $11 \mathrm{Exemplaren} \mathrm{des} \mathrm{E}$ i paras iten Schedius Kuwanne in $1 \mathrm{~J}$ ah r über $2 \mathrm{Mi} 11 \mathrm{i}$ on en Individuen zuerziehen, indem auch in Winter durch Zucht im Warmhaus die Generationsfolge ohne Unterbrechung aufrecht erhalten wurde. Auch die Zucht des eine relativ geringe Vermehrungsziffer aufweisenden Calosoma sycophanta lieferte gute Resultate, so daß bis zum Jahr 1911 bereits über 20000 Exemplare ausgesetzt werden konnten. Über die dabei zur Verwendung gekommenen Zuchtgeräte usw., die zum Teil sehr nachahmenswert sind, wird in folgenden Kapitel noch einiges berichtet werden.

So bedeutet der gigantische Kampf, den die Amerikaner gegen den Schwammspinner führen, a uch für die deutsche Forstentomologie einen gewaltigen Fortschritt, ja ich möchtefast sagen, den bedeutungsvollsten Fortschritt, den unsere forstentomologische Wissenschaft in dem letzten Dezenniumzuverzeichnen hat. Es ist deshalb durchaus notwendig, daß der deutsche Forstentomologe Kenntnis von diesem Kampe hat und die entsprechenden Lehren daraus $\mathrm{zi}$ e ht.

Was die praktischen Erfolge des bisherigen Kampfes betrifft, so ist die Zeit noch viel zu kurz, um ein definitives Urteil darüber fällen zu können, es wird vielleicht noch ein Dezennium darüber hingehen, bis man etwas klarer sieht. Immerhin sind schon eine Reihe befriedigender positiver Erfolge zu verzeichnen, insofern, als bereits eine Anzahl der importierten Parasiten und Raubinsekten ${ }^{1}$ ) sich gut eingebürgert haben und von Jahr zu Jahr sich weiter verbreiten und stärker vermehren, so daß also schon ein gewisses Gegengewicht gegen die Schwammspinnervermehrung vorhanden ist, wenn dasselbe vorläufig auch noch viel zu gering ist. - Mag der definitive Erfolg ausfallen, wie er will, immer wird dieses Werk, das an Kühnheit und Großzügigkeit einzig dasteht, ein Ruhmesblatt in der Geschichte der angewandten Entomologie darstellen. Schon wegen der zahlreichen, wichtigen biologischen Entdeckungen und der neuen Versuchsmethoden, die es gezeitigt, sodann aber auch, weil es uns, wie kaum ein zweites Werk, einen tiefen Einblick verschafft hat in das Wirken der für die Erhaltung des Gleichgewichtes so bedeutungsvollen Parasiten und Raubinsekten.

Wir haben in diesem kurzen historischen Überblick eine Reihe von Fällen dargestellt, in denen die parasitäre Bekämpfung angewandt wurde und teilweise unzweifelhafte Erfolge gezeitigt hat. Daraus geht jedenfalls so viel hervor, daß es durchaus keine Utopie, sondern daß es tatsächlich möglich ist, durch Schonung, Zufuhr und künstliche Vermehrung

1) Zu den gut eingebürgerten Arten gehören die beiden Eiparasiten Anastatus bifasciatus Fonsk. und Schedius Kuwanae How., verschiedene Tachinen, der Puppenparasit Monodontomerus aereus Walk. und der Puppenräuber Calosoma sycophanta $L$. - Ausführlicheres darüber ist zu finden in Escherich, Die angewandte Entomologie in den Vereinigten Staaten. 
von Parasiten und Raubinsekten, Schädlingskalamitäten wirksam zu bekämpfen. Daraus hat des weiteren die Wissenschaft die Pflicht abzuleiten, mit aller Gründlichkeit sich dieser Methode anzunehmen, und zu untersuchen, inwieweit dieselbe gegen die verschiedenen Schädlinge mit Erfolg anzuwenden ist. Denn solange die Wissenschaft nicht alle überhaupt in Betracht kommenden Möglichkeiten geprüft hat, solange hat sie ihre Pflicht nicht getan.

Wenn wir diesen Weg betreten wollen — und es ist die höchste Zeit, daß wir ihn betreten, - so werden wir dabei folgende Gesichtspunkte im Auge zu behalten haben:

1. Zunächst sind unsere diesbezüglichen Bestrebungen auf solche Schädlinge zu richten, bei denen ein Erfolg der parasitären Bekämpfung nicht a priori ausgeschlossen oder wenigstens höchst unwahrscheinlich ist.

Eine Bekämpfung mit Parasiten wird meist nur da Erfolg haben, wo das Übel a uf Parasitenmangel zur ückzuführe 11 ist. Das ist aber durchaus nicht bei allen Kalamitäten der Fall. Es gibt eine ganze Reihe von Insektenkatastrophen, die in anderen Ursachen begründet sind; so hängt z. B. die Borkenkäfervermehrung weit weniger von der Abnahme der Parasiten und Räuber als vielmehr von der Zunahme des Brutmaterials ab. Was würde es in diesem Falle nützen, Clerus formicarius und die verschiedenen Schlupfwespen heranzuziehen, wenn man nicht gleichzeitig dafür sorgt, daß die vertrocknenden Bäume entfernt werden. Oder nehmen wir die Phylloxera, die in den Weinländern Europas so unendliche Verluste verursacht. Es dürfte schwerlich gelingen, ihr mit natürlichen Feinden zu begegnen. Denn es ist weniger der Mangel an solchen, welcher diesen amerikanischen Eindringling zu einer so furchtbaren Plage in Europa 1nacht, als vielmehr die geringere Widerstandsfähigkeit unserer Reben gegen die Angriffe der Laus. Solche Beispiele ließen sich noch um vieles vermehren.

2. Sodann sind unter den der biologischen Bekämpfung a ipriori zugänglichen Schädlingen zuerst diejenigen in Angriff zu nehmen, bei denen die technische Bekämpfung versagt oder bei unverhältnismäßig hohen Kosten nur zweifelhafte Erfolge erzielt werden.

Hierher kann man z. B. die Kieferneule oder den Kiefernspanner und auch die Nonne zählen, ferner die verschiedenen forstlichen Blattwespen usw.

3. Man sollte nicht eher an die praktische Verwendung der Parasiten denken, bevor nicht deren Lebensgeschichte in allen Einzelheiten wissenschaftlich erforscht und deren Wirkungsweise auf den Schädling genau festgestellt ist. Dieser Grundsatz stellt das Axiom der parasitären Bekämpfung dar, das unter allen Umständen befolgt werden muß, wenn man zu Erfolgen gelangen will.

Da nun in dieser Beziehung unsere Kenntnisse selbst über die alltäglichsten und wichtigsten Parasiten und Raubinsekten unserer forstlichen Schädlinge noch kaum im Anfangsstadium stehen, so hat die forstentomologische Wissenschaft noch eine gewaltige Aufgabe zu erledigen, wenn sie dieser Forderung genügen soll. Gehören doch die P'arasiten an und für sich zu den am schwierigsten zu erforschenden Tieren, deren Studium hohe Anforderungen an Zeit, Scharfsinn, technische Geschicklichkeit, Geduld usw. stellt. Es kommt auch nicht bloß darauf an, die Vermehrungsziffer und die Entwicklungsweise der einzelnen Stadien zu erforschen, es muß auch die Abhängigkeit des Parasiten von den äußeren Faktoren, ferner seine Verbreitung und Verteilung über das Verbreitungsgebiet des Schäd- 
lings festgestellt werden, es muß untersucht werden, inwieweit er selbst wieder unter Parasiten und Raubinsekten zu leiden hat, sodann ob er auch auf andere Schädlinge geht, ob er Zwischenwirte bedarf und viele andere Punkte mehr. Um alle diese Fragen in absehbarer Zeit erledigen zu können, ist eine Vermehrung des wissenschaftlichen Hilfspersonals an unseren forstentomologischen Instituten ein dringendes Erforder$\mathrm{n}$ is, um so mehr als in vielen Fällen ein längerer Aufenthalt draußen in den Schädlingsgebieten notwendig sein dürfte. Des weiteren wird erforderlich sein, daß die Praxis nicht allzuschnell greifbare Erfolge haben will, sondern daß sie der Wissenschaft Zeit $1 \ddot{a} \beta \mathrm{t}$, ihre Aufgabe ungestört und in $\mathrm{Ruhe} z u$ erledigen. Man möge sich doch allmählich daran gewöhnen, die angewandte Entomologie mit dem gleichen Maße zu messen wie die anderen naturwissenschaftlichen Disziplinen und die Heilwissenschaften.

4. Was die praktische Ausübung der parasitären Bekämpfung betrifft, so sind verschiedene Wege möglich:

Der nächstliegende Weg besteht darin, den vorhandenen Parasiten und Raubinsekten den weitgehendsten Schutz zu gewähren, - z. B. in der Weise, daß man den in der Bodenstreu sich verpuppenden Parasiten nicht durch Streuentnahme die Verpuppungsmöglichkeit nimmt, oder dadurch daß man bei Parasiten, die auf Zwischenwirte angewiesen sind, darauf achtet, daß die Nahrungspflanze des Zwischenwirtes erhalten bleibt; oder dadurch, daß man Raubinsekten, die in Fanggräben und andere Fangapparate geraten, wieder in die Freiheit setzt usw. Ferner ist darauf zu sehen, daß die Haufen der roten Waldameise möglichst wenig gestört werden und vor allem das Sammeln der Puppen völlig unterbleibt (dafür existieren ja auch gesetzliche Bestimmungen). Wo Schädlingsraupen zu einem gewissen Prozentsatz (dessen Höhe sich nach der Vermehrungsgröße des betr. Parasiten zu richten hat) mit Parasiten besetzt sind, hat die Tötung der Raupen event. zu unterbleiben, um die ansteigende Parasitenvermehrung nicht aufzuhalten. Wo es sich um vollgeleimte Bestände handelt, kann diese Maßnahme ohne Bedenken ausgeführt werden, da ja der ganze Wald durch die Leimung gewissermaßen in einen großen Zwinger verwandelt ist; man hat nur darauf zu sehen, daß die über dem Leimring sitzenden Raupen abgekehrt werden. Eventuell kann man auch zu dem Mittel greifen, daß man die Raupen oder Puppen des Schädlings in Käfige, die im Walde errichtet werden, zusammensperrt, aus denen wohl die Parasiten, nicht aber die Schmetterlinge entweichen können. Alle die hier genannten Maßnahmen sind übrigens schon stets mehr oder weniger geübt worden; so ist das Entfernen des Puppenräubers aus Käfergräben eine jedem Praktiker geläufige Sache, ebenso ist vom Töten der Nonnenraupen bei stärkerem Tachinenbefall vielerorts Abstand genommen und auch das Errichten von Raupenzwingern im Walde zum Zweck des Parasitenschutzes ist bei Nonnenkalamitäten schon mehrfach versucht worden.

Ein anderer Weg der parasitären Bekämpfung besteht in der direkten Zufuhr von Parasiten und Raubinsekten in das befallene Gebiet. In welcher Weise dieselbe geschehen kann, dafür finden sich in der obigen historischen Übersicht eine Reihe von Beispielen. Es sei hier auf die hauptsächlichsten Möglichkeiten kurz hingewiesen.

Wo das Vorkommen eines Parasiten auf engbegrenzte Lokalitäten (Horste) beschränkt ist, empfiehlt es sich, Raupen oder Eier oder Puppen des 
Schädlings (je nach der Parasitenart) in jenen Horsten zu sammeln und in die parasitenfreien Abteilungen überzuführen. (Dabei ist durch geeignete Vorkehrungen zu verhindern, daß die miteingeführten nicht parasitierten Raupen usw. nicht entkommen können [siehe S. 336].)

Desgleichen kann, was schon von Ratzeburg vorgeschlagen und auch bereits mehrfach ausgeführt wurde, versucht werden, der so überaus wirksamen roten Waldameise (Formica rufa), deren Haufen ja in ihrem Vorkommen meist ziemlich vereinzelt anzutreffen sind, eine allgemeinere Verbreitung zu geben, indem man einen Haufen in mehrere kleinere Haufen teilt und dieselben in den verschiedenen Arten des Revieres anzusiedeln sucht. Man muß bei dieser Staatenzertrümmerung resp. künstlichen Kolonisation darauf achten, daß in jeder Abteilung genügend Arbeiter und Brut vorhanden sind, damit die neuen Kolonien auch lebensfähig sind und sich entwickeln können.

Eine weitere Möglichkeit der Räuber- oder Parasitenzufuhr ist dann gegeben, wenn ein Schädling in verschiedenen Gegenden eines Landes zeitlich verschieden auftritt, in der Weise, daß die Kalamität hier erst im Beginne, dort aber bereits im Erlöschen begriffen ist, was z. B. bei den großen Nonnenperioden nicht selten eintritt. Man kann in solchen Fällen von dort, wo die Kalamität im Erlöschen begriffen ist oder noch besser, wo sie eben erloschen ist, und wo gewöhnlich Parasitenreichtum herrscht, Parasiten in großen Mengen beziehen, um sie an die Orte der beginnenden Kalamität zu schaffen. So konnte man, um ein konkretes Beispiel zu erwähnen, während der letzten großen Nonnenkalamität lesen, daß im Hannoverschen ein größerer Nonnenkahlfraß stattgefunden hat, trotzdem eine ungeheure Menge von Tachinen vorhanden war, während gleichzeitig von anderen Orten gemeldet wurde, daß die Nonne am Beginne einer Vermehrung zu stehen scheine. In einem solchen Falle stünde nun gar nichts im Wege, in dem kahlgefressenen, für den Abtrieb bestimmten Revier im zeitigen Frühjahr den Boden gründlich nach Tachinentönnchen absuchen zu lassen und diese in das im ersten Beginne einer Kalamität stehende Revier zu bringen; es würde dadurch in dem letzteren gleich von Anfang an ein günstiges Verhältnis zwischen Tachinen und Raupen geschaffen, was sicherlich $n_{i}$ cht ohne Einfluß auf die Nonnenvermehrung bleiben würde, ja vielleicht zu einer direkten Koupierung der Vermehrung führen könnte.

Wo es sich ferner um Schädlinge mit einer großen geographischen Verbreitung handelt, sind die Parasitenverhältnisse vielfach verschieden, insofern als in dem einen Teil des Verbreitungsgebietes z. B. eine andere Tachinenart vorkommt als in dem anderen. Hier könnte nun versucht werden, die Parasitenreihen der verschiedenen geographischen Bezirke zu vereinigen und dadurch eine weit stärkere Parasitenwirkung zu erreichen. Es müßte besonderes Augenmerk auf solche Länder gerichtet werden, in denen der betr. Schädling wenig zur Übervermehrung neigt, da anzunehmen ist, daß hier möglicherweise bessere, wirksamere Parasiten den Schädling in seiner Vermehrung bedrängen. $\mathrm{Da} a$ die verschiedenen Parasiten, selbst solche, die sich systematisch nahe stehen, große Unterschiede in der 
Wirksamkeit aufweisen können, geht aus den im hiesigen Institut gemachten Untersuchungen Prells über die Nonnen- und Eulentachine, Parasetigena segregata und Panzeria rudis hervor, von denen die erstere schlechter an den Parasitismus angepaßt ist als die letztere und infolgedessen auch nur eine geringere Wirksamkeit entfalten kann.

Dieser letztgenannte Umstand legt ferner den Gedanken nahe, zu versuchen, besonders gut wirkende Parasiten von einem IVirt auf einen anderen zu gewöhnen. Nehmen wir z. B. an, irgend ein Spinner habe eine ausgezeichnet arbeitende Tachine, so wäre zu erproben, ob diese Tachine nicht dahin zu bringen wäre, auch an einen anderen verwandten,

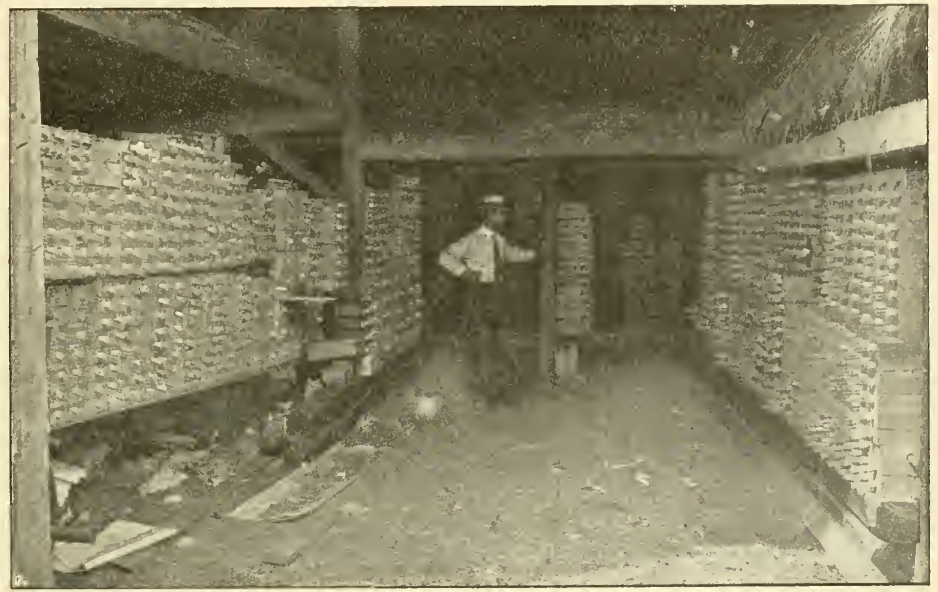

Fig. 217. Fabrikmäßige Zucht von Eiparasiten zur Bekämpfung des Schwammspinners in Amerika. (Aus Escherich.)

als schlimmer Schädling auftretenden Spinner (z. B. Nonne) zu gehen. Auch $i_{n}$ dieser Beziehung verweise ich auf die Arbeiten Prells, der bereits den Anfang dazu gemacht hat. Er viersuchte die so sehr wirksame Eulentachine auf die Nonne überzuführen, wobei der Anfang auch gelang: die kleinen auf den Nadeln lauernden Tachinenlarven bohrten sich (allerdings nur, wenn sie eine Zeitlang gehungert hatten) in die vorbeilaufenden Nonnenraupen ebenso ein, wie in die Eulenraupen, doch starben sie meist vor der ersten Häutung in der Nonne ab, wahrscheinlich weil ihnen die Zusammensetzung des Nonnenblutes nicht zusagte. Es heißt nun, mit anderen ebenso brauchbaren Tachinen und anderen Schädlingen weitere Versuche in dieser Richtung zu machen. Das Prellsche Experiment hat wenigstens das eine ermutigende Ergebnis gezeitigt, daß eine für monophag geltende Tachine unter Umstäuden dazu zu bringen ist, auch fremde Raupen anzunehmen (vgl. hierzu auch das über die parasitäre Bekämpfung des Baumwollkapselkäfers durch Herbeiführung von „biologischen Krisen“ Gesagte, siehe S. 338). 
Endlich wäre noch die künstliche („fabrikmäßige“) Parasitenzucht in besonderen Zuchtanstalten zu bedenken, die uns in den Stand setzen würde, stets ein Heer der wichtigsten Parasiten und Räuber zur Verfügung zu haben, um sie gleich beim Beginne einer Kalamität gegen den noch schwachen Feind aussenden zu können. Daß solche Zuchten möglich sind, haben die Amerikaner bewiesen (Fig. 217); sie haben uns auch die Wege gezeigt, auf denen dieselben am besten anzustellen sind. Neben den Tachinen und Schlupfwespen kämen als besonders geeignete Objekte die Coccinellen und sodann vielleicht auch die Spinnen in Betracht, deren Zucht und Ansiedlung am wenigsten Schwierigkeiten bereiten dürften (vgl. Schwangart, Über die Traubenwickler usw.).

Damit sind wohl die wichtigsten Richtungen angegeben, die fürs erste bei der praktischen Ausführung der parasitären Bekämpfung in Betracht zu ziehen sind. Zweifellos werden sich noch eine ganze Reibe anderer Möglichkeiten ergeben, sobald man erst einmal begonnen hat, das Problem systematisch zu bearbeiten.

\section{d) Verbreitung von Mykosen und anderen Infektionskrankheiten.}

Über die Bekämpfung mittels Mykosen und anderen Infektionskrankheiten gilt annähernd dasselbe, was soeben über die parasitäre Bekämpfung gesagt wurde, d. h. daß wir auch in dieser Beziehung noch ganz am Anfang unserer Erkenntnis stehen. Es wurden zwar, da die Wirkung der epidemisch auftretenden, akuten Krankheiten, die plötzlich ungezählte Mengen von Schädlingen dahinraffen, viel augenfälliger und drastischer sich kund tut als die Wirkung der Parasiten, der Verbreitung solcher Raupenseuchen usw. im allgemeinen schon etwas mehr Interesse entgegengebracht als der künstlichen Verbreitung der Parasiten. Doch meistens erlahmte das Interesse gewöhnlich schnell wieder, sobald die angestellten Versuche mit einem Mißerfolg endeten.

Was zunächst die künstliche Verbreitung von Mykosen betrifft, so wurde schon oben (S. 284-289) bei der Besprechung der insektentötenden Pilze das Wichtigste gesagt. Den dortigen Angaben ist ja im allgemeinen nicht sehr viel erfreuliches zu entnehmen, wenn auch in einigen Fällen unzweifelhafte Erfolge zu verzeichnen waren. Gewöhnlich erzielte man wohl im Laboratorium sehr gute Infektionserfolge, während sie draußen im großen mehr oder weniger versagten; so erging es mit der Nonnenbekämpfung vermittelst Botrytis Bassiana, so erging es mit der Maikäferbekämpfung vermittelst Botrytis tenella, so erging es mit der Heuschreckenbekämpfung vermittelst Sporotrichum, und so erging es mit der Verwendung verschiedener Isarien usw. Als Hauptgrund für die Mißerfolge im großen wird gewöhnlich der Umstand angeführt, daß das Gedeihen der Pilze von verschiedenen äußeren Bedingungen (wie Feuchtigkeit, geschwächte Widerstandsfähigkeit der Raupen usw.) abhängig sei, und daß es eben außerhalb der menschlichen Machtsphäre liege, solche Bedingungen künstlich zu schaffen. ${ }^{1}$ ) Wir sollten uns aber bei derartigen Überlegungen keineswegs beruhigen;

1) Vergl. dagegen $\mathrm{Schwangart}$, der durch besondere Kulturmethoden (,Anhäufelung") die Vermehrung vorhandener pathogener Pilze erstrebte und auch erreichte. 
denn einerseits werden sich vielleicht Pilzarten finden lassen, die weniger anspruchsvoll sind, und sodann werden auch die Insekten gewisse Perioden in ihrem Leben haben, in denen sie hinfälliger sind und infolgedessen geeigneter für eine Pilzinfektion; außerdem dürften sich auch die verschiedenen Insektenarten an und für sich verschieden empfänglich gegen die Pilze verhalten (so erfahren wir z. B. durch Schwangart, daß solche Insekten, die normalerweise unterirdisch leben, der Verpilzung weniger ausgesetzt sind als dic an der Luft lebenden Insekten). Jedenfalls ist durchaus kein Grund vorhanden, jetzt schon die Flinte ins Korn zu werfen. Wir schließen uns vielmehr in dieser Beziehung voll den Ausführungen des berühmten französischen Gelehrten Paul Marchal an, die hier wörtlich wiedergegeben seien: "Wenn in der Praxis die Ergebnisse (mit der künstlichen „Verbreitung von Mykosen) noch recht ungleich und nicht immer so günstig „waren, wie der Anfang erhoffen ließ, bestehen doch gewichtige Gründe „für die Annahme, daB diese Unsicherheit mit unseren noch un„genügenden Kenntnissen von den natürlichen Vorbedingungen der „Wirksamkeit dieser Pilze und mit der unzulänglichen, eben auf "unserer mangelhaften Kenntnis beruhenden Technik zusammen„hängt. Denn diese wird verschieden sein müssen, je nach der Art der zu „verwendenden Pilze sowohl wie nach den Lebensbedingungen der einzelnen "Insektenarten, an denen sie leben. Es bleibt also noch sehr viel zu er„forschen übrig. Es gilt zu ermitteln, welches im Einzelfall die günstigste "Zeit, welches das der Ansteckung am meisten ausgesetzte Stadium des "Schädlings, welches die richtigen Methoden für die Vermehrung und Ver„breitung des Krankheitserregers sind, wie die Virulenz von Kulturen durch „geeignete Nährböden auf der Höhe gehalten werden kann. Man muß „rechnen mit Schwierigkeiten der praktischen Durchführung, vor allen mit „den durch die klimatischen Verhältnisse gestellten Vorbedingungen usw." "Nichts aber berechtigt uns zu der Behauptung, daß diese Hindernisse unüber„windlich seien. Manche Ergebnisse sind im Gegenteil dazu angetan, uns zu „ermutigen. Doch nur konsequente Untersuchung mit dem Ziele, „allmählich alle Seiten des Problems aufzuklären und das Studium „selbst immer mehr zu vertiefen, werden uns Klarheit verschaffen, welche „praktische Bedeutung diese Methoden werden erreichen können“.

Betreffs der anderen, nichtpilzlichen Infektionskrankheiten ist es beinahe noch schlechter bestellt, insofern, als wir ja bei vielen derselben noch gar nicht eimmal wissen, um welchen Erreger es sich handelt. Es trifft dies vor allem für die forstlich am meisten in Betracht kommenden Polyederkrankheiten zu, über deren Erreger die Forscher heute noch recht geteilter Meinung sind (siehe S. 302). Solange wir aber über diesen Punkt noch nicht klar sind, können wir auch nicht erwarten, daß die Praxis sichere Ergebnisse erzielt. Gerade bezügl. der Polyederkrankheiten dürfte es übrigens geboten sein, keinem allzugroßen Optimismus sich hinzugeben, schon aus dem Grunde, weil die Erfahrung besonders der letzten Jahre gelehrt hat, daß die Krankheit mitunter auf ganz engbegrenzte Orte beschränkt bleiben kann, ohne sich wesentlich auszubreiten. IVenn schon unter natür- 
lichen Verhältnissen am Ende einer Nonnenkalamität (wo wir doch eine allgemeine Schwächung der Raupen anzunehmen geneigt sind) die Krankheit mitunter keine größere Verbreitung zu erlangen vermag, so dürften die Bedingungen für eine künstliche Verbreitung der Krankheit beim Beginn einer Kalamität wohl noch weniger günstig sein.

Welch große Hoffnungen hatte die Praxis Anfangs der Neunziger Jahre des vorigen Jahrhunderts auf die Wipfelkrankheit (die ja eine Polyederkrankheit ist) gesetzt, als Medizinalrat Hofmann und v. Tubeuf ihre Untersuchungen bekannt gaben, und ein Bakterium als den Verursacher der Krankheit nannten. Manche Praktiker glaubten schon, mit Hilfe dieses Bakteriums der Nonne völlig Herr zu sein, und zahlreich sind die Versuche, die seit dieser Zeit im Großen wie im Kleinen ausgeführt wurden. Erstmalig ist der Versuch, die Nonne im großen durch künstliche Verbreitung der Wipfelkrankeit zu bekämpfen, wohl in den herzoglich Ratiborschen Forsten in Oberschlesien durch Forstmeister Schmidt unternommen worden.

Es dürfte sich verlohnen, mit einigen. Worten darauf einzugehen, einmal des historischen Interesses wegen, und sodann, um zu zcigen, wohin a $11 \mathrm{zu}-$ große Begeisterung im Verein mit einem halben Verstehen der wissenschaftlichen Ergebnisse und Methoden führen kann. Forstmeister $\mathrm{Schmidt}$ hat seine Versuche in einer klcinen Schrift ausführlich beschrieben, wo bezüglich des Verfahrens, das bei der Infektion der Wälder angewandt wurde, folgendes mitgeteilt wird: ,Außer jenen (allgemein gebräuchlichen „Bakteriennährböden) verwendete ich auch Fleisch, und zwar Rind- und Pferde„fleisch, welches ich in Kolben, mit ctwas Wasser verschen, an verschiedenen Tagen „in kochendes Wasser gebracht hatte. Ich verwendete auch nicht sterilisiertes „Fleisch. Sowohl sterilisiertes als auch nicht sterilisiertes Fleisch wurde rein und „,mit Kartoffelbrei derartig vereinigt verwandt, daß der Brei über die durch Messer,einschnitte vielfach geöffnete Oberfläche des Fleischstückes dünn gestrichen wurde. „Nach der Impfung des Bazillus und der Mischkultur auf die genannten Nährböden „entstanden üppige Pilzwucherunger. Auf Kartoffeln und Brei, sowie auf mit „Kartoffelbrei versehenem Fleisch zeigten sich eiterähnliche, übelriechende halb,flüssige Massen. Die an gesunden Raupen bewirkten Infektionen mit den von ,den verschiedenen Nährböden entnommenen Spaltpilzen verliefen günstig, indem „,die meisten Raupen starben. Die besten Resultate aber ergaben die Infektions„,stoffe, die von mit Kartoffelbrei versehenem Fleisch und aus Gelatinekultur ent„, nommen waren. Ich ließ deshalb in dem Hauptfraßherd an verschiedenen Orten „frisches Pferdefleisch aushängen, überstrich die durch Messereinschnitte empfäng„lich gemachte Oberfläche mit sterilisiertem Kartoffelbrei und impfte hierauf „Kulturen von den oben beschriebenen Nährböden“ usw. usw. „Einige Zeit nachher ,trat in jenem Infektionsgebiet die Flacherie auf, sich schnell über das Fraßgebiet ,verbreitend. Der Beweis, daß die Flacherie durch jene Infektion hervorgerufen ,worden sei, läßt sich zwar nicht erbringen, ich möchte dies aber bestimmt an„nehmen“ usw.

Ein so gründliches Mißverstehen bakteriologischer Arbeit, wie es in diesem Fall vorliegt, gehört, wenigstens in der Literatur, glücklicherweise zu den vereinzelten Erscheinungen; doch auch die zahlreichen anderen Versuche, die in dieser Richtung bis in die neueste Zeit angestellt wurden, sind, wenn sie auch auf einem höheren Niveau stehen, mehr oder weniger lückenhaft und jedenfalls nicht beweisend. Gewöhnlich liegt allen diesen Versuchen folgender Gedankengang zugrunde: Man bringt verseuchtes Material (wipfelkranke Raupen oder aus solchen hergestellte Präparate) in eine „gesunde“ 
Abteilung, in der bisher „keine Spur“ von Wipfelkrankheit „zu bemerken“ war. Wenn nun nach einiger Zeit deutliche Anzeichen der Wipfelkrankheit auftreten, so wird daraus geschlossen, daß die Infektion durch das Einbringen des verseuchten Materials bewirkt wurde, daß also die Infektion von Erfolg begleitet war. Dieser Schluß hängt aber insofern in der Luft, als in keinem dieser Fälle nachgewiesen ist, daß die Versuchsabteilung wirklich "gesund" war und nicht bereits die Wipfelkrankheit in latenter Form unter den Raupen geherrscht hat (siehe S. 300 ff.). Zum mindesten hätte eine Anzahl Raupen aus dem angeblich gesunden Bestand mikroskopisch auf das Vorhandensein von Polyedern untersucht werden müssen, was aber bisher niemals geschehen ist (vgl. darüber auch Wahl). So kann stets der Einwand erhoben werden, daß die akute Form der Krankheit in dem betreffenden Jahr ohnehin, auch ohne künstliche Infektion eingetreten sein würde, um so mehr als es sich in den meisten der diesbezüglichen Versuche um Orte mit älterem Nonnenbefall gehandelt hat. (In ganz frisch befallenen Beständen, mit noch sehr geringer Nonnenvermehrung, ist, so viel mir bekannt, bisher noch keine Infektion in obiger Weise „erzielt" worden.)

Was die Art der Ausführung der Infektionsversuche betrifft, so wurden die verschiedcnsten Verfahren angewandt, von denen die wichtigsten hier angeführt seien:

Eckstein stellt folgende Punkte auf, welche für die in verschicdencn preußischen Revieren seinerzeit mit der künstlichen Infizierung beauftragten Beamten als Richtschnur dienen sollten, nämlich

1. Die Infektion wird ausgeführt A. durch Impfung, B. durch Auslegen der Reinkulturen an der Futterpflanze.

2. Die Impfung geschieht dadurch, daß mit einer Präpariernadel der zu impfenden Raupe eine Spur Impfstoff in den After gebracht wird, aber ohne dabei die Raupe zu verletzen.

3. Da die Bakterienkrankheiten sich im allgemeinen von gewissen Zentren aus verbreiten, so müssen solche künstlich geschaffen werden. Dies erreicht man dadurch, daß man geimpfte Raupen in größerer Zahl, etwa 50, an je einem Stamme hinauf laufen läßt und mehrere nebeneinander stehende Stämme in dieser Weise besetzt.

4. Das Auslegen von Reinkulturen an Futterpflanzen geschieht dadurch, daß man a) den flüssigen Inhalt der Röhrchen auf die Nadeln, respektive Blätter gießt, welche demıächst den Raupen zum Futter dienen werden, oder b) den festen Inhalt aus den zerschlagenen Röhrchen vorsichtig, ohne die Bakterien, d. h. den weißlichen, bräunlichen oder gelblichen Utberzug des Nährbodens abzuwischen, herausnimmt und dahin bringt, event. etwas verteilt, wo die Raupen am dichtesten sitzen.

5. Da auch hierbei Infektionsherde geschaffen werden müssen, so können die Reinkulturen in einer der folgenden Weisen ausgelegt werden: a) Die Reinkulturen werden unter Leimringen da an die Stämme mit einem glatt geschnittenen Hölzchen gestrichen, wo die Raupen am dichtesten sitzen. b) Auf jungen Kiefern, respektive Fichten wird die Reinkultur an die Nadeln der Zweige gebracht. c) Im hohen Holze können einige Äste abgeschlagen und in den Boden gesteckt werden. Nachdem diese mit zahlreichen Raupen besetzt sind, werden die Reinkulturen aufgestrichen. d) In Raupengräben und Fanglöchern werden kleine Zweige - so klein, daß sie den Raupen keine Gelegenheit zum Entwischen bieten - die mit Reinkulturen bestrichen wurden, ausgelegt.

6. Ist die Schlaffsucht hie und da zum Ausbruche gekommen, so können, aber erst nachdem das Umsichgreifen der Erkrankung beobachtet wurde, kranke und tote Raupen gesammelt und an anderen Orten ausgelegt werden. 
7. Vor allzu weitgehender Verteilung ist dabei wie bei dem Auslegen der Bakterienkulturen zu warnen.

8. Die Röhrchen sind nicht der allzu großen Sonnenhitze auszusetzen. Der Watteverschluß der Röhrchen ist, außer bei der Infektion, nicht zu lüften.

9. Die zum Impfen verwandten Präpariernadeln müssen, bevor zur Infektion mit einer zweiten Bakterienart geschritten wird, in Spiritus gründlich abgerieben werden. Hölzchen sollten nur einmal verwendet werden.

10. Die einzelnen Versuche müssen räumlich möglichst getrennt voneinander - 100-200 $\mathrm{m}$ - angestellt werden."

In A m e rik a, wo man Versuche mit der künstlichen Verbreitung der Polyederkrankheit des Schwammspinners (der sog. „Wilt") machte, führte man folgende Methoden aus: Im Kleinen benützte man cine Mischung aus frischgestorbenen Raupen, Wasser und etwas Leim, die entweder auf den Stamm aufgestrichen oder mit einem Spritzapparat in die Krone gebracht wurde; im großen suchte man die Infektion dadurch zu bewerkstelligen, daß man eine größere Menge abgestorbener oder absterbender Raupen in einem hängemattenähnlich aufgehängten Beutel in der Krone verschiedener Bäume anbrachte, und zwar in der Weise, daß der vorherrschende Wind die Krankheitskeime von den behängten Bätumen in die zu bekämpfenden Abteilungen tragen mußte. Das zur Infektion notwendige kranke Material suchte man - gestützt auf die Angaben E. F is chers, wonach durch Darreichung von nassem Futter die "Flacherie" erzeugt werden könne - dadurch sich zu verschaffen, daß man stets eine große Anzahl von Raupen in Käfigen mit riassem Futter bedachte. Sobald diese Zuchten nun Symptome der Krankheit aufwiesen, wurden sie dann in den genannten Hängematten im Walde aufgehängt ( $R$ e if $f$, W., The Wilt Disease or Flacherie of the Gypsy Moth. Boston 1911). Auf die Unzulänglichkeit dieser Versuche wurde von Es che rich bereits hingewiesen (Naturw. Zeitschrift für Land- und Forstwirtschaft 1913). Hier sei nur erwähnt, daß bei den $R$ e if $f$ schen Versuchen außer der Erfüllung der oben erwähnten Forderung auch noch der Nachweis fehlt, daß die durch Darreichung nassen Futters in den Käfigen erzeugte Krankheit mit der draußen in den Wäldern (als vermeintliche Folge der Infektion) aufgetretenen auch wirklich identisch war.

Ein weiteres Verfahren zur Bekämpfung der Nonne mit Hilfe von Polyederkrankheiten wurde in neuerer Zeit von Bolle vorgeschlagen. Derselbe zielt daraufhin, die Gelbsucht der Seidenraupe zur Infektion zu verwe n d e n, und zwar derart, daß eine mit zerflossenen gelbsüchtigen Seidenraupen hergestellte Brühe mit Torf vermengt an verschiedenen Stellen der betreffenden Wälder in Körben oder dgl. aufgehängt werden sollte. Diese Methode hätte, falls sie sich verwirklichen ließe, den großen Vorzug, daß man stets, auch schon beim ersten Beginn.von Nonnenkalamitäten, genügenden Infektionsstoff zur Verfügung hätte. Es sei aber in dieser Hinsicht daran erinnert, daß man heute bezügl. der Wirkung des Gelbsuchtgiftes der Seidenraupe auf Nonnen noch geteilter Meinung ist, daß somit erst diese Frage einwandfrei zu lösen wäre.

Einen von den bisher genannten abweichenden Weg zur Verbreitung der Polyederkrankheit schlägt Klö ck vor. Von der Annahme ausgehend, daß die Krankheit zuerst an solchen Orten akut auftritt, wo infolge gänzlicher oder wenigstens starker Entnadelung ungünstige Nahrungsbedingungen eingetreten sind, und sich dann von dort allmählich verbreitet, suchte $\mathrm{Klö} \mathrm{ck}$ solche $\mathrm{Kr}$ ankheitsherde künstlich zu schaffen, so daß die akute Seuche eher zum Ausbruch kommen würde, als unter natürlichen Umständen zu erwarten wäre. Er empfiehlt hierzu folgende Maßnahmen:

„1. Auf entsprechend großen Flächen jüngerer und noch wenig durchforsteter Bestände, welche zumeist den Ausgangspunkt für Nonnenfraßherde bilden, wären $\mathrm{zu} \mathrm{B}$ eginn der $\mathrm{FraBz}$ eit nach vorausgegangener Leimung des Hauptbestandsmaterials Durchforstungen einzulegen, wobei als Hauptmoment in Betracht käme, daß das gesamte niedergelegte Material mit den daran befindlichen Raupenmassen oder zum mindesten die mit Raupen dicht besetzten Gipfelstücke bis zum Ende der Fraßzeit an Ort und Stelle unberührt liegen bleiben müßten." 
„2. In älteren angehend haubaren oder haubaren Beständen, welche auf Grund des konstatierten Eierbelages ohnehin dem Kahlfraß und sodann der Axt zum Opfer fallen müßten, wären gleichfalls zu Beginn der Fraßzeit entsprechend große Flächen nach vorausgegangener Isolierung mittels eines ca. $50 \mathrm{~m}$ breiten geleimten Streifens kahl zu hauen, und das hierbei angefallene Material in der oben beschriebenen Weise zu behandeln. Bei der Auswahl der betreffenden Flächen wird darauf zu achten sein, daß dieselben möglichst zentral liegen, um der voraussichtlich sich zuerst an dem gefällten Material einstellenden Wipfelkrankheit Gelegenheit zu größtmöglicher Ausbreitung im übrigen Bestandteile zu geben."

$\mathrm{K} l$ ö ck ist der Meinung, daß er mit dieser Methode gute Erfolge erzielt habe, indem sich von dem künstlich geschaffenen Seuchenherd die Wipfelkrankheit so ausgebreitet habe, daß die Gefahr von seinem Bezirk rechtzeitig abgewendet werden konnte. - Der Vorschlag $\mathrm{Klö} \mathrm{cks}$ hat zweifellos manches für sich, da derselbe dem natürlichen Weg, auf welchem der Ausbruch der Krankheit in vielen Fällen vor sich $z u$ gehen scheint, am nächsten kommen dürfte. Doch ist ein Beweis für die Wirkung des Verfahrens in der Tatsache, daß nach Anwendung desselben in jenen Gebieten die Krankheit ausgebrochen ist, ebensowenig erbracht wie in den obigen Fällen.

Es liegt also heute trotz der zahlreichen Versuche noch kein einziger Fall vor, der die Möglichkeit einer künstlichen Verbreitung der Polyederkrankheiten im Walde strikte bewiesen hätte. Das sollte uns aber nicht abhalten, weiter zu forschen und weiter Versuche anzustellen. Vor allem dürfte es notwendig sein, noch weitere Forschungen über die Natur des Erregers, über seine Vermehrungs- und Verbreitungsbedingungen anzustellen, um eine sichere Basis für künstliche Infektionsversuche zu schaffen. Vordem bedeuten alle derartigen Experimente mehr ein Raten, denn ein zielbewußtes Arbeiten. Da die Polyederkrankheit, wie oben (S. 302) ausgeführt, eine ziemliche Verbreitung unter den Insekten (nicht nur unter den Raupen der Schmetterlinge, sondern auch unter den Blattwespenlarven usw.) zu haben scheint, so würde ein event. Erfolg der auf eine künstliche Infektion hinzielenden Bestrebungen von der allergrößten Bedeutung für die Schädlingsbekämpfung werden.

Mit den anderen der im vorigen Kapitel genannten Krankheiten, den Bakterien- und Nosemaseuchen, hat man sich in der forstlichen Praxis noch kaum beschäftigt. Es ist aber gewiß empfehlenswert, in der Zukunft bei den Bekämpfungsversuchen der verschiedenen Forstschädlinge auch dieser verheerenden Mächte sich zu erinnern, vielleicht ist der eine oder andere unserer Waldverderber besonders empfänglich gegen die Erreger jener Krankheiten. Es ist um so mehr angezeigt, unsere Forschungen nicht lediglich auf die Wipfelkrankheit (und die übrigen Polyederkrankheiten) zu beschränken, sondern auch auf die anderen Seuchen auszudehnen (wenn diese fürs erste auch kein spezielles Interesse für die Forstinsekten zu haben scheinen), als man in der letzten Zeit in dem Coccobacillus acridiorum und Coccobacillus cajae Mikroorganismen von außerordentlicher Pathogenität und Virulenz kennen gelernt hat, und mit dem ersteren auch, wie es scheint, gute Erfolge bei der Bekämpfung der Wanderheuschrecken in Mexiko erzielte (D'Herelle).

Auch mit Nosema, welches aus Seidenzüchtereien ja stets in genügender Menge zu haben ist, solltcn Infektionsversuche an den verschiedenen Forst- 
schädlingen gemacht werden, nachdem dessen Pathogenität und leichte Verbreitung durch die verheerenden Seuchen, an denen die Seidenzüchtereien früher (vor der Einführung des Zellensystems) so arg zu leiden hatten, genügend dargetan ist. -.. So gibt es also auch auf dem Gebiet der Verbreitung von Insektenkrankheiten zum Zwecke der Schädlingsbekämpfung noch unendlich viel zu tun. Ja, fast alles ist hier noch Problem. Jahrzehnte langes eingehendes Studium wird nötig sein, Klarheit in die so überaus schwierigen Fragen zu bringen, und viele Enttäuschungen in praktischer Hinsicht werden wir vielleicht erleben. Doch darf diese Überlegung niemals ein Grund sein, von vornherein auf die Inangriffnahme dieser Probleme verzichten zu wollen.

\section{Die technische Bekämpfung.}

\section{a) Allgemeine Gesichtspunkte.}

Die technische Bekämpfung bezweckt die direkte Vernichtung (oder Abhaltung) der Schädlinge auf chemischem oder mechanischem Wege. "Vom theoretischen Standpunkt läßt sich dieselbe gegen alle vier Hauptlebensstadien eines Schädlings, gegen Ei, Larve, Puppe und Imago anwenden; desgleichen in jeder Jahreszeit. Gegen welches Stadium im bestimmten Einzelfalle vorzugehen ist, und zu welchem Zeitpunkte, hängt vor allen Dingen von der Lebensweise des betreffenden Schädlings ab. Eine völlige Vertrautheit mit der Lebensweise des Schädlings ist also die wesentliche Vorbedingung eines günstigen Erfolges, und eine solche zu vermitteln, ist die Aufgabe der folgenden Bände dieses Werkes. In zweiter Linie wird man darauf zu sehen haben, daß die Vertilgungsmaßregeln in eine Zeit gelegt werden, in welcher die nötigen Arbeitskräfte am leichtesten verfügbar sind. - Im allgemeinen wird man gegen das Stadium und zu dem Zeitpunkte zu operieren haben, in welchem der Schädling am leichtesten zugänglich ist, in welchem es ferner möglich ist, viele Individuen auf einmal zu vernichten. Es wird sich ferner bei sonst gleichen Umständen empfehlen, stets gegen das am längsten dauernde Stadium vorzugehen, weil dieses die größte zeitliche Ausdehnung der Bekämpfungsmaßregeln gestattet. Endlich ist es besonders angezeigt, die Schädlinge hinwegzuräumen, ehe sie zur Fortpflanzung schreiten können." (N.)

Beispiele von Vertilgungsmaßregeln, welche sich gegen das $\mathrm{E}$ is t a dium richten, sind das Sammeln und Vernichten der Eierringe des Ringelspinners oder der Eierschwämme des Schwammspinners.

Im L a rvenzus t ande werden sehr viele forstschädliche Schmetterlinge bekämpft, z. B. der Kiefernspinner, die Nonne, die Eule u. a. Auch die Bekämpfung der Borkenkäfer durch Fangbäume sollte namentlich eine $\mathrm{L}$ a r venvertilgung sein, da ein vorsichtiger Forstmann mit dem Schälen der Fangbäume nicht bis zur Verpuppung warten wird. Vertilgungsmaßregeln, die speziell gegen die $\mathrm{P}$ u p p e gerichtet sind, werden meist nur angewendet bei solchen Schmetterlingen, welche in diesem Stadium überwintern, z. B. bei Kieferneule und Kiefernspanner.

Bekannte Beispiele von Vertilgung schädlicher I magines sind das Sammeln des Maikäfers, des großen braunen Rüsselkäfers, des Nonnenfalters, der ungeflügelten Frostspannerweibchen usw.

Wo es sich um besonders schlimme Schädlinge handelt, die wenig Angriffspunkte zu einer radikalen Bekämpfung bieten, da geht man event. ge ge $\mathrm{n}$ die verschiedenen $\mathrm{Stadien} \mathrm{vor,} \mathrm{um} \mathrm{die} \mathrm{Wirkung} \mathrm{zu} \mathrm{erhöhen;} \mathrm{so} \mathrm{sucht} \mathrm{man}$ 
im Kampf gegen die Nonne sowohl die Raupe (in erster Linie), als auch die Puppe und die Imago zu vernichten.

Wie es möglich ist, durch richtige Wahl des Zeitpunktes der Vertilgung viele Individuen auf eimmal zu töten, dafür liefert ebenfalls die Nonne einen guten Beleg. Das Vernichten der Raupen ist bei diesem Tiere in der Zeit am erfolgreichsten, in welcher die aus den einzelnen Eierhaufen geschlüpften, späterhin sich zerstreuenden Räupchen noch familienweise in den sog. Spiegeln zusammensitzen. Desgleichen wird die Vertilgung der Raupen des Goldafters, Liparis chrysorrhoea $L$., am leichtesten im Winter besorgt, wenn sie zwischen versponnenen Blätterı, den sog. „Raupennestern“, in größeren Scharen zusammensitzen.

In vielen Fällen wird aber zur Erreichung eines wirklichen Erfolges nicht allein die Berücksichtigung der passenden Jahreszeit genügen, sondern auch die passende Tageszeit oder passende Witterung gewählt werden müssen. So ist z. B. ein erfolgreiches Sammeln der Maikäfer mittels Schütteln größerer Bäume nur in den frühen Morgenstunden oder bei naßkaltem Wetter möglich, weil bei warmen, sonnigen Tagen die herabfallenden Käfer während des Sturzes die Flügel ausbreiten und davonfliegen. Dergleichen kann ein bequemes und erfolgreiches Sammeln der am Tage unterirdisch lebenden Raupen der Kiefernsaateule nur in der Nacht, wenn sie, hervorgekommen, die oberirdischen Teile der Kiefernpflänzchen angehen, bei Laternenlicht vorgenommen werden.

Das vorhin angeführte Beispiel der Vertilgung der Raupen des Goldafters in ihren Nestern ist auch gültig für die Bemerkung, daß es wünschenswert ist, de $n$ a $\mathrm{m} l$ äng sten da u e r nde $n \mathrm{Zustand}$ zur Vertilgung zu wählen. Gestattet doch gerade die Länge der Winterruhe im Raupenneste dem Obstzüchter, die Vertilgungsmaßregeln $\mathrm{zu}$ einer ihm bequemen Zeit und so gründlich, als er es nur irgend wünscht, vorzunehmen. Überhaupt scheint das Überwinterungsstadium, als das längste, in sehr vielen Fällen die erfolgreichste Bekämpfung möglich zu machen, vorausgesetzt, daß sich die Tiere nicht etwa in unzugänglichere Schlupfwinkel zurückziehen. Letzterer Fall kommt z. B. bei den Engerlingen vor, die sich in Winter tiefer in die Erde eingraben.

Bezüglich der Art der technischen Bekämpfung lassen sich zwei Hauptrichtungen unterscheiden, die eine sucht den Schädlingen durch chemische Mittel beizukommen, während die andere auf mechanischem Wege die Vertilgung resp. die Schadlosmachung erstrebt. Wir wollen die erstere kurzweg als die chemische, die letztere als die mechanische Methode bezeichnen, wobei jedoch gleich zu bemerken ist, daß die beiden nicht immer scharf voneinander zu trennen sind.

\section{b) Die chemischen Methoden. ${ }^{1}$ )}

Die chemische Bekämpfung spielt gegenüber den forstlichen Schädlingen nicht jene große Rolle wie gegenüber den landwirtschaftlichen, vor allem den Obst- und Weinbauschädlingen, und zwar aus dem einfachen Grunde, weil die große Ausdehnung der Forsten und die Höhe der Bäume in Beständen eine allgemeine Anwendung chemischer Mittel (soweit es sich um flüssige oder staubförmige handelt) aus technischen und finanziellen Gründen erschwert. Das Bereich der chemischen Bekämpfung ist daher in der Forstentolomogie ein beschränktes: es bezieht sich vornehmlich auf solche

1) Eine zusammenfassende Darstellung der wichtigsten chemischen Mittel findet sich in Holl rung, Handbuch der chemischen Mittel gegen Pflanzenkrankheiten. Berlin 1898. (Zweite Auflage erscheint 1914.) 
Formen des Forstes, die dem landwirtschaftlichen oder gärtnerischen Charakter nahe kommen, also Pflanzgärten und Kulturen; in Beständen kann sie nur dann zur Anwendung kommen, wenn es sich um einzelne Bäume oder wenigstens um eng umschriebene Insektenherde handelt.

Die chemische Methode schließt eine ganze Reihe verschiedener Verfahren in sich, die sich zusammenfassen lassen unter den Begriffen: Allgemeine und lokale Giftbehandlung derinsektenbefallenen Pflanzen und Giftbehandlung des Bodens.

Die allgemeine Giftbehandlung ist da indiziert, wo die Schädlinge mehr oder weniger zerstreut auf der Pflanze vorkommen, so daß eine Einzelbehandlung ausgeschlossen ist; sie kann bestehen in $\mathrm{Be}$ spritzen, Bestäuben und Räuchern.

Das am meisten zur Anwendung kommende Verfahren ist das Bespritzen der befallenen Pflanzen mit Flüssigkeiten, die auf die Schädlinge tötlich wirken. Der große Vorzug des Spritzens liegt darin, daß die Giftflüssigkeit infolge des starken Druckes und der feinen Verstäubung in relativ kurzer Zeit und mit geringer Arbeit unter größter Sparsamkeit im Verbrauch an alle, auch entferntere Stellen der zu behandelnden Pflanze gebracht werden kann. Die anzuwendende Spritzflüssigkeit richtet sich nach dem zu bekämpfenden Schädling, und zwar nicht nur nach der Art seiner Nahrungsautnahme (ob kauend oder saugend), sondern auch nach seiner spezifischen Empfindlichkeit. Es hat sich im Laufe der Zeit durch tausendfältige Erfahrung herausgestellt, daß die verschiedenen Insektenarten (mitunter auch solche, die im System nahe stehen), sich recht verschieden gegen die einzelnen Gifte verhalten können, indem die einen eine stärkere Konzentration ertragen als die anderen, oder überhaupt unempfindlich sind, während die anderen daran zugrunde gehen. Aber nicht nur das Verhalten des betreffenden Insektes gegen das Gift ist zu berücksichtigen, sondern ebenso auch die Wirkung des Giftes auf die Pflanze, auf der der Schädling lebt. Viele der angepriesenen Spritzmittel töten wohl prompt die Schädlinge, mit denen sie in Berührung kommen, bringen aber nicht weniger prompt die Pflanzen oder wenigstens die Teile, die damit benetzt wurden, zum Absterben. Oft macht sich die verderbliche Wirkung des Giftes auf die Pflanzen erst nach längerer Zeit geltend, was recht verhängnisvoll werden kann, wenn man näılich, in der Meinung von dessen Unschädlichkeit bereits zur Anwendung im großen übergegangen ist. Man sollte also jedenfalls längere Zeit, womöglich eine Vegetationsperiode abwarten, bevor man ein endgültiges Urteil über das betreffende Gift fällt.

Die Zahl der Spritzmittel ist Legion. Man braucht nur die verschiedenen Kataloge der Fabriken, die sich mit der Herstellung von Pflanzenschutzmitteln befassen, ${ }^{1}$ ) einzusehen, um einen Begriff von der Produktivität auf diesem Gebiet zu bekommen. Und fortwährend werden neue Mittel in

1) Als die bekanntesten Bezugsquellen für chemische Pflanzenschutzmittel sind zu nennen: Dr. No e r d l inger in Floersheim, E. A. M e rk in Darmstadt, Gehe \& Cie. in Dresden, $\mathrm{K}$ ahlba u $\mathrm{m}$ in Adlershof bei Berlin. 
den Handel gebracht, die als sicherwirkend gegen diesen oder jenen Schädling gepriesen und mit den verschiedensten Namen belegt werden. Vielfach sind die neuen Mittel schlechter als die alten, wie wir selbst im hiesigen Institut mehrfach zu erfahren Gelegenheit hatten. Man sollte sich deshalb bei der Auswahl der Mittel niemals lediglich auf die reklamehaften Anpreisungen allein verlassen, sondern nicht versäumen, vor der Anwendung bei einem der zuständigen Institute über den Wert des Mittels anzufragen.

Wir unterscheiden unter den Spritzmitteln im allgemeinen „Magengifte" und "Kontakt- oder Berührungsgifte“. Die ersteren werden mit der Nahrung aufgenommen und wirken vom Darmtraktus aus vergiftend, während die letzteren durch die bloße Berührung mit der Haut resp. Bedeckung des Körpers den Tod des Schädlings verursachen. Die Bezeichnung „Kontakt- oder Berührungsgifte“ ist insofern nicht sehr günstig gewählt, als den hierherzuzählenden Mitteln eine ganz verschiedene Wirkungsweise zukommen kann; so handelt es sich bei dem einen Mittel (z. B. Schwefelkalkbrühe) um Ätzwirkung, bei dem anderen (Öle usw.) um Erstickung, bei dem dritten um Gasvergiftung usw., so daß es sich vielleicht empfehlen würde, die Gruppe „Kontaktgifte“ aufzulösen. Bei manchen Giften ist man sich übrigens über die Art ihrer Wirkung noch nicht klar.

Im folgenden seien einige der wichtigsten Spritzgifte, die für den Forstmann in Betracht kommen, genannt:

Unter den Magengiften sind als die wirksamsten die verschiedenen Arsenikmittel zu nennen, unter denen das Bleiarseniat (Plumbum arsenikosum) entschieden die erste Stelle einnimmt. Wenn es auch im Preis etwas teurer ist als die anderen Arsenikpräparate (Schweinfurtergrün, Londonpurpur usw.), so hat es doch so viele Vorzüge, daß die Preisdifferenz mehr als ausgeglichen wird. Vor allem schadet seine Anwendung den Pflanzen so gut wie garnicht, und sodann bleibt es (wohl infolge der kolloidalen Eigenschaften des Bleis), weit besser an den Blättern haften als die übrigen, was von der größten Bedeutung für ein Spritzmittel ist. Natürlich gebietet die Giftigkeit der Arsenikpräparate für Mensch und Tier besondere Vorsicht und eine Beschränkung ihrer Anwendung. So muB bei der Verwendung im Walde stets auf die Gefahr, die dem Wild durch Äsung arsenhaltiger Pflanzenteile erwachsen kann, Rücksicht genommen werden. Man wird Arsenbespritzungen daher nur dort vornehmen, wo das Wild keinen Zutritt hat, also in eingezäunten Pflanzgärten, Kulturen usw. Sind diese Bedingungen gegeben, so kamn das Arsen vorzügliche Dienste gegen die verschiedensten blatt- und nadelfressenden Insekten leisten, wie z. B. Brachyderes, Blattwespen, überwehte Nonnenraupen usw. ${ }^{\mathbf{1}}$ )

In Amerika steht das Bleiarseniat in der höchsten Gunst und es wird dort gegen ein ganzes Heer von Insekten damit gekämpft, wie z. B. gegen den Apfelwickler, den Pflaumenrüßler, den Schwammspinner, den Ulmenblattkäfer usw. Trotz dieser weitverbreiteten Anwendung, selbst bei Alleebäumen in der Stadt, sind Fälle von Vergiftungen nicht bekannt geworden, ein Zeichen, daß man mit der Angstlichkeit nicht zu weit zu gehen braucht. Über die ausgezeichnete Wirkung des Bleiarseniates konnte sich der Verfasser selbst mehrfach in Amerika überzeugen.

1) Vergl. hierzu die ausgezeichnete Zusammenstellung von Fulmek. 
Die gegen den Schwammspinner bespritzten Laubbäume zeigten ihr volles Laub, während die unbespritzten meistens starke Spuren des Fraßes erkennen ließen. Am deutlichsten konnte man die Wirkung an den Alleebäumen von Boston erkennen: im Bereich von Cambridge, wo nicht gespritzt wurde, waren alle die schönen alten Ulmen vom Ulmenblattkäfer kahl gefressen und dem Absterben nahe (teilweise auch schon abgestorben), während in dem dicht daran anschließenden Arlington, wo mehrmalige Spritzungen vorgenommen worden waren, fast alle Bäume ihren vollen Laubschmuck behalten hatten.

Man bezieht das Bleiarseniat am besten in Form einer dicken Paste, damit ein Verstäuben des giftigen Produktes vermieden wird. Von dieser Paste verwendet man $1 / 2-1 \mathrm{~kg}$ auf $100 \mathrm{l}$ Wasser.

Man kann das Bleiarseniat auch in Verbindung mit $\mathrm{Kupferkalkbr}$ ü he als Arsen-Kupferbrühe (z. B. Arsen-Cupretta von D r. N o e r d ling e r) verwenden zur gemeinsamen Bekämpfung von tierischen und pilzlichen Schädlingen, während Kupferverbindungen allein gegen tierische Schädlinge im allgemeinen von nur geringer Wirkung sind. Mit B or dela is e r B r üh e soll man nach verschiedenen nencren Berichten allerdings ganz gute Erfolge (?? der Verf.) gegen Nonncnraupen erzielt haben (für kleinere Raupen $2 \%$, für größere $21 / 2 \%$ Lösung).

Als ein weiteres brauchbares Spritzmittel gegen Raupen und andere kauende Insekten ist neuerdings Chlorbarium empfohlen worden. Eckstein hat damit gute Erfolge gegen die Nonne erzielt, und zwar in einer Mischung ron $1^{1} / 2 \mathrm{~kg}$ auf $100 \mathrm{l}$ Wasser; bei einer geringeren Konzentration blieben die Raupen zum großen Teil am Leben, während eine stärkere Konzentration die Bäume beschädigte. Un ein besseres Haftenbleiben der Flüssigkeit zu erzielen, empfiehlt sich der Zusatz von Melasse. Der Preis stellt sich bei C. A. F. Kahlbaum, Adlershof bei Berlin auf 35 Pf. pro Kilogramm, $100 \mathrm{~kg}$ auf $24 \mathrm{M}$.

Weite Verbreitung als Spritzmittel hat ferner das Karbolineum erfahren, welches in zahllosen Marken und unter den verschiedensten Namen (Karbolineum, Lohsol, Lauril-Karbolineum, Floria-Karbolineum usw.) in den Handel gebracht wird. Gegen Forstinsekten ist bisher vor allem das Arbolineum, eines der mit Wasser emulgierbaren Karbolineumpräparate, in Anwendung gekommen, und wie es scheint, mit gutem Erfolg.

Besondere Beachtung verdient des weiteren das Nikotin, welches sowoh] als Magengift als auch als Kontaktgift eine hervorragende Rolle einnimmt. Es wird gewöhnlich mit anderen Stoffen (wie Schmierseife, Spiritus, Kolophonium usw.), welche ein besseres Eindringen und Festhaften bewirken, angewendet. M. Schwartz empfiehlt vor allem folgende Gemische:

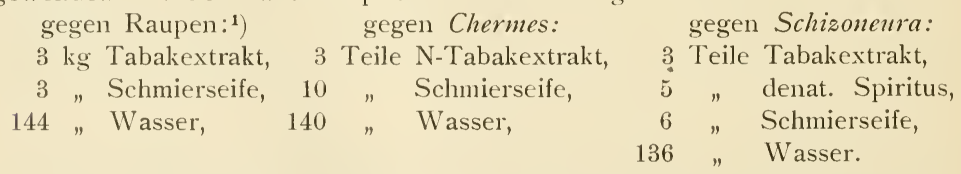

Um auch die stark behaarten Raupen ausreichend mit der Nikotinlösung benetzen zu können, empfiehlt sich ein Zusatz von Harz und Ammoniak in folgender Weise:

1) Schwangart empfiehlt gegen den Traubenwickler $1 \frac{1}{2} \mathrm{~kg}$ Tabakextrakt, $1 / 2$ bis $1 \mathrm{~kg}$ Schmierseife auf $100 \mathrm{l}$ Wasser. 
$3 \mathrm{~kg}$ Tabakextrakt,

3 " Schmierseife,

1 "Kolophonium in 31 denaturiertem Spiritus gelöst,

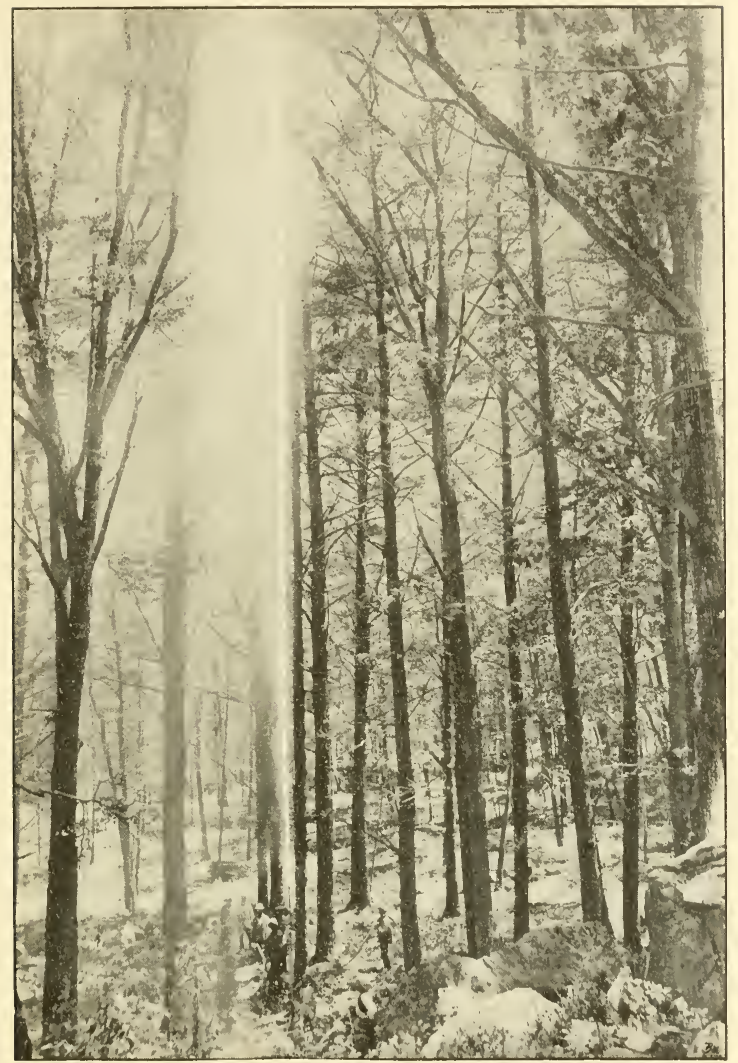

Fig. 218. Spritzen im Hochwald mit einer Motorspritze, Bei $300 \mathrm{~m}$ Schlauchlänge kann eine Strahlenhöhe von $30 \mathrm{~m}$ erreiclıt werden. (Phot. Fitzhenry-Guptill.) Aus Escherich.

31 Salmiakgeist, 137 "Wasser.

Ferner kann auch Nießwurz der Mischung beigesetzt werden, wodurch die Blätter oder Nadeln gewissermaßen immun gemacht werden, indem die meisten Raupen den damit behandelten Pflanzenteil meiden. M. Schwartz empfiehlt folgende Mischung:

$3 \mathrm{~kg}$ Tabakextrakt,

3 "Schmierseife, 


\section{1 denaturierten Spiritus, 500 g pulverisierte Nießwurz, 141 l Wasser.}

Die Kosten betrugen bei den Versuchen für je ein ca. $2 \mathrm{~m}$ hohes Bäumchen (Obstbaum) ca. 5 Pf.

Bezügl. des Tabakextraktes herrschen nach den Untersuchungen $\mathrm{S} c \mathrm{~h}$ w a $\mathrm{n}$ garts große Unterschiede im Nikotingehalt. Es ist daher auf die Auswahl der

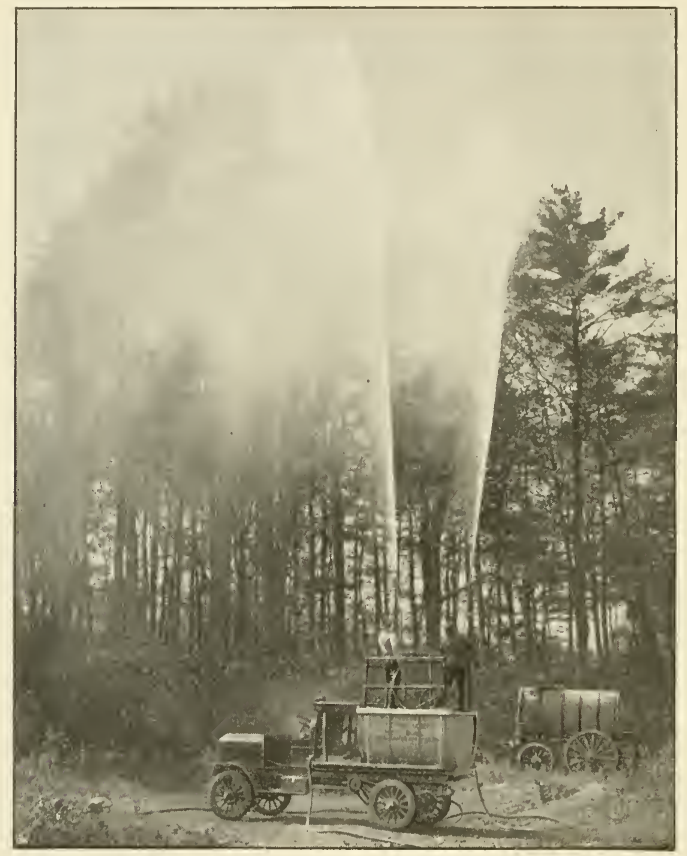

Fig. 219. Motorspritze (auf Automobil) mit zwei Schläuchen. (Phot. Fitzhenry-Guptill.) Aus Escherich.

Präparate besonderer Wert zu legen. Eine recht konstante Zusammensetzung hat die von der Administration des Tabaks in Frankreich staatlich hergestellte Nicotine titrée. Da jedoch das französische Präparat von den staatlichen Verkaufsstellen in Frankreich nicht nach Deutschland abgegeben wird und nur indirekt durch Vermittlung von Privatpersonen bezogen werden kann, kann dasselbe für den praktischen Gebrauch in Deutschland nur wenig in Betracht kommen. Nach $\mathrm{Schwangart}$ ist auch das von der Firma Merk in Darmstadt hergestellte Rohnikotin ein technisch und chemisch einwandfreies Fabrikat, welches einen Nikotingehalt von $99,4 \%$ aufweist. Besonders empfehlenswert ist nach demselben Autor der von der Firma A. W. Everth in Hamburg (Kajen 22) in den Handel gebrachte amerikanische Tabakextrakt „Black Leaf", der annähernd konstant 
$10,04 \%$ Nikotin enthält. Erstklassig ist auch der Óster reichische Regieextrakt, der (ohne Zoll) ${ }^{1}$ ) pro Kilogramm nur 1,40 M. (gegen 2,20 M. von Everths "Black Leaf") kostet.

Ähnlich wie die Nikotingemische wirkt Quassiabrühe, aus einem Absud von $1^{1 / 2} \mathrm{~kg}$ Quassiaholz (Panamaspäne) und $1 \frac{1}{2}-2 \mathrm{~kg}$ Schmierseife in 1001 Wasser hergestellt. Quassiabrühe wird dort verwendet, wo der Geruch des Nikotins vermieden werden soll (Fulmek). - Gegen eine ganze Reihe saugender Insekten genügt übrigens auch eine einfache Schmierseifenlösung (ohne Tabakextrakt) mit etwas Petroleumzusatz $\left(1^{1 / 2} \mathrm{~kg}\right.$ Schmierseife, $1 / 21$ Petroleum auf 1001 Wasser.) Vor allem gegen verschiedene Pflanzenläuse kann die Anwendung dieses einfachen Mittels guten Erfolg bringen.

Endlich sei noch auf die Schwefelkalkbrühe (Kalifornische Brühe) hingewiesen, die seit langer Zeit in Amerika in größtem Maßstabe angewandt wird und jetzt auch in Deutschland mehr in Aufnahme zu kommen scheint, allerdings in erster Linie als Fungizid. Da sie jedoch auch ein wirksames Insektizid darstellt, vor allem gegen Schildläuse (wird sie doch als Hauptbekämpfungsmittel gegen die San-José-Schildlaus angewandt), sollte man sich gegebenenfalls dieses billigen Mittels ${ }^{2}$ ) erinnern (vgl. Fulmek, Die Schwefelkalkbrühe).

Für Schwefelkalkbrühe sind besondere Spritzen notwendig, da Kupfer von der Brühe stark angegriffen wird und die chemische Zusammensetzung der Brühe selbst hierdurch verändert und ihre Wirksamkeit herabgemindert wird. Man verwendet für Schwefelkalkbrühe Spritzen, welche im Inneren verzinkt sind oder solche aus Stahlblech oder aus anderen Metallegierungen, die von der Brühe nicht angegriffen werden (B. W a h 1 ).

Was die Spritzapparate ${ }^{3}$ ) betrifft, so dürfte man in den meisten Fällen mit den gewöhnlichen selbsttätigen Schüttespritzen, die am Rücken getragen werden, auskommen. Die Reichweite kann ja event. durch einzusetzende Bambusrohre etwas vergrößert werden. Wo es sich aber um die Rettung einzelner großer Bäume handelt, da ist zu stärkeren Modellen event. mit Motorbetrieb zu greifen. Wie weit man mit solchen Kraftspritzapparaten bereits gekommen ist, zeigen die in Amerika hundertfach in Betrieb stehenden „Power sprayers“, mit denen man bei einer Schlauchlänge von 2-300 $\mathrm{m}$ Bäume von $30 \mathrm{~m}$ Höhe bespritzen kann (Fig. 218 u. 219). Es dürfte sich zweifellos sehr empfehlen, daß große Forstverwaltungen, Stadtgemeinden, botanische Gärten, Besitzer von großen Parks usw. sich eine solche Kraftspritze zulegen, um einzelne wertvolle alte Bäume oder auch besonders wertvolle Bestandesteile bei eventuellem Insektenbefall retten zu können.

1) Durch Bundesratsbeschluß fällt der Zoll bei Verwendung gegen Rebschädlinge weg.

$\left.{ }^{2}\right)$ Großvertrieb für $\mathrm{Schwefelkalkbrühe:} \mathrm{Agrikulturabteilung} \mathrm{der}$ Schwefelproduzenten-G. 111. b. H. in Hamburg I, Mönkebergstr. 9. - Weitere Bezugsquellen: Agra ria, Fabrik landwirtschaftl. Artikel, Dresden-A. 16, und die anderen auf S. 352 genannten Firmen.

$\left.{ }^{3}\right)$ Für Spritzapparate seien folgende Bezugsquellen genannt: Holder in Metzingen (Württbg.), Goehlers Witwe Nachfolger in Freiberg (Sa.), letztere Firma liefert auch alle anderen zur Insektenbekämpfung nötigen Apparate. 
I)ie renommierteste Fabrik für die großen Kraftspritzen ist Fitzhen $\mathrm{r} \mathrm{y}$ Guptill in Cambridge Mass. Der Preis der stärksten Spritzen beträgt ca. $4000 \mathrm{Ml}$. Ubrigens werden neuerdings auch in Deutsehland Spritzen mit Motorbetrieb hergestellt, wie aus dem Katalog der Firma Holder in Metzingen hervorgeht.

Gegen das Spritzen tritt das Bestäuben bezügl. der Anwendbarkeit weit zurück; hat es doch auch dem Spritzverfahren gegenüber verschiedene Nachteile. Es ist vor allem vielmehr von dem Wetter abhängig als das letztere, indem z. B. starke Winde die Ausführung ummöglich machen. Ferner ist die gleichmäßige Verteilung auf alle Blätter oder Nadeln bei staubförmigen Stoffen schwieriger als bei flüssigen, und endlich ist auch die Wirkung der Staubmittel unbeständiger als die der letzteren, indem sie durch Winde abgeweht oder durch Regen leicht abgeschwemmt werden können. Andererseits hat das Bestäubungsverfahren den Vorteil des leichteren Transportes und der Entbehrlichkeit des Wassers, und außerdem wird manchen Mitteln im staubförmigen Zustand auch eine stärkere Wirkung nachgesagt als im flüssigen oder gasförmigen Zustand. Als die hauptsächlichsten Bestäubungsmittel ${ }^{1}$ ) kommen in Betracht: Tabakstaub, Schwefelblume, Schwefelleber, Insektenpulver, Naphthalinkalkpulver usw. In forstlichen Betrieb eignet sich das Bestäubungsverfahren nur in Pflanzgärten oder jungen Kulturen, und wird hier gegen Blattläuse, Afterraupen und vor allem gegen Erdflöhe angewendet. Zur Verstäubung der pulverförmigen Stoffe bedient man sich besonderer Apparate, die mit Blasbälgen versehen sind. Zur Vornahme der Bestäubung empfiehlt es sich, einmal möglichst windstille Tage und sodann die Morgenstunden, in denen die Pflanzen noch die Morgenbetauung tragen, zu wählen.

Während der letzten großen Nonnenkalamität in Sachsen wurde der Vorschlag gemacht, das Bestäubungsverfahren in großen in den Beständen durchzuführen, und es wurde sogar auch ein Apparat konstruiert, durch den die Staubmassen hoeh in die Luft gesehleudert werden können. Der Vorsehlag hat aber wenig Anklang gefunden; auch hat man nichts darüber erfahren, ob der Apparat irgendwo in der Praxis in Gebrauch gekommen ist und ob irgendwelche greifbaren Erfolge damit erzielt sind. -

In noch geringerem Ansehen als das Bestäuben steht das Räuchern in der Forstentomologie. Es wird bis jetzt nur in ganz wenig Fällen angewendet; eigentlich nur gegen die beiden Tannentriebwickler. Die Rauchentwicklung wird in diesen Fällen in der Weise bewirkt, daß das ron der Durchforstung stammende Reisig in regelmäßiger Verteilung auf Haufen gesetzt und angezündet wird. Das grüne Material liefert einen dicken Rauch, unter dessen Einwirkung, zumal bei feuchtem Wetter, die Raupen massenhaft zu Boden fallen, wo man sie zusammenfegen und vernichten kann. Es frägt sich, ob das Räucherverfahren nicht doch vielleicht auch in der Forstentomologie weiter ausgebaut werden kann.2) Im allgemeinen scheinen

1) Nach M. Schwartz ist die Verschiedenheit in der Einwirkung der pulverförmigen und gasförmigen Gifte wohl dadurch zu erklären, daß ,das Insekt bereits die ersten schwachen Gasspuren wahrzunehmen und darauf durch Schließung der Tracheen zu reagieren vermag. Das Pulver dagegen wird erst nach dem Eindringen der Teilchen in die Atemöffnung wahrgenommen. Der Versehlußmeehanismus (siehe oben S. 72) tritt alsdann für das Tier zu spät in Tätigkeit.“

$\left.{ }^{2}\right)$ Der vor wenigen Jahren gemachte Vorschlag, mit Schwefeldämpfen die Nonne zu bekämpfen, hat, wie nicht anders zu erwarten war, allseitige Zurückweisung erfahren. 
die Raupen ja schr unempfänglich gegen Rauchwirkung zu sein, wie wir uns selbst durch verschiedene Versuche überzeugen konnten: so blieb z. B. der dickste Qualm, der durch Verbrennung von mit den verschiedensten Stoffen getränkten Sägespänen scheinbar ohne jede Wirkung auf die Nonnenraupen, die sich nicht einmal von ihrem Sitz rertreiben ließen. Dies schließt aber nicht aus, daß vielleicht doch noch Stoffe gefunden werden, deren Verbrennungsgase eine empfindlichere Wirkung auf die Raupen oder andere Schädlinge auszuüben vermögen.

Wo die Schädlinge an einzclnen eng umschriebenen Stellen konzentriert, ferner gut sichtbar und erreichbar sind, oder wenn es sich um einzelne, besonders große, mechanisch schwer zu erreichende Schädlinge handelt, kanı die chemische Bekämpfung in der Weise ausgeführt werden, daß nur die betr. Stellen, resp. die dort angehäuften Schädlinge mit dem Gift behandelt werden ("lokale chemische Behandlung"). Solche Fälle liegen z. B. vor bei den Eischwämmen des Schwammspinners, die weithin sichtbar sind und zahlreiche Keime enthalten, fermer bei den Raupennestern des Goldafters und des Prozessionsspinners, bei den Spiegeln der jungen

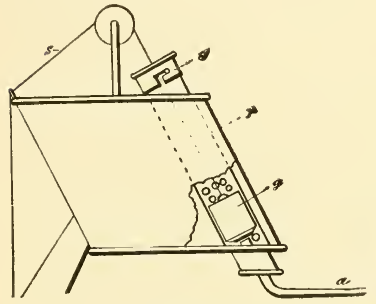

Fig. 220 a.

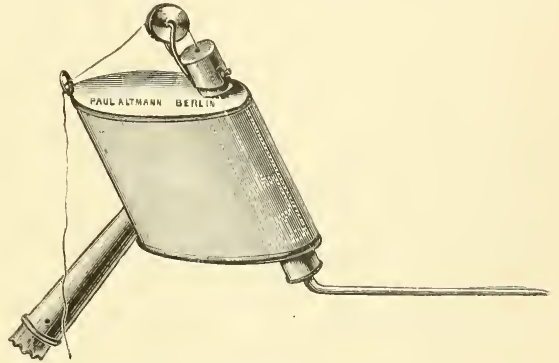

Fig. 220 b.

Petroleumkanne zur Tötung der Eier des Schwammspinners. Nach Rörig.

Nonnenraupen, bei den Kolonien von Rindenläusen ans Stamm, bei den Larven von Zeuzera, Sesien usw. Die Ausführung der lokalen Behandlung kann in verschiedener Weise geschehen, am einfachsten dadurch, daß man die Schädlinge mit einem in die Giftlüssigkeit getauchten Pinsel oder Wergbausch oder dgl. bestreicht oder betupft. So kann man die Eischwämme des Schwammspinners dadurch abtöten, daß man sie mit Petroleum bepinselt, oder die Nonnenspiegel dadurch, daß man sie mit Öl betupft usw. Um die Giftflüssigkeit in genau abgemessenen Quantitäten an die besetzten Stellen bringen zu können, ist von Rörig ein besonderer Apparat konstruiert worden, der aus einer auf einer Stange befindlichen Kanne mit einem dümnen Ausflußrohr besteht, dessen Verschluß von unten aus in der leichtesten Weise bewerkstelligt werden kann (Fig. 220a u. b). Die Anwendung dieses Apparates hat den Vorzug, bei größter Sparsamkeit des Materials eine genügende Durchtränkung der betr. Stelle zu gewährleisten; außerdem kann man ihn für verschiedene Zwecke gebrauchen, nicht nur zum 
Abtöten der Eischwämme (wofür er ursprünglich konstruiert wurde), sondern auch zur Durchtränkung der Raupennester, wie vor allem der Prozessionsspinnernester. Bei der lokalen Behandlung, besonders bei dem Vcrfahren gegen die Eischwämme empfiehlt es sich, der Flüssigkeit einen Farbstoff beizumischen (Rörig benutzte Alkanin, einen roten Pflanzenfarbstoff, der dem Petroleum eine tief schwarzrote Färbung verleiht), um eine Kontrolle über die behandelten Stellen zu haben.

Die lokale Behandlung kann naturgemäß nur in relativ beschränktem Maße Anwendung finden, wo eben die obigen Bedingungen erfüllt sind. In dieser Beziehung steht sie der Spritzmethode wesentlich nach, andererseits aber hat sie das vor ihr voraus, daß sie sicherer und sparsamer arbeitet.

Eine Anwendung der ,lokalen Methode“ in großem Maßstab konnte der Verfasser in Amerika sehen, wo Hunderte von Arbeitern damit beschäftigt waren, die Eischwämme des Schwammspinners mit Kreosot zu bepinseln. Um die höher sitzenden Schwämme zu behandeln, wurden Leitern benützt, was gegenüber der Methode, mit langen Stangen von unten aus die Behandlung vorzunehmen, zweifellos den großen Vorteil besitzt, daßeinmal ein Übersehen von Schwämmen weniger leicht vorkommt und sodann auch die Bepinselung gründlicher ausgeführt werden kann.

Wo es sich um Insekten handelt, die im Boden leben resp. im Boden ihre Entwicklung durchmachen, sucht man denselben durch Behandlung des Bodens mit Giftstoffen beizukommen. Es können dabei verschiedene Verfahren zur Anwendung gelangen. Das verbreitetste ist die Schwefelkohlenstoffinjektion, welcher der Gedanke zugrunde liegt, Schwefelkohlenstoff in den Boden einzubringen, damit dessen sich im Boden verbreitende Dämpfe die dort befindlichen Larven usw. abtöten. Die Einbringung des Schwefelkohlenstoffes kann entweder dadurch geschehen, daß man Löcher (mit dem Pflanzeisen) in den Boden stößt, die Flüssigkeit eingießt und dann das Loch wieder schließt. Oder man verwendet Gelatinekapseln, die mit Schwefelkohlenstoff gefüllt sind (die sog. Jamainschen Kapseln, 1000 Stück à $2^{1} / 2 \mathrm{~g}$ flüssigen Schwefelkohlenstoffes kosten ca. 25 M. bei L. Möller in Erfurt), die man in die Löcher einwirft. Oder man gebraucht, was neuerdings meistens geschieht, eine Bodeninjektionsspritze (ein mit einer Kompressionspumpe versehener hohler Stahlstab), bei deren Anwendung die Arbeit des Löcherstoßens völlig in Wegfall kommt.

Um das Verfahren erfolgreich zu gestalten, sind verschiedene Momente zu berücksichtigen: Vor allem kommt es auf eine richtige Dosierung an; denn zu geringe Einspritzungen wirken nicht tödlich auf die Insekten, zu starke dagegen wirken tödlich auf die Pflanzen. So hat man sich also zunächst durch eine Reihe Versuche über die anzuwendende Quantität zu vergewissern. Nach Decoppet läßt sich die günstigste Wirkung auf Engerlinge, gegen die ja das Verfahren in erster Linie angewendet wird, mit $40-50 \mathrm{~g}$ für den Quadratmeter, verteilt auf 6 Einstichlöcher, erzielen. Doch spielt dabei natürlich auch die Bodenbeschaffenheit eine wesentliche Rolle, insofern als lehmige Böden die Dämpfe schwerer durchtreten lassen als lockere sandige. Ferner ist zu bedenken, daß die Schwefelkohlenstoffdämpfe in ihrer verhältnismäßigen Schwere die Tendenz haben, nach unten zu sinken; es dürfen 
demnach die Löcher resp. die Einstiche nicht zu tief gemacht werden; jedenfalls nicht tiefer als die zu bekämpfenden Larven sich befinden.

Die Schwefelkohlenstoffbehandlung läßt sich außer gegen den Engerling auch gegen noch verschiedene andere Wurzelinsekten anwenden, wie z. B. gegen Otiorhynchus, Brachyderes usw., und zwar nicht nur als Vertilgungs-, sondern auch als Vorbeugungsmittel bei der Anlage von Kulturen. Auch gegen die Maulwurfsgrille kann man Schwefelkohlenstoff benutzen, indem man die Flüssigkeit einfach in ihre Gänge eingießt und das Eingangsloch zutritt.

Neben dem Schwefelkohlenstoff hat man noch alle möglichen anderen Flüssigkeiten zum Einbringen in den Boden empfohlen, wie Karbolsäure, Schmierseifenwasser usw.; doch keine derselben kommt in ihrer Wirkung dem Schwefelkohlenstoff gleich.

Eine weitere chemische Bodenbehandlung als Kampfmittel gegen Schädlinge besteht in der Verwendung von pulver-oder staubförmigen Produkten, die entweder in den Boden durch Umgraben gebracht oder aber einfach auf der Oberfläche aufgestreut werden. Die erstere Methode verfolgt den $Z_{w e c k}$, die in der Erde befindlichen Tiere zu töten, die letztere dagegen zielt hauptsächlich darauf ab, die Weibchen vom Eindringen in den Boden und der Eiablage daselbst abzuhalten.

Zum Untergraben wird hauptsächlich Tabakstaub empfohlen; doch muß dieser schon in großen Quantitäten verwandt werden, wenn er wirken soll. Vill gibt als wirksame Dose gegen Engerling $1 \mathrm{Ztr}$. auf $20 \mathrm{qm}$ an. Ferner soll auch Kainit sich gut bewähren gegen Erdraupen, Drahtwürmer usw. - Zur Bodenbestreuung verwendet man gewöhnlich Ätzkalkstaub von feingemahlenem, ungelöschtem Ätzkalk. Die Bestreuung muß derartig sein, daß der Boden wie mit einer leichten Schneedecke überzogen erscheint, wozu nach Vill ca. $40 \mathrm{Ztr}$. pro Hektar Pflanzgartenfläche notwendig ist. Da die Bestreuung den Käfer von der Eiablage abhalten soll, so muß sie in der Zeit der Fortpflanzung vorgenommen werden, und zwar mehr als einmal: „zum ersten Mal, sobald die ersten Käfer in Kopula gefunden werden, zum zweiten Mal, wenn der Kalkstaub durch Witterungseinflüsse gelöscht resp. nicht mehr sichtbar ist, und event. zum dritten Mal, wenn die Flugzeit sehr lange sich ausdehnt." Der Erfolg dieser Methode ist ein durchschlagender, indem die Maikäfer den Ätzkalk absolut meiden und auch die verschiedenen kleinen und mitunter recht schädlichen Rüsselkäfer darin umkommen. Der einzige Nachteil dieser Methode besteht darin, daß sie bei anhaltend nasser Witterung nicht anwendbar ist (Vill).

Endlich sei noch auf eine andere chemische Bekämpfungsmethode von Bodeninsekten hingewiesen, die in Frankreich und Amcrika rerschiedentlich versucht wurde: nämlich Entwicklung von Blausäuredämpfen im Boden. Man verfuhr dabei in der Weise, daß man wässerige Zyankaliumlösung ganz ähnlich wie Schwefelkohlenstoff in $10-20 \mathrm{~cm}$ tiefe Löcher eingoß und diese wieder zumachte. Die Wirkung dieses Mittels soll langsam, aber vollständiger sein als diejenige des Schwefelkohlenstoffs; die Insekten sollen sich nicht vor dem Mittel fürchten und die Pflanzen sollen selbst bei recht kräftigen Dosen 
nicht lciden. Es wurden 6-15 Löcher pro Quadratmeter mit je 8-10 ccm ciner $20 \%$ igen Zyankaliumlösung (=15 $20 \mathrm{~g}$ Zyankaliumlösung pro Quadratmeter) verwendet (Mamelle). Da Zyankalium eines der stärksten Gifte ist, so ist bei dessen Verwendung größte Vorsicht gebofen. Jedenfalls darf die Blausäuremethode nur unter sachkundiger Leitung ausgeführt werden.

\section{c) Die mechanischen Methoden.}

Die nächstliegende und einfachste Methode ist das direkte Entfernen resp. Vernichten der Schädlinge. Am leichtesten kann diese Methode da ausgeübt werden, wo es sich um Schädlinge handelt, die in dichten Mengen konzentriert beisammensitzen, wie z. B. die Lophyrus-Arten. Hier kann man durch einfaches Abstreifen der besetzten Äste und Zerdrücken der Larven mit der Hand vieles erreichen. Ebenso kann man die jungen Nonnenräupchen, die noch in Spiegeln zusammensitzen, in großer Zahl mechanisch vernichten, indem man die Spiegel zerdrückt, wozu man kürzere oder längere, mit einem

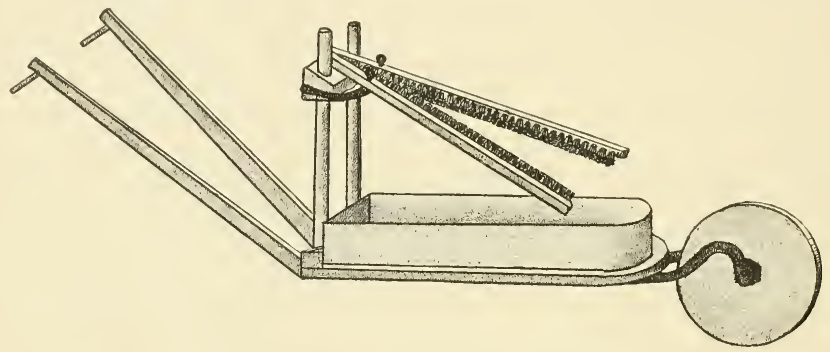

Fig. 221, Krahes Käferfalle. Aus Eckstein.

Lappen- oder Wergbausch versehene Stangen benutzt. Um die Wirkung zu erhöhen, kann man den Bausch mit Öl tränken, worauf schon oben bei der chemischen Methode hingewiesen wurde.

Auch bei Nonnenfaltern, die ja den Tag über meist ruhig an den Stämmen sitzen und durch ihre weiße Färbung leicht zu entdecken sind, wird die mechanische Vernichtung durch Zerdrücken vielfach angewendet. Natürlich soll das Vernichtungswerk geschehen, noch bevor das Weibchen seine Eier abgelegt hat. Welche Unmengen von Faltern auf diese Weise getötet werden können, ist in dem eben ausgefochtenen großen Nonnenkampf in Sachsen bewiesen worden, wo z. B. im Jahre 1908 im Forstbezirk Dresden allein über 12 Millionen Falter gesammelt wurden.

Für Weideninsekten, die oft in ungeheueren Mengen die ganzen Weiden bedecken und bei denen ein Abstreifen mit der Hand zu zeitraubend wäre, hat man einen Abstreifapparat geschaffen, (Krahes Käferfalle, Fig. 221) bestehend aus zwei langen Bürsten, die auf ein ebenso langes schmales einrädeıiges Karrengestell beweglich aufmontiert sind. Indem man mit dem Karren durch die befallene Kultur hinfährt, streift man die Insekten mit Hilfe der beiden Bürsten von den Pflanzen ab, die in eine auf dem Karren angebrachte, mit Wasser und Petroleum gefüllte Wanne fallen. 
Sollen Insekten gefangen werden, die sich in den Baumkronen befinden, so müssen sie aus der Krone herabgeschüttelt oder geprellt werden. Bei stärkeren Bäumen, die nicht wohl im ganzen zu schütteln oder zu prellen sind, könneı die einzelnen Zweige mit Hakenstangen geschüttelt werden. Um die herunterfallenden Insekten bequem sammeln zu können, empfiehlt es sich, Tücher unterzulegen oder zu halten, auf denen die Insekten leicht zusammenkehrt oder zusammengeschüttet werden können. Die Tücher müssen natürlich mindestens so groß sein wie der Umfang der Krone. ${ }^{\mathbf{1}}$ ) Wo es sich um das Abschütteln kleiner Bäumchen handelt, klopft man die Insekten am besten in einen untergehaltenen Schirm (sog. Klopfschirm). Bei

gut fliegenden Insekten (z. B. Maikäfer) hat das Abschütteln zu früher Morgenzeit zu geschehen, wenn die Tiere von der Nachtkühle noch erstarrt sind, da sie sonst beim Aufstören sofort zum Flug übergehen. Beim Prellen der Bäume ist darauf zu achten, daß keine Quetschwunden erzeugt werden; deshalb sind besonders Aststumpfe zum Anschlagen zu wählen. Außerdem sind die zum Prellen bestimmten Äxte an ihrer Rückseite mit Werg oder Lappen zu umwinden.

Handelt es sich um Eigelege,

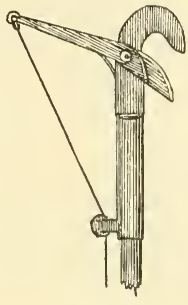

Fig. 222 a. Raupenschere.

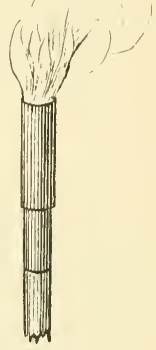

Fig. 222 b. Raupenfackel.

Aus Eckstein. einzelnen $Z$ weigen sitzen (wie z. B. die Eiringel des Ringelspinners, oder die Ananasgallen, oder die Nester von Goldafterraupen, oder um Minierer, die in einzelnen $Z$ weigen leben, oder die Raupen von Triebwicklern usw.) so hilft man sich am besten dadurch, daß man die betreffenden Äste oder Triebe einfach abschneidet oder abbricht und verbrennt. Sitzen die Zweige sehr hoch, so bedient man sich hierzu der Raupenschere (Fig. 222a). Bei den Raupennestern kann man auch zu dem Mittel des Abbrennens greifen, das mit Hilfe der Raupenfakeln (Fig. 222 b) sich bequem ausführen läßt.

In welcher Ausdehnung das Verfahren des Abschneidens der Nester ausgeübt werden kann, zeigt die Bekämpfung des Goldafters in Amerika, wo jährlich Millionen von Nestern abgeschnitten und zu meterhohen Haufen aufgetürmt und rerbrannt werden.

Handelt es sich bei dieser Vernichtungsarbeit um die Nester von Raupen, deren Berührung dem Menschen Nachteil bringen kann, wie die Prozessionsspinnerraupen, so hat der Arbeiter sich durch Handschuhe, umgebundene Tücher, Bestreichen der Hände und des Gesichtes mit Öl usw. gegen diese Schädlichkeit zu schützen.

Besondere Vorkehrungen sind beim Fang von springenden Insekten notwendig, wie z. B. der Erdflöhe. Man sucht dieselben dadurch festzuhalten,

1) Welch ausgezeichneten Erfolge durch konsequentes Sammeln (Abschüttelı) erzielt werden können, zeigt die großzügig durchgeführte Maikäferbekämpfung des Forstmeisters P uster in Kandel (Pfalz). 
daß man sie auf eine mit einer klebenden Masse bestrichene Unterlage abklopft. Man nimmt dazu gewöhnlich sog. „Teerschlitten“, die aus einem einfachen Stück Pappe, das mit Raupenleim bestrichen ist, bestehen, und die zwischen den Pflanzenreihen (in Pflanzgärten oder Kulturen) hindurch gezogen werden, während gleichzeitig die Pflanzen abgeklopft werden.

Weit schwieriger und zeitraubender ist das direkte Entfernen der im Boden lebenden Insekten. Wo es sich um ganz lockere Böden und gleichzeitig größere Insekten (wie z. B. Saateulenraupen) handelt, da kann man einfach mit den Fingern die Tiere aus dem Sand herausschleudern. Meist aber wird man zum Spaten greifen müssen, um den Boden umzugraben und die darin befindlichen Insekten bloßzulegen. Event. sind auch die Pflanzen herauszunehmen, um die an den Wurzeln sitzenden Larven abzuschütteln und dann wieder einzupflanzen.

Insekten, die in der Bodendecke überwintern, kann man event. durch "Streurechen“ vernichten, d. h. dadurch, daß man die Bodendecke abzieht und auf Haufen zusammenbringt, in denen die Puppen usw. der betr. Schädlinge meist von selbst zugrunde gehen. Bei manchen schlimmen Schädlingen, wie z. B. Kiefernspanner, ist das Streurechen gegenwärtig das einzige mechanische Mittel, das einigermaßen Erfolg verspricht. (Über die Vernichtung der Bodeninsekten durch Schweine und Hühnereintrieb ist oben bei der biologischen Bekämpfung berichtet.)

Das Fangen der Insekten kann dadurch wesentlich erleichtert und erfolgreicher gemacht werden, daß man sie durch Anlockungsmittel an einzelnen Stellen zusammenzieht, wodurch die Schädlinge gewissermaß3en aus dem befallenen Gebiet extrahiert werden, oder vielmehr aus deren zerstreutem Vorkommen ein lokales, engbegrenztes gemacht wird. Solcher Anlockungsmittel gibt es eine ganze Reihe:

Die meisten laufen darauf hinaus, den Schädlingen möglichst günstige Nahrungsmittel- und Brutgelegenheit darzubieten. So kann man z. B. die Drahtwürmer durch „Fangpflanzen“ anlocken, indem man Salat, der von den Drahtwürmern vor allen anderen Pflanzen vorgezogen wird, zwischen die Saat- und Pflanzreihen und die die Beete trennenden IVege sät. Die von den Larven angenommenen Salatpflanzen werden welk und scheinen etwas in den Boden gezogen zu sein. Man hebt diese Pflanzen heraus und wird in der bis auf die äußere Haut ausgehöhlten Wurzel oder sogar weiter oben den Drahtwurm finden. Ist die Pflanze leer, so befindet sich die Larve bereits auf dem Wege zu einer nächsten, in welcher sie am anderen Tage gefunden werden wird. Auch aufgeschnittene Kartoffeln, welche abends ausgelegt werden, können als Köder benutzt werden.

Ein sehr bekanntes und vielgebrauchtes Anlockungsmittel sind die „Fangrinden“, die hauptsächlich zum Sammeln des großen braunen Rüsselkäfers und der wurzelbrütenden Hylesinen benutzt werden. Die Rindenstücke (von je $20-30 \mathrm{~cm}$ im Quadrat) müssen vom frisch gefällten Stamm genommen sein (da sie ja dem Käfer Nahrung darbieten sollen), und werden mit der Bastseite auf den Boden gelegt und mit einem Stein beschwert. Das Sammeln 
der Käfer geschieht durch vorsichtiges Aufheben und Umdrehen der Rinde und Lesen der an dieser und auf dem Boden sitzenden Individuen. Trocken gewordene Rindenstücke müssen durch frische ersetzt werden, wobei die alte Rinde zum Schutz des frischen Stückes auf das letztere gelegt werden kann (Fig. 223 b). In Kiefernrevieren verwendet man auch „Fangkloben“, zu welchen man frisch gefälltes, dünnrindiges Kiefernholz benutzt; sie werden in ganz ähnlicher Weise gehandhabt wie die Fangrinden (Fig. 223a). Um die Anziehungskraft dieser Fangmittel zu erhöhen, hat man auf die Fangrinden und Fangkloben etwas Terpentin gegeben. Doch sind die Meinungen über die Wirkung dieses Zusatzes recht verschieden; wahrscheinlich spielt hier auch die Qualität des Terpentins eine Rolle.

Beruhten die bisher genannten Anlockungsmittel im wesentlichen auf der Darbietung von besonders zusagender Nahrung, so bestehen die folgenden hauptsächlich in einer Darbietung von möglichst günstigen Brutgelegenheiten. So sucht man die eben genannten Schädlinge außer durch Fangrinden auch noch durch „Brutknüppel“ aus den bedrohten Kulturen heraus-

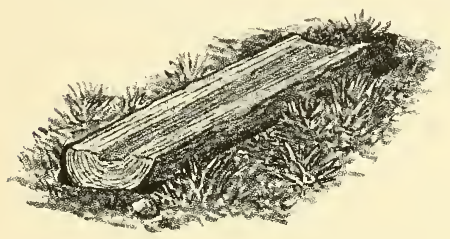

Fig. 223 a. Fangkloben.

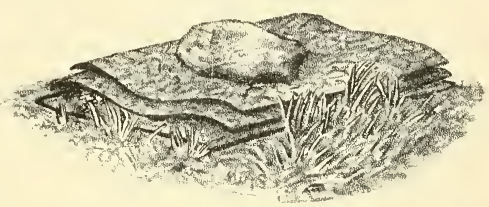

Fig. 223 b. Fangrinden, zweimal erneuert. Aus Eekstein.

zuziehen. Das I'rinzip derselben besteht darin, daß je eine Anzahl (etwa armdicker und $3 / 4 \mathrm{~m}$ langer) Knüppel zusammen eingegraben werden, wo sie von den Weibchen der genannten Schädlinge aufgesucht und mit Eiern belegt werden. Nach einiger Zeit werden die Knüppel wieder herausgenommen und die darin befindliche Brut vernichtet. Forstmeister Grobmann sucht die Anziehungskraft der Brutknüppel dadurch noch zu steigern, daß er über die Knüppel frisches Reisig legt, welches zum Zweck der Befestigung und längeren Frischhaltung in der Mitte mit Erde bedeckt wird, so daß nur die äußeren Enden der Zweige frei hervorragen. Dadurch wird den Käfern neben der Brutgelegenheit zugleich auch zusagende Nahrung dargeboten. Die Erfolge dieser kombinierten Methode waren sehr zufriedenstellende.

Eine sehr wichtige Rolle unter den hierherzählenden Fangmethoden spielen die sog. „Fangbäume“, welche ein wirksames Bekämpfungsmittel gegen viele Borkenkäfer und andere rindenbrütende Käfer (Cerambyciden, Pissodes usw.) darstellen. Die Methode beruht darauf, daß frisch gefällte Bäume von den genannten Schädlingen gern als Brutmaterial angenommen werden, da sie sich eben in einem für sekundäre Schädlinge gerade geeigneten Zustand befinden. Und so braucht man nur eine genügende An- 
zahl solcher Fangbäume zu werfen, um die größte Zahl der Borkenkäfeı usw. aus dem Walde herauszuziehen. Da die Fortpflanzungsbereitschaft der Borkenkäfer sich über eine längere Zeit erstreckt, die Bäume aber allmählich ihre Anziehungskraft verlieren, so muß dafür gesorgt werden, daß von Zeit zu Zeit neue Bäume gefällt werden. Besonders wichtig ist es ferner, daß die Fangbäume stets revidiert und zur rechten Zeit entrindet werden. Am besten geschieht die Entrindung, noch bevor die Larven zur Verpuppung schreiten; es ist dann gar nicht einmal notwendig, daß die Rinde verbrannt wird, da die Larven, wenn sie freigelegt sind, ron selbst zugrunde gehen. - Von Sedlaczek ist vorgeschlagen worden, auch stehende Bäume als Fangbäume zu präparieren, indem man die Rinde derartig ringelt, daß der Saftstrom unterbrochen wird; sie sollen für gewisse Borkenkäferarten wirksamer sein als die gefällten. Näheres darüber wird im 2. Band bei Besprechung der Borkenkäfer mitgeteilt werden.

Endlich hat man auch das Licht als Anlockungsmittel dem Kampf gegen die Schädlinge dienstbar zu machen gesucht. Von der allbekannten Erscheinung ausgehend, daß die nächtlichen Insekten, vor allem die Nachtschmetterlinge, zum Licht geflogen kommen, hoffte man durch Aufstellen von starken Lichtquellen im Walde einen Massenfang gewisser Schädlinge erzielen zu kömnen. Im großen Maßstabe wurde der Versuch zum ersten Male während der Nonnenkalamität in Bayern (1890/92) unternommen. Es wurden Bogenlampen aufgestellt und in Verbindung mit einem starken Saugapparat (Exhaustor) gebracht, welcher die vom Licht angezogenen Schmetterlinge durch ein weites Rohr in ein mit einer Flüssigkeit gefülltes Gefäß saugen sollte. Der Apparat entsprach durchaus nicht den Erwartungen; jedenfalls stand der Erfolg in gar keinem Verhältnis zu den hohen Kosten, so daß man vollständig von ihm abkam (Pauly). Auch alle späteren in den Handel gebrachten Lichtfangapparate haben, soweit es sich um die Vertilgung von Forstinsekten handelte, einen durchschlagenden Erfolg nicht gehabt, so daß man heute von der Lichtfangmethode als Bekämpfungsmittel ziemlich allgemein abgekommen ist.

Eine weitere Methode der mechanischen Bekämpfung besteht darin, die Schädlinge in Fanggräben auf ihren Wegen zum Fraßgebiet abzufangen und so das letztere freizuhalten. Natürlich kann diese Methode nur gegen solche Schädlinge geübt werden, welche flugunfähig sind oder wenigstens von ihrem Flugvermögen nur geringen Gebrauch machen, also bodenbewohnende Larven, wie Engerlinge oder Erdraupen, flügellose Kurzrüßler und ganz besonders gegen den flugunlustigen Hylobius. Die hauptsächlichste Indikation für die Anlage von Fanggräben ist Schutz der Kulturen. Es werden zu diesem $Z$ wecke die betreffenden Kulturen allseitig mit Fanggräben umgeben; wo außerdem noch bereits in der Kultur befindliche Schädlinge, wie z. B. Saateulenraupen, abgefangen werden sollen, sind neben dem Umfassungsgraben noch weitere Gräben in der Kultur anzulegen, welche die letztere durchqueren und mit dem Umfassungsgraben in Verbindung stehen. Die Tiefe der Gräben beträgt gewöhnlich ca. $30 \mathrm{~cm}$, die Breite kanı ungefähr 
ebensoviel betragen, sie kann aber auch etwas schmäler sein. Die Hauptsache ist, daß die Wände (oder wenigstens die der Kultur zugewandte) senkrecht abfallen und möglichst glatt sind. Auch die Sohle des Grabens ist zu ebnen und von dem überflüssigen lockeren Erdreich zu reinigen, des leichteren Sammelns halber. Aus demselben Grunde sind im Graben in regelmäßigen Abständen (von vielleicht $10 \mathrm{~m}$ ) Löcher auszuheben, in denen die im Graben hin- und herlaufenden Käfer sich sammeln, wodurch die Arbeit des Entfernens wesentlich erleichtert wird (Fig. 224). Von größter Wichtigkeit ist es, daß der Graben fängisch gehalten, d. h. daß er stets von hineinfallenden Ästen, Laub usw. gereinigt wird, daß event. abgefallene Wände wiederhergestellt und geglättet werden usw. Von Zeit zu Zeit müssen die Gräben abgesammelt werden, wobei besonders darauf zu achten ist, daß Nützlinge, die mit gefangen sind (wie Calosoma, Mistkäfer; Eidechsen usw.), wieder in
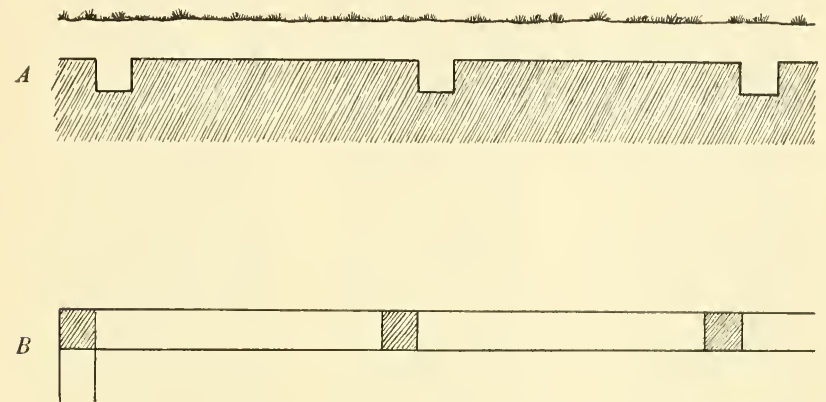

Fig. 224. Fanggraben zur Bekämpfung des Hylolius. A Längsschnitt. $B$ von oben gesehen, die Falllöcher sind gestreift. Aus Eckstein.

Freiheit gesetzt werden. - Die Erfolge, die man mit den Fanggräben, vor allem gegen Hylobius, erzielt hat, sind sehr zufriedenstellende, und es empfiehlt sich jedenfalls, überall, wo die Anlage solcher Gräben technisch leicht ausführbar ist, zu diesem Mittel zu greifen.

Auf dem gleichen Prinzip wie die Fanggräben beruhen die Fanglöcher und die Fangtöpfe, nur handelt es sich hier um vereinzelte kleinere Fangstellen, die in großer Anzahl über das zu schützende Gebiet verteilt werden können. Fanglöcher werden z. B. angewendet gegen Engerlinge; sie werden in diesem Falle mit Moos gefüllt, in dem sich die Engerlinge gern aufhalten. Fangtöpfe nimmt man vor allem gegen die Maulwurfsgrille. Es können Blumentöpfe, Konservenbüchsen, abgeschlagene Flaschen usw. dazu benutzt werden; es ist nur darauf zu achten, daß der obere Rand des Topfes nicht vorsteht, sondern eher etwas tiefer liegt als die Erdoberfläche; die Erde wird möglichst fest angedrückt und gerundet, so daß die heranlaufenden Werren abstürzen müssen. Die Fangtöpfe werden zwischen den Saatbeeten in 3 bis 5 m Abstand eingegraben. Man kann die Wirkung noch erhöhen, wenn man die einzelnen Fangtöpfe mit Latten verbindet, die etwas in den Boden ver- 
senkt, ungefähr $5 \mathrm{~cm}$ hervorsehen: die Werren, die an diese Latten hingeraten, laufen dann daran entlang und werden so direkt zu den Fangtöpfen geleitet (Eckstein).

Außer diesen Fanggräben, Fanglöchern und Töpfen werden noch zahlreiche Insektenfallen, vor allem $R$ üsselkäferfallen, in denen sich die Käfer „massenweise“ fangen sollen, in den Handel gebracht. Doch keine ron allen angepriesenen Fallen hat sich so bewährt, daß sich ihre Einführung im großen empfehlen würde. Jedenfalls ist nicht anzuraten, viel Geld für derartige Apparate auszugeben. Man sollte in dieser Beziehung überhaupt als Regel aufstellen, neue in den Handel kommende Apparate nicht gleich im großen anzuschaffen, bevor nicht einwandfreie Versuche (am besten durch die Versuchsanstalten) angestellt worden sind. Große Summen Geldes könnten auf diese Weise gespart und besseren Zwecken zugeführt werden. Dies gilt übrigens nicht nur für die Käferfallen, sondern in gleicher Weise auch für alle übrigen zahlreichen "Neuerfindungen" auf dem Gebiete des Pflanzenschutzes, z. B. Lichtfang- und Leimapparate, Spritzmittel usw.

Als eines der wichtigsten der mechanischen Bekämpfungsmittel ist der Leimring zu nennen. Er verfolgt denselben Zweck wie der Raupengraben, nämlich die Schädlinge vom Fraßort abzuhalten; nur handelt es sich hier um Bauminsekten, die vom Aufsteigen in die Krone abgehalten werden sollen, während der Raupengraben zur Abhaltung der Erdinsekten dient. Die Wirkung des Leimringes ist durchschlagend bei solchen Insekten, die gezwungen sind, gemäß ihrer Entwicklung vom Boden auf dem Stamm zur Krone zu kriechen, wofür die bekanntesten Beispiele die aus dem Boden kommenden flügellosen Weibchen der Frostspanner oder die im Boden überwinternden Raupen des Kiefernspinners darstellen.

Aber auch bei anderen Insektenarten, deren Biologie obige Forderung nicht ausnahmslos erfüllt, kann der Leimring Ausgezeichnetes leisten, wofür die Nonne ein Beispiel liefert: Die Eiablage dieses Schädlings ist oft über den ganzen Stamm verteilt, so daß ein Teil der Räupchen oberhalb des Leimringes auskommt und also ungehindert in die Krone zum Fraß sich begeben kann. Ein großer Prozentsatz dieser anfangs freien Räupchen kommt aber nachträglich doch noch in die Gewalt des Leimringes, da sie nämlich die Gewohnheit haben, sich bei Störungen usw. abzuspinnen. Dadurch gelangen sie, soweit sie nicht durch untere Äste aufgefangen werden, unterhalb des Leimringes und werden nun beim Wiederaufbaumen vom Leimring abgehalten. Wir sprechen in solchen Fällen von der "sekundären Wirkung" des Leimringes. Wie groß dieselbe sein kann, wurde neuerdings durch die Versuche von Escherich und Weißwange zahlenmäßig festgestellt. Ganz ähnlich wie die Nonnenraupen verhalten sich auch noch andere Spinnerraupen, wie z. B. die Räupchen des Schwammspinners, worüber die Amerikaner interessante Versuche angestellt haben. Bei allen diesen Raupen kann also, trotzdem sie teilweise oberhalb des Leimes geboren werden, der Leimring als Bekämpfungsmittel angezeigt sein. 
Auch bei an und für sich flugfähigen Insekten, die aber von ihrem Flugvermögen nur ungern Gebrauch machen, kann der Leimring Gutes leisten. So berichtet Forstmeister Sihler von recht befriedigenden Erfolgen des Leimringes gegen Lyda hypotrophica, deren flugunlustige Weibchen zunächst am Stamme hinaufkriechend die Krone zu erreichen suchen und auf dieser Wanderung durch den Leimring abgehalten werden können. In diesem Falle müssen aber die Weibchen sobald als möglich getötet werden, da sie sonst, von der Fortpflanzungsnot getrieben, sich doch noch zum Über-

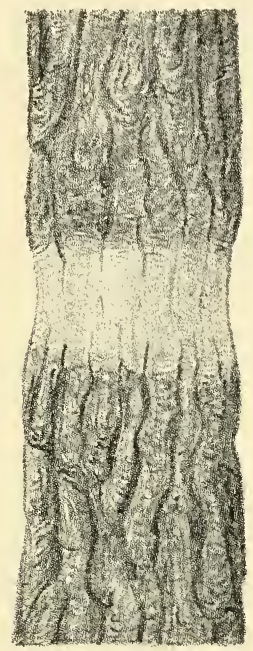

a

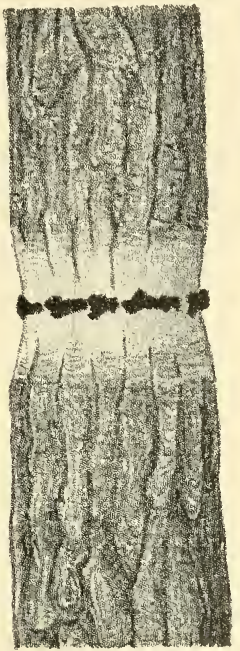

$b$

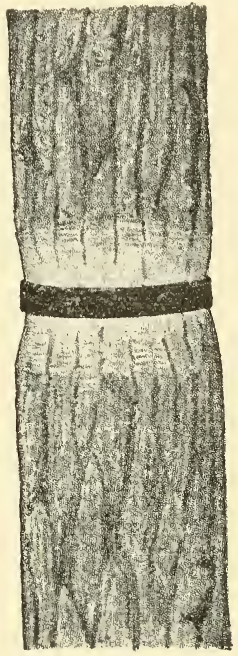

$c$

Fig. 225. Leimtechnik: Kiefernstamm, $a$ gerötet; $b$ mit dem vermittelst des Spatels aufgetragenen Leim; $c$ mit fertigem Leimring, entstanden durch Überstreichen des in $b$ aufgetragenen Leimes mit dem Glättholz. Aus Eckstein.

fliegen des Leimhindernisses aufraffen würden. Endlich kann selbst bei solchen Raupen, die ihrer ganzen Biologie nach gar nicht oder nur sehr spärlich und zufällig unter den Leimring geraten, der letztere mit Erfolg in Anwendung gebracht werden, wenn man das Leimen mit Abschütteln resp. Prellen verbinden kann. So kann man z. B. die Raupen der Kieferneule in Stangenhölzern durch dieses kombinierte Verfahren bis zu einem hohen Prozentsatz unschädlich machen resp. unter den Leimring bringen, wie eine (1913) in dieser Weise auf Veranlassung von Geh. Oberforstrat Neumeister rorgenommene erfolgreiche Bekämpfung der Eule im Dresdener Bezirk dargetan hat.

Die Leimringbekämpfung ist bei Obstbaumzüchtern schon seit langer Zeit gegen die Frostspanner im Gebrauch. Wenn das Verfahren im forstlichen Betrieb erst später allgemeinere Bedeutung erlangt hat, so liegt dies 
daran, daß der im Obstbau gebrauchte Leim (resp. Fanggürtel) für die großen forstlichen Verhältnisse viel zu teuer war, und daß ferner der Teer, den man anfangs gegen Forstinsekten anwandte, zu bald seine Fängigkeit verlor. Erst nachdem es der chemischen Industrie gelungen war, dem Teer durch eine Art Verseifungsprozeß eine längere Fängigkeitsdauer zu geben und so in

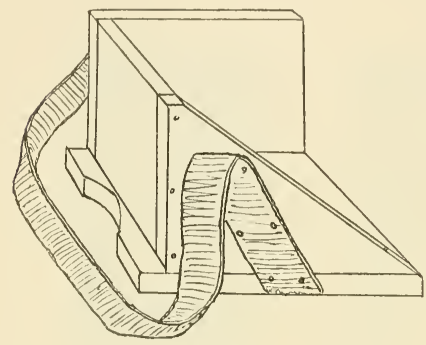

Fig. 226 a.

Tragekasten für Leim. (N.)
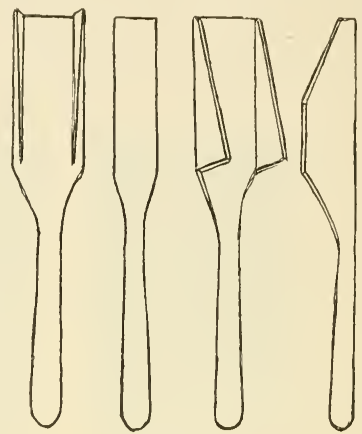

Fig. 226 b.

Spatel und Glättholz. Verschiedene Formen. (N.)

dem „Raupenleim“1) ein ebenso billiges wie geeignetes Klebemittel zu schaffen, konnte man an eine Anwendung des Leimringes im großen gehen, und heute steht derselbe unter den technischen Kampfmitteln gegen einige unserer gefährlichsten Schädlinge zweifellos an erster Stelle. Hat doch der Kiefernspinner durch ihn allein seine Schrecken verloren.

Die Wirkung des Leimringes beruht natürlich in erster Linie auf seiner Klebekraft; doch auch schon der Geruch allein, der von demselben ausgeht,

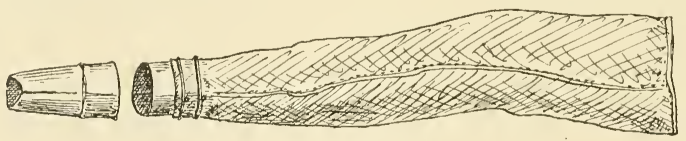

Fig. 227. Der Ecksche Leimschlauch. (N.)

wirkt auf manche Insekten abhaltend. Manche Larven allerdings machen sich wenig aus dem Geruch, wie z. B. die Blattwespenlarven, was man sehr schön gelegentlich der oben (S. 369) erwähnten Kieferneulenbekämpfung sehen konnte. Während die Eulenraupen alle schon vor dem Leimring Halt machten

1) Als die renommiertesten Leimfirmen seien genannt: Hein rich Er$111 \mathrm{isch}$ in Burg bei Magdeburg, $\mathbb{A}$. W ing e $\mathrm{n} \mathrm{roth}$ in Mannheim, Schindle $\mathrm{r}$ \& M ützell Nachfolger in Stettin, P. H of $\mathrm{f} m$ a $n \mathrm{n}$ in Freiberg. Der Preis pro Doppelzentner schwankt zwischen 14 und $20 \mathrm{M}$. - 
und keine auf den Leim kroch, versuchten die Lophyrus-Larven über den Leim zu laufen und blieben samt und sonders auf dem Leimring kleben.

Je nachdem der Leimring tiefer oder höher am Stamm angelegt wird, unterscheiden wir eine Tief- und Hochleimung. Die erstere, die etwa in Brusthöhe vorgenommen wird, ist bei solchen Schädlingen indiziert, die vom Boden aus aufsteigen müssen, wie z. B. gegen den Kiefernspinner, oder bei dem mit Prellen kombinierten Verfahren. Die Hochleimung in $4-6 \mathrm{~m}$ Höhe wird der Tiefleimung überall da überlegen sein, wo die Eiablage über den ganzen Stamm verteilt ist (wie bei der Nonne); denn je höher in diesem Falle der Leimring sitzt, desto mehr Räupchen werden primär von ihm abgefangen.

Die Ausführung des Leimens zerfällt in zwei Akte, nämlich: 1. die Vorrichtung der Leimstelle und 2. das Auftragen des Leimes. Die Vorrichtung besteht hauptsächlich in der Glättung der betreffenden Rindenpartie. Handelt es sich um die an und für sich ziemlich glatte Rinde von jungen Kiefern oder Fichten, so genügt es, die Leimstelle mit einer Drahtbürste abzureiben oder mit der stumpfen Seite des Schnitzmessers abzuschaben; wo es sich aber um dickborkige Rinde alter Bäume handelt, da muß die grobrissige Borke abgeschnitzt werden, bis eine glatte Ringfläche entsteht, - ein Vorgang, den man als „Röten“ bezeichnet (Fig. 225a). Beim zweiten Akt, dem Auftragen des Leimes, ist darauf zu achten, daß der Ring geschlossen ist und überall dem Stamme aufsitzt, daß er sodann möglichst gleichmäßig ist, d. h. überall die erforderliche Dicke und Breite aufweist, dass ferner dabei mit dem Material möglichst sparsam umgegangen wird, und daf3 endlich die Arbeit in möglichst kurzer Zeit erledigt werden kann. Um diese Forderungen zu erfüllen, sind eine ganze Menge Leimapparate konstruiert und in den Handel gebracht worden, von denen aber nur ganz wenige sich als wirklich brauchbar erwiesen haben. Heute stehen hauptsächlich folgende in Verwendung: der Leimspatel, der Ecksche Leimschlauch, die Ringlersche Leimquetsche, die Jankesche Leimspritze und die Leimstricke.

Das primitivste Werkzeug ist der Spatel (Fig. 226 b), der einen einfachen Holzstab von der ungefähren Breite des zu machenden Leimringes darstellt. Mit ihm wird der Leim, der in einem Tragekasten (Fig. 226a) mitgeführt wird, auf die gerötete Stelle aufgetragen, worauf mit einem besonderen Glättholz der gänzlich unregelmäßige Ring glatt gestrichen werden muß. Das Verfahren macht also drei verschiedene Instrumente notwendig; außerdem ist unvermeidlich, daß meistens etwas Leim abfällt.

Der Leimschlauch (Fig. 227) bedeutet dem Spatel gegenüber einen wesentlichen Fortschritt, vor allem bezügl. der Einfachheit und Schnelligkeit der Arbeit. Der Schlauch, der aus undurchlässig gemachtem Segeltuch besteht, hat nur eine Öffnnng, die mit einem abnehmbaren Mundstück von der Breite und Dicke des gewünschten Leimbandes versehen ist. Es bedarf nur eines leichten Druckes auf den gefüllten Schlauch, um die erforderliche Quantität Leim aus dem Mundstück auszudrücken, während man gleichzeitig um den Stamm herumfährt und den Ring legt. Zur Füllung der Schläuche sind besondere, nicht gerade billige Füllapparate notwendig (Fig. 228). 
Die Ringlersche Leimquetsche (Fig. 229), von der Form einer alten

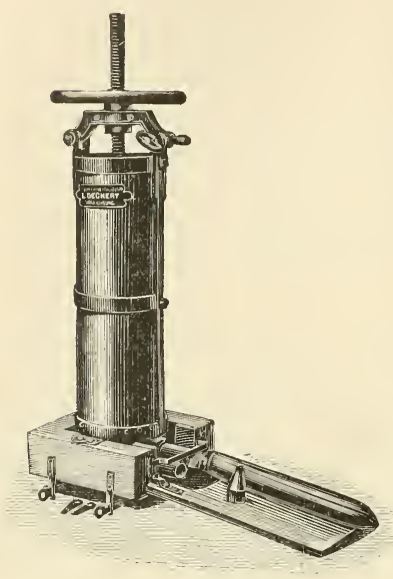

Fig. 228. Decherts Füllapparat für den Leimschlauch. Aus Eckstein. Lichtputzschere, beruht im Prinzip darauf, daß der Leim aus dem pyramidenförmig gestalteten Leimbehälter mit Hilfe einer scherenförmig mit diesem verbundenen Klappe durch eine kleine Öffnung herausgequetscht wird. Die Quetsche hat verschiedene Nachteile: die Arbeit mit ihr wirkt auf die Dauer ermüdend, und sodann tritt gewöhnlich beim Schließen des Klappdeckels mehr oder weniger Leim zwischen dem Deckel und dem Behälter aus, was Leimverlust und Schmutzerei bedeutet.

Der Jankesche Apparat ${ }^{1}$ ) endlich (Fig. 230 $a, b$ u. $c$ ) beruht auf dem Prinzip der Leimspritzen, d. h. er besteht aus einem Zylinder, aus dem der Leim mit Hilfe eines Stempels durch eine schmale, mit einem kleinen Mundstück versehene Öffnung herausgepreßt wird. Die Vorwärtsbewegung des Stempels geschieht vermittelst eines nach Scherenart zu bedienenden Hebelapparates, dessen einer an der Spitze rechtwinklig gebogener

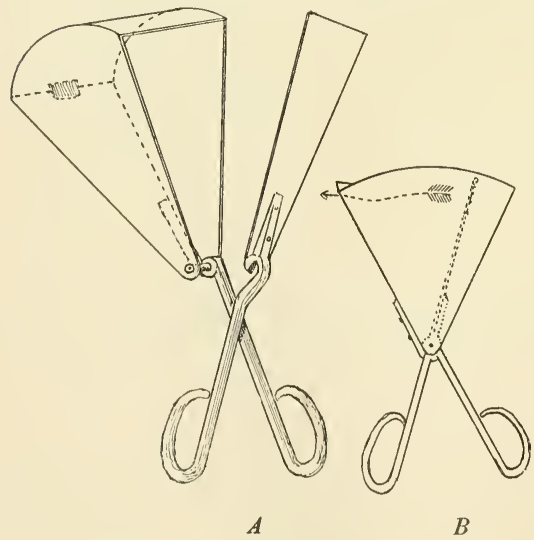

Fig. 229. Die Ringlersche Leimquetsche. A Auseinandergenommen; $B$ Kleinere Profilansicht. (N.) Hebelarm in die an der Triebstange angebrachten Zähne eingreift. Es genügt ein relativ schwacher Druck auf diesen Hebelarm, um den Stempel vorwärts zu treiben. Ist die Schere geschlossen, so wird sie von neuenı geöffnet, der gebogene Hebelarm, der an der Spitze einen kurzen beweglichen Finger besitzt, greift damit in den nächsten Zahn ein, und nun kann die Schere wieder geschlossen werden usw. Man verfährt also etwa so, wie wenn man mit einer großen Tuchoder Papierschere arbeitet, und es ist dabei, dank der sehr günstigen Hebelwirkung, kaum mehr Kraftanstrengung notwendig, als man beim Schneiden eines dünnen Kartons gebraucht. Der Stempel ist am Rande mit Filz gedichtet, so daß ein Durchtreten des Leimes nach hinten aus-

1) $\mathrm{Zu}$ beziehen vom Erfinder $\mathrm{M}$ a $\mathrm{x} J$ a $\mathrm{n} \mathrm{k}$ e in Putzkau, Sachsen (Preis 4,50 M.). 
geschlossen ist. An dem Vorderende der Spritze ist ein abnehmbarer Handgriff angebracht, an dem man mit der linken Hand, der sicheren Führung halber, den Zylinder festhalten kann, während man mit der rechten die Schere in Bewegung setzt. Doch ist diese zweihändige Bedienung wohl nur bei Frauenarbeit nötig, während bei Männerarbeit der Handgriff entfernt werden und die Spritze sehr gut mit einer Hand bedient werden kann. Dieses
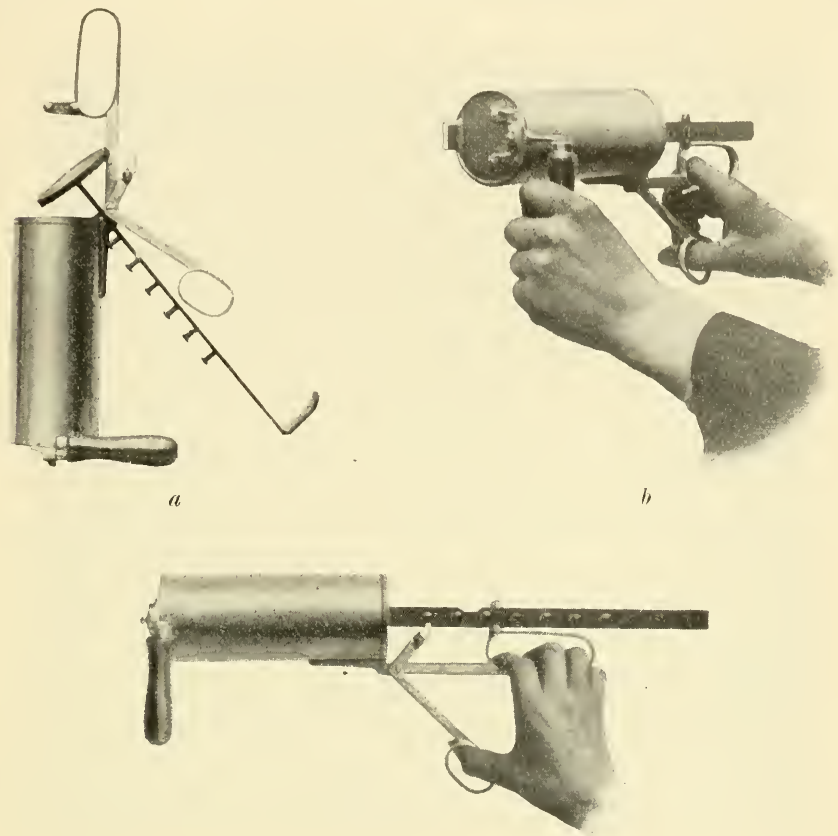

c

Fig. 230. J ankesche Leimspritze.

$a$ Stempel herausgenommen, $b$ und $c$ im Gebrauch (ein- und zweihändig).

letztere Moment in Verbindung mit dem überraschend geringen Kraftaufwande, der zur Bedienung des Apparates notwendig ist, und der überaus reinlichen und sparsamen Arbeit erhebt die Jankesche Spritze unserer Meinung nach über alle bisherigen Leimapparate, und sie dürfte wohl berufen sein, der Leimapparat der Zukunft zu werden.

Durch die einhändige Bedienung der Jankeschen Spritze ist - abgesehen davon, daß durch sie die Tiefleimung ohne weiteres höher anzubringen ist (Fig. 231), als es bei den zweihändigen Apparaten tunlich ist (was bei manchen Bekämpfungen, z. B. Nonne, einen entschiedenen Vorteil bedeutet) - 
auch das Problem der Hochleimung der Lösung wesentlich näher gebracht. Wenn man bis jetzt so wenig zu der Hochleimung gegriffen hat, trotz der großen Vorzüge, die sie bei gewissen Insekten gegenüber der Tiefleimung hat, so lag dies hauptsächlich an den zu hohen Kosten resp. an dem Fehlen brauchbarer Methoden. Dieser Hinderungsgrund dürfte durch die Erfindung Jankes wesentlich verkieinert worden sein. Jedenfalls lehren die Erfahrungen, die Herr Oberförster Weiske in Oberholz und Herr Oberförster Cunit in

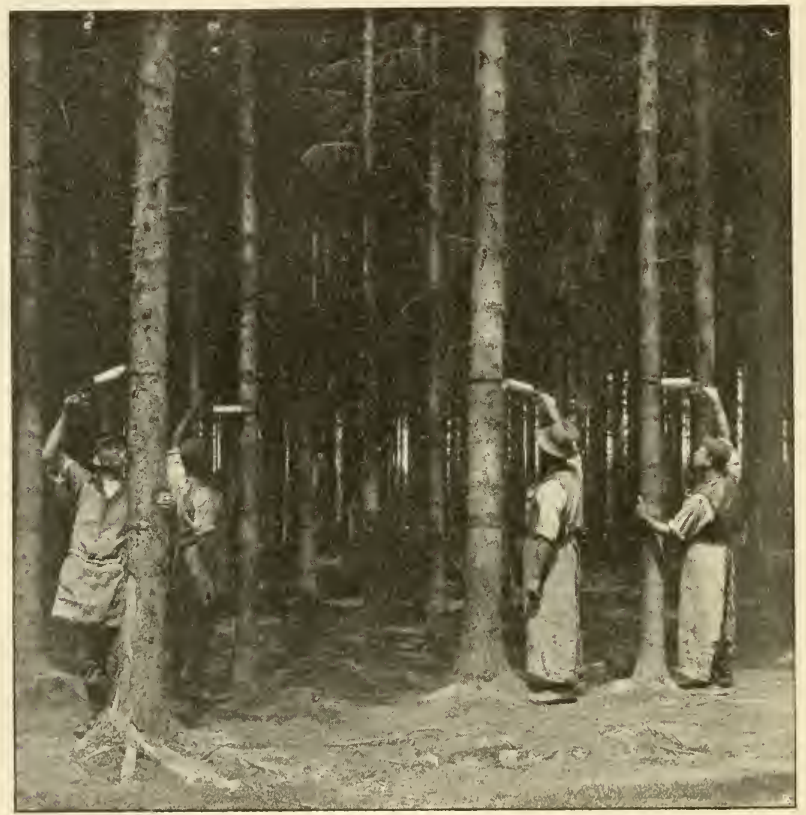

Fig. 231. Tiefleimen mit der J a nkeschen Spritze. Die leichte einhändige Bedienung ermöglicht ein höheres Anlegen des Leimringes als mit den bisher gebräuchlichen Apparaten. (Aufgenommen in Oberholz bei Leipzig.)

Flößberg damit gemacht haben, daß durch die Jankesche Spritze das Hochleimen nicht nur sehr erleichtert ist, sondern auch die $K_{o s t e n}{ }^{1}$ ) so reduziert

1) Die Kosten des Hochleimens dürften nach den dem Verfasser gemachten Mitteilungen durchschnittlich ca. 28-35 M. pro Hektar betragen (die früher vom Verfasser gegebenen Zahlen vo11 25-28 M. waren etwas zu niedrig gegriffen). Herr Oberförster C u n it in Flößberg gelangte sogar noch zu wesentlich günstigeren Resultaten, wie aus folgenden Daten zu ersehen ist: Die Hochleimung erfolgte auf einer Fläche von 17,51 ha, und kostete bei 678 Stunden Arbeit 201,55 M. Es kamen somit auf 1 ha $11,51 \mathrm{M}$. ohne anteilige Leimkosten, die 139,19 M. (also 7,95 M. pro 
sind gegenüber früherer Hochleimverfahren, daß die Mehrkosten gegenüber der Tiefleimung durch die wesentlich größere Wirkung der Hochleimung zweifellos reichlich gerechtfertigt sind.

Die Ausführung der Hochleimung (Fig. 232) mit der Jankeschen Spritze geschieht von $4-5 \mathrm{~m}$ hohen Leitern aus, welche der Sicherheit halber mit Eisenschuhen versehen sind; ausserdem empfiehlt es sich, die oberen Enden der Leiter mit einem kräftigen Hanfstrick zu verbinden, dor sich beim Anlegen der Leiter dem Stamm anschmiegt und so der letzteren einen festen Halt verleiht (empfohlen von Oberforstmeister Schleinitz). Zur Reinigung der Leimstelle (Entfernung der Äste usw.) wird ein kräftiges schwertartiges Instrument, das sog. "Schwert" benutzt, welches mittels einer Drahtschlinge am oberen Ende der Leiter angehängt ist. Der Arbeiter besteigt mit der gefüllten Leimspritze die Leiter, reinigt rasch mit dem Schwert die Umgebung der Leimstelle, hält sich mit der linken Hand fest (an der Leiter oder am Stamm) und legt mit der rechten den Leimring an. Gewöhnlich geschieht dies mit zweimaligem Ansetzen, einmal links, einmal rechts herum; geschickte Arbeiter vermögen indes auch mit nur einmaligem Ansetzen, in einem Zug, den Ring zu legen. Ob so oder so, in beiden Fällen ist die Arbeit des Leimens in wenigen Sekunden erledigt.

Die Leimstricke stellen möglichst rauhe Stricke dar, die in Raupenleim getaucht und dadurch fängisch gemacht werden. Sie werden heute fast ausschließlich für Hochleimung verwandt und zwar vielfach in Verbindung mit Apparaten, welche die Anbringung der Stricke in der gewünschten Höhe vom Boden aus ermöglichen, so daß Leitern entbehrlich werden.

Hektar) betrugen; so stellten sich also die Gesantkosten der Hochle i m ung auf 19,46 M. p ro Hekt a r.

Um einen Vergleich der Kosten der Hochleimung mit denen der Tiefleimung herbeizuführen, wurde eine benachbarte gleichwertige Abteilung mit der J a n k eschen und der Ringlerschen Quetsche tiefgeleimt. Die Leimung kostete bei 268 Arbeitsstunden für das Röten und 457 Arbeitsstunden für das Leimen 211,25 M. bei einer Fläche von 16,69 ha, som it $12,66 \mathrm{M}$. p r o Hektar (ohne a 11 teilige Leimkosten) gegen 11,51 M. bei der Hochleimung! Dieses überraschende Resultat, daß die Tiefleimung teurer zu stehen $\mathrm{kam}$ als die Hochleimung, erklärt sich daraus, daß bei der letzteren das Röten in Wegfall kam. Trotzdem aber dürfte es sich hier um a b norm niedere Kosten handeln, die wohl nur unter ganz besonders günstigen Umständen zu erzielen waren.

Uber die Zeit, welche die Hochleimung beansprucht, liegen folgende Angaben von Herrn Oberförster $\mathrm{Cu} n \mathrm{it}$ vor: Eine Fläche von 1 a Größe mit 20 Bäumen wurde von einem Arbeiter in 24 Minuten geleimt; das ergäbe ca. 50 Bäume pro Stunde. Eine andere Fläche von 4 a mit 58 Bäumen wurde von 4 Arbeitern in 15 Minuten geleimt, was einem Arbeitslohn von 0,5 Pf. pro Baum (bei 30 Pf. Stundenlohn) gleichkommt. -

Die T i ef 1 e im ung kostete in Sachsen im Jahre 1908 ca. 16-24 M. pro Hektar, durchschnittlich 19 M., bei einem Leimverbrauch von durchschnittlich $61 \mathrm{~kg}$ - gegenüber den Leimungskosten 1907 von durchschnittlich $22 \mathrm{M}$. Der Unterschied erklärt sich einmal aus der gesteigerten Ubung der Arbeiter und sodann daraus, daß es sich 1908 vielfach um Leimungen von Flächen handelte, die schon 1907 geleint worden waren, und bei denen infolgedessen - da die neuen Ringe aut die alten gelegt wurden - die Arbeit des Rötens zum Teil erspart werden konnte. 
So wurde schon vor längerer Zeit von Wappes ein Apparat konstruiert, mit dem man die Strickenden vom Boden aus zusammenknoten konnte; und neuerdings ist ein Strick-Hochleimapparat in den Handel gekommen, dem die Idee zugrunde liegt, durch kräftiges Schleudern den Strick in der gewünschten Höhe mehrmals um den Stamm herum zu schlingen, so daß er ohne weiteres vermöge seiner Kraft haften bleibt.

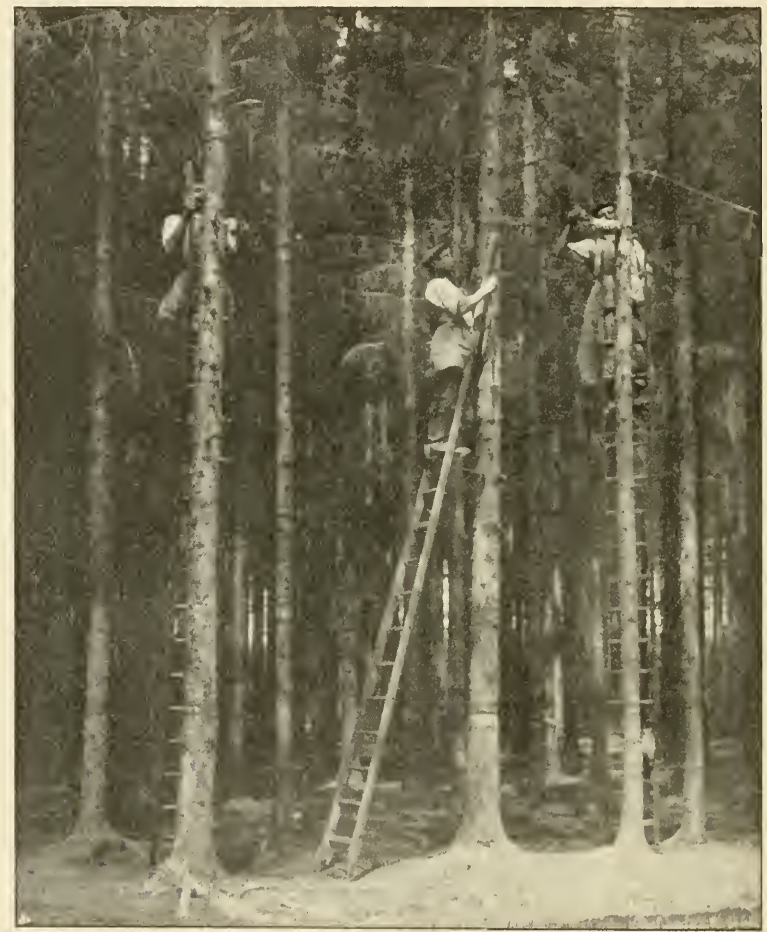

Fig. 232. Hochleimung mittelst Leiter und J ankescher Spritze. (Aufgenommen in Oberholz bei Leipzig.)

Dieser letztere (vom Oberförster $\mathrm{Schönfelder} \mathrm{konstruierte)} \mathrm{Apparat}$ (Fig. 233) besteht aus einem mit einem Deckel $D$ verschließbaren Blechgefäß $G$. An dem letzteren befindet sich eine Spule $S p$, von der ein gerauhter Strick durch das Führungsrohr $R$ in das mit Leim gefüllte Gefäß und von da durch die zusammensteckbare Blechrohrleitung $L$ ins Freie läuft. Der (leer) nur 3,5 kg wiegende Apparat wird an dem Tragseil $T$ bequem von dem Arbeiter getragen.

Um den Apparat gebrauchsfertig zu machen, setzt man zunächst die Leitung $L$, die am unteren Ende beweglich (durch Gummischlauch) mit dem Kasten verbunden ist, bis zur gewünschten Höhe zusammen und zieht gleichzeitig den Strick mit durch. Hierauf füllt man das Gefäß zu $4 / 5$ mit flüssigem Raupenleim und zieht 
den Strick so weit heraus, bis eine etwa 2-3 m lange geleimte Strickbahn erscheint. Hiernach hängt der Arbeiter den Apparat rechtsseitig (mit durchgestecktem rechten Arm) um den Hals, faßt mit beiden Händen das Leitungsrohr und schlägt mit diesem nach Art eines Peitschenhiebes das herabhängende Strickende in der gewünschten Höhe um den Stamm. Je nach der herausragenden Stricklänge wird sich der Strick ein oder mehrere Male um den Stamm schlingen, alsdann wird durch Rückwärtsgehen des Arbeiters eine beliebige Länge des beleimten Strickes herausgezogen, und nun schneidet ein zweiter Arbeiter mit einer Stangenschere den Leimstrick hart am Stamm ab, so daß das beleimte Strickende wie zuvor von dem Leitungsrohr herabhängt.

Die Idee des Strick-Hochleimapparates ist zweifellos eine sehr gute; und als der Apparat während der Forstversammlung in Bautzen (1910) vorgeführt wurde, fand er auch allgemeinen Beifall. Bei der Anwendung in der Praxis jedoch rersagte er mehr oder weniger: Des öfteren brach die Rohrleitung, ferner spritzte der Leim beim Schleudern weit herum und "leimte" noch die recht entfernt stehenden Zuschauer, während der wenige am Strick hängen gebliebene Leim in kurzer Zeit austrocknete, so daß die Raupen bald kein Hindernis mehr in ihm fanden; sodann ist in Beständen, die einigermaßen dicht stehen, das Arbeiten sehr erschwert, indem der Strick bald da, bald dort an Ästen usw. hängen bleibt, und endlich ist auch die Handhabung des Apparates auf die Dauer recht ermüdend. So

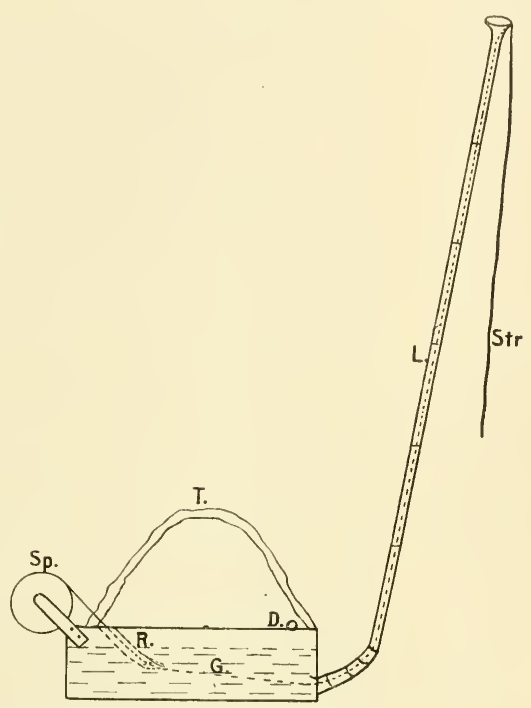

Fig. 233. Strick-Hochleimapparat der Firma Erbstöber \& Haubert (Dresden).

konnte denn auch der Apparat

bis heute keinen rechten Anklang in der Praxis finden. Es dürfte ihm auch für die Zukunft, selbst wenn die oben gerügten Mängel beseitigt werden sollten, keine allzugünstige Prognose gestellt werden, und zwar außer aus den schon genannten Gründen auch noch deshalb, weil man nie sicher ist, ob der Leimstrick auch überall richtig aufliegt und weil ferner auch die mitunter recht wichtige Reinigung der Umgebung der Leimstelle unterbleibt.

Diese letzteren Gründe treffen mehr oder weniger für alle Hochleimapparate zu; außerdem kommt bei solchen Hochleimapparaten, bei denen schwere Leimquetschen - oder Spritzen auf 3-4 m hohen Stangen angebracht sind, als weiterer Nachteil hinzu, daß hier von einer einigermaßen sicheren Führung nicht mehr die Rede sein kann. 
Wenn wir ordentlich hochleimen wollen, müssen wir unbedingt zur Leiter greifen, und daß dies kein Hindernis ist (weder in finanzieller noch in technischer Hinsicht), haben die Erfahrungen in Oberholz und Flößberg zur. Genüge gezeigt.

Über die Dauer der Fängigkeit des Leimringes lassen sich keine allgemeingültigen Angaben machen. Das mindeste aber, was man von cinem

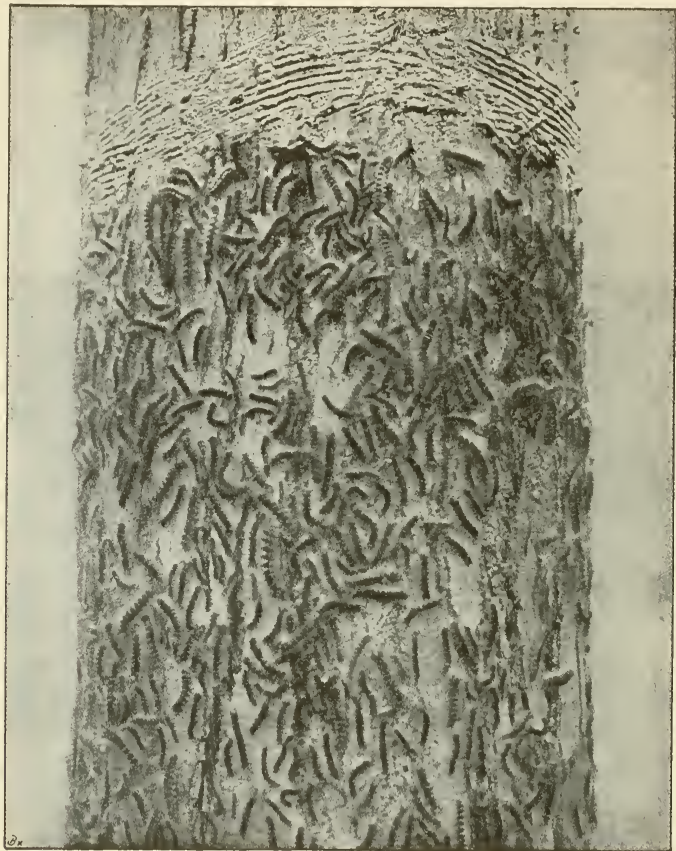

Fig. 234. Aufgekämmter Leimring, mit zahlreichen daruntersitzenden Schwammspinnerraupen. (Amerika.) Aus Escherich.

brauchbaren Leim verlangen kann, ist, daß er während einer Saison fängisch bleibı. Doch behalten gute Qualitäten weit länger ihre fängische Eigenschaft, und hat Verfasser selber schon Leimringe gesehen, die im 2. Jahre noch wirksam waren. ${ }^{1}$ ) Wenn nun die oberste Schicht einzutrocknen beginnt, so

1) Die Verschiedenheit der Fängigkeitsdauer hängt nicht allein von den verschiedenen Bezugsquellen des Leims ab, sondern auch von den Jahrgängen. Nur zu of kann man hören, daß der Leim, von der gleichen Fabrik bezogen, in diesem Jahr nicht so gut ist als im vergangenen. Es scheint demnach, daß die Erzielung eines stets gleichbleibenden bestimmten Fängigkeitsgrades mit gewissen technischen Schwierigkeiten verknüpft ist. 
kann man zunächst als einfachstes Auffrischungsverfahren das $\Lambda$ ufkämmen mit einem Kamm aus Blech oder Holz versuchen (Fig. 234), ein Verfahren, das in Amerika, wo der Leim sehr teuer ist, allgemein geübt wird, und das wenigstens für einige Wochen die Dauer der Leimwirkung verlängern kann. Wenn der Vertrocknungsprozeß weitere Fortschritte macht, kann man event. durch Überpinseln mit einem billigen Pflanzenöl den Leim wieder erweichen (Eckstein).

Der Raupenleim findet übrigens nicht nur als Leimring Verwendung, sondern wird auch noch in verschiedener anderer Form gebraucht. Von der Verwendung des Leimes zu "Teerschlitten" war oben schon die Rede. Des weiteren wird der Leim zur Herstellung von Leimstangen benutzt, die, gleichwie die Raupengräben, die am Boden kriechenden Schädlinge abhalten sollen, und die, wie die Gräben, hauptsächlich zur Isolierung von Kulturen (aber auch Beständen) benutzt werden. Es braucht kaum gesagt zu werden, daß die Stangen gut auf dem Boden aufliegen müssen und daß die Leimseite stets fängisch zu halten ist, indem aufgewehte Blätter, Nadeln, Aststückchen usw. entfernt resp. mit neuem Leim überstrichen werden. Und endlich wird der Leim auch noch als Leimanstrich benutzt, um Rindeninsekten vom Fraß, Benagen oder Einbohren in die Rinde abzuhalten (z. B. Hylobius, Dendroctomus micans und andere).

$\mathrm{Zu}$ letzteren Zwecken benützt man übrigens an Stelle von Leim auch noch verschiedene andere Stoffe. So hat sich z. B. als Vorkehrungsmittel gegen Hylobiusfraß ein e infaches $\mathrm{Sch} 1$ ämmen der Pflanzen in Ziegellehm oder dick angerühter Kalkmilch vor dem Einsetzen sehr gut bewährt. Desgleichen kann man den Anflug von Borkenkäfern, Bupresten usw. durch einen Anstrich der gefährdeten Stämmchen mit einem erhärtenden Brei schützen; man gebraucht dazu gewöhnlich eine Mischung von Lehm, Kalk, Kuhdung zu gleichen Teilen mit Wasser zu einem dickflüssigen Brei zusammengerührt, event. kann man demselben noch etwas Tabaksbrühe oder Rinderblut beimischen. -

\section{Beurteilung der Notwendigkeit und Möglichkeit der Bekämpfung.}

Nicht bei jedwedem Auftreten von forstschädlichen Insekten hat der Forstmann ohne weiteres zu Bekämpfungsmaßregeln zu greifen. Er wird vielmehr in jedem Einzelfall besonders erwägen müssen, inwieweit die allgemeinen forst- und volkswirtschaftlichen Rücksichten deren Anwendung wünschenswert oder nötig machen. Jede zur Bekämpfung eines Schädlings getroffene Maßregel bezweckt ja doch schließlich die Verhinderung oder Minderung einer Schmälerung des wirtschaftlichen Vermögens. Daraus folgt, daß Bekämpfungsmaßregeln nur dann empfehlenswert sind, wenn deren Erfolg im richtigen Verhältnis zu dem durch sie bewirkten Aufwande an Arbeit und Kapital steht.

Der Forstwirt muß sich daher zunächst darüber klar zu werden suchen, ob der Fraß ein solcher ist, daß sich eine Bekämpfung wirklich lohnt. Dies wird der Fall sein, wenn durch sie wertvolle Bestände oder Kulturen, oder auch einzelne wertrolle Bäume voraussichtlich vor dem gänzlichen oder teilweisen Eingehen geschützt werden können, oder wenn zu befürchten ist, daß die Unterlassung der Bekämpfung eine gefährliche Steigerung und weitere 
Ausbreitung des Fraßes zur Folge haben könne. Andererseits würde die Bekämpfung zu unterlassen sein, einmal wenn die Beschädigungen nur unbedeutender Natur sind, die sich nur in einer geringen Zuwachsverminderung des Bestandes geltend machen, oder nur einen geringen Ausfall von Pflanzen (in Kulturen usw.) zur Folge haben; sodann, wenn die natürlichen Gegengewichte ein selbstständiges Erlöschen des Fraßes bald erwarten lassen; und endlich auch in solchen Fällen, in denen der Fraß schon so weit vorgeschritten ist, daß ein menschliches Eingreifen voraussichtlich keinen Erfolg mehr verspricht.

Ein richtiges Urteil hierüber abzugeben ist mitunter sehr schwierig, und der Forstmann wird in dieser Beziehung oft genug in die gleiche Verlegenheit kommen, wie der Arzt, der in zweifelhaften Fällen sich für cinen bestimmten Weg der Therapie entscheiden soll. Nur gründliches Wissen, eingehende Untersuchung aller in Betracht kommender Faktoren werden in Verbindung mit einem scharf geübtem Blick und feinem biologischen Taktgefühl in solchen Fällen dazu führen können, das Richtige bezügl. der Prognose zu treffen. Als Grundlage der Beurteilung sind hauptsächlich folgende Punkte zu berücksichtigen: 1. der Grad der Übervermehrung der Schädlinge, 2. der Gesundheitszustand der Schädlinge und 3. die äußeren Faktoren, das sind die klimatischen, geologischen, waldbaulichen Verhältnisse usw. des befallenen Gebietes.

\section{Untersuchung über den Vermehrungsgrad der Schädlinge.}

In vielen Fällen wird der Forstmann direkt durch den einfachen Augenschein bei Begehung der in Frage kommenden Bestände über die Menge der vorhandenen Schädlinge sich orientieren können. Es trifft dies vor allem für an sich leicht wahrzunehmende, auffallende Schädlinge zu, wie z. B. die Prozessionsspinnerraupen, Nonnenfalter, schwärmende Kiefernspanner usw.

In anderen Fällen, wo es sich um unscheinbare Insekten handelt, oder um solche, die verborgen leben unter der Rinde oder im Boden oder hoch oben in der Baumkrone, wird der Forstmann nach anderen indirekten Kennzeichen urteilen müssen oder eine planmäßige Untersuchung anzustellen haben.

Von indirekten Kennzeichen kommt das allgemeine Aussehen des Bestandes, die Stärke der Entnadelung oder Entlaubung, die Verfärbung der Nadeln, reichliches Vorhandensein von Harzausfluß oder Bohrmehl, sowie bei Raupen oder Maikäfern die Menge des von ihnen erzeugten Kotes in Betracht. Letztere ist besonders in alten, starken Beständen, deren Bäume sich nicht schütteln lassen, also bei Kiefernspinnerfra 3 im Hochwalde, bei Eichenwicklerfraß auf alten übergehaltenen Eichen usw. wichtig, und es kann hier den Forstmann nicht bloß das Gesicht, sondern auch das Gehör belehren, da mitunter der Kot so massig erzeugt wird, daß sein Herabfallen ein rieselndes Geräusch hervorbringt. Auch die Ansammlung insektenfressender Vögel, z. B. des Kuckucks, in einem Bestande wird vom aufmerksamen Forstmanne wohl beobachtet werden. 
Planmäßige Untersuchungen sind in Form des Probesammelns anzustellen; sie werden hauptsächlich da vorzunehmen sein, wo begründeter Verdacht auf eine größere Schädlingsgefahr besteht, sei es, daß derselbe in direkten Beobachtungen begründet ist, oder darin, daß in Nachbarrevieren der betr. Schädling vermehrt auftritt, oder daß es sich um eine allgemeine Vermehrungsperiode des betr. Schädlings handelt. Das Probesammeln kann sich auf die verschiedenen Stadien des Schädlings beziehen. So sucht man sich z. B. bei der Nonne über die Stärke des Befalls dadurch zu vergewissern, daß man eine Anzahl Stämme fällen läßt und dieselben gründlich nach den Eiern absucht, um deren Zahl festzustellen (Probeeiern). Wenn die Zahl der gefällten und abgeeierten Stämme genügend groß ist, so kann man sich aus den Befunden ein annäherndes Bild von dem Befall und der Verteilung über die einzelnen Abteilungen machen. Der Übersichtlichkeit halber können die Befunde kartographisch dargestellt werden, wodurch die Aufstellung des Kriegsplanes wesentlich erleichtert werden kann.

Zahlreicher sind die Fälle, wo sich das Probesammeln auf das Larvenstadium bezieht. Dasselbe kann in der verschiedensten Weise ausgeübt werden: Am einfachsten dadurch, daß man eine Anzahl Pflanzen nach den Raupen usw. absucht, oder dadurch, daß man probeweise die verschiedenen der oben (siehe S. $361 \mathrm{ff}$.) angegebenen Fangmethoden anwendet, wie z. B. Fanglöcher, Fanggräben, Fangbäume oder den Leimring. Besonders der letztere kommt in Form von streifen- oder platzweisen Probeleimungen ziemlich häufig zur Anwendung, vor allem bei Nonnen- und Kiefernspinnerbefall. Ein weiteres recht empfehlenswertes Mittel zur Eruierung der in den Kronen fressenden Raupenmengen stellen die sog. Kotfänge dar, deren Prinzip darin besteht, aus der aufgefangenen Kotmenge auf die Zahl der Raupen zu schließen. Um dies einigermaßen zutreffend ausführen zu können, ist es unbedingt notwendig, zu wissen, wieviel Kot eine einzelne Raupe pro Stunde oder Tag produziert. Bis heute fehlen aber noch systematisch angestellte Versuche in dieser Beziehung, und so ist es dringend geboten, solche Untersuchungen wenigstens für die wichtigsten Schädlinge baldigst anzustellen. Denn solange wir über die Kotproduktion der einzelnen Raupe (für jedes ihrer Stadien usw.) nicht Bescheid wissen, haben alle auf den Kotmengen aufgebauten Schätzungen nur bedingten Wert. Die Ausführung der Kotfänge geschieht in der Weise, daß man Tücher oder Papier im Kronenbereich auslegt und den darauf fallenden Kot in bestimmten Zeiträumen feststellt, entweder durch Zählung der Kotballen oder durch Messung oder Wägung. Auch durch Schütteln resp. Prellen einzelner Bäume kann man sich einen ungefähren Begriff von der Zahl der in der Krone befindlichen Raupen verschaffen.

Wo es sich um Raupen handelt, die im Boden überwintern (Kiefernspinner), kann man sich am besten dadurch ein Urteil über die ungefähr vorhandenen Mengen verschaffen, daß man die Bodendecke im Umkreis einer Anzahl von Stämmen durchsuchen läßt (Probesuchen). Die Ausführung des Probesuchens, zu dem am besten Frauen herangezogen werden, geschieht in der Weise, daß vorsichtig vom Stamm anfangend zunächst eine etwa $20 \mathrm{~cm}$ breite und ${ }^{1}$, $\mathrm{m}$ lange Moosplagge umgeschlagen, an 
der Unterseite betrachtet und gegen den Körper der Arbeiterin hingeschoben wird. Durch Wiederholung dieser Prozedur wird die entblößte Fläche vergrößert bis zur Entfernung von etwa $1 \mathrm{~m}$ vom Stamm (Fig. 235). Bei gelindem Wetter und lockerer Bodendecke benutzt man zu dieser Arbeit die Hand, bei Frost und filzigem Pflanzenwuchs eine kurzstielige Harke. Ist die Moosdecke abgesucht und zurückgeschoben und sind die darin gefundenen Insekten in einen kleinen Topf (Tasse, Blechbüchse) gelesen, dann wird unter ganz langsamem Abschaben der Humusschichte die freigelegte Fläche bis auf den Rohboden durchsucht. Um einen Vergleich der an verschiedenen Orten erzielten Fangergebnisse zu ermöglichen, ist es notwendig, daß die abgesuchten Flächen gleich groß und in gleicher Weise behandelt sind. Im allgemeinen nimmt man sie kreisrund mit einem Halbmesser von $1 \mathrm{~m}$ vom Stamm ab gemessen, man kann aber auch nach Quadratmetern absuchen lassen, d. h. größere Flächen von einer bestimmten Quadratmeterzahl (Eck stein).

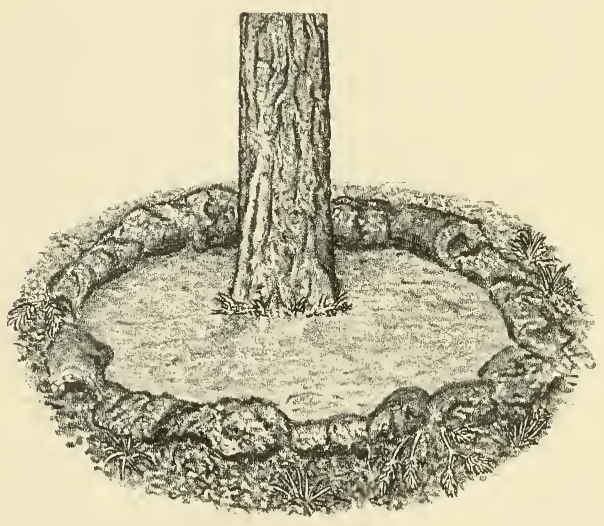

Fig. 235. Umgewendete Bodendecke um eine Kiefer, zum Zweck des Probesuchens. Aus Eckstein.

In gleicher Weise wie die im Boden überwinternden Raupen werden auch die hier überwinternden Puppen (Eule, Spanner, Schwärmer Blattwespen usw.) durch Probesuchen zur Feststellung des Vermehrungsgrades der betr. Schädlinge benutzt. Endlich kann auch durch Probesammeln von Imagines eine annähernde Orientierung über die Höhe des Befalls erlangt werden, z. B. beim großen braunen Rüsselkäfer oder Maikäfer oder bei der Nonne usw. Die Ausführung des Sammelns kann in der oben ausgeführten Weise vor sich gehen. Für die Nonne und auch andere Nachtschmetterlinge kommt außerdem ein Probefang mit Hilfe von Lichtquellen in Betracht; man kann hierzu Zinkfackeln oder helleuchtende Lampen mit oder ohne Selbstfangvorrichtung, wie sie von Entomologen zu ihren Nachtfängen benutzt werden, verwenden. Man kann auf diese Weise leichter und event. auch schon frühzeitiger von der Anwesenheit eines Schädlings Kenntnis erhalten, als es durch die bloße Beobachtung möglich wäre.

Bei all den Probesammlungen, wie wir sie hier geschildert haben, ist zu bedenken, daß sie nur eine a nnähernde Schätzung erlauben, und da $\beta$ a uch bei gründlicher Ausführung des Probesuchens, Probeeierns usw. stets nur ein Teil der wirklich vorhandenen Schädlinge aufge- 
funden wird. Nach Eckstein dürften z. B. beim Probesammeln der Kieferspinnerraupen nur ca. $50 \%$ der tatsächlich vorhandenen Individuen erbeutet werden, und beim Probeeiern der Nonne ist nach den Erfahrungen, die der Verfasser gemacht hat, der Prozentsatz der gefundenen Eier gegenüber den tatsächlich vorhandenen noch geringer, was ja aus der Kleinheit der Objekte und dem versteckten Vorkommen leicht erklärlich erscheint.

\section{Untersuchung des Gesundheitszustandes der Schädlinge.}

Um zu einer einigermaßen richtigen Prognose resp. einer richtigen Entscheidung über die zu treffenden Bekämpfungsmaßregeln zu gelangen, genügt es nicht, über die Menge der vorhandenen Schädlinge sich Aufschluß $\mathrm{zu}$ verschaffen, sondern wir müssen auch ebenso dringlich den Gesundheitszustand der Schädlinge zu ermitteln suchen. Denn die Vorhersage wird ganz anders lauten müssen, wenn die Schädlinge durchgehends gesund sind, als wenn ein großer Teil von ihnen krank ist; und es kann vorkommen, daß bei dem gleichen Grad der Vermehrung die Prognose in dem einen Fall äußerst ungünstig ist und kostspielige Bekämpfungsmaßregeln indiziert, im anderen Fall dagegen so günstig, daß überhaupt keine Bekämpfungsmaßregeln notwendig werden.

Es kommt aber bei diesen Feststellungen nicht nur auf die Zahl der erkrankten Schädlinge an, sondern auch auf die Art der Erkrankung, indem eben die eine Krankheit schnellere Fortschritte macht als die andere; ferner ist auch in Erwägung zu ziehen, ob nicht vielleicht Umstände (z. B. Hyperparasiten) eingetreten sind, welche der weiteren Ausbreitung der Krankheit entgegenstehen usw. Es kommen bei der Untersuchung über den Gesundheitszustand hauptsächlich in Betracht: Parasitenbefall, Mykosen und andere Infektionskrankheiten, und Krankheiten unbekannter Natur.

Parasiten können in jedem Stadium vorkommen, doch wird es sich für unseren Zweck in der Praxis vornehmlich um das Ei-, Larven- und Puppenstadium des Schädlings handeln. Die Feststellung des Parasitenbefalls kann in verschiedener Weise geschehen, durch den bloßen Augenschein, durch Sektion und durch Zucht usw. Wo es sich um Eier oder Puppenparasiten handelt, die bereits ausgeflogen sind, kann man meistens an der Form der Ausflugöffnungen deutlich erkennen, ob Parasiten vorhanden waren, worauf ja oben bereits hingewiesen wurde. Wenn z. B. die Eier des Kiefernspinners kleine regelmäßige, runde Löcher aufweisen, so wissen wir, daß die Eier parasitiert waren (vergl. Fig. 192 S. 249); durch Zählung dieser Eier und Vergleichung mit den gesunden können wir sodann einen annähernden Begriff von der Höhe des Parasitenbefalls erlangen. Ebenso läßt sich mit den Puppen verfahren, wenn deren von der Norm abweichenden Ausflugöffnungen auf das frühere Vorhandensein von Parasiten schließen lassen. Außerdem kann man bei einiger Übung mitunter auch schon aus dem Aussehen der Puppen und vor allem aus deren Unbeweglichkeit die Besetzung mit Schmarotzern erkennen. - Auch bei Raupenparasiten können wir zuweilen schon durch den bloßen Augenschein den Befall feststellen, wenn nämlich die Parasiteneier außen auf dem Körper des Schädlings abgelegt werden, wie bei vielen Tachinen, oder aber wenn es sich um nackte Raupen handelt, bei denen die 
Stichstelle als dunkler Fleck sichtbar ist. Da jedoch die Zahl der Tachineneier auf dem Schädling durchaus nicht immer mit dem Grade der Tachinose im Einklang steht (siehe oben S. 252), und da auch die dunklen Stichflecke auf nackten Raupen nicht immer deutlich zu sehen sind, so wird man, falls eine genaue Feststellung der Höhe des Parasitenbefalls erwünscht ist, stets zur Sektion greifen müssen. Dieselbe bietet keine großen Schwierigkeiten dar und kann von jedem Praktiker vorgenommen werden. Es wird eine Anzahl Raupen (vielleicht hundert oder zweihundert aus jeder Abteilung) gesammelt und mit Äther getötet. Darauf schneidet man jede einzelne Raupe in einer flachen Schale mit Wasser mit einer feinen Schere der ganzen Länge nach auf,1) womöglich ohne Verletzung des Darms. Sind Schmarotzerlarven vorhanden, so werden dieselben von dem Wasser bald aus den Eingeweiden herausgespült und als weiße Maden leicht erkannt werden. Wird das Wasser trübe, was besonders dann geschieht, wenn der Darm verletzt wurde, so muß dasselbe erneuert werden. Anfänger haben sich zu hüten, daß sie nicht Stücke des Raupenleibes, z. B. die gelblichen Anlagen der Geschlechtsorgane oder Teile des Fettkörpers für Parasitenlarven halten. In zweifelhaften Fällen wird die Untersuchung mit der Lupe sofort Aufschluß geben. Sind die Parasitenlarven noch sehr klein, so kann die Untersuchung allerdings recht mühsam und zeitraubend werden. Man kann sich in solchen Fällen damit helfen, daß man die Raupen noch einige Zeit im Zuchtkäfig aufzieht, um die Parasiten größer werden zu lassen, ein Verfahren, das z. B. bei den aus dem Winterlager stammenden Raupen des Kiefernspinners häufig geübt wird. Will man Puppen auf Schmarotzer untersuchen, so bricht man dieselben einfach in der Mitte auf und drückt sie in eine Wasserschale aus, wobei die Schmarotzer, die im allgemeinen in der Puppe meist in vorgerückteren Entwicklungsstadien enthalten sind, gewöhnlich ohne weiteres deutlich erkennbar zum Vorschein kommen.

Auch durch Aufsuchung und Zählung der Schmarotzerpuppen kann man einen Begriff von der Höhe des Parasitenbefalls sich verschaffen. Am bekanntesten sind die weißen Cocons der kleinen Schlupfwespen (Braconiden), die oft haufenweise die getöteten Raupen bedecken; auch andere Schlupfwespencocons findet man nicht selten im Fraßgebiet unter Leimringen usw. Eine systematische Feststellung der Zahl der Parasitenpuppen kann vor allem bei solchen Schädlingen vorgenommen werden, die sich im Boden verpuppen (z. B. Kieferneule oder Spanner usw.). Es geschieht dies in der Weise, daß beim Probesuchen der Schädlingspuppen zugleich auch alle in der Bodendecke befindlichen Tachinentönnchen und Schlupfwespencocons gesammelt und gezählt werden. Diese Untersuchung setzt allerdings eine gewisse Vertrautheit mit den in Frage kommenden Parasiten voraus, weil man sonst eventuell durch Berücksichtigung harmloser, saprophytischer

1) Eckstein wendet eine andere Methode an: er schneidet das Hinterende der Raupe ganz knapp ab, legt dann die Raupe auf eine Glasplatte und quetscht ihren Inhalt mit einem fest aufgedrückten Glasstab vom Kopf nach hinten zu streichend aus. In dem ausgequetschten Inhalt sind die Parasiten gewöhnlich ohne Schwierigkeit zu finden. 
oder aus anderen Wirten stammender parasitischer Insekten (besonders Fliegen) zu falschen Schlüssen bezügl. der Befallshöhe gelangen kann. - Um zu einem dem tatsächlichen Parasitenbefall einigermaßen entsprechenden Bild bei den eben genannten Schädlingen zu gelangen, genügt es übrigens nicht, die beim Probesuchen zutage geförderten Parasitentönnchen und Cocons in Rechnung zu stellen, da ja auch noch eine Anzahl ron Parasiten in den Puppen selbst sich befinden könmen. Es muß also in diesen Fällen auch noch eine besondere Untersuchung der Puppen vorgenommen werden. Um ein Beispiel hierfür anzuführen, so hat das hiesige Institut in diesem Herbst große Quantitäten „Bodendeckeninhalt" aus verschiedenen Eulenrevieren erhalten, um eine Prognose über den Verlauf der Eulenkalamität zu geben: Es wurde zunächst der Inhalt der Sendungen sortiert, d. h. die Eulenpuppen von den Parasitenpuppen und die letzteren nach den Arten getrennt, ferner alle übrigen Puppen, die zur Eule in keinem Verhältnis standen, entfernt. Sodann wurden genaue Zählungen vorgenommen (natürlich stets auf bestimmte Flächeneinheiten bezogen); und endlich wurden noch von jeder Probe eine größere Anzahl Puppen durch Aufbrechen auf die Anwesenheit von Schmarotzern untersucht, deren Ergebnis in manchen Fällen die auf der einfachen Zählung der gefundenen Tönnchen und Cocons beruhenden Schätzungen noch wesentlich beeinflußt hat.

Endlich kann man zur Feststellung des Parasitismus auch noch zur Zucht greifen, indem man eine Anzahl Schädlinge in Parasitenzuchtkästen (siehe unten) einbringt und die daraus auskommenden Parasiten zählt.

Wie oben (S. 244) ausgeführt, kann das Fortschreiten des Parasitismus mitunter wesentlich durch Auftreten von Hyperparasiten gehemmt werden. Es darf daher bei den Untersuchungen über die Höhe des Parasitismus diese Frage nicht außer acht gelassen werden; d. h., es muß die Zahl der von Hyperparasiten besetzten Schmarotzer bei der Kalkulation in Abzug gebracht und sodann auch das event. Fortschreiten des Hyperparasitismus in Rechnung gezogen werden. Wir selbst haben in den letzten Jahren mehrfache Erfahrungen in dieser Beziehung gemacht, indem z. B. die Tönnchen der Nonmentachine aus mehreren Orten von dem hyperparasitisch lebenden Trauerschweber (Anthrax) zu einem ziemlich hohen Prozentsatz besetzt waren, desgleichen zahlreiche Cocons eines in Eulen schmarotzenden Banchus.

Wenn wir den Hyperparasitismus in solchen Fällen unberücksichtigt lassen, so werden wir event. zu einem falschen Bild über den Stand des Parasitismus gelangen. Die Feststellung des Hyperparasitismus kann heute in den meisten Fällen nur durch Zucht bewerkstelligt werden. Wenn wir aber erst einmal etwas besser über die Erscheinung des Hyperparasitismus unterrichtet sein werden und wenigstens für unsere wichtigsten Schädlinge die in Frage kommenden Hyperparasiten und vor allem deren Larvenformen kennen und unterscheiden gelernt haben werden, so wird auch diese Aufgabe sich vielleicht einfacher und leichter gestalten.

Was die Untersuchung auf Mykosen betrifft, so werden sich diese häufig schon im Walde durch den bloßen Augenschein feststellen lassen, 
indem die mit Pilzen infizierten Larven oder Raupen zuweilen mißfarbige Flecke zeigen, oder indem man auch ein oder das andere eingegangene, äußerlich mit Pilzfäden (bezw. Fruchtkörper) bedeckte Tier findet. Manchmal macht sich das Vorhandensein einer Mykose dadurch bemerkbar, daß die Raupen usw. nach dem Wipfel der Fraßpflanze (gleichwie die wipfelkranken Nonnenraupen) zustreben, wie dies z. B. mehrfach bei empusakranken Eulenraupen beobachtet worden ist. Sodann kann auch eine makroskopische Untersuchung mitunter einigen Aufschluß geben: man braucht nur die verdächtigen Raupen (z. B. Kiefernspinnerraupen aus dem Winterlager) oder Puppen auseinanderzureißen oder zu brechen, um die Anwesenheit von Pilzen event. schon an der bloßen Veränderung des Inhaltes erkennen zu können, indem dieser milchig getrübt erscheint, oder, wenn die Verpilzung schon weiter fortgeschritten, zu einer zähen kautschukartigen Masse umgewandelt ist, und außerdem einen charakteristischen aromatischen Pilzgeruch verbreitet (Cordyces militaris, siehe S. 271, Anm.). Wo die makroskopische Untersuchung Zweifel läßt, da hat man zur mikroskopischen Untersuchung überzugehen, oder aber durch Einzwingerung einer Anzahl Raupen aus dem verdächtigen Gebiet sich Gewißheit zu verschaffen. Wenn man die zu untersuchenden Raupen in feuchte Gefäße bringt und außerdem warm hält, so wird sich schon in kurzer Zeit ( 1 bis wenigen Tagen) die Anwesenheit von Pilzen durch Hervorbrechen von Pilzfäden kund tun.

Ähnlich wie bei den Mykosen hat man bei der Untersuchung der verschiedenen anderen Infektionskrankheiten zu verfahren. Man wird auch hier zuerst auf die verschiedenen äußeren Kennzeichen („Wipfeln“, Schlaffwerden, Freßunlust usw.) zu achten haben; diese Beobachtungen werden zu ergänzen sein durch mikroskopische Untersuchung, die nach dem Vorhandensein der Erreger oder sonstiger mikroskopischer Symptome (Polyeder!) zu fahnden hat. Und gegebenenfalls sind endlich die Raupen eine Zeitlang in Zwingern zu halten und genau zu beobachten und event. wiederholt mikroskopisch zu untersuchen. Über die Symptome, die mikroskopischen wie die makroskopischen, ist alles wissenswerte oben gesagt.

Was endlich die Krankheiten unbekannter Natur betriff, so habe ich hier vor allem das Absterben der Eier im Auge, wie es z. B. bei Nonneneiern verschiedentlich konstatiert worden ist. Wenn das Absterben in großem Maßstabe eintritt, wie es von uns vor einigen Jahren beobachtet und beschrieben worden ist, so bedeutet dies natürlich eine wesentliche Verbesserung der Prognose. Als das hauptsächlichste Symptom der Krankheit ist das Auftreten von Luftblasen zu nennen (weshalb Wolff dieselbe als „Blasenkrankheit“ bezeichnet hat). Da dieses Symptom aber erst in einem späten Stadium der Krankheit eintritt, und es mitunter von großer Wichtigkeit ist, möglichst frühzeitig über die Ausdehnung der Krankheit Bescheid zu erhalten, so bleibt in solchen Fällen fürs eıste kein anderer Weg, als die Eier in feuchter Wärme zu „treiben“, wodurch die gesunden Eier zum vorzeitigen Ausschlüpfen gebracht werden können. Das hiesige Institut hat seit einigen Jahren in jedem Winter eine große Zahl Nonneneier in dieser Weise auf ihren Gesundheitszustand untersucht. 


\section{Untersuchung des befallenen Bestandes.}

In welcher Weise die verschiedenen äußeren Faktoren, wie die klimatischen, geologischen waldbaulichen Verhältnisse eines Bestandes bei der Stellung der Prognose Berücksichtigung zu finden hat, ist oben (S. $214 \mathrm{ff}$.) bereits ausgeführt worden, und braucht daher hier nicht nochmals geschildert zu werden. Nur auf einen Punkt muß hier eingegangen werden, der vielfach große Schwierigkeiten bereitet, nämlich ob die Beschädigung eines Bestandes oder eines Baumes derart ist, dath sie unrettbar das Absterben zur Folge hat (so daß jede Bekämpfungsmaßregel überflüssig wäre und nur die Entfernung der befallenen Objekte bleibt), oder ob sie noch Aussicht auf Erholung bestehen läßt, so daß event. Bekämpfungsversuche angezeigt sind. In der vorigen Auflage dieses Werkes gaben Judeich und Nitsche folgende Anhaltspunkte:

Die Beachtung des Standortes ist insofern wichtig für die Vorhersage, als im allgemeinen die Gefahren durch Insektenbeschädigungen dann am größten sind, wenn ungünstiger Standort einen kümmerlichen Wuchs der Bäume bedingt, während günstigere Standortsverhältnisse die Widerstandskraft derselben stärken.

$\mathrm{Daß}$ von unseren héimischen $\mathrm{Holzarten}$ die $\mathrm{L}$ a u b hölzer im allgemeinen weit weniger empfindlich sind als Nadelhölzer, daß sie namentlich in den höheren Altersstufen einer wirklich tödlichen Verletzung durch Insektenfraß viel weniger ausgesetzt sind, wurde früher schon erwähnt (vgl. S. 215). Man wird deshalb in älteren Laubholzbeständen selten notwendig haben, kostspielige Bekämpfungsmaßregeln anzuwenden. Bei Raupenfraß, wie z. B. bei Fraß von Dasychira pudibunda L., Geometra brumata L., Tortrix viridana $L$. usw. wird in der Regel nichts zu tun sein, weil die Kosten der Vertilgungsnaßregeln meist größer sein würden, als der durch den Fraß bewirkte Verlust an Zuwachs oder Samen. Von Borkenkäfern, Buprestiden, Bockkäfern oder anderen im Holze lebenden Insekten heimgesuchte a 1 te Bäume kann man, obgleich sie den Fraß meist jahrelang aushalten, ohne Verlust entfernen, soweit dies nötig erscheint, um eine weitere Ausbreitung des Übels zu verhindern. Man braucht sich aber damit nicht zu übereilen. Empfindlicher sind $\mathrm{j}$ ü n g e r e Bäume, namentlich frisch gepflanzte Heister. Borkenkäfer, einige Buprestiden und Rüsselkäfer, Raupen usw. können junge Buchen, Eichen, Eschen, Rüstern, Birken usw. schwer schädigen und schon in einem Jahre töten. Man bemerkt dies meist zur rechten Zeit, um die kranken Stämmchen noch vor Ausfliegen der Käferbrut entfernen zu können. Ein sicheres Kennzeichen ist namentlich das schneller als beim Nadelholze eintretende Welken der Blätter; auch an der Rinde verdächtiger Bäumchen wird man bei aufmerksamer Untersuchung die Bohrlöcher entdecken. Sehr leicht ist es, Raupen- oder Käfer$\mathrm{fra} B$ an den Blättern zu bemerken. In allen den hier genannten Fällen ist also die Prognose nicht sehr schwierig, aber auch meist nicht notwendig.

Etwas anderes ist es mit den weit empfindlicheren $\mathrm{N}$ a delhöl zern, diese crfordern größere Aufmerksamkeit. Nicht bloß die alten, sondern auch die jungen und ganz jungen Bestände sind viel mehr der Gefahr ausgesetzt, durch Insektenfraß vernichtet oder schwer geschädigt zu werden, als Laubhölzer von demselben Alter.

Bei jungen Nadelhölzern treten die Symptome sehr bestinmt auf. Keimlinge und selbst etwas ältere Pflanzen lassen als schwächliche Individuen die tödliche Erkrankung leicht erkennen. Wenn die noch zarten Wurzeln von Engerlingen abgefressen werden, so lassen die Pflänzchen noch an demselben Tage die Nadeln hängen, und man braucht gar nicht das Rotwerden derselben abzuwarten, um ihren Tod vorauszusagen. Schwächere Beschädigungen heilen die Pflanzen wohl auch wieder aus. Die stets mit dem Tode verknüpfte Schädigung der jungen Kiefern durch Larven von Pissodes notatus Fabr. kennzeichnet sich im Juni und Juli leicht 
durch Welken der Triebe, ebenso sterben von Hylesinus cunicularius Er. befallene junge Fichten sehr bald ab. Leicht beurteilen sich auch die Schäden, welche an jungen Kiefern und Fichten durch den Fraß des großen Rüsselkäfers, an Kiefern durch die Saateule hervorgerufen werde1. Die Prognose bereitet hier keine Schwierigkeiten. Insoweit als die etwa zu ergreifenden Mabregeln vom Zustande der Pflanze selbst abhängen, kann man ruhig abwarten, ob sich dieselben erholen oder nicht, ehe man für die eingegangenen durch Ausbesserung der Kultur Ersatz schafft.

In ä 1 te $\mathrm{r}$ en Nadelholzbeständen handelt es sich dagegen um den Schutz und die Erhaltung wirtschaftlicher Objekte, welche leicht und schnell nicht wieder ersetzt werden können. Sichere Todeskennzeichen fehlen hier zwar ebenfalls nicht, sind aber nicht immer so deutlich ausgesprochen, wie bei den jungen Pflanzen. Plötzliches Absterben kommt beim alten Baum nicht vor, das Absterben erfolgt mehr allmählich. So grünt manchmal der Wipfel noch längere Zeit, während unten am Stamme die Rinde sich bereits loslöst: ein sicheres Kennzeichen des Todes. Wir müssen schon zufrieden sein, wenn sich die bestimmten Todeszeichen noch vor Winter oder während des Winters einstellen, damit die Axt dem Verderben des Holzes vorbeugen kann. - Zunächst ist hier der Fraß der Rinden-, Bast- und Holzbeschädiger, in der Hauptsache also der Käferfraß, von dem der Nadelbeschädiger, also hauptsächlich dem Raupenfraß, zu unterscheiden.

„Im Falle eines KäferfraBes, welcher im Nadelholze für jüngere und alte Bäume gleich gefährlich ist, gewöhnlich auch zum baldigen Abtriebe drängt, ist zuerst die Rinde zu beobachten, an der sich die Borkenkäfer durch Bohrlöcher und Wurmmehl, Pissodes piniphilus Hbst. und harcyniae Hbst. sowie Tetropium luridum L. u. A. durch Harztropfen verraten. Das Bleichen und Rotwerden der Nadeln tritt zuweilen bald ein, bei Fichte schneller als bei Kiefer; manchmal bleibt es auch bis zum Winter oder bis zum nächsten Frühjahre aus. Dies ist z. B. bei Fraß von Pissodes piniphilus der Fall und bei Borkenkäfern dann, wenu der Anflug erst im Spätherbst erfolgte. Von Borken- oder Stangenrüsselkäfern befallene Bäume sind im Gewöhnlichen unrettbar verloren. Sie bieten also keine Schwierigkeiten bezügl. der Prognose und müssen schon wegen der Gefahr der Weiterverbreitung des Übels unter allen Umständen gefällt, bei Borkenkäferfraß auch entrindet und entfernt werden, selbst für den Fall, daß der betroffene Bestand nicht mehr zu retten ist, um so mehr aber, wenn letzteres noch möglich. Nur bei glücklicherweise seltenen, besonderen Unglücksfällen ist diese Möglichkeit ausgeschlossen, weun man gegen Borkenkäfer mit Fällung von Fangbäumen stets in richtiger Weise vorgeht.

„Schwierige Zweifel entstehen dagegen oft bei den Nadelfressern, bei $\mathrm{R}$ a upenfra $B$, da der Tod oder die mögliche Genesung des befallenen Baumes nicht bloß von der Art des Nadelholzes und von der Insektenart abhängt, sondern ganz wesentlich von der Intensität des Fraßes und von der Witterung. Nur in seltenen Fällen werden einzelne Stämme wirklich tot gefressen, d. h. inmitten des Fraßes getötet. Der Abtrieb eilt hier zwar nicht so sehr wie bei „Wurmtrocknis“, weil sich die Schädlinge nicht innerhalb der Fraßobjekte entwickeln, und man Zeit hat, die Kranken länger zu beobachten, allein die Frage danach, ob und welche Vertilgungsmittel zu ergreifen sind, muß wesentlich auch nach dem Zustand des befallenen Bestandes entschieden werden. Ist letzterer einmal rettungslos verloren, so sind zu seinem Schutze keine Kosten aufzuwenden, sondern uur zur Verbreitung des Übels in Nachbarbestände. Lärche und Tanne werden seltener eingehendere Untersuchungen notwendig machen, viel öfter Fichte und Kiefer.

„Als Zeichen eines bald zu erwartenden Todes nach Raupenfraß gilt das Trocknen und Welken der Knospen, sowie das Auftreten von Borkenkäfern, Hylesinen und Bockkäfern. Wenn die Knospen beim Durchschneiden nirgends mehr grüne Nadelchen zeigen, dann ist allerdings der Baum tot, indessen kann man nicht umgekehrt aus dem grünen Inhalte der Knospen stets 
auf Gesundheit schließen; dergleichen Bäume sterben trotzdem manchmal plötzlich ab.

„Für die Fichte kommt besonders der Fraß der Nonne in Betracht, der nicht selten den Tod herbeiführt, manchmal aber wenig schadet. In der Regel zeigen die Fichten meist ein früheres Rotwerden der Nadeln als die Kiefern, so bei Nonnenfraß, oft schon im Herbste. Es ist das sehr auffallend, wenn scheinbar nur eine so geringe Beschädigung der Bäume stattfand, daß ein Viertel oder selbst die Hälfte der Benadelung erhalten blieb. Im Sommer ist also die Prognose äußerst schwierig und unsicher. $\mathrm{Kiefer} \mathrm{n}$ halten einen viel stärkeren Fraß aus als Fichten. Ma11 wird also bei Nonnenfraß an Kiefer wohl meistens auf Wiedergenesung hoffen dürfen. Auch nach dem Fraße der Forleule hat man wiederholt beobachtet, daß sich trotz fast vollständigen Kahlfraßes die Bäume wieder erholten, selbst solche, bei denen schon viele Knospen abgestorben waren, ein Beispiel, welches lehrt, daß man mit der Vorhersage des Todes vorsichtig sein muß. Andererseits ist infolge des durch Kiefernspanner eingetretenen Kahlfraßes, allerdings unter Hinzutritt anderer ungünstiger Umstände, schon unerwartet der Tod eingetreten. Noch größere Schwierigkeiten bietet die Vorhersage in Kiefernbeständen beim Fraß des Spinners, und ist man in früheren Zeiten nicht selten wegen irriger Vorhersage zu schnell mit dem Abtriebe vorgegangen. Allerdings ist auch bei Kiefern die Zerstörung der Knospen in großer Ausdehnung eine Todesursache. Je mehr Knospen zerstört wurden, desto zahlreicher treten auch andere Anzeichen schwerer Erkrankung hervor, wie Rosetten und Scheidentriebe (vgl. S. 212). Einzeln, also unbedeutend, erscheinen Rosetten auch nach Spanner-, zuweilen auch nach Eulen- und Nonnenfraß, massenhaft jedoch nach dem Fraß des Kiefernspinners, und sind immer mit kümmerlicher Ausbildung der Jahresringe verknüpft. Hat man auch dann noch bezügl. der Vorhersage Zweifel, so untersuche man, ob der Weichbast schon gelbfleckig oder wässerig wird oder sich gar zunderartig auflöst, in hohem Grade „,aufgebacken“ erscheint, und ob dem letzten Jahresringe nicht schon Harzkanäle und Herbstholz, „Braunholz“, fehlen. In vielen Fällen sind, selbst ohne Eintritt der Bildung von Rosetten, schon die vorhergehenden Ringe mehr oder weniger abnorm; teils sind sie sehr schmal, teils zeigen sie „Harzketten“, welche immer ein bedeutendes Sinken der Lebenstätigkeit bekunden. An einzelnen sehr zweifelhaften Bäumen kann man dann auch ,fenstern“, d. h. man schneidet ein Rindenfenster von einigen Quadratzentimetern aus, um auf dem dadurch entblößten Splinte die austretenden Harztröpfchen beobachten zu können. Dies kann zum Vergleiche zwischen gesunden und kranken Stämmen sowohl im Winter, wie im Sommer geschehen. Kleine und sehr sparsame Harztröpfchen verraten eine bereits eingetretene Schwäche des Baumes."

\section{Durchführung der Bekämpfung.}

Die Möglichkeit der Durchführung zweckmäßiger Bekämpfungsmaßregeln hängt natürlich auch ab von den Hilfsmitteln, über welche der Waldbesitzer verfügen kann. Der Kleinbesitzer ist meist nicht in der Lage, so bedeutende Kosten aufzuwenden wie der Großbesitzer, wie namentlich der Staat. Da aber auch ein kleiner Wald zum Herde für die Ansteckung weiterer Bezirke werden, also eine Gefahr für die Allgemeinheit bringen kann, und da der Wald außer seinem direkten wirtschaftlichen Werte für den Besitzer auch eine weitere Bedeutung für das Volkswohl überhaupt hat, so wird es die Aufgabe des Staates, die wirtschaftlichen Maßregeln der Kleinbesitzer durch Gewährung des Rates von Sachverständigen, unter Umständen auch durch Arbeitskräfte (Militär oder Sträflinge), sowie durch Vorstreckung des nötigen Geldes zu unterstützen, die Bekämpfung der Forstschädlinge aber gesetzlich zu fordern (N.). 
In letzterer Beziehung ist bisher im deutschen Reiche der Schutz gegen schädliche Forstinsekten zum größten Teil der Partikulargesetzgebung ${ }^{1}$ ) überlassen, was für den einzelnen Bundesstaat unter Umständen recht verhängnisvoll werden kann. Nehmen wir z. B. an, daß eine allgemeine Nonnenperiode einsetzt: in dem einen Staat wird nun sofort unter Anwendung der landesgesetzlichen Vorschriften eine allgemeine intensive Bekämpfung eingeleitet, im Nachbarstaat dagegen wird nichts gegen den Schädling unternommen, - so kann es sich ereignen, daß die Vorsichtsmaßnahmen des ersteren Staates durch die Nachlässigkeit des letzteren zum Teil zunichte gemacht werden, indem die Nonne, nachdem sie hier die Wälder kahl gefressen, über die Grenze in die direkt benachbarten noch gut erhaltenen Wälder zieht. Es ist daher zweifellos berechtigt, wenn Beck die Forderung eines Reichs-Pflanzenschutzgesetzes aufstellt. Allerdings sind heute die Grundbcdingungen für ein solches Gesetz gerade in bezug auf die schlimmsten Forstschädlinge, wie z. B. die Nonne, noch nicht gegeben: Wenn man auf der einen Seite der Ansicht huldigt, daß gegen die Nonne überhaupt nichts unternommen werden kann, auf der anderen Seite aber die Überzeugung besteht, daß die Nonne bei rechtzeitigem Einschreiten erfolgreich bekämpft werden kann, so wird es noch eines weiten Weges bis zu einer gesetzlichen Regelung dieser Frage bedürfen. Was vor allem not tut, ist eine planvolle Erforschnng unserer wichtigsten Forstschädlinge, die aber, wie der Verfasser verschiedentlich ausgeführt hat, ohne eine gründliche Reform unseres bisherigen entomologischen Versuchswesens kaum erzielt werden dürfte. ${ }^{2}$ ) Nur dann, wenn die einzelnen Schädlingsprobleme gründlich erforscht sind und man über die anzuwendenden Bekämpfungsmaßnahmen sich einigermaßen geeinigt haben wird, kann an eine reichsgesetzliche Regelung im Sinne Becks gedacht werden.

\section{Literatur.}

(Siehe auch das Literaturverzeichnis für das vorhergehende Kapitel [S. 304-306]).

B eck, R., Die Insekten- und Pilzkalamitäten im Walde. Thar. Forstl. Jahrb. 1909 (Leipzig-Band), S. $1-65$.

Berlepsch, Hans Freiherr von, Der gesamte Vogelschutz, seine Begründung und Ausführung. Gera.

B e r n e r, P., Ein neues Mittel zur Vertilgung des Nonnenfalters. Deutsche ForstZeitg. 23. Bd., 1908, S. 784-786. (Lichtfang mit Quarzlampen.)

Decoppet, Vernichtung der Engerlinge in den Forstgärten (gekürzte deutsche Übersetzung). Schweiz. Zeitschr. f. Forstwesen 1912, S. 122-129. (Referat im Forstwiss. Zentralblatt 1913, S. 266-267.)

1) Siehe M ü 11 er, P., Das Forst- und Feldstrafgesetz für das Königreich Sachsen. Leipzig 1909. (Auf Seite 147 u. 148 sind die einschlägigen Gesetze der verschiedenen Staaten zusammengestellt).

$\left.{ }^{2}\right)$ Um die so dringend notwendige Reform unserer Wissenschaft in die Wege zu leiten, hat sich vor kurzem die, ,Deut sche Gesellschaft für a $11 \mathrm{gew}$ a nd te Entomologi e" mit dem Sitz in Tharandt konstituiert. Sic wird durch Jahresversammlungen, Herausgabe einer Zeitschrift, Verfassung von Denkschriften, Bildung von Fachausschüssen zur Bearbeitung der einzelnen Fragen usw. ihrem Ziele nahezukommen suchen. (Beitrittsanmeldungen sind an das Zoologische Institut in Tharandt zu richten.) 
Dolles, Streifzug im Gebiete von Feinden unserer schädlichen Waldinsekten. Forstl.-nat. Zeitschr. Bd. 6 (1897), S. 257-270.

Eckstein, K., Die Technik des Forstschutzes gegen Tiere. Mit 52 Textabbildungen. Berlin 1904.

- Wie untersucht man, ob Kiefernraupen (Lasiocampa pini) von Parasiten besetzt sind. Deutsche Forst-Zeitg. 22. Bd., 1907, Nr. 3, S. 53-55.

- Zur Bekämpfung der Nonne. Deutsche Forst-Zeitg. 24. Bd., 1909, S. 462. (Anwendung von Chlorbarium.)

Escherich, K., Tote Nonneneier. Nat. Zeit. f. Forst- u. Landw. 1911, S. 237 ff.

- Nonnenprobleme. Nat. Zeitschr. f. Forst- u. Landw. 1912, Heft 2/3.

- Fortschritte der Leimtechnik. Tharandt. Forstl. Jahrbuch, Bd. 64 (1913), S. 78 - 88.

Fulmek, Leop., Die Schwefelkalkbrühe. Mitteil. K. K. Pflanzenschutzstation. Wien 1913.

- Zur Arsenfrage im Pflanzenschutzdienst, bes. betreffend das Bleiarseniat. Arch. f. Chemie und Mikroskopie 1913. Heft 6.

- Nencrungen im Pflanzenschutz (Zoolog. Teil). Wien 1913.

G rohmann, Die Generation des großen braunen Rüsselkäfers (Hylobius abietis) und seine Bekämpfung. Tharandt. Forstl. Jahrb. 64, 1913, S. 325-361.

H a e ne 1, K a r l, Unsere heimischen Vögel und ihr Schutz. Würzburg 1913.

Hen nicke, R. Car l, Vogelschutzbuch. Stuttgart 1911.

- Handbuch des Vogelschutzes. Magdeburg 1912.

He relle, F. de, Sur la propagation dans la Republique Argentine, de l'epizootic des Santerelles du Mexique. Compt. rend. Ac. Sc. Paris F. 154, No. 9. (26 Février 1912.)

H e $B, \mathrm{R}$ i c hard, Der Forstschutz. 3. Aufl. Leipzig 1898-1900.

$\mathrm{H}$ i ese mann, M a r in, Lösung der Vogelschutzfrage nach Freiher $r$ in on Berlepsch. Leipzig.

$\mathrm{H}$ of $\mathrm{m}$ a $n, \mathrm{O} \mathrm{m}$ a r, Insektentötende Pilze mit besonderer Berücksichtigung der Nonne. Frankfurt a. M. 1891.

Hollrung, M., Handbuch der chemischen Mittel gegen Pflanzenkrankheiten. Berlin 1898. (Neue Auflage erscheint 1914.)

K 1 o e ck, Neue Anregung aus der forstlichen Praxis zur Bekämpfung der Nonne. Forstwiss. Zentralbl. 1910, S. $109 \mathrm{ff}$. u. 1911, S. $377 \mathrm{ff}$.

M a m e 11 e, Th., Sur l'emploi du cyanure de potassium comme insecticide souterrain. Compt. rendus Ac. Sc. Paris Bd. 150, 1910, S. 1096-1098.

M a r c ha 1, P a u1, Rapport sur les travaux accomplis par la Mission d'étude de la Cochylis pendant l'année 1911. Paris (Ch. Béranger) 1912.

Nördlinger, H., Ratgeber über Pflanzenkrankheiten und deren Bekämpfung. Flörsheim a. Main.

P a u 1 y, A.. Die Nonne in den bayerischen Waldungen 1890. Frankfurt a. M. 1891. Enthält einiges über Lichtfang.

Puster, Ein Jahrzehnt im Kampf mit dem Maikäfer. Forstw. Zentr.-Blatt 32 (1910), S. 633-649.

- Ein Maikäferkrieg. Ebenda 33 (1911), S. 577-586.

Put s che r, Neuere Erfahrungen und Urteile über die Nonnenbekämpfung. Zeit. f. Forst- u. Jagdw. 1911, S. 675-693.

- Über den Stand der Nonnenkalamität. Berichte der 53.-55. Versammlung des Sächs. Forstvereins 1909-1911.

Re iff, W., The Wilt-Disease or Flacherie of the Gypsy Moth. Boston 1911.

Rörig, Ein neues Verfahren zur Bekämpfung des Schwammspinners. Arb. Biol. Anstalt f. Land- u. Forstw. 1. Bd., 1900, S. 255-260.

Sch midt, A l ex., Die Nonne. Darstellung der Bekämpfung mit besonderer Berücksichtigung des von dem V'erfasser zur Anwendung gebrachten InfektionsVerfahrens. Ratibor 1895.

Schwangart, Fr., Das Traubenwickler-Problem und das Programm der angewandten Entomologie. Mitt. des Deutschen Weinbau-Vereins 1913.

- Thüringer „Vogeltränken“. Nat. Zeit. für Land- u. Forstw. 1912, S. 328-332.

Schwartz, M., Zur Bekämpfung der Raupenplagen. Arb. aus der Kais. Biol. Anstalt f. Land- u. Forstwirtschaft Bd. VII, 1910, S. 521-526.

- t'ber einige neue und alte Mittel zur Bekämpfung schädlicher Insekten. Ebenda Bd. VI, 1908, S. 493-497. 
Schwartz, M., Erprobte Mittel gegen tierische Schädlinge. Flugblatt Kais. Biol. Anstalt p. 46.1909.

S edlaczek, W., Versuche mit verschiedenen Arten von Fangbäumen zur Bekämpfung der Borkenkäfer. Centr. f. d. gesamte Forstwesen. XXXIV (1908). S. $45-73$.

Sihler, Uber das Auftreten der Fichtengespinstblattwespe in den Fichtenwaldungen Oberschwabens. Silva 1913. Nr. 31 (Leimring gegen Lyda hypotrophica).

Vil1, Der Kampf gegen die Engerlinge in den Pflanzgärten. Nat. Zeitschr. f. Forst- u. Landw. 6. Jahrg. 1908, S. 280-284.

W a h 1, B r., Die Bekämpfung der Blattläuse. Monatshefte f. Landwirtschaft 1913.

W e i $B$ w a ng e, Versuche über das Abbaumen der Nonnenraupen und die Wirkung des Leimringes. Tharandter Forstl. Jahrb. Bd. 64 (1913), S. 160-177. 
Kapitel VIII.

\section{Allgemeine Übersicht über das System der Insekten. \\ Mit einem Anhang: \\ Anleitung zur Anlegung einer forstentomologischen Sammlung.}

\section{Das System der Insekten.}

Es ist für den Forstmann durchaus notwendig, daß er auch mit der Klassifizierung der Insekten einigermaßen vertraut ist. Denn nur dann wird er imstande sein, sich in der überaus mannigfaltigen Gesellschaft der ihm entgegentretenden Insektenformen zurecht $\mathrm{zu}$ finden und $\mathrm{zu}$ einer richtigen Bestimmung der ihn interessierenden Arten zu gelangen. Vor allem muß er wissen, in welche Ordnungsgruppe resp. Ordnung ein Insekt gehört. Der größte Teil der im Walde auftretenden Formen wird ja in dieser Beziehung keine Schwierigkeiten bereiten; wird doch jeder einen Schmetterling von einem Käfer unterscheiden können. Immerhin kommen aber auch eine ganze Anzahl Formen vor, welche trotz großer äußerer Ähnlichkeit ganz verschiedenen Ordnungen angehören. Ich erinnere nur z. B. an den Hornissenschwärmer, der in seiner Form und noch mehr in seiner Färbung stark an eine Hornisse erinnert, oder an manche Fliegen, die in ihrer Färbung und Behaarung sehr WVespen oder Hummeln ähneln, oder an die kleinen Formen der Phryganiden (Köcherfliegen), die oft Kleinschmetterlingen zum Verwechseln ähnlich sind usw. In solchen Fällen muß man die charakteristischen Merkmale der einzelnen Ordnungen kennen, um vor Verwechselungen und Irrtümern sich zu sichern.

Im folgenden sei eine kurze Übersicht über die Hauptkategorien (Ordnungsgruppen) der Insektenklasse gegeben. Auf die Unterkategorien (Ordnungen, Familien usw.) soll dagegen hier nicht weiter eingegangen werden, da diese im speziellen Teil bei jeder Ordnungsgruppe eingehend behandelt werden sollen.

Die Klassifizierung der Insekten hat im Laufe der Zeiten verschiedene wesentliche Wandlungen durchgemacht, und zwar im Sinne einer immer weitergehenden Teilung. In manchen heute noch im Gebrauch befindlichen älteren Lehrbüchern (wie z. B. im „Leunis“) findet man eine Einteilung der Insekten in folgende 9 Ordnungen: Thysanuren, Orthopteren, Neuropteren, Coleopteren, Strepsipteren, Hymenopteren, Lepidopteren, Dipteren und Hemipteren. Eingehende Studien anatomischer und entwicklungsgeschichtlicher Art haben aber dargetan, dab in diesen Ordnungen vielfach recht 
heterogene Gruppen vereinigt waren. Besonders galt dies für die Ordnung der Orthopteren, die in eine Anzahl gesonderter Ordnungen zerlegt werden mußte; auch die Ordnung der Neuropteren erwies sich als unnatürlich usw. Es ist das Verdienst Fr. Brauers, das lange Zeit geltende alte System von den gröbsten Fehlern gereinigt zu haben. Er setzte an Stelle des alten Systems ein neues, nach welchem die Insekten in zwei Unterklassen (die Apterygogenea und die Pterygogenea) und 16 Ordnungen zerlegt wurden. Die starke Vermehrung der Ordnungen ist vor allem in der Aufteilung der alten Ordnung der Orthopteren in nicht weniger als 7 Ordnungen (Dermapteren, Ephemeriden, Odonaten, Plecopteren, Orthoptera genuina, Corrodentia und Thysanoptera) begründet, ferner in der Aufteilung der Neuropteren in drei Ordnungen, die Neuroptera s. str., die Panorpatae und die Trichopteren.

Das Brauersche System bedeutete einen wesentlichen Fortschritt bezügl. der natürlichen Gruppierung und fand auch fast allgemeine Annahme. Und auch heute noch bildet es die Grundlage des Insektensystems, wenn auch weiteres Eindringen in morphologische Details und einige überraschende Entdeckungen neuer Insektenformen (die Proturen) noch manche Änderungen notwendig gemacht haben. Es ist vor allem Handlirsch, der sich um die weitere Ausgestaltung des Systems verdient gemacht hat; daneben sind noch Börner, Prell u. a. als Reformatoren tätig gewesen.

Wir werden uns hier in der Hauptsache an das Handlirschsche System (mit der Prellschen Modifikation) halten, wobei wir jedoch - dem praktischen Zwecke des Buches entsprechend - die 22 Ordnungen in eine Anzahl Ordnungsgruppen zusammenfassen, um eine leichtere Handhabung und größere Übersichtlichkeit zu erlangen. So stellen wir unter die Ordnungsgruppe der Orthopteroidea 7 Ordnungen, unter die Ordnungsgruppe der Lepidopteroidea 3 Ordnungen usw. Wir kommen auf diese Weise zu 9 Ordnungsgruppen, die zum Teile den alten Ordnungen entsprechen (z. B. die Hymenopteroidea den Hymenopteren), zum Teil aber eine mehr oder weniger veränderte Zusammensetzung aufweisen (so sind z. B. die Pediculiden jm neuen System nicht mehr bei den Wanzen, sondern bei den Orthopteren untergebracht, oder die Trichopteren und die Panorpaten nicht mehr bei den Neuropteren, sondern mit den Lepidopteren zu einer Ordnungsgruppe zusammengestellt usw.).

Als Grundlage zur Einteilung dienen die verschiedensten Merkmale: vor allem die Art der postembryonalen Entwickung (Mctamorphose), ferner das Fehlen oder der Besitz von Flügelı, die Beschaffenheit der Flügel, die Mundwerkzeuge, die Abdominalanhänge, das Verhälnis der drei Brustringe zueinander und verschiedener anatomischer Merkmale, wie Zahl der Malpighischen Gefäße usw.

Die Berücksichtigung aller dieser Merkmale führt zur Aufstellung folgender Kategorien der Insektenklasse.

\section{Unterklasse: Anamerentoma.}

Verlassen das Ei nicht mit vollständiger Segmentzahl; Mundteile vollständig in die Kopfkapsel verlagert („entotroph“); stets ungeflügelı, am Abdomen ohne Styli und Cerci. Hierher die Ordnungen: Protura und Collembola. 


\section{Unterklasse: Holomerentoma.}

Verlassen das Ei mit vollständiger Segmentzahl, Mundgliedmaßen meist frei („ektotroph“); umfaßt die meisten Insekten.

\section{Ordnungsgruppe: Thysanuroidea.}

Stets flügellos; meist zarthäutige Tiere mit langen Fühlern, und wohlausgebildeten Cerci und Styli am Abdomen. Hierher die Ordnungen: Entognatha (Campodea, Japyx) und Ectognatha (Machilis und Lepisma).

\section{Ordnungsgruppe: Orthopteroidea.}

Mundgliedmaßen meist beißend (selten saugend); die beiden Flügelpaare entweder ungleich (Vorderflügel pergamentartig), oder aber gleichartig, oder ganz fehlend; Prothorax meist groß und frei beweglich; Cerci meist vorhanden, Larven stets primär; postembryonale Entwicklung eine Epimorphose. Hierher die Ordnungen: Orthoptera (Feld- und Laubheuschrecken und Grillen), Phasmodea (Stabheuschrecken), Dermaptera (Ohrwürmer), Thysanoptera (Blasenfüße), Oothecaria (Schaben und Fangheuschrecken), Corrodentia (Termiten, Holzläuse, Federlinge und echte Läuse).

\section{Ordnungsgruppe: Amphibiotica.}

Mundgliedmaßen beißend; zwei Paar gleichartiger häutiger netzadriger Flügel, zahlreiche Malpighische Gefäße, Abdomen mit Cerci, Larven wasserbewohnend, mit Tracheenkiemen. Hemimetabole oder prometabole Entwicklung. Hierher die Ordnungen: Ephemeridae (Eintagsfliegen), Plecoptera (Uferfliegen) und Odonata (Libellen).

\section{Ordnungsgruppe: Neuropteroiden.}

Mundteile beißend, Prothorax wohl entwickelt und frei, zwei Paar gleichartiger häutiger und meist auch gleich großer Flügel; Larven räuberisch lebend, z.um Teil mit Saugzangen versehen. Holometabole Entwicklung, mit freier Puppe. Hierher die Ordnungen: Neuroptera (Ameisenlöwen, Florfliegen, Kamelhalsfliege).

\section{Ordnungsgruppe: Coleopteroidea.}

Mundwerkzeuge beißend, Vorderflügel meist zu Flügeldecken umgebildet; Hinterflügel gewöhnlich unter den Vorderflügeln eingefaltet (oder fehlend), Prothorax gut entwickelt und frei beweglich. Vier oder 6 Malpighische Gefäße. Holometabole Entwicklung nit freier Puppe. Hierher die Ordnungen: Coleoptera (Käfer) und Strepsiptera (Stylopiden).

\section{Ordnungsgruppe: Hymenopteroidea.}

Mundwerkzeuge beißend oder leckend; die zwei Flügelpaare gleichartig, häutig, (oder auch fehlend), Hinterflügel kleiner als Vorderflügel; Prothorax klein, Pronotum meistens mit den Mesonotum verwachsen, zahlreiche (mindestens 6 Malpighische) Gefäße. Holometabole Entwicklung mit freier Puppe. Ilierher die Ordnung: Hymenoptera (Hautflügler, Immen). 


\section{Ordnungsgruppe: Lepidopteroidea.}

Mundteile oft stark rückgebildet (beißend oder saugend); Prothorax klein, frei oder mit dem Mesothorax verwachsen, Metathorax kleiner als der Mesothorax oder beide gleich groß. Flügel meist wohlausgebildet, nur selten fehlend, gleichartig, häutig, unbeschuppt oder meist beschuppt. Larven raupenähnlich. Holometabole Entwicklung mit freier oder bedeckter Puppe. Hierher die Ordnungen: Panorpatae (Scorpionsfliegen), Trichoptera (Köcherfliegen) und Lepidoptera (Schmetterlinge).

\section{Ordnungsgruppe: Dipteroidea.}

Mundteile saugend oder stechend; nur die Vorderflügel wohlausgebildet, die Hinterflügel zu kleinen Schwingkölbchen rückgebildet; Prothorax meist klein; Larven stets ohne Beine, entweder mit Kopfkapsel oder ohne solche. Holometabole Entwicklung mit freier (resp. Tönnchenpuppe) oder bedeckter Puppe. Hierher die Ordnungen: Diptera (Zweiflügler, Fliegen) und Suctoria (Flöhe).

\section{Ordnungsgruppe: Hemipteroidea.}

Mundteile stechend und saugend; Prothorax groß, gewöhnlich frei; Flügel zuweilen ganz fehlend, zuweilen nur im weiblichen Geschlecht, meist vier (selten zwei) Flügel vorhanden, entweder gleichartig oder die Vorderflügel als Halbdecken. Entwicklung Epimorphose oder Hemimetabolie. Hierher die Ordnung: Hemiptera (Wanzen, Cicaden, Pflanzenläuse und Blattflöhe).

Um die charakteristischen Merkmale der einzelnen Ordnungsgruppen deutlicher hervortreten zu lassen, sind im folgenden die 9 Ordnungsgruppen der Holomerentoma in Form einer dichotomischen Tabelle angeordnet, wobei aber gleich zu bemerken ist, daß bei der Aufstellung der Charakteristik manche aberrante Formen unberücksichtigt geblieben sind, zumal solche, die für den Forstmann an und für sich kein Interesse besitzen.

\section{(Siehe Tabelle S. 397.)}

Was die hier eingehaltene Reihenfolge betrifft, so soll diese keineswegs etwa die phylogenetische Entwicklung ausdrücken. Die verschiedenen Ordnungsreihen sind vielmehr als von einem gemeinsamen Urahnen ausgehend zu betrachten, die ihre Entwicklung nebeneinander und unabhängig voneinander genommen haben. Alle Ordnungen resp. Ordnungsreihen sind daher, um mit Handlirsch zu reden, ungefähr gleichwertig und gleichweit voneinander entfernt; man kann sie also stellen, wie es einem beliebt.

Wir werden im speziellen Teil (aus praktischen Gründen) folgende Anordnung treffen: der 2. Band soll die Thysannroidea, Orthopteroidea, Amphibiotica, Neuropteroidea und die Coleopteroidea behandeln, der 3. Band die Lepidopteroidea und der 4. Band endlich die noch verbleibenden Hymenopteroidea, Dipteroidea und Hemipteroidea. 
Tabelle über die Ordnungsgruppen der Holomerentoma.

Stets ungeflügelt (primär flügellos); die drei Thoraxsegmente frei, annähernd einander gleich; meist mit mehreren Paaren Styli Thysanuroidea.

Epimor-

phose

(s. lat.).
( Mundgliedmaßeu meist beißend. Nur selten (Läuse) stechend und saugend, wobei die Unterlippe zu einem Bohrstachel umgebildet ist (während Mandib. und Max. rückgebildet sind)

Orthopteroidea. flügelt, durch sekundäre Rückbildung der Flügel; höchstens ein Paar Styli vorhanden.

\section{Mundgliedmaßen stets stechend und saugend; Schnabel (aus Ober- und Unterlippe gebildet) mit 4 aus den umgebildeten Mandibeln $u$. Maxillen bestehenden Stechborsten}

Hemipteroidea (partim).

\section{Hemi- oder Prometa- bolie}

Holometabolie
Mundgliedmaßen beißend, Larven wasser-, Imagines luftlebend; Larven mit Tracheenkiemen (Wasseratmung)

Amphibiotica.

Mundgliedmaßen stechend und saugend; Larven wie die Imagines, für die Luftatmung organisiert

Hemipteroidea (partim).

Vorderflügel zu Elytren umgebildet (selten, bei Strepsipteren, rückgebildet)

Coleopteroidea.

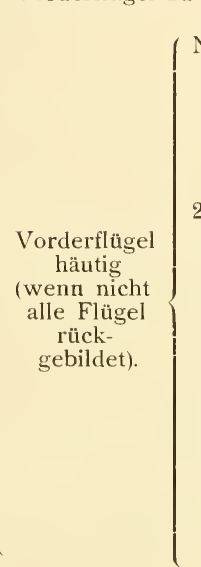

Nur die Vorderflügel wohl ausgebildet, Hinterflügel zu kleinen "Schwingkölbchen" reduziert. Selten (Lausfliegen, Flöhe) vollkommen flügellos. Mundgliedmaßen saugend oder stechend. Larven stets völlig beinlos und vielfach auch ohne deutliche Kopfkapsel

Dipteroidea.

$2 \begin{gathered}\text { Paar häutige } \\ \begin{array}{c}\text { Flügel vorhanden } \\ \text { (oder beide Paare }\end{array}\end{gathered}\left(\begin{array}{c}\text { Prothorax wohl ent- } \\ \text { wickelt und frei; die } \\ 4 \text { Flügel annähernd } \\ \text { gleich groß } \\ \text { Neuropteroidea. }\end{array}\right.$
rückgebildet), Larven entweder beinlos (dann aber stets mit Kopfkapsel) oder aber mit Beinen, und zwar außer Brustbeinen vielfach auch noch mit Bauchbeinen.

\section{maßen} beißend oder leckend.
Prothorax klein, Pronotum mit dem Mesonotum verwachsen; Hinterflügel kleiner als die Vorderflügel Hymenopteroidea.

Mundgliedmaßen meistens saugend (Saugrüssel); nur selten beißend, dann aber der Kopf schnabelförmig verlängert; Larven stets mit Beinen

Lepidopteroidea.

\section{Die Nomenklatur.}

Die Nomenklatur ist das Schmerzenskind der Zoologen. Es sind im Laufe der Zeiten bezügl. der Namengebung der Tiere eine Reihe von Fehlern gemacht worden; man suchte dieselben wieder gut zu machen, gelangte aber dabei auf unrichtige Wege, so daß wir in eine Konfusion hineingeraten sind, die ihresgleichen sucht und die eine ernste Gefahr für unsere Wissenschaft bedeutet. Sind wir doch heute bereits vielfach an dem Punkte angelangt, daß jeder eine andere zoologische Sprache spricht, so daß wir uns untereinander kaum mehr verstehen. Der eine spricht von Noctua piniperda, der andere von Panolis piniperda und der dritte ron Panolis griseovariegata drei verschiedene Namen für ein und dasselbe Tier, die Kieferneule. Oder der eine spricht von Ips und meint einen Nitiduliden, der andere spricht 
ebenfalls von $I p s$, meint aber einen Borkenkäfer - also ein und derselbe Name für zwei verschiedene Tiere, usw. - Und nehmen wir verschiedene Lehrbücher und systematische Spezialwerke heran, so finden wir auch da das gleiche Tier vielfach mit verschiedener Benennung bedacht.

Die Ursache zu dieser beispiellosen Konfusion ist in verschiedenen Momenten zu suchen: Bekanntlich benennen wir die Arten nach der von Linné eingeführten binären Nomenklatur, d. h. die wissenschaftliche Bezeichnung der Art (Spezies) setzt sich zusammen aus zwei lateinischen Namen, einem Gattungs- und einem Artnamen, welche sich gewissermaßen verhalten wie Familien- und Vorname bei den Menschen. ${ }^{1}$ ) Hinter den Artnamen ist stets der Name desjenigen Autors zu setzen (gewöhnlich in Abkürzungen), welcher dem betreffenden Tier diese Bezeichnung gegeben hat; also z. B. Melolontha vulgaris Fab. (oder einfach $F$.) bedeutet, daß Fabricius dem Maikäfer diesen Namen gegeben hat.

Würden nun diese Namen stets richtig angewendet, d. h. stets nur für das Tier gebraucht worden sein, das der ursprüngliche Autor damit meinte, und würde stets auf die bereits beschriebenen Arten Rücksicht genommen worden sein, so daß jedes Tier nur einmal beschrieben worden wäre, so gäbe es keine Nomenklaturstreitigkeiten und wäre alles klar. Dem ist jedoch leider nicht so! Ëinmal sind sehr häufig von späteren Autoren die alten Namen falsch angewendet worden und sodann ist mindestens ebenso häufig eine Art von verschiedenen Autoren immer wieder unter anderem Namen beschrieben worden. Als bekanntes Beispiel für den ersteren Fall sei die Benennung des großen braunen Rüsselkäfers genannt.

Diesen hatte Linné Curculio abietis getauft, dagegen den einen kleinen braunen Rüsselkäfer Curculio pini. Ratzeburg verwechselte nun diese Tatsache, und bezeichnete den großen braunen Rüsselkäfer als Curculio pini, den kleinen dagegen als Curculio abietis. Sobald nun dieser Irrtum bemerkt wurde, mußte derselbe natürlich korrigiert werden, obgleich vermöge der ungemein weiten Verbreitung der Ratzeburgischen Werke der Name Curculio pini sich bereits allenthalben in der Forstwelt für den berüchtigten Kulturverderber eingebürgert hatte. - Nun kommt in diesem Falle noch etwas anderes hinzu: Die Gattung Curculio wurde mit der Zeit durch fortwährende Neuentdeckungen so umfangreich, daß sich in $\mathrm{ihr}$ ohne weiteres verschiedene natürliche Gruppen ergaben, welche von späteren Autoren in den Rang von besonderen Gattungen erhoben wurden. So hat Schönherr von der Gattung Curculio die Gattung Hylobius abgetrennt mit den Merkmalen des Curculio abietis, und Germar die Gattung Pissodes mit den Merkmalen des Curculio pini, und nun hatte der große braune Rüsselkäfer'den Namen Hylobius abietis zu führen und der kleine braune Rüsselkäfer den Namen Pissodes pini, beide natürlich mit dem Autornamen der Art, also L. (Linné).

1) Neuerdings wird vielfach auch die trinäre Nomenklatur angewendet, indem die Abarten (Varietäten, geographische Rassen) einfach dem Artnamen angefügt werden, z. B. Lucanus cerous capreolus Fueßl. Wir werden diesem Brauche nicht folgen, sondern die Varietäten durch das Zeichen „var." von dem Artnamen abtrennen, und also in obigem Beispiel schreiben Lucanus cervus L. var. capreolus Fueßl. 
In solchen Fällen, wo ein Artname unter eine andere Gattung gestellt wird, wie in den ebengenannten Fällen, wird der Autorname neuerdings vielfach auch in eine Klammer gesetzt; also Hylobius abietis (L.).

Nicht überall liegen die Verhältnisse so einfach, wie hier. Oft ist es sehr schwierig, aus der kurzen Beschreibung zu ersehen, welches Tier der betr. Autor eigentlich gemeint hat. Wenn die Originalexemplare (die sog. Typen) noch vorhanden sind, so läßt sich darnach noch eine bestimmte Entscheidung treffen; wo die Typen jedoch nicht mehr vorhanden sind, da wird man event. überhaupt zu keiner sicheren Entscheidung mehr kommen können, und dann beginnen die Zweifel und Unsicherheiten, die zu Streitigkeiten und Verwirrung führen.

Dazu kommt das zweite der oben genannten Momente, nämlich, daß eine und dieselbe Art von mehreren Autoren unter verschiedenen Namen beschrieben wurde. Für diese Fälle wurde das sog. Prioritätsgesetz aufgestellt, das auf dem 6. Internationalen Zoologenkongreß in Bern (im Jahre 1904) folgende Fassung erhielt (Art. 25 der Internationalen Regeln der zoologischen Nomenklatur):

Gültiger Name einer Gattung oder einer Art kann nur der Name sein, mit dem sie zuerst bezeichnet worden ist, unter der Bedingung,

a) daß dieser Name veröffentlicht und definiert oder angedeutet worden ist, und

b) daß der Autor den Grundsätzen der binären Nomenklatur folgte.

Als Datum für das Inkrafttreten des Prioritätsgesetzes wurde das Jahr 1758 festgesetzt, in welchem die 10. Ausgabe des Linnéschen "Systema Naturae" erschienen ist.

Wo also eine Art mehrmals beschrieben wurde, ist darnach lediglich der älteste Name zu verwenden, während die späteren Namen als sog. Synonyme darunter gesetzt werden, z. B.:

Cerambyx heros Scopol, oder

\section{Cerambyx cerdo $L$.}

\section{Callidium dilatatum Payk, Callidium aeneum Deg. aurichalceum Gmel., venosum Eschsch., variabile $F$.}

D. h. im 1. Beispiel ist der Name Cerambyx cerdo L. der allein gültige, C. heros Scop. dagegen Synonym; und im ¿2. Beispiel ist Callidium aeneum Deg. der allein gültige Name, während alle übrigen 4 Synonyme darstellen. Bei vielen Arten ist die Zahl der Synonyme noch wesentlich größer, und wenn man die vielbändigen Katologe der verschiedenen Insektenordnungen durchsieht, so wird einem bald klar, daß weitaus der größte Raum von den Synonymen eingenommen wird.

Mit dem Prioritätsgesetz glaubte man, eine klare Grundlage für die zoologische Nomenklatur geschaffen zu haben und mit Hilfe desselben in einiger Zeit zu einer einwandfreien, für alle Zeiten festgelegten Namengebung zu gelangen. Die Erfahrung lehrte uns aber das Gegenteil. Kaum hatte einer geglaubt, den ältesten Namen gefunden zu haben, so kam schon ein anderer, der mit 
einem noch älteren Namen aufwartete, bis auch dieser wieder mit einem noch ehrwürdigeren Namen geschlagen wurde usw. Die Folge davon war, daf3 man in jeder neuen Auflage eines Werkes andere Namen vorfand. Es hat sich mit der Zeit die Prioritätsjagd zu einer Art Sport herausgebildet, der manchem als Selbstzweck und der Inbegriff zoologischer Weisheit erschien. Diese Prioritätsschnüffler vergaßen ganz, daß die Nomenklatur doch hauptsächlich ein Verständigungsmittel darstellen soll, um uns auf bequeme und kurze Weise über die einzelnen Tierformen unterhalten zu können; ihnen schien die Nomenklatur vielmehr dazu geeignet, möglichst schwierige Rätselaufgaben daraus zu bilden, in der Meinung, daß der wissenschaftliche Zoologe keine größeren Aufgaben hat, als Rätsel zu lösen.

Es hat denn auch in der letzten Zeit eine starke Bewegung eingesetzt, dem unvernünftigen Treiben der extremen Prioritätsjäger ein Ende zu bereiten, indem man wenigstens die Zulassung von Ausnahmen von dem Gesetz erstrebte. Was hat es doch für einen Zweck, $100 \mathrm{Jahr}$ alte oder noch ältere jedem geläufige und verständige Namen durch neue zu ersetzen, nur weil gefunden wurde, daß das Tier noch einige Jahre früher von einem anderen (weniger bekannten) Autor unter einem anderen Namen beschrieben worden war. Die Hauptsache ist doch eine stabile Nomenklatur. Von dieser Überlegung ausgehend, hat man den Vorschlag gemacht, daß man die gebräuchlichsten alteingebürgerten Namen von dem Prioritätsgesetz unabhängig machen und sie als ein für allemal feststehend proklamieren sollte, gleichgültig, ob später noch ein älterer Name entdeckt werde oder nicht. Man schlug vor, eine Liste solcher außerhalb des Gesetzes stehender Namen aufstellen. Es wäre dies jedenfalls ein sehr guter Ausweg gewesen, aus der großen Nomenklaturkalamität herauszukommen. Es würde auch sicherlich gelungen sein, sich über die Arten, die eine solche Ausnahmestellung genießen sollten, zu einigen. - Leider ging jedoch dieser Vorschlag auf dem letzten Internationalen Zoologenkongreß in Monaco (1913) nicht durch; es wurde aber wenigstens so viel erreicht, daB nunmehr Ausnahmen zulässig sind. So braucht von jetzt ab das Prioritätsgesetz keine Anwendung zu finden, wenn ein Name für nur eine Gattung 50 Jahre lang bis 1890 in wissenschaftlichen Arbeiten, Katalogen u. a. gebraucht worden ist; und ferner, wenn der Name, der nach dem Prioritätsgesetz der älteste ist, 20 Jahre keinen Eingang in die wissenschaftliche Systematik gefunden hat. - Zweifellos wird die Bewegung damit noch nicht zu Ende sein; vor allem sollte man darauf hinarbeiten, daß man sich doch noch zu dem obigen Ausweg entschließen möchte, nämlich Listen von Tiernamen aufzustellen, die als absolut unveränderlich zu gelten haben. Nur damit dürften wir allmählich zu einer einigermaßen konstanten und übereinstimmenden Nomenklatur, wenigstens für die bekanntesten und wichtigsten, in unseren Lehrbüchern stets wiederkehrenden Tierarten gelangen.

Was unsere Stellung zur Nomenklaturfrage betrifft, so werden wir in Hinblick darauf, daß das Werk für die Praxis bestimmt ist, bestrebt sein, so weit es irgend geht, an den alt eingebürgerten Namen festzuhalten, vor allem bezügl. der Artnamen. Nur wo zwingende Gründe, z. B. Aufdeckung einer irrtümlichen Anwendung, vorliegen, werden wir uns entschlieBen, den 
in der Praxis geläufigen Artnamen durch einen neuen zu ersetzen. Für die Praxis kommt ja der Artname auch in erster Linie in Betracht, da wir vielfach nur ihn zur Bezeichnung eines Schädlings heranziehen; so sprechen wir z. B., wenn es sich um Borkenkäfer handelt, allgemein nur vom „typographus" oder "calcographus", oder wo es sich um Kleinschmetterlinge handelt, vom "buoliana" oder "resinella" usw. - Bezüglich der Gattungen werden wir den Begriff oft weiter fassen, als es in den systematischen Spezialwerken geschieht. Jedenfalls wollen wir die auf recht geringen Unterschieden beruhende Genera-Aufteilung, wie sie in neuerer Zeit vielfach geübt wird, und die mitunter soweit geht, daß beinahe auf jede Art oder jede zweite Art eine Gattung kommt, nicht mitmachen. Der Gattungsbegriff, wie er in diesem der Praxis dienenden Werke zur Anwendung kommt, deckt sich in manchen Fällen mit dem Begriff der Unterfamilie oder sogar auch Familie in systematischen Spezialwerken; so werden wir z. B. für alle Lipariden, die in den Spezialwerken in eine Reihe verschiedener Gattungen zerlegt sind, den Gattungsnamen "Liparis" gebrauchen usw. Wir werden aber stets Sorge tragen, sowohl bezügl. der Gattungen wie der Arten, daß auch die neuesten Namen - gewöhnlich in Klammern - beigefügt werden und im Register zu finden sind, damit auch der der neuesten Nomenklatur und Systematik huldigende Forscher sich zurechtfinden kann.

\section{Anhang.}

\section{Anleitung zur Anlegung einer forstentomologischen Sammlung.}

Nur derjenige wird den Aufgaben der Forstentomologie vollkommen gerecht werden können, der sich durch praktische Übung einen scharfen entomologischen Blick erworben hat. Am besten kann dies dadurch erreicht werden, daß der Forstmann sich selbst eine forstentomologische Sammlung anlegt. Dabei wird sein Interesse für die Insekten wachsen, je vollkommener die Sammlung wird. Und event. kann dabei auch eine spezielle Insektengruppe ihn so fesseln, daß er dieselbe zu seinem Spezialstudium wählt und er so auch an der Förderung der Wissenschaft aktiren Anteil nimmt. Der Fälle sind ja nicht wenig, in denen praktische Forstwirte durch Bearbeitung einer Spezialgruppe der forstentomologischen Wissenschaft wesentliche Dienste geleistet haben.

\section{Das Sammeln von Forstinsekten.}

Das Sammeln von Insekten läßt sich nicht aus Büchern lernen, es gehört dazu vor allem praktische Erfahrung und Übung. Am schnellsten und besten wird man die Sammelkunst dadurch sich aneignen, daß man mit einem erfahrenen Sammler sich in Verbindung setzt und möglichst viel Exkursionen mit ihm gemeinsam macht. Es hat daher auch nicht viel Zweck, hier jede einzelıe Sammeltätigkeit bis ins Detail zu schildern; es dürfte genügen, wenn die Hauptregeln, die beim Sammeln zu beachten sind, hier angeführt werden.

Zunächst einige Worte über die Ausrüstung: Wer auf eine forstentomologische Sammelexkursion ausgeht, hat sich mit einer Anzahl von 
Sammelutensilien zu versehen, von denen hauptsächlich folgende in Betracht kommen:

ein Stemmeisen mit Hammer

ein kräftiges Messer

eine Säge (der Bequemlichkeit halber eine $\int$ Rinden- und Holzinsekten, zusammenklappbare)

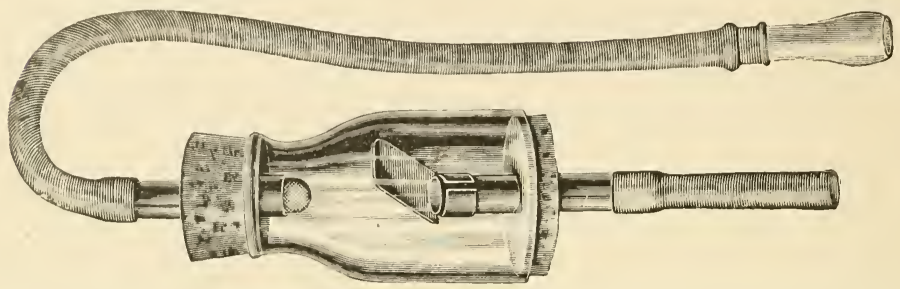

Hig. 236. Exhaustor. Sammelglas zum schnellen und sicheren Einsammeln der Insekten aus dem Klopfschirm, aus Fraßgängen usw. (Katalog von Winkler \& Wagner, Wien XVIlI, Dittesgasse 11.)

ein Klopfschirm, zum Abklopfen der auf Bäumen und Sträuchern lebenden Insekten;

ein Insektenfangnetz, zum Fangen der fliegenden Insekten;

eine Pinzette | zum Ergreifen und Aufnehmen kleiner und kleinster ein Pinsel $\mathfrak{j}$

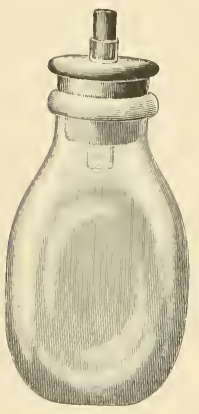

$u$

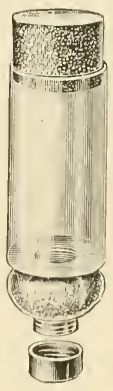

b

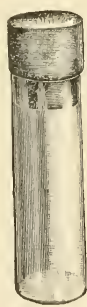

c

Fig. 237. Verschiedene Tötnngsgläser. a Tötungsglas mit zwei flachen Seiten (zum bequemeu Einstecken) zum Töten von Insekten mit Äther oder Schwefeldioxyd. Das Glas ist für Käfer usw. mit grobeu sägespänen oder Papierschnitzel oder Holzwolle etwa zur Hälfte zu füllen Das kleine Röhrchen im Kork dient zum Einwerfen kleiner Insekten. $b$ Tötuugsglas mit Kugel. Die Kugel, die von außen zugänglich ist, wird mit Watte gefüllt, auf die Ather getropft wird. Es kann auch Zyaukali mit Gips in die Kngel gegossen werden. c Präparatenglas. (Katalog von Winkler \& Wagner.)

Insekten;

(an Stelle der Pinzette und des Pinsels kann auch ein sog. „Exhaustor" [Fig. 236] benutzt werden, mit dessen Hilfe man durch Saugwirkung die kleinen Insekten am schnellsten, mühelosesten und sichersten aufnehmen kann);

verschiedene Tötungsgläser (Fig. 237), und zwar: einige zur trockenen Tötung mit Essigäther, Zyankali oder Schwefeldioxyd (für empfindliche, fein behaarte Insekten usw.), zum Teil mit Fließpapierschnitzel o. dgl. gefüllt, z. T. (Schmetterlinge) ohne solche; auBerdem eine größere Anzahl kleinerer, möglichst starkwandiger sog. Präparatengläser mit schwachem Alkohol (50 bis $70 \%$ ) gefüllt (zur Aufnahme weniger empfindlicher Käfer, Larven usw.); 
eine Anzahl leere Präparatengläser (zur lebenden Aufbewahrung gesammelter Kleinschmetterlinge);

eine Anzahl Insektennadeln;

eine Blechschachtel mit Torfeinlage (zum Einstecken getöteter

größerer Schmetterlinge);

einige größere und kleinere Blechschachteln (Raupenschachteln);

einige größere und kleinere Leinwandsäckchen;

ein ca. $1 \mathrm{qm}$ großes Tuch.

Um alle diese Utensilien unterzubringen, bedient man sich am besten einer Umhängetasche; oder man läßt sich seine Sammeljoppe möglichst weit machen und mit so viel Taschen versehen, als nur irgend angängig. Es dürfte sich sehr empfehlen, die gesamten Ausrüstungsgegenstände von einer Spezialfirma zu beziehen, da man dann sicher ist, wirklich brauchbare Utensilien zu einem angemessenen Preise $\mathrm{zu}$ erhalten.

Als eine der renommiertesten Firmen dieser Branche ist zu nennen: W i n k l e r \& Wagner, Naturhistorisches Institut, Wien XVIII, Dittesgasse 11, die alle auf Entomologie bezüglichen Gerätschaften in bester Konstruktion und Ausführung liefert. Des weiteren kommen in Betracht: E. A. Böt t c h e r, Berlin C. 2, Brüderstraße 15, H. K r e y e in Hannover, W. S c h 1 ü te $\mathrm{r}$ in Halle a./Saale, F. O. K ön ig in Erfurt, Johannes-Str. 72.

Begibt man sich nun, so ausgerüstet zum Sammeln in den Wald, so wird man im allgemeinen auf folgende Punkte sein Augenmerk zu richten haben: Abgestorbene, absterbende, gefällte Stämme mit Bohrmehlhäufchen, gelockerter Rinde usw. bieten Aussicht auf Holz- und Rindeninsekten; man hat sie daher genau zu untersuchen, indem man die Rinde losstößt und event. mit Säge und Meißel tiefer in das Holz eindringt. Dasselbe gilt für abgestorbene oder abgefallene Äste und Zweige, ferner für Klafterholz oder Stockholz oder Reisighaufen usw., auch für scheinbar gesunde Stämme, die Spechteinschläge oder Harzausflüsse oder Bohrmehl zeigen. Hat man nun die Käfer usw. unter der Rinde oder im Holz bloßgelegt, so nimmt man sie mit der Pinzette oder dem Pinsel (oder auch mit dem Exhaustor) auf und bringt sie in ein Tötungsglas. Handelt es sich um Borkenkäfer oder dergleichen, so kann man dieselben in eine der alkoholgefüllten Präparatengläser geben, zusammen mit den event. dabei gefundenen Larven und Puppen. Soll auch das dazugehörige Fraßstück mitgenommen werden (am besten in kleinen Säcken), so ist in das betreffende Gläschen ein kleiner Papierzettel zu geben, auf dem mit Bleistift eine Nummer zu schreiben ist, welche mit der Nummer des Fraßstückes übereinstimmt. Natürlich sind dann keine weiteren Insekten in das betreffende Gläschen zu bringen. Sind nur Larven unter der Rinde usw. zu finden und will man die Artzugehörigkeit der Larven eruieren, so ist das betreffende Aststück usw. nach Hause zu transportieren, um dort die Entwicklung vollenden zu lassen (siehe unten).

Des weiteren ist auf die Veränderung der Blätter oder der Nadeln zu achten; wo diese gelb gefärbt erscheinen oder Substanzverluste (Löcher, Scharten, Minen usw.) zeigen, ist der Urheber dieser Erscheinung zunächst auf den beschädigten Blättern und Nadeln zu suchen. Es ist dabei event. Blatt für Blatt auf der Ober- und Unterseite genauestens zu untersuchen, oder 
aber man kann auch den Klopfschirm zu Hilfe nehmen und die befallenen Äste in denselben abklopfen. Es wird dabei natürlich alles mögliche in den Schirm kommen; doch wird der einigermaßen Vertraute keine großen Schwierigkeiten haben, die verschiedenen Insekten mit den Blattbeschädigungen in den richtigen Zusammenhang zu bringen. Bei dem Sammeln mit Klopfschirm empfiehlt es sich, für die verschiedenen Baumarten verschiedene Tötungsgläser zu benützen, so daß die von Fichten oder Kiefern oder Lärchen usw. geklopften Insekten getrennt werden.

Ist der Urheber der Blattbeschädigung nicht mehr auf den Blättern selbst $z u$ finden, so ist daran zu denken, daß seine Fraßzeit vielleicht schon vorüber und er in ein anderes Entwicklungsstadium eingetreten ist. So kann sich die Raupe bereits in die Puppe verwandelt haben; daher sind alle für die Verpuppung in Betracht kommenden Stellen in der Umgebung der Beschädigung abzusuchen, also Astwinkel, Rindenritzen und vor allem die Bodendecke, in der ja eine ganze Reihe von Insekten sich verpuppen. Die Entwicklung des Schädlings kann aber noch weiter gediehen sein, es kann bereits der Falter ausgekommen und dieser zur Eiablage geschritten sein. Es ist daher auch auf die eventuellen Eigelege an den Blättern, Nadeln oder am Stamm zu achten.

Das Vergilben der Nadeln und Welken der Blätter deutet oft auch besonders bei jungen Pflanzen - auf Wurzelinsekten hin. Der Verdacht auf solche wird um so größer sein, wenn an dem oberirdischen Teil der Pflanze keine Schädlinge zu finden sind. Um der eventuellen Wurzelinsekten habhaft zu werden, reißt man die betreffenden Pflänzchen aus und untersucht die Wurzeln auf die event. daran sitzenden Insekten. Um nichts zu übersehen, klopft man die Wurzeln am besten auf ein ausgebreitetes Tuch aus.

Ferner ist auch auf Wachstumshemmungen oder Deformationen der Pflanzen oder Gallenbildungen zu achten. In den meisten Fällen wird man in den betreffenden Pflanzenteilen, soweit sie von dem Schädling noch nicht verlassen sind, Larven finden. Um die Imago zu erhalten, wird man daher gut tun, die deformierten Teile oder die Gallen, soweit es möglich ist, abzuschneiden und zu Hause in ein Zuchtglas zu bringen.

Kommt man gerade zu der Flugzeit eines Schädlings in den Wald, so tritt das Netz in Aktion, mit dem die an den Waldrändern fliegenden Kleinschmetterlinge oder die schwärmenden Borkenkäfer oder Blattwespen oder Ichneumonen u. dgl. gefangen werden.

Um Dämmerungs- und Nachtfalter zu erhalten, kann man auch besondere Lockmittel anwenden, von denen Licht und Köder die Hauptrolle spielen. Zum Lichtfang bediene man sich einer möglichst starken Lichtquelle. Am vorteilhaftesten ist eine Azetylenlampe, auf einem Stock mit kräftiger spitzer Zwinge befestigt, so daß er leicht festgesteckt werden kann, darunter ein weißes Tuch ausgebreitet und ferner ein zweites ebensolches Tuch in einiger Entfernung quer zum Lichtkegel ausgespannt. Von Stunde zu Stunde erscheinen andere Arten, die, wenn sie sich auf die beleuchteten Flächen niederlassen oder an ihnen entlang schwirren, mit dem Giftglas, im Fluge aber mit dem Netz gefangen werden können (Spuler). Der Lichtfang kann kombiniert werden mit dem Köderfang, der besonders für Eulen und Spanner gute 
Resultate liefert. Als Grundlage des Köders nimmt man ein Gemisch von gekochtem Bier (braunes Landbier) und Sirup, dieser Masse füge man warm Honig in kleinerer Menge (1 EBlöffel auf $1 / 2$ l) und nach dem Erkalten Amylnitrit (Apfel-, Birnenäther) bei, von diesem jedoch nur wenige Tropfen. Als Köderplätze empfehlen sich vor allem nach Süden und Westen gelegene Waldränder oder Ränder von Lichtungen und freistehende Bäume. Man säubert in Brusthöhe die Rinde an einer etwa $10 \mathrm{~cm}$ breiten und $10-20 \mathrm{~cm}$ hohen Stelle und streicht zunächst einen dicken Köder als Grundlage am späten Nachmittag auf. Später verwendet man zum Nachstreichen dünneren Köder, dem man etwas Glyzerin (1 Eßlöffel auf 1 l) zufügen kanı, damit er länger feucht bleibt. Die Anstrichstellen nehme man nicht zu dicht beieinander und beginne, namentlich im ersten Frühjahr und Herbst, nicht zu spät. - Am besten für den Licht- und Köderfang sind warme Abende bei bedecktem Himmel. Besonders gierig sind die Tiere am schwülen Abend vor warmem Regen, doch auch bei leichtem Regen ist der Fang lohnend. Bei kühler Temperatur, Tau oder starkem Winde wird sich die Mühe nicht lohnen (Spuler).

Eine besonders reiche Ausbeute endlich wird der Sammler da machen, wo zur Bekämpfung einer Kalamität Fangvorrichtungen im großen angebracht sind. So kann man in geleimten Beständen un!er den Leimringen die rerschiedensten Insekten, deren man sonst nur schwer habhaft werden kann, erbeuten; ebenso können die Fanggräben oder Fanggruben ein reiches Sammelresultat ergeben.

Die Zucht der Insekten.

Das Sammeln ist zu ergänzen durch die Zucht. Viele für den Forstmann wichtige Insekten, wie z. B. die Buprestiden, sind als Imagines draußen im Walde nur selten zu finden, während man sie zur Zucht leicht in größerer Anzahl erhalten kann. Ferner sind die draußen gefangenen Insekten, vor allem Schmetterlinge, häufig bereits stark abgeflogen, so daß sie für eine Sammlung sich nicht mehr eignen; in diesen Fällen wird man ebenfalls durch Zucht sich in den Besitz tadelloser Exemplare setzen können. Besonders wertvoll ist die Zucht für das Parasitenstudium; ist es doch größtenteils nur auf diesem Wege möglich, über die Parasiten eines Schädlings sich Klarheit zu verschaffen. Die $Z$ ucht dient aber nicht nur zur Bereicherung der Sammlung und der Feststellung der Parasiten, sondern sie gibt uns auch Gelegenheit, mit den Lebensgewohnheiten des betreffenden Insekts uns vertraut zu machen, biologische Experimente anzustellen, indem man die Raupen usw. bestimmten Bedingungen aussetzt und deren Wirkung auf jene beobachtet usw. So muß also der Forstentomologe auch mit der Praxis der Insektenzucht vertraut sein.

Handelt es sich um Holz oder Rinden bewohnende Larven, so bietet deren Zucht keine Schwierigkeiten. Wenn man die betreffenden larvenbesetzten Ast- oder Stammstücke einfach in einen passenden Behälter (aus Glas, Blech usw.) gibt und dafür sorgt, daß sie nicht zu sehr austrocknen, so werden sich die Larven gut weiterentwickeln und Imagines ergeben. Man kann die Äste usw. auch in Säcken einbinden (Pauly); es empfiehlt sich 
aber dann, die Enden der Stücke mit Paraffin zu überziehen, um die zu schnelle Verdunstung hintanzuhalten. Wenn es einem nicht darauf ankommt, die Zugehörigkeit der Imagines zu den einzelnen Fraßstücken zu ermitteln, sondern es lediglich darauf abgesehen hat, Imagines für die Sammlung zu erhalten, so braucht man die einzelnen Holz- oder Rindenstücke nicht zu separieren. Man kann in solchen Fällen alles eingetragene Material in einem gut schließenden kleinen Zimmer oder einer Kammer unterbringen und braucht dann nur und von Zeit zu Zeit die Wände, Fenster, den Boden usw. dieser sog. "Käferkammer" gründlich abzusuchen, um eine gute Ausbeute zu machen.

Raupen und Larven, die von Blättern, Nadeln usw. leben, müssen in besonderen Zuchtkästen untergebracht werden. Für kleine Raupen und besonders für die Aufzucht aus dem Ei kann man dazu kleine Einmachgläser verwenden, die oben mit Gaze zugebunden werden; für größere Raupen benützt man am besten Holzkästen, deren Seitenwände und Decke mit Gaze, am vorteilhaftesten mit Drahtgaze, bezogen sind, um Luft und Licht möglichst reichlich Zutritt zu gewähren.

Von besonderer Wichtigkeit ist bei diesen Aufzuchten die stete Versorgung mit frischem Futter. Gewöhnlich sucht man das Futter dadurch frisch zu erhalten, daß man die Zweige usw. der Fraßpflanze in ein kleines Gefäß mit Wasser steckt. Doch hat diese Methode einen gewissen Nachteil, indem durch die reichliche Aufnahme von Wasser die Nahrung in ihrer Zusammensetzung wesentlich verändert wird. Manche in den Zuchtkästen ausbrechenden Krankheiten sind vielleicht diesem Umstande zuzuschreiben. Es ist daher, wo es angängig ist, zu empfehlen, die nötige Frische des Futters durch inöglichst häufiges Wechseln zu erreichen zu suchen. Erleichtert kann diese Arbeit dadurch werden, daß man die Zeit, zu der die betr. Raupen ihre Mahlzeiten einzunehmen pflegen - die einen Raupen fressen z. B. nur des Nachts, die anderen nur in den Vormittagsstunden usw. - feststellt; dann braucht man ja nur dafür zu sorgen, daß zu diesen Zeiten frisches Futter vorhanden ist.

Ein weiteres wichtiges Moment, das bei den Zuchten zu berücksichtigen ist, ist die Reinlichkeit. In diesem Punkte kann man nicht peinlich genug sein. Der Kot, faulende Pflanzenteile usw. sind stets zu entfernen. Ferner ist scharf darauf zu achten, ob die Raupen Krankheitssymptome zeigen (Durchfall, Freßunlust, schlaffe Haltung usw.). Ist dies der Fall, so sind die Raupen sofort in andere Kästen überzuführen und zwar die gesunden getrennt von den kranken, während der alte Kasten gründlichst zu desinfizieren ist (durch Auspinseln mit Formalin).

Wenn die Raupen ausgewachsen sind und zur Verpuppung schreiten wollen, so sind sie am besten in einen besonderen Verpuppungskasten zu bringen, in dem alle für die Verpuppung in Betracht kommenden Gelegenheiten gegeben sind, also Erde zur Verpuppung im Boden, Torfabfälle, Moos, Holzstückchen usw.

Bei Raupen, Puppen usw., die überwintern, ist dafür zu sorgen, daß sie in ähnliche Verhältnisse wie in der Natur gebracht werden. Man stellt daher die betreffenden Kästen zum mindesten in ein kaltes Zimmer, besser 
noch direkt ins Freie vor das Fenster oder auf den Balkon o. dgl.; am besten stellt man den Käfig in den Garten und nimmt die Decke desselben weg, so daf. auch der Schnee Zutritt hat. In diesem Falle soll aber der Boden des Kastens ebenfalls aus Drahtgaze bestehen, damit das Wasser usw. durchlaufen kann. - Bei einer Anzahl von Raupen gelingt es allerdings, auch durch eine geeignete Behandlung die Überwinterungsperiode ganz auszuschalten, so daß die Verpuppung wesentlich früher als in der Natur stattfindet. Bei diesem sog. Treiben muß man jedoch darauf achten, daß die Raupen in feuchter Wärme (Treibhauswärme) gehalten werden; außerdem empfiehlt es sich, nur solche Raupen zum Treiben zu nehmen, welche noch nicht zur Winterruhe sich begeben und also das Fressen noch nicht eingestellt hatten.

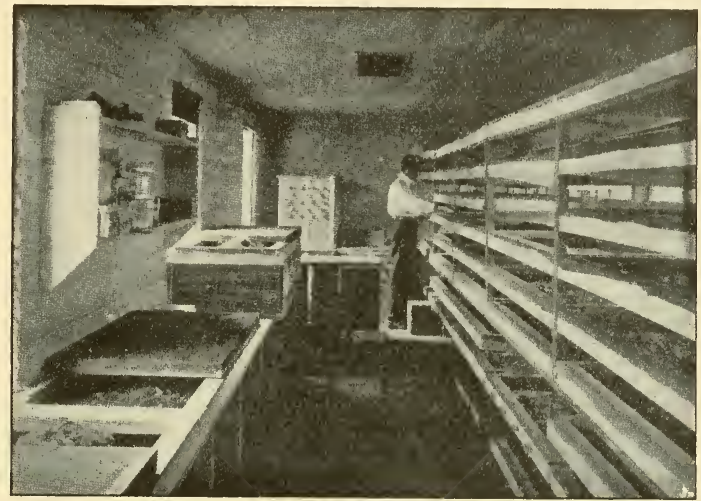

Fig. 238. Aufzucht von großen Raupenmassen in sog. Fiskeschen Raupenzuchtrahmen. Nach Fiske.

Neuerdings werden vielfach auch offene $Z$ uchtkästen (die sog. „Fiskeschen Raupenzuchtrahmen“) benützt. Dieselben bestehen aus einem ca. $10 \mathrm{~cm}$ hohen einfachen Holzrahmen, dessen oberer Rand eine nach innen vorspringende Leiste trägt; auf der Unterseite dieser Leiste ist Raupenleim aufgetragen, der das Entweichen der Raupen verhindert. Der Boden des Kastens wird durch Stoff gebildet, der an den unteren Rändern des Rahmens festgenagelt wird. Die Kästen sind also oben vollständig offen, was für das Gedeihen der Raupen, für die Beobachtung, den Wechsel des Futters usw. von großem Vorteil ist. Daß der Boden von Stoff ist, ermögiicht eine rasche Erneuerung desselben, was die Reinigung der Kästen nach ansteckenden Krankheiten usw. leicht und einfach gestaltet. Weitere Vorteile der Fiskeschen Rahmen liegen in der Billigkeit und der Raumersparnis; können sie doch in größerer Zahl mit einigem Zwischenraum übereinandergestellt werden (Fig. 238). Sie sind daher besonders da zu empfehlen, wo es sich um die Aufzucht großer Mengen Raupen handelt. 
Endlich wäre noch die „Beutelmethode" zu nennen, die darin besteht, daß man die aufzuziehenden Raupen draußen in einem Gazebeutel um die Enden eines Zweiges der Futterpflanze einbindet. Natürlich muß die betreffende Stelle gewechselt werden, sobald die Nadeln oder Blätter abgefressen sind. Die Methode hat den Vorteil, daß sie wenig Arbeit erfordert und das Futter in vollkommen natürlichem Zustand sich befindet. Andererseits kann diese Methode nur da ausgeübt werden, wo man vor dem Eingreifen unberufener Hände sicher ist. Auch in starken Rauchgegenden kann die Methode

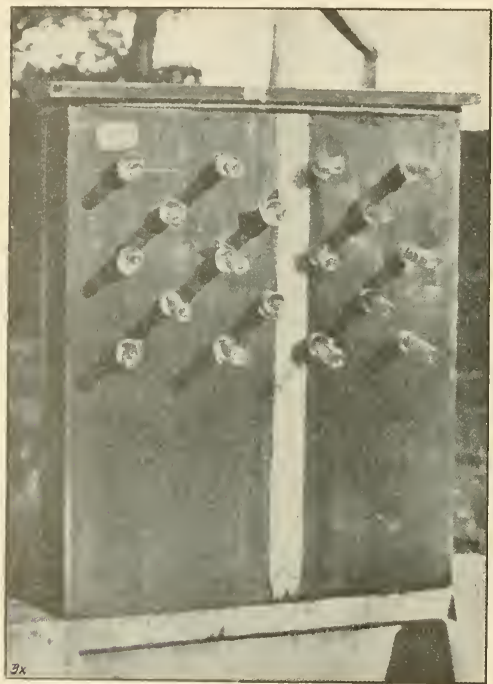

Fig. 239. Großer Parasitenkasten mit zahlreichen Glastuben. Aus Escherich. zu Mißerfolgen führen, da die Gaze durch den Ruß usw. bald verstopft wird, und dann die Blätter usw. ihr Chlorophyll mehr oderweniger verlieren.

Besondere Bedeutung erlangt die Zucht für das Parasitenstudium. Soll dasselbe systematisch betrieben werden, so kommt es darauf an, daß möglichst alle aus einer Raupenzucht usw. auskommenden Parasiten in unsere Hände gelangen. Nun weiß aber jeder, der sich mit Parasitenzucht abgegeben hat, wie mühsam und zeitraubend es ist, die kleinen Parasiten aus den gewöhnlichen Gazekäfigen herauszufinden; und wo es sich gar um die kleinsten Formen der Proktotrupiden handelt, werden dieselben zum großen Teil überhaupt nicht entdeckt. Um diese Mißstände zu beseitigen, benützt man besondere Parasitenkästen, am besten die sog. kalifornischen oder amerikanischen Parasitenkästen. Dieselben stellen Kästen aus Pappe oder Holz dar, in deren Vorderwand ein oder mehrere Löcher gebohrt sind, in welche Glastuben (Präparatengläser) mit dem geschlossenen Ende nach außen gekehrt, gesteckt sind. Damit die Zylinder möglichst fest in den Löchern stecken, wird ein Konus aus aufgerollter Pappe zwischen Zylinder und Lochrand eingeschoben; so kann man den Durchmesser des Loches durch Verschiebung des Konus nach innen oder außen verkleinern oder vergrößern und damit die event. Größenunterschiede, die bei den Gläsern immer bestehen, leicht ausgleichen. Die Größe der Kästen ist sehr verschieden, je nach dem Material, welches sie aufzunehmen haben: wo es sich um Eiparasiten handelt, genügen ganz kleine Formen von etwa $5 \times 15 \times 10 \mathrm{~cm}$; sollen aber z. B. die Parasiten aus den Winternestern des Goldafters gezogen werden, so nimmt man ganz große 
Kästen von $1 / 2$ oder $1 \mathrm{~m}$ Höhe, um recht viel Nester darin unterbringen zu können (Fig. 239).

Kommen nun in solchen Kästen Parasiten aus, so streben diese meistens dem Licht zu und begeben sich daher in die Glastuben. Man braucht also nur die letzteren zu revidieren, um die Parasiten zu erhalten. Dies bedeutet nicht nur eine große Zeitersparnis, sondern auch eine weit größere Genauigkeit der Arbeit, als sie bei dem alten System selbst bei äußerster Sorgfalt möglich war. Denn es werden hier die kleinsten Formen ebenso präzise weggefangen wie die größten. Von italienischen Entomologen sind die amerikanischen Kästen etwas modifiziert worden, indem sie die Glastuben anstatt an der Seite an der Decke anbringen (und zwar in größerer Zahl). Diese Modifikation ist darin wohl begründet, daß viele Parasiten die Gewohnheit haben, zuerst nach der Decke des Zuchtkastens zu streben.

Nicht alle Parasiten, die aus den Raupen und Puppen herauskommen, streben dem Licht zu; manche von ihnen sind im Gegenteil luzifug, d. h. begeben sich aus dem Licht in die Dunkelheit. Dahin gehören vor allem die Tachinenlarven, die, nachdem sie die Wirtsraupe verlassen, sich im Boden einbohren, um sich da zu verpuppen. Diesen Eventualitäten ist Rechnung

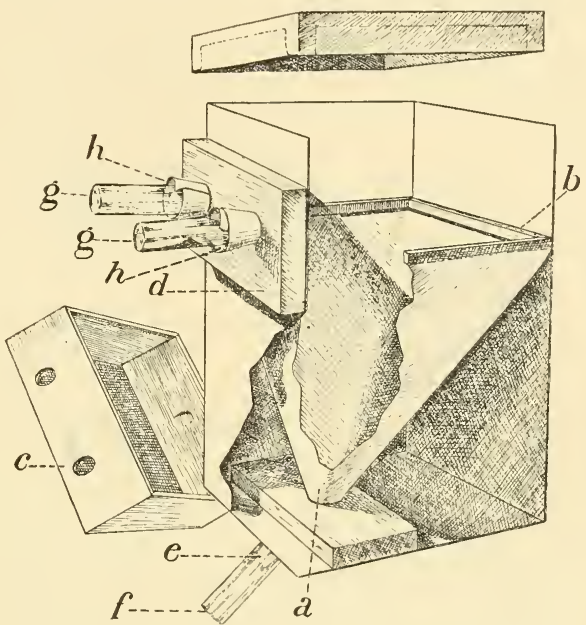

Fig. 240. Kombinierter Parasitenzuchtkasten. $q$ Glastuben für die flie renden, dem Licht zustrebenden Parasiten; ef Glastuhe zum Auffangen der durch das Gitter $c$ (welches auf dem Rahmen $b$ liegt) fallenden Tachinenlarven. Nach Howard u. Fiske. getragen durch kombinierte Kästen (Fig. 240), die sowohl für die lichtzustrebenden als für die den Boden aufsuchenden Formen eingerichtet sind. Sie sind zu diesem Zweck durch ein Drahtgitter in eine obere und untere Abteilung zerlegt, deren jede mit Glastuben versehen ist; die Raupen oder Puppen werden in der oberen Abteilung untergebracht, von wo aus die Hymenopteren-Parasiten in die oberen Glastuben fliegen, während die sich ausbohrenden Tachinenlarven durch das Gitter fallen und durch den darunter befindlichen Trichter in die untere, schräg nach unten gerichtete Tube geleitet werden. So kann man also in den kombinierten Kästen beide Kategorien von Parasiten (die fliegenden lichtfreundlichen und die lichtscheuen Maden) in den Glastuben abfangen. 
Die Tachinenmadeṇ müssen natürlich möglichst schnell aus den Fanggläsern entfernt und in die Verpuppungsbehälter gebracht werden. ${ }^{\mathbf{1}}$ )

\section{Das Präparieren der Insekten und Fraßstücke.}

Die gesammelten und gezüchteten Insekten müssen, soweit sie der Sammlung einverleibt werden sollen, präpariert werden, was in folgender Weise zu geschehen hat:

Die getöteten Imagines werden auf Fließpapier ausgebreitet, von den daran haftenden Schmutzteilchen usw. gereinigt und dann, soweit sie nicht zu klein sind, aufgespießt („genadelt“), wozu man sich besonderer Insektennadeln (am besten der sog. "Idealnadeln") bedient, die von den obengenannten Firmen zu beziehen sind, und in verschiedenen Stärken (Nr. 0-4), je nach der Größe der betreffenden Insekten, zur Verwendung kommen. Die Käfer, die meisten Wanzen und einige Orthopteren (z. B. Blattiden) werden durch die rechte Flügeldecke (im vorderen Drittel) aufgesteckt. Bei den übrigen

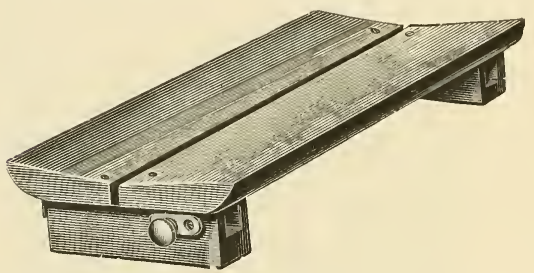

Fig. 241. Verstellbares Spannbrett. für kleine und große Schmetterlinge verwendbar. (Katalog von Winkler \& Wagner.) Insekten (Schmetterlingen, Hymenopteren,Dipteren usw.) wird die Nadel durch den Thorax gestochen. Die mit Flügeldecken versehenen Insekten werden im allgemeinen mit anliegenden Flügeln präpariert. Bei den Schmetterlingen, bei denen ja die Hauptzeichnung auf den Flügeln sich befindet, werden die Flügel auf besonderen „Spannbrettern" (Fig. 241) ausgespannt und in dieser Lage getrocknet, so daß sie bei der Abnahme vom Spannbrett in derselben bleiben. Bei den übrigen Insekten mit häutigen Flügeln genügt es im allgemeinen, die Flügel in die normale Ruhelage (mehr oder weniger schräg abstehend) zu bringen; doch empfiehlt es sich auch bei diesen Insekten, wenigstens einige Individuen nach Art der Schmetterlinge aufzuspannen, um das für die Bestimmung oft so wichtige Flügelgeäder deutlich sichtbar zu machen. Bei den Käfern beschränkt sich die Präparation darauf, daß3 man die Beine und Fühler möglichst symmetrisch anordnet und sie derart an den Körper anlegt, daß sie nicht sperrig abstehen; bei Käfern mit sehr langen Beinen ist es zum besseren Schutz der Tarsen vorzuziehen, die Beine gekreuzt unter den Leib zu schieben. Vielfach bleiben die Extremitäten ohne weiteres in der Lage, die man ihnen gibt; wo dies nicht der Fall ist, steckt man die zu präparierenden Käfer usw. auf sog. „Torfklötze“ (d. s. ca. $4 \mathrm{~cm}$ starke, mit weißem Papier überzogene Torfplatten) und befestigt die einzelnen Glieder in der gewünschten Lage mit Nadeln (Tréd1).

1) Für diesen Zweck benutzt man gewöhnlich engmaschige Drahtzylinder mit festem Boden und abnehmbarem Deckel, die bis an den oberen Rand in die Erde eingegraben werden. 
Soll eine Sammlung ein schönes Aussehen bekommen, so ist neben einer möglichst gleichmäßigen Präparation vor allem auch darauf zu achten, daß die Insekten in ungefähr gleicher Höhe auf der Nadel stecken, etwa so hoch, daß $1 / 3$ der Nadel noch über dem Insekt herausragt.

Handelt es sich um kleine und kleinste Insekten, so können dieselben nicht ohne weiteres genadelt werden, da man dafür zu dünne Nadeln verwenden müßte, die bei der Normallänge zu wenig Widerstand beim Einstecken usw. bieten und daher abbiegen würden usw. Man hilft sich in solchen Fällen damit, daß man die betr. Insekten nicht direkt auf die Nadel bringt, sondern auf eine an der Nadel befestigte Unterlage. Für kleine Käfer, Wanzen und ähnliche Insekten benützt man einfach ein Kartonblättchen, auf welchem man das Insekt aufklebt. Es sind verschiedene Formen von sog. "Aufklebeplättchen" im Gebrauch. Am meisten empfehlen sich die dreieckigen Plättchen (Fig. 242), da bei denselben die Beine und der größte Teil der Unterseite sichtbar bleiben, besonders wenn das Insekt quer

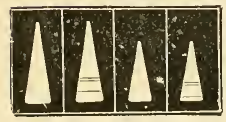

Fig. 242. Dreieckige Aufklebeplättchen für Kleinkäfer usw.

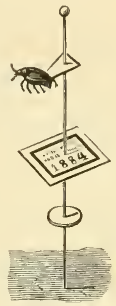

Fig. 243. Ein auf ein dreieckiges Plättchen aufgeklebter Kleinkäfer mit Fundortetikette (N.).

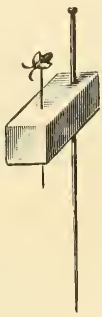

Fig. 244. Ein vermittelst einer Minutienuadel auf einem $\mathrm{Ho}$. lunderklötzchen aufgestecktes Kleininsekt.

aufgeklebt wird, wie in Fig. $243 \mathrm{zu}$ sehen ist. Die Orientierung hat so zu geschehen, daß die Nadel bei vorwärtsgerichtetem Tier rechts von demselben zu stecken kommt, damit beim Einstecken mit der rechten Hand das Tier von der Hand unberührt bleibt. Als Klebemittel verwendet man einen möglichst hellen und möglichst wenig spröden Leim, entweder starkes Gummi arabicum, das mit $1 \%$ Glyzerin und etwas Zucker versetzt ist, oder Syndetikon (Fischleim). - Bei den Kleinschmetterlingen, kleinen Hymenopteren, Fliegen usw. anderen zarten Kleininsekten benützt man feinen, kurzen Silberdraht (oder noch besser sog. Minutiennadeln), mit dem die Insekten aufgespießt und dann in ein auf der Insektennadel befestigtes Stïck Holundermark eingesteckt werden (Fig. 244). Die Kleinschmetterlinge müssen zuerst gespannt werden, wie die Großschmetterlinge, um die Zeichnung der Flügel sichtbar zu machen. Die Silberdrahtmethode kann natürlich auch für die anderen Insekten (Käfer usw.) angewandt werden und stellt zweifellos die schönste und für die Bestimmung zweckmäßigste Präparationsmethode dar; doch beansprucht sie viel mehr Zeit und Geschicklichkeit als das Aufkleben, so daß man im allgemeinen bei solchen Insekten, die das Aufkleben ertragen, diese einfachere Methode anwenden wird. 
Ist nun ein Insekt genadelt und präpariert, so ist unverzüglich eine kleine Etiquette an der Nadel anzubringen, auf welcher Fangzeit, Fundort und sonstige Bemerkungen zu notieren sind. Nur in dieser Weise sorgfältig etikettierte Tiere können für wissenschaftliche Bearbeitungen einen Wert erlangen.

Eine forstentomologische Sammlung soll neben den Imagines womöglich auch die verschiedenen Jugendzustände der Schädlinge enthalten. Ist es doch für den Forstmann überaus wichtig, auch die Eier, Larven und Puppen der Forstschädlinge genau zu kennen und zur Vergleichung in späteren Fällen aufzuheben. Die Eier und Puppen werden einfach in ein Tötungsglas (am besten Zyankali) gebracht und dann langsam getrocknet.

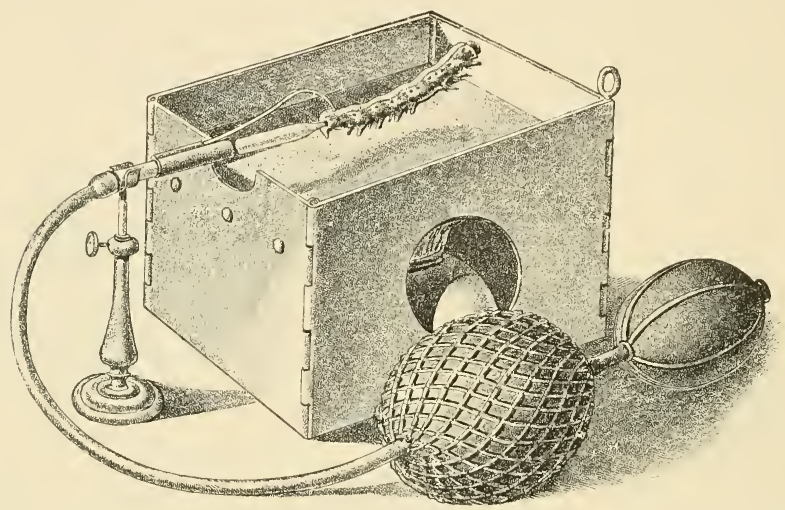

Fig. 245. Ansblaseapparat nit Handgebläse. mit vernickeltem Präparierofen samt dicker Kupferplatte, die durch eine spirituslampe erhitzt wird. Das Glasrohr mit dem Präparat ist auf einem Stativ angebracht, so daß eine Hand freibleibt. (Katalog von Winkler \& Wagner.)

Um das Einschrumpfen zu verhindern und der Luft Zutritt in das Innere der Eier und Puppen zu verschaffen, werden die betr. Objekte mit einer feinen Nadel angestochen; größere Objekte bedürfen natürlich mehrerer Stiche als kleine. Die schönsten Eierpıäparate erhält man, wenn man solche Eier verwendet, die kurz vor dem Ausschlüpfen stehen, da in diese bereits ein größeres Luftquantum eingetreten ist.

Weit umständlicher als die Präparation der Eier und Puppen gestaltet sich die Präparation der Larven, die in zweierlei verschiedener Weise geschehen kann, entweder durch Aufblasen oder Härten. Die erstere Methode wird hauptsächlich für Schmetterlingsraupen und Afterraupen angewandt, außerdem zuweilen auch für andere kräftiger chitinisierte größere Insektenlarven, die letztere vor allem für die weißen, weichen farblosen Larven und Puppen (Pupae liberae) der Käfer Hymenopteren, Dipteren usw.

Beim Aufblasen der Raupen wird folgendermaßen verfahren: Die Raupe wird in einem Glas oder unter der Glasglocke mit einigen Tropfen 
Äther betäubt; dann legt man sie zwischen weiches Fließpapier und streift mit einem runden Stabe von vorn nach hinten darüberwalzend den Inhalt der Raupe langsam durch den After aus, wobei sich früher oder später der Enddarm nach außen stülpt. Bei größeren Raupen muß das Papier mehrmals erneuert werden, bis der Raupeninhalt völlig entleert ist. $\mathrm{Zu}$ starkes Drücken vermeide man, da sonst die Haut verletzt wird oder die Haare ausgehen. Ist der Balg vollständig leer, so wird in die Afteröffnung ein passender Grasstengel gesteckt, von denen man 4- こ Größen vorrätig haben muß; an diesen Stengel wird die Raupe mit einer abgezwickten feinen Nadelspitze oder einem Klebstoff befestigt und nun wird durch denselben Luft eingeblasen, während man die Raupe gleichzeitig über eine erhitzte Metallplatte oder in einen erhitzten Glaszylinder hält. Es gibt auch komplette Ausblaseapparate (Fig. 245), bei denen die Raupen anstatt auf einen Grasstengel auf eine dünn ausgezogene Glasröhre gestec'kt und mit einer besonderen Haltevorrichtung festgehalten werden, während sie mit einem Handgebläse aufgeblasen werden, oder sogar mit einem Gebläse mit Fußbetrieb, welch letztere Einrichtung den Vorteil hat, daß man die beiden Hände frei hat und mit Hilfe derselben der Raupe die gewünschte Form geben kann. Beim Blasen ist zu beachten, daß zu starkes Blasen den Balg zu sehr ausdehnt und dadurch der Raupe eine unnatürliche Form gibt. Das Einblasen ist so lange fortzusetzen, bis der Balg vollkommen trocken ist. Das gute Präparieren der Raupen erfordert große Übung und Erfahrung. Die ausgeblasenen Raupen werden entweder an einem Halm, der in den After gesteckt ist, befestigt und daran genadelt, oder aber auf präparierte Fraßpflanzen geklebt. Grüne Raupen verlieren ihre natürliche Färbung durch das Ausblasen meist so sehr, daß man sie künstlich auffärben muß.

Was die andere Methode, die Härtung der Larven, betrifft, so geschieht dieselbe nach dem in Zoologenkreisen allbekannten Semperschen Verfahren zur Herstellung anatomischer Trockenpräparate. Scheidter gibt für die Präparation der Larven folgende Vorschriften:

1. Die Larven werden zunächst in Wasser gekocht, und zwar werden ganz kleine Larven am besten lebend in ein Glas gegeben und mit sprudelndem Wasser überbrüht und in diesem dann bis zum Erkalten stehen gelassen; größere Larven $(1 \mathrm{~cm})$ bringt man in ein Reagenzglas mit kaltem Wasser und erhitzt dieses auf einer Flamme bis zum Kocheı; ist dies erreicht, so entfernt man sie von der Flamme. Ganz große Larven (Engerlinge usw.) läßt man 1-2 Minuten kochen. Beim Kochen werden die Larven oft stark aufgetrieben, was man dadurch wieder gut machen kann, daß man an wenig sichtbaren Stellen, am besten zwischen den Segmenten, einige Nadelstiche macht. Die Puppen jeder Größe werden am besten nur mit siedendem Wasser überbrüht und in diesem stehen gelassen; wenn man sie siedet, so spreizen sie ihre Flügel in unnatürlicher Weise vom Körper. Zweck des Abkochens ist hauptsächlich, die Eiweißstoffe zum Gerinnen zu bringen. Ist das Wasser erkaltet, so wird es möglichst vollständig abgegossen und sodann werden die Larven und Puppen dem Härtungsprozeß unterworfen. Sie werden zu diesem Zweck 
2. zunächst in $70 \%$ igen, dann in $80 \%$ igen und $90 \%$ igen und schließlich in sog. absoluten Alkohol gebracht, um das in ihnen enthaltene IVasser zu entfernen. In jeder dieser Flüssigkeiten verbleiben sie dann, je nach der Größe, 1-3 Wochen; namentlich im absoluten Alkohol sollten sie möglichst lange bleiben, wobei derselbe event. mehrmals zu wechseln ist. Um möglichst alles in der Larve und im absoluten Alkohol enthaltene Wasser herauszubckommen, kann man dem letzteren in einem dichten Leinensäckchen kalziniertes Kupfervitriol beigeben, das, sobald es bläulich, d. h. wasserhaltig geworden ist, durch ein neues zu ersetzen ist. Um den Alkohol besser in die Larve usw. eindringen zu lassen, empfiehlt es sich, einige ganz feine Schnitte an wenig bemerkbaren Stellen des Larvenkörpers anzubringen.

3. Nach der Alkoholbehandlung kommen die Larven und Puppen in Xylol, und zwar werden sie dahin ganz allmählich übergeführt, indem man sie zuerst in eine Mischung von $2 / 3$ absol. Alkohol und $1 / 3$ Xylol, dann in eine Mischung von $1 / 3$ absol. Alkohol und $2 / 3$ Xylol und schließlich in reines Xylol bringt. In jeder dieser Flüssigkeiten bleiben sie wiederum $1-3$ Wochen, je nach der Größe der Objekte. Hauptsächlich sind sie in reinem Xylol genügend lange $\mathrm{zu}$ lassen.

4. In gleicher allmählicher Weise werden sie nun in Terpentin übergeführt, wieder zuerst in eine Mischung von $2 / 3$ Xylol und $1 / 3$ Terpentin und dann in $1 / 3$ Xylol und $2 / 3$ Terpentin und schließlich in reines Terpentin. Verbleiben hierin wie vorher. Im allgemeinen sollen sie im Xylol wie im Terpentin so lange bleiben, bis sie fast durchsichtig geworden sind.

5. Hierauf werden sie aus dem Terpentin herausgenommen und auf einem reinen Löschblatt langsam getrocknet. $\mathrm{Zu}$ rasches Trocknen, namentlich auf einem warmen Ofen, ist meist nachteilig, da dadurch eine große Anzahl der Larven einschrumpft. Am besten bedeckt man die zu trocknenden Larven mit einem zweiten Löschblatt oder einer Glasglocke usw., um ein Verstauben derselben zu verhindern. Das Trocknen dauert nun wieder, je nach der Größe, bis zu 8 Tagen.

Die so präparierten Larven usw. können nun in die Sammlung gesteckt werden. Grosse Larven und Puppen werden wie Käfer usw. mit einer Insektennadel ungefähr in halber Länge und je nach der Gestalt und Form der Larven entweder von der Seite her (so namentlich bauchwärts gekrümmte Larven) oder vom Rücken her vorsichtig durchstochen. Kleinere Larven und Puppen werden auf Klebeplättchen aufgeklebt wie die kleinen Käfer usw. Nur benutzt man hierzu rechteckige Plättchen, und zwar wo es sich um weiße Larven handelt, schwarze, auf denen sich die weißen Larven gut abheben. Man kann die gehärteten Larven und Puppen auch in den Frafstücken in ihrer natürlichen Lage befestigen und damit schöne biologische Präparate herstellen.

Die hier beschriebene Härtungsmethode erscheint auf den ersten Blick etwas umständlich; in Wirklichkeit macht sie jedoch nur ganz wenig Arbeit und erfordert eigentlich nur Zeit. ${ }^{\mathbf{1}}$ ) Sie hat aber den großen Vorteil, daß sie

1) Ein wesentlich kürzeres Verfahren empfiehlt D e e g ner: Die Larven und Puppen werden $1 / 2-1$ Minute gekocht, nachdem sie chloroformiert in kaltes. 
einmal die natürliche Form der Larven und Puppen gar nicht verändert, und sodann ermöglicht, daß eine beliebig große Zahl von Larven usw. auf einmal präpariert werden können. Am besten richtet man sich gleich einen größeren Vorrat der notwendigen Mischungen zurecht, die natürlich entsprechend zu etikettieren sind. Die zu präparierenden Larven usw. werden in ein Präparatenglas gebracht und dann die Flüssigkeiten der Reihe nach hinzugegossen, nachdem die vorhergehende immer abgeschüttet wurde. Die Zeit, zu welcher die Flüssigkeiten gewechselt werden, ist stets genau zu notieren. Man kann in ein Glas gleichzeitig 3-4 verschiedene Larvenarten usw. bringen, vorausgesetzt, daß sich dieselben leicht voneinander unterscheiden Jassen (z. B. die Larven von Borken-, Blatt-, Bock- und Laufkäfern). (Scheidter.)

Von besonderem Werte für den Forstmann sind ferner die Fraßstücke. Sind sie es doch vielfach, an denen man den Schädling ohne weiteres erkennen kann. Es sind daher auch die Fraßstücke zu sammeln und zu Vergleichszwecken aufzubewahren. Handelt es sich um befressene Blätter, so werden dieselben genau so präpariert wie für das $\mathrm{He}$ barium. Umfangreiche frische Pflanzenteile wie auch Blattgallen usw. kann man durch Trock-

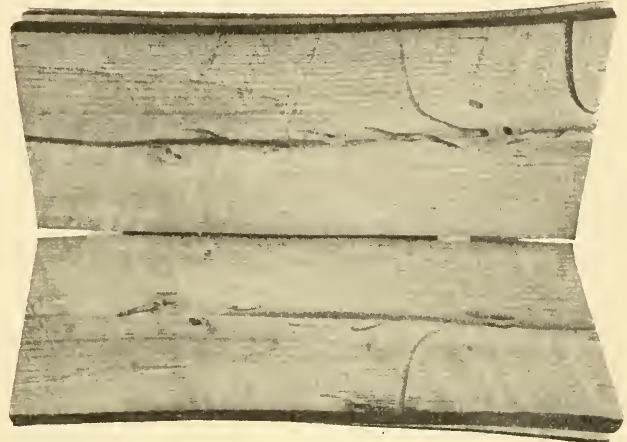

Fig. 246. Fraßstïck von Sirex, in Scheiben geschnitten und buchförmig montiert. (Tharandter Sammlung. nen in heißem Sande in ihren natürlichen Formen erhalten, wenn man es nicht vorzieht, sie in

Wasser gebracht worden sind. Man achte aber bei den Larven, vor allem Raupen darauf, daß sie vor der Behandlung nicht längere Zeit gehungert haben, weil sonst häufig später Schrumpfungen auftreten, welche das Präparat verderben. Nachdem das Wasser erkaltet ist, werden die Tiere je 24 Stunden in folgenden Flüssigkeiten belassen: $40 \%$ Alkohol, $60 \%$ Alkohol, $90 \%$ Alkohol, absolutem Alkohol, AlkoholXylol (zu geichen Teilen), Xylol. Die dem Xylol entnommenen Objekte werden am besten auf Fließpapier im Thermostaten getrocknet und dann genadelt. In vielen Fällen erhalten sich die Farben sehr gut (Rhopalocera z. T., Bombyciden, Geometriden, viele Noctuiden und Mikrolepidopteren). Da, wo sie verblassen oder verloren gehen, muß man eine nachträgliche Färbung vornehmen. Bei empfindlichen grünen Eulenraupen kann man event. dadurch ganz gute Resultate erzielen, daß man den einzelnen Alkoholstufen eine ziemlich starke, durch Auskochen von Blättern gewonnene alkoholische Chlorophyllösung zusetzt (P. Schulze). Die De egenersche Methode ist mir aus eigener Erfahrung nicht bekannt, so daß ich nicht sagen kann, ob die damit erzielten Resultate denen der S e mper sche11 Methode, nach der bisher im hiesigen Institut die Trockenpräparate hergestellt wurden, völlig gleichkommen. 
Flüssigkeiten (Alkohol oder Formalin) aufzubewahren. Fraßgänge in Holz und Rinde bereiten die wenigsten Schwierigkeiten. Man hat hauptsächlich darauf zu sehen, daß die Fraßstücke handlich zugeschnitten und größere dünne Rindenstücke zwischen Brettern flach gepreßt werden. Sind die Gänge tief im Holz verborgen, so werden geschickt gelegte Längs- und Querschnitte, sowie glücklich gesprungene Spaltstücke häufig das Fraßbild deutlich erkennen lassen. Gehen die Gänge durch den ganzen Querschnitt des Stammes, so kann man das betr. Stammstück in eine größere Anzahl Längsscheiben zerlegen, die auf der einen Seite mit Bändern zusammengehalten werden, so daß man die Scheiben wie Blätter eines Buches aufschlagen kann (Fig. 246).

Erfahrungsgemäß unterliegen die Fraßstücke mit der Zeit den Angriffen verschiedener Schadinsekten. Namentlich berindete Nadelholzstücke werden durch die Larven von Anobium molle L. gründlichst zerstört, und die Laubhölzer, obgleich weniger gefährdet, sind den Angriffen ron Bockkäfern, z. B. von Hylotrupes bajulus L., Callidium violaceum $L$. und variabile $L$. ausgesetzt. Es empfiehlt sich daher, die Frabstücke vor der Einverleibung in die Sammlung zu vergiften, was am einfachsten dadurch geschieht, daß man die Stücke gründlich mit einer nicht zu starken Lösung von arseniksauerem Natron bepinselt; kleinere Stücke kann man auch eine Zeitlang darin liegen lassen. Vor der Vergiftung streicht man die Stücke am besten mit Spiritus an, damit das Konservierungsmittel leichter einzieht. Die Arseniklösung ist so zu verdünnen, daß ein auf eine schwạze Unterlage gebrachter Tropfen beim Trocknen keinen nennenswerten weißen Fleck hinterläßt. $\mathrm{Zu}$ beachten ist bei dieser Methode, daß arseniksaueres Natron ein starkes Gift und zugleich eine Lauge ist, so daß also Vorsicht bei der Ausführung der Vergiftung anzuwenden ist. Neben dem arseniksaueren Natron wird auch Chlorzink als Präventivmittel verwendet, und zwar in gesättigter alkoholischer Lösung; in diesem Fall ist natürlich das Vorstreichen mit Spiritus nicht notwendig.

Die Bestimmung der Forstinsekten.

Von jedem praktischen Forstmann muß vorausgesetzt werden, daß er so weit naturwissenschaftlich vorgebildet ist, daß er von einem Insekt weiß, in welche Ordnung oder Ordnungsgruppe es gehört, d. h. daß er einen Käfer von einer Wanze oder einem Schmetterling usw. zu unterscheiden vermag; und ferner, daß er wenigstens bei den wichtigsten Ordnungen auch annähernd die Familie erkennt, der ein als Schädling auftretendes Insekt zuzurechnen ist. So dürfte es kaum einen Forstmann geben, der einen Rüsselkäfer oder Borkenkäfer oder Bockkäfer nicht gleich als solchen ansprechen würde. Es ist daher meistens unnötig, daß beim Bestimmen eines erbeuteten Insektes ganz von vorne angefangen wird, und erst die Ordnungsgruppe, dann die Ordnung und Familie festgestellt wird, um dann endlich erst die Gattung und Art zu eruieren, sondern die Bestimmung kann vielmehr gewöhnlich gleich bei der Familie oder Gattung einsetzen. Nehmen wir an, ein Forstmann findet einen Borkenkäfer, so wird er gleich zur Familie der Borkenkäfer sich wenden und dort die Gattung und Art zu be- 
stimmen suchen. Ist er schon etwas bewanderter, so wird er auch bereits wissen, ob es sich um einen Hylesinen oder Ipinen usw. handelt und kann dementsprechend gleich bei dieser Unterfamilie mit der Bestimmung beginnen.

In den speziellen Bänden dieses Werkes werden alle Insekten, welche in unseren Waldungen als forstlich beachtenswert auftreten, in systematischer Reihenfolge behandelt und so gekennzeichnet werden, daß sie darnach sicher bestimmt werden, können. Wo es sich um größere Familien und Gattungen handelt, werden zunächst die Gattungen resp. die Arten in Form von dichotomischen Tabellen dargestellt, mit deren Hilfe man ehestens zum Ziele gelangen kann. Wo die Unterscheidung besonders schwierig ist, werden die Unterschiede außerdem noch in eingehendster Weise expliziert und event. durch Zeichnungen klar gemacht werden, so daß jeder zu einer sicheren Erkennung gelangen kanm.

Größere Schwierigkeiten bietet mitunter die Bestimmung der Larven dar, ja in vielen Fällen ist dieselbe überhaupt nicht mit Sicherheit auszuführen. So sind wir heute bei den wenigsten Ichneumonidenlarven, Tachinenmaden, Rüsselkäferlarven usw. imstande, nach den morphologischen Merkmalen allein die Aıtzugehörigkeit festzustellen. Zweifellos existieren zwischen den Larven der einzelnen Ichneumonen usw. Unterschiede wie bei den Imagines; sie müssen aber erst durch eingehendstes Studium festgestellt werden.

Große Bedeutung können in solchen Fällen, wie überhaupt für die Bestimmung eines Forstinsekts, die Fraßstücke erlangen. Sind doch die Fraßspuren vieler Forstinsekten so charakteristisch, daß man an ihnen allein ohne weiteres den Urheber erkennen kann. Jedenfalls lassen sich dieselben zur Unterstützung der Bestimmung eines Insektes in vielen Fällen ausgezeichnet verwenden, da doch oft die Unterschiede in der Fraßfigur wesentlich auffallender sind, als die Unterschiede der betreffenden Insekten selber. Ich brauche nur an den großen und kleinen Waldgärtner zu erinnern, die als Imagines gar nicht leicht zu unterscheiden sind, während die Fraßbilder der beiden gänzlich voneinander abweichen. Auch schon die Berücksichtigung der Fraßpflanze allein kann bei der Bestimmuug große Dienste leisten und

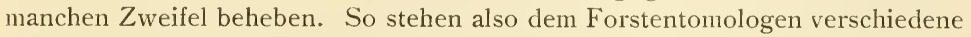
Mittel zur Verfügung, die ihm zur richtigen Bestimmung eines Insekts verhelfen können.

Der Anlage dieses Werkes entsprechend, das speziell die forstlich beachtenswerten Insekten behandelt, darf man natürlich nicht erwarten, jedes überhaupt im Walde gefangene Insekt darnach bestimmen zu können. Denn eine große Anzahl von im Walde lebenden Insekten ist forstlich bedeutungslos und daher in diesem Werke nicht berücksichtigt. Will man solche Insekten bestimmen, so muß man eben zu Spezialwerken greifen, an denen ja wenigstens für die wichtigsten Ordnungen wie die Käfer und Schmetterlinge - kein Mangel ist (siehe Literatur: Werke zur Bestimmung mitteleuropäischer Insekten). 
Wo es sich nicht um große Insekten mit sehr auffallenden Merkmalen handelt, wird man sich zur Bestimmung einer Lupe bedienen müssen, deren Stärke (Vergrößerung) sich nach der Größe des Objektes, resp. der zur Unterscheidung herangezogenen Merkmale zu richten hat. Im allgemeinen genügen die bekannten Einschlaglupen mit zwei oder drei verschieden starken Linsen, die einzeln oder kombiniert verwendet werden können.

Eine große Auswahl von Lupen findet sich in dem Katalog von Wink le r $\& W$ a g n e r in Wien (siehe S. 401), von denen hier nur einige Typen genannt seien: für die einfachsten Ansprüche kann genügen die „GroBe Taschen1 u pe in Hornf a s s un g“, mit 3 bikonvexen Linsen im Durchmesser von $30 \mathrm{~mm}$, je 5 fach, zusammen 15 fach vergrößernd (Preis $5 \mathrm{Kr}$.); etwas mehr leistet die „Doppel-Einschlaglupe mit Schildpattschalen" (Fig. $247 \mathrm{~A}$ ) mit 2 je 5 fach vergrößernden Bikonvexlinsen und einem Konvexlinsensystem mit 20 facher Vergrößerung (I'reis $8 \mathrm{Kr}$.); bedeutend klarere und differenziertere Bilder ergeben die "A planatischen $\mathrm{L}$ insen $\mathrm{n}$ ach $\mathrm{Ste}$ inheil", die in verschic-

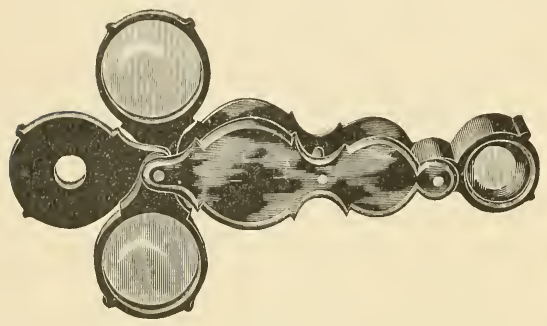

$A$

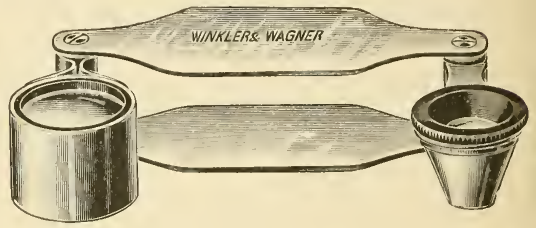

$B$

Fig. 247. Lupen zum Insektenbestimmen. A Doppel-Einschlaglupe mit Schildpattschalen mit 2 je 5 fach vergrößernden Bikonvex-Linsen und einem Konvexlinsensystem mit 20 facher Vergrößerung; $B$ Doppel-Einschlaglupe mit einem 15 fach vergrößernden Aplanaten nach Steinheil und einer achromatischen Lupe mit 30 facher Vergrößerung.

dener Vergrößerung (10-, 15- und $25 \mathrm{fach}$ ) geliefert werden (Preis $15 \mathrm{Kr}$.). Für die meisten Fälle ausreichend wird die „Doppeleinschlaglupe“ (Fig. 247, B) sein, die mit cinem großen 15 fach vergrößernden Aplanaten nach S t e in he il und einer achromatischen Lupe mit 30 facher Vergrößerung versehen ist (Preis $30 \mathrm{Kr}$.). Ganz vorzügliche Lupen liefern auch die bekannten Mikroskopfirmen E. Leitz in Wetzlar und C. Z e i B in Jena. Die letztere Firma hat vor einigen Iahren speziell für entomologische Zwecke eine Doppeleinschlaglupe in den Handel gebracht, die in optischer Hinsicht unübertroffen dasteht. Sie ist ausgestattet mit einer 10- und einer $27 \mathrm{fach}$ vergrößernden Lupe, die ein astigmatisch vollständig korrigiertes Sehfeld besitzt. Jedem, der sich eingehender mit entomologischen Studien befassen will, sei die Anschaffung dieser Zeiß-Lupe aufs dringendste empfohlen. Der scheinbar etwas höhere Preis (42 M.) wird durch die glänzende optische Leistung der Gläser mehr wie ausgeglichen.

Wo es sich um ganz kleine Objekte und sehr schwierig festzustellende Unterschiede handelt, wie z. B. um die Fühlergliederzahl winziger Käfer oder um feinste Skulpturverhältnisse der Flügeldecken usw., wird man event. zum Mikroskop greifen müssen, wozu im allgemeinen die in der Fleischbeschau gebräuchlichen hinreichend sind. Wer die Kosten nicht zu scheuen braucht und sich in den Besitz des besten optischen Hilfsmittels, das für Bestimmungszwecke existiert, setzen will, der möge sich ein sog. Binokularmikroskop 
anschaffen, welches ein vollkommen plastisches Sehen ermöglicht. Für entomologische Institute, die viel mit Bestimmungen zu tun haben, gehört ein Binokularmikroskop zum unentbehrlichen Instrumentarium, zumal es auch zur Herstellung anatomischer Präparate von kleinen Insekten vorzügliche Dienste leistet (betr. Bezugsquellen für Mikroskope siehe die ebengenannten Firmen).

Aufbewahrung und Einordnung der präparierten Insekten.

Sind die gesammelten Insekten präpariert, etikettiert und bestimmt, so sind sie in gutschließenden Kästen aufzubewahren. Man verwendet hierzu am besten besondere "Insektenkästen" aus Holz, die mit einem abnehmbaren Glasdeckel veısehen sind. Der Boden der Kästen ist mit Insektentorf ausgelegt, der mit einem möglichst glatten Papier überzogen ist. Vor allem sehe man auf einen gutgearbeiteten DeckelverschluB mit Nut und Feder; nur dadurch kann man seine Sammlung vor der Zerstörung durch Schadinsekten schützen. Die Insektenkästen werden von den auf S. 401 genannten Firmen in der verschiedensten Ausführung und den verschiedensten Größen geliefert; als gangbarste Größe sei empfohlen $30 \times 40 \times 6$.

$\mathrm{Zu}$ einer guten Erhaltung der Sammlung gehört ferner, daß die Kästen an einem trockenen Ort aufbewahrt und nicht zu sehr dem Licht ausgesetzt werden. Denn Feuchtigkeit führt zur Verschimmlung der Insekten und Licht bleicht die Farben aus. Das Aufhängen der Sammlung an der Wand (als Wandschmuck) ist daher zu vermeiden; es müßte denn sein, daß über die Glasscheibe ein dunkler Vorhang gezogen wird. Als Präventivmittel gegen Schadinsekten kann man stark riechende Substanzen in den Kasten bringen. Am meisten verwendet wird hierzu Naphthalin, das man entweder lose in den Kasten streuen kann oder in Form ron Naphthalinkugeln einsteckt. Es sei aber betont, daß das Naphthalin keineswegs einen absoluten Schutz gegen das Eindringen von Schadinsekten bedeutet und der Hauptschutz stets in dem guten VerschluB zu erblicken ist. - Sind Schadinsekten bereits in einer Sammlung vorhanden, so sind die befallenen Kästen zu desinfizieren; weitaus am besten eignet sich hierzu der Schwefelkohlenstoff, durch den weder die Insekten noch die Nadeln Schaden leiden.

Aber nicht nur unter Schadinsekten, sondern auch unter verschiedenen anderen Einflüssen haben die Insektensammlungen zu leiden. Oben ist schon des Schimmels Erwähnung getan, der an feuchten Orten viel Unheil anrichten kann. Eine weitere unangenehme Erscheinung ist das Öligwerden, dem eine ganze Anzahl Insekten in besonderem Maße ausgesetzt sind und durch welches das Aussehen der Insekten stark beeinflusst wird. Glücklicherweise hat man Mittel, die ölig gewordenen Insekten zu entfetten: man benutzt dazu Benzin, Chloroform oder Äther oder auch ein Gemisch davon, und zwar in der Weise, daß man die betr. Insekten einige Zeit $(1 / 2-2$ Tage) in die Flüssigkeit steckt.

Was die Einordnung der Sammlung betrifft, so soll jeder Entomologe darnach streben, eine möglichst große Übersichtlichkeit, Gleichmäßigkeit und Sauberkeit zu erreichen. Je sauberer, übersichtlicher und schöner eine 
Sammlung eingeordnet ist, desto mehr Freude wird sie dem Sammler machen, und desto mehr wird sie sein Interesse erwecken. Wo es sich um eine rein systematische Sammlung handelt, achte man darauf, daß die Insekten in geraden Reihen gesteckt werden - man kann zu diesem Zweck Fäden spannen, oder aber schwach karriertes Papier zum Überziehen des Torfbodens benutzen - ferner, daß zwischen den einzelnen Arten ein gleichmäßiger Zwischenraum eingehalten wird, daß die Familien-, Gattungs- und Artetiketten sich durch verschiedene Größe und Ausstattung (verschieden starke Umrandung) auszeichnen, und daß dieselben so angebracht sind, daß die Schrift von den Insekten möglichst wenig rerdeckt wird. - Wo es sich um eine biologische Sammlung handelt, in der nicht nur die Imagines, sondern auch

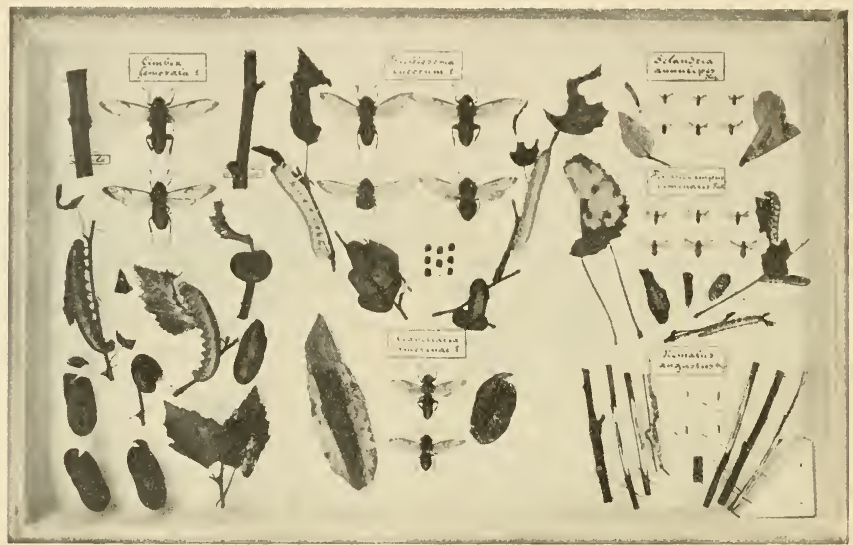

Fig. 248. Beispiel für die Einordnung einer biologischen Sammlung. Laubholz-Blattwespen. (Tharandter Sammlung.)

die Entwicklungsstadien, Fraßstücke usw. enthalten sind - Forstentomologen sollten sich vor allem eine solche Sammlung anlegen -, da ist natürlich die Ordnung in Reihen nicht immer durchführbar. Doch sollte man auch in diesen Fällen sich Mühe geben, durch geschickte gruppenweise Anordnung der zusammengehörenden Insekten und Fraßstücke usw. die Übersichtlichkeit zu wahren und der Sammlung zugleich ein schönes Aussehen zu geben (Fig. 248). Es gehört hierzu allerdings ein gewisser künstlerischer Sinn.

\section{Literatur.}

Das System der Insekten und Nomenklatur.

Börner, C., Zur Systematik der Hexapoden. Zoolog. Anzeiger XXVII. Bd., 1906, S. $511 \mathrm{ff}$.

B r a er, Fr., Systematisch-zoologische Studien. Sitzungsber. der Kais. Akad. der Wissensch. XCI. Bd., I. Abt. (Maiheft), 1885.

Escherich, K., Insekten. Handbuch der Naturwissenschaften Bd. V, S. $501 \mathrm{ff}$. $\mathrm{H}$ and $1 \mathrm{irsch}$, A., Die fossilen Insekten und die Phylogenie der rezenten Formen. Handbuch. Leipzig 1906-1908. 
Pre11, H., Anamerentoma und Holomerentoma, eine neue Einteilung der Hexapoden. Zoolog. Anzeiger XXXIX. Bd., 1912, S. 357-365.

Règles internationales de la Nomenclature zoologique, adoptées par les Congrès internationaux de Zoologie. (Internationale Regeln der zoologischen Nomenklatur.) Paris (F. R. de Rudeval) 1905.

\section{Präparation usw.}

Deegener, P., Uber die Konservierung von Insektenlarven und -puppen für Sammlungen. Zoolog. Anzeiger XL. Bd., 1912, S. $29 \mathrm{ff}$.

F riese, H., Neue Zeiß-Lupen. Allgem. Zeitschrift für Entomologie Bd. 8, 1903, S. 267.

M ü h 1, Raupen und Schmetterlinge. Stuttgart 1908.

- Larven und Käfer. Praktische Anleitung zum Sammeln, Züchten und Präparieren. Stuttgart 1909.

Scheidter, Fr., Trockenpräparation von Larven und Puppen. Entom. Blätter, IV. Bd., 1908, S. 61-64.

T r édi, Rud., und C u r t i, M., Normalpräparation von Käfern. Entom. Blätter, IV. Jahrgang, 1908, S. 121-128.

$$
\begin{aligned}
& \text { Bestimmung werke für die verschiedenen Insekten- } \\
& \text { ordnungen. }
\end{aligned}
$$

C a 1 we r - S c ha u f $\mathrm{B}$, Käferbuch, Naturgeschichte der Käfer Europas. 6. Aufl. Mit 48 farbigen Tafeln. Stuttgart 1913." (Anfängern sehr zu empfehlen.)

Enslin, E., Die Tenthredinoidea Mitteleuropas. Deutsche Entom. Zeitschrift 1912. (Noch nicht vollendet.)

Fi e ber, Fr. X., Die europäischen Hemipteren. Wien 1861.

Hof $\mathrm{m}$ a n n, E., Die Raupen der Großschmetterlinge Europas. Stuttgart 1893. (Mit zahlreichen bunten Tafeln.)

H o u a d, C., Les Zoocéidies des Plantes d'Europe. 2 Bände. Paris 1908.

L a m p e rt, R., Die Großschmetterlinge Deutschlands. Stuttgart. (Mit zahlreichen bunten Tafeln.)

L i n d ing e r, L., Die Schildläuse (Coccidae). Stuttgart 1912.

M e 1 i c h a r, L., Cicadinen von Mitteleuropa. Berlin 1896.

$\mathrm{R}$ a t z e burg, J. T h. C h., Die Ichneumonen der Forstinsekten. Berlin 1844-1852.

Reitter, Ed., Fanna germanica. Die Käfer. Stuttgart. (Mit zahlreichen bunten Tafeln.)

R ü b s a a me n, Ew. H., Die Zoocecidien. I. Bd. Stuttgart 1911. Ein groß angelegtes, mit zahlreichen bunten Tafeln ausgestattetes Werk. (Im Erscheinen begriffen.)

Sch i ner, J. R., Fauna austriaca. Die Fliegen (Dipteren). 2 Bände. Wien 1862.

$\mathrm{Sch}$ e e h te nda 1, D. H. R. von, Die Gallenbildungen (Zoozedien) der deutschen Gefäßpflanzen. Zwickaı 1891.

Schmiedeknecht, O., Die Hymenopteren Mitteleuropas. Jena 1907.

S e idlitz, G., Fauna baltica. Die Käfer. (Ohne Abbildungen.) Königsberg 1891.

Spuler, Arnold, Die Schmetterlinge Europas. 3. Bd. Stuttgart 1908. (Mit zahlreichen bunten Tafeln.)

$\mathrm{T}$ ü m p e 1, R., Die Geradeflügler Mitteleuropas. Eisenach 1901. (Mit zahlreichen bunten Tafeln.) 


\section{Namenregister. ${ }^{1}$}

\section{A.}

Adler 125.

Adolph 35 .

Altum, B. 221225226229 230232304314.

\section{B.}

Bachmetjew, P. 818283 * $\begin{array}{llllll}84 & 85 & 114 & 174 & 185 & 223\end{array}$ 304.

Baer, W. 209*228 230234 $270^{*} 271286287290304$.

Bail 265285286290.

Balbiani 297.

Ballowitz, E. 119184.

Bary, A. de 268* $272278^{*}$ $281 * 290$.

Bauer, A. 54114.

Beck, R. 390.

Bejerinck 206207.

Bengtsson, S. 288290.

Berger, E. W. 287290.

Berlepsch, H. v. 231390.

Berlese, A. $1114^{*} 15^{*} 37^{*}$ $40 * 41^{*} 4851^{*} 52^{*} 53^{*}$ $5477^{*} 88^{*} 112^{*} 114139 *$.

Berner, P. 390.

Bernhard, C. 121184.

Biedermann, W. 69114.

Blanc, G. R. 294.

Blochmann 117*.

Blunck, H. 120* 184 .

Blüthgen 287.

Boas, J. C. 131* 304.

Bocchia, J. 293305.

Bolle, J. 288290293297 302303305348.

Bongardt 8788115 .

Bordas 112\%.

Borgmann, W. $218315 \mathrm{fl}$. 320.

Börner, C. 303248 127* 156160184185394420.
Borries, H. 226304.

Böttcher, E. A. 403.

Brandt $140^{*}$.

Brauer, Fr. $74^{*} 118^{*} 152^{*}$ 394420.

Brefeld, O. $261 * 264 * 285$ 290.

Brongniart $135^{*}$.

Buckton 257.

Buchner, P. 274290.

Bugnion 7.

Burgess, A. F. 141304.

Burmeister 112\%.

Bütschli, O. 11.

\section{c.}

Calwer-Schaufuss 421 .

Chamisso, v. 286.

Chapmann, W. 302, 305.

Chernel, v. 232.

Chesire 292.

Cheyne 292.

Claus-Grobben $1144^{*}$.

Cobelli 61.

Cohn, F. 286290.

Comstock $35^{*} 3648$.

Conte, A. 288291.

Crisp 226304.

Cuenot 86.

Cunit 374375.

Curti, M. 421.

D.

Dalla Torre 304.

Danysz, J. 290.

Decoppet 360390 .

Deegener, P. $6998 \quad 114$ $142150185+14415421$.

Delacroix 279288291 .

Demandl, C. 115.

Demoll, R. 103* 115.
D'Herelle, F. 294305349 391.

Döderlein 4448 .

Doflein, Fr. $48295^{*} 296^{*}$ 297305

Dolles 391.

Dufour, J. 288290.

Dzierzon 124125.

E.

Eckstein, K. 201* 221245 $\begin{array}{lllll}257^{*} & 258 & 286 & 290 & 347\end{array}$ $354362^{*} 363^{*} 365^{*} 367^{*}$ $368 \quad 369^{*} 372^{*} 379382^{*}$ 383384389.

Eggers, Fr. 98115.

Emerton 15 4*.

Emery $47^{*}$.

Engler-Prantl 289.

Enslin, F. 421.

Ermisch, H. 370.

Escherich, K. 29*48 112 $\begin{array}{lllll}115 & 139^{*} & 142 & 173 & 184\end{array}$ $\begin{array}{llllll}185 & 220 & 238 & 247 & 251^{*}\end{array}$ $\begin{array}{lllll}270 * & 271 & 274 & 287 & 290\end{array}$ $\begin{array}{lllll}299 & 300 & 301^{*} & 302 & 303\end{array}$ $\begin{array}{llllll}304 & 305 & 320 & 343^{*} & 348\end{array}$ $355^{*} 356^{*} 368378^{*} 391$ $408 * 420$.

Everth, A. 356 .

\section{F.}

Fabre, J. 15̃ 185 .

Fabricius 398.

Fawcett, H. S. 290.

Fieber, Fr. X. 421.

Fischer, E. 302305348.

Fiske, W. F. 239241248 $249251^{*} 304407^{*} 409^{*}$.

Fitzhenry-Guptill 358.

Folsom, J. W. 4891.

$\left.{ }^{1}\right)$ Auf den mit versehenen Seiten finden sich die Namen unter den dort befindlichen Abbildungen. 
Forel, A. 9093115254 .

Frank, A. 288290.

Friese, H. 421.

Fron, G. 282290.

Fuchs, G. 174185.

Fulmek 35:3 357391.

\section{G.}

Gaita, v. $60^{\%}$.

Ganglbauer $27 \%$.

Gegenbaur 32.

Gehe 352.

Germar 398.

Giard, A. $28028+288290$.

Glaser, R. IV. 302305.

Goehlers Witwe 357.

Goette, A. $911121 \%$.

Göldi, E. A. 193220.

Gorka, S. 68114.

Graber, V. $486097^{*} 104$.

Grohmann 256365391.

Grob, J. 48117119184.

Gvozdenovič, Fr. 286290.

\section{$\mathrm{H}$.}

Haenel, K. 391.

Handlirsch, A. 11394396 420.

Hartig, R. $210 \quad 212$ 216 218221274285290.

Harz 288.

Hatschek $73^{*}$.

Hauser 94*.

Heider $139^{*} 140^{\text {* }} 184$.

Heidrich 304.

Heinze, K. 304.

Henking 117*.

Henneguy, L. F. $48122^{\text {: }}$ $135 * 149 *$

Hennicke, C. R. 391.

Hennicke-Naumann 304.

Hennings, C. 170171172 173174185.

Herpig 252.

Hertwig, R. $1120^{*} 71^{*} 104$.

Hef, R. 221391.

Hesse, R. $22 \quad 35485657$ $\begin{array}{lllllll}58 & 59 & 60 & 69 & 76 & 95 & 96\end{array}$ $98 \quad 99 * 102 \quad 114115$.

Heymons, R. 9111248 $\begin{array}{lllll}115 & 119 & 139 & 141 & 142\end{array}$ $\begin{array}{lllll}152^{*} & 154 & 156 & 158 & 159\end{array}$ 160184185 .

Hiesemann, M. 391.

Hochreuter, R. 115.

Hoffmann, P. 370.
Hofmann, O. 346391.

Hofmann, E. 421.

Holder 357358.

Hollrung, M. 351391.

Hopkins 337.

Houard, C. 205421.

Houlbert, C. 48.

Howard, L. O. 239248 $250251^{\text {t* }} 304338409^{*}$.

Huber 191.

\section{J.}

Janet, Ch. $78^{*} 114$.

Janke, M. 372373.

Johnas, W. 115.

Jonescu, C. N. 90* 115.

Jordan, H. $2249 \quad 70114$ 226.

Judeich, J. F. 387.

\section{K.}

Kahlbaum 3502.

Kahle, W. 128184.

Kaltenbach, J. H. 213221.

Keller, C. 256257258304.

Kerner v. Marilaun 207 221.

Kieffer 166 *

Kihlmann 273.

Kirchner, O. 188220.

Kleine 286291.

Klöck 348349391.

Knoche, E. 109* 115142 $\begin{array}{llll}170 & 173 \quad 174 & 177182184\end{array}$ 185223302304305.

Kochi, C. 48.

Koebele 337.

Kolbe, H. J. 26*37* 48.

König, F. O. 403.

Korschelt $139^{*} 140^{*} 151^{\text {* }}$ 184.

Krahe 362.

Krasan 212.

Krassilistschik, J. M. 290 302.

Kreye, H. 403.

Kunckel d'Herculais $135^{*}$ $149^{\div} 159$.

Küster, E. $20 \check{2} 206207221$.

\section{L.}

Lakon, G. $258 \mathrm{ff}$.

Lampert, C. 421 .

Landois, H. 61114.

Lang $74^{*} 89^{*} 107^{*}$.

Lécaillon 136 *
Lèger 259 .

Leisewitz, W. $146^{*} 185$ 235304.

Leitz, E. 418.

Leuckart $68117^{*}$.

Leydig $92 *$.

Lichtenstein 84.

Lindau, G. $271^{*} 279^{*} 286$ 290.

Linden, M. v. 175185.

Lindinger, L. 421.

Lindner, P. 274290.

Link, J. A. 304.

Linné 188398.

Loos, K. 304 .

Lyonet $\check{5} 144$.

M.

Maaßen 274297298305.

Mamelle, Th. 361391.

Marchal, P. 128129184 345391.

Marey $57 \%$

Marzocchi, v. 302305.

Mc. Attee 184 .

Meinert $164^{*}$.

Melichar, L. 421.

Merk 352356.

Metzger, A. 175305.

Miall, L. C. $48163^{*}$.

Mìddeldorpf 286 .

Miyajima, M. 299300 301* $30^{\circ} 305$

Möller, L. 360.

Mordwilko 84.

Moser, W. G. 316.

Moult, le 288290.

Mühl 419.

Müller, J. 101.

Müller, G. W. $148 * 185$.

Müller, P. 390.

Nagel 70 .

\section{N.}

Needham $35^{*} 3648$.

Nees von Esenbeck 281\%.

Neger, Fr. 191273.

Neumeister 369.

Newport 80.

Nielsen, J. C. 251253305.

Nitsche, H. 208311387.

Nördlinger, H. 352354391.

Nüßlin, O. $107109111113^{\text {t }}$

$\begin{array}{llllll}114 & 115 & 127 & 170 & 174 & 177\end{array}$

$179181 \quad 185218219221$

304313. 
0.

Olsen-Sopp 273287290.

Oudemans, J. Th. $17 * 305$.

\section{P.}

Packard, A. S. $25 \div 4855$ $118^{*} 152^{*} 161^{*} 167 * 186$.

Pagenstecher 128*.

Palmén 76 \%.

Pannewitz, von 195 .

Pantel, J. 251305.

Parton 75.

Pasteur 297.

Pauly, A. 366391405.

Peckham, G. u. E. 255305.

Perrand, J. 291.

Petri 277.

Petrunkewitsch $60^{*} 114$.

Pfurtscheller $145^{*} \quad 147^{\text {: }}$ $169^{*}$.

Phillips, C. F. 192220.

Picard, F. 295305.

Pietschker, H. 90 91* 115 .

Pocock, R. J. 11.

Prell, H. $11 \quad 14 \quad 1649251$ 305343394421.

Prillieux 288291.

Prochnow, O. 61114.

Prowazek, S. v. 302306.

Puster 363391.

Putscher 314391.

\section{R.}

Rabenhorst $279 \% 289$.

Ramann 220.

Ratzeburg, J. Th. $77163^{\text {* }}$ $164^{*} 166^{*} 172 \quad 185193$ $\begin{array}{lllll}212^{*} & 214 & 221 & 223 & 241\end{array}$ 247250305342398421 .

Rayband 274291.

Redtenbacher 35 .

Rees, von 151 \%

Regen $61^{*}$.

Reh 8284156.

Reichert 304.

Reiff, W. 348391.

Rey 304.

Riedel, M. 88115 .

Riley 16131 .

Ritzema Bos 254:

Rolfs, P. H. 287291.

Rörig, G. 227230231232 $304359 * 360391$.

Rösel von Rosenhof $162^{*}$. Roß, H. 205206221.

Rössig 206.
Rübsaamen, E. H. 221421.

Ruby 274291.

Rungius, H. 63* 64*68 6814 .

\section{S.}

Saccardo 279: 280289.

Sachs 267.

Sasaki 300.

Sauvageau, C. 291.

Scheidter, Fr. 121* 122 $129132 * 133^{*} 134 * 135$ * 184413415421.

Schenk 93 94*.

Scheuring 103115 .

Schewyreuv 247305.

Schindler \& Mützell 370.

Schiner, J. R. 421.

Schlechtendal, D. H. R. v. 421 .

Schleh 304 .

Schleinitz 375.

Schlüter, W. 403.

Schmeil $155^{*}$.

Schmidt, A. 346391.

Schmiedeknecht, O. 421.

Schneider-Orelli, O. 191 220.

Schönfelder 376.

Schönherr 398.

Schröder, Chr. 48.

Schrödter $163^{\ddagger}$.

Schultz 285.

Schulze, P. 415.

Schwabe, J. 98* 115.

Schwangart, Fr. 258282 287289291302305343 345354356391.

Schwartz, M. 355358391.

Sedlaczek, W. 66114312 392.

Seidlitz, G. 421.

Sernander, R. 190: 191 221.

Sharp, D. $48118^{*} 162^{*}$ 164* 196305 .

Siebold, v. $119^{*} 124$.

Sihler 369392.

Silvestri, F. 128* 129 159: 184185.

Simroth 310 .

Sinz 235 .

Sobolew 235.

Sorauer 194.

Sprengel, Ch. C. 188189.

Spuler, A. $118^{*} 404405$ 421.
Standfuß, M. 174175185 297304306.

Steche, O. 114.

Stein $108^{*}$.

Stempell, WV. 296297306.

Störmer 286291.

Suckow $107 * 149$ \%

Swammerdamm 166.

\section{T.}

Tangl, Fr. 288291.

Taschenberg $40^{*} 256^{*}$.

Tauber, P. 226304.

Thaxter $263275^{*}$.

Thélohan 295 .

Thienemann 153.

Thomas 205207.

Tiedemann 311.

Timaeus, Fr. 305.

Townsend, Ch. 251305.

Trédl, R. 410421.

Tubeuf, C. v. $262^{*} 279$

$285286288291302 \quad 306$ 346.

Tulasne, L. R. et C. $268^{\circ}$ 273286291.

Tümpel, R. 421.

U.

Uhlig 173185.

\section{V.}

Vaney, C. 288291.

Vater 232.

Verhoeff, C. W. 4960114 856305.

Vill 361392.

Vogel, R. 70 94: 98115.

Voß, Fr. 4954114.

Vuillemin, P. 277282291.

\section{W.}

Wachtl, Fr. 232235304.

Wagener 258.

Wagner, N. 127226227.

Wahl, Br. 293299300 *

306347357392.

Wappes 376 .

Webster 247.

Weiske 236374.

Weismann 223.

Weißmann, A. 304.

Weißwange 368392. 
Werneburg 179.

Westwood $156^{\circ}$.

Wheeler, W. 48.

White, G. F. 292306.

Wingenroth, A. 370.
Winkler \& Wagner 402 $403410 \mathrm{ff}$.

Wize, K. 290.

Wolff, M. 302306386.

Woodworth, C. W. 3549.

\section{Z.}

Zander, E. $21^{*} 28 * 30^{*} 48$ $57 * 58^{*} \quad 67 * 75 \quad 78^{*} \quad 79 *$ $86 \quad 107292296298306$. Zeiß, C. 418.

Zopf, W. 289.

\section{Sachregister.}

A.

Aaskäfer 256.

Abbrennen 363.

Abdomen $31236 \mathrm{ff}$.

Acanthis 233.

Acron 12.

Actia 253.

Adern $31 \mathrm{ff}$.

Aegerita 284.

Aestivales 126.

After 67.

Afterfüsse 148.

Afterklappen 57.

Afterraupen 164.

Agelastica 129134 .

Agrilus 210.

Agrotis, schwarze Muskardine 266.

Akrocecidien 207.

Alauda 232.

Algenpilze 260 .

Ameisen 29254333.

- als Pflanzenverbreiter $190 \mathrm{ff}$.

Ameisenlöwe 162195 .

Amnion 139.

Amphibiotica 395397.

Anabiotischer Zustand 84 .

Anamerentoma 394.

Anamerie 144153.

Ananasgallen 208209.

Anastatus 24() 241248249 250339.

Anergates 33.

Angel 20.

Ankerfrass 199.

Anlegungv. Sammlungen.

Anlockungsmittel 364 .

Anobium 203, Klopflaute 59 .
Anomalon circumflexum 239243247248.

Anopheles 193.

Anophthalmus 103.

Ansteckende Ruhr 298.

Antennen $17 \mathrm{ff}$.

Anthonomus 194334337.

Anthrax 170237244385 .

Anthribus 245.

Anthus 232.

Apanteles 240243249250 .

Apfelblütenstecher 334 .

Aphis 84.

Apiosporium 274.

Apoderus 17.

Appendix vermiformis 64 .

Appositionsbilder 102.

Apus 233.

Aradus 43.

Arbeiter 47.

Arbolineum 354.

Arctia 129.

Argyrophylax 243.

Arrhenotokie 125.

Arsen-Cupretta 354.

Arsenikmittel 353.

Arseniksaures Natron 416.

Arthropoden 1.

Arvicola 227.

Aschersonia 276.

Asci 269.

Ascomyceten 269.

Ascosporen 269.

Aspergillus 274.

Astacus 4 .

Atelocerata 8910 .

Attelabus 131.

Ätzkalkstaub 361.

Aufblasen der Raupen 412.

Aufkämmen 379.
Aufklebeplättchen 411 .

Augen $98 \mathrm{ff}$.

- acone usw. 101.

Augenformen 100.

Ausblaseapparate 412413 .

Aussenskelett 2.

autochthone Vermehrung 310.

Azygosporen 261.

\section{B.}

Bachstelzen 232.

Bacillus-Arten $292 \mathrm{ff}$.

Bacterium monachae 302.

Baëtis 76 .

Bakterienkrankheiten 292.

Bakterienseuchen 349 .

Balaninus 46 .

Banchus 168385 .

Bauchfüsse 148 .

Bauchmark 75089.

Baumfalk 235.

Baumweissling 311 .

Baumwollkapselkäfer 337 .

Beeinflussbare Insekten 174.

Begattungstasche $110 \mathrm{ff}$.

Begattungszeichen 123.

Beinformen 3031 .

Bekämpfung, biologische 314.

- parasitäre $340 \mathrm{ff}$.

- technische 314315317.

Berührungsgifte $3 \tilde{3}$.

Bespritzen 352.

Bestand, eiserner 222.

Bestandspflege 320 .

Bestandsverderber 198 .

Bestäuben 352358.

Bestäubungsmittel 358 . 
Bestimmen von Insekten $416 \mathrm{ff}$.

Beutelgallen 208.

Beutelmethode 408 .

Bibio 4599164.

Biene,Mundwerkzeuge 21 .

Biologische Methode 314 .

Biorhiza, Heterogonie $125 \mathrm{ff}$.

Biston 175.

Black Leaf 356.

Blastoderm 8138 .

Blastophaga 189246.

Blattlauslöwen 256 .

Blattminen 200.

Blattskelettierung 199202.

Blattwickler 201.

Blaurake 233.

Blausäuredämpfe 361 .

Bleiarseniat 354 .

Blepharipa 240241252.

Blut 80 .

Blutkiemen 77.

Blutkreislauf $79 \mathrm{ff}$.

Bodeninjektionsspritze 360.

Bombyx 129.

- var. arbusculae 175 .

Bombyxarten, Generation 180.

Bordelaiser Brühe 3 5̃4.

Borkenkäfer 311 .

Botrytis $273277 \mathrm{ff} 287 \mathrm{ff}$.

Brachyderes 254258353 361.

Braconiden 245.

Brutknüppel 365 .

Brutpest 292.

Buchfink 232

Buntspecht 234.

Bursa copulatrix $110 \mathrm{ff}$.

Bürstentriebe 211.

\section{c.}

Calcino 277.

Calopteryx 45 .

Calosoma $34141 \quad 163240$ 255334339.

Caprimulgus 233.

Carabus 70334 .

Carcelia 240253.

Cardo 20.

Carpogon 275.

Cecidien $205 \mathrm{ff}$.

Cecidomyia 197.

Cellaris 126.
Cephalon 312.

Cephalosporium 277.

Cephalothorax 3899 .

Cerambyx 163197.

Ceratostomella 273.

Cerci $38 \mathrm{ff}$.

Cetoura 168.

Chalcididen 244246.

Chalcis 240244250 .

Champagnerpfropforgan 93.

Cheimatobia 46.

Chelicerata 8910.

Chemische Bekämpfung 351.

Chermes 206209257.

- Heterogonie 126.

Chilopoden 257.

Chimabacche 46 .

Chironomus 77132 ff. 134 164.

Chiroptera 225.

Chitin 2.

Chitinpanzer $\tilde{~}$.

Chlamydozoen 295302.

Chloëon 45121.

Chlorbarium 354 .

Chlorzink 416.

Chordotonalorgane $96 \mathrm{ff}$.

Chorion 117.

Chylus 69.

Cicada septemdecim 176.

Cicindela 2733.

Cimbex 165201203.

Cladosporium 281.

Cleonus 266287.

Clerus 195236256337340.

Clypeus 15.

Clytra 167.

Cnethocampa, Generation 178.

- Eiablage 133.

Coccinelliden 253254333 343.

Coccobacillus 294.

Coleopteroidea 395397.

Compsilura 240241252.

Coracias 233.

Cordiceps $270 \mathrm{ff}$. 286 .

Cordicepsarten 272.

Coremium 269.

Cornaliasche Körperchen 295.

Cornea 100.

Corpora lutea 107111.

Corvidae 230.
Cossus 165197.

Coxa $29 \mathrm{ff}$.

Crossocomia 240.

Crypten (Regenerations-) 66.

Cryptorhynchus 198217.

Cucujiden 256.

Cuticula 240 ff. $51 \mathrm{ff}$.

Cychrus 16.

Cynips calycis 194 .

\section{D.}

Dachs 226.

Darmkanal 65062 ff. 148 .

Dauersporen 261.

Deegenersche Methode 415.

Deilephila $81 \mathrm{ff}$.

Deutocerebrum 90.

Deutoplasma 117.

Dimorphismus $44 \mathrm{ff}$.

- larvaler 159.

Dipteroidea 396397.

Dotterhaut 107117.

Drosseln 232.

Drüsen 52 ff. 147.

Ductus ejaculatorius 113 .

Duftschuppen 42 .

Dünndarm $66 \mathrm{ff}$.

Durchforstung 324.

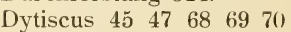

$\begin{array}{lllll}75 & 82 & 112 & 120 & 163 .\end{array}$

E.

Eccoptogaster 174.

Ei $117 \mathrm{ff}$.

Eiche 322.

Eichelhäher 230.

Eichhorn 226.

Eierstöcke 105 ff. 106107

Eiformen 118.

Eihäute $139 \mathrm{ff}$.

Eikapseln $134 \mathrm{ff}$.

Eikelch $105 \mathrm{ff}$.

Eileiter $109 \mathrm{ff}$.

Eiplatten $132 \mathrm{ff}$.

Eiringel $132 \mathrm{ff}$.

Eiröhren, panoistische usw. $105 \mathrm{ff}$.

Eischale 107117.

Eischwämme $134 \mathrm{ff}$.

Eisprenger 141.

Eistadium 141350 .

Eitaschen $133 \mathrm{ff}$.

Eizahl 129.

Eizeilen 132 ff.

Eizelle 117. 
Ektadenien 113.

Ektoderm 138.

Elaiosome 191.

Elasmostethus 136.

Elateridenlarven 256 .

Elytra $32 \mathrm{ff}$.

Embryo 138.

Emigranten 126.

Empusa 260 ff. 285289.

Encyrtus 128129.

Engerling 163197360.

Engerlingfraß 203.

Entoderm 138.

Entomophthora 263286.

Entomophthora-Arten 265 266.

Entomophthoraceen $260 \mathrm{ff}$. 285.

Entoskelett 27.

Entrindungen 325.

Epeira 49257258.

Ephialtes 247.

Epimerum 27.

Epimorphose 143 ff. 153 ff.

Epipharynx 15.

Episternum 27.

Erinaceus 226.

Erlenzeisig 233.

Eulophus 246.

Eupeleteria 252.

Evaniiden 246.

Exhaustor 366402.

Exkretionsorgane 7.

Exuvialflüssigkeit 144 .

\section{F.}

Facettenaugen $98 \mathrm{ff}$.

Fadenpilze $268 \mathrm{ff}$.

Faltenwespen 254.

Fangbäume 365.

Fanggräben 366 .

Fangkloben 364.

Fanglöcher 367 .

Fangpflanzen 364 .

Fangrinden 364 .

Fangtöpfe 367.

Fasan 235.

Faulbrut 292.

Feldheuschrecke 135154 161.

Femur $29 \mathrm{ff}$.

Fettkörper $5185 \mathrm{ff}$.

Fettsucht 302.

Fettzellen 85.

Fichte 321326389.

Filzgallen 207.
Finkenvögel 232.

Fiskesche Tabellen $239 \mathrm{ff}$.

Fiskesche Zuchtkästen 407.

Flacherie 292.

Flagellum 19.

Fleckenkrankheit 296.

Fledermäuse 225327.

Fliegenschnäpper 233.

Flohkrebs 9.

Florfliegen 256.

Flugbewegung 56 .

Flügelgeäder $35 \mathrm{ff}$.

Flügellosigkeit 33 .

Flügelmuskel 79 .

Fluglaute 61 .

Flugleistungen 58.

Flugmuskulatur 57.

Flugzeiten $181 \mathrm{ff}$.

Flußkrebs 4.

Follikelzellen 106.

Fonscolombia 84.

Formica rufa 191254336 342.

Forsteinrichtung 324.

Fortpflanzungsorgane $104 \mathrm{ff}$.

Fraßherde 308.

Freibrüter 330.

Fringillidae 232.

Frons 15.

Fruchthälter 110.

Frühjahrsfraß 218.

Fühler, Formen $17 \mathrm{ff}$.

- der Larven 147.

Fuchs 226327.

Fundatrigeniae 126.

Fundatrix 126.

Fungi imperfecti 269.

Furchung, superficielle 8.

Furchungszellen 138.

Fusarium 284.

Futterglocke 331.

Futterhaus, hessisches $330 \mathrm{ff}$.

G.

Galeruca 238.

Gallen $205 \mathrm{ff}$.

Gallwespen 125.

Gammarus 9.

Gamogenese 116.

Ganglien $88 \mathrm{ff}$.

Gattina 296.

Gehirn 75090.

Gehör 96 ff.

Geißel 19.
Gelbsucht 302348 .

Genae 15.

Generation $176 \mathrm{ff}$.

Geotrupes 55100 .

Germinogonie 128.

Geruch 92 ff.

Geruchsorgane $95 \mathrm{ff}$.

Geschlechtsorgane 7 .

Geschmack $92 \mathrm{ff}$.

Geschmacksorgane $96 \mathrm{ff}$. $104 \mathrm{ff}$.

Gésier 64 .

Giftbehandlung 352.

Giftstachel 40 .

Glossa $21 \mathrm{ff}$.

Glossina 193.

Glühwürmchen 87 .

Goldafter 351.

Goldammer 233.

Goniops 136.

Grabwespen 254.

Grapholitha 265286.

Grasmücken 232.

Grasserie 302.

Grillen 60.

Großkahlschlag 323.

Grauspecht 235.

Grubenkegel 93.

Grundmembran $51 \mathrm{ff}$.

Grünspecht 235.

Gryllotalpa 34136.

Gryllus 19.

Gula 1415.

Gyrinus 100.

Gyrococcus 302.

H.

Haare $40 \mathrm{ff}$.

Halobates 187.

Halsschild 26.

Halteren 32.

Härtung der Larven $413 \mathrm{ft}$.

Hautdrüsen $52 \mathrm{ff}$.

Hautsinnesorgane 9293.

Häutungsdrüsen 144 .

Heerwurm 311.

Hefepilze 274.

Hemerobius 257.

Hemielytra 32 .

Hemimetabolie $144 \mathrm{ff}$. $155 \mathrm{ff}$.

Hemipteroidea 396397.

Hemiteles 245.

Herbstfraß 218.

Herde (der Massenvermehrung) 308. 
Hermaphroditen 104.

Herz $77 \mathrm{ff}$.

Hessenfliege 128334.

Heterogonie 125 ff. 128.

Heuschrecken 60.

Heuschreckenpest 294.

Hiemalis (Chermes) 126.

Hinterdarm $66 \mathrm{ff}$.

Hinterkiefer 2021.

Hirundo 233.

Hochleimung $371374 \mathrm{ff}$.

Hoden $111 \mathrm{ff}$.

Höhlenbrüter 329 .

Holomerentoma 395.

Holomerie 144153.

Holometabolie $144 \mathrm{ff}$. $155 \mathrm{ff}$.

Holzameise 203.

Holzbock 4 .

Holzwespe $2840 \quad 163 \quad 197$ 203.

Honigbieñe 21, Eizahl 129.

Hopfenspinner 204.

Hornisse 203.

Hornissenschwärmer 121.

Hörstift 97.

Hüfte $29 \mathrm{ff}$.

Hüftgriffel 29.

Hühnereintrieb 322 .

Hühnervögel 235.

Hylesinus 182199.

Hylobius 112184198203 $256366 \mathrm{ff}$.

Hymenopteroidea 395397.

Hypermetabolie 153158.

Hypermetamorphose 158 .

Hyperparasiten $237 \quad 338$ 385.

Hyphomyceten 276.

Hypodermis $251 \mathrm{ff}$.

Hypognath 16.

Hyponomeuta $128 \mathrm{ff}$.

Hypopharynx $23 \mathrm{ff}$.

\section{I.}

Icerya $193253336 \mathrm{ff}$. Ichneumon disparis 240 247.

Ichneumoniden $245 \mathrm{ff}$.

Igel 226 .

Imaginalanlagen 150 .

Imagostadien $151 \mathrm{ff}$.

Infektionskrankheiten

343 ff. 386.

Innenlippe 23.

Insectivora 226 .
Insektenfresser 226.

Insektenherde 308 .

Insektenkästen 419 .

Insektennadeln 403410 .

Insektenpulver 358 .

Intercalarsegment 5 .

Intima 62.

Ips typographus $113 \quad 170$ $172 \mathrm{ff} .311$.

Isaria 272281 ff. 287.

Isosoma 246.

Ixodes 4 .

\section{J.}

Jamainsche Kapseln 360.

Jankescher Apparat 372 ff.

Jugendformen 142.

Jungfernzeugung 124.

Juvenalformen 142.

\section{K.}

Käferkammer 406.

Kahlschlagwirtschaft 308 .

Kainit 361.

Kalamitäten 214.

Kalksucht 277.

Kältestarre $82 \mathrm{ff}$.

Kamelhalsfliege $162 \quad 195$ 256.

Kappenzelle 94.

Karbolineum 354.

Katastrophale Insekten 214.

Katastrophen 214.

Kaumagen 6264 .

Keimbläschen 117.

Keimblätter $138 \mathrm{ff}$.

Keimdrüsen $105 \mathrm{ff}$.

Keimstreif 8138 .

Keimzellen $117 \mathrm{ff}$.

Kernpilze 269.

Kiefer 322326389.

Kieferneule 262.

Kieferneule, Parasiten 242.

Kiefernsaateule 203.

Kiefernspinner $157 \quad 166$ 249318

Kiefernspinner, Kalamität 243.

Kittdrüsen 110.

Klauenapparat $29 \mathrm{ff}$.

Klopflaute 59.

Klopfschirm 363402404 .

Klunkern 208.

Knopperngallen 208.
Köderfang 404.

Kokonbrecher 170.

Kokons 167.

Kommissuren 88.

Konidien 260269.

Kontaktgifte 353.

Kopfblase 170.

Kopula $120 \mathrm{ff}$.

Kotfänge 381 .

Krabbenspinnen 258.

Krähen 230.

Krankheiten, unbekannter Natur 386.

Krebsbildungen 208.

Kreuzbefruchtung 188.

Kreuzspinne 49.

Krisen, biologische 338 .

Kropf $62 \mathrm{ff}$.

Kuckuck $228 \mathrm{ff}$.

Küchenschabe 1520.

Kulturverderber 198 2:1)

Kupferkalkbrühe 354 .

L.

Labium 2021.

Laboulbeniaceen 274.

Labrum $1523 \mathrm{ff}$.

Lachmöve 236.

Lachnus 206.

Laden 20.

Laichschnüre 134.

Laminae anales 37.

Lampyris $4687 \mathrm{ff}$.

Laniidae 231.

Lärche 322 .

Lärchenwickler 311.

Larus 236.

Larven, primäre usw. $142 \mathrm{ff} .161 \mathrm{ff}$.

Larvenzustand 350 .

Lasius 191.

Latenz 170174.

Laterigraden 258.

Laubhölzer 386.

Laufkäfer 255.

Lautäußerungen 59 .

Lebensdauer 183.

Lebia 159.

Lecanium 258337.

Legeröhre 38.

Legescheide 39.

Leimanstrich 379.

Leimen 371.

Leimquetsche, Ringlersche 371372

Leimring 368 ff. 405 . 
Leimschlauch, Eckscher 370371.

Leimspatel 370371.

Leimspritze, Jankesche 371.

Leimstangen 379.

Leimstricke 371375.

Lepidopteroidea 396397.

Lepisma 33.

Leptura 45.

Lerchen 232.

Leuchtorgane $86 \mathrm{ff}$.

Leydigsche Kegel 93.

Libellen 155 .

- Begattung 122.

Libellenlarve, Mundwerkzeuge 21 .

Libellula 187.

Lichtfangmethode $366 \mathrm{ff}$. 404.

Lichtquellen 382.

Lina 147.

Liparis 45351.

- monacha, Generation 178.

Lithobius 257.

Lobus intern., extern. 20.

Löcherfraf3 199.

Lohsol 354.

Lophyrus 45160.

- Generation 176179

Lucaniden 45 .

Luftsäcke 73 .

Lupen 418.

Lyda $\begin{array}{lllll}129 & 165 & 174 & 227 .\end{array}$

Lysiphlebus 309.

Lytta 194

\section{M.}

Machilis 29333956 .

Maden 164

Magengifte 353.

Mahlzahn 20.

$\begin{array}{lllll}\text { Maikäfer } & 45 & 95 & 121 & 158\end{array}$ 163171324351.

- Fraßogebiete 326 .

Malachius 53.

Malacodermata 87.

Malpighische Gefäße 66 bis 70 .

Mandibeln $20 \mathrm{ff}$.

Mantelgallen 208.

Mantispa 152.

Markgallen 208.

Markröhrenfraß 203.

Matrix 51.
Mauersegler 233.

Maulwurf 226327.

Maulwurfsgrille $34 \quad 204$ 361.

Mäuse 226.

Mäusebussard 235.

Maxillen $20 \mathrm{ff}$.

Mediansegment $28 \mathrm{ff}$.

Megastigmus 246.

Meisen $230 \mathrm{ff}$.

Meisendose 331.

Melanospora 273.

Melasoma 129.

Meloiden 158.

Melolontha, Generation 178.

Membrana basilaris $51 \mathrm{ff}$.

Mentum $21 \mathrm{ff}$.

Mesadenien 113.

Mesochorus 245.

Mesoderm 138.

Mesothorax $26 \mathrm{ff}$.

Metamorphose $143 \mathrm{ff}$. $155 \mathrm{ff}$.

Metathorax $26 \mathrm{ff}$.

Meteorus 243.

Methoden, chemische 351.

Miastor 127.

Microcera 273.

Micrococcus 294302.

Micropyle 117.

Microsporidium 302.

Micryphantes 258.

Migrantes alatae 126 .

Mikroskop 418.

Mimikry 43.

Mistkäfer 55 .

Mitteldarm $65 \mathrm{ff}$.

Mittelkiefer $20 \mathrm{ff}$.

Mondvogel 121133.

Monodontomerus 240248 339.

Mordella 99.

Mordspinnen 258.

Motacillidae 232.

Mucor mucedo 267.

- Arten 268.

Mucoraceen 266.

Mundgliedmaßen $19 \mathrm{ff}$.

Mundhöhle 62 .

Mus 227.

Muscardine 277.

Muscicapa 233.

Muskel, Kraftleistung 55.

Muskelschichte 54 .

Muskelsystem $54 \mathrm{ff}$.
Mykosen $258 \mathrm{ff} .343 \mathrm{ff}$. 385.

Myriangium 274.

Myriapoden 811 .

Myrmekochoren $190 \mathrm{ff}$.

Myxomyceten 259.

N.

Nachahmung 43 .

Nachtschwalbe 233.

Nadelholzanbau 323.

Nadelhölzer 387.

Nagelgallen 208.

Naphthalinkalkpulver 358.

Naturverjüngung 323.

Nebenhoden 113.

Nebenzungen $21 \mathrm{ff}$.

Nebria 265.

Necrophorus $6068 \quad 129$.

Necydalis 44 .

Nematus 209308.

Nervensystem 88 ff. 150 .

Netzaugen $98 \mathrm{ff}$.

Neuropteroidea 395397.

Nießwurz 355.

Nikotin 354.

Nisthöhlen $329 \mathrm{ff}$.

Nitiduliden 256.

Nonne $183 \quad 200 \quad 224 \quad 243$ 250302312314319325 351.

Nonnenkalamität 243.

Nonnenraupe, Häutungen 175 .

Normalzahl 222.

Nosema 295 ff. $349 \mathrm{ff}$.

Novius $193253254336 \mathrm{ff}$.

0 .

Oberlippe $1523 \mathrm{ff}$.

Oberschlundganglion 90 .

Occiput 15.

Ocellen $98 \mathrm{ff}$.

Oenocyten 86.

Oesophagus $62 \mathrm{ff}$.

Oesophagusstiel 64 .

Ohrwürmer 256.

Olocrates 259.

Öligwerden von Insekten 419.

Onthophagus 55 .

Oospora 276277287.

Ophionectria 273287.

Orchestes 200202212.

Orgyia 46250.

Oriolus 229.

Orthopteroidea 395397. 
Ortsbewegungen $55 \mathrm{ff}$.

Oryctes 4655 .

Ovarien $105 \mathrm{ff}$.

Ovidukte $109 \mathrm{ff}$.

Ovipositor 39.

\section{P.}

Paedogenesis $127 \mathrm{ff}$.

Palaeococcus 254.

Palpus $20 \mathrm{ff}$.

Panolis 262282.

Panzeria 343.

Paraglossen $21 \mathrm{ff}$.

Parameren 39120.

Parasetigena $178 \quad 240243$ 251253343.

Parasiten 195 ff. 236332 ff. 340 ff. 383.

Parasitenreihe 338342 .

Parasitenzucht $339 \quad 343$ 408 ff.

Paridae $230 \mathrm{ff}$.

Parthenogenese 7117124 .

Patagia 36.

Pébrine 295.

Pedes spurii 148.

Pemphigus $8 \downarrow 208$.

Penis 120.

Pentatoma 23.

Perikardialzellen 86 .

Peripatus 10.

Periplaneta 1520.

Perisporiaceen 274.

Perithecien 269.

Perkinsiella 337.

Petroleum 357.

Pezomachus 245.

Phalangium 258.

Phalera 121133.

Pharyngealdrüsen 65 .

Pharynx 62.

Phryganidenlarve 149.

Phryxe 253.

Phylloscopus 232.

Phylloxera 340.

Phytonomus 265.

Picromerus 257.

Picus $233 \mathrm{ff}$.

Pieris 4445263264 .

Pieper 232.

Pigmentfarben 42 .

Pigmentwanderung 132 .

Pilze, insektentötende 258.

Pilzförmige Körper (Gehirn) 90.

Pimpla 247248.
Pirol 229.

Pissodes 198.

Pleuren 26.

Pleurocecidien 207.

Polyeder $299 \mathrm{ff}$.

Polyederkrankheiten $299 \mathrm{ff}$.

Polyembryonie $128 \mathrm{ff}$.

Polygnotus 128.

Polygraphus 100 .

Polymetabolie $158 \mathrm{ff}$.

Polymorphismus $44 \mathrm{ff}$.

Pontania 206.

Porenplatten 93.

Powersprayers 357.

Präparieren von Insekten 410.

Präpupa 160.

Prätarsus $29 \mathrm{ff}$.

Prellen 363369.

Primitivrinne 138.

Prioritätsgesetz 399.

Probeeiern 381.

Probeleimungen 381.

Probesammeln 381382.

Probesuchen 381.

Proctotrypiden 246.

prognath 16.

Prometabolie $155 \mathrm{ff}$.

Prospaltella 337.

Prothorax $26 \mathrm{ff}$.

Protocerebrum 90.

Pselaphus 99.

Pseudobranchien 76.

Pseudochrysalis $158 \mathrm{ff}$.

Pseudonymphe 160.

Psyche 46127183.

Pteromalus 246248250.

Ptychoptera 74.

Punktaugen $98 \mathrm{ff}$.

Pupa libera, obtecta 165 ff.

- coarctata 168.

Puppe $144151165 \mathrm{ff}$.

Puppenräuber 255.

Puppenstadium 350.

Puppenwiegen 167.

Pygidium 37.

Pylorus 66.

Q.

Quassiabrühe 357.

R.

Raife $38 \mathrm{ff}$.

Raptatores 235.

Rattenschwanzlarve 74 .

Raubvögel 235.
Raubinsekten 195236

$253 \mathrm{ff} .332 \mathrm{ff} .341 \mathrm{ff}$.

Räuchern 352358.

Raupenzwinger 334 .

Raupenfackeln 363.

Raupenleim 370.

Receptaculum seminis $110 \mathrm{ff}$.

Rectaldrüsen 67.

Rectum $66 \mathrm{ff}$.

Reibungslaute 59 .

Reichspflanzenschutzgesetz 390.

Respirationstöne 61 .

Retina 99.

Rhabdom $99 \mathrm{ff}$.

Rhaphidia 162256.

Rhynchites 130201.

Rhyssa 95131247.

Rindenplatzfraß 201.

Ringelspinner 133.

Ringeltaube 235.

Rodentia 226.

Rosettentriebe 212.

Röten 371.

Rückengefäß $\$ 077 \mathrm{ff}$.

Rüssel 64 .

Rüsselkäfer 323324325

Rüsselkäferfallen 368 .

\section{S.}

Saccharomyceten 274 .

Saisondimorphismus 46 .

Saitenorgane $96 \mathrm{ff}$.

Salticoidae 258.

Samen 119.

Samenfäden $111 \mathrm{ff}$.

Samenleiter 113.

Samenpatrone 120.

Samentasche $110 \mathrm{ff}$.

Sammeln von Insekten 401.

Sammelutensilien $402 \mathrm{ff}$.

Saperda 130206.

Saturnia 174.

Saugmagen 63.

Scapus 19.

Schädigungen, physiol., techn., primäre, sekund. 197.

Schaft 19.

Schartenfraß 199.

Schaumfleck 136.

Schedius 240241248339.

Scheide $109 \mathrm{ff}$.

Scheidentriebe 212. 
Scheinpuppe $158 \mathrm{ff}$.

Schenkel $29 \mathrm{ff}$.

Schenkelring $29 \mathrm{ff}$.

Schiene $29 \mathrm{ff}$.

Schildchen 26.

Schildwanzen 33134141 257.

Schizoneura 208.

Schlaffsucht 292.

Schlund 62.

Schlunddrüsen 65 .

Schlundkommissur 7.

Schlundring 90.

Schlupfwespen $245 \mathrm{ff}$.

Schmetterling, Mundwerkzeuge $24 \mathrm{ff}$.

Schmierdrüsen 110.

Schmierseife 354357.

Schreitbewegungen 55 .

Schrilleisten 60.

Schuppen $40 \mathrm{ff}$.

Schuppenkolben $134 \mathrm{ff}$.

Schützende Ähnlichkeit 43.

Schwalben 233.

Schwalbenschwanz 99.

Schwammspinner 122231 338 ff., Parasitenfolge 240.

Schwanzstück 37.

Schwarzspecht 235.

Schwarzwild 327.

Schwebfliegen 256 .

Schwefelblume 358.

Schwefelkalkbrühe 357 .

Schwefelkohlenstoff 360 .

Schwefelleber 358.

Schweineeintrieb 327.

Schwimmbewegungen 56 .

Schwindsucht 292.

Schwingkölbchen 32.

Scolopendra 310.

Scolopophor 96.

Scutellista 337.

Scutellum 26.

Seeorgane 98.

Segmentierung, heteronome $2 \mathrm{ff}$.

Segmentplatten 2.

Sekrete der Drüsen 53.

Sektion (von Larven) 384.

Semipupa 160.

Sempersches Verfahren 412.

Sensilla 93.

Serosa 139.
Sexuales (Chermes) 126.

Silpha 256.

Simulia 193.

Sinneshaare 93.

Sinneskegel 93.

Sinneskuppeln 94.

Sinodendron 46.

Sirex 163197.

Sklerotien 259.

Sorex 226.

Spannbretter 409.

Spatel (Leim) 370.

Spechte $233 \mathrm{ff}$.

Speicheldrüsen $64 \mathrm{ff}$.

Speiseröhre $62 \mathrm{ff}$.

Sperling 332.

Spermatocyste 111.

Spermatogonien 111.

Sphaeropsidales 276.

Sphaerostilbe 273287.

Sphinx 80.

Spicaria 282.

Spinndrüsen 149.

Spinnen 257343.

Spiralfaden 71.

Spitzmäuse 226.

Sporangien 266.

Sporen 29.

Sporotrichum 277287344.

Sporozoen 295.

Springbewegungen 56 .

Springspinnen 258.

Spritzapparate 357.

Spritzmittel $352 \mathrm{ff}$.

Stäbchensaum 66.

Stamm 20.

Stammutter (Chermes) 126.

Standortspflege 320 .

Staphyliniden 255334.

Star 229.

Steatodia 258

Stechmücke, Mundwerkzeuge 22.

Stegomyia 193.

Sternum 26 ff. 37.

Stiftchenträger 96.

Stiftkörperchen 94.

Stigmatomyces 275 .

Stigmen $71 \mathrm{ff}$.

Stigmenverschlüsse 72 .

Stipes 20.

Streifenkulturen 326.

Streptococcus 292.

Strickhochleimapparat 376 ff.
Strickleiternervensystem 789 .

Stidulationslaute 59 .

Streurechen 363.

Strukturfarben 42.

Stubenfliege 99.

Sturnus 229.

Styli $38 \mathrm{ff}$.

Subimago 152156.

Submentum $21 \mathrm{ff}$.

Superpositionsaugen 102.

Superpositionsbilder 102.

Sylviidae 232.

Synonyme 398.

Syrphiden 256.

T.

Tabakextrakt $354 \mathrm{ff}$.

Tabakstaub 358361 .

Tachina japonica 240.

- larvarum 240251253.

Tachinen 250 ff. 343.

Tachinentönnchen 168 .

Tachinierung 252.

Tachinose 252.

Talpa 226.

Tardigraden 10.

Tarichium 266286.

Tarsus $29 \mathrm{ff}$.

Taster $20 \mathrm{ff}$.

Tastsinn $92 \mathrm{ff}$.

Tauben 235.

Täuschende Forstinsekten 214.

Tausendfüsse 257.

Teerschlitten 364379 .

Tegulae 36 .

Teleas 249326.

Teleiocerata 9 .

Telson 1237.

Temperatur der Insekten $81 \mathrm{ff}$.

Tentorium 17.

Tereas 125.

Tergum 2637.

Termiten 129.

Termitoxenia 7104 .

Tetragnatha 257.

Tetropium 100197198.

Thalessa 131.

Thelytokie 124 .

Theridium 257.

Theronia 240.

Thomiscus 258.

Thorax $31225 \mathrm{ff}$.

Thysanuroidea 395397.

Tibia $29 \mathrm{ff}$. 
Tiefleimung 371375 .

Tomicus 45 .

Tönnchenpuppe 168.

Torfklötze 410.

Tortrix 43199.

Torubiella 273.

Totenkopf, Lautorgan 61.

Totenuhr 59.

Tötungsgläser 402 .

Toxophore 4153 .

Toxoptera 309.

Toxotus 45 .

Tracheen $71 \mathrm{ff}$.

Tracheenkiemen $76 \mathrm{ff}$.

Tracheensystem 50149.

Tränken für Vögel 331 .

Treiben der Raupen 407.

trichogene Zellen 51.

Tricholyga 240.

Trichome 41.

Tritocerebrum 91.

Triungulinus 158.

Trochanter $29 \mathrm{ff}$.

Trochilium 121.

Trockenpräparation von Larven $413 \mathrm{ff}$.

Troilus 257.

Trommelfellorgane $96 \mathrm{ff}$.

Trommellaute 62 .

Trypanosoma 299.

Tsetsefliege 193.

Turbanaugen 101.

Turdidae 232.

Turmfalk 235 .

Tympanalorgane $96 \mathrm{ff}$.

\section{U.}

Überflüge $310 \mathrm{ff}$.

Überjährigkeit 174 .
Überliegen 174.

Überwinterungsstadien $179 \mathrm{ff}$.

Ulmenblattkäfer 238.

Unterlippe $20 \mathrm{ff}$.

Unterschlundganglien 91 .

Upupa 233.

Ursamenzellen $111 \mathrm{ff}$.

Uterus 110.

\section{V.}

Vacuole 94.

Vagina $109 \mathrm{ff}$.

Valvula cardiaca 64 .

- pylorica 66.

Vanessa 4647.

Vasa deferentia 113.

Ventilschlauch 64 .

Ventiltrichter 64 .

Ventralsinus 79.

Verdauung $69 \mathrm{ff}$., extraintestinale 70 .

Vergiften v. Fraßstücken 416.

Vertex 15.

Verticillium 280.

Vesiculae seminales 113.

Vespa crabro 312.

Vesperugo 225.

Virginogeniae 126.

Viviana 253.

Vogelfeinde 332.

Vogelschutz $328 \mathrm{ff}$.

Vogelschutzgesetze 332 .

Vorbeugung $312315 \mathrm{ff}$.

Vorderdarm $62 \mathrm{ff}$.

Vorderkiefer 20.

Vormagen 6264 .

\section{W.}

Wachsbildungen 4253 .

Wachsdrüsen 53.

Waldameise $2 \check{5} 336342$.

Wärmestarre $82 \mathrm{ff}$.

Wärmetod $82 \mathrm{ff}$.

Wasserjungfer 99.

Weidenbohrer 99.

Weidenrosen 208.

Weibtanne 322.

Wendehals 235.

Wespenbussard 235.

Wiedehopf 23.

Wildschwein 227

Wilt (des Schwammspinners) 302348 .

Winterei 126.

Winterfütterung 331 .

Wipfelkrankheit 302346 .

Wirrzöpfe 208.

Witterungseinflüsse $\quad 217$ 223 ff. 307309.

Wollringel $134 \mathrm{ff}$.

Wollschildlaus 253336 .

Würger 231.

Wurzelfraß 203404.

\begin{tabular}{l}
\multicolumn{1}{c}{ Z. } \\
Zellen 35. \\
Zentralnervensystem 7. \\
Zoogamie 189. \\
Zuchtanstalten 343. \\
Zunge 21 24. \\
Zuwachsverlust 211. \\
Zwergfell $78 \mathrm{ff}$. \\
Zwitter 46 104. \\
Zygobothria 240. \\
Zygosporen 261.
\end{tabular}


Zu Escherich, Forstinsekten. I. Bd.

\section{Nachträge}

zum

\section{Druckfehlerverzeichnis (Seite 49:3).}

Es wird gebeten, die Änderungen vor dem Lesen vorzunehmen.

Seite 106, Zeile 2 von unten ist hinter „Sie gruppieren sich“ einzusetzen: „in den polytrophen Eiröhren".

Seite 113, Zeile 7 von oben lies: Samenblasen stat Samentaschen.

Seite 129, Zeile 8 von unten lies: Kieferneule 300-500 statt 200-300.

Seite 154 , Zeile 11 von oben lies: Umwandlung statt Verwandlung.

Seite 380, Zeile 15 von unten ist das Wort "indirekten" zu streichen, und drei Zeilen weiter unten ist das Wort „indirekten“ durch „solchen" zu ersetzen. 



\section{Druckfehlerverzeichnis und Nachträge.}

Es wird gebeten, die hier verzeichneten Druckfehler vor dem Lesen des Buches richtig zu stellen:

Seite 9 , Zeile 6 von unten lies: aberrant statt aborrant.

Seite 33, Bezeichnung der unteren Figur lies: Fig. 36 statt Fig. 34.

Seite 35, Zeile 7 von unten lies: Comstock statt Comstok.

Seite 62, Zeile 19 und 24 von unten lies: Hinterdarm statt Enddarm.

Seite 67, Figurenerklärung lies: bei Ed Hinterdarm statt Enddarm, ferner „wie auf den Fig. 59 u. 61 " statt 60 u. 61.

Seite 107, Zeile 3 von oben ist hinter Eifach zu setzen: (im weiteren Sinne).

Seite 107, Zeile 3 von unten lies: Fig. 94 statt Fig. 96.

Seite 138, Figurenerklärung bei $A$ lies: Teilung statt Teile.

Seite 139, Zeile 15 von oben lies: eigentliches Entoderm statt eigentlicher Entoderm.

Seite 142 , Zeile 11 von oben lies: deutlich statt vollkommen.

Seite 247, Erklärung der Fig. 190 lies: „Eine Schlupfwespe (Lysiphlebus), eine Blattlaus anstechend“ statt „Eine Blattlaus usw. eine Blattlaus anstechend".

Seite 302, letzte Zeile lies: Bolle (nach persönlicher Mitteilung) statt Schwangart.

Seite 357 , Zeile 3 von oben ist nachzutragen:

Neuerdings werden von verschiedenen Seiten auch die Präparate der „Elsässischen Tabakmanufaktur" in Straßburg-St. Ludwig empfohlen, darunter besonders die Marke "Wetterfest". Bei Bezug im großen (zunächst für weinbauliche Zwecke) will diese Firma gute Nikotinlaugen zu etwa demselben Preise abgeben, wie die Österreichische Regie ihre Extrakte. 

Verlag von Paul Parey in Berlin SW. 11, Hedemannstrabe 10 u. 11.

Anfang 1914 beginnt zu erscheinen:

\title{
Zeitschrift
}

\section{für \\ angewandte Entomologie.}

Herausgegeben von

\author{
Prot. Dr. K. Escherich, \\ und \\ Prof. Dr. F. Schwangart, \\ Professor der Zoologie an der Kgl. Forstakademie \\ Tharandt, \\ Vorstand der Zoolog. Station an der Kgl. Lehr- \\ und Versuchsanstalt fuir Wein- und Obstbau in \\ Neustadt a. Haardt.
}

Wir stehen gegenwärtig im Zeichen einer Reform der angewandten Entomologie in Deutschland. Bis vor kurzem war diese Wissenschaft in Deutschland arg verkannt und vernachlässigt, so daß wir uns in dieser Beziehung den meisten anderen Kulturnationen gegenüber in starker Rückständigkeit befunden haben. Erst in neuester Zeit beginnt man - aufmerksam gemacht durch die Anstrengungen und Erfolge des Auslandes - auch bei uns der angewandten Entomologie sich mehr anzunehmen und ihr das allgemeine Interesse entgegenzubringen, das ihr gemäß ihrer tief in das Kulturleben einschneidenden Bedeutung zusteht.

Inauguriert wurde die Reformbewegung durch die Gründung einer „Deutschen Gesellschaft für angewandte Entomologie“, die in kurzer Zeit so erstarkte, $\mathrm{daB}$ sie bereits nach einem halben Jahr nach der Gründung eine glänzend besuchte Versammlung (in Würzburg) mit einem überaus vielseitigen und interessanten Programm abhalten konnte. Der Verlauf der Versammlung bewies, daß in Deutschland zahlreiche angewandt entomologische Interessen und Kräfte vorhanden sind; dieselben waren aber bisher zerstreut und isoliert, so daß sie zu keiner größeren Gesamtwirkung gelangen konnten.

Dieser bestehenden Zersplitterung und Kraftvergeudung entgegen$z$ uarbeiten, soll einmal durch die genannte Gesellschaft bewirkt werden, und sodann durch die Herausgabe einer Zeitschrift, die mit Beginn des Jahres 1914 unter dem obigen Titel erscheinen wird, und zwar unter der Redaktion von Prof. Dr. K. Escherich-Tharandt und Prof. Dr. F. Schwangart-Neustadt a. Haardt. Die neue Zeitschrift wird in zwanglosen Heften von wechselndem Umfang ausgegeben werden. Jeder Band wird ca. 25 Druckbogen enthalten und kostet 20 M. (für Mitglieder der Gesellschaft für angewandte Entomologie nur $13 \mathrm{M}$.).

In der Zeitschrift werden die Verhandlungen der Gesellschaft für angewandte Entomologie zum Abdruck kommen, ferner größere und kleinere, reich illustrierte Originalarbeiten, Referate, Mitteilungen, Personalnachrichten aus dem Gesamtgebiet der angewandten Entomologie (Pflanzenpathologie, medizinische Entomologie, Bienen- und Seidenraupenzucht usw.), und so wird sie den Mittelpunkt des angewandt entomologischen Lebens in Deutschland bilden und die zu einer gedeihlichen Entwicklung der Wissenschaft so notwendige Verbindung zwischen den verschiedenen Gebieten der angewandten Entomologie herstellen. Die neue Zeitschrift dürfte für forstliche und landwirtschaftliche Kreise eben so unentbehrlich sein wie für medizinisch-hygienische, koloniale, bienen- und seidenzüchterische usw.; ebenso wird sie in keinem zoologischen Institut und keiner entomologischen Bibliothek fehlen dürfen.

Die Namen der Herausgeber wie des Verlages bürgen dafür, daß die neue Zeitschrift sowohl inhaltlich als bezügl. der Ausstattung dem hohen Zwecke, dem sie dienen soll, in jeder Weise gerecht werden wird.

Das erste Heft wird zu Anfang des Jahres 1914 erscheinen und Aufsätze über Rebschädlinge, Bedeutung des Vogelschutzes für die Forstentomologie, über die Tse-TseFliege, über afrikanische Seidenzucht, über die Lebensweise der Raupenfliegen, über die angewandte Entomologie in Italien, über die Notwendigkeit der Reformen der Entomologie in Deutschland, über die angewandte Entomologie in den Kolonien, über Getreideschädlinge usw. enthalten. 


\section{K. Escherich,}

\section{Die angewandte Entomologie in den Vereinigten Staaten.}

Eine Einführung in die biologische Bekämpfungsmethode. Zugleich mit Vorschlägen zu einer Reform der Entomologie in Deutschland.

Mit 61 Textabbildungen. 196 Seiten. Preis $6 \mathrm{M}$.

Selten hat ein entomologisches Buch so viel Aufsehen erregt und so allgemeine und begeisterte Zustimmung gefunden wie die Escherich'sche Reformschrift, und selten sind Reformgedanken so schnell in die Wirklichkeit umgesetzt worden wie die in dieser Schrift dargelegten Vorschläge, - ein Zeichen, daß der Verfasser zur rechten Zeit den rechten Weg gezeigt hat.

Aus den zahlreichen Aufsätzen und Besprechungen, die über das Escherich'sche Amerikabuch in den Zeitschriften des In- und Auslandes erschienen sind, seien nur einige Sätze hier wiedergegeben:

Geh.-Rat von Rümker schreibt in der „Deutschen Landwirtschaftlichen Presse" vom 19. März 1913:

"Dieses höchst verdienstliche und interessante Buch zeigt in allgemein verständlicher, klarer. Weise nicht nur, was man in Amerika getan und erreicht hat, sondern auch, wie wir dieses Vorbild auf unsere deutschen Verhältnisse übertragen können, und es wäre im Interesse der besunders für die Landwirtschaft und unsere Kolonien praktisch so bedeutsamen Sache von gröbtem Werte, wenn dieses Buch nicht nur in den Kreisen der Praxis und Wissenschaft, sondern auch in denen der Verwaltung und der zuständigen Ministerien bekannt und beachtet würde . .

Eine frische Brise amerikanischer Großzügigkeit und praktischen Sinnes weht einem aus diesem Buche entgegen, das an vielen Stellen die nur durch Unkenntnis der Verhältnisse entschuldbare hochmütige Verurteilung amerikanischer Einrichtungen mit Recht geißelt . . .

Eine weitere Anregung kann man aber auch aus diesem Buche in der Richtung entnehmen, daß die Pflanzenpathologie ein Gebiet ist, das sich, wie selten eins, für internationale Bearbeitung eignet, und daß sie daher ein sehr dankbares Objekt für die gründlichere Bearbeitung im Rahmen des Internationalen landwirtschaftlichen Instituts in Rom sein w ürde, wenn man ihr dort die entsprechenden Arbeitskräfte widmen wollte." ...

Prof. Dr. E. A. Göldi (Bern) schreibt in einem längeren Aufsatz in der "Frankfurter Zeitung":

"Vor wenigen Wochen ist ein Buch erschienen, das den Finger auf eine wunde Stelle in der bisherigen Organisation des naturwissenschaftlichen Hochschulunterrichtes legt und sowohl durch seinen Inhalt, als durch die Persönlichkeit des Verfassers und dessen Stellung in den Reihen der führenden Naturforscher der Aufmerksamkeit der Regierungen, den akademischen Lehrkörpern und dem gesamten Kreise derjenigen Gebildeten, welche den Forderungen der Zeit zugänglich sind, angelegentlich empfohlen werden kann. Es ist verfaßt von Prof. Escherich... Das neue Buch ist ein brillant geschriebener Rapport desienigen, was der Verfasser auf einer speziellen Studienreise nach den Vereinigten 
Staaten beobachten konnte... Wir schließen wiederholend, daß den Unterrichtsministerien im besonderen und allen denjenigen Kreisen, die sich ein Urteil über die Möglichkeit und Art und Weise einer zeitgemäßen Ausgestaltung des akademischen Lehrplanes bilden möchten, die höchst verdienstvolle Propaganda-Schrift von Prof. Escherich als bahnbrechend aufs wärmste empfohlen ist."

Regierungsdirektor Dr. Wappes (Speyer) schreibt im „Forstwissenschaftlichen Centralblatt" (November 1913):

"Wenn ich eine Besprechung des Werkes unternehme, so geschieht es, weil wir in dem Werke nicht nur eine literarische Erscheinung zu erblicken haben, sondern eine $T$ at, die auch für das Forstfach von wichtigen Folgen sein wird, die Einleitung eines entomologischen Dienstes in Deutschland ... . Professor Escherich hat sich nicht damit begnügt, seine Reformgedanken darzulegen, sondern hat sie auch in die Tat umzusetzen gewußt, und so kann ich heute mitteilen, daß die Gründung einer „Deutschen Gesellschaft für angewandte Entomologie“ fertige Tatsache ist ... Für heute möchte ich allen Fachgenossen, auch wenn sie kein besonderes Interesse für Entomologie haben, empfehlen, das Escherich'sche Werk zu lesen, schon um das viele allgemein Belehrende und Anregende aufzunehmen, das in so reichem Maße geboten wird. Die Begeisterung für wissenschaftliches Forschen in Verbindung mit dem weitschauenden Blick für das praktisch Mögliche und Wertvolle kann uns nur zum Muster dienen.“

Dr. Aulmann vom Berliner Museum schreibt in der „Deutschen Entom. Zeitschrift":

... „Die vorliegende Schrift dürfte als eine der verdienstvollsten Arbeiten auf dem Gebiete der angewandten Entomologie, welche in den letzen Jahren erschienen sind, anzusprechen sein ... Es wäre sehr zu wünschen, daß die Arbeit Escherichs als ständiges Inventar auf dem Schreibtisch der an diesen Fragen interessierten Kreise liegen möchte...."

Prof. Dr. Fritz Schwangart, Leiter der Zoologischen Station der Königl. Lehr- und Versuchsstation für Obst- und Weinbau in Neustadt a. Haardt, schreibt in einem längeren Artikel in der „München Augsburger Abendzeitung“ betitelt "Die angewandte Entomologie, ein Stiefkind der deutschen Kultur":

. . „K. Escherich, einer unserer tüchtigsten Insektenbiologen, ist weiteren Kreisen besonders durch seine Ameisen- und Termitenstudien bekannt geworden; in den letzten Jahren hat er sich ganz den Aufgaben der angewandten Entomologie hingegeben; aus dieser Zeit stammen seine speziellen Arbeiten über die Nonne und sein vortreffliches Reformburch, Die angewandte Entomologie in den Vereinigten Staaten'."

Die „Deutsche Tageszeitung“ schließt ihre Besprechung mit den Worten: ... "So darf man das Buch wohl als ein Vollkommenes bezeichnen, das bei glänzender Stoffbeherrschung sein Gebiet erschöpft und für die deutsche Landwirtschaft beachtenswerte Ausblicke eröffnet ..."

Geh.-Rat von Seelhorst schreibt am Schluß seiner Besprechung im „Journal für Landwirtschaft":

... „Jedem, der die ungeheueren Schäden kennt, welche die deutsche Land- und Forstwirtschaft durch Insekten erleidet, wird die Lektüre des anregend geschriebenen Buches den Wunsch erwecken, daß die Vorschläge des Verfassers von den maßgebenden Stellen berücksichtigt werden."

Die „Rewiew of Applied Entomology“ (London) schließt ihre längere Besprechung:

... "The book contains a large mass of useful and well arranged information and provides an excellent summary of the subject." 


\title{
Die Lehre vom Waldschutz.
}

\author{
Von Dr. H. von Fürst,
}

Königl. Forstdirektor, Direktor a. D. der ehem. Forstlichen Hochschule in Aschaffenbnrg.

Zugleich siebente, neubearbeitete Auflage von

Kauschingers Lehre vom Waldschutz.

Mit 5 Tafeln. Gebunden, Prois 4 M. 50 Pf.

In leicht faßlicher Form geschrieben und in seiner neuesten Auflage den Fortschritten der Wissenschaft und Praxis entsprechend ergänzt, ist das Buch zum Unterricht sowohl wie auch zum Selbststudium gleich brauchbar. Es lehrt alle die Gefahren kennen, welche den Wald bedrohen (Frost, Hitze, Schnee, Sturm, Blitz, schädliche Pflanzen, Tiere und Menschen), und gibt die Mittel an, dieseu Gefahren vorzubeugen oder doch ihre schädlichen Folgen tunlichst einzuschränken.

\section{Forstliche Zoologie.}

Von Dr. Karl Eckstein,

Professor an der Königlichen Forstakademie in Eberswalde.

Mit 660 Textabbildungen. Gebunden, Preis $20 \mathrm{M}$.

Das vorliegende Werk soll dem Forstmann eine Übersicht über das gesamte Tierreich geben, vor allem aber die den forst- und landwirtschaftlichen Kulturpflanzen schädlichen Tiere eingehender behandeln. Es ist also in erster Linie für den Forstmann geschrieben, weiterhin natïrlich anch für jeden Zoologen, der sich eingehender mit diesem speziellen Gebiete seines Faches beschäftigen will.

\section{Die Technik des Forstschutzes gegen Tiere.}

Anleitung zur Ausführung von Vorbeugungs- und Vertilgungsmaßregein

in der Hand des Revierverwalters, Forstschutzbeamten und Privatwaldbesitzers.

Von Dr. Karl Eckstein,

Professor an der Forstakademie Eberswalde, Dirigent der zoologischen Abteilung des forstlichen Versuchswesens in Preußen.

Mit 52 Textabbildungen. Gebunden, Preis 4 M. $50 \mathrm{Pf}$.

Die zur Bekämpfung forstschädlicher Tiere nötigen Mabregeln sind hier so klar und praktisch beschrieben, daß jedermann die angegebenen Vertilgungsmittel wird mit Erfolg zur Anwendung bringen können.

\section{Die Kiefer und ihre tierischen Schädlinge.}

Von Dr. Karl Eckstein,

Professor an der Forstakademie Eberswalde.

Erster Band: Die Nadeln.

Mit 22 farbigen Lichtdrucktafeln nach Zeichnungen des Verfassers. Kart., Preis 36 M.

\section{Leitfaden der Forstinsektenkunde.}

\section{Von Dr. Otto Nüßlin,}

Großh. Bad. Geh. Hofrat, Prof. der Zoologie und Forstzoologie an der Technischen Hochschule, Vorstand am Großh. Naturalienkabinet in Karlsruhe.

Zweite, neubearbeitete Auflage.

Mit 432 Textabbildungen und den Bildnissen hervorragender Forstentomologen. In Leinen gebunden, Preis $12 \mathrm{M}$.

Dem allgemein empfundenen Bedürfnis nach einem knappen, reich illustrierten praktischen Lehrbuch der Forstinsektenkunde dürfte das vorliegende Werk in der vortrefflichsten Weise entsprechen. Seine Vorzüge sind vor allem: möglichst kurze und knappe Form, didaktische Anordnung mit Bevorzugung analytischer Tabellen, sodann volle Berücksichtigung des wissenschaftlichen Charakters, der neuesten Forschungsmethoden und Literatur. 


\title{
Illustriertes Forst- und Jagd-Lexikon.
}

\author{
Zweite, neubearbeitete Auflage.
}

Unter Mitwirkung hervorragender Fachmänner aus Wissenschaft und Praxis herausgegeben von Dr. H. von Fürst,

Königl. Forstdirektor und Direktor a. D. der ehem. Königl. Forstlichen Hochschule Aschaffenburg. Mit 860 Textabbildungen. In Halbleder gehunden, Preis $23 \mathrm{M}$.

Das illustrierte Forst- und Jagd-Lexikon enthält Tausende einzelner Artikel und bietet so die IÏ̈lichkeit schneller Orientierung über alle nur erdenklichen Fragen, die beim Lesen der Zeitschriften wie draußen im Wald an den Land- und Forstwirt herantreten. Sein Preis ist im Verhältnis zum Gebotenen auBerordentlich niedrig.

\section{Die Forstbenutzung.}

\author{
Ein Lehr- und Handbuch.
}

Begründet von Geh. Rat, Professor Dr. Karl Gayer-München.

Zehnte, vermehrte Auflage,

bearbeitet von Professor Dr. Heinrich Mayr-München.

Mit 1 Porträt, 356 Textabbildungen und 1 Farbendrucktafel. Gebunden, Preis $15 M$.

Die zehnte Auflage des weitbekannten Werkes ist die erste nach dem Tode seines Begründers. Herausgegeben von Professor Mayr, der sich bereits an der Herausgabe der neunten Auflage wesentlich beteiligte, stellt sie eine umfassende Neubearbeitung dar.

Sie dürfte einer freundlichen Aufnahne in weitesten Kreisen gewiß sein. Auch die Besitzer älterer Auflagen des Werkes werden in der neuen Auflage so viel des Neuen und Wichtigen finden, dab sie diese nicht werden entbehren können.

\section{Waldbau auf naturgesetzlicher Grundlage.}

Ein Lehr- und Handbuch, bearbeitet von Professor Dr. Heinrich Mayr-München. Mit 27 Textabbildungen und 3 Tafeln. Gebunden, Preis 15 M.

Dieses neu erschienene Werk, das erste Lehrbuch des Waldbanes auf naturgesetzlicher Grundlage, bringt vollkommen neue Gesichtspunkte und wird für jeden Forstwirt und Waldbesitzer eine ungemein anregende, hochwillkommene Gabe sein.

Die in ihm aufgestellten Grundsätze stehen so im Mittelpunkte des allgemeinen forstwirtschaftlichen Interesses, daß jeder aus eigenem Studium heraus zu ihnen wird Stellung nehmen müssen.

\section{Vorträge über Pflanzenschutz}

der Abteilung fir Pflanzenkrankheiten des Kaiser-Wilhelms-Institnts fïr Landwirtselıaft in Bromberg.

Herausgegeben von Dr. Schander.

Erstes Heft: Forstschutz. I.

Mit 61 Textabbildungen. Preis $1 \mathrm{M}$. $20 \mathrm{Pf}$. 25 Stück $25 \mathrm{M}$. 50 Stück $45 \mathrm{M}$.

Inhalt: Einflub der Holzkrankbeiten auf die Verarbeitung und Verwertung des Holzes. - Die Nonne. - Die schüttekrankheit der Kiefer und ihre Bekämpfung. - Die Borkenkäfer, ihre Schäden uud ihre Bekämpfung. - Rostkrankheiten der Kiefer und Fichte und Triebschwinden der Kiefer.

Zweites Heft: Forstschutz. II.

Mit 52 Textabbildungen. Preis $1 \mathrm{M}$. 60 Pf. 25 Stück 35 M. 50 Stück $60 \mathrm{M}$.

Inhalt: Die Bedeutung der Samenprovenienzfrage. - Der forstliche Kulturbetrieb und seine Krankheiten. - Forstlich wichtige Schildläuse.

\section{Tabellen zur Bestimmung schädlicher Insekten nach den Fraßbeschädigungen. Von R. Koch, \\ Königlich Bayerischer Forstamtsassessor.}

Fichte und Tunne. Mit 150 Textabbildungen. Gebunden, Preis $3 \mathrm{M}$.

kiefer und Liirche. Mit 217 Textabbildungen. Gebunden, Preis 1 M. 50 Pf. 


\section{Handbuch der Pflanzenkrankheiten.}

Dritte, vollständig neubearbeitete Auflage,

in Gemeinschaft mit

Prof. Dr. G. Lindau.

Privatdozent an der Universität Berlin, und

Assistent am Naturhist. Mnseum in Hamburg,

herausgegeben von

Geh. Reg.-Rat Prof. Dr. P. Sorauer, Berlin.

Erster Band: Die nichtparasitären Krankheiten.

Bearbeitet von Geh. Reg.-Rat Prof. Dr. P. Sorauer.

Mit 208 Textabbildungen. 891 Seiten. Gebunden, Preis 36 M.

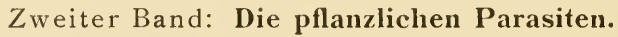

Bearbeitet ron Prof. Dr. G. Lindau.

Mit 62 Textabbildungen. 550 Seiten. Gebunden, Preis $20 M$.

Dritter Band: Die tierischen Feinde.

Bearbeitet von Dr. L. Reh.

Mit 386 Textabbildungen. 774 Seiten. Gebunden, Preis 33 M.

Der Besitz eines umfassenden Werkes über Pflanzenkrankheiten und damit die Erwerbung eingehender Kenntnisse auf diesem so außerordentlich wichtigen Gebiete ist für jeden gebildeten Land- und Forstwirt in hohem Grade wünschenswert und rein praktisch von größtem Nutzen.

Die neue, dritte Auflage des Handbuchs der Pflanzenkrankheiten stellt gegenüber der früheren Auflage ein vollständig neues Werk dar.

Seiner ganzen Anlage nach ist Sor a uers Handbuch der Pflanzenkrankheiten in seiner dritten Auflage als das zurzeit umfassendste, in jeder Hinsicht grundlegende Werk des mächtig sich entwickelnden Gebietes der Phytopathologie zu bezeichnen, wie es keine andere Nation besitzt und dessen Anschaffung warm zu empfehlen ist.

\section{Die Forsteinrichtung.}

\section{Von Dr. Friedrich Judeich,}

weil. Königl. Sächsischer Geheimer Oberforstrat, Direktor der Forstakademie zu Tharand.

Sechste, ergänzte Auflage

von Dr. Max Neumeister,

Königl. Sächsischer Geheimer Oberforstrat, Direktor der Forstakademie zu Tharand.

Mit einer Karte in Farbendruck. Gebunden, Preis 10 M. 50 Pf.

$\mathrm{DaB}$ bereits sechs Auflagen von dem berühmten Judeich'schen Buche vorliegen, ist ein beredtes Zeugnis für seine grobe Beliebtheit. Es ist in der Tat ein ganz ausgezeichnetes Buch, gleich wertvoll für Wissenschaft wie Praxis. - Die Urteile forstwissenschaftlicher Autoritäten sind durchweg glänzend. 



